

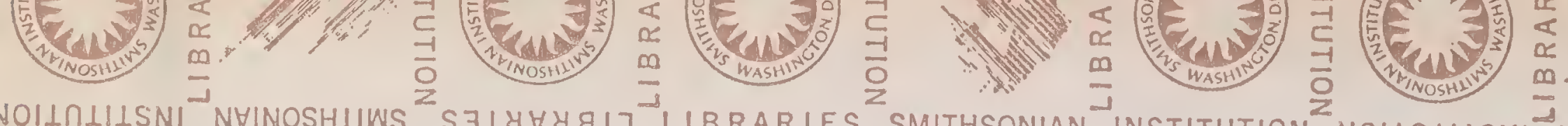

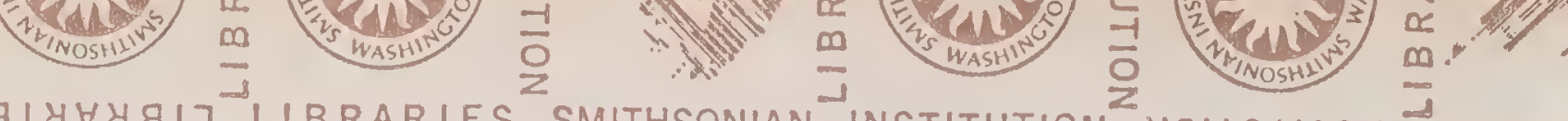
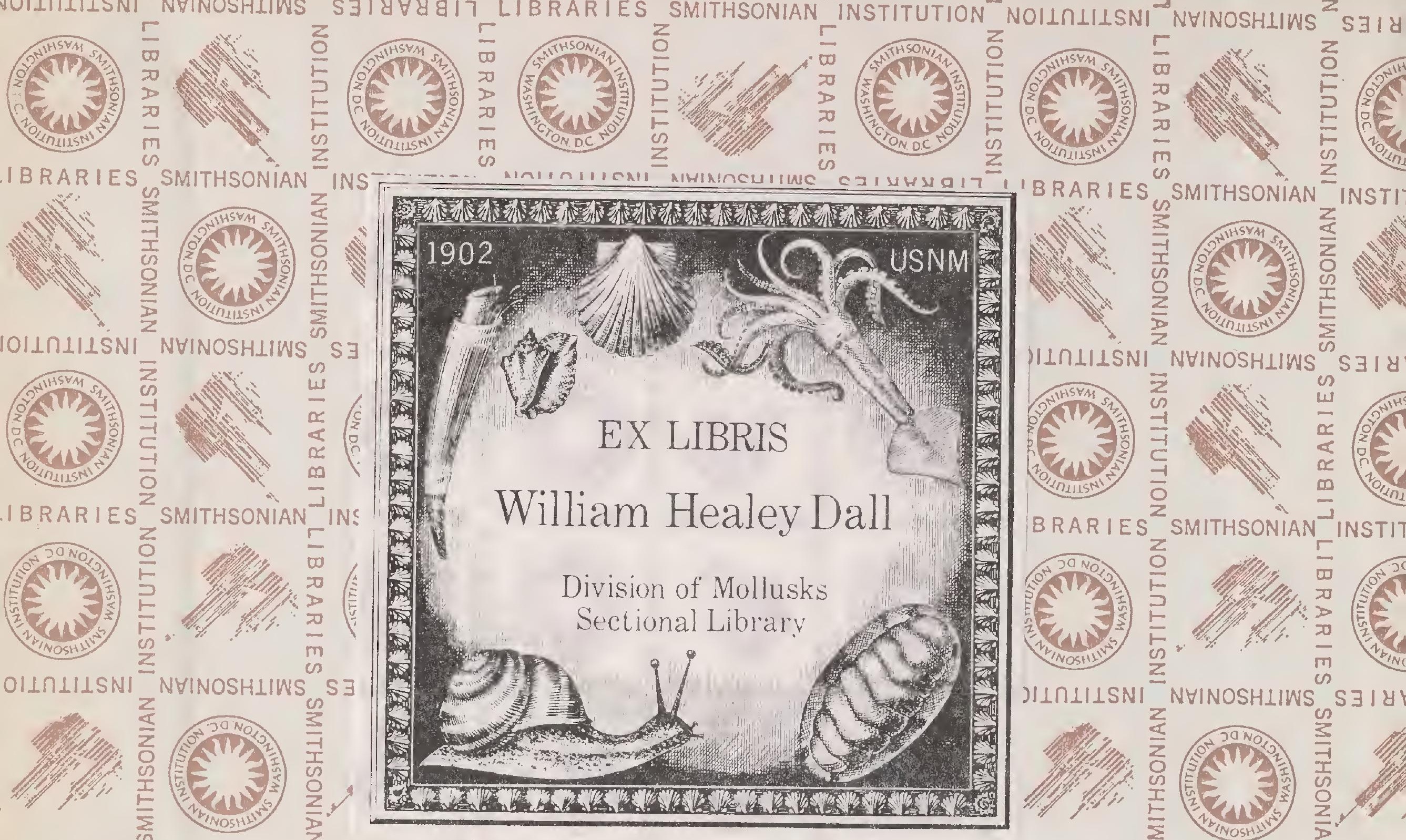

SMITHSONIAN INSTI
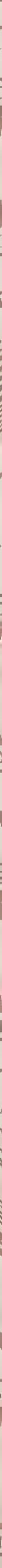

IBRARIES SMITHSONIAN
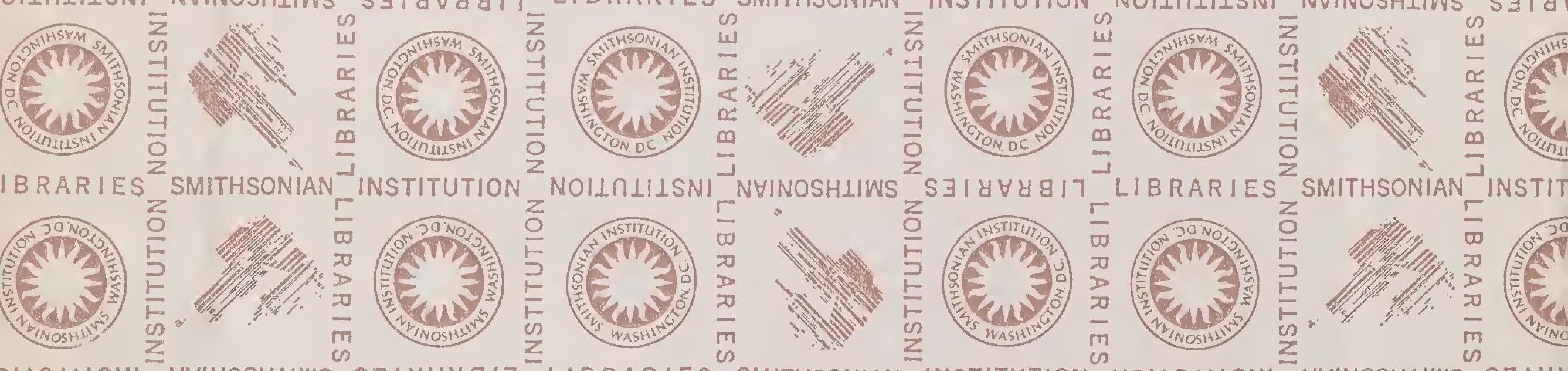

IIกLIISNI

NBINOSHLIWS

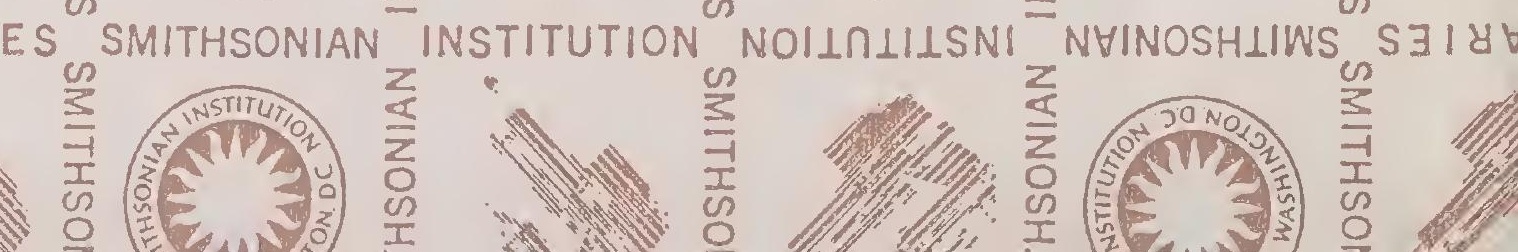







$$
\begin{aligned}
& \frac{x_{x}}{x+3} \\
& P_{a l}-20
\end{aligned}
$$




\section{S y s tem at is ches \\ Conchylien - Cabinet \\ von}

\section{Martini und Chemnitz.}

In Verbindung mit

Dr. Philippi, Dr. Pfeiffer, Dr. Dunker, Dr. Römer, Weinkauff, Clessin, Dr. Brot,

Th. Löbbecke, Dr. v. Martens, Schmalz, Dr. Thiele, Dr. Wagner und Dr. Haas

neu herausgegeben und vervollständigt

von

Dr. H. C. Küster,

nach dessen Tode fortgesetzt von

Dr. W. Kobelt.

Ersten Bandes Achtzehnte Abtheilung.

Neue Folge.

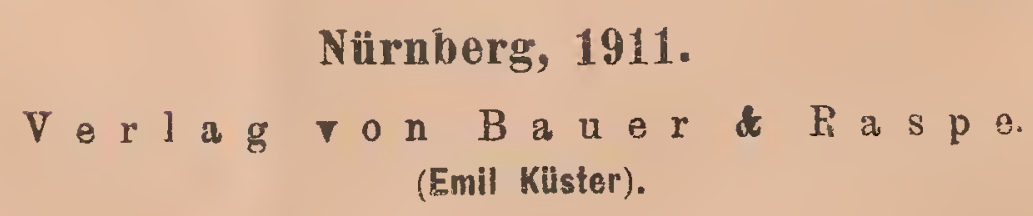




\title{
Die Familie
}

\author{
der \\ He 1 i c i n id a e. \\ Neue Folge.
}

Von

Dr. Anton Wagner.

Nürnberg, 1911.

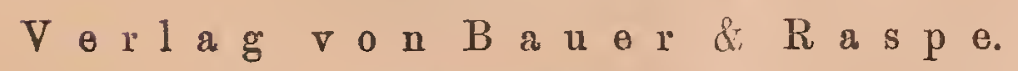

(Emil Küster.) 


$$
Q^{24^{2 x}}
$$




\section{Familie Helicinidae.}

Das Gehäuse linsen, kegelförmig bis kugelig, vollkommen ungenabelt, dagegen mit einem die Insertionen des Mundsaumes verbindenden, mehr minder dicken und ausgebreiteten Basalkallus versehen. Die Mündung wird nur unbedeutend, zumeist aber gar nicht durch den vorletzten Umgang ausgeschnitten. Im Gaumen findet sich eine von der Spindel ausgehende und im Bogen zur Naht veriaufende Schmelzfalte, welche einen festen Deckelschluss unterstützt und nur bei wenigen Formen ganz verkümmert ist. Weitere Falten und zahnartige Bildungen auf der Mündungswand oder dein Mundsaume sind nur bei einigen Gruppen kräftig entwickelt, ebenso Einschnitte und Einbuchtungen am Uebergange des Basalrandes in die Spindel, welche dann einem mehr oder minder deutlichen Fortsatze des Deckels entsprechen und ebenfalls einen festen Deckelschluss unterstützen.

Der Deckel ist stets stark asymetrisch mit Zuwachsstreifen nach dem Paludinentypus, aber mit beginnender spiraler Anlage*).

Das Verbreitunırsgebiet der Heliciniden úmfasst gegenwärtig Amerika mit den Antillen, die Inselwelt des stillen und indischen Ozeans mit Australien und vom Festlande Asiens Südchina und Finterindien.

Bei Betrachtung dieses Verbreitungsgebietes fällt es auf, dass dasselbe unabhängig von der gegenwärtigen Verteilung der Kontinente sich vorzüglich über die Inseln und Küstengebiete des stillen Ozeans erstreckt. Wohl bilden in Amerika die Antillen, in der alten Welt die Seychellen und Mauritius den westlichsten respektive östlichsten Grenzpunkt, doch fehlen Heliciniden in Afrika, Europa und dem grössten Teile von Asien vollkommen (auch von Ceylon Madagaskar, Neu Seeland und Van-Diemensland sind mir dieselben nicht bekannt).

In diesem Gebiete lassen sich zwei Zentren nachweisen, welche durch besonderen Reichtum an Formen und Individuen ausgezeichnet sind. Es sind dies einerseits die Antillen mit Zentralamerika, andererseits die Inseln und Küstengebiete, welche zwischen dem indischen und stillen Ozean gelegen sind. Beide Zentren beherbergen durchwegs eigentümliche Geschlechter und sind derzeit von einander unabhängig, doch deuten einige auffallende Analogien auch hier auf einen gemeinsamen, wenn auch weit zurückreichenden Ursprung. So entsprechen die Formen des Genus Geotrochatella Fischer, welche auf Hinteriudien beschränlit sind (die

*) Zam Verständnisse der hier and weiter angewendeten terminologischen Bezeichnungen folgt unten eine ausfibrliche Terminologie des Helicinidendeckels.

I. 18. II.

16. II. 1907. 
sehr nahe verwandte Pseudotrochatella undulata Morelet findet sich nur mehr fossil auf Mauritius) den Formen des Genus Priotrochatella Fischer von der Isla de Pinos bei Cuba; eine weitere Analogie stellen die Formen der Genera Waldemaria A. J. Wagner aus Japan und Miluna A. J. Wagner aus Südchina gegenüber Hendersonia occulta Say dar, welche mir nur aus dem Südosten der Vereinigten Staaten von Nordamerika bekannt ist. Ferner ist eine năhere Verwandschaft zwischen den Formen des Genus Sulfurina Möllendorff, welche vorzüglich die Philippinen bewohnen und den auf den Antilleul lebenden Alcadien nicht zu verkennen. Das Auftreten dieser analogen Formen ist um so bemerkenswerter, als die Fundorte derselben durch Gebiete getrennt werden in welche zahlreiche, aber nicht näher verwandte Formen, also keine Uebergänge vorkommen.

Schon auf den Philippinen und Molukken, besonders aber auf den Neu Guinea benachbarten Inselgruppen des Bismarcks archipels, der Salomonen, Louisiaden und Palau Inseln leben Formen, welche ich in dem Genus Palaeohelicina zusammenfasse; dieselben weisen eine oft auffallende Uebereinstimmung mit den Formen des Genus Helicina auf, welches nach meiner Auffassung nur auf Amerika beschränkt ist und in grösster Formenzahl in Südamerika vorkommt; aber auch hier fehlt die Brücke, denn die Heliciniden, welche auf den östlicher gelegcnap, also Amerika mehr benachbarten Inselgruppen leben (die Genera Sturanya, Orobopisana und Aphano conia) sind wieder echt altweltliche Formen und mit den südamerikanischen Helicinen nicht näher ver'wandt.

Die Gruppierung der einzelnen Formen nach ihrer näheren Verwandtschaft, die entsprechende Aneinanderreihung solcher Gruppen zu einem Systeme erfordert zunächst die genaueste Kenntnis dieser Formen, welche in ausreichendem Masse uur durch die Beobachtung der Objekte erreicht werden kann; nur die besten Abbildungen können Ersatz bieten, selten die besten Beschreibungen. Diese Bedingung konnte ich nur teilweise erfüllen und unterscheide dementsprechend bei der Aufzählung die von mir untersuchten Formen von solchen, welche ich nur nach den erlangbaren Literaturnachweisen mehr minder unsicher beurteilen konnte. Auf diese Weise mache ich auf die mir bekannten Lücken des Systems aufmerksam und suche zur Ergänzung desselben anzuregen.

Es erscheint auffallend, dass gerade die so schwierig zu untersuchenden und dementsprechend auch schwierig zu beschreibenden Heliciniden durch so zahlreiche Beschreibungen ausgezeichnet wurden; diese reiche Literatur stellt jedoch keinen gleichwertigen Fortschritt in der Kenntnis dieser Formen dar, denn seit bald 100 Jahren werden eben alle Sammelergebnisse nahezu systemlos und ohne Anlehnung an das Bekannte aneinandergereiht. Die Beschreibungen sind aus diesem Grunde vielfach unzureichend und die grosse Zahl der beschriebenen Formen erklärt sich aus der zunehmenden Schwierigkeit das anscheinend Bekannte zu beherrschen. Diese Unsicherheit ist gewiss auch durch den Umstand herbeigeführt worden, dass zur Unterscheidung der eliciniden zunächst nur die Merkmale des Gehäuses 
herangezogen werden, während der Deckel als anscheinend undankbares Beobachtungsobjekt vernachlässigt wurde. Eine sorgfältige Untersuchung des Helicinendeckels hat jedoch ergeben, dass auch an diesem Organe eine Fülle konstanter Merkmale ohne besondere Schwierigkeit zu beobachten ist, welche in Verbindung mit den Merkmalen des Gehäuses die Systematik dieser Familie wesentiich unterstützen.

\section{Terminologie des Helicinendeckels.}

Bei allen Deckelschnecken besteht die erste Anlage des Deckels aus einem der Form der Mündung angepassten Plättchen, dem Nukleus oder Embryonaldeckel, welcher auch am ausgewachsenen Deckel, ăhnlich, wie die Embryonalwindungen am Gehäuse zu erkennen ist. Dieser Embryonaldeckel besitzt noch keine Zuwachsstreifen, doch ist bei einzelnen Formen schon eine mehr minder deutliche spirale Anlage vorhanden.

Entsprechend dem Wachstum der Mündung vergrössert sich auch die Fläche des Deckels, doch findet diese Flächenzunahme sehr verschiedenartig statt. Im Allgemeinen lassen sich zwei Haupttypen der Flächenzunahme unterscheiden, welche ich als Paludinen und $\mathbf{M}^{\prime}{ }^{\prime}$ wientypus bezeichne.

Beim Paludinentypus liegt der Nukleus mehr minder zentral und die Flächenzunahme des Deckels findet in der Weise statt, dass an der Peripherie des Nukleus, neue ringförmive Zonen, konzentrisch wie die Jahresringe eines Baumes angesetzt werden (Paludina, Bythinia, Ampullaria, Melantho, Lioplax etc.).

Bei dem Melanientypus vergrössert sich der Deckel in der Weise, dass neue Zonen nur an einem Teil der Peripherie gebildet werden; so entsteht der Deckel mit spiraler Anlage (Neritidae, Melanidae, Cyclostomidae, Cyclophoridae etc.). Beide Wachstumstypen finden sich in zahlreichen Entwicklungsformen, andererseits werden auch Uebergangsformen beobachtet.' So findet auch bei dem Paludinentypus die Zunahme der Wachstumsringe gewöhnlich mehr minder einseitig statt, sodass der Neukleus selten ganz zentral liegt, häufig aber mehr minder exzentrisch und dem Rande genähert erscheint. Extreme Entwicklungsformen des Paludinentypus, wie sie bei den Heliciniden beobachtet werden, lassen bereits eine beginnende Spirale Anlage mit $1 / 4$ bis $3 / 4$ Umgängen erkennen und liefern so den Beweis, dass zwischen beiden Wachstumstypen kein absoluter Gegensatz besteht. Da ich den Paludinentypus genetisch als die älteste Deckelform betrachte, er'scheinen mir auch die Heliciniden als die ältesten Landschnecken.

Der wesentliche Teil des Deckels ist der untere, häutige oder hornartige Teil desselben, "die Hornplatte"; dieselbe besteht aus zwei dicht aneinanderliegenden Membranen, von welchen die untere stets hornartig oder häutig bleibt, während die obere von verschiedenartigen Kalkinkrustationen bedeckt wird. Diese Kalkinkrustationen sind vom hinfälligen reifartigen Belage bis zur dicken knochenartigen Kalkplatte entwickelt und stellen oft 
mannigfach gestaltete Skulpturen dar; ich bezeichne dieselben im Allgemeinen als „Kalkplat te."

Eine Eigentümlichkeit des Helicinendeckels besteht darin, dass die Flächenzunahme an den einzelnen Teilen der Peripherie verschiedenartig, bald rascher, bald langsamer ist, wodurch die konzentrischen Zuwachsringe gegen einander und den Nukleus in bestimmter Weise verschoben oder verdreht erscheinen und so zu komplizierten Bildungen Anlass geben.

Bei der Beschreibung des Helicinendeckels beachte ich ferner nachstehende Verhältnisse:

Den Umriss oder die Form des Deckels, welche entsprechend der Form der Mündung alle Uebergänge von der schief birnförmigen oder retortenförmigen, halbherzförmigen, halbeitörmigen, dreieckigell bis zur viereckigen Kontur darstellt; dementsprechend kann man an dem Deckel im Allgemeinen einen "Spindelrand ", welcher der Mündungswand anliegt, ferner einen "A ussenrand" und "Oberrand" unterscheiden.

Je nach der besonderen Form des Deckels gehen diese Ränder im Winkel oder Bogen in einander über. Um eine genaue Lokalisierung am Deckel zu ermöglichen bezeichne ich den Winkel am unteren Ende des Spindelrandes als "Spi ndelwinkel", im Gegensatze zum oberen und Aussenwinkel.

Verbindet man dell oberen und den Spindelwinkel del einzelnen Zuwachsringe, so entsteht in Folge des asymetrischen Flächenwachstums des Helicinidendeckels eine zumeisst S-förmig gebogene Linie, welche über den Nukleus verläuft. Die so konstruierte Linie findet sich nun auf der Unterseite des Helicinidendeckels als mehr minder erhobene und deutliche Kante, welche ich als "Sigmakante" bezeichne.

Diese Sismakante, weist bei den einzelnen Formen eine sehr verschiedenartige Entwickelung auf, dieselbe ist mehr weniger gebogen bis gestreckt, mehr weniger erhoben bis undeutlich; ihre Krümmung ist der Ausdruck einer beginnenden spiralen Anlage des Deckels.

Die Unterseite des Deckels wird durch die Sigmakante in zwei meist verschieden breite Teile, die "Aussenseite" und "Spindelseite" geteilt.

Auf der Unterseite des Deckels ist ferner die Lage des Nukleus im Verhältnis zur Peripherie und dem Spindelrande festzustellen. Zentral ist der Nukleus, wenn derselbe vom Spindel und oberen Winkel, ebenso vom Spindel und Aussenrande annähernd gleich weit entfernt ist; andererseits kann der Nukleus als exzentrisch und dem Spindelrande oder dem Spindelwinkel mehr minder genähert bezeichnet werden.

Bei dem Deckel mit spiraler Anlage ist mitunter schon am Nukleus die spirale Anlage erkennbar. Bei randstänigem Nukleus stellt die Sigmakante eine gestreckte Linie dar und die Spindelseite der Platte ist auf einen schmalen Saum beschränkt, oder verschwindet nahezu vollkommen. 


\section{Subfamilie Apiopomatinae.}

Gehäuse kugelig, helixartig mit verhältnismässig grosser aus einem Umgange bestehender Enıbryonalschale. Derkel birnförmig mit seitlich gelsrümmter Spitze, unvollkommen spiral angelegt mit $3 / 4$ Umgängen. Der Nukleus spiral angelegt, exzentrisch und dem Spindelwinkel genährt. Die Sigmakante stellt zumeist nur einen einfachen Bogen dar, welcher vom oberen Winkel zum Nukleus verlauft; der untere Teil vom Nukleus bis zum Spindelwinkel ist mitunter angedeutet.

Die Verbreitung der hier vereinigten Genera erstreckt sich über Japan, Südostchina und den südöstlichen Teil der Vereinigten Staaten von Nordamerika. Die auffallende Uebereinstimmung der asiatischen Formen mit der einzigell Art aus Nordamerika (Hendersonia occulata Say) elstreckt sich nicht nur auf den Deckel, sondern auch auf das Gehăuse.

\section{Genus Waldemaria A. J. Wagner.}

Genus Waldemaria A. J. Wagner, Helicinenstudien in: Denk. Ak. W'ien rol. 77, p. 362, 1905.

Gehäuse kugelig, helixartig mit wenig erhobenem abgerundet. kegelförmigem Gerinde, glănzender, aber hinfälliger Epidermis und feiner Radialskulptur. Die Mündung etwas durch den vorletzten Umgang ausgeschnitten, mit umgeschlagenem und verdicktem Mundsaum. Der balbkreisförnig ausgebreitete Basalkallus ist ziemlich dick.

Deckel mit fester, gegen den Spindelrand an Dicke zunehmender Kalkplatte, wenig erhobener, aber deutlicher Sigmakante, welche vom Spindel und Aussenrand annähernd gleich weit entfernt ist. Der Nukleus nahezu zentral und vom Spindel und Aussenrand gleich weit entfernt. Verbreitungsgebiet Japan.

\section{Waldemaria japonica A. Adams.}

Taf. 1, Fig. 1, 13, 14, 15.

Helicina japonia A. Adams in Ann. Mag. nat. hist. 3 d. ser. 8, p. 141, 1861.

" $\quad$ Pfeiffer Mon. Pneum. III. p. 227, 1865.

$" \quad$ Sowerby Thes. 3. p. 287, T. 271, Fig. 227-228, 1866.

$" \quad$ Martens, Ostas Zool., p. 15, 1867.
$n \quad$ A. J. Wagner, Helicinenstudien in: Denk. Ak. Wien, vol. 77, T. 1. fig. 19, a, b, b, Fig. 12, p. 362, 1905. 
Gehăuse kugelig mit wenig erhobenem, abyerundet kegeförmigem Gewinde, festschalig, gelbbraun mit glänzender, hinfälliger Epidermis, dicht und fein schief radial und leicht Sförmig gerippt. Die $4^{1} \frac{1}{2}$ gewölbten Ungänge nehmen ziemlich langsam und regelmässig zu; der letzte ist kaum ein drittel breiter, als der vorletzte, an der Peripherie gerundet und steigt vorne sehr wenig und langsam herab. Die schief birnförmige Mündung is̄t schief, der weisse und lippenartig verdichte Mundsaum umgeschlagen und häufig verdoppelt. Die kurze, dicke Spindel geht im Bogen in den Basalrand über und bildet am Uebergange eine abgerundete, kanm vol'springende Ecke. Der ziemlich dicke, feingekörnelte Basalkullus ist weiss, zumeist undeutlich begrenzt.

$$
\mathrm{D}=10, \mathrm{~d}=9, \mathrm{H}=7 \mathrm{~mm} \text {. }
$$

Deckel mit glånzender, rotbrauner Hornplatte, sonst typisch Ich beurteile diese Art nach Exemplaren von Tsukuba auf Nippon (im Berliner k. Museum, leg. Hilgendorf); der Originalfundort lautet nach Adams Tabu-Sima, Dimensionen sind bei der Originaldiagnose nicht angeführt. Kleinere Exemplare mit kräftigem bis verdoppeltem Mundsaum kenne ich ausserdem von Asinoiu und Tohishima, Uego in Japan.

\section{Waldemaria japonica reiniana Kobelt.}

Helicina japonica var. reiniana Kobelt, in Fauna jap. extramar. T. 10, F. 12-13, 1879.

Waldemaria japonica reiniauad. J. Wagner Helicinenstudie, in : Denk, Ak. Wien, vol. 77,

T. 1, F. 11 und 18 a, b, p. 362, 1905 .

Gehäuse viel grösser, zitron- bis rotgelb, mit stärker gewölbten, rascher zunehmenden Umgängen, Mundsaum und Basalkallus braungelb.

Fundort: Ibuki-Omi in Japan.

$$
\mathrm{D}=15, \mathrm{~d}=12.5, \mathrm{H}=11.5
$$

Bei den zahlreichen von mir untersuchten Exemplaren war die Epidermis grössenteils verwittert, die Schale vielfach mit grünen Algen überzogen, obwohl die Tiere anscheinend lebend gesammelt und sonst vollkommen frisch waren.

\section{Waldemaria japonica expolita Pilsbry.}

Helicina reinii var. expolita Pilsbry (teste Hirase).

Waldemaria japonica expolita A. J. Wagner, Helicinenstudien in: Denk. Ak. Wien. vol 77, p. $863,1905$.

Gehäuse grösser, jedoch dünnschaliger, nicht gerippt, nur ungleichmässig und fein radial gestreift, gelbbraun bis kastanienbraun mit auffallend glänzender, am letzten Umgange erhaltener Epidermis. Der Mundsaum und Basalkallus gelblich, die abgerundete Ecke am Uebergange der Spindel in den Basalkallus etwas deutlicher vorspringend. 


$$
\mathrm{D}=14, \mathrm{~d}=12, \mathrm{H}=10 \mathrm{~mm} \text {. }
$$

Deckel: die Kalkplatte zarter und dünner.

Fundorte: Katsugan-Awa auf Shikoku und Senzen-Awaji auf Nippon; die Exemplare von letzgenanntem Fundorte sind etwas kleiner und besitzen eine noch deutlicher vorspringende Ecke am unteren Ende der Spindel.

\section{Waldemaria japonica uzensis Pilsbry.}

Helicina reinii var. azen is Pilsbry (teste Hirase).

Gehäuse ăhnlich der japonica reiniana Kobelt, jedoch grösser, kastanienbraun, auffallend kraftiger gerippt. Das kegelförmige, nicht abgerundete Gewinde besteht aus 5 nahezu flachen Umgängen.

$$
\mathrm{D}=17, \mathrm{~d}=14, \mathrm{H}=13 \mathrm{~mm} \text {. }
$$

Deckel mit kräftiger, gelbbrauner Kalkplatte und dunkelrotbrauner Hornplatte.

Fundort: Nishigo-Uzen in Japan.

\section{Genus Miluna A. J. Wagner.}

Genus Miluna A. J. Wagner, Helicinenstudien in: Denk. Ak. Wien. vol. 77, p. 863, 1905.

Gehäuse mit sehr zartem, nur an der Spindel deutlicherem Basalkallus und nur auf der Oberseite entwickelter Radialskulptur

Deckel mit sehr dünner, krustenartiger Kalkplatte, exzentrischem, dem Spindelwinkel genăhertem Nukleus; die Sigmakante nur angedeutet und dem Aussenrande genähert.

Verbreitungsgebiet: Südchina.

Die einzige Art dieses Genus erinnert noch recht auffallend an die japanischen Formen des Genus Waldemaria; der wesentliche Unterschied besteht in der Bauart des Deckels, welcher hier einen nahezu randständigen und dem Spinuelwinkel sehr genaherten Nukleus aufweist und so bei der deutlicher gewordenen spiralen Anlage mit 3/4 Umgängen den Beginn des Melanientypus darstellt. Nur das Vorhandensein von Uebergangsformen, wie sie das Genus Waldemaria darstellt bestimmt mich, diese und ähnliche Formen bei der Familie der Heliciniden zu belassen.

\section{Miluna josefinae A. J. Wagner. Taf. 1, Fig. 3, 7, 8, 9.}

Miluna josefinae A. J. Wagner Helicinenstudien, in: Denk. Ak. Wien, vol. 77, T. I. F. 13 and F. 20 a, b, c. p. $863,1905$. 
Gehănse breit kegelförmig mit gutgewölbter halbkugeliger Basis, ziemlich dünnschalig, gelblich hornfarben, wáchsglänzend. Die Skulptur besteht aus schief radialen, feinen und regelmassigen Rippchen auf der Oberseite, welche auf der Peripherie des letztell Umganges scharf begrenzt sind und auf der Uuterseite in schwache Streifen übergehen. Das ziemlich erhobene Gewinde besteht aus $4^{1} / 2$ langsam und regelmässig zunehmenden, gewölbtel Umgängen; der letzte ist gerundet, kaum breiter, als der vorletzte und steigt unmittelbar vor der Müudung eil wenig herauf. Die halbkreisförmige, wenig schiefe Mündung wird deutlich durch den vorletzten Umgang ausgeschinitten, der weisse Mundsaum erweitert, verdickt und umgeschlagen. Die kurze, dicke Spindẹ! geht im Bogen in den Basalrand über und bildet am Uebergange eine deutliche, abgerundete Ecke.

Der sehr dünne Basalkallus ist nur im Unkreise der Spindel angedeutet.

$$
\mathrm{I}=5 \cdot 5, \mathrm{~d}=4 \cdot 5, \mathrm{H}=4 \mathrm{~mm} \text {. }
$$

Deckel: typisch.

Fundort: Rarlung-Hubei, China.

\section{Genus Hendersonia A. J. Wagner.}

Gehăuse gedrückt kegelig mit 5 bis 6 langsam und regelmăssig zunehmenden Umgängen, dichter Radialskulptur, schwachgekieltem letzten Ungange und hinter dem Basalrande leicht eingeschnürter Mündung.

Deckel nahezu retortenförmig gekrümmt mit sehr dünner, krustenartiger Kalkplatte, randstanndigem, dem Spindelwinkel genähertem Nukleus und wenigg erhobener, aber deutlicher und dem Aussenrande genäherter Sigmakante.

Verbreitung: Südosten von Nordamerika.

\section{Hendersonia occulta Say.}

Taf. 1, Hig. 2, 10, 11, 12.

Oligyra occulta Say Transsylv. Journ. of. Medic. IV. p. 529.

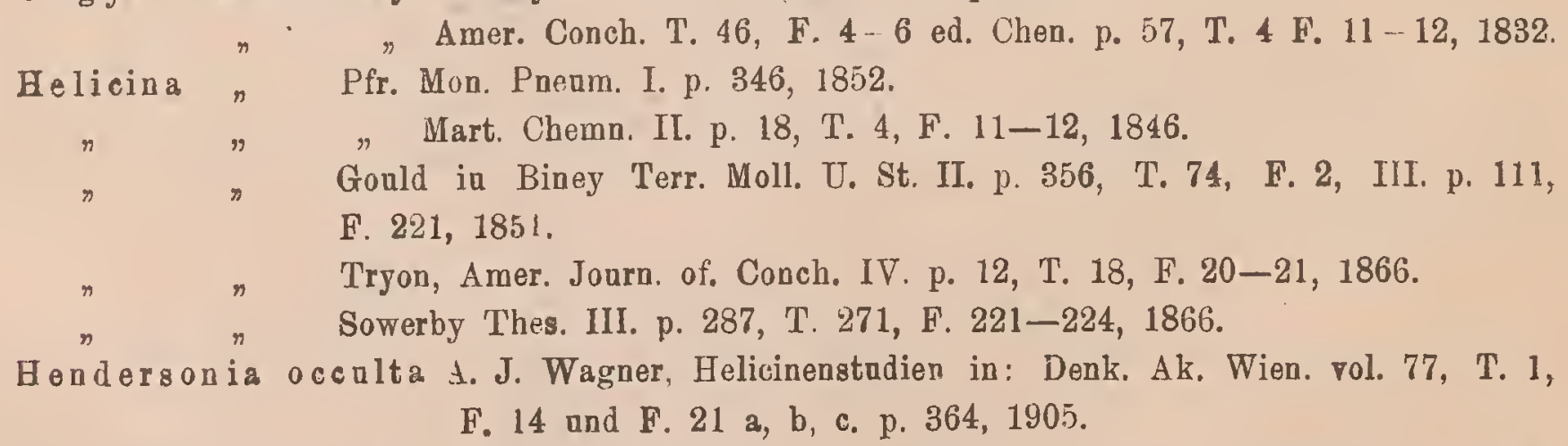

Gebäuse gedrückt kugelig, ziemlich dickschalig, zitrongelb bis dunkel rotbraun, wenig glänzend bis matt. Die Skulptur besteht aus schief S-förmig gebogenen, dicken und feinen 
Rippenstreifen, welche auf der Ober- und Unterseite gleichmässig entwickelt sind. Das ziemlich erhobene, abgerundet kegelförmige Gewinde besteht aus 5 bis $5 \frac{1}{2}$ sehr langsam und regelmässig zunehmenden kaum gewölbten, stumpfgekielten Umgängen, der letzte ist an der Peripherie stumpfkantig, gegen die Mündung zu fast gekielt und steigt vorne langsam, aber deutlich unter den Kiel herab. Die Naht zwischen den unteren Ungängen ist deutlich kantig.

Die abgerundet dreieckige Mündung ist sehr schief und hinter dem Basalrande etwas eingeschnürt; der Mundsaum verdickt bis verdoppelt, gelblich weiss oder hellbräunlich, der Basalrand etwas umgeschlagen, der Oberrand au der Insertion stark vorgezogen. Die kurze, dicke Spindel geht im Bogen in den Basalrand über und bildet am Uebergange eine abgerundete, deutlich vorspringende Ecke. Der Basalkallus dünn und zart.

Deckel: typisch.

$$
\mathrm{D}=6, \mathrm{~d}=5.5, \mathrm{H}=4.7 \mathrm{~mm}
$$

Fundorte: Ich beurteile die Art nach Exemplaren von Jowa City; eine etwas grössere, zum Teile zitrongelbe Form mit 5 $\frac{1}{2}$ Ungängen kenne ich aus Virginien. Auffallend grosse Exemplare mit entsprechend kräftiger Skulptur erhielt ich fernel mit der Fundortsangabe

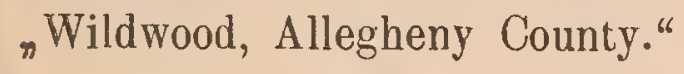

\title{
Il. Subfamilie Pseudotrochatellinae.
}

Gehäuse breit bis flachkegelförmig mit leicht gewölbter bis nahezu flacher Basis, welche in der Spindelgegend eingedrückt ist; $6-8$ langsam zunehmenden, scharf und flügelförmig gekielten Umgängen, auffallend schiefer Mündung. Die sehr schiefen Zuwachsstreifen der Schale sind kräftig bis schuppenartig entwickelt.

Deckel: schmal trapezoidisch mit abgerundeten Winkeln am unteren schmäleren Ende, konkavem Spindel, konvexem Aussenrande und 3/4 Umgängen. Der Nukleus mit angedeuteter spiraler Anlage ist exzentrisch und dem Spindelwinkel sehr genähert; seine Längsachse steht senkrecht zur Längsachse des Deckels. Die Sigmakante ist nur bogenförmig gekrümmt.

\section{Genus Pseudotrochatella Nevil.}

\author{
Pseudotrochatell a Nevil S. As. Soc. Bengal. vol. 50. p. 126, 1881. \\ (part.) A. J. Wagner, Helicinenstudien in: Denk. Ak. Wien. vol. 77, \\ p. $365,1905$.
}

Gehäuse linsenförmig mit stumpfem Apex und sechs gekielten Uıngangen; die Embryonalschale besteht aus $11 / 2$ spiralgestreiften Umgängen und springt nicht warzenartig vor.

I. 18. II.

22. II. 1906. 


\title{
7. Pseudotrochatella undulata Morelet. \\ Taf. 2, Fig. 5, 6, 7 .
}

\author{
Helicina und a lat a Morelet J. de Conch. V. 26, p. 172, 1878. \\ Pseudotrochatella undulata Nevil J. As. Soe. Beng. p. 126, 1881.
}

Gehäuse linsenförmig, in der Spindelgegend tief eingedrückt, ziemlich festschalig; das ziemlich erhobene, abgerundete Gewinde besteht aus 6 flachen, langsam und regelmăssig zunehmenden Umgängen; dieselben besitzen sämtlich einen wellenförmig gefalteten Kiel, welcher bei den oberen Umgängen den folgenden dicht angelegt ist, am letzten eine frei vorspringende wellenförmig gefaltete Kielkrause darstellt. Die Skulptur besteht aus dichten und feinen Spiralstreifen auf der Embryonalschale, die folgenden besitzen etwas schiefe, d chte und leicht wellenförmig gebogene Radialrippchen, welche auf der Oberseite durch $2-3$, auf der Unterseite durch zahlreiche Spirallinien gekerbt und unterbrochen erscheinen. Die annăhernd trapezoidische, mondförmig ausgeschnittene Mündung ist schief, der Mundsaum leicht verdickt; der Oberrand gerade, an der Insertion etwas vorgezogen, der Basalrand breit umgeschlagen. Ein Basalkallus nur angedeutet.

$$
\mathrm{D}=14, \mathrm{~d}=12 \cdot 2, \mathrm{H}=6 \cdot 5 \mathrm{~mm} \text {. }
$$

Deckel: unbekannt.

Fundort: Mauritius (subfossil).

Ich beurteile diese Form nach zwei gut erhaltenen Exemplaren, welche ich von Herrn Evenor Dupont aus Mauritius erhalten habe. Der anscheinend zarte und leicht verwitterbare Deckel ist auch bei diesen Exemplaren nicht mehr vorhanden, doch zeigen die übrigen Merkmale der Schale eine auffallende Uebereinstimmung mit den Formen dieser Subfamilie aus Hinterindien. Die abweichende Beschaffenheit der Embryonalschale, welche hier spiral gestreift ist und aus $1 \frac{1}{2}$ gekielten Umgängen besteht (bei den lebenden Arten der Subfamilie ist die Embryonalschale, glatt oder radial gestreift, an der Peripherie gerundet ragt zitzenartig vor und besteht nur aus einem rasch zunehmenden Umgange) rechtfertigt auch die generische Trennung von den năchstverwandten Formen Hinterindiens.

\section{Genus Geotrochatella P. Fischer.}

Geotrochatella P. Fischer Cat. Moll. Inodo-Chine in Bull. Soc. Hist. nat. Autan IV, p. 113, 1891.

^ H. Fischer J. de Conch. vol. 41, p. 85, 1893.

n Dautzenberg J. de Conch. vol. 43 p. 19, 1895.

Psendotrochatella (part.) A. J. Wagner Helicinenstadien, in: Denk. Akt. Wien, rol. 77, p. 365, 1905. 
Gehăuse mit sechs Umgäng en; die aus einem Umgange bestehende Embryonalschale gewölbt und an der Peripherie gerundet, der Nukleus dementsprechend warzenartig vorspringend, die übrigen Umgänge mit flügelartig vorspringendem und wellenförmig gefalteten Kiel, welcher bei den oberen Umgängen dem folgenden dicht angelegt ist, am letzten eine wellenförmig gefaltete Kielkrausse darstellt; auf diese Weise entstehen oberhalb der Naht regelmässig angeordnete Grübchen uud Rarlialfalten. Der letzte Umgang ausserdem vorne nicht herabsteigend, die Mündung sehr schief, der dünne Basalkallus zumeisst nur angedentet.

Deckel mit zarter, hinfälliger, der Hornplatte dicht anliegender Kalkplatte, leistenartig erhobener Sigmakante, welche dem Aussenrande annăhernd parallel und etwas genähert verlauft.

Verbreitung: Hinterindien, Südchina.

8. Geotrochatella mouhoti Pfeiffer.

Taf. 1, Fig. 5, 6, 20, 21.

Helicina mo tachoti Pfeiffer Pr. Z. S. of London, p. 136, 1860.

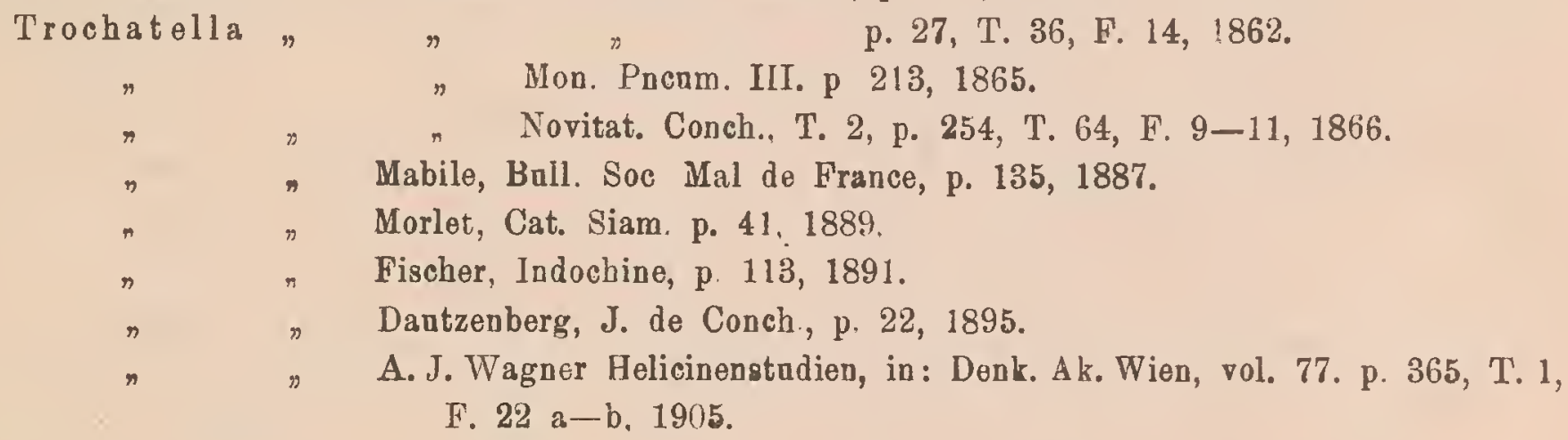

Gehäuse breit kegelförmig mit nahezu flacher, in der Spindelgegend leicht eingedrückter Basis, ziemlich festschalig, gelblich bis graugelb mit unregelmässigen milchigen Flecken und gelber Spitze; matt. Die Skulptur besteht auf den zwei ersten Umgängen aus sehr feinen und ziemlich dichten Streifen, auf den folgenden Umgängen aus sehr schiefen ungleichmässigen, auf dem letzten Umgange nahezu schuppenartigen Zuwachsstreifen; die Grübchen und Falten über der Naht sind ziemlich seicht und nur anf den unteren Umgängen deutlich. Anf der Unterseite sind ausserdem sehr feine, undeutliche Spirallinien vorhanden. Das regelmăssig breit kegelförmige Gewinde besteht aus 6 nahezu Hachen Umgängen, von welchen die zwei ersten rascher, die folgenden langsam und regelmässig zunehmen. Die schief nach unten und aussen gerichtete Kielkrause ist ziemlich breit aber dünn, scharf und zerbrechlich.

Die im Profil lanzettförmige Mündung ist sehr schief und schwach mondförmig ausgeschnitten, der Mundsaum erweitert, kaum verdickt; der Oberrand konvex, an der Insertion stark vorgezogen, dünn und fast gerade, der Basalrand konkav eingezogen, leicht verdickt und umgeschlagen.

Der sehr dünne und nur durch den Glanz bemerkbare Basalkallus verbindet in S-förmigem Bogen die lnsertionen des Mundsaumes. 
Deckel: typisch, rotbraun gefärbt.

$$
\mathrm{D}=18, \mathrm{~d}=16 \cdot 4, \mathrm{H}=8 \cdot 8 \mathrm{~mm} \text {. }
$$

Verbreitung: Gebiet der Laos in Hinterindien; nach Dautzenberg Srakeo, Ong-Son in Siam, Luang Prabang am oberen Mekong.

\title{
9. Geotrochatella jourdyi (Crosse, ms.) Dautzenberg.
} Taf. 1, Fig. 18, 19.

\author{
Helicina (Trochatella) gredleriana, var. L. Morlet (von Möllendorff) Liste de coyuilles \\ recueillies an Tonkin par. M. Jourdy, p. 5, 1887. \\ Geotrochatella jourdyi Dautzenberg J. de Conch. v. 43, p. 25, T. 5, F. 1, 1895.
}

Gehäuse breitkegelförmig mit leicht gewölbter Basis, ziemlich festschalig, oben grauweiss bis schmutziggelb mit gelber Spitze, unten griinlichgelb, matt. Das breitkegelförmige Gewinde ist unter der Spitze leicht konkav und besteht aus $5 \frac{1}{2}$ bis 6 Umgängen, von welchen die zwei ersten leicht gewölbt, die folgenden nahezu flach sind. Die Skulptur besteht auf den zwei ersten Umgängen aus dichten und feinen Radialstreifen, auf den folgenden aus dichten, ziemlich gleichmässigen und kräftigen radialen Zuwachsstreifen, welche auf den unteren Umgängen durch ziemlich dichte Spiralstreifen gegittert erscheinen. Die Unterseite ist fein und dicht, aber deutlich spiral und radial gestreift.

Die wellenförmigen Grübchen und Falten über der Naht zind zahlreich und auch auf den oberen Umgängen deutlich sichtbar. Die sehr schiefe Mündung ist schwach mondförmig ausgeschnitten, der Mundsaum hellgelb, deutlich verdickt, der Oberand gerade, an der Insertion vorgezogen und leicht konvex, der Basalrand umgeschlagen und konkav eingezogen. Der Basalkallus hellgelb, sehr dünn und zart.

$$
\mathrm{D}=22, \mathrm{~d}=19, \mathrm{H}=12 \mathrm{~mm} \text {. }
$$

Deckel : typisch.

Fundort: Krieou in Archipel des Fa-tsi-Long.

Ich beurteile diese Art nach Originalexemplaren des Autors. Von G. mouhoti Pfeiffer unterscheidet sich vorstehende Art durch das unter der Spitze leicht konkave Gewinde, den stärker vorspringenden Apex, die viel dichteren und gleichmässigeren Zuwachsstreifen, die deutlichen, auch auf der Oberseite vorhandenen Spirallinien, die weniger schiefe Mündung, die zahlreicheren und deutlicheren Grübchen über der Naht und den verdickten Mundsaum; von G. martensi Gredler durch die Grösse, Beschaffenheit des Gewindes, die kräftigere Skulptur, die deutlichen und zahlreichen Grübchen über der Naht, die Färbung, und die weniger schiefe Mündung mit verdicktem Mundsaum. 


\section{Geotrochatella martensi Gredler.}

Taf. 2, Fig. 1, 2.

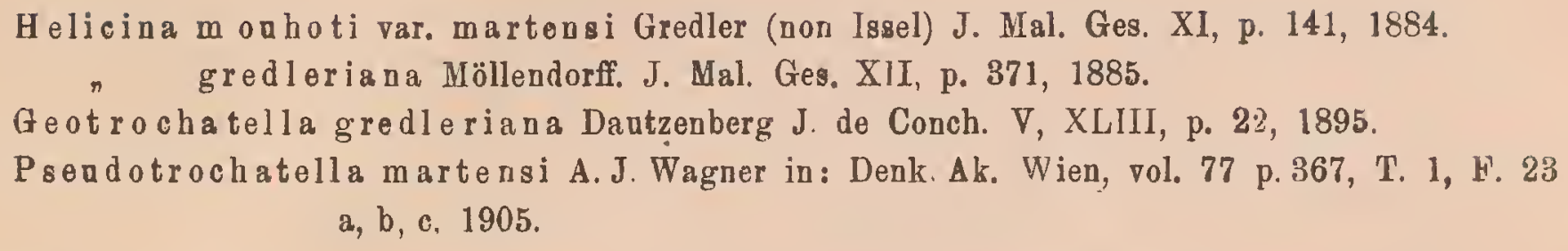

Gehäuse breit kegelförmig mit leicht gewölbter Basis, ziemlich dünnschalig und zerbrechlich, gelblich hornfarben mit unregelmässigen milchigen Flecken, die oberen Umgänge gelb (mit eingetrocknetem Tier graugrün).

Die Skulptur besteht auf den zwei oberen Umgängen aus dichten und feinen Radialstreifen, die folgenden besitzen ungleich mässige, sehr schiefe, radiale Zuwachsstreifen, welche nur auf dem letzten Umgange stärker entwickelt sind, die Basis ist ausserdem sehr schwach, nahezu erloschen, spiral gestreift. Die Falten und Grübchen über der Naht sind flach, oft undeutlich, die Kielkrause dünn, scharf und sehr zerbrechlich.

Das erhobene Gewinde besteht aus $5 \frac{1}{2}$ langsam und regelmässig zunehmenden Umgăngen.

Die sehr schiefe Mündung ist leicht mondförmig ausgeschnitten, der Mundsaum kaum verdickt, der Oberand gerade, an der Insertion vergezogen, etwas konvex, der Basalrand umgeschlagen und konkav. Die sehr kurze Spindel bildet am Uebergange in den Basalrand eine abgerundete Ecke. Der Basalkallus sehr dünn, nur angedeutet.

Deckel typisch

$$
\mathrm{D}=10.3, \mathrm{~d}=10, \mathrm{H}=6.3 \mathrm{~mm} \text {. }
$$

Fundorte: Guang-Hsi und Hupé in China.

\section{Ge otrochatella insignis Dautzenberg.} Taf. 2, Fig. 3, 4.

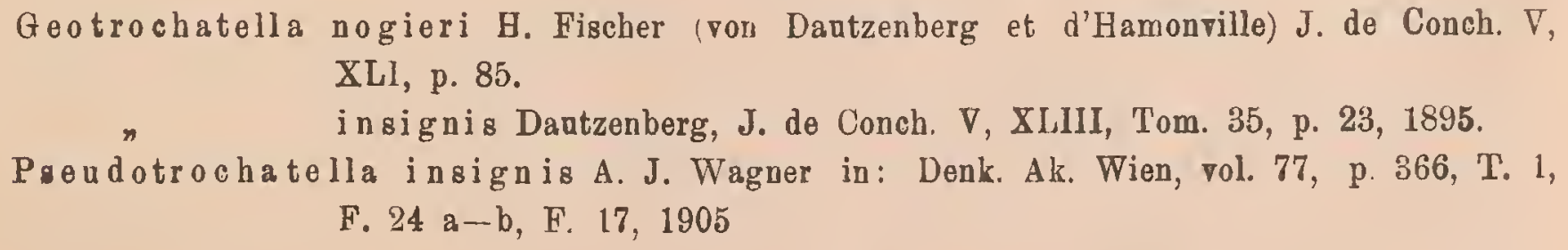
XLl, p. 85. insignis Dantzenberg, J. de Conch. V, XLIII, Tom. 35, p. 23, 1895.

Pseudotrochatella insign is A. J. Wagner in: Denk. Ak. Wien, vol. 77, p. 366, T. 1, F. 24 a-- b, F. 17,1905

Gehäuse breit kegelförmig mit flach gewölbter in der Spindelgegend leicht eingedrückter Basis; ziemlich dünnschalig, etwas durchscheinend, gelbweiss bis gelblich hornfarben mit grünlichem Stich und unregelmässigen milchigen Flecken. Die Skulptur besteht auf den zwei ersten 
Umgängen aus dichten schief radialen Rippenstreifen, auf den folgenden aus sehr schiefen, ungleichmässigen, ziemlich kräfígen Zuwachsstreifen; die Falten und Grübchen über der Naht sind zahlreich, aber flach, die Kielkrause dünn, scharf und sehr zerbrechlich.

Das flach kegelförmige, unter der Spitze konkave Gewinde ist ziemlich erhoben und besteht aus 6 Umgängen, von welchen die zwei ersteu leicht gewölbt sind und rascher zunehmen, die übrigen sind flach bis leicht konkav und nehmen langsam und regelmässig zu.

Die im Profile annähernd schmal trapezoidische Mündung ist sehr schief und wird durch den vorletzten Umgang leicht ausgeschnitten; der Mundsaum ist erweitert, der Oberrand an der Insertion vorgezogen, konvex, dünn und scharf, der Basalrand konkav, leicht verdickt und umgeschlagen, die sehr luurze Spindel geht im Bogen in den Basalrand über und bildet am Uebergange eine wenig vorspringende, abgerundete Ecke Der sehr dünne, nur durch den Glanz erkennbare Basalkallus verbindet in S-förmigem Bogen die Insertionen des Mundsaumes.

$$
\mathrm{D}=21, \mathrm{~d}=18, \mathrm{H}=10 \mathrm{~mm}
$$

Deckel auf der Vorderseite mit sehr dünner, klustenartiger Kalkplatte, auf der Unterseite rotbraun mit kräftig erhobener Sigmakante, welche am unteren Ende löffelartig verbreitert ist; sonst typisch.

Ich beurteile diese Art nach Originalexemplaren des Autors vom Fundorte Haiphong in Tonkin. Von allen bekannten Formen des Genus unterscheidet sich vorstehende Art durch das niedrige Gewinde, die verhältnismässig schwächeren Zuwachsstreifen die flachen Grübchen und Falten über der Naht und an der Kielkrause; die von mir untersuchten Exemplare zeigen nur ausnahmsweise bei starker Vergrösserming eine Spur von feinen und undeutlichen spirallinien.

\section{Geotrochatella nogieri Dautzenberg et d'Hamonville.} Taf. 1, Fig. 16, 17.

\footnotetext{
Trochatella nogieri Dautzenberg et d'Hamonville, in: J. de Conch V. 35, p. 301, $188 \%$. Geotrochatella nogieri L. Morlet, J. de Conch. V. 40, p. 328, T. 8, F. 1, 1892.

* " Dautzenberg J. de Conch. V. 43, p. 23, 1895.

Pseudotrochatella nogieri A. J. Wagner, in: Denk. Ak. Wien vol. 77, p. 368, 1905.
}

Gehăuse breitkegelförmig mit leicht gewölbter Basis, unter der Spitze etwas konkav, ziemlich festschälig. Das erhobene Gewinde besteht aus $6 / 2$ langsam zunehmenden Umgăngen, die zwei ersten sind leicht gewölbt, die folgenden flach bis etwas konkav, der letzte oben eingedrückt. Die Skulptur besteht aus feinen dichten, sehr schiefen radialen Zuwachsstreifen, welche am letzteu Umgange stärker werden, gegen die Mündung zu nahezu in Rippenstreifen übergehen; die Unterseite ist ausserdem sehr fein und etwas wellenförmig spiral gestreift. Die Grübchen und Falten über der Naht sind deutlich und zahlreich, die Kielkrause deutlich wellenförmig gebogen, aber schmal.

Die sehr schiefe Mündung ist schmal trapezoidisch und durch den vorletzten Umgang leicht ausgeschnitten; der Oberrand sehr stark vorgezogen, lippenartig verdickt und umge- 
schlagen, der konkave Basalrand ebenfalls verdickt und umgeschlagen, am Uebergange in die kurze Spindel eine abgerundete, wenig vorspringende Ecke. Der Basalkallus sehr dünn.

Deckel: typisch.

$$
\mathrm{D}=25, \mathrm{~d}=20, \mathrm{H}=14 \mathrm{~mm} \text {. }
$$

Fundort: Than-Moi in Tonkin; die Abbildung und Beschreibung nach einem Originalexemplare des Autors.

\title{
Genus Calybium L. Morelet.
}

\author{
Calybiam L. Morelet, in: J. de Conch. V. 39, p. 316, 1891. \\ n $\quad$ V. 40, p. $326,1892$.
}

Schale und Deckel, «ie bei dem Genus Geotrochatella P. Fischer, an der Spindel und Mündungswand jedoch 5 zahnartige Schmelzfalten.

\section{Calybium masiei L. Morelet.}

Taf. 2, Fig. 8, 9, 10, 11 .

\author{
Caly bi am masi ei L. Morelet, in: J. de Conch V. 39, p. 316, 189\%. \\ ॠ Fischer, V. 40, p. 327, T. 8, F. 2, 1892.
}

Gehäuse flach kegelförmig mit leicht gewölbter Basis, das ziemnlich erhobene Gewinde besteht aus $51 / 2$ langsam und arkcheinend unregelmässig zunehmenden Umgängen indem die übergreifende Kielkrause an den oberen Umgängen durch Verwitterung verschieden breit erscheint; der erste Umgang ist glatt, die zwei folgenden fein und dicht rippenstreifig, beide leicht gewölbt, die übrigen flach bis leicht konkav, oben mit sehr schiefen ziemlich kräftigen bis nahezu schuppenartigen Zuwachsstreifen; der letzte unten fein und dicht radial gestreift, daneben unter der Lupe auch sehr feine bis erloschene Spirallinien. Die Färbung ist schmutzig gelblichgrün, die oberen Umgänge rötlich mit weisslichen unregelmässigen Flecken an der Naht und der Oberseite. Die Grübchen und Faiten über der Naht sind flach und seicht, die wellenförmig gefaltete Kielkrause an der Peripherie des letzten Umganges scharf, aber an den von mir untersuchten Exemplaren ziemlich schmal. Die Mündung sehr schief, der Oberrand des Mundsaumes scharf und gerade, an der Insertion sehr stark vorgezogen, der Basalrand umgeschlagen, verdickt, beim Uebergange in die kurze Spindel eine stumpfe, wenig vorspringende Ecke bildend. An der Mündungswand fünf Falten, zwei stärker gebogene nächst der Spindel, eine längere unter der Naht, dazwischen zwei kürzere und niedrigere. Der Basalkallus in der Umgebung der Spindel leicht verdickt, sonst nur durch stärkeren Glanz angedeutet.

$$
D=20.5, d=18, H=8 \mathrm{~mm} \text {. }
$$


Deckel: wie bei den Formen des Genus Geotrochatella Fischer.

Fundort: Khain-Kent im Gebiete der Laos.

Die Abbildung und Beschreibung nach einem von Dautzenberg mitgeteilten Exemplare.

Das Auftreten von Gaumenfalten bei dieser Art ist nicht vereinzelt, denn Spuren solcher Falten findei sich auch bei Formen anderer Genera z. B. bei Priotrochatella stellata Velas Zuez.

\title{
Genu.s Priotrochatella Fischer.
}

\author{
Genus Priotrochatella Fischer J. de Conch. V. 41, p. 88, 1893.
}

n $n \quad$ A. J. Wagner, in: HelicineustudienDenk. Ak. Wien. vol, 77, p 369 1895.

Gehäuse mit kräftiger Radial und Spiralskulptur, der warzenartig vorsprinzende Embryonalumgang ist glatt und nimmt regelmässig zu, dás Gewinde besteht aus 8 Umgängen.

Deckel mit weisser, ziemlich kräftiger, vorne koukaver Kalkplatte, welche an den Rändern leistenartig von der iformplatte absteht; die wenig erhobeue Sigmakante verläuft in stark gekrümmtem, spiralen Bogen vom Nukleus zur Mitte des Spindelrandes.

Verbreitung: auf der Insel Cuba und der benachbarten Isla de Pinos (Fichteninsel).

\section{Priotrochatella conslellata Morelet.}

Helicina constellata Morelet, in: Rev. zool. p. 144, 1847.

\begin{tabular}{|c|c|c|}
\hline & & \\
\hline & & \\
\hline rachatella & $n$ & Pfeiffer Mon Pnenm I n $334,1852$. \\
\hline$n$ & & M Mart. Ch. 1I, p. 8, T. 9, F. $40-41,1852$. \\
\hline$"$ & , & Crosse J. de Conch. vol. 38, p. $310,1390$. \\
\hline$"$ & $n$ & Sowerby Thes. III. p 296. T. 278, F. $450,1866$. \\
\hline
\end{tabular}

Priotrachatella constellata A. J. Wagner, in: Helicinenstndien Denk. Ak. Wien. vol. 77. p. $370,1905$.

Gehäuse kegelförmig mit nahezu flacher Basis und griffelförmiger Spitze; ziemlich festschalig, gelblich mit weisser Skulptur und weissen Flecken, matt. Der glatte Embryonalumgang ist milchweiss und glănzend, die Skulptur der folgenden Umgänge besteht auf der Oberseite aus 3-5 ziemlich scharfon, aber niedrigen Spiralrippen, welche am letzten Umgange schwächer werden, ferner sind hier S-förmig gebogene, rippenartig erhobene, auf dem letzten Umgange nahezu schuppenartige radiale Zuwachsstreifen vorhanden. Das erhobene, unter der Spitze leicht konkave Gewinde besteht aus 8 langsam zunehmenden Umgăngen, von welchen die 2 ersten gewölbt, die folgenden nahezu flach sind; der letzte steigt auffallend unter den vorletzten herab, ist unten leicht gewölbt und in der Mitte etwas eingedrückt. 
Die 6 unteren Umgånge sind ferner. scharf gekielt; der Kiel ragt an denselben krausenartig vor und ist ziemlich regelmässig gezähnt.

Die sehr schiefe Mündung ist unsymetrisch blattförmig geformt; der Mundsaum kaum erweitert, der Oberrand fast gerade, an der Insertion vorgezogen, der Basalrand umgeschlagen, kaum verdickt geht im winkeligen Bogen in die kurze Spindel über; der Aussen rand entsprechend dem Kiel eckig vorgezogen.

Deckel: typisch.

$$
\mathrm{D}=13, \mathrm{~d}=12, \mathrm{H}=7 \mathrm{~mm} \text {. }
$$

Fundort: Sierra de Cristalles auf Isla de Pinos bei Cuba.

\section{Priotrochatella stellata Velasquez. Taf. 1, Fig. 4, Taf. 2, Fig. 12, 13.}

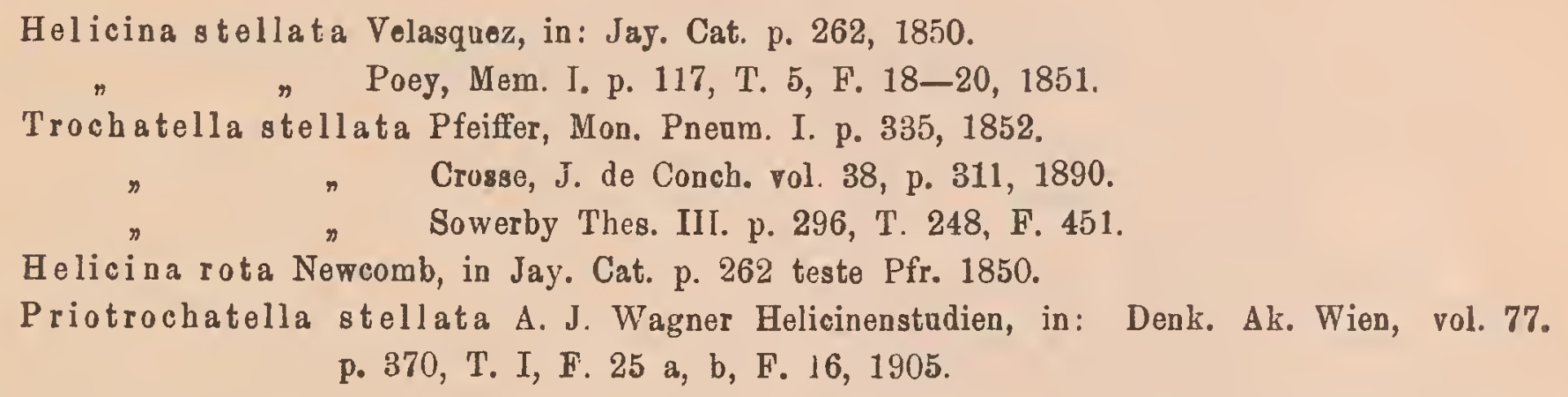

Gehäuse flachkegelförmig mit leicht gewölbter Basis, ziemlich festschalig; gelblich mit weissen unregelmässigen Flecken und weisser Skulptur, matt. Die Skulptur besteht auf der Oberseite der Umgänge aus je 5 bis 6 ziemlich scharfen Spiralrippchen, welche auf dem letzten Umgange schärfer werden, ferner sind radiale, schief S-förmig gebogene, ziemlich gleichmässige, rippen- bis schuppenförmige Zuwachsstreifen vorhanden, die Basis ist gleichmässig und fein radial und spiral gerippt.

Das erhobene Gewinde besitzt eine griffelförmig vorspringende Spitze und ist unter derselben leicht konkav; von den 8 langsam und regelmässig zunehmenden Umgängen sind die 2 ersten gewölbt, die folgenden nahezu flach, scharf und flügelförmig gekielt, der Kiel ist sternförmig gezăhnt und ragt an allen Umgängen krausenförmig vor. Der letzte Umgang steigt vorne nur wenig unter den Kiel herab. Die sehr schiefe trapezoidische Mündung ist leicht mondförmig ausgeschnitten und besitzt an der Mündungswand, parallel der Naht eine deutliche Gaumenfalte; der Mundsaum ist dünn, der Oberrand an der Insertion vorgezogen und gerade, der Basalrand leicht umgeschlagen. Die sehr kurze Spindel geht im Bogen in den Basalrand über. Der sehr dünne Basalkallus verbindet die Insertionen der Mundränder.

$$
\mathrm{D}=13, \mathrm{~d}=11 \cdot 5, \mathrm{H}=7 \mathrm{~mm} \text {. }
$$

Deckel: typisch.

Fundort: Isla de Pinos bei Cuba.

I. 18. II. 


\section{Subfamilie Helicininae.}

Deckel dreieckig bis halbkreisförmig mit einem viertel Umgange; der Nukleus ohne spirale Anlage, zentral oder mehr minder exzentrisch und dem Spindelrande mehr minder genăhert. Die Sigmakante als Ausdruck der beginnenden spiralen Anlage des Deckels mehr minder S-förmig gebogen, vom oberen Winkel über den Nukleus zum Spindelwinkel verlaufend.

Das Verbreitungsgebiet fällt mit jenem der Familie zusammen, doch sind in China und Hinterindien Vertreter dieser Subfamilie nur von einzelnen Punkten an der Küste nachgewiesen.

\section{Genus Sulfurina Möllendorff.}

Sectio Sulfurina Möllendorff, in: Bericht Senkenb. Ges. p. 141, 1893.

Genas Sulfurina A. J. Wagner Helicinenstudien, in: Denk Ak. Wien, vol. 77, p. 371, 1905.

Gehäuse kugelig, kegel- bis linsenförmig, im frischen Zustande glänzend und lebhaft gelb gefürbt, ziemlich dünnschalig. Die schwach entwickelte Skulptur besteht nebst sehr feinen radialen Zuwachsstreifen aus sehr feinen, nur unter der Luppe sichtbaren Spirallinien, welchen bei nicht abgeriebenen Exemplaren sehr feine und hinfăllige Fältchen der Epidermis entsprechen (bei frisch gesammelten Exemplaren haftet diesen Fältchen mitunter eine Schmutzkruste an). Die wenig schiefe Mündung wird durch den vorletzten Umgang nicht ausgeschnitten; der Mundsaum ist stets umgeschlagen, aber wenig verdickt, der Oberrand an der Insertion wenig vorgezogen, der Basalrand gegen die Insertion zu langsam verschmälert, vor dem Uebergange in die Spindel leicht ausgebuchtet. Die kurze, gewöhnlich nach rechts gebogene Spindel bildet am Uebergange in den Basalrand eine zumeist deutliche Ecke. Im Gaumen findet, sich eine von der Spindel ausgehende radial gestellte Schmelzfalte, welche zumeist bis zur Naht verläuft und einen festen Deckelschluss unterstützt. Der halbkreisförmig ausgebreitete Basalkallus ist in der Mitte ziemlich dick, an den Rändern aber nur durch den Glanz deutlich bemerkbar.

Deckel: dreieckig bis halbeiförmig mit geradem Spindelrand und konkaver Vorderseite. Die ziemlich dicke und häufig perlmutterglänzende Kalkplatte ist am Spindelrande leistenartig von der Hornplatte abgehoben. Der Nukleus zentral und mit seiner Längsachse schief zum Spindelrand gestellt; die Sigmakante stark.S-förmig gebogen, leistenartig erhoben, im mittleren Teile verdickt und oft von Granulationen bedeckt.

Verbreitungsgebiet: Das Zentrum des Verbreitungsgebietes dieses Genus liegt anscheinend auf den Philippinen von woher bis jetzt die meisten Formen bekannt geworden 
sind und wo dieselben nach den Sammelergebnissen auch in grosser Individuenzahl leben. Charakteristische Sulfurinen kenne ich ausserdem von den Nikobaren und Andamanen, Sumatra, Borneo, Celebes, Halmahera und Batjan, den Aru-Inseln, Neu-Guinea und von zahlreichen kleineren in diesem Gebiete liegenden Inseln. Dúrch. Färbung und stärkere Epidermisfalten abweichende, aber noch immer durch die wesentlichen Merkmale der Sulfurinen gekennzeichnete Formen, leben ferner auf den Palau-Inseln und auf Ponapé der Ostkarolinen.

\section{Formenkreis Citrina.}

\section{Sulfurina citrina Grateloup.}

Taf. 2, Fig. 15, Taf. 3, Fig. 1, 2, 3.

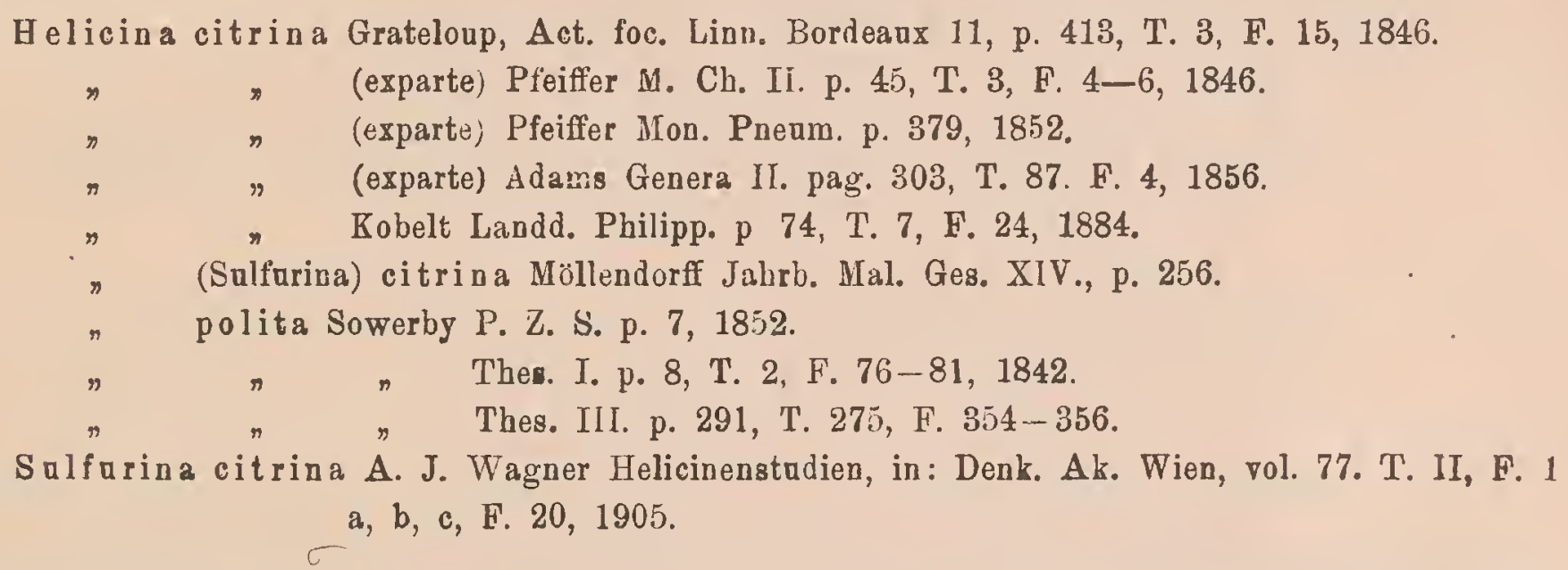

Gehăuse dicklinsenförnig, zienlich dünnschalig, glänzend, citrongelb mit gelblichweissem oder orangefarbenem Mundsaum, durchscheinend, sehr fein radial gestreift. Das flachkegelförmige, wenig erhobene Gewinde besteht aus $4^{1} \frac{1}{2}$ flachen, ziemlich rasch zunehmenden Umgängen, der letzte ist an der Peripherie stumpf kantig, mehr als $1 / 3$ breiter, wie der vorletzte und steigt vorne nicht herab. Die wenig schiefe, abgerundet dreieckige Mündung ist etwas breiter als hoch; der Mundsaum innen leicht verdickt erweitert und umgeschlagen. Die Einbuchtung des Basalrandes vor dem Uebergange in die kurze Spindel ist sehr "schwach, die Ecke daselbst deutlich vorspringend. Der in der Mitte ziemlich dicke Basalkallus ist lichter, als das Gehäuse und sehr fein gekörnelt.

$$
\begin{gathered}
D=14.5, d=11.6, H=8.5 \mathrm{~mm} \\
D=16, d=13, H=10 \mathrm{~mm} .
\end{gathered}
$$

Deckel: vorne perlmutterglänzend, hinten dunkelorange mit stark S-förmigg gekrümter, verdickter und erhobener Sigmakante.

Fundorte: die Insel Luzon und die Küsteninseln Alabat und Catanduanes.

Ich beurteile diese Art nach Exemplaren, welche mir Möllendorff mit der Fundortsangabe "Tayabas, Luzon" als typisch übergeben hat 


\section{Sulfurina citrina apostasis A. J. Wagner. \\ Taf. 3, Fig. 4. \\ Sulfurina citrina apostasis A. J. Wagner Helicinenstudien, in: Denk, Ak. Wien, rol. 77. T. II, F. 2, p. 372, 1905 .}

Gehăuse kleiner, dünnschaliger, das Gewinde mehr erhoben, die Umgänge deutlich gewölbt, der letzte weniger zusammengedrückt, nur am Beginne leicht gewinkelt, gegen die Mündung zu gerundet.

$$
\mathrm{D}=13, \mathrm{H}=7.8 \mathrm{~mm} \text {. }
$$

Deckel mit weniger erhobener Sigmakante, sonst wie bei der typischen Form.

Fundorte: Camarines und Mazaraga auf Luzon.

\section{Sulfurina citrina bicolor Möllendorff (nomen). Taf. 3, Fig. 6.}

Helicina citrina Pfeiffer (exparte) in Chemn. ed II, T. 7, F. 1-2, 1846.

Sulfurina citrina bicolor.A. J. Wagner Helicinenstadien, in: Denk. Ak. Wien, vol. 77, T. II, F. 3, p. 372, 1905.

Gehäuse kleiner, orangegelb, auf der Oberseite milchig getrübt und häufig violetbraun gebändert; das Gewinde etwas höher, der letzte Umgang mehr gerundet, langsamer zunehmend, mit stumpfer aber noch deutlicher Kante; die Mündung so breit als hoch.

$$
\mathrm{D}=11 \cdot 2, \mathrm{H}=7 \cdot 5 \text {. }
$$

Deckel: wie bei der typischen Form.

Fundort: Klaveru, Nord-Luzon (Originalexemplar Möllendorffs).

\section{Sulfurina citrinella celebica Sarasin. Taf. 3, Fig. 5 .}

Helicina citrinella var. celebica Sarasin, Celebes.

Gehăuse kleiner mit höherem Gewinde, langsamer zunehmenden Umgăngen;

Fundort: Kalaiua und Buol auf Celebes.

$$
\mathrm{D}=7, \mathrm{H}=5 \mathrm{~mm} \text {. }
$$




\section{Sulfurina citrinella Möllendorf. \\ Taf 3, Fig. 7, 8, 9, 10.}

Helicina (Sulfurina) eitrinella Möllendorff (exparte) Ber. Senkenb. Ges. p. 141, 1893.

Sulfurina citrinella A. J. Wagner Helicinenstadien, in: Denk. Ak. Wien, vol. 77, T. II, F. 4 a, b, c. p. $373,1905$.

Gehăuse gedrückt kugelig, ziemlich dünnschalig, durchscheinend, glänzend, lichtgelb bis orange mit sehr feinen radialen Zuwachsstreifen. Das wenig erhobene, flachkegelförmige Gewinde besteht aus 4 kaum gewölbten ziemlich rasch zunehmenden Ungängen; der letzte ist fast doppelt so breit wie der vorletzte, an der Peripherie mehr minder deutlich gewinkelt und steigt vorne langsam und wenig herab. Die abgerundet dreieckige Mündunq ist wenig schief, so breit als hoch, der gelbe Mundsaum kaum verdickt, erweitert, schmal umgeschlagen. Die Einbuchtung am Uebergange des Basalrandes in die Spindel deutlich, die abgerundete Ecke daselbst vorspringend.

$$
\mathrm{D}=10 \cdot 3, \mathrm{H}=7 \mathrm{~mm} \text { (nach Möllendorff) }
$$

$$
\mathrm{D}=11 \cdot 2, \mathrm{~d}=9, \mathrm{H}=7 \cdot 3 \mathrm{~mm} \text { (vom Fundorte Dingalan). }
$$

Deckel vorne perlmutterglänzend, hinten hellgelb, die Sigmakante deutlich schwächer gebogen, wie bei S. citrina Grat, sonst typisch.

Fundorte: Ich beurteile diese Art nach Fxemplaren, welche ich vom Autor mit der Fundortsangabe "Dingalan, Mittel Luzon" erhalten habe, entsprechende, nur etwas deutlicher gewinkelte Exemplare befinden sich mit der Fundortangabe „Angat, Luzon, leg. Jagor“ im k. Museum zu Berlin. Möllendorff verzeichnet für diese Art noch die Fundorte Marinduque, Burias und Leyte auf den Philippinen; die von demselben Autor zitierten Vorkommnisse dieser Art auf Cebu, Catanduanes und Mindoro entsprechen nach meiner Auffassung nicht mehr der typischen Form.

\section{Sulfurina citrinella subglobosa Möllendorff. Taf. 4, Fig. 6, 7.}

Helicina (Sulfurina) citrinella var. subglobosa Möllendorf Ber. Senkenb. Ges.p. 143, 1893. Salfarina parva subglobosa A. J. Wagner Helicinenstudien, in: Denk. Ak. Wien, rol. 77. Taf. II, F. 16 a, b. p. 378, 1905.

Gebäus kleiner mit stårker erhobenem Gewinde und mehreren hinfälligen Spiralfalten der Epidermis, welchen an abgeriebenen Exemplaren eingedrürkte Spirallinien entsprechen; die $4 \frac{1}{2}$ deutlicher gewölbten Umgänge nehmen langsamer $\mathrm{zu}$, der letzte ist mehr zusammengedrückt.

$$
\mathrm{D}=9, \mathrm{~d}=7 \cdot 5, \mathrm{H}=6 \mathrm{~mm} \text {. }
$$


Deckel auf der Rückseite oft dunkelgelb, sonst wie bei der typischen Form.

Fundort: Ich beurteile diese Form nach Exemplareu vom Originalfundorte Palanan in N. O. Luzon; vollkommen entsprechende Exemplare kenne ich ausserdem von Digollorin. Libmanan und der Insel Catanduanes bei Luzon, eine kleinere Form von Limutan-Morong, Arayat und Rasignit auf Luzon. Kleine Exemplare dieser Form sind von Sulfurina parva Sow oft schwierig zu unterscheiden; S. citrinella subglobosa Mlldff. hat ein mehr erhobenes kegelförmiges Gewinde, der letzte Ungang 'ist deutlicher zusammengedrückt, an der Peripherie gewinkelt, die Mündung so breit als hoch, die Epidermisfalten zahlreicher. S. parva hat ein weniger erhobenes, abgerundet kegelförmiges Gewinde, der letzte Umgang weist gewöhnlich nur zwei Epidermisfalten auf, ist gleichmässig gerundet und etwas aufgeblasen, die Mündung höher als breit.

\title{
22. Sulfurina euchromia A. J. Wagner.
}

\author{
Taf. 3, Fig. 13, 14.
}

Helicina (Sulfurina) citrinella Möllendorff (exparte), in: Ber. Senkenb. Ges. p. 143, 1893. Sulfurina enchromia A. J. Wagner Helicinenstudien, in: Denk. Ak. Wien, rol. 77, T. II, F. 5 a, b. p. $373,1905$.

Gehäuse flach kegelförmig mit gewölbter Basis, zitrongelb mit 2 milchweissen Binden an Naht und Kiel, selten einfarbig gelb, ziemlich festschalig, glänzend und sehr fein radial gestreift. Das ziemlich erbobene Gewinde besteht aus $4^{1} / 2$ kaum gewölbten, regelmässig zunehmenden Umgängen, der letzte ist zusammengedrückt an der Peripherie deutlich stumpfkantig und steigt vorne nicht herab. Die Kante an der Peripherie ist abgeflacht und wird durch zwei parallele Linien begrenzt, welchen an frischen Exemplaren zarte und hinfällige Spiralfalten der Epidermis entsprechen. Die abgerundet dreieckige Mündung ist wenig schief, der Mundsaum kaum verdickt, erweitert und umgeschlagen. Die Einbuchtung am Uebergange des Basalrandes in die sehr kurze Spindel ist kaum angedeutet, die stumpfe Ecke daselbst kaum vorspringend. Der gelbliche, fein gekörnelte Basalkallus ist in der Mitte ziemlich dick und auch am Rande deutlich begrenzt.

$$
\mathrm{D}=9 \cdot 4, \mathrm{~d}=7 \cdot 5, \mathrm{H}=6 \mathrm{~mm} .
$$

Deckel wie bei S. citrinella Mlldff.

Fundort: Insel Olango bei Cebu. .

Die vorstehende Form lässt sich weder mit S. citrina Grat. noch mit S. citrinella Mlldff. vereinigen und stellt den Typus einer auf den südlichen Philippinen verbreiteten Formenreihe dar.

\section{Sulfurina euchromia bicincta Möllendorff.}

Taf. 3, Fig. 15, 16, 17.

Helieina citrinella var. bicincta Möllenłorff, in: Ber. Senckenb. Ges. p. 144, 1893. 
Sulfurina euchromia a picata A. J. Wagner Helicinenstadien, in: Denk. Ak. Wien, vol. 77. T II, F. 6 a, b, c. p. 374, 1905.

Gehäuse dünnschaliger, stets einfärbig orangegelb, deutlich stumpfgekielt; entlang des Kieles verlaufen zwei parallele Epidermisfalten, welche bei ausgewachsenen Exemplaren zumeist abgerieben sind und dann mitunter durch feine Spirallinien angedeutet werden.

Deckel wie bei der typischen Form.

$$
\mathrm{D}=9, \mathrm{~d}=7 \cdot 3, \mathrm{H}=58 \mathrm{~mm} \text {. }
$$

Fundort: Die Inseln Panaaon bei Leyte, Surigao bei Mindanao und nach zwe Exemplaren des k. Museums in Berlin die Insel Talaver.

\section{Sulfurina euchromia apicata Möllendorf.}

Tat. 3, rig. 18.

Helicina (Sulfurina) c i trinella var. a picat a Möllendorff, in: Ber. Senckenb. Ges.p. 144, 1893. Sulfurina euchromia apicata A. J. Wagner Helicinenstudien, in: Denk. Ak. Wien. vol. 77 , T. II, F. 7 , p. 374, 1905.

Gehäuse wie bei S. euchromia bicincta Mlldff.; das Gewinde jedoch häufig mehr erhoben, der letzte Umgang etwas rascher zunehmend; die oberen Umgänge lebhaft rotbraun, der letzte milchig getrübt

Deckel wie bei der typischen Form.

$$
\mathrm{D}=9, \mathrm{H}=6 \mathrm{~mm} \text {. }
$$

Fundorte: oberer Butuan, Davao und Bislig auf Nordost-Mindanao.

\section{Sulfurina euchromia taviensis A. J. Wagner. Taf. 3, Fig. 11, 12. \\ Sulfurina parva taviensis A. J. Wagner Helicinenstudien, in: Denk. Ak. Wien, vol. 77. T. II, F. 17 a, b. p. $378,1905$.}

Gehäuse kleiner, hellzitronengelb mit einer milchweissen Binde an der Naht der unteren Umgänge, die deutlicher gewölbten Umgänge nehmen rascher zu, der letzte ist an der Peripherie nur undeutlich stumpfkantig, die parallelen Spiralfalten jedoch vorhanden; die Ausbuchtung und Ecke am Uebergange des Basalrandes der Mündung in die Spindel sind deutlicher.

Deckel wie bei der typischen Form.

$$
\mathrm{D}=6, \mathrm{H}=4 \cdot 2 \text {. }
$$

Fundorte: Die Inseln Tawi-Tawi im Sulu-Archipel; auf der Insel Sulu= Jolo lebt eine sehr ähnliche, nur etwas grössere Form, welche anstatt der Nahtbinde nur eine weisberandete Naht besitzt. 


\title{
26. Sulfurina martensi Issel.
}

Taf. 3, Fig. 22, 23, 24.

\author{
Helicina martensi Issel, Bornen, p. 81, T. 6, F. 23-25, 1870. \\ citrina var. minor Martens. Mal. Bl. XX, p. 161, 1873. \\ Sulfurina martensi A. J. Wagner Helicinenstadien, in: Denk, Ak. Wien, vol. 77, T. II, \\ F. 8 a, b, c. p. 374,1905 .
}

Gehäuse kegelförmig mit gewölbter Basis, dünnschalig, einfärbig gelb, glänzend und sehr fein radial gestreift. Das kegelförmige Gewinde besteht aus $4^{1} / 2$ nahezu flachen ziemlich langsam und regelmässig zunehmenden Umgången; der letzte ist im Beginne stumpf gekielt, gegen die Mündung zu nahezu gerundet und steigt vorne nicht herab; entlang des Kieles verlaufen zwei feine, hinfällige Spiralfalten der Epidermis. Die wenig schiefe Mündung ist abgerundet dreieckig, der kaum verdickte Mundsanm erweitert und umgeschlagen. Die Einbuchtung am Uebergange des Basalrandes in die kurze Spindel ist seicht, die Ecke daselbst jedoch deutlich vorspringend. Der in der Mitte verdickte, am Rande undeutlich begrenzte Basalkallus heller, als das Gehäuse.

$$
\mathrm{D}=6 \cdot 5, \mathrm{~d}=5 \cdot 8, \mathrm{H}=5 \mathrm{~mm} \text {. }
$$

Deckel beiderseits gelblich gefärbt mit ziemlich dünner Kalkplatte und nur im mittleren Teile stärker erhobener und verdickter Sigmakante.

Fundorte: Die Inseln Labuan, Paluan und Borneo.

\section{Sulfurina martensi. sumatrana A. J. Wagner.}

Sulfurina martensi sumatrana A. J. Wagner Helicinenstadien in: Denk. Ak. Wien, val. 77, p. 375,1905 .

Gehäuse mit deutlicher gewölbten Umgängen, der letzte an der Peripherie gerundet. $\mathrm{D}=6.5, \mathrm{~d}=5 \cdot 8, \mathrm{H}=5 \mathrm{~mm}$.

Deckel wie bei der typischen Form.

Fundort: Insel Sumatra.

\section{Sulfurina behniana Pfeiffer.} Taf. 3, Fig. 19, 20, 21.

Helicina behniana Pfeiffer Pr. Z. S. p. 29, 1865.

"
$" \quad$ Mon. Pneum., III, p. 237, 1878.

Sulturina bebniana A. J. Wagner Helicinenstadien, in: Denk. Ak. Wien, vol. 77, T. II, F. 9 a, b, c, p. 375,1905 . 
Gehăuse flachkegelförmig mit gewölbter Basis, ziemlich dünnschalig, durchscheinend, glänzend, gelb bis rotbraun gefärbt, mit sehr feinen radialen Zuwachsstreifen. Das ziemlich erhobene, kegelförmige oder leicht abgerundete Gewinde besteht aus $4^{1} / 2$ ziemlich langsam und regelmässig zunehmenden kaum gewölbten bis nahezu flachen Umgängen; der letzte ist stumpf gekielt und steigt vorne nicht herab. Die abgerundet dreieckige Mündung ist wenig schief, der Mundsaum kaum verdickt, umgeschlagen. Die Einbuchtung am Uebergange des Basalrandes in die Spindel ist ziemlich deutlich, die abgerundete Ecke daselbst deutlich vorspringend. Der in der Mitte etwas verdickte Basalkallus ist heller bis weisslich und undeutlich begrenzt.

$$
\mathrm{D}=5 \cdot 8, \mathrm{~d}=4, \mathrm{H}=4 \mathrm{~mm} \text {. }
$$

Deckel gelblich bis hornfarben mit fester Kalkplatte, die Sigmakante besonders im unteren nahezu senkrechten Ast ziemlich erhoben.

Fundort: die Nikobaren.

Von S. martensi Issel durch das niedrigere etwas abgerundete Gewinde, den schärferen Kiel, die etwas rascher zunehmenden Umgänge und die dunkle Färbung unterschieden.

\section{Sulfurina neglecta Tapparone-Canefri.}

Taf. 3, Fig. 28, 29, 30.

Helicina negelecta Tapparone-Canefri; Nuova Guin. Suppl. p. 78, T. 1, F. 16-17.

Aphanoconia neglecta A. J. Wagner Helicinenstudien, in: Denk. Ak. Wien, rol.77, T. IV, F. 16 a-b, p. 393,1905

Gehäuse kegelförmig mit gewölbter Basis, ziemlich dünnschalig, gelb, gelbrot oder hornfarben. Die Skulptur besteht nebst sehr feinen radialen Zuwachsstreifen aus ziemlich dichten, eingedrückten Spirallinien auf der Ober- und Unterseite, welchen an frischen Exemplaren hinfällige Spiralfalten der Epidermis entsprechen. Das kegelförmig erhobene Gewinde besteht aus $41 / 2$ nahezu flachen, ziemlich langsam und regelmässig-zunehmenden Umgängen; der letzte ist an der Peripherie deutlich stumpf kantig, im Beginne nahezu stumpfgekielt und steigt vorne wenig unter den Kiel herab. Die abgerundet dreieckige Mündung ist wenig schief, der Mundsaum kaum verdickt und umgeschlagen. Die Einbuchtung am Uebergange des Basalrandes in die Spindel fehlt, die winkelige Ecke ist deutlich vorspringend. Der helle, gekörnelte Basalkallus ist ziemlich dünn, aber deutlich begrenzt.

$$
\mathrm{D}=5 \cdot 4, \mathrm{~d}=4 \cdot 7, \mathrm{H}=4.4 \mathrm{~mm} \text {. }
$$

Deckel mit gelblicher, perlmutterglänzender, ziemlich fester Kalkplatte; die Sigmakante nur im unteren nahezu senkrechten Aste stärker erhoben.

Fundort: Insel Jobbi nördlich von Neu-Guinea. Ich beurteile diese Art nach einem im k. Museum in Berlin befindlichen Originalexemplare. Nach der Beschaffenheit des Deckels und Mundsaumes (welche Teile des Gehäuses ich anlässlich meiner ersten Publikation über I. 18. II.

29. IV. 1907. 
Helicinen nur an einem verwitterten Exemplare ungenau beobachten konnte und dementsprechend die Art bei den Genus Aphano conia m. einteilte) ist die vorstehende Art eine sichere Sulfurina. Von der ähnlichen S. martensi Issel unterscheidet sich dieselbe durch das weniger glänzende Gehäuse, das höhere Gewinde, den deutlicheren Kiel und die dichten Spirallinien.

\section{Sulfurina laurae A. J. Wagner.}

Taf. 3, Fig. 25, 26, 27.

Sulfurina lanrae A. J. Wagner Helecinenstudien, in: Denk. Ak. Wien, vol. 77, T. II, F. 11, a. b, c, p 376, 190i.

Gehüuse breit kegelförmig mit gut gewölbter Basis, festschalig, undurchsichtig, einfärbig gelb oder unter der Peripherie des letzten Umganges rotbraun gebändert; mit feinen radialen Zuwachsstreifen. Das ziemlich erhobene Gewinde besteht aus $4^{1} / 2$ regelmåssig zunehmenden, nahezu flachen Umgängen, der letzte ist zusammengedrückt, an der Peripherie stumpfkantig und steigt vorne wenig, aber deutlich herab. Die abgerundet dreieckige Mündung ist schief, der weisse Mundsaum lippenartig verdickt und umgeschlagen. Die Einbuchtung am Uebergange des Baselrandes in die Spindel, ebenso die Ecke daselbst sind deutlich. Der feingekörnelte Basalkallus in der Mitte etwas verdickt und heller, als das Gehäuse, undeutlich begrenzt.

$$
\mathrm{D}=10, \mathrm{~d}=8 \cdot 5, \mathrm{H}=7 \mathrm{~mm} \text {. }
$$
erhoben.

Deckel mit gelblich gefärbter, ziemlich dicker Kalkplatte, die Sigmakante deutlich

Fundort: Halmahera.

\section{Sulfurina bensoni $n$. \\ Taf. 4, Fig. 1, 2, 3 .}

Gehäuse sehr klein, kegelförmig mit gewölbter Basis, gelbbraun mit 2 weissen Binden an Naht und Kiel, die oberen Umgänge hellrotbraun. Die Skulptur besteht nebst sehr feinen radialen Zuwachsstreifen aus einigen nur unter der Lupe sichtbaren und fast erloschenen Spirallinien. Das kegelförmig erhobene Gewinde besteht aus 4 langsam und regelmässig zunehmenden, flachen Umgängen, der letzte ist stumpf gekielt und steigt vorne sehr wenig und langsam unter den Kiel herab. Die abgerundet dreieckige Mündung ist wenig schief, der Mundsaum kaum verdickt und wenig ausgebreitet; die Ausbuchtung am Uebergange des Basalrandes in die Spindel ist seicht, die Ecke daselbst deutlich sichtbar. Der ziemlich dicke Basalkallus ist deutlich begrenzt. 


$$
\mathrm{D}=3 \cdot 6, \mathrm{~d}=3 \cdot 3 \mathrm{H}=2 \cdot 6 \mathrm{~mm} \text {. }
$$

Deckel beiderseits gelblichweiss mit ziemlich dicker fein gekörnelter Kalkplatte und deutlich erhobener Sigmakante.

Fundort: Nikobaren. Die mir vorliegenden Exemplare dieser Form erhielt ich von den Herrn Sowerby und Fulton; dieselben weissen einige Uebereinstimmung mit der Beschreibung der mir bisher nicht zu Gesicht gekommenen Helicina scrupulum Benson auf, sind jedoch kleiner, es fehlen die 2 roten Bănder über der Peripherie, der letzte Umgang ist deutlich stumpfgekielt und die Mündung nicht mondförmig (soll wohl bedeuten ausgeschnitten).

\title{
32. Sulfurina spha eridium Möllendorff.
}

\author{
Taf. 4, Fig. 4, 5.
}

\author{
Helicina (Sulfurina) p haeridium Möllendorff Nachr. Bl. V p. 15. \\ Sulfurina sphaeridium A. J. Wagner Helicinenstadien, in: Denk. Ak. Wien, rol. 77, T. II, \\ F. 10 a, b, c, p. $375,1905$.
}

Gehäuse sehr klein, flachkegelförmig mit annăhernd halbkugeliger Basis und stumpfem Apex, ziemlich festschalig glänzend, blassgelb bis horngelb, oben bräunlich bis rötlich. Die Skulptur besteht nebst sehr feinen radialen Zuwachsstreifen aus einigen weitlaufigen und hinfälligen Spiralfalten der Epidermis. Das ziemlich erhobene Gewinde besteht aus $3^{3 / 4} \mathrm{kaum}$ gewölbten, regelmässig zunehmenden Umgängen; der letzte ist im Beginne stumpfkantig, gegen die Mündung zu nahezu gerundet und steigt vorne wenig herab. Die wenig schiefe Mündung ist annähernd halbkreisförmig, der Mundsaum kaum verdickt und umgeschlagen.

Die Einbuchtung am Uebergange des Basalrandes in die Spindel, ebenso die Ecke daselbst sind nur angedeutet, der hellere feingekörnelte Basalkallus, in der Mitte verdickt, undeutlich begrenzt.

$$
\mathrm{D}=4, \mathrm{~d}=3, \mathrm{H}=2.5 \mathrm{~mm} \text {. }
$$

Deckel gelblich mit verhältnismässig dicker Kalkplatte, aber wenig erhobener Sigmakante.

Fundort: Insel Tablas der Philippinen (die Beschreibung und Abbildung nach Originalexemplaren des Autors).

\section{Formenkreis Globulina A. J. Wagner.}

\section{Sulfurina crossei Pfeiffer.}

Taf. 4, Fig. 14, 15, 16.

Helicina erosnei Pfeiffer Mon. Pnenm. III. p. 223, 1865.

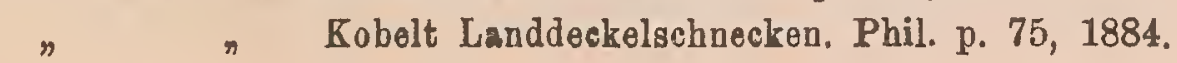


Helicina crossei Sowerby Thes. III. p. 291, T. 275, F. 357.

Sulfurina crossei A. J. Wagner Helicinenstudien, in: Denk. Ak. Wien, rol. 77, T. III, F. 1 a, b, c, p. 367,1905

Gehäuse gedrückt kugelig, ziemlich festschalig, einfärbig dunkel orange, glänzend mit feinen radialen Zuwachstreifen. Das wenig erhobene, etwas abgerundete Gewinde besteht aus $4 \frac{1}{2}$ wenig gewölbten, ziemlich rasch zunehmenden Umgangen; der letzte ist etwas aufgeblasen, an der Peripherie gerundet und nur im Beginne etwas zusammengedrückt, vorne nicht herabsteigend. Die halbkreisförmice Münung ist sehr wenig schief, der orangefarbene Mundsaum erweitert, leicht verdickt und schmal umgeschlagen. Die Einbuchtung am Uebergange des Basalrantes in die Spindel, ebenso die spitzwinkelige Ecke daselbst sind deutlich sichtbar. Der gleichfarbige Basalkallus ist in der Mitte verdickt, im Umkreise der Spindel deutlich begrenzt.

$$
\mathrm{D}=10 \cdot 6, \mathrm{~d}=8 \cdot 9, \mathrm{H}=7 \cdot 5 \mathrm{~mm} .
$$

Deckel vorne perlmutterglänzend, hinten oränge mit stark erhobener und verdickter Sigmakante.

Fundort: Palanan, Nordost-Luzon.

\section{Sulfurina parva Sowerby.}

Taf. 4, Fig. 17, 18, 19.

Helicina parva Sowerby P8. Z. S. p. 8, 1842.

n $\rightarrow$ Thes. p. 8, T. 2, F. 8\%.

n $n \quad$ Pfeiffer, Mon. Pnenm. I p. 397, 1852.

$" \quad \pi \quad$ Kobelt Landd. Philipp. p. 75, 1884.

n Möllendorff, Jahrb. Mal. Ges. XIV. p. 257, 1867.

๓ Sowerby Thes. p. 286, T. 271, F. 210.

Sulfurina parva A. J. Wagner Helicinenstadien, in: Denk. Ak. Wien, rol. 77, T. II, F. 12 a, b, c, p. 377, 1905 .

Gehäuse gedrückt kreiselförmig, ziemlich festschalig, durchscheinend, glänzend, hellgelb bis zitrongelb, der letzte Umgang häufig etwas milchig getrübt, die oberen Umgänge mitunter rötlich. Die Skulptur besteht nebst sehr feinen radialen Zuwachsstreifen aus einigen hinfalligen, zarten Spiralfalten der Eipidermis welchen an abgeriebenen Schalen, feine eingedrückte Spirallinien entsprechen (zwei Spirallinien an der Peripherie sind zumeist sichtbar). Das niedrige, abgerundet kegelförmige Gewinde besteht aus $4 \frac{1}{2}$ ziemlich langsam und regelmässig zunehmenden, leicht gewölbten Umgängen, der letzte ist wenig breiter, als der vorletzte, an der Peripherie gerundet und steigt vorne nicht herab. Die halbkreisförmige Mündung ist schief, der weisse Mundsaum kaum verdickt, kurz ausgebreitet, die Einbuchtung am Uebergange des Basalrandes in den Spindelrand undeutlich, die stumpfe Ecke daselbst 
kaum vorspringend. Der glänzende, feingekörnelte, in der Mitte hellere und deutlicher verdickte Basalkallus ist ziemlich deutlich begrenzt.

$$
\mathrm{D}=6, \mathrm{~d}=5 \cdot 2, \mathrm{H}=4 \cdot 4 \mathrm{~mm} \text {. }
$$

Deckel vorne perlmutterglänzend, hinten gelblich mit ziemlich dicker Kalkplatte und in der Mitte stärker erhobener und gebogener Sigmakante.

Fundorte: die Inseln Luzon, Katanduanes, Marinduque, Panay, Cubu, Samar, Mindanao, Bohol, Panglao, Mindoro und Balagnan der Philippinen; ferner lebt diese Art auch auf zahlreichen Inseln des indischen Ozeans zwischen Celebes und Neu-Guinea. Innerhalb dieses grossen Verbreitungsgebietes wurden zahlreiche, wenn auch nur wenig abweichende, aber anscheinend konstante Lokalformen beobachtet. Eine sichere Unterscheidung dieser Formen wird aber stets nur bei genauer Beachtung des Fundortes möglich sein.

\section{Sulfurina parva minima A. J. Wagner.}

Taf. 4, Fig. 27, 28.

Sulfarina parva minima A. J. Wagner Helicinenstudien, in: Denk. Akt. Wien, rol. 77, T. II, F. 15 a, b, p. 377,1905

Gehäuse sehr klein, hell zitronengelb, nahezu kugelig mit nur 4 deutlicher gewölbten Umgăngen.

$$
\mathrm{D}=5, \mathrm{H}=3.6 \mathrm{~mm} \text {. }
$$

Deckel wie bei der typischen Form.

Fundort: Insel Katanduanes der Philippinen.

$$
\begin{aligned}
& \text { 36. Sulfurina parva globulina Möllendorff (nomen). } \\
& \text { Taf. 4, Fig. } 20,21 . \\
& \text { Helicina (Sulfurina) globulina Möllendorff (nomen) Verz. der auf den Philipp. lob. Laud- } \\
& \text { moll., in: Abhandl. Naturforsch. Ges., vol. XXII., p. 182, 1897. } \\
& \text { Sulfurina parva globulin a A. J. Wagner Helicinenstudien, in: Denk. Ak. Wien, vol. 77, } \\
& \text { T. II, F. } 13 \text { a, b, c, p. 377, 1905. }
\end{aligned}
$$

Gehăuse grösser, festschaliger, zitron- bis orangegelb; die Spiralfalten der Epidermis selten angedeutet, die $4 \frac{1}{2}$ Umgänge mehr gewölbt und rascher zunehmend, der letzte starker erweitert, weniger zusammengedrückt.

$$
D=8 \cdot 5, d=7 \cdot 5, H=6 \mathrm{~mm} .
$$

Deckel wie bei der typischen Form.

Fundorte: Tablas, Romblon, Monte Bulagao, Cagayan und Paurian auf Luzon. 


\section{Sulfurina parva hy alina Hartmann. \\ Taf. 4, Fig. 24, 25.}

Helicina hyalin a Hartmann, in: Pr. Akad. Philad. p. 285, T. 3 F. 6, 1880.

Sulfurina parva hyalins A. J. Wagner Helicinenstadien, in: Denk. Ak. Wien, vol. 77, T. II, F. 14 a, b, p. 378, 1905.

Gehäuse kreiselförmig, dünnschaliger, hellorangegelb. Das auffallend erhobene Gewinde besteht aus $4 \frac{1}{2}$ langsamer zunehmenden Umgängen, der letzte ist gerundet; die weniger schiefe Mündung höher, als breit.

Deckel wie bei der typischen Form.

$$
D=5.5, d=4.8, H=4.7 \mathrm{~mm} .
$$

Fundort: Berg Halcone auf Mindoro der Philippinen.

\section{Sulfurina parva electrina Pfeiffer.}

Taf. 4, Fig. 22, 23.

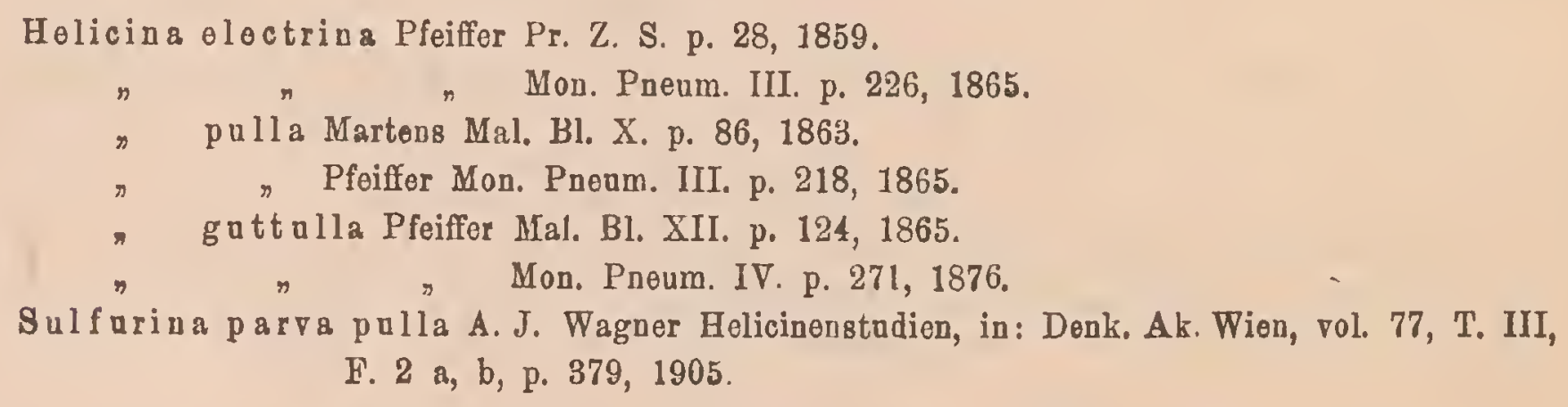

Gehăuse einfärbig hellgelb, rotgelb bis dunkelorange, die oberen Umgänge dunkler, bei hellgelber Grundfarbe rötlich; der letzte Umgang ist etwas aufgeblasen, mehr gerundet und steigt vorne etwas herab.

Deckel wie bei der typischen Form.

$$
\mathrm{D}=6 \cdot 2, \mathrm{~d}=5 \cdot 8, \mathrm{H}=4.4 \mathrm{~mm} \text {. }
$$

Fundorte: die Inseln Halmahera, Batjan, sowie die Aru-Inseln. Ich hatte Gelegenheit die angeführten Formen nach Exemplaren von den Originalfundorten zu vergleichen und finde, dass dieselben in ihren wesentlichen Merkmalen vollständig übereinstimmen und auch von der typischen Form der Philippinen nur wenig verschieden sind.

\section{Sulfurina parva elata n.}

Taf. 4, Fig. 26.

Holicina parva. Sarasin. 
Gehäuse kreiselförmig mit auffallend erhobenem Gewinde, der letzte Umgang vorne etwas herabsteigend.

Deckel wie bei der typischen Form.

$$
\mathrm{D}=5, \mathrm{H}=4 .
$$

Fundort: Maros auf Celebes.

\author{
40. Sulfurina parva tomiana Rolle (nomen?) \\ Taf. 4, Fig. 31, 32. \\ Sulfurina parva tomiana A. J. Wagner Helicinengtudien, in: Denk. Ak. Wien, vol. 77, \\ T. II, F. 19 a, b, c, p. 379, 1905.
}

Gehăuse ziemlich festschalig, kugelig mit weniger erhobenem, abgerundetem Gewinde, rotgelb bis dunkelorange oder gelbbraun mit undeutlichen, hinfälligen Spiralfalten der Epidermis; die 4 leicht gewölbten Umgänge nehmen regelmässig zu, der letzte ist gerundet, etwas aufgeblasen und steigt vorne sehr wenig herab. Der ziemlich dicke und glänzende Basalkallus ist mit dem Gehauuse gleichfärbig.

Fundort: Insel Tukan Bessi südöstlich von Celebes.

\title{
41. Sulfurina parva selajarensis A. J. Wagner. \\ Taf. 4, Fig. 29, 30.
}

Sulfurina parva selajarensis A. J. Wagner Helicinenstudien, in: Denk. Ak. Wien, rol. 77, T. II, F. 18 a, b, c, p. $379,1905$.

Gehäuse kleiner, kugeliger mit nur $31 / 2$ nahezu flachen, rascher zunehmenden Umgăngen, der letzte vorne ein wenig herabsteigend; hellgelb, häufig milchig getrübt, die oberen Umgänge dunkler.

Deckel wie bei der typischen Form.

$$
\mathrm{D}=5, \mathrm{~d}=4 \cdot 4, \mathrm{H}=3 \cdot 6
$$

Fundort: Insel Selajer = Saleyer südlich von Celebes.

\section{Sulfurina parva micholitzi Möllendorff (nomen).}

Taf. 5, Fig. 5, 6 .

Helicina (Sulfarina) micholitzi Möllendorff, in: Verach. Abhandl. naturforseh. Ges, vol. 22, p. 182 (nomen).

Sulfurina micholitzi Möllendorff, in: Denk. Ak. Wien, rol. 77, T. III, F. 3 a, b, p. 379, 1905 . 
Gehäuse kugelig kreiselförmig, die Grundfarbe dunkelgelb mit einer milchweissen Nahtbinde und einer milchig getrübten mehr minderbreiten Zone unter der Peripherie. Die Umgänge etwas flacher, der letzte mit einigen Spiralfalten der Epidermis, vorne ein wenig herabsteigend. Die Ecke am Uebergange des Basalrandes in die Spindel deutlicher vorspringend.

$$
\mathrm{D}=5, \mathrm{~d}=4 \cdot 4, \mathrm{H}=3 \cdot 6 \mathrm{~mm} \text {. }
$$

Deckel beiderseits gelblich, sonst der typischen Form entsprechend.

Fundorte: die Inseln Ilin und Calamian südwestlich von Minodoro. Die Exemplare von Ilin sind durchwegs kleiner, die Unterseite des letzten Umganges ist milchig getrübt, so dass von der gelben Grundfarbe nur ein gelbes Band über der Peripherie übrigbleibt.

\title{
43. Sulfurina zelebori Pfeiffer.
}

\author{
Taf. 5, Fig. 1, 2, 3 .
}

\author{
Holicina zelebori Pfeiffer, in: Verh. Zool. bot. Ges. Wien, vol. 17 p. 807, 1867. \\ Pachystoma zelebori Frauenfeld, in: Verh. Zool. bot. Ges. Wien, rol, 19, p. 859, 1869. \\ Heli cin a \\ J. de Conch., p. 237, 1872. \\ alfurina \\ $n \quad$ Pfeiffer Mon. Pneum. IV. p. 247, 1876. \\ \#. J. Wagner Helicinenetadien, in: Denk. Ak. Wien, vol. 77, T. III, \\ Fig. 5 a, b, c, p. 380, 1905 .
}

Gehăuse klein, kegelförmig mit gewölbter Basis, feschalig glänzend, blass strohgelb, der letzte Umgang hăufig milchig getrübt.

Das ziemlich erhobene Gewinde besteht aus 4 langsam und regelmăssig zunehmenden, leicht gewölbten Umgängen, der letzte ist gerundet und steigt vorne ein wenig herab. Die annăhernd halbkreisförmige Mündung ist schief, der weisse Mundsaum kaum verdickt, kurz ausgebreitet. Die Einbuchtung und Ecke am Uebergange des Basalrandes in die kurze Spindel ist undeutlich. Der ziemlich dicke, glänzende Basalkallus ist mit dem Gehäuse gleichfărbig.

$$
\mathrm{D}=4 \cdot 4, \mathrm{~d}=3 \cdot 8, \mathrm{H}=3 \cdot 4 \mathrm{~mm} \text {. }
$$

Fundort: die Nikobaren.

\author{
44. Sulfurina zelebori amphibola A. J. Wagner. \\ Taf. 5, Fig. 4. \\ Sulfurina zelebori amphibola A. T. Wagner Helicinenstadien, in: Denk. Ak. Wien, vol. \\ 77, T. III, F. 4, p. $380,1905$.
}

Gehäuse grösser, kugelig kreiselförmig, gelblich hornfarben bis braun; häufig mit dunkler Spitze und milchiger Trübung der unteren Umgănge, auf welchen dann die Grundfarbe nur in zwei verschieden breiten, gelbbraunen bis dunkelbraunen Binden hervortritt. Der letzte 
Umgang ist mehr gerundet und steigt vorne deutlicher herab, der Mundsaum mehr aus. gebreitet.

$$
\mathrm{D}=5, \mathrm{H}=3.8 \mathrm{~mm} \text {. }
$$

Deckel wie bei der typischen Form.

Fundort: die Andamanen. Die vorstehende Form wird gegenwärtig konstant mit Helicina scrupulum Benson verwechselt, nach der Beschreibung besitzt diese mir unbekannte Form ein linsenförmiges Gehäuse, mit stumpfkantigem letzten Umgange und eine dreickige, mondförmige Mündung, dürfte also wahrscheinlich der Sulfurina bensoni m. von den Nikobaren oder Aphanoconia nicobarica Philippi verwandt sein.

Nachstehende Formen besitzen eine kräftigere Epidermis mit deutlicher Spiralsulptur und eine abweichende Färbung; dieselben dürften besondere Formenkreise repräsentieren.

\section{Sulfurina jickelii A. J. Wagner.}

Taf. 5, Fig. 7, 8, 9.

Sulfurina jickelii A. J. Wagner Helicinenstudien, in: Denk. Ak. Wien, vol. 77, T. IV, F. 1, a, b, c, p. 381,1905 .

Gehäuse sehr klein, gedrückt kugelig, ziemlich festschalig, gelblich hornfarben bis hellrotbraun, glänzend. Die Skulptur besteht nebst feinen radialen Zuwachsstreifen aus dichten und feinen, eingedrückten Spirallinien, welche auf den oberen Umgängen deutlicher sind. Das wenig erhobene, abgerundete Gewinde besteht aus $3^{3 /}{ }_{4}$ ziemlich rasch zunehmenden, nahezu flachen Umgăngen, der letzte ist etwas zusammengedrïckt, im Beginne undeutlich kantig und steigt vorne sehr wenig herab. Die halbkreisförmige Mündung ist wenig schief, der Mundsaum kaum ausgebreitet. Die Einbuchtung und Ecke am Uebergange des Basalrandes in die kurze Spindel ganz undeutlich. Der ziemlich dicke, glänzende Basalkallus, gelblich gefärbt, deutlich begrenzt.

$$
\mathrm{D}=3 \cdot 8, \mathrm{~d}=3, \mathrm{H}=2 \cdot 2 \mathrm{~mm} \text {. }
$$

Deckel unbekannt.

Fundort: Stirling range in Britisch Neu-Guinea.

\section{Sulfurina sturanii A. J. Wagner.}

Taf. 4, Fig. 8, 9, 10.

Sulfurina staranii A. J. Wagner Helicinenstudien, in: Denk. Akt. Wien, vol. 77. T. III, F. 6 a, b, c, d, p. 381, 1905.

I. 18.11 . 
Gehäuse breit kegelförmig mit gewölbter Basis, ziemlich festschalich, gelblich bis rötlich hornfarben, durchscheinend, im frischen Zustande matt mit ziemlich dichten Spiralfalten der Epidermis, abgerieben glänzend mit sehr feinen und dichten eingedrückten Spirallinien.

Das kegelförmig erhobene Gewinde besteht aus $4 \frac{1}{2}$ ziemlich langsam und regelmässig zunehmenden, leicht gewölbten Umgängen, der letzte ist etwas zusammengedrückt, an der Peripherie stumpfkantig und steigt vorne nicht herab.

Die abgerundet dreieckige Mündung ist ziemlich schief, der Mundsaum weiss, verdickt, ziemlich ausgebreitet und umgeschlagen. Die Einbuchtung am Uebergange des Basalrandes in die Spindel, ebenso die Ecke daselbst sind undeutlich. Der dünne Basalkallus ist heller, als das Gehăuse, glänzend, fein gekörnelt und nur im Umkreise der Spindel deutlich begrenzt.

$$
\mathrm{D}=62, \mathrm{~d}=5 \cdot 2, \mathrm{H}=5 \mathrm{~mm}
$$

Deckel mit ziemlich dicker, matter Kalkplatte und wulstig verdickter, deutlich erhobener Sigmakante, vorne schmutzig weiss, rückwärts gelblich gefärbt.

Fundort: Aibukit, Palau-Inseln.

\section{Sulfurina humilis Hombron et Jaquinot. \\ Taf. 4, Fig. 11, 12, 13.}

Helicina hamilis Hombron et Jaquinot, Voy. Pol. Snd. Zool. V. p. 45, T. II, F. 27-31. Pfeiffer Mon. Preum. II. p. 190, 1858.

$" \quad " \quad$ Sowerby Thes. p. 292, T. 276, F. 371, 1866.

n Möllendorff in J. of Mal. v. 7, p. 120, 1900.

Salfarina $n$ A. J. Wagner Helicinenstadien, in: Denk, Ak. Wien, vol. 77, T. III, F. 7 $a, b, c$, und F. 19, 1905.

Gehäuse gedrückt kreiselförmig, ziemlich festschalig, schmutzig graugelb oder rötlich hornfarben mit rötlicher Spitze, im frischen Zustande matt, mit ziemlich weitläufigen Spiralfalten der Epidermis und mit fest anhaftendem Schmutz bedeckt; abgerieben glanzend mit schief radialen, leicht S-förmig gebogenen, etwas ungleichmässigen Zuwachsstreifen. Das ziemlich erhobene, abgerundet kegelförmige Gewinde besteht aus 4 ziemlich rasch zunehmenden, leicht gewölbten Umgängen; der letzte ist etwas zusammengedrückt stumpf kantig, gegen die Mündung zu gerundet und steigt vorne sehr wenig herab. Die annähernd halbkreisförmige Mündung ist wenig schief, der Mundsaum kaum verdickt, sehr kurz ausgebreitet. Die Einbuchtung und Ecke am Ueberganye des Basalrandes in die kurze dicke Spindel sind sehr undeutlich, der Basalkallus verhăltnismässig dick, glänzend, lichter als das Gehåuse und deutlich begrenzt.

Deckel mit gelblicher, feingekörnelter, ziemlich dicker Kalkplatte, niedriger Sigmakante.

Fundort: die Ostkarolinen; meine Exemplare von Ponapé. 


\section{Subgenus Kosmetopoma A. J. Wagner.}

Subgenns Kosmetopoma A. J. Wagner Helicinenstudien, in: Denk. Ak. Wien, vol. 77 p. $382,1905$.

Gehäuse scharf gekielt, die Einbuchtung am Uebergange des Basalrandes in die kurze, dicke Spindel sehr deutlich, die spitze Ecke daselbst auffallend vorspringend.

Deckel dreieckig mit scharfem oberen und Aussenwinkel, abgerundetem Spindelwinkel. Der Nukleus zentral, die Sigmakante stumpfwinkelig gebogen, der untere Ast stärker erhoben und nahezu senkrecht. Die Oberseite der dicken, glasartig glänzenden Kalkplatte mit einer auffallenden Skulptur, welche aus 3 bis 4 konzentrisch angeordneten, dem Aussen- und Oberrande parallelen, radial gefalteten Leisten besteht Die Aussenseite der Hornplatte dunkelorange gefärbt

Verbreitung: die Insel Mindanao.

\section{Sulfurina (Kosmetopoma) amaliae Kobelt. Taf. 5, Fig. 10, 11, 12, 13.}

Helicina amaliae Kobelt Landd. Philipp. p. 74, T. 7, F. 25, 1884.

Sulfurina (Kosmetopoma) amaliae A. J. Waguer Helicinenstunien, in: Denk. Ak. Wien, vol. 77, T. IV, F. 2 a, b, F. 3, p. 382, 1905

Gehäuse dicklinsenförmig, festschalig, dnrchscheinend einfärbig zitrongelb, im frischen Zustande wenig glänzend bis matt, mit sehr feinen, schief radialen Zuwachsstreifen.

Das etwas konvexe, ziemlich erhobene Gewinde besteht aus $4^{1} \frac{1}{2}$ ziemlich rasch zunehmenden, kaum gewölbten Umgängen, welche durch eine lichter berandete Naht geschieden werden; der letzte ist scharfkantig mit lichterem, fadenförmigem Kiel und steigt vorne nicht herab. Die dreieckige Mündung ist wenig schief, der weisse Mundsaum kaum verdickt schmal umgeschlagen. Die Einbuchtung am Uebergange des Basalrandes in die kurze dicke, Spindel sehr deutlich, die spitze Ecke daselbst deutlich vorspringend. Der gleichfarbige, sehr fein gekörnelte, glänzende Basalkallus in der Mitte etwas verdickt, undeutlich begrenzt.

$$
\mathrm{D}=14-17, \mathrm{~d}=12-15, \mathrm{H}=8.5-10 \mathrm{~mm} \text {. }
$$

Deckel typisch.

Fundort: Bislig auf der Insel Mindanao. Abbildung und Beschreibung nach Fxemplaren vom Originalfundort. 


\section{Genus Sturanya A. J. Wagner.}

Gen a Sturanya A. J. Wagner Helicinenstudien, in: Denk. Ak. Wien, vol. 77, p. 383, 1905.

Gehäuse mittelgross bis sehr klein, festschalig bis dickschalig, mit geradem scharfen Mundsaume und einer erhobenen Schmelzfalte im Gaumen. Die Skulptur besteht nebst feinen und etwas ungleichmässigen radialen Zuwachsstreifen aus sehr hinfălligen Spiralfalten der Epidermis, welchen bei abgeriebenen Exemplaren nur ausnahmsweisse eingedrückte Spirallinien entsprechen. Der Basalkallus ist nur im Umkreise der Spindel stärker verdickt, daselbst deutlich begrenzt, hăufig leistenartig erhoben.

Deckel sehr ähnlich dem Sulfusinendeckel mit zentralem oder nahezu zentralem Nukleus, deutlich S-förmig gebogener nnd erhobener Sigmakante. Die feste und ziemlich dicke Kalkplatte ist glänzend oder fein gekörnelt, zumeist mit einer zentralen, etwas unregelmässigen Vertiefung, welche in der Form annähernd dem Umrisse des Deckels entspricht und wie ein Substanzverlust aussieht.

Verbreitung: Die Samoa, Viti, Tonga, Salomons, Hervey, Galapagos, Sandwichsinseln und die Karolinen; vermutlich auch die Norfolk Inseln und die Neuen Hebriden.

Die Formen des Genus Sturanya machen den Eindruck von verkümmerten oder unausgewachsenen Sulfurinen, sind jedoch bestimmt vollkommen entwickelte Tiere und unterscheiden sich von den Vertretern des Genus Sulfurina Möllendorff vor allem durch den stets scharfen und geraden Mundsaum, sowie die Beschaffenheit des Deckels, dessen Nukleus deutlich etwas exzentrisch und dem Spindelrand genähert ist, so dass auch die Spindelseite des Deckels schmäler erscheint; die Sigmakante ist weniger gebogen, die Kalkplatte des Deckels bei den meisten Formen mit einer zentralen Vertiefung versehen. Das Zentrum des Verbreitungsgebietes liegt anscheinend auf den Samoa- und Viti-Inseln.

\section{Sturanya plicatilis Mousson.}

Taf. 5, Fig. 14, 15, 16, 17, 18.

Heli cin a phicatilis Mousson, J. de Conch., p. 178, 1865.

$\begin{array}{cll}" & & \text { Brazier, Pr. Z. S. p. 322, } 1871 . \\ " & \# & \text { Pfeiffer, Mon. Pneum. IV. p. 251, } 1876 . \\ \text { Sturanya } & " & \text { A. J. Wagner Helicinenstudien, in: Den }\end{array}$

Fig. 8 a, b, c, p. 383, 190 .

Gehäuse breit kegelförmig mit gut gewölbter Basis, dickschalig, junge und frische Exemplare mit einer glänzend gelblichen, oder grünlich gelben, sehr hinfälligen Epidermis; ausgewachsene Exemplare fast durchgehends ohne Epidermis, kalkartig weiss oder gelblich 
mit deutlichen, etwas ungleichmässigen, schief radialen Zuwachsstreifen und sehr undeutlichen bis erloschenen Spirallinien und Spiralfalten (grosse Exemplare sind häufig mit grünen Algen überzogen). Das kegelförmige, ziemliclı erhobene Gewinde besteht aus 5 rasch zunehmenden flacben Umgängen; der letzte ist mehr als doppelt so breit wie der vorletzte, kantig bis stumpf gekielt und steigt vorne nicht herab. Die annähernd halbkreisförmige, etwas unregelmässige Mündung ist ziemlich schief, der Mundsaum gerade und scharf. Die kurze Spindel geht winkelig in den Basalrand über, am Uebergange findet sich ein sehr undeutlicher abgerundeter Vorșprung. Der sehr dicke glasartig glänzende Basalkallus . ist im Umkreise der Spindel ohrförmig abgehoben.

Deckel gelblich-weiss mit glasartig glänzender Kalkplatte und deutlicher zentraler Vertiefung, die Sigmakante leistenartig erhoben, sonst typisch.

Fundort: Samoa-Inseln (Upolu, Sawai).

\section{Sturanya beryllina Gould.}

Taf. 5, Fig. 19, 20, 21.

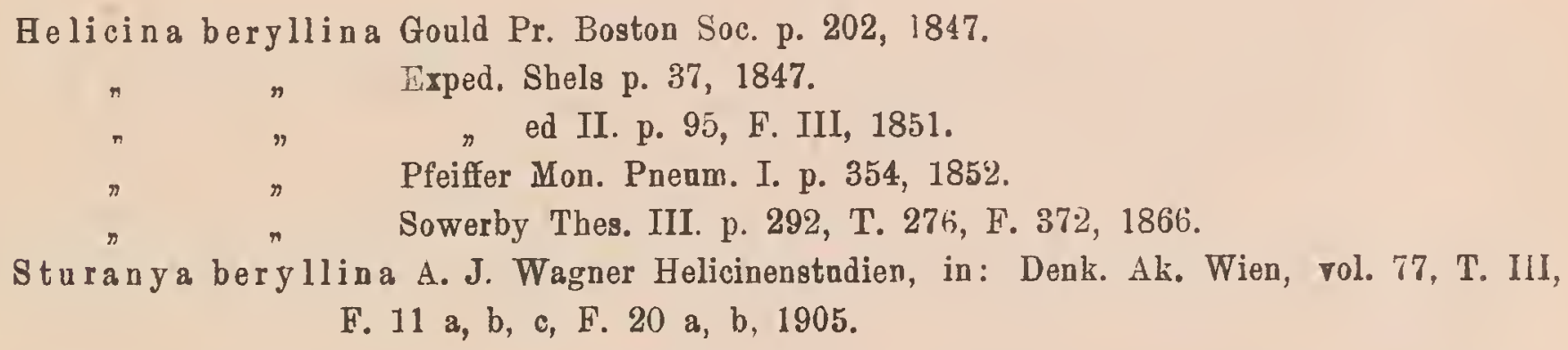

Gehäuse gedrückt kreiselförmig, ziemlich dickschalig, die oberen Umgänge durchscheinend, junge und frische Exemplare mit einer glänzenden Epidermis, abgerieben matt. Der letzte Umgang kalkartig weiss oder gelblich-grün, die oberen gelb-grün, orange bis purpurfarben, häufig mit einer helleren Nahtbinde; sehr fein, schief radial gestreift. Das ziemlich erhobene, breit kegelförmige Gewinde besteht aus $4 \frac{1}{2}$ gut gewölbten ziemlich rasch zunehmenden Umgången, der letzte ist etwas aufgeblasen gerundet und steigt vorne nicht herab. Die annähernd halbkreisförmige Mündung ist schief, der Mundsaum gerade und scharf; der Basalkallus glasartig glänzend, fein gekörnelt, in der Mitte ziemlich dick und heller gefärbt, aber nur in Umkreise der Spindel deutlich begrenzt.

$$
\mathrm{D}=10, \mathrm{~d}=8, \mathrm{H}=7 \text {. }
$$

Deckel vorne glasglänzend mit zentraler Vertiefung, rückwärts gelblich mit leistenförmig erhobener, in der Mitte verdickter Sigmakante.

Fundort: die Viti-Inseln. 


\section{Sturanya beryllina tutuilana $n$.}

Taf. 5, Fig. 22, 23, 24.

Gehäuse mit stärker erhobenem Gewinde, die $4 \frac{1}{2}$ Umgănge nehmen langsamer zu, der letzte ist etwas zusammengedrückt, unter der Peripherie gewinkelt.

Deckel wie bei der typischen Form.

$$
\mathrm{D}=7 \cdot 6, \mathrm{~d}=6 \cdot 4, \mathrm{H}=6 \mathrm{~mm} \text {. }
$$

Fundort: die Insel Tutuila der Samoa-Gruppe. Die Originalexemplare im k. Museum zu Berlin.

\section{Sturanya jetschini A. J. Wagner. \\ Taf. 5, Fig. 25-30.}

Sturanya jetschini A. J. Wagner Helicinenstadien, in: Denk. Ak. Wien, vol. 77, T. III, F. 14 a, b, c, Fig. 21 a, b, 1905.

Gehäuse gedrückt kreiselförmig, festschalig, mit feinen schief radialen etwas ungleichmässigen Zuwachsstreifen, mit einer zarten, aber ziemlich beständigen Epidermis. Die Grundfarbe schmutzig weiss oder graugelb, mit braunen radial gestriemten Zonen über und unter der Peripherie, sowie einer weissen Kielbinde und gelber Spitze häufig einfärbig grauweiss oder mit einer rotbraunen Binde über der Naht und Peripherie. Das ziemlich erhobene, kegelförmige Gewinde besteht aus $4^{1} / 2$ kaum gewölbten, ziemlich rasch zunehmenden Umgängen; der letzte ist zusammengedrückt, an der Peripherie gewinkelt bis stumpfkantig und steigt vorne undeutlich oder gar nicht herab.

Die abgerundet dreieckige Mündung ist schief, der Mundsaum gerade und scharf. Der wenig verdickte, glasartig glänzende Basalkallus ist gelblich oder weișslich und wenig deutlich begrenzt.

$$
\mathrm{D}=8, \mathrm{~d}=6 \cdot 5, \mathrm{H}=6 \mathrm{~mm} .
$$

Deckel vorne glänzend mit zentraler Vertiefung, hinten licht hornfarben, mit verhältnismässig niedriger Sigmakante.

Fundorte: Upolu und Tutuila der Samoa-Gruppe, Viti-Inseln (Kanathea).

Von St. beryllina Gould durch die Farrbung und die flachen, rascher zunehmenden Umgänge unterschieden.

\section{Sturanya singularis n.}

Taf. 6, Fig. 1-3.

Gehäuse kugelig, festschalig, glänzend mit sehr feinen, schiefradialen und leicht S-förmig. gebogenen Zuwachsstreifen; die Grundfarbe braungelb, die Oberseite der zwei letzten Um- 
gănge bis unter die Peripherie milchig getrübt, rötlich bis weiss mit einer gelblichen, undeutlichen Binde über der Peripherie. Das ziemlich erhobene Gewinde ist abgerundet kegelförmig und besteht aus $44_{2}^{1}$ ziemlich langsam und regelmässig zunehmenden, kaum gewölbten Umgângen, der letzte ist an der Peripherie gleichmässig gerundet und steigt vorne kaum merklich und langsam herab, die halbkreisförmige Mündung ist schief im Gaumen hellgelb, der Mundsaum gerade und scharf. Der ziemlich dünne, glänzende Basalkallus ist gelblichweiss und nur im Umkreise der Spindel deutlicher begrenzt.

$$
\mathrm{D}=5, \mathrm{~d}=4 \cdot 6, \mathrm{H}=4 \mathrm{~mm} \text {. }
$$

Deckel vorne weiss, glasglänzend mit verhăltnismässig grosser zentraler Vertiefung, die Sigmakante ziemlich erhoben, sonst typisch.

Fundort: Uea (Wallis-Insel) zwischen den Viti- und Samoa-Inseln.

Die Art ist besonders durch ihre kugelige Form und die Färbung von allen mir bekannten Formen des Genus unterschieden; das Originalexemplar im k. Museum zu Berlin.

\title{
54. Sturanya carolinarum Möllendorff.
}

Taf. 6, Fig. 4-6.

Helicina ca rolinarum Möllendorff, J. of Mal. V. 7, p. 121, 1900.

Sturanga $刃$ A. J. Wagner Helicinenstudien, in: Denk. Ak. Wien, vol. 77 T. III, F. 9 a, b, c, d. p. $386,1905$.

Gehäuse breit kegelförmig mit gewölbter Basis, festschalig, glänzend mit sehr feinen radialen Zuwachsstreifen; einfärbig hell bis zitrongelb, bäufig mit einer rotbraunen Binde über der Peripherie und rötlicher Spitze. Das ziemlich erhobene, abgerundet kegelförmige Gewinde besteht aus 4 regelmässig zunehmenden, leicht gewölbten Umgängen, der letzte ist zusammengedrückt, an der Peripherie undẹutlich gewinkelt und steigt vorne langsam, aber deutlich herab. Die abgerundet dreieckige Mündung ist schief, der Mundsaum gerade und scharf. Der ziemlich dicke, gleichfarbige Basalkallus ist deutlich begrenzt.

$$
\mathrm{D}=4, \mathrm{~d}=3 \cdot 6, \mathrm{H}=3 \mathrm{~mm} \text {. }
$$

Deckel: durchscheinend, gelblich ohne deutliche Vertiefung an der Vorderseite und niedriger Signalkante.

Fundort: Ponapé der Karolinen; meine Exemplare vom Autor erhalten.

\section{Sturanya epicharis n.}

\author{
Taf. 6, Fig. 7-9.
}

Gehäuse gedrückt kugelig, ziemlich festschalig, durchscheinend, leicht seidenglănzend mit feinen, dichten, etwas ungleichmässigen, aber verbältnismässig krăftigen und deutlich er- 
hobenen radialen Zuwachsstreifen, sowie einigen sehr feinen und dichten Spirallinien auf den obersten Umgängen; einfärbig hellgelb mit rötlicher Spitze. Das niedrige, abgerundet kegelförmige Gewinde besteht aus $31 / 2$ gut gewölbten, ziemlich rasch zunehmenden Umgängen; der letzte ist etwas zusammengedrückt, an der Peripherie gerundet und steigt vorne sehr langsam aber deutlich herab. Die halbkreisförmige Mündung ist schief, der Mundsaum scharf und gerade; der ziemlich dicke, hellere Basalkallus deutlich begrenzt.

$$
D=5, \mathrm{~d}=4.5, \mathrm{H}=3,7 \mathrm{~mm} \text {. }
$$

Deckel weiss, durchscheinend, vorne ohne zentrale Vertiefung, mit wenig erhobener Sigmakante.

Fundort: die Insel Lukunor der Carolinen.

Von St. carolinarum Mlldff. durch das niedrige Gewinde, die stärker gewölbten, rascher zunehmenden Umgänge unterschieden. Die mir vorliegenden Exemplare von den Herrn Sowerby und Fulton mitgeteilt.

\section{Sturanya multicolor Gould.}

Taf. 6, Fig. 10-12.

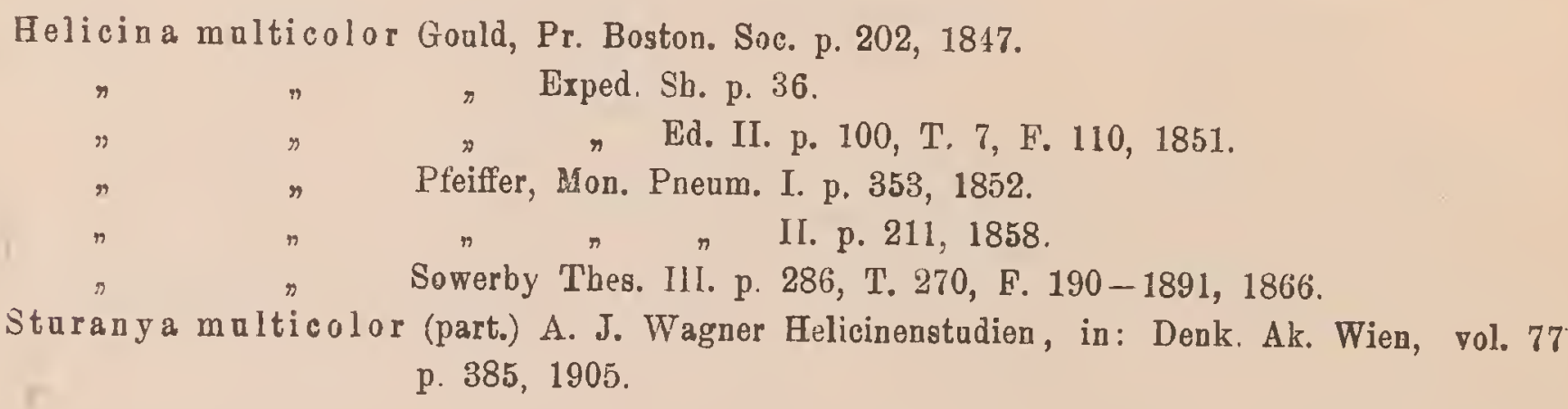

Gehäuse breitkegelförmig mit gewölbter Basis, festschalig, glänzend mit feinen, leicht S-förmig gebogenen, schief radialen Zuwachsstreifen; die Grundfarbe gelh bis lebhaft rotbraun mit milchigen Striemen auf den unteren Umgängen, welche mitunter die Grundfarbe nahezu verdecken, zumeist ist auch ein braunes bis rotbraunes Band über der Peripherie vorhanden, welches durch die milchigen Striemen unterbrochen wird. Das ziemlich erhobene, kegelförmige Gewinde besteht aus 4 ziemlich langsam und regelmässig zunehmenden, leicht gewölbten Umgängen, der letzte ist gewinkelt bis stumpfkantig und steigt vorne nicht herab. Die abgerundet dreieckige Mündung ist schief, der Mundsaum scharf und gerade; der Basalkallus gelblich, in der Mitte heller, ziemlich dick und deutlich begrenzt.

$$
\mathrm{D}=5, \mathrm{~d}=4 \cdot 6, \mathrm{H}=4 \mathrm{~mm} \text {. }
$$

Deckel vorne weiss, fein gekörnelt, ohne zentrale Vertiefung, rückwärts gelblich mit. erhobener und verdickter Sigmakante.

Fundort: Tonga-Tabu der Tonga-Inseln. 
Ich habe diese unter anderem durch die radialen Striemen gekennzeichnete Art mit einer anderen, ebenfalls auf Tonga-Tabu lebenden Form des Genus vermengt und die Abbildung in: Helicinenstudien v. 77. T. 3. F. 13 a, b, c, d, 1905 nach dieser neueu Art angefertigt.

\section{Sturanya multicolor vavauensis n.}

Taf. 6, Fig. 13-14.

Gehäuse flachkegelförmig mit leicht gewölbter Basis, stärker erhobenem Gewinde und rascher zunehmenden Umgängen; die gelbe bis gelbbraune Grundfarbe wird bis auf die oberen Umgănge und radiale mitunter zickzackförmige Striemen auf den unteren Umgängen durch eine milchige Trübung verdeckt; der letzte Umgang ist stärker zusammengedrückt, an der Peripherie stumptkantig bis stumpf gekielt und steigt vorne langsam, aber deutlich etwas unter den Kiel herab. Hinfällige Spiralfalten der Epidermis sind regelmăssig vorhanden.

Deckel wie bei der typischen Form.

$$
\mathrm{D}=5, \mathrm{H}=3.8 \mathrm{~mm} \text {. }
$$

Fundort: Vavau der Tonga-Inseln; die Originalexemplare im k. Museum zu Berlin.

Unter der Bezeichnung Helicina testudinalis Mousson sah ich stets nur Sturanya multicolor Gould mit deutlichen Striemen und einem zusammenhängenden Bande über der Peripherie.

\section{Sturanya rubiginosan. \\ Taf. 6, Fig. 18-21.}

Gehäuse kegelförmig mit abgeflachter Basis, festschalig, wenig glänzend, mit deutlichen, leicht S-förmig gebogenen, schiefradialen Zuwachsstreifen, rotbraun mit einer helleren Binde auf der zweiten Hälfte des letzten Umganges. Das kegelförmig erhobene, an den Seiten leicht konvexe Gewinde besteht aus $4^{1} / 2$ langsam und regelmässig zunehmenden, gewölbten Umgängen, der letzte ist zusammengedrückt, an der Peripherie gewinkelt bis stumpfkantig und steigt vorne nicht herab. Die abgerundet dreieckige Mündung ist schief, der Mundsaum gerade und scharf. Der dicke, glasglänzende Basalkallus ist in der Mitte heller, im Umkreise der Spindel leistenförmig erhoben, sonst deutlich begrenzt.

$$
\mathrm{D}=5 \cdot 8, \mathrm{~d}=5, \mathrm{H}=4.5 \mathrm{~mm} \text {. }
$$

Deckel vorne weiss, gekörnelt, ohne zentrale Vertiefung, die Sigmakante deutlich erhoben, nicht verdickt.

Fundort: Tonga-Tabu.

Von St. multicolor Gould, mit welcher ich die vorstehende Art früher verwechselt habe, I. 18. II. 
unterscheidet sich dieselbe durch das höhere Gewinde, die grössere Zahl der langsamer zunehmenden, stärker gewölbten Uingänge, den auffallend zusammengedrückten letzten Umgang, die flachere Basis und die rotbraune Färbung ohne Striemen.

\title{
59. Sturanya interna Mousson.
}

Taf. 6, Fig. 15-17.

\author{
Helicina interna Mousson J. de Conch. XVIII, p. 201, T. 8, F. 6 and XIX, p. 24, 1870. \\ Staranya interna A. J. Wagner Helicinenstadien, in: Denk. Ak. Wien, vol. 77, T. III, \\ F. 12 a, b, c. p. 384,1905 .
}

Gehäuse kegelförmig mit gewölbter Basis, festschalig; frische Exemplare mit erhaltenèr Epidermis matt, mit feinen, ziemlich dichten, sehr hinfälligen Spiralfalten der Epidermis, welchen an abgeriebenen Exemplaren keine eingedrückten Spirallinien entsprechen; weisslich, gelblich oder rötlich, milchig getrübt mit dunkleren, durchscheinenden, radialen Striemen und gelber Spitze; die schief radialen Zuwachsstreifen sehr fein, bis undeutlich. Das kegelförmig erhobene Gewinde besteht aus 5 langsam und regelmässig zunehmenden, leicht gewölbten Umgängen, der letzte ist an der Peripherie stumpfkantig und steigt vorne langsam und wenig herab.

Die abgerundet dreieckige Mundung ist wenig schief, innen gelblich, der Mundsaum scharf und gerade, der ziemlich dicke Basalkallus gekörnelt, mit dem Gehäuse gleichfärbig und deutlich begrenzt.

$$
D=6 \cdot 4, d=5 \cdot 6, H=5 \cdot 6 \mathrm{~mm} .
$$

Deckel beiderseits gelblich, vorne gekörnelt ohne zentrale Vertiefung, die Sigmakante deutlich erhoben, nicht verdickt.

Fundort: die Viti-Inseln.

\section{Sturanya parvula Pease.}

Taf. 6, Fig. 22-24.

\author{
Helicina parvala Pease Amer. J. of Conch. IV. p. 156, T. 12, F. 10, 1868. \\ Pfeiffer Mon, Pneam. IV. p. 249, 1875. \\ Sturanya $\pi$ A. J. Wagner Helicinenstadien, in: Denk. Ak. Wien, vol. 77, T. III, \\ F. 10 a, b, c, 1905 .
}

Gehäuse annähernd gedrückt kreiselförmig, festschalig, wenig glänzend, mit verhältnismässig kräftigen, leicht wellenförmig gebogenen, schief radialen Zuwachsstreifen (frische Exemplare mit eingetrocknetem Tier sind dunkel gefleckt und besitzen einige hinfällige Spiralfalten der Epidermis) licht hornfarben mit einem verwaschenen dunkleren Bande an der 
Oberseite des letzten Umganges. Das ziemlich erhobene Gewinde besteht aus $3^{1 / 2}$ gewölbten, rasch zunehmenden Umgängen, der letzte ist mehr als doppelt so breit, wie der vorletzte, über der Peripherie deutlich gewinkelt und steigt vorne nicht herab. Die annähernd viereckige Mündung ist nahezu senkrecht, der Mundsaum gerade und scharf, entsprechend der Kante des letzten Umgangs buchtig ausgeschnitten, der horizontale Basalrand geht im rechten Winkel in die Spindel über. Der auffallend dicke, gelbbraune und glänzende Basalkallus ist deutlich begrenzt.

$$
\mathrm{D}=3, \mathrm{~d}=2 \cdot 6, \mathrm{H}=2 \mathrm{~mm} \text {. }
$$

Deckel gelblich, vorne glänzend ohne zentrale Vertiefung, mit wenig erhobener Sigmakante.

Fundort: die Hervey-Inseln (Aitutaki).

\section{Sturanya modesta Pfeiffer.}

Taf. 6, Fig. 25-29.

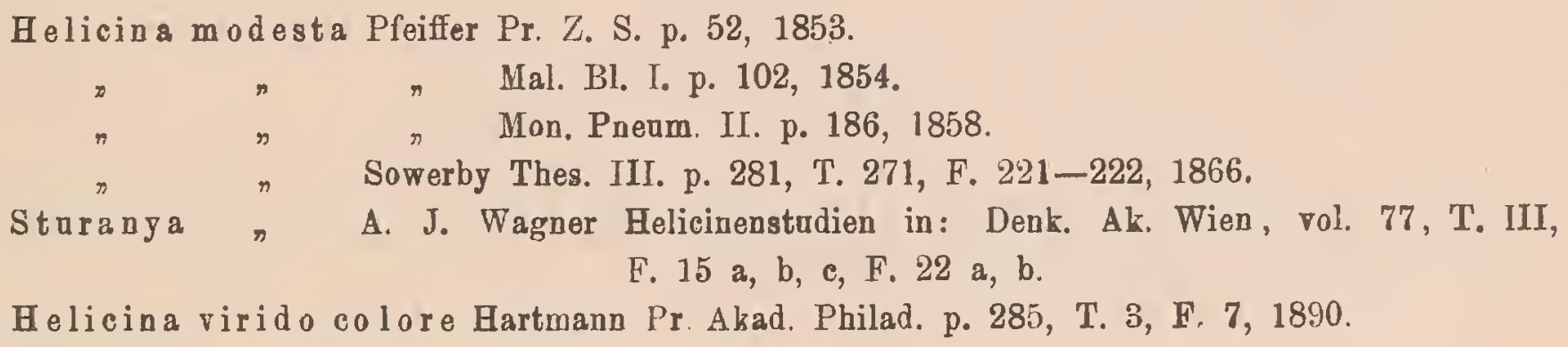

Gehäuse kugelig, festschalig, mit einer matten hinfälligen Epidermis und ziemlich dichten Spiralfalten der Epidermis, abgerieben glănzend mit sehr feinen bis undeutlichen radialen Zuwachsstreifen; zitrongelb mit einer lichten bis weissen Zone entlang der Naht. Das wenig erhobene, abgerundet kegelförmige Gewinde besteht aus 4 regelmässig zunehmenden, leicht gewölbten Umgăngen, der letzte ist an der Peripherie gleichmässig gerundet und steigt vorne lāngsam, aber deutlich herab. Die halbkreisförmige Mündung ist schief, der Mundsaum scharf und gerade, der ziemlich dicke Basalkallus glänzend, lichter, als das Gehäuse und deutlich begrenzt.

$$
\mathrm{D}=5 \cdot 4, \mathrm{~d}=5, \mathrm{H}=4 \mathrm{~mm} \text {. }
$$

Deckel vorne weiss, mit glänzender zentraler Vertiefung, rückwärts gelblich mit wenig verdickter Sigmakante.

Fundort: die Salomonen, nach Pfeiffer auch die Neuen Hebriden (Tana).

\section{Sturany a la cinios a Mighels.}

Taf. 6, Fig. 30-33.

Helicina laciniosa Mighels Pr. Bost. Soc. p. 19, 1845.

Gould Exped. Shels, p. 99, T. 108, 1851. 
Helicina laciniosa Pfeiffer Mon. Pneum. I. p. 352, 1852.

$\begin{array}{lll}\text { Sturanya } & \pi & \text { Sowerby Thes. III. p. 280, T. 267, F. 49. } \\ \text { A. J. Wagner Helieinenstdien, in: Denk. Ak. Wien, vol. 77, T. III, }\end{array}$ H. 16 a, b, c.

Gehăuse breit kegelförmig mit gewölbter Basis, festschalig, kaum glänzend mit schief radialen, leicht S-förmig gebogeneu Zuwachsstreifen und ziemlich dichten, hinfälligen Spiralfalten der Epidermis; die Grundfarbe gelblich hornfarben mit rotbraunen, ziemlich verwaschenen, radialen Zickzackstriemen. Das flachkegelförmige Gewinde besteht aus 4 leicht gewölbten, ziemlich rasch zunehmenden Umgängen, der letzte ist etwas zusammengedrückt, an der Peripherie gerundet und steigt vorne langsam und wenig herab. Die abgerundet dreieckige Mündung ist wenig schief, der Mundsaum gerade uund scharf, der lichtere, ziemlich dicke Basalkallus deutlich begrenzt.

$$
\mathrm{D}=6.5, \mathrm{~d}=6, \mathrm{H}=4 \mathrm{~mm} \text {. }
$$

Deckel: vorne weiss und gekörnelt ohne zentrale Vertiefung, rückwärts gelblich mit niedriger Sigmakante.

Fundort: die Sandwichs-Inseln (Kauai).

Nach der Beschreibung und Abbildung gehören noch nachstehende Arten, welche ich nicht gesehen habe, dem Genus Sturanya an.

Sturanya fulgurata Baird in Brenchley's: „Cruise of H. M. S. Curacoa", p. 448, t. 41, f. 3-4, 1873.

Fundort: Samoa-Inseln.

Sturanya julii Baird in Brenchley's: "Cruise of H. M. S. Curacoa", p. 449, t. 41, f. 5-6, 1873. Fundort: Cockatov-Insel der Salomonen.

Sturanya norfolkensis Pfeiffer in: Pr. Z. S. p. 391, 1856.

Fundort: Norfolk-Inseln.

Sturanya pictella Pfeiffer in: Pr. Z. S. p. 392, 1856.

F'undort: Norfolk-Inseln.

Sturanya rotelloidea Mighels in: Pr. Boston. Soc. p. 19, 1848.

Fundort: Oahu der Sandwichs-Inseln.

Sturanya rudis Pfeiffer in: Pr. Z. S. p. 102, 1855.

Fundort unbekannt (wahrscheinlich Südseeinseln).

Sturanya strigata Baird in Brenchley's: "Cruise of H. M. S. Curacoa", p. 450, t.41, f. 9-10, 1873. 
63. Sturanya nesiotica Dall.

Taf. 14, Fig. 3-6.

Helicina (Idesa) nesiotica Dall Nautilus V, p. 97, 1892.

nesiotica Stearns Pr. U. S. Nat. Mus. XVI, p. 418, 1893.

${ }_{\quad} \quad$ Dall. Pr. u. S. Nat. Mas XIX, p. 451, T. 15, F. 1. 2, T. 17, F. 12, 1896.

Gehäuse klein, gedrückt kugelig, mit Hach gewölbter Basis, festschalig gelbbraun bis rotbraun, mitunter mit einer lebhaft rotbraunen Binde auf der Oberseite und einer lichteren Zone unter der Naht des letzten Umganges; glänzend mit sehr feinen Zuwachsstreifen. Das niedrige, abgerundet kegelförmige Gewinde besteht aus 4 kaum gewölbten, langsam und regelmässig zunehmenden Umgängen; der letzte ist etwas zusammengedrückt, an der Peripherie gerundet und steigt vorne langsam und sehr wenig herab. Die abgerundet dreieckige Mündung ist schief, der Mundsaum scharf und gerade. Der dicke, wenig glänzende, mit dem Gehäuse gleichfarbige Basalkallus ist am unteren Rande leistenartig erhoben und deutlich begrenzt.

$$
\mathrm{D}=4, \mathrm{~d}=3.5, \mathrm{H}=3.1 \mathrm{~mm} \text {. }
$$

Deckel: abgerundet dreieckig mit verhältnismässig dicker, feingekörnelter, gelblicher Kalkplatte, ohne deutliche zentrale Vertiefung, sonst typisch.

Fundort: die Insel Albemarle der Galapagos; die mir vorliegenden Exemplare aus dem K. Museum in Berlin.

\section{Sturanya nesiotica wolfi Reibisch.}

Taf. 14, Fig. 7-8.

He licina wolfi Reibisch Isis III, p. 17, T. 2, F. 13, 1892.

Gehäuse breit kegelförmig mit flacher Basis; das niedrigere Gewinde besteht aus 4 rascher zunehmenden, flachen Umgängen, der letzte ist mehr zusammengedrückt und deutlich stumpfkantig.

$$
\mathrm{D}=4, \mathrm{~d}=3 \cdot 6, \mathrm{H}=2.9 \mathrm{~mm} .
$$

Deckel wie bei der typischen Form.

Fundort: die Chattam-Insel der Gallapagos.

Die Formen der Sturanya nesiotica Dall zeigen eine auffallende Uebereinstimmung mit den Arten des Genus von den Samoa- und Tonga-Inseln; wăre die Fundortsangabe nicht verbürgt (nach der Etikette stammen die mir vorliegenden Exemplare des k. Museums in Berlin von D. Wolf), so hätte ich an eine Verwechslung gcdacht. 


\section{Genus Alcadia Gray (ex rect. mea).}

Alcadia Gray Syn. Brit. Mus. p. 134. 1840.

Gehăuse kegelförmig bis kugelig; die zumeist gebogene Spindel endigt unten mit einer Ecke, einem Knoten oder einem verschiedenartig geformten, längeren Fortsatz und wird vom Basalrande der Mündung durch einen mehr, minder tiefen Ausschnitt geschieden.

Deckel halbeiförmig, halbeliptisch bis halbkreisförmig mit spitzem oberen Winkel und geradem oder S-förmig gebogenem Spindelrand. Die zumeist feste bis knochenartige Kalkplatte nimmt gegen delı Aussenrand zu langsam an Dicke ab, der Nukleus ist dem Spindelrande etwas bis sehr genăhert, die Sigmakante zumeist deutlich S-förmig gebogen und als Kante erhoben. Nach aussen vom unteren Aste der Sigmakante ist der Deckel der Fläche nach winkelig gebogen, wodurch eine die Sigmakante im spitzen Winkel treffende, vom Nukleus zum Aussenrande verlaufende Furche entsteht; am Ende dieser Furche befindet sich ein mehr minder deutlich vorspringender Fortsatz des Deckelrandes, welcher häufig rinnenförmig gebogen ist.

Verbreitunggebiet: die grossen und kleinen Antillen, Südmexico, Zentralamerika, der Nordosten und Osten von Südamerika.

Ich vereinige in diesem Genus eine grosse Zahl von Formenreihen, welche bisher vielfach als Helicina bezeichnet wurden; dieselben werden vor Allem durch einen charakteristischen Einschnitt zwischen Spindel und Basalrand der Mündung gekennzeichnet. Dem Einschnitte entsprechend findet sich am Deckelrande ein winkeliger Vorsprung. Diese Einrichtung, welche einerseits einen sicheren Deckelschluss unterstützt wird durch eine auch bei anderen Gruppen der Familie häufig vorhandene Falte im Gaumen ergänzt, welche besonders dann deutlich entwickelt erscheint, wenn der Ausschnitt am Basalrande der Mündung seichter wird, oder nahezu verschwindet. In zahlreichen Fällen wird durch den rinnenartig gebogenen Fortsatz des Deckels und den Ausschnitt des Basalrandes eine Lücke gebildet, welche bei geschlossenem Deckel die Luftzirkulation ermöglicht.

\section{Subgenus Eucaladia n.}

Gehäuse kugelig bis flachkugelig mit niedrigen zumeist abgerundetem Gewinde. Die Skulptur besteht nebst feinen radialen Zuwachsstreifen aus reihenförmig angeordneten (spiral und radial) Wärzchen und Borsten der Epidermis, welche wie diese ziemlich hinfällig sind. Der letzte Umgang ist zumeist gerundet, stärker erweitert oder etwas aufgeblasen. Der Mundsaum kurz ausgebreitet und umgeschlagen, nur ausnahmsweise stärker verdickt. Die 
stark nach vorn und aussen gekrümmte Spindel endet mit einem längeren, verschieden gestalteten Fortsatze oder einer deutlichen Ecke und wird vom Basalrande der Mündung durch einen zumeist tiefen, spaltförmigen, winkeligen oder halbkreisförmigen Ausschnitt geschieden.

Deckel halbkreisförmig bis halbeiförmig mit S-förmig gebogenem, selten geradem Spindelrand und feingekörnelter ziemlich fester bis knochenartiger Kalkplatte; der Nulkleus dem Spindelrande etwas genähert, die Sigmakante kräftig entwickelt und gebogen, die Furche neben dem unteren Aste derselben tief, der Fortsatz am Aussenrande des Deckels winkelig vorspringend, selten abgerundet.

Das Verbreitungsgebiet der mir bekannten Formen der Gruppe erstreckt sich anscheinend über die Bahama Inseln, die grossen Antillen, sowie den Nordosten und Osten von Südamerika. Das Zentrum des Verbreitungsgebietes liegt auf der Insel Jamaica, wo zahlreiche und auffallende Arten neben einander leben; schon auf den Inseln Cuba und Haiti treten die Eualcadien stark gegen die Vertreter anderer Gruppen des Genus zurück und nur vereinzelt werden dieselben in den übrigen Teilen des Verbreitungsgebietes beobachtet. Die einzelnen Arten haben verhăltnismässig sehr kleine Verbreitungsbezirke und sind den Inseln, auf welchen sie vorkommen, eigentümlich, nur Alcadia foveata Pfeiffer scheint über die JungfernIuseln und Portorico verbreitet zu sein.

\title{
Formenkreis Palliata n.
}

\author{
65. Alcadia (Eualcadia) palliata C. B. Adams. \\ Taf. 7, Fig. 1-4. \\ Helicina palliata C B. Adams, Contr. Conch. I. p. 13, 1849.

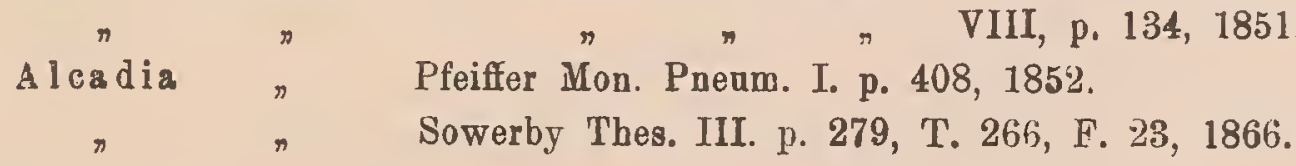

Gehäuse gedrückt kugelig, festschalig, etwas durscheinend rotbraun; im frischen Zustande matt mit schief radialen, leicht S-förmig gebogenen, feinen und ziemlich gleichmässigen Zuwachsstreifen, sowie hinfälligen, in sehr dichten Spirallinien angeordneten, gleichmässigen und kurzen Borsten; auf dem vorletzten Umgange sind mitunter einige Borstenreihen etwas stärker entwickelt. Das niedrige, leicht abgerundete Gewinde besteht aus $5^{1 / 2}$ leicht gewölbten, ziemlich langsam und regelmässig zunehmenden Umgängen; der letzte ist gerundet, etwas aufgeblasen und steigt vorne langsam, aber deutlich herab. Die schiefe Mündung ist abgerundet dreieckig, der weisse, gelbliche oder rötliche Mundsaum verdickt, ziemlich ausgebreitet und umgeschlagen, der Oberrand an der Insertion vorgezogen. Die stark nach vorne gebogene Spindel endet mit einem spatelförmigen Fortsatz und wird vom Basalrande der Mündung durch einen tiefen, spaltförmigen Einschnitt geschieden, welcher nach rückwärts in eine den Basalkallus begrenzende, seichte Rinne übergeht. Der gelbliche oder röt- 
liche Basalkallus ist in der Mitte stark verdickt und gekörnelt, nach oben zu undeutlich begrenzt.

$$
\mathrm{D}=15 \cdot 5, \mathrm{~d}=13, \mathrm{H}=11 \mathrm{~mm} \text {. }
$$

Deckel halbkreisförmig mit spitzem oberen Winkel und deutlichem spitzwinkeligem Fortsatze am Aussenrande. Die weisse, dicke, feingekörrelte Kalkplatte wird gegen den Aussenrand $\mathrm{zu}$ dünner und erscheint hier auf der dunklen Hornplatte rötlich durchscheinend. Die Hornplatte ist am Spindelrande gelbbraun, nach aussen zu lebhaft rotbraun gefärbt, die Furche neben dem unteren Aste der Sigmakante tief.

Fundort: die Insel Jamaica.

Der historische Typus der Formenreilie ist wohl Alcadia brownei Gray; diese Form ist jedoch in den Sammlungen auffallend selten vertreten und wird auch zumeist mit A. palliata C. B. Adams verwechselt. Die schwierige Unterscheidung dieser nahe verwandten Formen wird jedenfalls erleichtert, wenn die seltene von der allgemein bekannten Form abgeleitet wird.

Alcadia palliata var. labiosa Adams zeichnet sich durch einen auffallend dicken, nahezu verdoppelten Mundsaum aus Unter den Exemplaren des A. palliata C. B. Adams aus dem k. Museum in Berlin fand ich eines, bei dem der Einschnitt des Basalrandes bis auf einen kurzen spitzwinkeligen Spalt geschlossen ist. $D_{a}$ dieses Merkmal bei den Alcadien nach meiner Beobachtung sehr konstant ist, so handelt es sich im vorliegenden Falle entweder um eine Abnormität oder eine neue Art.

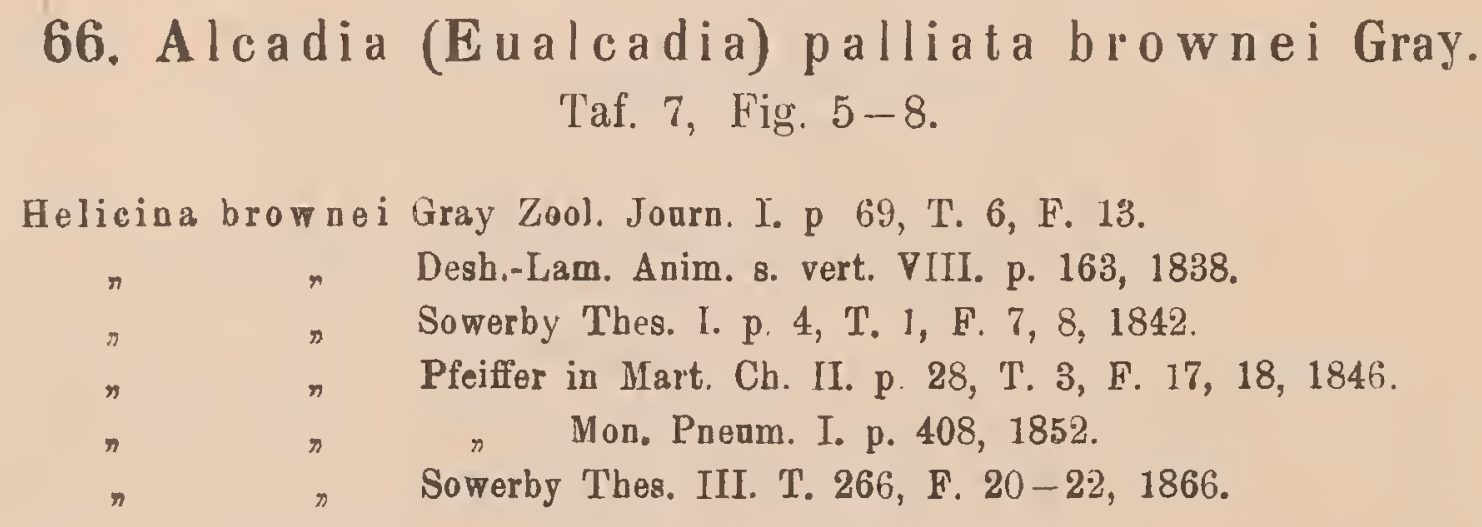

Gehäuse kleiner, dünnschaliger, mitunter hellzitrongelb gefärbt, mit nur 5 etwas rascher zunehmenden Umgängen; die Skulptur besteht aus weitläufigeren Reihen etwas stärkerer Borsten, zwischen welchen sich noch dichtere Reihen kleiuer Wärzchen befinden. Der Einschnitt zwischen Spindel und Basalrand der Mündung ist verhältnismässig breiter

$$
\mathrm{D}=12, \mathrm{~d}=10, \mathrm{H}=8-9 \mathrm{~mm} \text {. }
$$

Deckel wie ber typischen Form

Fundort: die Insel Jamaica.

Die Höhe des Gewindes und die Wölbung der Umgănge sind bei dieser Form ziemlich 
veränderlich; ich bilde zwei extrem entwickelte Exemplare ab, welche vielleicht konstanten Lokalformen entsprechen.

\title{
67. Alcadia (Eualcadia) hollandi C. B. Adams. Taf. 7, Fig. 9-12.
}

\author{
Helicina hollandi C. B. Adams Contr. to Conch. I. p. 13, 1849. \\ Alcadia Pfeiffer, Mon. Pneam. 1. p. 409, 1852. \\ n $n$ Mart. Ch. II. p. 73, T. 10, F. 18-20.
}

Gehäuse gedrückt kugelig, ziemlich dünnschalig und durchscheinend, gelbbraun bis kastanienbraun. Neben feinen, ziemlich gleichmässigen Zuwachsstreifen, finden sich dichte Reihen sehr feiner, etwas ungleicher Borsten. Das niedrige, abgerundete Gewinde besteht aus 5 wenig gewölbten, langsam und regelmässig zunehmenden Umgängen; der letzte ist gerundet und steigt vorne langsam, aber deutlich herab, Die schiefe Mündung ist abgerundet dreieckig, der weisse Mundsaum leicht verdickt, kurz ausgebreitet und umgeschlagen; die nach vorne gebogene Spindel endigt mit einem kurzen, spatelförmigen Fortsatz und wird vom Basalrande der Mündung durch einen spitzwinkeligen, ziemlich tiefen Einschnitt geschieden, welcher nach rückwärts in eine seichte Rinne verlängert ist. Der glänzende, in der Mitte stärker verdickte Basalkallus ist ziemlich deutlich begrenzt.

$$
\mathrm{D}=10-12, \mathrm{~d}=9-10, \mathrm{H}=7 \cdot 5-8.5 \mathrm{~mm} \text {. }
$$

Deckel mit dicker, weisser, grob gekörnelter Kalkplatte, welche am Spindelrande fein gesăgt ist, sonst, wie bei A. palliata C. B. Adams.

Fundort: die Insel Jamaica.

A. hollandi C. B. Adams ist den beiden vorherangeführten Formen ähnlich, unterscheidet sich jedoch von denselben unter anderem bestimmt durch die weniger gewölbten Umgänge, das mehr gerundete Gewinde, den kürzeren Fortsatz am unteren Ende der Spindel, den viel seichteren Einschnitt am Basalrande der Mündung, welcher nach hinten nur in eine kurze und undeutliche Furche verlängert ist; auffallend ist ferner auch die grobe Körnelung der Kalkplatte des Deckels.

\section{Alcadia (Eualcadia) major Gray.}

\author{
Taf. 7, Fig. 25.
}

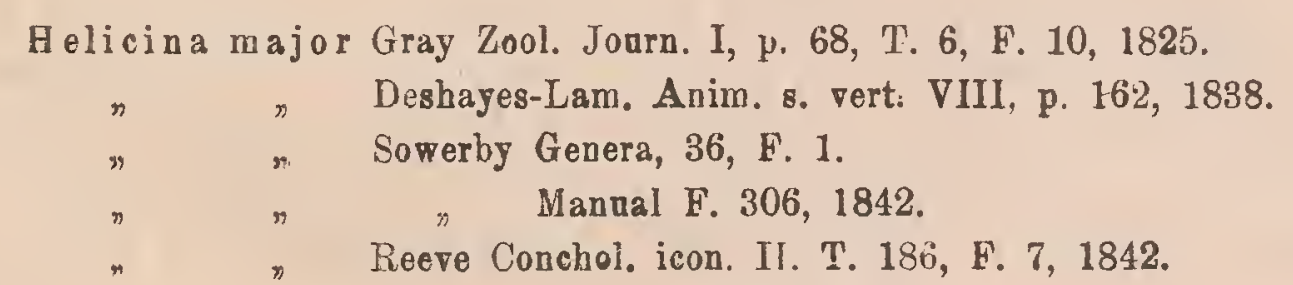

I. 18. II.

8. IX. 1907. 


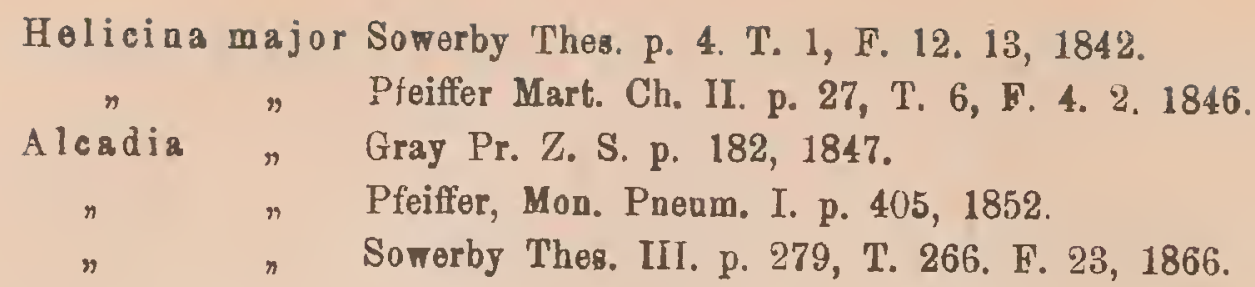

Der oben citierten Beschreibung Pfeiffers habe ich hinzuzufügen: Gehäuse im frischen Zustande matt mit sehr dichten Reihen feiner und gleichartiger Wärzchen; der Einschuitt am Uebergange des Basalrandes in die Spindel seicht und abgerundet. Deckel' annähernd halbkreisförmig mit leicht S-förmig gebogenem Spindelrand, dicker, leicht glänzender, sehr fein gekörnelter Kalkplatte; die Hornplatte gelblich mit rotbrauner Randzone, die Sigmakante deutlich S-förmig gebogen und leistenförmig erhoben, die Furche neben der Sigmakante deutlich, der Fortsatz am Aussenrande spitzwinkelig.

Fundort: die Insel Jamaica.

$$
\mathrm{D}=22, \mathrm{~d}=18, \mathrm{H}=15 \mathrm{~mm} \text {. }
$$

Alcadia gossei Pfeiffer in: Mart. Ch. II. p. 28, T. 6, Fig. 11-12, 1848 von Jamaica, unterscheidet sich nach Angabe des Autors nur durch etwas geringere Dimensionen, die mehr gerundete Peripherie und den seichteren Ausschnitt am Uebergange der Spindel in den Băsalrand der Mündung von der vorstehenden Art, dürfte demnach der Formenreihe derselben angehören.

\section{Alcadia (Eualcadia) citrinolabris C. B. Adams.}

Taf. 7, Fig. 13-15.

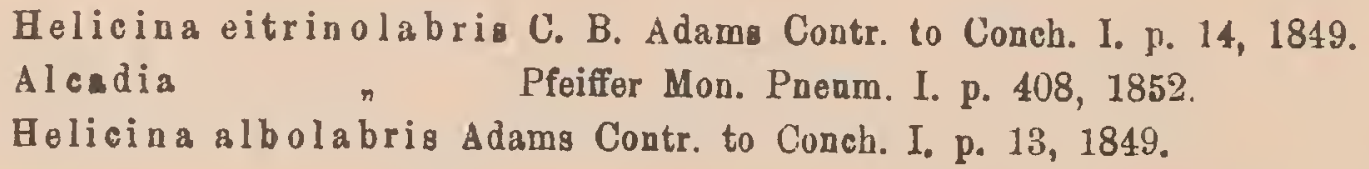

Gehảuse gedrückt kugelig oder breit kegelförmig mit halbkugeliger. Basis, festschalig, rotbraun mit einer helleren bis gelbbraunen Zone entlang der Naht des letzten Umganges und um die Mündung, leicht glänzend bis matt. Die Skulptur besteht nebst feinen, etwas ungleichmăssigen radialen Zuwachsstreifen aus dichten Reihen (spiral und gleichzeitig radial angeordnet) ziemlich kurzer Borsten; auf den mittleren Uningăngen sind auch weitläufige Reihen stärkerer Borsten sichtbar. Das ziemlich erhobene bis niedrige Gewinde besteht aus $4 \frac{1}{2}-5$ leicht gewölbten, ziemlich langsam zunehmenden Umgängen, der letzte ist gerundet und steigt vorne langsam, aber deutlich herab. Die halbeiförmige Mündung ist schief, der weisse oder hellgelbe Mundsaum verdickt, ausgebreitet und umgeschlagen; der Oberrand an der Insertion stark vorgezogen, wenig konvex; die kurze, nach vorn und aussen gebogene Spindel endigt mit einem ziemlich spitzen, zahnartigen Vorsprung und wird vom Basalrande der Mündung durch einen halbkreisförmigen, wenig tiefen, aber deutlichen Ausschnitt geschieden. Der 
glänzende Basalkallus ist weiss oder hellgelb, ziemlich dick und besonder's im Umkreise der Spindel deutlich begrenzt.

$$
\mathrm{D}=14-16, \mathrm{~d}=12-13, \mathrm{H}=10-12 \mathrm{~mm} .
$$

Deckel annähernd halbkreisförmig mit geradem Spindelrand, spitzem oberen Winkel und spitzwinkelig vorspringendem Fortsatz am Aussenrande des Deckels. Die ziemlich dicke Kalkplatte ist fein gekörnelt, die Hornplatte im Zentrum gelbbraun, an der Peripherie lebhaft rotbraun, die Sigmakante am Nukleus winkelig gebogen, leistenförmig erhoben, die Furche neben dem unteren Aste derselben deutlich.

Auch diese Art scheint nach dem mir vorliegenden Materiale ziemlich veränderlich; die beiden abgebildeten Exemplare zeigen recht auffallende Unterschiede bezüglich der Höhe des Gewindes und der mehr minder raschen Zunahme der Umgänge. Von der ähnlichen A. major Gray unterscheidet sich vorstehende Art durch konstant geringere Dimensionea, die etwus weitläufigeren und stärkeren Härchen oder Borsten, die Färbung, den schärferen und mehr vorspringenden zahnartigen Fortsatz am unteren Ende der Spindel, sowie den tieferen Ausschnitt am Uebergange der Spindel in den Basalrand der Mündung.

\section{Alcadia (Eualcadia) consanguinea C. B. Adams. Taf. 7, Fig. 19-21}

Gehäuse gedrückt kugelig oder nahezu kugelig; festschalig, gelb, braun bis rotbraun, durchscheinend. Die Skulptur besteht nebst feinen, zienlich gleichmässigen radialen Zuwachsstreifen aus längeren Borsten, welche in ziemlich dichten Reihen (radial und spiral) angeordnet sind. Das wenig erhobene, abgerundete Gewinde besteht aus $41 / 2-5$ kaum gewölbten, lanısam und regelmässig zunehmenden Ungängen, der letzte ist an der Peripherie gerundet, unten etwas abgeflacht und steigt vorne langsam, aber deutlich herab. Die annăhernd halbkreisförmige Mündung ist wenig schief, der weisse oder gelbliche Mundsaum wenig verdickt, kurz ausgebreitet, und umgeschlagen, der Oberrand an der Insertion wenig vorgezogen, dann etwas niedergedrückt. Die kurze Spindel ist nach vorne und aussen gebogen und endigt mit einem kurzen, vorne abgerundeten, spatelförmigen Fortsatz; an Uebergange in den Basalrand der Mündung ein recht bis spitzwinkeliger, ziemlich tiefer Ausschnitt. Der schmutziggelbe oder gelbbraune Basalkallus ist fein gekörnelt, im Umkreise der Spindel stärker verdickt und deutlich begrenzt.

$$
\text { D }=15, d=12 \cdot 8, \mathrm{H}=105-11.5 \mathrm{~mm} \text {. }
$$

Deckel halbkreisförmig mit schwach konvexem Spindelrand und spitzem oberen Winkel. Die dicke Kalkplatte ist ziemlich grob gekörnelt, am Spindelrande fein gesägt. Die Horn- 
platte in der Mitte gelblich, an den Rändern gelbbraun bis rotbraun, die S-förmig gebogene Sigmakante stark erhoben, die Furche neben dem unteren Aste derselben tief, der Fortsatz am Aussenrande des Deckels spitzwinkelig vorspringend.

Fundort: Westmoreland auf Jamaica.

\section{Alcadia (Eualcadia) microstoma C. B. Adams.}

Taf. 7, Fig. 22-24.

Helicina microstoma C. B. Adams Contr. to Conch. VIII. p. 135, 1850.

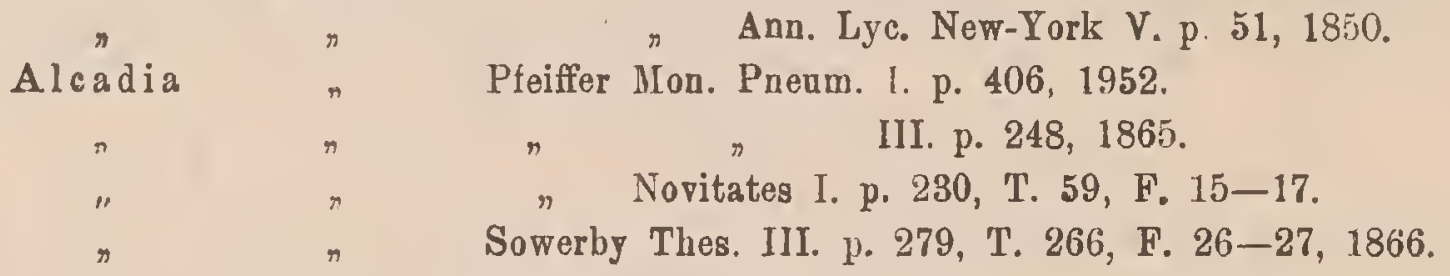

Gehăuse flach kegelförmig mit gewölbter Basis, festschalig etwas durchscheinend, hellgelb, hellrotbraun mit einer breiten, weisslichen Zone entlang der Naht und einer dunkleren Zone hinter der. Mündung. Die Skulptur besteht nebst feinen, etwas ungleichmässigen Zuwachsstreifen aus dichten Reihen feiner Borsten; auf den mittleren Umgängen finden sich auch einige weitläufigere Reihen stärkerer Borsten. Das niedrige Gewinde besteht aus $4 \frac{1}{2}-5$ gewölbten und ziemlich rasch zunehmenden Umganngen; der letzte ist nahezu doppelt so breit, wie der vorletzte, etwas zusammengedrückt, an der Peripherie gerundet und steigt vorne langsam, aber tief herab. Die halbeiförmige Mündung ist schief, der Gaumen rotbraun; der weisse Mundsaum leicht verdickt, ausgebreitet und umgeschlagen, der Oberrand an der Insertion stark vorgezogen, dann etwas niedergedrückt. Die kurze Spindel ist nach vorn gebogen und endet mit einem flachen, spatelförmigen Fortsatz, der Ausschnitt anı Basalrande der Mündung verhältnismässig breit und ziemlich tief. Der ziemlich dünne, hellrotbraune Basalkallus ist undeutlich begrenzt.

$$
\mathrm{D}=16-17, \mathrm{~d}=12-13, \mathrm{H}=9-10 \mathrm{~mm} \text {. }
$$

Deckel: mir unbekannt.

Fundort: die Insel Jamaica.

\section{Alcadia (Eualcadia) solitaria C. B. Adams.}

Taf. 9, Fig. $23-26$.

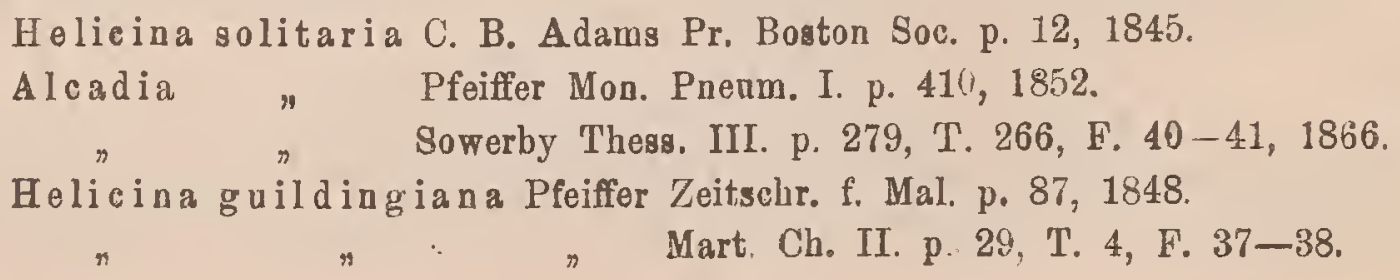


Gehäuse flachkugelig, ziemlich festschalig, durchscheinend, hellgelb mit brauner Zone entlang der Naht, oder hellrotbraun. Die Skulptur besteht nebst feinen und gleichmässigen radialen Zuwachsstreifen aus ziemlich dichten Reihen feiner Wärzchen, (an frischen Exemplaren wahrscheinlich kurzer Borsten). Das niedrige, abgerundete Gewinde besteht aus $3{ }^{1} / 2-4$ nahezu flachen, ziemlich rasch zunebmenden Ungăngen; der letzte ist etwas zusammengedrückt, an der Peripherie gerundet, doppelt so breit, als der vorletzte und steigt vorne langsam und wenig herab. Die halbeiförmige Mündung ist wenig schief, der kaum verdickte, gelbliche Mundsaum kurz ausgebreitet, der Oberrrand an der Insertion ziemlich vorgezogen. Die kurze nach aussen gekrümmte Spindel endigt in einen kurzen zahnartigen Vorsprung; der Ausschnitt an Uebergange der Spindel in den Basalrand ist ziemlich seicht, aber deutlich. Der dünne, glänzende Basalkallus gelblich, ziemlich deutlich begrenzt.

$$
\mathrm{D}=7 \cdot 5-9, \mathrm{~d}=6-7 \cdot 5, \mathrm{H}=4.5-5.5 \mathrm{~mm} \text {. }
$$

Deckel halbkreisförmig mit leicht S-förmig gebogenem Spindelrand, spitzem oberen Winkel und deutlichem, etwas abgerundetem Fortsatze an Aussenrande des Deckels. Die gelbliche, verhältnismässig dicke Kalkplatte fein gekörnelt, die Hornplatte gelbbraun mit leistenförmig erhobener Sigmakante und deutlicher Furche neben dem unteren Aste derselben.

Fundort: die Insel Jamaica.

\section{Alcadia (Eualcadia) gonostoma (Gundlach) Poey. Taf. 8, Fig. 5-8.}

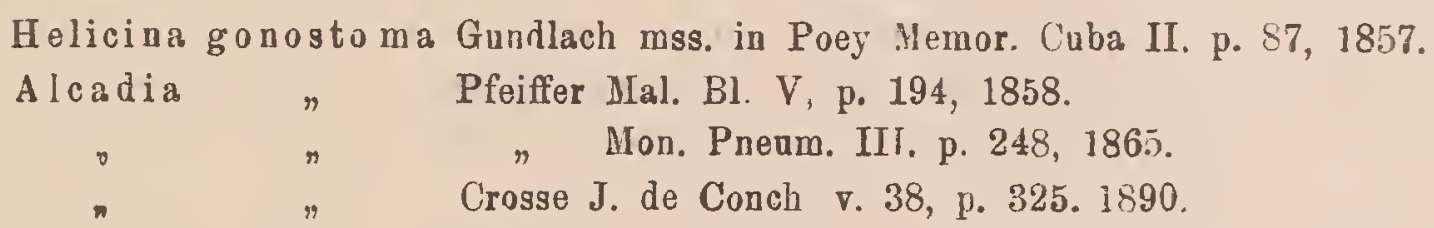

Gehäuse breitkegelförmig mit halbkugeliger Basis, ziemlich dünnschalig, durchscheinend, gelblich bis rötlich hornfarben. Die Skulptur besteht nebst feinen radialen Zuwachsstreifen aus sehr dichten Reihen feiner Wärzchen oder kurzer feiner Borsten. Das niedrige, breitkegelförmige Gewinde besteht aus $4^{1} / 2$ leicht gewölbten, ziemlich langsam und regelnässig zunehmenden Umgängen; der letzte ist gerundet und steigt vorne nicht herab. Die halbeiförmige Mündung ist wenig schief, der dünne Mundsaum kurz ausgebreitet, der Oberrand an der Insertion wenig vorgezogen, dann niedergedrückt und im abgerundeten Winkel vorgezogen, der Basalrand durch einen breiten, annähernd halbkreisförmigen Ausschnitt von der Spindel getrennt. Die kurze nach vorn und aussen gebogene Spindel endet mit einer etwas abgerundeten, aber deutlich vorspringenden Ecke. Der ziemlich düme, feingekörnelte, glänzende Basalkallus ist weiss und deutlich begrenzt, nächst der Spindel leistenförmig abgehoben.

$$
\mathrm{D}=7 \cdot 5, \mathrm{~d}=6 \cdot 4, \mathrm{H}=6 \mathrm{~mm} \text {. }
$$

Deckel halbkreisförmig mit S-törmig gebogenem Spindelrande, ziemlich dicker, gelblicher 
und feingekörnelter Kalkplatte. Die Hornplatte gelbbraun mit wenig gebogener, aber leistenförmig erhobener Sigmalante, deutlicher Furche neben dem unteren Aste derselben und abgerundetem, undeutlichen Fortsatze am Aussenrande des Deckels.

Fundort: Trinidad auf Cuba.

\title{
Formenkreis Hispida.
}

\author{
74. Alcadia (Eualcadia) velutina Poey. \\ Taf. 8, Fig. $1-3$ \\ Helicina velutina Poey Memor. Cuba II. p. 35, T. 4, F. 6. 7, 1857. \\ „ $\quad$ Pfeiffer Mal. B1. V. p. $5,1858$. \\ $\rightarrow \quad$ Mon. Pnenm. II. p. 223, 1858. \\ $\rightarrow \quad$ Crosse J. de Conch. r. 38, p. 325, 1890. \\ n $\rightarrow$ Sowerby Thes. III. p. 279, t. 266, F. 32, 1866.
}

Gehäuse flacbkegelförmig mit gewölbter Basis, ziemlich durchschemend, gelbbraun bis rotbraun Die Skulptur besteht nebst deutlicheu, ungleichmässigen, schiefradialen Zuwachsstreifen aus sehr dichten und feinen Spirallinien kurzer Borsten; auf der Unterseite sind ausserdem weitlăufige Spirallinien längerer und stärkerer Borsten vorhanden, welche im Umkreise der Spindel nahezu schuppenartig werdell. Das wenig erhobene, flach kegelförmige Gewinde besteht aus $5-\left.5^{1}\right|_{2}$ leicht gewölbten, ziemlich langsam und regelmässig zunehmenden Umgängen; der letzte ist zusammengedrückt, an der Peripherie undeutlich stumpfkantig und steigt vorne langsam und wenig herab. Die abgerundet dreieckige Mündung ist schief, der Mundsaum einfach oder kaum verdickt, kurz ausgebreitet. Die stark nach vorn und aussen gebogene, kurze Spindel endigt mit einem nach unten rinnenförmig vertieften, zahnartigen Fortsatz und wird vom Basalrande der Mündung durch einen tiefen und verhältnismässig breiten Einschnitt geschieden, welcher nach rückwärts in eine seichte den unteren Teil des Basalkallus begrenzende Furche übergeht. Der weisse, gekörnelte Basalkallus ist nur in der Mitte stärker verdickt, nach oben undeutlich begrenzt.

$$
\mathrm{D}=9-10 \cdot 5, \mathrm{~d}=8-8 \cdot 75 \mathrm{H}=6 \mathrm{~mm} \text {. }
$$

Deckel halbkreisförmig mit S-förmig gebogenem Spindelrande und wenig vorspringendem, aber deutlichem, winkligen Fortsatze am Aussenrande des Deckels. Die Kalkplatte nur am Spindelrande ziemlich dick und gelblich, nach aussen zu dünn und rotorange gefärbt. Die Hornplatte lebhaft rotbraun, am Spindelrande gelblich, mit ziemlich erhobener Sigmakante und deutlicher Furche neben dem unterell Aste derselben.

Fundort: Guane auf Cuba. 
75. Alcadia (Eualcadia) dissimulans Poey.

Taf. 8, Fig. 4-7, Fig. 24.

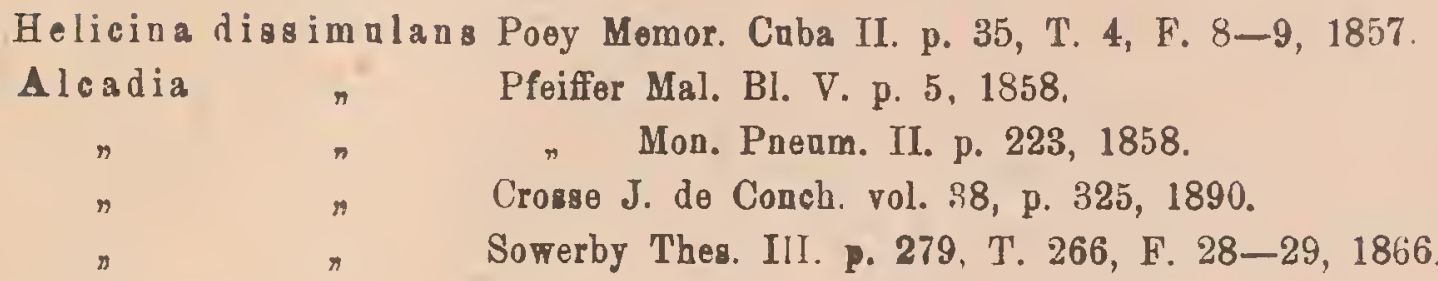

Gehäuse flachkegelförmig mit gewölbter Basis, riemlich dünnschalig und durchscheinend; schmutziggelb, gelbbraun bis rotbraun, matt. Die Skulptur besteht nebst feinen, etwas ungleichmassigen schiefradialen Zuwachsstreifen aus dichten Reihen sehr feiner und kurzer Borsten; auf der Unterseite ausserdem aus weitläufigen Reihen längerer und stärkerer Borsten. Das niedrige Gewinde besteht aus $\mathbf{5}$ nahezu flachen oder wenig gewölbten Umgängen, der letzte ist etwas zusammengedrückt, an der Peripherie stumpflantig und steigt vorne langsam und wenig herab. Die abgerundet dreieckige Mündung ist schief, der weisse oder gelbliche, kaum verdickte Mundsaum kurz ausgebreitet; der Oberrand an der Insertion wenig vorgezogen, dann herabgedrückt und etwas vorgezogen. Die kurze Spindel ist stark nach vorne gebogen, endigt mit einem abgerundeten zahnartigen Fortsatz und wird vom Basalrande der Mündung durch einen ziemlich tiefen Einschnitt geschieden. Der gelbliche, fein gekörnelte Basalkallus ist dünn und undeutlich begrenzt.

$$
\mathrm{D}=9-10, \mathrm{~d}=7 \cdot 6, \mathrm{H}=6 \mathrm{~mm} \text {. }
$$

Deckel mit gelbbrauner Hornplatte, sonst wie bei A. velutina Poey. Von der auffallend ähnlichen A. velutina Poey unterscheidet, sich vorstehende Art bestimmt durch die auf der Unterseite kürzeren und schwächeren Borsten, die flacheren, rascher zunehmenden Umgänge, den herabgedrückten Oberrand der Mündung, die weniger gebogene Spindel, deren Fortsatz kürzer und niemals rinnenförmig ausgehöhlt ist und schliesslich durch den auffallend seichteren Ausschnitt am Basalrande der Mündung.

Fundort: Guane auf Cuba.

Die Abbildung auf Taf. 8, Fig. 4-7 entspricht nach meiner Auffassung der typischen Form von Guane, wăhrend Fig. 24 derselben Tafel ein grösseres Exemplar init niedrigem Gewinde, rotbrauner Färbung darstellt und anscheinend der anderen Geschlechtsforu entspricht.

76. Alcadia (Eualcadia) hispida Pfeiffer. Taf. 8, Fig. 8-12.

Helicina hispida Pfeiffer Archiv f. Naturg. I. p. 355, 1839.

" " Sowerby Thes. p. 4, T. 5, F. 112, 113, 1842. 


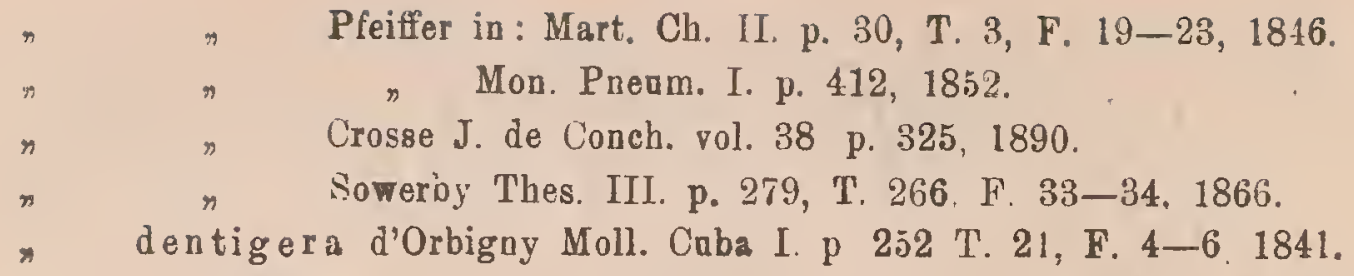

Gehäuse gedrückt kugelig, dünnschalig, durchscheinend, gelbbraun bis rotbraun. Das mehr minder erhobene bis niedrige Gewincie ist breit kegelförmig und besteht aus $4 \frac{1}{2}$ leicht gewölbten, ziemlich rasch zunehmenden Umgängen; der letzte ist nahezu doppelt so breit, wie der vorletzte und steigt vorne langsam und wenig herab. Die Skulptur besteht nebst sehr feinen, etwas ungleichmässigen, schiefradialen Zuwachsstreifen aus sehr dichten Reihen sehr feiner und kurzer Borsten; an der Peripherie und auf der Unterseite. sind ausserdem weitläufige Reihen stärkerer und längerer Borsten vorhanden. Die halbeiförmige Mündung ist wenig schief, der gelbliche oder weisse Mundsanm ist kaum verdickt, kurz ausgebreitet; der Oberrand vor der Insertion etwas herabgedrückt und konvex vorgezogen. Die kurze Spindel ist stark nach vorne und aussen gebogen und endigt mit einem vorne abgerundeten, unten rinnenförmig ausgehöhlten, zahnartigen Vorsprung. Der Ausschnitt am Basalrande der Mündung ist ziemlich tief, Der dünne, glänzende, fein gekörnelte Basalkallus ist weiss oder mit dem Gehäuse gleichfarbig, an seinem unteren Rande leistenförmig abgehoben und durch eine Furche begrenzt.

$$
\mathrm{D}=6, \mathrm{~d}=55, \mathrm{H}=4-4.3 \mathrm{~mm} \text {. }
$$

Deckel halbkreisförınig mit S-förmig gebogenen Spindelrande und stumpfwinkeligem, oft undeutlichein Vorsprung am Aussenrande des Deckels. Die Kalkplatte ziemlich dünn, gelblich und fein gekörnelt; die Hornplatte schmutzigweiss mit gelbbraunem Rande. Die Sigmakante ziemlich niedrig, die Furche neben dem unteren Aste derselben seicht.

Fundort: die Insel Cuba.

Ich beurteile die Art nach Originalexemplaren des Autors von Matanzas (aus dem k. Museum in Berlin); die wesentliehen Unterschiede, welche meine Beschreibung gegenüber derjenigen des Autors aufweist sind wohl auf meine bessere Lupe zurückzuführen.

\section{Alcadia (Eualcadia) fallax n. Taf. 8, Fig. 13-15.}

Gehäuse etwas gedrückt kugelig, dünuschalig durchscheinend, gelbbraun bis rotbraun mit hellerem Apex und heller Zone um die Mündung. Die Slkulptur besteht nebst feinen, ziemlich gleichmässigen, schief radialen Zuwachsstreifen aus dichten Reihen sehr feiner, kurzer Borsten, welche gegen die Spindel zu langsam länger und stärker werden. Das niedrige, abgerundete Gewinde besteht aus $4^{1} / 2$ leicht gewölbten ziemlich rasch zunehmenden Umgängen, der letzte ist gerundet, nahezu doppelt so breit, wie der vorletzte und-steigt 
vorne langsam, aber ziemlich tief herab. Die halbkreisförmige Mündung ist wenig schief der Gaumen hellrotbraun, der weisse, kaum verdickte Mundsaum fast gerade, der Oberrand an der Insertion wenig vorgezogen, etwas konvex, der Aussenrand kurz ausgebreitet, der Ausschnitt des Basalrandes ziemlich tief, annăhernd halbkreisförmig. Die kurze Spindel ist stark nach volne gebogen und endigt mit einem abgerundeten zahnartigen Vorsprung. Der ziemlich dïnne weisse, feingekörnelte Basalkallus ist nur im unteren Teile deutlich begrenzt.

$$
\mathrm{D}=7, \mathrm{~d}=6, \mathrm{H}=5.2 \mathrm{~mm} \text {. }
$$

Deckel halbkreisförmig mit S-förmig gebogenem Spindelrande, abgerundetem, wenig vorspringendem Fortsatz am Aussenrande. Die ziemlich dünne Kalkplatte ist gelblich und feingekörnelt. Die Hornplatte gelbbraun mit niedriger, im unteren Aste senkrechter Sigmakante and deutlicher Furche.

Fundort: Neu-Providence der Bahama Inseln.

Diese Art wird derzeit als A minima d'Orb. bezeichnet, unterscheidet sich jedoch von derselben durch die Dimensionen, die kugelige Gestalt, das verhältnismässig niedrige, abgerundete Gewinde mit viel rascher zunehmenden, gerundeten Umgängen, die weniger hinfälligen, deutlicheren Borsten, ferner durch die Beschaffenheit, der Mündung, welche unter anderen einen tieferen Ausschnitt am Basalrande und dementsprechend auch einen deutlicheren Fortsatz am Aussemrande des Deckels aufweist.

\section{Alcadia (Eualcadia) minima d'Orbigny.}

Taf. 8, Fig. 20-23.

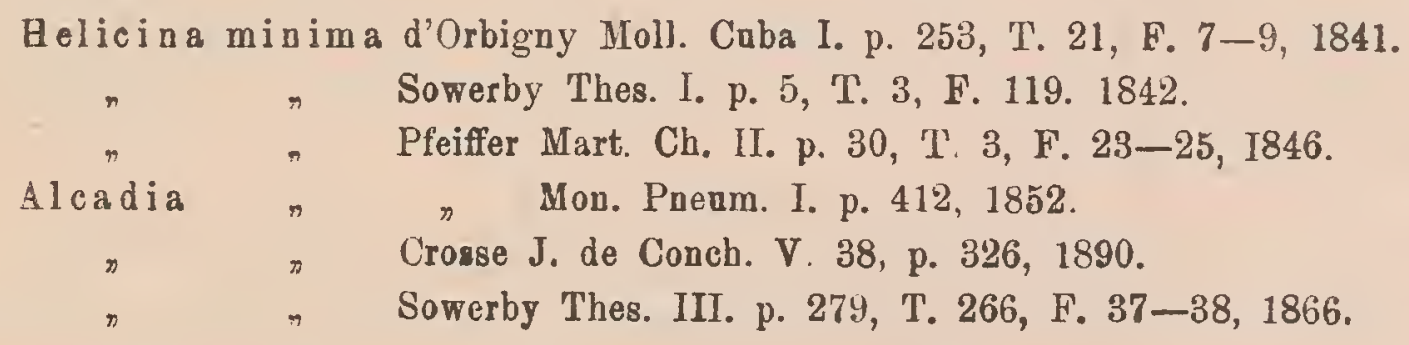

Gehäuse verhältnismässig klein, gedrückt kugelig, ziemlich dünnschalig, durchscheinend gelbbraun oder rotbraun. Die Skulptur besteht nebst deutlichen und ungleichmässigen radialen Zuwachsstreifen aus dichten Reihen sehr feiner, kurzer, hinfälliger Borsten. Das niedrige, breitkegelförmige Gewinde besteht aus $4-41 / 2$ gewölbten, langsam und regelmässig zunehmenden Umgängen, der letzte ist an der Peripherie undeutlich stumpfkantig und steigt vorne langsam und wenig herab. Die abgerundet dreieckige Mündung ist wenig schief, der weisse Mundsaum kaum verdickt und ausgebreitet. Die kurze nach vorn gebogene Spindel endigt mit einem kurzen spitzwinkeligen Vorsprung und wird vom Basalrande der Mündung durch einen seichten, annähernd halbkreisförmigen Ausschnitt geschieden. Der weissliche, ziemlich diunne und gekörnelte Basalkallus ist nur im Unkreise der Spindel deutlich begrenzt.

I. 18. II. 18. IX. 1907. 
$\mathrm{D}=4 \cdot 4, \mathrm{~d}=4, \mathrm{H}=3 \cdot 2 \mathrm{~mm}$.

Deckel halbkreisförmig mit S-förmig gebogenem Spindelrande und winkligem, wenig vorspringendem Fortsatz am Aussenrande. Die dünne feingekörnelte Kalkplatte gelblich und am Spindelrande leistenförmig von der Hornplatte abgehoben. Die Hornplatte ist in der Mitte gelblich, am Aussenrande rotbraun, mit wenig erhobener Sigmakante, aber deutlicher Furche neben dem unteren Aste derselben.

Fundort: nur die Insel Cuba, da die Angaben über das Vorkommen auf den Bahamas anscheinend auf Verwechslung mit A. fallax m. bcruht.

\title{
79. Alcadia (Eualcadia) proxima Gundlach. Taf. 9, Fig. 4-8.
}

Helicina proxima Gondlach mss. apud Poey Mem. Caba II, p. 61857.

Aloadia proxima Pfeiffer Mal. Bl. V. p. 49, 1858.

$n \quad n$ Mon. Pneum. III. p. 250, 1865.

r Crosse J. de Conch. vol. 38 p. 326, 1890.

Gehäuse verhältnismässig sehr klein, kegelförmig mit halbkugeliger Basis, dünnschalig, durchscheinend, licht hornfarben oder schmutziggelb. Die Skulptur besteht nebst feinen radialen Zuwachsstreifen aus sehr feinen und kurzen, in dichten Spirallinien angeordneten Härchen. Das ziemlich erhobene, leicht abgerundete Gewinde besteht aus 4 gewölbten, ziemlich rasch zunehmenden Umgängen, der letzte ist $1 / 3$ breiter, als der vorletzte, an der Peripherie gerundet und steigt vorne langsam und wenig herab. Die abgerundet dreieckige Mündung ist wenig schief, der dünne Mundsaum kurz ausgebreitet. Die nahezu senkrechte Spindel endigt mit einer wenig vorspringenden, aber ziemlich scharfen Ecke, der Ausschnitt am Basalrande ist schwach bis undeutlieh.

$$
\mathrm{D}=5, \mathrm{~d}=42, \mathrm{H}=3 \cdot 7 .
$$

Deckel mit verhältnismässig kräftiger, glasartig glänzender Kalkplatte, welche am oberen Winkel in einen ziemlich spitzen Fortsatz ausgezogen ist. Die Hornplatte gelbbraun mit deutlich erhobener, aber wenig gebogener Sigmakante; die F'urche und der Fortsatz am Aussenrande des Deckels sind deutlich vorhanden.

Fundort: Bayamo auf Cuba. Ich beurteile die Art nach Exemplaren vom Originalfundorte, mitgeteilt von $\mathrm{Ph}$. Dautzenberg.

\author{
80. Alcadia (Eualcadia) foveata Pfeiffer. \\ Taf. 9, Fig. 1-3. \\ He licina foreata Pfeiffer Pr. Z. S. p. 53, 1853 \\ ᄁ $\gg$ Mal. Bl. I p. 107, 1854.
}


Helicina foreata Shnttleworth Diagn. n. Moll. vol. 7 p. 154, 1855.

Pfeiffer Mon. Pnenm. II. p. 204, 1858.

A lcadia rubella Pfeiffer Pr. Z. S. p. 60, 1853.

Gehäuse breitkegelförmig mit halbkugeliger Basis, ziemlich dünnschalig, einfärbig gelb, gelbbraun bis rotbraun, häufig mit einer hellen Zone entlang der Naht des letzten Umganges and 2 weisslichen Binden an und unter der Peripherie. Die Skulptur besteht nebst etwas ungleichmässigen, schief radialen Zuwachsstreifen aus sehr feinen Wärzchen und Härchen, welche in sehr dichten Spirallinien angeordet sind. Das ziemlich erhobene, etwas abgerundete Gewinde besteht aus 5 leicht gewölbten, langsam und regelmässig zunehmenden Umgängen, der letzte ist gerundet, oder undeutlich kantig und steigt vorne langsam, aber deutlich herab; der Apex deutlich vorspringend. Die halbeiförmige Mündung ist schief, der weisse Mundsaum kaum verdickt, sehr kurz ausgebreitet. Die nach vorne gebogene Spindel endigt mit einer scharfen, deutlich vorspringenden Ecke und wird vom Basalrande der Mündung durch einen seichten Ausschnitt geschieden. Der gelbliche, gekörnelte Basalkallus ist im unteren Teile stärker verdickt, gut begrenzt, in der Nabelgegend gegen die Spindel durch eine eingedrückte Furche abgesetzt.

$$
\mathrm{D}=6 \cdot 6, \mathrm{~d}=6, \mathrm{H}=5 \mathrm{~mm} \text {. }
$$

Deckel: halbkreisförmig mit S-förmig gebogenem Spindelrande und spitzem, oberen Winkel; die gelbliche, ziemlich feste Kalkplatte fein gekörnelt. Die Hornplatte gelblich mit nur im unteren Teile deutlich erhobener Sigmakante; die Furche neben der Sigmakante deutlich, der Fortsatz am Aussenrande des Deckels abgerundet, sehr undeutlich.

Fundorte: die Inseln St. Thomas, St. Jan, Viezue und Portorico.

Alcadia rubella Pfr. ist nach dem mir vorliegenden Material mit der vorstehenden Art vollkommen identisch.

\title{
81. Alcadia (Eualcadia) bahamensis Pfeiffer.
}

\author{
Taf 9, Fig. 9-12.
}

Schasicheila bahamensis Pfeiffer Mal. Bl. IX, p. 154, 1882.

ᄁ „ Mon. Pnenm. III. p. 247, 1805.

\# $\quad$ Bendall Pr. Mal. Soc. London I p. 294, 1895.

» miniuscula Binney Ano. Lyc. New-York VII p. 351, nec Pfr.

Gehäuse flachkugelig, ziemlich dünnschalig, durchscheinend, oben rotbraun, unten heller gefärbt. Die Skulptur besteht nebst S-förmig gebogenen, ungleichmässigen Zuwachsstreifen aus etwas weitläufigen, auf der Unterseite dichteren Spiralreihen feiner Härchen. Das niedrige Gewinde besteht aus $4^{1} / 2$ leicht gewölbten, ziemlich rasch zunehmenden Umgängen, welche durch eine eingedrückte Naht geschieden werden, der letzte ist etwas zusammengedrückt, an der Peripherie gerundet und doppelt so breit, wie der vorletzte. Die halbkreisförmige Mün- 
dung ist wenig schief. Der Mundsaum kaum verdickt, sehr kurz ausgebreitet; der Oberrand an der Insertion eingezogen, dann nahezu im rechten Winkel vorgezogen. Die nach vorne und aussen gebogene Spindel endigt mit einem ziemlich spitzen, scharf vorspringenden Fortsatz und wird vom Basalrande der Mündung durch einen breiten halbkreisförmigen Ausschnitt geschieden. Der gekörnelte, ziemlich dicke Basalkallus ist deutlich begrenzt.

$$
\mathrm{D}=5 \cdot 5-6 \cdot 5, \mathrm{~d}=4 \cdot 8-5 \cdot 6, \mathrm{II}_{1}=3 \cdot 6 \mathrm{~mm} \text {. }
$$

Deckel halbkreisförmig mit konkavem Spindelrand und zu einem spitzen Fortsatz ausgezogenem oberen Winkel. Die ziemlich feste Kalkplatte fein gekörnelt. Die gelbliche Hornplatte mit leistenförmig erhobener, aber wenig gebogener Sigmakante, die Furche und der Fortsatz am Aussenrande deutlich.

Fundort: die Insel Neu-Providence der Bahamas.

Diese Art wird derzeit allgemein als Schasicheila bezeichnet; doch erinnert nur der tiefe Ausschnitt an der Insertion des Oberrandes der Mündung all die Formen dieses zentralamerikanischen Genus, während alle übrigen Merkmale, besonders die Beschaffenheit des Basalrandes der Mündung und der Deckel dem Genus Alcadia entsprechen.

\title{
Formenkreis Intusplicata $\mathrm{n}$.
}

\author{
82. Alcadia (Eualcadia) intusplicata Pfeiffer. \\ Taf 9, Fig. 17-19. \\ Helicina intusplicata Pfeiffer Pr. Z. S. p. 98, 1850. \\ $n$ \\ Mon. Pneam. I. p. 364, 1852. \\ $\pi \quad$ Sowerby Thes. III. F. 60, 61, 1866. \\ " Bland. Ann. Lyc. New-York XI p. 149, 1875. \\ n $" \quad$ Crosse J. de Conch. vol. 39, p. 186, 1891.
}

Gehäuse gedrücktkugelig ziemlich festschalig, durchscheinend, hellrotbraun. Die schwache Skulptur besteht nebst sehr feinen etwas ungleichmässigen Zuwachsstreifen aus sehr feinen bis undeutlichen Spirallinien und einer Reihe stärkerer Haarnarben entlang der Naht, (anscheinend sind frische Exemplare fein und hinfällig behaart). Das wenig erhobene, breıtlregelförmige Gewinde besteht aus $4^{1} \frac{1}{2}$ leicht gewölbten, ziemlich rasch zunehmenden Ungängen, der letzte ist im Beginne et,was zusammengedrüclkt, an der Peripherie gerundet und steigt vorne langsam und sehr wenig herab. Die halbkreisförmige Mündung ist schief, der Mundsaum weiss oder gelblich, leicht verdickt und kurz ausgebreitet. Im Gaumen eine ziemlich hohe, den Mundsaum nicht erreichende Spindelfalte. Die kurze Spindel ist etwas nach vorne und aussen gebogen, am Uebergange zum Basalrande findet sich nur eine undeutliche, abgerundete Ecke. Der dünne Basalkallus ist undeutlich begrenzt.

$$
\mathrm{D}=7 \cdot 6-10, \mathrm{~d}=6 \cdot 8-8 \cdot 5, \mathrm{H}=6-7.5 \mathrm{~mm} \text {. }
$$


Deckel: halbkreisförmig mit leicht S-förmig gebogenem, nahezu geradem Spindelrande und zu einem spitzen Fortsatze ausgezogenem oberen Winkel. Die weisse, fein gekörnelte Kalkplatte, besonders am Spindelrande stärker verdickt und leistenförmig erhoben. Die gelbbraune Hornplatte mit wenig gebogener, und nur im unteren Aste leistenförmig erhobener Sigmakante; die Furche neben dem unteren Aste der Sigmakante tief, der Fortsatz am Aussenrande des Deckels undeutlich.

Fundort: Mt. Platon auf Haiti.

\section{Alcadia (Eualcadia) intusplicata smithiana Pfeiffer.}

Taf. 9, Fig. 20-22.

HeIicina smithiana Pfeiffer Mal. BI. XIII p. 90, 1966.

"n $n$ Mon. Pneam. IV p. 264, 1876.

Gehäuse grösser, dünnschaliger, hellgelb oder hellrotbraun; das Gewinde verhältnismässig niedriger, die Umgänge rascher zunehmend, der letzte doppelt so breit, wie der vorletzte und mehr aufgeblasen.

$$
\begin{array}{ll}
D=12, d=9, D=8 \mathrm{~mm} . & \text { Fundort: Port-au-Prince. } \\
D=13, d=10, D=9 \mathrm{~mm} . & \text { Fundort: Miragoane. }
\end{array}
$$

Deckel wie bei der typischen Form.

Fundorte: Port-au-Prince und Miragoane auf Haiti.

\section{Alcadia (Eualcadia) succinea Pfeiffer.}

Taf. 9, Fig. 13-16.

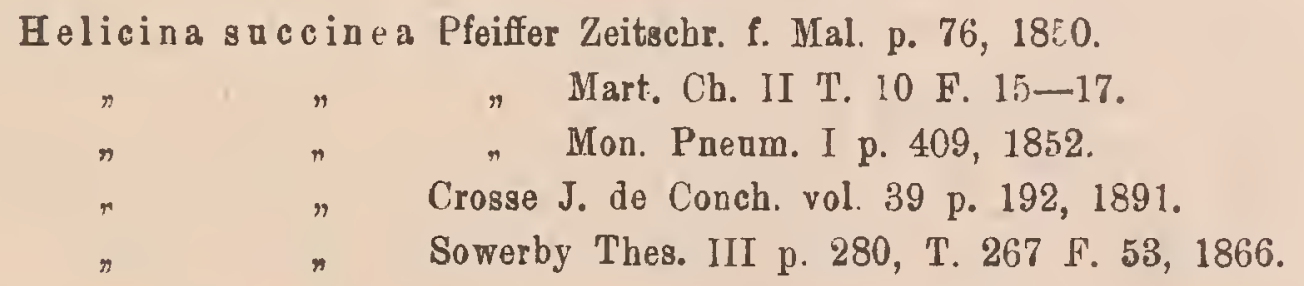

Gehäuse breitkegelförmig mit halbkugeliger Basis, dünnschalig, durchscheinend, hellgelb oder hellrotbraun. Die Skulptur besteht nebst deutlichen, ungleichmässigen Zuwachsstreifen aus dichten Reihen feiner Härchen zwischen welchen 6 weitläufige Reihen.stärkerer dunkelbrauner Borsten verlaufen, ebenso befinden sich mehrere Reihen längerer Borsten im Umkreise der Spindel. Das ziemlich erhobene, kegelförmige Gewinde besteht aus $4 \frac{1}{2} 2 \mathrm{kaum}$ gewölbten bis flachen, ziemlich rasch zunehmenden Umgängen, der letzte ist etwas zusammengedrückt, gerundet, $1 / 3$ breiter, als der vorletzte und steigt vorne langsam, aber deutlich herab. Die halbeiförmige Mündung ist wenig schief, der Mundrand dünn und kurz ausge- 
breitet; der Oberrand an der Insertion wenig vorgezogen, konvex und etwas herabgebogen. Die kurze Spindel ist nahezu senkrecht und endigt unten mit einem spitzen, kurzen Fortsatz; am Uebergange zum Basalrand befindet sich ein seichter, winkeliger Einschnitt. Der dünne, lichte, gekörnelte Basalkallus ist zumeist.undeutlich begrenzt und in der Nabelgegend gegen die Spindel zu durch eine Furche abgesetzt.

$$
\mathrm{D}=8 \cdot 4, \mathrm{~d}=7 \cdot 6, \mathrm{H}=6 \mathrm{~mm} \text {. }
$$

Deckel halbkreislörmig mit S-förmig gebogenem Spindelrand und spitzem oberen Winkel. Die ziemlich dicke, gekörnelte Kalkplatte leicht rötlich und konkav. Die rotgelbe Hornplatte mit gebogener und leistenförmig erhobener Sigmakante, tiefer Furche und deutlichem Fortsatz am Aussenrande des Deckels.

Fundort: St. Domingo.

\title{
Formenkreis Sericen n.
}

\author{
85. Alcadia (Eualcadia) sericea Drouët. \\ Taf. 10, Fig. 1-4. \\ Helicina sericea Drouët Moll. Guyane p. 75, T. 2, F. 18-20 \\ Pfeiffer Mon. Pneum. III p. 250, 1865.
}

Gehäuse kugelig kreiselförmig oder breit kegelförmig mit halbkugeliger Basis, ziemlich dünnschalig, durchscheinend, gelblich oder rötlich hornfarben. Die Skulptur besteht nebst feinen radialen Zuwachsstreifen aus dichten Reiben feiner und kurzer Härchen, welche überall gleichmässig stark und dicht stehen. Das ziemlich erhobene, abgerundet kegelförmige Gewinde besteht aus $4^{1} / 2$ langsam und regelmässig zunehmenden, leicht gewölbten Umgăngen; der letzte ist gerundet und steigt vorne langsam und wenig herab. Die halbkreisförmige Mündung ist wenig schief, der weisse oder rötliche Mundsaum kaum verdickt, kurz ausgebreitet und umgeschlagen; der Oberrand an der Insertion wenig vorgezogen, der Basalrand konvex. Die kurze, nahezu senkrechte Spindel endigt unten mit einer abgerundeten, wenig vorspringenden Ecke und wird vom Basalrande der Mündung durch einen seichten Ausschnitt geschieden. Der dünne, weisse, glänzende Basalkallus ist undeutlich begrenzt.

$$
\mathrm{D}=6, \mathrm{~d}=5, \mathrm{H}=5 \mathrm{~mm} \text {. }
$$

Deckel halbeiförmig mit nahezu geradem Spindelrande und spitzem oberen Winkel, die feste, gelbliche Kalkplatte fein gekörnelt, die rötliche Hornplatte mit wenig gebogener, nur im unteren Aste leistenförmig erhobener Sigmakante, ziemlich tiefer Furche, aber abgerundetem, wenig vorspringenden Fortsatz am Aussenrande.

Fundort: Cayenne; meine Exemplare von $\mathrm{Ph}$. Dautzenberg. 


\author{
86. Alcadia (Eualcadia) sericea Kühni Pfeiffer. \\ Taf. 10, Fig. 5-7. \\ Helicina Kühni Pfeiffer Mal. Bl. XIX, p. 76, T. 2, F. 11, 12, 1872. \\ $" \quad " \quad$ Mon. Pneum. IV. p. 268, 1876.
}

Gehăuse kleiner. kugeliger, glänzend mit sehr feinen Zuwachsstrelfen, ohne Spur von Narben oder Härchen. Das Gewinde besteht nur aus 4 Umgängen, der letzte steigt vorne nicht herab; die Mündung ist weniger schief, der Basalrand nicht konvex; die Ecke am unteren Ende der Spindel ist undeutlich, ebenso der Ausschnitt am Uebergange zum Basalrande der Mündung seichter.

Deckel wie bei der typischen Form.

$$
\mathrm{D}=5, \mathrm{~d}=4 \cdot 3, \mathrm{H}=4 \cdot 1 \mathrm{~mm} .
$$

Fundort: Surinam am Oberlaufe des Surinamflusses und Cayenne; meine Exemplare mitgeteilt von Dautzenberg.

\title{
87. Alcadia (Eualcadia) sericea paraënsis Pfeiffer. \\ Taf. 10, Fig. 8-11.
}

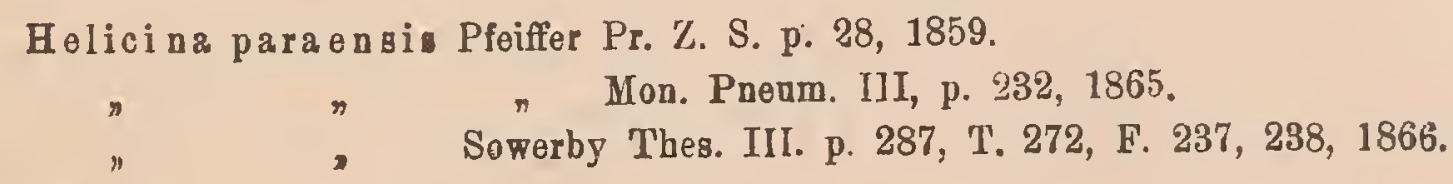

Gehäuse mehr gedrückt kugelig mit etwas rascher zunehmenden, flacheren Umgängen, der letzte an der Peripherie undeutlich stumpfkantig. Die Harchen der Epidermis feiner und kürzer, dieselben sehr hinfällig und an Musealexemplaren selten vorhanden. Der weisse Mundsaum mehr ausgebreitet und deutlicher verdickt, die Ecke am unteren Ende der Spindel deutlicher vorspringend, der Basalrand konvex.

Deckel wie bei der typischen Form.

$$
\mathrm{D}=6, \mathrm{~d}=5, \mathrm{H}=5 \mathrm{~mm} \text {. }
$$

Fundorte: Para und Jukaty in Brasilien. 


\title{
Formenkreis Incrustata $n$.
}

\section{Alcadia (Eualcadia) incrustata (Gundlach) Pfeiffer. \\ Taf. 16, Fig. 5-8.}

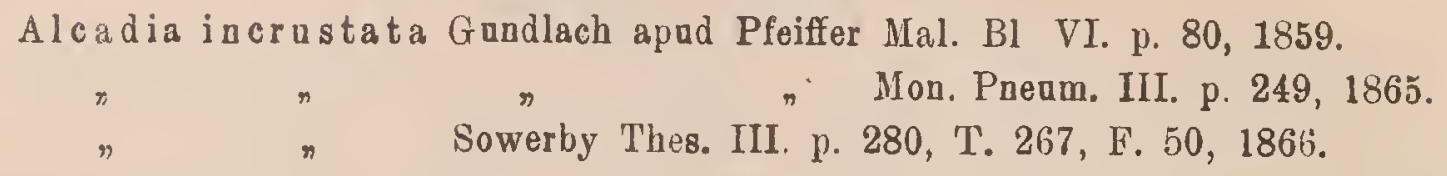

Gelıäuse breit kegelförmig mit gewölbter Basis, ziemlich festschalig, gelblich hornfarben bis rötlich, zumeist mit einer schwarzen Schmutzkruste bedeckt. Die Skulptur besteht nebst deutlichen, ungleichmässigen Zuwachsstreifen aus dichten Spiralreihen hinfälliger kurzer Borsten, zwischen welchen auch einige weitläufigere Reihen stärkerer Borsten verlaufen. Das niedrige, leicht konvexe Gewinde besteht aus $4 \frac{1}{2}$ gewölbten, regelmässig zunehmenden Umgängen; der letzte ist gerundet und steigt vorne langsam, aber deutlich herab. Die halbkreisförmige Mündung ist schief, der weisse oder gelbliche Mundsaum verdickt bis verdoppelt, kurz ausgebreitet. Die nach vorn gebogene Spindel endet mit einer abgerundeten, deutlich vorspringenden Ecke und wird vom Basalrande der Mündung durch einen seichten Ausschnitt geschieden. Der gelbliche, glänzende, ziemlich dünne Basalkallus ist zumeist undeutlich begrenzt.

$$
D=8 \cdot 5, d=7, H=6 \mathrm{~mm} \text {. }
$$

Deckel halbkr'eisförmig mit gebogenem Spindelrand und spitz ausgezogenem oberen Winkel; die ziemlich dicke, gelbliche Kalkplatte ist am Spindelrand leistenförmig erhoben und von der Hornplatte durch eine tiefe Furche abgesetzt. Die sigmakante ist leicht S-förmig gebogen, aber ziemlich niedrig, die Furche neben dem unteren Aste derselben tief, der Fortsatz am Aussenrande des Deckels deutlich.

Fundort: die Insel Cuba (Yateras, Guantanamo und Baracoa)

\section{Alcadia (Eualcadia) nuda (Arango) Pfeiffer.}

\author{
Taf. 16, Fig. 9-12.
}

Helicina nuda Arango apad Pfeiffer Mal. Bl. XIII. p. 63, 1866.

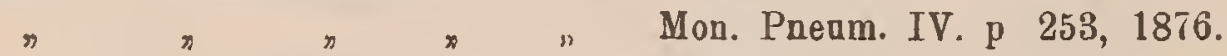

„ Arango Contr. Faun. Mal, Cab. p. 50, 1880.

" Crosse J. de Conch. vol. 38, p. 317, T. 6, F. 5, 1890.

Gehäuse breitkegelförmig mit flachgewölbter Basis, festschalig gelblichweiss, matt mit ungleichmässigen Zuwachsstreifen und einigen feinen, undeutlichen Spirallinien, welchen vermatlich kurze, sehr hinfällige Borsten entsprechen. Das niedrige, flachkegelfö rmige Gewinde 
besteht aus 5 kaum gewölbten bis flachen, ziemlich rasch zunehmenden Umgängen, der letzte ist $1 / 3$ breiter, wie der vorletzte, an der Peripherie undeutlich kantig und steigt vorne nicht herab. Die abgerundet dreieckige Mündung ist schief, der weisse Mundsaum stark verdickt, kurz assgebreitet und ungeschlagen. Die nach vorne und aussen gebogene Spindel endet mit einem runden, vorspringenden Höcker und wird vom Basalrande der Mündung durch einen seichten, aber deutlichen Ausschnitt geschieden. Der ziemlich dicke, glasartig glänzende, weisse Basalkallus ist deutlich begrenzt.

$$
\mathrm{D}=15 \cdot 2, \mathrm{~d}=12 \cdot 8, \mathrm{H}=18 \cdot 8 \mathrm{~mm} \text {. }
$$

Deckel halbeiförmig mit S-förmig gebogenem Spindelraud and ziemlich spitzem oberen Winkel. Die dicke, rötliche, glänzende Kalkplatte ist am Spindelraride leistenförmig erhoben; die Hornplatte ist in der Mitte gelblich, am Aussenrande rotbraun, die S-förmig gebogene Sigmakante ziemlich niedrig, die Furche neben dem unteren Aste derselben tief, der Fortsatz am Aussenrande des Deckels abgerundet aber deutlich.

Fundort: Die Insel Cuba (Barigua).

\section{Subgenus Leialcadia $\mathrm{n}$.}

Gehäuse kegelförnnig mit gewölbter Basis bis flachkugelig; die glänzende und lebhafı gefärbte Epidermis ist beständig, die zarte Skulptur besteht zumeist nur aus sehr feinen bis undeutlichen radialen Zuwachsstreifen, neben diesen sind nur selten feine Spirallinien vorhanden. Der Mundsaum ist zumeist nur leicht verdickt und ausgebreitet, der Aussensaum häufig breit bis lappenartig ausgezogen und umgeschlagen, gegen die Insertionen zu rasch verschmălert. Die wenig gebogene bis senkrechte Spindel endet unten mit einer zumeist wenig vorspringenden bis undeutlichen Ecke und wird vom Basalrande der Mündung durch einen winkeligen oder halbkreisförmigen, aber ziemlich seichten bis flachen Ausschnitt geschieden.

Deckel mit spitzem oft zu einem Fortsatze ausgezogenem oberen Winkel, dünner bis krustenartiger Kalkplatte, welche nur am Spindelrande leistenartig verdickt ist und von der Hornplatte durch eine Furche geschieden wird; der Nukleus dem Spindelrande sehr genähert, die Sigmakante wenig gebogen und nur im unteren Aste leistenartig erhoben; die Furche neben derselben ziemlich tief und immer deutlich, der Fortsatz am Aussenrande des Deckels zumeist abgerundet und wenig vor springend.

Das Verbreitungsgebiet deckt sich mit jenem des Genus. Die in dieser Gruppe vereinigten Formen werden besonders durch die glänzende, beständige Epidermis und die abgeschwächten Merkmale der Mündung und des Deckels gekennzeichnet; einzelne Formen erinnern an die Sulfurinen der Philippinen; so finde ich Alcadia megastoma C. B. Adams von Jamaica in den Sammlungen oft als Sulfurina citrina Grat. bezeichnet.

I. 18. II.

18. IX. 1907. 


\title{
Formenkreis Megastoma n.
}

\author{
90. Alcadia (Leialcadia) megastoma C. B. Adams. \\ Taf. 10, Fig. 12-15.. \\ Helicina megastoma C. B. Adams Contr. to Cunch. I. p. 14, 1849. \\ Alcadia $\quad n \quad$ Pfeiffer Mon. Pneum. I. p. 411, 1852. \\ $\pi \quad$ Sowerby Thes. III. p. 280, T. 267, F. 46-48, 1866. \\ Helicina affinis Adams Pr. Boston Soc [I, p. 102, 1846.
}

Gehäuse gedrückt kugelig oder breit kegelförmig, festschalig durchscheinend, hellgelb bis braungelb. Frische Exemplare sollen eine sammetartige, bänderartig unterbrochene Epidermis besitzen, meine Exemplare sind durchwegs glatt und glänzend mit sehr feinen radialen Zuwachsstreifen. Das niedrige, breit kegelförmige Gewinde besteht aus 4 ziemlich rasch zunehmenden, gewölbten Umgängen; der letzte ist aufgeblasen, gerundet, und steigt vorne langsam und wenig herab. Die halbkreisförmige Mündung ist wenig schief, der hellgelbe Mundsaum leicht verdickt, kurz ausgebreitet. Die kurze Spindel weicht nach rückwärts zurück und endigt mit einer winkeligen, wenig vorspringenden Ecke, der Ausschnitt am Uebergange zum Basalrande ist seicht, bis undeutlich, der glänzende etwas verdickte und heller bis weiss gefärbte Basalkallus ziemlich deutlich begrenzt.

$$
\begin{aligned}
& D=7 \cdot 2, d=6 \cdot 2, H=5.6 \mathrm{~mm} . \\
& D=8, d=6.5, H=5 \mathrm{~mm} .
\end{aligned}
$$

Deckel halbkreisförmig mit geradem Spindelrand und spitzem oberen Winkel, die verhältnismässig dicke Kalkplatte gelblich und fein gekörnelt, die Hornplatte in der Mitte und am Spindelrande gelblich, am Aussenrande rotbraun oder orange. Die Sigmakante gebogen und ziemlich erhoben, die Furche neben dem unteren Aste derselben deutlich, der Fortsatz am Aussenrande winkelig und deutlich vorspringend.

Fundort: die Insel Jamaica.

\author{
91. Alcadia (Eualcadia) megastoma dubiosa C. B. Adams. \\ Taf. 10, Fig. 16-20. \\ Helicina d ubiosa C. B. Adams Contr. to Conch. VI. p. 93, 1850. \\ Alcadia $\quad$ Pfeiffer Mon. Pneum. I. p. 410, 1852
}

Gehäuse breitkegelförmig mit flach gewölbter Basis, zumeist lebhaft rotbraun mit stăra keren und etwas ungleichmässigen radialen Zuwachsstreifen. Die Umgänge nehmen deutlich langsamer zu, der letzte ist mehr zusammengedruickt, weniger aufgeblasen. Der weisse Mundsaum mehr verdickt und besser ausgebreitet. 
Deckel wie bei der typischen Form.

$$
\begin{aligned}
& D=7, d=6, H=5.4-5 \mathrm{~mm} . \\
& D=8, d=7, H=5 \mathrm{~mm} .
\end{aligned}
$$

Fundort: die Insel Jamaica.

Diese Form ist wie der Typus mit Rücksicht auf die Höhe des Gewindes und die mehr minder rasche Zunahme der Umgänge einigermassen veränderlich; die Unterschiede von der typischen Form sind sehr gering, nach meinem Material aber konstant.

\title{
92. Alcadia (Leialcadia) neebiana Pfeiffer.
}

Taf. 10, Fig. 21-25.

\author{
Helicina neebiana Pfeifter Mal. Bl. IX. p. 8, 1862. \\ " " Mon. Pneum. III. p. 225, 1865 \\ " Crosse J. de Conch. vol. 38, p. 318, 1890.
}

Gehäuse nahezu kugelig, ziemlich festschalig, durchscheinend, gelbbraun, die oberen Umgänge rötlich; lebhaft glänzend mit sehr feinen Zuwachsstreifen. Das niedrige, abgerundet kegelförmige Gewinde besteht aus $4 \frac{1}{2}$ nahezu flachen, ziemlich rasch zunehmenden Ungängen; der letzte ist gerundet, etwas aufgeblasen, $1 / 3$ breiter, wie der vorletzte und steigt vorne wenig, aber deutlich herab. Die halbkreisförmige Mündung ist wenig schief, der weisse Mundsaum leicht verdickt, kurz ausgebreitet; der Oberrand an der Insertion etwas vorgezogen. Die kurze, nach aussen gebogene Spindel endigt mit einer abgerundeten, aber deutlichen Ecke, der Ausschnitt am Uebergange zum Basalrande ist seicht und breit, hinter demselben befindet sich im Gaumen eine von der Spindel ausgehende Falte. Der weisse, glänzende Basalkallus ist nur im unteren Teile stärker verdickt und deutlich begrenzt.

$$
\mathrm{D}=10 \cdot 5, \mathrm{~d}=8.5, \mathrm{H}=7.8 \mathrm{~mm} \text {. }
$$

Deckel halbeiförmig mit geradem Spindelrand und spitz ausgezogenem oberen Winkel, die rötliche matte Kalkplatte ist am Spindelrande knochenartig dick; die Hornplatte im Zentrum gelb, an der Peripherie rotbraun, mit leistenförmig erhobener, nahezu gestreckter Sigmakante, tiefer Furche und deutlichem Fortsatze am Aussenrande.

Fundort: Monte Toro auf Cuba.

Von A. magastoma C. B. Adams durch die kugelige Form, das niedrigere, abgerundete Gewinde, die flachen Umgänge, den auffallenden Glanz der Epidermis und die Beschaffenheit der Mündung gut zu unterscheiden. 


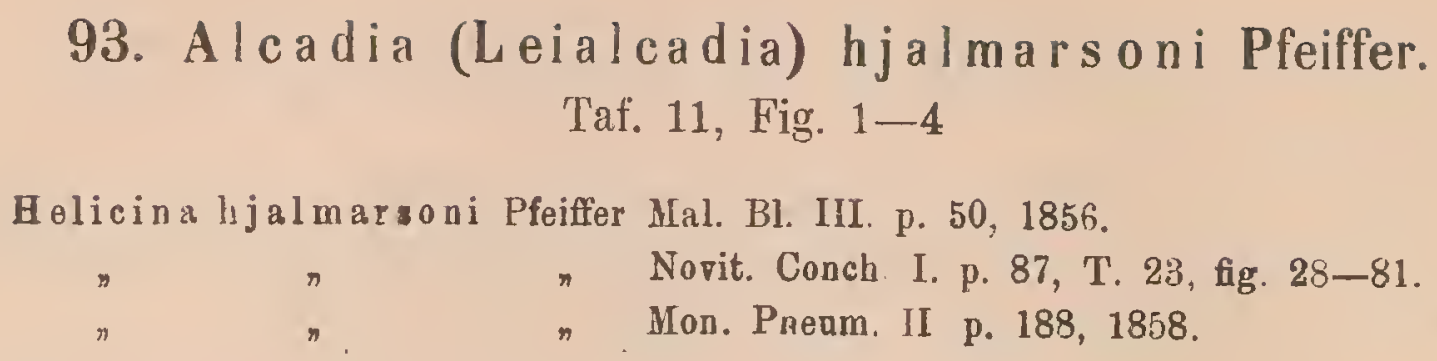

Gehäuse flachkugelig, festșchalig, durchscheinend, gelbbraun bis grünbraun; die oberen Umgänge, ebenso eine Zone entlang der Naht und hinter der Mündung rotbraun; lebhaft glänzend mit feinen bis undeutlichen radialen Zuwachsstreifen. Das wenig erhobene Gewinde ist abgerundet und besteht aus 4 nahezu Hachen, rasch zunehmenden Umgängen, der letzte ist etwas zusammengedrückt, an der Peripherie gerundet, unten abgeflacht und steigt vorne langsam herab. Die halbeiförmige Mündung ist schief, der gelbliche Mundsaum leicht verdickt, kaum ausgebreitet oder stumpf und gerade. Die fast gerade, nur wenig gedrehte Spindel weicht ein wenig nach rückwärts aus und geht im rechten Winkel ohne Ecke und Ausschnitt in den Basalrand über. Der ziemlich dicke Basalkallus ist weiss, glänzend und deutlich begrenzt; in der Nabelgegend ist derselbe quer zur Spindel durch eine gebogene Furche abgesetzt.

$$
D=7-8, d=6 \cdot 6-7, H=5 .
$$

Deckel halbkreisförmig mit leicht konkavem Spindelrand und spitz ausgezogenem oberen Winkel; die ziemlich dünne Kalkplatte ist gelbbraun bis rotbraun und fein gekörnelt; die rotbraune Hornplatte mit niedriger Sigmakante, seichter Furche und undeutlichem Fortsatz am Aussenrande des Deckels.

Fundort: die Insel Portorico (Caguana).

\section{Formenkreis Nitida n.}

\section{Alcadia (Leialcadia) nitida Pfeiffer.} Taf. 11. Fig. 5-8.

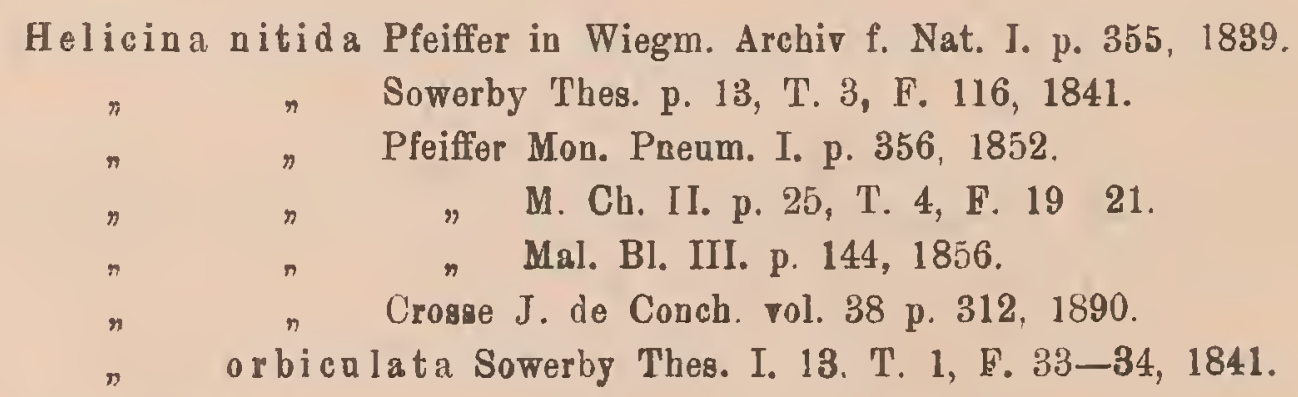

Gehäuse flachkugelig, ziemlich dünnschalig, durchscheinend, gelbbraun bis hellrotbraun (Heischfarben), lebhaft glänzend mit sehr feinen bis undeutlichen Zuwachsstreifen. Das 
niedrige, flachkegelförmige Gewinde besteht aus $4 \frac{1}{2}-5$ ziemlich rasch zunehmenden, nahezu Hachen Umgăngen, der letzte ist etwas zusammengedrückt, an der Peripherie gerundet und steigt vorne nicht herab. Die abgerundet dreieckige Vündung ist wenig schief, der dünne Mundsaum nur entsprechend dem Aussenrande sehr kurz ausgebreitet, der Oberrand konvex nach vorn gezogen und etwas herabgebogen. Die kurze nach vorne und aussen gebogene Spindel endet mit einer ziemlich scharfen Ecke und wird vom Basalrande der Mündung durch einen seichten, aber breiten Ausschnitt geschieden. Der weisse, gekörnelte und glänzende Basalkallus ist in der Mitte stärker verdickt, sonst ziemlich deutlich begrenzt; in der Nabelgegend gegen die Spindel durch eine quere, bogenförmige Furche abgesetzt.

$$
\begin{aligned}
& D=7, d=6, H=4.5 \mathrm{~mm} . \\
& D=8, d=7,{ }^{\prime} H=5.5 \mathrm{~mm} .
\end{aligned}
$$

Deckel halbeiförmig mit S-förmig gebogenem Spindelrand und spitz ausgezogenem oberen Winkel. Die ziemlich dünne Kalkplatte ist gelbbraun und fein gekörnelt; die hellrotbraune Hornplatte mit gebogener, ziemlich erhobener Sigmakante, deutlicher Furche und winkeligem Fortsatze am Aussenrande.

Fundort: der Insel Cuba (Matanzas).

95. Alcadia (Leialcadia) rolunda d'Orbigny. Taf. 11, Fig. 13.

Helicina rotunda d'Orbigny Moll. Caba I, p. 25f, T. 21, F. 1-3, 1841.

Gehäuse kugelig kreiselförmig, fest:schalig, etwas durchscheinend, zitrongelb, hellgelb mit hellrotbraunem Gewinde oder gelbbraun, lebhaft glänzend, mit feinen, aber deutlichen und etwas ungleichmässigen, radialən Zuwachsstreifen und einigen undeutlichen, nahezu erloschenen Spirallinien. Das ziemlich erhobene, kegelförmige Gewinde ist leicht konvex und besteht aus $5-51 / 2$ nahezu flachen, langsam und regelmässig zunehmenden Umgängen; der letzte ist gerundet, unten abgeflacht, an der Mündung leicht eingeschnürt und steigt vorne wenig herab. Die abgerundet dreieckige Mündung ist wenig schief, der dünne gelbe Mundsaum kurz ausgebreitet; der Oberrand etwas herabgebogen, aber nicht vorgezogen. Die Spindel ist leicht nach vorne und aussen gebogen und endigt unten mit einer etwas abgerundeten, aber scharf vorspringenden Ecke und wird vom Basalrande der Mündung durch einen seichten und breiten Ausschnitt geschieden. Der glänzende, zitrongelbe Basalkallus ist ziemlich dünn bis zart und undeutlich begrenzt.

$$
\mathrm{D}=6 \cdot 4-8, \mathrm{H}=5-7 \cdot 5 \text {. }
$$

Deckel: halbkreisförmig mit S-förmig gebogenem Spindelrande und zu einem spitzen Fortsatz ausgezogenem oberen Winkel. Die dünne bis krustenartige Kalkplatte ist fèin gekörnelt. Die Hornplatte rotbraun nit leicht gebogener und deutlich erhobener Sigmakante, ziemlich tiefer Furche und deutlichem winkeligen Fortsatz am Aussenrande.

Fundort: die Insel Cuba (Rangel, Guajaibon, Monte Toro). 


\title{
96. Alcadia (Leialcadia) rotunda campanula Pfeiffer. \\ Taf. 11, Fig. 9-12.
}

\author{
Helicina campanula Pfeiffer Pr. Z. S. p. 120, 1848. \\ $n \quad n \quad$ M. Ch. II. p. 41, T. 9, F. $12-13$.
}

Gehăuse durchschnittlich grösser, glockenförmig mit auffallend höherem, kegelförmigem Gewinde und $3 \frac{1}{2}$ flachen, langsamer zunehmenden Umgăngen.

Deckel, wie bei der typischen Form.

$$
\mathrm{D}=9, \mathrm{~d}=8, \mathrm{H}=8.5 \mathrm{~mm} \text {. }
$$

Fundort: die Insel Cuba.

\section{Alcadia (Leialcadia) rotunda glabra Gould. Taf. 11, Fig. 15--18. \\ Helicina g labra Gould Pr. Boston Soc. I. p. ${ }^{3} \stackrel{3}{5}^{8}$. \\ „ Pay Memor. Cuba II. p. 6, 1856.}

Gehäuse kleiner, dünnschaliger, breit kegelförmig mit Hachgewölbter Basis, graugelb, gelblich bis rötlich hornfarben. Das breitkegelförmige Gewinde besteht nur ans $41{ }_{2}^{1}$ etwas rascher zunehinenden Umgängen, der letzte ist mehr zusanmengedrückt, die Mündung velhältnismässig breiter. Die Ecke am unteren Ende der Spindel ist schärfer und springt deutlicher vor, der Ausschnitt am Uebergange zum Basalrande der Mündung tiefer; der gekörnelte Basalkallus weiss.

$$
\text { I }=6, d=5, \mathrm{H}=4.5 \mathrm{~mm} .
$$

Deckel, wie bei der typischen Form, nur zarter und heller gefärbt.

Fundort: Guane auf Cuba; diese Form ist sehr veränderlich; ihre Zugehörigkeit zur Formenreihe der A, rotunda d'Orb. wird durch mehrere von mir beobachtete Uebergangsformen erwiesen.

98. Alcadia (Leialcadia) rotunda montana Wright.

Taf. 11, Fig. $19-21$.

Helicina montana Wright apud Pfeiffer Mal. Bl. Xl. p. 160, 1864.

Pfeiffer Mon. Pnerm. III. p. 220, 1865.

Gehäuse verhältnismässig sehr klein, mehr niedergedrückt, gelb, gelblich hornfarben: oder rötlich. Das flachkegelförmige Gewinde besteht aus $4-4 \frac{1}{2}$ deutlicher gewölbten, 
rascher zunehmenden Umgängen, der letzte ist zusammengedrückt, an der Peripherie im Beginne stumpfkantig, gegen die Mündung zu gerundet, der Basalkallus weiss oder mit dem Gehäuse gleichfarbig.

$$
\mathrm{D}=4 \cdot 5, \mathrm{~d}=4 \cdot 2, \mathrm{H}=32 .
$$

Fundort: die Insel Cuba (Vuelto Abajo).

\title{
99. Alcadia (Leialcadia) trochulina dorbigny.
}

Taf. 13, Fig. 22-24. Taf. 14, Fig. 2.

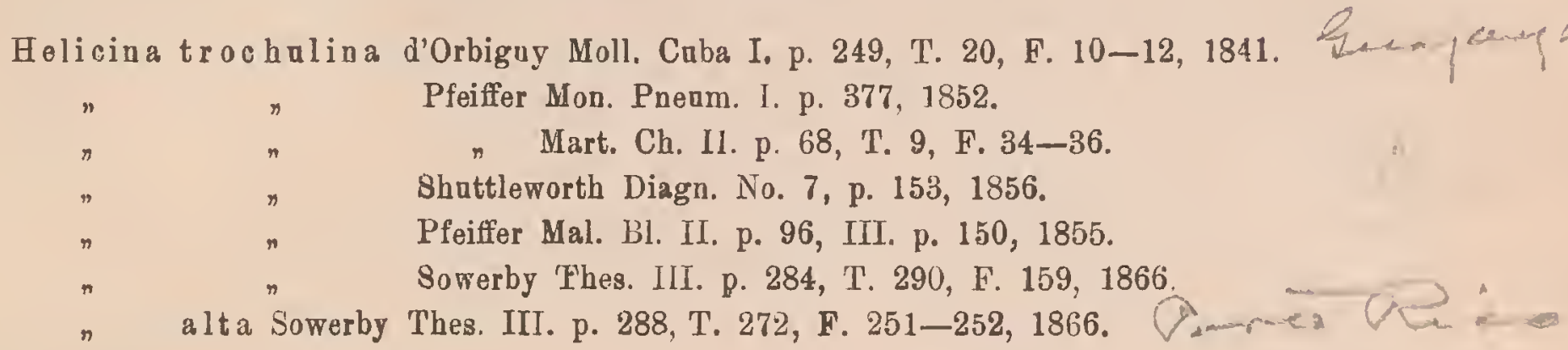

Gehäuse kegelförmig mit halbkugeliger Basis, dünnschalig, durchsichtig gelb bis lebhaft rotbraun, glatt und glänzend mit sehr feinen bis undeutlichen radialen Zuwachsstreifen. Das regelmässig kegelförmige Gewinde besteht aus 5-5/2 nahezu Hachen sehr langsam und regelmässig zunehmenden Umgängen, der letzte ist im Beginne mehr minder deutlich kantig, unten abgeflacht, vor der Mündung leicht eingeschnürt und steigt vorne sehr wenig oder gar nicht herab. Die abgerundet dreieckige Mündung ist wenig schief, der weisse Mundsaum kaum verdickt, kurz ausgebreitet, der Oberrand an der Insertion vorgezogen. Die sehr kurže Spindel ist leicht nach vorne gebogen, am Uebergange in den Basalrand findet sich eine stumpfe, wenig vorspringende Ecke und dann ein seichter, breiter Ausschnitt. Ein dünner glänzender Basalkallus ist nur im Umkreise der Spindel angedeutet.

Deckel halbkreisförmig mit S-förmig gebogenem Spindelrand und spitz ausgezogenem oberen Winkel; die Kalkplatte sehr zart, krustenartig und zerbrechlich, die rotbraune Hornplatte mit niedriger, leicht gebogener Sigmakante, seichter Furche und abgerundetem Fortsatz am Aussenrande.

Fundort: die Insel Portorico (Por'to de Luquillo, Arceibo).

\section{Formenkreis Mamilla n.}

\section{A lcadia (Leialcadia) mamilla Weinland.}

Taf. 12, Fig. 19-20.

\author{
Alcadia mamilla Weinlaud Mal. Bl. IX p. 197, 1812. \\ $\begin{array}{lll}n & n & \text { Pfeiffer Mon. Pneum. III. p. 249, } 1865 . \\ n & n & \text { Crosse J. de Conch. vol. } 39 \text { p. 192, } 1891 .\end{array}$
}


Gehăuse kegelförmig mit Hachgewölbter Basis, festschalig glănzend mit sehr feinen Zuwachsstreifen, die Grundfarbe rotbraun mit hellgelber Basis, weissem Apex, einem rotbraunen, milchweiss eingesäumtem Bande unter der Peripherie und milchigen Zickzackstriemen auf der Oberseite, welche mitunter die Grundfarbe nahezu verdecken. Das ziemlich erhobene Gewinde ist leicht abgerundet und besteht aus $5-5^{1} / 2$ leicht gewölbten, langsam und regelmässig zunehmenden Umgängen; der letzte ist unten abgeflacht, vor der Mündung eingeschnürt und steigt vorne ziemlich tief herab. Die abgerundet dreieckige Mündung ist schief, im Gaumen rotbraun gefärbt, der dünne, weisse Mundsaum zienlich ausgebreitet und umgeschlagen; der Oberrand an der Insertion etwas vorgezogen. Die nur wenig nach vorue und aussen gebogene Spindel endigt mit einem griffelartigen, abgerundeten, ziemlich langen Fortsatz und wird vom Basalrande der Mündung durch einen ziemlich tiefen, halbkreisförmigen Ausschnitt geschieden. Der glänzende, dünne Basalkallus ist mit der Basis gleichfarbig und undeutlich begrenzt; in der Nabelgegend grübchenartig vertieft.

$$
\mathrm{D}=7-8, \mathrm{~d}=6-7, \mathrm{H}=6-7 \mathrm{~mm} \text {. }
$$

Deckel halbkreistörmig mit geradem Spindelrand und spitz ausgezogenem oberen Winkel. Die ziemlich dünne Kalkplatte ist fein gekörnelt, am Spindelrande stärker verdickt und leistenartig erhoben; die gelbbranne Hornplatte mit gestreckter, nur im unteren Aste deutlich erhobener Sigmakante, seichter Furche neben derselben und abgerundetem, aber deutlichem Fortsatz am Aussenrande des Deckels.

Fundort: Haiti.

\section{Alcadia (Leialcadia) concinna (Gundlach) Pfeiffer.}

Tat. 12, Fig. 15-18.

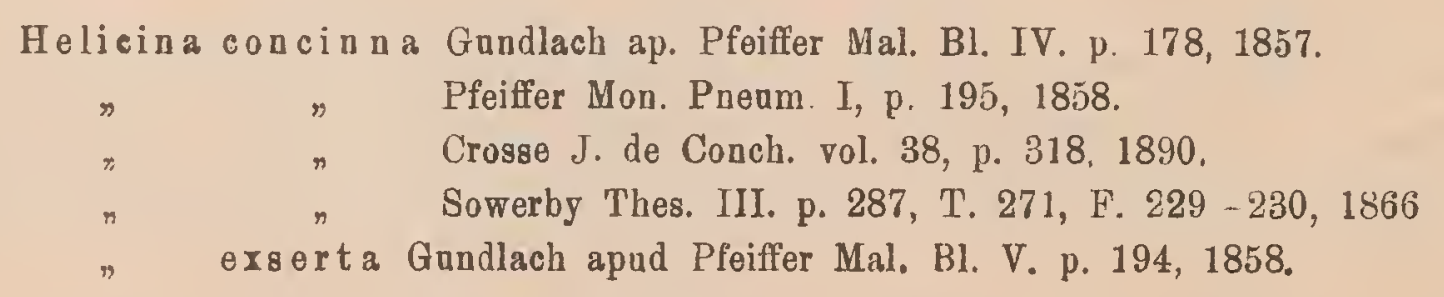

Gehäuse gedrückt kugelig, festschalig, gelblichweiss mit hellgelbem oder gelbbraunem Gewinde und mitunter einer schmalen Binde an der Naht und Peripherie. Die Sikulptur besteht nebst feinen, etwas ungleichmässigen radialen Zuwachsstreifen aus dichten und feinen Spirallinien der Epidermis, welchen wahrscheinlich kurze Härchen entsprechen. Das niedrige, abgerundete Gewinde besteht aus $4^{1} / 2-5$ gewölbten, langsam und regelmässig zunehmenden durch eingedrückte Naht geschiedenen Umgängen; der letzte ist an der Peripherie gerundet, vor der Mündung eingeschnürt und steigt vorne tief herab. Die halbeiförmige Mündung ist schief, im Gaumen gelb oder hellrotbraun gefärbt; der weisse leicht verdickte Mundsaum kurz ausgebreitet, und umgeschlagen, der Oberrand an der Insertion etwas vorgezogen. Die 
kurze nach vorne gekrümmte Spindel endigt mit einem abgerundeten, stielartigen Fortsatz und wird vom Basalrande der Mündung durch einen halbkreisförmigen, ziemlich tiefen Ausschnitt geschieden.

Der ziemlich dicke, weisse, zitronengelbe oder rotbraune Basalkallus ist deutlich begrenzt.

$$
\mathrm{D}=65-8, \mathrm{~d}=5 \cdot 6-7 \cdot 4, \mathrm{H}=5-5 \cdot 4 \mathrm{~mm} \text {. }
$$

Deckel wie bei A. mamilla Weinland.

Fundorte: Cabo de Cruz und Santjago de Cuba auf Cuba.

Alcadia exserta, (Gundlach) Pfeiffer wird nur mitunter grösser und hat hăufig einen weissen oder nur hellgeben Basalcallus, Merkmale, welche auch bei der typischen Form beobachtet werden und keinen Unterschied begründen.

\section{Alcadia (Leialcadia) gundlachi Pfeiffer.}

Taf. 11, Fig. 22- 25

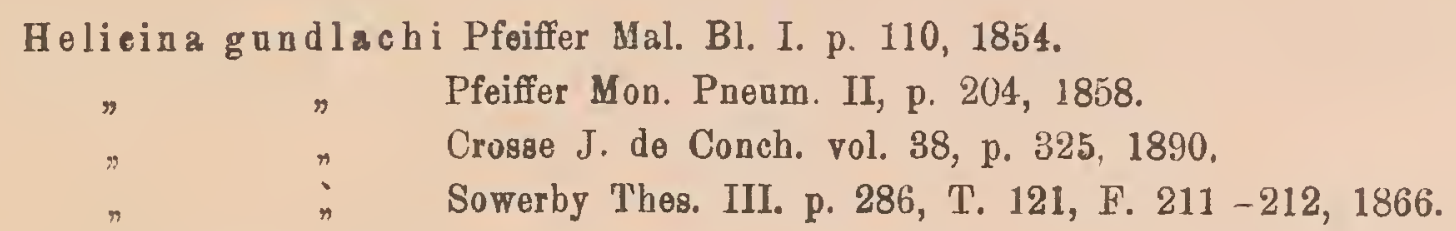

Gehäuse breitkegelförmig mit flachgewölbter Basis, ziemlich festschalig, gelblich bis rötlich hornfarben mit einer weissen Zone entlang der Naht und mitunter 2 schmalen Binden an der Peripherie; glänzend mit sehr feinen und etwas ungleichmässigen radialen Zuwachsstreifen. Das niedrige, regelmässig kegelförmige Gewinde besteht aus 5 gewölbten, langsam und regelmässig zunehmenden, durch eingedrückte Naht geschiedenen Ungängen; der letzte ist an der Peripherje undeutlich kantig, vor der Mündung leicht eingeschnürt und steigt vorne ziemlich tief herab. Die abgerundet dreieckige Mündung ist schief, der dünne, weisse Mundsaum ganz kurz ausgebreitet, der Oberrand an der Insertion etwas vorgezogen. Die nach vorne gebogene Spindel endigt unten mit einem abgerundeten, griffelförmigen Fortsatz und wird vom Basalrande der Mündung durch einen halbkreisförmigen, ziemlich tiefen Ausschnitt geschieden. Der ziemlich dünne gelbliche Basalkallus ist undeutlich begrenzt.

$$
\mathrm{D}=6, \mathrm{~d}=5 \cdot 3, \mathrm{H}=4 \cdot 2 \mathrm{~mm} \text {. }
$$

Deckel hellhornfarben, sonst wie bei A. mamilla Weinland.

Fundort: San Juan de los Pinos.

I. 18. II. 


\title{
Formenkreis Bellula n.
}

\author{
103. Alcadia (Leialcadia) bellula (Gundlach) Pfeiffer. \\ Taf. 12, Fig. 1-8.

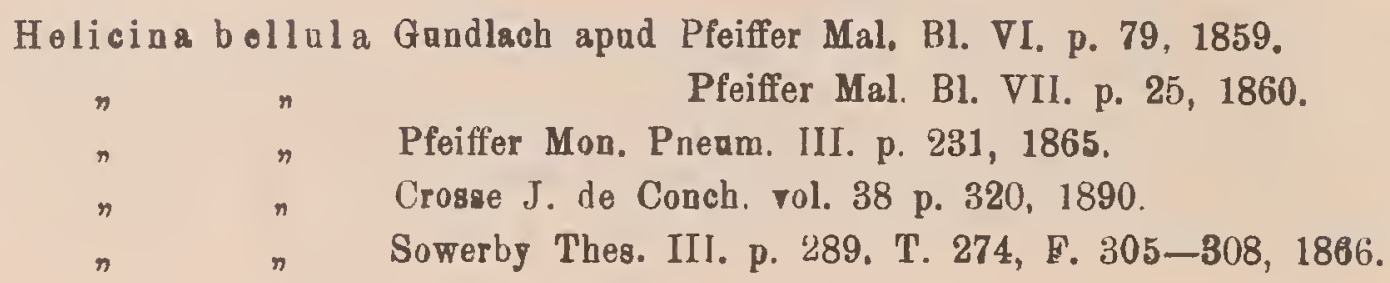

An den mir bekannt gewordenen Fundorten der A. bellula Pfeiffer findet man regelmässig zwei auffallend verschiedene Formen dieser Art ohne Uebergänge neben einander, welche jedoch einzelne der betreffenden Lokalform eigentümliche Merkmale gemeinsam aufweisen. Ich halte diese am gleichen Fundorte lebenden konstanten Formen nicht für verschiedene Arten, sondern für Geschlechtsunterschiede derselben Lokalform und bezeichne dieselben zunächst mit den Buchstaben $\alpha$ und $\beta$ bis die anatomische Untersuchung die Frage entscheidet.

Fig. $1-5$.

๙) Gehăuse kegelförmig mit halbkugeliger Basis, festschalig, zitrongelb, die mittleren Umgänge häufig lebhaft rotbraun, ebenso ist mitunter eine schmale rotbraune Binde entlang der Naht der unteren Umgänge vorhanden; glänzend mit sehr feinen bis undeutlichen $\mathrm{Zu}$ wachsstreifen. Das ziemlich erhobene, abgerundet kegelförmige Gewinde besteht aus $\mathbf{4}^{1 / 2}$ leicht gewölbten bis nahezu flachen Umgängen; der letzte ist unten abgeflacht, an der Peripherie gerundet, vor der Mündung eingeschnürt und steigt vorne ziemlich tief herab. Die abgerundet dreieckige Mündung ist wenig schief, der dünne gelbliche Mundsaum an den Insertionen schmal, entsprechend dem Aussenrande aber zungenförmig ausgebreitet und erweitert. Die kurze nach hinten und aussen gerichtete Spindel endet unten mit einer abgerundeten, sehr wenig vorspringenden Ecke; der Ausschnitt am Uebergange zum Basalrande der Mündung ist sehr seicht und undeutlich. Der dünne, gelbe, lebhaft glänzende Basalkallus ist ziemlich undeutlich begrenzt.

$$
\mathrm{D}=7.5, \mathrm{~d}=6, \mathrm{H}=6.5 \mathrm{~mm} \text {. }
$$

Deckel halbkreisförmig mit leicht S-förmig gebogenem Spindelrande und spitzem oberen Winkel. Die krustenartig dünne Kalkplatte ist nur am Spindelrande deutlich verdickt. Die Hornplatte hellrotbraun mit niedriger, wenig gebogener und dem Spindelrande ziemlich genăherter Sigmakante, seichter Furche und abgerundetem Fortsatz am Aussenrande.

Fundort: Yateras auf Cuba.

Fig, 6-8.

§) Gehăuse durchschnittlich grösser mit höherem, konvexem Gewinde, welches aus 5 deutlich langsamer zunehmenden Umgängen besteht, der letzte steigt vorne tiefer herab; 
die Mündung höher, schmäler und schiefer, der Mundsaum mit schmalem zungenförmigen Fortsatz des Aussenrandes; einfärbig gelb oder mit schmalem rotbraunen Bande an der Peripherie.

Fundort: Yateras auf Cuba.

$$
\mathrm{D}=8, \mathrm{~d}=6.5, \mathrm{H}=7.5 \mathrm{~mm} .
$$

\section{Alcadia (Leialcadia) bellula bellissima n. Taf. 12. Fig. 9-12.}

a) Fig. 9-10. Gehäuse kleiner, niedriger, graublau oder hellgelb durchscheinend mit einer breiten milchweissen Nahtbinde und lebhaft kastanienbraunen oberen Windungen; der Mundsaum mehr erweitert mit breiterem zungenartigen Fortsatz.

Fundort: Baracoa auf Cuba.

$$
D=6, d=5, H=5.2 \mathrm{~mm} \text {. }
$$

ß) Fig. 11-12. Gehäuse kleiner, niedriger, geib oder grau mit milchweisser Binde entlang der Naht, zitrongelbem Apex und kastanienbraunen mittleren Windungen (die angeführten Unterschiede beziehen sich auf A. bellula $\left.\mathrm{Pfr}^{2}, \not \beta\right)$.

Fundort: Baracoa auf Cuba.

$$
\mathrm{D}=6 \cdot 7, \mathrm{~d}=5 \cdot 7, \mathrm{H}=5 \cdot 7 \mathrm{~mm} \text {. }
$$

\section{Alcadia (Leialcadia) bellula leptochila n.}

$$
\text { Taf. 12, Fig. 13-14. }
$$

a) Gehäuse viel kleiner, gedrückt kugelig, dünnschaliger, einfarbig rotbraun oder gelb mit breiter rotbrauner Binde auf der Oberseite, der dïnne Mundsaum weniger erweitert, der zungenartige Fortsatz des Aussenrandes viel schmäler.

Fundort: Monte Toro auf Cuba.

$$
\mathrm{D}=5 \cdot 2, \mathrm{~d}=4 \cdot 5, \mathrm{H}=4 \cdot 2 \mathrm{~mm} \text {. }
$$

$\beta$ ) Gehäuse, wie bei A. bellula Pfr. $\beta$, nur viel kleiner, niedriger mit nur $4^{1 / 2}$ rascher zunehmenden Umgăngen.

Fundort: Monte Toro auf Cuba.

$$
\mathrm{D}=6, \mathrm{~d}=5 \cdot 5, \mathrm{H}=5 \cdot 5 \text {. }
$$

106. Alcadia (Leialcadia) spectabilis (Gundlach) Poey.

Taf. 13, Fig. 13-16.

Helicina spectabilis Gandlach in Poey Memor. Caba II, p. 5, 1846.

Pfeiffer Mon. Pnenm. III. p. 230, 1858. 


\author{
Helicina spectabilis Crosse J. de Conch. vol. 38 p. 320, 1890. \\ " Sowerby 'Fhes. III. p. 287, T. 227, F. 246-247, 1866.
}

Gehäuse kegelförmig mit halbkugeliger Basis, festschalig, hellgelb oder hellrotbraun mit einer rotbraunen Binde an Peripherie und Naht, sowie rotbraunem Apex; glänzend mit undeutlichen Zuwachsstreifen. Das abgerundet kegelförmige Gewinde besteht aus 5 leicht gewölbten, ziemlich langsam und regelmässig zunehmenden Umganngen, der letzte ist gerundet und steigt vorne langsam und wenig herab. Die kurze, etwas nach aussen gebogene Spindel endet mit einer abgerundeten, wenig vorspringenden Ecke und wird vom Basalrande der Mündung durch einen seichten, breiten, aber deutlichen Ausschnitt geschieden. Der dünne, gelbe, glänzende Basalkallus ist undentlich begrenzt, in der Nabelgegend findet sich ein furchenartiges Grübchen. Die breit halbeiförmige Mündung ist wenig schief, der leicht verdickte Mundsaum erweitert und breit umgeschlagen.

$$
\mathrm{D}=7-8, \mathrm{~d}=6.2-7, \mathrm{H}=6.8 \mathrm{~mm} \text {. }
$$

Deckel halbkreisförmig mit geradem Spindelrand und spitz ausgezogenem Spindelwinkel, beiderseits dunkel zinoberrot mit gelbem Spindelrande. Die Kalkplatte krustenartig dünn mit dickerem, leistenartig erhobenem Spindelrande; die Hornplatte mit wenig gebogener, dem Spindelrande genäherter, nur im unteren Aste deutlich erhobener Sigmakante, deutlicher. Furche und winkligem Fortsatze am Aussenrand.

Fundort: die Insel Cuba (Bayamo, Buenavista).

\title{
107. Alcadia (Leialcadia) spectabilis venusta n. Taf. 13, Fig. 17-18.
}

Gehäuse kleiner, breit kegelförmig mit flachgewölbter Basis, hellgelb mit einer rotbraunen Binde an Naht und Peripherie, sowie dunkel rotem Apex. Das kegelförmige, weniger konvexe Gewinde besteht nur aus 4 Umgängen, der letzte ist unten abgeflacht; die abgerundet dreieckige Mündung ist weniger schief, der Mundsaum kurz ausgebreitet.

$$
\mathrm{D}=5 \cdot 4, \mathrm{~d}=4 \cdot 8, \mathrm{H}=4 \cdot 2 \mathrm{~mm}
$$

Deckel wie bei der typischen Form.

Fundort: die Insel Cuba (Santjago de Cuba, Bayamo, Rancho Lucas).

\section{Formenkreis Ampliata.}

\section{Alcadia (Leialcadia) ampliata C. B. Adams. Taf. 13, Fig. 10-12.}

Helicina mpliata C. B. Adams Contr. to Cunch. No. 7 p. 101, 1850.

Pfeiffer Mon. Pneum. I. p. 371, 1852. 
Helicina ampliata Pfeiffer Mon. Pneum. II. p. 192, 1858.

$" \quad$ Sowerby Thes. III. p. 289, T. 274, F. 300-301, 1866.

Gehäuse breit kegelförmig mit flacher Basis, festschalig, ziemlich glänzend mit feinen, aber deutlichen Zuwachsstreifen, gelblich weiss. Das breit kegelförmige Gewinde besteht aus $51 \%$ leicht gewölbten, rasch zunehmenden Umgängen, welche durch eingedrückte Naht geschieden werden; der letzte ist verhältuismässig gross, unter der Peripherie stumpflkantig, unten abgeflacht und steigt vorne langsam aber ziemlich tief herab. Die abgerundet dreieckige Mündung ist sehr schief, der gelbe Mundsaum dünn; der Oberrand an der Insertion stark vorgezogen, dann etwas herabgedrückt, der Aussenrand erweitert und ausgebreitet, der Basalrand gegen die Insertion rasch verschmälert und etwas umgeschlagen. Die kurze Spindel ist stark nach aussen gebogen, am Uebergange zum Basalrand findet sich nur ein seichter, sehr breiter, undeutlicher Ausschnitt. Der dicke gelbe Basalkallus ist deutlich begrenzt; in der Nabelgegend ein seichtes Grübchen.

$$
\mathrm{D}=18, \mathrm{~d}=15, \mathrm{H}=12 \mathrm{~mm} \text {. }
$$

Deckel : unbekannt,

Fundort: die Insel Jamaica.

\section{Alcadia (Leialcadia) ampliata fuscocallosa n. Taf. 13, Fig. 1-5.'}

Gehäuse kleiner, kegelförmig mit gewölbter Basis, sehr verschieden gcfärbt und gezeichnet; grauweiss, schmutziggelb oder hellbraun mit dunkleren Radialstriemen und undeutlichen Spiralbändern. Neben feinen und ungleichmässigen Zuwachsstreifen sind unter der Lupe dichte, sehr feine Spirallinien vorhanden, welche anscheinend hinfälligen Härchen entsprechen. Das höhere, kegelförmige Gewinde besteht nur aus 5 gewölbten viel langsamer zunehmenden Umgängen, der letzte ist unten nicht abgeflacht, an der Peripherie gerundet und steigt rorne sehr tief herab. Die halbeiförmige Mündung ist breiter und höher, der hell bis dunkelgelbe Mundsaum ist zumeist dicker und breiter umgeschlagen, der rotbraune Basallaallus mehr minder veldickt bis schwielenartig und halbkreisförmig begrenzt; der Ausschnitt am Uebergange der Spindel zum Basalrande der Mündung ist deutlicher.

$$
D=11 \cdot 5, d=9 \cdot 3, H=10 \cdot 3 \mathrm{~mm} \text {. }
$$

Deckel halbkreisförmig mit geradem Spindelrand und spitz ausgezogenem oberen Winkel, beiderseits lebhaft rotbraun mit weissem Spindelrand. Die dünne bis krustenartige Kalkplatte ist am Spindelrande leistenförmig verdickt und erhoben. Die Hornplatte mit nahezu gestreckter, dem Spindelrande sehr genäherter, nur im unteren Aste deutlich erhobener Sigmakante, seichter Furche neben der Sigmakante und undeutlichem, abgerundeten Fortsatz an Aussenrande.

Fundort: die Insel Jamaica. 
Diese Form wird allgemein mit Alcadia aurantia Gray und Helicina jamaicensis Sowerby verwechselt; die Unterschiede werden am besten durch den Vergleich der Abbildungen ersichtlich gemacht. Ich habe A. ampliata fuscocallosa m. früher für die typische Form gehalten, von welcher sie so auffallend abweicht, dass die Artberechtigung derselben sehr wahrscheinlich ist.

\author{
110. Alcadia (Leialcadia) aurantia Gray. \\ Taf. 13, Fig. 6-9. \\ Helicina anrantia Gray Zool. Joürn. I. p. 67 T. 6 F. 8. \\ $" \quad$ Desh. Lam. VIII. p. 101, 1838. \\ „ Pfeiffer Mart. Ch. H. p 36, T. 1, F. 18, 19, 1846. \\ " $\quad$ Mon. Pneum. I p. 363, 1852. \\ Helcina pyrrhostoma Menke Syn. I. p. 79, 1828.
}

Gehäuse breit kegelförmig mit halbkugeliger Basis, schmutzig gelb, bräunlich oder blaugrün mit einer dunkleren Binde an der Naht und Peripherie; ziemlich festschalig glänzend mit feinen, etwas ungleichmässigen Zuwachsstreifen. Das ziemlich erhobene, leicht konvexe Gewinde besteht aus 5 gewölbten, ziemlich rasch zunehmenden Umgängen, der letzte ist gerundet, etwas aufgeblasen und steigt vorne langsam nnd wenig herab. Die halbkreisförmige Mündung ist schief, im Gaumen, hellgelb oder hellbraun, der or'tngefarbige Mundsaum verdickt, rechtwinkelig ausgebreitet und umgeschlagen; der Oberrand an der insertion vorgezogen. Die kurze, nach aussen gebogene Spindel bildet am Uebergange in den Basalrand einen stumpfen Höcker; ein seichter Ausschnitt des Basalrandes ist nur bei Exemplaren mit dünnem Mundsaum angedentet. Der glänzende, dicke Basalkallus ist wie der Mundsaum orange gefärbt, deutlich begrenzt, an der Basis oft leistenförmig erhoben.

$$
\mathrm{D}=11, \mathrm{~d}=9, \mathrm{H}=9 \mathrm{~mm} \text {. }
$$

Deckel: halbkreisförmig mit geradem Spindelrande und spitz ausgezogenem oberen Winkel; die weisse, ziemlich dünne Kalkplatte ist fein gekörnelt. Die rotbraune Hornplatte mit wenig gebogener, aber deutlich erhobener Sigmakante, ziemlich tiefer Furche und abgerundetem, aber deutlichen Fortsatz am Aussenrande des Deckels.

Fundort: die Insel Jamaica.

\title{
Formenkreis Tamsiana $\mathrm{n}$.
}

\section{Alcadia (Leialcadia) nemoralis Guppy.}

Taf. 13, Fig. 19-21. Taf. 14, Fig. 1.

Helicina nemoralis Guppy Ann. Mag. N. H. (3), XVII, p. 46, 1866.

» $\quad$ Pfeiffer Mon. Pneum. IV. p. 265, 1876. 
Holicina nemoralis Smith J. of. Conch. VIII. p. 249, 1896.
" zonata Guppy Ann. Mag. N. H. (3) XIV, p. 247, nec Lesson, 1864.

Gehäuse kegelförmig mit halbkugeliger Basis, ziemlich festschalig, gelbweiss oder hellgelb mit einer kastanienbraunen oder rotbraunen Nahtbinde, die Oberseite mitunter gelb oder hellrotbraun; glänzend mit feinen Zuwachsstreifen und unter der Lupe sichtbaren sehr feinen und dichten Spirallinien. Das ziemlich erhobene, kegelförmige Gewinde besteht aus $5^{1 / 2}$ gewölbten, regelmässig zunehmenden Umgängen, der letzte ist an der Peripherie undeutlich kantig bis fast gekielt, unten etwas abgeflacht und steigt vorne nicht herab. Die breit halbeiförmige Mündung ist schief, der weisse Mundsaum leicht verdickt, breit umgeschlagen, der Oberrand an der Insertion etwas vorgezogen. Die nach aussen und hinten gebogene Spindel endigt unten mit einer schwachen, abgerundeten Ecke und wird vom Basalrande der Mündung durch einen seichten, aber deutlichen Ausschnitt geschieden. Der dünne, weisse, gekörnelte Basalkallus ist undeutlich begrenzt.

$$
\text { I) }=13, \mathrm{~d}=11 \cdot 3, \mathrm{H}=11 \cdot 3 \mathrm{~mm} \text {. }
$$

Deckel halbkreisförmig mit geradem Spindelrand und spitzem oberen Winkel, beiderseits dunkel rotbraun gefärbt. Die sehr dünne, krustenartige Kalkplatte ist am Spindelrand deutlicher verdickt und leistenförmig erhoben. Die gestreckte Sigmakante ist dem Spindelrande sehr genähert und nur im unteren Aste deutlich erhoben; die Furche neben derselben ziemlich tief, der Fortsatz am Anssenrande abgerundet und undeutlich.

Fundort: die Insel Trinidad.

112. Alcadia (Leialcadia) tamsiana Pfeiffer. Taf. 14, Fig. 26-29

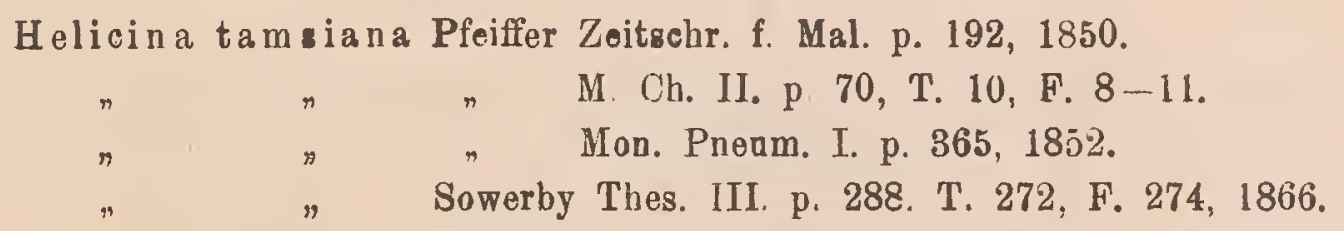

Gehäuse kegelförmig mit halbkugeliger Basis, ziemlich dünnschalig und durchscheinend, gelblich bis rötlich hornfarben, ziemlich glänzend mit feinen, ungleichmässigen Zuwachsstreifen und sehr feinen und dichten Spirallinien auf der Ober- und Unterseite. Das kegelförmige Gewinde besteht aus $4^{1} / 2$ gewölbten, ziemlich rasch zunehmenden Umgängen, der letzte ist an der Peripherie undeutlich kantig bis nahezu gerundet und steigt vorne nicht herab. Die breit halbeiförmige Mündung ist wenig schief, der weisse dünne oder nur leicht verdickte Mundsaum ist ziemlich breit umgeschlagen, der Oberrand an der Insertion etwas vorgezogen und wie der Basalrand verschmälert. Die kurze nach aussen gebogene Spindel endet mit einer schwachen, kaum vorspringenden Ecke und wird vom Basalrande der Mündung durch 
einen sehr seichten Ausschnitt geschieden. Der weisse, glänzende und gekörnelte Basalkallus ist ziemlich dünn und nur im unteren Teile deutlich begrenzt; in der Nabelgegend ein furchenartiges Grübchen.

$$
\mathrm{D}=9, \mathrm{~d}=7 \cdot 7, \mathrm{H}=7.5 \mathrm{~mm} .
$$

Deckel halbkreisförmig mit geradem Spindelrand und spitzem oberen Winkel, die dünne feingekörnelte Kalkplatte ist am Spindelrande stärlker verdickt, leistenartig erhoben und durch eine tiefe Furche von der Hornplatte abgesetzt. Die Hornplatte am Spindelrande gelbbraun, nach aussen dunkel kastanienbraun mit deutlich gebogener, aber niedriger Sigmakante, ziemlich seichter Furche und abgerundetem, aber deutlichen Fortsatz am Aussenrande.

Fundort: Verezuela und wahrscheinlich Columbien.

\title{
113. Alcadia (Leialcadia) lamsiana appuni Martens. Taf. 14, Fig. 30-31. \\ Helicina columbiana var. appani Martens Moll. Venez. p. 161, 162, T. 1, F. 1-2, 1873.
}

Gehäuse durchschnittlich grösser und festschaliger, die Grundfarbe milchig getrübt weiss mit durchscheinenden Punkten und einer grüngelben oder rötlichen, breiten Binde auf der Oberseite. Das mehr erhobene Gewiude besteht aus $4 \frac{1}{2}$ bis 5 nahezu flachen, langsamer zunehmenden Umgängen, der letzte hat eine deutlichere Kante.

Deckel, wie bei der typischen Form.

$$
\mathrm{D}=14, \mathrm{~d}=12, \mathrm{H}=12 \mathrm{~mm} \text {. }
$$

Fundort: Porto Cabello in Venezuela.

Ich beurteile die Form nach Originalexemplaren des Autors aus dem k. Museum zu Berlin.

\author{
114. A lcadia (Leialcadia) columbiana Philippi. \\ Taf. 14, Fig. 32-35. \\ Helieina columbiana Philippi Zeitsehr. f. Mal. p. 126, 1847. \\ $\leadsto \quad$ Pfeiffer Mon. Pneam. I. p. 308, 1852 \\ $" \quad$ Pfeiffer M. Ch. II. p. 52, T. 2, F. 1-3, T. 7, F. 7. \\ $\eta \quad$ Sowerby Thes. III. p. 288, T. 272, F. 261-263, 1866.
}

Gehäuse kegelförınig mit flachgewölbter Basis, festschalig gelbweiss mit durchscheinenden dunkieren Punkten, einer gelben Zone um die Mündung und gelber Spitze oder rötlich mit einer rotbraunen breiten Binde auf der Oberseite und gelblicher Basis, mitunter auch einfärbig gelb; ziemlich glänzend mit feinen ungleichmässigen Zuwachsstreifen und dichten, eingedrückten Spirallinien auf der Ober- und Unterseite. Das kegelförmige, wenig konvexe 
Gewinde besteht aus $4^{1} / 2-5$ ziemlich langsam und regelmässig zunehmenden, nahezu flachen oder nur leicht gewölbten Umgängen; der letzte ist ziemlich scharf gekielt, unten abgeflacht und steigt vorne nicht herab. Die abgerundet dreieckige Mündung ist schief, der gelbliche oder rötliche Mundsaum verdickt, kurz ausgebreitet und umgeschlagen. Die sehr kurze Spindel ist leicht nach innen gebogen und bildet am Uebergange in den Basalrand eine abgerundete undeutliche Ecke und einen seichten Ausschnitt. Der glănzende, weisse, gekörnelte Basalkallus ist nur in der Mitte deutlich verdickt, undeutlich begrenzt, in der Nabelgegend ein furchenartiges Grübchen.

$$
\mathrm{D}=11, \mathrm{~d}=9 \cdot 5, \mathrm{H}=9 \mathrm{~mm} \text {. }
$$

Deckel wie bei A. tamsiana Pfeiffer.

Fundorte: Columbien und Venezuela (Caracas).

Ich hatte Gelegenheit zahlreiche Exemplare dieser Art zu untersuchen) auch Pfeiffers Originale), dieselben stammen angeblich zum Teile aus Columbien, zum Teile aus Venezuela, stimmen jedoch auffallend mit einander überein; ein verlässlicher und genauer Fundort ist mir derzeit nicht bekannt.

\section{Formenkreis Gemma n.}

\section{A l cadia (Leialcadia) oweniana Pfeiffer. Taf. 1?, Fig. 21- 25.}

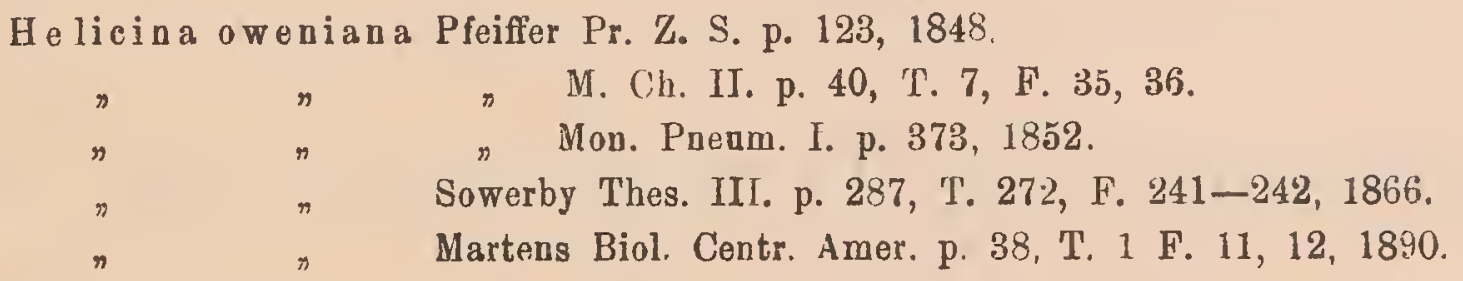

Gehäuse kegelfơrmig mit flachgewölbter Basis, ziemlich dünnschalig, hellgelb bis grüngelb, nach oben dunkler mit schmaler, weisser Nahtbinde und rotbrauner bis dunkel karminroter Spitze; glänzend mit sehr feinen bis undeutlichen Zuwachsstreifen und undeutlichen bis nahezu erloschenen Spirallinien; bei stärkerer Vergrösserung erscheint die Fpidermis ausserdem sehr fein, aber ziemlich unregelmässig gefaltet. Das kegelförmig erhobene Gewinde besteht aus $5 \frac{1}{2}$ flachen, langsam und regelmässig zunehmenden Umgängen; der letzte ist im Beginne undeutlich kantig bis gerundet und steigt vorne nicht herab. Die halbeiförmige Mündung ist wenig schief, der orangefarbene Mundsaum ausgebreitet, im Winkel abstehend, ziemlich verdickt und mitunter rinnenförmig ausgehöhlt. Die kurze Spindel ist leicht nach aussen gebogen, am Uebergange in den Basalrand findet sich eine stumpfe wenig vorspringende Ecke und ein seichter Ausschnitt. Der dünne, weisse oder gelbliche Basalkallus ist glänzend und undeutlich begrenzt.

I. 18. II.

$$
D=9, d=8 \cdot 3, H=7.6 \mathrm{~mm} .
$$


Deckel halbkreisförmig mit S-förmig gebogenem Spindelrande und spitz ausgezogenem oberen Winkel; die lebhaft rotbraune, dünne Kalkplatte ist am Spindelrande leistenförmig erhoben und durch eine Furche von der Hornplatte abgesetzt. Die rotbraune Hornplatte mit leicht gebogener, aber nur im unteren Aste leistenförmig erhobener Sigmakante, ziemlich tiefer Furche neben derselben und stumptwinkeligem, wenig vorspringendem Fortsatze am Aussenrande.

Fundort: nur im Südmexico (Chiapas).

\title{
116. Alcadia (Leialcadia) oweniana anozona Martens. Taf 12, Fig. $26-28$. \\ Helicina anozona Martens Pr. Z. S. p. 649, 1857. \\ » ${ }$ J. B. Mal. Ges. III. p 261, T. 9, F. 7, 1875.
}

Das Gehäuse breit kegelförmig mit flachyewölbter Basis, lebhafter gefärbt; hellgelb, braunviolet mit gelbweisser Nahtbinde, und lichter gefärbter Spitze. Die Spiralstreifen sind deutlicher, die Umgänge etwas mehr gewölbt, das Gewinde zumeist niedriger, der Mundsaum zitrongelb.

$$
\mathrm{D}=8 \cdot 5, \mathrm{~d}=7 \cdot 5, \mathrm{H}=7.8 \mathrm{~mm} .
$$

Deckel wie bei der typischen Form.

Fundort: Guatemala (Vera paz, Coban).

\section{Alcadia (Leialcadia) oweniana coccinostoma Morelet.} Taf. 12, Fig. 29.

\author{
Helic in a coccinost om a Morelet Test. noviss. I. p. 19, 1849. \\ Sowerby Thes. III. p. 289, T. 273, F. 295-296, 1866.
}

Gehăuse durchschnittlich kleiner mit niedrigerem Gewinde und deutlicher gewölbten Umgängen, der letzte mehr aufgeblasen und gerundet, auch unten weniger abyeflacht; grauweiss oder graugelb mit undeutlicher Nahtbinde und dunkelorangefarbenem oder zinoberrotem Mundsaum. Die Spirallinien deutlicher.

$$
\mathrm{D}=7, \mathrm{~d}=6, \mathrm{H}=6 \cdot 3 .
$$

Deckel wie bei der typischen Form.

Fundort: Guatemala (Pe乞ten, Betalulen, Vera paz?) 


\section{Alcadia (Leialcadia) gemma Preston. \\ Taf 14, Fig. $17-18$.}

Helicina gemma Preston J. of. Malae. vol. X, p. 4, 1903.

Gehäuse kegelförmig mit gewölbter Basis, ziemlich dünnschalig, durchscheinend; zitrongelb mit dunkel karminroter Spitze, zinoberrotem bis dunkel orangefarbenem Mundsaum und einer gleichgefärbten Zone hinter der Mündung; glänzend, sehr fein radial gestreift. Das spitzkegelförmige Gewinde besteht aus 5 leicht gewölbten, langsam und regelmässig zunehmenden Umgängen; der letzte ist gerundet, unten abgeflacht und steigt vorne langsam und wenig herab. Die breit halbeiförmige Mündung ist wenig schief, der leicht verdickte Mundsaum kurz ausgebreitet, umgeschlagen und rechtwinkelig abstehend. Die nahezı senkrechte Spindel endigt mit einer abgerundeten, undeutlichen Ecke, der Ausschnitt am Uebergango zum Basalrande der Mündung ist sehr seicht. Der dünne Basalkallus undeutlich begrenzt.

$$
\mathrm{D}=6.5, \mathrm{~d}=6, \mathrm{H}=7 \mathrm{~mm} \text {. }
$$

Deckel halbeiförmig mit stark S-förmig gebogenem Spindelrand und spitzem oberen Winkel. Die krustenartig dünne Kilkplatte ist am Spindelrand leistenförmig erhoben und durch eine Furche von der Hornplatte abgesetzt. Die lebhaft rotbraune Hornplatte mit niedriger dem Spindelrande sehr genäherter Sigmakante, seichter Furche aber deutlichem Fortsatz am Aussenrande.

Fundort: Costarica.

\footnotetext{
119. Alcadia (Leialcadia) beatrix Angas.

Taf. 14, Fig. $19-22$.

Helicina beatrir Angas Pr. Z S. p. 484, T. 40, F. 13, 1879.

Pilsbry Pr. Acad. Philad. 1891.

Gehäuse kegelförmig mit gewölbter Basis, ziemlich festschalig, die oberen Umgänge kastanienbraun mit einer milchweissen Binde unter der Naht, der letzte schmutzig gelb oder gelbgrün, glänzend mit undeutlichen Zuwachsstreifen und sehr feinen Spirallinien auf den oberen Umgängen. Das kegelförmige, leicht konvexe Gewinde besteht aus $5-5 \frac{1}{2}$ nahezu Hachen, langsam und regelmässig zunehmenden Umgängen, der letzte ist unten abgeflacht, an der Peripherie gerundet, hinter der Mündung leicht eingeschnürt und steigt vorne nicht herab. Die halbeiförnige Mündung ist schief, der leicht verdickte, weisse Mundsaum kurz ausgebreitet und umgeschlagen; der Oberrand an der Insertion stark vorgezogen, der Basalrand konvex. Die kurze, nur wenig nach aussen gebogene Spindel endet mit einer undeutlichen, abgerundeten Ecke, der Ausschnitt am Uebergange zum Basalrande der Mündung is sehr seicht. Der zarte, glänzende Basalkallus undeutlich begrenzt.
} 


$$
\mathrm{D}=9 \cdot 3, \mathrm{~d}=8 \cdot 3, \mathrm{H}=9 \cdot 7 \mathrm{~mm} .
$$

Deckel wie bei Alcadia gemma Preston, die Hornplatte jedoch hellrotbraun.

Fundort: Costarica.

Nach Martens ist diese Art nur Varietät von Helicina flavida Menke. Der Originalfundort der H. flavida Menke ist die Insel Jamaica; dort wurde diese Art jedoch nicht wieder gefunden und betrachte ich dieselbe als verschollen. Die Helicina flavida, welche moderne Autoren aus Mexico und Zentralamerika anführen ist zum Teile Alcadia (Leialcadia) fragilis Morelet, zum Teile Helicina (Retorquata) brevilabris Pfr., H. brevilabris incominada m., wohl auch Helicina (Retorquata) trossula Morelet. Von allen diesen Formen unterseheidet sich vorstehende Art unter anderem durch die ganz abweichende Beschaffenheit der Mündung.

\title{
120. Alcadia (Leialcadia) beatrix nicaraguae n. Taf. 14, Fig. 23, 24.
}

Gehäuse grösser, mit höherem Gewinde, hell gelbgrün mit einem dunkleren, gelbgrünen Bande über der Naht; der letzte Umgang an der Basis mehr abgeflacht.

Deckel wie bei der typischen Form.

$$
\mathrm{D}=10, \mathrm{~d}=8 \cdot 3, \mathrm{H}=11 \mathrm{~mm} \text {. }
$$

Fundort: Nikaragua.

\section{Alcadia (Leialcadia) beatrix confusa n. \\ Taf. 14, Fig. 25. .}

Gehăuse viel kleiner, dünnschaliger, gelbgrün mit rötlichem Gewinde; das niedrigere, konvexe Gewinde besteht nur aus $4 \frac{1}{2}$ deutlicher yewölbten Umgängen, der letzte ist unten weniger abgeflacht.

Deckel wie bei der typischen form.

$$
\mathrm{D}=7 \cdot 3, \mathrm{H}=7 \cdot 2 \text {. }
$$

Fundort: Costarica.

\author{
Taf. 14, Fig. 9-12. \\ Helicina fragilis Morelet Test. noviss. II. p. 17. 1851. \\ $n \quad$ Pfeiffer Mon. Pneum. I. p. 368, 1852.
}

122. Alcadia (Leialcadia) fragilis Morelet.

Gehäuse kegelförmig mit gewölbter Basis, dünnschalig durchscheinend, gelblich oder rötlich hornfarben, mitunter mit einer breiten, rötlichen Binde auf der Oberseitc, weiss be- 
randeter Naht und dunkelkarminroter Spitze; glănzend mit feinen etwas ungleichmässigen Zuwachsstreifen und undeutlichen, sehr feinen Spirallinien. Das regelmässig kegelförmige Gewinde besteht aus $5 \frac{1}{2}$ leicht gewölbten, langsam und regelmässig zunehmenden Umgängen, der letzte ist an der Peripherie gerundet oder mehr minder deutlich kantig und steigt vorne nicht herab (mitunter ein wenig hinauf). Die kurze nahezu senkrechte Spindel endet unten mit einer abgerundeten, aber deutlich vorspringenden Ecke und wird vom Basalrande der Mündung durch einen seichten Ausschnitt geschieden. Die halbkreisförmige Mündung ist wenig schief, der weisse verdickte Mundsaum kurz ausgenreitet und umgeschlagen Der dünne, glänzende Basalkallus ist undeutlich begrenzt

$$
\mathrm{D}=6, \mathrm{~d}=5 \cdot 2, \mathrm{H}=6 \mathrm{~mm} \text {. }
$$

Deckel wie bei Alcadia genima Preston, die Hornplatte jedoch gelblich hornfarben.

Fundorte: Guatemala (Verapaz, Coban, Cutilquit); Costarica: (Shirores, Talamanca).

\section{Alcadia (Leialcadia) fragilis mohriana Pfeiffer.}

Taf. 14, Fig. 13-i6.

Helicina mohriana Pfeiffer Mal. Bl. VIIl, p. 172, 1861.

- Mon. Pnenm. III. p. 219.

Gehäuse durchschnittlich kleiner mit höherem, schmäleren Gewinde besser gewölbten Umgängen und mehr abgeflachter Basis.

Deckel, wie bei der typischen Form.

$$
\mathrm{D}=5 \cdot 4, \mathrm{H}=5.4 \mathrm{~mm} \text {. }
$$

Fundorte: Orizaba und Cordova in Mexico.

\section{Subgenus Analcadia n.}

Gehäuse breit, bis flach kegelförmig mit gewölbter Basis, bestandiger, aber wenig glänzender und zumeist feingerunzelter Epidermis. Neben den verhăltnismăssig kräftigen und ungleichmässigen, radialen Zuwachsstreifen sind häufig in Spiralreihen geordnete, ziemlich hinfällige Borsten der Epidermis vorhanden. Der Mundsaum ist dünn, der Oberrand gerade, der Aussen- und Basalrand kurz ausgebreitet und umgeschlagen. Die sehr kurze, nach vorn und aussen gebogene Spindel endet mit einer stumpfen, abgerundeten, aber deutlich vorspringenden Ecke, der Ausschnitt am Uebergange zum Basalrand der Mündung ist seicht, breit und undeutlich. Deckel breit halbeiförmig oder abgerundet dreieckig mit leicht gebogenem Spindelrand und zumeist spitz ausgezogenem oberen Winkel. Die Kalkplatte ist krustenartig dünı und nur am Spindelrande von der Hornplatte deutlich abgesetzt, die 
Hornplatte zumeist dunkel gefärbt. Der Nukleus ist dem Spindelrande sehr genähert, die Sigmakante stark gebogen, aber nur in unteren Aste deutlich als Leiste erhoben; die Furche neben derselben zumeist seicht, aber deutlich, der Fortsatz am Aussenrande des Deckels abgerundet und undeutlich.

Verbreitung: die Inseln Haiti, Portorico, ferner die kleinen Antillen, Venezuela und Zentralamerika.

Von dieser Gruppe sind mir jedenfalls nur die wenigsten Formen bekannt, denn ich vermute, dass noch zahlreiche auf den kleinen Antillen vorkommende Helicinen (welche ich nicht gesehen habe) hierher gehören. Die Merkmale der Alcadien erscheinen bei diesen Formen sehr abgeschwächt, sind jedoch noch deutlich erkennbar. Der Nukleus und die Sigmakante sind dem Spindelrande sehr genähert, letztere aber im unteren Aste noch deatlich erhoben und durch eine Furche vom Aussenteile der Platte abgesetzt. Ebenso weist die Beschaffenheit der Spindel und des Basalrandes der Mündung, ferner die zumeist borstige Epidermis lie nachstehenden Formen bestimmt zu den Alcadien. Andererseits ist auch die nahe Verwandtschaft zu den Formen der Gruppe Retorquata m. des Genus Helicina Lam. nicht z.u verkennen.

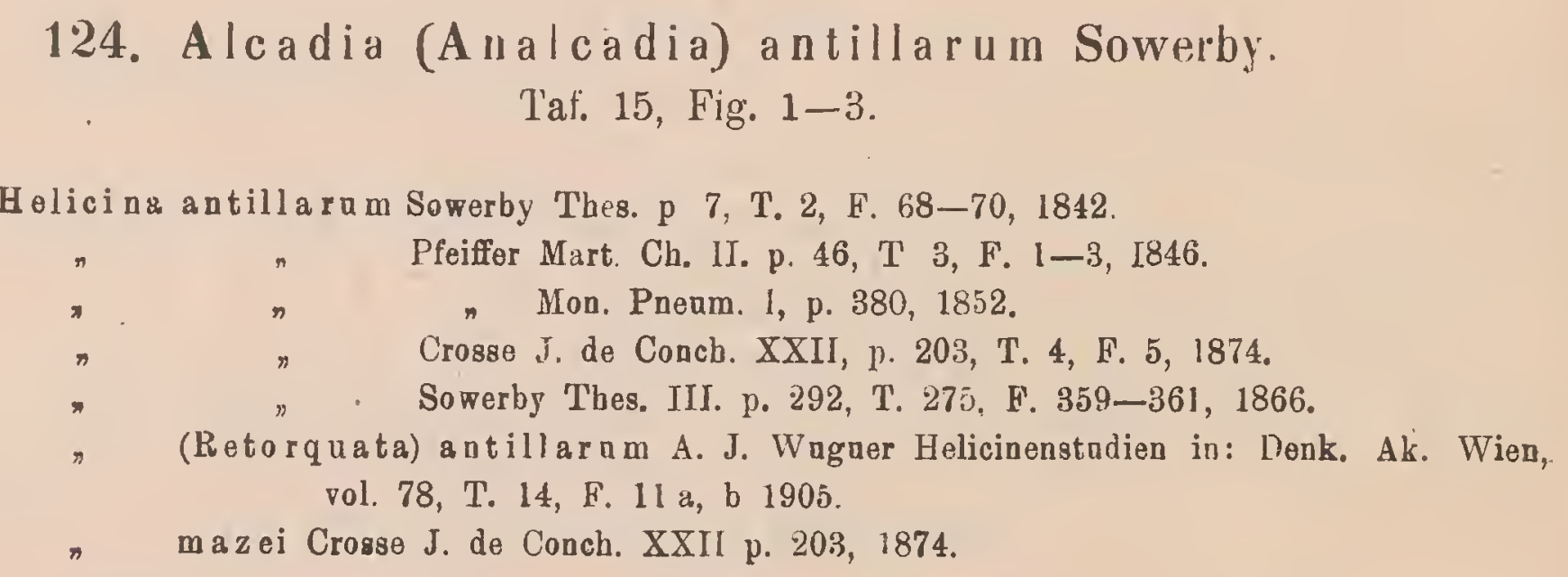

Gehäuse flachisegelförmig, ziemlich dünnschalig und durchscheiuend, gelbgrün, orange bis hellrotbraun mit milchweisen oder gelblichen Flecken und Striemen, welche sich an der Peripherie zu einer Fleckenbinde verdichten, unten die Grundfarbe nahezu verdecken. Neben deutlichen, ungleichmăssigen Zuwachsstreifen sind ziemlich dichte, punktierte Spirallinien vorhanden, welche hinfälligen Borsten der Epidermis entsprechen. Das niedrige Gewinde besteht aus $4-4^{1} /_{2}$ wenig gewölbten, ziemlich rasch zunehmenden Umgängen; der letzte ist zusammengedrückt, unten besser gewölbt, an der Peripherie undeutlich stumpfkantig und steigt. vorne sehr wenig oder gar nicht herab. Die abgerundet dreieckige Mündung ist schief, der gelbliche, kaum verdickte Mundsaum kurz ausgebreitet und umgeschlagen, der Oberrand nahezu gerade und scharf. Die kurze nach aussen gebogene Spindel bildet am Uebergang: 
in den Basalrand eine stumpfe, wenig vorspringende Ecke. Der weisse gekörnelte Basalkallus ist dünn und undeutlich begrenzt, in der Nabelgegend ein seichtes Grübchen.

$$
\mathrm{D}=16, \mathrm{~d}=14, \mathrm{H}=10 \mathrm{~mm} \text {. }
$$

Deckel abgerundet dreieckig mit spitz ausgezogenem oberen Winkel; die dünue Kalkplatte rotbraun, sonst typisch.

Fundorte: die Inseln Guadeloupe und Martinique.

\section{Alcadia (Analcadia) rufa Pfeiffer. \\ Taf. 15, Fig. 4-6.}

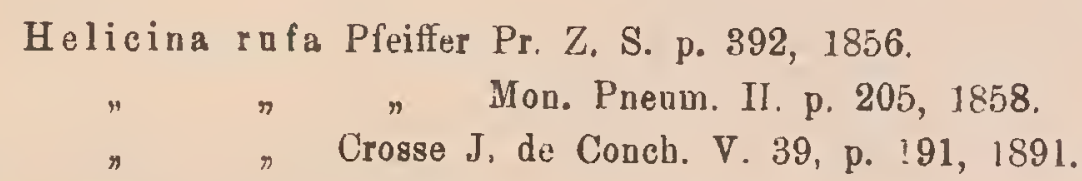

Gehäuse flachkegelförmig mit gewölbter Basis, ziemlich dünnschalig und durchscheinend, rotbraun mit gelber Zone hinter der Mündung. Die Skulptur besteht nebst deutlichen, ungleichmässigen Zuwachsstreifen aus ziemlich weitläufigen Spiralreihen kurzer, starrer Borsten, welche auf der Unterseite dichter und feiner werden. Das niedrige, abgerundet kegelförmige Gewinde bewinde besteht aus 5 nahezu flachen, ziemlich rasch zunehmenden Umgängen; der letzte ist zusammengedrückt, nahezu doppelt so breit, wie der vorletzte, an der Peripherie undeutlich kantig und steigt vorne langsam, aber deutlich herab. Die abgerundet dreieckige Mündung ist schief, der zitrongelbe Mundsaum kaum verdickt, kurz ausgebreitet, der Oberrand gerade, an der Insertion vorgezogen, der Aussen- und Basalrand leicht umgeschlagen. Die kurze nach vorn gebogene Spindel endet mit einer stumpfen, wenig vorspringenden Ecke, der Ausschnitt am Uebergange in den Basalrand der Mündung nur angedeutet. Der ziemlich dünne, gelbe und gekörnelte Basalkallus ist undeutlich begrenzt.

$$
\mathrm{D}=12, \quad \mathrm{~d}=10, \mathrm{H}=7 \cdot 5 \mathrm{~mm} \text {. }
$$

Deckel abgerundet dreieckig, dunkelorange mit hellerem Spindelrande, sonst typisch.

Fundorte: Yunca und el Salado in S. Domingo; meine Exemplare vom Originalfundorte mitgeteilt von $\mathrm{Ph}$. Dautzenberg.

\section{Alcadia (Analcadia) rufa salleana Pfeiffer.}

Taf. 35, Fig. 7-y.

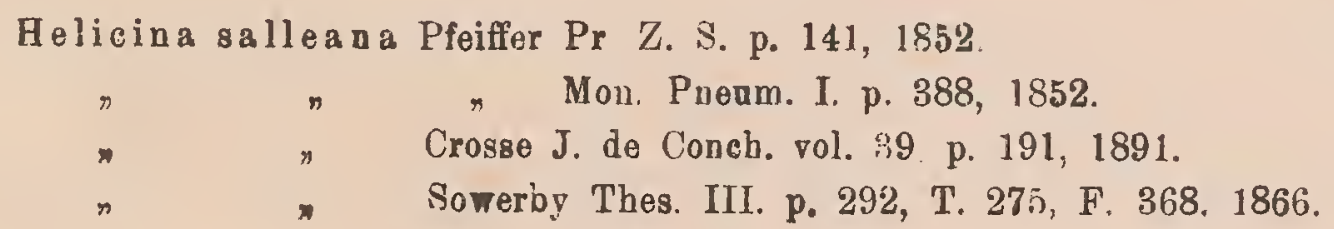


Gehäuse kleiner, heller rotbraun mit niedrigerem Gewinde, welches nur aus $4 \frac{1}{2}$ deutlicher gewölbten und etwas rascher zunehmenden Umgängen besteht; der Mundsaum und Basalkallus gelblich.

$$
\mathrm{D}=8, \mathrm{~d}=7 \cdot 2, \mathrm{H}=5 \mathrm{~mm} .
$$

Fundort: die Insel Haiti.

\section{Alcadia (Analcadia) humilis Guppy.}

Taf. 15, Fig. 10-12.

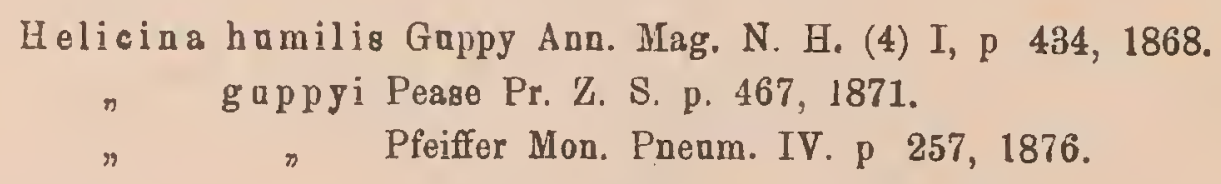

Gehäuse flachkegelförmig mit gewölbter Basis, nahezu linsenförmig, ziemlich festschalig, hellrotbraun; die Skulptur besteht nach den mir vorliegenden etwas verwitterten Exemplaren: nur aus verhältnismässig kräftigen, ungleichmässigen Zuwachsstreifen. Das niedrige, etwas abgerundete Gewinde besteht aus $3 \frac{1}{2}$ bis 4 nahezu flachen, ziemlich rasch zunehmenden Ungängen; der letzte ist zusammengedrückt, an der Peripherie stumpf gekielt und steigt vorne sehr wenig oder gar nicht herab. Die dreieckige Mündung ist schief, der Mundsaum kaum verdickt, kurz ausgebreitet, der Oberrand gerade und an der Insertion vorgezogen, der Aussen- und Basalrand leicht umgeschlagen. Die nach vorne gebogene, kurze Spindel endet mit einer stumpfen, dentlich vorspringenden Ecke und wird vom Basalrande der Mündung durch einen seichten, aber deutlichen Ausschnitt geschieden. Der dünne gekörnelte Basalkallus ist ziemlich deutlich begrenzt.

$$
\mathrm{D}=8, \mathrm{~d}=7 \cdot 5, \mathrm{H}=5 \mathrm{~mm} \text {. }
$$

Fundort: die Insel Dominica der kleinen Antillen.

Helicina humilis Hombron et Jaquinot gehört zum Genus Sulfurina Mlldff.

\section{Alcadia (Analcadia) haitensis Maltzan.}

Taf. 15, Fig. 13-15

Holicina haitensis Maltzan Nachr. Bl, XX, p. 182, 1888.

ॠ Crosse J. de Conch. vol, 39 p. 188, 1891.

Gebäuse gedrückt kreiselförmig; ziemlich festschalig, durchscheinend, gelbbraun bis rotbraun, leicht glänzend. Die Skulptur besteht nebst feinen Zuwachsstreifen aus ziemlich dichten Spiralreihen feiner Borsten. Das niedrige, leicht abgerundete Gewinde besteht aus $4 \frac{1}{2}$ wenig gewölbten, ziemlich rasch zunehmenden Umuängen; der letzte ist etwas zusammengedrückt, an der Peripherie stumpfkantig und steigt vorne langsam und deutlich herab. 
Die abgerundet dreieckige Mündung ist schief, der weisse oder gelbliche Mundsaum leicht verdickt und kurz ausgebreitet. Die kurze Spindel ist etwas nach aussen gebogen und eadet mit einer winkeligen, deutlichen Ecke. Der gelbe, gekörnelte Basalkallus ist deutlich begrenzt und in der Nabelgegend gegen die Spindel durch eine Furche abgesetzt.

$$
\mathrm{D}=8 \cdot 8, \mathrm{~d}=8, \mathrm{H}=6 \mathrm{~min} \text {. }
$$

Deckel halbkreisförmig mit geradem Spindelrand, gelblicher, gekörnelter Kalkplatte, gelbbrauner Hornplatte, sonst typisch.

Fundort: Sanssouci auf Haiti.

\section{Alcadia (Analcadia) dysoni Pfeiffer.}

Taf. 15, Fig. 20-22.

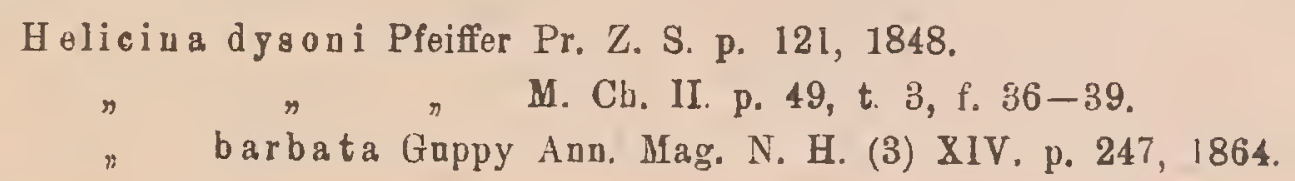

Gehäuse flach kegelförmig mit gewölbter Basis, festschalig, etwas glänzend, hellgelbbraun oder hellrotbraun mit 3 etwas verwaschenen, braunen oder rotbraunen Binden und einer helleren, durch die dunklen Binden begrenzten Zone an der Peripherie. Die Skulptur besteht neben deutlichen und etwas ungleichmässigen Zuwachsstreifen aus ziemlich dichten Spiralreihen verhältnismässig kräftiger Borsten, welche auf der' Unter'seite dichter und feiner werden. Das niedrige Gewinde besteht aus $4 \frac{1}{2}$ leicht gewölbten, ziemlich rasch zunehmęnden Umgängen; der letzte ist gerundet und steigt vorne langsam und sehi wenig herab. Die halbeiförmige Mündung ist schief, im Gaumen hellbraun; der weisse leicht verdickte Mundsaum kurz ausgebreitet, der Oberrand gerade und an der Insertion etwas vorgezogen. Die Spindel ist etwas nach vorn und aussen gebogen und endet mit einer ziemlich scharfen, deutlich vorspringenden Ecke: der Ausschnitt am Uebergange zum Basalrand der Mündung ist seicht, aber deutlich. Der dünue, weisse oder gelbliche Basalkallus ist ziemlich deutlich begrenzt, in der Nabelgegend gegen die Spindel durch eine Furche abgesetzt.

$$
\mathrm{D}=7, \mathrm{~d}=6 \cdot 2, \mathrm{H}=5 \mathrm{~mm} \text {. }
$$

Deckel halbkreisförmig mit wenig gebogenem Spindelrand, krustenartiger weisser Kalkplatte und gelbbrauner, an der Peripherie lebhaft kastanienbrauner Hornplatte, sonst typisch.

Fundorte: Venezuela (Cumana, Maturin, Caracas, Guanta) und die Insel Trinidad.

I. 18. II. 


\title{
130. Alcadia (Analcadia) dysoni bocourti Crosse et Fischer.
}

Taf. 15, Fig. 16-19.

\author{
Helicina bocourti Crosse et Fischer J. de Conch. XVII, p. 251, 1869. \\ Pfeiffer, Mon. Pneum. IV. p. 266, 1876.
}

Gehäuse, kleiner, kegelförmig mit weniger gewölbter Basis, höherem, inehr konvexem Gewinde, welches aus $4^{1} / 2$ flachen, langsamer zunehmenden Umgängen besteht; der letzte ist im Beginne deutlich kantig, nur gegen die Mündung zu gerundet. Die Grundfarbe ist heller, gelblich oder rötlich, die Binden dunkler und schärfer begrenzt.

$$
\mathrm{D}=6.2, \mathrm{~d}=5 \cdot 5, \mathrm{H}=4.5 \mathrm{~mm} \text {. }
$$
Form.

Deckel mit zarter, gelber und durchsichtiger Kalkplatte, sonst wie bei der typischen

Fundorte: Belize in Britisch Honduras, Insel Bonacca im Golf von Honduras und Nicaragua.

\author{
131. Alcadia (Analcadia) guadeloupensis Sowerby. \\ Taf. 16, Fig. 20-22. \\ Helicina ga adelo upensis Sowerby Thes. p. 7, t. 2, f. 68-79, 1842.

$\begin{array}{ccc}\eta & n & \text { Pfeiffer in: Mart. Ch. II. p. 46, t. 3, F. 1-3, } 1846 . \\ \eta & n & \text { Mon. Pneum. I. p. 380, 1852. } \\ \eta & n & \text { Sowerby Thess. III. p. 292, t. 275, f. 362,366, 367, } 1866 .\end{array}$

Gehäuse dicklinsentörmig, festschalig, gelbbraun bis rotbraun, wenig glănzend mit deutlichen, ungleichmässigen und sehr schiefen Zuwachsstreifen; mit der Lupe sind ausserdem feine punktierte Spirallinien sichtbar, welche anscheinend hinfälligen Borsten der Epidermis entsprechen. Das flachkegelförmige Gewinde besteht aus $4^{1} \frac{1}{2}$ wenig gewölbten, regelmässig zunehmenden Ungängen; der letzte ist an der Peripherie kantig bis nahezu gerundet und steigt vorne langsam aber deutlich herab. Die abgerundet dreieckige Mündung ist schief, der orangegelbe Mundsaum verdickt, kurz ausgebreitet; der Oberrand an der Insertion vorgezogen und nahezu gerade. Die kurze nach vorn und aussen gebogene Spindel endet mit einer winkeligen, stark vorspringenden Ecke, der Ausschnitt am Basalrande der Mündung ist seicht, aber deutlich. Der weisse oder gelbliche Basalkallus ist gekörnelt und ziemlich deutlich begrenzt; in der Nabelgegend ein furchenartiges Grübchen.$$
\mathrm{D}=9 \cdot 2, \mathrm{~d}=8 \cdot 2, \mathrm{H}=7 \mathrm{~mm} \text {. }
$$

Deckel halbkreisförmig mit wenig gebogenem Spindelrand, beiderseits hellrotbraun gefarbt; sonst typisch.

Fundort: die Insel Guadeloupe. 
132. Alcadia (Analcadia) macmurrayi Pfeiffer.

Taf. 16, Fig. $17-19$.

Helicina maemurrayi Pfeiffer Mal. Bl. XI. p. 155, 1867.

» Mon. Pneum. II. p. 225.

$n$ Novitat. Conch. V. II. p. 256, T. 54, F. 15.16.

Gehäuse breitkegelförmig mit gewölbter Basis, festschalig, durchscheinend, einfärbig gelbgrün bıs rotbraun oder mit 1-2 rotbraunen Binden; glänzend mit deutlichen, sehr schiefen und ungleichmässigen Zuwachsstreifen. Das ziemlich erhobene Gewinde besteht aus $4^{1} / 2$ leich九 gewölbten, ziemlich langsam und regelmässig zunehmenden Umgängen; der letzte ist gerundet und steigt vorne ziemlich tief herab. Die halbeiförmige Mündung ist schief, der gelbliche Mundsaum leicht verdickt; der Oberrand gerade und an der Insertion etwas vorgezogen, der Aussen- und Basalrand kurz ausgebreitet und umgeschlagen. Die nach vorn und aussen gebogene Spindel bildet am Uebergang in den Basalrand nur eine stumpfwinkelige, wenig vorspringende Ecke. Der dünne, weisse, glänzende Basalkallus ist undeutlich begrenzt.

Deckel mir unbekannt.

$$
D=10 \cdot 7, d=10, H=8.3 \mathrm{~mm} .
$$

Fundort: die Insel Santa Lucia.

\title{
133. Alcadia (Analcadia) platychila Mühlfeldt.
}

\author{
Taf. 16, Fig. 1-2.
}

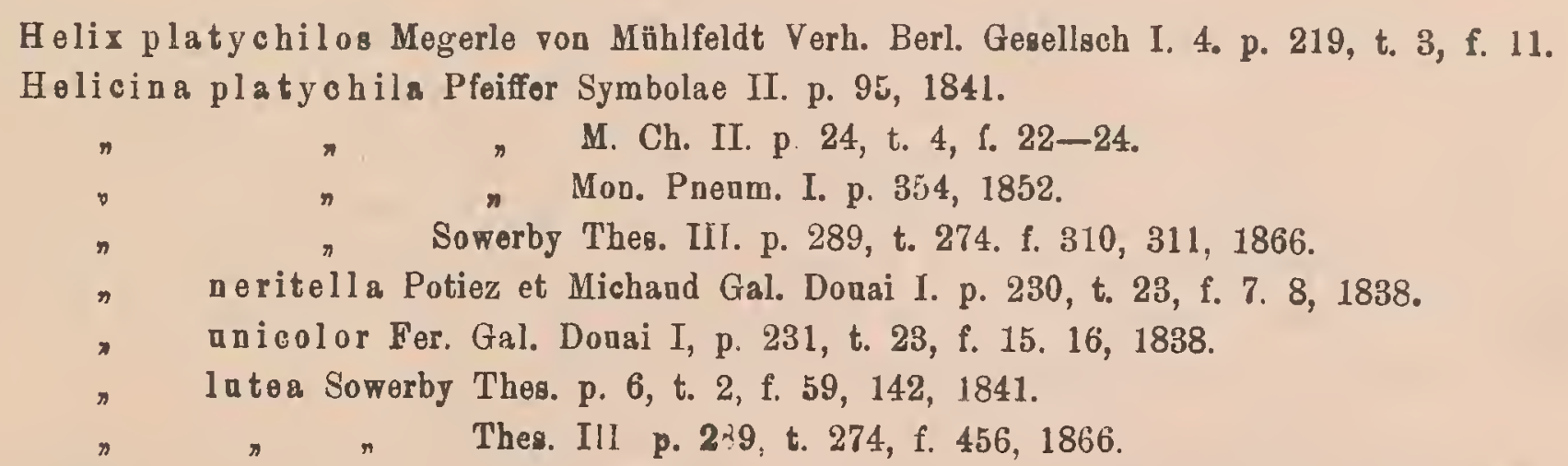

Gehäuse kegelförmig mit flachgewölbter Basis, festschalig, durchscheinend, zitrongelb oder rötlich hornfarben, wenig glänzend mit feinen etwas ungleichmässigen Zuwachsstreifen und undeutlichen feinen Spirallinien. Das ziemlich erhobene Gewinde besteht aus 5 flachen langsam und regelmässig zunehmenden Umgängen; der letzte ist an der Periphorie stumpfkantig und steigt vorne langsam und sehr wenig herab; der Apex springt deutlich vor. Die 
abgerundet dreieckige Mündung ist sehr schief, der weisse oder gelbe Mundsaum ist etwas verdickt, der Oberrand an der Insertion vorgezogen und gerade, der Aussen- und Basalrand kurz ausgebreitet und leicht umgeschlagen. Die kurze, nach aussen gebogene Spindel ist unten leicht verdickt, der Ausschnitt am Uebergange in den Basalrand der Mündung sehr

flach. Der weisse oder gelbe, ziemlich dicke Basalkallus ist deutlich begrenzt.

$$
\mathrm{D}=9, \mathrm{~d}=8, \mathrm{H}=6.5 \mathrm{~mm} \text {. }
$$

Deckel halbkreisförmig mit wenig gebogenem Spindelrand, sehr dünner, durchscheinender Kalkplatte und gelbbrauner Hornplatte, sonst typisch.

Fundort: die Inseln Martinique, Guadeloupe und Santa Lucia.

\title{
134. Alcadia (Analcadia) phasianella Pfeiffer.
}

\author{
Taf. 16, Fig. $3-4$. \\ Helicina phasianella Pfeiffer Mal Bl. III. p. 50, 1856.

\begin{tabular}{lll}
$n$ & $n$ & \multicolumn{1}{c}{ Novitat. Conch. I. p. 87. t. 23, f. 24-27. } \\
$n$ & $n$ & Pfeiffer, Mon. Pneum. II. p. 199, 1858. \\
$n$ & $n$ & Crosse J. de Conch vol. 39, p. 187. 1891. \\
& $n$ & Sowerby Thes. III. p. 286, t. 271, f. 204, 205, 1866.
\end{tabular}

Gehăuse kegelförmig mit flachgewölbter Schale, ziemlich festschalig, einfärbig gelb oder weiss mit gelber Spitze, einem schmalen rotbraunen Bande unter der Peripherie und einem aus unregelmässigen braunen Flecken zusammengesetzten, breiten Bande auf der Oberseite der unteren Umgänge; wenig glänzend mit feinen, ungleichmăssigen Zuwachsstreifen und einer fein gerunzelten Epidermis. Das ziemlich erhobene, leicht konvexe Gewinde besteht aus 5 gewölbten, ziemlich langsam zunehmenden Umgängen; der letzte ist gerundet, unten abgeflacht und steigt vorne langsam, aber ziemlich tief berab. Die halbeiförmige Mündung ist scbief, der weisse Mundsaum zumeist nur wenig verdickt; der Oberrand gerade und an der Insertion vorgezogen, der Aussen- und Basalrand kurz ausgebreitet. Die kurze nach vorne und aussen gebogene Spindel endet mit einer abgerundeten, aber ziemlich deutlichen Ecke; der Ausschnitt am Basalrande der Mündung ist seicht. Der gelbe, glănzende, in der Mitte stärker verdickte Basalkallus ist zumeist deutlich begrenzt.

$$
\mathrm{D}={ }^{-7} \cdot \overline{5}, \mathrm{~d}=7, \mathrm{H}=6 \cdot 2 \mathrm{~mm} \text {. }
$$

Deckel halbkreisförmig mit wenig gebogenem Spindelrand, sehr zarter, krustenartiger Kalkplatte und rotbrauner Hornplatte, sonst typisch.

Fundorte: die Inseln Portorico, Vieque, St. Jan. 
135. Alcadia (Analcadia) striata Lamarck.

Taf. 16, Fig. 13-16.

is $\%$

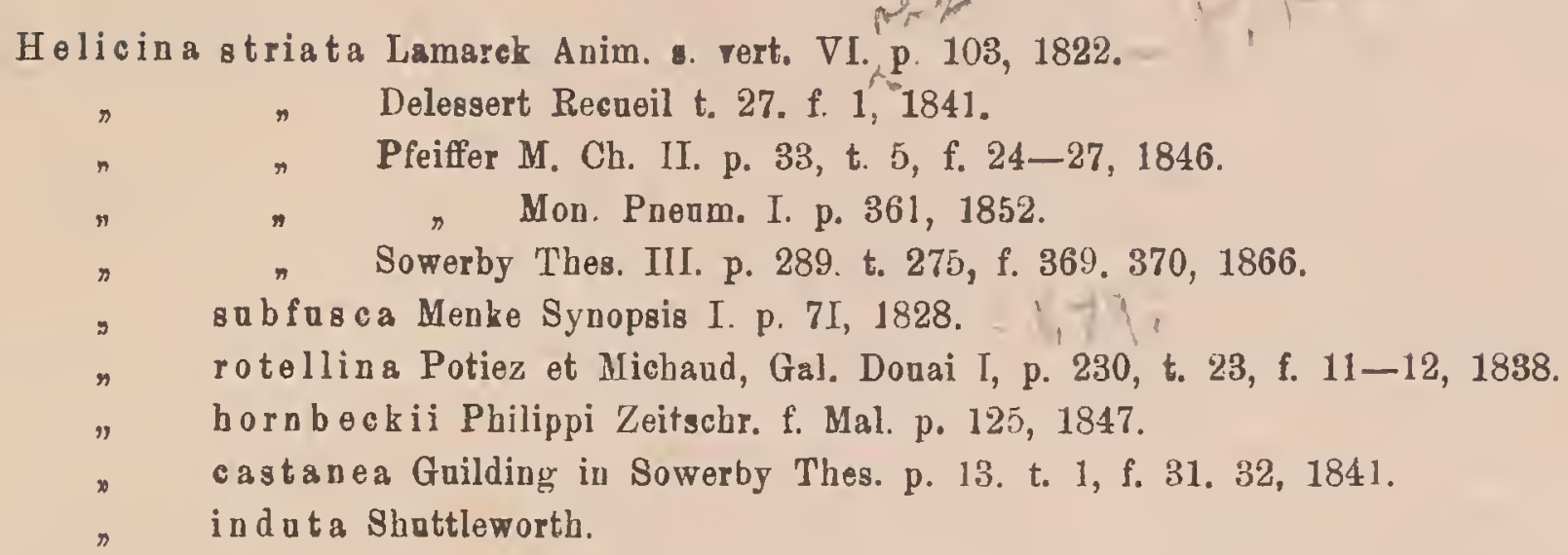

Gehäuse halbkugelig mit weniger gewölbter Basis, ziemlich dünnschalig, einfärbig hellgelb, gelbbraun bis rotorange, wenig glänzend bis matt, mit feinen, S-förmig gebogenen, ziemlich gleichmăssigen, auf den oberen Umgängen nahezu rippchenartigen Zuwachsstreifen. Das niedrige, abgerundete Gewinde besteht aus $5 \frac{1}{2}$ kaum gewölbten, ziemlich langsam zunehmenden Umgängen; der letzte ist gerundet und steigt vorne wenig herab. Die abgerundet dreieckige Mündung ist schief, der gelbe, leicht verdickte Mundsaum-kurz ausgebreitet, der Aussen- und Basalrand mitunter etwas umgeschlagen. Die kurze, nach vorn und aussen gebogene Spindel ist am Uebergange zum Basalrande der Mündung knotenartig verdickt. Der gelbe, gekörnelte Basalkallus ist nur in der Mitte. stärker verdickt und undeutlich begrenzt. $\mathrm{D}=13, \mathrm{~d}=11, \mathrm{H}=9 \mathrm{~mm}$.

Deckel abgerundet dreieckig mit geradem Spindelrand, dünner, gekörnelter Kalkplatte und rotbrauner Hornplatte; die Sigmakante auch im oberen Aste deutlich erhoben.

Fundorte: die Inseln Portorico, St. Thomas, Tortola.

Alcadia striata Lam. scheint au einzelnen Fundorten selten vollkommen auszuwachsen; solche Jugendformen ohne Mundsaum und einer geringeren Zahl von Umgängen werden als Helicina subfusca Menke bezeichnet.

\section{Subgenus Emoda H. \& A. Adams (ex rect. mea.)}

Emoda (part.) H. \& A. Adams 1856.

Gehäuse verhăltnismässig gross, fest- bis dickschalig, kegelförmig oder kugelig. Die ziemlich beständige, oft lebhaft gefärbte Epidermis besitzt häufig borstige Spiralfalten, welchen an abgeriebenen Exemplaren eingedrückte Spirallinien, selten auch Spiralleisten ent- 
sprechen; ausserdem sind radiale Zuwachsstreifen vorhanden, welche oft kräftig bis rippen-artig entwickelt sind. Das niedrige, abgerundete Gewinde besteht aus $31 / 2$ bis $4 \frac{1}{2}$ ziemlich langsam zunehmenden, kaum gewölbten bis Hachen Umgängen, der letzte ist etwas aufgeblasen, an der Peripherie gerundet oder stumpfkantig. Die Mündung ist sehr schief, der Mundsaum verdickt bis verdoppelt, der Oberrand an der Insertion vorgezogen, gerade oder leicht herabgebogen, der Aussenrand ausgebreitet. Die nach vorn und aussen gekrümmte Spindel endigt mit einer knotenartig verdickten Ecke und wird vom Basalrande der Mündung durch einen seichten, aber deutlichen Ausschnitt geschieden. Der dicke Basalkallus ist deutlich begrenzt, an den Råndern oft leistenartig erhoben.

Deckel halbkreistörmig bis abgerundet dreieckig mit spitzem oberen, stumpfem Spindelwinkel und geradem oder nur leicht konkavem Spindelrande. Die dicke und feste Kalkplatte ist am Spindelrande zumeist knochenartig verdickt und erhoben, am Spindelwinkel nach hinten gebogen. Der Nukleus dem Spindelrande ziemlich genähert, die Sigmakante wenig gebogen und nur im unteren Aste stärker erhoben; die Furche neben dem unteren Aste der Sigmakante ist ziemlich seicht, der Vorsprung des Deckelrandes an Ende derselben stunıfwinkelig oder abgerundet. Die Spindelseite der Platte ziemlich schmal.

Verbreitung: die Insel Cuba.

136. Alcadia (Emoda) sagraiana d'Orbigny.

Tuf. 17, Fig. 1-4, Taf. 18, Fig. 13.

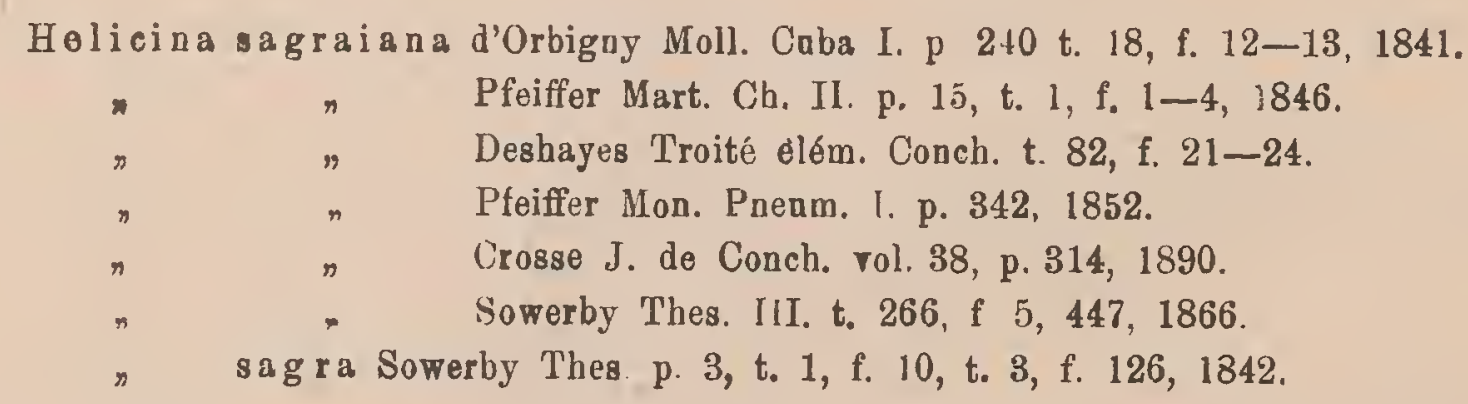

Gehäuse breit kegelförmig mit flachgewölbter Basis, dickschalig, ziemlich glänzend; die oberen Umgănge gelbbraun bis violetbraun, der letzte saftgrün oder braungrün mit dunkleren Striemen, häufig mit einem helleren schmalen Bande an der Peripherie. Die Epidermis auf den oberen Umgängen hinfällig. Die Skulptur besteht aus verhăltnismässig schwachen und ungleichmässigen, S-förmig gebogenen Zuwachsstreifen, selten sind undeutliche Spirallinien vorhanden. Das ziemlich erhobene breit kegelförmige Gewinde besteht aus $4 \frac{1}{1} / 2$ leicht gewölbten Umgăngen; die oberen nehmen langsam und regelmåssig, der letzte gegen die Mündung rascher $\mathrm{zu}$, derselbe ist ferner an der Peripherie stumpfkantig bis gerundet und steigt vorne deutlich unter die Kante herab. Die sehr schiefe Mündung ist abgerundet dreieckig 
innen rotbraun oder weiss; der weisse oder zitrongelbe Mundsaum gerade, innen verdickt; der Oberrand an der Insertion vorgezogen. Die kurze breite Spindel ist stark nach aussen gebogen und endet mit einer ziemlich scharfen, deutlich vorspringenden Ecke, vom Basalrande der Mündung wird dieselbe durch einen halbkreisförmigen Ausschnitt geschieden. Der ziemlich dicke, glasartig glänzende Basalkallus ist in der Mitte weiss oder gelb, an der Peripherie durchsichtig, deutlich begrenzt, an den Rändern leistenartig erhoben.

$$
D=25-26 \cdot 5, d=20-21 \cdot 5, H=16-17 \mathrm{~mm} \text {. }
$$

Deckel halbkreisförmig mit geradem Spindelrand, die fein gekörnelte Kalkplatte am Spindelrande knochenartig verdickt, gegen den Aussenrand zu allmăhlig dünner und hellrotbraun gefärbt; die Hornplatte braunorange mit ziemlich gebogener, aber nur im unteren Aste stărker erhobener Sigmakante, tiefer Furche neben derselben, aber abgerundetem Fortsatze am Aussenrande des Deckels.

Fundort: der westliche Teil der Insel Cuba.

Alcadia sagraiana d'Orb. ist mit Rücksicht auf die Höhe und Wölbung des Gewindes, die mehr oder minder rasche Zunahme der Umgănge, die Beschaffenheit des letzten Umganges und des Mundsaumes sehr verănderlich; ich gehe bei der Beurteilung der zahlreichen Formen von Exemplaren aus, welche Gundlach in Rangel auf Cuba gesammelt hat。 Vereinzelt leben an diesem Fundorte auch Exemplare, welche durch das niedrige, abgerundete Gewinde, deu gerundeten, unten mehr gewölbten letzten Umgang recht auffallend von der typischen Form abweichen, jedoch durch Ụebergănge mit derselben zusammenhăngen. Taf. 17 Fig. 4.

\section{Alcadia (Emoda) sagraiana catalinensis Pfeiffer. Taf. 17, Fig. 5-6.}

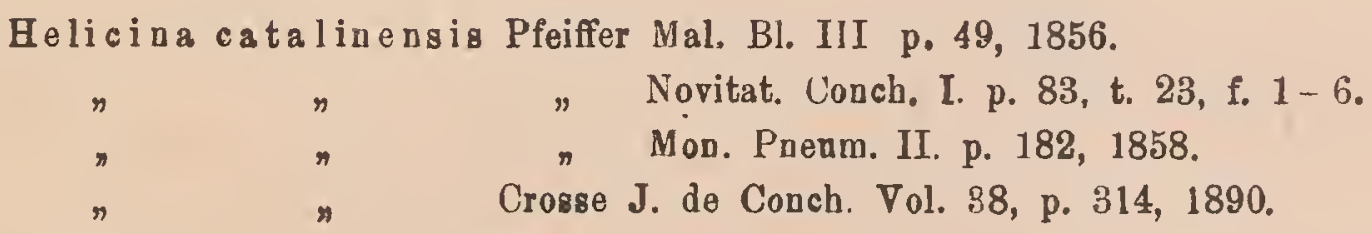

Gehăuse kleiner, rotbraun; der letzte Umgang nur ausnahmsweise dunkelgrün, an der Peripherie undeutlich kantig und langsamer zunehmend; der Mundsaum und Basalkallus gelb, der Ausschnitt am Basalrande der Mündung seichter.

$$
\mathrm{D}=22, \mathrm{~d}=18, \mathrm{H}=14.5 \mathrm{~mm} \text {. }
$$

Deckel wie bei der typischen Form.

Fundort: Catalina in Westcuba; eine sehr ähnliche Form, welche jedoch einen blaugrün gefärbten letzten Ungang mit lichtem, schmalen Bande an der Peripherie, sowie ziemJich deutliche Spirallinien besitzt, kenne ich von Salladero auf Cuba. 
138. Alcadia (Emoda) sagraiana emoda Pfeiffer. Taf. 17, Fig. 7-9.

Helicina emoda Pfeiffer Novitat. Conch.II. p. 253, t. 64, fig. 6-8, 1859.

» $\rightarrow \quad$ Pfeiffer Mon. Pneum. III. p. 221, 1855.

" Crosse J. de Conch. Vol. 38, p. 313, 1890.

Gehäuse grösser, dickschaliger, halbkugelig mit flach gewölbter Basis; die oberen Umgänge rotbraun bis violetbraun, der letzte gelbgrün oder dunkel braungrün, mitunter mit einer helleren Binde an der Peripherie. Das niedrigere, halbkugelige Gewinde besteht aus $4-4^{1 / 2}$ langsamer zunehmenden Umgangen; der letzte ist undeutlich stumpfkantig, unten abgeflacht. Der gelbliche bis hellrotbraune Mundsaum ist auffallend verdickt bis verdoppelt, ebenso der Basalkallus dicker mit stärker erhobenen Răndern.

$$
\mathrm{D}=31, \mathrm{~d}=25 \cdot 5, \mathrm{H}=19 \mathrm{~mm} \text {. }
$$

Fundorte: Pfeiffer beschreibt diese Form nach verwitterten Exemplaren vom Monte Toro auf Cuba, meine Exemplare stammen von Ressoladero, Louis Lazo und Sumitero auf Cuba; dieselben entsprechen vollkommen der Abbildung Pfeiffers in Nov. Conch., weniger jedoch der Beschreibung, da das Gewinde nicht rein kegelförmig, sondern zumeist abgerundet und nahezu halbkugelig ist.

\section{Alcadia (Emoda) briarea Poey.}

Taf. 17, Fig. 10-12, Taf. 18, Fig. 14.

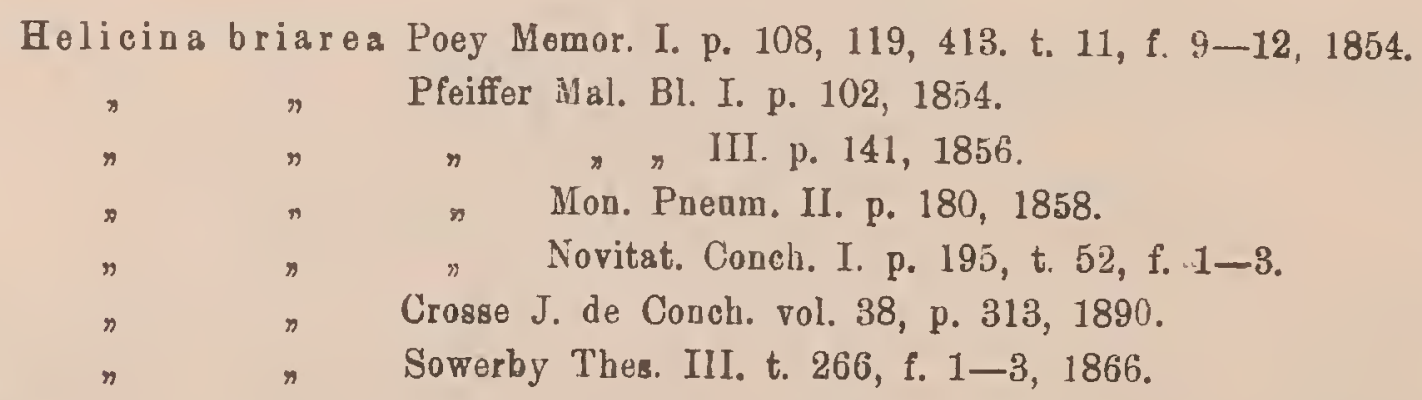

Gehäuse breitkegelförmig, nahezu halbkugelig mit flachgewölbter Basis, dickschalig, lebhaft rotbraun mit braungelber Basis und ebensolchen Binden an der Peripherie und Naht der unteren Umgänge. Die Skulptur besteht nebst feinen und etwas ungleichmåssigen Zuwachsstreifen aus ziemlich weitläufigen Spiralfalten der Epidermis auf dem letzten Umgange. Das niedrige, abgerundet kegelförmig Gewinde besteht aus $4^{1} / 2$ nahezu flachen, langsam. und regelmässig zunehmenden Umgăngen; der letzte nimmt gegen die Mündung rascher zu, ist etwas zusammengedrückt, an der Peripherie undeutlich kantig und steigt vorne wenig. 
unter die Kante herab. Die halbeiförmige Mündung ist sehr schief, der weisse Mundsaum stark verdickt, fast gerade, der Oberrand an der Insertion vorgezogen, in den leistenförmig erhobenen Rand des Basalkallus übergehend. Die kurze, breite Spindel ist nach aussen gebogen und endigt mit einer abgerundeten, aber deutlichen Ecke; der Ausschnitt am Uebergange zum Basalrande der Mündung ist seicht. Der glänzende, durchsichtige Basalkallus ist besonders an den Rändern stärker verdickt, in der Mitte weiss, deutlich begrenzt.

$$
\mathrm{D}=31, \mathrm{~d}=24, \mathrm{H} 18 \mathrm{~mm} \text {. }
$$

Deckel wie bei Alcadia sagraiana d'Orbigny.

Fundort: Trinidad auf Cuba.

Von den Formen der A. sagraiana d'Orb. durch flachere F'orm, die Färbung, die deutlichen Spiralfalten der Epidermis langsamer zunehmende Umgänge, den seichteren Ausschnitt am Basalrande der Mündung und den dünneren Basalkallus unterschieden.

\section{Alcadia (Emoda) pulcherrima Lea. Taf. 19, Fig. $1 \cdots 4$.}

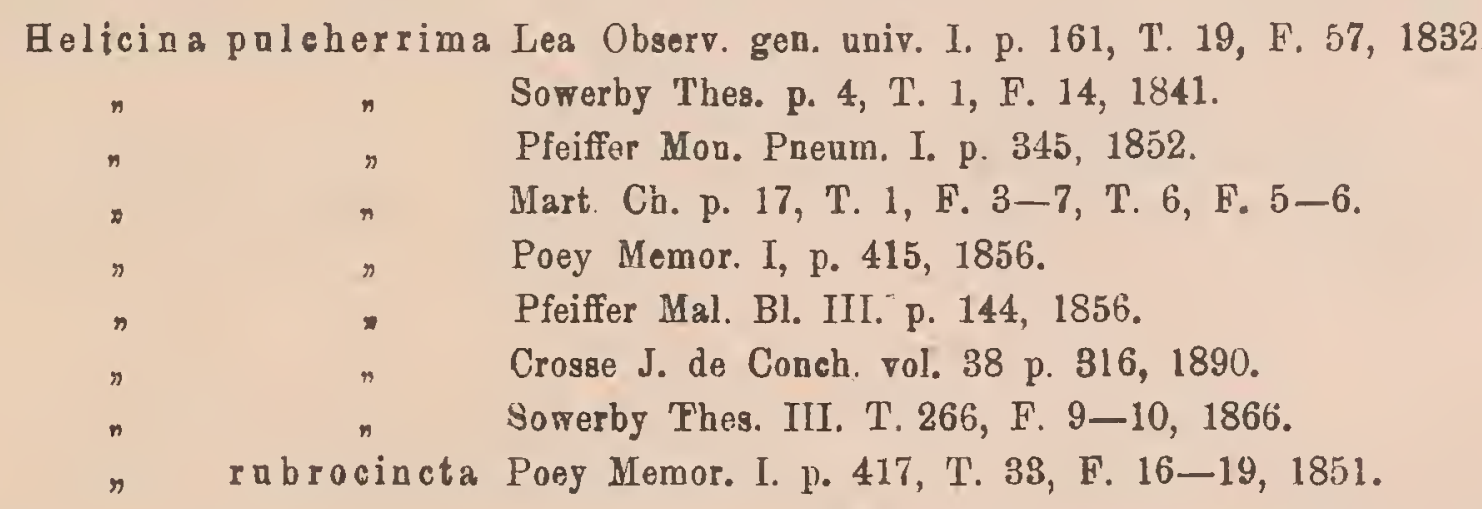

Gehäuse etwas gedrückt kugelig, festschalig, leicht durchscheinend und glänzend, die oberen Umgänge hell rotbraun, der letzte grüngelb mit rötlichem Stich; an der Peripherie eine schmale, helle und darunter eine dunkelrotbraune Binde. Die oberen Umgänge sind ziemlich fein und ungleichmässig radial gestreift, der letzte nahezu rippchenartig, die Rippchen ziemlich gleichmässig, auf der Unterseite schwächer; auf den mittleren Umgängen sind häufig etwas weitläufige, sehr feine bis undeutliche Spirallinien vorbanden. Das halbkugelige Gewinde besteht aus $4-4^{1} / 2$ nahezu flachen, ziemlich langsam und regelmässig zunehmenden Umgängen; der letzte ist gerundet und steigt vorne kurz herab. Die halbeiförmige Mündung ist schief, im Gaumen hellrotbraun; der weisse, innen lippenartig verdickte Mundsaum gerade mit nahezu scharfem Rande; der Oberrand an der Insertion vorgezogen, dann etwas konkav ausgebuchtet, Die kurze breite Spindel ist nach aussen gebogen und endigt mit einer abgerundeten Ecke; der Ausschnitt am Uebergange zum Basalrande der Mündung seicht, aber deutlich. Der dicke, weisse, am Rande durchscheinende Basalkallus ist glanzend und deutlich begrenzt.

I. 18. II.

8. XII. 1907. 


$$
\mathrm{D}=16-20, \mathrm{~d}=13-17, \mathrm{H}=11.5-14 \mathrm{~mm} \text {. }
$$

Deckel annähernd halbkreisförmig mit spitz ausgezogenem oberen Winkel, geradem Spindelrand und verhältnismässig.grossem Nukleus. Die Hornplatte in der Mitte gelblich, am Rande hellrotbraun; die Sigmakante auch im unteren Aste ziemlich niedrig, sonst typiscb.

Fundort: die Insel Cuba; ich beurteile diese Art nach Exemplaren von Santjago de Cuba und fasse dieselben als typisch auf.

\section{Alcadia (Emoda) pulcherrima crassa d’0rbigny. Taf. 19, Fig. 5-6.}

Helicina crassa d'Orbigny Cuba I. p. 243, T. 19, F. 5-6, 1841.

$n \quad$ Crosse J. de Conch. vol. 38, p. 395, 1890.

Gehäuse mehr gedrückt kugelig mit niedrigerem Gewinde, hellgelb mit undeutlicher gelber Binde an der Peripherie; die Rippchen am letzten Umgange deutlich schwächer und ungleichmässiger, der letzte Umgang im Beginne deutlich stumpfkantig.

$\mathrm{D}=16.5, \mathrm{~d}=14, \mathrm{H}=11 \mathrm{~mm}$.

Deckel wie bei der typischen Form.

Fundort: Cajo seco westlich von Cuba (nach Exemplaren des k. Museums in Berlin, gesammelt von Gundlach.

\section{Alcadia (Emoda) pulcherrima planospira n.} Taf. 19. Fig. 8-10.

Gehăuse flachkugelig, lebhaft rotbraun mit einer schmalen gelben und einer breiteren braunen Binde an der Peripherie, gelbgerandeter Naht und gelben Radialstriemen auf dem letzten Umgange; die Radialrippchen am letzten Umyange viel schwächer, die eingedrückten Spirallinien jedoch auf allen Umgängen deutlich. Das auffallend flachere Gewinde besteht nur aus $3^{1} / 2$ bis 4 mehr gewölbten, rascher zunehmenden Umgängen; der letzte ist mehr zusammengedrïckt, an der Peripherie gerundet.

$$
D=17.5, d=14, \mathrm{H}=10 \mathrm{~mm} .
$$

Deckel wie bei der typischen Form.

Fundort: die Insel Cuba. 
143. Alcadia (Emoda) pulcherrima bayamens Poey. Taf. 18, Fig. 1-4.

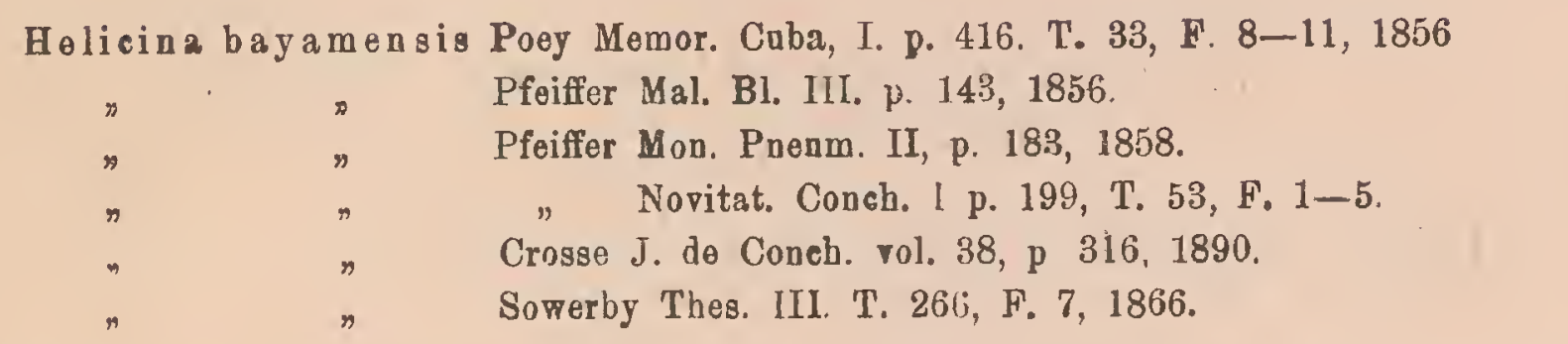

Gehäuse grösser dickschaliger, breit kegelförmig mit flachgewölbter Basis; die oberen Umgänge rotbraun oder hell grüngelb, der letzte olivengrün mit dunkleren bis rotbraunen Striemen, sowie häufig mit einer helleren, rotbraun berandeten Binde an der Peripherie. Die Zuwachsstreifeñ und Rippchen sind ungleichmăssiger, die Spirallinien nur angedeutet. Das weniger abgerundete, breit kegelförmige Gewinde besteht nur aus $3^{1} / 2$ deutlicher gewölbten, rascher zunehmenden Umgängen. Der Mundsaum ist viel dicker mit stumpfem Rande, die abgerundete Ecke am unteren Eade der Spindel deatlicher vorspringend.

$$
\mathrm{D}=24, \mathrm{~d}=19, \mathrm{H}=15 \mathrm{~mm} \text {. }
$$

Deckel beiderseits lebhaft rotbraun, sonst wie bei der typischen Form.

Fundorte: Bayamo und Caimanera auf Cuba.

\section{Alcadia (Emoda) pulcherrima titanica Poey.}

Taf. 17, Fig. 13-15. Taf. 18, Fig. 16.

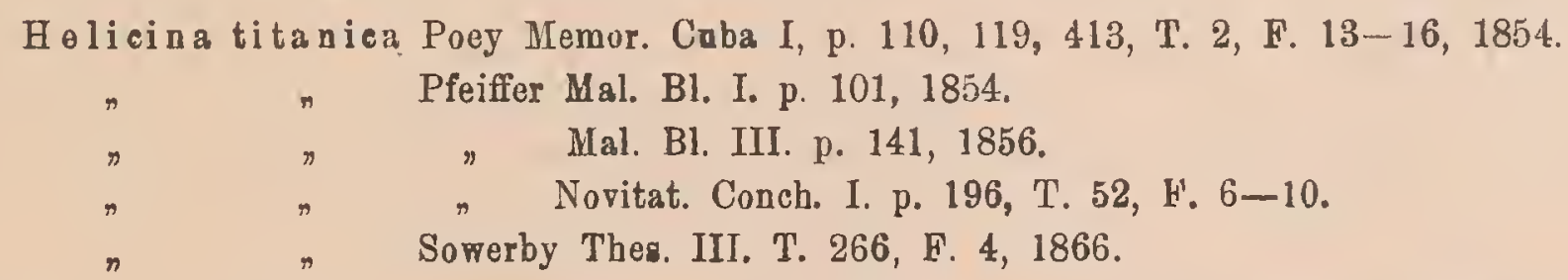

Gehäuse viel grösser und dickschaliger, breit kegelförmig mit gewölbter Basis, wenig glănzend; die oberen Umgänge rotbraun bis violettbraun, der letzte gelbgrün bis braungrün mit dunkleren Radialstriemen und einer hellen unten dunkel berandeten Binde an der Peripherie. Die Zuwachsstreifen und Rippchen ungleichmässiger und verhältnismässig schwächer, die Spirallinien sehr fein und undeutlich. Das verhältnismässig niedrigere, breit kegelförmige Gewinde ist weniger abgerundet und besteht nur aus 4 rascher zunehmenden Umgängen; der letzte ist im Beginne undeutlich stumpflkantig. Der Mundsaum ist mehr verdickt und stumpf, die nach vorne und aussen gebogene Spindel endet mit einem deutlicher vorspringenden, abgerundeten Höcker. 


$$
\mathrm{D}=28, \mathrm{~d}=22, \mathrm{H}=20 \mathrm{~mm} \text {. }
$$

Deckel rotbraun mit lichterer Kalkplatte, sonst wie bei der typischen Form. Fundort: Baracoa auf Cuba.

\section{A lcadia (Emoda) silacea Morelet.}

Taf. 18, Fig. $10-12$ und 15 .

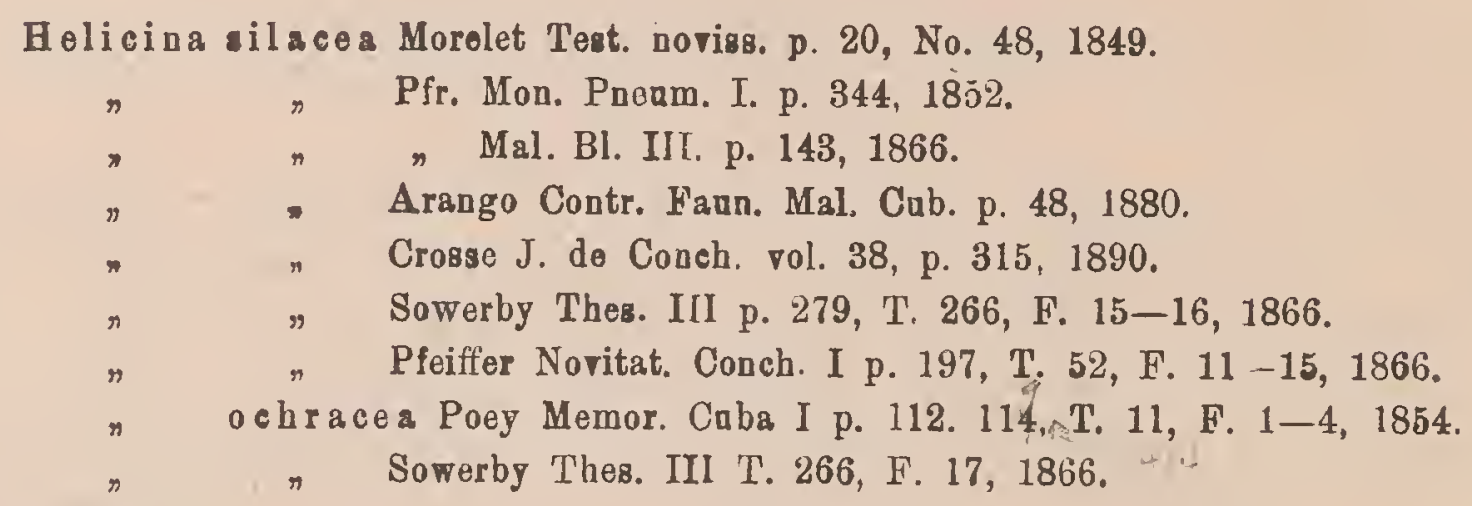

Gehäuse kegelförmig bis breit kegelförmig mit flachgewölbter Basis, dickschalig matt; die Grundfarbe zitrongelb oder hellrotbraun, der vorletzte Umgang weiss, der letzte olivengrün oder rotbraun gestriemt mit einer helleren, unten dunkelberandeten Binde an der Peripherie. Die Oberfläche der oberen Umgange ist ziemlich fein, aber ungleichmässig radial gestreift, bei den 2 letzten Umgängen sehr ungleichmässig radial gefaltet (am letzten Umgange werden die Falten gegen die Mündung zu wieder gleichmässiger und schwächer). Das niedrige kegelförmige Gewinde besteht aus $4^{1} / 2$ nahezu flachen, ziemlich rasch zunehmenden Umgăngen; der letzte ist etwas zusammengedrückt, an der Peripherie gerundet bis stumpfkantig und steigt vorne unter die Kante herab. Die abgerundet-dreieckige oder breithalbeiförmige Mündung ist schief, im Gaumen weiss oder hellbraun. Der weisse Mundsaum stark verdickt und ausgebreitet, der Oberrand an der Insertion stark vorgezogen, gerade; der Aussenrand umgeschlagen. Die kurze, breite Spindel ist nach vorne und aussen gebogen und endet mit einem abgerundeten, vorspringenden Knoten; der winkelige Ausschnitt am Uebergange zum Basalrande der Mündung ist deutlich; der dicke, weisse, am Rande durchscheinende Basalkallus deutlich bəgrenzt.

$$
\mathrm{D}=25-30, \mathrm{~d}=20-22, \mathrm{H}=16-18 \cdots 20 \mathrm{~mm} \text {. }
$$

Deckel halbkreisförmig mit geradem Spindelrand, rotbraun mit lichterer Kalkplatte, und nur im unteren Aste deutlich erhobener Sigmakante; sonst typisch.

Fundorte: Gibara und am Flusse Yunque bei Baracoa auf Cuba; die Exemplare vom letztgenannten Fundorte sind zumeist gelb gefärbt. Die Art ist mit Rücksicht auf die Grösse, Höhe des Gewindes, und die mehr minder deutliche Kante des letzten Umganges ziemlich veränderlich; von der Formenreihe der Alcadia (Emoda) pulcherrima Lea unterscheidet sich dieselbe durch das kegelförmige Gewinde, die rascher zunehmenden Umgänge, die auffallend 
ungleichmăssigen Radialfalten und die Beschaffenheit der Mündung, steht derselben aber jedenfalls sehr nahe.

\section{Alcadia (Emoda) submarginata Gray.}

Taf. 19, Fig. 7 und Fig. 11-13

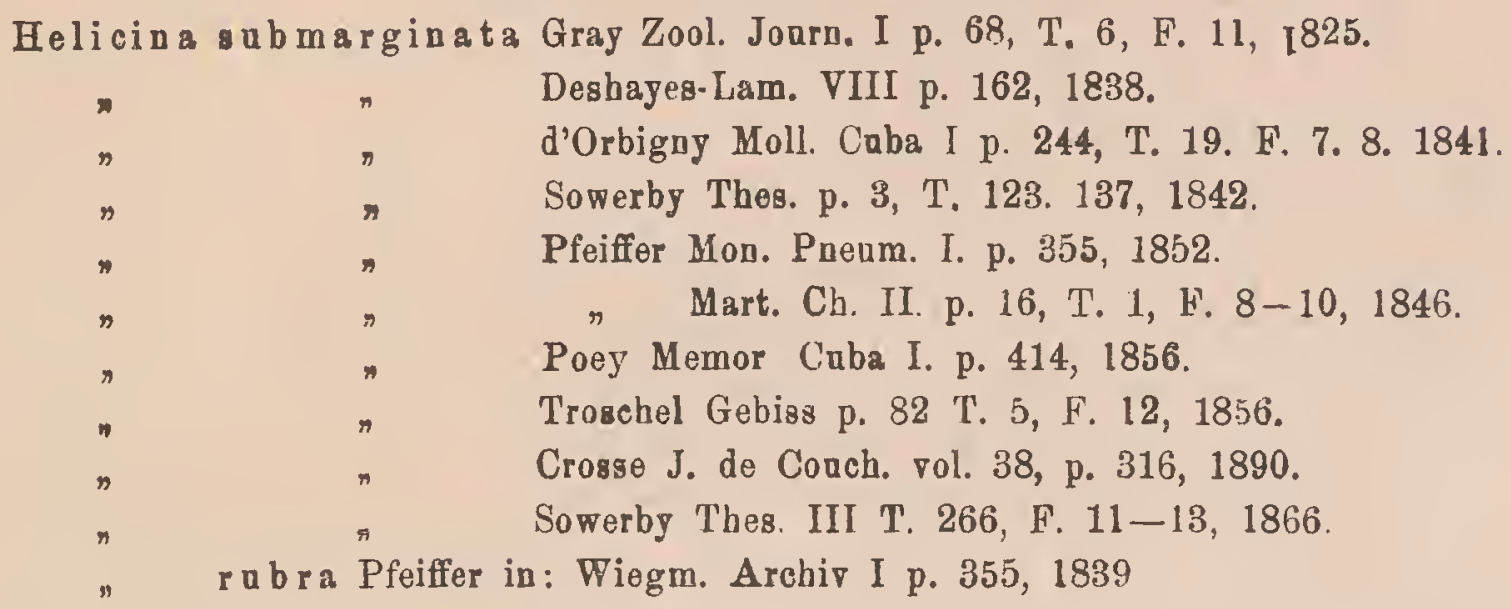

Gehäuse kegelförmig mit gewölbter Basis, festschalig, etwas durchscheinend, matt; hell gelbbraun bis rotbraun, häufig mit einer helleren, ziemlich undeutlichen Binde an der Peripherie. Die Skulptur besteht nebst ziemlich feinen, etwas ungleichmăssigen radialen Zuwachsstreifen aus dichten Spiralfalten der Epidermis, welchen an abgeriebenen Exemplaren feine, eingedrückte Spirallinien entsprechen. Das ziemlich erhobene, kegelförmige Gewinde besteht aus $4^{1} / 2$ fast flachen, regelmässig zunehmenden Umgängen; der letzte ist gerundet oder stumpfkantig und steigt vorne langsam, aber deutlich unter die Peripherie herab. Die halbeiförmige Mündung ist schief, im Gaumen gelblich oder rötlich, der weisse oder gelbe Mundsaum leicht verdickt, gerade und stumpí; der Oberrand all der Insertion stark vorgezogen, Die kurze breite Spindel ist etwas nach aussen gebogen und endigt mit einer abgerundeten, leicht vorspringenden Ecke; der Ausschnitt am Basalrande der Mündung ist sehr seicht. Der weisse, ziemlich dicke Basalkallus ist am Rande durchsichtig und deutlich begrenzt.

$$
\mathrm{D}=18, \mathrm{~d}=14, \mathrm{H}=12 \mathrm{~mm} \text {. }
$$

Deckel halbkreisförmig mit leicht konvexem Spindelrand und spitz ausgezogenem oberen Winkel. Die feingekörnelte, rötliche Kalkplatte ist verhältnismässig dick, die rotbraune Hornplatte mit auch im oberen Aste deutlicher, im unteren Aste leistenförmig erhobener Sigmakante, tiefer Furche neben derselben und winkeligem Fortsatz am Aussenrande.

Fundorte: Matanzas, Limonar, Canasi und Saltadero auf Cuba.

Diese Art variirt an den mir bekannten Fundorten nur mit Rücksicht auf die Grösse, Färbung und die mehr minder deutliche Kante des letzten Umganges. 


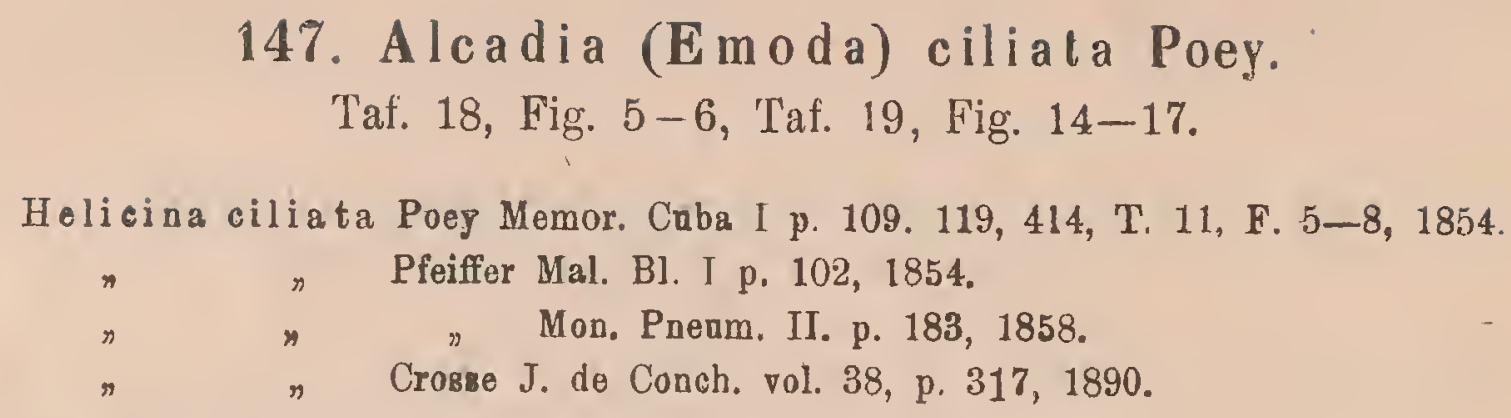

Gehäuse gedrückt kugelig, festschalig, matt, hellrotbraun mit helleren bis gelben Binden an der Peripherie und Naht. Die Skulptur besteht nebst feinen, etwas ungleichmässigen radialen Zuwachsstreifen aus dichten Spiralreihen ziemlich hinfälliger, abwechselnd stärkerer und feinerer Epidermisfalten, welchen an abgeriebenen Exemplar enhäufig feine, eingedrückte Spirallinien entsprechen. Das niedrige, abgerundet kegelförmige Gewinde besteht aus 5 kaum gewölbten, ziemlich rasclı zunehmenden Umgängen; der letzte ist stumpfkantig oder gerundet und steigt vorne langsam und wenig unter die Peripherie herab. Die abgerundet dreieckige oder halbeiförmige Mündung ist schief, innen hellrotbraun mit weissen Binden, der weisse Mundsaum lippenartig verdickt; der Oberrand an der Insertion vorgezogen, gerade und stumpf, der Aussenrand ausgebreitet und leicht umgeschlagen, der Basalrand gegen die Insertion zu rasch verschmälert, stumpf und gerade. Die kurze, breite Spindel ist nach aussen gebogen und endet mit einem abgerundeten, wenig vorspringenden Höcker; der Ausschnitt am Uebergange zum Basalrande der Mündung ist seicht, aber deutlich. Der Basalkallus in der Mitte dick, weiss, am Rande durchscheinend, zumeist undeutlich begrenzt.

$$
\mathrm{D}=21-25, \mathrm{~d}=17-20, \mathrm{H}=14: 5-16.5 \mathrm{~mm} \text {. }
$$

Deckel halbkreisförmig mit geradem Spindelrand und verhăltnismăssig dicker, bläulich durchscheinender Kalkplatte; die Hornplatte rotbraun, die Sigmakante nur im unteren Aste leistenförmig erhoben; die Furche naben derselben tief, der Fortsatz am Aussenrande des Deckels winkelig.

Fundorte: Trinidad und Banao auf Cuba; die Exemplare von letztgenanntem Fundorte sind bellzitrongelb mit lichtem Bande an der Peripherie nnd erreichen zumeist die Dimen. sionen: $\mathrm{D}=27, \mathrm{~d}=22, \mathrm{H}=17 \mathrm{~mm}$.

\section{Alcadia (Emoda) ciliata guisana n. Taf. 18, Fig. $7-9$.}

Gehăuse grösser, hellgelb mit einer verwaschenen, breiten, hellrotbraunen Binde auf der Oberseite der unteren Umgänge, sowie einem weissen unten rotbraun berandeten schmalen Bande an der Peripherie und gelbweisser Basis. Die Skulptur besteht nebst sehr ungleichmässigen, radialen Zuwachsstreifen aus ziemlich dichten, hinfälligen Spiralfalten der Epidermis; 
an abgeriebenen Exemplaren entsprechen den Epidermisfaiten ziemlich erhobene Spiralleisten, welche am letzten Umgange schwächer werden und in der 2. Hälfte in punktförmig eingedrückte Spirallinien übergehen. Das abgerundete Gewinde besteht nur aus 4 deutlicher gewölbten, langsamer zunehmenden Umgängen; der letzte ist etwas aufgeblasen, an der Peripherie undeutlich stumpfkantig und steigt vorne stärker herab. Der weisse, glänzende Mundsaum ist kurz ausgebreitet und umgeschlagen; die Ecke am unteren Ende der Spindel mehr abgerundet, der Ausschnitt des Basalrandes sehr seicht bis undeutlich.

$$
\mathrm{D}=27, \mathrm{~d}=21, \mathrm{H}=17 \mathrm{~mm}
$$

Deckel wie bei der typischen Form.

Fundort: Guisa auf Cuba.

\title{
Genus Entrochatella Fischer (ex rect. mea).
}

\author{
Trochtella Swainson nec Lesson Treat. on Mal. p. 337, 1840. \\ Helicina Lamarck (part.) \\ Eutrochatella Fischer Manaal. p. 796, 1885.
}

Gehăuse flach bis spitzkegelförmig mit verhältnismässig sehr kleiner, als ziemlich scharfe Spitze vorspringender. Embryonalwindung und 5-8 anfangs sehr langsam, zum Schlusse rascher zunehinenden Ũmgängen.

Deckel abgerundet dreieckig oder annähernd trapezoidisch mit konvexem oder S-förmig gebogenem Spindelrand und nach hinten gebogenem Spindelwinkel. Die dicke bis knochenartige Kalkplatte ist leicht konkav, am Spindelrande wallartig erhoben; dieser Wulst wird von der Hornplatte durch eine Furche geschieden, welche gegen den Spindelwinkel an Tiefe zunimmt und daselbst oft grübchenartig vertieft ist. Die Sigmakante wenig gebogen, nur an dem etwas vertieften Nukleus winkelig gebrochen und im unteren Aste stärker erhoben. Der Nukleus dem Spindelrande genähert, die Spindelseite der Platte ziemlich schmal.

Verbreitungsgebiet: Die Formen des Genus Eutrochatella Fischer leben derzeit nahezu ausschliesslich auf den grossen und kleinen Antillen; nur eine Form ist sicher auch von Guatemala nachgewiesen. Die hier zusammengefassten Formen stellen mit Rücksicht auf die Form der Schale und Beschaffenheit des Deckels eine Analogie zu den Formen des altweltIichen Genus Geophorus Fischer dar; unter anderen Eigentümlichkeiten zeigen auch hier viele Formen eine rauhe Oberflache mit anhaftender Erd oder Schmutzkruste, was auf eine älınliche Lebensweise (im Mulm unter Steinen und Felsspalten) schliessen lässt.

Die bei einzelnen Formen des Genus Alcadia beobchteten Verschiedenheiten der Schale bei dem männlichen und weiblichen Tiere sind hier besonders auffallend bemerkbar und bei einer Formenreihe (Eutrochatella regina Morelet) auch durch die anatomische Untersuchung festgestellt. Diese Unterschiede bestehen vorzüglich in der mehr minder raschen Zunahme 
und Wölbung der Umgänge und besonders in der verschiedenen Beschaffenheit der Mündung und des Mundsaumes; dementsprechend sind auch geringe Unterschiede in der Form des Deckels bemerkbar. Leider reicht mein Material nur in wenigen Făllen aus um gewisse Formenunterschiede der Schalen bestimmt auf die beiden Geschlechtsformen zurückzuführen, ebenso kann nur die anatomische Untersuchung die Entscheidung treffen ob eine bestimmte Form als Männchen oder Weibchen aufzufassen ist. Einige auffallend unterschiedene Geschlechtsformen haben bisher Anlass gegeben dieselben als verschiedene Arten zu bezeichnen: Z. B. E. regina Morelet und E. subunguiculata Poey.

\section{Subgenus Eutrochatella s. str.}

Gehäuse fest bis dickschalig, kegelförmig und gekielt bis kugelig und gerundet; die kräftige Skulptur besteht nebst radialen Zuwachsstreifen aus dichten, vielfach gekörnelten Spiralreifen. Der Mundsaum ist innen verdickt, zumeist kurz ausgebreitet, oft umgeschlagen; der Oberrand fast gerade, der Basalrand gegen die Insertion zu wenig verschmälert; am Uebergange des Basalrandes in die flache oder leicht ausgehöhlte Spindel weder ein Ausschnitt noch eine vorspringende Ecke. Der zumeist dünne Basallkallus wenig ausgebreitet.

Deckel: typisch.

Das Verbreitungsgebiet dieser Gruppe erstreckt sich vorzüglich über die Inseln Jamaica und Haiti; nur 2 Formen sind von der Insel Cuba bekannt, ebenso leben einige, besonders. durch den dicken Basalkallus abweichende Formen auf den südlichen Bahama Inseln.

\section{Formenkreis Granifera n.}

149. Eutrochatella (Eutrochatella) pulchella Gray. Taf. 20, Fig. 5-9, Fig. 17.

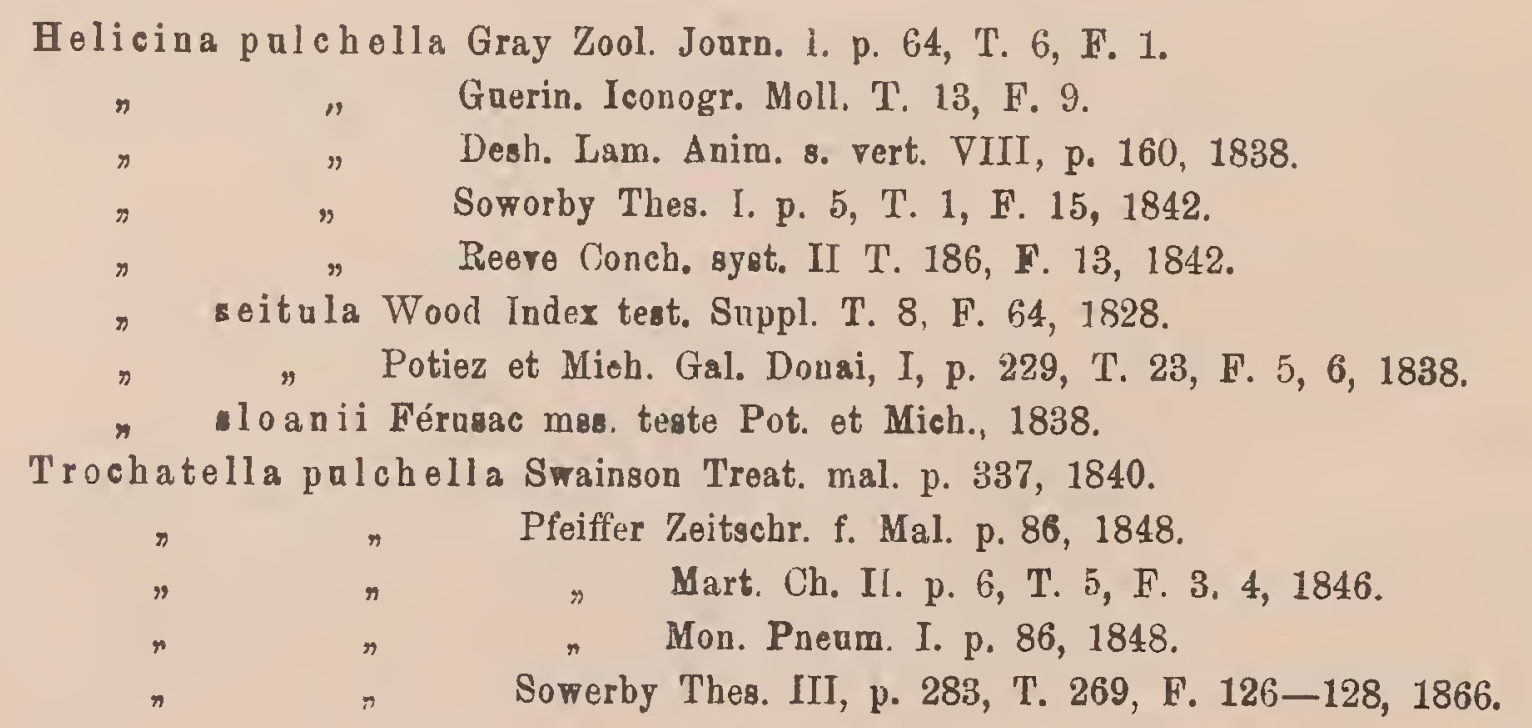


Von dieser Art leben am gleichen Fnndorte zwei deutlich unterschiedene Formen, welche ich als Geschlechtsformen auffasse und zunăchst mit den Buchstaben $\alpha$ und $\beta$ bezeichne.

Forma $\alpha$. Taf. 20, Fig. 6, 8, 9.

Gehăuse breit kegelförmig mit gewölbter bis halbkugeliger Basis, ziemlich festschalig, matt; die Grundfarbe hellgelb oder grünlichgelb mit weissen Flecken, Fleckenbinden und Striemen, sowie einer unterbrochenen rotbraunen Binde an der Peripherie; häufig sind auch zwei schwächere rotbraune Binden über und unter der Peripherie vorhanden, welche jedoch nur am Mundsaume deutlich sichtbar werden. Das Gewinde besteht aus $51 / 2-61 / 2$ leicht gewölbten bis flachen, wellig gekielten Umgăngen, welche dementsprechend durch eine mehr minder wellig gezähnte Naht geschieden werden; die oberen Windungen über der Naht kantig bis treppenförmig, der letzte beiderseits stärker gewölbt, rascher runehmend, vorne wenig oder gar nicht herabsteigend. Die Skulptur besteht nebst schwachen, etwas ungleichmässigen Zuwachsstreifen aus ziemlich krätigen; oft wellenförmig gebogenen und unterbrochenen Spiralleisten (7-8) uuf der Ober'seite und zahlreichen dichteren, aber schwächeren Spiralleisten auf der Unterseite. Die weite und sehr schiefe Mündung ist annähernd halbeiförmig, oder abgerundet dreieckig, innen gelblich und weiss gefleckt. Der dünne oder nur leicht verdickte, etwas wellige Mundsaum weit ausgebreitet, der Oberrand an der Insertion vorgezogen, verschmålert und fast gerade; der Basalrand umgeschlagen, an der Insertion kaum verschmälert, etwas abstehend und so einen falschen Nabelritz zeigend. Die kurze breite, fast senkrechte Spindel geht im gleichmässigen Bogen in den Basalrand über. Der dünne, schmale Basalkallus verbindet fast geradlinig die Insertionen des Mundsaumes.

$$
\mathrm{D}=14, \mathrm{~d}=10, \mathrm{H}=10 \cdot 4 \mathrm{~mm} \text {. }
$$

Forma $\beta$. Taf. 20, Fig. 5, 17.

Gehäuse durchschnittlich kleiner, kegelförmig bis spitzkegelförmig mit weniger gewölbter Basis; das höhere Gewinde besteht aus $51 / 2-6$ langsamer zunehmenden Ümgängen; der letzte nimmt auffallend langsamer zu, ist beiderseits weniger gewölbt und steigt vorne ziemlich tief unter den Kiel herab; die Mündung ist dementsprechend weniger erweitert, annăhernd hálbkreisförmig, der Mundsaum weniger ausgebreitet.

$$
\mathrm{D}=12, \mathrm{~d}=9, \mathrm{H}=11 \mathrm{~mm} \text {. }
$$

Deckel abgerundet dreieckig mit S-förmig gebogenem Spindelrande, sonst typisch.

Fundorte: Ich beurteile die Art zunächst nuch Exemplaren von Boxwalk auf Jamaica, habe ausserdem zahlreiche Exemplare mit der Fundortsangabe „Jamaica untersucht; abgesehen von den beschriebenen Geschlechtsformen sind bei dieser Art wohl Grössenunterschiede, sonst aber nur geringe Abweichungen bezüglich der mehr minder kräftigen und gekörnelten Spiralskulptur, sowie der Färbung vorhanden. Unter der Bezeichnung Trochatella grayana Pfeiffer habe ich stets nur kleinere Exemplare der E. pulchella Gray, Forma $\alpha$ gesehen und zweifle nicht, dass E. grayana Pfr. nur eine Geschlechtsform dieser Art dastellt. Die AbbilI. 18. II. 
dung auf Taf. 20, Fig. 8, 9 ist nach einem Originalexemplare der Trochatella grayana Pfr. ausgeführt.

\title{
150. Eutrochatella (Eutrochatella) tankervilli Gray.
}

\author{
Taf. 20, Fig. 1-4.
}

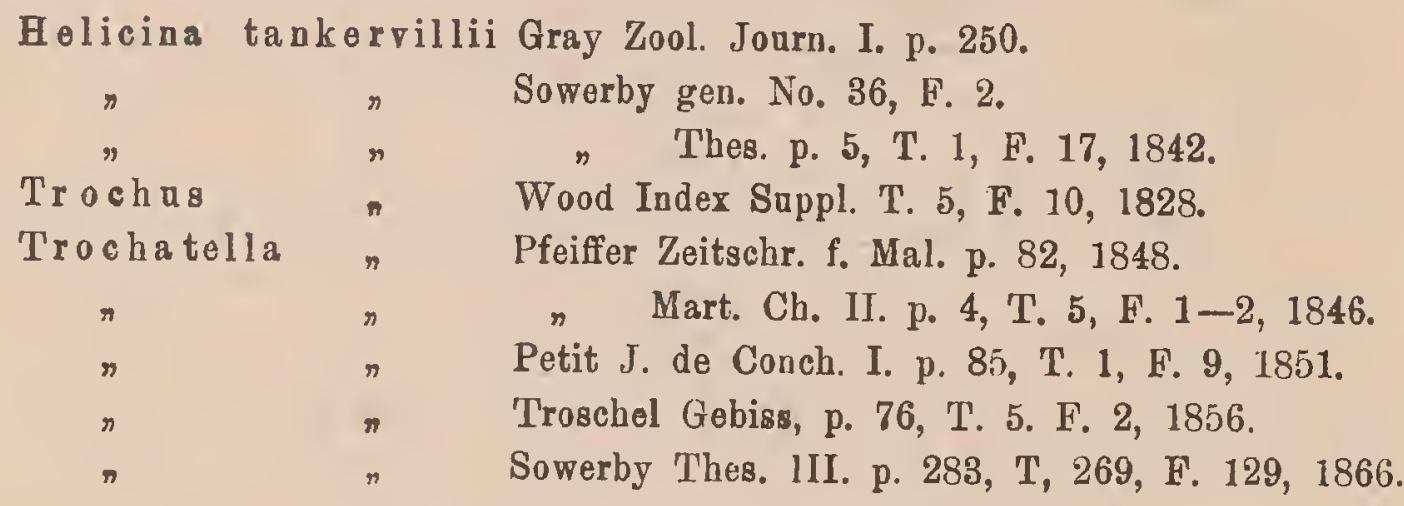

Forma $\alpha$. Taf. 20, Fig. 2.

Gehäuse breit kegelförmig mit gewölbter Basis, festschalig, matt; die Grundfarbe hellzitrongelb oder gelblichweiss mit weisser Skulptur und je einer rotbraunen, Fleckenbinde über und unter dem Kiele. Die Skulptur besteht nebst ziemlich kräftigen Zuwachsstreifen aus kräftigen gekörnelten Spiralreifen (8-9 auf der Oberseite des letzten Umganges), welche auf der Unterseite dichter, aber nur wenig schwächer werden. Das Gewinde besteht aus $5^{1} / 2-6$ ziemlich rasch zunehmenden wellig gekielteu Umgängen, welche dementsprechend durch eine wellige Naht geschieden werden; die oberen Umgänge sind flach, über der Naht kantig, der letzte beiderseits gewölbt, mit scharfem gezahnten Kiele versehen, vorne sehr wenig oder gar nicht herabsteigend. Die schiefe Mündung ist dreieckig, weiss und glänzend; der iunen leicht verdickte, am Rande dünne und etwas wellige Mundsaum ist ausgebreitet und winkelig umgeschlagen; der Oberrand an der Insertion stark vorgezogen, der Basalrand nicht verschmälert, in nahezu rechtenı Winkel in die flache, etwas zurückweichende Spindel übergehend. Der dünne, weisse, durch den Glanz angedeutete Basalkallus ist wenig ausgebreitet und verbindet in kurzem Bogen die Insertionen des Mundsaumes.

$$
\begin{aligned}
& D=25, d=20 \cdot 5, H=20 \mathrm{~mm} . \\
& D=14, d=10.5, H=11 \mathrm{~mm} .
\end{aligned}
$$

Deckel annähernd trapezoidisch mit leicht S-förmig gebogenem Spindelrand; die weisse Kalkplatte sehr fein gekörnelt, die gelbliche Hornplatte sehr zart.

Form a $\beta$. Taf. 20, Fig. 1.

Trochatella tankervillii Pfeiffer in Mart. Ch. II. T. 5, F. 1-2.

Gehäuse kegelförmig mit flacher gewölbter Basis; das höhere Gewinde besteht aus 
$5^{1} / 2$-6 langsamer zunehmenden Umgängen, der letzte ist kaum gewölbt bis flach, schärfer gekielt und steigt vorne deutlich unter den Kiel herab.

$$
\mathrm{D}=20, \mathrm{~d}=17 \cdot 5, \mathrm{H}=17 \mathrm{~mm} \text {. }
$$

Deckel abgerundet dreieckig, sonst wie bei Forma $\alpha$.

Fundort: die Insel Jamaica.

Nach dem mir vorliegenden Materiale ist diese Art 'bis auf die auffallenden Grössenunterschiede in den wesentlichen Merkmalen sehr konstant.

\section{Eutrochatella (Eutrochatella) chittiana Pfeiffer.} Taf. 20, Fig. 10, 11.

Trochatella chittiana Pfeiffer Pr. Z. Soc. 1857.

$$
\begin{aligned}
& " \quad \text { Mon. Pneum. II. p. I76, } 1858 . \\
& " \quad \text { Sowerby Thes. III. p. 283, T. 269, F. 151, } 1866 .
\end{aligned}
$$

Gehäuse kegelförmig mit flach gewölbter Basis, festschalig, matt; die Grundfarbe hellzitrongelb mit weisser Skulptur, zwei weissen Fleckenbinden an der Basis, häufig auch mit einer unterbrochenen, rotbraunen Binde entlang des Kieles. Die Skulptur besteht nebst schwachen Zuwachsstreifen aus ziemlich dichten und erhobenen Spiralreifen (6-7 auf der Oberseite des letzten Umganges), welchen auf der Unterseite sehr dichte aber schwache Spirallinien entsprechen. Das regelmässig kegelförmige Gewinde besteht aus $61 / 2-71 / 2$ durch wellenförmig berandete Naht geschiedenen Umgängen; die 3 oberen sind über der Naht kantig, die folgenden kaum gewölbt, der letzte stumpf und leicht wellenförmig gekielt, vorne wenig, aber deutlich herabsteigend. Die abgerundet dreieckige Mündung ist sehr schief, der weisse Mundsaum verdickt, ausgebreitet und umgeschlagen. Die kurze flache Spindel geht winkelig in den Basalrand über. Der ziemlich dicke, weisse und gut begrenzte Basalkallus ist. wenig ausgebreitet.

Deckel : unbekannt.

$$
\mathrm{D}=12, \mathrm{~d}=10 \cdot 5, \mathrm{H}=11 \mathrm{~mm} \text {. }
$$

Fundort: die Insel Jamaica.

Von E. pulchella Gray unterscheidet sich vorstehende Art durch das höhere Gewinde, die grössere Zahl der langsamer zunehmenden, flacheren Umgange, sowie die schärferen, weitläufigeren und nicht gekörnelten Spiralleisten.

\section{Eutrochatella (Eutrochatella)) josefinae C. B. Adams. Taf. 20, Fig. 12-14.}

Helieina jorefina C. B. Adams Contr. to. Conch. I. p. 14, 1849.

Trochatella josefina Pfeiffer Mon. Pneum. I. p. 335, 1852.

Helicina " Sowerby Thes. III. p. 296, T. 278, F. 449, 1866. 
Gehăuse flachkegelförınig mit flacher Basis, ziemlich festschalig, matt; die Grundfarbe ist oben gelbgrün, wird jedoch durch unregelmässige weisse Flecken und Striemen nahezu verdeckt, die Unterseite gelbbraun oder hellrotbraun. Die Skulptur besteht nebst schwachen, schiefen Zuwachsstreifen aus niedrigen bis undeutlichen, leicht wellig gefalteten Spiralleisten (6-7 auf der Oberseite des letzten Umganges) und sehr dichten und feinen, erhobenen Spirallinien auf der Unterseite. Das regelmässig flachkegelförmige Gewinde besteht aus 51/2 -6 flachen, ziemlich rasch zunehmenden Umgängen mit wellig gezahntem, scharfen Kiel; die oberen Umgänge über der Naht kantig, der letzte stark zusammengedrückt, vorne nicht herabsteigend. Die dreieckige, breite Mündung sehr schief, der weisse Mundșaum entsprechend dem Kiele rinnenförmig ausgezogen; der Oberrand dünn, fast gerade, der Basalrand leicht verdickt, bre $\mathrm{t}$ umgeschlagen. Die kurze, flache, zurückweichende Spindel geht nahezu rechtwinkelig in den Basalrand über; der Basalkallus dünn, wenig ausgebreitet.

$$
\mathrm{D}=10, \mathrm{~d}=8.5, \mathrm{H}=6 \mathrm{~mm} \text {. }
$$

Deckel trapezoidisch mit S-förmig gebogenem Spindelrand, schmutzigweisser Kalkplatte, gelblicher Horuplatte, sonst typisch

Fundort: die Insel Jamaica.

Die vorstehende Art zeigt mit Rücksicht auf die Merkmale des Gehäuses eine merkwürdige Uebereinstimmung mit den Formen des Genus Geotrochatella Fischer, unterscheidet sich von denselben vor allem durch die Beschaffenheit des Deckels; andererseits stellt dieselbe einen Uebergang zu den Formen des Genus Geophorus Fischer dar.

\section{Formenkreis Excavata n.}

\section{Eutrochatella (Eutrochatella) globosa Gray.} Taf. 20, Fig. 15. 16.

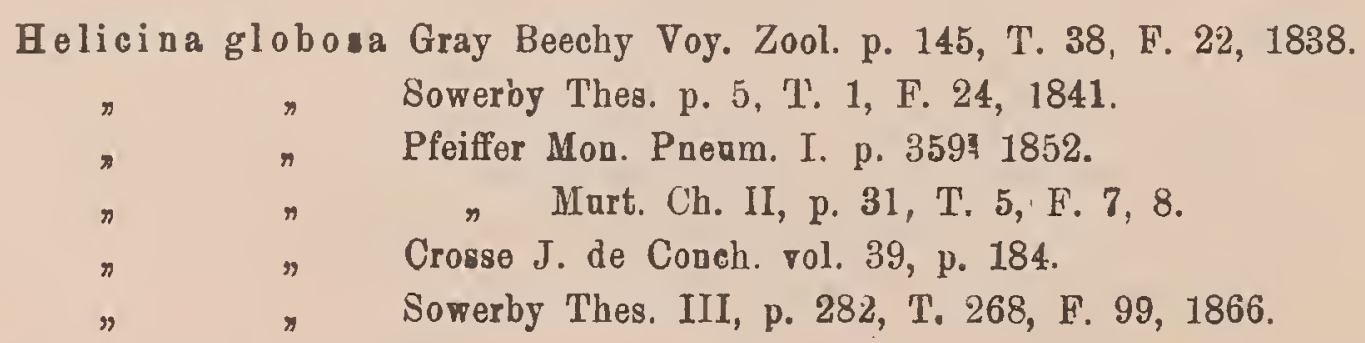

Gehäuse kreiselförmig kugelig, festschalig, glanzlos, gelblichweiss oder hellfleischfarben. Die Skulptur besteht nebst ungleichmässigen, schwachen Zuwachsstreifen aus dichten und feinen, auf dem letzten Ungange wellenförmig gebogenen Spiralreifen. Das ziemlich erhobene breitkegelförmige Gewinde läuft in eine ziemlich scharfe Spitze aus und besteht aus 6 nahezu flachen, durch eingedrückte Naht geschiedenen Unngängen; der letzte ist gerundet, doppelt so breit wie der vorletzte und steigt vorne langsam, aber deutlich herab. Die schiefe, halbei- 
förmige Mündung ist innen weiss, oder blassgelb; der weisse, innen etwas verdickte Mundsaum kaum ausgebreitet; der Oberrand an der Insertion vorgezogen, der Basalrand im winkligen Bogen in die breite, leicht ausgehöhlte Spindel übergehend; der schmale halbmondförmige Basalkallus dünn.

Deckel unbekannt.

$$
\mathrm{D}=16, \mathrm{~d}=13, \mathrm{H}=13 \mathrm{~mm} \text {. }
$$

Fundort: die Insel Haiti.

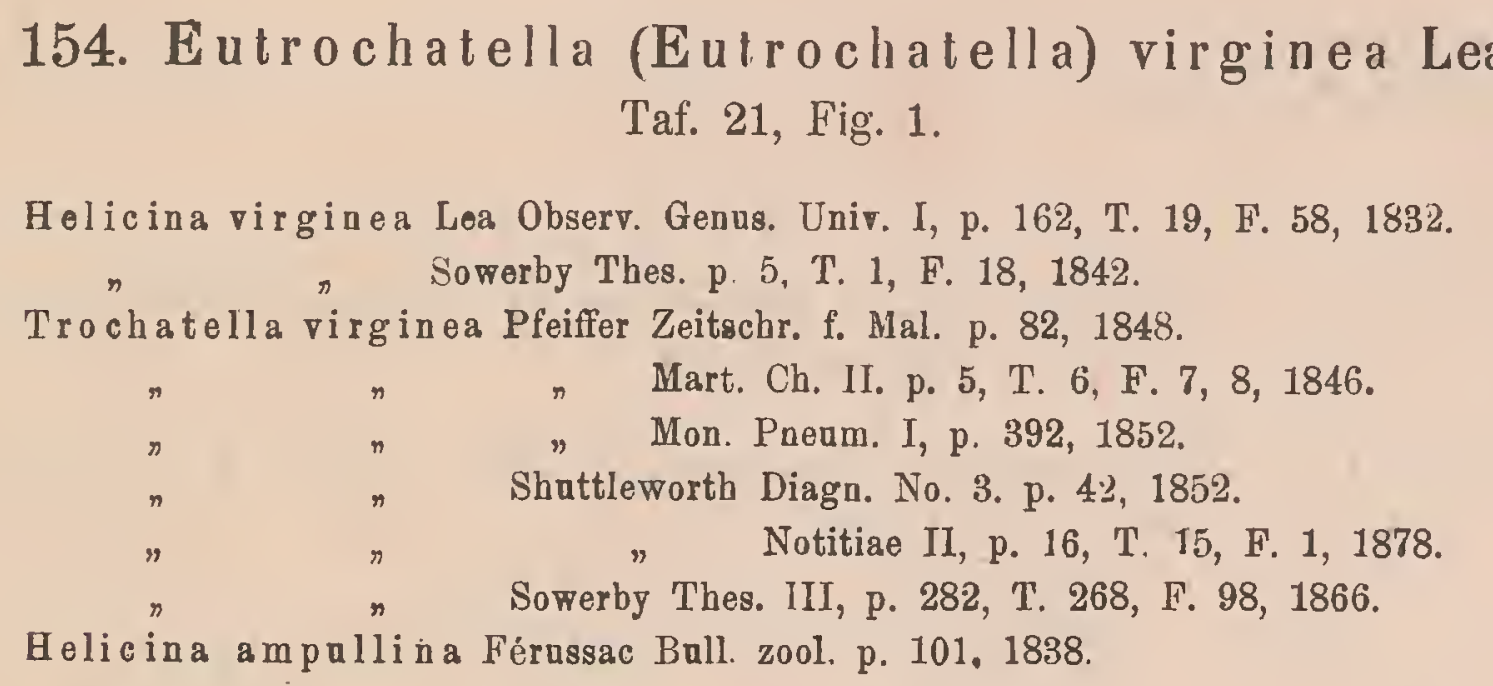

Gehăuse kugelig kreiselförmig, dickschalig, matt, die oberen Umgänge hellgelb, der letzte kalkartig weiss. Die Skulptur besteht nebst ungleichmässigen, ziemlich kräftigen $\mathrm{Zu-}$ wachsstreifen aus dichten Spiralreifen, welche auf der Oberseite des letzten Umganges etwas weitlăufiger werden. Das breit kegelförmige, unter der verbältuismässig sehr feinen Spitze etwas konkave Gewinde besteht aus $6 \frac{1}{2}$ ziemlich rasch zunehmenden Umgängen; die 3 oberen sind über der Naht leicht stumpfkantig, die 3 unteren leicht gewölbt, der letzte etwas aufgeblasen, gerundet, vorne ziemlich tief herabsteigend. Die halbkreisförmige, innen gelbe Mündung ist schief, der weisse Mundsaum innen verdickt; der Oberrand fast gerade, an der Insertion vorgezogen, der Aussen- und Basalrand kurz ausgebreitet. Die breite, ausgehöhlte Spindel läuft unten in eine abstehende Leiste aus und wird von der Basis des Gehäuses durch eine Furche geschieden. Der ziemlich dünne, aber deutlich begrenzte Basalkallus verbindet fast geradlinig die Insertionen des Mundsaumes.

Deckel unhekannt.

$$
\mathrm{D}=23, \mathrm{~d}=18, \mathrm{H}=19 \mathrm{~mm} \text {. }
$$

Fundort: die Insel Haiti (Baracon in San Domingo).

Von E. globosa Gray unterscheidet sich vorstehende Art durch die dickere Schale, die kräftigere Skulptur, deu weniger aufgeblasenen, vorne mehr herabsteigenden letzten Umgang, den dickeren, mehr ausgebreiteten Mundsaum, die Beschaffenbeit der Spindel und den schmäleren Basalkallus. 


\title{
155. Eutrochatella (Eutrochatella) virginea crassicostata Sow.
} Taf. 21, Fig. 2.

\author{
Helicina Crassicostata Sowerby mss.
}

Gehăuse kleiner mit höherem Gewinde, weniger erweitertem letzten Umgange und schärferen Spiralleisten.

Deckel unbekannt.

$$
\mathrm{D}=18 \cdot 5, \mathrm{~d}=14, \mathrm{H}=15 \mathrm{~mm}
$$

Fundort: die Insel Haiti.

\section{Eutrochatella (Eutrochatella) opima Shutleworth. Taf. 21, Fig. 6-8.}

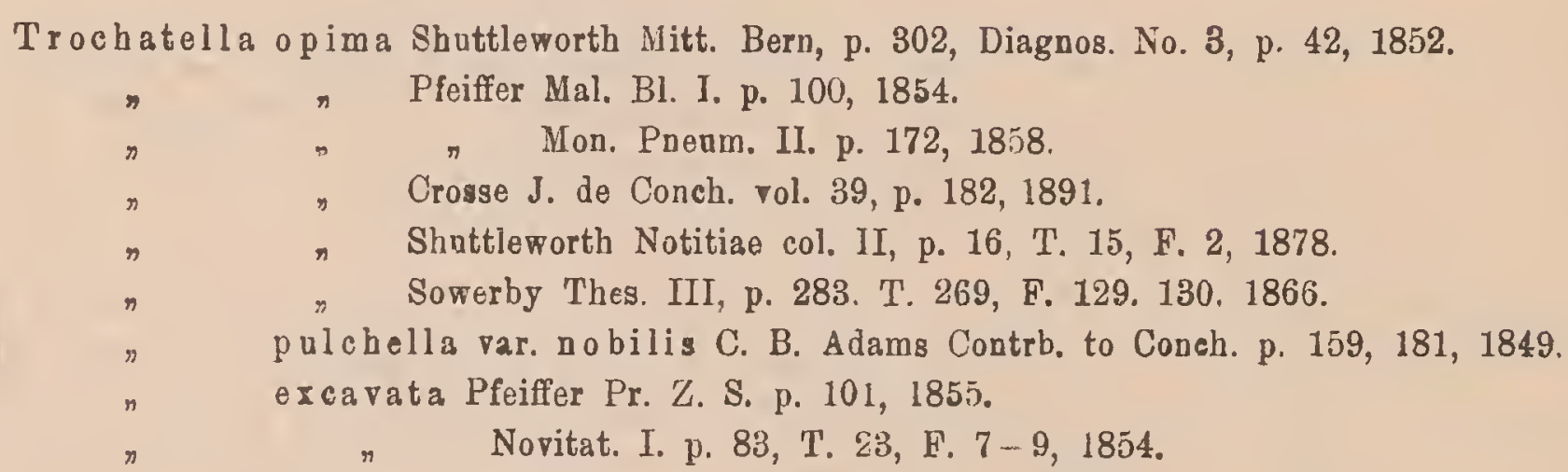

Gehäuse gedrückt kreiselförmig, mit griffelförmiger Spitze, festschalig, matt, gelblich oder hellfeischfarben. Die Skulptur besteht nebst feinen, ungleichmässigen Zuwachsstreifen aus ziemlich krăftigen und dichten, am letzten Umgange wellenförmig gebogenen Spiralreifen. Das breitkegelförmige Gewinde ist unter der Spitze etwas konkav uad besteht aus 6 leicht gewölbten, ziemlich rasch zunehmenden Umgängen; die obersten sind über der Naht kantig, der letzte aufgeblasen und gerundet, vorne langsam und ziemlich tief herabsteigend. Die halbkreisförmige Mündung ist schief, innen hellrotbraun, der weisse, innen leicht verdickte Mundsaum kurz ausgebreitet; der Oberrand an der Insertion vorgezogen und gerade, der Basalrand umgeschlagen, und im winkeligen Bogen in die breite, ausgehöhlte Spindel übergehend; der dünne Basalkallus an der Spindel leistenförmig abstehend.

$$
\mathrm{D}=14, \mathrm{~d}=10.5, \mathrm{H}=10 \mathrm{~mm} \text {. }
$$

Deckel halbkreisförmig mit leicht S-förmig gebogenem Spindelrand; die dicke knochenartige Kalkplatte in der Mitte mit einem unregelmässigen, dem spongiösen Teile eines Knochens vergleichbaren Substanzverlust; die gelbliche Hornplatte mit brauner Zone am Aussenrande; sonst typisch. 
Fundort: El Rincon in San Domingo.

Trochatella excavata Pfeiffer, welche der Autor ohne Fundortsangabe beschreibt ist dem Vergleiche von Originalexemplaren zur Folge mit vorstehender Art vollkommen identisch.

\section{Eutrochatella (Eutrochatella) chrysostoma Pfeiffer. Taf. 21, Fig. 3-5.}

Trochatella chrysostoma Shattleworth apud Pfeiffer Mon. Pneum. I, p. 330, 1852.

Gehäuse kegelförmig mit halbkugeliger Basis, festschalig, matt, weiss mit gelblicher Spitze. Die Skulptur besteht nebst sehr schwachen Zuwachsstreifen aus dichten, ziemlich scharfen Spiralreifen, welche auf der Unterseite dichter und schwächer werden. Das regelmässig kegelförmige, zugespitzte Gewinde besteht aus 6 ziemlich rasch zunehmenden, durch eine eingedrückte Naht geschiedenen Umgängen; die 3 oberen sind über der Naht kantig, die unteren leicht gewölbt, der letzte gerundet, vorne langsam und wenig herabsteigend. Die halbeiförmige. innen zitrongelbe Mündung ist schief, der dünne, gelbe Mundsaum kurz ausgebreitet, die zurückweichende kurze Spindel etwas verbreitert und ausgehöhlt. Der dünne, gelbliche Basalkallus wenig ausgebreitet und undeutlich begrenzt.

$$
\mathrm{D}=12, \mathrm{~d}=1 \mathrm{n}, \mathrm{H}=10 \mathrm{~min} \text {. }
$$

Deckel abgerundet dreieckig mit nahezu geradem Spindelrand und weisser, glänzender Kalkplatte; sonst typisch.

Fundort: die Insel Cuba.

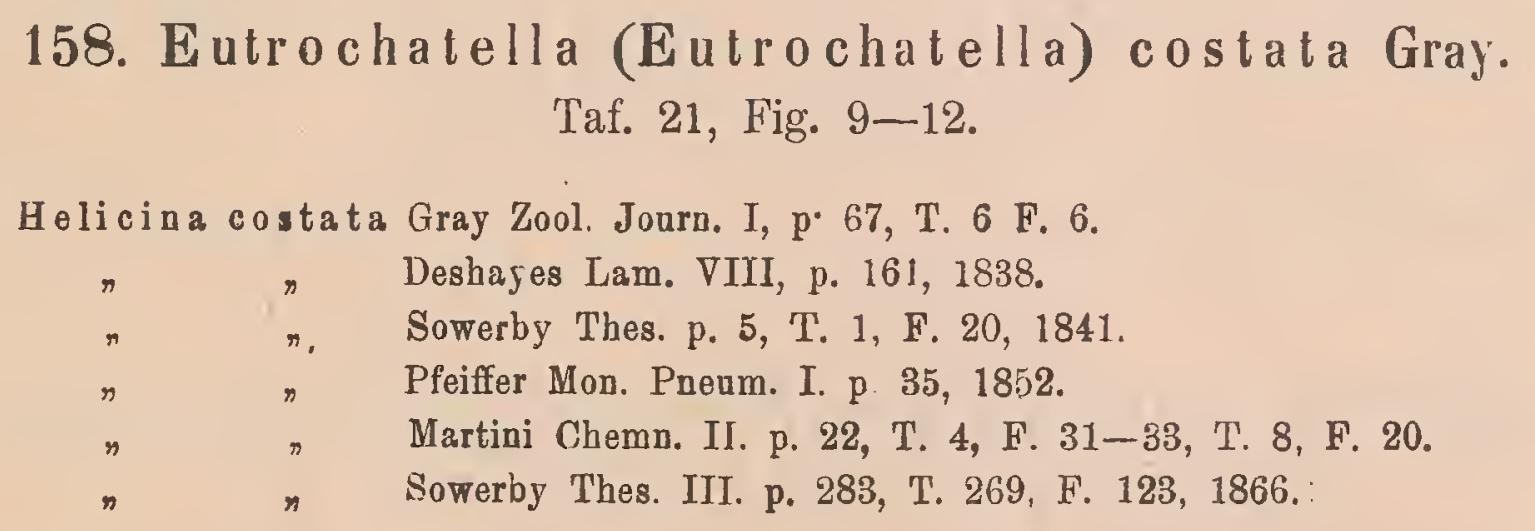

Gehäuse kegelförmig mit flach gewölbter Basis, dickschalig, matt, kalkartig weiss mit hellgelber Spitze. Die Skulptur besteht nebst vereinzelten undeutlichen Zuwachsstreifen aus dichten und erhobenen Spiralreifen, welche auf der Unterseite dichter und schwächer werden. Das etwas konvexe Gewinde besteht aus 6 durch seichte Naht geschiedenen Umgängen; die oberen über der Naht kantig, die 3-4 unteren leicht gewölbt, der letzte gerundet, unten abgeflacht, vorne langsam und deutlich herabsteigend. Die abgerundet dreieckige Mündung 
ist sehr schief, innen gelblich; der weisse Mundsaum innen verdickt, der Oberrand fast gerade und scharf, an der Insertion vorgezogen; der Aussenrand kurz ausgebreitet; der Basalrand gegen die Insertion zu etwas verschmälert. Die kurze, zurückweichende Spindel ist etwas verbreitert und konkav, der dünne Basalkallus undeutlich begrenzt.

$$
\mathrm{D}=8 \cdot 5, \mathrm{~d}=7, \mathrm{H}=8 \mathrm{~mm} \text {. }
$$

Deckel abgerundet dreieckig mit geradem Spindelrande, ziemlich dünner, gelbbrauner und fein gekörnelter Kalkplatte; sonst typisch.

Fundort: die Insel Jamaica (St. Anns).

\title{
159. Eutrochatella (Eutrochatella) eugeniana Weinland.
} Taf. 21, Fig. 13-14.

\author{
Helicina eugeniana Weinland Mal. Bl. Bl. IX, p. 197, 1862. \\ Trochatella " Pfeiffer Mon. Pnenm. III. p. 212, 1865. \\ " Crosse J. de Conch. vol. 39, p. 183, 1891.
}

Gehäuse breitkegelförmig mit flach gewölbter Basis, festschalig, hellgelb mit dunklerer Spitze, matt. Die Skulptur besteht nebst einigen undeutlichen radialen Zuwachsstreifen aus ziemlich dichten Spiralreifen, welche auf der Unterseite schwächer und dichter werden. Das leicht konvexe Gewinde besteht aus 5 wenig gewölbten Umgängen; die zwei obersten über der Naht kantig, der letzte gerundet, vorne wenig und langsam herabsteigend. Die abgerundet dreieckige Mündung ist sehr schief, innen gelblich; der weisse Mundsaum innen leicht verdickt, der Oberrand an der Insertion vorgezogeu, der Aussenrand ziemlich ausgebreitet, der Basalrand gegen die Insertion zu verschmälert. Die kurze, zurückweichende Spindel ist verbreitert und etwas ausgehöhlt. Der dünne, schmale Basalkallus undeutlich begrenzt.

Deckel unbekannt.

$$
\mathrm{D}=5 \cdot 3, \mathrm{~d}=4 \cdot 7, \mathrm{H}=4 \cdot 3 \text {. }
$$

Fundorte: Jerémié auf Haiti

\section{Eutrochatella (Eutrochatella) eugeniana weinlandi n.} Taf. 21, Fig. 15.

Das Gewinde höher mit flacheren, langsamer zunehmenden Umgängen, die Spiralleisten weitläufiger, auffallend höher und schärfer, der letzte Umgang vorne tiefer herabsteigend.

Deckel unbekannt.

$$
\mathrm{D}=5, \mathrm{H}=5 \mathrm{~mm} \text {. }
$$

Fundort: die Insel Haiti. 
161. Eutrochatella (Eutrochalella) elegantula Pfeiffer. Taf. 21, Fig. 16. 17.

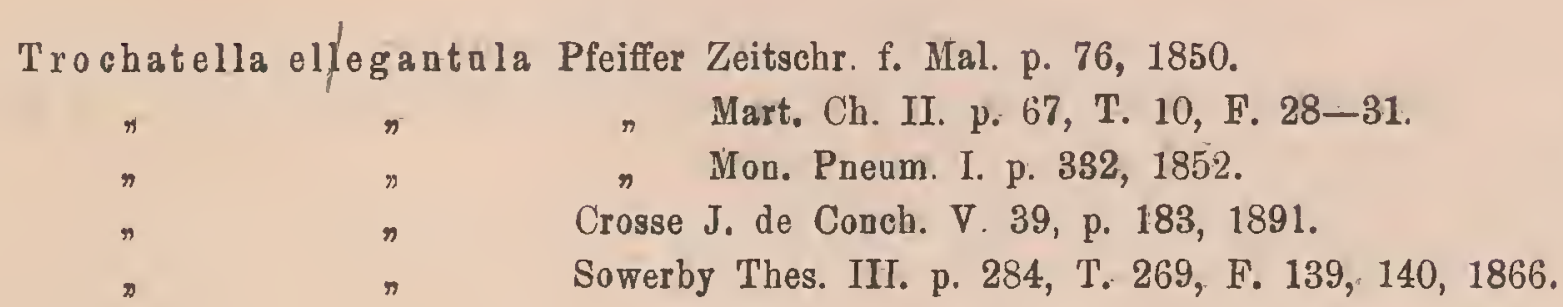

Gehäuse breit kegelförmig mit flach gewölbter Basis, ziemlich dünnschalig, hellrotbraun, matt. Die Skulptur besteht nebst ziemlich kräftigen, ungleichmässigen Zuwachsstreifen aus dichten Spiralleisten, welche auf der Unterseite dichter und schwächer werden. Das regelmässig kegelförmige Gewinde besteht aus 5 leicht gewölbten Umgängen, die oberen stumpfkantig, der letzte gerundet, vorne wenig oder nicht herabsteigend. Die abgerundet dreieckige Mündung ist schief, innen gelblich oder röthlich; der dünne, weisse Mundsaum kurz ausgebreitet, der Ober- und Basalrand an den Insertionen verschmälert. Die kurze Spindel wenig verbreitert, etwas nach aussen und hinten gebogen, der dünne Basalkallus undeutlich begrenzt.

$$
\mathrm{D}=4 \cdot 6, \mathrm{~d}=4, \mathrm{H}=4 \cdot 2 \mathrm{~mm} \text {. }
$$

Deckel unbekannt.

Fundort: San Domingo (Monte Cibao, Sierra de Monte Christo). Von E. eugeniana Weinland durch die mehr gewölbten Umgänge, den mehr gerundeten, vorne nicht herabsteigenden letzten Umgang, die schwächeren, gleichmässigeren und dichteren Spiralreifen; und d'en deutlicher ausgebreiteten Mundsaum unterschieden.

\section{Formenkreis Callida n.}

\section{Eutrochatella (Eutrochatella) callida Weinland.}

$$
\text { Taf 21, Fig. } 18-21 \text {. }
$$

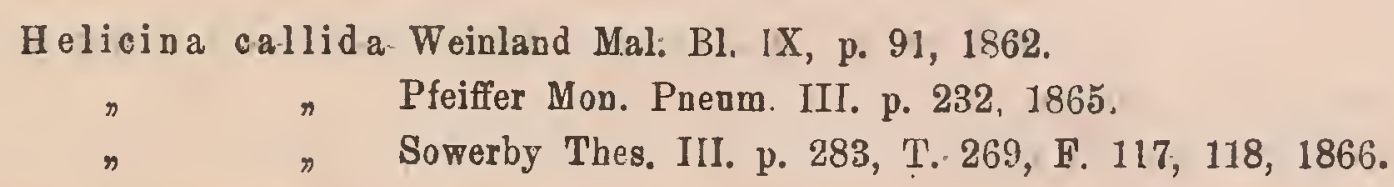

Gehäuse gedrückt kugelig mit griffelförmig vorspringender Spitze, dickschalig, weiss mit rötlicher Spitze: Die Skulptur besteht neben deutlichen, ungleichmässigen Z Zuwachsstreifen aus gleichmăssigen, dichten und ziemlich erhobenen Spiralireifen. Das unter der Spitze leicht konkave Gewinde besteht aus $5 \frac{1}{2}$ ziemlich langsam zunehmenden, kaum gewölbten, über der Naht kantigen bis gekielten Umgängen; der letzte ist im Beginne gekielt, gegen die Mündung nahezu gerundet, vorne wenig oder nicht herabsteigend. Die halbeiI. 18. II. 
förmige Mündung ist sehr schief, innen lebhaft gelbbraun, der weisse, gerade Mundsaum verdickt bis verdoppelt. Die sehr kurze Spindel ist nach aussen gebogen, am Uebergange zum Basalrande der Mündung ein seichter Ausschnitt. Der gelbbraune Basalkallus sehr dick, an den Răndern wulstig erhoben.

$$
D=5 \cdot 5, d=5, H=5 \mathrm{~mm} \text {. }
$$

Deckel abgerundet dreieckig mit geradem oder leicht konvexem Spindelrande und gelbbrauner, feingekörnelter Kalkplatte; sonst typisch.

Fundort: die Crooked Insel der Bahamas.

Die Art ist mit Rücksicht auf die Wölbung des Gewindes und den mehr minder scharfen Kiel der oberen Umgănge einigermassen veränderlich.

\section{Eutrochatella (Eutrochatella) littoricola Pfeiffer. Taf. 21, Fig. 22. 23.}

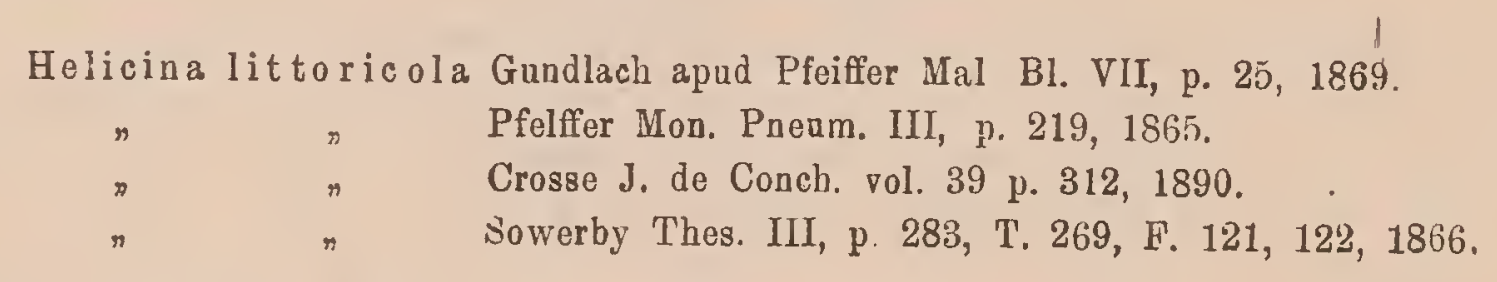

Gehäuse kugelig kegelförmig, dickschalig, matt, weiss oder röthlich mit gelblicher Spitze. Die SkuIptur besteht nebst schwachen, gleichmässigen Zuwachsstreifen aus dichten und feinen Spiralreifen. Das breit kegelförmige Gewinde besitzt eine vorspringende Spitze und besteht aus $4 \frac{1}{2}-5$ kaum gewölbten, ziemlich langsam zunehmenden Umgängen; die oberen sind über der Naht mehr minder deutlich kantig, der letzte gerundet, unten flacher, vorne langsam und wenig herabsteigend. Die halbeiförmige Mündung ist sehr schief, innen gelb oder orange; der Mundsaum gerade, zumeist verdoppelt. Die sehr kurze Spindel nach aussen gebogen, am Uebergange derselben zum Basalrande der Mündung ein deutlicher Ausschnitt. Der dicke, gelbe Basalkallus ist halbkreisförmig ausgebreitet, unten wulstig erhoben und deutlich begrenzt.

$$
\mathrm{D}=4 \cdot 7, \mathrm{~d}=4 \cdot 2, \mathrm{H}=4.6 \mathrm{~mm} \text {. }
$$

Deckel abgerundet dreieckig mit etwas konvexem Spindelrand ınd gelblicher, feingekörnelter Kalkplatte; soust typisch.

Fundort: die Insel Cnba (Baracoa).

Von E. callida Weinland durch geringere Dimensionen, die weniger vorspringende, stumpfere Spitze, die gerundeten Umgänge, die dichtere, schwächere Skulptur, sowie die Färbung der Schale und Mündung unterschieden. 
164. Eutrochatella (Eutrochatella) bryanti Pfeiffer.

Taf. 21, Fig. 24. 25.

Helicina bryanti Pfeiffer Mal. BI. XIV, p. 165, 1867.

n $\quad$ Mon. Pneum. IV. p. 262, 1876.

Gehăuse breit kegelförmig mit flachgewölbter Basis, festschalig, schmutzig weiss oder blass fleischfarben, matt. Die Skulptur besteht nebst einigen ungleichmăssigen Zuwachsstreifen aus dichten Spiralfurchen, welche auf der Unterseite schwächer werden. Das etwas abgerundete Gewinde besteht aus $41 / 2$ flachen durch eingedrückte Naht geschiedenen Umgăngen; der letzte ist im Beginne stumpf gekielt, gegen die Mündung nahezu gerundet, etwas zusammengedrückt und steigt vorne wenig, aber deutlich herab. Die abgerundet dreieckige Mündung ist sehr schief, innen orangerot oder hellrotbraun. Der gerade, stumpfe Mundsaum ist mitunter verdoppelt, die flache, etwas ausgehöhlte Spindel nach aussen gebogen. Der gelbweisse Basalkallus oben ziemlich dünn, im Umkreise der Spindel dicker und leistenförmig abstehend.

$$
\mathrm{D}=4 \cdot 6, \mathrm{~d}=4, \mathrm{H}=3 \cdot 5 \mathrm{~mm} \text {. }
$$

Deckel abgerundet dreieckig mit konvexem Spindelrand und rotbrauner, feingekörnelter Kalkplatte, sonst typisch.

Fundort: die Insel Inagua der Bahamas.

\title{
165. Eutrochatella (Eutrochatella) candida Pfeiffer. Taf. 22, Fig. $1-3$.
}

\author{
Helicin a candida Pleiffer Mal. BI. $V$ p. 145. T. 2, F. 13-26, 1858. \\ $" \quad$ " Mon. Pneum. III. p. 219, 1865.
}

Gehäuse kegelförmig mit flacher Basis, festschalig, weiss, kaum glänzend. Die Skulptur besteht nebst verhältnismässig kräftigen, ungleichmåssigen Zuwachsstreifen aus schwachen bis undeutlichen, eingedrückten Spirallinien. Das kegelförnige oder etwas abgerundete Gewinde besteht aus $4 \frac{1}{2}$ leicht gewölbten, durch eingedrückte Naht geschiedenen Umgängen; der letzte ist an der Peripherie stumpfkantig bis gerundet uud steigt vorn deutlich herab. Die abgerundet dreieckige Mündung ist sehr schief und dunkelorange gefärbt. Der gerade, stumpfe Mundsaum dunkelorange und häufig verdoppelt; die kurze dicke Spindel nach aussen gebogen. Der feingekörnelte, gelbliche Basalkallus ziemlich dünn, im Umkreise der Spindel leistenförmig absteheud.

Deckel wie bei der vorigen Art.

$$
D=4 \cdot 7, d=4, H=4 \mathrm{~mm} .
$$

Fundort: die Turks Insel der Bahanna-Gruppe. 


\section{Subgenus Ustronia $n$.}

Gehäuse breit bis spitz kegelförmig mit 5-9 langsam zunehmenden Umgăngen. Die zarte Skulptur besteht zuneist nur aus feinen radialen Zuwacbsstreifen, selten sind undeutliche Spiralreifen vorhanden. Der dünne, scharfe Mundsaum ist erweitert, der Oberrand vorgezogen und gerade, der Aussenrand ausgebreitet und umgeschlagen, der Basalrand gegen die Insertion zil rasch verschmälert, am Uebergange in die abgerundete Spindel eine seichte Ausbuchtung. Der gläuzende. oft lebhaft gefärbte Basalkallus nur im Umkreise der. Spindel stärker verdickt, wenig ausgebreitet. Deckel annähernd trapezoidisch mit winkelig gebogenen, konrexem Spindelrand. Die Sigmakante deutlich erhoben, jedoch nur am Nukleus winkelig gebrochen, sonst nahezu gestreckt; sonst die Merkmale des Genus.

Das Verbreitungsgebiet der Gruppe ist auf die Insel Cuba "beschränkt, wo dieselbe in zahlreichen Formen auftritt.

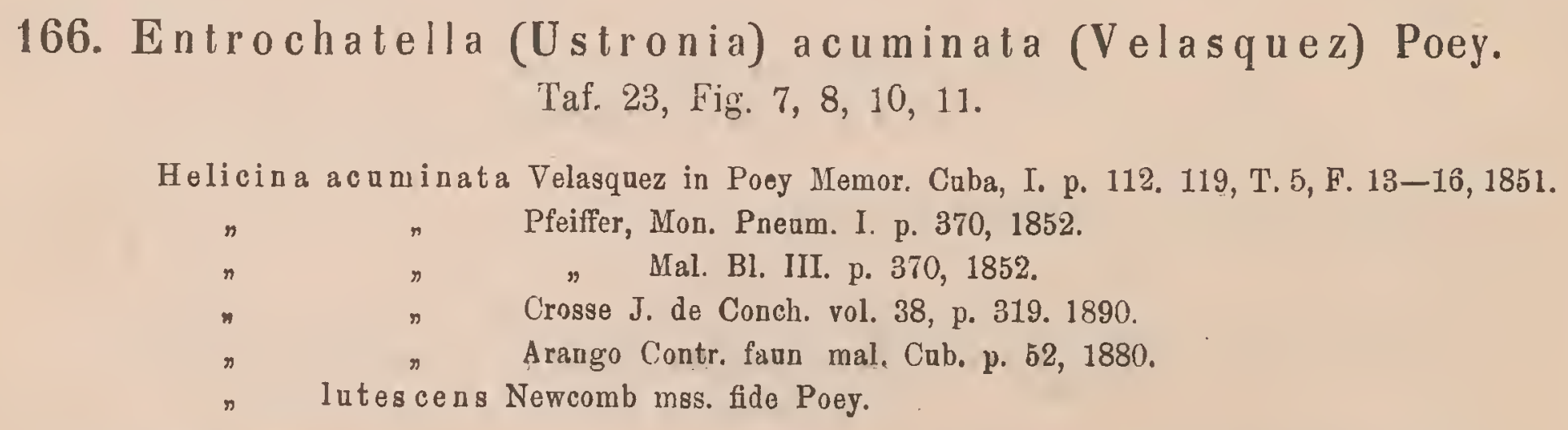

Gehäuse spitzkegelförmig mit halbkugeliger Basis, festschalig, gelbweiss bis hellgelb und rötlich, leicht glänzend. Die Skulptur besteht aus feinen, ungleichmässigen Zuwachsstreifen, daneben sind auf den oberen Umgängen unter der Lupe feine bis undeutliche Spirallinien sichtbar. Das spitzkegelförmige Gewinde besteht aus 7 leicht gewölbten, durch eingedrückte Naht geschiedenen Umgängen; die oberen Umgänge sind über der Naht etwas kantig, der letzte gerundet, vorne langsam, aber deutlich herabsteigend. Die halbkreisförmige Mündung ist sehr schief, innen zitrongelb, der gelbliche, dünne Mundsaum kurz ausgebreitet. Der Basalrand bildet mit der leicht abgeflachten, rotbraun gefärbten Spindel einen rechten Winkel; der seichte Ausschnitt am Uebergange ist deutlich. Der dünne, hellgelbe Basalkallus ist undeutlich begrenzt.

$$
\mathrm{D}=17, \mathrm{~d}=14, \mathrm{H}=18 \mathrm{~mm} \text {. }
$$

Deckel mit glänzender weisser Kalkplatte und gelbbrauner Hornplatte, sonst typisch. Fundort: San-Diego bei Rangel in Cuba. 


\section{Eutrochatella (Ustronia) acuminata columellaris Gundlach.} Taf. 23, Fig. 9.

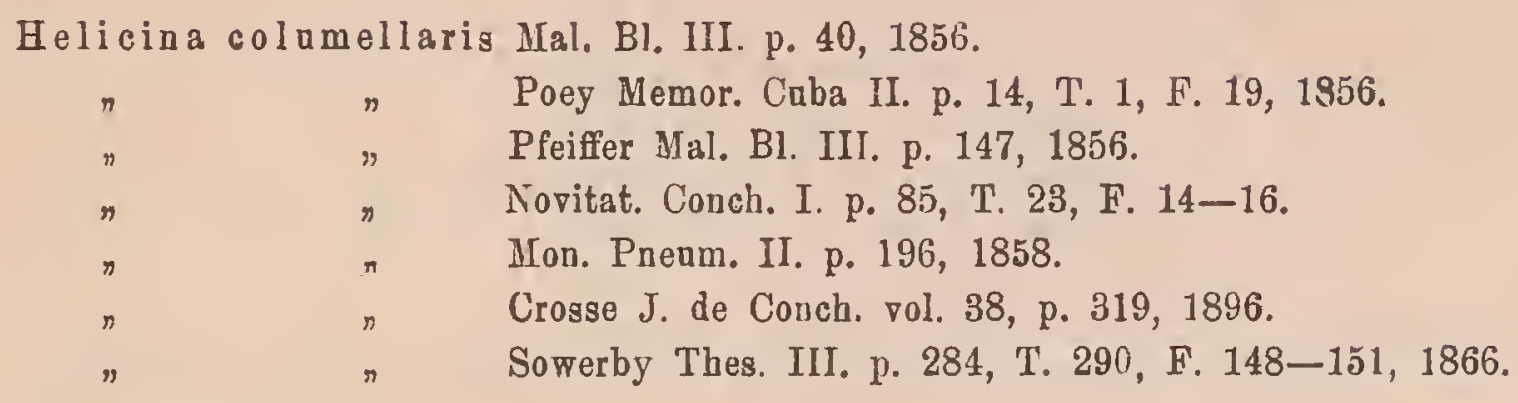

Die Umgänge flach, über der tieferen Nabt kantig, der letzte stumpfkantig; die Spirallinien deutlicher, auch auf dem letzten, unten abgeflachten, Umgänge vorhanden. Die Mündung abgerundet dreieckig.

$$
\mathrm{D}=14, \mathrm{~d}=12, \mathrm{H}=14 \mathrm{~mm} \text {. }
$$

Deckel wie bei der typischen Form.

Fundort: Rangel auf Cuba.

\section{Eutrochatella (Ustronia) acuminata blandiana Gundlach.} Taf. 23, Fig. 12.

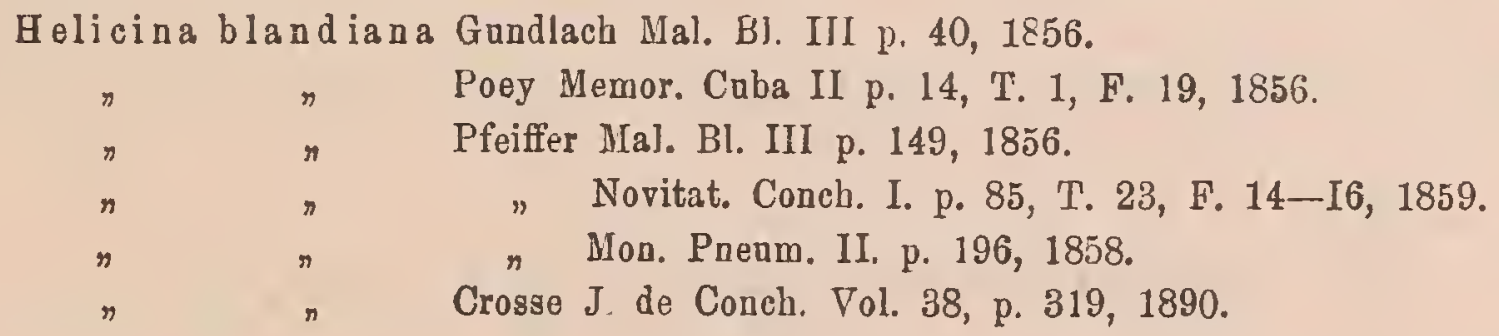

Gehäuse kleiner mit niedrigerem Gewinde, und rascher zunehmenden Umgăngen; die oberen Umgänge über der Naht gelzielt, der letzte etwas zusammengedrückt, an der Peripherie undeutlich stumpfkantig. Die Spirallinien deutlich und auch am letzten Umgange vorhanden, die Mündung und die Spindel zitrongelb bis orange gefürbt, die Basis flacher.

$$
D=12, d=10, H=10.5 \mathrm{~mm} \text {. }
$$

Deckel am Spindelrande zitrongelb bis orange, sonst wie bei der typischen Form.

Fundort: San Diego de los Banos bəi Rangel auf Cuba. 
169. Eutrochatella (Ustronia) sloanei d'Orbigny.

Taf. 23, Fig. 16.

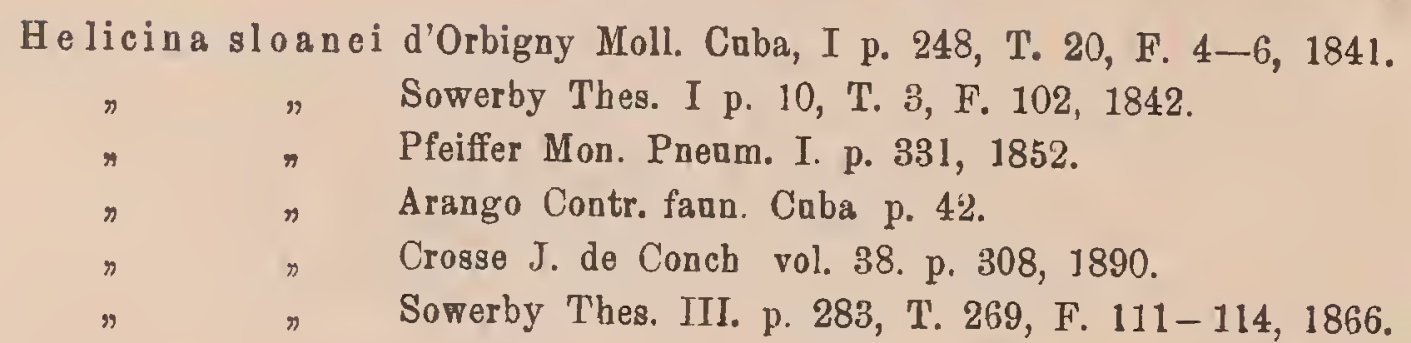

Gehäuse breitkegelförmig mit abgeflachter Basis bis kreiselförmig, ziemlich dünnschalig, hellgelb bis zitrongelb mit lichterem letzten Umgang, matt. Das kegelförmige, unter der Spitze mitunter konkave Gewinde besteht aus $61_{2}$ leicht gewölbten bis flachen Umgängen, welche durch eine ziemlich tiefe Naht geschieden werden. Die oberen Umgänge sind gekielt, der letzte etwas zusanmengedrücist, an der Peripherie stumpfkantig bis stumpfyekielt, vorne langsam, aber deutlich herabsteigend. Die Skulptur besteht nebst deutlichen, ungleichmässigen Zuwachsstreifen aus feinen, dichten etwas ungleichmässigen Spiralleistchen, welche am letzten Umgange schwăcher werden, oft nahezu erlöschen. Die abgerundet dreieckige Mündung ist schief, innen hellgelb, der Mundsaum dünn und scharf, kurz ausgebreitet; der Ausschnitt des Basalrandes am Uebergange in die etwas abgeflachte und zurückweichende Spindel ist seicht; der dünne glänzende Basalkallus mit dem Gehäuse gleichfärbig.

$$
\mathrm{D}=12, \mathrm{~d}=9.5, \mathrm{H}=9.5 \mathrm{~mm} \text {. }
$$
typisch.

Deckel mit auffallend glänzender, gelbbrauner und durchscheinender Kalkplatte, sonst

Fundort: Cerro del Cuzco, meine Exemplare von Havana und Matanzas auf Cuba.

\section{Eutrochatella (Ustronia) remota Poey.}

Taf. 23, Fig. 13-15.

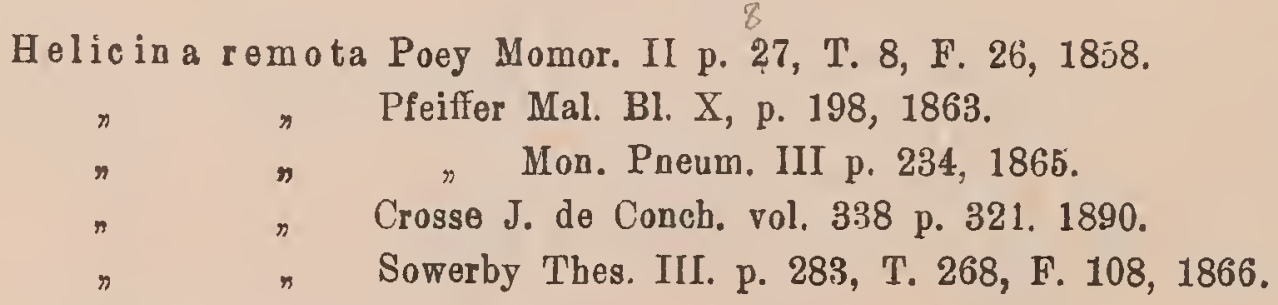

Gehäuse breit kegelförmig mit flachgewölbter Basis, hellfleischfarben, festschalig, matt, Die Skulptur besteht nebst deutlichen, etwas ungleichmässigen Zuwachsstreifen aus dichten, feinen und leicht wellenförmig gebogenen Spiralreifchen, welche auf der Unterseite des letzten Umganges dichter und schwächer werden. Das kegelförmige, etwas konvexe Gewinde besteht 
aus $61 / 2$ wenig gewölbten bis nahezu flachen Umgängen, welche durch eine eingedrückte Naht geschieden werden; der letzte ist unter der Peripherie stumpf gekielt und steigt vorne langsam und wenig herab. Die abgerundet dreieckige Mündung ist schief innen braurorange gefärbt, der weisse, dünne Mundsaum kurz ausgebreitet. Die Ausbuchtung am Uebergange des Basalrandes in die etwas abgeflachte Spindel ist deutlich, der dünne glänzende Basalkallus gelblichweiss.

$$
\mathrm{D}=17, \mathrm{~d}=15, \mathrm{H}=15 \mathrm{~mm} \text {. }
$$

Deckel mit milchweisser, glänzender Kalkplatte, sonst typisch.

Fundort: Guane und Vignales auf Cuba.

\section{Eutrochatella (Ustronia) wrighti Pfeiffer.}

Taf. 24, Fig. 6, 7.

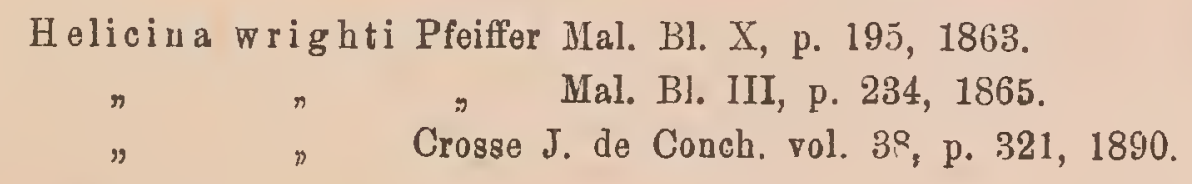

Gehäuse spitzkegelförmig mit flacher Basis, ziemlich festschalig, glänzend; die oberen Umgänge zitrongelb, der letzte rötlichweiss bis hell fleischfarben. Die Skulptur besteht nebst feinen Zuwachsstreifen aus sehr feinen und dichten, erhobenen Spirallinien, welche auf dem letzten Umgange nahezı erlöschen. Das zugespitzte Gewinde besteht aus $71 / 2$ Hachen, durch seichte Naht geschiedenen Uingängen; die oberen sind über der Naht kantig; der letzte unter der Peripherie kantig, vorne wenig oder gar nicht herabsteigend. Die abgerundet dreieckige, schiefe Mündung ist innen rotorange, der dünne, gelbliche Mundsaum kurz ausgebreitet. Der seichte Ausschnitt am Uebergange des Basalrandes in die abgerundete, orangerote Spindel ist deutlich; der dünne, orangerote Basalkallus glänzend.

$$
\mathrm{D}=10, \mathrm{~d}=9, \mathrm{H}=10.5 \mathrm{~mm} \text {. }
$$

Deckel dreieckig mit glänzender milchweisser Kalkplatte, sonst typisch.

Fundorte: Gebirge bei San Diego de los Banos und Vignales auf Cuba.

\section{Eutrochatella (Ustronia) wrighti xanthacmen. Taf. 25, Fig. 10, 11.}

Gehäuse kleiner mit leicht konvexem Gewinde und nur 6 deutlich gewölbten Umgängen; die oberen Umgänge über der Naht nicht kantig, der letzte unter der Peripherie stumpfkantig bis gerundet, unten mehr gewölbt, vorne deutlicher herabsteigend. Die Mün_ dung innen zitrongelb, der leicht verdickte Mundsaum, die Spindel und der dickere Basalkallus lebhaft braunorange gefärbt. Die Spirallinien schwächer entwickelt, die oberen Umgänge gelbbraun, die Spitze lebhaft rotbraun gefärbt. 
Deckel wie bei der typischen Form.

$$
D=8, d=7, H=8.5 \mathrm{~mm} \text {. }
$$

Fundort: Guajaibon in Cuba.

\section{Eutrochatella (Ustronia) scopulorum Morelet.}

Taf. 24, Fig. 16-18, Fig. 22-23.

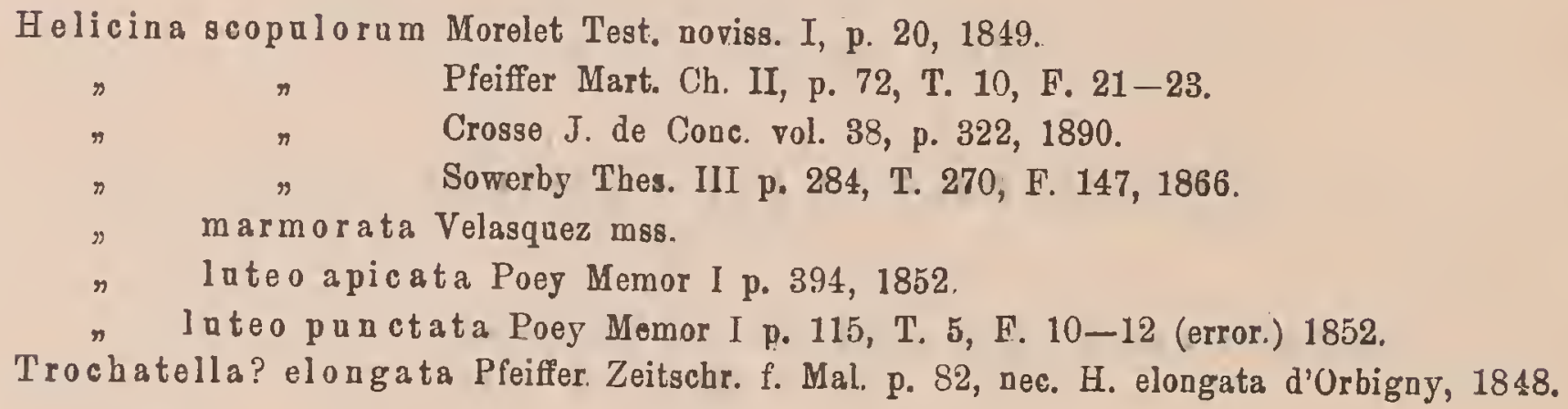

Gehăuse spitzkegelförmig mit flach gewölbter Basis, gelbweiss oder blassrot mit gelber oder gelbbrauner Spitze, leicht glänzend. Die Skulptur besteht nebst feinen Zuwachsstreifen aus ziemlich dichten erhobenen Spirallinien, welche am letzten Umgange schwächer werden, und nahezu verschwinden. Das an den Seiten leicht konvexe Gewinde besteht aus $7 \frac{1}{2}$ kaum. gewölbten durch leicht eingedrückte Naht geschiedenen Umgängen; die oberen sind gekielt, der letzte unter der Peripherie stumpf gekielt bis stumpfkantig und steigt vorne langsam und, wenig herab. Die abgerundet dreieckige Mündung ist sehr schief, innen hellgelb, der weisse Mundsaum leicht verdickt, kurz ausgebreitet; der Basalrand umgeschlagen, der Ausschnitt am Uebergange desselben in die weisse, abgerundete Spindel undeutlich. Der dünne, weisse Basalkallus im Umkreise der Spindel leistenartig ;abstehend.

$$
\mathrm{D}=6.5, \mathrm{~d}=5, \mathrm{H}=8 \mathrm{~mm} \text {. }
$$

Deckel dreieckig mit glänzender gelber Kalkplatte, sonst typisch.

Fundorte: die Fichteninsel bei Cuba.

Eutrochatella luteo apicata Poey ist dem Vergleiche von Originalexemplaren zur Folge auf unausgewachsene Exemplare der vorstehenden Art gegründet.

\section{Eutrochatella (Ustronia) pyramidalis Sowerby. Taf. 23, Fig. 17.}

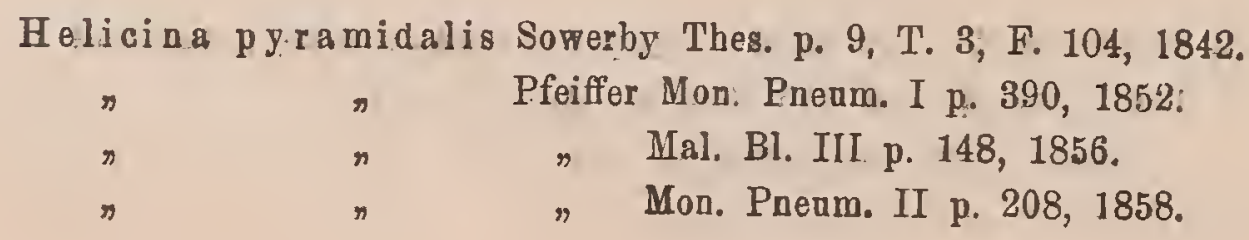


Helicina pyramidal is Crosse J. de Conch. vol. 38, p. 322, 1890.
"
" conica d'Orbigny Moll. Cabs I nec Pfeiffer, teste Crosse, 1841.

Gehäuse kegelförmig mit leicht gewölbter Basis, ziemlich dünnschalig, leicht glănzend, hellgelb mit gelber Spitze. Die Skulptur besteht nebst feinen, ungleichmässigen Zuwachsstreifen aus dichten, erhobenen Spiralstreifen, welche am letzten Umgange schwächer werden und nahezu erlöschen. Das etwas konkave Gewinde besteht aus $6^{1} / 2$ nahezu flachen Umgängen, welche durch eingedrückte Naht geschieden werden; die oberen sind über der Naht kantig, der letzte etwas zusammengedrückt, an der Peripherie stumpf gekielt und steigt vorne nicht herab. Die trapezoidische Mündung ist schief, innen gelblich gefärbt, der dünne, weisse Mundsaum kurz ausgebreitet. Der Basalrand etwas konvex, am Uebergange in die weisse, abgerundete Spindel, verschmälert und nicht ausgebuchtet. Der weisse Basalkallus dünn und glänzend.

$$
\mathrm{D}=8, \mathrm{~d}=7, \mathrm{H}=7 \mathrm{~mm} .
$$

Deckel annähernd trapezoidisch mit weisser, glänzender Kalkplatte, sonst typisch.

Fundort: Rangel auf Cuba.

\section{Eutrochatella (Ustronia) pyramidalis percarinatan.}

Taf. 23, Fig. 25.

Gehäuse kleiner, mit nur 51/2 flachen bis leicht konkaven Umgängen und schärferen, noch am letzten Umgange deutlichen Spirallinien; der letzte Umgang mehr zusammengedrückt und schärfer gekielt.

$$
\mathrm{D}=5.5, \mathrm{~d}=4.5, \mathrm{H}=4.5 \mathrm{~mm} \text {. }
$$

Deckel wie bei der typischen Form.

Fundort: Rangel auf Cuba.

176. Eutrochatella (Ustronia) straminea Morelet.

Taf. 23, Fig. 18-21.

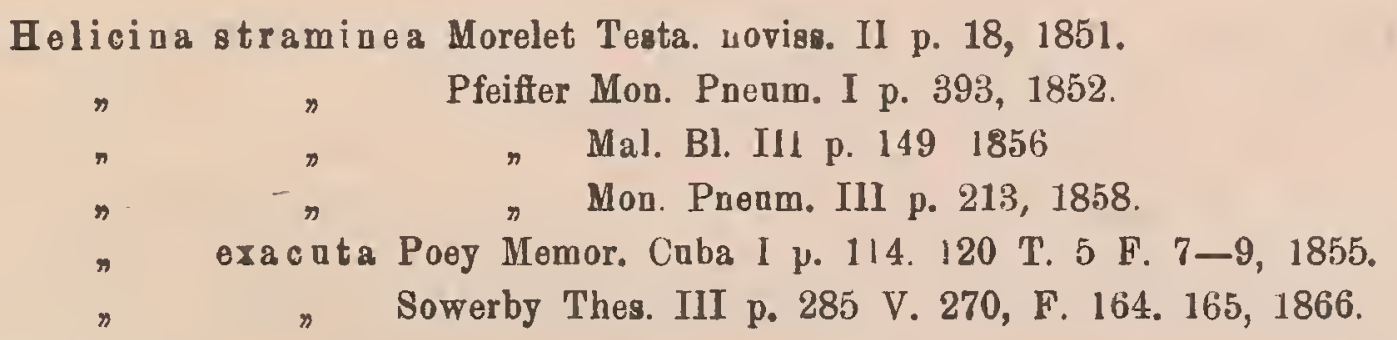

Gehäuse kegelförmig mit flachgewölbter Basis, ziemlich festschalig, leicht glänzend, I. 18. II. 
gelblichweiss mit gelber Spitze und einer gelben Zone unterhalb des Kieles, welche mitunter eine schärfer begrenzte Binde darstellt. Die Skulptur besteht nebst feinen, ungleichmässigen Zuwachsstreifen aus ziemlich dichten, erhobenen Spirallinien auf den oberen Umgăngen, welche auf dem letzten Umgange nahezu erlöschen. Das regelmässig kegelförmige Gewinde besteht aus $61 / 2$ nahezu flachen Umgängen; die oberen sind über der Naht gekielt, der letzte an der Peripherie scharf und zusammengedrückt gekielt und steigt vorne langsam und wenig unter den Kiel herab. Die sehr schiefe, dreieckige Mündung ist innen gelblich, der dünne oder nur leicht verdickte Mundsaum gelblichweiss, kurz ausgebreitet. Der seichte Ausschnitt am Uebergange des Basalrandes in die gelbliche, abgeflachte Spindel ist deutlich, der dünne, gelbliche Basalkallus glänzend.

Deckel dreieckigr mit glănzender, gelblicher Kalkplatte, sonst typisch.

Fundort: Rancho Lucas auf Cuba.

\section{Eutrochatella (Ustronia) straminea rubromarginata (Gundlach) Poey.}

Taf. 23, Fig. 22-23.

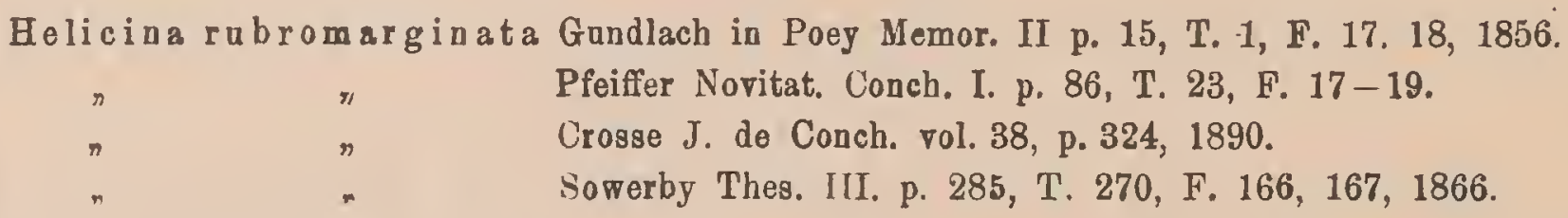

Gehäuse mit leicht konvexem Gewinde, schwächeren Spirallinien und stumpferem Kiel; die Oberseite des letzten Umganges mitunter schief gehämmert; unter dem weissen Kiele häufig eine rot oder braunorange gefärbte Zone, der leicht verdickte Mundsaum und der Basalkallus lebhaft rotorange.

$$
\mathrm{D}=8, \mathrm{~d}=7, \mathrm{H}=7.5 \mathrm{~mm} \text {. }
$$

Deckel mit milchweisser Kalkplatte, sonst wie bei der typischen Form.

Fundort: Guajaibon auf Cuba.

\section{Eutrochatella (Ustronia) festa Sowerby.}

Taf. 24, Fig. 5.

Helicina festa Gundlach ap. Sowerby Thes. III p. 284, T. 270, F. 148-151, 1866.

Das leicht konvexe Gewinde mit deutlicher gewölbten Umgängen, die Spirallinien auch auf den oberen Umgängen nahezu erloschen. Die oberen Umgänge über der Naht leicht kantig, der letzte unter der Peripherie stumpfkantig. Die Farbung ist gelblichweiss mit 
gelber Spitze, ohne dunkle Zone auf der Unterseite, dafür ist der leicht verdickte Mundsaum und der Basalkallus lebhaft rotorange gefärbt. Die Mündung halbeitörmig innen zitrongelb gefärbt.

$$
\mathrm{D}=8, \mathrm{~d}=7, \mathrm{H}=8.5 \mathrm{~mm} .
$$

Deckel annähernd trapezoidisch mit milchweisser Kalkplatte.

Fundort: Guajaibon auf Cuba.

\title{
179. Eutrochatella (Ustronia) straminea nodae Arango.
}

\author{
Taf. 24, Fig. 1-4.
}

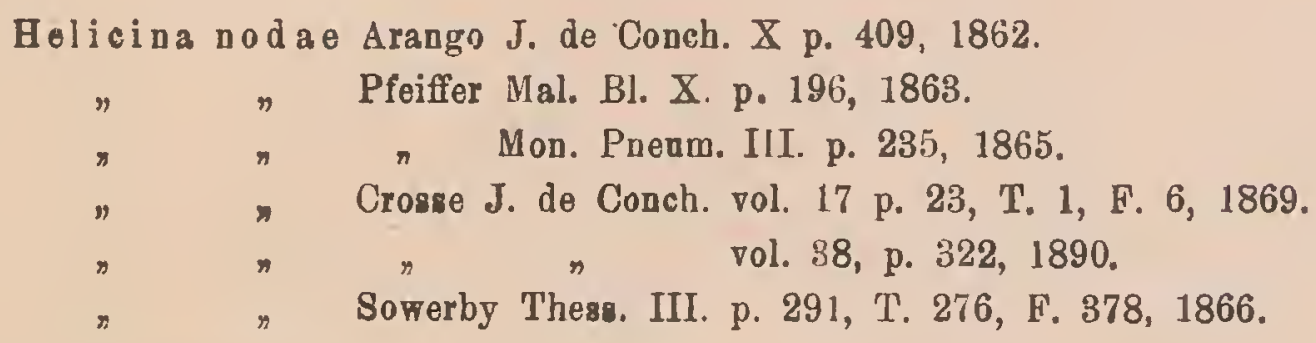

Gehäuse mit höherem, leicht konvexem Gewinde, gelblichweiss mit gelber Spitze. Die oberen Umgänge über der Naht leicht kantig, der letzte weniger zusammengedrückt, unten mehr gewölbt, unter der Peripherie stumpfkantig. Die Spirallinien schwächer, am letzten Umgange nahezu erloschen. Die abgerundet dreieckige Mündung innen zitrongelb, der Basalkallus orange gefärbt.

$$
\mathrm{D}=7 \cdot 5, \mathrm{~d}=6.5, \mathrm{H}=4.5 \mathrm{~mm} \text {. }
$$

Deckel dreieckig mit milchweisser, glänzender Kalkplatte.

Fundort: Sierra de Guira auf Cuba (legit Gundlach).

\section{Eutrochatella (Ustronia) straminea politula Poey.}

\author{
- Taf. 23, Fig. 24
}

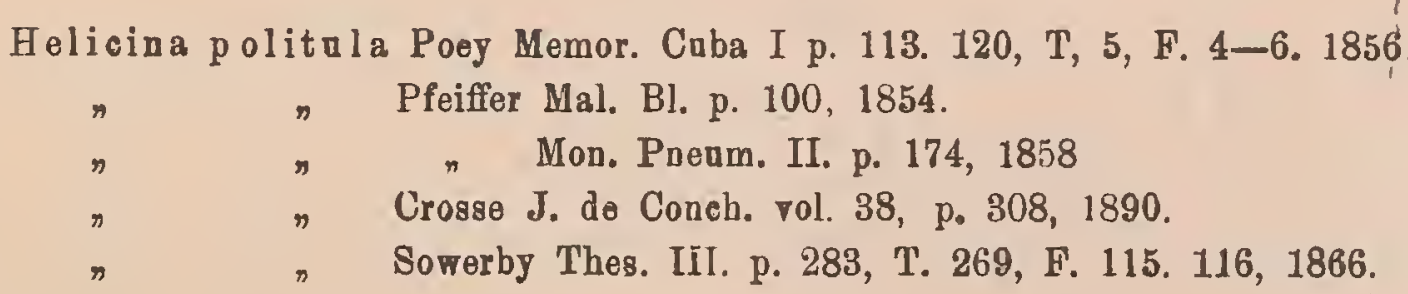

Gehäuse hell grünlichgelb mit dichteren und schärferen Spirallinien, welche auch am letzten Umgange deutlich sind. Die oberen Umgänge über der Naht kantig, der letzte weniger zusammengedrückt, unter der Peripherie stumpfkantig, vorne langsam und deutlich herabsteigend. Die abgerundet dreieckige Mündung innen grüngelb, der Mundsaum schmäler. 


$$
\mathrm{D}=6.5, \mathrm{~d}=5.5, \mathrm{H}=6.5 \mathrm{~mm} \text {. }
$$

Deckel mit gelblicher, feingekörnelter Kalkplatte.

Fundort: Rangel auf Cuba.

\title{
181. Eutrochatella (Ustronia) cisnerosi Arango.
}

Taf. 24, Fig. 19-21.

\author{
Helicina cisnerosi Arango Contr. faun. Caba p. 134, 1878. \\ » Crosse J. de Conch. vol. 38, p. 313, T. 6, F. 7, 1890
}

Gehăuse kegelförmig mit gewölbter Basis, ziemlich festschalig, leicht glänzend, gelbweiss mit unregelmăssigen rotbraunen Flecken über und uuter der Peripherie. Die Skulptur besteht nebst sehr feinen Zuwachsstreifen aus dichten, feinen, erhobenen Spirallinien, welche auf der Unterseite schwächer werden. Das spitzkegelförmige Gewinde besteht aus $5^{1 / 2}$ leicht gewölbten Umgăngen; der letzte im Beginne an der Peripherie gekielt gegen die Mündung zu kantig, vorne sehr wenig herabsteigend. Die abger undet dreieckige Münduug ist schief, innen gelbbraun, der dünne, weisse Mundsaum kurz ausgebreitet; der weisse, dünne Basalkallus undeutlich begrenzt.

$$
\mathrm{D}=3 \cdot 5, \mathrm{~d}=2 \cdot 5, \mathrm{H}=4 \cdot 2 \mathrm{~mm} \text {. }
$$

Deckel abgerundet dreieckig mit weisser, gekörnelter Kalkplatte, sonst typisch.

Fundort: Pinar del Rio auf Cuba.

\section{Eutrochatella (Ustronia) fuscula (Gundlach) Pfeiffer. Taf. 24, Fig. 14. 15}

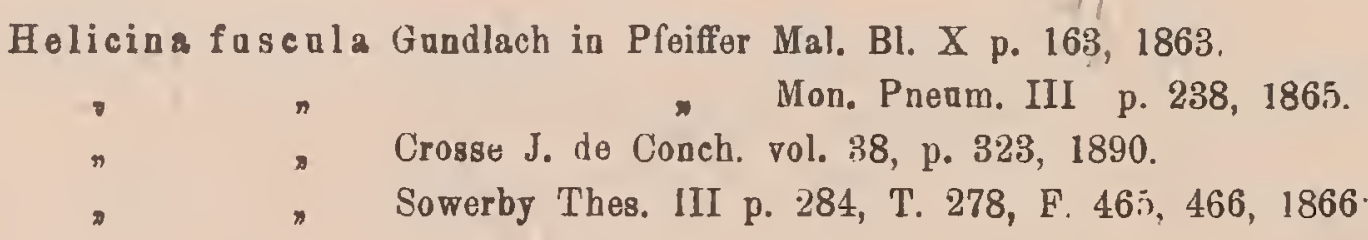

Gehăuse spitzkegelförmig mit gewölbter Basis, ziemlich dünnschalig, rotbraun mit dunkleren Striemen und einer weissen Zone um die Mündung oder gelbgrau mit gelber Spitze und einer braunen Binde über der Naht, sowie brauner Basis. Die Skulptur besteht zumeist nur aus feinen Zuwachsstreifen, mitunter sind unter der Lupe auch sehr schwache Spirallinien sichtbar. Das regelmässig kegelförmige Gewinde besteht aus $51 / 2-6$ gewölbten Umgängen, der letzte ist an der Peripherie kantig und steigt vorne nicht herab. Die abgerundet dreIeckige Mündung ist wenig schief, innen rotbraun, der weisse Mundsaum dünn ull kurz ausgebreitet. Der Basalrand ist konvex vorgezogen, am Uebergange desselben in die abgerundete 
Spindel ein seichter undeutlicher Ausschnitt. Der dünne, glanzende Basalkallus undeutlich begrenzt.

$$
\mathrm{D}=4, \mathrm{~d}=3 \cdot 4, \mathrm{H}=4.6 \mathrm{~mm} \text {. }
$$

Deckel dreieckig mit rotbrauner Kalkplatte, sonst typisch.

Fundort: Guajaibon und Guira de Luis Lazo auf Cuba.

183. Eutrochatella (Ustronia) alboviridis (Wright) Pfeiffer. Taf. 24, Fig. 12, 13.

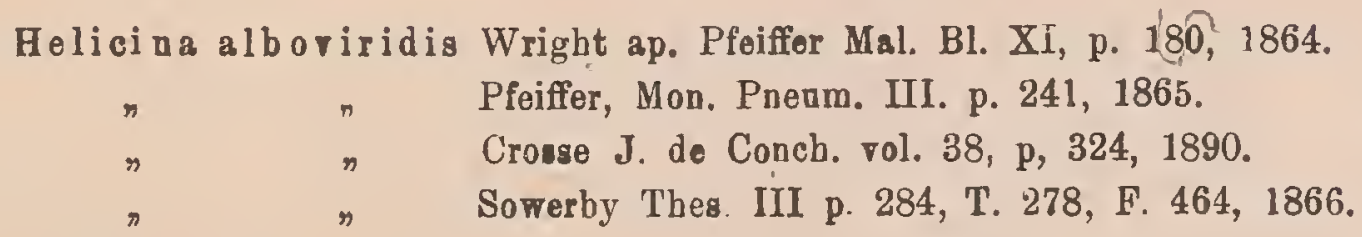

Gehăuse spitz kegelförmig mit gewölbter Basis, ziemlich festschalig, sehr fein radial gestreift, glānzend, grünlichgelb mit dunkler gefärbter Spitze, weissem Kiele und weisser Zone um die Mündung sowie 2 grüngelben Binden an der Basis. Das regelmässig kegelförmige Gewinde besteht aus 6 leicht gewölbten Umgăngen, der letzte stumpf gekielt, vorne nicht herabsteigend. Die abgerundet dreieckige Mündung ist wenig schief, innen grüngelb, der weisse dünne Mundsaum kurz ausgebreitet; der Basalrand umgeschlagen und konvex vorgezogen, am Uebergange desselben in die abgerundete Spindel ein seichter Ausschnitt. Der dünne, glänzende Basalkallus, durchsichtig und undeutlich begrenzt.

$$
\mathrm{D}=3 \cdot 6, \mathrm{~d}=3 \cdot 3, \mathrm{H}=4.6 \mathrm{~mm} \text {. }
$$

Deckel abgerundet dreieckig mit glänzender grüngelber Kalkplatte sonst typisch.

Fundort: Isabel Maria auf Cuba.

\section{Eutrochatella (Ustronia) methfesseli Pfeiffer.}

Taf. 24, Fig. 8, 9.

Troehatella methfesseli Pfeiffer Mal. Bl. IX, p. 8, 1802.

$\begin{array}{lll}\pi & n \quad \text { Mon. Pneum. III, p. 212, } 1865 . \\ & \pi & \text { Crosse J. do Conch. vol. 38, p. 308, } 1890 .\end{array}$

Gehäuse breit kegelförmig mit gewölbter Basis, ziemlich dünnschalig, leicht glănzend, grüngelb oder rotorange. Die Skulptur besteht zumeist nur aus verhältnismässig krăftigen sehr schiefen Zuwachsstreifen, unter der Lupe sind mitunter auch einzelne erhobene Spirallinien sichtbar. Das Gewinde besteht aus $4^{1 / 2}$ gewölbten Umgängen, der letzte ist gerundet und steigt vorne nicht herab. Die abgerundet dreieckige Mündung ist schief, der einfache oder leicht verdickte Mundsaum erweitert, kaum ausgebreitet; Oberrand und Basalrand sind 
etwas konvex vorgezogen, am Uebergange des Basalrandes in die kurze abgerundete Spindel ein seichter Ausschnitt; der zarte, glänzende Basalkallus undeutlich begrenzt.

$$
\mathrm{D}=3 \cdot 7, \mathrm{~d}=3 \cdot 2, \mathrm{H}=3.5 \mathrm{~mm} \text {. }
$$

Deckel abgerundet dreieckig mit gelbbrauner, ziemlich dünner Kalkplatte, sonst typisch. Fundort: Sagua auf Cuba.

\section{Eutrochatella (Ustronia) rubella (Wright) Pfeiffer. \\ Taf. 24, Fig. 24, 25.}

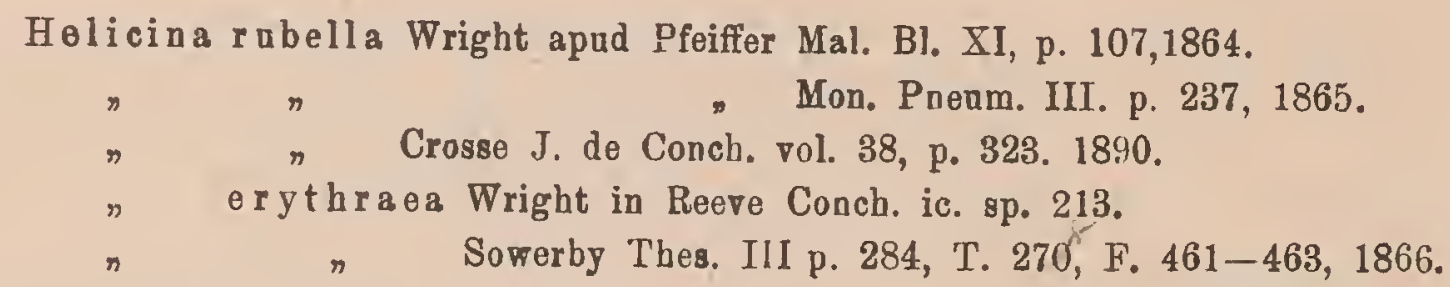

Gehăuse spitzkegelförmig mit gewölbter Basis, ziemlich dünnschalig, rotbraun oder gelbbraun; der letzte Umgang oft mit milchiger Trübung, welche einen violetten Anflug hervorruft; glänzend mit feinen ungleichmässigen Zuwachsstreifen. Das Gewinde besteht aus 7 kaum gewölbten Umgängen; der letzte ist unter der Peripherie undeutlich stumpfkantig bis gerundet und steigt vorne wenig oder gar nicht herab. Die abgerundet dreieckige Mündung schief, der dünne, gelbliche oder rotbraune Mundsaum kurz ausgebreitet; 'der Ausschnitt am Uebergange des Basalrandes in die kurze, abgerundete Spindel undeutlich. Der glänzende, dünne Basalkallus mit dem Gehäuse gleichfarbig, im Umkreise der Spindel oft stärker verdickt und wulstartig abstehend.

$$
\mathrm{D}=5 \cdot 5, \mathrm{~d}=5, \mathrm{H}=6 \mathrm{~mm} \text {. }
$$

Deckel abgerundet dreieckig mit glänzender, gelbbrauner Kalkplatte. sonst typisch.

Fundorte: Cayos de San Felipe und Cayos de San Diego auf Cuba.

\section{Eutrochatella (Ustronia) rubella citrino callossa n. Taf. 24, Fig. 26, 27.}

Gehäuse mit höherem, mehr zugespitzten Gewinde und $7 \frac{1}{2}$ flacheren, langsamer zunehmenden Umgăngen, der letzle deutlicher kantig bis stumpf gekielt. Die Grundfarbe hellgelb mit zitrongelber Spitze, ebensolchem Mundsaum und Basalkallus; der letzte Umgang mit einer fleischfarbenen Zone auf der Ober.eite. Der Mundsaum innen leicht verdickt, mehr ausgebreitet und umgeschlagen, der Basalkallus dicker.

$$
\mathrm{D}=6, \mathrm{~d}=55, \mathrm{H}=7.5 \mathrm{~mm} \text {. }
$$

Deckel mit glänzender rotbrauner Kalkplatte, sonst typisch. 
Fundort: Vignales auf Cuba.

Diese Form führt derzeit den Sammlungsnamen Helicina chryrochasma var. calloflava.

\title{
187. Eutrochatella (Ustronia) jugulata Poey.
}

\author{
Taf. 25, Fig. 1. 2.
}

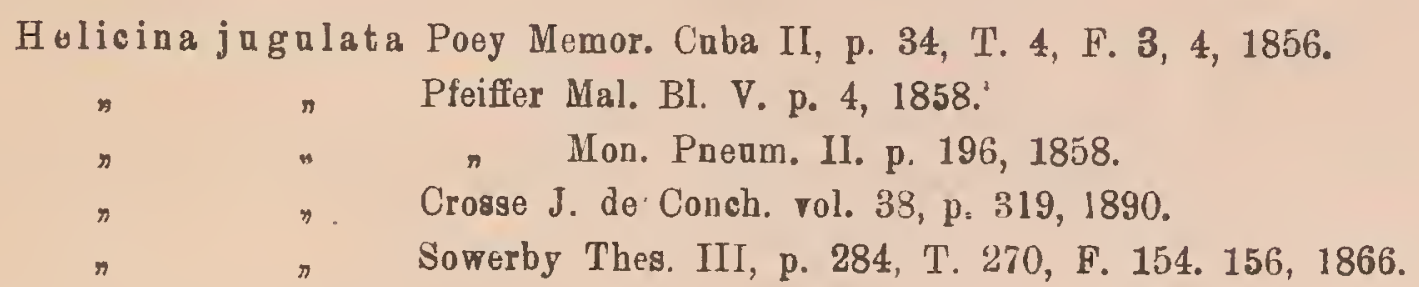

Gehäuse spitzkegelförmig, mit gewölbter Basis, festschalig, glänzend mit feinen ungleichmässigen Zuwachsstreifen; die oberen Umgänge hellrotbraun oder gelbbraun, der letzte gelblichweiss mit weisser Zone entlang der Naht. Das regelmăssig kegelförmige spitze Gewinde besteht aus $7 \frac{1}{2}$ leicht gewölbten Umgängen, der letzte etwas aufgeblasen, stärker gewölbt, im Beginne stumpfkantig, vorne nicht herabsteigend. Die halbeiförmige Mündung ist schief, innen rotbraun, der dünne, weisse, glänzende Mundsaum, ausgebreitet und umgeschlagen; der Basalrand am Uebergange in die kurze, abgerundete Spindel sehr verschmälert und etwas ausgeschnitten. Der glänzende, ziemlich dünne Basalkallus lebhaft rotbraun, an der Spindel wulstig abgehoben.

$$
\mathrm{D}=13, \mathrm{~d}=10, \mathrm{H}=14 \mathrm{~mm} \text {. }
$$

Deckel abgerundet dreieckig mit glänzender, lebhaft rotbrauner Kalkplatte, sonst typisch. Fundort: Guane auf Cuba.

\section{Eutrochatella (Ustronia) chrysochasma Poey.}

Taf. 25, Fig. 8, 9.

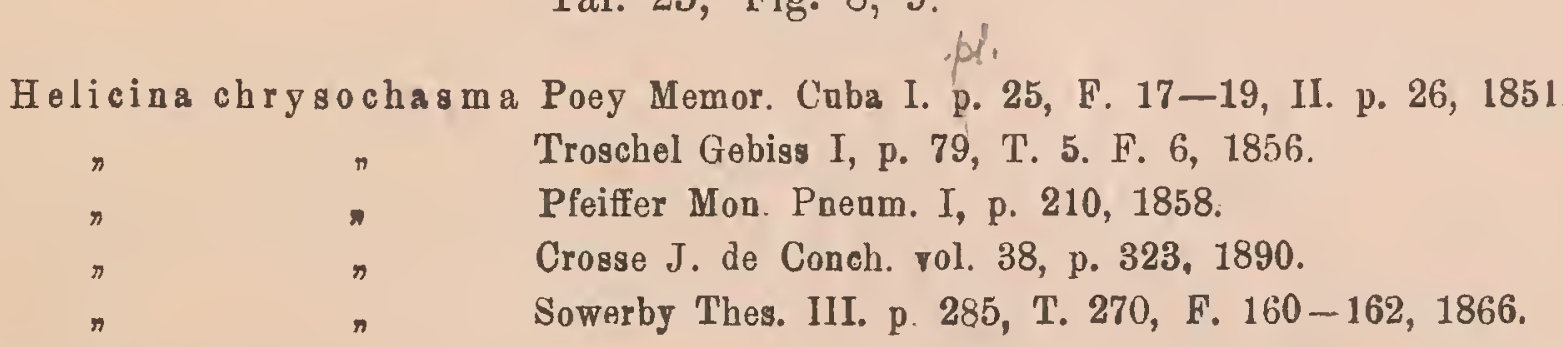

Gehäuse langkegelförmig mit flachgewölbter Basis, bläulich oder rötlich weiss, hăufig mit gelber oder rotbrauner Spitze; glänzend mit sehr feinen, ungleichmässigen Zuwachsstreifen. Das spitzkegelförmige, wenig konvexe Gewinde besteht aus $71_{2}-8^{1} / 2$ fast flachen, durch seichte Naht geschiedenen Umgängen; der letzte ist unter der Peripherie mehr, minder deutlich kantig und steigt vorne langsam und wenig herab. Die sehr schiefe, abgerundet drei- 
eckige Mündung ist innen zitrongelb oder rotorange. Der dünne Mundsaum orangegelb; der Oberrand fast gerade, an der Insertion vorgezogen, der Aussenrand ausgebreitet und umgeschlagen, der Basalrand gegen die Insertion zu rasch verschmälert, am Uebergange in die kurze abgerundete Spindel ein seichter Ausschnitt. Der ziemlich dicke und glänzende, unten wulstig verdickte Basalkallus rotorange gefärbt.

$$
\mathrm{D}=55, \mathrm{~d}=5, \mathrm{H}=7.5 \mathrm{~mm} \text {. }
$$

Deckel trapezoidisch mit S-förmig gebogenem Spindelrand und 'glänzender, gelbbrauner Kalkplatte; sonst typisch.

Fundort: Fluss Taco-Taco und Vignales auf Cuba.

Diese Art ist sehr veränderlich und tritt an anderen Orten der Insel in abweichenden Formen auf.

\section{Eutrochatella (Ustronia) chrysochasma jucunda (Gundlach) P feiffer.}

Taf. 25, Fig. 5-7.

Helicina jucunda Gundlach ap. Pfeiffer Mal. Bl. X, p. 197, 1863.

Gehäuse grösser mit breiterem, deutlicher konvexem Gewinde und mehr gewölbter Basis. Neben den kräftigeren Zuwachsstreifen sind mitunter undeutliche Spirallinien vorhanden, auch erscheint die Oberfläche des letzten Umganges bei einzelnen Exemplaren etwas gehämmert. Die Färbung ist zumeist lebhafter, fleischfarben oder schmutziggelb mit gelber oder lebhaft rotbrauner Spitze. Der letzte Umgang ist undeutlich stumpfkantig bis gerundet und steigt vorne mehr herab; die halbeiförmige Mündung lebhafter gelb bis rotorange gefarbt; der Mundsaum breiter.

$$
\begin{aligned}
& D=7 \cdot 5, d=6 \cdot 5, H=11 \mathrm{~mm} \text { von Guajaibon. } \\
& D=7, d=6, H=9.5 \mathrm{~mm} \text { von Vignales. }
\end{aligned}
$$

Deckel wie bei der typischen Form.

Fundorte: Guajaibon, Rangel, Vignales auf Cuba.

\section{Eutrochatella (Ustronia) chrysochasma hernandezi Wright. Taf. 25, Fig. 3, 4. \\ Helicina hernandezi Wright.}

Gewinde regelmässig spitzkegelförmig mit flacher Basis und 8 flachen Umgången; der letzte stumpfgekielt, vorne nicht herabsteigend. Die abgerundet dreieckige Mündung innen hellgelb, der schmale Mundsaum, ebenso der Basalkallus gelblich oder weiss. Das Gehäuse: weiss mit gelblicher Spitze.

$$
\mathrm{D}=4 \cdot 5, \mathrm{~d}=4 \cdot 2, \mathrm{H}=6.5 \mathrm{~mm} .
$$


Deckel mit hellgelber Kalkplatte, sonst wie bei der typischen Form.

Fundort: Vignales auf Cuba.

\title{
191. Eutrochatella (Ustronia) mestrei Arango.
}

Taf. 25, Fig. 10, 11.

Helicina mestrei Arango Contr. Faun. Cub. p. 138, 1878.

\author{
,$\quad$ Crosse J. de Conch. vol. 38, p. 313, T. 6, F. 6, 1890.
}

Gehäuse spitzkegelförmig mit flach gewölbter Basis, ziemlich dünnschalig, schmutzig gelb oder graugelb, glänzend mit feinen Zuwachsstreifen. Das regelmässig kegelförmige Gewinde besteht aus 7 flachen Ungängen, der letzte stumpfgekielt, vorne nicht herabsteigend. Die schiefe, abgerundet dreieckige Mündung ist innen gelb, der gelbliche Mundsaum dünn; der Oberrand an der Insertion vorgezogen, fast gerade, der Aussensaum ausgebreitet und umgeschlagen, der Basalrand gegen die Insertion zu rasch verschmälert: am Uebergange desselben in die kurze, abgerundete Spindel ein seichter, undeutlicher Ausschnitt. Der ziemlich dicke, glänzende Basalkallus gelblich.

$$
\mathrm{D}=5, \mathrm{~d}=4, \mathrm{H}=6 \mathrm{~mm} \text {. }
$$

Deckel trapezoidisch mit S-förmig gebogenem Spindelrand und gelblicher glänzender Kalkplatte, sonst typisch.

Fundort: Pinar del Rio auf Cuba.

Von E. chrysochasma Poey durch das regelmässig kegelförmige Gewinde mit breiterer Basis, den gekielten letzten Ungang, die weniger schiefe Mündung, die dünnere Schale und die Färbung unterschieden.

\section{Subgenus Hapata Gray.}

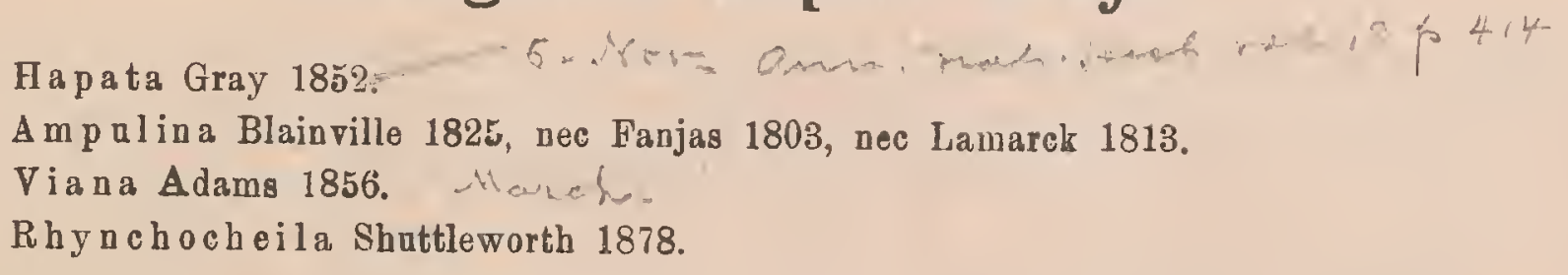

Die Schale des männlichen Tieres mit geradem, scharfen Mundsaum und einem buchtigen Ausschnitt am Uebergange des Oberrandes in den Aussenrand.

Deckel wie bei dem Subgenus Ustronia.

Verbreitung: die Insel Cuba.

I. 18. II.

2. II. 1908. 


\section{Eutrochatella (Hapata) regina Morelet.}

Tat. 25, Fig. 12, 13, 18, 19.

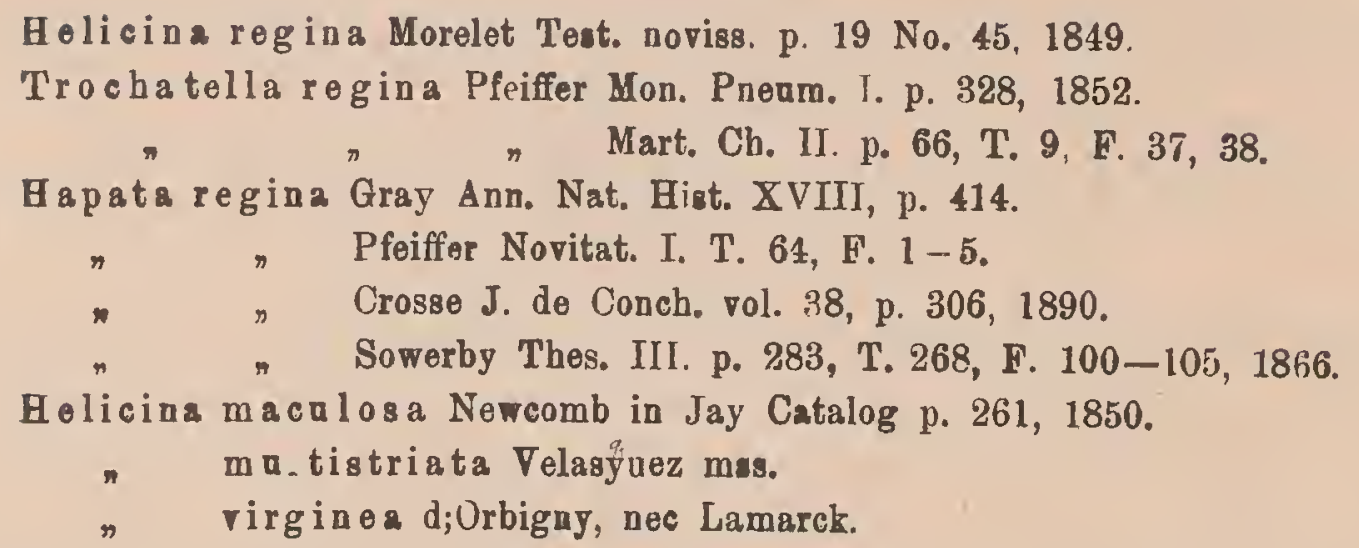

a. Gehäuse des männlichen Tieres: breit kegelförmig mit halbkugeliger Basis, dickschalig, wenig glänzend; gelb oder rotbraun mit weissen fleckenbändern, welche gegen die Mündung zu die Grundfarbe oft verdecken; hăufig mit rotbrauner, mehr minder intensiver Nahtbinde. Die Skulptur besteht nebst ungleichmässigen, deutlichen Zuwachsstreifen aus dichten, ungleichmässigen und niedrigen Spiralleisten, welche am letzten Umgange etwas wellenförmig gebogen sind, gegen die Mündung zü oft erlöschen. Das spitze Gewinde besteht aus 4 rasch zunehmenden, schwach gewölbten Umgăngen; die $2-3$ obersten sind kantig, der letzte aufgeblasen, gerundet, vorne ziemlich tief herabsteigend. Die abgerundet dreieckige Mündung ist schief, innen zitrongelb oder rötlich, der Mundsaum erweitert, gerade und scharf; der Oberrand an der Insertion vorgezogen, am Uebergange desselben in den Aussenrand befindet sich ein tiefer, dreieckiger Ausschnitt; der Basalrand geht im rechten Winkel in die flache, nahezu senkrechte Spindel über. Im Gaumen eine von der Spindel ausgehende, kurze Schmelzleiste. Der ziemlich dünne, glănzende Basalkallus, wenig ausgebreitet, deutlich begrenzt.

$$
\mathrm{D}=18-30, \mathrm{~d}=14.5-23, \mathrm{H}=15-21 \mathrm{~mm} .
$$

Deckel: abgerundet dreieckig mit $\mathrm{S}$ förmig gebogenem Spindelrand, spitz ausgezogenem oberen Winkel und nach hinten gebogenem Spindelwinkel; die dicke, gelbe oder rötliche Kalkplatte ist glatt, am Spindelrande wallartig erhoben, gegen die Hornplatte durch eine seichte Furche abgesetzt. Die gelbbraune Hornplatte mit dunklerem Rande an der Peripherie und S-förmig gebogener ziemlich erhobener Sigmakante. Der Nukleus deutlich vertieft, dem Spindelrande genähert.

$\beta$. Gehäuse des weiblichen Tieres: durchschnittlich mit höherem Gewinde, weniger gewölbten, langsamer zunehmenden Umgängen und schwächer aufgeblasenem letzten Umgange. Der Mundsaum innen leicht verdickt, stumpf oder kurz ausgebreitet, mitunter umgeschlagen; ohne Ausschnitt am Uebergange des Oberrandes in den Aussenrand.

Dimensionen und Deckel wie bei der männlichen Form. 
Verbreitung: die typische Form kenne ich von nachstehenden Fundorten der Insel Cuba: Organosgebirge, Rangel, Luis Lazo, San Cristobal, Catalina (Gehäuse auffallend klein), Sierra de Morales (mit schwächerer Spiralskulptur).

\title{
193. Eutrochatella (Hapata) regina laevigata Pfeiffer. Taf. 25, Fig. 14, 15.
}

Hapata regina var, laevigata Pfeiffer Mal. Bl. XI p. 186, 1864.

Die Umgänge deutlicher gewölbt, der letzte mehr aufgeblasen, in der 2. Hălfte etwas zusammengedrückt und stumpfkantig. Die Grundfarbe lebhaft zitrongelb, gelbbraun oder braunviolett mit einer rotbraunen, schmalen Binde an der Naht; hăufig sind auch 3 scharfbegrenzte, breite, weisse Bänder vorhanden. Die Zuwachsstreifen schwächer, die Spiralskulptur nur auf den oberen Umgăngen angedeutet oder nahezu erloschen. Die Verhältnisse des Mundsaumes wie bei der typischen Form.

$$
\mathrm{D}=18-25, \mathrm{~d}=14 \cdot 5-20, \mathrm{H}=15-21 \mathrm{~mm} \text {. }
$$

Deckel lebhafter gefärbt, sonst wie bei der typischen Form.

Fundorte: Pan de Azucar und Portales de Guane auf Cuba.

\section{Eutrochatella (Hapata) regina subunguiculata Poey.}

\author{
Taf. 25, Fig. 16, 17.
}

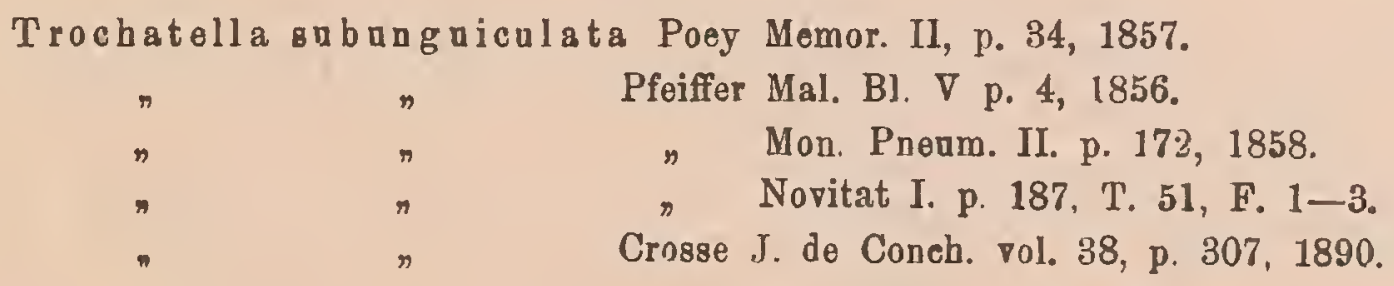

Gehäuse mit höherem Gewinde, kräftiger, ungleichmässiger Spiralskulptur, welche aus stärkeren und schwächeren, am letzten Ungange gewellten Spiralleisten besteht. Der Mundsaum der männlichen Form mit schwachem Ausschnitt.

$$
\mathrm{D}=24-27, \mathrm{~d}=19-21, \mathrm{H}=18-23 \mathrm{~mm} \text {. }
$$

Deckel wie bei der typischen Form.

Fundorte: Vignales, Guane und Salto Manantiales auf Cuba. 


\section{Subgenus Artecallosa $n$.}

Der Basalkallus zumeist auf eine leistenförmige, ziemlich erhobene Verdickung reduziert, welche die Insertionen des Mundsaumes verbindet und die Mündung verengt. Die Spiralskulptur stets vorhanden und zumeist deutlich Deckel abgerundet dreieckig mit geradem oder leicht S-förmig gebogenem Spindelrand; die ziemlich dünne Kalkplatte ist konkav und wird an der Peripherie durch eine tiefe Furche von der Hornplatte geschieden; sonst die Merkmale des Genus.

Verbreitungsgebiet: die Insel Cuba und Guatemala in Zentralamerika.

Die hier angeführten Formen weisen neben den Merkmalen des Genus noch Eigentümlichkeiten auf, welche mich zunächst veranlassen, dieselben als besondere Gruppe zusammenzufassen. Der Basalkallus ist mitunter ziemlich ausgebreitet, jedoch sehr zart und of kaum angedeutet; die Insertionen des Mundsaumes werden aber durch eine leistentörmig erhobene Schwiele verbunden, welche den Mundsaum verengt und jedenfills dem'Basalkallus entspricht. Auffallend ist ferner die tiefe Furche, welche die Hachkonkave Kalkplatte an der Peripherie von der Hornplatte absetzt. Die Beschaffenheit der Mündung und des Mundsaumes ist bei der sonstigen Uebereinstimmung der wesentlichen Merkmale merkwürdig verschieden; während eine Anzahl von Formen einen ausgebreiteten und breit umgeschlageneu Mundsaum aufweist, ist derselbe bei einer Rtihe von Formen gerade und scharf, wie bei unausgewachsenen Exemplaren der zuerst erwähnten Formen. Diese Verschiedenheit dürte auf die beiden Geschlechtsformen zurückzuführen sein, welche auch bei anderen Gruppen des Genus besonders Abweichungen in der Beschaffenheit des Mundsitumes erkenıen lassen. So halte ich E. rubicunda Pfr. und E. petrosa Pfr. nur tür Geschlechtsformen derselben Art.

\section{Eutrochatella (Artecallosa) petitiana d'0rbigny.} Taf. 22, Fig. $4-7$.

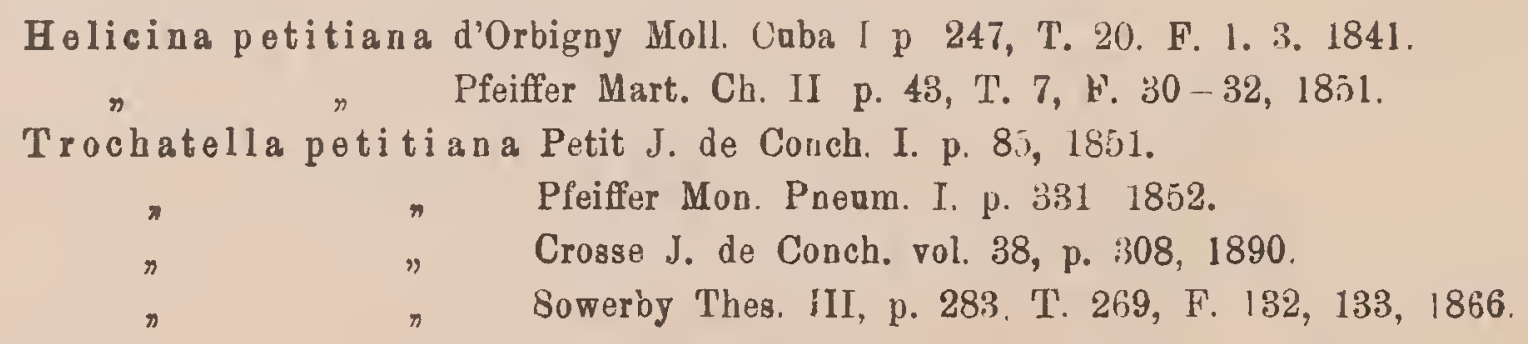

Gehăuse breitkegelförmig mit halbkugeliger Basis, dünnschalig, durchscheinend matt; hellgelb, der letzte Umgang gegen die Mündung zu lichter bis weisslich. Die Skulptur besteht nebst undeutlichen Zuwachsstreifen aus dichten und feinen, ain letzten Umgange welligen Spiralreifen, welche auf der Unterseite dichter werden. Das zugespitzte Gewinde besteht aus 
$51 / 2-6$ leicht gewölbten, ziemlich rasch zunehmenden Umgängen, welche durch eine leicht eingedrückte Naht geschieden werden; die oberen Umgănge über der Naht kantig, der letzte im Beginne etwas stumpfkantig, gegen die Mündung zu gerundet, vorne ein wenig hinaufsteigend. Die verhältnismässig grosse, schiefe Mündung ist innen gelb. der dünne Mundsaum erweitert, weit ausgebreitet, der Ober- und Basalrand an den Insertionen fast geflügelt. Die kurze, flache oder leicht ausgehöhlte Spindel weicht etwas zurück und geht im winkeligen Bogen in den Basalrand über. Der Basalkallus besteht aus einer leistenförmigen Verdickung, welche die Insertionen des Mundsaumes verbindet.

$$
\mathrm{D}=9, \mathrm{~d}=7, \mathrm{H}=7 \mathrm{~mm} \text {. }
$$

Deckel mit ziemlich dünner, weisser und gekörnelter Kalkplatte, sonst typisch.

Fundort: Jayua, Banao und Trinidad auf Cuba.

\section{Eutrochatella (Artecallosa) petitiana laticostan.} Taf. 22, Fig. 12.

Gehäuse festschaliger, gelblichweiss, der letzte Umgang mehr zusammengedrückt, an der Peripherie deutlicher kantig; die Spiralleisten auf der Oberseite viel weitläufiger, der Mundsaum breit umgeschlagen.

Deckel wie bei der typischen Form.

$$
D=12, d=9, H=9 \mathrm{~mm} \text {. }
$$

Fundort: die Insel Cuba.

$$
\begin{aligned}
& \text { 197. Eutrochatella (Artecallosa) rubicunda Pleiffer. } \\
& \text { Taf. 22, Fig. 8. } 9 . \\
& \text { Trochatella rabicanda Gundlach upud Pfeiffer Mal. Bl. IV. p. 111, } 1857 . \\
& \begin{array}{l}
" \quad \text { Mon. Pneum. II. p. 175, } 1858 . \\
" \quad \text { Crosse J. de Conch. vol. 38, p. 309, 1890. } \\
" \quad \text { Arango Contr, fanna mal. Caba p. 43. } \\
" \quad \text { Sowerby Thes. III, p. 284, T. 269, F. 141, 142, } 1866 . \\
\text { " capill a ce a Pfeiffer Mal. Bl. IV. p. 111, 1857. }
\end{array}
\end{aligned}
$$

Gehäuse kegelförmig mit flachgewölbter Basis, ziemlich dünnschalig, kaum glänzend, hellrotbraun oder gelb. Die Skulptur besteht nebst ungleichmässigen, schwachen Zuwachsstreifen aus ziemlich dichten, haarförmigen Spiralreifen, welche auf der Oberseite des letzten Umganges weitläufiger werden. Das regelmässig kegelförmige Gewinde besteht aus $5^{1} / 2$ leicht gewölbten, über der eingedrückten Naht kantigen Umgängen; der letzte an der Peripherie stumpfkantig, vorne langsam. aber deutlich unter die Kante herabsteigend. Die abgerundet dreieckige Mündung ist schief, der Mundsaum dünn oder kaum verdickt; der fast gerade Oberrand an der Insertion geöhrt, der Aussen- und Basalrand kurz 
ausgebreitet, gegen die Insertion zu verschmälert; die kurze, etwas zurückweichende Spindel geht im winkeligen Bogen in den Basalrand über. Der schmale, leistenförmige Basalkallus ver bindet die Insertionen des Mnndsaumes.

$$
\mathrm{D}=4 \cdot 6, \mathrm{~d}=4, \mathrm{H}=4 \cdot 6 \mathrm{~mm} \text {. }
$$

Deckel mit ziemlich dünner, glänzender, gelblich gefärbter Kalbplatte; sonst typisch.

Fundort: Trinidad auf Cuba.

Eutrochatella capillacea Pfeiffer ist hăufig gelb gefärbt, entspricht aber sonst vollkommen der vorstehenden Art.

\title{
198. Eutrochatella (Artecallosa) petrosa Peiffer.
}

Taf. 22, Fig. 10-12.

Trochatella petrosa Gundlach apud Pfeiffer Mal. Bl. IV. p. 111, 1857.

$» n$

n Mon. Pneum II, p. 174, 1858.

$" \quad n \quad$ Crosse J. de Conch. vol. 38, p. 309, 1890.

" $n \quad$ Sowerby Thes. III. T. 283, T. $\Sigma 69$, F. 136, 137, 1866.

Gehäuse im Vergleiche zu E. rubicunda Pfeiffer durchschnittlich etwas grösser, das Gewinde niedriger; die oberen Umgänge flacher, in der Mitte oft leicht eingedrückt, der letzte mehr erweitert, rascher zunehmend, vorne tiefer herabsteigend. Die Mündung annähernd halbkreisförmig, weniger schief; der dünne Mundsaum scharf und gerade; der schmale Basalkallus verbindet leisteuförmig die Insertionen des Mundsaumes.

Deckel wie bei E. rubicunda Pfeiffer.

$$
\mathrm{D}=6, \mathrm{~d}=5 \cdot 5, \mathrm{H}=5.5 \mathrm{~mm} \text {. }
$$

Fundort: Trinidad auf Cuba.

Eutrochatella petrosa Pfeiffer hat das Aussehen einer unausgewachsenen, aber grösser angelegten Eutrochatella rubicunda Pfeiffer und stellt nach meiner Ansicht eine Geschlechtsform derselben dar.

\section{Eutrochatella (Artecallosa) rupestris Pfeiffer.}

\author{
Taf. 22, Fig. 13, 14.
}

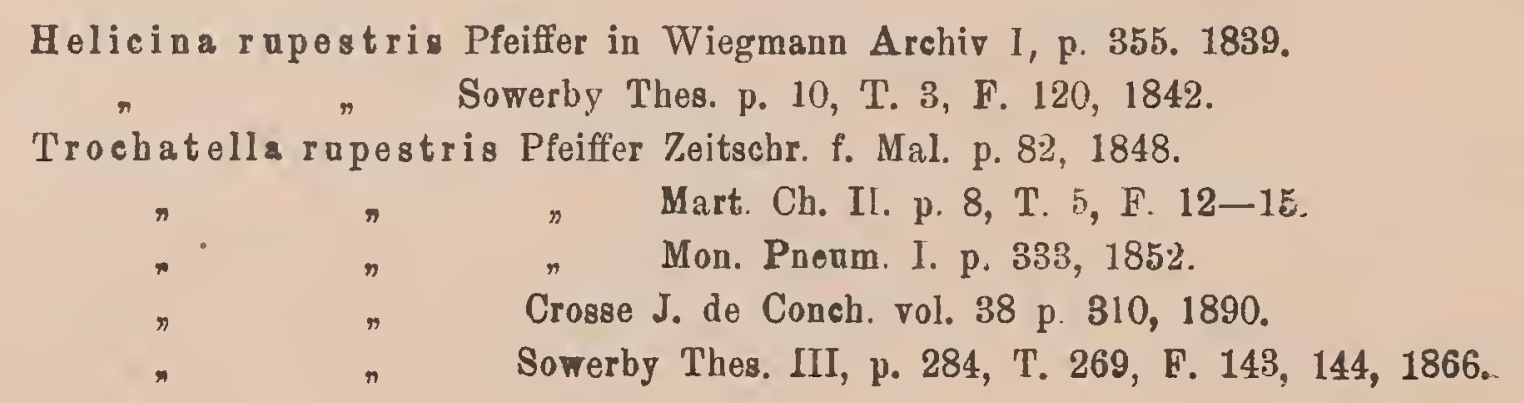


Gehä use kegelförmig mit gewölbter Basis, ziemlich dünnschalig, glanzlos, zitrongelb, mitunter brăunlich. Die Skulptur besteht nebst schwachen und ungleichmässigen Zuwachsstreifen aus dichten, haarförmigen Spiralreifen. Das kegelförmige Gewinde besteht aus $4^{1}{ }_{2}$ kaum gewölbten bis flachen Umgängen, welche über der eingedrü ckten Naht kantig bis gekielt sind; der letzte ist an der Peripherie stumpfkantig und steigt vorne langsam und tief herab. Die halbkreisförmige Mündung ist wenig schief, der Mundsaum scharf und gerade; der schmale Basalkallus verbindet leistenförmig die Insertionen des Mundsaumes.

$$
\mathrm{D}=4, \mathrm{~d}=3.8, \mathrm{H}=3.6 \mathrm{~mm} \text {. }
$$

Deckel mit weisser, fein gekörnelter Kalkplatte; sonst typisch.

Fundorte: Matanzas und Managua auf Cuba.

Von Eutrochatella petrosa Pfeiffer dnrch konstant geringere Dimensionen, die geringere Zahl der langsamer zunehmenden, deutlicher gekielten Umgänge, sowie den vorne tiefer herabsteigenden letzten Umgang unterschieden.

\section{Eutrochatella (Artecallosa) elongata d'Orbigny.} Taf. 23, Fig. 1-4.

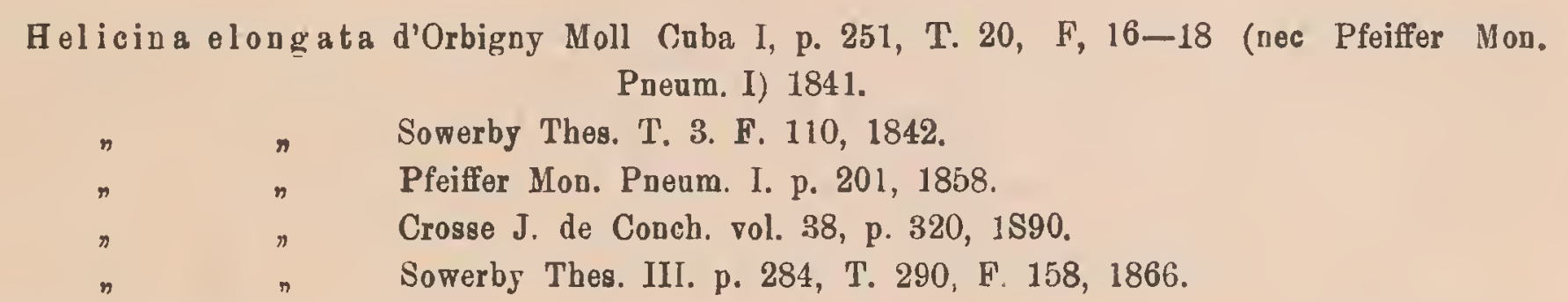

Gehãuse spitzkegelförmig mit gewölbter Basis, ziemlich festschalig; leicht glänzend mit schwachen Zuwachsstreifen und schief runzlich gehämmerter Oberfläche; gelbweiss oder rötlich mit dunkler gefärbter Spitze. Das regelmässig spitzkegelförmige Gewinde besteht aus $61 / 2$ leicht gewölbten, durch tief eingedrückte Naht geschiedenen Umgängen; die obersten über der Naht kantig der letzte undeutlich kantig, unten mit schwachen Spirallinien, vorne nicht herabsteigend. Die halbkreisförmige, wenig schiefe Mündung, innen lebhaft rotbraun oder gelbbraun; der weisse, dünne Mundsaum ausgebreitet und abstehend, der Basalrand gegen die Insertion rasch verschmälert. Der gelbliche, gekörnelte Basalkallus ist ziemlich dick und deutlich begrenzt, in der Verbindungslinie zwischen den Insertionen des Mundsaumes leistenförmig erhoben.

$$
\mathrm{D}=7, \mathrm{~d}=6, \mathrm{H}=8 \mathrm{~mm} \text {. }
$$

Deckel mit feingekörnelter, milchweisser Kalkplatte, sonst typisch.

Fundort: Guajaibon auf Cuba. 


\title{
201. Eutrochatella (Artecallosa) conica Pfeiffer. Taf. 23, Fig. 5, 6 .
}

\author{
Helicina conica Pfeiffer in: Wiegm. Archiv I p. 355, 1839 \\ Sowerby Thes. I, p. 9, T. 3, F. 101, 1841. \\ Trochatella conica Pfeiffer Zeitschr. p. 82, 1848. \\ " $\quad$ Mart Ch. II p. 7, T. 5, F 9-11. \\ $\quad$ Crosse J. de Canch. vol. 38, p. 309, 1890. \\ Helicina elegans d'Orbigny Moll. Caba I p 250, T. 20, F. 13-15, 1841.
}

Gehäuse spitzkegelförmig mit gewölbter Basis, ziemlich dünnschalig, wenig glänzend (im frischen Zustande mit einer Erdkruste bedeckt); gelblichweiss oder röthlich. Das regelmässig kegelförmige Gewinde besteht aus $5 \frac{1}{2}$ nahezu flachen durch eingedrückte Naht geschiedenen Umgängen; der letzte ist kantig bis stumpl gekielt und steigt vorne nicht herab. Die Skulptur besteht nebst deutlichen, ungleichmässigen Zuwachsstreifen aus haarförmigen, niedrigen Spiralleistchen, welche an der Peripherie des letzten Umganges dichter werden. Die abgerundet dreieckige, wenig schiefe Mündung ist innen hellrotbraun gefärbt; der gelbliche Mundsaum weit ausgebreitet, fast rechtwinkelig abstehend; der Basalrand gegen die Insertion rasch verschmälert. Der gelbliche, đünne Basalkallus halbkreisförmig ausgebreitet, in der Verbindungslinie der Insertionen des Mundsaumes leistenförmig erhoben.

$$
D=5.5, d=4 \cdot 5, \quad 1=6 \mathrm{~mm} \text {. }
$$

Deckel mit.rötlicher, feingekörnelter Kalkplatte, sunst typisch.

Fundort: Umgebung von Matanzas auf Cuba.

\section{Eutrochatella (Artecallosa) continua (Gundlach mss) Poey.} Taf. 22, Fig. $21-24$.

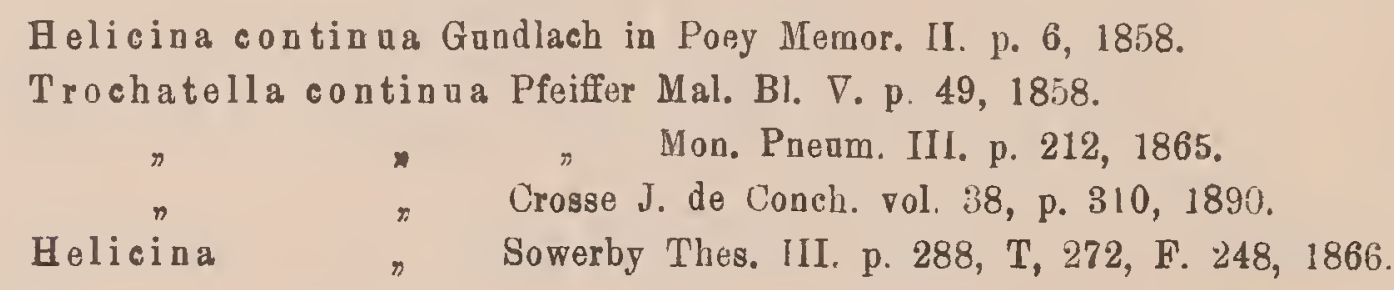

Gehäuse breitkegelförmig mit Hach gewölbter Basis, ziemlich dünnschalig, hellgelb, kaum glänzend; im frischen Zustande mit einer Erdkruste bedeckt. Diહ Skulptur besteht aus feinen, dichten Zuwachsstreifen, daneben sind bei stärkerer Vergrösserung sehr teine Spirallinien sichtbar. Das regelmässig kegelförmige Gewinde besteht aus $\left.4^{1}\right|_{2}$ leicht gewölbten, regelmässig zunehmenden Umgängen; der letzte an der Peripherie stumpfkantig, vorne nicht herabsteigend. Die sehr schiefe Mündung ist abgerundet viereckig, innen gelblich; der weisse: 
Mundsaum dünn und stumpf; der Oberrand vor der Insertion konvex vorgezogen und fast gerade, der Aussen- und Basalrand kurz ausgebreitet, winkelig in den aufsteigenden Spindelrand übergehend. Der Basalkallus wird nur durch eine dünne, glänzende Schwiele angedeutet, welche geradlinig die Insertionen des Mund̈saumes verbindet. In der Nabelgegend eine ziemlich tiefe, nabelartige Grube, welche der Basalkallus nicht bedeckt:

$$
\mathrm{D} \cdot=4, \mathrm{~d}=3 \cdot 3, \mathrm{H}=2.8 \mathrm{~mm} \text {. }
$$

Deckel trapezoidisch mit weisser, gekörnelter Kalkplatte, sonst typisch.

Fundort: Guisa auf Cuba.

\section{Eutrochatella (Artecallosa) callosa Poey.}

Taf. 22. Fig. 25-28.

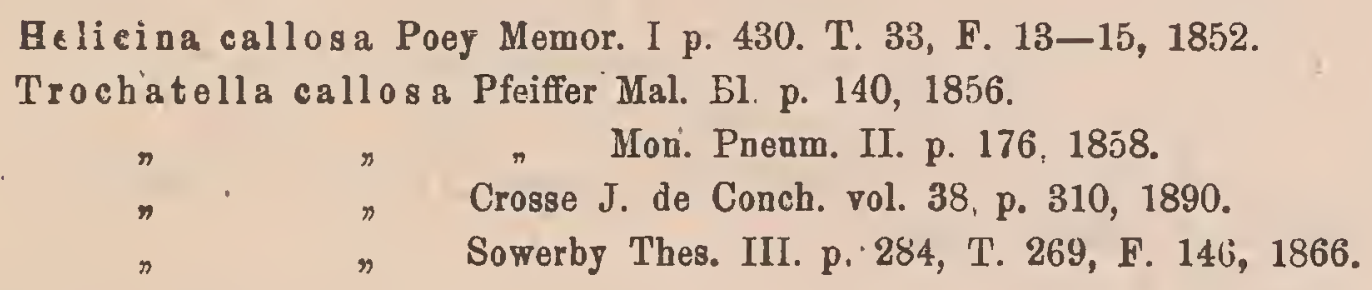

Gehäuse kegelförmig mit flachgewölbter, Basis, ziemlich festschalig, wenig glänzend, hellrotbraun mit einer weisslichen Zone um die Mündung: Die Skulptur besteht nebst feinen ungleichmässigen Zuwachsstreifen aus dichten, haarförmigen Spiralreifen, welche auf der Oberseite des letzten Umganges weitläufiger, auf der Unterseite schwächer werden. Das regelmässig kegelförmige Gewinde besteht aus $5^{1} / 2$ stumpf gekielten Umgängen; die oberen treppenförmig, flach oder etwas konkav, der letzte oben etwas gewölbt, an der Peripherie stumpf gekielt, bis stumpfkantig unten flach oder leicht konkav, vorne langsam und wenig herabsteigend. Die abgerundet dreieckige Mündung ist sehr schief, durch einen zahnartigen Kallus auf der Mündungswand verengt, der. Mundsaum kaum verdickt, fast gerade; der Oberrand an der Insertion konvex vorgezogen, der Basalrand zunächst konkav ausgeschnitten, an der Insertion ebenfalls konvex vorgezogen. Die kurze, nahezu senkrechte Spindel geht im winkeligen Bogen in den Basalrand über. Der ziemlich dicke, deutlich begrenzte Basalkallus ist halbkreisförmig ausgebreitet.

$$
\mathrm{D}=4 \cdot 7, \mathrm{~d}=4 \cdot 4, \mathrm{H}=4.8 \mathrm{~mm} \text {. }
$$

Deckel abgerundet dreieckig mit S-förmig gebogenem Spindelrand, die glänzende Kalkplatte stark konkav; sonst typisch.

Fundort: Fichteninsel bei Cuba. 


\title{
204. Eutrochatella (Artecollosa) pfeifferiana Pfeiffer.
} Taf. 22, Fig. 15, 16.

\author{
Helicina pfoiferiana Arango mss. apud Pfeiffer Mal. Bl. XIII, p. 64, 1866. \\ " $\quad$ Pfeiffer Mon. Pneum. IV. p. 252. \\ » Crosse J. de Conch. vol. 38, p. 312, 1890.
}

Gehäuse sehr klein, kegelförmig mit gewölbter Basis, matt dünnschalig, rotbraun gefărbt. Die Skulptur besteht nebst feinen, dichten Zuwachsstreifen aus sehr feinen, erhobenen Spirallinien. Das regelmässig kegelförmige Gewinde besteht aus $4^{1} / 2$ stumpfgekielten Umgăngen; die oberen treppenförmig, der letzte oben flach, an der Peripherie stumpfgekielt, unten gewölbt, vorne langsam ein wenig herabsteigend. Die halbeiförmige Mündung sehr schief, der Mundsaum gerade und scharf, die kurze Spindel im winkeligen Bogen in den Basalraud übergehend. Der zarte, glänzende Basalkallus schmal und undeutlich begrenzt.

$$
\mathrm{D}=2 \cdot 7, \mathrm{~d}=2 \cdot 5, \mathrm{H} 2 \cdot 3 \mathrm{~mm} \text {. }
$$

Deckel abgerundet dreieckig mit S-förmig gebogenem Spindelrand, hellrotbrauner zarter, wenig konkaver Kalkplatte, sonst typisch.

Fundort: Yunque die Baracoa auf Cuba.

Ich beurteile diese Art nach Exemplaren vom Originalfundorte, dieselben entsprechen vollkommen der Originaldiagnose, machen aber noch mehr als Eutrochatella petrosa Pfr. und E. rupestris Pfr. den Eindruck einer Jugendfurm.

\section{Eutrochatella (Artecallossa) microdina Morelet. Taf. 22, Fig. 17-20.}

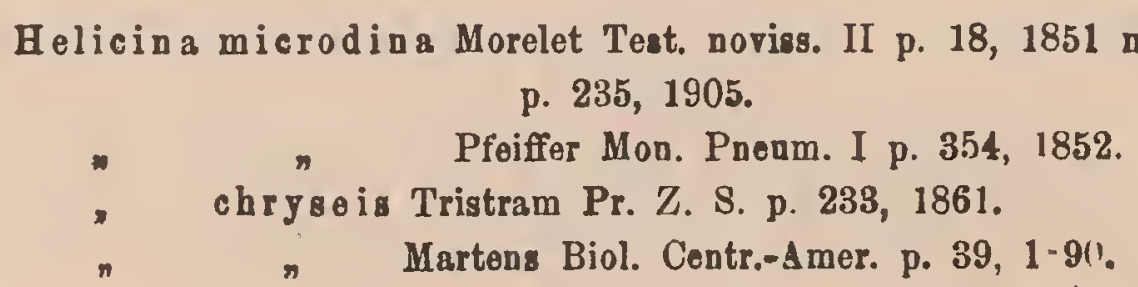

Gehäuse kegelförmig mit flachgewölbter Basis, ziemlich festschalig, hellgelb mit orangegelber Spitze, matt. Die Skulptur besteht nebst undeutlichen, feimen Zuwachsstreifen aus dichten, haarförmigen Spiralreifen, welche auf der Unterseite des letzten Umganges undeutlich werden. Das regelmăssig kegelförmige Gewinde besteht aus $4 \frac{1}{2}-5^{1 / 1} / 2$ stumplgekielten Umgängen; die oberen treppenförmig abgesetzt, der letzte etwas zusammengedrürkt, an der Peripherie kantig bis stumpfgekielt, vorne wenig herabsteigend. Die halbeiförmiıe Münduny sehr schief; der Mundsaum einfach und gerade; der dünne, schmale Basalkallus undeutlich begrenzt. 


$$
\mathrm{D}=3 \cdot 5, \mathrm{~d}=3, \mathrm{H}=3.5 \mathrm{~mm} .
$$

Deckel annähernd trapezoidisch mit dünner, durchscheinender Kalkplatte, sonst typisch. Fundort: Vera paz in Guatemala.

Eutrochatella chryseis Tristram entspricht etwas schlankeren, dunkler gefärbten Exemplaren der vorstehenden Art.

\title{
Genus Geophorus Fischer.
}

\author{
Geophoru s Fischer Manual p. 795, 1885.
}

Gehäuse kegelförmig bis linsenförmig mit warzenartig vorspringender Spitze. Das regelmässig kegelförmige oder nur leicht abgerundete Gewinde besteht aus $\left.4^{1}\right|_{2}$ bis $51 / 2$ leicht. gewölbten bis flachen, stets gekielten Umgängen; der Kiel häufig auch an den oberen Umgängen als ,mehr minder vorspringende Nahtkante sichtbar. Die Skulptur besteht nebst deutlichen, ungleichmässigen und gebogenen Zuwachsstreifen aus einer sehr feinen und dichten Körnelung der Epidermis, welche auch auf der glänzenden Embryonalwindung vorhanden ist; diese Körnelung bedingt ein mehr minder mattes Aussehen der Oberfläche und unterstützt die Bildung einer fest anhaftenden Erd- und Staubkruste, welche entlang der Zuwachss reifen oft rippenartige Auflagerungen bildet und den Kiel flügelartig verbreitert. Bei einigen Formen sind unter der Lupe undeutliche, feine Spirallinien nachweisbar, dagegen erscheint die Unterseite des Gehäuses oft sehr fein spiral gerunzelt. Die sehr schiefe Mündung ist zumeist trapezoidisch oder annähernd dreieckig und wird durch den vorletzten Umgang nur schwach ausgeschnitten. Der Mundsaum ist zumeist nur schwach verdickt, der Oberrand gerade, der Aussen- und Basalrand kurz ausgebreitet und umgeschlagen; der halbkreisförmig ausgebreitete Basalkallus stets dünn und wenig deutlich begrenzt.

Deckel dreieckig oder trapezoidisch mit leicht exzentrischem, dem Spindelrande und Spindelwinkel genähertem Nukleus; die Sigmakante nur.im unteren, vom Nukleus zum Spindelwinkel verlaufenden Aste deutlich erhoben, sonst nur an der winkeligen Biegung der Zuwachsstreifen erkennbar. Die feste bis knochenartige Kalkplatte ist flach konkav, am Spindelrande und besonders am Spindelwinkel stärkér verdickt und daselbst wulstig bis zungenartig erhoben; hier auch gegen die dünne Hornplatte durch eine Furche abgesetzt. Bei zahlreichen Formen finden sich in der Verdickung am Spindelwinkel der Kalkplatte auch karakteristische Gruben und Furchen, welche die Unterscheidung der Formen wesentlich unterstützen.

Das Verbreitungsgebiet erstreckt sich nach der gegenwärtigen Kenntnis der Formen über die Philippinen, Borneo Jawa, Timor, Celebes, Amboina und die kleinen Inselgruppen von der Jawa bis zur Banda-See. Das Genus umfasst anscheinend nur wenige Formenreihen oder Species, welche jedoch ein grosses Verbreitungsgebiet besitzen und in zahlreiche Formen 
zerfallen. Die Gleichförmigkeit der Gehäuse bietet dem Systematiker nur geringe Anhaltspunkte; Möllendorff hat zuerst auf die konstanten Merkmale des Geophorusdeckels aufmerksam gemacht und so einzelne Arten bestimmter abgegrenzt. Indem wir aber dem Deckel bei der Unterscheidung der Arten eine grössere Bedeutung zuerkennen erscheinen die Formenreihen des G. agglutinans Sowerby, G. lazarus Sowerby, G. oxytropis Gray und G. acutus Pfr. einander sehr nahe gerückt. Diese anscheinend gut abgegrenzten Arten besitzen einen auffallend übereinstimmenden Deckel, während die wesentlichen Merkmale der Gehăuse mit zunehmender Erforschung der Verbreitungsgebiete durch Uebergangsformen ausgeglichen werden. So folge ich nur dem praktischen Gebrauche, welcher auch die Uebersicht erleichtert, indem ich die genannten Formen noch als Spezies auseinanderhalte.

Die Formen des Genus Geophorus Fischer erinnern sowohl durch die Form des Gehăuses, als die Beschaffenheit des Deckels, welcher eine beginnende spirale Anlage erkennen lässt, an die Formen des Genus Geotrochatella Fischer aus den benachbarten Küstenländern des asiatischen Festlandes. Nach unserer gegenwärtigen Kenntnis berühren sich die Verbreitungsgebiete dieser Geschlechter nicht: in den noch wenig erforschten Gebirgen der Insel Sumatra oder auf der Halbinsel Malacea könnten jedoch Vertreter beider Geschlechter unvermittelt nebeneinanderleben oder durch Uebergangsformen vertreten sein.

Nach den Merkmalen des Deckels und der Gehăuse lassen sich die Formen des Genus zunächst in zwei Formenkreise teilen.

Der Formenkreis Agglutinans vereinigt die Formen mit einer wulstigen Verdickung der Kalkplatte am Spindelwinkel des Deckels und einer deutlich vorspringenden Ecke am Uebergange der Spindel in den Basalrand der Mündung; der Formenhreis Bothropoma die Formen mit Grübchen oder Furchen am Spindelwinkel der Kalkplatte des Deckels und undeutlicher oder fehlender Ecke am Uebergange der Spindel in den Basalrand der Mündung.

\section{Formenkreis Agglutinans $n$.}

206. Geophorus agglutinans Sowerby.

Taf. 26, Fig. 1-6, Fig. 11.

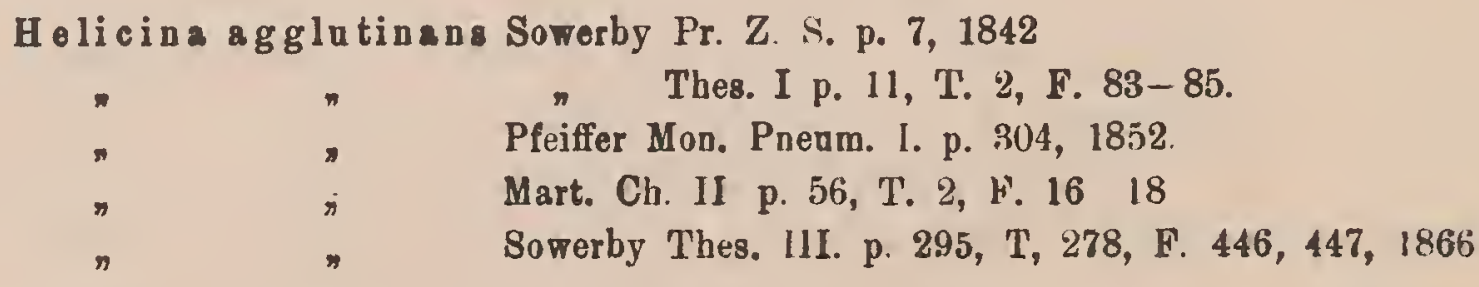

Gehäuse dicklinsenförmig oder flachkegelförmig mit leicht gewölbter Basis, zieulich dünnschalig matt; zitrongelb, grüngelb, oder schmutzị hellgelb, der Kiel, die Naht und ebenso die Umgebung der Mündung lichter bis weisslich gefärbr. Die teinen und dichten Zuwachsstreifen ungleichmässig, die Körnelung der Obertläche auf der Uber- und Unterseite 
gleichmăssig. Das flach kegelförmige, häufig etwas abgerundete Gewinde besteht aus $44_{2}^{1 / 2}-5$ ziemlich rasch zunehmenden, durch seichte Naht geschiedenen Umganngen; die oberen Umgänge nahezu flach, der letzte beiderseits deutlich gewölbt, vorne sehr wenig herabsteigend, im Beginne ziemlich scharf, aber wenig vorspringend, gegen die Mündung zu stumpfer gekielt. Die Mündung innen gelblich, der dünne oder nur leicht verdickte Mundsaum gelblich oder weiss gefärbt. Die leicht ausgehöhlte Spindel nach aussen und vorne gebogen, am Uebergang in den Basalrand der Mündung eine stumpfwinkelige, etwas abgerundete, aber deutlich vorspringende Ecke. Der dünne, gleichfarbige Basalkallus ist undeutlich begrenzt und nur durch den Glanz deutlicher hervortretend.

$$
\mathrm{D}=18, \mathrm{~d}=15, \mathrm{H}=10 \mathrm{~mm} \text {. }
$$

Deckel trapezoidisch mit abgerundeten Ecken und geradem Spindelrand. Die gelhbraune oder rotbraune Hornplatte in der Mitte lichter gefarbt; die fein gekörnelte, leicht glänzende Kalkplatte ist deutlich konkav, am Spindelrande und Spindelwinkel verdickt und wallartig erhoben; ohne Rinne oder Grübchen.

Fundorte: ein Originalexemplar dieser Art, welches mir die Herrn Sowerby und Fulton zur Verfügung gestellt haben, entspricht vollkommen der Form von der Insel Panay der Philippinen, welche auch Möllendorff als typisch betrachtet. Von der Insel Guimaras kenne ich zahlreiche Exemplare, welche durchschnittlich kleiner, festschaliger sind und eine grünlichgelbe Färbung mit weissem Kiel und Nahtstreifen besitzen; ich ziehe dieselben noch zur typischen Form; festschalige Exemplare dieses Fundortes mit etwas höherem Gewinde (Taf. 26, Fig. 6) bezeichnet Möllendorff als G. agglutinans var. pachychilus. Auf der Insel Tablas finden sich neben der typischen Form auch Exemplare, welche durch höheres Gewinde, schärferen Kiel und flacheren letzten Umgang zu G. agglutinans versicolor hinüberleiten (Taf. 26, Fig. 11).

\section{Geophorus agglutinans solidulus Möllendorff. Taf. 26, Fig. 7.}

Helicina (Geophorug) agglutinan var. solidula Möllendorff J. Senck. vol. 22 p. $179,1897$.

Gehăuse durchschnittlich kleiner, festschaliger, die oberen Umgănge gelbbraun bis orange, der letzte heller mit weissem Kiel und Nahtstreifen. Das höhere, leicht abogerundete Gewinde besteht aus 5 bis $51 / 2$ langsamer zunehmenden, flacheren Umyängen. Der weisse oder gelbliche Mundsaum ist lippenartig verdickt, der gelbe Basalkallus dicker und deutlichier begrenzt.

$$
\mathrm{D}=14, d=12, \mathrm{H}=9 \mathrm{~nm} \text {. }
$$

Fundort: nach Möllendorff die Insel Luban westlich von Luzon. 


\section{Geophorus agglutinans cyrtopoma Möllendorff. Taf. 26, Fig. 19-23. \\ Helicina (Geophoras) eyrtopoma Möllendorff Jabrb. Mal. Ges. p. 302, 1887.}

Gehause blass citrongelb oder gelbbraun mit lichterem letzten Umgang und weissem Naht und Kielstreifen; die Zuwachsstreifen dichter, die Körnelung deutlicher; das regelmässig kegelförmige Gewinde ist höher und besteht aus 5 langsamer zunehmendem, nahezu flachen Umgängen; der letzte ist schärfer gekielt. Der weisse Mundsaum ziemlich dick, die Ecke am Uebergang der Spindel in den Basalrand der Mündung deutlich schärfer.

$$
\mathrm{D}=7 \cdot 5-8, \mathrm{~d}=6.5-7, \mathrm{H}=5-5.5 \mathrm{~mm} \text {. }
$$

Deckel mit glänzender am Spindelwinkel kräftig verdickter Kalkplatte, sonst wie bei der typischen Form.

Fundort: ich beurteile diese Form nach Exemplaren des Autors vom Fundorte Morong auf Luzon und kann in denselben nur eine wenig abweichende Lokalform des weit verbreiteten G. agglutinans Sowerby erkennen; am nächsten steht dieselbe dem unten angeführten G.agglutinans versicolor Möllendorff.

\section{Geophorus agglutinans versicolor Möllendorff.} Taf. 26, Fig. 8-10, Fig. 12-15.

Helicina (Geophorus) agglutinans subsp. versicolor Möllendorff J. Senck, vol. 22, p. $179,1897$.

Gehäuse kleiner, rotbraun bis gelbbraun, die oberen Umgänge häufig orange, der Kiel und die Umgebung, der Mündung heller gefärbt. Das regelmässig kegelförmige Gewinde ist höher und besteht aus $4^{1} / 2-5$ kaum gewölbten bis flachen, langsamer zunehmenden Umgängen; der letzte Umgang beiderseits flacher und schärfer gekielt. Der Mundsaum mehr verdickt, die Ecke am Uebergange der Spindel in den Basalrand schärfer.

$$
\mathrm{D}=12, \mathrm{~d}=10, \mathrm{H}=7 \mathrm{~mm} \text {. }
$$

Deckel annähernd dreieckig mit weniger abgerundeten oberen Ecken; die Kalkplatte dünner, am Spindelrande und Spindelwinkel schwächer wallartig erhoben.

Fundorte: Ich beschreibe diese Form nach Exemplaren von der Insel Sibuyan, welche ich von Möllendorff erhalten habe; eine übereinstimmende Form kenne ich auch von der Insel Tablas. Auffallend lichte, zum Teil gelbweisse Exemplare, welche mit Rücksicht auf die Form des Gebäuses ebenfalls hierher gehören, erhielt ich von den Herrn Sowerby und Fulton mit der Fundortsangabe Insel Polillo (Taf. 26, Fig. 15). Auf den Inseln Romblon und Sibuyan leben neben der angeführten Form noch auffallend kleine, citron- bis orangegelb gefärbte 
Exemplare, welche Möllendorff unter der Bezeichnung G. agglutinans var. minima ver'sendet hat (Taf. 26, Fig. 12-14).

\section{Geophorus agglutinans mindorensis n.}

Taf. 26, Fig. 16-17.

Gehäuse flacher, hellzitrongelb oder schmutzig gelbbraun, mit lichterem Kiel und Nahtstreifen. Das regelmässig kegelförmige Gewinde ist niedriger und besteht aus 5 flachen, rascher zunehmenden Umgängen; der letzte ist beiderseits mehr zusammengedrückt, auffallend schärfer gekielt, vorne deutlicher herabsteigend; der gelbliche Mundsaum schwach gelippt.

$$
\mathrm{D}=14.5, \mathrm{~d}=11.5, \mathrm{H}=6.5-7 \mathrm{~mm} \text {. }
$$

Deckel hellgelb mit rötlicher Zone am Aussenrand, die Kalkplatte nur am Spindelwinkel wulstig verdickt.

Fundort: die Insel Mindoro; diese Form erinnert im Habitus auffallend an G. acutissimus Sowerby; die Beschaffenheit der Spindel und die mangelnden Grübchen am Spindelwinkel der Kalkplatte des Deckels lassen jedoch über die Zugehörigkeit derselben keinen Zweifel aufkoinmen.

\section{Geophorus agglutinans eos n.}

Taf. 31, Fig. 1-4.

Gehăuse sehr ähnlich dem G. agglutinans versicolor Möllendorff von der Insel Sibuyan, jedoch lebhafter gefärbt; die Spitze orange, die oberen Umgänge zinoberrot, der letzte gelb bis gelbbraun mit lichterem Kiel und Nahtstreifen. Das regelmässig kegelförmige Gewinde besteht aus $4 \frac{1}{2}$ ziemlich rasch zunehmenden, nahezu flachen Umgängen; der letzte mehr zusammengedrückt, bis zur Mündung scharf gekielt, vorne deutlich unter den Kiel herabsteigend. Der Mundsaum schwach weissgelippt. der dünne Basalkallus glănzend, die Ecke am Uebergange der Spindel in den Basalrand der Mündung schärfer.

$$
\mathrm{D}=12, \mathrm{~d}=10.5, \mathrm{H}=7 \cdot 5 \mathrm{~mm} \text {. }
$$

Deckel verhăltnismåssig breiter, als bei der typischen Form mit schărferem Ober- und Aussenwinkel, die Kalkplatte am Spindelwinkel starker verdıckt und wallartig erhoben.

Ich beschreibe diese Form nach Exemplaren von Berge Gunung Sekarat (G. Sakoeroech) an der Küste Ostborneos (Landschaft Kutei), welche mir Herr Thielə aus denı k. Museum zu Berlin zur Ansicht mitgeteilt hat. Anscheinend liegen mir Exemplare von zwei Lokalitäten des Berges vor, denn neben der beschriebenen Form zeigen einige Exemplare ein mehr abgerundetes Gewinde, weniger intensive Färbung und erreichen nur die Dimensionen $D=9 \cdot 5$, $d=8, H=6 \mathrm{~mm}$. Ferner sind noch Exemplare von der bellachbarten Küsteninsel PuloMiang vorhanden; dieselben entsprechen bis auf das etwas höhere, kegelförmige Gewinde und. die hellzitrongelbe Fărbung den vorangeführten kleinen Exemplaren vom Gunung Sekarat. 


\section{Geophorus lazarus Sowerby.} Taf. 27, Fig. $1-5$.

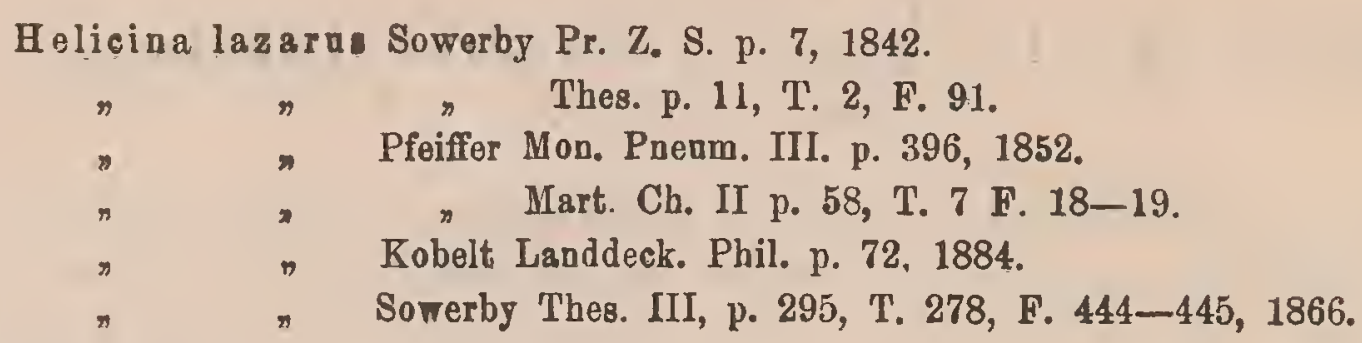

Sehr ăhnlich dem G. agglutinans Sowerby, das Gehăuse jedoch deutlicher gestreift, rauher gekörnelt und undeutlich spiral gerunzelt; einfärbig gelborange bis braungelb gefärbt. Das höhere, regelmässig kegelförmige Gewinde besteht aus $5-5^{1} / 2$ langsamer zunehmenden, kaum gewölbten bis flachen Umgăngen; der letzte ist stumpf gekielt und steigt vorne deutlich unter den Kiel herab. Der gelbe oder orangefarbene Mundsaum ist mehr ausgebreitet, die Ecke am Uebergange der Spindel in den Basalrand der Mündung stumpfer, mehr abgerundet und weniger vorspringend. Der dünne, gleichfarbige Basalkallus deutlich gekörnelt weniger glänzend.

$$
\mathrm{D}=11, \mathrm{~d}=10, \mathrm{H}=7 \cdot 5 \mathrm{~mm} \text {. }
$$

Deckel mit weniger ausgehöhlter, deutlicher gekörnelter Kalkplatte, sonst wie bei G. agglutinans Sowerby.

Das. Verbreitungsgebiet dieser Form erstreckt sich anscheinend nur über Nord- und Mittelluzon; die vorliegende Beschreibung gründet sich auf Exemplare von Palanan und Arayat in Nord Luzon. Im Süden der Insel Luzon treten Formen auf, welche als Uebergang zu G. agglutinans Sowerby aufgefasst werden können.

\section{Geophorus lazarus transitans n.}

\section{Taf. 26, Fig. 18.}

Gehäuse durchschnittlich grösser, hellzitron bis orangegelb, die Umgebung der Mündung und der Kiel lichter gefärbt. Das niedrigere Gewinde besteht aus $5-5^{1} / 2$ deutlicher gegewölbten Umgången; der letzte Umgang schärfer gekielt, die Ecke am Uebergange der Spindel in den Basalrand schärfer und deutlicher vorspringend, der Mundsaum weiss.

Deckel wie bei der typischen Form.

$$
D=12, d=10, H=7 \mathrm{~mm} \text {. }
$$

Fundort: Libmanan in der Provinz Camarines auf Luzon. Möllendorff zieht diese Form noch zum Typus, dieselbe könnte aber auch ebensogut mit der Formenreihe des G. agglutinans vereinigt werden, da sie einen Uebergang zu derselben bildet. Die rauhe Körnelung der 
Oberfläche entspricht wohl dem G. lazarus Sowerby, die Form des Gehäuses zeigt aber mehr Verhältnisse, wie sie für G. agglutinans Sowerby cbarakteristisch sind.

\section{Ge ophorus lazarus nanus Möllendorff.}

Taf. 27, Fig. 6-7.

Helicina (Geophoras) monticola nana Möllendorff (numen.).

Gehäuse konstant kleiner, orange- bis gelbbraun mit hellerem letzten Umgang und weisslichem Kielstreifen. Das niedrigere Gewinde besteht nur aus $4^{1} / 2$ deutlicher gewölbten Umgängen; der letzte Umgang ist schärfer gekielt, der Winkel am Uebergange der Spindel in den Basalrand der Mündung schärfer und deutlicher vorspringend, der leicht verdickte Mundsaum weiss.

$$
D=6, d=5, H=4 \mathrm{~mm} .
$$

Deckel mit glänzender Kalkplatte, sonst wie bei der typischen Form.

Fundort: Sibul in Mittelluzon.

\section{Geophorus lazarus inonticolus Mollendorff. Taf. 27, Fig. 8-10.}

Helicina monticola Möllendorff J. Senck. p. 180, 1897.

Gehäuse konstant kleiner, zitrongelb mit lichterem letzten Ungang. Das abgerundet kegelförmige Gewinde besteht aus $4^{1} / 2$ deutlicher gewölbten, langsamer zunelımenden Umgängen; der letzte Umgang unten auffallend flach, der Mundsaum weiss oder gelblich gefürbt; die Ecke am Uebergange der Spindel in den Basalrand etwas schärfer.

$$
\mathrm{D}=7, \mathrm{~d}=6, \mathrm{H}=5 \mathrm{~mm} \text {. }
$$

Deckel mit mehr abgerundetem Aussenwinkel, sonst wie bei der typischen Form Fundorte: Morong und Berg Limutan bei Morong in Mittelluzon.

\section{Geophorus oxytropis Gray.}

Taf. 27, Fig. 11-14.

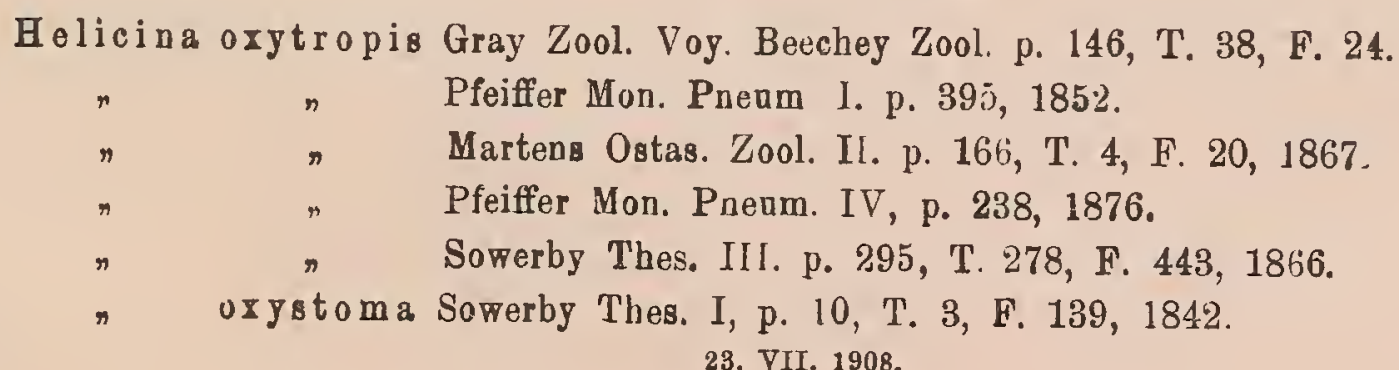

I. 18. II. 
Gehäuse sehr ähnlich dem G. agglutinans Sowerby und G. lazarus Sowerby, festschaliger mit durchschnittlich höherem Gewinde, verhăltnismässig grösser angelegter Embryonalschale und dementsprechend stumpfer vorspringendem Apex; hellzitrongelb, schmutziggelb oder hellrotbraun mit heller Zone um die Mündung und lichterem Kielstreifen. Die dichten und feinen Zuwachsstreifen sind ungleichmässig, die Körnelung wie bei G. agglutinans Sowerby; häufig sind auch schwach eingedrückte, feine Spirallinien vorhanden, welche besonders zu beiden Seiten des aufgetriebenen Kieles sichtbar werden. Die $5-5 \frac{1}{2}$ flachen oder kaum gewölbten Umgänge nehmen ziemlich langsam zu, der letzte steigt langsam und wenig unter den Kiel herab. Der kräftiger verdickte Mundsaum ist nahezu gerade und nur am Basalrand kurz verbreitert. Die Beschaffenheit der Spindel und die Ecke am Uebergange derselben in den Basalrand wie bei G. agglutinans Sowerby.

$\mathrm{D}=9, \mathrm{~d}=7 \cdot 5, \mathrm{H}=6 \mathrm{~mm}$. Fundort Maros auf Celebes.

Deckel wie bei G. agglutinans Sowerby.

Fundort: die Insel Celebes.

Als Typus dieser Formenreihe betrachte ich die Vorkommnisse von der Insel Celebes, welche mir in Exemplaren vom Fundorte Maros vorliegen (Taf. 27, Fig. 12-14); dieselben werden besonders durch das erhobene, regelmässig kegelförmige Gewinde, 5 flache, langsam zunehmende Umgänge, leicht aufgetriebenen Kiel und schwache Spirallinien gekennzeichnet. In der Sammlung der Herrn Sarasin in Basel befinden sich Exemplare vom Fundorte Malava auf Celebes, welche ein niedriges Gewinde, rascher zunehmende, deutlicher gewölbte Umgănge und einen mehr aufgetriebenen Kiel besitzen (Taf. 27, Fig. 11) und wohl auch der typischen Form angehören.

\section{Geophorus oxytropis orientalis n. Taf. 27, Fig. 15-20.}

Gehäuse festschalig, gelblich weiss oder rötlich mit niedrigerem, zumeist leicht abgerundetem Gewinde, welches aus $4 \frac{1}{2} 2$ rascher zunehmenden, deutlicher gewölbten Umgängen besteht. Der stärker aufgetriebene Kiel ist häufig auch auf den oberen Umgängen als stumpfe Nahtkante sichtbar.

$$
\mathrm{D}=10, \mathrm{~d}=85, \mathrm{H}=6 \mathrm{~mm} \text {. Fundort Kupang auf Timor. }
$$

Fundorte: Kupang und Atapupu auf Timor.

Eine ähnliche Form, welche nur die Dimensionen: $\mathrm{D}=7.5, \mathrm{~d}=6.5, \mathrm{H}=4.5 \mathrm{~mm}$ erreicht und durch die flachen Umgänge, sowie den schärferen, aber weniger aufgetriebenen Kiel zur typischen Form von Celebes hinüberleitet, sammelte E. von Martens auf Amboina (Taf. 27, Fig. 18-20). 


\section{Geophorus oxytropis jagori Martens.}

Taf. 27, Fig. 21-24.

Helicina jagori Martens in Pfeiffer Mon Pnenm. III, p. 243, 186 อ̆.

Gehäuse konstant kleiner rotbraun bis zitrongelb, mit feineren, mehr gleichmässigen Zuwachsstreifen. Das niedrigere kegelförmige Gewinde besteht aus $4 \frac{1}{2}$ leicht gewölbten bis Hachen Umgängen; der letzte zumeist beiderseits mehr gewölbt und stumpfer gekielt. Die Die Ecke am Uebergange der Spindel in den Basalrand schärfer, der Mundsaum dünner, doch stärker ausgebreitet.

$$
\mathrm{D}=7 \cdot 5, \mathrm{~d}=6 \cdot 5, \mathrm{H}=4.5 \mathrm{~mm} \text {. }
$$

Fundort: die Insel Java; eine anscheinend sehr variable Form, indem die Exeniplare eines Fundortes bald dem G. oxytropis orrentalis von Amboina, bald einem kleinen G. agglutinans Sowerby nahekommen und daneben alle Uebergänge vorhanden sind.

\section{Ge ophorus exsertus Martens. Taf. 30, Fig. 14-16.}

Helicina cxserta Martens Landschnecken d. Ind. Arch. Weber p. 220, T. 12, F. 16-19, 1891. " sundana Ancey Nantil. XIV p. 83, 1900.

Gehäuse flach kegelförmig mit flachgewölbter Basis, festschalig einfärbig hellgelb bis zitrongelb; die Obertläche durch feine aber deutliche Körnchen und Runzeln matt bis rauh, die Zuwachsstreifen deutlich und ungleichmässig. Das kegelförmige Gewinde besteht aus $41 / 2$ ziemlich rasch zunehmenden, flachen Umgängen; der erste gerundet, glänzend, aber unter der Lupe fein gekörnelt, die übrigen mit vorspringendem Nahtkiel, der letzte zusammengedrückt mit einem bis zur Mündung durchlaufenden, wulstig vorspringenden, beiderseits durch eine Furche berandeten Kiel; vorne langsam, aber deutlich unter den Kiel herabsteigend. Der gelbweisse Mundsaum mässig verdickt, kurz ausgebreitet; die kurze, leicht ausgehöhlte Spindel nach vorne und aussen grebogen, am Uebergange derselben in den Basalrand der Mündung eine stumpfe, vospringende Ecke. Der dünne, glänzende Basalkallus undeutlich begrenzt, mit dem Gehäuse gleichfarbig.

$$
\mathrm{D}=9, \mathrm{~d}=8, \mathrm{H}=6 \mathrm{~mm} .
$$

Deckel annähernd dreieckig mit leicht konkavem Spindelrand, stumpfem oberen und spitzem Aussenwinkel. Die gelbliche Kalkplatte flachkonkav, am Spindelwinkel etwas wulstig verdickt,

Fundort: die Insel Saleier südlich von Celebes. 
220. Geophorus exsertus major Sinith.

Taf. 30, Fig. 17-19.

Helicina exserta var. major Smith?

Gehäuse grösser, zitron- bis hellrotbraun, oben gekörnelt, unten fein spiral gerunzelt und etwas glänzend. Der Nahtkiel nur am zweiten Ungange deutlich vorhanden; der letzte Umgang deutlicher gewölbt, aber schärfer und weniger aufgetrieben gekielt.

Deckel wie bei der typischen Form.

$$
\mathrm{D}=10.5, \mathrm{~d}=9, \mathrm{H}=6.5 \mathrm{~mm} \text {. }
$$

Fundort: die Insel Saleier.

\section{Geophorus exsertus solidior Smith. \\ Taf. 30, Fig. 20.}

Gehäuse kleiner, dickschaliger, hellgelb bis lebhaft rotbraun mit weissem Kielstreifen und weisser Zone um die Mündung. Die Oberseite matt und rauh gekörnelt, die Unterseite leicht glänzend und fein spiral gerunzelt. Die oberen Umgänge mit vorspringendem stumpfem Nahtkiel, der letzte deutlicher gewölbt, weniger zusammengedrückt, vorne nicht herabsteigend, mit wulstig vorspringendem Kiel. Der Mundsaum auffallend verdickt bis verdoppelt, der dickere Basalkallus deutlich begrenzt.

Deckel wie bei der typischen Form.

$$
\mathrm{D}=8, \mathrm{~d}=7, \mathrm{H}=5 \mathrm{~mm} \text {. }
$$

Fundorte: die Inseln Kalao und Bonerate.

\section{Geopholus rolle i Sykes.}

Taf. 28, Fig. 18-20.

Helicina rollei Sykes J. Malac. VIII. p. 59, 1901.

Gehäuse flachkegelförmig mit flachgewölbter Basis, ziemlich festschalig, orange- bis gelbbraun mit weissem Naht und Kielstreifen; auf der Oberseite matt und schwach gekörnelt, unten leicht glänzend und undeutlich gerunzelt; ferner sind feine etwas ungleichmässige Zuwachsstreifen, unter der Lupe schwache Spirallinien vorhanden. Das regelmässig kegelförmige Gewinde besitzt eine warzenförmig vorspringende leicht glänzende Spitze und besteht aus $5^{1} / 2$ ziemlich rasch zunehmenden, flachen Umgängen; der letzte ist beiderseits zusammengedrückt, sehr scharf bis nahezu fügelförmig gekielt und steigt vorne nicht herab. Der weisse, leicht 
verdickte und glänzende Mundsaum ist überall gut ausgebreitet (auch entsprechend dem Oberrand); die nach vorue und aussen gebogene, etwas ausgeböhlte Spindel bildet am Uebergang in den Basalrand, eine stumpfwinkelige, leicht abgerundete, aber deutlich vorspringende Ecke. Der glasglänzende dünne Basalkallus ist undeutlich begrenzt.

Deckel unbekannt.

$$
\mathrm{D}=15, \mathrm{~d}=13, \mathrm{H}=9 \mathrm{~mm} \text {. }
$$

Fundort: die Kangean Inseln nordöstlich von Java.

Diese Art erscheint besonders durch den auch entsprechend dem Oberrand ausgebreiteten Mundsaum bemerkenswert, indem so ein wesentliches Merkmal des Genus in seiner Bedeutung herabgesetzt wird. Den Deckel dieser Art habe ich nicht gesehen, derselbe dürfte aber nicht wesentlich von den Merkmalen des Formenkreises abweichen.

\section{Geophorus acutus Pfeiffer.}

Taf. 28, Fig. 1-6, Fig. 10.

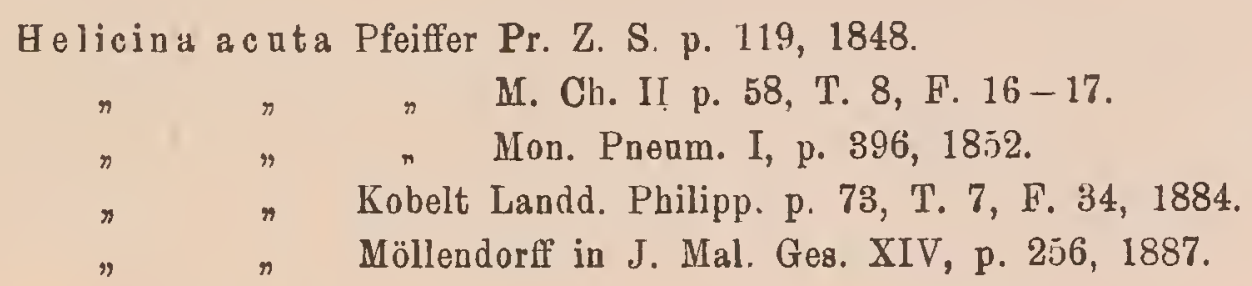

Gehäuse breitkegelförmig mit flachgewölbter Basis, ziemlich festschalig, einfärbig hellgelb bis zitrongelb, zumeist jedoch mit einem rotbraunen Bande auf der Oberseite, häufig auch einem solchen auf der Unterseite. Die Oberseite matt mit feiner Körnelung, die Unterseite sehr fein gerunzelt und etwas glänzend; die sehr feinen Zuwachsstreifen sind wenig ungleichmässig. Das regelmässig kegelförmige Gewinde besteht aus $5 \frac{1}{2}$ ziemlich rasch zunehmenden, leicht gewölbten bis flachen Umgängen; der letzte ist beiderseits leicht gewölbt, sehr scharf und zusammengedrückt gekielt und steigt vorne kaum herab. Der einfache oder nur leicht verdickte Mundsaum ist orange gefärbt; die kurze etwas ausgehöhlte Spindel ist nach aussen uud stark nach vorne gebogen, am Uebergange derselben zum Basalrand der Mündung eine rechtwinkelige, scharf vorspringende Ecke. Der zarte, gelbliche Basalkallus ist feingekörnelt und undeutlich begrenzt.

$$
\mathrm{D}=14, \mathrm{~d}=12, \mathrm{H}=8 \cdot \mathrm{mm} \text {. }
$$

Deckel dreieckig mit geradem Spindelrand; die gekörnelte Kalkplatte flachkonkav, am Spindelwinkel verdickt und etwas zungenförmig ausgezogen.

Fundorte: als Originalfundort führt Pfeiffer die Insel Cebu an, ich kenne die typische Form von dieser Insel nicht; Exemplare, welche jedoch vollkommen mit der Abbildung und Beschreibung des Autors übereinstimmen liegen mir aus dem Norden der Insel Samar vor; Möllendorff bezeichnet diese Form als G. acutus pyrrhochilus. Die typische Form, jedoch mit 
je einem rotbraunen Bande auf der Ober- und Unterseite findet sich ferner auf den Inseln Leyte und Siargao. Eine etwas kleinere Form mit höherem Gewinde und helleren bis erloschenen Bändern, welche ich von Bislig und Lianga auf Mindanao kenne, nennt Möllendorff Helicina acuta var. devians $(D=11.5, d=10, \dot{H}=7.5 \mathrm{~mm}$. Taf. 28, Fig. 10); eine sehr ăhnliche, jedoch einfärbig hellgelbe Form erhielt ich seinerzeit von Martens mit der Fundortsangabe Catbalogan auf Samar.

\section{Geophorua acutus peracutus n. Taf. 28, Fig. 7-9.}

Gehăuse flachlinsenförmig, dünnschaliger; die oberen Umgänge orange, der letzte mit einem rotbraunen, nur gegen den weissen Kiel zu scharf begrenzten Bande auf der Oberseite, die Unterseite rotbraun mit einem hellen bis weisslichen Fleck in der Mitte. Das flachere Gewinde besteht nur aus $4^{1} / 2$ verhältnismlässig grösser angelegten, rascher zunehmenden, flachen Umgăngen, welche zumeist durch einen weissen etwas vorspringenden Nahtkiel geschieden werden; der letzte Umgang mehr zusammengedrückt, sehr scharf, nahezu flügelförmig gekielt und vorne nicht herabsteigend. Der dünne gelblichweisse Mundsaum ist innen rotbraun eingesăumt, der zarte Basallkallus mit einem rotbraunen Fleck im Umkreise der Spindel.

$$
\mathrm{D}=14, \mathrm{~d}=12, \mathrm{H}=7 \mathrm{~mm} .
$$

Deckel wie bei der typischen Form.

Fundort: dis Insel Tablas.

Diese Form erinnert im Habitus auffallend an Geophorus acutissimus Sowerby, unterscheidet sich jedoch voll demselben wie der Typus durch die scharf vorspringende Ecke am Uebergange der Spindel in den Basalrand der Mündung, sowie durch den Deckel ohne Grübchen am Spindelwinkel der Kalkplatte.

\section{Geophorus acutus intermedius Möllendorff.} Taf. 28, Fig. 11-12.

Helicina lazarus subspec. intermedia Möllendorff J. Senck. vol. 22 p. 180, 1897.

Gehăuse kleiner mit deutlicheren und ungleichmăssigeren 'Zuwachsstreifen; die oberen Umgänge orange, der letzte heller mit weissem Naht und Kielstreifen. Die Umgänge werden durch eine deutlicher eingesenkte Naht geschieden, der letzte ist mehr gewölbt, stumpfer gehielt, der Mundsaum weiss.

Deckel wie bei der typhischen Form.

$$
\mathrm{D}=10,=8.5, \mathrm{H}=6 \mathrm{~mm} \text {. }
$$


Ich beurteile diese Form nach vom Autor mitgeteilten Exemplaren von der Insel Cebu; dieselben können wohl als Uebergang zur Formenreihe des G. agglutinans Sowerby aufgefasst werden, stehen aber dem G. acutus Pfr. jedenfalls viel näher, als dem G. lazarus Sowerby.

\section{Ge ophorus nitidulus Möllendorff. Taf. 28, Fig. 13-17.}

Helicina (Geophorus) nitidula Müllendorff J. Senck. vol. 22, p. 180, 1887.

Gehäuse flachkegelförmig mit flachgewölbter Basis, zienlich festschalig, hellockergelb bis orange, der letzte Umgang gegen die Mündung zu milchig getrübt mit weissem Kiel. Die Oberseite schwach gekörnelt und ziemlich glänzend, die Unterseite glatt und glänzend; die deutlichen Zuwachsstreifen ungleichmässig, ausserdem sind unter der Lupe feine Spirallinien regelmässig nachweisbar. Das regelmässig kegelförmige Gewinde besteht aus 5 deutlich gewölbten, durch leicht eingedrückte Naht geschiedenen Umgängen; der letzte Umgang ist etwas zusammengedrückt, beiderseits leicht gewölbt, an der Peripherie ziemlich scharf gekielt und steigt vorne nicht herab. Der weisse Mundsaum leicht verdickt; die Spindel nach aussen und vorne gebogen, am Uebergange derselben in den Basalrand eine rechtwinkelige, scharf vorspringende Ecke. Der dünne, feingekörnelte Basalkallus ist undeutlich begrenzt.

$$
\mathrm{D}=10, \mathrm{~d}=8.5, \mathrm{H}=6.5 \mathrm{~mm} \text {. }
$$

Deckel abgerundet dreieckig mit leicht konkavem Spindelrande, ziemlich spitzem oberen und abgerundetem Aussenwinkel. Die glänzende Kalkplatte ist am Spindelwinkel wulstig verdickt.

Fundort: Montalban bei Manila.

G. nitidulus Möllendorff zeichnet sich unter den Formen des Geuus besonders durch die schwache Körnelung, dementsprechend stärkeren Glanz und die deutlichen Spirallinien aus.

\section{Geophorus pseudomphalus Möllendorff. Taf. 29, Fig. $1-5$.}

Helicina (Geophoras) pseadomphala Möllendorff Nachr. Bl. vol. 26 p. 119, 1894.

Gehäuse flach bis breitkegelförmig mit flachgewölbter Basis, ziemlich festschalig; die oberen Umgånge zitrongelb, orange oder bräunlich, der letzte schmutzig gelb oder rötlich mit weissem Kielstreifen und weisser Zone um die Mündung; die Ober'seite fein gekörnelt, kaum glänzend, die Unterseite sehr fein spiral gerunzelt und glänzend; die feinen Zuwachsstreifen ungleichmässig, daneben unter der Lupe einige feine Spirallinien vorhanden. Das regelmässig kegelförmige Gewinde besteht aus 5 ziemlich langsam zunehmenden, flachen oder 
kaum gewölbten, durch eine leicht eingedrückte Naht geschiedenen Umgăngen; der letzte Umgang beiderseits leicht gewölbt, im Beginne ziemlich scharf, gegen die Mündung zu stumpfer gekielt, vorne langsam, aber deutlich unter den Kiel herabsteigend. Die Mündung innen gelbbraun gefärbt, der weisse Mundsaum innen schwach gelippt. Die stark ausgehöhlte und nach vorne gebogene Spindel bildet an Uebergange in den Basalrand eine rechtwinkelige, scharf vorspringende Ecke. In der Nabelgegend eine trichterförmig eingedrückte Grube; der dünne, glänzende Basalkallus undeutlich begrenzt.

$$
\mathrm{D}=8 \cdot 5, \mathrm{~d}=7 \cdot 5, \mathrm{H}=5.5 \mathrm{~mm} \text {. }
$$

Deckel schmal trapezoidisch mit geradem Spindelrand, glänzender, flachkonkaver Kalkplatte, welche am Spindelwinkel einen zungenartig vorspringenden, nach vorne und oben gerichteten Fortsatz bildet.

Fundort: Sibul in Mittelluzon.

Die nabelartige Vertiefung an der Basis des letzten Umganges, ebenso der zungenartige Fortsatz der Kalkplatte treten in diesem Formenkreise nicht unvermittelt auf, sondern stellen eine extreme Entwicklung sonst nur angedeuteter Merkmale dar:

\title{
Formenkreis Bothropoma.
}

\author{
228. Ge ophorus bothropoma Möllendorff. \\ Taf. 29, Fig. 20-23.
}

Helicina bothropoma Nachr. Bl. vol. 27 p. $148,189 E$.

Gehäuse breitkegelförmig mit schwach gewölbter bis nahezu flacher Basis, ziemlich dünnschalig, hellgelb mit lichterem letzten Umgang. Die Körnelung der Oberfläche sehr zart, die feinen und dichten Zuwachsstreifen ziemlich gleichınässig; unter der Lupe sind oft feine Spirallinien sichtbar. Das kegelförmige, mitunter leicht abgerundete Gewinde besteht aus $5 \frac{1}{2}$ schwach gewölbten bis nahezu flachen, ziemlich rasch zunehmenden Umgängen; der letzte oben schwach gewölbt, unten nahezu flach, scharf und zusammengedrückt gekielt, vorne nicht herabsteigend. Die Naht mitunter weiss berandet und an den unteren Umgängen schwach kantig; der weisse oder gelbliche Mundsaum sehr kurz ausgebreitet, innen schwach verdickt. Die kurze flache Spindel ist nur leicht nach aussen gebogen, am Uebergange derselben eine abgerundete kaum angedeutete Ecke, welche nur beim Anblick von vorne sichtbar wird. Der sehr düune Basalkallus glasartig glänzend.

$$
D=18, d=15, H=10 \mathrm{~mm} \text {. }
$$

Deckel schief trapezoidisch mit leicht konkavem Spindelrand, der Nukleus dem Spindelwinkel ziemlich genähert. Die dicke weisse Kalkplatte ist flach konkav mit einer unregelmässigen Grube am Spindelwinkel, welche durch eine höckerige Lamelle nach oben zu begrenzt wird. 
Fundort: Caramuan in Ostluzon.

Bei dieser Art tritt die schon früher hervorgehobene Uebereinstimmung einzelner Merkmale des Gehäuses und Deckels mit den Formen des Genus Geotrochatella Fischer deutlicher hervor. Die beginnende spirale Anlage des Deckels wird durch die exzentrische Verschiebung des Nukleus und das ungleichmässige Flächenwachstum deutlich erkennbar; die Aehnlichkeit in der Form des Gehäuses ist aber hier eine so auffallende, dass eben nur der Deckel über die systematische Stellung entscheidet.

\section{Geophorus acutissimus Sowerby.}

Taf. 30, Fig. 1-3, Fig. 8-9.

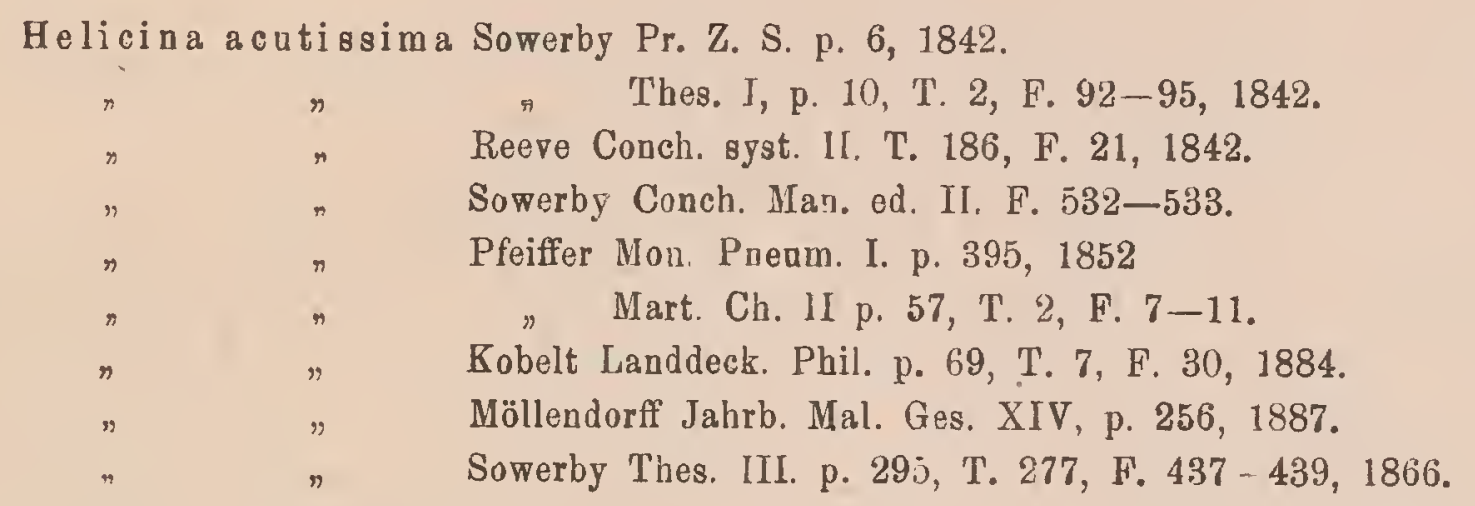

Gehäuse breit kegelförmig mit flach gewölbter Basis, festschalig, einfärbig sı:nmutzıg gelb mit lichterer Basis und einem weissen Kiel, welcher häufig auch an den oberen Umgängen als vorspringender, weisser Nahtfaden sichtbar wird; zumeist mit 3 rotbraunen Bändern (2 Bänder, welche den lichten Kiel einfassen und eines entlang der Naht der unteren Umgänge); die Bänder sind häufig mehr minder verschwommen, so dass die ganze Oberfläche und besonders die Basis rötlich gefärbt erscheint. Die Zuwachsstreifen sind deutlich und ungleichmässig, daneben unter der Lupe einige schwache Spirallinien sichtbar. Die Körnelung auf der Ober- nnd Unterseite gleichmässig, die Oberfläche dementsprechend überall matt. Das regelmässig kegelförmige, oder nur leicht abgerundete Gewinde besteht aus 5 flachen bis kaumi gewölbten Umgängen; der letzte ist scharf gekielt, unten leicht gewölbt bis flach, und steigt vorne sehr wenig oder gar nicht herab. Der gelbliche oder weisse Mundsaum ist leicht verdickt; die kurze Hache Spindel nach aussen gebogen, am Uebergange derselben in den Basalrand nur eine knotenartige Verdickung, aber keine deutliche Ecke. Der dünne, glänzende Basalkallus gelblich und undeutlich begrenzt.

$\mathrm{D}=16, \mathrm{~d}=14, \mathrm{H}=8.5 \mathrm{~mm}$. vom Fundorte: Sierra Bullones auf Bohol.

$\mathrm{D}=15, \mathrm{~d}=12 \cdot 5, \mathrm{H}=9 \cdot 5 \mathrm{~mm}$. vom Fundorte: Insel Leyte.

$D=12, d=10, H=7 \mathrm{~mm}$, vom Fundorte: Insel Siquijor.

Deckel trapezoidisch mit geradem Spindelrand, dicker, weisser, leicht konkaver Kalkplatte, welche am aufgetriebenen Spindelwinkel ein ziemlich tiefes, quäres Grübchen besitzt. I. 18. II. 27. VII. 1908. 
Fundorte: ich kenne die typische Form mit erhobenem Gewinde, flacher Basis, verwaschenen oberen, aber ziemlich scharfem unteren Kielband von den Inseln Bohol (Sierra Bullones und Westküste), Leyte und Siquijor. An diesen Orten variirt die Form vorzüglich nur mit Rücksicht auf die Grösse und das mehr minder abgerundet kegelförmige Gewinde.

\section{Geophorus acutissimus peraculissimus n. Taf. 30, Fig. 4-7:}

Gehäuse dünnschaliger, linsenförmig mit niedrigerem Gewinde, und deutlicher gewölbter Basis; der letzte Umigang ist zusammengedrückt und schärfer gekielt; die Färbung lebhafter, hellgelb, orange bis hellrotbraun; die oberen Bänder erloschen oder nur angedeutet, das untere Kielband häufig verschwommen. Die Unterseite leicht glänzend mit schwacher Körnelung, aber deutlicheren Spirallinien.

$$
D=17, d=14, H=8 \mathrm{~mm} \text {. vom Fundorte: Insel Cebu. }
$$

Fundorte: die Inseln Cebu und Negros; auch diese Form variiert an den einzelnen Fundorten besonders mit Rücksicht auf die Grösse, von der Insel Cebu kenne ich jedoch auch Exemplare, welche zur typischen Form hinüberleiten. Im k. Museum zu Berlin liegen auffallend kleine einfärbig hellrotbraune Exemplare des G.acutissimus $(D=9.5, d=8, H=5 \mathrm{~mm})$, welche nach der beiliegenden Originaletikette Möllendorffs als ${ }_{n}$ Helicina lazarus var. albocarinata Mlldff. vom Fundorte Insel Siquijor" bezeichnet werden. Mit Geophorus lazarus Sowerby hat diese Form bestimmt nichts zu tun, denn der Deckel zeigt das charakteristische Grübchen am Spindelwinkel der Kalkplatte. Ich ziehe diese Form noch zu G. acutissimus peracutissimus n., durch das höhere Gewinde, sowie den stumpferen Kiel, welche einzelne Exemplare aufweisen, wird aber auch ein Uebergang zur typischen Form angedeutet, welche auf dieser Insel ebenfalls nur in kleinen Exemplaren vorkommt.

\section{Geophorus acutissimus trochulus Möllendorff. Taf. 30, Fig. 10-13.}

Helicina acutissima subspec. trochulus Möllendorff J. Senck. vol. 32, p. 179, 1897.

Gehäuse kleiner, breitkegelförmig mit abgeflachter Basis, festschalig, zitrongelb mit gelbweisser Unterseite und weissem Kielstreifen. Die Zuwachsstreifen sind sehr fein und ziemlich gleichmässig. Das höhere abgerundet kegelförmige Gewinde besteht aus $4 \frac{1}{2}$ flachen bis leicht konkaven, langsamer zunehmenden Umgängen; der letzte ist oben leicht gewölbt, mit stärker vorspringendem, etwas aufgetriebenem Kiel, welcher auch auf den oberen Umgăngen als vorspringende Nahtkante sichtbar wird. Der weisse Mundsaum mehr verdickt.

$$
D=7 \cdot 5, d=6 \cdot 5, H=5 \mathrm{~mm} \text {. }
$$


Kalkplatte.

Deckel breiter, annähernd viereckig mit deutlichem Grübchen am Spindelwinkel der

Fundort: die Insel Romblon; diese Form nähert sich mit Rücksicht auf die Form des Gehăuses auffallend der Formenreihe des Geophorus trochiformis Sowerby.

\section{Geophorus trochiformis Sowerby.}

Taf. 29, Fig. 6-11.

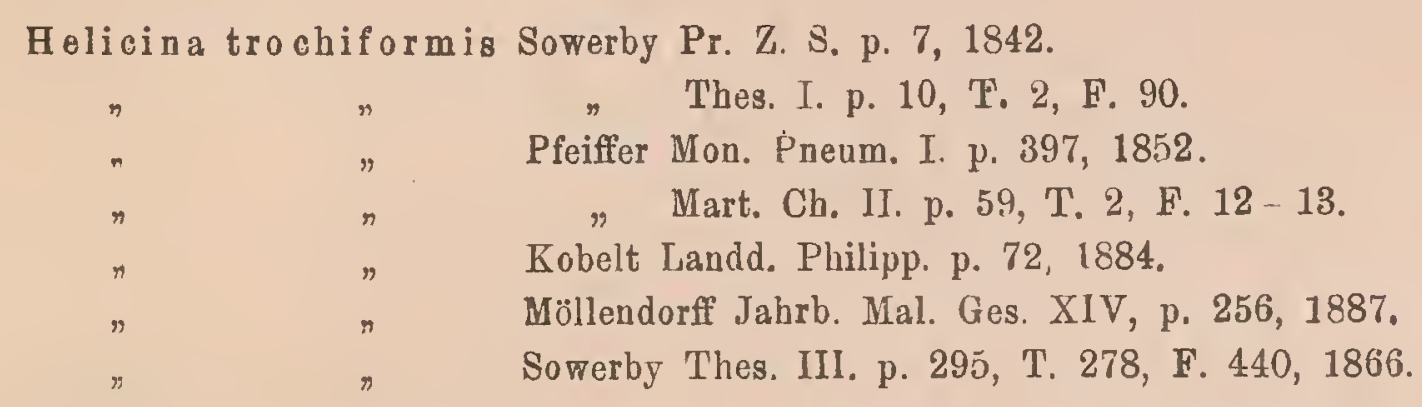

Gehäuse kegelförmig mit flachgewölbter Basis, einfärbig hellgelb bis zitrongelb mit lichterem letzten Umgang und weissem Kielstreifen. Die feinen Zuwachsstreifen sind ungleichmässig, die Körnelung sehr zart. Das regelmässig kegelförmige oder leicht abgerundete Gewinde besitzt eine verhaltnismässig stumpfe Spitze und besteht aus $4^{1} / 2$ flachen oder kaum gewölbten, ziemlich langsam zunehmenden Umgängen; der letzte ist oben deutlich gewölbt, mit ziemlich scharfem, leicht vorspringenden Kiel, welcher auch an den oberen Umgängen als weisser, vorspringender Nahtstreifen sichtbar ist; vorne wenig, aber deutlich unter den Kiel herab̀steigend. Der gelbliche Mundsaum dünner, kaum ausgebreitet, innen mit einer schwachen, lippenartigen Verdickung. Die kurze, flache oder nur wenig konvexe Spindel ist leicht nach aussen und hinten gebogen oder nahezu senkrecht; am Uebergange derselben in den Basalrand der Mündung eine stumpfe nach unten vorspringende Ecke, welche dementsprechend nur in der Ansicht von vorne deutlich sichtbar ist. Der dünne gelbliche Basalkallus ist undeutlich begrenzt.

$$
\mathrm{D}=6.5, \mathrm{~d}=5 \cdot 5, \mathrm{H}=5.5 \mathrm{~mm} .
$$

Deckel annähernd viereckig, wenig höher, als breit; die Kalkplatte am Spindelrande etwas verdickt und leistenförmig erhoben, am Spindelende in der Längsrichtung rinnenartig vertieft und nach rückwarts gebogen.

Fundorte: ich beurteile diese Art nach einem Exemplare vom Originalfundorte, der Insel Negros, welches sich im k. Museum zu Berlin befindet. (Taf. 29, Fig. 6-8); eine sehr ăhnliche Form mit deutlicheren Zuwachsstreifen, orangegelber Färbung, deutlicher gewölbten Umgängen und mitunter einer deutlicheren Ecke am unteren Ende der Spindel erhielt ich von Möllendorff mit der Fundortsangabe Karamuan auf S.-0.Luzon. Möllendorff führt die typische Form ausserdem von den Inseln Samar und Katanduanes an. 
233. Geophorus trochiformis subtrochiformis Möllendorff. Taf. 29, Fig. 12-14.

Helicina agg lutinans var, subtrochiformis Möllendorff J. Senck. vol. 22, p. 179, 1897.

Gehäuse hellgelb oder gelblichweiss mit niedrigerem, mehr abgerundeten Gewinde, stärker vorspringendem weissem Nahtstreifen, auffallend gewölbtem letzten Umgang und deutlicher vorspringender Ecke am Uebergange der Spindel in den Basalrand der Mündung.

Deckel wie bei der typischen Form.

$$
\mathrm{D}=7, \mathrm{~d}=6, \mathrm{H}=5.5 \mathrm{~mm} \text {. }
$$

Fundort: Monte Estravio auf der Insel Marinduque.

\section{Geophorus trochiformis conoidalis Möllendorff. Taf. 29, Fig. 15-16.}

Helicina agglutinans var. conoidalis Möllendorff J. Senck., vol. 22, p. 179, 1897.

Gehäuse grösser, dünnschaliger, die oberen Umgänge orange, der letzte hellgelb mit weissem Kielstreifen. Das weniger erhobene Gewinde besteht aus 5 etwas rascher zunehmenden, deutlicher gewölbten Umgängen; der letzte ist schärfer gekielt, unten abgeflacht, vorne nicht herabsteigend; die Ecke am Uebergange der Spindel in den Basalrand deutlicher vorspringend.

$$
\mathrm{D}=13.5, \mathrm{~d}=10.5, \mathrm{H}=8 \mathrm{~mm} \text {. }
$$

Deckel wie bei der typischen Form.

Fundort: die Insel Marinduque.

Die Form des Gehăuses erinnert sowohl an G. acutissimus Sowerby als an G. agglutinans Sowerby, doch entscheidet auch hier die Beschaffenheit des Deckels, welcher eine deutliche Furche und kein Grübchen an Spindelende der Kalkplatte besitzt, die Zugehörigkeit zur vorstehenden Formenreihe.

\section{Geophorus trochiformis gibbosulus Möllendorff.} Taf. 29, Fig. 17-19.

Helicina gibbosula Möllendorff J. Senck., vol. 22, p. 180, 1897.

Gehäuse grösser, hellgrün oder gelbgrün mit weisser oder gelbgrüner Mündung und einem weissen Kielstreifen. Das niedrigere Gewinde besteht aus $4 \frac{1}{2}$ rascher zunehmenden 
deutlicher gewölbten Umgängen; der letzte ist beiderseits mehr gewölbt, der Mundsaum stärker verdickt, der Basalkallus deutlicher begrenzt.

Deckel wie bei der typischen Form.

$$
\mathrm{D}=9, \mathrm{~d}=8, \mathrm{H}=6.5 \mathrm{~mm} \text {. }
$$

Fundort: Tayabas in Mittelluzon.

Auch diese Form liegt mir in Originalexemplaren des Autors vor; die Uebereinstimmung der wesentlichen Merkmale mit Geophorus trochiformis Sowerby ist zu auffallend, um die Art im Sinne Möllendorffs aufrecht zu erhalten.

\section{Zusatz zum Genus Geotrochatella P. Fischer.}

\section{Geotrochatella nogieri Dautzenberg et d'Hamonville.} Taf. 3i, Fig. 5.

Die Abbildung und Beschreibung unter Nr. 12, Taf. 1, Fig. 16, 17 wurde nach einem Originalexemplare entworfen, welches stark verwittert und ausgeblichen war; nun liegen mir frische Exemplare vom Originalfundorte Than-Moi in Tonkin vor und ist dementsprechend die Beschreibung zu ergänzen: das Gehäuse oben hellzitrongelb mit unregelmässigen weissen Flecken und heller bis weisser Kielkrause, unten gelblichweiss; die Kielkrause breit und stark wellenförmig gefaltet; die Basis in der Umgebung der Spindel flach eingedrückt.

Als weiteren Fundort führe ich das Massiv von Bac-Son, nordöstlich von Long-Son in Tonkin an; das mir vorliegende Exemplar dieses Fundortes zeigt eine auffallend stärker gewölbte Basis.

\section{Geotrochatella jourdyi excelsan.}

Taf. 31, Fig. 6-8.

Gehäuse grösser, festschaliger mit höherem, unter der Spitze weniger konkavem Gewinde; die Spiralstreifen sind auf der Oberseite kraftiger und auch auf den mittleren Umgängen noch deutlich vorhanden, auf der Unterseite jedoch schwächcr und dichter, als bei der typischen Form von Krieou. Der Mundsaum ist wulstig verdickt und wie der kraftige Basalkallus lebhaft zitrongelb gefärbt.

$$
\mathrm{D}=18, \mathrm{~d}=16 \cdot 5, \mathrm{H}=11 \mathrm{~mm} \text {. }
$$

Deckel, wie bei der typischen Form.

Fundort: Pedalongo in Tonkin; die Beschreibung und Abbildung nach Exemplaren des k. Museums in Berliu. Die Dimensionen der typischen Form sind bei No. 9 p. 12 unrichtig angegeben und betragen nur $\mathrm{D}=14, \mathrm{~d}=12, \mathrm{H}=7.5 \mathrm{~mm}$. 


\section{Geuns Aphanoconia A. J. Wagner.}

Genus Aphanoconia A. J. Wagner Helicinenstudien in Denkschriften der kaiserl. Akad. Wien v. 77 p. 388, 1905. Die Formenkreise Primeana A. J. Wagner (part.) Sublaevigata A. J. Wagner, Musiva A.I J. Wagner des Genus Orobophana A. J. Wagner, Helicinenstudien, in: Denkschriften der kaiserl. Akad, Wien. v. 77, p. $415,1905$.

Das Gehäuse klein, linsenförmig bis kegelförmig mit gewölbter Basis. Das zumeist niedrige und leicht konvexe Gewinde besteht aus $3{ }^{1} / 2-5$ ziemlich rasch zunehmenden, wenig gewölbten bis flachen Umgängen; der letzte ist gekielt oder doch deutlich kantig und steigt vorne wenig odel' gar nicht herab. Die dreieckige Mündung wir'd durch den vorletzten Umgang nicht ausgeschnitten; der zumeist nur wenig verdickte Mundsaum ist kurz ausgebreitet; der Oberrand fast gerade, der Basalrand oft umgeschlagen. Der halbkreisförmig ausgebreitete Basalkallus ist ziemlich dünn, aber deutlich begrenzt. Neben der unscheinbaren, gelblichen bis rötlichen Grundfarbe treten häufig radiale Zickzackstriemen auf, welche mitunter in der Mitte erlöschen und dann Fleckenbänder darstミllen, welche besonders an Naht und Kiel deutlich werden. Die Skulptur besteht neben den zumeist schwachen und ziemlich gleichmässigen Zuwachsstreifen vielfach aus feinen Spiralfalten der hinfälligen Epidermis, welchen an abgeriebenen Exemplaren zum Teile feine eingedrückte Spirallinien, bei einzelnen Formenkreisen aber auch mehr, minder erhobene Spiralleisten entsprechen. Die bei den Geschlechtern Geophorus Fischer und Eutrochatella Fischer fast regelmässig beobachtete Erdkruste, welche der Epidermis fest anhaftet, tritt auch bei einzelnen Formen dieser Gruppe auf.

Der Deckel dreieckig bis nahezu halbkreisförmig mit geradem oder konvexem Spindelrand, und verschmälertem bis zugespitzten unteren Ende, welches ausserdem nach rückwärts gebogen erscheint. Der Nukleus ist leicht exzentrisch und dem Spindelrande genähert, jedoch vom oberen Winkel und Spindelwinkel ziemlich gleich weit entfernt; seine Längsachse schief zur Längsachse des Deckels. Die Sigmakante ist wenig gebogen, am Nukleus jedoch winklig gebrochen und nur im unteren, nahezu senkrechten Aste als ziemlich steile Leiste erhoben, während der obere Ast zumeist nur an der winkeligen Knickung der Zuwachsstreifen erkennbar ist. Die Aussenseite der Platte höchstens 2 mal breiter, als die Spindelseite. Die ziemlich feste bis knochenartige Kalkplatte ist entsprechend dem Verlaufe der Sigmakante furchenartig eingebogen; diese Furche wird nach abwärts zu tiefer und erscheint gegen die Spindelseite durch eine ziemlich steil ansteigende Leiste der Kalkplatte begrenzt.

Das Verbreitungsgebiet erstreckt sich anscheinend über alle von Heliciniden bewohnten Länder der alten Welt. 
Es ist nicht gut möglich das Genus Aphanoconia durch eine kurze Diagnose ausreichend zu kennzeichnen, denn dasselbe umfasst eine Anzahl von Formenkreisen, welche eine nahe Verwandtschaft zu einander erkennen lassen, jedoch in ihren extremen Gliedern solche Merkmale vereinigen, dass hiedurch Uebergänge zu den Geschlechtern Sulfurina und Sturanya einerseits zu Geophorus und Orobophana anderseits vermittelt werden.

Am besten wird das Genus durch die Beschaffenheit des Deckels gekennzeichnet; die charakteristische Längsfurche der Kalkplatte, welche an der Spindelseite durch eine mehr minder steil ansteigende Leiste deutlich begrenzt wird, ebenso das verschmälerte und nach rückwärts gebogene Spindelende des Deckels werden bei allen Formenkreisen deutlich und gleichmässig beobachtet. Weniger charakteristisch ist die Beschaffenheit der Sigmakante, die mehr minder exzentrische Lage des Nukleus und das Verhältnis des Spindelteiles zum Aussenteile des Deckels. Diese Gebilde treten hier in einem Grade mittlerer Entwicklnug auf, so dass die Abgrenzung gegen ähnliche, wenn auch extreme Entwicklungsformen bei anderen Geschlechtern nicht immer genügend scharf durchführbar ist. Die Gehäuse weisen bei den einzelnen Formenkreisen vielfach sehr auffallende Merkmale auf, eine systematische Bedeutung gewinnen dieselben aber erst in Verbindung mit dem Deckel, denn ähnliche Gebäuse besitzen auch viele Formen der Geschlechter Palaeohelicina Wagner und Helicina s. str., daneben aber einen wesentlich verschiedenen Deckel. So Fird eine sichere Determination hier mehr, als bei anderen Geschlechtern der Familie von der genauen Untersuchung des Deckels abhängig gemacht.

\title{
Subgenus Aphanoconia s. str.
}

\section{Formenkreis Fulgora A. J. Wagner.}

\author{
238. Aphanoconia samoanan. \\ Taf. 31, Fig. 9-13. \\ Helicina falgora auctor. nec. Gould. \\ A. J. Wagner Helicinenstadien in Denk. Arad. Wien v. 77, p. 52, t. 6 \\ fig. $16 \mathrm{a}, \mathrm{b}, \mathrm{c} 1905$.
}

Gebäuse dicklinsenförmig, ziemlich dünnschalig und durchscheinend, glänzend mit undeutlichen Zuwachsstreifen. Die Grundfarbe gelblich hornfarben bis grünlich mit abwechselnd rotbraunen und milchweissen, radialen Ziekzackstriemen, welche an Naht und Kiei stärker hervortreten. Das regelnuassig breit kegrelförmige Gewinde besteht aus $4 \frac{1}{2} / 2$ leicht gewölbten bis nahezu flachen, ziemlich rasch zunehmenden Umgängen; der letzte ist beiderseits :gleichmässig gewölbt, scharf und zusammengedrückt gekielt und steigt vorne nicht herab. Die trapezoidische Mündung ist wenig schief, der weisse, kaum verdickte Mundssum kurz ausgebreitet, der Aussenrand entsprechend dem Kiele winkelig vorgezogen, den Basalrand kaum umgeschlagen. Die senkrechte, abgeflachte Spindel ist lebhaft rotbraun gefärbt und geht im 
rechten Winkel in den Basalrand über. Der dünne, durchsichtige Basalkallus ist wenig deutlich begrenzt.

$$
\mathrm{D}=6 \cdot 4-8 \cdot 5, \mathrm{~d}=54-7, \mathrm{H}=4 \cdot 4-5.5 \mathrm{~mm} .
$$

Deckel abgerundet dreieckig mit ziemlich dünner, durchscheinender und feingekörnelter Kalkplatte, sonst typisch.

Fundort: die Samoa Inseln (Upolu).

Die vorstehende Form wird gegenwärtig allgemein als Helicina fulgora bezeichnet; nach der Angabe des Autors lebt diese ähnliche Form jedoch auf den Sandwich-Inseln, hat aber inzwischen die Bezeichnung Helicina sandwichensis Souleyet erhalten, während die altere Bezeichnung von Mousson und Anderen auf die ähnlichen Vorkommnisse von den Samoa, Viti und Tonga Inseln angewendet wurden. Die Originaldiagnose passt so ziemlich auf beide hier angeführten Formen, so muss schliesslich die Fundortsangabe entscheiden.

\author{
239. Aphanoconia samoana vicina n. \\ Taf. 31, Fig. 14. \\ Aphanoconia falgora A. J. Wagner (part.) Helicinenstudien in: Denk. Akad. Wien. v. 77, \\ p. 53,1905 .
}

Das Gehăuse mit rascher zunehmenden Umgăngen, schärferem Kiel und mehr ausgebreitetem Mundsaum; die leicht nach vorne gebogene Spindel bildet am Uebergange in den Basalrand eine etwas abgerundete, aber deutliche Ecke.

$$
\mathrm{D}=7 \cdot 5, \mathrm{~d}=6, \mathrm{H}=4 \cdot 6 \mathrm{~mm} \text {. }
$$

Fundort: Viti Levu und Vannua Levu der Viti Inseln.

\title{
240. A phanoconia samoana diminuta Mousson. Taf. 31, Fig. 15. 16.
}

Helicina fulgora var. diminuta Monsson J. de Conch. p. 25, 1871.

Aphanoconia fulgora diminata A. J. Wagner Helicinenstudien in Denk. Akad. Wien. จ. 77, p. 53 , t. 6 , fig. $18 \mathrm{a}, \mathrm{b}, \mathrm{c}, 190$ 5.

Gehäuse kleiner, festschaligcr mit $4-4^{1} \frac{1}{2}$ etwas langsamer zunehmenden Umgăngen; die Zuwachsstreifen] sind an letzten Umgange deutlicher, ausserdem einige feine, eingedrückte Spirallinien vorhanden. Der Kiel deutlich stumpfer; die nach vorne gebogene Spindel bildet am Uebergange in den Basalrand eine deutlich vorspringende Dcke.

Deckel wie bei der typischen Form.

$$
\mathrm{D}=5 \cdot 8, \mathrm{~d}=5, \mathrm{H}=3.6 \mathrm{~mm} \text {. }
$$

Fundort die Tonga Inseln. 


\title{
241. A phanoconia zigzag Pease.
}

\author{
Taf. 31, Fig. 17-19.
}

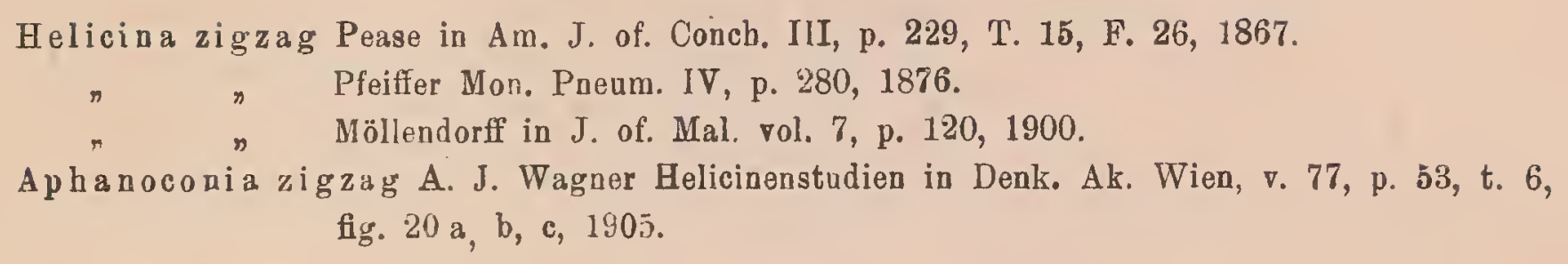

Gehause flachkegelförmig mit gut gewölbter Basis ziemlich dünnschalig, frische Exemplare matt; die Grundfarbe schmutziggelb oder grünlich mit abwechselnd rotbraunen und weissen Zickzackstriemen, welche am Kiel und Naht kräftiger sind. Die Skulptur besteht nur aus sehr feinen und gleichmässigen Zuwachsstreifen. Das flachkegelförmige, kaum abgerundete Gewinde besteht aus $4:{ }_{2}^{1}$ nahezu flachen, regelmässig zunehmenden Umgängen ; der letzte ist unten mehr gewölbt, in Beginne ziemlich scharf gekielt, in der zweiten Hălfte nur mehr stumpfkantig und steigt vorne kaum oder gar nicht unter den Kiel herab. Die dreieckige Mündung ist schief, der Mundsaum dünn, scharf und gerade. Die kurze, nabezu senkrechte Spindel ist etwas abgerundet und bildet mit dem Basalrand in der Frontalansicht eiren Winkel, von unten betrachtet ist daselbst jedoch keine Ecke vorhanden. Der ziemlich dünne, in der Mitte weissliche Basalkallus ist deutlich begrenzt.

$$
\mathrm{D}=6, \mathrm{~d}=5 \cdot 2, \mathrm{H}=4 \mathrm{~mm} \text {. }
$$

Deckel mit rötlicher, feingekörnelter Kalkplatte, sonst wie bei A. samoana Wagner.

Fundorte: die Inseln Oualan und Ponapé der Ostkarolinen.

Von A. samoana Wagner unterscheidet sich vorstehende Art durch das niedrigere, weniger abgerundete Gewinde, die flacheren Umgänge, den stumpferen Kiel, den scharfen und geraden Mundsaum, sowie die kürzere, abgerundete Spindel.

\section{Aphanoconia zigzag ponapensis A. J. Wagner.}

A phanoconiazigzag ponapensis A. J. Wagner, in: Denk. Ak. Wien. v. 77 p. 53, 1905.

Das Gehäuse grösser, dünnschaliger, mit schwächeren, oft erloschenen Zickzackstreifen und dann einfarbig hornbraun bis rotbraun. Der letzte Umgang ist stumpfer gekielt, gegen die Mündung zu gerundet.

$$
\mathrm{D}=7 \cdot 5, \mathrm{~d}=6 \cdot 5, \mathrm{H}=5 \mathrm{~mm} \text {. }
$$

Deckel rotbraun, sonst wie bei der typischen Gorm.

Fundort: Ponapé der Ostkarolinen.

I. 18. II. 


\title{
243. Aphanoconia articulata Pfeiffer.
}

Taf. 32, Fig. 1-3.

\author{
Helina articulata Pfeiffer Pr. Z. S. p. 53, 1853.

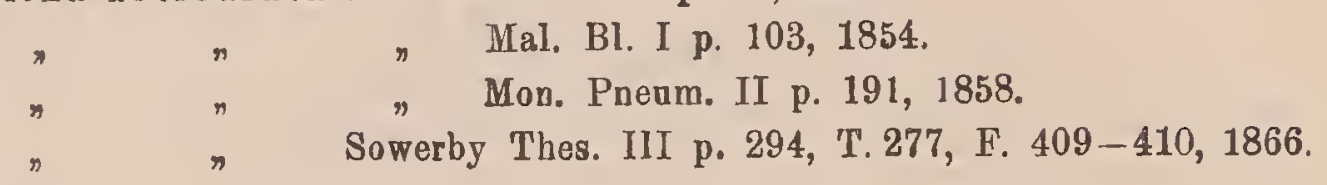

Gehäuse flachkegelförmig mit gut gewölbter Basis, ziemlich festschalig, im frischen Zustande matt mit einigen hinfälligen spiralen Epidermisfalten; abgerieben glänzend, sehr fein radial gestreift, nebst einigen undeutlichen und sehr feinen Spiralfurchen. Die Grundfarbe ist gelb, gelbbraun bis rötlich (mit eingetrocknetem Tier grüulich) mit braun und weiss gegliederten Băndern an Naht und Kiel als Ausdruck von in der Mitte erloschenen Zickzackstriemen. Das flachkegelförmige Gewinde besteht aus $3^{1 / 2}$ bis 4 ziemlich rasch zunehmenden, flachen Umgängen; der letzte ist unten stärker gewölbt, ziemlich scharf gekielt und steigt vorne kaum herab; oben ist der Kiel häufig durch eine eingedrückte Linie berandet und wird gegen die Mündung zu stumpfer. Die dreieckige Mündung ist schief, der weisse, leicht verdickte Mundsaum, kaum ausgebreitet. Die kurze, abgerundete Spindel geht im winkeligen Bogen in den Basalrand über und bildet daselbst nur eine undeutliche, kaum vorspringende Ecke. Der ziemlich dicke, in der Mitte weissliche Basalkallus ist deutlich begrenzt.

$$
\mathrm{D}=5 \cdot 2, \mathrm{~d}=4 \cdot 6, \mathrm{H}=3 \cdot 4 \mathrm{~mm} \text {. }
$$

Deckel mit gelblicher, feingekörnelter Kalkplatte, sonst wie bei A. samoana Wagner. Fundort: die Neuen Hebriden (Tanna, Vate).

\section{A phanoconia oceanica H. Pease.}

Taf. 32, Fig. 20-22.

Helicina oceanica H. Pease Ann. J. of Conch. 3, p. 226, 1867.

* $\quad$ Pfeiffer Mon. Pnenm. IV p. 252, 1876.

Aphanoconia oceanica A. J. Waguer Helicinenstudien in Denk. Ak. Wien. v. 77 p. 56, T. 7, F. $1 \mathrm{a}, \mathrm{b}, \mathrm{c}, 1905$.

Gehäuse linsenförmig, ziemlich dünnschalig, leicht glänzend, und sehr fein radial gestreift. Die Grundfarbe gelblich bis rötlich mit abwechselnd rotbraunen und milchweissen Zickzackstriemen. Das flachkegelförmige Gewinde besteht aus 4 ziemlich langsam zunehmenden, kaum gewölbten bis flachen Umgängen, welche durch eine eingedrückte Naht geschieden werden; der letzte ist ziemlich scharf gekielt und steigt sehr wenig, mitunter aber schon in der 2. Hälfte unter Kiel herab. Die dreieckige Mündung ist sehr schief, der weisse leicht verdickte Mundsaum sehr kurz ausgebreitet. Die kurze nach vorne gebogene Spindel bildet 
am Uebergange in den Basalrand eine stumpfe, aber deutliche Ecke. Der dünne, durchsichtige Basalkallus ist undeutlich begrenzt.

$$
\mathrm{D}=3 \cdot 8, \mathrm{~d}=3 \cdot 5, \mathrm{H}=2 \cdot 4 \mathrm{~mm} .
$$

Deckel annähernd halbkreisförmig mit verhăltnismässig dicker, feingekörnelter Kalkplatte; die Sigmakante im unteren Aste senkrecht und kräftig erhoben; sonst typisch.

Fundort: die Insel Apaiang der Gilbert Inseln (Kingsmill).

\section{A phanoconia fulgora Gould. Taf. 32, Fig. $12-15$.}

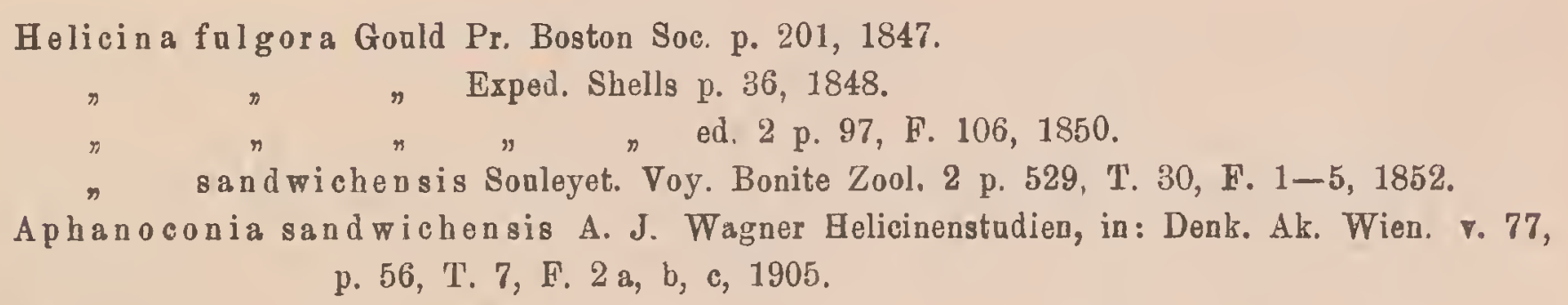

Gehäuse breit kegelförmig mit flachgewölbter Basis, ziemlich festschalig, wenig glänzend mit hinfälligen spiralen Epidermisfalten, abgerieben glänzend, sehr fein radial gestreift nebst einigen Spiralfurchen, welche mitunter den Kiel beranden oder doppelt erscheinen lassen, jedoch oft fehlen. Die Grundfarbe ist gelblich bis rotbraun mit abwechselnd weissen und rotbraunen Zickzackstriemen, welche an Naht und Kiel deutlicher hervortreten. Das breitkegelförmige, etwas abgerundete Gewinde besteht aus $4-4 \frac{1}{2}$ ziemlich rasch zunehmenden, nahezu flachen Umgängen; der letzte ist scharf gekielt und steigt wenig, häufig aber schon in der zweiten Halfte unter den Kiel herab. Die dreieckige Mündung ist schief, der dünne Mundsaum gerade. Die kurze, etwas abgeflachte Spindel ist leicht nach vorne gebogen, am Uebergange derselben in den Basalrand, befindet sich keine Ecke. Der dünne, gekörnelte Basalkallus ist nur im Umkreise der Spindel deutlicher begrenzt.

$$
\mathrm{D}=5, \mathrm{~d}=4 \cdot 3, \mathrm{H}=3 \cdot 2 \mathrm{~mm} \text {. }
$$

Deckel mit hellrotbrauner feingekörnelter Kalkplatte; sonst typisch.

Fundort: die Sandwich Inseln (Oahu).

Wie ich schon bei A samoana $\mathrm{n}$. bemerkt habe ist diese gleichfalls zickzackförmig gestriente und gekielte "Helicina" der Samoa Inseln mit der vorstehenden Art verwechselt worden; nachdem aber als Originalfundort der A. fulgora Gould die Sandwich Inseln angeführt werden und die vorstehende Form auch der Diagnose entspricht, muss diese auch die alte Bezeichnung erhalten. Es ist möglich, dass Gould auch die Formen von den Samoa und Tongainseln vorgelegen haben, jedenfalls hat er dieselben nicht unterschieden und so muss die Fundortsangabe den Ausschlag geben. 


\title{
246. Aphanoconia suturalis Martens.
}

Taf. 32. Fig. 4-9.

\author{
Helicina suturalis Martens MLonatsb. Akad. p. 120, 1864. \\ " $\quad$ Pfeiffer Mon. Pneum. p. 244, 1865. \\ n Martens Ostas. Zool. II p. 168, T. 4, F. 18, 1868. \\ " $\quad$ Sowerby Thes. III, p. ¿94, T. 277, F. 404-405, 1866. \\ Aphanoconia suturalis A. J. Wayner Helicinenstudien in: Denk Ak. Wien. v. 77, p. 55 \\ T. 6, F. $14 \mathrm{a}, \mathrm{b}, \mathrm{c}, 1905$.
}

Gehäuse linsenförmig, festschalig, wenig glänzend bis matt; die Grundfarbe schmutziggelb, hornfarben bis rotbraun mit ziemlich schmalen, abwechselnd rotbraunen und weissen Zickzackstriemen; mitunter sind die Striemen bis auf rot und weiss gegliederte Binden entlang dem Kiel und der Naht erloschen. Frische Exemplare sind matt, mit ziemlich entfernt stehenden, hinfälligen Spiralfalten der Epidermis, abgeriebene Exemplare glänzend mit sebr feinen Zuwachsstreifen. Das flachkegelförmige, mitunter etwas abgerundete Gewinde besteht aus 4 regelmässig zunehmenden, kaum gewölbten bis flachen Umgängen; der letzte ist scharf und zusammengedrückt gekielt und steigt vorne unmerklich oder gar nicht herab. Die dreieckige Mündung ist schief, der weisse, innen lippenartig verdickte Mundsaum ziemlich ausgebreitet: der Aussenrad entsprechend dem Kiele etwas winkelig vorgezogen. Die sehr kurze, abgerundete Spindel geht im winkeligen Bogen in den Basalrand über und bildet am Uebergange eine kaum vorspringende, stumpfe Ecke. Der durchsichtige, glänzende Basalkallus ist nur im Umkreise der Spindel merklich verdickt und deutlicher begrenzt.

$$
\mathrm{D}=9, \mathrm{~d}=8, \mathrm{H}=5.5 \mathrm{~mm} \text {. }
$$

Deckel dreieckig mit dicker, gelblicher, gekörnelter Kalkplatte; die Sigmakante im unteren, nahezu senkrechten Aste kräftig erhoben; sonst typisch.

Fundorte: die Inseln Ambon, Ceram, Buru und Saparua der Molukken; das einzige Exemplar, welches mir von der Insel Buru vorliegt, zeigt ein verbältnismässig niedriges stärker abgerundetes Gewinde. Taf. 32, Fig. 9.

\section{Aphanoconia suturalis dammerensis A. J. Wagncr. Taf. 32, Fig. 10.}

A phanoconia suturalis dammerensis A. \%. Wagner Helicinenstadien in Denk. Ak. Wien. v. 77, p. 55, T. 7, F. 3 a, b, c, 1905.

Gehäuse auffallend flachlinsenförmig, oben und unten weniger gewölbt mit deutlichen Spirallinien; die Zickzackstriemen zumeist auf gegliederte Naht und Kielbänder reduziert. 
Deckel wie bei der typischen Form.

$$
\mathrm{D}=9 \cdot 5, \mathrm{~d}=8, \mathrm{H}=4.5 \text {. }
$$

Fundort: die Insel Dammer der Molukken.

\section{Aphanoconia altivaga Ancey.}

Taf. 32, Fig. 11.

Helicina a Itivaga Ancey, in Naturaliste, v. 11, p. 204, 1889.

Aphanoconia altivaga A. J Wagner Helicinenstudien in: Denk. Ak Wien. v. 77, p. 55, T. 7, E. 3 a, b, c, 1905 .

Gehäuse abgerundet kegelförmig mit flachgewölbter Basis, festschalig, wenig glänzend; die Grundfarbe horngelb bis hellbraun mit abwechselnd weissen und rotbraunen Zickzackstriemen auf dem letzten Umgange, während die oberen Umgänge einfârbig oder nur mit einer gegliederten Nalitbinde versehen sind; neben dichten und feinen Zuwachsstreifen sind feine eingedrückte Spirallinien vorhanden, welche am letzten Umrange undeutlich werden. Das abgerundet kegelförmige Gewinde besteht aus 5 ziemlich langsam zunehmenden, fast flachen Umgangen, welche durch eine berandete Naht geschieden werden; der letzte ist scharf und zusanmmengedrückt gekielt und steigt schon in der zweiten Halfte etwas unter den Kiel herab. Die dreieckige Mündung ist schief, der weisse, verdickte Mundsaum ziemlich ausgebreitet, der Basalrand schmal umgeschlagen. Die kurze, senkrechte Spindel ist rotbraun gefärbt und bildet am Uebergange in den Basalrand eine stumpfe, aber deutlich vorspringende Ecke. Der ziemlich dicke, feingekörnelte Basalkallus ist in der Mitte milchig. getrübt, deutlich begrenzt.

Deckel wie bei A. suturalis Martens.

$$
\mathrm{D}=9, \mathrm{~d}=8, \mathrm{H}=6 \mathrm{~mm} .
$$

Fundort: die Samoa Inseln (Upolu, Savai).

\section{A phanoconia gallina Gassies.}

Taf. 32. Fig. 16-19.

Helicina gallina Gassies J. de Conch. v. 18, p. 145, 1870.

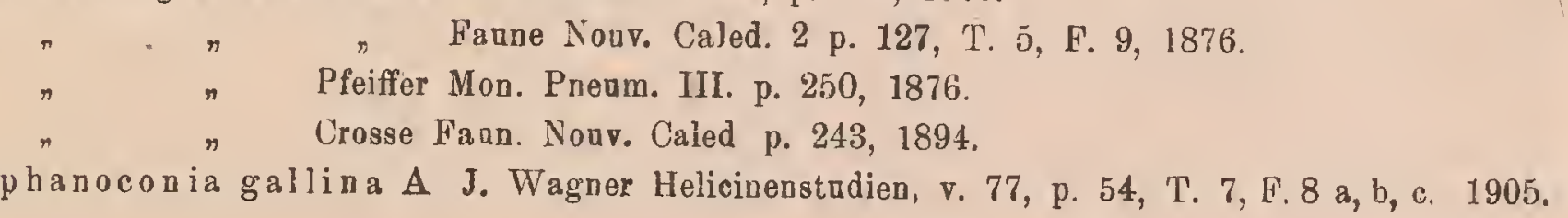

Gehäuse dicklinsenförmig bis flachkugelig, ziemlich dünnschalig, im frischem Zustande matt mit dichten, feinen Spiralfalten der Epidermis, abgerieben glänzend, sehr fein radial 
gestreift, nebst einigen feinen Spirallinien auf den oberen Umgăngen. Das niedrige, flachkegelförmige Gewinde besteht aus 4 rasch zunehmenden kaum gewölbten Umgängen, welche durch eine seichte Naht geschieden werden; der letzte ist unten mehr gewölbt, an der Peripherie stumpf gekielt, in der zweiten Hälfte nur mehr stumpflantig und steigt vorne nicht herab. Die abgerundet dreieckige Mündung ist ziemlich schief, der weisse Mundsaum zumeist scharf und gerade; nur vereinzelte Exemplare weissen einen leicht verdickten, kurzausgebreiteten Mundsaum auf. Die Grundfarbe ist gelblich, grünlich bis hellrotbraun mit weiss und rotbraun gegliederten Bändern am Kiel und der Naht der unteren Umgänge;-mitunter sind auch einige breite Zickzackstriemen vorhanden. Die kurze, etwas abgeflachte Spindel ist etwas nach vorne gebogen und bildet mit dem Basalrand der Mündung eine ziemlich scharfe, vorspringende Ecke. Der glänzende, weisslich getrübte Basalkallus ist ziemlich dünn, aber deutlich begrenzt.

$$
\mathrm{D}=5 \cdot 5, \mathrm{~d}=4 \cdot 5, \mathrm{H}=3.5 \mathrm{~mm} \text {. }
$$

Deckel gelblich mit zarter, fein gekörnelter Kalkplatte, sonst typisch.

Fundorte: Neu-Caledonien, die Pinien und die Loyalty-Inseln.

Die zahlreichen Exemplare dieser Art, welche ich in den Sammlungen gesehen habe, weisen einen geraden, scharfen Mundsaum auf; diese sind als unausgewachsen zu betrachten, da es mir gelungen ist, auch 2 Exemplere mit verdicktem, kurz ausgebreiteten Mundsaum zu finden.

\title{
Formenkreis Discoidea A. J. Wagner.
}

\author{
250. Aphanoconia pentheri A. J. Wagner. \\ Taf. 32, Fig. 23-26.
}

Aphanoconia pentheri A. J. Wagner Helicinenstudinm in: Denk. Ak. Wien. v. 77, p. 52, T. 7, F. 13 a, b, c, 1905.

Gehäuse linsenförmig, ziemlich festschalig, mit zarter, hinfälliger Epidermis; abgeriebene Exemplare sind sehr fein und dicht radial gestreift und nahezu seidenglänzend; grünlich gelb oder hellhornfarben mit hellem oder rötlichen Kielstreifen. Das niedrige, flach kegelförmige Gewinde besteht aus 4 kaum gewölbten, ziemlich rasch zunehmenden Umgängen, welche durch eine seichte, mitunter etwas kantige Naht geschieden werden; der letzte ist unten mehr gewölbt, an der Peripherie scharf gekielt und steigt vorne sehr wenig herab. Die dreieckige Mündung ist ziemlich schief, der gelbliche Mundsaum innen lippenartig verdickt, nahezu gerade, der Aussenrand entsprechend dem Kiele etwas winkelig vorgezogen. Die sehr kurze Spindel ist etwas nach aussen gebogen und bildet am Uebergange in den Basalrand eine undeutliche Ecke. Der ziemlich dicke gelbliche Basalkallus ist sehr fein gekörnelt und deutlich begrenzt. 


$$
\mathrm{D}=9, \mathrm{~d}=7 \cdot 5, \mathrm{H}=5.5 \mathrm{~mm} \text {. }
$$

Deckel dreieckig mit gelblicher, feingekörnelter Kalkplatte; sonst typisch.

Fundort: die Insel Tahiti.

\title{
251. A phanoconia discoidea Pease.
}

Taf. 33, Fig. 4-7.

\author{
Helicina discoidea Pease, Amer. Journ. of Conch. III, p. 226, 1866. \\ Pfeiffer, Mon. Pnenm. IV, p. 286, 1876. \\ Aphanoconia discoidea A. J. Wagner Helicinenstudien in: Denk. Ak. Wien, จ. 77, p.57, \\ T. 7, F. 4 a, b, c, 1905 .
}

Gehäuse linsenförmig, schwach glänzend schmutziggelb bis gelbbraun mit sehr feinen bis undeutlichen Zuwachsstreifen. Das flachkegelförmige Gewinde besteht aus 4 langsam und regelmässig zunehmenden, nahezu flachen Ungängen; der letzte ist scharf gekielt und steigt volne kaum herab; der Kiel wird mitunter durch eine Furche in zwei Rippen geteilt. Die dreieckige Mündung ist ziemlich schief, der weisse Mundsaum leicht verdickt, kurz ausgebreitet, der Aussenrand entsprechend dem Kiele schwach winkelig vorgezogen. Die kurze, abgerundete Spindel ist stark nach vorne gebogen und bildet am Uebergange in den Basalrand eine scharf vorspringeude Ecke. Der ziemlich dünne feingekörnelte Basalkallus ist mit dem Gehäuse gleichfärbig und deutlich begrenzt.

$$
\mathrm{D}=6.5 \mathrm{~s}, \mathrm{~d}=5 \cdot 5, \mathrm{H}=3.5 \mathrm{~mm} \text {. }
$$

Deckel mit dünner, zerbrechlicher, feingekörnelter Kalkplatte, sonst typisch.

Fundorte: die Inseln Tahaä, Raiatea und Tahiti.

Diese Art ist sehr veränderlich und finden sich auf den Gesellschaftsinseln zahlreiche Lokalformen, welche jedoch nur schwer gegeneineinander abzugrenzen sind.

\section{A phanoconia discoidea tumidior A. J. Wagner.} Taf. 33, Fig. 8-9.

\footnotetext{
Aphanoconia discoidea trumidior A. J. Wagner Helicinenstadien in Denk. Alrad. Wien, vol. 77 , p. 58, T. 7, F. 5 a, b, c, 1805 .

Aphanoconia discoidea faba A. J. Wagner Helicinenstadien in Denk. Akad. Wien. vol. 77 p. 58, T. 7, F. 6 à, b, c, 1905.

Helicina simulans Garrett? in: Acad. Philad. IX, 1885.
}

Gehäuse kleiner, zum Teile rotbraun gefärbt, mit höherem Gewinde, stumpfem Kiel und mehr gewölbter Basis; die Ecke am Uebergange der Spindel in den Basalrand der Mündung ist mehr abgerundet und weniger vorspringend. 
Deckel wie bei der typischen Form.

$$
\mathrm{D}=5 \cdot 2, \mathrm{~d}=4 \cdot 8, \mathrm{H}=3 \mathrm{~mm} .
$$

Fundorte: die Inseln Tahiti und Raiatea.

\section{A phanoconia discoidea subrufa A. J. Wagner. Taf. 33, Fig. 10.}

Aphanoconia discoidea sabrufa A. J. Wagner Helicienstadien in: Denk. Akad. Wien, vol. 77, p. 58, T. 7, F. 7 a, b, c, 1905.

Gehäuse sehr klein mit höherem, abgerundet kegelförmigem Gewinde, $3^{1} / 2$ deutlich gewölbten Umgängen und auffallend stumpferem Kiel; der letzte Umgang steigt vorne deutlich herab; die Ecke am Uebergange der Spindel in den Basalrand ist stumpfer bis undeutlich.

$$
\mathrm{D}=4 \cdot 2, \mathrm{~d}=36, \mathrm{H}=3 \mathrm{~mm} \text {. }
$$

Deckel wie bei der typischen Form.

Fundort: die Insel Raiatea.

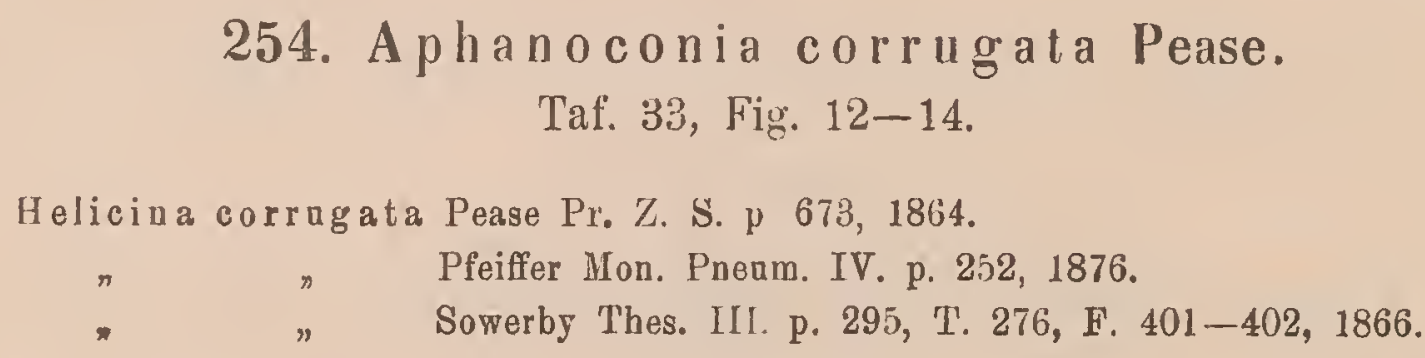

Gehäuse flachkegelförmig mit schwachgewölbter Basis ziemlich festschalig, einfärbig hellgelb bis rotbraun, fein und etwas ungleichmässig radial gestreift, matt. Das niedrige Gewinde besteht aus $4-4 \frac{1}{2}$ langsam zunehmenden, leicht gewölbten bis nahezu flachen Umgängen, welche durch eine fadenrandige Naht geschieden werden; der letzte ist unten flach, an der Peripherie ziemlich scharf gekielt und steigt vorne wenig, aber deutlich unter den Kiel herab; der Kiel beiderseits durch eingedrückte Spirallinien berandet. Die dreieckige Mündung ist schief; der Mundsaum kaum verdickt, kurz ausgebreitet, mit dem Gehäuse gleichfurbig; der Aussenrand entsprechend dem Kiele deutlich winkelig vorgezogen. Die sehr kurze Spindel ist nach vorne und aussen gebogen und bildet am Uebergange in den Basalrand eine deutlich vorspringende Ecke. Der dicke, feingekörnelte Basalkallus wird im Umkreise der Spindel durch eine ziemlich tiefe Furche begrenzt; parallel zu dieser Furche verlauft eine vom Basalrand ausgehende bogenförmige Leiste.

Deckel unbekannt.

$$
\mathrm{D}=5, \mathrm{~d}=5, \mathrm{H}=3 \mathrm{~mm} \text {. }
$$

Fundort: die Insel Raiatea. 
Diese Art weicht durch die eigentümliche Bildung des Basalkallus wesentlich von den anderen Formen der Gruppe $a b$.

\title{
255. Aphanoconia villosa Anton.
}

Taf. 33, Fig. 11.

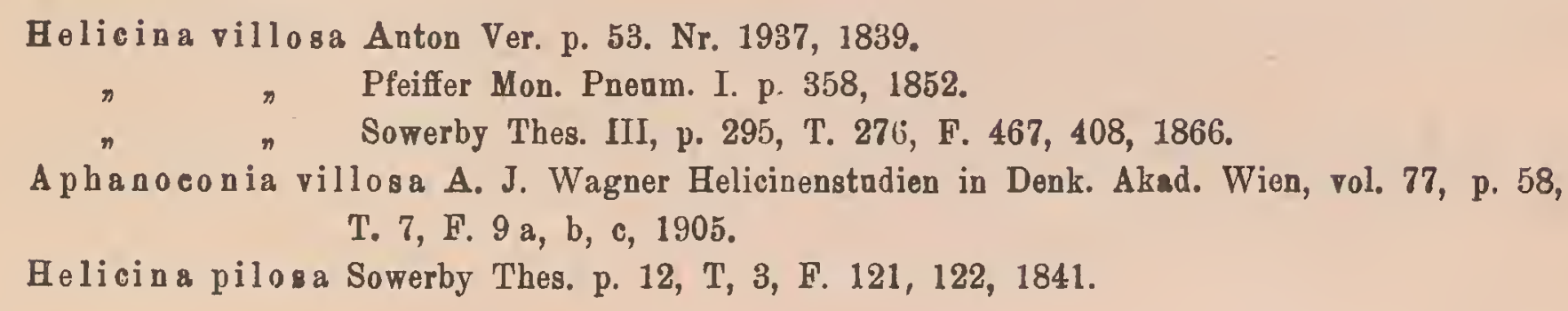

Gehäuse linsenförmig, dünnschalig, bräunlich hornfarben, matt seidenglănzend. Die Skulptur besteht nebst dichten und feinen Zuwachsstreifen; aus ziemlich dichten Spiralfalten der Epidermis, welche auf der Oberseite und dem Kiele in Gestalt von dünnen Lamellen oder Schuppen abstehen, auf der Unterseite nur niedrige Leisten darstellen. Das flachkegelförmige Gewinde besteht aus $4^{1} / 2$ ziemlich rasch zunehmenden, nahezu flachen Umgängen; der letzte ist an der Peripherie scharf gekielt und steigt vorne nicht herab. Die dreieckige Mündung ist schief, der kaum verdickte Mundsaum kurz ausgebreitet, der Aussenrand entsprechend dem Kiele etwas winkelig vorgezogen. Die kurze, nahezu senkrechte Spindel bildet am Uebergange in den Basalrand eine undeutliche Ecke; der dünne glänzende Basalkallus ist ziemlich deutlich begrenzt.

Deckel unbekannt.

$$
\mathrm{D}=5 \cdot 4, \mathrm{~d}=4 \cdot 8, \mathrm{H} 3 \cdot 2 \mathrm{~mm} \text {. }
$$

Fundort: die Insel Opara der Austral-Gruppe.

\section{Formenkreis Albocincta n.}

\section{Aphanoconia keiensis A. J. Wagner.}

Taf. 33, Fig. 21-24.

\author{
Aphanoconia keiensis A. J. Wagner Helicinenstedien in: Denk. Akad. Wien. vol. 77. \\ T. 6, F. 8 a, b, c, 1905 . \\ Helicina ragans Aneey.
}

Gehăuse dicklinsenförmig, festschalig, matt mit sehr feinen etwas ungleichmåssigen Zuwachsstreifen und ziemlich dichten, hinfälligen Spiralfalten der Epidermis, zitrongelb mit weissem Kiel. Das regelmässig kegelförmige, mitunter leicht abgerundete Gewinde besteht. I. 18. II. 
aus 4 ziemlich rasch runehmenden, flachen Umgängen; der letzte ist scharf gekielt, unten besser gewölbt und steigt vorne nicht herab; der Kiel beiderseits durch eingedrückte Linien berandet. Die dreieckige Mündung ist schief, der weisse Mundsaum leicht verdickt, kurz ausgebreitet; der Aussensaum entsprechend dem Kiele etwas winkelig vorgezogen. Die abgerundete, kurze Spindel ist etwas nach aussen gebogen und bildet am Uebergange in den Basalrand eine undeutliche, stumpfe Ecke. Der dünne, fein gekörnelte Basalkallus ist mit dem Gehäuse gleichfärbig und nur im Umkreise der Spindel deutlicher begrenzt.

$$
\mathrm{D}=6 \cdot 5, \mathrm{~d}=6, \mathrm{H}=4 \mathrm{~mm} \text {. }
$$

Deckel gelblich mit verhăltnismạssig dicker, feingekörnelter Kalkplatte und nur im unteren, nahezu senkrechten Ast kräftig erhobener Sigmakante; sonst typisch.

Fundort: die Kei-Inseln.

\title{
257. A phanoconia albocincta Hombron et Jacquinot.
}

Taf. 35, Fig. 5-9.

\author{
Helicina albocincta Hombron et Jacquinot Voy. Pol. Sud. Zool. V p. 46, T. 11, F. 36-39. \\ n Pfeiffer Mon. Pneum. II p. 217, 1858. \\ * Wallace Pr. Z. S. p. 414, 1865. \\ n Martens Ostas. Zool. II. p. 169, T. 23, F. 21, 1867. \\ \# $\quad$ Soworby Thes. III p. 293, T. 276, F. 403, 1866. \\ „ $\quad$ Tapp. Canefri Ann. Mus. Genova, IV, p. 563, 1874. \\ " $"$ "Faun. Nuov. Guin. p. 273, 1883. \\ Aphanoconia bandana hombroni A. J. Wagner Helicinenstudien in: Denk. Akad. Wien. \\ vol. 77, p. 50, 1905.
}

Gehäuse linsenförmig, ziemlich dünnschalig, rotbraun mit weissem Kiel und Nahtstreifen, im frischen Zustande matt mit feinen, dichten und hinfälligen Spiralfalten der Epidermis; abgerieben glänzend mit sehr feinen, bis undeutlichen Zuwachsstreifen. Das abgerundet kegelförmige Gewinde besteht aus $4-4 \frac{1}{2}$ ziemlich langsam zunehmenden, kaum gewölbten Umgăngen; der letzte ist zusammengedrückt gekielt, beiderseits gleichmässig gewölbt, vorne nicht herabsteigend. Die dreieckige Mündung ist schief, der rötliche, leicht verdickte Mundsaum kurz ausgebreitet; der Aussenrand entsprechend dem Kiele etwas winkelig vorgezogen. Die sehr kurze, abgerundete Spindel geht im gleichmässigen Bogen in den Basalrand über, am Uebergange findet sich nur eine knotenartige Verdickung. Der mit dem Gëhäuse gleichfärbige, feingekörnelte Basalkallus ist nur im Umkreise der Spindel stärker verdickt und deutlich begrenzt

$$
\mathrm{D}=6-7, \mathrm{~d}=4.5-5, \mathrm{H}=3.5 \mathrm{~mm} \text {. }
$$

Deckel mit fester, rötlicher, feingekörnelter Kalkplatte; sonst typisch.

Fundorte: die Aru- und Key-Inseln. 


\section{A phanoconia albocincta bandana Boettger.}

Helicina bandana Boettger Ber. Senkenb. Ges. p. 298, 1891.

albocincta Martens Ostas. Exped. Zool. II, p. 169, T. 4, F. 21.

A phanoconia bandana A. J, Wagner Helicinenstudien in Denk. Akad. Wien, vol 77, p. 49, T. 6, 6. $9 \mathrm{a}, \mathrm{b}, \mathrm{c}, 1905$.

Gehăuse kleiner, hell gelbbraun, mit höherem, mehr abgerundetem Gewinde stärker gewölbter Basis und hăufig stumpferem, weniger zusammen gedrücktem Kiel.

$$
\mathrm{D}=5, \mathrm{~d}=4.3, \mathrm{H}=3.5 \mathrm{~mm} \text {. }
$$

Deckel wie bei der typischen Form.

Fundort: die Banda-Inseln.

\section{A phanoconia dichroa Möllendorff.}

Taf. 34, Fig. 1-5.

Helicina (Pleuropoma) dichroa Möllendorf, Jahresber. Senckenb. Ges. p. 291, 1890.

A phanoconia dichroa A. J. Wagner Helicinenstadien in: Denk. Akad. Wien. vol, 77, p.47, T. 6, F. 」 a, b, c, 1905 .

Gehäuse breit kegelförmig mit gut gewölbter, nahezu halbkugeliger Basis, festschalig im frischen Zustande wenig glänzend bis matt mit ziemlich dichten, hinfälligen Spiralfalten der Epidermis; abgerieben leicht glanzend mit sehr feinen Zuwachsstreifen und sehr feinen eingedrückten Spirallinien; hellgelb bis rötlich mit dunkler gefärbter Spitze, undeutlichen lichteren Striemen oder hellen bis weissen Bändern an Naht und Peripherie. Das breitkegelförmige, mehr minder erhobene Gewinde besteht aus $4^{1} / 2$ kaum gewölbtẹn, ziemlich langsam zunehmenden Umgängen; der letzte ist stumpfkantig mit einer lichten bis weissen Zone entlang der Kante und steigt vorne wenig, aber deutlich unter die Kante herab. Die abgerundet dreieckige Mündung ist schief, der weisse Mundsaum verdickt und kurz ausgebreitet. Die kurze, abgerundete Spindel ist nach aussen gebogen und bildet am Uebergange in den Basalrand eine stumpfe, aber deutlich vorspringende Ecke. Der weisse, ziemlich dicke und fein gekörnelte Basalkallus ist deutlich begrenzt.

$$
\mathrm{D}=5, \mathrm{~d}=4 \cdot 2, \mathrm{H}=2 \cdot 5-3 \cdot 6 \mathrm{~mm} \text {. }
$$

Deckel annăhernd halbkreisförmig mit verhältnismässig dicker, fein gekörnelter, gelblicher Kalkplatte und zarter gelblicher Hornplatte; sonst typisch.

Fundorte: die typische Form führt Möllendorff zunächst von der Insel Cebu an, woher auch die mir vorliegenden Exemplare stammen; ausserdem soll dieselbe noch auf den Inseln Leyte und Negros vorkommen.

Die Sektion Pleuropoma, welche Möllendorff auf vorstehende Art begründet, soll sich 
besonders durch die Beschaffenheit des Deckels kennzeichnen; nach Möllendorff ist der Deckel kalkig ohne innere hornige Platte. Dieses Merkmal ist in Wirklichkeit nicht vorhanden, denn auch der Deckel von A. dichroa Mlldff, ebenso aller jener Formen, welche der Autor zu dieser Sektion zieht, besteht aus Kalk und Hornplatte. Bei der Prăpparation (Aufweichen in Wasser) löst sich die Kalkplatte zahlreicher Heliciniden sehr leicht von der zarten Hornplatte ab, welche dann an dem trockenen Tiere hängen bleibt und übersehen werden kann. Das weitere Merkmal der Sektion, "die schwache Querlamelle, welche in der Mitte geknickt ist" entspricht meiner Sigmakante uod kommt eben bei allen Gruppen der Familie vor. Da diese Sektion zunăchst auf ein künstliches Merkmal begründet wurde, erscheinen in derselben auch ziemlich heterogene Formen vereinigt und kann dieselbe nicht einmal als Formenkreis beibehalten werden.

\section{Aphanoconia dichroa boholensis Möllendorff. Taf. 34, Fig. 6.}

Helicina dichroa var. boholensis Möllendorff in: Jahresber. Senckenb. Ges, p. 291, 1890. Aphanoconia dichroa boholensis A. J. Wagner Helicinenstudien in: Denk. Akad. Wien, v. 77, p. 48, T. 6, F. $2,1905$.

Helicina dichroa var. pallescens Möllendorff Jahresber. Senckenb. Ges. p, 291, 1905.

Das Gehăuse kleiner, flacher mit mehr kielartiger Kante und mitunter deutlicheren Spirallinien.

$$
\mathrm{D}=4 \cdot 5, \mathrm{~d}=3 \cdot 6, \mathrm{H}=2 \cdot 5-3 \cdot 2 .
$$

Fundorte: Möllendorff beschreibt diese Form von der Insel Bohol, ich kenne übereinstimmende Exemplare auch von Cinalisayan bei Burias. Unter der Bezeichnung Helicina dichroa var. pallescens Möllendorff erhielt ich von Möllendorff Exemplare dieser Art mit der Fundortsangabe Balatanai bei Basilan, welche sich nur durch die lichtere Färbung von der vorstehenden Fornı unterscheiden

\section{A phanoconia dichroa siquijorica Möllendorff.} Taf. 34, Fig. 7 .

Helicina siquijorica Möllendorff Nachr. Bl., v. 20, p. 142, 1888.

Helicina dichroa rar. siquijorica Mölleudorff, Jahresber. Senckenb. Ges, p. 291, 1890.

Aphanoconia dichroa siquijorica A. J. Wagner Helicinonstudien in Denk. Akad. Wien. v. 77, p. 48, T. 6, F. 3,1905 .

Gehäuse dicklinsenförmig, dünnschaliger gelbbraun mit weissem Kiel und Nahtstreifen; das abgerundet kegelförmige Gewinde besteht nur aus 4 flachen, langsamer zunehmenden 
Umgången; der letzte ist unten weniger gewölbt, an der Peripherie stumpf gekielt und steigt håufig schon in der zweiten Halfte etwas unter dem Kiel herab, wodurch die Naht daselbst stumpfkantig erscheint. Die dreieckige Mündung ist schiefer.

Deckel wie bei der typischen Form.

$$
\mathrm{D}=4 \cdot 5-5 \cdot 2, \mathrm{~d}=4, \mathrm{H}=3-3 \cdot 4 \mathrm{~mm} \text {. }
$$

Fundort: die Insel Siquijor.

Diese Form steht auch der A. albocincta bandana Boettger sehr nahe und unterscheidet sich von derselben durch das höhere, melrr gewölbte Gewinde, die langsamer zunehmenden Umgänge, den stumpferen, etwas aufgetriebenen Kiel und besonders durch die deutliche Ecke am Uebergange der Spindel in den Basalrand der Mündung.

\title{
Formenkreis Trichroa A. J. Wagner.
}

\author{
262. Aphanoconia trichroa A. J. Wagner. \\ Taf. 35, Fig. 10-13. \\ Aphanoconia trichroa A. J. Wagner Helicinenstadien in: Denk. Akad. Wien. v. 77, p. 44, \\ T. 5, F. 15 a, b, c, 16,1905 .
}

Gehäuse breit kegelförmig mit gewölbter Basis, festschalig leicht glänzend und etwas durchscheinend; die Grundfarbe schmutzig gelb oder gelblich hornfarben mit zitrongelber Spitze, weissem Kiel und einem schmalen, scharfbegrenzten braunen Bande unterhalb des Kieles. Die Skulptur besteht neben sehr feinen Zuwachsstreifen aus niedrigen, uudeutlichen und ziemlich entfernt stehenden Spiralreifen auf der Oberseite. Das regelmässig breitkegelförmige Gewinde besteht aus $4 \frac{1}{2}$ regelmässig zunehmenden, flachen Umgängen; der letzte ist unten deutlicher gewölbt, an der Peripherie stumpf und etwas aufgetrieben gekielt und steigt vorne sehr wenig herab. Die abgerundet dreieckige Mündung ist wenig schief, der weisse Mundsaum leicht verdickt, ziemlich ausgebreitet; hinter demselben häufig eine braune Zone. Die kurze abgerundete Spindel ist nach aussen gebogen und bildet am Uebergange eine stumpfe, aber deutlich vorspringende Ecke. Der gelbliche, feingekörnelte Basalkallus ist ziemlich dick und deutlich begrenzt.

$$
\mathrm{D}=7, \mathrm{~d}=6, \mathrm{H}=4.5 \mathrm{~mm} \text {. }
$$

Deckel dreieckig mit zinmlich dicker, gelblicher und fein gekörnelter Kalkplatte; sonst typisch.

Fundort: die Insel Banguei nördlich von Borneo.

Von der Insel Sibutu, nordöstlich von Boıneo kenne ich ferner eine Form mit deutlicher abgerundetem, zum Teile höherem Gewinde, rötlicher, oben milchig getrübter Grundfarbe und schwächeren Spiralreifen, welche ich noch zur typischen Form ziehe. 
Helicina usukanensis Godwin Austen von der Insel Usukan bei Borneo ist mir nicht bekannt, dürfte jedoch nach der Beschreibung mit der vorstehenden Art nahe verwandt sein.

\section{A phanoconia trichroa candaramanica A. J. Wagner.}

A phanoconia trichroa candaramanica A. J. Wagner Helicinenstudien in: Denk. Akad. Wien, r. 77, p. 45, 1905.

Gehäuse lichter gefärbt, gelblichweiss mit schwächerem Bande unter dem Kiel; das niedrigere Gewinde ist abgerundet kegelförmig, die Spiralskulptur mit Ausnahme des ersten Umganges auf 2-3 feine, eingedrückte Spirallinien reduziert; der Kiel beiderseits durch eingedrückte Spiralfurchen berandet.

Deckel wie bei der typischen Form.

$$
\mathrm{D}=6.5, \mathrm{~d}=5.5, \mathrm{H}=4.5 \mathrm{~mm} \text {. }
$$

Fundort: Candaramanes.

\section{Aphanoconia trichroa calamianica A. J. Wagner. Taf. 35, Fig. 14.}

Aphanoconia trichroa calaminnica A. J. Wagner Hrlicinenstudien in: Denk. Akad. Wien, v. 77, T. 5, F. 17 a, b, 1905.

Gehăuse mit höherem kegelförmigen Gewinde und mehr abgeflachter Basis; die Spiralreifen wie bei der typischen Form, jedoch dentlicher und mitunter a uch auf der Unterseite vorhanden: Der schärfere Kiel wird beiderseits durch eine Spiralfurche berandet; das braune Band unter dem Kiel ist erloschen, der Aussenrand des Mundsaums entsprechend dem Kiele winkelig vorgezogen.

Deckel wie bei der typischen Form.

$$
\mathrm{D}=6.5, \mathrm{~d}=5.5, \mathrm{H}=4.5 \mathrm{~mm} \text {. }
$$

Fundort: die Insel Busnanga der Philippinen.

265. Aphanoconia derouledei Wattebled.

Taf. 34, Fig. 23-26.

Helicina derouledei Wattebledt, J. da Conch. v. 34, p. 66, T. 5, F. 2, 1886.

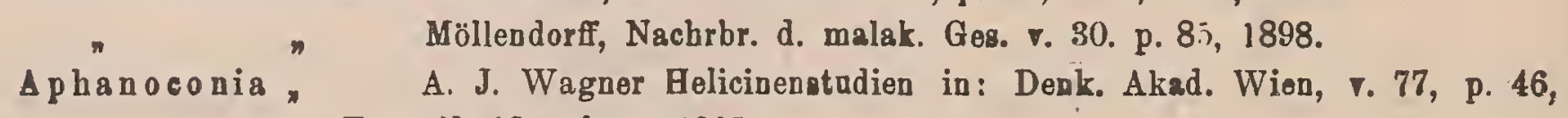
T. 5, F. 18 a, b, c, 1905 . 
Gehăuse kegelförmig mit gewölbter Basis, ziemlich festschalig, leicht glanzend mit sehr feinen Zuwachsstreifen. Die Grundfarbe durchscheinend zitron bis orangegelb mit verschieden breiten, milchig getrübten Binden und Zonen auf der Ober- und Unterseite der unteren Umgänge. Das regelmässig kegelförmige Gewinde besteht aus 4 schwach gewölbten, regelmässig zunehmenden Umgängen; der letzte ist stumpf gekielt und steigt vorne nicht herab. Die abgerundet dreieckige Mündung ist ziemlich schief, der weisse, leicht vérdickte Mundsaum ausgebreitet und umgeschlagen. Die kurze abgerundete Spindel ist etwas nach aussen gebogen und bildet am Uebergange in den Basalrand eine stumpfe aber dentlich vorspringende Ecke. Der gelbe, feingekörnelte Basalkallus ist dünn und nur im Umkreise der Spindel deutlicher begrenzt.

$$
D=5 \cdot 5, d=4 \cdot 5, H=3 \cdot 7 . \mathrm{mm} \text {. }
$$

Deckel abgerundet dreieckig hellgelb mit auffallend zarter und dünner Kalkplatte.

Fundort: Turon = Touranne in Annam.

266. A phanoconia borneensis Martens.

Taf. 35, Fig. : -4 .

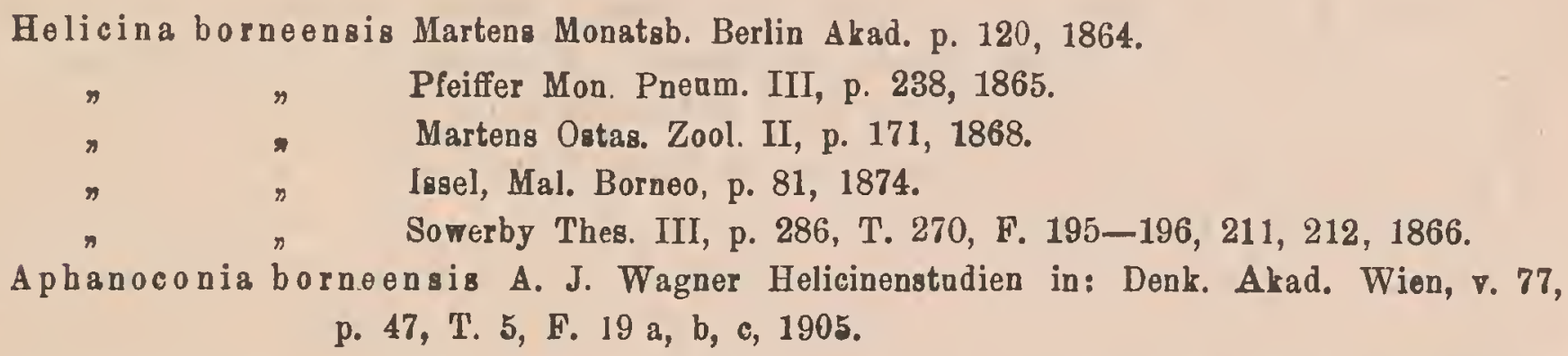

Gehäuse breitkegelförmig mit gewölbter Basis, ziemlich dünnschalig, wenig glänzend; gelbbraun bis fleischfarben mit weissen, milchig getrübten Binden an Naht und Peripherie der unteren Umgănge, zwischen welchen oft nur ein schmaler Streifen der durchscheinenden Grundfarbe übrig bleibt. Die deutlichen Zuwachsstreifen sind etwas ungleichmässig. Das abgerundet kegelförmige Gewinde besteht aus 4 langsam zunehmenden, kaum gewölbten Umgängen; der letzte ist an der Peripherie stumpfkantig und steigt vorne wenig, aber deutlich unter die Kante herab. Die abgerundet dreieckige Mündung ist wenig schief, der weisse, kaum verdickte Mundsaum kurz ausgebreitet. Die kurze leicht nach aussen gebogene Spindel bildet am Uebergange in den Basalrand eine stumpfe, wenig vorspringende Ecke.

$$
\mathrm{D}=4 \cdot 2, \mathrm{~d}=3 \cdot 6, \mathrm{H}=2 \cdot 8 \mathrm{~mm} \text {. }
$$

Deckel mit dünner, feingekörnelter Kalkpiatte, sonst typisch.

Fundort: Sing-Kawang auf Borneo. 


\section{Aphanoconia nicobarica Philippi.}

Taf. 34, Fig. 20-22.

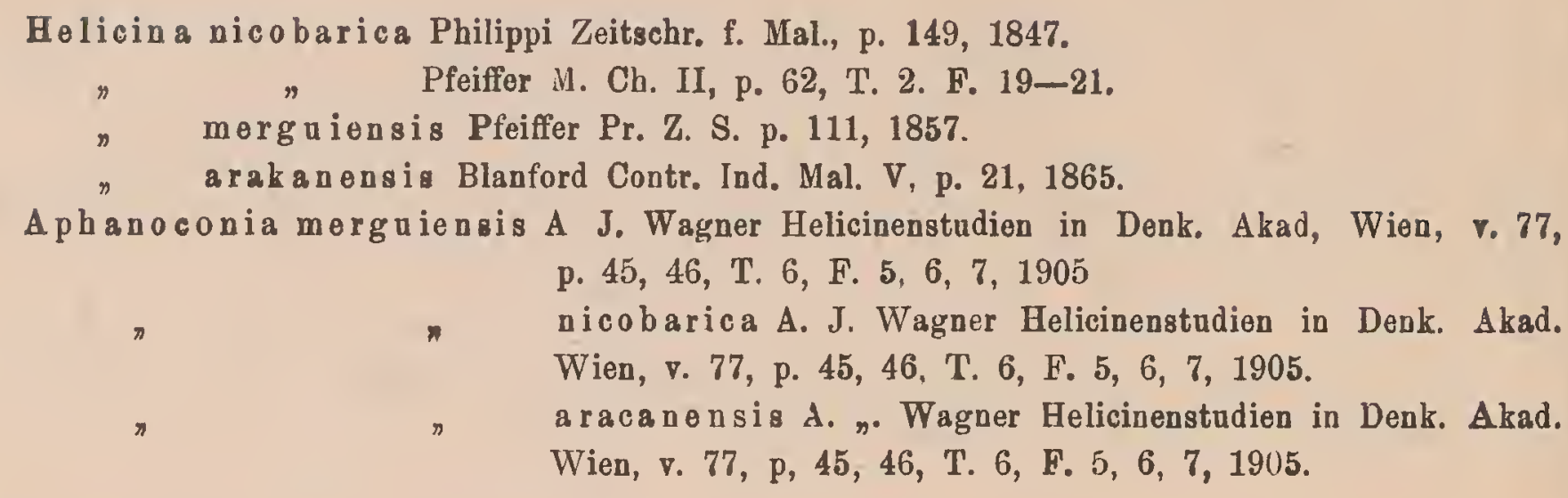

Gehäuse dicklinsenförmig, festschalig, leicht glänzend, schmutzig gelb oder fleischfarben mit verschieden breiten Binden und Zonen auf der Ober- und Unterseite, welche abwechselnd braun und durchscheinend oder milchig getrübt sind. Die Skulptur besteht nebst dichten und feinen Zuwachsstreifen aus dichten und feinen, eingedrückten Spirallinien, welche häufig sehr undeutlich werden. Das flach kegelförmige, leicht abgerundete Gewinde besteht aus $4-4^{1} / 2$ ziemlich rasch zunehmenden, flachen Umgängen; der letzte ist unten mehr gewölbt, an der Peripherie scharf gekielt und steigt öfter schon in der zweiten Hälfte ein wenig unter den Kiel herab. Die abgerundet dreieckige Mündung ist wenig schief, der weisse Mundsaum leicht verdickt, kurz ausgebreitet, der Basalrand umgeschlagen. Die sehr kurze, abgerundete Spindel ist etwas nach aussen gebogen und bildet am Uebergange in den Basalrand eine abgerundete, wenig vorspringende Ecke. Der gelbliche, feingekörnelte Basalkallus ist ziemlich dick und deutlich begrenzt.

$$
\mathrm{D}=5 \cdot 8, \mathrm{~d}=4 \cdot 8, \mathrm{H}=3.4-3.7 \mathrm{~mm} \text {. }
$$

Deckel gelblich mit ziemlich dünner, feingekörnelter Kalkplatte; die Sigmakante auch im oberen Aste leicht erhoben.

Verbreitung: die Nikobaren, Andamanen, Mergui Inseln, wie das benachbarte Küstengebiet von Birma (Tenasserim). - Ich hatte Gelegenheit Exemplare von den angeführten Fundorten zu vergleichen und finde, dass die Art in Bezug auf die Höhe des Gewindes, die Färbung und die mehr minder deutliche Spiralstreifung etwas veränderlich ist; konstante Merkmale, welche die Abgrenzung eiver Form bedingen, konnte ich jedoch nicht feststellen. Die unter den Synonymen angeführten Arten liegen mir in Originalexemplaren vor. 


\title{
268. A phanoconia sykesi Möllendorff。
}

Taf. 33, Fig. 1-3.

Helicina (Plearopoma) sykesi Möllendorff Nachr. d. Mal. Ges. p. 207, 1902.

Gehäuse dicklinsenförmig, festschalig, etwas durchscheinend, wenig glänzend; die Grundfarbe gelbbraun bis rötlich; die oberen Umgänge einfărbig gelb, die 2 letzten mit lichteren bis weisslichen Fleckenzeichnungen, welche auf der Oberseite zwei Zonen mit einem undeutlichen braunen Bande in der Mitte bilden; auf der Unterseite überwiegt die gelbbraune Grundfarbe, und ist zumeist nur eine schniale weissliche Fleckenbinde vorhanden. Die Fleckenbinden lassen undeutlich die Anordnung von Zickzackstriemen erkennen. Die Skulptur besteht nebst sehr feinen bis undeutlichen Zuwachsstreifen aus dichten und feinen Spiralreifen, welche auf der Unterseite schwächer werden. Das flachkegelförmige, leicht konvexe Gewinde besteht aus 4 kaum gewölbten, ziemlich rasch zunehmenden Umgängen, welche teilweise durch eine berandete Naht geschieden werden; der letzte ist beiderseits gleich gewölbt, scharf und zusammengedrückt gekielt und steigt vorne nicht herab. Die dreieckige Mündung ist wenig schief, der weisse, leicht verdickte Mundsaum kurz ausgebreitet, der Aussenrand entsprechend dem Kiele winkelig vorgezogen, der Basalrand umgeschlagen. Die sehr kurze, abgerundete Spindel ist etwas nach aussen gebogen, am Uebergange in den Basalrand findet sich eine knotenartige Verdickung und daneben eine seichte Einbuchtung. Der ziemlich dicke, weisse Basalkallus ist deutlich begrenzt.

Deckel unbekannt.

$$
\mathrm{D}=10, \mathrm{~d}=8, \mathrm{H}=\mathrm{s} \cdot \mathrm{mm} \text {. }
$$

Fundort: die Insel Tomia südöstlich von Celebes.

Die Abbildung und Beschreibung nach einem von den Ferrn Fulton und Sowerby mitgeteilten Exemplare.

\section{Aphanoconia andaunanica Benson.}

Taf. 34, Fig. 11-i3.

\author{
Helicina andamanica Benson Ann. Mag. N. H. (3), p. 194, 1860. \\ $\begin{array}{cll}\text { Aphanoconia } & \eta & \text { Pfeiffer Mon. Pnerm. III. p. 244, } 1865 . \\ & \text { A. J. Wagner Helicinenstadien in Denk. Akad. Wien. v. 77, p. 50, }\end{array}$ \\ T. 6, F. $11 \mathrm{a}, \mathrm{b}, \mathrm{c}, 1905$.
}

Gehäuse dicklinsenförmig, ziemlich festschalig, leicht glänzend schmutzig gelb, hellgelb, bis rotbraun mit undeutlichen helleren bis milchigen Flecken, welche mitunter die Anordnung von radialen Zickzackstriemen erkennen lassen; sehr fein und dicht radial, sowie spiral gestreift. Das flachkegelförmige, etwas konvexe Gewinde besteht aus $4-4^{1} / 2$ kaum gewölbten 
bis flachen, ziemlich rasch zunehmenden Umgängen; der letzte ist beiderseits gleichmässig schwach gewölbt, scharf gekielt und steigt vorne nicht herab. Die dreieckige Mündung ist schief; der weisse, bis gelbbraune, ziemlich dicke Mundsaum ist kurz ausgebreitet; der Aussenrand entsprechend dem Kiele winkelig vorgezogen, der Basalrand umgeschlagen. Die kurze, abgerundete Spindel ist etwas nach aussen gebogen, am Uebergange in den Basalrand findet sich eine abgerundete, wenig vorspringende Ecke. Der weisse, ziemlich dicke und gekörnelte Basalkallus ist deutlich begrenzt

$$
\mathrm{D}=10, \mathrm{~d}=8, \mathrm{H}=5-6 \mathrm{~mm} \text {. }
$$

Deckel mit verhăltnismässig dïnner, fein gekörnelter, gelb bis rotbrauner Kalkplatte, sonst typisch.

Fundort: die Andamanen.

\section{A phanoconia the obaldiana G. und H. Nevill. Taf. 34 , Fig. $8-10$.}
Helicina theobaldiana G. und H. Nevill, Journ. As. Soe. Beng. v. 40, p. 8, T. 1, F. 8, 1871 . $n \quad$ Pfeiffer Mon. Pneum. 4, p. 284, 1876.
" Martens Mitth. zool Samml. Berlin, v. 1 p. 6, 1898.

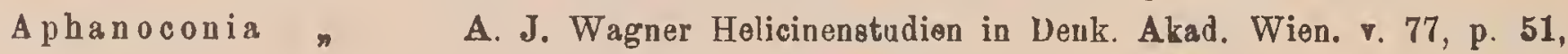 T. 6, F. 10 a, b, c, 190E.

Gehăuse dicklinsenförmig gelbbraun bis rotbraun mit lichterem Kiel, ziemlich dünnschalig und durchscheinend; frische Exemplare matt mit ziemlich dichten deutlich erhobenen Spiralfalten der hinfălligen Epidermis, häufig auch mit einer festanhaftenden Erdkruste bedeckt; abgerieben ziemlich glatt und glänzend mit sehr feinen Zuwachsstreifen. Das breitkegelförmige, häufig etwas konvexe Gewinde besteht aus 4 ziemlich rasch zunehmenden, kaum gewölbten bis flachen Umgängen; der letzte ist unten deutlicher gewölbt, scharf aber nicht zusammengedrückt gekielt und steigt vorne nicht herab. Die abgerundet dreieckige Mündung ist wenig schief, der dünne, lichter gefärbte Mundsaum kurz ausgebreitet, der Aussenrand entsprechend dem Kiele etwas winkelig vorgezogen. Die sehr kurze, abgerundete Spindel ist etwas nach aussen gebogen; am Uebergange in den Basalrand findet sich eine abgerundete, kaum vorspringende Ecke. Der dünne, in der Mitte weisse Basalkallus ist ziemlich deutlich begrenzt.

$$
\mathrm{D}=8, \mathrm{~d}=7, \mathrm{H}=5.5 \mathrm{~mm} \text {. }
$$

Deckel gelblich oder rötlich mit fester, feingekörnelter Kalkplatte, sonst typisch.

Fundort: die Seychellen; meine Exemplare von den Inseln Silhouette und Mache. Auf letztgenanntem Fundorte lebt neben typischen Exemplaren auch eine Form mit niedrigerem, mehr abgerundeten Gewinde, deutlicher vorspringendem Winkel am Uebergange der Spindel in den Basalrand, lichterer Färbung und einer undeutlichen Binde auf der Oberseite des letzten Umganges; dieselbe erreicht die Dimensionen $\mathrm{D}=5, \mathrm{~d}=4.5, \mathrm{H}=3 \mathrm{~mm}$. 


\author{
271. A phanoconia dunkeri Pfeiffer. \\ Taf. 34 , Fig. 14-19. \\ Helicina d unkeri Pfeiffer Verb. d. Zool. bot. Ges. Wien. p. 808, 1867. \\ \#, Mon. Pneum. IV, p. 285, 1876. \\ Aphanoconia dunkeri A. J. Wagner Helicinenatudien in Denk. Akad. Wien, จ. 77, T. 6, \\ F. 12 a, b, c, p 51, 1905 .
}

Gehäuse linsenförmig, festschalig, etwas seidenglänzend und sehr fein radial gestreift; schmutziggelb, hellgelb bis rötlich mit undeutlichen Flecken und Bändern. Das flachkegelfö:mige, leicht konvexe Gewinde besteht aus $4 \frac{1}{2}$ kaum gewölbten oder nahezu flachen, zjemlich rasch zunehmenden Umgängen, welche durch eirie lichter berandete bis kantige Naht geschieden werden; der letzte ist sehr scharf und zusammengedrückt gekielt und steigt vorne nicht herab Die dreieckige Mündung ist schief, der weisse. Mundsaum leicht verdickt, kurz ausuebreitet; der Aussenrand entsprechend dem Kiel winkelig vorgezogen, der Basalrand umgeschlagen. Die kurze, abgerundete Spindel ist nach aussen gebogen, am Uebergange derselben zum Basalrand der Mündung findet sich eine leichte Verdickung. Der ziemlich dicke, milchig getrübte Basalkallus ist deutlich begrenzt.

$$
D=10 \cdot 5, d=9, \mathrm{H}=6 \mathrm{~mm} \text {. }
$$

Deckel mit ziemlicher dicker gekörnelter, gelblicher Kalkplatte und auch im oberen Aste leicht erhobener Sigmalsante, sonst txpisch.

Fundort: die Nicobaren (Camorta).

\title{
Formenkreis Sculpta A. J. Wagner.
}

\author{
272. Aphanoconia sculpta Martens. \\ Taf. 35, Fig. 18-20. \\ Helicina scalpta Martens Monatsb. Berlin Akad p. 120, 1864. \\ Pfeiffer Mon. Pneum., III, p. 236, 1865. \\ $\pi$ Martens Ostas Zool, II, p. 167, T. 4, F. 17, 1868. \\ A phanoconia sculpta A. J. Wagner Helicinenstadien in Dents. Akad. Wien, v. 77, p. 48, \\ T. 5, F. $13 \mathrm{a}, \mathrm{b}, 1905$.
}

Gehäuse breit kegelförmig mit flach gewölbter Basis, ziemlich dickschalig, einfärbig schmutzig weiss, schwach glänzend. Die Skulptur besteht nebst deutlichen, etwas ungleichmässigen Zuwachsstreifen aus ziemlich weitläufigen, dünnen und niedrigen Spiralreifen (4-5 auf der Oberseite des letzten Umganges). Das leicht konvexe Gewinde besteht aus $4^{1} / 2$ ziemlich rasch zunenmenden Umgängen die oberen sind kaum gewölbt, der letzte flach, mitunter 
etwas konkav, zusammengedrückt und ziemlich scharf gekielt, vorne nicht herabsteigend. Die dreieckige Mündung ist schief; der weisse, dicke bis nahezu verdoppelte Mundsaum ziemlich ausgebreitet, der Aussenrand entsprechend dem Kiel etwas winkelig vorgezogen. Die sehr kurze, abgerundete Spindel ist etwas nach aussen gebogen und bildet am Uebergange in den Basalrand eine kaum vorspringende, knotenartige Verdicknng. Der ziemlich dicke, weisse und feingekörnelte Basalkallus ist deutlich begrenzt.

Deckel unbekannt.

$$
\mathrm{D}=8 \cdot 5, \mathrm{~d}=7 \cdot 5, \mathrm{H}=5.5 \mathrm{~mm} \text {. }
$$

Fundort: Kupang auf der Insel Timor.

\section{A phanoconia halaensis E. Smith.}

Taf. 35, Fig. 21. 22.

Helicina kalaoensis Edgar Smitl, Ann. Mag. N. H. (6) 18, p. 151, T. 10, F. 14, 1896.

Aphanoconia kalaoensis A. J. Wagner Helicinenstadien in Denk. Akad. Wien, v. 77, p. 42 T. 5, F. 12 a, b, c, 1905 .

Gehăuse breit kegelförmig mit gewölbter Basis, dickschalig, matt, mit undeutlichen Zuwachsstreifell, aber krättigen Spiralleisten $(4-5$ auf der Oberseite des letzten Umganges); die Grundfarbe hellgelbbraun bis rötlich mit abwechselnd braunen und weissen Zickzackstriemen auf den unteren Umgángen; die Zickzackstriemen sind hăufig unterbrochen oder verwaschen. Das regelmässig kegelförmige Gewinde besteht aus 4 kaum gewölbten, ziemlich rasch zunehmenden Umgängen, welche durch eine leicht eingedrückte Naht geschieden werden; der letzte ist unten deutlicher gewölbt, an der Peripherie stumpfgekielt und steigt vorne nicht herab. Die abgerundet dreieckige Mündung ist schief, der weisse dicke Mundsaum nahezu verdoppelt und ausgebreitet. Die kurze, abgerundete Spindel ist nach aussen gebogen und bildet am Uebergange in den Basalrand; eine stumpfe, ziemlich deutlich vorspringende Ecke. Der ziemlich dicke, in der Mitte gelbliche Básalkallus ist deutlich begrenzt.

$$
\mathrm{D}=6, \mathrm{~d}=5, \mathrm{H}=5.3 \mathrm{~mm} \text {. }
$$

Deckel gelblich oder rötlich mit verhältnismässig dünner, feingelrörnelter Kalkplatte; sonst typisch.

Fundort: die Insel Kalao nördlich von Flores.

\section{A phanoconia submucronata Möllendorff.}

Taf. 35, Fig. 15-17.

Aphanoconia submucronata A. J. Wagner Helicinenstudien in Denk. Akad. Wien, v. 77, p. 44, T. 5, F. 14 a, b, e, 1905 . 
Gehäuse kegelförınig mit gewölbter Basis, ziemlich dickschalig, wenig glänzend bis matt; schmutzig gelb bis rötlich hornfarben mit gelber Spitze. Die Skulptur besteht nebst ungleichmässigen Zuwachsstreifen aus ziemlich weitläufigen und liedrigen bis undeutlichen Spiralreifen (4-5 auf der Oberseite des letzten Umganges), welchen bei frischen Exemplaren hinfällige Spiralfalten der Epidermis entsprechen; auf dem 2. Umgange sind die Spiralleisten deutlich, mitunter rippchenartig ausgeprägt. Das regelmässig kegelförınige Gewinde besteht aus $4 \frac{1}{2}$ ziemlich langsam zunehmenden, kaum gewölbten bis flachen Umgăngen; der letzte ist ziemlich scharfkantig und steigt vorne nicht herab. Die im Gaumen gelbbraune Mündung ist schief, der weisse, innen leieht verdickte Mundsaum kurz ausgebreitet. Die abgerundete, leicht nach aussen gebogene Spindel bildet am Uebergange in den Basalrand eine deutlich vorspringende, ziemlich scharfe Lcke. . Der in der Mitte gelbliche, dünne Basalkallus ist ziemlich gut begrenzt.

$$
\mathrm{D}=6, \mathrm{~d}=5 \cdot 4, \mathrm{H}=4.8 \mathrm{~mm} .
$$

Deckel abgerundet dreieckig mit lebhaft perlmutter glänzender Kalkplatte und gelb. brauner Hornplatte, sonst typisch.

Fundort: Konstantinhaven in Deutsch Neu-Guinea.

Diese Form wurde mir seinerzeit von Möllendorff mit der angeführten Bezeichnung übergeben, doch finde ich die entsprechende Beschreibung in der mir zugänglichen Literatur nicht.

\section{Aphanoconia timorensis. \\ Taf. 33, Fig. 15-19.}

Gehäuse dicklinsenförmig oder breitkegelförmig mit flacher Basis; ziemlich dünnschalig, etwas durchscheinend, leicht glänzend, schmutzig hellgelb mit weissem Kielstreifen. Die Skulptur besteht nebst deutlichen, etwas ungleichmässigen Zuwachsstreifen aus einigen niedrigen, bis undeutlichen Spiralleisten auf den mittleren Umgängen. Das etwas abgerundete Gewinde besteht aus $4^{1} / 2$ ziemlich langsam zunehmenden, kaum gewölbten bis flachen Umgängen; der letzte ist unten flacher, an der Peripherie ziemlich stumpfgekielt und steigt vorne langsam, aber-deutlich unter den Kiel herab. Die dreieckige Mündung ist schief, der Mundsaum kaum verdickt, sehr kurz ausgebreitet, der Basalrand etwas umgeschlagen. Die kurze, abgerundete Spindel ist nach aussen gebogen und bildet am Uebergange in den Basalrand eine stumpfe, aber ziemlich deutlich vorspringende Ecke. Der mit dem Gehäuse gleichfarbige und fein gekörnelte Basalkallus ist ziemlich dünn, aber deutlich begrenzt.

$$
\mathrm{D}=6.5, \mathrm{~d}=5.4, \mathrm{H}=4 \mathrm{~mm} \text {. }
$$

Deckel dreieckig mit verhältnismässig grobgekörnelter Kalkplatte; sonst typisch.

Fundort: Atapupu auf Timor. Die Originalexemplare im K. Museum zu Berlin; :esammelt von E. v. Martens. 


\section{Aphanoconia semisculpta Ancey.}

Taf. 36, Fig. 1-5.

\section{Helicina semisculpta Ancey?}

Gehäuse linsenförmig, festschalig, wenig glänzend; schmutzig gelb mit gelber Spitze und weissem Kiel; mitunter sind undeutliche weisse Radialstriemen, sowie eine verwaschene gelbe oder gelbbraune Binde unter dem Kiele vorhanden. Die Skulptur besteht neben verbältnismässig kräftigen und ungleichmässigen Zuwachsstreifen, aus kräftigen Spiralleisten auf der Oberseite (5-6 auf dem letzten Umgange), während die Unterseite nur feine und dichte Zuwachsstreifen aufweist. Das flachkegelförmige Gewinde besteht aus $4^{1 / 2}$ flachen, ziemlich rasch zunehmenden Umgängen, welche durch eine flache, aber berandete Naht geschieden werden; der letzte ist scharf gekielt und steigt vorne fast gar nicht herab. Die dreieckige Mündung ist schief, der weisse, verdickte Mundsaum kurz ausgebreitet, der Aussenrand entsprechend dem Kiele etwas winkelig vorgezogen. Die kurze, etwas abgeflachte Spindel ist etwas nach aussen gebogen und bildet an Uebergange in den Basalrand eine undeutliche, knotenartige Verdickung. Der dünne, weisse Basalkallus ist undeutlich begrenzt.

$$
\mathrm{D}=12, \mathrm{~d}=11, \mathrm{H}=7.5 \mathrm{~mm} \text {. }
$$

Deckel mit dicker, knochenartiger Kalkplatte und zarter gelblicher Hornplatte, soust typisch.

Fundort: die Kei-Inseln; diese Form steht der Helicina aruana Pfr., mit welcher ich sie früher verwechselt babe, jedenfalls sehr nahe; nach der Beschreibung unterscheidet sie sich von dieser Art nur durch den dickeren Mundsaum und den Mangel einer roten Binde unter dem Kiel.

\section{A phanoconia parumsculptan.}

Taf. 36, Fig. 6-10.

Gehăuse dicklinsenförmig, ziemlich dünnschalig, leichtglänzend, gelblich hornfarben mit undeutlichen, lichteren Flecken und Striemen. Die Skulptur besteht nebst deutlichen, ungleichmässigen Zuwachsstreifen aus einigen undeutlichen Spiralreifen auf der Oberseite der mittleren Umgänge, ausserdem sind sowohl auf der Oberseite, als auf der Unterseite schief nach vorne, gegen den Kiel absteigende Runzeln vorhanden. Das flachkegelförmige, etwas konvexe Gewinde besteht aus $4 \frac{1}{2}$ leicht gewölbten, ziemlich rasch zunehmenden Umgängen; der letzte ist im Beginne ziemlich scharf gekielt, gegen die Mündung zu stumpfer und steigt mitunter schon in der zweiten Hälfte etwas unter dem Kiel herab. Die dreieckige Mündung ist schief, der kaum verdickte Mundsaum sehr kurz ausgebreitet. Die kurze, abgerundete Spindel ist etwas nach aussen gebogen und bildet am Uebergange in den Basalrand nur eine 
Leichte Verdickung. Der glänzende, durchsichtige Basalkallus ist nur im Umkreise der Spindel deutlich verdickt und daselbst durch eine seichte Furche begrenzt.

$$
\mathrm{D}=8.5, \mathrm{~d}=7, \mathrm{H}=5.5 \mathrm{~mm} \text {. }
$$

Deckel mit dünner, glănzender, gelblicher Kalkplatte, sonst typisch.

Fundort: die Insel Viti Lewu; nach Exemplaren des k. Museums zu Berlin.

\title{
Formenkreis Geoplioroides $n$.
}

\section{Aphanoconia tectiformis Mousson.}

Taf. 36, Fig. $11-15$.

\author{
Helicina tectiformis Mousson J. de Coneh. r. 18, p. 199, T. 8, F. 7, 1870. \\ (Trochatella) tectiformis Brazier Pr Z. S. p. 322, 1861. \\ , \\ Pfeiffer Mon. Pneum. IV, p. 250, 1876.
}

Gehäuse linsenförmig bis breitkegelförmig mit flacher Basis, festschalig, kaum glänzend bis matt; gelblichweiss mit grüngelber bis orangegelber Spitze, Die Skulptur besteht neben deutlichen, ungleichmässigen Zuwachsstreifen aus ziemlich dichten ungleich abstehenden, ziemlich scharfen Spiralleisten anf der Oberseite, sowie sehr dichten und feinen, bis undeutlichen Spirallinien auf der Unterseite. Das flach bis breit kegelförmige, abgerundete Gewinde besteht aus $4^{1} / 2$ bis 5 rasch zunehmendeu, leicht gewölbten Umgängen; der letzte ist sebr scharf bis flügelförmig gekielt und steigt vorne nicht herab. Die dreieckige Mündung ist sehr schief; der dicke weisse Mundsaum ausgebreitet, der Basalrand umgeschlagen. Die sehr kurze, abgerundete Spindel geht im Bogen in den Basalrand über. Der weisse, glănzende Basalkallus ist nur im Umkreise der Spindel deutlich verdickt und begrenzt.

$$
\mathrm{D}=13, \mathrm{~d}=11 \cdot 5, \mathrm{H}=7-8 \mathrm{~mm} \text {. }
$$

Deckel mit dicker, weisser und glänzender Kalkplatte; sonst typisch.

Fundort: die Viti-Inseln.

\author{
279. Aphanoconia sophiae Brazier. \\ Taf. 36, Fig. 16-20. \\ Helicina sop hiae Brazier Pr. Linn. Soc. Nen S. Wales, I, p. 4, 1876 ، \\ Pfeiffer Mal. Bl. v. 24, p. 156 .
}

Gehäuse flachkegelförmig mit Hacher Basis, festschalig, kaum glänzend, gelbweiss oder grünlichweiss mit grünlichgelber Spitze; die Skulptur besteht nebst deutlichen ungleichmässigen Zuwachsstreifen aus dichten und feinen Spiralreifen, welche auf der Unterseite nur in einer Zione entlang dem Kiele noch schwach vorhanden sind, in der Mitte aber erlöschen. 
Das Gewinde besteht aus 4 rasch zunehmenden Umgängen, welche durch eine weisse gekielte Naht geschieden werden; die oberen Umgänge sind flach, der letzte flachkonkav, unten sehr flach gewölbt, an der Peripherie sehr scharf und zusammengedrückt gekielt, vorne nicht herabsteigend. Die dreieckige Mündung ist schief, der weisse Mundsaum nahezu verdoppelt, aber kaum ausgebreitet; der Basalrand etwas umgeschlagen und konkar eingebuchtet. Die sehr kurze etwas abgeflachte Spindel geht in gleichmässigem Bogen in den Basalrand über; der ziemlich dicke, weisse und gekörnelte Basalkallus ist deutlich begrenzt.

$$
\mathrm{D}=7 \cdot 5, \mathrm{~d}=6 \cdot 5, \mathrm{H}=4.5 \mathrm{~mm} \text {. }
$$

Deckel annähernd schief trapezoidisch weiss mit dicker nahezu knochenartiger Kalkplatte; sonst typisch.

Fundort: die Treasury-Inseln.

\section{A phanoconia rogosiuscula Ancey (nomen). Taf. 36, Fig. 21-25.}

Helicina rogosiascula Ancey (nomen)?

Gehäuse breit kegelförmig mit flacher Basis, festschalig, matt, gelblichweiss, rötlichweiss mit gelber Spitze. Die Skulptur besteht neben ungleichmässigen Zuwachsstreifen aus dichten, ziemlich kräftigen Spiralreifen, welche auf, der Unterseite dichter und schwächer werden. Das wenig konvexe Gewinde besteht aus $4^{1} / 2$ nahezu flachen, regelmässig zunehmenden Umgängen, welche durch eine gekielte Naht geschieden werden; der letzte ist sehr scharf und zusammengedrückt gekielt und steigt vorne langsam etwas unter den Kiel herab. Die dreieckige Mündung ist schief, der kaum verdickte Mundsaum nur am Basalrande kurz ausgebreitet. Die sehr kurze, etwas abgeflachte Spindel geht im Bogen in den Basalrand über, der weisse Basalkallus ist nur im Umkreise der Spindel deutlich verdickt und begrenzt.

$$
\mathrm{D}=8, \mathrm{~d}=7, \mathrm{H} 5 \mathrm{~mm} \text {. }
$$

Deckel mit dicker, weisser und gekörnelter Kalkplatte; sonst typisch.

Fundort: die Samoa-Inseln.

\section{Formenkreis Ogasavarana A. J. Wagner.}

281. A phanoconia ogasavarana Pilsbry. Taf. 37, Fig. 1-5.

Helicina ogasavarana Pilsbry Pr. Akad. Philadelphia, V, 54 p. 25, 1902.

Aphanoconia ogasavarana A. J. Wagner Helicinenstudien in Denk. Akad. Wien, vol. 77, p. 395 , T. 5 , F. 5 a, b, c, 1805 . 
Gehäuse linsenförmig, festschalig, wenig glänzend bis matt einfărbig gelblich hornfarben mit hinfälliger gelbbrauner Epidermis. Die Skulptur besteht nebst deutlichen, ungleichmăssigen Zuwachsstreifen aus dichten Spiralfalten der Epidermis, welchen auf der Oberseite deutliche eingedrückte Spirallinien entsprechen; auf der Unterseite werden dieselben undeutlich oder verschwinden ganz. Das flachkegelförmige Gewinde besteht aus $4-4 \frac{1}{2}$ leicht gewölbten, ziemlich rasch zunehmenden Ungängen, welche durch eine etwas eingedrückte Naht geschieden werden; der letzte ist beiderseits flach gewölbt, an der Peripherie stumpf gekielt und steigt vorne langsam, aber deutlich unter den Kiel herab. Die dreieckige Mündung ist sehr schief, der weisse, verdickte Mundsaum kurz ausgebreitet, der Basalrand umgeschlagen. Die kurze nach vorn uud aussen gebogene Spindel bildet am Uebergange in den Basalrand eine stumpfe, aber deutliche Ecke. Der etwas verdickte, durchsichtige und feingekörnelte Basalkallus ist ziemlich deutlich begrenzt.

$$
\mathrm{D}=5 \cdot 5, \mathrm{~d}=4.5, \mathrm{H}=3 \cdot 2-3.5 \mathrm{~mm} \text {. }
$$

Deckel gelblich, durchscheinend, dreieckig mit zarter, gekörnelter Kalkplatte; sonst typisch.

Fundort: die Bonin-Inseln; die mir vorliegenden Exemplare sind mit der Fundortsangabe Hahajima-Ogasawara versehen, was anscheinend der japanischen Bezeichnung für die genannten Inseln entspricht. Pilsbry fasst die vorstehende Form als Typus einer formenreichen Gruppe auf, welche auf den Bonin-Inseln leben und zum Teil recht auffallend von einander abweichen. In früheren Publikationen habe ich einzelne dieser Formen als selbstständige Arten aufgefasst; in dem reichen Material, welches jetzt durch den Sammler Hirase auch nach Europa gelangt, sind jedoch Uebergangsformen enthalten, welche die grosse Veränderlichkeit dieser Formen erweisen und wahrscheinlich machen, dass dieselben nur Glieder einer Formenreihe darstellen.

\section{A phanoconia ogasawarana discrepans Pilsbry.}

Taf. 37, Fig. 6.

Helicina ogasawarana rar. discrepans Pilsbry Pr. Akad. Philadelphia V, 54, p. 25, 1902.

Aphanoconia ogasawarana discrepans A. J. Wagner Helicinenstudien in Denk. Arad. Wien. p. 77, T. 5, F. 7 à, b, c, p. 395, 1905.

Gehäuse kleiner mit schwächeren bis undeutlichen Spirallinien; der letzte Umgang weniger zusammengedrückt, die Unterseite mehr gewölbt, der Kiel auffallend stumpfer.

$$
\mathrm{D}=4 \cdot 4, \mathrm{~d}=3 \cdot 8, \mathrm{H}=3 \mathrm{~mm} \text {. }
$$

Deckel wie bei der typischen Form.

Fundort: Bonin-Inseln - Chichijima Ogasawara.

I. 18. II.

25. I. 1909. 


\title{
283. A phanoconia ogasawarana imotojimana Pilsbry. Taf. 37, Fig. 7.
}

Helicina ogasawarana var. imotojimana Pilsbry.

Gehäuse kleiner, die Umgange und besonders der letzte mehr gewölbt, weniger zusammengedrückt, stumpfer gekielt bis stumpfkantig; die Ecke am Uebergange der Spindel in den Basalrand undeutlich, die Spiralskulptur nahezu wie bei der typischen Form.

Deckel wie bei der typischen Form.

$$
\mathrm{D}=4 \cdot 5, \mathrm{~d}=3 \cdot 8, \mathrm{H}=3 \text {. }
$$

Fundort: Imotoyima Ogasawara.

\author{
284. A phanoconia ogasawarana optima Pilsbry. \\ Taf 37, Fig. 8-10, Fig. 12. \\ Helicina ogasawarana var. optima Pilsbry. \\ Aphanoconia optima A. J. Wagner Helicinenstudien in Denk. Ak. Wien. v. 77 T. 5 \\ F. 9 a, b, c, p. 397,1905 .
}

Gehäuse grösser, lebhaft rotbraun gefärbt mit undeutlichen bis erloschenen Spirallinien; das höhere, etwas abgerundet kegelförmige Gewinde besteht aus $41 / 2$ nahezu fiachen Umgãngen; der letzte ist weniger zusammengedrückt, unten mehr gewölbt, an der Peripherie scharf und zusammengedrückt gekielt, vorne kaum herabsteigend. Der weisse oder gelbliche Mundsaum kräftiger verdickt, aber kürzer ausgebreitet, der Basalrand nicht umgeschlagen. Die Ecke am Uebergange der Spindel in den Basalrand stumpfer, weniger vorspringend; der gelbliche bis rotbraune Basalkallus deutlicher begrenzt.

$$
\mathrm{D}=6 \cdot 6, \mathrm{~d}=6, \mathrm{H}=4 \mathrm{~mm} \text {. }
$$

Deckel gelblich mit festerer, weniger durchscheinender Kalkplatte, sonst typisch.

Fundort: Nishijima und Chichijima Ogasawara.

Unter der Bezeichnung Helicina ogasawarana var. rex Pilsbry erhielt ich von Herrn Dautzenberg ein anfallend grosses, in den übrigen Merkmalen jedoch der vorstehenden Form vollkommen entsprechendes Exemplar mit der Fundortsangabe Hahajina Ogasawara. Die Grössenverhältnisse desselben betragen: $\mathrm{D}=9, \mathrm{~d}=8, \mathrm{H}=5.5 \mathrm{~mm}$; die Abbildung auf Taf. 27, Fig. 12. 
285. A phanoconia ogasawarana arata Pilsbry. Taf. 37, Fig. 11.

Helicina yoshiwarana var. arata Pilsbry Proc. Akad. Philadelpbia, V, 54, p. 25 und 26 1902.

Aphanoconia arata A. J. Wagner Helicinenstadien in: Denk. Ak. Wien, v. 77, p. 397 T. 5, F. 8 a, b, c, 1905 .

Gehäuse hell hornfarben bis rotbraun mit ziemlich weitläufigen Spirallinien auf der Oberseite; das flach kegelförmige Gewinde besteht aus 4 flachen Umgängen; der letzte ist zusammengedrückt, scharf gekielt und steigt vorne sehr wenig unter den Kiel herab. Der Mundsaum kurz ausgebreitet und umgeschlagen, verdickt bis nahezu verdoppelt; die Ecke am Uebergange der Spindel in den Basalrand abgerundet und undeutlich.

$$
D=5 \cdot 8, d=5 \cdot 2, H=3 \cdot 4 \mathrm{~mm} \text {. }
$$

Deckel wie bei der typischen Form.

Fundort: Hahajima Ogasawara.

\title{
286. A phanoconia yoshiwarana Pilsbry.
}

Taf. 37, Fig. 13-14.

\author{
Helicina yoshiwarana Pilsbry Proc. Akad. Philadelphia, V, 54, p. 25, 1902. \\ Aphanoconia yoshiwarana A. J. Wagner Helicinenstudien in: Denk. Ak. Wien. จ. 77, \\ T. 5, F. 3 a, b, o, p. 396, 1905.
}

Gehăuse breitkegelförmig mit gewölbter Basis, festschalig, ziemlich glănzend, schmutziggelb bis rotbraun. Die Skulptur besteht nebst ungleichmässigen Zuwachsstreifen aus dichten und feinen Spiralfurchen, welche auf der Unterseite auffallend schwächer werden. Das leicht konvexe Gewinde besteht aus 4 gewölbten, ziemlich rasch zunehmenden Umgängen; der letzte ist an der Peripherie undeutlich stumpfkantig bis gernndet und steigt vorne langsam und wenig herab. - Die abgerundet dreieckige Mündung ist schief, der weisse Mundsaum kurz ausgebreitet, umgeschlagen und verdickt. Die sehr kurze Spindel ist leicht nach aussen gebogen und bildet am Uebergange in den Basalrand keine Ecke. Der Basalkallus ist im Umkreise der Spindel ziemlich dick und deutlich begrenzt, nach oben zu dünner und undeutlich.

$$
\mathrm{D}=4 \cdot 6, \mathrm{~d}=4, \mathrm{H}=3 \cdot 4 \mathrm{~mm} \text {. }
$$

Deckel dreieckig mit verhältnismässig fester, feingekörnelter Kalkplatte, gelblich, wenig durchscheinend; sonst typisch.

Fundort: Hahajima Ogasawara. 


\section{Aphanoconia yoshiwarana microtheca Pilsbry. Taf. 37, Fig. $15-19$.}

Helicina yoshiwarana var. microtheca Pilsbry, Proc. Akad. Nat. Se. Philadelphia V,54, p. 25, 1902.

Aphanoconia yoshiwarana microtheca A. J. Wagner, Helicinenstadien in: Denk. Akad, Wien. v. 77, p. 396, T. 5, F. 4, 1905.

Gehăuse kleiner, flachkegelförmig mit gewölbter Basis, gelbweiss bis rotbraun. Die Spirallinien sind dichter, feiner und verschwinden oft bis auf einige Spiralfalten der Epidermis gänzlich; das niedrigere Gewinde besteht nur aus $3 \frac{1}{2}$ schwăcher gewölbten Umgăngen; der letzte ist stärker zusammengedrückt und deutlicher kantig.

Deckei wie bei der typischen Form.

$$
\mathrm{D}=4, \mathrm{~d}=3 \cdot 2, \mathrm{H}=2 \cdot 4 \mathrm{~mm} \text {. }
$$

Fundort: Hahajima Ogasawara.

\section{A phanoconia yoshiwarana comes Pilsbry.}

Taf. 37, Fig. 20-22.

Helicina comes Pilsbry.

Gehäuse sehr klein, gedrückt kugelig, ziemlich festschalig, leicht glänzend mit gelbbrauner bis rotbrauner Epidermis, welche auf den oberen Umgängen zumeist abgerieben ist. Die Skulptur besteht nebst sehr feinen Zuwachsstreifen aus einigen hinfälligen Spiralfalten der Epidermis, welchen sehr feine eingedrückte Spirallinien entsprechen. Das niedrige Gewinde besteht aus 3 ziemlich rasch zunehmenden, gewölbten Umgängen; der letzte ist etwas aufgeblasen, gerundet und steigt vorne nicht herab. Die halblrreisförmige Mündung ist ziemlich schief; der weisse oder gelbliche Mundsaum verdickt bis nahezu verdoppelt, aber kaum ausgebreitet. Die kurze, etwas abgeflachte Spindel bildet an Uebergange in den Basalrand keine vorspringende Ecke. Der durchscheinende, feingekörnelte Basalkallus ist dick und deutlich begrenzt.

$$
\mathrm{D}=3 \cdot 5, \mathrm{~d}=3, \mathrm{H}=2.5 \mathrm{~mm} \text {. }
$$
typisch.

Deckel abgerundet dreieckig, rötlich mit rerhältnismässig dicker Kalkplatte; sonst

Fundort: Nakawoshima, Bonin-Inseln.

Die vorstehende Form erhielt ich von den Herrn Sowerby und Fulton mit der angeführten Bezeichnung und Fundortsangabe. 


\section{Subgenus Sphaeroconia $\mathrm{n}$.}

Gehäuse kegelförmig mit gewölbter Basis bis kugelig; das mehr minder konvexe bis abgerundete Gewinde besteht aus $3 \frac{1}{2}$ bis $4 \frac{1}{2}$ langsam zunehmenden Umgängen, der letzte ist kantig oder gerundet; der Mundsaum gleichmåssig, auch entsprechend dem Oberrande ausgebreitet.

Deckel dreieckig bis halbeiförmig mit hăufig abgerundetem, weniger nach hinten gebogenem Spindelwinkel. Die Kalkplatte flachkonkav mit seichter Furche neben der wallartigen Verdickung des Spindelrandes. Die Sigmakante gleichmässig S-förmig gebogen, hăufig auch im oberen Aste deutlich erhoben und dem Spindelrande mehr genähert; der Spindelteil dementsprechend schmäler, oft nur $1 / 4$ von der Breite der Platte betragend.

Das Verbreitungsgebiet dieser Gruppe erstreckt sich über die Bonin-Inseln, Liu Kiu, Formosa, Hainan, Hongkong, Tonking, die Palau Inseln, Neu-Guinea mit dem BismarkArchipel und den Lousiaden, die York-Halbinsel vom Festlande Australiens, ferner die neuen Hebriden, Neu Caledonien, die Fiji, Tonga, Samoa, Elice und Paumotu Inseln.

Der Mittelpunkt dieses Verbreitungsgebietes liegt anscheinend auf den Inselgruppen zwischen Neu-Guinea und Neu-Caledonien, wo die Gruppe in zahlreichen und gut gekennzeichneten Formen auftritt.

Während die oben beschriebenen Formen des Genus Aphanoconia s. str. noch deutlich einzelne Merkmale des Genus Geophorus Fischer aufweisen, wie das flache und gekielte Gehäuse, den geraden Oberrand der Mündung und auch mit Rücksicht auf die Beschaffenheit des Deckels eine grosse Uebereinstimmung mit diesem Genus erkennen lassen, erscheinen diese Merkmale bei den hier zusammengefassten Formen sehr abgeschwächt und vielfach geschwunden. Das Gewinde ist mehr erhoben und abgerundet, die langsam zunehmenden Umgänge kantig bis gerundet, der Mundsaum gleichmässig ausgebreitet. Am Deckel erscheint die Biegung des Spindelwinkels nach hinten oft sehr schwach, die Sigmakante ist gleichmässiger, in beiden Aesten gebogen und dem Spindelrande oft sehr genähert, so dass ein allmähliger Uebergang zu den Formen des Genus Palaeohelicina (mit randständigem Nukleus des Deckels) bemerkbar wird. So ist auch hier eine scharfe Trennung der Gruppen, sowie eine ausreichende Kennzeichnung derselben durch konstante Merkmale nur unvollkommen durchführbar. Um so wichtiger erscheint es mir die anscheinend nahe verwandten Formen in Formenkreise zusammenfassen, da hiezu schon die Uutersuchung der Hartteile genügende Anhaltspunkte bietet. Oft sind es sonst untergeordnete Merkmale, wie Färbung und Skulptur, welche durch ihr charakteristisches Auftreten auf eine nahe Verwandtschaft hinweisen. 


\title{
Formenkreis Verecunda $n$.
}

\author{
289. Aphanoconia (Sphaeroconia) verecunda Gould. \\ Taf. 37, Fig. 23-27.
}

Helicina verecunda Gould, Pr. Bost. Soc. 6, p. 426, 1859.

" Pfeiffer Mon. Pneum. III, p. 236, 1865.

A phanoconia verecunda A. J. Wagner Helicinenstudien in Denk. Ak. Wien, v. 77, p. 389, T. 4, F. 7 a, b, c, 1905 .

Gehăuse kegelförmig mit flachgewölbter Basis, festschalig, leicht glänzend, fein und etwas ungleichmässig radial gestreift nebst dichten und sehr feinen Spirallinien; die Grundfarbe gelblich bis rötlich hornfarben mit etwas verwaschenen milchigen Radialstriemen, die oberen Windungen rotbraun bis orange (mit eingetrockneten Weichteilen grünlich). Das ziemlich erhobene, leicht konvexe Gewinde besteht aus $4 \frac{1}{2}$ leicht gewölbten, langsam zunehmenden Umgängen; der letzte ist an der Peripherie undeutlich gewinkelt bis gerundet und steigt vorne nicht herab. Die abgerundet dreieckige Mündung ist wenig schief, innen gelbbraun; der gelbliche oder weisse Mundsaum schwach verdickt, kurz ausgebreitet und umgeschlagen; die dünne, abgerundete Spindel ist etwas nach aussen gebogen und bildet am Uebergange in den Basalrand eine deutlich vorspringende winkelige Ecke. Der ziemlich dünne, deutlich gekörnelte und gelbliche Basalkallus ist zumeist wenig deutlich begrenzt.

$$
\mathrm{D}=6, \mathrm{~d}=5, \mathrm{H}=4.5-5 \mathrm{~mm} \text {. }
$$

Deckel: abgerundet dreieckig, beiderseits hellrotbraun gefärbt mit ziemlich dicker, feingekörnelter Kalkplatte; sonst typisch.

Fundort: Liu-Kiu-Inseln, Loo-choo.

\section{A phanoconia (Sphaeroconia) hungerfurdiana Möllendorff. Taf. 38, Fig. 1-5.}

Helicin a hangerfordia na Möllendorff, J. Mal. Ges. p. 182, 354, 1882.

Aphanoconia hangerfordiana A. J. Warper Helicinenstadien in: Denk. Ak. Wien. v. 77, p. 389 , T. 4, F. 10 a, b, c, 1905.

Gehäuse breit kegelförmig mit gewölbter Basis, ziemlich dünnschalig, glänzend, mit feinen, etwas ungleichmässigen Zuwachsstreifen und dichten. sehr feinen Spirallinien; , einfärbig gelb, orange bis rotbraun, der letzte Umgang hăufig etwas milchig getrübt. Das leicht konvexe Gewinde besteht aus 4 kaum gewölbten, ziemlich langsam zunehmenden Umgängen; der letzte ist im Beginne etwas gewinkelt und steigt vorne sehr wenig herab. Die halbkreisförmige Mündung ist wenig, schief, der weisse wenig verdickte Mundsaum kurz umgeschlagen. 
Die dünne abgerundete Spindel ist etwas nach aussen gebogen und bildet am Uebergange in den Basalrand eine ziemlich deutliche, winkelige Ecke. Der weissliche, feingekörnelte Basalkallus ist dünn und nur im unteren Teile deutlicher begrenzt.

$$
\mathrm{D}=5, \mathrm{~d}=4, \mathrm{H}=3.8 \mathrm{~mm} \text {. }
$$

Deckel halbeiförmig, beiderseits gelbbraun oder orange, mit ziemlich dicker, feingekörnelter Kalkplatte; sonst typisch.

Fundort: Hongkong.

\section{A phanoconia (Sphaeroconia) hungerfordiana formosana Schmacker et Boeltger. \\ Taf. 38, Fig. 10-14.}

Heilina hungerfordi ana formosana Schmacker et Boettger Nachr. Bl. p. 186, 1891. Aphanoconia hangerfordiana formosana A. J. Wagner Helicinenstadien, in: Denk. Ak. Wien. v. 77, p. 390, T. 4, F. 11 a, b, 1905.

Gehăuse durchschnittlich grösser mit deutlicher gewölbten Umgängen, sowie schwacher bis erloschener Spiralskulptur; der letzte Umgang deutlich kantig, der weisse Mundsaum mehr ausgebreitet und umgeschlagen.

$$
D=3 \cdot 6, d=4 \cdot 7, H=4 \mathrm{~mm} .
$$

Deckel wie bei der typischen Form von Hongkong.

Fundort: Bankimtsong auf Formosa,

\section{A phanoconia (Sphaeroconia) hungerfordiana tonkinensis Möllendorff. \\ Taf. 38, Fig. 6-9.}

Gehäuse ohne Spur einer Spiralstreifung mit etwas langsamer zunehmenden, deutlicher gewölbten Umgängen; gelbbraun bis rotbraun mit einer lichteren Zone um die Mündung und zwei lichteren milchig getrübten Bändern an der Peripherie und Naht.

$$
D=5, d=4.0, H=3.8 \mathrm{~mm} \text {. }
$$

Deckel wie bei der typischen Form.

Fundort: Bach Mru in Tonking. 
293. Aphanoconia (Sphaeroconia) hungerfordiana halongensis A. J. Wagner.

Taf. 38, Fig. 15-17.

Aphanoconia halongensis A. J. Wagner Helicinenstadinm in: Denk. Ak. Wien, $\nabla .77$, T. 6, F. 4 a, b, c, p. 404, 1905.

Gehäuse mit flach kegelförmigem, konvexem Gewinde, 4 langsamer zunehmenden, deutlich gewölbten Umgängen; ohne Spur von Spirallinien, jedoch mit feinen Runzeln der Epidermis. Der letzte Umgang mehr zusammengedrückt, an der Peripherie stumpflkantig; die Ecke am Uebergange der Spindel in den Basalrand deutlicher vorspringend.

$$
\mathrm{D}=5, \mathrm{~d}=4 \cdot 2, \mathrm{H}=3.4 \mathrm{~mm} \text {. }
$$

Deckel wie bei der typischen Form.

Fundort: Halong in Tonking.

\title{
294. A phanoconia (Sphaeroconia) hainanensis Möllendorff.
} Taf. 38, Fig. 18-20.

\author{
Helicina hangerfordiana var. ha inanensis Möllendorff J. Mal. Ges, p. 355, 1882. \\ Helicina hainanensis Möllendorff J. Mal. Ges. p. 182, 1882. \\ Aphanoconia hainanensis A. J. Wagner Helicinenstadien in Denk. Ak. Wien, v. 77, T. 4, \\ F. $12 \mathrm{a}, \mathrm{b}, \mathrm{c}, 1905$.
}

Gehäuse breitkegelförmig mit gewölbter Basis, ziemlich dünnschalig, leicht glänzend mit deutlichen, ungleichmässigen Zuwachsstreifen; einfärbig hellgelb bis rotbraun. Das kegelförmige, leicht konvexe Gewinde besteht aus $4 \frac{1}{2}$ lángsam zunehmenden, deutlich gewölbten Umgängen; der letzte ist deutlich kantig und steigt vorne langsam und wenig unter die Kante herab. Die abgerundet dreieckige Mündung ist wenig schief; der weisse, wenig verdickte Mundsaum kurz ausgebreitet; die dünne, abgerundete Spindel ist nahezu senkrecht und bildet am Uebergange in den Basalrand eine deutlich vorspringende, winkelige Ecke. Der ziemlich dünne, mit dem Gehăuse gleichfarbige Basalkallus ist nur im unteren Teile deutlich begrenzt. $\mathrm{D}=4 \cdot 7, \mathrm{~d}=4, \mathrm{H}=3 \cdot 6 \mathrm{~mm}$.

Deckel unbekannt.

Fundort: die Insel Haynan. 


\section{Aphanoconia (Sphaeroconia) hainanensis badia Schmacker et Boeltger.}

T'af. 38, Fig. 21-2?.

Helicina badia Schmacker et Boettger, Nachr. Bl., p. 185, T. 2, F. 8, 1891.

Aphanoconia hainanensis badia A. J. Wagner Helicienstudien in: Denk. Akad. Wien, vol. 77, T. 4, F. 13 a, b, c, p. 391, 1905.

Gehäuse kleiner, hellgelb, orange bis rotbraun mit einigen ziemlich weitläufigen, eingedrückten Spirallinien; der letzte Umgang gekielt, mehr zusammengedrückt.

$$
D=3 \cdot 6, d=3 \cdot 3, H=2 \cdot 6 \mathrm{~mm} .
$$

Fundort: südliches Forniosa (Takao und Südcap.).

Von der Formenreihe der hungerfordiana Möllendorff unterscheiden sich die vorstehenden Formen durch das höhere Gewinde, die grössere Zahl der langsamer zunehmenden Umgänge, die weitlăufigen Spirallinien, die deutlicher kantigen bis gekielten Umgănge und die schärfer vorspringende Ecke am Uebergange der Spindel in den Basalrand.

\section{A phanoconia (Sphaeroconia) osumiensis Pilsbry. Taf. 38, Fig. 23-26.}

A phanoconia osumiensis A. J. Wagner, Helicinenstudien. in: Denk. Ak. Wien, v. 77, T. 4. T. 9 a, b, 1905 .

Gehäuse breitkegelförmig mit gewölbter Basis, verhăltnismăssig festschalig, wenig glănzend mit feinen etwas ungleichmässigen Zuwachsstreifen und der Andeutung einer feinen Spiralstreifung; einfärbig rotbraun. Das ziemlich erhobene, etwas konvexe Gewinde besteht aus 4 kaum gewölbten, langsam zunehmenden Ungăngen; der letzte ist stumpf gekielt und steigt schon in der 2ten Hälfte etwas unter den Kiel herab. Die abgerundet dreieckige Mündung ist wenig schief, der gelbliche Mundsaum leicht verdickt, sehr kurz ausgebreitet. Die nahezu senkrechte, etwas verbreitete Spındel bildet am Uebergange in den Basalrand eine wenig vorspringende, abgerundete Ecke. Der dünne, im Zentrum weisse Basalkallus ist undeutlich begrenzt.

$$
\mathrm{D}=3 \cdot 5, \mathrm{~d}=3 \cdot 2, \mathrm{H}=2 \cdot 5 \mathrm{~mm} \text {. }
$$

Deckel dreieckig, weiss mit rötlichen Rändern und verhältnismässig fester, grobgekörnelter Kalkplatte; sonst typisch.

Fundort: Kikai, Osumi, Japan.

I. 18. II.

27. I 1909. 


\section{A phanoconia (Sphaeroconia) capsula Pilsbry. \\ Taf. 39, Fig. 1-6. \\ He licina capsula Pilsbry- Proc. Acad. Philadelphia, V, 54, p. 25, 1902. \\ Sturanga capsula A. J. Wagner, Helicinenstudien, in: Denk. Akad. Wien. vol. 77, T. 4, F. $4 \mathrm{a}, \mathrm{b}, \mathrm{c}, 1905$.}

Gehäuse kegelförmig mit gewölbter Basis, ziemlich dünnschalig, leicht glänzend, hornfarben bis rötlich; die Skulptur besteht nebst etwas ungleichmässigen, feinen Zuwachsstreifen aus einigen Spiralfalten der Epidermis, abgeriebene Exemplare zeigen ausserdem, besonders auf den oheren Umgängen eine dichte und sehr feine Spiralstreifung. Das regelmässig kegelförmige, ziemlich erhobene Gewinde besteht aus $4^{1 / 2}$ langsam zunehmenden, deutlich gewölbten Umgängen; der letzte ist stumpfkantig und steigt vorne wenig herab. Die abgerundet dreieckige Mündung ist ziemlich schief, der' wenig verdickte Mundsaum kaum ausgebreitet, fast gerade. Die nahezu senkrechte, etwas abgeflachte Spindel bildet am Uebergange in den Basalrand eine undeutliche oft fehlende Ecke. Der dünne, weissliche Basalkallus ist gekörnelt und undeutlich begrenzt.

$$
\mathrm{D}=5 \cdot 2, \mathrm{~d}=4 \cdot 6, \mathrm{H}=4 \cdot 4 \mathrm{~mm} .
$$

Deckel abgerundet dreieckig mit verhältnismässig dicker, weisser und feingekörnelter Kalkplatte; der Spindelwinkel deutlich nach rückwärts gebogen, die Sigmakante im unteren Aste auffallend stärker erhoben.

Fundort: die Bonin-Inseln.

Ich habe diese Form früher bei dem Genus Sturanya m. eingeteilt, doch lagen mir damals nur unausgewachsene Exemplare ohne Deckel vor.

\section{Aphanoconia ( $S$ phaeroconia) yaeyamensis Pilsbry. Taf. 39, Fig. $7-10$.}

Helicina ya yamensis Pilsbry, Proc. Akad. Philadslphia, V, 53, p. 497, 1901.

Sturanya yaeyamensi s A. J. Wagner Helicinenstudien, in: Denk. Akad. Wien. จ. 77, T.4, F. 6 a, b, e, p. 388,1905 .

Gehäuse breitkegelförmig mit gewölbter Basis, ziemlich dünnschalig, wenig glänzend mit feinen Zuwachsstreifen und ziemlich dichten Spiralfalten der Epidermis; einfärbig hornfarben bis rotbraun. Das schwach konvexe Gewinde besteht aus $4-4^{1 /} / 2$ langsam zunehmenden, deutlich gewölbten Umgăngen; der letzte ist schwach kantig bis gerundet und steigt vorne langsam herab. Die abgerundet dreieckige Mündung ist schief, der Mundsaum stumpf und fast gerade. Die kurze, abgerundete Spindel bildet am Uebergange in den Basalrand 
keine Ecke; der ziemlich dicke, gekörnelte Basalkallus ist mit dem Gehäuse gleichfarbig, in der Mitte weisslich und deutlich begrenzt.

$$
\mathrm{D}=3.5, \mathrm{~d}=3, \mathrm{H}=2.8 \mathrm{~mm} \text {. }
$$

Deckel abgerundet dreieckig mit verhältnismässig dicker Kalkplatte una undeutlicher Furche neben dem Spindelrand beiderseits rötlich gefürbt, sonst typisch.

Fundort: die Loo-choo Inseln in Japan (Yaeyama).

\title{
Formenkreis Reticulata A. J. Wagner.
}

\section{Aphanoconia (Sphaeroconia) sphaeroconus Möllendorff.} Taf. 39, Fig. 15-18.

\author{
Helicina (Sulfarina) sphaeroconas Möllendorff, Pr. Mal Soc. Lond. I, p. 240, T. 15, \\ F. $10,1894$. \\ A phanoconia sphaeroconas A. J. Wagner Helicinenstudien, in: Denk. Akad. Wion. v. 77, \\ T. 4, F. 15 a, b, c, p. 392. 1905.
}

Gehăuse kegelförmig mit gewölbter Basis, festschalig, schmutziggelb bis rötlich mit gelber Spitze und einer verwaschenen braunvioletten Zone auf der Oberseite der unteren Umgänge; im frischen Zustande matt mit ziemlich dichten Spiralfalten der Epidermis, abgerieben leicht glänzend mit dichten und feinen, eingedrückten Spirallinien, welche auf der Peripherie und Unterseite weitläufig und tiefer werden. Das regelmåssig kegelförmige Gewinde besteht aus $4^{1} / 2$ nahezu flachen, langsam zunehmenden Umgängen, welche durch eine eingerdückte Naht geschieden werden; der letzte ist etwas zusanmengedrückt, deutlich kantig, bis stumpf gekielt und steigt vorne nicht herab. Die abgerundet dreieckige Mündung ist wenig schief, innen gelbbraun bis orange gefärbt; der gelbe, leicht verdickte Mundsaum glockenförmig erweitert, ziemlich ausgebreitet; der Aussenrand oft im abgerundeten Winkel vorgezogen. Die nahezu senkrechte, abgerundete Spindel bildet am Uebergange in den Basalrand eine ziemlich scharfe und vorspringende Ecke. Der gelbe Basalkallus ist nur im Umkreise der Spindel deutlich verdickt und begrenzt.

$$
\mathrm{D}=8, \mathrm{~d}=7, \mathrm{H}=7 \mathrm{~mm} \text {. }
$$

Deckel abgerundet dreieckig mit dicker, perlmutterglänzender Kalkplatte, unten rotorange; sonst typisch.

Fundort: Konstautinhaven in Neu-Guinea. 
300. Aphanoconia (Sphaeroconia) gouldiana Forbes. Taf. 40, Fig. $1-4$.

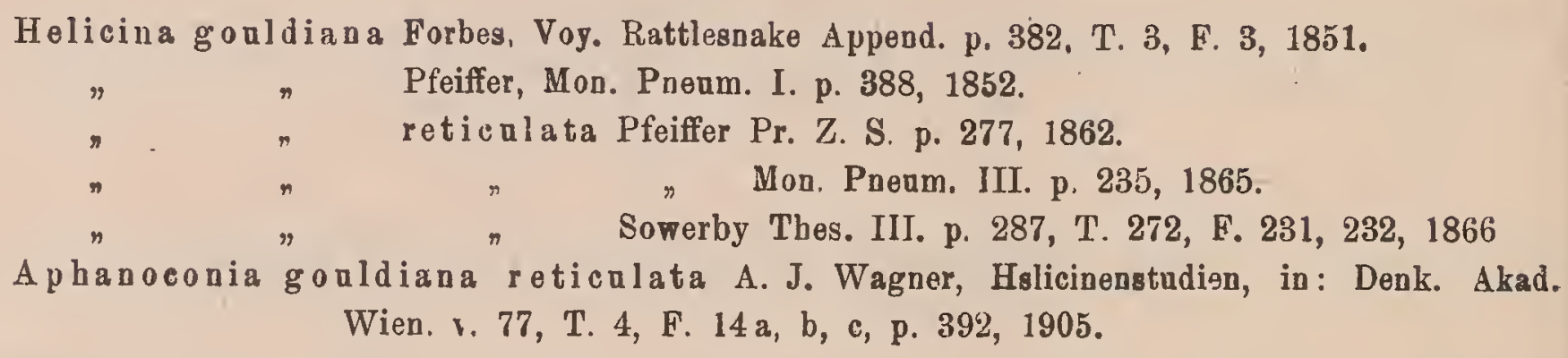

Gehãuse breit kegelförmig mit gewölbter Basis, annåhernd kreiselförmig, festschalig, leicht glänzend, gelbbraun, rotbraun bis braun violett und milchig getrübt mit durchscheinenden Zickzackstriemen, welche häufig in unregelmässige Flecken aufgelöst sind. Die Skulptur besteht nebst feinen Zuwachsstreifen aus dirhten und feinen Spiralreifen, welche überall gleichmässig sind. Das regelmässig kegelförmige Gewinde besteht aus $4-41 / 2$ nahezu flachen, langsam zunehmenden Umgăngen; der letzte ist kantig bis schwach gewinkelt und steigt vorne wenig herab. Die abgerundet dreieckige Mündung ist wenig schief, innen gelbbraun bis rotbraun; der gelbliche, schwach verdickte Mundsaum kurz ausgebreitet. Die ziemlich kurze, abgerundete Spindel ist nach aussen gebogen und bildet am Uebergange in den Basalrand eine abgerundete, kaum vorspringende Ecke. Der dünne, gelbliche Basalkallus ist gekörnelt und nur im Umkreise der Spindel deutlich begrenzt.

$$
\mathrm{D}=6.5-7, \mathrm{~d}=5.5-6, \mathrm{H}=5-55 \mathrm{~mm} \text {. }
$$

Deckel halbeiförmi g, gelbbraun bis rotbraun. mit kastanienbrauner Zone am Aussenrand, ziemlich dicker, feingekörnelter Kalkplatte; sonst typisch.

Fundort: Queensland; der Originalfundort Cap Flattery auf der Halbinsel York. H. reticulata Pfr. ist dem Vergleiche von Originalexemplaren zur Folge mit vorstehender Art identisch, stammt auch vom gleichen Fundort.

\section{Aphanoconia (Sphaeroconia) subreticulata n. Taf. 40, Fig. 5-9.}

Gehäuse kegelförmig mit flachgewölbter Basis, festschalig, hellgelb mit weisslicher Spitze und zwei scharf begrenzten milchweissen Bändern an der Peripherie und Naht; aufder Unterseite finden sich häufig auf gelblichem Grund einige schmale und undeutliche, weisse Binden. Die Skulptur besteht nebst feinen Zuwachsstreifen aus dichten und feinen eingedrückten Spirallinien, welche auf der Unterseite etwas schwächer werden. Das regelmässig kegelförmige Gewinde besteht aus $4^{1} / 2$ kauın gewölbten, langsam zunehmenden Umgăngen, der 
letzte ist stumpfkantig, gegen die Mündung zu nahezu gerundet und steigt vorne kaum herab. Die abgerundet dreieckige Mündung ist wenig schief, innen gelb; der weisse, leicht verdickte Mundsaum kurz ausgebreitet. Die ziemlich kurze, oben etwas verbreiterte Spindel ist nach aussen gebogen und bildet am Uebergange in den Basalrand nur einen wenig auffallenden Knoten. Der ziemlich dünne, gelbliche Basalkallus ist gekörnelt und nur im Umkreise der Spindel deulicher begrenzt.

$$
\mathrm{D}=6, \mathrm{~d}=5 \cdot 2, \mathrm{H}=4.6 \mathrm{~mm} \text {. }
$$

Deckel halbeiförmig, gelblich mit rotbrauner Zone am Aussenrande. Die ziemlich dicke, gekörnelte Kalkplatte ist flach konkav mit undeutlicher Furche neben dem Spindelrand; der Spindelwinkel nicht nach hinten gebogen; die Sigmakante gleichmässig gebogen, dem Spindelrande sehr genähert.

Fundort: Neue Hebriden.

Diese neue Art steht der A. gouldiana Forbes sehr nahe und unterscheidet sich von derselben durch etwas geringere Grösse, dus niedrige Gewinde, die flacheren Umgånge, die schwächere Spiralskulptur und besonders durch die auffallende Färbung; jedenfalls ist das Auftreten so nahestehender Formen auf dem Festlande Australiens und den Neuen Hebriden sehr bemerkenswert.

\author{
302. Aphanoconia (Sphaeroconia) macgillivrayi Pfeiffer. \\ Taf. 41, Fig. 1-5. \\ Helicina macgillivrayi Pfeiffer, Pr. Z. S. p. 102, 1855. \\ $\eta \quad$ " Mon. Preum. II, p. 206, 18 อั8. \\ n Sowerby Thes. III, p. 290, T. 275, F. 337, 338, 1866. \\ Orobophana mediana vermiculata A. J. Wagner, Helicinenstudien, in: Denk. Akad. Wien, \\ จ. 77, T. 8, F. 4 a, b, c, p. $424,1905$.
}

Gehäuse breitkegelförmig mit gewölbter Basis, festschalig, im frischen Zustande wenig glänzend mit sehr feinen Z:uwachsstreifen und ziemlich dichten, aber sehr hinfälligen Spiralfalten der Epidermis; an etwas abgeriebenen Exemplaren sind ausserdem dichte und sebr feine Spirallinien vorhanden, welche auf dem letzten Umgange sehwächer bis undeutlich werden; daneben sind auf dem letzten Umgange und besonders auf der Unterseite hăufig einige weitlaufigere, aber deutlichere, und punktierte Spirallinien sichtbar, welche den abgeriebenen Spiralfalten entsprechen. Die mannigfaltige Färbung ist bald schmutzigweiss, gelb, gelbbraun, rotbraun oder violett; einfärbig oder mit einer zumeist rotbraunen Binde über der Peripherie; diese Binde ist bald schmal und scharf, bald zu einer breiten Zone mit mehr minder verwaschenen Rändern erweitert, welche die ganze Oberseite der Umgänge bis auf ein schmales, lichtes Nahtband einnimmt. Mitunter finden sich auch Exemplare, welche auf dunklem, durchscheinenden Grund, milchig getrübte bis weissliche, undeutliche Zickzack- und 
Radialstriemen besitzen; diese Striemen erscheinen auf den mittleren Umgăngen teilweise in innregelmässige Flecken aufgelöst und verdecken auf dem letzten Umgange die Grundfarbe gänzlich. Das flachkegelförmige, mitunter etwas konvexe Gewinde besteht aus $4^{1 / 2}$ langsam zunehmenden, nahezu Hachen Umgängen; der letzte ist undeutlich kantig bis gerundet und steigt vorne langsam, aber deutlich herab. Die halbeiförmige, schiefe Mündung ist innen je nach der Grundfarbe gelblich bis rotbraun; der leicht verdickte, weisse Mundsaum ist ausgebreitet, der Oberrand an der Insertion vorgezogen und gerade. Die oben verbreiterte Spindel ist nach aussen gebogen und bildet beim Uebergange in den Basalrand der Mündung keine Ecke. Der gelbliche, glanzende Basalkallus ist im Umkreise der Spindel deutlich verdickt und daselbst durch eine seichte Furche begrenzt.

$$
\begin{aligned}
& D=5 \cdot 5, d=4.5, H=4 \mathrm{~mm} . \\
& D=6.5, d=5.5, H=4.5 \mathrm{~mm} .
\end{aligned}
$$

Deckel abgerundet dreieckig, beiderseits rotbraun. Die ziemlich dicke feingekörnelte Kalkplatte flachkonkav, mit wallartiger Verdickung am Spindelrand und Spindelwinkel, sowie undeutlicher Furche; der Spindelwinkel nicht nach rückwärts gebogen, die Sigmakante in beiden Aesten leicht erhoben, gleichmässig S-förmig gebogen und dem Spindelrande sehr genăhert.

Fundorte: die Pinien-Inseln, Lifu und Neu-Caledonien. Eine bezüglich der Färbung, Skulptur und Höhe des Gewindes, sowie der mehr minder deutlichen Kante des letzten Umganges ziemlich variable Art, welche von der unten angeführten Lokalform schwer zu trennen ist, da anscheinend selbst auf enger begrenztem Fundorte auch Uebergangsformen auftreten.

\author{
303. Aphanoconia macgilicrayi mediana Gassies. \\ Taf. 41, Fig. 6 . \\ Helicina median a Gassies, J, de Conch. 18, p. 145, 1870. \\ Pfeiffer Mon. Pneum. IV p. 249, 1876. \\ Gassies Faun. Nouv. Caléd. II p. 128, 1871. \\ Crosse J. de Conch. v. 42, p. 403, 1894. \\ Faun. Nour. Caléd. p. 246, 1894. \\ Orobophana mediana A. J. Wagner Helicinenstudien, in: Denk. Akad. Wien, v. 77, T. 8 , \\ F. 2 a, b, c, p 424,190 .
}

Gehäuse gedrückt Hachkegelförmig mit gewölbter Basis und deutlicheren Zuwachsstreifen; neben der dichten und feinen Spiralstreifung sind eingedrückte und punktierte Spirallinien vorhanden, welche weitläuflger und tiefer sind (die Erhebungen neben denselben bezeichnet der Autor in der Originaldiagnose als Längsrippen); an frischen Exemplaren entsprechen diesen punktierten Furchen hinfällige Spiralfalten der Epidermis. Neben der weissen, gelben, grünlichen braunen oder violetten Grundfarbe sind zumeist milchige Radial und Zickzack- 
striemen vorhanden, welche häufig in Fleckenbänder aufgelöst erscheinen, auf dem letzten Ungange die Grundfarbe ganz verdecken. Das niedrigere Gewinde besteht aus $4-4^{1} / 2$ flachen, etwas rascher zunehmenden Umgängen; der letzte ist mehr zusammengedrückt, deutlicher kantig bis stumpf gekielt.

Deckel wie bei der typischen Form.

$$
\mathrm{D}=5.5, \mathrm{~d}=4.5, \mathrm{H}=3.5 \mathrm{~mm} \text {. }
$$

Fundorte: Ich beurteile diese Form zunächst nach Originalexemplaren von Noumea (Garten der Artillerie-Direktion), welche mir Herr Dautzenberg mitgeteilt hat und kenne dieselbe ausserdem von nachstehenden Punkten Neu-Caledoniens: Bai von Uaraî (die Exemplare zum Teile stumpf gekielt), Canala (grosse Exemplare mit stumpfer Kante $D=6 \cdot 5$, $\mathrm{d}=5.5, \mathrm{H}=4.5 \mathrm{~mm}$ ). Baie du Prony (grosse Exemplare mit stumpfer Kante; die dichten Spirallinien der oberen Ungänge deutlich und auch auf dem letzten Umgange vorhanden; $\mathrm{D}=7, \mathrm{~d}=6, \mathrm{H}=5 \mathrm{~mm}$ ). Unter der Bezeichnung Helicina miniuscula Pfeiffer von NeuCaledonien erhielt ich stets Exemplare der vorstehenden Form.

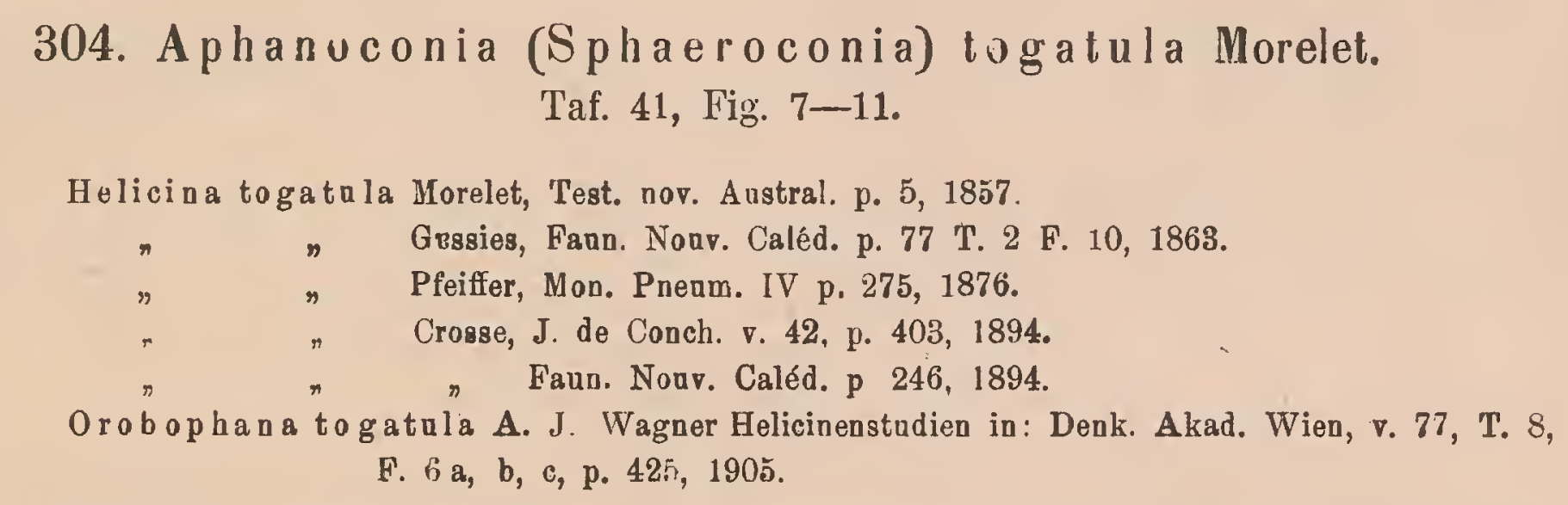

Gehäuse abgerundet kegelförmig mit gewölbter Basis, festschalig, leicht glänzend; die Grundfarbe gelbbraun bis rotbraun mit milchig getrübten, lichteren Radialstriemen, welche zumeist in mehrere schmale Bänder aufgelöst sind, auf dem letzten Umgänge die Grundfarbe oft nahezu verdecken. Die Skulptur besteht nebst deutlichen, ungleichmåssigen Zuwachsstreifen aus ziemlich dichten, eingedrückten Spirallinien auf den unteren Umgängen, welchen hinfällige Spiralfalten der Epidermis entsprechen; daneben erscheint die Epidermis fein gerunzelt. Das leicht konvexe Gewinde besteht aus $4-4 \frac{1}{2}$ Umgängen, von welchen die oberen ziemlich langsam zunehmen und deutlich gewölbt sind, während der letzte flacher ist und langsamer zunimmt; an der Peripherie ist der letzte Umgang nur im Beginne undeutlich kantig, gegen die Mündung gerundet und steigt vorne kaum herab. Die halbeiförmige, schiefe Mündung ist innen gelbbraun, der weisse oder gelbliche Mundsaum leicht verdickt, kurz ausgebreitet und umgeschlagen. Die oben verbreiterte und etwas abgeflachte Spindel ist etwas nach aussen gebogen und bildet am Uebergange in den Basalrand eine abgerundete, 
wenig vorspringende Ecke. Der weisse, wenig glänzende, feingekörnelte Basalkallus ist im unteren Teile deutlich verdickt und durch eine Furche begrenzt.

$$
\mathrm{D}=5, \mathrm{~d}=4, \mathrm{H}=3 \cdot 6 \mathrm{~mm} \text {. }
$$

Deckel balbeiförmig, beiderseits gelbbraun gefärbt, sonst wie bei A. macgillivray Pfeiffer.

Fundorte: Ich beurteile diese Art nach Exemplaren von Teremba in Neu-Caledonien, welche mir Herr Dautzenberg mitgeteilt hat; entsprechende Exemplare besitze ich ausserdem von der Bai Uarai in Neu-Caledonien, sowie solche mit der allgemeinen Fundortsangabe Neu-Caledonien; dementsprechend dürfte A. tagatula Morelet nicht nur auf den Originalfundort "Insel Art" beschränkt sein. Von den Formen der A. macgillivrayi Pfeiffer unterscheidet sich vorstehende Art besonders durch die wesentlich verschiedene Mikroskulptur; die feinen Spirallinien der oberen Umgänge fehlen hier gänzlich, dagegen sind schwache, wenig eingedrückte und weitlăufigere Spirallinien auf den unteren Umgängen vorhanden; dieselben werden oft sehr undeutlich und schwinden mitunter vollkommen, ferner erscheint die Epidermis fein gerunzelt. Die oberen Umgänge sind deutlich gewölbt, der letzte nimmt rascher zu; der Oberrand der Mündung ist an der Insertion weniger vorgezogen, die abgerundete Ecke am Uebergange der Spindel in den Basalrand deutlicher. 305. Aphanoconia (Sphaeroconia) gassiesiana Crosse.
Taf. 40 , Fig. $16-18$.

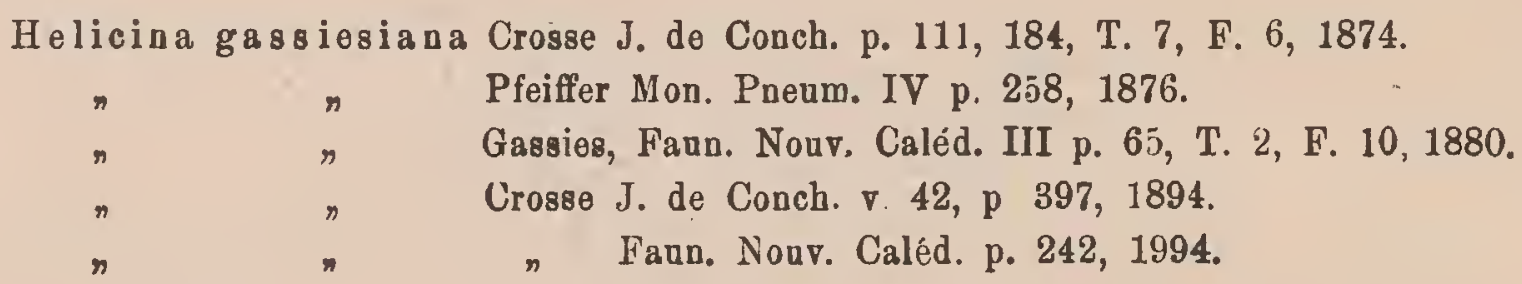

Gehäuse kegelförmig mit flachgewölbter Basis, festschalig wenig glänzend, einfärbig: schmutzig weiss. Die Skulptur besteht nebst feinen, ungleichmässigen Zuwachsstreifen aus sehr feinen, dichten oft nahezu erloschenen Spirallinien auf den oberen Umgängen, sowieeinigen weitläufigen, undeutlichen Spiralfurchen auf dem letzten Umgange, welchen hinfällige Spiralfalten der Epidermis entsprechen; ferner erscheint die Epidermis fein gerunzelt. Das regelmässig kegelförmige Gewinde besteht aus $4 \frac{1}{2}$ flachen anfangs langsam, vom vorletzten Umgang an rascher zunehmenden Umgängen; der letzte ist. im Beginne stumpf gekielt, gegen die Mündung nahezu gerundet und steigt vorne ziemlich rasch und deutlich unter den Kiel herab. Die abyerundet dreieckige Mündung ist schief, innen milchweiss oder gelblich; der weisse, leicht verdickte Mundsaum kurz ausgebreitet, der Oberrand an der Insertion vorgezogen, fast gerade, der Aussenrand entsprechend der Kante, mitunter etwas winkelig ausgezogen, der verschmalerte Basalrand umgeschlagen. Die oben verbreiterte Spindel ist nach aussen gebogen und bildet am Uebergange in den Basalrand eine abgerundete, undeutliche Ecke. Der glänzende, weisse Basalkallus ist im Umkreise der spindel etwas verdickt. jedoch undeutlich begrenzt. 


$$
\mathrm{D}=8.5, \mathrm{~d}=7, \mathrm{H}=6 \mathrm{~mm} \text {. }
$$

Deckel abgerundet dreieckig, beiderseits gelbbraun bis rotbraun gefärbt. Die ziemlich dicke Kalkplatte ist feingekörnelt, flachkonkav mit wallartiger Verdickung am Spindelrande und Spindelwinkel, jedoch undeutlicher Furche neben derselben; der Spindelwinkel nur schwach nach rückwärts gebogen, die Sigmakante gleichmässig S-förmig gebogen, in beiden Aesten leicht erhoben, dem Spindelrande sehr genähert.

Fundorte: ich beurteile diese Form nach einem Originalexemplare des Autors vom Mont Cogui in Neu.Caledonien; dasselbe weist wesentlich grössere Dimensionen auf, als in der Originaldiagnose verzeichnet sind. Kleinere Exemplare, welche nur die Dimensionen $\mathrm{D}=6.5$, $\mathrm{d}=5.5, \mathrm{H}=4.8$ erreichen, kenne ich nur mit der Fundortsangabe "Neu-Caledonien."

\section{Aphanoconia (Sphaeroconia) gassiesiana sticta n. Taf. 40, Fig. 24-25.}

Gehäuse dickschaliger, gelblichweiss oder rötlich fleischfarben, die oberen Umgänge hellgelb. Neben den feinen Spirallinien der oberen Umgänge besteht die kräftigere Spiralskulptur noch aus ziemlich dichten, deutlich eingedrückten und punktierten Spirallinien auf den mittleren und unteren Umgängen. Das niedrigere Gewinde besteht aus $4-41 / 2$ rascher zunehmenden schwach gewölbten bis nahezu flachen Umgängen; der letzte ist im Beginne stumpf gekielt, gegen die Mündung zu nur leicht kantig; unter dieser Kante ist ausserdem eine zweite schwächere Kante vorhanden, so dass die Peripherie abgeflacht erscheint. Der Basalkallus ist dicker und unten durch eine von der Spindel ausgehende, seichte Furche begrenzt; die Ecke am Uebergange der Spindel in den Basalrand deutlich vorspringend.

$$
\mathrm{D}=8, \mathrm{~d}=7, \mathrm{H}=5.3 \mathrm{~mm} \text {. }
$$

Deckel gelb oder rötlich mit dicker, gekörnelter Kalkplatte, sonst wie bei der typischen Form.

Fundort: Bai von Uaraï in Neu-Caledonien; anscheinend kommt diese Form aber auch an anderen Orten der Insel vor, da ich auch Exemplare mit der Fundortsangabe "Neu-Caledonien" erhalten habe.

\section{Aphanoconia (Sphaeroconia) gassiesiana allochroan. Taf. 40, Fig. 19-23.}

Gehäuse dännschaliger und zumeist lebhafter gefärbt; schmutzig gelb, hellgelb, rötlich fleischfarben, gelbbraun bis dunkel rotbraun, auf durchscheinendem Grunde sind ausserdem milchig getrübte Zickzack- und Radialstriemen vorhanden, welche auf dem letzten Umgange zu Bändern zusammenfliessen oder die Grundfarbe verdecken. Die Skulptur besteht neben feinen Zuwachsstreifen aus sehr feinen und dichten Spirallinien auf den oberen Umgängen;

I. 18. II. 
an frischen Exemplaren sind ausserdem ziemlich dichte, sehr hinfällige Spiralfalten der Epidermis vorhanden, welchen jedoch keine eingedrückten Spirallinien entsprechen. Das regelmässig kegelförmige Gewinde besteht aus $4 \frac{1}{2}$ kaum gewölbten bis flachen langsam zunehmenden Umgängen; der letzte ist im Beginne undeutlich kantig, gegen die Mündung nahezu gerundet. Die. Mündung ist je nach der Grundfarbe innen hell oder dunkel gefärbt; die Ecke am Uebergange der Spindel in den Basalrand fehlt.

$$
\mathrm{D}=7, \mathrm{~d}=6, \mathrm{H}=5 \mathrm{~mm} \text {. }
$$
Form.

Deckel gelbbraun oder rotbraun mit dünner Kalkplatte, sonst wie bei der typischen

Fundort: die Pinien Insel bei Neu-Caledonien.

\section{Aphanoconia (Sphaeroconia) laeta Crosse.}

Taf. 40 , Fig. $10-12$.

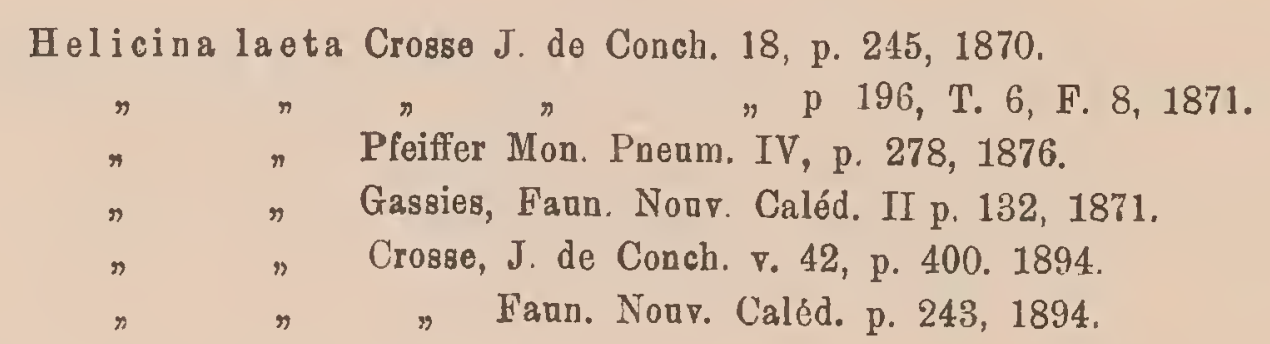

Gehäuse flachkugelig, festschalig, im frischen Zustande matt mit dichten Spiralreihen, kurzer Borsten, abgerieben leicht glänzend mit dichten, punktierten Spirallinien auf der Oberund Unterseite; die feinen, ziemlich gleichmässigen Zuwachsstreifen stark gebogen. Neben der gelbbraunen bis rotbraunen Grundfarbe sind milchig getrübte, lichtere Zickzackstriemen vorhanden, welche auf dem letzten Umgange mehr minder zusammenfliessen, jedoch ' zumeist ein Band der Grundfarbe an der Peripherie freilassen. Das flachkegelförmige, abgerundete Gewinde besteht aus 4 nahezu flachen, ziemlich lasch zunehmenden Umgängen; der letzte ist etwas zusammengedrückt, an der Peripherie stumplkantig, in der zweiten Hälfte nahezu gerundet und steigt vorne ziemlich tief herab. Die abgerundet dreieckige Mündung ist sehr schief, innen rotbraun; der weisse oder gelbliche Mundsaum wenig verdickt, kurz ausgebreitet, der Oberrand an der Insertion vorgezogen, fast gerade, der Basalrand umgeschlagen. Die kurze, oben verbreiterte und etwas abgeflachte Spindel ist nach aussen gebogen und bildet am Uebergange in den Basalrand eine abgerundete, ziemlich vorspringende Fcke. Der gelbe, feingekörnelte Basalkallus ist im Umkreise der Spindel ziemlich dick und durch eine von der Spindel ausgehende seichte Furche deutlich begrenzt.

$$
\mathrm{D}=11, \mathrm{~d}=9, \mathrm{H}=7 \mathrm{~mm} \text {. }
$$

Deckel abgerundet dreieckig, beiderseits gelbbraun; die ziemlich dicke, gekörnelte Kalkplatte ist flachkonkav mit seichter, aber deutlicher Furche neben der Verdickung des Spindel- 
randes; der Spindelwinkel schwach uach rückwärts gebogen. Die "Sigmakante gleichmässsig' aber schwach gebogen, in beiden Aesten stark erhoben, dem Spindelrande sehr genăhert.

Fundort: Neu-Caledonien (Berg Mou, Bai von Prony).

\author{
309. A phanoconia (Sphaeroconia) noumeensis Crosse. \\ Taf. 40, Fig. 13-15. \\ Helicina noumeensis Crosse, J. de Conch. 22, p. 111, 186, T. 4, F. 7, 1874. \\ Pfeiffer Mon. Pneum. IV. p. 259, 1876. \\ Gassis, Faun. Nouvell. Caléd. III. p. 66, T. 2, F. 12, 1880. \\ Crosse J. de Conch. n. 42, p. 405, 1894. \\ "Fann. Nouvell. Caléd. p. 248, 1894.
}

Gehäuse verhältnismässig klein, kegelförmig mit flachgewölbter Basis, żiemlich festschalig, wenig glänzend, einfärbig gelblichweiss, gelbbraun oder röthlich fleischfarben. Die Skulptur besteht nebst deutlichen, feinen Zuwachsstreifen aus sehr feinen und dichten Spirallinien, welche überall ziemlich gleichmässig vorhanden sind. Das regelmässig kegelförmige, ziemlich erhobene Gewinde besteht aus $4^{1} / 2$ gewölbten, durch eine deutlich eingesenkte Naht geschiedenen Umgängen; der letzte ist undeutlich kantig bis gerundet und steigt vorne sehr wenig herab. Die wenig schiefe Mündung ist annähernd halbeiförmig, innen mit dem Gehäuse gleichfarbig; der weisse oder gelblicher Mundsaum ist dünn und fast gerade. Der dünne durcheinende Basalkallus nur im Umkreise der Spindel deutlicher begrenzt. Die kurze, abgerundete Spindel ist senkrecht und bildet am Uebergange in den Basalrand eine zarte, aber deutliche Ecke.

$$
\mathrm{D}=3 \cdot 4, \mathrm{~d}=3, \mathrm{H}=3 \mathrm{~mm} \text {. }
$$

Deckel halbeiförmig beiderseits hellrotbraun gefärbt. Die verhältnismässig feste, feingekörnelte Kalkplatte mit ziemlich deutlicher Furche; der Spindelwinkel etwas nach hinten gebogen, die Sigmakante gleichmässig gebogen und dem Spindelrande sehr genähert.

Fundort: Noumea auf Neu-Caledonien.

\title{
310. Aphanoconia (Sphaeroconia) eduardi A. J. Wagner. Taf. 39, Fig. 19-23.
}

Aphanoconia eduardi A. J. Wagner Helicinenstbdien in: Denk. Akad. Wien. vol. 77. T. 4, F. 17 a, b, c, p. $393,1905$.

Gehäuse kegelförmig mit gewölbtel Basis, festschalig, etwas durchscheinend, hellgelb mit zitrongelber Spitze und einem rotbraunen, ziemlich scharf begrenzten Bande über der Peripherie und der Naht des vorletzten Umganges; wenig glänzend mit schwachen Zuwachs- 
streifen, aber dichten und feinen Spiralfurchen auf der Ober- und Unterseite. Das ziemlick erhobene, regelmässig kegelförmige Gewinde besteht aus $4-4^{1} / 2$ ziemlich langsam zunehmenden, kaum gewölbten Umgången; der letzte ist im Beginne nahezu stumpf gekielt, in der zweiten Hälfte kantig und steigt vorne kaum herab. Die halbeiförmige Mündung ist nahezu senkrecht, der weisse, wenig verdickte Mundsaum ausgebreitet und umgeschlagen, gegen die Insertionen zu verschmälert. Die kurze, senkrechte Spindel ist dünn, abgerundet und bildet am Uebergange in den Basalrand eine ziemlich scharfe, vorspringende Ecke. Der gelbliche, durchscheinende und glänzende Basalkallus ist feingekörnelt und nur in der Nähe der Spindel deutlich begrenzt.

$$
\mathrm{D}=7 \cdot 1, \mathrm{~d}=6 \cdot 3, \mathrm{H}=5 \cdot 7 \mathrm{~mm} \text {. }
$$

Deckel abgerundet dreieckig, beiderseits gelblich gefärbt. Die matte, ziemlich dicke Kalkplatte mit deutlicher Furche, der Spindelwinkel nach hinten gebogen, die Sigmakante gleichmăssig gebogen, im unteren Aste stärker erhoben, dem Spindelrande sehr genähert.

Fundort: die Insel Tagula der Louisiaden.

Das abgebildete Exemplar im k. Museum zu Berlin.

\section{Aphanoconia (Sphaeroconia) braueri A. J. Wagner.} Taf. 39, Fig. 24-27.

Aphanoeonia braueri A. J. Wagner Helicinenstadien in Denk. Akad. Wien, vol. 77, T. 4, F. 20 a, b, c, p. 394, 1905.

Gehăuse breitkegelförmig mit gut gewölbter Basis, festschalig, leicht glănzend mit schwachen, ungleichmässigen Zuwachsstreifen und dichten Spiralfurchen, welche auf der Unterseite etwas dichter und schwăcher werden. Das regelmässig flachkegelförmige Gewinde besteht aus $4 \frac{1}{2}$ nahezu flachen, ziemlich rasch zunehmenden Umgängen; der letzte ist unten mehr gewölbt, an der Peripherie stumpf gekielt und steigt vorne nicht herab. Die Färbung braungelb oder fleischfarben mit zitrongelber Spitze. Die abgerundet dreieckige Mündung ist sehr wenig schief, innen braunorange; der milchweisse, leicht verdickte Mundsaum ausgebreitet und umgeschlagen, gegen die Insertionen zu verschmälert. Die kurze, abgerundete Spindel ist leicht nach aussen gebogen und bildet am Uebergange in den Basalrand eine ziemlich scharfe, deutlich vorspringeude Ecke. Der glänzende, gelbe, gekörnelte Basalkallus ist dünn und nur im Umkreise der Spindel deutlich begrenzt.

$$
\mathrm{D}=9, \mathrm{~d}=7, \mathrm{H}=6 \mathrm{~nm} \text {. }
$$

Deckel dreieckig, unten gelblich, oben weiss. Die ziemlich dünne, aber feste Kalkplatte ist wenig glänzend, die Furche neben dem Spindelrand nur gegen den Spindelwinkel zu deutlich, der Spindelwinkel wenig nach rückwärts gebogen; die Sigmakante gleichmässig gebogen, in beiden Aesten erhoben und dem Spindelwinkel ziemlich genähert.

Fundort: die Inse] Woodlark. 


\title{
312. A phanoconia (Sphaeroconia) pelevensis Shykes. Taf. 39, Fig. 11-14.
}

\author{
Helicina pelerensis E. R. Shykes, Proc. of the Malac. Soc. p. 260, F. 1, 1901. \\ Aphanoconia pelevensis A. J. Wagner Helicinenstudien in: Denk. Akad. Wien, 7.77, T. 4, \\ F. 18 a, b, c, 19 a. b, 1905 .
}

Gehăuse kegelförmig mit flachgewölbter Basis, ziemlich festschalig, wenig glänzend; die Grundfarbe weiss, gelblich oder rötlich, häufig mit einigen schwachen violetten Bändern. Die Skulptur besteht nebst feinen, undeutlichen Zuwachsstreifen aus dichten und feinen Spirallinien auf den unteren Umgängen; auf dem letzten Umgange werden häufig auch einige seichte und weitläufige Spiralfurchen sichtbar, welchen hinfallige Spiralfalten der Epidermis entsprechen. Das ziemlich erhobene, kegelförmige Gewinde besteht aus $4 \frac{1}{2}$ leicht gewölbten, langsam zunehmenden Umgăngen; der le tzte ist unten abgeflacht, an der Peripherie undeutlich kantig bis gerundet und steigt vorne wenig herab. Die abgerundet dreieckige oder halbeiförmige Mündung ist schief, innen gelb oder rotbraun; der weisse, wenig verdickte Mundsaum ausgebreitet, der Oberrand an der Insertion vorgezogen. Die kurze, oben verbreiterte Spindel ist senkrecht, und bildet am Uebergang in den Basalrand eine schwache, undeutliche Eeke. Der dünne, glänzende, mit dem Gehäuse gleichfarbige Basalkallus ist fein gekörnelt und nur im unteren Teile deutlich begrenzt.

$$
\mathrm{D}=4 \cdot 8, \mathrm{~d}=4, \mathrm{H}=3 \cdot 8-4 \mathrm{~mm} \text {. }
$$

Deckel dreieckig, beiderseits gelbbraun gefärbt. Die ziemlich dicke Kalkplatte ist matt mit einer deutlichen Furche neben dem Spindelrand; der Spindelwinkel ist deutlich nach rückwärts gebogen, die Sigmakante gleichmässig gebogen, im unteren Aste stärker erhoben, dem Spindelrande genähert.

Fundort: die Insel Coröre der Palau-Inseln.

\section{Formenkreis Porphyrostoma n.}

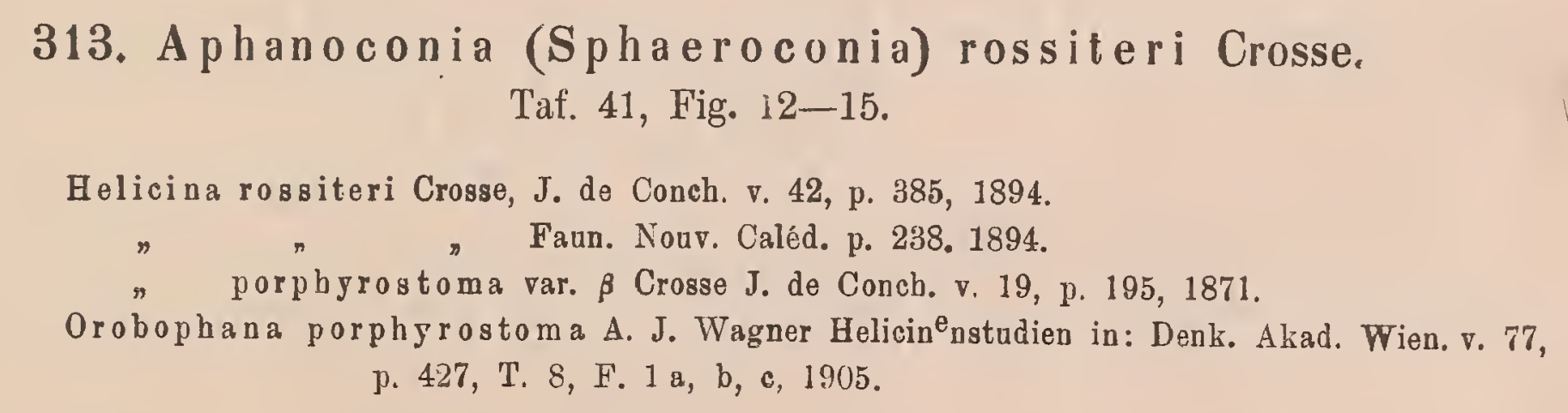

Gehäuse kegelförmig mit flachgewölbter Basis, ziemlich festschalig, wenig glänzend bis 
matt; die Grundfarbe schmutziggelb oder rötlich mit weisser oder zitrongelber Spitze und einer verwaschenen hellvioletten. Zone' um die Mündung; häufig ist ein violettes "oder rotbraunes, verschiedenbreites Band auf der Oberseite vorbanden, welches mitunter die Grundfarbe auf den oberen Umgängen ganz verdeckt; ein gleichgetärbtes, jedoch mehr verschwommenes Band ist mitunter auch auf der Unterseite vorhanden. Die Skulptur besteht nebst feinèn; bis undeutlichen Zuwachsstreifen aus sehr feinen bis undeutlichen Spirallinien auf den oberen Umgängen (auch Spiralfalten der Epidermis dürften bei frischen Exemplaren vorhanden sein). Das ziemlich erhobene, regelmässig kegelförmige Gewinde besteht aus $4^{1} / 2-5$ nahezu flachen, ziemlich langsam zunehmenden Umgängen; der letzte ist unten abgeflacht, an der Peripherie undeutlich stumpfkantig bis gerundet und steigt vorne nicht herab. Die abgerundet dreieckige Mündung ist wenig schief, innen orange- oder gelbbraun; der milchweisse, leicht verdickte Mundsaum ausgebreitet, an den Insertionen verschmälert. Die abgerundete, kurze. Spindel ist nach aussen gebogen und bildet am Uebergange in den Basalrand eine winkelige, ziemlich vorspringende Ecke. Der lebhaft orange gefärbte Basalkallus ist matt, ziemlich dick und deutlich begrenzt.

$$
\mathrm{D}=10, \mathrm{~d}=8, \mathrm{H}=8.5 \mathrm{~mm} \text {. }
$$

Deckel ábgerundet dreieckig, beiderseits gelbbraun mit einer rotbraunen Zone am Spindelrand. Die feste, feingekörnelte Kalkplatte ist flachkonkav mit einer undeutlichen Furche neben dem Spindelrand; der Spindelwinkel kaum nach rückwärts gebogen. Die Sigmakante gleichmässig gebogen und in beiden Aesten deutlich erhoben, dem Spindelrand sehr genähert.

Fundort: Neu-Caledonien (Baie du Prony).

Die vorstehende Art wird vielfach mit A. porphyrostoma Crosse verwechselt; die Unterschiede sind an den Abbildungen deutlich ersichtlich.

\section{A phanoconia (Sphaeroconia) porphyrostoma Crosse. Taf. 41, Fig. 16-17.}

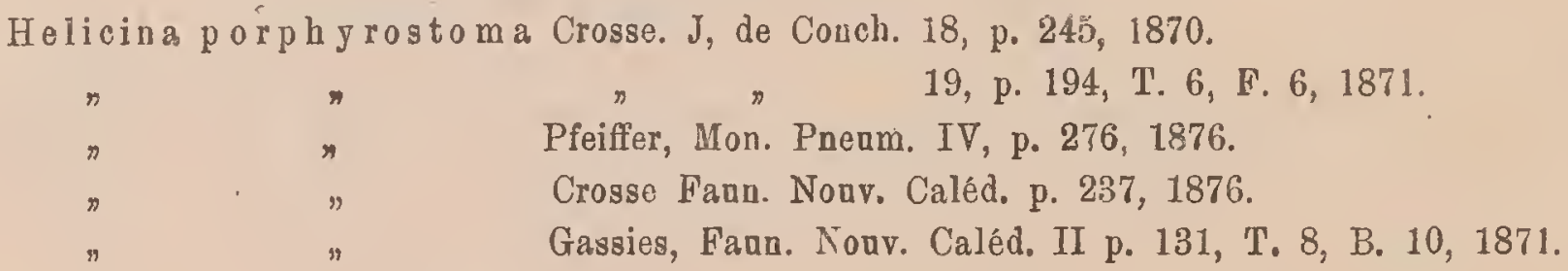

Gebäuse flachkugelig, festschalig, wenig glänzend, schmutzigweiss mit gelblicher spitze und verwaschenen gelbgrauen Radialstriemen. Neben ungleichmässigen, feinen Zuwachsstreifen finden sich am letzten Umgange einige seichte Spiralfurchen, welchen hinfällige Spiralfalten der Epidermis entsprechen, auch ist die Oberfäche daselbst etwas gerunzelt. Das breitkegelförmige, etwas konvexe Gewinde besteht aus $4-4 \frac{1}{2}$ nahezu flachen, ziemlich langsam 
zunehmenden Umgången; der letzte ist an der Peripherie undeutlich stumpfkantig bis gerundet und steigt vorne wenig herab. Die halbeiförmige Mündung ist schief und wie der Mundsaum und Basalkallus lebhaft rotbraun gefärbt; der wenig verdickte Mundsaum kurz ausgebreitet, der ziemlich dünne Basalkallus deutlich begrenzt. Die kurze Spindel ist nach aussen gebogen und bildet am Uebergange in den Basalrand eine deutliche, winkelige Ecke. $\mathrm{D}=7, \mathrm{~d}=5.5, \mathrm{H}=4.5 \mathrm{~mm}$.

Deckel halbeiförmig, beiderseits lebhaft rotbraun mit dunkler Zone am Aussenrandel, sonst typisch.

Fundort: Neu-Caledonien.

\section{Aphanoconia (Sphaeroconia) mariae n.}

Taf. 41, Fig. 18-22.

Gehäuse kegelförmig mit gewölbter Basis, leicht glänzend, ziemlich düunschalig, durchscheinend, schwefelgelb mit einer violetten Zone um die Mündung; neben feinen, bis undeutlichen Zuwachsstreifen sind feine, zumeist undeutliche Spirallinien vorhanden. Das regelmässig flachkegelförmige Gewinde besteht aus $4-4 \frac{1}{2}$ schwach gewölbten, ziemlich rasch zunehmenden Umgängen; dnr letzte ist etwas zusammengedrückt, im Beginne deutlich kantig, gegen die Mündung nahezu gerundet und steigt vorn nicht herab. Die abgerundet dreieckige Mündung ist wenig schief mit einer rotbraunen Zone hinter dem Mundsaum; der milchweisse Mundsaum ausgebreitet und umgeschlagen, der Oberrand an der Insertion verschmälert und vorgezogen; die abgerundete, senkrechte oder leicht nach aussen gehogene Spindel endigt unten mit einer scharfen Ecke, welche jedoch nur bei der Vorderansicht deutlich sichtbar ist; mit dem Basalrand bildet die Spindel einen nahezu rechten Winkel. Der durchsichtige, glasartig glänzende Basalkallus ist dünn und nur im Umkreise der Spindel deutlich begrenzt.

$$
D=9, d=7, \mathrm{H}=7 \mathrm{~mm} \text {. }
$$

Deckel abgerundet dreieckig, hellrotorange mit weisser Zone am Spindelrand. Die krustenartig dünne, feingekörnelte Kalkplatte ist nur am Spindelrande leistenartig verdickt und erhoben, die Furche neben dieser Verdickung ziemlich deutlich; der Spindelrand deutlich nach rückwärts gebogen. Die gleichmässig gebogene Sigmakante ist nur im unteren Aste stärker erhoben, dem Spindelrande sehr genähert.

Fundort: die Viti-Inseln.

Ich benenne diese Art, welche bisher in der Literatur nicht verzeichnet ist mit Beziehung auf meine Mitarbeiterin Frau Doktor Marie Fröhlich. 
316. Aphanoconia (Sphaeroconia) sublaevigata Pfeiffer. Taf. 41, Fig. 23-27.

\author{
Helicina sublaevigata Pfeiffer Pr. Z. S. p. 87, 1852.
}

$\begin{array}{lll}n & \text { Mon. Pnenm. I p. 384, } 1852 . \\ n & \text { Sowerby Thes. III, p. 290, T. 274, F. 339, 340, } 1866 .\end{array}$

Orobophana snblaevigat'a A. J. Wagner Helicinenstudien in: Denk. Akad. Wien. vol. 77 T. 7, F. 17 a, b, c, p. $426,1905$.

Gehäuse breitkegelförmig mit flachgewölbter Basis, festschalig, glänzend mit deutlichen, ungleichmässigen Zuwachsstreifen; schmutzig weiss, lichthornfarben bis rötlich, mit einer hellbraunen oder violetten Zone unter der Peripherie, mitunter einem hellen Bande an der Peripherie; häufig ist auch hinter dem Mundsaume eine violette, verwaschene Zone bemerkbar. Das regelmässig breitkegelförmige Gewinde besteht aus $4^{2} / 2$ leicht gewölbten, ziemlich langsam zunehmenden Umgängen, welche durch eine etwas eingedrückte Naht geschieden werden; der letzte ist deutlich kantig, im Beginne oft stumpf gekielt und steigt vorne wenig oder gar nicht herab. Die halbeiförmige Mündung ist wenig schief, innen zumeist lebhaft rotbraun gefärbt; der weisse, leicht verdickte Mundsaum ausgebreitet und umgeschlagen, der Oberrand an der Insertion vorgezogen und verschmälert. Die abgerundete Spindel ist nach aussen gebogen, und bildet am Uebergange in den Basalrand eine abgerundete, deutlich vorspringende Ecke. Der weissliche, glänzende Basalkallus ist ziemlich dünn, aber deutlich begrenzt.

$$
\mathrm{D}=8, \mathrm{~d}=6.5, \mathrm{H}=5.8 \mathrm{~mm} \text {. }
$$

Deckel abgerundet dreieckig, in der Mitte gelblich mit rotbraunen Rändern. Die ziemlich dicke, feingekörnelte Kalkplatte mit seichter Furche neben dem Spindelrand; der Spindelwinkel etwas nach rückwärts gebogen; die Sigmakante gleichmässig gebogen, in beiden Aesten erhoben, dem Spindelrande genähert.

Fundort: die Neuen Hebriden, meine Exemplare von der Insel Espiritu Santo.

Ich habe diese Art früher mit Palaeohelicina layardi Hartmann vermengt, welche ihr äusserlich ähnlich sieht, jedoch durch die spiral gerippten oberen Umgänge und den Deckel mit randständigem Nukleus leicht zu unterscheiden ist.

\title{
317. Aphanoconia (Sphaeroconia) mouensis Crosse. Taf. 42 , Fig. 23-24.
}

Helicina mouensis Crosse, J. de Conch. XVIII p. 246, 1870.

$\begin{array}{llll}" & " & & \text { XIX p. 197. T. 6, F. 5, } 1870 . \\ " & " & \text { Pfeiffer Mon. Pneum. IV p. 255, 1878. } \\ " & " & \text { Gassies, Faun. Nouv. Caléd. II p. 130, T. 8, F. 9, } 1871 .\end{array}$


Hel icina monensis Crosse, Fann. Nonr. Caléd. p. 240, 1894.

$\rightarrow$ J. de Conch. v. 42 p. $397,1894$.

Gehäuse nahezu kugelig, ziemlich festschalig, fast glatt, glänzend, gelblichweiss bis zitrongelb. Das abgerundet kegelförmige Gewinde besteht aus $3^{1} / 2$ nahezu flachen, ziemlich langsam zunehmenden Umgăngen; der letzte gerundet, vorn langsam und wenig herabsteigend. Die halbeiförmige Mündung ist innen schmutzigweiss; der weisse Mnndsaum kurz ausgebreitet; die abgerundete Spindel nach aussen gebogen. Der ziemlich dicke Basalkallus ist rotbraun und deutlich begrenzt.

$$
\mathrm{D}=4, \mathrm{~d}=3, \mathrm{H}=2.5 \mathrm{~mm} \text {. }
$$

Deckel halbeiförmig, beiderseits rotbraun, sonst wie bei A. mondaini Crosse.

Fundort: Berg Mou auf Neu-Caledonien.

\section{Aphanoconia (Sphaeroconia) mondaini Crosse. Taf. 42 , Fig. 9-13.}

Helicina mondaini Crosse, J. de Conch. v. 35, p. 364, 1887.

$$
\pi \quad n \quad \text { v. } 42, \text { p. } 397, \text { T. 7, F. 7, } 1894 .
$$

Gehäuse kegelförmig mit flacher Basis, ziemlich dünnschalig, glatt, glänzend mit sehr feinen Zuwachsstreifen; gelblichweiss bis braungelb und milchig getrübt, nur die oberen Umgănge, und eine schmale Fleckenbinde über der Naht der unteren Umgänge, ebenso eine kreisförmige Zone auf der Unterseite sind dunkelbraun und durchscheinend. Das ziemlich erhobene Gewinde ist abgerundet und besteht aus 4 nahezu flachen, langsam zunehmenden Umgängen; der letzte ist gerundet, unten abgeflacht und steigt vorne kaum merklich herab. Die halbeiförmige Müudung ist wenig schief, innen gelblich; der weisse kaum verdickte Mundsaum kurz ausgebreitet, die Spindel sehr kurz und abgerundet; der gelbliche, dünne und glänzende Basalkallus undeutlich begrenzt.

$$
\mathrm{D}=5, \mathrm{~d}=4, \mathrm{H}=4 \mathrm{~mm} \text {. }
$$

Deckel annähernd halbkreisförmig beiderseits rotbraun gefärbt; die verhăltnissmässig dicke Kalkplatte ist matt mit undeutlicher Furche neben dem Spindelrand; der Spindelwinkel nicht nach rückwärts gebogen. Die gleichmässig gebogene und in beiden Aesten deutlich erhobene Sigmakante ist dem Spindelrande genähert.

Fundort: Baie du Prony in Neu-Caledonien. 


\section{Aphanoconia (Sphaeroconia) mondaini fasciolatan. Taf. 42, Fig. 14-17.}

Gehäuse konstant grösser, mit niedrigerem, abgerundetem Gewinde; die Grundfarbe gelbbraun bis rotbraun mit zwei lichten bis weissen, verschieden breiten Bändern an der Peripherie und Naht der unteren Ungänge; auf der Oberseite der unteren Umgănge sind ausserdem abwechselnd milchig getrübte und dunkle Zickzackstriemen vorhanden, welche auf der Unterseite in dunkelbraune Radialstriemen übergehen; hinter dem Mundsaume eine violette Zone. Der letzte Umgang steigt vorne langsam, aber deutlich herab, die verhältnismăssig breitere Mündung ist innen gelbbraun nebst einer dunkelrotbraunen Zone hinter dem weissem, mehr ausgebreiteten Mundsaum. Die oben verbreiterte und abgeflachte Spindel ist etwas nach aussen gebogen und bildet am Uebergange in der Basalrand eine schwache, zumeist undeutliche Ecke. Der gelbliche Basalkallus ist dicker. und deutlich begrenzt.

$$
\mathrm{D}=7 \cdot 5, \mathrm{~d}=6, \mathrm{H}=5 \cdot 5 \mathrm{~mm} \text {. }
$$

Deckel lebhaft rotbraun mit weisslich angelaufener, feingekörnelter Kalkplatte; dieselbe flach konkav, ohne Furche neben dem Spindelrand; die Sigmakante dem Spindelrande mehr genähert; sonst wie bei der typischen Form.

Fundort: Canala in Neu-Caledonies.

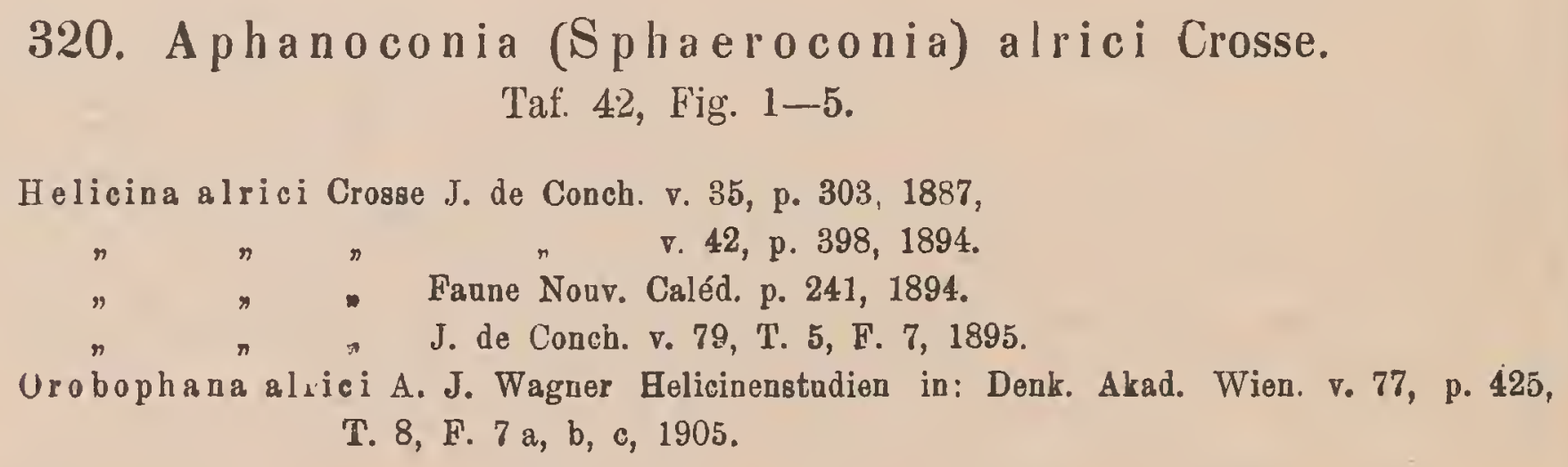

Gehäuse gedrückt kugelig, ziemlich festschalig, im frischen Zustande wenig glänzend mit sehr hinfälligen Spiralfalten der Epidermis; abgerieben, leicht glänzend, fast glatt mit feinen bis undeutlichen Zuwachsstreifen und sehr feinen, schwer sichtbaren Spirallinien. Schmutzig weiss, gelbbraun, hellviolet bis rotbraun, durchscheinend, oder milchig getrübt; hăufig mit undeutlichen Zickzackstriemen auf den mittleren Umgängen, dunkle Exemplare mit lichteren Binden an Naht und Peripherie: konstant mit einer violetten Zone um die Mündung. Das niedrige, abgerundet flachkegelförmige Gewinde besteht aus 4 ziemlich langsam zunehmenden flachen Umgängen; der letzte unten abgeflacht, in der zweiten Hälfte rascher zunehmend, sehr undeutlich kantig bis gerundet, vorne wenig herabsteigend. Die 
halbeiförmige Mündung ist schief, innen rotbraun mit einer dunkelrotbraunen Zone hinter dem milchweissen, gut ausgebreiteten Mundsaum; der Oberrand an der Insertion vorgezogen, fast gerade, der Basalrand verschmälert und etwas umgeschlagen. Die oben verbreiterte und etwas abgeflachte Spindel ist nach Aussen gebogen und bildet am Uebergange in den Basalrand eiue schwache, kaum vorspringend Ecke. Der gelbliche oder weisse Basalkallus ist glänzend, fein gekörnelt, ziemlich dick und deutlich begrenzt.

$$
\mathrm{D}=6.5, \mathrm{~d}=5 \cdot 5, \mathrm{H}=5 \mathrm{~mm} \text {. }
$$

Deckel abgerundet dreieckig, beiderseits gelbbraun bis rotbraun mit dunkler Zone am Spindelrand. Die ziemlich dicke Kalkplatte ist fein gekörnelt, flach konkav mit undeutlicher Furche neben dem Spindelrand; der Spindelwinkel nicht nach rückwärts gebogen. Die Sigmakante gleichmässig gebogen in beiden Aesten deutlich erhoben, dem Spindelrande sehr genähert.

Fundorte: Canala in Neu-Caledonien und die Pinieninsel,

\section{Aphanoconia (Sphaeroconia) dautzenbergi n.}

Taf. 42, Fig. 6-8, Fig. 25-26.

Gehäuse breit bis flachkegelförmig mit flachgewölbter Basis, ziemlich dünnschalig; frische Exemplare matt mit dichten Spiralreihen, kurzer, hinfälliger Borsten, abgerieben leicht glänzend mit feinen, ungleichmässigen Zuwachsstreifen. Die Grundfarbe gelblich, rötlich fleischfarben bis rotbraun, oft mit undeutlichen Bändern und Radialstriemen, ebenso ist die Unterseite von der Peripherie an zumeist dunkler gefärbt, diese dunklere Zone scharf begrenzt. Das abgerundete Gewinde besteht aus $4^{1} / 2$ leicht gewölbten, langsam zunehmenden Umgängen; der letzte ist schwach kantig bis gerundet und steigt vorne deutlich unter die Kante herab. Die halbeiförmige Mündung ist schief, innen gelblich oder rötlich; der weisse, wenig verdickte Mundsaum ausgebreitet und umgeschlagen, der Oberrand an der Insertion vorgezogen und verschmälert, der Basalrand in der Mitte etwas vorgebogen. Die oben verbreiterte und deutlich abgeflachte Spindel ist wenig nach aussen gebogen oder nahezu senkrecht und bildet am Uebergange in den Basalrand keine Ecke. Der ziemlich dicke weisslich getrübte Basalkallus ist leicht glänzend und deutlich begrenzt.

$$
\mathrm{D}=7 \cdot 5, \mathrm{~d}=6, \mathrm{H}=5 \mathrm{~mm} \text {. }
$$

Deckel abgerundet dreieckig, beiderseits gelblich oder rötlich mit einer dunkleren Zone am Spindelrand. Die ziemlich dicke Kalkplatte ist feingekörnelt mit einer deutlichen Furche neben dem Spindelrand; die Sigmakante gleichmässig gebogen, in beiden Aesten deutlich erhoben, dem Spindelrande genähert.

Fundort: Neu-Caledonien.

Diese neue Form unterscheidet sich von der nächstverwandten A. alrici Crosse durch die grössere Zahl der langsamer zunehmenden, deutlich gewölbten Umgänge, die abweichende 
Färbung, die borstige Epidermis, und besonders durch die abweichende Beschaffenheit des Mundsaumes.

\section{Formenkreis Pachystoma A. J. Wagner.}

322. Aphanoconia (Sphaeroconia) pachystoma E. A. Smith. Taf. 42, Fig. 19-22.

Helicina pachystoma E. A. Smith J. of Mal. p. 21, T. 2, F. 14. 1896.

Orobophana pachystoma A. J. Wagner Helicinenstudien in Denk. Akad. Wien v. 77, p. 432 , T. 7, F. 13 a, b, c 1905 .

Gehäuse kreiselförmig, dickschalig, leicht glänzend, hellgelb mit zitrongelber Spitze oder mit einem breiten rotbraunen Bande an Peripherie und Naht, welches oft die Grundfarbe auf den oberen Umgängen verdeckt. Die Skulptur besteht nebst feinen bis undeutlichen Z Zuwachsstreifen aus einigen Spiralfalten der Epidermis. Das regelmässig breit kegelförmige Gewinde besteht aus $4-4^{1} / 2$ gewölbten, ziemlich rasch zunehmenden Umganggen; der letzte ist undeutlich kantig oder gerundet und steigt vorne ziemlich tief herab. Die halbeiförmige, innen gelbliche Mündung ist wenig schief, der dicke weisse Mundsaum ausgebreitet und etwas umgeschlagen. Die abgerundete Spindel ist nach aussen gebogen und bildet am Uebergange in den Basalrand eine abgerundete aber deutlich vorspringende Ecke. Der mit, dem Gehăuse gleichfarbige Basalkallus ist ziemlich dick, sehr fein gekörnelt und ziemlich deutlich begrenzt.

$$
\mathrm{D}=8 \cdot 3, \mathrm{~d}=7, \mathrm{H}=7 \mathrm{~mm} \text {. }
$$

Deckel halbeiförmig, beiderseits zitrongelb mit rotbrauner Zone am Aussenrande. Die dicke Kalkplatte ist flachkonkav, am Spindelwinkel nach hinten gebogen, ohne deutliche Furche; die Sigmakante gleichmässig gebogen, in beiden Aesten wenig erhoben und dem Spindelrande sehr genăhert.

Fundorte: Admiralitats-Insel und Neu-Pommern im Bismark-Archipel; im Berliner Museum liegen vollkommen übereinstimmende Exemplare mit der Fundortsangabe „Saipan, Mariannen." Ich bezweifle die Richtigkeit dieses Fundortes.

\section{Aphanoconia (Sphaeroconia) pachystoma ponsonbyi \\ E. A. Smith. \\ Taf. 42, Fig. 18.}

Helicina ponsonbyi E. A. Smith, in: P. zool. Soc. London, p. 266, T. 22, F. 9, 1884.

Orobophana pachystoma ponsonbyi A. J. Wagner, Helicinenstadien, in: Denk. Akad, Wien, v. 77, T. 7, F. 14 a, b, c, p. 433, 1905. 
Gehäuse kleiner, dünnschaliger, einfärbig hellgelb mit dunkler Spitze. Die Umgänge nehmen langsamer $\mathrm{zu}$, der letzte ist deutlich kantig und steigt vorne wenig oder gar nicht herab.

$$
\mathrm{D}=6, \mathrm{~d}=5, \mathrm{H}=5 \mathrm{~mm} \text {. }
$$

Deckel wie bei der typischen Form.

Fundort: die Admiralitäts-Inseln; Wild-Insel, Pigeon-Insel.

\title{
324. Aphanoconia (Sphaeroconia) garrettiana Hartmann. Taf. 47, Fig. $1-5$.
}

\author{
Helicina garrettiana Hartmann, Pr. Acad. Philadelphia p. 287, T. 3, F. 11, 1890. \\ Orobophana garrettianaA. J. Wagner Helicinenstudien in Denk. Akad. Wien, vol. 77,
} p. 428 , T. 7, F. 10 a, b, 1905.

Gehäuse breit kegelförmig mit gewölbter Basis, festschalig; gelblich hornfarben oder rötlich mit dunkler gefärbter Spitze und einer milchweissen Zone an der Naht der unteren Ungänge; glänzend mit sehr feinen bis undeutlichen Zuwachsstreifen. Das regelmässig breitkegelförmige Gewinde besteht aus 4 leicht gewölbten, regelmässig zunehmenden Umgängen, welche durch eine schwach eingedrückte Naht geschieden werden; der letzte ist etwas zusammengedrïckt, an der Peripherie jedoch gerundet und steigt vorne nicht herab. Die halbeiförmige oder annähernd halbkreisförmige Mündung ist schief (innen nach Angabe des Autors tief rot, weisse Exemplare jedoch gelblich); der weisse, bisweilen rötliche Mundsaum ausgebreitet, umgeschlagen und deutlich verdickt. Der weisse, gekörnelte Basalkallus ziemlich dünn, aber deutlich begrenzt. Die Spindel ist leicht nach aussen und vorne gebogen, am Uebergange derselben in den verschmälerten Basalrand eine abgerundete etwas vorspringende Ecke.

$$
\mathrm{D}=4.5, \mathrm{~d}=3 \cdot 8, \mathrm{H}=3.5 \mathrm{~mm} \text {. }
$$

Deckel abgerundet dreieckig mit leicht S-förmig gebogenem Spindelrand; die feste, weisse Kalkplatte ist deutlich gekörnelt mit deutlicher Furche neben dem Spindelrand und etwas nach rückwärts gebogenem Spindelwinkel. Die zarte gelbliche Hornplatte löst sich sehr leicht von der Kalkplatte ab; der Nulkleus dem Spindelrande nur genähert, die in beiden Aesten deutlich erhobene Sigmakante nur im oberen Aste gebogen, im unteren nahezu gestreckt.

Fundort: Tu-Apu der Marquesas; ich beurteile diese Form nach einem vom Autor stammenden Exemplare, welches von der Originaldiagnose etwas abweicht. Zunăchst ist die Färbung nicht scharlachrot, sondern gelblich hornfarben bis dunkelorange, ferner die Naht nicht tief, sondern seicht, die Dimensionen etwas bedeutender; anscheinend liegt mir also ein etwas abweichendes Exemplar vor, welches jedoch mit Rücksicht auf die Uebereinstimmung der wesentlichen Merkmale doch nur eine individuelle Variation derselben Form darstellt. 
Aphanoconia garrettiana Hartmann steht im Genus dem Formenkreise Porphyrostoma von Neu-Caledonen am nächsten, ist jedoch als Vertreter eines besonderen Formenkreises aufzufassen.

\section{Formenkreis Musiva A. J. Wagner.}

\section{A phanoconia (Sphaeroconia) musiva Gould. Taf. 43, Fig. 5-9.}

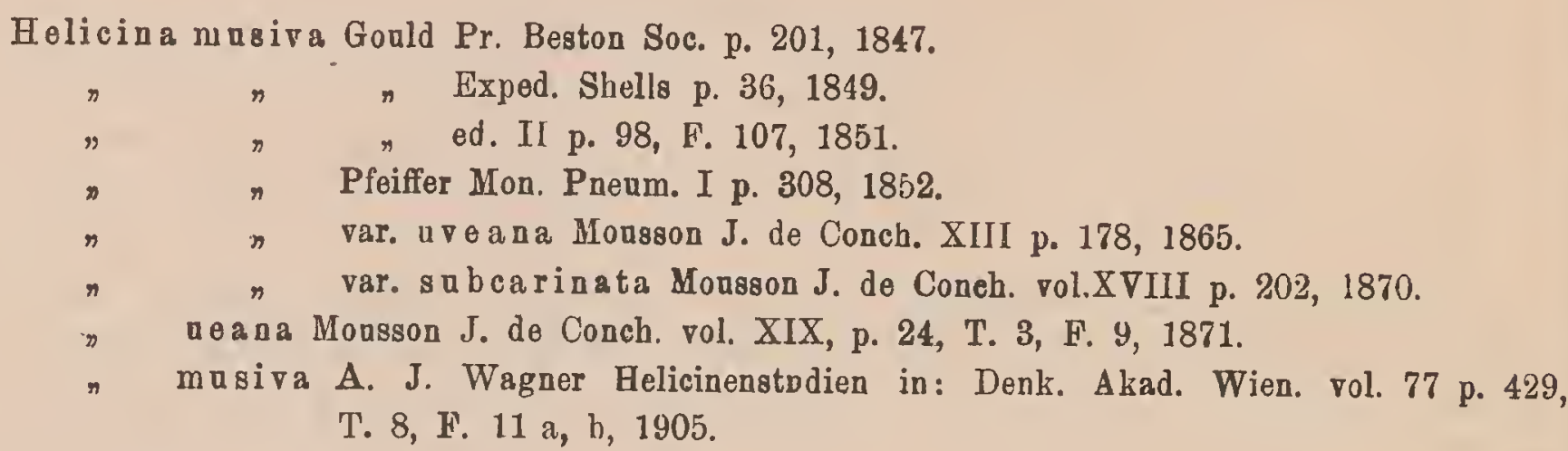

Gehäuse breitkegelförmig mit gewölbter Basis, festschalig, im frischen Zustande matt mit ziemlich dichten Spiralfalten der Epidermis, abgerieben glänzend mit sebr feinen Zu* wachsstreifen und einigen eingedrückten, feinen Spirallinien; die Grundfarbe gelblich, grünlich, rötlich, die oberen 'Umgänge einfärbig, die unteren mit abwechselnd rotbraunen und weissen Zickzackstriemen. Das etwas abgerundete Gewinde besteht aus 4 leicht gewölbten regelmässig zunehmenden Umgängen, welche durch eine seichte Naht geschieden werden; der letzte ist im Beginne mehr minder deutlich kantig, gegen die Mündung zu gerundet und steigt vorne langsam, aber deutlich herab. Die halbeiförmige oder abgerundet dreieckige Mündung ist schief, der weisse oder gelbliche Mundsaum verdickt, aber sehr kurz ausgebreitet, der Oberrand an der Insertion vorgezogen. Die abgeflachte, kurze Spindel ist nach aussen gebogen, am Uebergange derselben in den verschmålerten Basalrand keine vorspringende Ecke. Der ziemlich dicke, durchscheinende Basalkallus ist glänzend und deutlich begrenzt.

$$
\begin{aligned}
& D=5.4, d=4.5, H=3.4 \mathrm{~mm} . \\
& D=4, d=3 \cdot 2, H=2.5 \mathrm{~mm} .
\end{aligned}
$$

Deckel halbeiförmig mit nahezu geradem Spindelrand. Die feste, glänzende Kalkplatte ist gelblich oder rötlich mit deutlicher Furche neben dem Spindelrand und nach hinten gebogenem Spindelwinkel. Die Sigmakante nur im unteren nahezu gestreckten Aste deutlich erhoben; sonst typisch.

Fundorte: die Tonga-Inseln und die Insel Uea, angeblich auch die Samoa-Inseln. Ich gehe bei der Beurteilung dieser weitverbreiteten Art von der Form der Tonga-Inseln aus, welche besonders durch eine deutliche Kante am Beginne des letzten Umganges gekenn- 
zeichnet ist. Mousson nennt diese Form var. subcarinata; dieser Autor beschreibt nur Varietäten der Helicina musiva Gould, die typische Form hat derselbe nicht fixiert. Mit der typischen Form der Tonga-Inseln in den wesentlichen Merkmalen übereinstimmende, nur zum Teil kleinere Exemplare kenne ich von den Inseln Uea und Nukufetau; Mousson bezeichnet dieselbe als - var. uveana.

\section{Aphanoconia (Sphaeroconia) musiva rotundata Mousson.}

Taf. 43, Fig. 10.

Helicina mugiva var, rotundata Monsson J. de Conch. vol. XXI, p. 107, 1873.

Das Gehäuse dünnschaliger, die Zickzackstriemen heller, mitunter erloschen, der letzte Umgang auch im Beginne gerundet oder undeutlich kantig.

Deckel wie bei der typischen Form.

$$
\mathrm{D}=4, \mathrm{~d}=3 \cdot 5, \mathrm{H}=2.5 \mathrm{~mm} \text {. }
$$

Fundort: die Ellice-Insel (Waitupu, Funafuti, Nukufetau).

\section{A phanoconia (Sphaeroconia) musiva vitiensis Mousson.}

$$
\text { Taf. 43, Fig. } 4 .
$$

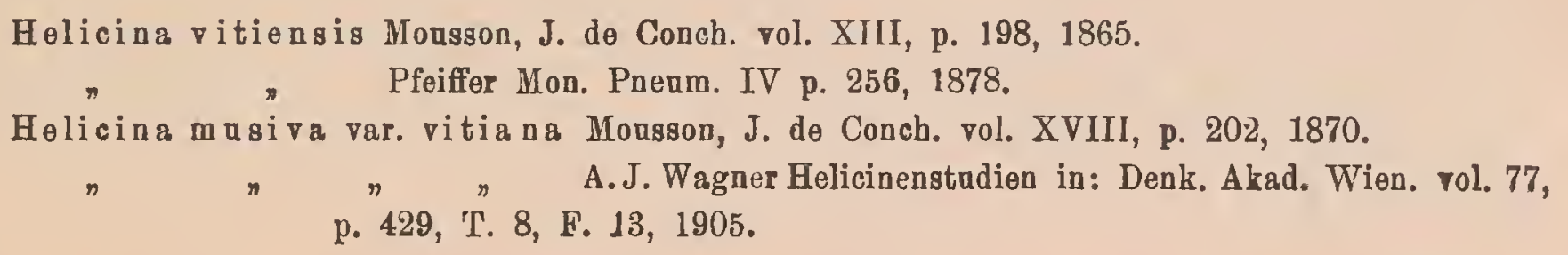

Gehăuse flacher, dicklinsenförmig; die Grundfarbe häufig weiss oder gelblich mit weniger lebhaften, braunen Zickzackstriemen und dichteren Spiralfalten der Epidermis. Das niedrigere Gewinde besteht aus 4 nahezu flachen, etwas rascher zunehmenden Umgängen; der letzte ist mehr zusammengedrückt; unten mehr abgeflacht, an der Peripherie bis zur Mündung stumpfkantig. Die Mündung breiter, der weissliche, wenig durchscheinende Basalkallus gekörnelt.

$$
\begin{aligned}
& D=5 \cdot 2, d=4 \cdot 5, H=3 \mathrm{~mm} . \\
& D=4, d=3 \cdot 5, H=2.5 \mathrm{~mm} .
\end{aligned}
$$

Deckel wie bei der typischen Form.

Fundort: die Viti-Inseln.

Unter der Bezeichnung Helicina subangulata Pease von rer Insel Raiatea besitze ich ein angebliches Originalexemplar des Autors, welches mit der typischen Form des Aphanoconia musiva Gould identisch ist, ich bezweifle auch die Richtigkeit der Fundortsangabe. 


\section{A phanoconia (Sphaeroconia) mariei Crosse.}

Taf. 43, Fig. 1-3.

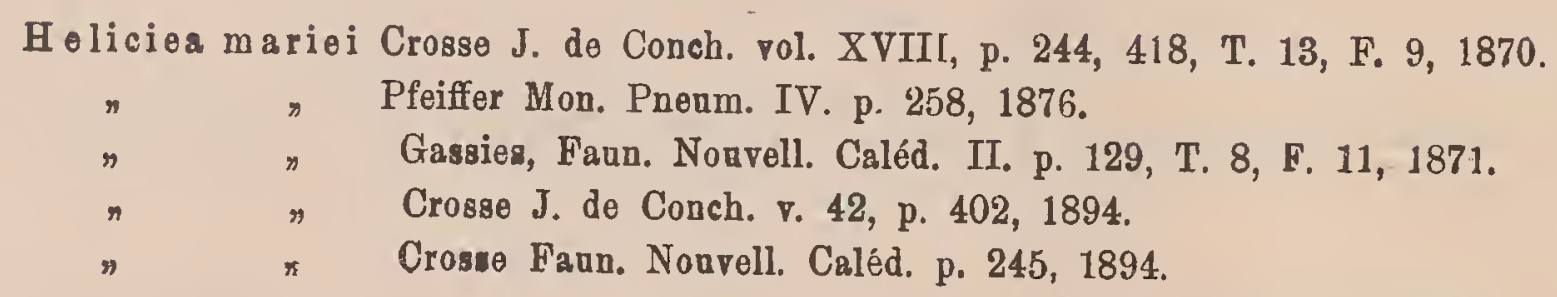

Gehäuse dicklinsenförmig, ziemlich dünnschalig, etwas durchscheinend; gelbbraun mit grünlichem Stich und abwechselnd weissen und braunen Zickzackstriemen, welche besonders an Naht und Kiel schärfer hervortreten; häufig erlöschen die Zickzackstriemen im mittleren Teil, so dass nur weiss und braungegliederte Naht und Kielbinden übrig bleiben; frische Exemplare matt mit etwas weitläufigen Spiralfalten der Epidermis, abgerieben glänzend mit sehr feinen Zuwachsstreifen und einigen feinen, eingedrückten Spirallinien. Das flachkegelförmige, kaum gewölbte Gewinde besteht aus 4 nahezu flachen, ziemlick rasch zunehmenden Umgängen, welche durch eine seichte Naht geschieden werden; der letzte ist zusammengedrückt, oben und unten flach gewölbt, an der Peripherie stumpf gekielt und steigt vorne wenig unter den Kiel herab. Die dreieckige Mündung ist schịef, innen weiss oder gelblich, der lichte Mundsaum einfach bis scharf. Die verbreiterte, etwas ausgehöhlte Spindel ist nach aussen gebogen und bildet am Uebergange in den Basalrand eine deutlich vorspringende, winkelige Ecke. Der glänzende, etwas durchscheinende Basalkallus ist ziemlich dick und deutlich begrenzt.

$$
\mathrm{D}=5, \mathrm{~d}=4.5, \mathrm{H}=2.7 \mathrm{inm} \text {. }
$$

Deckel dreieckig mit leicht S-förmig gebogenem Spindelrand. Die feste, sehr fein gekörnelte gelbliche Kalkplatte ist nur flach konkav, ohne Furche. Die Sigmakante ziemlich gleichmässig gebogen, aber nur im unteren Aste deutlicher erhoben; sonst typisch.

Fundort: Neu-Caledonien (Bai von Uaraii).

Diese Art unterscheidet sich von Aphanoconia gallina Gassies, welche ich oben irrtümlich im Formenkreise Fulgora eingeteilt habe (No. 249) nur durch das mehr linsenförmige Gehäuse, den deutlichen Kiel, den mehr zusammengedrückten letzten Umgang und die schwächeren, sowie weitläufigeren Spiralfalten der Epidermis. Aphanoconia gallina Gassies erscheint demnach nur als Lokelform der vorstehenden Art und wird die Bezeichnung derselben besser lauten: Aphanoconia (Sphaeroconia) mariei gallina Gassies. 
329. Aphanoconia (Sphaeroconia) baudinensis Smith.

Taf. 43 , Fig. $11-13$.

Orobophana walkeri A. J. Wagner Helicinenstudien in: Denk. Akad. Wien. v. 77, T. 8, F. $14 \mathrm{a}, \mathrm{b}, \mathrm{c}, \mathrm{p} .430,1905$.

Gehäuse flachkugelig mit gewölbter Basis, ziemlich festschalig, wenig glänzend, hellbraun mit lichter bis weisser Zone an der Naht und Peripherie; sehr fein radial gestreift, nebst einigen schwachen Spirallinien. Das abgerundete Gewinde besteht aus 4, kaum gewölbten, regelnıässig zunehmenden Umgängen; der letzte ist unten flacher, an der Peripherie im Beginne deutlich stumpfkantig, gegen die Mündung zu gerundet und steigt vorne sehr wenig herab. Die abgerundet dreieckige Mündung ist schief, innen braun, der gelbliche Mundsaum sehr kurz ausgebreitet, verdickt; der Oberrand an der Insertion vorgezogen. Die kurze breite Spindel ist etwas nach aussen gebogen, am Uebergange in den Basalrand keine wahrnehmbare Ecke; der dicke, gelbliche Basalkallus leicht glänzend, deutlich begrenzt.

$$
\mathrm{D}=4, \mathrm{~d}=3 \cdot 6, \mathrm{H}=2 \cdot 6 \mathrm{~mm} \text {. }
$$

Deckel abgerundet dreieckig mit geradem Spindelrand; die gelbliche Kalkplatte ist fest, wenig glänzend mit seichter Furche; die übrigen Verhältnisse typisch.

Fundort: die Insel Baudin; ich verwechselte diese Art früher mit Helicina walkeri, vom Festlande Australiens.

\section{Aphanoconia (Sphaeroconia) littoralis Montrouzier.}

$$
\text { Taf. 43, Fig. 17-21. }
$$

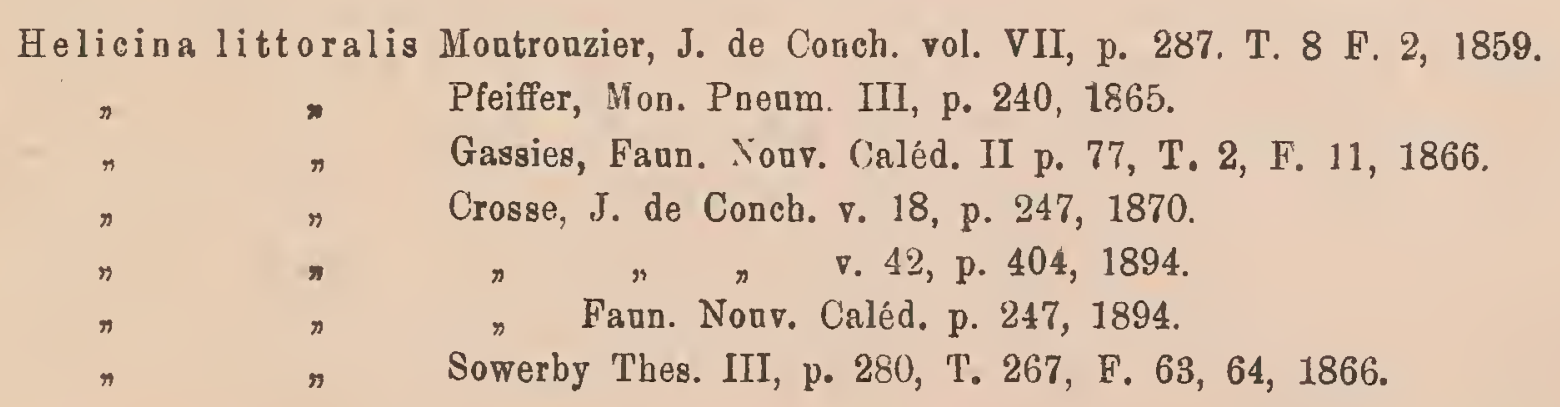

Gehäuse breit bis flach kegelförmig mit gewölbter Basis, ziemlich dünnschalig, durchscheinend, gelblich oder rötlich hornfarben; wenig glauzend mit sehr feinen bis undeutlichen Zuwachsstreifen, sowie nur unter der Lupe sichibaren sehr feinen und dichten Spirallinien. Das regelmässig breit kegelförmige Gewinde besteht aus $31 / 2$ bis 4 leicht gewölbten, ziemlich langsam zunehmenden Umgängen, welche durch eine deutlich eingedrückte Naht geschieden werden; der letzte ist an der Peripherie kantig und steigt vorne deutlich unter die Kante herab. Die abgerundet dreieckige Mündung ist schief, der weisse Mundsaum verdickt, ausI. 18. II. 
gebreitet und leicht umgeschlagen; der Oberrand an der Insertion vorgezogen. Die kurze etwas abgerundete Spindel geht ohne Ecke in den Basalrand über; der dünne, weissliche Basalkallus ist fein gekörnelt und nur im Umkreise der Spindel deutlich begrenzt.

$$
\mathrm{D}=3, \mathrm{~d}=2 \cdot 6, \mathrm{H}=2 \mathrm{~mm} \text {. }
$$

Deckel abgerundet dreieckig mit weisser, verhältnismässig fester Kalkplatte; dieselbe nur flach konkav ohne deutliche Furche; in den übrigeu Verhăltuissen typisch.

Fundort: Neu-Caledonien.

\section{Aphanoconia (Sphaeroconia) minutissiman.}

Taf. 43, Fig. 14-16.

Gehäuse flachkugelig mit flachgewölbter Basis, dünnschalig, durchscheinend, wenig glănzend mit feinen Zuwachsstreifen und sehr feinen und dichten Spiralfalten der Epidermis; gelblich oder rötlich hornfarben. Das niedrige, abgerundete (rewinde besteht aus $31 / 2$ regelmässig zunehmenden, schwach gewölbten Ungängen, welche durch eine deutlich eingedrückte Naht geschieden werden; der letzte ist etwas zusaminengedrückt, an der Peripherie gerundet oder undeutlich kantig und steigt vorue kaum merklich heráb. Die halbeiförmige Mündung ist wenig schief, der schwach verdickte Mundsaum sehr kurz ausgebreitet, der Oberrand an der Insertion wenig vorgezogen. Die kurze, abgerundete Spindel ist unten etwas nach aussen gebogen und bildet am Uebergange in den Rasalrand keine Ecke; der dünne, weissliche Basalkallus ist fein gekörnelt und nur im Umkreise der Spindel deutlich begrenzt.

$$
\mathrm{D}=2 \cdot 6, \mathrm{~d}=2 \cdot 3, \mathrm{E}=1 \cdot 7 \mathrm{~mm} \text {. }
$$

Deckel abgerundet dreieckig; die glänzende, verhăltnismåssig feste Kalkplatte mit schwacher Furche neben dem Spindelrand; in den übrigen Verhältnissen typisch.

Fundort: Neu-Caledonien.

Von der jedenfalls nahe verwandten Aphanoconia littoralis Montrouzier unterscheidet sich vorstehende neue Art durch geringere Dimensionen, dünnere Schale, das niedrigere, abgerundete Gewinde, welches nur aus $31 / 2$ rascher zunehmenden Umgăngen besteht, die deutlicheren Spiralfalten der Epidermis und besonders durch die Verhältnisse der Mündung; die Mündung ist weniger schief, der dünne, schmale Mundsaum oben nur wenig vorgezogen; der letzte Umgang ist schliesslich mehr zusamınengedrückt, an der Peripherie gerundet oder nur undeutlich kantig. 


\title{
Formenkreis Inconspicua n.
}

\section{Aphanoconia (Sphaeroconia) küsteriana Pfeiffer. Taf. 43, Fig. 22-26.}

\author{
Helicina küsteriana Pfeiffer Zeitschr. f. Ma!. p. 88, 1848. \\ $\pi \quad n \quad$ M. Ch II. p. 50, T. 9, F. 22. 25. \\ " " Mon. Pnenm. I, p 385, 1852.
}

Sulfurina küsteriana A. J. Wagner Helicinenstudien in: Denk. Akad. Wien, v. 77, p. 382 , T.3, F. 18 a, b, c, 1905.

Gehäuse gedrückt kugelig mit flächer gewölbter Basis, ziemlich dünnschalig, etwas durchscheinend gelblich bis rötlich hornfarben; im frischen Zustande matt mit dichten, kurz behaarten Spiralfalten der Epiderınis, abgerieben glänzend mit undeutlichen Zuwachsstreifen. Das niedrige, abgerundete Gewinde besteht aus $3 \frac{1}{2}$ leicht gewölbten, regelmässig zunebmenden Umgängen; der letzte ist gerundet und steigt vorne wenig und langsam herab. Die halbeiförmige Mündung ist ziemlich schief; der leicht verdickte Mundsaum ist gelblich oder rötlich und kurz ausgebreitet, der Oberrand an der Insertion etwas vorgezogen. Die kurze, abgerundete Spindel ist unten nach aussen gebogen und bildet am Uebergang in den Basalrand eine abgerundete, wenig vorspringende Ecke. Der ziemlich dicke, sehr fein gekörnelte, aber glänzende Basalkallus ist durchscheinend und deutlich begrenzt.

$$
\mathrm{D}=4, \mathrm{~d}=3 \cdot 5, \mathrm{H}=2 \cdot 7 \mathrm{~mm} \text {. }
$$

Deckel breit halbeiförmig mit geradem Spindelrand; die weisse, feingekörnelte Kalkplatte ist zart und zerbrechlich, flach konkav ohne deutliche Furche. Die gleichmässig gebogene Sigmakante nur im unteren Aste deutlicher erhoben.

Fundorte: die Inseln Tahiti und Bora-bora.

Von Tahiti kenne ich auch eine etwas kleinere Form mit höherem Gewinde, deutlicher herabsteigendem letzten Umgang, sowie einer deutlicheren Ecke am unteren Ende der Spindel.

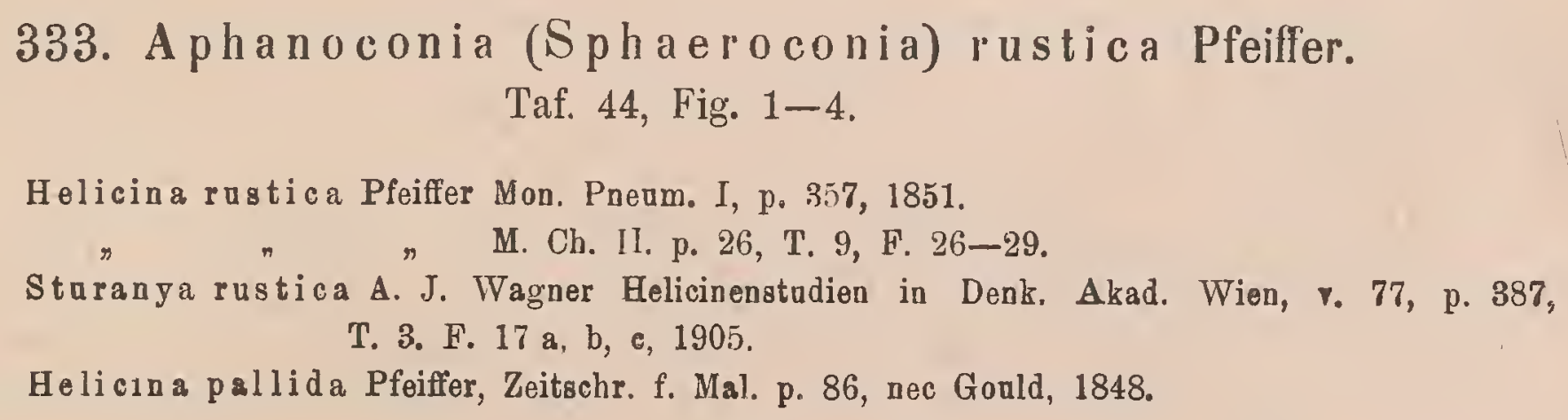

Gehäuse breit kegelförmig mit flachgewölbter Basis, dünnschalig durchscheinend, gelb- 
lich hornfarben, wenig glänzend mit kräftigen, ungleichmässigen, rippchenartigen Zuwachsstreifen. Frische Lxemplare sind zumeist mit einer festen Schmutzkruste bedeckt, welche besonders an den rippenartigen Zuwachsstreifen haftet. Das regelmässig kegelförmige Gewinde besteht aus $3 \frac{1}{2}$ gut gewölbten, ziemlich rasch zunehmenden Umgängen, welche durch eine tiefe Naht geschieden werden; der letzte ist etwas zusammengedrückt, an der Peripherie gerundet und steigt vorne ziemlich tief herab. Die-breit halbeiförmige Mündung ist sehr schief, der dünne Mundsaum schwach erweitert. Die verbreiterte Spindel geht ohne Ecke in den Basalrand über; der feingekörnelte, ziemlich dünne und durchscheinende Basalkallus ist deutlich begrenzt

$$
\mathrm{D}=2 \cdot 8, \mathrm{~d}=2 \cdot 5, \mathrm{H}=2 \mathrm{~mm} \text {. }
$$

Deckel breit halbeiförmig mit leicht S-łörmig gebogenem Spindelrand; die zarte, feingekörnelte Kalkplatte ist gelblich mit seichter Furche neben dem Spindelrand, die Sigmakante undeutlich; in den übrigen Verhältnissen typisch.

Fundort: die Insel Tahiti.

\section{A phanoconia (Sphaeroconia) rusticanan. \\ Taf. 44, Fig. 8-10.}

Gehäuse breitkegelförmig mit, flachgewölbter Basis, verhăltnismässig festschalig, durchscheinend, gelbbraun; seidenglänzend mit gleichmässig dichten, feirien und S-förmig gebogenen Zuwachsstreifen. Das regelmassig kegelförmige Gewinde besteht aus $31 / 2$ gewölbten, regelmässig zunehmenden Umgången, welche durch eine deutlich eingedrückte Naht geschieden werden; der letzte ist an der Peripherie gelundet und steigt vorne deutlich herab. Die abgerundet dreieckige Mündung ist schief; der Mundsaum einfach, kaum ausgebreitet oder gerade, der Oberrand vor der Insertion etwas vorgezogen. Die kurze, abgerundete Spindel ist etwas nach aussen gebogen und bildet am Uebergange in den Basalrand keine Ecke. Der weissliche, gekörnelte Basalkallus ist dick und deutlich begrenzt.

$$
\mathrm{D}=4, \mathrm{~d}=3 \cdot 5, \mathrm{H}=2.5 \mathrm{~mm} \text {. }
$$

Deckel abgerundet dreieckig mit leicht S-förmig gebogenem Spindelrand; die gelbliche, sehr fein gekörnelte Kalkplatte ist nur am Spindelrand stärker verdickt, gegen den Aussenrand zu dünner bis krustenartig zart; die Furche neben dem Spindelrand seicht, die Sigmakante undeutlich.

Fundort: die Insel Borabora; die beschriebenen und abgebildeten Exemplare im K. Museum zu Berlin.

Von Aphanoconia rustica Pfeiffer unterscheidet sich vorstehende Art durch die feste Schale, die gleichmässig dichten und feinen Zuwachsstreifen (nicht Rippchen), welche der Oberfläche einen schwachen Seidenglanz verleihen; die langsamer zunehmenden Umgånge, den weniger zusammengedrückten letzten Unıgang und dem entsprechend eine höhere Mündung; schliesslich durch den auffallend dicken Basalkallus. 


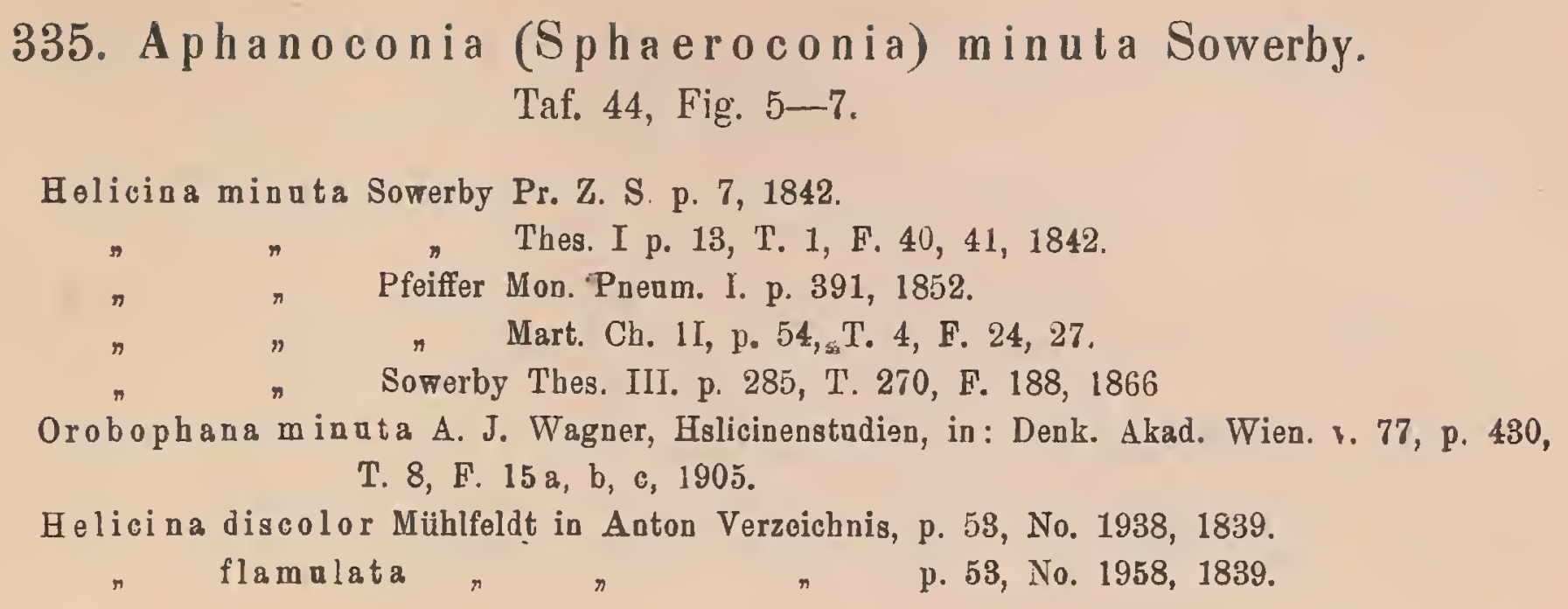

Gehäuse flachkugelig, ziemlich festschalig, etwas durchscheinend, gelblich hornfarben oder rötlich; wenig glänzend mit ungleichmässigen, ziemlich deutlichen Zuwachsstreifen, ausserdem mit ziemlich dichten und feinen Spiralfalten der Epidermis. Das niedrige, abgerundete Gewinde besteht aus $3^{1 / 4}$ nahezu flachen, ziemlich rasch zunehmeuden Umgängen; der letzte ist etwas zusammengedrückt, an der Peripherie undeutlich kantig und steigt vorne wenig, aber deutlich unter die Kante herab. Die breit halbeiförmige Mündung ist schief, der gelbliche, deutlich verdickte Mundsaum kurz ausgebreitet. Die kurze, abgeflachte Spindel bildet am Uebergange in den Basalrand keine Ecke. Der in der Mitte weisse, an den Rändern durchscheinde, glänzende Basalkallus ist ziemlich dick und deutlich begrenzt.

$$
\mathrm{D}=3 \cdot 5, \mathrm{~d}=3, \mathrm{H}=2 \mathrm{~mm} \text {. }
$$

Deckel breit halbeiförmig, mit nahezu geradem Spindelrand; die weisse, feingekörnelte Kalkplatte ist ziemlich fest mit seichter Furche neben dem Spindelrand aber leicht nach hinten gebogenem Spindelwinkel; die Sigmakante im unteren Aste deutlich erhoben, im Uebrigen die typischen Verhältnisse.

Fundorte: die Inseln Opara und Oheatora.

\section{A phanoconia (Sphaeroconia) inconspicua Pfeiffer. Taf. 44, Fig. 11-13.}

Helicina inconspicua Pfeiffer Zeitschr. f. Mal. p. 86, 1848.

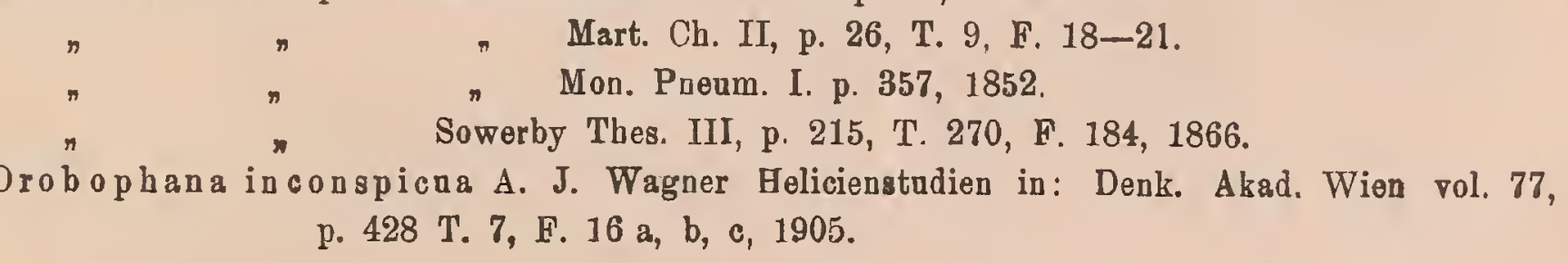


Gehäuse gedrückt kugelig; festschalig, licht horngelb mit dunkler gefärbter Spitze und einer weisslichen Zone um die Mündung; glänzend mit undeutlichen Zuwachsstreifen. Das flachkegelförmige Gewinde besteht aus $3 \frac{1}{2}$ gewölbten, ziemlich rasch zunehmenden Umgăngen; der letzte ist etwas aufgeblasen, unten flacher, an der Peripherie gerundet und steigt vorne deutlich herab. Die halbkreisförmige Mündung ist schief, der weisse Mundsaum leicht verdickt, kurz ausgebreitet; die kurze, nahezu senkrechte Spindel unten abgeflacht, am Uebergange derselben in den Basalrand keine Ecke. Der glänzende, durchscheinende Basalkallus ist besonders im unteren Teile stärker verdickt und deutlich begrenzt.

$$
\mathrm{D}=2 \cdot 5-3, \mathrm{~d}=2 \cdot 2-2 \cdot 6, \mathrm{H}=1 \cdot 6-2 \mathrm{~mm} \text {. }
$$

Deckel abgerundet dreieckig mit verhăitnissmässig dicker, glasglänzender Kalkplatte; die Oberseite der Kalkplatte flachkonkav mit seichter Furche nehen dem Spindelrand; die Sigmakante leicht gebogen, in beiden Aesten schwach erhoben.

Fundort: die Insel Tahiti.

\section{Aphanoconia (Sphaeroconia) pazi Hidalgo. \\ Taf. 44, Fig. 14-18. \\ Heli cina pazi Hidalgo mss., Crosse J. de Conch. vol. XIII, p. 221, T. 6, F. 8, 1865.
" Pfeiffer Mon Pneum. IV p. 277, 1876.}

Gehäuse breitkegelförmig mit halbkugeliger Basis, ziemlich dünnschalig, durchscheinend, gelblich hornfarben; im frischen Zustande mit hinfälliger, brauner Epidermis und zienulich dichten Spiralfalten derselben, abgerieben glänzend mit undeutlichen Zuwachsstreifen. Das regelmässig breitkegelförmige Gewinde besteht aus $3^{1} / 2$ gut gewölbten, ziemlich langsam zunehmenden Umgängen; der letzte ist unten etwas abgeflacht, an der Peripherie gerundet und steigt vorne kaum merklich herab. Die breit halbeiförmige Mündung ist ziemlich schief, höher, als breit, der dünne oder kaum verdickte Mundsaum sehr kurz ausgebreitet, mit dem Gehăuse gleichfarbig. Die kurze, unten abgeflachte Spindel geht ohne Ecke in den Basalrand über; der ziemlich dicke, leicht glänzende und durchscheinende Basalkallus ist deutlich begrenzt.

$$
D=2 \cdot 8, d=2 \cdot 5, H=2 \mathrm{~mm} .
$$

Deckel abgerundet dreieckig mit leicht S-förmig gebogenem Spindelrand und nach hinten gebogenem Spindelwinkel; die feste Kalkplatte ist gelblich oder rötlich, sehr fein gekörnelt, mit deutlicher Furche neben dem Spindelrand; die Sigmakante in beiden Aesten deutlich erhoben; die übrigen Verhältnisse typisch.

Fundort: Mangarewa Gruppe (Gambier-Inseln). 


\section{Genus Orobophana A. J. Wagner.}

Genus Orobophana A. J. Wagner, Helicinenstudien. in: Denk. Ak. Wien. v. 77, p. 415, 1905.

Gehäuse kugelig bis linsenförmig, fest bis dickschalig, mit glänzendem, dicken Basalkallus. Der Mundsaum kurz ausgebreitet oder fast gerade, aber innen lippenartig verdickt; die kurze, dicke Spindel nach aussen gebogen. Das niedrige und abgerundete Gewinde besteht aus 4 bis 5 nahezu flachen, langsam zunehmenden Umgängen. Die schwache Skulptur besteht zumeist nur aus feinen Zuwachsstreifen, daneben sind häuflg dichte, feine und sehr binfällige Spiralfalten der Epidermis vorhanden, selten jedoch feine eingedrückte Spirallinien. Deckel breit halbeiförmig oder abgerundet dreieckig mit geradem oder schwach S-förmig gebogenem Spindelrand. Die zumeist gekörnelte Kalkplatte ist aın Spindelrande stärker bis knochenartig verdickt, gegen den Aussenrand zu allmählig dünner bis krustenartig zart; die Oberseite derselben flach konkav mit sehr seichter oder undeutlicher Rinne neben dem Spindelrand. Der Nukleus dem Spindelrande sehr genähert, die Sigmakante schwach gebogen, oft nahezu gestreckt; der untere senkrechte Ast deutlich erhoben und oft durch eine vom Nukleus zum Aussenrand verlaufende Furche begrenzt. Die Spindelseite der Platte 4 bis 8 mal schmäler wie die Aussenseite.

Verbreitung: die Formen des Genus sind von Neu-Caledonien, den Viti, Samoa, Hervey, Gesellschaftsinseln, den Paumotu, Marquesas und Sandwich-Inselı bekannt geworden; diese Inselgruppen stellen ein zusammenhängendes Gebiet dar, welches westlich in Neu-Caledonien seine Grenze findet. Schon auf den Neuen Hebriden ist das Vorkommen hierhergehörender Formen zweifelhaft, auf den Salomonen, Louisiaden und dem Festlande Australiens kommen dieselben bestimmt nicht mehr vor. Die entsprechenden Vorkommnisse der Sandwich-Inseln sind derzeit noch isoliert, machen es aber sehr wahrscheinlich, dass Formen des Genus Orobophana m. auch auf den zentralpolynesischen Sporaden leben.

Durch Ausscheidung der Formenkreise Primeana m., Sublaevigata m., Musiva m., Diversicolor m. und Pachystoma m. wurde der Umfang des Genus Orobophana m. gegenüber meiner Auffassung desselben im ersten Teil der Helicinenstudien wesentlich eingeengt. In dem hier angegebenen Umfange stellt das Genus ungezwungen eine natürliche Gruppe dar, welche durch auffallende Merkmale der Schale und des Deckels gut gekennzeichnet erscheint. Eine nahe Verwandtschaft zeigen die Formen dieses Genus besonders zu den Formenkreisen Musiva m., Porphyrostoma m. und Inconspicua m. des Subgenus Sphaeroconia m.; dieselben erweisen sich als Uebergangsglieder, indem die Form der Schale für den Anschluss an das Genus Orobophana spricht, während der Deckel noch deutlich cie Merkmale des Genus Aphanoconia m. erkennen lässt. Extrem entwickelte Formen des Genus Orobophana m., welche besonders auf den Paumotu und Marquesas auftreten, besitzen einen Deckel mit einem 
dem Spindelrande sehr genäherten Nukleus und sehr schmaler Spindelseite der Platte, kommen also Verhältnissen nahe, welche für das Genus Palaeohelicina m. charakteristisch sind; die Berücksichtigung der übrigen Verbältnisse, besonders die Beschaffenheit der Schale lässt jedoch über die Zugehörigkeit auch dieser Formen keinen Zweifel aufkommen.

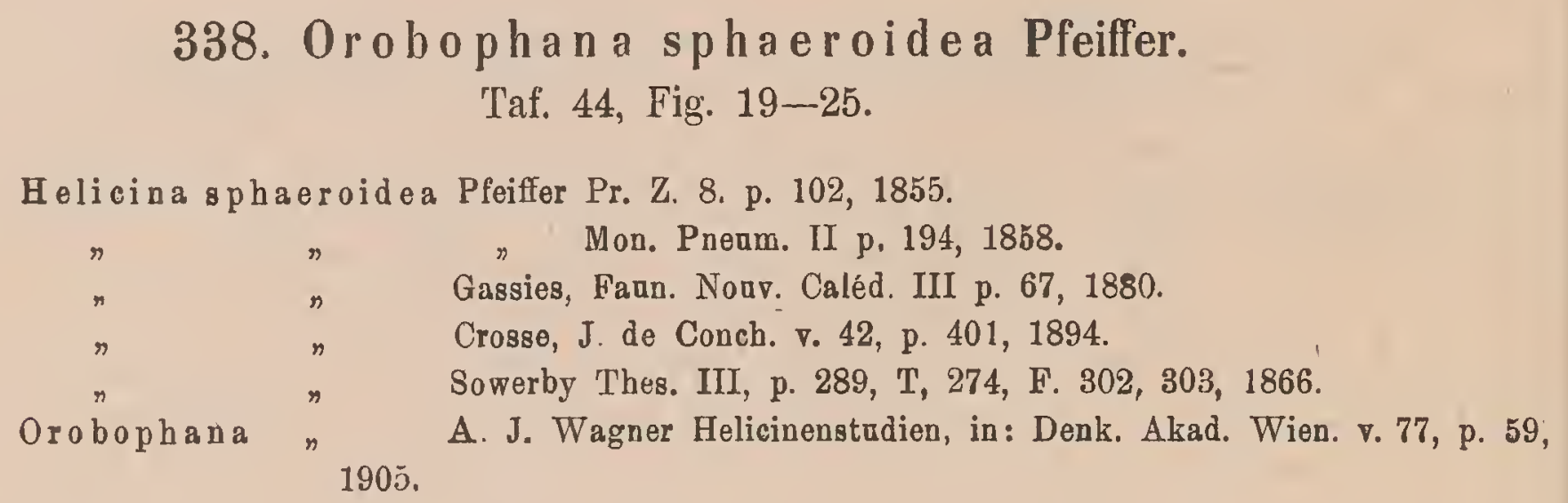

Gehäuse annähernd kugelig, fest bis dickschalig, gelblichweiss, rötlich oder grünlich; im frischen Zustande matt mit feinen, gebogenen Zuwachsstreifen und dichten, hinfälligen Spiralfalten der Epidermis, abgerieben leicht glänzend mit einigen feinen oder undeutlichen Spirallinien. Das niedrige, abgerundet kegelförmige Gewinde besteht aus $4 \frac{1}{2}$ langsam zunehmenden, flachen Umgängen; der letzte ist unter der Peripherie undeutlich kantig und steigt vorne wenig, aber zumeist deutlich herab. Die abgerundet dreieckige Mündung ist schief, innen weiss, gelblich, rötlich oder braun gefärbt. Der weisse oder gelbliche Mundsaum ist kurz ausgebreitet, leicht verdickt. Die kurze, dicke Spineel ist nach aussen und vorne gebogen, am Uebergange in den Basalrand findet sich eine Spitze, aber wenig vorspringende Ecke. Der weisse oder gelbliche, glänzende Basalkallus ist dick und deutlich begrenzt.

$$
\mathrm{D}=8, \mathrm{~d}=7, \mathrm{H}=6.5 \mathrm{~mm} \text {. }
$$

Deckel halbeiförmig, mit geradem Spindelrand; die gelbliche oder rötliche Kalkplatte ist ziemlich dick, fein gekörnelt, am Spindelrand und Spindelwinkel wallartig erhoben, vorne flach konkav; die Sigmakante nahezu gestreckt; in den übrigen Verhältnissen typisch.

Fundorte: der historische Typus findet sieh angeblich nur auf den Loyalty Inseln, ich kenne vollkommen entsprechende Exemplare auch von der Pinien-Inseln bei Neu-Caledonien (Taf. 44, Fig. 19-23). Von der Prony Bai in Neu-Caledonien besitze ich Exemplare mit halblkugeliger Oberseite, abgeflachter Basis und deutlicherer Kante unter der Peripherie des letzten Umganges (Taf. 44, Fig. 24); Exemplare mit mehr erhobenem, kegelförmigem Gewinde erhielt ich ferner mit der Fundortsanuabe Neu-Caledonien (Taf. 44, Fig. 25). 
339. Orobophana sphaeroidea lifouana Crosse.

Taf. 44, Fig. 26. Taf. 45, Fig. 1-2.

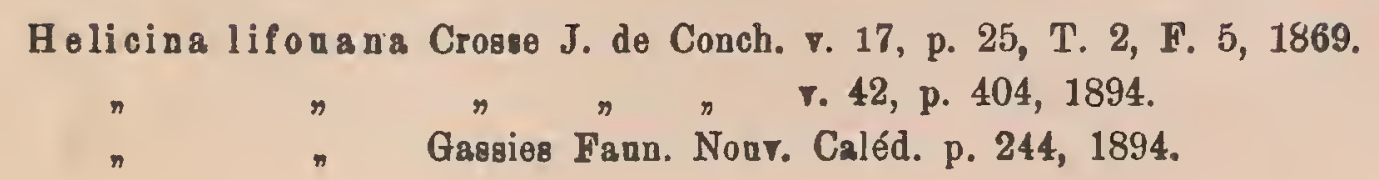

Gehäuse durchschnittlich grösser mit verhältnismässig niedrigerem, mehr abgerundetem Gewinde, welches aus $4^{1} / 2$ bis 5 Umgängen besteht.

$\mathrm{D}=11, \mathrm{~d}=8 \cdot 5, \mathrm{H}=8 \mathrm{~mm}$.

Deckel wie bei der typischen form.

Fundort: die Insel Lifu der Loyalti-Inseln und die Pinien-Insel bei Neu-Caledonien.

\section{Orobophana $t$ ahitens is Pease. Taf. 45 , Fig. $4-7$.}

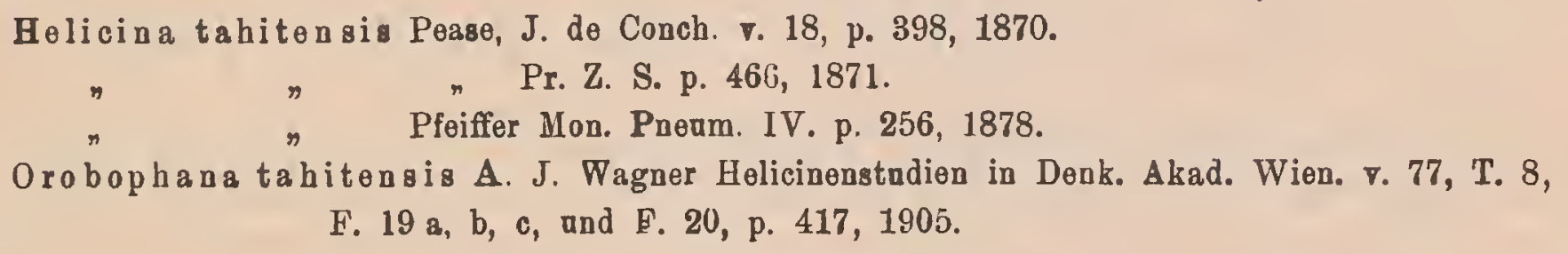

Gehăuse annähernd halbkugelig mit abgeflachter Basis, dickschalig, hellgelb, orange bis lebhaft rotbraun; wenig glänzend bis matt mit feinen bis undeutlichen Zuwachsstreifen. Das niedrige, abgerundete Gewinde besteht aus $4 \frac{1}{2}$ kaum gewölbten, langsam und regelmässig zunehmenden Umgängen; der letzte ist unter der Peripherie stumpfkantig bis gerundet und steigt vorne ziemlich tief herab. Die abgerundet dreieckige Mündung ist schief, innen gelb oder rotbraun, der gerade oder kaum ausgebreitete Mundsaum innen verdickt. Die sehr kurze, abgerundete Spindel ist nahezu winkelig nach aussen gebogen und geht allmählich (ohne Ecke oder Knoten) in den Basalrand über. Der ziemlich dicke und glänzende Basalkallus ist in der Mitte weiss, am Rande gelb und deutlich begrenzt.

$$
\mathrm{D}=6.5, \mathrm{~d}=5.5, \mathrm{H}=4 \mathrm{~mm} \text {. }
$$

Deckel abgerundet dreieckig mit geradem Spindelrand, beiderseits gelb gefürbt. Die verhältnismässig dicke, feingekörnelte Kalkplatte ist sehr flach konkav, am Spindelrande kaum stärker erhoben, am Spindelwinkel schwach nach rückwarts gebogen. Die Sigmakante nahezu gestreckt, auch im unteren Aste wenig erhoben; der Aussenteil der Platte durchschnittlich $4 \mathrm{mal}$ so breit, wie der Spindelteil.

Fundorte: die Inseln Tahiti, Raiatea, Huahine und Tubai der Gesellschafts-Inseln. I. 18. II. 
Orobophana pisum Philippi kenne ich nur nach einem Exemplar des k. k. Wiener Hofmuseams; dasselbe ist der vorstehenden Art sehr ähnlich und unterscheidet sich von derselben nur durch das mehr kugelförmige, weniger abgerundete Gewinde, die mehr gewölbte Unterseite, die deutlicher eingedrückte Naht, sowie durch die etwas höher liegende Kante des letzten Umganges. Diese Form soll auf den Sandwich-Inseln vorkommen, ist dort aber in neuer Zeit anscheinend nicht mehr gesammelt worden. Ich glaube, dass die Fundortsangabe "Sandwich-Inseln" unrichtig ist und die Form wahrscheinlich von den GesellschaftsInseln stammt.

\author{
341. Orobophana flavescens Pease. \\ Taf. 45, Fig. 3 . \\ Helicina flavegeens Pease Amer. J. of Conch. III, p. 288. T. 15, F. 25, 1867. \\ $\pi \quad \pi$ Pr. Z. S. p. 467, 1871. \\ y Pfeiffer Mon. Pneum. IV p. 260, 1876. \\ Orobophana flavescens A. J. Wagner, Helicinenstudien, in: Denk. Akad. Wien. vol. 77, \\ T. 8, F. $21 \mathrm{a}$, b, c, p. $417,1905$. \\ Helicina pacifica Pease Amer. J. of Conch, I, p. 291, T. 5, F. 7, 1865.
}

Gehăuse breitkegelförmig mit abgeflachter Basis, fest bis dickschalig, gelblich, grünlich bis strohgelb; wenig glănzend bis matt mit schwachen bis undeutlichen Zuwachsstreifen, sowie dichten Spiralfalten der Epidermis, welche zum Teil mit kurzen Borsten versehen sind. Das ziemlich erhobene und abgerundete Gewinde besteht aus $4^{1} / 2$ langsam zunehmenden, leicht gewölbten Umgăngen; der letzte ist unter der Mitte deutlich kantig bis stumpf gekielt unten stark abgeflacht und steigt vorne ziemlich tief herab. Die abgerundet dreieckige Mündung ist schief, der Mundsaum gerade, oder kaum ausgebreitet, gelblich und zumeist krăftig verdickt. Die kurze, dicke Spindel ist winkelig nach aussen gebogen und geht allmählig in den Basalrand über. Der gelbliche, glänzende Basalkallus ist dick und deutlich begrenzt.

$$
\mathrm{D} \doteq 4-5, \mathrm{~d}=3 \cdot 5-4 \cdot 5, \mathrm{H}=3-4 \mathrm{~mm} \text {. }
$$

Deckel abgerundet dreieckig mit geradem Spindelrand, beiderseits gelblich gefärbt; die feingekörnelte Kalkplatte ist nur am Spindelrand stärker verdickt, gegen den Aussenrand zu allwăhlig dünner, kaum konkav, nahezu flach: die übrigen Verhăltnisse, wie bei Orobophana tahitensis Pease.

Fundorte: die Hervey (Cooks) Inseln, Mangaia, Raratonga, Atiu.

Ich beurteile diese Art nach Originalexemplaren des Autors von der Insel Raratonga und finde dieselbe sehr verănderlich. Die Abweichungen beziehen sich auf die Dimensionen, die Höhe und Wölbung des Gewindes, sowie die mehr minder entwickelte Kante des letzten Umganges, welche mitunter als stumpfer Kiel bezeichnet werden kann; unten berandet habe 
ich den Kiel jedoch niemals gefunden, obwohl der Autor dieses Merkmal in die Beschreibung aufgenommen hat.

\author{
342. Orobophana brazieri Pease. \\ Taf. 45, Fig. 8. \\ Helicina brazjeri Pesse J. de Coneb. vol. 18, p. 397, 1870. \\ Pfeiffer Mon. Pueam. IV p. 260, 1876. \\ Orobophana brazieri A. J. Wagner Helicinenstadien, in: Denk. Akad. Wien, v. 77, T. 8, \\ F. 22 , p. 4171905 .
}

Gehăuse abgerundet breitkegelförmig, fest bis dickschalig, hell bis dunkelgelb; im frischen Zustande matt mit dichten Spiralfalten der hinfälligen Epidermis, abgerieben leicht glänzend mit deutlichen, jedoch ungleichmässigen Zuwachsstreifen. Das ziemlich erhobene konvexe Gewinde besteht aus $4 \frac{1}{2}$ schwach gewölbten, ziemlich langsam zunehmenden Umgängen, welche durch eine deutlıch eingedrückte Naht geschieden werden; der letzte ist unter der Mitte stumpf gekielt. der Kiel unten durch eine eingedrückte Linie berandet; an der Basis flacher gewölbt und steigt vorne nicht herab. Die abgerundet dreieckige Mündung ist schief, innen gelb; der mit dem Gehăuse gleichfărbige Mundsaum gerade oder kaum ausgebreitet, innen zumeist kraftig verdickt; der Aussenrand entsprechend dem Kiele etwas vorgezogen. Die kurze, dicke Spindel winkelig nach aussen gebogen; am Uebergange in den Basalrand der Mündung eine schwache Einbuchtung. Der ziemlich dicke, mit dem Gehäuse gleichfarbige und glanzende Basalkallus ist deutlich begrenzt.

$$
\mathrm{D}=6, \mathrm{~d}=5, \mathrm{H}=4.5 \mathrm{~mm} \text {. }
$$

Deckel beiderseits gelblich mit leicht nach rückwărts gebogenem Spindelwinkel. Die glånzende, gekörnelte Kalkplatte ist am Spindelrande schwach wallartig erhoben, gegen den Aussenrand zu dünner, vorne flach konkav. Die Sigmakante gestreckt, im unteren Aste deutlich erhoben; die übrigen Verhältnisse wie bei 0 . tahitensis Pease.

Fundort: die Savage-Insel Niue. Auch diese Art ist mit Rücksicht auf die Höhe und Wölbung des Gerrindes, sowie den mehr minder stumpfen Kiel, welcher mitunter unten nicht berandet ist, ziemlich veränderlich.

\title{
343. Orobophana solidula Gray.
} Taf. 45, Fig. 13.

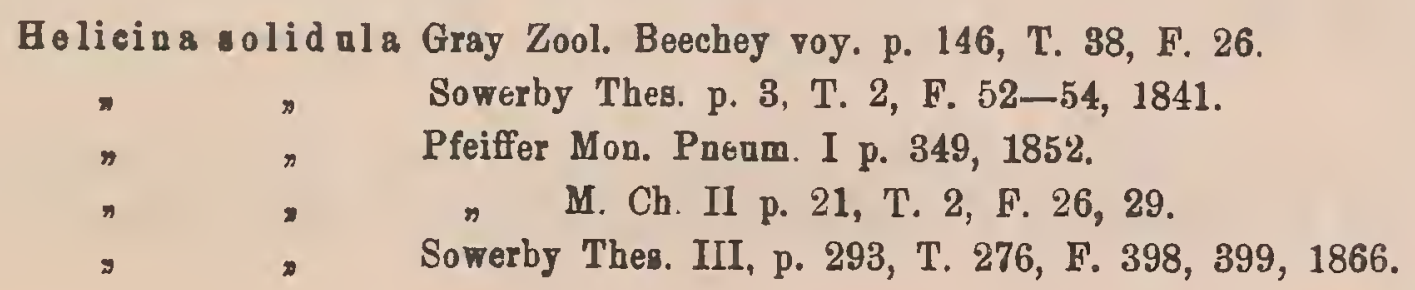


Gehăuse halbkugelig mit flachgewölbter Basis, dickschalig, leicht glănzend mit schwachen bis undeutlichen Zuwachsstreifen; die Oberseite gelbweiss oder rötlich, die Unterseite dunkler bis orange gefărbt. Das niedrige, abgerundete Gewinde besteht aus $4^{1} / 2$ bis 5 flachen, ziemlich langsam zunehmenden Umgängen; der letzte ist gekielt, der Kiel unten durch eine eingedrückte Linie berandet, vorne sehr wenig unter den Kiel herabsteigend. Die abgerundet dreieckige Mündung ist sehr schief, innen gelb; der mit dem Gehăuse gleichfarbige Mundsaum gerade, innen kräftig verdickt, mitunter verdoppelt. Die kurze, dicke Spindel ist winkelig nach aussen gebogen und geht allmählig in den Basalrand über. Der ziemlich dicke, gelbe und glänzende Basalkallus ist deutlich begrenzt.

Deckel nicht beobachtet.

$$
\mathrm{D}=6 \cdot 5, \mathrm{~d}=5 \cdot 5, \mathrm{H}=3.5 \mathrm{~mm} \text {. }
$$

Fundort: die Elisabeth-Insel der Paumotu Gruppe. In meinen früheren Publikationen (Helicinenstudien) habe ich diese Form mit Orobophana colorata Pease verwechselt.

\section{Orobophana solidula colorata Pease.}

Taf. 45, Fig. 9-10.
Helicina colorata Pease, Am. J. of Conch. vol. 4 p. 156, T. 12, F. 9, 1868.
$\rightarrow \quad$ Pfeiffer Mon. Pneum. IV, p. 260, 1876.
Orobophana colorata A. J. Wagner Belicinenstudien, in: Denk. Ak. Wien. v. 77, p. 418, T. 8, F. 23, 1905.
ᄁ colorata solidala A. J. Wagner Helicinenstudien in Denk. Ak. Wien. v. 77, p. 419, T. 8, F. 24, 1905.
Helicina a naensis Mousson J. de Conch. vol. 18, p. 66, T. 5, F. 6, 1869.

Gehäuse kleiner, dünnschaliger, gelbweiss, gelb, rötlich fleischfarben bis rotbraun, im frischen Zustande matt mit hinfälligen Spirallinien der Epidermis, abgerieben glänzend mit deutlichen Zuwachsstreifen und einigen feinen, eingedrückten Spirallinien auf den oberen Umgängen. Das durchschnittlich höhere Gewinde besteht nur aus 4, mitunter schwach gewölbten und durch eine deutlicher eingesenkte Naht geschiedenen Umgången; der letzte ist schărfer gekielt, der Kiel hăufig auch oben berandet.

$$
\mathrm{D}=5, \mathrm{~d}=4.5, \mathrm{H}=3 \mathrm{~mm} \text {. }
$$

Deckel abgerundet dreieckig mit schwach nach rückwärts gebogenem Spindelwinkel, beiderseits gelbbraun. Die gekörnelte Kalkplatte ist nur am Spindelrande dicker und wallartig erhoben, gegen den Aussenrand zu rasch dünner bis krustenartig verlaufend. Die Sigmakante auch im unteren Aste niedrig; die übrigen Verbăltnisse wie bei Orobophana tahitensis Pease.

Fundort: die Insel Anaa der Paumotu Gruppe; diese Form ist mit Rücksicht auf die Höhe und Wölbung des Gewindes, die mehr minder eingesenkte Naht und den mehr minder 
scharfen und berandeten Kiel ziemlich veränderlich. Trotz der grossen Entfernung der Fundorte ist die Uebereinstimmung mit 0 . solidula Gray eine auffaliende; so dürften auch auf den zahlreichen zwischenliegenden Eilanden ăhnliche Formen leben.

\section{Orobophana solidula raiateae A. J. Wagner. Taf. 45, Fig. 11.}

Orobophana colorata raiateae A. J. Wagner Helicinenstudien in: Denk. Ak. Wien. จ. 77, p. 418,1905 .

Gehăuse kleiner, verhăltnisnıăssig dickschalig, dunkelgelb bis orange, glänzend mit feinen eingedrückten Spirallinien (im fri-chen Zustande anscheinend mit hinfälligen Spiralfalten der Epidermis). Das Gewinde wie bei O. colorata Pease, die Umgange jedoch deutlicher gewölbt; der letzte Umgang durchschnittlich stumpfer gekielt, oft nur stumpfkantig.

$\mathrm{D}=\mathrm{E}, \mathrm{d}=4, \mathrm{H}=2.8 \mathrm{~mm}$.

Deckel wie bei Orobophana solidula colorata Pease.

Fundort: die Insel Raiatea der Gesellschafts-Inseln.

346. Orobophana culminans Mousson.

Taf. 45, Fi:. 12.

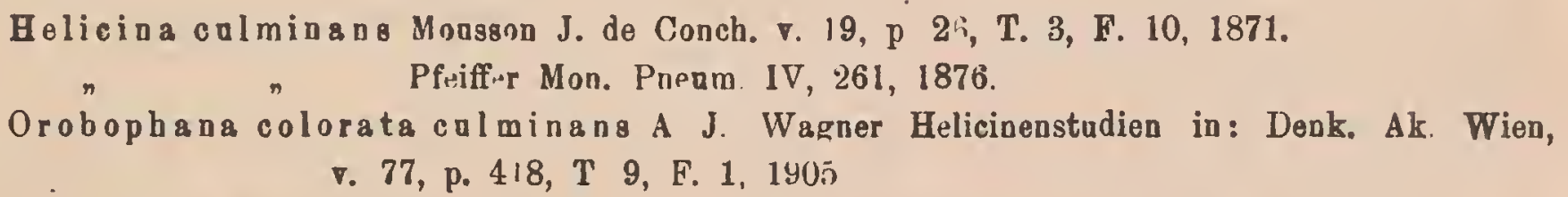

Gehăuse flach halbkugelig mit flachgewölbter Basis, festschalig, gelb mit lichterem letzten Umgang und weissem Kiel: wenig wăızend bis matt mit feinen, etwas ungleichmässigen Zuwachsstreifen; auf den oberen Ungången sind unter der Lıpe häufig feine, eingediückte Spirallinien sichtbalr. Das niedrige, abgerundete Gewinde besteht aus $4-41 / 2$ schwach gewölbten bis flachen Umgăngen, welche durch eıne leicht eingedrückte Naht geschieden werden; der letzte nimmt rascher zu, ist ziemlich scharf gekielt, unter dem Kiel tief eingedrückt, vorne deutlich unter den Kiel herabsteigenıl. Die abgerundet dreieckige Mündung ist sehr schief, innen gelb; der gelbliche Mundsaum kurz, aber deutlich ausgebreitet, innen leicht verdickt; der Oberrand an der Insertion vor»ezoyen, der Aussenrand entsprechend dem Kiel winkelig ausgezoyen. Die kurze, abyerundete Spındel ist winkelig nach aussen gebogen und geht allmăhlig in den Basalrand über. Der ziemlich dünne, hellgelbe und glänzende Basalkallus ist deutlich begrenzt. 
Deckel unbekannt.

$$
\mathrm{D}=6, \mathrm{~d}=5, \mathrm{H}=3.5 \mathrm{~mm} \text {. }
$$

Fundort: die Insel Vavau der Tonga Inseln.

\section{Orobophana oberwimmeri $n$. \\ Taf. 45, Fig. 14-18.}

Gehäuse dicklinsenförmig, festschalig, leicht glänzend mit feinen, etwas ungleichmässigen Zuwachsstreifen und einigen undeutlichen Spirallinien auf den oberen Umgăngen; gelbbraun, rotbraun bis kastanienbraun mit einer verschieden breiten milchig getrübten bis weissen Zone über dem Kiele des letzten Umganıes. Dis niedrige, halbkugelige Gewinde besteht aus $3 \frac{1}{2}$ flachen Ungängen, welche durch eine deutlich eingedrückte Naht geschieden werden; der letzte Umgang ist stumpf gekielt, der Kiel unten durch eine tief eingedrückte Linie berandet; vorne langsam und wenig herabsteigend. Die abyerundet dreieckige Mündung ist schief, innen gelbbraun bis rotbraun; der mit dem Gehäuse gleichfarbige Mundsaum, sehr kurz ausgebreitet, innen verdickt, der Oberrand an der In iertion vorgezogen, der Basalrand etwas konvex vorgezogen. Die kurze, abgeruniete Spindel ist winkelig nach aussen gebogen und geht allmählig in den Basalrand über. Der dünne, glänzende und durchscheinende Basalkallus ist ziemlich deutlich begrenzt.

$$
\mathrm{D}=4, \mathrm{~d}=3 \cdot 3, \mathrm{H}=2 \cdot 5 \mathrm{~mm} \text {. }
$$

Deckel abgerundet dreieckig mit leicht nach rückwärts gebogenem Spindelrand, beiderseits hellrotbraun gefärbt. Die feingekörnelte Kalkplatte ist ziemlich dünn und nur am Spindelrande wallartig erhoben und stärker verdickt; die übrigen Verhältnisse wie bei Orobophana tahitensis Pease.

Fundort: die Samoa-Inseln; die Beschreibung und Abbildung nach Exemplaren des K. Museums in Berlin.

Diese neue Art steht der Orobophana culminans Mousson von den Tonga-Inseln am nächsten; sie unterscheidet sich von derselben abgesehen von den geringen Dimensionen und der lebhaften Färbung durch das mehr abgerundete Gewinde, die geringere Zahl der Uıngänge, den stumpfen Kiel und die abweichende Beschaffenheit der Mündung.

\section{Orobophana semperi Mousson.}

Taf. 46 , Fig. $15-16$.

Helicina semperi Mons8on J. de Conch. vol. 18, p 201, T. 8, F. 8, 1870.

Pfeiffer, Mon. Pneum. IV, p. 278, 1876.

Orobophana semperi A. J. Wagner Helicinenstadium in: Denk. Ak. Wien. v. 77, p.419, T. 9, F. 3-4, 1905. 
Gehäuse gedrückt kugelig, dickschalig, im frischen Zustande matt mit dichten Spiralfalten der hinfalligen Epidermis, abgerieben glänzeud mit feinen und etwas ungleichnıässigen Zuwachsstreifen; unter der Lupe sind auch feine Spirallinien auf den oberen Umgängen nachzuweisen; die Grundfarbe ist gelb oder hellrotbraun, auf dem letzten Umgang sind regelmässig abwechselnd rotbraune und milchiye Zickzackstriemen vorhanden, welche mitunter verschwommen und undeutlich erscheinen. Das niedrige, abgerundete Gewinde besteht aus $4 \% 2$ kaum gewölbten, ziemlıch rasch zunehmenden Umgängen, welche durch eine leicht eingedrückte Naht geschieden werden; der letzte ist gerundet oder undeutlich stumpfkantig und steigt vorne langsam, aber deutlich herab. Die abgerundet dreieckige Mündung ist schief: innen lebhaft gelb, hell bis dunkel rotbraun. Der weisse oder gelbliche Mundsaum ist kurz ausuebreitet, iınen verdickt. Die kurze, dicke Spindel ist nach aussen gebogen, am Uebergange in den Basalrand der Mündung findet sich eine seichte Einbuchtung. Der dicke, glänzende Basalkdllus ist in der Mitte weiss und deutlich begrenzt.

Deckel unbekannt.

$$
\mathrm{D}=9, \mathrm{~d}=7, \mathrm{H}=6 \mathrm{~mm} \text {. }
$$

Fuudort: Oneata der Viti-Inseln.

\section{Orobophana pohliana Garrett. \\ Taf. 46, Fig. 17-18.}

Helicina pobliana Garrett Pr. Z. S. p. 313, 1887.

Gehăuse dicklinsenförmig mit leicht vorspringender Spitze, dickschalig, leicht glänzend mit feinen etwas ungleichmåssigen Zuwachsstreifen sowie einigen niedrigen Spiralreifen auf den oberen Ungängen (triscbe Exenıplare besitzen anscheinend dichte Spiralfalten der hinfălligen Epillermis); gelbbraun, rötlich fleischfarben bis rotbraun mit lichtem Kiel und einer lichten Zone un die Mündung. Das niedrige, halbkugelig abgerundete Gewinde besteht aus $4^{1 / 2}$ bis 5 Hachen, ziemlich rasch zunehmenden Umgăngen; der letzte ist stumpfgekielt, der Kiel unten durch eine eingedrückte Furche berandet; vorne kaum unter den Kiel herabsteigend. Die abyerundet dıeieckige Mündung ist sehr schief, innen rötlish oder lebhaft orange gefärbt. Der gelbliche Mundsaum ist gerade, aber kräftig verdickt bis verdoppelt. Die sehr kurze, dicke spindel ist nach aussen gebogen, am Uebergange in den Basalrand eine seichte Einbuchtung. Der gelbliche, glasglänzende Basalkallus ist dick und deutlich begrenzt.

Deckel unbekannt

$$
\mathrm{D}=9, \mathrm{~d}=7 \cdot 5, \mathrm{H}=5.5 \mathrm{~mm} \text {. }
$$

Fundort: die In $•$ el Vatu der Viti-Inseln. Die Abbildung und Beschreibung nach Originalexerpplaren, mitgeteilt von Herrn Dautzenberg in Paris. Von der nächstverwandten Orobophana semperi Mous:on unterscheidet sich vorstehende Art durch das linsenförmige, gekielte Gehăuse, die deutlichen spiralleisten, den Mangel der Zickzackstriemen, den vorne nicht herabsteigenden letzten Umgang, sowie den dicken Mundsaum. 


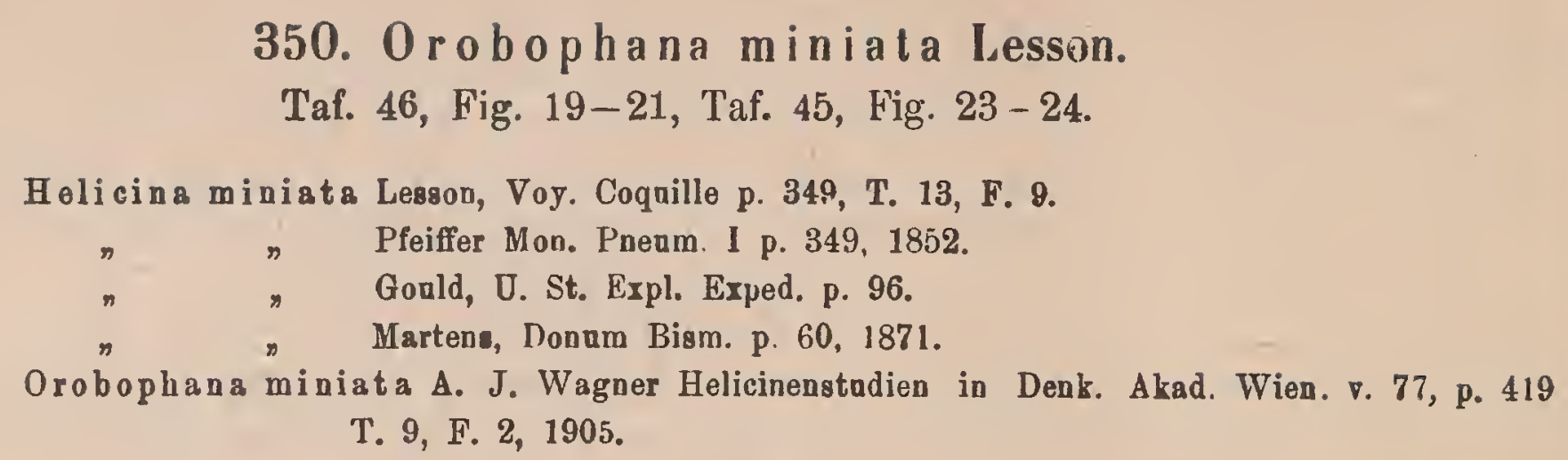

Gehäuse breitkegelförmig oder halbkugelig mit gewölbter Basis, ziemlich glänzend mit feinen, etwas ungleichmässigen Zuwachsstreifen; gelb, rötlich bis rotbraun mit heller Basis und einer hellen Zone entlang der Naht des letzten Umganges, welche sich häufig über die ganze Oberseite des letzten Umganges ausbreitet. Das ziemlich erhobene oder niedrige Gewinde besteht aus $4^{1} / 2$ kaum gewölbten bis flachen, ziemlich lanæsam zunehmenden Umgängen; der letzte ist im Beginne scharf gekielt, gegen die Mündung nahezu gerundet und steigt vorne wenig oder gar nicht herab. Die abgerundet dreieckige Mündung ist sehr schief, innen gelb oder rötlich; der gerade innen kräftig verdickte Mundsaum ist entsprechend dem Kiele winkelig vorgezogen. Die dicke Spindel ist winkelig nach aussen gebogen, am Uebergange derselben in den Basalrand eine seichte, aber dentliche Einbuchtung. Der weisse oder gelbliche Basalkallus ist dick, glasglänzend, an den Insertionen dès Mundsaumes leistenförmig erhoben und gut begrenzt.

$$
\mathrm{D}=8 . \mathrm{d}=7, \mathrm{H}=5-5.5 \mathrm{~mm} \text {. }
$$

Deckel breit halbeiförmig mit geradem Spindelrand, beiderseits gelbbraun bis rotbraun. Die dicke, gekörnelte Kalkplatte ist flach konkav; die Sigmakante in beiden Aesten undeutlich; die übrigen Verhältnisse typisch.

Fundort: die Insel Borabora der Gesellschaftsinseln, angeblich auch auf den Marquesas gesammelt.

\section{Orobophana albolabris Hombron el Jacquinot. Taf. 46 , Fig. $1-4$.}

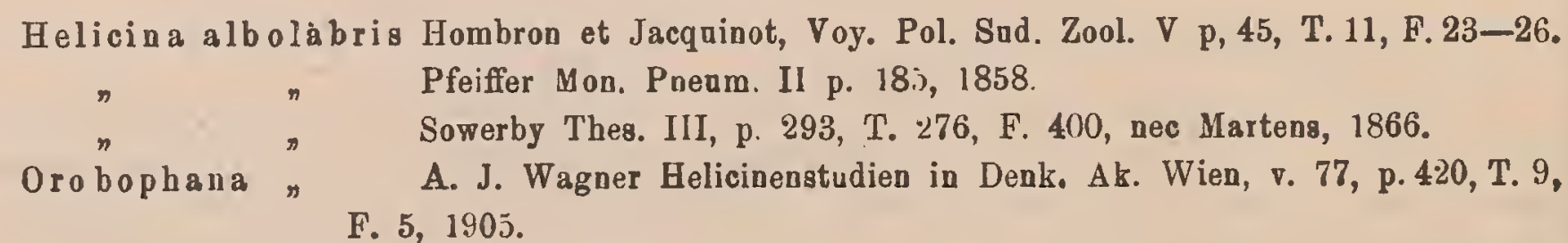

Gehäuse dicklinsenförmig, fest bis dickschalig, wenig glänzend bis matt mit feinen Zu- 
wachsstreifen; schmutziggelb, rotgelb bis rotbraun mit einer helleren bis weisslichen Zone um die Mündung, häufig auch mit heller bis weisser Naht und Kielbinde. Das niedrige, flachkegelförmige, mehr minder abgerundete Gewinde besteht aus 4 bis $4 \frac{1}{2}$ leicht gewölbten bis flachen Umgängen, von welchen die oberen langsam, die zwei letzten rascher zunehmen; der letzte ist im. Beginne ziemlich scharf gekielt, unter dem Kiele mehr minder tief eingedrückt und steigt vorne deutlich unter den Kiel herab. Die abgerundet dreieckige Mündung ist sehr schief, innen gelblich oder rötlich; der gelbliche Mundsaum gerade, innen mehr minder verdickt; der Oberrand an der Insertion vorgezogen, ebenso der Aussenrand entsprechend dem Kiele etwas winkelig ausgezogen. Die kurze Spindel ist nach aussen gebogen und geht allmăhlich in den Basalrand über. Der gelbliche oder weisse Basalkallus ist sehr fein gekörnelt, etwas durchscheinend, an den Insertionen des Mundsaumes oft leistenartig erhoben, dick und gut begrenzt.

$$
\mathrm{D}=6-85, \mathrm{~d}=5-7, \mathrm{H}=3-4 \mathrm{~mm} \text {. }
$$

Deckel abgerundet dreieckig mit leicht S-förmig gebogenem Spindelrand; am Spindelrande beiderseits weiss, gegen den Aussenrand zu gelbbraun gefärbt; die dünne, feingekörnelte Kalkplatte flachkonkav; die Sigmakante in beiden Aesten schwach erhoben, gleichmässig gebogen; die übrigen Verhältnisse typisch.

Eine sehr veränderliche Art; die Abweichungen betreffen vorzüglich die Form des Gewindes, welches bald abgerundet und Hach, bald mehr erhoben und kegelförmig gefunden wird, auch die Beschaffenheit des Kieles, des Mundsaumes und des Basalkallus ist selbst bei Exemplaren des gleichen Fundortes ziemlich verschieden, doch kommen alle denkbaren Umgänge vor.

\section{Orobophana maugeriae Gray.} Taf. 46, Fig. 5-7.

Helicina mangeriae Gray, Zool. Journ. I, j. 251, 1825.

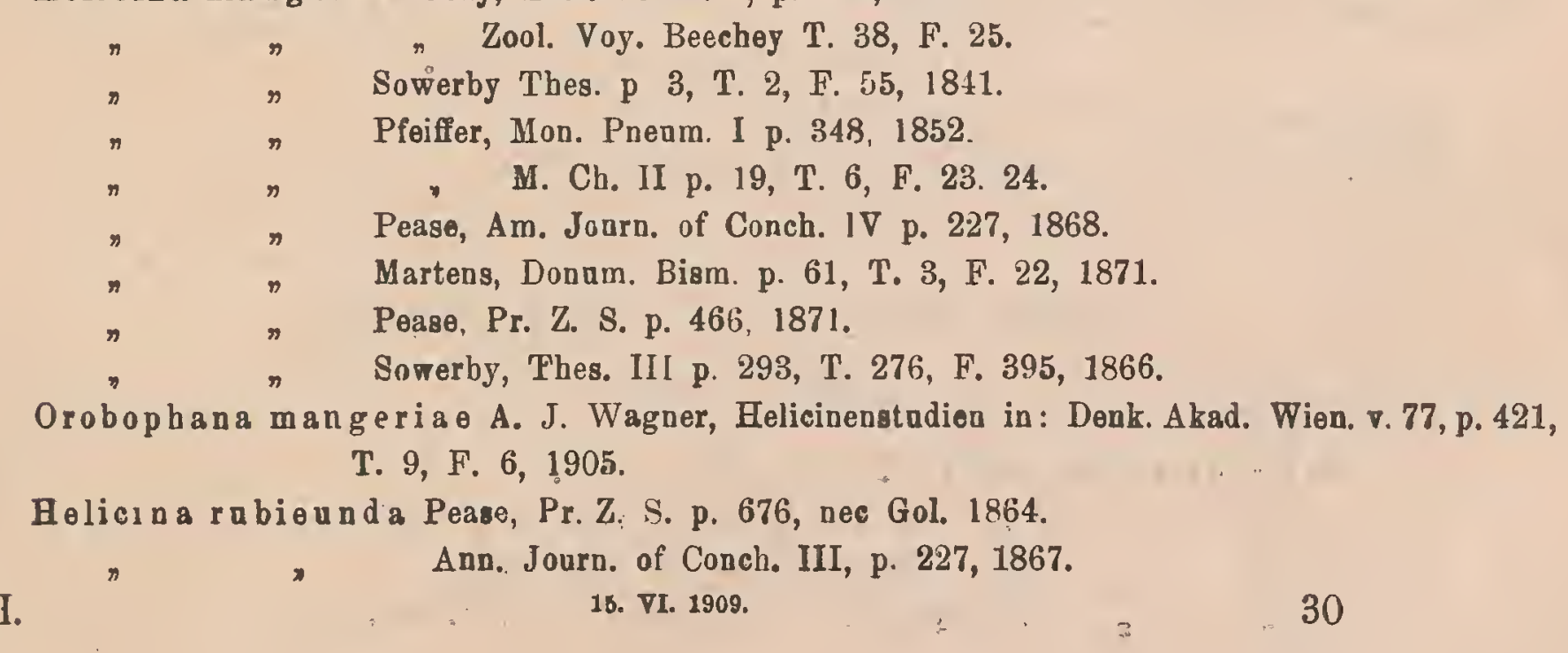

I. 18. II. 
Gehäuse dicklinsenförmig, dickschalig, glänzend mit feinen bis undeutlichen Zuwachsstreifen; die Grundfarbe schmutziggelb, hellbraun bis rotbraun mit milchig getrubbten, weissen oder gelblichen Bandern an der Naht und unter der Peripherie, ferner einem lichten Flecke um den Basalkallus, welcher von einer dunklen Binde der Grundfarbe begrenzt wird. Das abgerundete, niedrige bis flache Gewinde besteht aus $4^{1} / 4$ flachen oder schwach konvexen Umgăngen, von welchen die ersten lanusam, die zwei letzten rascher zunehmen; der letzte ist stumpf gekielt und steigt vorne nicht herab. Die abgerundet dreieckige, durch den dicken Basalkallus verengte Mündung ist schief, innen gelb bis rotbraun; der gerade Mundsaum kräftig verdickt bis verdoppelt, gelblich bis ol'ange, der Aussenrand entsprechend dem Kiele etwas winkelig vorgezogen. Die dicke Spindel winkelig nach aussen gebogen, am Uebergang in den Basalrand seicht eingebuchtet. Der glănzende, citron bis orangegelbe Basalkallus ist sehr dick, an den Rändern wulstig erhohen.

$$
\mathrm{D}=14, \mathrm{~d}=12, \mathrm{H}=8 \mathrm{~mm} \text {. }
$$

Deckel dreieckig mit geradem Spindelrand, beiderseits gelbbraun; die dünne Kalkplatte feingekörnelt, flach konkav; die leicht gebogene Sigmakante nur im unteren Aste schwach erhoben, der Nukleus dem Spindelrande sehr genăhert; in den übrigen Verhältnissen typisch.

Fundorte: die Inseln Tahiti und Raiatea.

\section{Orobophana maugeriae albinea Pease.}

Taf. 46 , Fig. 8 .

Helicina albinea Pease, Pr. Z. S., p. 466, 1871.

Urobophana mangeriae albinea A. J. Wagner Helicinenstadien in: Denk. Ak. Wien. v. 77, p. 421, T. 9, F. 7, 1905.

Gehăuse dünnschaliger, schärfer gekielt; Mundsaum und Basalkallus sind auffallend dünner, gelblich oder weiss gefärbt.

$$
\mathrm{D}=13, \mathrm{~d}=10 \mathrm{H}=6.5,
$$

Deckel wie bei der typischen Form.

Fundort: die Insel Tahaä der Gesellschafts-Inseln.

\section{Orobophana rohri Pfeiffer.}

Taf. 45, Fig. $19-21$.

Helicias rohri Pfoiffor Pr. Z. S. p. 124, 1818.

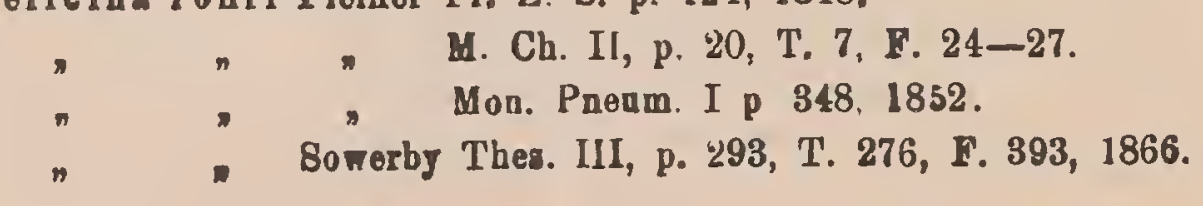


Orobophana rohri A. J. Wagner Helicinenstadien in Denk. Ak. Wien, จ. 77, p. 422, T. 9, F. 8, 1905 ,

Gehäuse kegelförmig mit flachgewölbter Basis, dickschalig matt mit deutlichen, ungleichmässigen Zuwachstreifen und einer rauhen, auf dem letzten Umgange sogar höckerigen Oberfläche; einzelne Exemplare weisen auch ziemlich dichte und feine Spirallinien auf. Die Grundfarbe ist schmutzig gelb oder gelbbraun mit einer rotbraunen Binde über dem Kiel und an der Naht. hăufig auch einer zweiten Binde auf der Unterseite; der Apex gelb oder hellbraun.

Das regelmässig kegelförmige Gewinde besteht aus 5 kaum gewölbten bis flachen, langsam zunehmenden Umgängen, welche durch eine ziemlicb tiefe, hăr.ig fadenförmig berandete Naht geschieden werden; der letzte ist deutlicher gewölbt, $\mathrm{g} \in$ kielt; der Kiel vorspringend und beiderseits durch eingedriickte Linien berandet; vorne ziemlich tief unter den Kiel herabsteigend. Die abgerundet dreieckige Mündung ist sehr schief, innen gelb oder rotbraun, der weisse Mundsaum kurz ausgebreitet, innen verdickt. Die kurze, abgeflachte Spindel ist nach aussen gebogen, am Uebergange in den Basalrand ein seichter, aber deutlicher Ausschnitt. Der weisse, glänzende Basalkallus ist dick, an den Rändern oft wulstig erboben und gut begrenzt.

$$
\mathrm{D}=9 \cdot 5, \mathrm{~d}=8, \mathrm{H}=7 \mathrm{~mm} .
$$

Deckel abgerundet dreieckig mit leicht gebogenem Spindelrand, beiderseits hellrotbraun. Die feinçekörnelte Kalkplatte nur am Spindelrand wallartig erhoben und verdickt, gegen den Aussenrand zu allmählich dünner bis krustenartig, flachkonkav. Die Sigmakante leicht S-förmig gebogen, wenig erhoben, dem Spindelrande sehr genähert; in den übrigen Verhältnissen typisch.

Fundort: die Marquesas-Inseln.

\section{Orobophana rohri nukahivana n.}

Taf. 45 , Fig. 22.

Gehäuse kleiner, die Oberfläche glatt mit undeutlichen Zuwachsstreifen; das Gewinde besteht nur aus $4 \frac{1}{2}$ deutlicher gewölbten Umgăngen.

Deckel wie bei der typischen Form.

$$
D=7, d=6, H=5 \mathrm{~mm} \text {. }
$$

Fundort: die Insel Nukahiva der Marquesas; das abgebildete Exemplar im k. Museum für Naturkunde in Berlin. 


\section{O robophana uberta Gould. \\ Taf. 46, Fig. 9-12.}

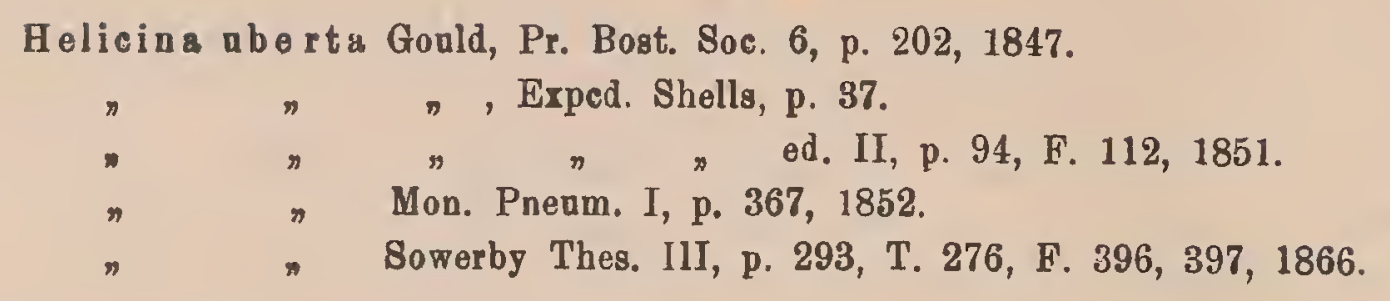

Gehäuse kugelig, festschalig, einfärbig hellgelb und undurchsichtig, ziemlich glănzend mit feinen, etwas ungleichmässigen Zuwachsstreifen. Das niedrige, abgerundet kegelförniige Gewinde besteht aus 4 wenig gewölbten, ziemlich rasch zunehmenden Umgängen, welche durch eine leicht eingedrückte Naht geschieden werden; der letzte ist gerundet, vorne eingeschnürt und tief herabsteigend. Die breit haibeiförnnige Mündung ist schief, innen gelb; der dünne, gelbe Mundsaum sehr kurz ausgebreitet. Die kurze, etwas abgeflachte Spindel ist nach aussen gebogen, am Uebergange in den Basalrand eine seichte, aber deutliche Einbuchtung. Der auffallend dicke, zitrongelbe Basalkallus ist glänzend, an den Rändern wallartig erhoben und gut begrenzt.

$$
\mathrm{D}=4.5, \mathrm{~d}=4, \mathrm{H}=3.5 \mathrm{~mm} .
$$

Deckel breit halbeiförmig mit schwach konvexem Spind+lrand, beiderseits rötlich hornfarben; die dünne, glänzende Kalkplatte flach konkav; die leicht gebogene, nur im durchfallenden Licht erkennbare Sigmakante dem Spindelrande sehr genăhert; in den übrigen Verhältnissen typisch.

Fundort: die Sandwich-Inseln. Ich habe diese Art in früheren Publikationen mit Orobophana constricta Pfeiffer verwechselt.

\section{5̃7. Orobophana constricta Pfeiffer.} Taf. 46, Fig. 13-14.

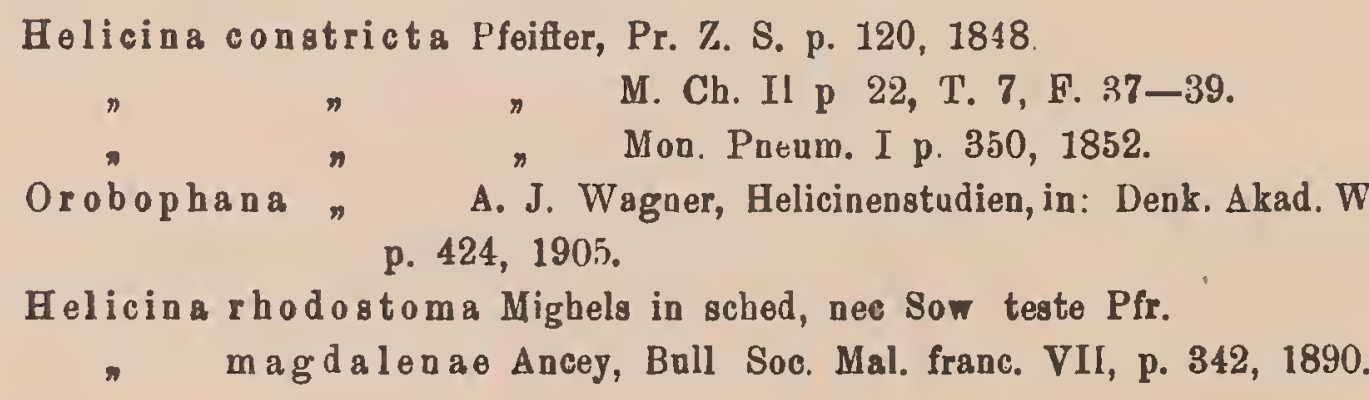

Gehăuse breit kegelförmig mit gewölbter Basis, fest bis dickschalig mit sehr hinfälliger gelbbrauner Epidermis. Frische Exemplare sind ziemlich glänzend mit feinen, etwas 
ungleichmässigen Zuwachsstreifen und einigen undeutlichen, eingedrückten Spirallinien. Die Grundfar be hell gelbbraun; häuflg kommen rotbraune Zickzackstriemen vor, welche besonders an Naht und Kiel der oberen Umyänge sichtbar werden; die Mündung und der Basalkallus werden von einer rotorangefarbenen Zone eingefasst. Das niedrige, flachkegelförmige Gewinde besteht aus 4 Hachen, oder schwach konkaven, ziemlich rasch zunehmenden Umgängen, welche durch eine ziemlich eingedrückte Naht geschieden werden; der letzte ist vorne eingeschnürt, steigt mehr niinder tief, aber deutlich unter den Kiel herab und ist an der Peripherie kantig bis stumpf gekielt; der Kiel unten häufig durch eine eingedrückte Linie berandet. Die breit eiförınige Münilung ist sehr schief, innen rotorange gefärbt; der gelbe oder rotorangefarbene Mundsaum gerade und stumpf. Die kurze, etwas abgeflachte Spindel ist nach aussen gebogen, am Uebergange in den Basalrand eine seichte Ausbuchtung. Der feingekörnelte, gelbe bis orangefarbene Basalkallus ist auffallend dick, am Rande wallartig erhoben.

$$
\mathrm{D}=5 \cdot 5, \mathrm{~d}=4.5, \mathrm{H}=3 \cdot 5 \mathrm{~mm} \text {. }
$$

Deckel wie bei Orobophana uberta Gould.

Fundort: die Sandwich-Inseln (Oahu).

Von Orobophana uberta Gould unterscheidet sich diese Art durch das flachere, kantige oder gekielte Gehäuse, die Spiralskulptur und die Färbung. Helicina magdalenae Ancey ist von vorstehender Art nicht zu unterscheiden.

\title{
Genus Palaeohelicina A. J. Wagner.
}

\author{
Genus Palaeobelicina A. J. Wagner Helicinenstadien in Denk. Akad. Wien v. 77, p. 435, \\ 1905 . \\ Genas Orobophaua A. J. Wagner (part.) Helicinenstadien in: Denk. Akad. Wien, v. 77, \\ p. 415,1905 .
}

Gehäuse linsenförmig bi` kegelförmig mit gewölbter Basis, festschalig mit ziemlich beständiger Epidermis, welche nur ausnahmsweise hinfallige Spiralfalten aufweist. Das ziemlich erhobene, kegelförmige Gewinde besteht aus 4-5 regelmässig oder ziemlich rasch zu nehmenden Umgängen; der dünne bis undeutliche Basalkallus ohne Furche oder Grübchen neben der Spindel. Am ersten Umgange nach der Embryonalwindung sind unter der Lupe konstant einige erhobene Spirallinien oder feine Spiralrippchen sichtbar; dieses Merkmal ist besonders bei sonst glatten oder nur schwach :piral gestreiften Schalen auffallend.

Deckel abgerundet dreieckig bis dreieckig mit nahezu randständigem oder vollkommen randständi:-em Nukleus, welcher aber vom Spindel und oberen Winkel annähernd gleich weit entfernt ist; die Sigmakante schwach gebogen oder gestreckt; die Spindelseite der Platte auf einen schmalı $\mathrm{n}$ bis uudeutlichen Saum reduziert. Die Kalkplatte fest bis krustenartig dünn und zart.

Die mir bekannt gewordenen Formen des Geuus leben auf den Philippinen, den Inseln Halmahera, Gebe, Jobi, dem Bismark Archipel, den Salomonen, Louisiaden, der Ostküste von 
Neu-Guinea, den Neuen-Hebriden, Neu-Caledonien und dem Festlande von Australien; damit ist das Verbreitungsgebiet der Gruppe wohl noch nicht abgeschlossen, da das bisher isolierte Auftreten auf den Inseln Halmahera und Gebe vermuten lăsst, dass ähnliche Formen auch auf den zahlreichen Inseln in dem Gebiete zwischen den Philippinen und Neu-Guinea vorkommen.

Der vollkommen randständige Nukleus des Deckels stellt eine extreme Bildung dar, welche in ähnlicher Weise noch bei den Formen des Genus Helicina s. str. vorkomnt. Wie wesentlich die genaue Beobachtung des Deckels die Systematik unterstützt ist auch bei vorstehender Gruppe ersichtlich, indem die hier auf Grund dieses Merkmales vereinigten Formen auch gemeinsame Merkmale der Schale erkennen lassen; für sich allein betrachtet erwiesen sich die Schalenmerkmale zur sicheren Abgrenzung des Genus als unzureichend, indem ăhnliche Schalenformen auch bei anderen Gruppen mit abweichenden Deckel vorkommen. Ueber das Verhăltnis dieses Genus zum Genus Helicina s. str. werde ich bei der Besprechung des. selben berichten.

\title{
Subgenus Palaeohelicina s. str.
}

Gehäuse mit deutlicher, aus dichten Reifen, oder eingedrückten Linien bestehender Spiralskulptur.

Deckel mit nahezu randstăndigem Nukleus, schwach gehogener, im unteren Aste deutlich erhobener Sigmakante. Der Spindelteil der Platte ist auf einen schmalen, aber noch deutlichen Randstreifen reduziert. Die feste Kalkplatte ist am Spindelrande leistenartig erhoben, daselbst von der Hornplatte durch eine Furche geschieden, am Spindelwinkel schwach nach hinten gebogen.

Verbreitungsgebiet: die Louisiaden und Salomonen.

\section{Formenkreis Kalokonia A. J. Wagner.}

\author{
358. Palaeohelicina moquiniana Recluz. \\ Taf. 47, Fig. 6-10. \\ Helicina moquiniana Recluz, J. de Conch. II, p. 212, T. 5, F. 8, 1851. \\ Pfeiffer Mon. Pneum. I, p. 393, 1852. \\ $\quad$ Mal. Bl. I p. 108, 1854. \\ " Mon. Pueum. II p. 213, 1856. \\ Sowerby Thes. III, p. 294, T. 277, F. 419. 420, 1866. \\ Adam s Genera II, p. 305, 1856. \\ A. J. Wagner Helicinenstudien in Denk. Akad. Wien, r. 78, p. 408, \\ T. 10, F. 1, 1905 .
}


Gehäuse kegelförmig mit halbkugeliger Basis, festschalig, glänzend mit feinen, ungleichmăssigen Zuwachsstreifen, sowie niedrigen aber dichten Spiralreifen, welche unter dem Kiele etwas dichter und schwächer werden; die Grundfarbe gelblichweiss oder gelb mit milchweissen und rotbraunen Zickzackstriemen, welche mitunter undeutlich werden oder verschwinden; häufig ist auch ein rotbraunes Band unter dem weissen Kiele vorhanden, welches nach oben scharf, nach unten undeutlich begrenzt ist. Das spitz kegelförmige Gewinde besteht aus 5 gewölbten Umgängen, von welchen die erșten drei ziemlich langsam, die zwei letzten rasch zunehmen; der letzte ist stärker gewölbt, etwas aufgeblasen, an der Peripherie im Beginne gekielt, gegen die Mündung zu nur kantig bis gerundet und steigt vorne nicht herab. Die abgerundet dreieckige Mündung ist schief, innen gelb mit durchscheinender rotbrauner Zeichnung; der weisse, lippenartig verdickte Mundsaum ausgebreitet und umgeschlagen; der Oberrand an der Insertion stark vorgezogen. Die dreieckige, etwas abgeflachte Spindel ist nach hinten gebogen und bildet am Uebergange in den Basalrand eine (in der Profilansicht sichtbare) winkelig vorspringende Ecke. Der dünne, glänzende, gelbliche Basalkallus ist undeutlich begrenzt.

$$
\mathrm{D}=16, \mathrm{~d}=13, \mathrm{H}=12 \mathrm{~mm} \text {. }
$$

Deckel abgerundet dreieckig mit leicht S-förmig gebogenem Spindelrand, beiderseits lebhaft rotbraun mit lichtem Spindelrand. Die feingekörnelte, verhältnismässig dünne Kalkplatte ist am Spindelrand auffallend leistenförmig verdickt, am Spindelwinkel deutlich nach hinten gebogen; in den übrigen Verhältnissen typisch.

Fundorte: die Salomons-Inseln, angeblich auch die neuen Hebriden.

\title{
359. Palaeohelicina moquiniana christovalensis A. J. Wagner.
}

\author{
Taf. 47, Fig. 11.
}

\section{Palaeohelicina maquiniana christoralensis A. J. Wagner Helicinengtudien in Denk. Akad. Wien, จ. 78, T. 10, F. 2, p. 205, 1905.}

Gehäuse kleiner, dünnschaliger mit regelmässig kegelförmigem Gewinde, welches aus 5 kaum gewölbten, langsamer zunehmenden Umgăngen besteht; auch der letzte Umgang nimmt regelmässig zu und ist nicht aufgeblasen.

Deckel wie bei der typischen Form.

$$
\mathrm{D}=13, \mathrm{~d}=10, \mathrm{H}=20 \mathrm{~mm} \text {. }
$$

Fundort: die Insel San Christoval der Salomonen. 


\section{Palaeohelicina moquiniana ecarinata $n$. \\ Taf. 47, Fig. 12.} gerundet.

Gehäuse hellgelb mit undeulichen weisslichen Flecken; der letzte Umgang vollkommen

Deckel wie bei der typischen Form.

$$
\mathrm{D}=15, \mathrm{~d}=13, \mathrm{H}=12 \mathrm{~mm} .
$$

Fundort: die Salomonen.

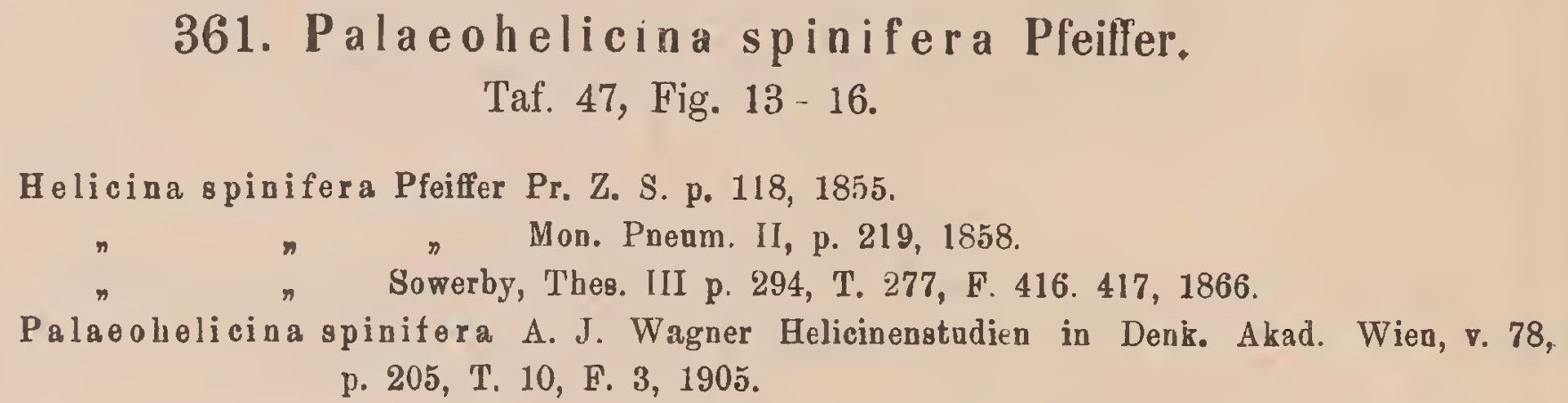

Gehăuse kegelförmig mit halbkugeliger Basis, ziemlich dünnschalig, leicht glänzend mit feinen bis undeutlichen Zuwachsstreifen und dichten, niedrigen Spiralreifen, welche unterhalb. des Kieles dichter werden. Die Grundfarbe ist gelb, rötlich fleischfarben oder lebhaft rotbraun; einfärbig oder mit hellen und braunen Zickzackstriemen, welche zumeist in Flecken aufgelöst erscheinen; so finden sich auch Exemplare mit zusammenhängenden oder gegliederten Binden über der Naht and dem Kiel. Das regelmässig -kegelför'mige Gewinde besteht aus $4 \frac{1}{2}$. leicht gewölbten, ziemlich rasch zunehmenden Umgängen; der letzte ist beiderseits gleichmăssig gewölbt, an der Peripherie gewöhnlich ziemlich scharf gekielt (einzelne Exemplare sind gegen die Mündung zu nur kantig) und steigt vorne nicht kerab. Die abgerundet dreieckige Mündung ist wenig schief, innen gelb oder rotbraun mit durchscheinenden Flecken und Bändern; der weisse, ziemlich verdickte Mundsaum ziemlich kurz ausgebreitet und umgeschlagen. Die kurze, abgerundete Spindel lauft unten in eine scharf vorspringeıde, etwas. abgerundete Ecke aus, welche leicht nach vorne gebogen ist. Der dünne, glänzende, mit dem Gehäuse gleichfärbige Basalkallus ist undeutlich begrenzt.

$$
\mathrm{D}=11, \mathrm{~d}=9, \mathrm{H}=8.5 \mathrm{~mm} \text {. }
$$

Deckel abgerundet dreieckig mit leicht S-förmig gebogenem Spindelrand, beiderseits lebhaft rotbraun mit lichterem Spindelrand. Die ziemlich dünne, gekörnelte Kalkplatte ist am Spindelrand leistenartig erhoben, der Spindelwinkel deutlich nach rückwärts gebogen; in den übrigen Verhältnissen typisch.

Fundort: die Insel Guadalcanar der Salomonen. 


\title{
362. Pala eohelicina spinifera inflata A. J. Wagner.
}

Taf. 47, Fig. 17-18.

Palaeohelicina spinifera inflata A. J. Wagner Helicinenstudien II in Denk. Akad. Wien. จ. 78, p. 206, T. 10, F. 6,190 .

Gehăuse grösser, festschaliger mit verhältnismässig niedrigerem Gewinde, mehr gewölbten, rascher zunehmenden Umgången und schwăcheren Spiralreifen. Der letzte Umgang nur kantig bis gerundet, vorne wenig, aber deutlich herabsteigend; die Ecke am unteren Ende der Spindel stumpfer und weniger vorspringend, der Mundsaum dicker und mehr ausgebreitet.

$$
\mathrm{D}=13, \mathrm{~d}=10, \mathrm{H}=9.5 \mathrm{~mm} \text {. }
$$

Deckel wie bei der typischen Form.

Fundort: Neu-Irland; eine auffallend übereinstimmende, nur etwas kleinere Form erhielt ich ferner von den Herrn Sowerby und Fulton mit der Fundortsangabe "Insel Isabel" der Salomonen.

\author{
363. Pala ohelicina e gregia Pfeiffer. \\ Taf. 47, Fig. 19--22. \\ Holicina egregia Pfeiffer Pr. Z. S. p. 118, 1855. \\ " $\quad$ Mon. Pneum., II, p. 195, 1858. \\ $\pi \quad$ Sowerby, Thes. III p. 288, T 272, F. 272, 1866. \\ Palaeohelicina spinifera egregia A. J. Wagner Helicinenstudien II. in Dent. Akad. \\ Wien, r. 78, p. 206, T. 10, F. 4, 1905.
}

Gehăuse breitkegelförmig mit halbkugeliger Basis, ziemlich dünnschalig; im frischen Zustande matt mit dichten und feinen Spiralfalten der hinfälligen Epidermis, abgerieben glänzend mit sehr feinen bis undeutlichen, eingedrückten Spirallinien. Die Grundfarbe gelb mit lichterem letzten Umgang; einfärbig oder mit einem scharf begrenzten rotbraunen Bande unter der Peripherie des letzten Umganges und einer bräunlichen Zone auf der Oberseite. Das ziemlich niedrige, breitkegeltörmige Gewinde besteht aus $4^{1} / 2$ gewölbten, ziemlich rasch zunehmenden Umgängen; der letzte etwas aufgeblasen, gerundet oder undeutlich kantig, vorne langsam und sehr wenig herabsteigend Die abgerundet dreieckige Mündung ist wenig schief, innen gelb mit durchscheinenden Bändern; der weisse, lippenartig verdickte Mundsaum ausgebreitet und umgeschlagen; der Oberrand vor der Insertion etwas konvex vorgezogen, der Basalrand beim Uebergange in die Spindel seicht konkav eingebuchtet. Die kurze, abgerundete Spindel ist etwas nach vorne gebogen und lauft in eine scharf vorspringende, etwas abgerundete Ecke aus. Der glänzende, gelbe Basalkallus ist fein gekörnelt und undeutlich begrenzt.
I. 18. II.
18. IV. 1909. 
Deckel wie bei Palaeohelicina spinifera Pfeiffer.

$$
\mathrm{D}=11, \mathrm{~d}=9, \mathrm{H}=8 \mathrm{~mm} \text {. }
$$

Fundort: die Insel Guadalcanar der Salomonen.

Diese Art ist der P. spinifera Pfeiffer sehr nahe verwandt und von derselben durch geringe, aber anscheinend konstante Merkmale unterschieden. Abgesehen von der schwachen bis undeutlichen Spiralskulptur ist die Bänderung, wenn vorhanden, sehr charakteristisch. Das scharfbegrenzte Band tritt hier immer unter der Peripherie auf, während es bei der vorigen Art stets über dem Kiele beobachtet wird. Zickzackstriemen und Fleckenbander treten hier niemals auf, dafür verdichtet sich die dunklere Zone der Oberseite bei einzelnen Formen zu einer breiten, ziemlich scharf begrenzten, aber lichteren Binde über dem Kiele und der Naht der unteren Umgänge; daneben ist dann stets auch das untere scharf begrenzte schmale Band vorhanden, welches bei P. spinifera Pfeiffer imıner fehlt; schliesslich mache ich noch auf die charakteristische Beschaffenheit des Mundsaumes an seinen Insertionen aufmerksam. Diese Art scheint besonders mit Rücksicht auf die Höhe des Gewindes, die mehr minder deutliche Wölbung der Umgänge, die mitunter deutlichere Kante des letzten Umganges und die mehr minder deutliche Spiralskulptur sehr veränderlich zu sein; dementsprechend sind mehrere, zum Teil recht auffallend unterschiedene Lokalformen bekannt geworden.

\title{
364. Palaeohelicina egregia isabelensis A. J. Wagner.
}

Taf. 48, Fig. 1-2.

\author{
Palaeohelicina pinifera isabelensis A. J. Wagner Helicinenstudien II, in: Denk. \\ Akad. Wien, v. 78 , p. 207, T. 10, F. 5, 1905.
}

Gehäuse lebhafter gefärbt; die Grundfarbe orange mit lichterem, rötlichgelbem letzten Umgang, hellem Kielstreifen und lebhaft rotbraunem Bande unter dem Kiel; auch die bräunliche Zone auf der Oberseite des letzten Umganges ist hier hăufiger und deutlicher, wie bei der typischen Form von Guadalcanar. Das Gewinde höher mit $4 \frac{1}{2}-5$ schwächer gewölbten bis nahezu flachen, langsamer zunehmenden Umgängen; der letzte in der ersten Hälfte regelmässig stumpfkantig, mitunter nahezu stumpfgekielt. Die eingedrückten Spirallinien unter der hinfälligen Epidermis sind hier deutlicher.

$$
\mathrm{D}=9-11, \mathrm{~d}=7 \cdot 5-9, \mathrm{H} 7-9 \mathrm{~mm} \text {. }
$$

Deckel wie bei der typischen Form.

Fundort: die Insel Isabel der Salomonen.

Diese Form entspricht mit Rücksicht auf die Beschaffenheit des Gewindes und die Färbung mehr der Beschreibung Peiffers, doch wird ausdrücklich die Form von Guadal canar als typisch angeführt; schliesslich spricht Pfeiffer von einem gerundeten letzten Umgang, während hier regelmässig eine Kante beobachtet wird. 
365. Palaeohelicina egregia incerta $n$.

Taf. 47, Fig. 23-24.

Gehäuse kleiner, dünnschaliger mit weitläufigeren Spiralfalten der Epidermis; die eingedrückten Spirallinien abgeriebener Exemplare sind sehr schwach bis undeutlich. Die Grundfarbe hellgelb mit einem schmalen braunen Bande unter der Peripherie des letzten Umganges und einem breiten, braunen bis rotbraunen Bande über der Peripherie und der Naht der oberen Umgănge; dieses Band verdeckt die Grundfarbe auf den oberen Ümgăngen hăufigg vollkommen, auf den 2 letzten Umgängen bleiben nür 2 schmale, lichte bis weisse Streifen an der Peripherie und Naht frei. Das erhobene kegelförmige bis spitzkegelförmige Gewinde besteht aus $41 / 2$ leicht gewölbten langsamer zunehmenden Umgängen; der letzte ist beiderseits flacher gewölbt, im Beginne deutlich kantig, gegen die Mündung zu gerundet und steigt vorne wenig, aber deutlich unter die Kante herab. Der schwach verdickte Mundsaum kurz ausgebreitet, die Ecke am unteren Ende der Spindel weniger scharf vorspringend.

Deckel wie bei der typischen Form.

$$
\mathrm{D}=8 \cdot 5, \mathrm{~d}=7, \mathrm{H}=7 \cdot 5 \text {. }
$$

Fundort: die Insel Isabel der Salomonen.

366. Palaeohelicina solitaria Edg. A. Smith.

Taf. 48, Fig. 3-5.

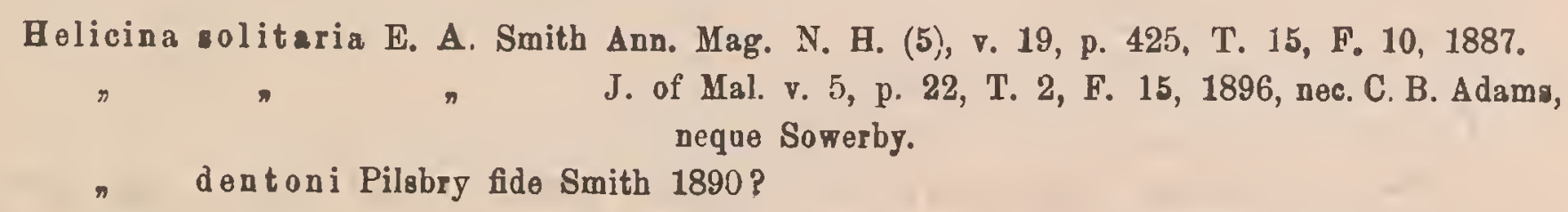

Gehäuse kegelförnig mit gewölbter Basis, ziemlich festschalig, wenig glänzend mit schwachen bis undeutlichen Zuwachsstreifen, sowı undeutlichen bis nahezu erloschenen Spirallinien; einfärbig gelbweiss, milchig getrübt mit durchscheinenden Flecken, hăufig mit zwei unterbrochenen, rötlichen Zonen über und unter der Peripherie des letzten Umganges. Das regelmässig kegelförmige Gewinde besteht aus 4 kaum gewölbten, regelmăssig zunehmenden Umgängen; der letzte ist fadenförmig gekielt und steigt vorne sehr wenig herab. Die abgerundet dreieckige Mündung ist wenig schief, innen rotbraun; der hellgelbe Mundsaum leicht verdickt, ziemlich kurz ausgebreitet und umgeschlagen. Die kurze, abgerundete Spindel ist nach aussen gebogen; am Uebergange derselben in den Basalrand eine winkelige, deutlich vorspringende Ecke. Der ziemlich dicke, weissliche Basalkallus ist deutlich begrenzt.

$$
\mathrm{D}=8-10, \mathrm{~d}=7-8 \cdot 5, \mathrm{H}=7-8 \mathrm{~mm} \text {. }
$$


Deckel annăhernd halbkreisförmig mit schwach gebogenem Spindelrand, ziemlich dicker weiser Kalkplatte, lebhaft rotbrauner Hornplatte; in den übrigen Verhalltnissen typisch.

Fundort: Mont Astrolabe in Brisch Neu-Guinea.

\title{
Formenkreis Rhabdokonia A. J. Wagner.
}

\section{Palaeohelicina fischeriana Montrouzier.}

Taf. 48, Fig. 6-9.

\author{
Helieina fischeriana Montrouzier, J. de Conch. $\nabla, 11, T .5$, F. 3, p. 76, 1863. \\ Pfeiffer, Mon. Pnenm. III. p. 241, 1865.
}

Palaeohelicina fischeriana A. J. Wagner Belicinenstudien in: Denk. Akad. Wien, v. 77, p. 435, T. 9, F. 10. 12,1905 .

Gehăuse flachkegelförmig mit gewölbter Basis, festschalig, leicht glänzend mit schwachen bis undeutlichen Zuwachsstreifen, sowie niedrigen, aber deutlichen Spiralreifen, welche aut der Oberseite ungleichmăssig und ziemlich weitläufig (6-7 auf dem letzten Umgang), unter dem Kiele dichter sind; die Grundfarbe gelb bis rot orange mit weissen und rotbraunen Zickzackstriemen, welche häufig in unregelmässige Streifen und Flecken aufgelöst sind, an der Naht und dem Kiel deutlicher hervortreten. Das regelmassig breit bis flachkegelförmige Gewinde besteht aus $5 \frac{1}{2}$ flachen, regelmässig zunehmenden Umgängen; nur der letzte nimmt etwas rascher zu, ist an der Peripherie scharf und zusammengedrückt gekielt und steigt vorne nicht herab. Die dreieckige Mündung ist schief, innen gelb oder rotbraun mit durchscheinenden dunklen Flecken und Bändern. Der weisse, leicht verdickte Mundsaum ausgebreitet; der Oberrand an der Insertion vorgezogen und fast gerade, der Basalrand umgeschlagen, gegen die Insertion zu verschmälert und schwach konkav eingebuchtet. Die kurze Spindel ist nach aussen gebogen, am Uebergange in den Basalrand eine abgerundete, wenig vorspringende Ecke. Der Basalkallus sehr dünn, mit dem Gehäuse gleichfarbig, leicht glänzend und undeutlich begrenzt

$$
\mathrm{D}=17, \mathrm{~d}=14, \mathrm{H}=11 \mathrm{~mm} \text {. }
$$

Deckel dreieckig mit geradem Spindelrand und schwach nach rückwärts gebogenem Spindelwinkel. Die feste, weisse und feingekörnelte Kalkplatte ist flach konkav, am Spindelrande nur schwach wallartig erhoben, die Hornplatte gelbbraun; in den übrigen Verhältnissen typisch.

Fundort: die Insel Woodlark östlich von Neu-Guinea. 
368. Palaeohelicina fischeriana congener E. A. Smith. Taf. 48, Fig. 10.

\author{
Helicina congener E. A. Smith, Ann. Mag. N. H. (6), จ. 4, p. 203, T. 13, F. 17. \\ Palaeohelicina fischeriana congener A. J. Wagner Helicinenstudien, in: Denk. Akalo \\ Wien. จ. 77 , p. 436,1905
}

Gehäuse grösser mit kräftigeren und dichteren Spiralreifen (10 auf der Oberseite des letzten Umganges); die oberen Umgänge deutlicher gewölbt, der letzte rascher zunehmend, mehr zusammengedrückt, nahezu doppelt so breit wie der vorletzte.

$$
\mathrm{D}=20, \mathrm{~d}=17, \mathrm{H}=13 \mathrm{~mm} \text {. }
$$

Deckel mit rotbrauner Hornplatte, sonst wie bei der typischen Form.

Fundort: die Insel St. Aignan der Lousiaden.

\title{
369. Palaeohelicina fischeriana phronema A. J. Wagner. Taf. 48, Fig. 11-12.
}

\author{
Palaeobelicina fischeriana phronema $\mathbf{A}$, Wagner Helicinenstadien in Denk. Akad. \\ Wien, vol 77, p. 436, T. 9 F. $11,1905$.
}

Gehäuse grösser, glanzlos, einfärbiug schmutziggelb oder braungelb, häufig mit schmalen, dichten, hellbraunen Zickzackstriemen; an Kiel und Naht findet sich ausserdem oft ein schmales braun und gelb gegliedertes Band als Ausdruck von sonst erloschenen Zickzackstriemen. Die deutlich gewölbten Umgänge nehmeu etwas rascher zu, der letzte ist weniger zusammengedrückt, beiderseits leicht gewölbt und auffallend stumpfer gekielt. Der Ausschnitt am Uebergange des Basalrandes in die Spindel ist sehr seicht bis undeutlich; der in der Mitte weisse Basalkallus deutlich gekörnelt. Die Spiralreifen gleichmässig und dichter (10-12 auf der Oberseite des letzten Unganges).

$$
\mathrm{D}=20, \mathrm{~d}=18, \mathrm{H}=14 \mathrm{~mm} \text {. }
$$

Deckel mit dicker weisser Kalkplatte und lebhaft rotbrauner Hornplatte, sonst wie bei der typischen Form von der Insel Woodlark.

Fundort: die Insel Fergusson.

\section{Palaeohelicina fischeriana elegans n.} Taf. 48, Fig. 13.

Gehäuse dünnschaliger, einfärbig gelb bis braunorange, matt mit dichten, gleichmässigen Spiralreifen (10-12 auf der Oberseite des letzten Umganges). Das höhere, regelmåssig 
kegelförmige Gewinde besteht aus 5 leicht gewölhten, langsamer zunehmenden Umgangen; der letzte ist scharf und zusammengedrückt gekielt. Der Ausschnitt am Uebergange des. Basalrandes in die Spindel, ebenso die abgerundete Ecke am unteren Ende der Spindel sind. deutlich; der in der Mitte weisse, dünne Basalkallus gekörnelt.

$$
\mathrm{D}=17, \mathrm{~d}=14, \mathrm{H}=12 \mathrm{~mm} \text {. }
$$
typisch.

Deckel beiderseits rotbraun mit gelblichem Spindelrand, in den übrigen Verhältnissen

Fundort: die Insel Fergusson.

Diese Form verdanke ich den Herrn Sowerby und Fulton, welche mich stets mit interessantem Studienmaterial versorgen. Auf den ersten Anblick zeigt diese Form einige Aehnlichkeit mit P. fischeriana phronema $\mathrm{m}$., welche ebenfalls von deI Inse! Fergusson stammt; P. fischeriana elegans $m$. ist jedoch kleiner, stets einfärbig, besitzt ein höheres, regelmässig kegelförmiges Gewinde, langsamer zunehmende Umgänge und einen auffallend schärferen Kiel; auffallend ist auch die deutliche Einbuchtung am Uebergange des Basalrandes in die Spindel, welche bei $\mathrm{P}$. fischeriana phronema $\mathrm{m}$. nahezu fehlt.

\title{
371. Pala o ohelicina insularum Hedley.
}

Taf. 48, Fig. 14-18.

\author{
Helicina insularum Hedley, Proe. Linnean Soc. of New-Sonth. Wales, 2. ser. vol. 6, m. 113. \\ T. 12, F. 44, 1891. \\ Palaobhelicina fischeriana lampra A. J. Wagner Helicinenstudien in: Denk. Arad. \\ Wien, จ. 77, p. 436, 1905.
}

Gehăuse dicklinsenförmig, festschalig, matt mit ungleichmässigen, sehr feinen bis undeutlichen Zuwachsstreifen, sowie dichten, ziemlich erhobenen Spiralreiten (10-12 auf der Oberseite des letzten Umganges), welche unterhalb des Kieles dichter, aber nicht schwächer werden; die Grundfarbe hellgelb mit weisser Spitze; hăufig ist auch ein ziemlich scharf begrenztes rotbraunes Band auf der Oberseite der unteren Umgänge vorhanden. Das breitkegelförmige, mitunter etwas abgerundete Gewinde besteht aus $4^{1} \frac{1}{2}$ leicht gewölbten, ziemlich rasch zunehmenden Umgången; der letzte ist beiderseits gleichmåssig gewölbt, ziemlich scharf gekielt und steigt vorne nicht herab. Die abgerundet dreieckige Mündung ist wenig . schief, iunen citrongelb; der weisse, leicht verdickte Mundsaum ausgebreitet; der Oberrand an der Insertion wenig vorgezogen, fast gerade, der Aussenrand umgeschlagen, der Basalrand gegen die Insertion zu verschmälert, am Uebergange in die Spindel deutlich eingebuchtet. Die kurze, abgerundete Spindel ist nach aussen gebogen und bildet am Uebergange in den Basalrand eine deutlich vorspringende, etwas abgerundete Ecke. Der citrongelbe, gekörnelte Basalkallus ist sehr dünn und undeutlich begrenzt.

$$
\mathrm{D}=14, \mathrm{~d}=11, \mathrm{H}=9-10 \mathrm{~mm} \text {. }
$$


Deckel dreieckig mit geradem Spindelrand. Die dicke, gekörnelte Kalkplatte ist rotviolett, die Verdickung des Spindelrandes gering, der Spindelwinkel schwach nach rückwärts gebogen; die Hornplatte roturaun; in den übrigen Verbältnissen typisch.

Fundort: die Insel Sudest oder Tagula der Louisiaden.

\section{Palae ohelicina coxeni Brazier.}

Taf. 49, Fig. 1-4.

Helicina coresi Brazier, Pr. Linn. Soc. N. S. Wales, I, p. 111, 1876.

Palaeohelicina coxeni A. J. Wagner Helicinenstadien in: Denk. Akad. Wien. v. 77, p.439, T. 9 , F. 19,1905 .

Gehäuse breitkegelförmig mit gewölbter Basis, festschalig, wenig glänzend oder matt; graugelb oder hellrotbraun mit lichteren und dunkleren Flecken, welche zu undeutlichen Radialstriemen angeordwet sind, an einzelnen Exemplaren auch zickzackförmig verlaufen. Die skulptur besteht neben schwachen ungleichmässigen Zuwachsstreifen aus dichten und feinen Spiralreifen, welche auf der Unterseite noch dichter werden, am ersten Umgange nach der Embryonalwindung jedoch verhältnismassig kräftiger und weitläufiger erscheinen. Das ziemlich erhobene, schwach konvexe Gewinde besteht aus $4 \frac{1}{2}$ ziemlich langsam zunehmenden Umะängen; die oberen sind leicht gewölbt nnd werden dnrch eine deutlich eingedrückte Naht geschieden, die 2 letzten nahezu flach mit seichter Naht; der letzte beiderseits gleichmässig gewölbt, an der Peripherie stumpf gekielt, vorne wenig, aber deutlich unter den Kiel herabsteigend. Die abyerundet dreieckige Mündurg ist schief, innen gelbbraun oder rotbraun, der weisse, leicht verdickte Mundsaum sehr kurz ausgebreitet; die kurze, abgerundete Spindel ist nach vorn und aussen gebogen, am Uebergange in den Basalrand der Mündung eine winkelige, deutlich vorspringende Ecke. Der in der Mitte weisse, feingeliörnelte Basalkallus ist an seinen Rändern durchsichtì und und undeutlich begrenzt.

$$
\mathrm{D}=12, \mathrm{~d}=10 \cdot 5, \mathrm{H}=9 \mathrm{~mm} \text {. }
$$

Deckel abgerundet dreieckig mit gelblicher, gekörnelter Kalkplatte, welche am Spindelrande kräftiger verdickt unil wallartig erhoben ist; die Hornplatte dunkel rotbraun mit gelbem Nukleus und Spindelrand; die übrigen Verhältnısse typisch.

Fundort: die Yule-Insel und angeblich auch Neu-Guinea.

373. Palaeohelicina filiae A. J. Wagner.

Tuf 49, Fig. $5-8$.

Palaeohelicina filiae A J. Wagner Helieinenstudien in: Denk. Akad. Wien, т. 77, p. 439, T. 9, F. 141905. 
Gehăuse breitkegelförmig mit gewölbter Basis, festschalig, leicht glänzend oder matt, gelbrot oder lachsrot mit undeutlichen. lichteren Striemen. Die Skulptur besteht nebst.sehr schwachen und ungleichmässigen Zuwachsstreifen aus dichten, feinen und niedrigen Spiralreifen, welche auf der Unterseite' noch dichter werden. Das ziemlich erhobene schwach konvexe Gewinde besteht aus $4^{1} / 2$ nahezu flachen, ziemlich langsam zunehmenden Umgängen; der letzte ist unten mehr gewölbt. an der Peripherie scharf gekielt und steigt vorne sehr wenig oder gar nicht herab. Die abgerundet drieckige Mündung ist schief, innen lebhaft. gelbbraun, der gelbliche Mundsaum leicht verdickt, kurz ausgebreitet, auch aussen von einer helleren, oder gelben Zone eingefasst; der Aussenrand entsprechend dem Kiele schwach winkelig vorgezogen, der konkave Basalrand umgeschlagen. Die kurze, abgerundete Spindel ist nach aussen und vorne gebogen, am Uebergange in den Basalrand eine winkelige, scharf vorspringende Ecke. Der gelbe, gekörnelte Basalkallus ist nur in der Mitte stärker verdickt, an den Rändern undeutlich begrenzt.

$$
D=12, d=10, H=8 \mathrm{~mm} .
$$

Deckel abgerundet drejeckig mit dünner, krustenartiger Kalkplatte, rotbrauner, nur am Nukleus und Spindelrande gelbbrauner Hornplatte; in den übrigen Verhältnissen typisch.

Fundort: die Louisiaden.

Von P. coxeni Brazier unterscheidet sich diese Art durch die Färbung, die flachen, rascher zunehmenden Umgăng, die weitläufigeren Spirałreifen, den scharfen Kiel und die dünne Kalkplatte des Deckels.

\section{Palaeohelicina ruffocallosa Sykes.}

Taf. 49, Fig. $9-12$.

Helicina raffocallos a E. R. Sykes, Proc. of the Malac. Soc. 4, p. 260. 1901.

Palaeohelicina ruffocallosa A. J. Wagner Helicinenstadien in Denk. Akad. Wien, v. 77, p. 437 , T. 9 , F. $16,1905$.

Gehăuse flachkegelförmiı mit flach gewölbter Basis, glänzend, festschalig; weiss mit violettem Anflug oder violettbraun mit milchiger Trübung; häufig mit einer violettbraunen, mehr minder verwaschenen Binde über der Naht und dem Kiel. Die Skulptur besteht nebst schwachen, ungleichmässigen Zuwachsstreifen aus niellrigen, ziemlich dichten Spiralreifen, welche auf der Oberseite des letzten Umganges weitläufiger und schwächer werden. Das leicht konvexe Gewinde besteht aus $4^{1} / 2$ nahezu flachen, ziemlich $r$ ssch zunehmenden Umgängen; der letzte ist oben deutlicher gewölbt, an der Peripherie scharf und zusammengedrückt gekielt und steigt vorne nicht herab. Die dreieckige Mündung ist schief, breiter als hoch, innen lebhaft. rotbraun, der weisse, leicht verdickte Mundsaum ausgebreitet; der Oberrand an der Insertion: vorgezogen, fast gerade, der Aussenrand entsprechend dem Kiele etwas winkelig ausgezogen, der Basalrand umgeschlagen. Die abgerundete, ziemlich kurze Spindel ist etwas nach aussen. 
und vorn gebogen, am Uebergange in den Basalrand der Mündung eine stumpfwinkelige, ziemlich vorspringende Ecke. Der gekörnelte, ziemlich dicke Basalkallus ist zumeist lebhaft rotbraun gefärbt und deutlich begrenzt.

$$
\mathrm{D}=9 \cdot 11, \mathrm{~d}=7 \cdot 5-9, \mathrm{H}=5-6 \cdot 5 \mathrm{~mm} \text {. }
$$

Deckel dreieckig, beiderseits gelbbraun bis rotbraun gefärbt; die ziemlich dicke, feingekörnelte Kalkplatte ist am Spindelrande leistenartig erhoben und daselbst durch eine Furche von der Hornplatte abgesetzt; die übrigen Verhältnisse typisch.

Fundort: Pililu der Palau-Inseln.

Vorstehende Art wird häufig mit der im Habitus åhnlichen, ebenfalls auf Pililiu lebenden Aphanoconia heterochroa m. verwechselt; sie unterscheidet sich von der genannten Art abgesehen von der Färbung, welche namentlich mit Rücksicht auf den Basalkallus nicht ganz konstant ist (einzelne Exemplare besitzen einen weissen oder nur an den Rändern rötlichen Basalkallus) durch das konvexe Gewinde, die schwächere und weitläufigere Spiralskulptur, den weniger ausgebreiteten, schmăler umgeschlagenen Mundsaum, die weniger gebogene Spindel und die auffallend stumpfere und weniger vorspringende Ecke am Uebergange der Spindel in den Basalrand der Mündung. Der Deckel der vorstehenden Art weist schliesslich die Merkmale des Genus Palaeohelicina, jener die des Genus Aphanoconia genügend charakteristisch auf.

\author{
375. Pala eohelicina hara A. J. Wagner. \\ Taf. 49 , Fig. 13-15. \\ Palaeohelicina hara A. J. Wagner Helicinenstudien in: Denk, Akad. Wien. v. 78, p. 204, \\ T. 10, F. $18,1905$.
}

Gehäuse breit kegelförmig mit gewölbter Basis, festschalig, leicht glänzend; die Grundfarbe gelbweiss oder hellzitrongelb mit gelber Spitze und einem rotbraunen, ziemlich scharf begrenzten Bande über der Naht und dem Kiel; der letzte Umgang häufig violettbraun angelaufen. Die Skulptur besteht nebst schwachen und ungleichmässigen Zuwachsstreifen aus niedrigen, dichten und feinen Spiralreifen, welche auf der Ober- und Unterseite gleichmässig entwickelt sind. Das ziemlich erhobene, regeluăssig kegelförmige Gewinde besteht aus $4^{1} / 2$ leicht gewölbten, ziemlich rasch zunehmenden Umgången; der letzte ist beiderseits gleichmässig gewölbt, an der Peripherie scharf gekielt und steigt vorne nicht herab. Die dreieckige Mündung ist wenig schief, der Gaumen gelb oder rotbraun; der gelbliche, leicht verdickte Mundsaum ziemlich ausgebreitet; der Aussenrand entsprechend dem Kiele winkelig ausgezogen, der Basalrand umgeschlagen. Die etwas abgeflachte Spindel leicht nach aussen gebogen, am Uebergange derselben in den Basalrand der Mündung eine abgerundete wenig vorspringende Ecke. Der gelbe, gekörnelte Basalkallus ist ziemlich dünn, deutlich begrenzt.

I. 18. II.

$$
\mathrm{D}=8 \cdot \bar{n}-9, \mathrm{~d}=6.5-7, \mathrm{H}=6 \mathrm{~mm} \text {. }
$$


Deckel unbekannt.

Fundort: Britisch Neu-Guinea; mitgeteilt von Sowerby und Fulton.

Von den ähnlichen Formen der Palaeohelicina stanleyi Forbes (- asphaleia A. J. Wagner, - sinus Hedley, - rosselensis Hedley) unterscheidet sich vorstehende Art durch das höhere, regelmässig kegelförmige nicht konvexe Gewinde, die deutlich gewöibten, rascher zunehmenden Ungänge, den breiteren und entsprechend dem Kiele winkelig vorgezogenem Mundsaum und die nahezu senkrechte Spindel, welche am Uebergange in den Basalrand der Mündung nur eine schwach vorspringende Ecke bildet.

\author{
376. Palae ohelicina stanleyi Forbes. \\ Taf. 49, Fig. 16-20. \\ Helicina stanleyi Forbes, Voy. Rattlesnake, Append, p. 381, T. 3, F. 4, 1851. \\ $\rightarrow \quad$ Pfeiffer Mon. Pneurn. I p. 401, 1852. \\ Palaeohelicina stanleyi A. J. Wagner Helicinenstadien in: Denk. Akad. Wien. vol. 77, \\ p. 438, T. 9, F. $17,1905$.
}

Gehäuse breit kegelförmig, mit gewölbter Basis, festschalig, leicht glänzend, schmutzig hellgelb, hellgelbbraun oder rötlich, einfarbig oder mit einem rotbraunen, mehr minder scharf begrenzten Bande über der Naht und dem Kiel. Die Skulptur besteht aus ziemlich dichten, verhältnismässig lirättigen Spiralreifen, welche auf der Unterseite auffallend dichter und schwächer werden; die Zuwachsstreifen schwach bis undeutlich. Das ziemlich erhobene, leicht konvexe Gewinde besteht aus $4^{1} / 2$ kaum gewölbten bis flachen, regelmässig zunehmenden Umgängen; der letzte ist beiderseits gleichmässig gewölbt, scharf gekielt uud steigt vorne nicht herab. Die dreieckige, ziemlich schiefe Mündung ist kaum breiter als hoch, inuen gelb; der weisse, leicht verdickte Mundsaum kurz. ausgebreitet; der Aussenrand entsprechend dem Kiele wenig ausgezogen, der Basalrand kaum umgeschlagen Die kurze, abgerundete Spindel ist nach vorne und aussen gebogen, am Uebergange derselben in den Basalrand der Mündung eine deutliche, winkelig vorspringende Ecke. Der ziemlich dünne, gelbliche Basalkallus ist undeutlich begrenzt.

$$
\mathrm{D}=6 \cdot 5-7 \cdot 5, \mathrm{~d}=5 \cdot 5-6 \cdot 5, \mathrm{H}=45-5 \mathrm{~mm}
$$

Deckel dreieckig, Alachkonkav, mit dünner, krustenartiger Kalkplatte, welche auch am Spindelrande nicht wesentlich verdickt ist. Die Llurnplatte gelbbraun, mit undeutlicher, gestreckter Sigmakante und sehr schmalem Spindelteil der Platte; in den übrigen Verhältnissen typisch.

Fundorte: die Louisiaden und die benachbarten Küstengebiete von Neu-Guinea (nneine Exemplare sind mit den Fundortsangaben "Mailu" und "Lorne Range" in Britisch Neu-Guinea versehen. 


\title{
377. Palaeohelicina stanleyi sinus Hedley.
}

Taf. 49 , Fig. $21-22$.

Helicina insularum var, sin ns Hedley, in: Proc. Lin. Soc. N. S. Wales, v. 6, p. 113, T. 12, F. 45, 1891 .

Gehäuse einfärbig oder gebändert, wie die typische Form; das Gewinde konstant niedriger mit $4-4 \frac{1}{2}$ rascher zunehmenden Umgăngen, der Mundsaum mehr ausgebreitet und deutlich umgeschlagen.

Deckel wie bei der typischen Form.

$$
\mathrm{D}=8, \mathrm{~d}=7, \mathrm{H}=4.5 \mathrm{~mm} .
$$

Fundort: Neu-Guinea; Village of Mita, Milne Bay, Village of Polatona, Bentley Bay.

\author{
378. Palaeohelicina stanleyi rosselensis Hedley. \\ Taf 50, Fig. $2-3$. \\ Helicina insularum var. rosselensis Hedloy, in Proc. Lin. Soc. N. S. Wales r. 6, p. 114, \\ 1891.
}

Eas Gehäuse durchschnittlich grösser mit höherem, mehr konvexem Gewinde und deutlicher gewölbten, langsamer zunehmenden Umgängen; die Spirallinien etwas weitläufiger, die Färbung lebhatter; die oberen Umgänge gelb, die 2 letzten hellfleischfarben mit innen orangefarbener Mündung und zitrongelbem Basalkallus. Die Spindel mehr gebogen, die Ecke am Uebergange derselben in den Basalrand der Mündung deutlicher vorspringend.

$$
\mathrm{D}=10.5, \mathrm{~d}=8.5, \mathrm{H}=7 \mathrm{~mm} \text {. }
$$

Deckel wie bei der typischen Form.

Fundort: die Insel Rossel.

Ich beurteile die beiden vorangeführten Formen nach Exemplaren von den Originalfundorten und finde keine nähere Verwandtschaft mit Palaeohelicina insularum Hedley; diese Art weist neben den auffallend verschiedenen Dimensionen stets ein regelmässig kegelförmiges Gewinde, eine kurze, nahezu senkrechte Spindel, welche am Uebergange in den Basalrand der Müudung nur eine undeutliche, abgerundete Ecke bildet, sowie einen stark abweichenden Deckel mit dicker Kalkplatte auf, wie er besonders für die Formenreihe der Palaeohelicina fischeriana Montrouzier charakteristisch ist. Die Formen aus der Reihe der Palaeohelicina stanleyi Forbes besitzen dagegen einen Deckel mit dünner, krustenartiger Kalkplatte, undentlicher, gestreckter Sigmakante, sehr schmalem Spindelteil der Platte, entsprechen diesbezüglich also nahezu den Verhältnissen, welche für das unten angeführte Subgenus Ceratopoma Möllendorff charakteristisch sind; nur die Form und Skulptur der Schale veranlasst mich diese Formen als Uebergangsglieder noch der vorstehenden Gruppe anzureihen. 


\section{Palaeohelicina stanlei asphaleia A. J.: Wagner.}

Taf. 50, Fig. 1.

Palaeoholicina tanleji asphaloia A. J. Wagner, Helicinenstudien, in: Denk. Akad, Wien, v. 77, p. 438, T. 9, F. 18, 1905.

Gehăuse konstant grösser, zitrongelb bis hellgelbbraun. mit einem schmalen, zumeist lebhaften und scharf begrenzten, rotbraunen Bande über der Naht und dem Kiel. Das niedrigere Gewinde besteht aus 4 flachen, rascher zunehmenden Umgängen; der letzte Umgang mehr zusammengedrückt und schärfer gekielt; đie Spiralreifen auf der Oberseite dichter und feiner.

Deckel wie bei der typischen Form.

$$
\mathrm{D}=8 \cdot 5-10, \mathrm{~d}=7-8.5, \mathrm{H}=5-6 \mathrm{~mm} \text {. }
$$

Fundorte: Nelı-Pommern und Neu-Mecklenburg.

\section{Subgenus Ceratopoma Möllendorff.}

Ceratopoma (Sectio) Möllendorff in Ber. Senckenb. Ges. p. 139, 1893.

Gehäuse mit schwacher, zumeist nur aus feinen Zuwachsstreifen bestehender Skulptur, doch weist der erste Umgang nach der Embryonalwindung konstant einige deutliche Spiralreifen auf; daneben sind mitunter feine bis undeutliche Spirallinien auch auf den unteren Umgängen vorhanden.

Deckel mit vollkommen randständigem Nukleus und gestreckter, undeutlicher Sigmakante; der Spindelteil der Platte besteht nur aus einem schmalen, oft undeutlichen Hautsaum. Die Kalkplatte krustenartig dünn und zerbrechlich, so dass bäufig nur die Hornplatte zur Beobachtung gelangt (Ceratopoma!) - .

Das Verbreitungsgebiet der hier zusammengefassten Formen erstreckt sich über die Philippinen, Molukken, die Neuen Hebriden, Neu=Caledonien und den Nordosten von Australien.

\section{Formenkreis Contermina.}

380. Palaeohelicina (Ceratopoma) caroli Kobelt.

Taf. 50, Fig. 9-12.

Helicina caroli Kobelt, Landd. Philipp. p. 70, T. 7, F. 26-27, 1884.

n $\quad$ Möllendorff, Bor. Senckenb. G. p. 139, 1893. 
Palaeobelicina (Ceratopoma) caroli A. J. Wagner Helicinentudien in Dent. Arad. Wien .. 78, T. 10, F. 7, p. 207, 1905.

Gehäuse linsenförmig, unten auffallend flacher, festschalig, underchsichtig, matt; grauweiss oder hellgelb mit einem violetten Anflug am letzten Umgang und der Umgebung der Mündung. Die Skulptur besteht aus feinen, schiefen, etwas ungleichmässigen Zuwachsstreifen, welche nach dem Kiel und vor der Mündung deutlicher werden. Die Embryonalschale fein gekörnelt, der erste Umgang nach dieser weist einige feine Spiralreifen auf. Das breit kegelförmige Gewinde besteht aus $4 \frac{1}{2}$ ziemlich flachen, regelmässig zunehmenden Umgängen; der letzte nimmt etwas rascher zu, ist oben leicht konvex, mit scharfem, zusammengedrücktem, leicht gesägtem Kiel und steigt vorne nicht herab. Die sehr schiefe Mündung ist dreieckig, innen lebhaft kastanienbraun gefärbt. Der gelbliche Mundsaum erweitert und lippenartig verdickt; der Oberrand an der Insertion vorgezogen, fast gerade, der Basalrand umgeschlagen. Die sehr kurze Spindel ist abgerundet und nach aussen gebogen, am Uebergange in den Basalrand der Mündung flndet sich eine wenig vorspringende knotenartige Verdickung. Der glänzende, dünne Basalkallus ist in der Mitte lebhaft kastanienbraun gefärbt, an den Rändern undeutlich begrenzt.

$$
\mathrm{D}=15, \mathrm{~d}=12, \mathrm{H}=9 \mathrm{~mm} \text {. }
$$

Deckel abgerundet dreieckig, durchsichtig gelbbraun, in den übrigen Verhältnissen typisch.

Fundort: die Philippinen; die mir vorliegenden Exemplare von Siargao.

\section{Pala eohelicina (Cerat opoma) caroli emaculata Möllendorff.} Taf. 50, Fig. 13 .

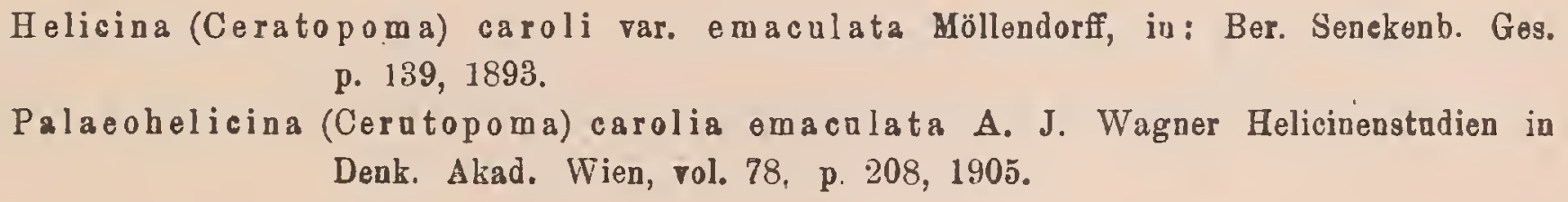

Gehäuse dünnschaliger, zitrongelb bis hellorange mit weissem reifartigen Anflug und schwächeren Zuwachsstreifen. Die Ober- und Unterseite gleichmässig gewölbt; das Gewinde flacher mit rascher zurehmenden Umgängen. Der Mundsaum weiss, der Gaumen und Basalkallus zitron- bis orangegelb.

$$
\mathrm{D}=15, \mathrm{~d}=12.5, \mathrm{H}=7-6 \mathrm{inm} .
$$

Deckel wie bei der typischen Form.

Fundorte: die Inseln Mindanao, Samar und Leyte der Philippinen. 


\title{
382. Pala eohelicina (Ceralopoma) hennigiana Möllendorff. Taf. 50, Fig. 14-16.
}

\author{
Helicina (Ceratopoma) hennigiana Höllendorff, Nachr. Bl. p. 184, 1893. \\ Palaeobelicina (Ceratopoma) honnigiana d. J. Wagner Helicinenstadien in Denk. \\ Akad. Wien, v. 78, p, 208, T. 10, F. 8, 1905.
}

Gehäuse linsenförmig, ziemlich festschalig, leicht glänzend mit feinen, schiefen und etwas úngleichmässigen Zuwachsstreifen, sowie dichten und sehr feinell Spirallinien. Die Grundfarbe gelblichweiss, hellgelb, tleischfarben bis rotbraun mit gelbel Spitze und einem schmalen rotbraunen Bande unter dem Kiele, welches selten ganz erlischt. Das breit bis flachkegelförmige, mehr, minder abgerundete Gewinde besteht aus $44_{2}^{1}-5$ ziemlich rasch zunehmenden nahezu flachen Umgängen; der letzte ist unten deutlicher gewölbt, an der Peripherie scharf und zusammengedrückt gekielt und steigt vorne wenig oder gar nicht herab. Die abgerundet dreieckige Mündung ist schief, der gelbliche oder weisse Mundsaum leicht verdickt, gut ausgebreitet; der Oberrand an der Insertion vorgezogen, der Aussenrand entsprechend dem Kiel winkelig vorgezogen, der Basalraud umgeschlagen. Die kurze, abgerundete Spindel ist nach aussen gebogen und bildet am Uebergange in den Basalrand der Mündung eine winkelige, deutlich vorspringende Ecke. Der hellgelbe Basalkallus ist in der Mitte ziemlich verdickt, an den Ränderu undeutlich begrenzt.

$$
\mathrm{D}=11.5-12 \cdot 5, \mathrm{~d}=9-10, \mathrm{H}=6.5 \mathrm{~mm} \text {. }
$$

Deckel dreieckig, lebhaft rotbraun mit krustenartiger, gekörnelter, aber ziemlich fester Kalkplatte; in den übrigen Verhältnissen typisch.

Fundort: Kagayan auf Nord-Luzon.

\section{Pala ohelicina (Ceratopoma) contermina Kobelt. Taf. 50, Fig. 17-19.}
Helicina contermina Semper mss. in Kobelt Philipp. Landd. p. 76, T. 7, F. 32, 1884. $"$ Martens Ostas. Zool. II p. 76, 1867.
Palaoohelicina (Ceratopoma) contermina A. J. Wagner Helicinenstadien in: Denk. Akad. Wien. vol. 88, p. 209, T. 10, F. 9, 1905.

Gelıäuse dicklinsenförmig, beiderseits ziemlich gleichmässig gewölbt, ziemlich festschalig, wenig glänzend bis matt. Die Grundfarbe schmutziggelb oder hellbraun, unter dem hellen bis weissen Kiele eine braune nach abwärts verschwimmende Zone, welche mitunter erlischt; die ersten Umgange mitunter zitrongelb, Die Skulptur besteht aus feinen, etwas ungleichmässigen Zuwachsstreifen und feinen, dichten Spirallinien, welche auf der Unterseite nahezu verschwinden. Das breitkegelförmige, deutlich abgerundete Gewinde besteht aus $4-4^{1} / 2$ regel- 
măssig zunehmenden nahezu flachen Umgängen; der letzte ist fadenförmig gekielt und steigt vorne nicht herab. Die abgerundet dreieckige Mündung ist wenig schief, der gelbliche Mundsaum lippenartig verdickt und kurz ausgebreitet; der Oberrand an der Insertion etwas vorgezogen und fast gerade, der Aussenrand entsprechend dem Kiele mitunter etwas winkelig ausgezogen, der Basalrand umgeschlagen. Die sehr kurze, abgerundete Spindel bildet ain Uebergang in den Basalrand der Mündung eine abgerundete, schwach vorspringende Ecke. Der glänzende, hellgelbe Basalkallus ist ziemlich dick und deutlich begrenzt.

$$
\mathrm{D}=6, \mathrm{~d}=5 \cdot 5, \mathrm{H}=4 \mathrm{~mm} \text {. }
$$

Deckel abgerundet dreieckig, hellhornfarben mit sehr zarter und hinfälliger Kalkplatte in den übrigen Verhältnissen typisch.

Fundorte: Die typische Form erhielt ich von Möllendorff mit der Fundortsangabe Paurian auf Nord-Luzon, vollkommen übereinstimmende Exemplare kenne ich ausserdem von "Antonio Cabayat" auf Luzon. In Cagayan auf Luzon findet sich eine Form, welche eine lebhaftere rotbraune Färbung und schwächere bis undeutliche Spirallinien aufweist.

384. Pala ehelicina (Ceratopoma) contermina camiguinensis

A. J. Wagner.

Taf. 50, Fig. 20-21. Palaeobelicina (Ceratoma) contermina camiguinensis A. J. Wagner Helicienstudien
in: Denk. Akad. Wien. v. 78, p. 210, T. 10, Fig. 10, 1905.

Gehăuse flachlinsenförmig, beilierseits weniger gewölbt, dünnschaliger, einfärbig gelblich oder rötlich hornfarben. Die Skulptur besteht nur aus feinen Zuwachsstreifen, während die Spirallinien vollkommen erloschen sind. Der letzte Umgang ist mehr zusimmengedrückt, auffallend schürfer gekielt; die Mündnng schiefer, der Mundsaum kürzer ausçebreitet und dünner; die Ecke am Uebergange der Spindel in den Basalrand der Mündung abgerundet und undeutlich; der dünne, mit dem Gehäuse gleichfarbige Basalkallus undeutlich begrenzt.

$$
\mathrm{D}=6, \mathrm{~d}=5 \cdot 3, \mathrm{H}=3 \cdot 6 \mathrm{~mm} \text {. }
$$

Deckel wie bei der typischen Form.

Fundort: Camiguin in Nord-Luzon; diese Form steht in der Mitte zwischen P. contermina Kobelt und Palaeohelicina rosaliae Pfr. und dürfte eine selbstsändige Art darstellen 


\title{
385. Pala ehelicina (Ceratopoma) rosaliae Pfeiffer. Taf. 51, Fig. $1-3$.
}

\author{
Heliciea roealia Pfeiffer J. de Conch. vol. 11, p. 72 T. 2, F. 5, 1863. \\ $\rightarrow \quad$ Mon. Pneum. IV. p. 243, 1865. \\ \# Kobelt Landdeck. Philipp. p. 71, 1884. \\ " Sowerby Thes. III. p. 295, T. 277, F. 436, 1866. \\ Palaeohelicina (Ceratopoma) rosaliae A. J. Wagner, Helicienstudien, in: Denk. Akad. \\ Wien. v. 78, p. 209 , T. 10 , F. $11,1905$.
}

Gehăuse linsenförmig, fəstschalig, hellgelb bis braungelb mit einer helleren undeutlich begrenzten Zone entlang der Naht und an der Peripherie des Basalkallus; wenig glänzend bis matt mit sehr feinen bis undeutlichen Zuwachsstreifen. Uas flach kegelförmige Gewinde besteht aus 4 regelmässig zunehmenden nahezu flachen Umgängen; der letzte ist unten deutlicher gewölbt, an der Peripherie scharf und zusammengedrückt gekielt und steigt vorne sehr wenig oder gar nicht herab; der Kiel ist lichter bis weiss, mitunter schwach gesägt; die Naht der unteren Umgänge heller fadenförmig berandet. Die dreieckige Mündung ist sehr schief, innen zitron- bis braungelb gefärbt; der gelbliche bis weisse Mundsaum lippenartig verdickt, kurz ausgebreitet; der Oberrand an der Insertion vorgezogen und fast gerade, der Aussenrand entsprechend dem Kiel winkelig ausgezogen; der Basalrand umgeschlagen. Die kurze, abgerundete Spindel ist nach aussen gebogen und bildet am Uebergange in den Basalrand der Mündung eine deutlich vorspringende, etwas abgerundete Ecke Der zitrongelbe Basalkallus ist nur in der Mitte etwas verdickt, an den Randern dünn und undeutlich begrenzt.

$$
\mathrm{D}=7 \cdot 5, \mathrm{~d}=6 \cdot 5, \mathrm{H}=4 \mathrm{~mm} .
$$

Deckel abgerundet dreieckig, hellgelbbraun mit sehr zarter anflugartiger Kalkplatte; in den übrigen Verhältnissen typisch.

Fundorte: Baler und Digollorin auf Nord-Luzon

\section{Pala eohelicina (Ceratopoma) quadrasi Möllendorff. Taf. 51, Fig. 4-6.}

\author{
Helicina quadrasi Möllendorff in: Nachr. Bl., v. 28, p. 15, 1896. \\ Palaeohelicina (Ceratopoma) quadrasi A. J. Wagner Helicinenstudien in: Denk. Akad. \\ Wien. v. 78, p. 210 , T. 10, F. $12,1905$.
}

Gehäuse annähernd kugelig kegelförmig, ziemlich festschalig, wenig glänzend bis matt mit sehr feinen etwas ungleichmässigen Zuwachsstreifen (unter der Lupe sind mitunter auch einige feine Spirallinien auf den unteren Umgängen sichtbar); lebhaft zitrongelb mit dunklerer 
Spitze und einer fleischfarbenen, etwas verwaschenen Zone hinter der Mündung. Das abgel'undet kegelförmige Gewinde besteht aus $4 \frac{1}{2}$ nahezu Hachen, ziemlich langsam zunehmenden Umgängen; der letzte ist beiderseits gleichmässig gewölbt, an der Peripherie stumpf, aber dentlich gekielt und steigt vorne nicht herab. Die halbeiförmige Mündung ist wenig schief, innen rotorange gefärbt; der hellfeischfarbene Mundsaum lippenartig verdickt, kurz ausgebreitet; der Oberrand an der Insertion schwach vorgezogen, der Basalrand etwas umgeschlagen. Die kurze, nahezu senkrechte Spindel ist abgerundet und bildet am Uebergange in den Basalrand der Mündung eine abgerundete, undeutliche Ecke, Der dünne mit dem Gehäuse gleichfarbige Basalkallus ist undeutlich begrenzt.

$$
\mathrm{D}=6, \mathrm{~d}=5 \cdot 5, \mathrm{H}=4.5 \mathrm{~mm} \text {. }
$$

Deckel abgerundet dreieckig, gelbbraun mit sehr zarter, anflugartiger Kalkplatte; in den übrigen Verhältnissen typisch.

Fundort: Manamban bei Casiguran auf Luzon.

\title{
Formenkreis Taeniata.
}

\section{Palaeohelicina (Ceratopoma) idae Pfeiffer.}

Taf. 50, Fig. 22-24.

\author{
Helicina id $a \in$ Pfeiffer, Pr. Z. S. p. 339, 1856. \\ " Martens Ostas. Exped. Zool. II, p. 170, T. 4, F. 19, 1867. \\ $\quad$ Kobelt in Abh. Senckenb. Ges. v. 24, p. 41, 1897. \\ Aphanoconia idae A. J. Wagner, Hslicinenstadign, in: Denk. dkad. Wien. ı. 77, p. 399, \\ T. 5, F. $11,1905$. \\ Palaeohelicina (Ceratopoma) idae A. J. Wagner Helicinenstudien, in: Denk. Akad. Wien. \\ จ. 78, p. 211,1905 .
}

Gehäuse breitkegelförmig mit gewölbter Basis, festschalig, gelb, orange bis rotbraun mit einer weisslichen Trübung auf der Oberseite der unteren Umgänge und einer helleren Zone hinter der Mündung; leicht glänzend his matt mit feinen etwas ungleichmässigen Zuwachsstreifen und ziemlich weitläufigen, feinen und eingedrückten Spirallinien auf der Oberund Unterseite, welchen bei frischen Exemplaren hinfällige Spiralfalten der Epidermis eatsprechen. Das regelmässig kegelförmige, mehr minder erhobene Gewinde besteht aus $4^{1} / 2$ ziemlich rasch zunehmenden, leicht gewölbten Umgängen; der letzte ist etwas zusammengedrïckt, beiderseits gleichmässig schwach gewölbt und steigt vorne langsam, aber deutlich herab; an der Peripherie finden sich 2 mehr minder deutliche Spiralkanten, zwischen welchen das Gehäuse abgeflacht erscheint. Die abgerundet dreieckige Mündung ist schief, innen zitrongelb gefärbt; der weisse Mundsaum innen leicht verdickt, kurz ausgebreitet; der Basalrand etwas umgeschlagen. Die kurze, etwas abgeflachte Spindel ist nach aussen gebogen und I. 18. II. 10. V. 1909. 
bildet am Uebergange in den Basalrand der Mündung eine deutlich vorspringende Ecke. Der zitrongelbe, feingekörnelte Basalkallus ist ziemlich dick, undeutlich begrenzt.

$$
\mathrm{D}=7-8, \mathrm{~d}=6-7, \mathrm{H}=4.5-5.5 \mathrm{~mm} \text {. }
$$

Deckel halbherzförmig, gelbbraun mit sehr zarter, krustenartiger Kalkplatte, in den übrigen Verhältnissen typisch.

Fundort: die Molnkken (Ceram, Buru, Ambon, Hulaliu-Harruku).

\title{
388. Palaeohelicina (Ceratopoma) zoae Pfeifer,
}

Taf. 51, Fig. 7-9.

\author{
Helicina zoa e Pfeiffer, Mal. Bl. V, p. 124, 1865. \\ " $"$ Mon. Pneum. V, p. 276, 1876. \\ $n \quad$ Sowerby Thes. III, p. 292, T. 276, F. 377, 1866. \\ " Kobelt Abhandl. จ. Senckenb. Ges V, p. 24, T. 5, F. 13-15, 1897.
}

Palaeohelicina (Ceratopoma) zoae A. J. Wagner Helicienstudien in: Denk. Akad. Wien, vol. 78, p. 210, T. 10, F. $14,1905$.

Gehäuse breitkegelförmig mit flachgewölbter Basis, ziemlich festschalig, zitrongelb, orange bis bräunlich und fleischfarben mit 2 milchweissen Binden an Kiel und Naht; leicht glänzend bis matt mit deutlichen, etwas ungleichmässigen Zuwachsstreifen und einigen schwachen, eingedrückten Spirallinien auf den oberen Umgängen. Das regelmässig kegelförmige Gewinde besteht aus $4 \frac{1}{2}$ flachen Umgängen; der letzte ist etwas zusammengedrückt, beiderseits gleichmässig schwach gewölbt, an der Peripherie im Beginne stumpfkantig, gegen die Mündung zu gerundet und steigt vorne langsam, aber deutlich herab. Die abgerundet dreieckige Mündung ist schief, innen zitron- bis orangegelb, der weisse Mundsaum innen schwach verdickt, kurz ausgebreitet; der Basalrand kaum umgeschlagen. Die kurze, etwas abgeflachte Spindel ist nach aussen gebogen und bildet am Uebergange in den Basalrand der Mündung eine deutlich vorspringende Ecke. Der zitrongelbe, feingekörnelte Basalkallus ist ziemlich dick, aber undeutlich begrenzt.

$$
\mathrm{D}=9, \mathrm{~d}=7 \cdot 5, \mathrm{H}=6 \mathrm{~mm} \text {. }
$$

Deckel abgerundet dreieckig, rotorange mit sehr zarter, anflugartiger Kalkplatte, in den übrigen Verhältnissen typisch.

Fundort: die Insel Halmahera.

Die vorstehende Art steht der P. idae Pfr. wohl sehr nahe, unterscheidet sich aber bestimmt von derselben durch die Grösse, Färbung, die fehlenden Spirallinien auf den unteren Umgangen, die fehlende oder nur sehr undeutliche Doppelkante an der Peripherie des letzten Umganges, die flachen Umgänge, den dünnen und kürzer ausgebreiteten Mundsaum. 


\title{
389. Palaeohelicina (Ceratopoma) zoae gebeana Smith.
} Taf. 51, Fig. 10-13.

\section{Helicina gebeana Smith}

Gehäuse mit leicht konvexem Gewinde; die Umgänge deutlicher gewölbt, der letzte weniger zusammengedrückt, oben mehr gewölbt; die Spirallinien nur auf dem ersten Umgange angedeutet.

$$
\mathrm{D}=8.5, \mathrm{~d}=7, \mathrm{H}=5.5 \mathrm{~mm} .
$$

Deckel wie bei der typischen Form.

Fundort: die Insel Gebi, östlich Halmahera.

\section{Palaeohelicina (Ceratopoma) jobiensis Topparone Canefri.} Taf. 51, Fig. 14-17.

\author{
Helicina jobiensis Tapparone Canefri, Fanaa Nuova Guinea Suppl. p. 77, T. 2, F. 22-23, \\ 1886. \\ Aphanoconia jobiensis A. J. Wagner, Helicinenstndien, in: Denk. Akad. Wieu. v. 77, \\ p. 399 , T. 5 , F. $10,1905$.
}

Gehăuse breitkegelförmig mit flachgewölbter Basis, festschalig, schmutzig gelb, gelbbraun bis rötlich fleischfarben mit orangefarbener Spitze; leicht glänzend oder matt mit feinen, etwas ungleichmässigen Zuwachsstreifen und ziemlich weitläufigen, eingedrückten Spirallinien. Das regelmässig kegelförmige Gewinde besteht aus $4^{1} / 2$ leicht gewölbten bis nahezu flachen ziemlich rasch zunehmenden Umgängen; der letzte ist etwas zusammengedrückt, beiderseits gleichmässig flach gewölbt, an der Peripherie stumpfkantig (die abgeflachte Kante erscheint im Beginne wie bei P. idae Pfeiffer durch 2 stumpfe Kiele begrenzt) und steigt vorne langsam, aber deutlich herab. Die abgerundet dreieckige Mündung ist schief, innen zitron- oder orangegelb, der gelbliche, leicht verdickte Mundsaum ziemlich ausgebreitet; der Oberrand an der Insertion etwas vorgezogen, der Basalrand umgeschlagen. Die kurze, abgeflachte Spindel bildet am Uebergange in den Basalrand der Mündung eine deutlich vorspringende Ecke. Der zitrongelbe, dünne und gekörnelte Basalkallus ist undeutlich begrenzt.

$$
\mathrm{D}=9.5, \mathrm{~d}=8, \mathrm{H}=6.5-7 \mathrm{~mm} \text {. }
$$

Deckel dreieckig, orangegelb mit dünner, krustenartiger Kalkplatte; in den übrigen Verhältnissen typisch.

Fundort: die Insel Jobi in der Gulvink-Bai und Kapaor auf Neu-Guinea.

Auch diese Form habe ich früher unrichtig bei dem Genus Aphanoconia m. eingeteilt so lange mir nur Exemplare ohne Deckel vorgelegen haben. 


\title{
391. Palaeohelicina (Ceratoporna) primeana Gassies.
}

\author{
Taf. 50, Fig. 4-8.
}

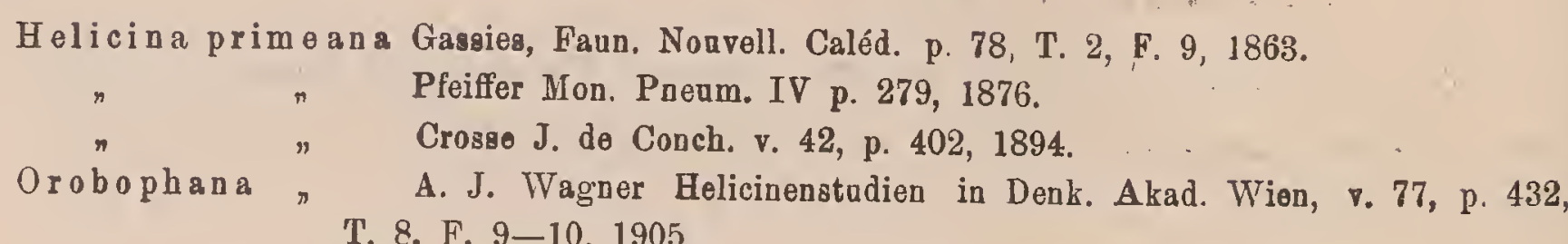

Gehäuse gedrückt kugelig oder breitkegelförmig mit gewölbter Basis, festschalig; sehr verschieden gefärbt, einfärbig milchweiss, gelb, violett, rotbraun, häuflg mit lichter oder dunkler gefärbter Spitze, lichten Bändern auf dunklem Grund oder dunklen Bändern auf lichtem Grund; leicht glänzend bis matt mit feinen etwas ungleichmässigen Zuwachsstreifen (einige feine Spiralreifen sind nur auf dem ersten Umgang nach der Embryonalwindung, wie bei allen Formen dieser Gruppe vorhanden). Das regelmässig flachkegelförmige oder leicht abgerundete Gewinde besteht aus 4 ziemlich langsam zunehmenden, nahezu flachen Umgăngen; der letzte ist beiderseits gleichmässig gewölbt, an der Peripherie mehr minder deutlich stumpfkantig und steigt vorne langsam ein wenig herab. Die abgerundet dreieckige Mündung ist schief, innen mit der Oberfläche gleichfärbig; der weisse, gelbliche oder rötliche Mundsaum schwach verdickt, kurz ausgebreitet, der Aussen- und Basalrand etwas umgeschlagen. Die kurze, abgeflachte Spindel ist nach aussen gebogen und bildet am Uebergange in den Basalrand der Mündung eine stumpfe, aber deutlich vorspringende Ecke. Der glänzende, weisse oder gelbliche Basalkallus ist dün und undeutlich begrenzt.

$$
\mathrm{D}=7 \cdot 5-8, \mathrm{~d}=6 \cdot 5-7, \mathrm{H}=5-6 \mathrm{~mm} \text {. }
$$

Deckel halbeiförmig, gelbbraun mit zarter, anflugartiger Kalkplatte, in den übrigen Verhältnissen typisch.

Fundorte: Neu-Caledonien, die Loyalty- und Pinien-Insel.

P. primeana Gassies wird vielfach mit anderen, äusserlich ähnlichen Heliciniden NeuCaledoniens verwechselt; sie ist derzeit die einzige mir bekannte Art des Genus Palaeohelicina aus Neu-Caledonien und unterscheidet sich dementsprechend bestimmt von allen anderen dort vorkommenden Formen durch den dünnen, nahezu häutigen Deckel mit randständigem Nukleus, ebenso durch die Spiralreifen des ersten Umganges, während die unteren Umgänge nur radiale Zuwachsstreifen aufweisen. Unter der Bezeichnung Helicilla caledonica und Helicina novae caledoniae Baird aus Neu-Caledonien erhielt ich stets nur vorstehende Art. 


\section{Palaeohelicina (Ceratopoma) layardi Hartmann.}

Taf. 51, Fig. 18-21.

Helicina lay ardi Hartmann, Pr. Acad. Philad. p. 251, T. 13, F. 6, 1888.

Orobophana sublaevigata layardi A. J. Wagner, Helicinenstudien. in: Denk. Ak. Wien. v. 77 , p. 427 , T. 7 , F. 18,1905 .

Gehäuse breitkegelförmig mit flachgewölbter Basis, ziemlich dünnschalig, leicht glänzend bis matt mit sehr feinen bis undeutlichen Zuwachsstreifen; neben den Spiralreifen des ersten Umganges sind unter der Lupe mitunter auch auf den ünteren Umgängen einige sehr feine, eingedrückte Spirallinien sichtbar. Die Grundfarbe weiss oder schmutziggelb, zumeist mit 2 verschieden breiten rotbraunen Binden je auf der Ober- und Unterseite, welche mitunter die Grundfarbe bis auf eine lichte Kielbinde vollkommen verdecken; zuweilen ist nur eine Binde vorhanden, seltener fehlen dieselben gänzlich. Das regelmässig kegelförmige oder nur leicht abgerundete Gewinde besteht aus 4 regelmässig zunehmenden schwach gewölbten oder nahezu flachen Umgängen; der letzte ist etwas zusammengedrückt, unten abgeflacht, an der Peripherie mehr minder deutlich kantig, mitunter nahezu stumpfgekielt, gegen die Mündung zu mehr gerundet und steigt vorne langsam, aber deutlich herab. Die abgerundet dreieckige Mündung ist schief, innen mit durchscheinenden Bändern; der gelbliche Mundsaum leicht verdickt, kurz ausgebreitet. Die ziemlich kurze und dünne Spindel ist nach vorne und aușsen gebogen; am Uebergange derselben in den Basalrand der Vündung findet sich eine ziemlich scharf vorspringende Ecke. Der gelbliche Basalkallus ist ziemlich dünn, fein gekörnelt and undeutlich begrenzt.

$$
\mathrm{D}=6.5-8, \mathrm{~d}=5 \cdot 5-6 \cdot 8, \mathrm{H}=4.3-5.5 \mathrm{~mm} \text {. }
$$

Deckel abgerundet dreieckig, rotbraun mit zarter krustenartiger Kalkplatte; in den übrigen Verhältnissen typisch.

Fundort: die Neuen Hebriden; ineine Exemplare von den Insèln: Vaté, Espiritu Santo und Esfoti. Nach den sehr zahlreichen Exemplareu, welche ich zu untersuchen Gelegenheit hatte, ist diese Art sowohl bezüglich der Färbung und Grösse, als auch mit Rücksicht auf die Höhe des Gewindes, die mehr minder deutliche Kante des letzten Umganges sehr veränderlich und hat aus diesem Grunde anscheinend schon melrere Namen erhalten. So habe ich unter den Bezeichnungen Helicina bairdi Reeve, Helicina taeniata Quoy stets nur vorstehende Art erhalten. Helicina taeniata Quoy wird in der Originaldiagnose als gekielt bezeichnet; es ist jedoch warscheinlich, dass auch diese Form von der Insel Vanikoro mit P. layardi Hartmann der Neuen Hebriden identisch ist und gebührt dann der ălteren Bezeichnung die Priorität. 


\title{
Formenkreis Diversicolor.
}

\author{
393. Palaeohelicina (Ceratopoma) diversicolor Cox. \\ Taf. 52, Fig. 5-7.

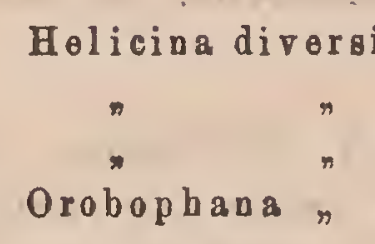 \\ Cox Pr. Z. S. p. 375, 1866. \\ "Mon. Austral. Landsch. p. 105, T. 17, F. 9. \\ Pfeiffer, Mon. Pneam. IV p. 275, 1876. \\ A. J. Wagner Helicinenstudien in: Denk. Akad. Wien, v. 77, p. 431,
} T. 5, F. $1,1905$.

Gehăuse kugelig kreiselförmig, festschalig, matt, mit feinen, ungleichmässigen Zuwachsstreifen; unter der Lupe sehr fein gerunzelt, mit einigen undeutlichen Spirallinien, im frischen Zustande ausserdem mit hinfälligen Spiralfalten der Epidermis. Die Grundfarbe schmutzig gelb oder rötlich fleischfarben mit gelber oder weisslicher Spitze; die mittleren Umgänge hăufig violett oder rotbraun. Das breitkegelförmige, hăufig etwas abgerundete Gewinde besteht aus $4-4^{1} / 2$ ziemlich langsam zunehmenden, schwach gewölbten bis nahezu fachen Umgängen; der letzte ist unten flacher, an der Peripherie undeutlich kantig bis stumpf gekielt und steigt vorne nicht herab. Die halbeiförmige Mündung ist wenig schief, innen weiss oder gelblich; der weisse leicht verdickte Mundsaum kurz ausgebreitet, der Basalrand etwas umgeschlagen. Die kurze, abgerundete Spindel bildet am Uebergange in den Basalrand eine stumpfe, deutlich vorspringende Ecke. Der gelbliche, feingekörnelte Basalkallus ist ziemlich dünn und undeutlich begrenzt.

$$
\mathrm{D}=5 \cdot 5, \mathrm{~d}=4 \cdot 5, \mathrm{H}=4.5 \mathrm{inm} \text {. }
$$

Deckel halbeiförmig, gelbbraun mit sehr zarter, anflugartiger Kalkplatte; in den übrigen Verhältnissen typisch.

Fundort: Queensland (Richmond).

Helicina dryatonensis Pfeiffer wird in der Originaldiagnose als „fast gekielt, unten konvexer" bezeichnet; auch Exemplare der vorstehenden Art sind mitunter stumpf gekielt, doch unten mehr abgeflacht Die mir von den Herrn Sowerby und Fulton mitgeteilten Exemplare der H. dryatonensis Pfeiffer (Fundort: Queensland) sind von vorstehender Art nicht zu unterscheiden; so erscheint es sehr wahrscheinlich, dass beide hier genannten Arten identisch sind.

\section{Palaeohelicina (Ceratopoma) jana Cox.}

Taf. 52, Fig. 1-4.

Helicina jana Cox Pfeiffer Pr. Z. S. p. 647, T. 52, F. 13, 1871.

» Pfeiffer Mon. Pneum. IV p. 256, 1878. 
Orabophana jana A. Wagner, Helicinenstudien, in: Denk. Akad. Wien. v. 77, p. 432, T. 6, F. 23, 1905.

Helicina macleayi Brazier Pr. Linu. Soc. N. S. Wales I, 1879.

Gehäuse breitkegelförmig mit gewölbter Basis, ziemlich festschalig, leicht glänzend mit feinen etwas ungleichmässignn Zuwachsstreifen; frische Exemplare anscheinend mit hinfälligen Spiralfalten der Epidermis. Feine Spiralreifen auf dem ersten Umgange nach der Embryonalschale sind wie bei allen Formen dieser Gruppe vorhanden, ausserdem sind nur ausnahmsweise aüch auf den mittleren Umgängen einige undeutliche Spirallinien bemerkbar. Die Grundfarbe gelblich oder gelbbraun mit gelber Spitze und häufig lichterem letzten Umgang. Das regelmässig kegelförmige oder leicht konvexe Gewinde besteht aus 4 regelmăssig zunehmenden, kaum gewölbten bis flachen Umgängen; der letzte ist beiderseits gleichmässig gewölbt, an der Peripherie etwas stumpf, aber deutlich gekielt und steigt vorne wenig herab. Die abgerundet dreieckige Mündung ist wenig schief, innen hellgelb oder hellbraun; der weisse oder gelbe Mundsaum leicht verdickt, mitunter fast verdoppelt, sehr kurz umgeschlagen oder gerade. Die kurze, abgerundete Spindel bildet am Uebergange in den Basalrand eine abgerundete, aber deutliche Ecke. Der ziemlich dicke, feingekörnelte und mit dem Gehäuse gleichfarbige Basalkallus ist deutlich begrenzt.

$$
\mathrm{D}=4 \cdot 3, \mathrm{~d}=3 \cdot 5, \mathrm{I}=3 \mathrm{~mm} \text {. }
$$

Deckel abgerundet dreieckig, gelbbraun mit sehr zarter, krustenartiger Kalkplatte; in den übrigen Verhältnissen typisch.

Fundorte: Ich beurteile diese Art zunächst nach Exemplaren vom Origlnalfundorte Port Macquarie in Ostaustralien; unter der Bezeichnung Helicina macleayi Brazier von Cardwell in Queensland erhielt ich entsprechende Exemplare, welche zum Teile grösser sind und mitunter einen etwas schärferen Kiel aufweisen, aber weder als Art noch als Lokalform unterschieden werden könuen.

\section{Palaeohelicina (Ceratopoma) gladstonensis Cox.}

Taf. 52, Fig. 8-10.

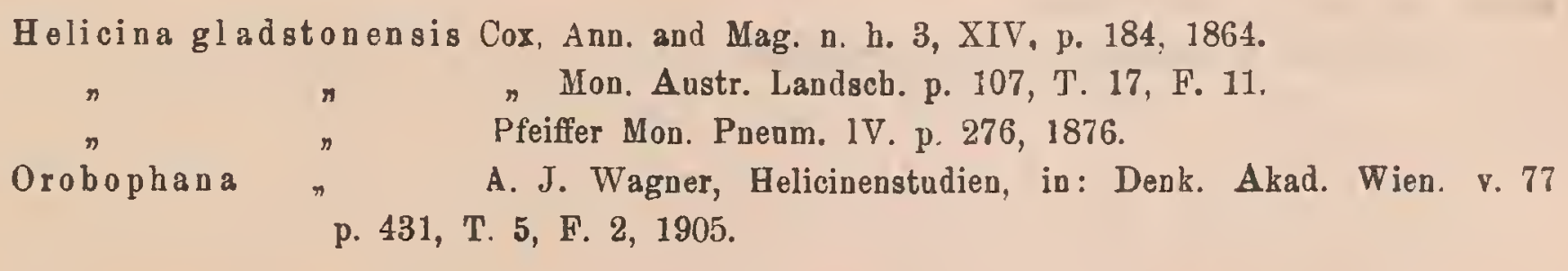

Gehäuse breitkegelförmig mit flachgewölbter Basis, ziemlich dünnschalig, hellrotbraun mit lichterem letzten Umgang und unregelmässigen weisslichen Flecken; wenig glänzend mit deutlichen, unregelmässigen Zuwachsstreifen, sehr feinen Rnnzeln; frische Exemplare ausserdem mit hinfälligen Spiralfalten der Epidermis. Das regelmässig flachkegelförmige Gewinde 


\section{4}

besteht aus $31 / 2-4$ regelmässig zunehmenden, nahezu flachen Umgängen; der letzte ist stumpfgekielt, beiderseits gleichmässig flach gewölbt und steigt vorne sehr wenig oder fast gar nicht unter den Kiel herab. Die abgerundet dreieckige Mündung ist wenig schief, der weisse, leicht verdickte Mundsaum sehr kurz, ausgebreitet oder fast gerade. Die sehr kurze, abgerundete Spindel bildet am Uebergange in den Basalrand der Müudung eine stumpfe, ziemlich deutlich vorspringende Ecke. Der dünne, fein gekörnelte Basaikallus ist mit den Gehäuse gleichfärbig und undeutlich begrenzt.

$$
\mathrm{D}=3 \cdot 6, \mathrm{~d}=3, \mathrm{H}=2 \cdot 5 \mathrm{~mm} \text {. }
$$

Deckel abgerundet dreieckig, gelblich hornfarben mit sehr zarter, anflugartiger Kalkplatte; in den übrigen Verhältnissen typisch.

Fundorte: Gladstone bei Port Curtis in Queensland.

\section{Palaeohelicina (Ceratopoma) fumigata Cox.}

Taf. 51, Fig. 23-25.

Orobophana famigata (Cox) A. J. Wagner Helicinenstadien. in: Denk. Akad. Wien, r. 77, p. 432, T. 4 , F. $21-22,1905$.

Gehäuse annähernd kreiselförmig, ziemlich dünnschalig, leicht glänzend mit sehr feinen Zuwachsstreifen; gelb bis braun oranga mit gelber Spitze und einer milchig getrübten Zone auf der Oberseite der unteren Umgänge. Das breit kegelförmig Gewinde besteht aus $4 \frac{1}{2}$ langsam zunehmenden, gut gewölbten Umgängen; der letzte ist unten etwas abgeflacht, an der Peripherie gerundet oder undeutlich stumpfkantig und steigt vorne langsam herab. Die halbeiförmige Mündung ist schief, innen gelbbraun, der Mnndsaum dünn und gerade. Der mit dem Gehäuse gleichfarbige, feingekörneite Basalkallus dünn und undeutlich begrenzt. Die kurze, abgerundete Spindel bildet am Uebergange in den Basalrand der Mündung eine stumpfe Ecke.

$$
\mathrm{D}=3 \cdot 5, \mathrm{~d}=3, \mathrm{H}=2 \cdot 6 \mathrm{~mm} .
$$

Deckel beiderseits braunorange, abgerundet dreieckig mit glănzender, am Spindelrande etwas verdickter Kalkplatte.

Fundort: Rockhampton in Queensland. 


\title{
Genus Hemipoma A. J. Wagner.
}

Gears Hemipoma A. J. Wagner, Helicinenstudien, in: Denk. Akad. Wien, v. 77, p. 433, 1905.

Gehäuse linsenförmig, gekielt mit leicht mondförmig ausgeschnittener Mündung.

Deckel abgerundet dreieckig mit konkavem Spindelrand und ziemlich spitz ausgezogenem oberen und Spindelwinkel; die verhältnismässig dicke Kalkplatte flachkonkav, der Nukleus dem Spindelrande genähert, die Zuwachsringe des Deckels sehr undeutlich. Auf der Unterseite des Deckels ist eine Hornplatte nicht erkennbar, dafür findet sich an der Stelle der Sigmakante (der übrigen Heliciniden) eine erhobene und ziemlich dicke Kalkleiste.

Verbreitungsgebiet: Japan.

Dieses Genus wurde zunächst für zwei Formen errichtet, welche besonders durch die Beschaffenheit des Deckels von allen mir bekannten Heliciniden abweichen. Der Deckel besteht aus einer festen bis knochenartigen Kalkplatte ohne erkennbarer Hornplatte (möglicherweise bleibt die hautartige Hornplatte bei der Prăparation an den Weichteilen hängen). Die konzentrischen Zuwachsstreifen sind hier nur sehr undeutlich sichtbar, ein exzentrischer und dem Spindelrande genäherter Nukleus ist aber nachweisbar. Auf der Unterseite, annähernd parallel dem Spindelrande findet sich eine auffallende wulst- oder leistenartige Verdickung, welche jedoch der Sigmakante bei den übrigen Heliciniden nicht entspricht, sondern einen Muskelansatz darstellt.

\section{Hemipoma hakodadiense Hartmann.}

Taf. 52, Fig. 14-17.

\author{
Helicina hakodadiensis Hartmann Pr. Akad. Philad. p. 286, T. 3, F. 8, 1890. \\ Hemipoma hakodatiense A. J. Wagner Helieinenstudien, in: Denk. Akad. Wien. 7.77 \\ p. 433, T. 7, F. 10 and $20,1905$.
}

Gehäuse flachkegelförmig mit gut gewölbter, nahezu halbkugeliger Basis, ziemlich dünnschalig, einfärbig gelbbraun; leicht glänzend mit feinen, etwas ungleichmässigen Zuwachsstreifen und sehr feinen, dichten, nur unter der Lupe sichtbaren Spirallinien, welche auf der Unterseite nahezu verschwinden. Das regelmässig kegelförmige Gewinde besteht aus $3^{1} / 2^{-4}$ kaum gewölbten bis flachen, regelmässig zunehmenden Umgängen; der letzte ist unten mehr gewölbt, stumpf gekielt und steigt vorne sehr langsam und wenig unter den Kiel herab. Die annähernd halbkreisförmige Mündung ist wenig schief, innen mit dem Gehäuse gleichfärbig; der gelbliche oder weisse, kaum verdickte Mundsaum ist sehr kurz ausgebreitet oder fast gerade. Die kurze, leicht nach aussen gebogene und abgerundete Spindel bildet am UeberI. 18. II. 
gang in den Basalrand eine undeutliche, abgerundete Ecke. Der weisse, gekörnelte Basalkallus ist besonders im Umkreise der Spindel deutlich verdickt und begrenzt.

$$
\mathrm{D}=5-5 \cdot 5, \mathrm{~d}=4 \cdot 5-5, \mathrm{H}=3-3 \cdot 4 \mathrm{~mm} \text {. }
$$

Deckel gelblichweiss, leicht glänzend, etwas durchscheinend mit hoher, aber schmaler Leiste auf der Unterseite; in den übrigen Verhăltnissen typisch.

Fundorte: Hakodati und Kayabe Ozima in Japan.

\title{
398. Hemip oma sadoense H. A. Pilsbry.
}

Taf. 52, Fig. 11-13.

Helicina sadoensis H. A. Pilsbry et Y. Hirase, New. Landshells of. Japan. Empire, in: The Nautilns, v. 16, p. 128.

Hemipoma aadaense A. J. Wagner, Helicinenstadien, in: Denk. Akad. Wien. v. 77, p. 434, T. 7, F. 11, 1905.

Gehäuse sehr ähnlich dem Himipoma hakodadiense Hartmann, jedoch festschaliger, grünlichgelb bis hellrotbraun mit etwas deutlicheren Spirallinien auf der Oberseite; der letzte Umgang ist schärfer und zusammengedrückt gekielt und steigt vorne nicht herab; der gelbbraune Mundsaum kräftig verdickt, nahezu verdoppelt.

$$
\mathrm{D}=4 \cdot 5, \mathrm{~d}=4, \mathrm{H}=2 \cdot 6 \mathrm{~mm} \text {. }
$$

Deckel mit kräftiger und dicker Leiste auf der Unterseite, in den übrigen Verhăltnissen typisch.

Fundort: Sotokaifa Sado in Japan.

\section{Nachtrag zum Genus Aphanoconia A. J. Wagner.}

\author{
399. A phanoconia hirasei H. A. Pilsbry. \\ Taf. 52, Fig. 18-19.
}

Helicina hiranei H. A. Pilsbry, Proc. Atad. of Nat. Sc. Philadeplphia, V, 54, p. 26, 190\%. Hemi poma hirasei A. J. Wagner, Helicinenstudien in': Denk. Akad. Wien, v. 77, p. 434, T. 7, F. 12,1905 .

Gehäuse flachlinsenförmig, ziemlich festschalig gelblichweiss bis gelblich hornfarben; wenig glänzend mit feinen S-förmig gebogenen Zuwachsstreifen und sehr feinen und dichten Spirallinien, welchen an frischen Exemplaren hinfällige Spiralfalten der Epidermis entsprechen. Das flachkegelförmige Gewinde besteht aus $4 \frac{1}{2}$ flachen, gekielten, regelmässig zunehmenden Umgängen, welche häufig durch eine leicht berandete Naht geschieden werden; der letzte ist zusammengedrückt, unten mehr gewölbt, sehr scharf und vorspringend gekielt und steigt mit- 
unter schon im Beginne etwas unter den Kiel herab. Die dreieckige Mündung ist sehr schief, innen gelblich; der weisse, lippenartig verdickte Mundsaum ausgebreitet; der Oberrand an der Insertion vorgezogen, der Basalrand leicht umgeschlagen. Die sehr kurze Spindel bildet am Uebergange in den Basalrand der Mündung eine undeutliche Ecke; der weisse, gekörnelte Basalkallus ist nur im Umkreise der Spindel deutlicher verdickt und begrenzt.

$$
\mathrm{D}=6 \cdot 5, \mathrm{~d}=5 \cdot 6, \mathrm{H}=3 \mathrm{~mm} \text {. }
$$

Deckel unbekannt.

Fundort: Hahajima Ogasawara, Bonin-Inseln.

Der Deckel dieser Form ist mir auch heute unbekannt; die Form und Beschaffenheit des Gehäuses veranlasst mich aber dieselbe im Genus Aphanoconia m. bei dem Formenkreise Ogasawarana einzuteilen.

\title{
400. Aphanoconia papuana E. A. Smith.
}

Taf. 52, Fig. 20-24.

\begin{abstract}
Helicina papuana E. A. Smith, in: Ann. Mag. (6), XVI, p. 365, T. 20, p. 19, 1895.
Palaeobelicina (Ceratopoma) papuana A. J. Wagner, Helicinenstudien, in: Dent. Akad.
\end{abstract} Wien, v. 78, p. 211, T. 10, F. 13 et $17,1905$.

Gehäuse linsenförmig, ziemlich festschalig, schmutzig gelb, hellzitrongelb bis hellrotbraun mit einer hellen oder rötlichen Zone hinter der Münlung; leicht glänzend bis matt mit sehr feinen, etwas ungleichmässigen Zuwachsstreifen, sowie einigen erhobenen Spirallinien auf der Oberseite der unteren Umgänge, welche häufig ganz verschwinden. Das breitkegelförmige, leicht konvexe Gewinde besteht aus 4 schwach gewölbten bis nahezu flachen Umgăngen, welche ziemalich langsam zunehmen und durch eine leicht berandete Naht geschieden werden; der letzte ist unten mehr gewölbt, an der Peripherie mehr minder scharf gekielt und steigt vorne langsam und wenig unter den Kiel herab. Die abgerundet dreieckige Mündung ist schief, innen gelblich, orange oder rotbraun; der gelbliche oder rötliche Mundsaum leicht verdickt, kurz ausgebreitet; der Oberrand an der Insertion etwas vorgezogen, fast gerade, der Basalrand leicht umgeschlagen. Die kurze, dünne Spindel ist nach aussen und vorne gebogen; am Uebergange in den Basalrand der Mündung findet sich eine etwas abgerundete, deutlich vorspringende Ecke. Der dünne, glänzende, mit dem Gehäuse gleichfarbige Basalkallus ist undeutlich begrenzt.

$$
\mathrm{D}=7, \mathrm{~d}=6, \mathrm{H}=4.2 \mathrm{~mm} .
$$

Deckel dreieckig, rotbraun mît lichtem Spindelrande; die ziemlich dünne, aber feste Kalkplatte mit seichter Furche neben dem erhobenen Spindelrand, die Sigmakante in beiden Aesten niedrig; in den übrigen Verhältnissen dem Genus Aphanoconia m. entsprechend.

Fundort: Konstantinhaven in Deutsch-Neu-Guinea. 
Auch diese Form erweist sich nach genauer Untersuchung des Deckels als sichere Aphanoconia aus dem Formenkreise der Albocincta.

\section{Aphanoconia heterochroa A. J. Wagner. \\ Taf. 53, Fig. $1-4$.}

Palaeobelicina heterochroa A. J. Wagner in: Denk. Akad. Wien, v. 77, p. 436, t. 9 , F. $13,15,1905$.

Gehăuse linsenförmig, festschalig, leicht glänzend, gelblichweise mit 2 verschieden breiten und scharfen rotbraunen Bändern ober und unterhalb des lichten Kieles; ein drittes schwächeres Band verläuft unter der Naht der zwei letzten Umgänge und erscheint fast regelmässig durch milchige Flecken und Radialstriemen unterbrochen. Das untere Kielband findet sich mitunter in zwei schmale Binden geteilt oder in Flecken aufgelöst. Die Skulptur besteht nebst feinen, ungleichmässigen Zuwachsstreifen aus dichten und feinen Spiralreifen, welche auf der Oberseite des letzten Umganges etwas weitläufiger werden. Das flach kegelförmige Gewinde besteht aus $4^{1} \frac{1}{2}$ ziemlich rasch zunehmenden kaum gewölbten Umgängen; der letzte ist doppelt so breit wie der vorletzte, zusammengedrückt und scharf gekielt, vorne nicht herabsteigend.

Die dreieckige Mündung ist schief, der weisse Mundsaum lippenartig verdickt und erweitert; der Oberrand fast gerade und an der Insertion vorgezogen, der Aussenrand entsprechend dem Kiele mehr minder spitzwinkelig ausgezogen, der Basalrand umgeschlagen. Die ziemlich verlängerte, leicht nach aussen gebogene Spindel bildet am Uebergange in den Basalrand eine winkelig vorspringende, etwas abgerundete Ecke. Der dünne, weisse und gekörnelte Basalkallus ist undeutlich begrenzt.

$$
\mathrm{D}=13, \mathrm{~d}=10.5, \mathrm{H}=7-8 \mathrm{~mm} \text {. }
$$

Deckel dreieckig mit rechtem oberen, spitzen Aussen- und abgerundetem Spindelwinkel, welcher ausserdem leicht nach hinten gebogen erscheint. Die dicke, fein gekörnelte Kalkplatte ist gelblich mit deutlicher Furche neben dem Spindelrand. Die Hornplatte gelbbraun; in den übrigen Merkmalen die typischen Verhältnisse des Genus Aphanoconia.

Fundort: Die Palau-Inseln (Pililiu).

Diese Art zeigt mit Rücksicht auf die Verhältnisse des Gehäuses eine grosse Aehnlichkeit mit Palaeohelicina ruffocallosa Sykes, dementsprechend habe ich dieselbe auf Grund deckelloser Exemplare zuerst bei dem Genus Palaeohelicina eingeteilt. Die Verhältnisse des Deckels entsprechen jedoch vollkommen dem Genus Aphanoconia m. und bedingen die Einteilung dieser Art in den Formenkreis der Aphanoconia fulgora Gould. 


\title{
Genus Helicina Lamarck ex rect. mea.
}

\author{
Genus Helicina A. J. Wagner Helieinenstudien in Denk. Akad. Wien v. 78, p. 212, 1905.
}

Gehäuse linsenförmig bis kugelig, mit $3 \frac{1}{2}-5^{1} / 2$ Umgăngen, sowie einer beständigen, oft lebhaft gefärbten Epidermis. Die schwach entwickelte Skulptur besteht vielfach nur aus radialen Zuwachsstreifen, häufig sind auch eingedrückte Spirallinien oder niedrige Spiralreifen vorhanden; ausserdem erscheint die Oberfläche zuweilen uneben, die Epidermis fein gerunzelt, Borsten wurden jedoch an derselben nicht beobachtet. Der Mundsaum ist stets mehr minder erweitert, ausgebreitet und umgeschlagen; der Bașalkallus nur im Umkreise der Spindel mehr minder deutlich verdickt, an der Peripherie jedoch dünn und undeutlich begrenzt. In der Nabelgegend findet sich konstant eine von der Spindel ausgehende eingedrückte Furche oder ein Grübchen

Deckel dreieckig. halbeiförmig oder birnförmig mit gekrümmter Spitze. Die dünne bis krustenartig zarte Kalkplatte ist am Spindelrande deutlicher verdickt, leistenartig erhoben und von der Hornplatte durch eine deutliche Furche abgesetzt. Der Nukleus liegt nahezu randständig, erscheint aber auch häufig etwas dem Spindelwinkel genähert; die Spindelseite der Platte ist dementsprechend auf einen schmalen, S.förmig gebogenen Saum beschränkt, welcher jedoch gegenüber dem Aussenteil der Platte zumeist etwas wulstartig verdickt erscheint. Die Sigmakante ist nur im durchfallenden Lichte als leicht S-förmig gebogene Grenzlinie angedeutet.

Das Verbreitungsgebiet der Formen dieses Genus Kontinent, soweit daselbst tropisches oder subtropisches K!ima herscht, die Antillen und Bahama-Inseln. Von den Galapagos-Inseln sind mir nur Vertreter des Genus Sturanya A. J. Wagner bekannt.

Ich beschränke das alte Genus Helicina Lamarck auf einen Teil der amerikanischen Heliciniden, für welche dasselbe auch ursprünglich aufgestellt wurde. Auch so ist noch eine grosse Zahl recht auffallend verschieden gestalteter Formen übrig geblieben, so dass es schwierig ist, gemeinsame Gattungsmerkmalc am Gehäuse und Deckel zu finden. In diesem Falle sind auch weniger auffallende Merkmale, wenn sie nur konstant $\mathrm{zn}$ beobachten sind, wertvoll. Ein solches Merkmal ist die oben angeführte Furche in der Nabelgegend neben der Spindel; dieses konstante Merkmal ermöglicht vor Allem eine sichere Trennung der Formen dieses Genus von den auffallend ăhnlichen Formen des altweltlichen Genus Palaeohelicina A. J, Wagner. Die Beschaffenheit der Mündung und die Struktur des Deckels mit vollkommen rändstăndigem Nukleus unterscheiden die Formen des Genus Helicina Lam. von den ebenfalls auf Amerika beschränkten Geschlechtern Eatrochatella Fischer und Alcadia Gray. Auf den Antillen und in Südmexiko werden jedoch auch Helicinen beobachtet, welche 
besonders mit Rücksicht auf die Form des Gehäuses eine grosse Aehnlichkeit mit Formen des Genus Alcadia aufweisen, ebenso wie auch einzelne Formen dieses Genus die charakteristischen Merkmale nur sehr undeutlich erkennen lassen; eine Ergänzung des von mir auf die Merkmale der Schale und des Deckels aufgebauten Systems der Heliciniden wird wohl die geplante Untersuchung der Radula bringen. Für die Untersuchung der Weichteile ist wohl das entsprechende Material derzeit nicht zu erlangen. Troschel beschreibt in seiner Publikation „das Gebiss der Schnecken" nur amerikanische Heliciniden. Die entsprechenden Abbildungen bestätigen schon heute die von mir durchgeführte Gruppenverteilung. Besonders anregend zu weiteren Untersuchungen erscheint mir die Bemerkung Troschels, dass er bei den von ihm untersuchten Formen der Gattungen Alcadia und Helicina keine wesentlichen Abweichungen an der Radula gefunden hätte; die von Troschel untersuchten Formen des Genus Helicina habe ich schon mit Rücksicht auf die Beschaffenheit des Gehäuses bis auf zwei noch zweifelhafte Formen bei dem Genus Alcadia Gray eingeteilt; Troschel hat also gar keine typischen Formen des Genus Helicina untersucht. Auch die von mir durchgeführte, feste Abgrenzung des Genus Eutrochatella Fischer, ebenso die Einteilung desselben in mehrere Gruppen wird schon zum Teile durch die Untersuchungen Troschels bestătigt. Die bei den Geschlechtern Alcadia Gray und besonders Eutrochatella Fischer beobacbtete Erscheinung, dass mănnliche und weibliche Tiere auch auffallende Unterschiede am Gehäuse erkennen lassen, tritt auch hier bei einigen Formenreihen in überraschender Weise auf. Auch hier werden diese Unterschiede besonders an der Mündung des Gehäuses bemerkbar. Das Auftreten von Exemplaren am gleichen Fundorte, welche anscheinend derselben Form angehören, sich jedoch durch ein recht auffallendes und konstantes Merkmal an der Mündung unterscheiden, hat mir viel Kopfzerbrechen gemacht. Die Unterschiede sind eben so bedeutend, dass solche Formen konstant als verschiedene Arten aufgefasst werden; irh habe in den Helicinenstudien für entsprechende Formen sogar verschiedene Formenkreise aufgestellt. Z. B. Den Formenkreis Angulata für die Formen aus der Verwandtschaft der Helicina angulata Sow. und den Formenkreis Variabilis für die Formen aus der Verwandtschaft der Hel. variabilis Wagner. Heute betrachte ich die Angulata-Formen nur als Geschlechtsunterschiede entsprechender Variabilisformen. So lange freilich die anatomische Untersuchung diese Annahme nicht bestätigt, bleibt auch mir nichts anderes übrig, als solche Geschlechtsformen als verschiedene Arten gelten zu lassell.

Formenkreis Angulata A. J. Wagner, Helicinenstudien 2, in: Denkschr. Akad. Wien. v. 78 p. $228,1905$.

\section{Formenkreis Variabilis A. J. Wrgner, Helicinenstudien 2, 1205.}

Da wie oben ausgeführt die Formen des Formenkreises der Helicina variabilis Wagner anscheinend nur Geschlechtsunterschiede entsprechender Formen aus dem Formenkreise der 
Helicina angulata Sowerby darstellen, so vereinige ieh beide Formenkreise, um neben jeder Angulataform die entsprechende Variabilisform anführen und mit derselben vergleichen zu können.

\section{Helicina brasilieusis Gray.} Taf. 53, Fig. 5-8.

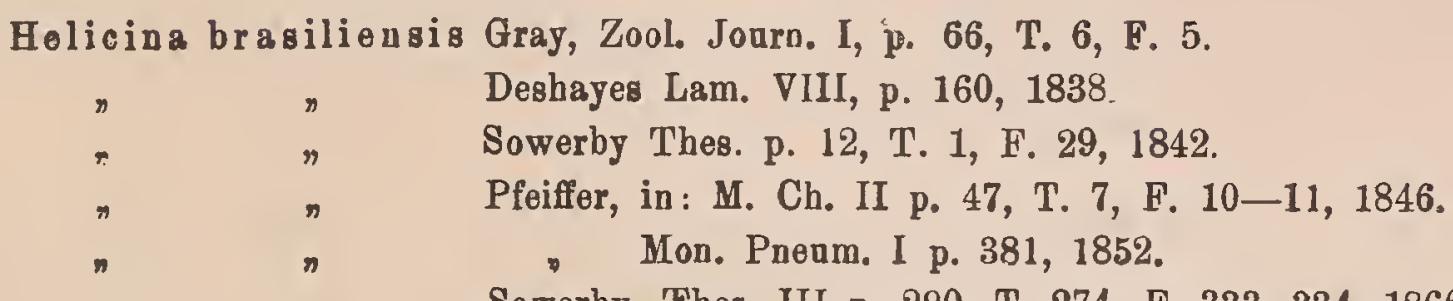

Sowerby, Thes. III p. 290, T. 274, F. 333, 334, 1866.

A. J. Wagner Helicinenstudien in: Denir. Akad. Wien, v. 78, p. 289, T. 13, F. 7,1905

Gehäuse gedrückt kugelig mit kegelförmigem Gewinde, ziemlich dünnschalig, leicht glänzend, gelblich oder rötlich fleischfarben mit unregelmässigen weisslichen Flecken, hăufig auch mit einem schmalen rotbraunen Bande unter der Peripherie; die Spitze zumeist dunkler gefärbt. Die Skulptur besteht nebst sehr feinen bis undeutlichen Zuwachsstreifen aus dichten, sehr feinen Spiralreifen, welche auf der Oberseite des letzten Umganges weitlänfiger und etwas ungleichmässig, auf der Unterseite schwächer, dichter und etwas gewellt erscheinen. Das mehr minder erhobene, regelmässig kegelförmige Gewinde besteht aus $4-4{ }^{1} / 2$ gewölbten, regelmässig zunehmenden Umgängen; der letzte ist etwas aufgeblasen, an der Peripherie gerundet oder undeutlich kantig und steigt vorne nicht herab. Die annähernd halbeiförmige Mündung ist nahezu senkrecht, hinter dem Mundsaum häufig mit einem zarten violetten Anflug. Der weisse, leicht verdickte Mundsaum umgeschlagen, der Oberrand an der Insertion nicht vorgezogen. Die dünne, senkrechte Spindel ist verlängert, geht rechtwinkelig in den Basalrand der Mündung über und bildet daselbst eine zienlich scharf vorspringende Ecke. Die Basis des Gehäuses neben der Spindel grübchenartig eingedrückt, das Grübchen durch eine von der Spindel ausgehende eingedrückte Bogenlinie nach hinten zu begrenzt. Der dünne, durchsichtige und glasglänzende Basalkallus ist sehr undeulich begrenzt.

$$
\mathrm{D}=7 \cdot 5, \mathrm{~d}=6.5, \mathrm{H}=5.5 \mathrm{~mm} \text {. }
$$

Deckel halbeiförmig, am Aussenrande beiderseits mit einer rotbraunen Zone, gegen den Spindelrand zu gelbbraun. Die Kalkplatte krustenartig dünn und zerbrechlich; in den übrigen Verhältnissen typisch.

Fundorte: Ich" gehe bei der Beurteilung dieser veränderlichen Art von Exemplaren aus, welche ich von Schlüter in Halle mit der Fundortsangabe Blumenau in Brasilien erhalten habe. Eine sehr ähnliche Form kenne ich ausserdem von Sao Paolo; die betreffenden 
Exemplare sind kleiner mit nur 4 Umgängen, die Mündung verhältnismässig grösser und mehr gerundet; der Mundsaum dicker und mehr ausgebreitet. Taf. 53, Fig. 8.

\title{
403. Helicina brasiliensis menkeana Philippi.
}

Taf. 53, Fig. 9-10 und Fig. 14-16.

\author{
Helicina menkeana Philippi, Zeitscur. f. Mal. p. 126, 1847. \\ n $\quad$ Pfeiffer M. Ch. II, T. 2, F. 22, 23, 1847. \\ » fasciata Delessert, recueil. T. 27, F. 2, nec. Lam. 1841. \\ $"$ oresigena Orb. synops. p. 28. ?
}

Gehäuse grösser, dickschaliger, breit kegelförmig mit gewölbter Basis, zumeist einfärbig gelblich oder gelbbraun. Die Spiralleisten kräftiger, die $4 \frac{1}{2}-5$ Umgănge schwächer gewölbt, der letzte nicht aufgeblasen, mehr gedrückt, mit deutlicher Kante an der Peripherie, vorne mitunter schwach herabsteigend. Die Mündung schiefer, der Mundsaum dicker bis verdoppelt, der Oberrand etwas vorgezogen; die rotbraune Zone hinter dem Mundsaum deutlicher, das Grübchen neben der Spindel tiefer.

$$
\begin{gathered}
D=9, d=7.5, H=6.5 \mathrm{~mm} \text { vom Fundorte: Sao Paolo. } \\
D=11, d=9, H=8.5 . \mathrm{mm} \text { vom Fundorte: Minas Geraes. }
\end{gathered}
$$

Deckel wie bei der typischen Form.

Ich kenne diese Form zunächst von Sao Paolo; durch ihre Dimensionen, die gedrücktere Form und die deutliche Kante bildet dieselbe einen Uebergang zu Helicina angulata Sowerby. Exemplare vom Fundorte Minas Geraes sind noch grösser, mit höherem Gehäuse, kräftigeren und etwas ungleichmässigen Spirallinien, sowie nahezu verdoppeltem Mundsaum. Taf. 53, Fig. 14. Aehnliche Exemplare kenne ich auch vom Fundorte Jaguary, doch weisen dieselben bereits einen deutlichen stumpfen Kiel auf.

\section{Variabilisform der Helicina brasiliensis menkeana Philippi.}

\section{Helicina densestriata $n$.}

Taf. 53, Fig. 11-13.

Gehăuse breitkegelförmig mit gewölbtel Basis, festschalig, wenig glänzend, einfarbig schmutzig gelb oder hellrotbraun. Die Skulptur besteht nebst feinen, ungleichmässigen Zuwachsstreifen aus dichten, feinen, auf der Oberseite der unteren Umgänge ungleichmăssigen Spiralreifen. Das regelmässig kegelförmige Gewinde besteht aus $4-\dot{4}^{1} / 4$ regelmässig zunehmenden schwach gewölbten Umgängen; der letzte ist an der Peripherie deutlich kantig bis stumpfgekielt und steigt vorne nicht herab. Die abserundet dreieckige Mündung ist schief; der leicht verdickte, weisse oder gelbliche Mundsaum kurz ausgebreitet, kaum umge= 
schlagen; der Oberrand an der Insertion etwas vorgezogen. Die dünne Spindel ist senkrecht und geht winkelig in den Basalrand über; am Uebergange keine vorspringende Ecke. In der Nabelgegend neben der Spindel nur ein schwacher Eindruck; der dünne, glänzende Basalkallus undeutlich begrenzt.

$$
D=7 \cdot 5, d=6.5 \mathrm{H}=5,
$$

Deckel unbekannt.

Fundort: Serra do Mar, Rio grande do Sul (leg. v. Königswald, die Exemplare im k. Museum zu Berlin.

Diese Form unterscheidet sich von $H$. brasiliensis menkeana Philippi, wesentlich nur durch die Verhältnisse der Mündung, deren Merkmale hier abgeschwächt erscheinen.

\section{Helicina angulata Sowerby. Taf. 54, Fig. 1-5.}

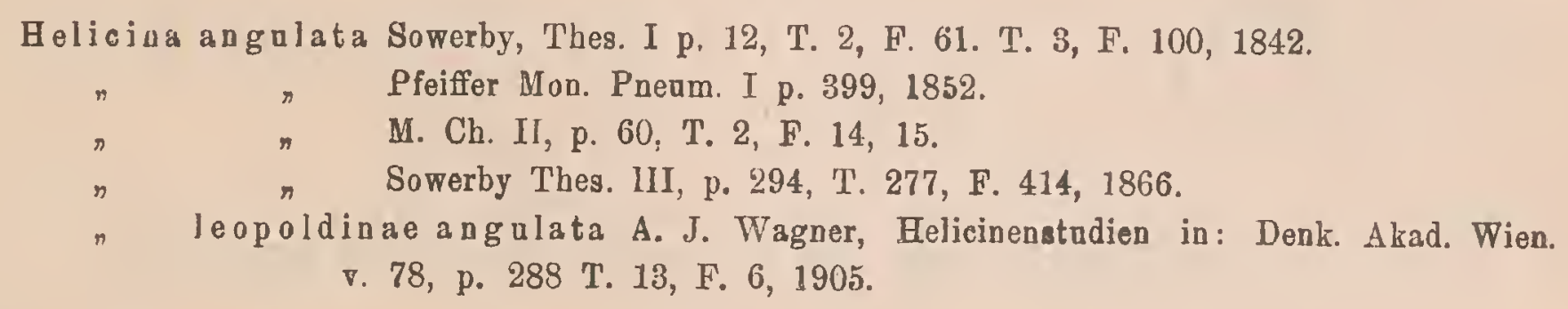

Gehäuse breit kegelförmig mit gewölbter Basis oder annähernd dicklinsenförmig, festschalig durchscheinend, leicht glänzend, gelb mit undeutlichen weisslichen Flecken und Striemen, sowie einer violetten bis rotbraunen Zone hinter dem Mundsaum. Die Skulptur besteht nebst feinen, gebogenen und ungleichmässigen Zuwachsstreifen aus dichten, niedrigen Spiralreifen, welche auf der Unterseite viel schwächer werden oder nahezu erlöschen. Das leicht konvexe Gewinde besteht aus $4-4^{1} / 2$ ziemlich rasch zunehmenden, leicht gewölbten Umgängen; der letzte ist beiderseits gleichmässig gewölbt, an der Peripherie stumpf bis scharf gekielt und steigt vorne nicht herab. Die abgerundet dreieckige Mündung ist wenig schief, mit einer rotbraunen Zone hinter dem Mundsaum. Der weisse Mundsaum leicht verdickt, ausgebreitet und umgeschlagen, der Obelrand an der Insertion kaum vorgezogen. Die dünne senkrechte Spindel geht winkelig in den Basalrand über, am Uebergange eine etwas abgerundete, deutlich vorspringende Ecke. In der Nabelgegend neben der Spindel ein seichtes, durch eine eingedrückte Bogenlinie begrenztes Grübchen. Der dünne, weisse Basalkallus sehr undeutlich begrenzt.

$$
D=11, d=9, H=7 \mathrm{~mm} \text {. }
$$

Deckel halbeiförmig, beiderseits dunkel kastanienbraun. Die dünne, fein gekörnelte,
I. 18. II.
4. II. 1910. 
leicht glänzende Kalkplatte konkav, am Spindelrande dicker und leistenförmig erhoben; in den übrigen Verhältnissen typisch.

Fundorte: Neu-Freiburg und Sao Paolo in Brasilien.

\section{Helicina angulata leopoldinae A. J. Wagner. \\ Taf. 54, Fig. 11.}

Helicina leopoldinae A. J. Wagner Helicinenstudien in Dent. Akad. Wien, จ. 78, p. 228, T. 13, F. 4,1905 .

Gehäuse grösser, mit weitläufigeren, schärferen Spiralreifen, welche auf der Unterseite dichter und schwächer, aber immer deutlich sind, die $4^{1} / 2$ Umgänge sind nahezu flach, die Mündung verhältnismässig stärker erweitert, der Mundsaum schmäler, das Grübchen in der Nabelgegend tiefer und deutlicher begrenzt.

$$
\mathrm{D}=14, \mathrm{~d}=12, \mathrm{H}=9.5 \mathrm{~mm} \text {. }
$$

Deckel abgerundet dreieckig, beiderseits dunkel rotbraun, in den übrigen Verhältnissen typisch.

Fundort: S. Leopoldina in Brasilien.

\section{Variabilisform der Helicina angulata Sowerby.}

\section{Helicina inaequistriata Pilsbry.}

Taf. 54, Fig. 6-10.

Helicina inaequistriata Pilsbry, in: Pr. Ac. Philadelphia p. 394, 1900.

Gehăuse von demjenigen der H. angulata Sowerby nur durch die Verhältnisse der Mündung abweichend. Der Mundsaum kürzer ausgebreitet, weniger umgeschlagen, die Spindel kürzer, die Ecke am Uebergange derselben in den Basalrand der Mündung abgerundet bis undeutlich; die Furche neben der Spindel weniger eingedrückt

$$
\mathrm{D}=10, \mathrm{~d}=8.5, \mathrm{H}=7 \mathrm{~mm} \text {. }
$$

Deckel rotbraun, sonst wie bei $H$. angulata Sowerby.

Fundort: Ruiz da Serra in Sao Paolo, Brasilien, mit der typischen Form der H. angulata Sowerby zusammenlebend. Pilsbry beschreibt den letzten Umgang als "deutlich kantig;" auch ich finde einzelne Exemplare dieser Form stumpfer gekielt, wie dies auch bei H. angulata Sowerby zu beobachten ist. 
408. Helicina wettsteini A. J. Wagner.

Taf. 53, Fig. 17-19.

Helicina wettsteini A. J. Wagner Helicinenstudien in Denk. Akad. Wien, จ. 78,p. 229, T. 13, F. 5, 1905.

Gehäuse breit kegelförmig mit gewölbter Basis, festschalig, leicht glänzend, die Grundfarbe gelblich hornfarben bis braunviolett mit unregelmässigen weisslichen Flecken und Striemen, -sowie einer violettbraunen Zone hinter dem Mundsaum; über dem Kiel und der Naht der untern Umgänge ist häufig ein rotbraunes, ziemlich scharf begrenztes Band vorhanden, welches auf der Oberseite der oberen Umgänge die Grundfarbe oft vollkommen verdeckt. Die Skulptur besteht nebst feinen, ungleichmässigen, schiefradialen Zuwachsstreifen aus niedrigen, dichten Spiralreifen, welche am letzten Umgange ungleichmässig und weitläufiger, auf der Unter'seite etwas schwächer werden. Das niedrige, regelmässig kegelförmige Gewinde besteht aus $4^{1} / 2$-5 leicht gewölbten bis nahezu flachen, ziemlich rasch zunehmenden Umgängen; der letzte ist etwas zusammengedrückt, an der Peripherie ziemlich scharf gekielt und steigt vorne nicht herab. Die dreieckige Mündung ist schief, der weisse ziemlich dicke Mundsaum breit umgeschlagen; der Oberrand an der Insertion etwas vorgezogen. Die dünne, senkrechte Spindel geht winkelig in den Basalrand über, am unteren Ende derselben befindet sich eine scharf vorspringende zahnartige Ecke. In der Nabelgegend, neben der Spindel ein verhältnismässig tiefer, grübchenartiger Eindruck. Der Basalkallus nur angedeutet.

$$
\mathrm{D}=13, \mathrm{~d}=10, \mathrm{H}=8.5 \mathrm{~mm} \text {. }
$$

Deckel abgerundet dreieckig, beiderseits lebhaft kastanienbraun gefärbt mit zarter, feingekörnelter Kalkplatte; in den übrigen Verhältnissen typisch.

Fundorte: Serra Parana-Piacaba und Sao Sebastiao in Sao Paolo, Brasilien. Die Variabilisform dieser Art ist mir noch nicht bekaunt geworden.

\section{Variabilisform der Helicina iguapensis Pilsbry.}

\section{Helicina caracolla Moricand.}

Taf. 54, Fig. 12-15.

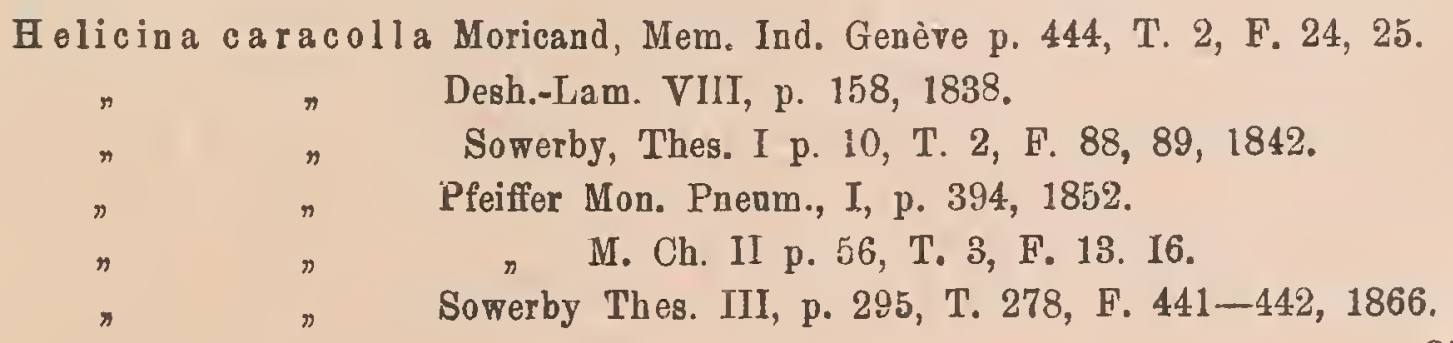


Helicina caracolla A. J. Wagner Helicinenstndien in Denk. Ak. Wien, v. 78, p. 227, T. 13, F. 3, 1905 .

Gehäuse flachlinsenförmig, ziemlich festschalig, etwas durchscheinend leicht glänzend, gelblich hornfarben bis rotbraun. Die Skulptur besteht nebst feinen, schiefradialen Zuwachsstreifen aus dichten, feinen Spiralreifen, welche auf dem letzten Umgange weitlăufiger, auf der Unterseite dichter und etwas gewellt erscheinen. Das regelmässig flach kegelförmige oder schwach konvexe Gewinde besteht aus $4^{1} / 2$ bis 5 nahezu flachen, rasch zunehmenden Umgängen; der letzte ist zusammengedrückt, sehr scharf gekielt, beiderseits gleichmässig gewölbt und steigt vorne nicht herab. Die dreieckige Mündung ist sehr schief, der weisse, leicht verdickte Mundsaum breit umgeschlagen; der Oberrand an der Insertion vorgezogen. Die kurze, abgerundete Spindel ist nach Aussen gebogen, und bildet am Uebergange in den Basalrand der Mündung nur eine abgerundete knotenartige Verdickung. Die Nabelgegend nur undeutlich eingedrückt; der glänzende, weisse oder gelbliche Basálkallus, nur im Umkreise der Spindel deutlich verdickt, sonst undeutlich begrenzt.

$$
\mathrm{D}=17, \mathrm{~d}=14, \mathrm{H}=9 \mathrm{~mm} \text {. }
$$

Deckel dreieckig, beiderseits rotbraun mit lichterem Spindelrand. Die feingekörnelte, ziemlich feste Kalkplatte ist am Spindelrand auffallend leistenförmig erhoben; in den übrigen Verhältnissen typisch.

Fundort: Brasilien (Alameda).

\section{Helicina caracolla moreletiana Pfeiffer.}

Taf. 54, Fig. 16.

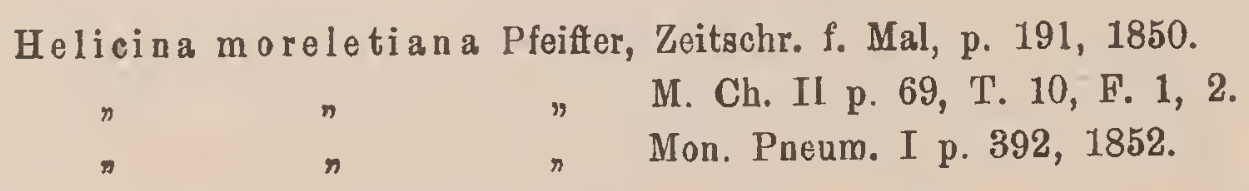

Gehäuse grösser, festschaliger, gelblichweiss bis rotgelb; die Spiralreifen kräftiger, der Mundsaum dicker und breiter umgeschlagen.

Deckel wie bei der typischen Form.

$$
\mathrm{D}=21, \mathrm{~d}=17, \mathrm{H}=11 \mathrm{~mm} \text {. }
$$

Fundort: Bahia in Brasilien. Ein zweifelloses Exemplar dieser Form, welches sich von H. caracolla Mor. eigentlich nur durch die bedeutenderen Dimensionen unterscheidet, liegt im k. Museum zu Berlin mit der Fundortsangabe Bahia. Diese Fundortsangabe halte ich für vollkommen zuverlässig und hat die vorstehende Form dementsprechend nicht mehr als verschollen zu gelten. 


\section{Angulataform der Helicina caracolla Moricand.}

\section{Helicina iguapensis Pilsbry.}

Taf. 54, Fig. 17-19.

\section{Helicina iguapensis Pilsbry, in: Pr. Acad. Philadelphia p. 393, 1900.}

Gehäuse von demjenigen der H. caracolla Mor. nur durch die Beschaffenheit der Spindel unterschieden: Spindel länger, abgeflacht, und winkelig in den Basalrand übergehend; am unteren Ende derselben eine zahnartige, scharf vorspringende Ecke. Die Farbe des mir vorliegenden Exemplares ist gelblichweiss mit undeutlichen weissiichen Flecken.

$$
\mathrm{D}=17, \mathrm{~d}=14, \mathrm{H}=10 \mathrm{~mm} \text {. }
$$

Deckel wie bei $\mathrm{H}$. caracolla Mor.

Fundort: Iguape in Sao Paolo, Brasilien.

\section{Helicina leptrotopis n.}

Tat. 54, Fig. 20-21.

Gehäuse breit kegelförmig mit gewölbter Basis, dünnschalig, durchscheinend, wenig glänzend, hellgelb mit lichterem letzten Umgang. Die Skulptur besteht nebst feinen, ungleichmässigen, schiefradialen Zuwachsstreifen aus sehr feinen, ziemlich dichten Spiralreifen, welche am letzten Umgange ungleichmässig, auf der Unterseite schwächer und etwas wellig gebogen erscheinen. Das regelmässig kegelförmige oder nur schwach konvexe Gewinde besteht aus 5 ziemlich rasch zunehmenden, nahezu flachen Umgängen; der letzte ist zusammengedrückt und an der Peripherie scharf gekielt, vorne nicht herabsteigend; in der 2. Halfte des letzten Umganges ist auf der Unterseite ausserdem ein zweiter, stumpfer Kiel angedeutet. Die dreieckige Mündung ist schief, der weisse Mundsaum schwach verdickt, ziemlich kurz ausgebreitet und umgeschlagen; der Oberrand an der Insertion vorgezogen. Die dünne, nahezu senkrechte Spindel geht winkelig in den Basalrand über und bildet am Uebergange nur eine kaum vorspringende, knotenartige Verdickung. Die Nabelgegend schwach eingedrückt, durch eine leicht eingedrückte Linie begrenzt. Der weisse, feingelzörnelte Basalkallus nur im Umkreise der Spindel deutlich verdickt, undeutlich begrenzt.

Deckel unbekannt.

$$
\mathrm{D}=13, \mathrm{~d}=11, \mathrm{H}=8.5 \mathrm{~mm} \text {. }
$$

Fundort: Sao Paolo, Brasilien.

Die vorstehende Art bildet einen Uebergang von H. caracolla Mor. zú H. variabilis Wagner und stellt eine Variabilisform dar, deren entsprechende Angulataform mir jedoch nicht bekannt ist. E. von Martens bezeichnete dieselbe als H. carinata d'Orbigny. 


\section{Helicina variabilis Wagner.}

Taf. 55, Fig. $1-5$.

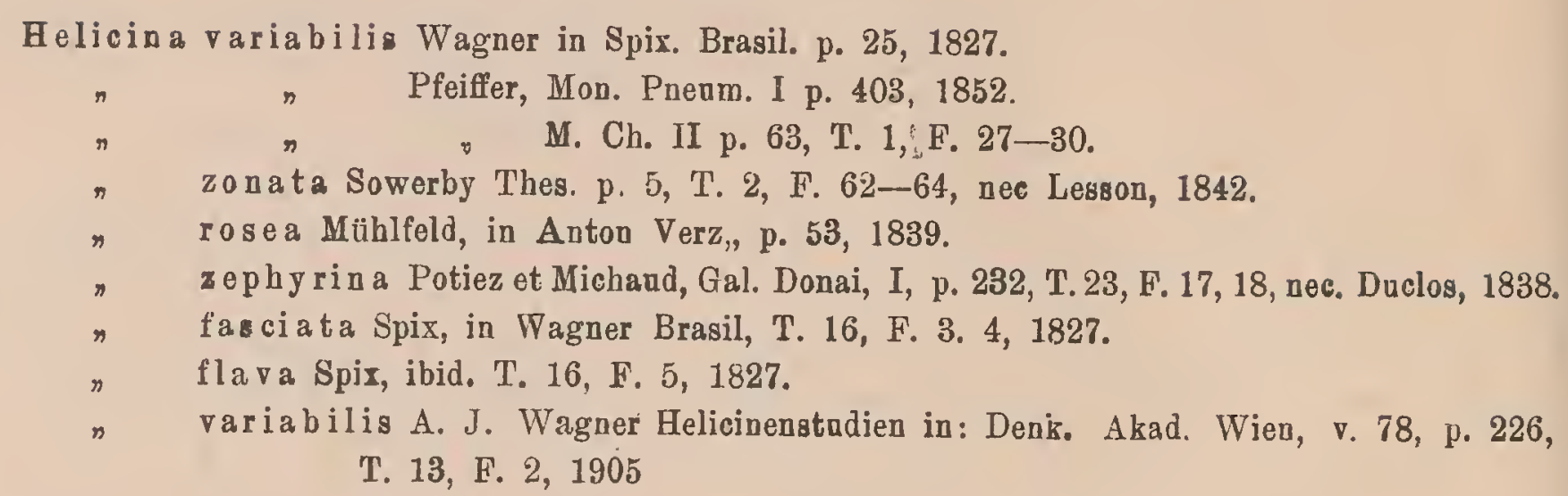

Gehäuse annähernd halbkugelig mit flach gewölbter Basis, festschalig, leicht glänzend; einfarbig gelblich bis rötlich hornfarben, häufig mit rotbraunen bis braunvioletten breiten Bändern auf der Ober- und Unterseite, welche nur schmale Streifen der lichteren Grundfarbe entlang dem Kiel und der Naht freilassen. Die sehr wechselnde Skulptur besteht nebst feinen, ungleichmässigen, schiefradialen Zuwachsstreifen aus ziemlich dichten, aber ungleichmässigen Spiralreifen und Spiralfurchen, welche auf der Oberseite des letzten Umganges weitläufiger, auf der Unterseite dichter und schwächer werden, mitunter nahezu erlöschen. Das annähernd halbkugelige, mehr minder erhobene Gewinde besteht aus 5-51/2 leicht gewölbten bis nahezu flachen Umgängen, welche ziemlich langsam und regelmässig zunehm $n$; der letzte ist unten stark abgeflacht, an der Peripherie mehr minder scharf gekielt und steigt vorne nicht herab; auf der Unterseite ist ausserdem ein zweiter, mehr minder deutlicher und stumpfer Kiel vorhanden. Die abgerundet dreieckige Mündung ist schief, der lippenartig verdickte, weisse, bräunliche oder zitrongelbe Mundsaum ist ziemlich ausgebreitet; der Oberrand an der Insertion vorgezogen, fast gerade oder etwas berabyebogen, der Aussen- und Basalrand umgeschlagen. Die kurze, abgerundete Spindel ist nach Aussen gebogen, am Uebergange in den Basalrand findet sich eine kaum vorspringende, knotenartige Verdickung. Eine furchenartiger Eindruck oder ein Grübchen sind in der Nabelgegend zumeist nur angedeutet. Der weisse Basalkallus ist im Umkreise der Spindel oft ziemlich verdickt, jedoch undeutlich begrenzt.

$$
\mathrm{D}=13-16, \mathrm{~d}=11-13, \mathrm{H}=9-11 \mathrm{~mm} \text {. }
$$

Deckel abgerundet dreieckig, beiderseits dunkel kastanienbraun gefärbt, mit ziemlich dünner, feingekörnelter, flachkonkaver Kalkplatte; in den übrigen Verbältnissen typisch.

Fundort: Brasilien (Bahia, Iguape in Sao Paolo). 


\section{Angulataform der Helicina variabilis Wagner.}

\section{Helicina angulifera n. \\ Taf. 55, Fig. 6-8.}

Gehäuse sehr ähnlich demjenigen der $\mathrm{H}$. variabilis Wagner; die $4 \frac{1}{2}$ Umgänge nehmen jedoch rascher $\mathrm{zu}$, die verlängerte Spindel ist nach vorne gebogen. geht im rechten Winkel in den Basalrand über und bildet am Uebergange eine auffallende zahnartige Ecke.

$$
\mathrm{D}=10.5-13 \cdot 5, \mathrm{~d}=8 \cdot 5-11, \mathrm{H}=7.5-9 \mathrm{~mm} \text {. }
$$

Deckel wie bei $\mathrm{H}$. variabilis Wagner. lebend.

Fundort: Bahia in Brasilien, mit Helicina variabilis am gleichen Fundorte zusammen-

\section{Helicina tile i Pfeiffer.}

Taf, 55, Fig. 11-12.

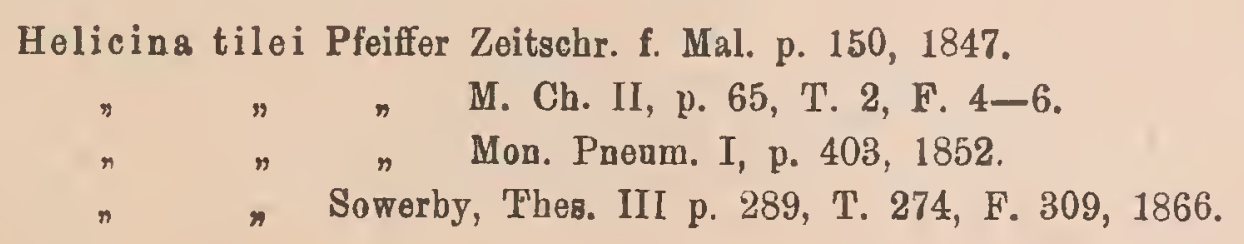

Gehäuse kegelförmig mit flachgewölbter Basis, festschalig, leicht glänzend, zitrongelb mit hellerem letzten Umgange. Nach der Originaldiagnose ist das Gehäuse glatt, an dem mir vorliegenden Exemplare bemerke ich jedoch eine schwache Andeutung von radialen Zuwachsstreifen und einigen sehr undeutlichen Spirallinien, auch erscheint dasselbe etwas abgerieben. Frische Exemplare dürften demnach eine deutliche Skulptur besitzen. Das ziemlich erhobene Gewinde ist schwach konvex und besteht aus 5 langsam zunehmenden, schwach gewölbten Umgängen; der letzte ist unten abgetlacht, unter der Peripherie stumpf gekielt und steigt vorne deutlich unter den Kiel herab; ein zweiter Kiel ist an meinem Exemplare nur durch eine stumpfe Kante angedeutet. Die halbeiförmige Mündung ist sehr schief, der weisse Mundsaum lippenartig verdickt, ziemlich kurz ausgebreitet und umgeschlagen; der Oberrand an der Insertion stark vorgezogen. Die kurze, nahezu senkrechte und etwas abgeflachte Spindel geht winkelig in den Basalrand über und bildet am Uebergange eine winkelig vorspringende Ecke. Die Nabelgegend leicht eingedrückt und durch eine eingedrückte Querlinie begrenzt. Der dünne, weisse Basalkallus ziemlich deutlich begrenzt.

$$
\mathrm{D}=9, \mathrm{~d}=7 \cdot 5, \mathrm{H}=7 \mathrm{~mm} \text {. }
$$

Deckel unbekannt.

Fundort: Brasilien. 
Ich beurteile diese nahezu verschollene Art nach einem Originalexemplare; dasselbe steht trotz der Andeutung eines zweiten Kieles der H. brasiliensis menkeana Philippi näher, als der $H$. variabilis Wagner.

\title{
416. Helicina rotundata n.
}

Taf. 55, Fig. 15-16.

Gehäuse breitkegelförmig mit flachgewölbter Basis, festschalig, schwach durchscheinend, wenig glänzend; gelblich hornfarben mit lichterem bis weissen letzten Umgang. Die Skulptur besteht nebst deutlichen, sehr ungleichmässigen Zuwachsstreifen aus dichten, feinen, ziemlich erhobenen Spiralreifen, welche auf der Unterseite viel schwăcher werden und nahezu erlöschen. Das breit kegelförmige, etwas abgerundete Gewinde besteht aus 5 langsam und regelmässig zunehmenden, schwach gewölbten Umgängen; der letzte ist gerundet, unten etwas abgeflacht und steigt vorne deutlich herab. Die halbeiförmige Mündung ist sehr schief; der weisse lippenartig verdickte Mundsaum kurz ausgebreitet und umgeschlagen; der Oberrand an der Insertion vorgezogen. Die kurze, abgeflachte und nahezu senkrechte Spindel bildet am Uebergange in den Basalrand eine leicht vorspringende, zahnartige Ecke. Die Nabelgegend leicht eingedrückt und durch eine schwach eingedrückte Querlinie begrenzt. Der dünne, gelbliche Basalkallus ist ziemlich undeutlich begrenzt.

$$
\mathrm{D}=8.5, \mathrm{~d}=7 \cdot 2, \mathrm{H}=6.5 \mathrm{~mm} \text {. }
$$

Deckel unbekannt.

Fundort: Brasilien; diese neue Form unterscheidet sich von H. tilei Pfeiffer mit der sie bezüglich der Beschaffenheit der Mündung vollkommen übereinstimmt durch den vollkommen gerundeten letzten Umgang und die ausgesprochene Spiralskulptur. Dieselbe könnte auch als Form der so variablen $H$. brasiliensis Gray aufgefasst werden, unterscheidet sich jedoch von derselben bestimmt durch den auffallend herabsteigenden letzten Umgang.

\author{
417. Helicina haemastoma Moricand. \\ Taf. 55, Fig. 13-14. \\ Helicina haemast oma Moricand, Mém. Soc. Genève, 9 p. 36, T. 3, F. 67, 1841.

$\begin{array}{lll}n & & \text { Pfeiffer, M. Ch. II, p. 42, T. 1, F. 20, } 21 . \\ \eta & n & \text { Sowerby, Thes. III p. 289, T. 273, F. 452, } 1866 .\end{array}$

Gehäuse annähernd kreiselför'mig mit abgeflachter Basis, festschalig, leicht glänzend bis matt; die Grundfarbe grauweiss, gelblich oder rötlich, die Oberseite lebhafter gefärbt, die ersten Umgånge rotorange bis zinoberrot, ebenso der Mundsaum und Basalkallus. Die Skulptur besteht nebst schwachen und ungleichmässigen Zuwachsstreifen aus dichten, niedrigen und 
feinen Spiralreifen, welche am letzten Umgange schwächer bis undeutlich werden. Das ziemlich erhobene, annähernd halbkugelige Gewinde bestelt aus $4^{1} / 2$ nahezu flachen, langsam und regelmässig zunehmenden Umgängen; der letzte gerundet, unten abgeflacht, vorne nicht herabsteigend. Die halbeiförmige Mündung ist schief. Der lippenartig verdickte Mundsaum kurz ausgebreitet; der Oberrand an der Insertion vorgezogen, fast gerade oder etwas herabgebogen, der Aussen- und Basalrand etwas umgeschlagen. Die nahezu senkrechte, abgeflachte Spindel bildet am Uebergange in den Basalrand der Mündung eine stumpfe, wenig vorspringende Ecke. Die Nabelgegend schwach furchenartig eingedrückt. Der dünne, undeutlich begrenzte Basalkallus in der Mitte, wie der Mundsaum lebhaft rotorange gefärbt.

$$
\mathrm{D}=9, \mathrm{~d}=8, \mathrm{H}=8 \text {. }
$$

Deckel nach Angabe des Autors tief blutrot gefärbt, die übrigen Verbăltnisse unbekannt. Fundort: Brasilien.

\section{Helicina besckei Pleiffer.}

Taf. 55, Fig. 10.

Helicina besokei Pfeiffer Pr. Z. 8. p. 120, 1848.

A. J. Wagner Helicinenstudien, in Denk. Akad. Wien, Ү. 78, p. 227, T. 13 , F. 8,1905 .

Gehäuse breit kegelförmig oder fast halbkugelig mit flach gewölbter Basis, festschalig, wenig glünzend, zitrongelb mit lichterem letzten Umgang und einer rotbraunen Nahtbinde, welche scharf begrenzt bis zur Embryonalwindung reicht. Die Skulptur besteht nebst schwachen bis undeutlichen Zuwachsstreifen aus niedrigen, ziemlich dichten Spiralreifen auf den mittleren Umgängen, welche auf dem letzten Umgange und der Basis weitlăufiger und schwächer werden oder erlöschen. Das mehr minder erhobene und abgerundete Gewinde besteht aus $4 \frac{1}{2}-5$ im Beginne schwach gewölbten und langsam zunehmenden, zum Schlusse nahezu flachen und rascher zunehmenden Umgängen; der letzte ist unten etwas abgeflacht, an der Peripherie stumpf gekielt und steigt vorne nicht herab. Auf der Unterseite werden mitunter ein zweiter stumpfer Kiel, ebenso einige stärkere, weitläufige und stumpfe Spiralleisten sichtbar, auch erscheint die Oberfläche des letzten Umganges häufig uneben, wie gehämmert. Die abgerundet dreieckige Mündung ist wenig schief; der ziemlich dicke, weisse Mundsaum kurz ausgebreitet und umgeschlagen, der Oberrand an der Insertion vorgezogen. Die kurze, fläche Spindel ist etwas nach Aussen gebogen, am Uebergange derselben in den Basalrand der Mündung findet sich eine knotenartige Verdickung. Der weisse, dünne und glänzende Basalkallus ist undeutlich begrenzt. In der Nabelgegend eine schwach eingedrückte Querfurche.

Deckel unbekannt.

$$
\mathrm{D}=16-17, \mathrm{~d}=13-14, \mathrm{H}=11-13 \mathrm{~mm} .
$$

Fundort: Neu-Freiburg in Brasilien.

I. 18. II.

31. II. 1910. 


\title{
419. Helicina lundi Beck.
}

Taf. 55, Fig. 17-19.

Helicina lnndi Beck mss. in Pfeiffer, Mon. Pnenm. II p. 216, 1858.

$n \quad \pi$ A. J. Wagner Helicinenstudien, in: Denk. Akad. Wien. v. 78, p. 230, T. 13, F. 13, 1905.

Gehäuse breit kegelförmig mit gewölbter Basis, festschalig, gelblich hornfarben oder braungelb, die oberen Umgänge orange, wenig glänzend bis matt. Die Skulptur besteht nebst dichten, feinen und ungleichmässigen Zuwachsstreifen aus sehr dichten und feinen Spirallinien, welche auf der Unterseite wellig gebogen erscheinen, mitunter nahezu erlöschen; auf der Oberseite werden mitunter auch einige stärkere, stumpfe Spiralleisten sichtbar. Das regel. mässig kegelförmige Gewinde besteht aus $4 \frac{1}{2}$ ziemlich langsam zunehmenden, nahezu flachen Umgängen, welche jedoch durch eine Kante unter der Naht stufenartig abgesetzt sind; der letzte ist etwas zusammengedrückt, an der Peripherie gekielt und steigt vorne nicht herab. Die abgerundet dreieckige Mündung ist schief; der weisse Mundsaum leicht verdickt, kurz ausgebreitet; der Oberrand an der Insertion vorgezogen, gerade, der Basalrand schwach umgeschlagen. Die kurze, abgeflachte Spindel ist etwas nach Aussen und vorn gebogen und bildet am Uebergange in den Basalrand der Mündung eine deutlich vorspringende Ecke. . In der Nabelgegend eine undeutlich eingedrückte Querleiste. Der ziemlich dicke, weisse Basalkallus ist gekörnelt und deutlich begrenzt.

Deckel unbekannt.

$$
\mathrm{D}=8, \mathrm{~d}=7, \mathrm{H}=5.5 \mathrm{~mm} \text {. }
$$

Fundort: Lupa da Pedro in Brasilien.

\section{Formenkreis Concentrica A. J. Wagner.}

\section{Helicina concentrica Pfeiffer.}

Taf. 56, Fig. $1-5$.

\author{
Helicina concentrica Pfeiffer Pr. Z. S. p. 129, 1848.
}

Gehäuse breit kegelförmig mit gewölbter Basis, festschalig, leicht glänzend, gelblich hornfarben bis hellrotbraun oder fleischfarben mit feinen weisslichen Fleckenzeichnungen und lichtem bis weissen Kiel. Die Skulptur besteht nebst feinen bís undeutlichen Zuwachsstreifen aus einigen stumpfen und weitläufigen Spiralleisten, welche mitunter nahezu erlöschen, daneben sind unter der Lupe schief nach vorne herabsteigende Runzelstreifen der Epidermis sichtbar. Das regelmässig kegelförmige, ziemlich erhobene Gewinde besteht aus $4^{1 / 2}$ leicht gewölbten, ziemlich rasch sunehmenden Umgängen; der letzte ist beiderseits gleichmässig gewölbt, an der Peripherie scharf gekielt und steigt vorne sehr wenig oder gar nicht unter 
den Kiel herab. Die dreieckige Mündung ist ziemlich schief, der weisse oder gelbliche, lippenartig verdickte Mundsaum ausgebreitet und umgeschlagen; der Oberrand an der Insertion vorgezogen. Die kurze, dicke und abgerundete Spindel ist nach Aussen gebogen, am Uebergange in den Basalrand findet sich eine leichte, knotenartige Verdickung. Der milchweisse, oder gelbliche, glänzende, mitunter fein gekörnelte Basalkallus ist im Umkreise der Spindel stärker verdickt, nach hinten dnrch eine Furche begrenzt. In der Nabelgegend ein entlang der Spindel furchenartig verlängertes Grübchen.

$$
\mathrm{D}=9, \mathrm{~d}=8, \mathrm{H}=6.5 \mathrm{~mm} \text {. }
$$

Deckel dreieckig, beiderseits lebhaft kastanienbraun mit einem weisslichen oder gelbbraunem Fleck in der Umgebung des Nukleus. Die feingekörnelte, flach konkave Kalkplatte ist dünn, am Spindelrande jedoch zu einer deutlich erhobenen Leiste verdickt; die übrigen Verhältnisse des Deckels sind typisch.

Fundort: Venezuela (Merida).

Ich betrachte Helicina concentrica Pfr. als Typus eines im nördlichen Südamerika (Venezuela, Columbien, Peru, Bolivia) weit verbreiteten und für diese Länder charakteristischen Formenkreises auf. Das linsenförmige bis kegelförmige Gehăuse dieser Formen ist gekielt, die Spiralskulptur zumeist deutlich, nur selten vollkommen erloschen, die kurze Spindel gebogen, in der. Nabelgegend ein furchenartig verlängertes, entlang der Spindel nach abwärts verlängertes Grübchen.

\section{Helicina pandiensis A. J. Wagner.}

Taf. 56, Fig. 6-10.

Helicina pandiensis A. J. Wagner Helicinenstudien in: Denk. Akad. Wien, v. 78, p. 221, T. 12, F. 41905.

Gehäuse breit kegelförmig mit gut gewölbter Basis, festschalig, leicht glänzend, gelblich hornfarben oder gelbgrau mit undeutlichen weisslichen Striemen und Bändern. Die Skulptur besteht nebst sehr feinen bis undeutlichen Zuwachsstreifen aus einigen stumpfen (5-6) Spiralleisten auf der Oberseite, welche am letzten Umgange ungleichmässig werden; daneben erscheint die Epidermis unter der Lupe sehr fein gerunzelt. Das ziemlich erhobene, etwas abgerundet kegelförmige Gewinde besteht aus 5 ziemlich langsam zunehmenden, leicht gewölbten Umgängen; der letzte ist beiderseits gewölbt, an der Peripherie scharf gekielt und steigt vorne wenig oder nicht herab. Die dreieckige Mündung ist ziemlich schief; der weisse, leicht verdickte Mundsaum kurz ausgebreitet, der Oberrand an der Insertion vorgezogen und fast gerade, der Aussenrand entsprechend dem Kiele schwach winkelig ausgezogen, der Basalrand schmal umgeschlagen. Die kurze, abgerundete Spindel ist nach aussen und vorn gebogen, am Uebergange in den Basalrand der Mündung eine stumpfe, aber deutlich vorspringende Ecke. Der gelbliche, gekörnelte Basalkallus ist nur im Umkreise der 
Spindel deutlich verdickt, nach binten durch eine Furche begrenzt. In der Nabelgegend ein deutliches, furchenartig verlängertes Grübchen.

$$
\mathrm{D}=9, \mathrm{~d}=7.5, \mathrm{H}=6.5 \mathrm{~mm} .
$$

Deckel abgerundet dreieckig mit einer kastanienbraunen Zone entlang dem Aussenrande, in der Mitte und am Spindelrande gelbbraun; die dünne, fein gekörnelte Kalkplatte ist flach konkav, am Spindelrande zu einer stumpfen Leiste verdickt und erhoben.

Fundort: Pandi in Neu-Granada.

Von Helicina concentrica Pfeiffer unterscheidet sich vorstehende Art durch das leicht konvexe Gewinde, die grössere Zahl der im Beginne langsamer zunehmenden Umgänge, die deutlichere und nur auf der Oberseite vorhandene Spiralskulptur und besonders durch die Beschaffenheit der Mündung. Der Mundsaum ist dünner, kürzer ausgebreitet, die Spindel nach vorne und aussen gebogen mit einer deutlich vorspringenden Ecke am Uebergange in den Basalrand.

\section{Helicina schlüteri A. J. Wagner. \\ Taf. 56, Fig. 11-14.}

Helicina sehltuteri A. J. Wagner Helicinenstadien in: Denk. Akad. Wien. v. 78, p. 221, T. 12, F. 5, 1905.

Gehäuse kegelförmig mit gewölbter Basis, festschalig, durchscheinend, leicht glänzend; die Grundfarbe gelb bis rotbraun mit milchigen Flecken und Striemen. Die Skulptur besteht nebst deutlichen, ungleichmässigen Zuwachsstreifen aus ziemlich weitläufigen, niedrigen Spiralreifen, welche auf der Oberseite der 2 letzten Umgänge weitläufiger $(6-7)$, eigentümlich gewellt und unterbrochen erscheinen, auf der Unterseite auffallend dichter und schwächer werden; ferner erscheint die Oberfäche uneben und werden besonders auf den mittleren Umgängen schiefradiale nach vorne absteigende Wülste sichtbar. Das mehr minder erhobene, regelmässig kegelförmige Gewinde besteht aus $4 \frac{1}{2}-5$ ziemlich rasch zunehmenden, schwach gewölbten Umgängen; der letzte ist beiderseits gleichmăssig gewölbt, etwas zusammengedrückt, an der Peripherie, im Beginne ziemlich scharf gekielt, gegen die Mündung zu stumpfer bis kantig und steigt vorne nicht herab. Die abgerundet dreieckige Mündung ist ziemlich schief, der weisse, lippenartig verdickte Mundsaum ausgebreitet und umgeschlagen; der Oberrand an der Insertion etwas vorgezogen. Die kurze, abgerundete Spindel ist nach aussen gebogen, am Uebergange derselben in den Basalrand der Mündung weder ein Knoten noch eine Ecke. Der weisse, gekörnelte Basalkallus nur im Umkreise der Spindel deutlich und nach hinten durch eine seichte Furche begrenzt, nach vorne zu durchsichtig und undeutlich. In der Nabelgegend ein undeutliches, furchenartiges Grübchen.

$$
\mathrm{D}=9.5-11, \mathrm{~d}=8-9.5, \mathrm{H}=7.5 \mathrm{~mm} \text {. }
$$

Deckel abgerundet dreieckig, beiderseits rotbraun mit leicht nach rückwärts gebogenem 
Spindelwinkel, die dünne gekörnelte Kalkplatte ist Hach konkav und nur am Spindelrande leistenartig erhoben und verdickt; die übrigen Verhăltnisse des Deckels typisch.

Fundort: Callanga in Peru.

\section{Helicina schlüteri chanchamayensis n.}

Taf. 56, Fig. 15-17.

Gehäuse grösser, dünnśchaliger, rotbraun mit dunklerem Kiel und mitunter gelbem Gewinde. Das niedrige Gewinde besteht aus 5 rascher zunehmenden, Hlachen Umgängen; der letzte ist mehr zusammengedrückt, bald stumpf, bald scharf gekielt. Die Mündung verhältnismässig breiter, der dünnere Mundsaum kürzer ausgebreitet, der Basalkallus bräunlich bis zitrongelb gefärbt. Dit ungleichmässigen Zuwachsstreifen sind kräftiger, ebenso besteht die Spiralskulptur aus weitläufigeren, schärferen und dünneren Spiralleistchen; im übrigen ist die Oberfläche nicht uneben und wulstig.

Deckel wie bei der typischen Form.

$$
\mathrm{D}=14, \mathrm{~d}=11.5, \mathrm{H}=9 \mathrm{~mm} \text {. }
$$

Fundort: Chanchamayo in Peru.

\section{Helicina schlüteri densesulcata n. Taf. 56, Fig. 18.}

Gehäuse grösser, dünnschaliger, schmutziggelb oder graugelb mit unregelmässigen weisslichen Fleckenzeichnungen. Das regelmässig kegelförmige oder leicht konvexe Gewinde besteht aus $5-5 \frac{1}{2}$ schwach gewölbten, ziemlich rasch zunehmenden Umgängen; der letzte ist unten flacher gewölbt, an der Peripherie stumpf gekielt bis kantig und steigt vorne sehr wenig oder gar nicht herab. Die Skulptur besteht nebst feinen, ungleichmässigen Zuwachsstreifen aus feinen und dichten Spiralreifen auf den ersten Umgängeu, welchen auf der Oberseite der unteren Umgänge ziemlich dichte, aber ungleichmässig abstehende Spiralfurchen, auf der Unterseite dichte, niedrige, etwas wellig gebogene Spiralreifen entsprechen. An frischen Exemplaren erscheint auch die Epidermis der unteren Umgänge deutlich gerunzelt. Am Uebergange der Spindel in den Basalrand der Mündung eine abgerundete, oft undeutliche, stumpfwinkelige Ecke.

$$
\mathrm{D}=14, \mathrm{~d}=12, \mathrm{H}=9-10 \mathrm{~mm} \text {. }
$$

Deckel beiderseits gelbbraun mit einer lichteren Zone entlang dem Spindelrand; die verhältnismässig feste Kalkplatte entlang dem Spindelrande ziemlich dick und als stumpfe Leiste erhoben; in den übrigen Verbältnissen typisch.

Fundort: Chanchaniayo in Peru; die Exemplare im K. Museum zu Berlin.

Diese Form steht den oben angeführten Formen der Helicina schlüteri A. J. Wagner 
wohl recht nahe, unterscheidet sich aber bestimmt durch die abweichende Spiralskulptur, welche hier zum Teil aus Spiralfurchen besteht, ebenso auch dio Form des letzten Umganges. Es ist wahrscheinlich, dass auch diese Unterschiede auf Geschlechtsformen zurückzuführen sind.

\section{Helicina lirifera Ancey.}

Taf. 56, Fig. 19-23.

Helicı na lirifera Aucey, J. of. Coneh. Leeds, VII, p. 96, 1892.

Gehäuse dicklinsenförmig, ziemlich festschalig, durchscheinend, leicht glänzend, einfarbig gelbbraun. Die Skulptur besteht nebst dichten, feinen, aber deutlichen Zuwachsstreifen aus ziemlich weitläufigen, feinen, aber deutlich erhobenen Spiralreifen, welche auf der Oberseite des letzten Umganges weitläufiger und kräftiger, auf der Unterseite etwas dichter und schwächer werden. Das regelmässig flach kegelförmige Gewinde besteht aus 5 flachen, ziemlich rasch zunehmenden Umgängen; der letzte ist beiderseits gleichmässig flach gewölbt, an der Peripherie scharf und zusammengedrückt gekielt, vorne kaum merklich, oder gar nicht herabsteigend. Die dreieckige Mündung ist ziemlich schief, der weisse oder gelbliche, leicht verdickte Mundsaum ist ziemlich kurz ausgebreitet; der Oberrand an der Insertion etwas vorgezogen, fast gerade, der Basalrand umgeschlagen. Die kurze, dünne Spindel ist etwas nach aussen und vorn gebogen; am Uebergange in den Basalrand der Mündung findet sich eine winkelige, etwas vorspringende Ecke. Der weissliche, dünne und gekörnelte Basalkallus ist nach hinten durch eine seichte Furche begrenzt, nach vorn zu undeutlich. In der Nabelgegend ein undeutlicher furchenartiger Eindruck.

$$
\mathrm{D}=12, \mathrm{~d}=10, \mathrm{H}=8 \mathrm{~mm} \text {. }
$$

Deckel abgerundet dreieckig mit gelbbrauner Hornplatte, weisser, ziemlich fester, gekörnelter Kalkplatte, welche am Spindelrande leistenförmig verdickt und erhoben erscheint; in den übrigen Verhältnissen typisch.

Fundort: Santa Cruz de la Sierra in Bolivia.

Diese Form steht der Formenreihe der Helicina schlüteri m. jedenfalls sehr nahe und unterscheidet sich von derselben im wesentlichen nur durch das konstant schärfer gekielte, linsenförmige Gehäuse, die feinere, schärfere und regelmässige Skulptur, sowie die deutliche Ecke am Uebergange der Spindel in den Basalrand der Mündung. Ich beurteile die Art nach einem Originalexemplar des Autors. 


\section{Helicina fulva d'0rbigny.}

Taf. 55, Fig. 20-23.

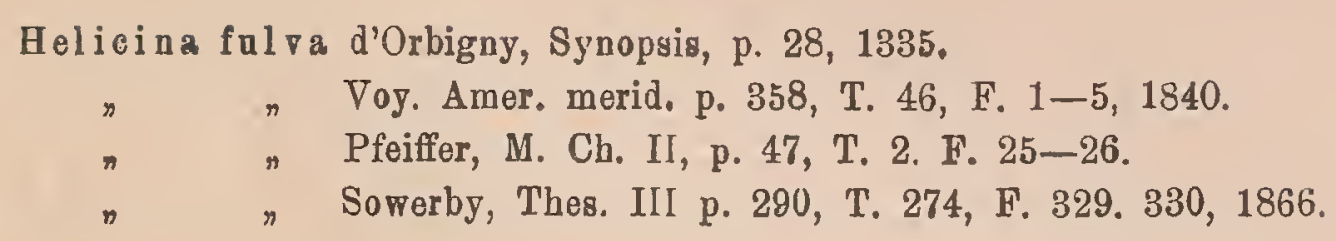

Gehäuse gedrückt kreiselförmig oder flachkegelförmig mit gut gewölbter Basis, festschalig, wenig glänzend, einfarbig zitrongelb orler röthlich hornfarben. Die Skulptur besteht nebst sehr feinen, etwas ungleichmässigen Zuwachsstreifen aus ziemlich dichten, aber niedrigen Spiralreifen, welche gegen die Mündung zu schwächer werden, auf der Unterseite erlöschen. Das zugespitzte, flach kegelförmige Gewinde besteht aus $5-5 \frac{1}{2}$ nahezu flachen, ziemlich langsam zunehmenden Umgängen; der letzte ist gerundet oder nur im Beginne undeutlich stumpfkantig, beiderseits gleichmässig gewölbt und steigt vorne unmerklich oder gar nicht herab. Die breit halbeiförmige Mündung ist wenig schief, der weisse, lippenartig verdickte Mundsaum ziemlich kurz ansgebreitet und umgeschlagen; der Oberrand an der Insertion kaum vorgezogen. Die ziemlich kurze, etwas abgeflachte Spindel ist leicht nach aussen gebogen und bildet am Uebergange in den Basalrand der Mündung eine stumpfwinkelige, wenig vorspringende Ecke. Der weisse oder gelbliche, fein gekörnelte Basalkallus ist nur in der Mitte etwas verdickt, ziemlich undeutlich begrenzt. In der Nabelgegend eine ziemlich deutlich eingedrückte Querfurche.

$$
\begin{aligned}
& D=11.5, \mathrm{~d}=9, \mathrm{H}=8 \mathrm{~mm}, \text { Fundort: Chiquita Bolivia. } \\
& \mathrm{D}=13, \mathrm{~d}=11, \mathrm{H}=9 \mathrm{~mm}, \text { Fundort: Corumba Agosta, Bolivia. }
\end{aligned}
$$

Deckel unbekannt.

Fundorte: Chiquita und Corumba Agosta in Bolivia.

Diese Art steht mit Rücksicht auf den gerundeten letzten Umgang bisher isoliert in diesem Formenkreise, entspricht demselben jedoch bezüglich der Skulptur und Beschaffenheit der Mündung.

\section{Helicina ernesti Martens. Taf. 57, Fig. 1-5.}

Helicina concentrica var. ernesti Martens, Moll. Venezuela p. 5, T. 1 F. 2, 1873.

H'elicina ernesti A. J. Wagner Helicinenstudien in: Denk. Akad. Wieu, vol. 78, p. 222, T. 12, F. 6, 1905.

Gewinde flach kegelförmig mit flach gewölbter Basis, festschalig, wenig glänzend bis matt; schmutzig gelb oder zitrongelb mit weisslichen undeutlichen Bändern, Striemen und 
Fiecken, sowie einem schmalen, oft verwaschenen Bande entlang dem Kiele und der Naht der unteren Umgänge. Die Skulptur besteht nebst dichten, feinen, S-förmig gebogenen Zuwachsstreifen aus einigen niedrigen und undeutlichen Spiralreifen auf den unteren Umgangen, welche auf der Unterseite zumeist vollkommen erlöschen. Das regelmässig flachkegelförmige Gewinde besteht aus $4 \frac{1}{2}$ kaum gewölbten bis flachen ziemlich rasch zunehmenden Umgängen; der letzte ist zusammengedrückt und sehr scharf gekielt und steigt vorne sehr wenig unter den Kiel herab. Die dreieckige Mündung ist ziemlich schief, der mit dem Gehäuse gleichfarbige und leicht verdickte Mundsaum ziemlich kur' ausgebreitet; der Oberrand an der Insertion stark vorgezogen, der Aussenrand entsprechend dem Kiel innen rinnenförmig vertieft, mitunter auch winkelig vorgezogen, der Basalrand umgeschlagen. Der weisse oder gelbliche Basalkullus ist fein gekörnelt, in der Mitte ziemlich dick; nach hinten durch eine seichte Furche begrenzt, nach vorn dünn und undeutlich. Die kurze, abgerundete Spindel ist nach vorne und aussen gebogen und bildet am Uebergange in den Basalrand der Mündung eine winkelige, deutlich vorspringende Ecke. In der Nabelgegend ein schwach bis undeutlich eingedrücktes Grübchen.

$$
\mathrm{D}=16, \mathrm{~d}=13, \mathrm{H}=10 \mathrm{~mm} \text {. }
$$

Deckel annähernd trapezoidisch mit spitzem Aussenwinkel und abgerundetem Spindelwinkel, beiderseits kastanienbraun mit lichterem Spindelrande. Die ziemlich feste, feingekörnelte Kalkplatte ist flach konkav, am Spindelrande und Spindelwinkel leistenförmig erhoben und verdickt. Der Nukleus auch dem Spindelwinkel etwas genähert; die übrigen Verhältnisse typisch.

Fundort: Umgebung von Caracas in Venezuela.

Mit H. concentrica Pfeiffer hat vorstehende Art eben nur die Gruppenmerkmale gemeinsam, repräsentiert aber unbedingt eine selbständige und stark abweichende Formenreihe.

\section{Helicina ernesti rhynchostoma (Shuttleworth) Pfeiffer. Taf. 56, Fig. 24.}

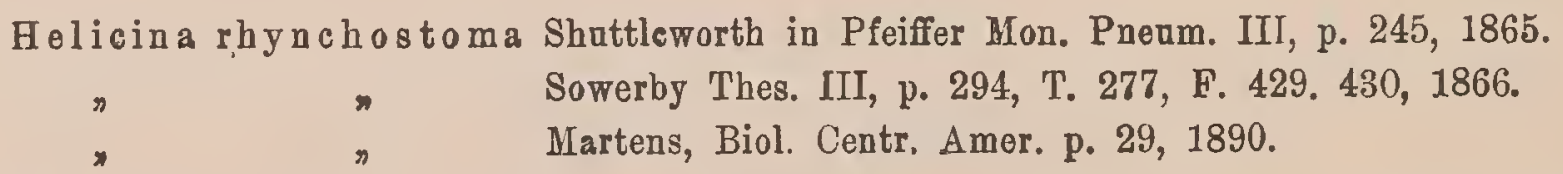

Gehăuse grósser, flacher mit 5 nahezu flachen, etwas rascher zunehmenden Umgängen; der letzte ist mehr zusammengedrückt mit deutlich rotbraun berandetem Kiel, welcher auch an den ünteren Umgängen als vorspringende Nahtkante sichtbar ist. Die Skulptur und besonders die Runzeln der Epidermis sind deutlicher. Die Ecke am Uebergange der mehr nach vorn und aussen gebogenen Spindel ist schärfer und deutlicher vorspringend; der Aussenrand der Mündung, entsprechend dem Kiele leicht geschnäbelt.

$$
\mathrm{D}=16 \cdot 5-19, \mathrm{~d}=14-16, \mathrm{H}=10-11 \mathrm{~mm} \text {. }
$$


Deckel wie bei der typischen Form.

Fundort: Columbien (Campanera).

Diese Form unterscheidet sich nur durch die bedeutenderen Dimmensionen und dementsprechend kräftiger ausgeprägte Merkmale von H. ernesti Martens.

\section{Helicina la us . A. J. Wagner.}

Taf. 57, Fig. 9-12.

Helicina ernesti laus A. J. Wagner Helicinenstadien in Denk. Akad. Wien v. 78, p. 222, T. 12, F. 12, 1905.

Gehåuse breit kegelförmig mit gewölbter Basis, dünnschalig, durchscheinend, leicht glänzend; die Grundfarbe gelblichweiss, gelb bis hellrotbraun mit milchigen Flecken, welche zu Radialstriemen und Spiralbändern angeordnet sind. Die Skulptur besteht nebst dichten, sehr feinen Zuwachsstreifen aus dichten, feinen, etwas unregelmåssigen, eingedrückten Spirallinien, welche etwas wellig gebogen erscheinen, mitunter nahezu erlöschen; in diesem Falle werden einige undeutliche Spiralreifen, sowie feine Runzeln der Epidermis sichtbar. Das regelmässig kegelförmige Gewinde besteht aus $4 \frac{1}{2}-5$ ziemlich rasch zunehmenden, leicht gewölbten Umgängen; der letzte ist unten mehr gewölbt, an der Peripherie sehr scharf gekielt und steigt vorne nicht herab; der Kiel wird auch auf den unteren Umgängen als vorspringende Nahtkante sichtbar. Die abgerundet dreieckige Mündung ist wenig schief; der kaum verdickte weisse Mundsum ist kurz ausgebreitet, der Oberrand an der Insertion vorgezogen und fast gerade, der Aussenrand entsprechend dem Kiele etwas winkelig vorgezogen oder leicht geschnäbelt, innen rinnenartig eingedrückt, der Basalrand umgeschlagen. Die kurze abgerundete Spindel ist nach vorne und aussen gebogen; am Uebergange derselben in den Basalrand der Mündung findet sich eine winkelig vorspringende Ecke. Der weisse, gekörnelte Basalkallus ist in der Mitte deutlich verdickt, nach hinten durch eine seichte Furche begrenzt, nach vorne durchsichtig und sehr undeutlich. In der Nabelgegend ein deutliches, furchenartiges Grübchen.

$$
\mathrm{D}=13.5, \mathrm{~d}=11, \mathrm{H}=8 \mathrm{~mm} .
$$

Deckel beiderseits kastanienbraun mit lichterer Zone am Spindelrand. Die krusten. artig dünne, gekörnelte Kalkplatte nur am Spindelrande leistenartig verdickt und erhoben; in den übrigen Verhältnissen typisch.

Fundorte: die ersten Exemplare dieser Art, erhielt ich mit der Fundortsangabe Venezuela, welche mir nicht richtig erscheint, da ich inzwischen vollkommen entsprechende Exemplare mit den zuverlăssigen Fundortsangaben Rio Ucayali (einem Nebenfluss des Amazonas im nordöstlichen Peru) und Rio Jurua (Nebenfluss des A mazonas, welcher in Peru entspringend nach längerem Laufe in Brasilien mündet) erhalten habe. Die Exémplare vom Rio Jurua entsprechen mit ihren dichten und feinen Spirallinien der von mir zuerst beschriebenen Form,

I. 18. II.

9. III. 1910.

37 
wăhrend die Exemplare vom Rio Ucayali nahezu erloschene Spirallinien, dafür einige undeutliche Spiralleisten aufweisen. Ich bezeichne diese Form als Helicina laus ucayalensis n. Ich habe Helicina laus n. ursprünglich bei der Formenreihe der $H$. ernesti Martens angeführt, die auffallenden Unterschiede bezüglich der Form der Schale, der Beschaffenheit der Skulptur und Mündung veranlassen mich jedoch dieselbe als selbständige Art zu betrachten.

\section{Helicina conus $n$.}

Taf. 57, Fig. 6-8.

Gehäuse spitzkegelförmig mit flachgewölbter Basis, ziemlich festschalig, wenig glänzend bis matt; hellzitrongelb mit milchigen Flecken, welche zu undeutlichen Bändern und Striemen angeordnet sind, sowie einer schmalen rotbraunen Nahtbinde. Die Skulptur besteht neben feinen bis undeutlichen Zuwachsstreifen aus dichten ziemlich erhobenen Spiralleisten auf den mittleren und unteren Umgängen, welche auf der Unterseite bis auf sehr feine, nur unter der Lupe sichtbare Spiralfalten der Epidermis vollkommen erlöschen. Das regelmässig spitzkegelförmige Gewinde besteht aus 5 kaum gewölbten, langsam zunehmenden Umgängen; der letzte ist unten flach gewölbt, an der Peripherie scharf gekielt und steigt vorne kaum unter den Kiel herab Die dreieckige Mündung ist schief; der weisse, kaum verdickte Mundsaum kurz ausgebreitet, der Oberrand an der Insertion vorgezogen und gerade, der Basalrand umgeschlagen. Die abgeflachte, kurze Spindel ist nach aussen gebogen, am Uebergange derselben in den Basalrand der Mündung weder ein Knoten noch eine Ecke. Der weisse gekörnelte Basalkallus nur im Umkreise der Spindel deutlich verdickt, an den Răndern durchsichtig und undeutlich begrenzt. In der Nabelgegend ein seichtes, furchenartiges Grübchen.

$$
\mathrm{D}=9, \mathrm{~d}=8, \mathrm{H}=8 \mathrm{~mm} \text {. }
$$

Deckel unbekannt.

Fundort: Chanchamayo in Peru; die Exemplare im K. Museum zu Berlin.

\section{Helicina phakos $n$. Taf. 57, Fig. 13-16.}

Gehăuse linsenförmig, ziemlich dünnschalig, durchscheinend, leicht glänzend; hellzitrongelb oder rötlich fleischfarben mit weisslich getrübten Spiralbändern und Spirallinien. Die Skulptur besteht nebst sehr feinen bis undeutlichen Zuwachsstreifen aus erhobenen, sehr feinen und dichten Spirallinien, welche auf der Unterseite dichter und schwăcher werden und nur unter der Lupe sichtbar sind. Das abgerundet, breit kegelförmige Gewinde besteht aus 4-41/2 ziemlich rasch zunehmenden, leicht gewölbten Umgăngen; der letzte ist beiderseits gleichmässig gewölbt, an der Peripherie scharf gekielt und steigt vorne nicht herab. Die abgerundet dreieckige Mündung ist wenig schief, der kaum verdickte, weisse oder gelbliche 
Mundsaum kurz ausgebreitet; der Oberrand an der Insertion vorgezogen, fast gerade, der Basalrand umgeschlagen. Die kurze, abgerundete Spindel ist nach aussen und vorn gebogen, am Uebergange derselben in den Basalrand der Mündung findet sich eine stumpfwinkelige, deutlich vorspringende Ecke. Der weissliche oder durchscheinende, feingekekörnelte Basalkallus ist nur im Umkreise der Spindel deutlich verdickt, jedoch undeutlich begrenzt. In der Nabelgegend ein seichtes, furchenartiges Grübchen, welches mitunter undeutlich wird.

$$
\mathrm{D}=7 \cdot 5-8 \cdot 5, \mathrm{~d}=6-7, \mathrm{H}=4 \cdot 5-5 \cdot 5 \mathrm{~mm} \text {. }
$$

Deckel dreieckig, beiderseits lebhaft kastanienbraun mit zarter, krustenartiger auch am Spindelrände nur schwach verdickter Kalkplatte; in den übrigen Verhältnissen typisch.

Fundort: Rio Juraty (Zufluss des oberen Amazonas).

\title{
432. Helicina infesta $\mathrm{A}$. J, Wagner.
}

Taf. 57, Fig. 17-19.

\author{
Helicina infesta A. J. Wagner Helicinenstudien in: Denk. Akad. Wien, v. 78, p. 223, T. 7, \\ F. 12,1905 .
}

Gehäuse linsenförmig, festschalig, kaum glänzend, graugelb, weiss marmoriert mit einem schmalen rotbraunen Kiel und Nahtbande. Die Skulptur besteht nebst schwachen, ungleichmässigen und leicht S-förmig gebogenen Zuwachsstreifen aus einigen niedrigen und sehr undeutlichen Spiralreifen, ausserdem erscheint die Oberfäche etwas uneben und fein runzelfaltig. Das flachkegelförmige, unter der Spitze leicht konkave Gewinde besteht aus $41 / 2-5$ rasch zunehmenden, kaum gewölbten bis flachen Umgăngen; der letzte ist beiderseits gleichmässig zusammengedrückt, an der Peripherie sehr scharf gekielt und steigt vorne nicht herab. Der Kiel wird auch auf den unteren Umgängen als leicht vorspringende Nahtkante sichtbar. Die dreieckige Mündung ist wenig schief, der weisse, lippenartig verdickte Mundsaum verhăltnismässig kurz ausgebreitet; der Oberrand an der Insertion vorgezogen und fast gerade, der Basalrand umgeschlagen. Die kurze, abgerundete Spindel bildet am Uebergange zum Basalrand der Mündung eine undeutliche Verdickung. Der weisse, glänzende und feingekörnelte Basalkallus ist im Unkreise der Spindel ziemlich dick, sonst undeutlich begrenzt. In der Nabelgegend ein seichtes, furchenartiges Grübchen.

Deckel unbekannt.

$$
\mathrm{D}=18, \mathrm{~d}=16, \mathrm{H}=11 \mathrm{~mm} \text {. }
$$

Fundort: Venezuela. 


\title{
433. Helicina sulfurea Ancey.
}

\author{
Taf. 58, Fig. 1-3.
}

Helicina salfurea Ancey, Journ. Conch. v. 7, 1892.

Gehäuse kegelförmig mit nahezu halbkugeliger Basis, ziemlich dünnschalig, durchscheinend, leicht glänzend; schwefelgelb mit weisslich getrübten und unterbrochenen Spirallinien und Spiralbändern. Die Skulptur besteht nebst sehr feinen und undeutlichen Zuwachsstreifen aus sehr dichten und feinen Spiralreifen, welche auf der Unterseite schwächer, dichter, bis undeutlich werden. Das regelmässig kegelförmige Gewinde besteht aus 4 langsam zunehmenden nahezu flachen Umgängen; der letzte ist unten stärker gewölbt, an der Peripherie gekielt und steigt vorne kaum merklich unter den Kiel herab. Die abgerundet dreieckige Mündung ist wenig schief, der gelbliche, kaum verdickte Mundsaum kurz ausgebreitet; der Oberrand an der Insertion kaum vorgezogen und fast gerade, der Basalrand leicht umgeschlagen. Die kurze etwas abgeflachte Spindel ist nach vorne gebogen und bildet am Uebergange in den Basalrand der Mündung eine deutlich vorspringende Ecke. Der durchsichtige, fein gekörnelte Basalkallus ist im Umkreise der Spindel ziemlich dick, jedoch undeutlich begrenzt; in der Nabelgegend ein furchenartiger Eindruck.

Deckel unbekannt.

$$
\mathrm{D}=6.5, \mathrm{~d}=5.5, \mathrm{H}=4.5 \mathrm{~mm} \text {. }
$$

Fundort: St. Cruz de la Siera, Bolivia. Ich beurteile diese Art nach einem Originalexemplare des Autors.

\section{Helicina decoros a $n$. Taf. 58, Fig. $4-6$.}

Gehäuse spitz kegelförmig mit flach gewölbter Basis, dünnschalig, durchscheinend, mattglänzend mit sehr feinen, etwas ungleichmässigen Zuwachsstreifen; unter der Lupe sind auch undeutlich sehr feine, eingedrückte Spirallinien sichtbar; einfärbig gelblichweiss. Das regelmässig kegelförmig Gewinde besteht aus $4^{1} \frac{1}{2}$ nahezu flachen, langsam zunehmenden Umgängen; der letzte ist unten abgeflacht, an der Peripherie scharf gekielt; der Kiel auch am vorletzten Umgange als deutlich vorspringende, scharfe Nahtkante sichtbar. Die dreieckige Mündung ist schief, der weisse kaum verdickte Mundsaum sehr kurz ausgebreitet; der Oberrand an der Insertion kaum vorgezogen und fast gerade, der Basalrand umgeschlagen. Die kurze, abgerundete Spindel ist nach aussen gebogen, am Uebergange derselben in den Basalrand der Mündung eine undeutliche Verdickung. Der weisse, dünne Basalkallus ist undeutlich begrenzt; in der Nabelgegend ein undeutlicher Eindruck.

$$
\mathrm{D}=12, \mathrm{~d}=10, \mathrm{H}=9 \mathrm{~mm} \text {. }
$$


Deckel unbekannt.

Fundort: Muzo in Columbien; das vorliegende Exemplar im K. Museum zu Berlin.

\section{Helicina steindachneri A. J. Wagner.}

Taf. 58, Fig. 12-16.

Helicina steindachneri A. J. Wagner Helicinenstudien in: Denk. Akad. Wien. r. 78, p. 224, T. 12, F. $9,1905$.

Gehäuse kegelförmig bis spitz kegelförmig mit flachgewölbter Basis, ziemlich dünnschalig, etwas durchscheinend, leicht glänzend; hellgelb, gelbbraun bis hellrotbraun, weisslich marmoriert, mit rotbraun berandetem Kiel. Die Skulptur besteht nebst feinen, leicht S-förmig gebogenen und etwas ungleichmässigen Zuwachsstreifen aus einigen undeutlichen und nur unter der Lupe sichtbaren Spirallinien und Spiralreifen, auch erscheint die Epidermis sehr fein runzelfaltig. Das regelmässig kegelförmige, mehr minder erbobene Gewinde besteht aus 5 leicht gewölbten, ziemlich rasch zunehmenden Umgängen; der letzte ist unten flacher, an der Peripherie scharf und zusammengedrückt gekielt und steigt vorne nicht herab. Die dreieckige Mündung ist wenig schief, der weisse oder gelbliche Mundsaum lippenartig verdickt, verhältnissmässig kurz ausgebreitet und umgeschlagen; der Oberrand an der Insertion vorgezogen. Die kurze, abgerundete Spindel ist nach aussen gebogen, am Uebergange derselben in den Basalrand der Mündung eine undeutliche Verdickung. Der gelbliche, dünne Basalkallus ist undeutlich begrenzt; in der Nabelgegend ein schwacher Eindruck, welcher mitunter fehlt.

$$
D=13-16 \cdot 5, \mathrm{~d}=11-14, \mathrm{H}=11 \mathrm{~mm} \text {. }
$$

Deckel dreieckig mit abgerundetem Spindelwinkel, beiderseits lebhaft schwarzbraun mit kastanienbraunem Spindelrand. Die feingekörnelte Kalkplatte ist krustenartig dünn und zerbrechlich, auch am Spindelrande nur wenig erhoben.

Fundort: Frontino in Neu-Granada (Columbien).

\section{Helicina steindachneri superstructa A. J. Wagner. Taf. 58, Fig. 17.}

Helicina steindachneri superstructa A. J. Wagner Helicinenstadien in: Denk. Akad. Wien. vol. 78, p. 225, T. 12, F. 11, 1905.

Der Aussenrand des Mundsaumes entsprechend dem Kiele in einen löffelartig ausgebreiteten, innen rinnenartig eingedrückten und schief nach oben gerichteten Schnabel ausgezogen. In den übrigen Verhältnissen vollkomen mit der typischen Form übereinstimmend. 


$$
D=15, d=12, H=10.5 \mathrm{~mm} .
$$

Deckel beiderseits kastanienbraun, sonst wie bei der typischen Form.

Fundort: Frontino in Neu-Granada

Auch hier ist die auffallende Beschaffenheit der Mündung bei sonst vollkommen übereinstimmendem Gehäuse auf die beiden Geschlechtsformen zurückzuführen.

\section{Helicina ocanensis A. J. Wagner. Taf. 58, Fig. 7-11.}

Helicina ocanensis A. J. Wagner, Helicinenstudien, in: Denk. Akad. Wien. v. 78, p. 223, T. 12 , F. 10,1905 .

Gehäuse flachkegelförmig mit gewölbter Basis, ziemlich festschalig, etwas durchscheinend, wenig glänzend bis matt; die Grundfarbe gelbgrün, graubraun bis gelbbraun mit unregelmässigen weisslichen Flecken und Striemen marmoriert. Die Skulptur besteht nebst deutlichen, etwas ungleichmässigen Zuwachsstreifen aus einigen sehr undeutlichen Spiralreifen, auch ist die Epidermis deutlich runzelfaltig. Das regelmässig flach kegelförmige Gewinde besteht aus $4^{1} / 2$ im Beginne langsam, dann rasch zunehmenden, kaum gewölbten bis flachen Ungängen; der letzte ist zusammengedrückt, beiderseits gleichmasssig flach gewölbt, an der Peripherie stumpfkantig bis stumpfgekielt und steigt vorne nicht herab. Die abgerundet dreieckige Mündung iśt schief, der weisse oder gelbliche, leicht verdickte Mundsaum ist verhältnissig kurz ausgebreitet und umgeschlagen; der Oberrand an der Insertion vorgezogen. Die kurze, etwas abgeflachte Spindel ist nach aussen gebogen, am Uebergange in den Basalrand der Mündung nnr etwas verdickt, oder etwas wulstig vorspringend. Der nur im Umkreise der Spindel deutlich verdickte, gelbliche, feingekörnelte Basalkallus ist undeutlich begrenzt; in der Nabelgegend ein deutlich eingedrücktes Grübchen.

$$
\mathrm{D}=17, \mathrm{~d}=14, \mathrm{H}=11 \mathrm{~mm} \text {. }
$$

Deckel halbkreisförmig, beiderseits lebhaft kirschbraun gefärbt. Die dünne, aber feste Kalkplatte ist flachkonkav, glänzend, am Spindelrand verdickt und leistenförmig erhoben; in den übrigen Verbaltnissen typisch.

Fundort: Ocana in Nelt-Granada.

\section{Formenkreis Punctisulcata.}

\section{Helicina punctisulcata Martens.}

Taf. 59, Fig. 6-8.

Helicina punctisuleata Martens, Biol. Cent. Amer. Moll. p. 36, T. 1 F. 10, 1890.

A. J. Wagner Helicinenstudien in Denk. Akad. Wien. v. 78, T. 11, F. 11, p. 218, 1905. 
Gehäuse kegelförmig mit abgeflachter Basis, festschalig, wenig glänzend; die Grundfarbe gelblichweiss, hornfarben bis rotbraun, die oberen Umgänge dunkler, häufig mit 2-3 schmalen braunen Binden. Die Skulptur besteht nebst feinen, etwas ungleichmässigen Zuwachsstreifen aus ziemlich weitlăufigen Spiralfurchen, welche am Grunde fein punktiert erscheinen, auf der Unterseite auffallend schwächer werden, oft nahezu erlöschen. Das regelmässig breitkegelförmige Gewinde besteht aus $5-5 \frac{1}{2}$ ziemlich langsam zunehmenden, kaum gewölbten bis nahezu flachen Umgängen; der letzte ist mehr minder deutlich stumpfkantig, unten flacher und steigt vorne wenig und langsam herab. Die abgerundet dreieckige Mündung ist schief, innen hell bis zitrongelb, der weisse Mundsaum etwas verdickt, kurz ausgebreitet. Die kurze, etwas abgeflachte Spindel ist leicht nach aussen gebogen und bildet am Uebergange in den Basalrand der Mündung eine stumpfe, wenig vorspringende Ecke. Der gelbe, feingekörnelte, wenig glänzende Basalkallus ist nur im Umkreise der Spindel stärker verdickt, an der Peripherie undeutlich begrenzt; in der Nabelgegend ein seichtes furchenartiges Grübchen.

$$
\mathrm{D}=8-9.5, \mathrm{~d}=7-8.5, \mathrm{H}=6-7.5 \mathrm{~mm} \text {. }
$$

Deckel annähernd halbkreisförmig, beiderseits rotorange bis lebhaft rotbraun gefărbt. Die krustenartig dünne, feingekörnelte Kalkplatte ist am Spindelrande deutlich verdickt und leistenartig erhoben.

Fundort: Omitteme in der Provinz Guerero, Südwest-Mexico.

Ich beurteile diese Art noch Originalexemplaren des Autors.

\section{Helicina punctisulcata zunilèsis n.}

Taf. 59, Fig. 9.

Gehäuse grösser mit höherem Gewinde und langsamer zunehmenden Umgängen, einfärbig gelblich hornfarben. Die auffallend tieferen Spiralfurchen sind auch auf der Unterseite deutlich vorhanden. Der Mundsaum ist mehr ausgebreitet und umgeschlagen, der verhăltnismässig dünnere Basalkallus weisslich.

Deckel wie bei der typischen Form.

$$
D=10.5, d=9, H=9.5 \mathrm{~mm} \text {. }
$$

Fundort: Vulkan Zunil in Guatemala; nach einem Exemplar des k. Museums in Berlin.

\section{Helicina amoena Pfeiffer.}

Taf. 59, Fig. 10-12.

Heli çina amoena Pfeiffer Pr. Z. S. p. 119, 1848.

$\begin{array}{cccc}n & n & n & \text { M. Ch. II p. 58, p. 55, T. 8, F. 13-15. } \\ n & n & n & \text { Mon. Pneum. I. p. 386, 1852. } \\ \eta & n & \text { Sowerby Thes. III. p. 292, T. 276, F. 383, } 1866 .\end{array}$


Helicina amoena Martens Pr. Z. S. p. 649, 1875.

Biol. Zentr. Amer p. $28,1890$.

A. J. Wagner Helicinenstudien in: Denk. Ak. Wien, จ. 78, p. 219, T. 12, F. 1, 1905.

Gehäuse flach bis breitkegelförmig mit flachgewölbter Basis, ziemlich festschalig, wenig glänzend bis matt; die Grundfarbe gelblichweiss bis lebhaft zitrongelb mit rosenfarbenen Zonen, welche mitunter verschwommene breite Binden an der Peripherie und Naht darstellen; häufig sind auch unregelmässige milchige Flecken und Striemen vorhanden, welche die rosenfarbenen Zonen zum Teil verdecken und abschwächen. Die Skulptur besteht nebst schwachen, ungleichmässigen Zuwachsstreifen aus ziemlich weitlăufigen eingedrückten, stellenweise unterbrochenen Spirallinien auf den mittleren und unteren Umgängen, welche auch auf der Unterseite deutlich eutwickelt sind; ausserdem erscheint die Epidermis unter der Lupe sehr fein gerunzelt. Das flachkegelförmige, etwas abgerundete Gewinde besteht aus $5-51 / 2$ kaum gewölbten Umgängen, von welchen die oberen langsam, die zwei letzten rascher zunehmen; der letzte ist unten flacher, an der Peripherie stumpfkantig bis stumpf gekielt und steigt vorne wenig oder gar nicht herab. Die abgerundet dreieckige Mündung ist sehr schief, der gelbliche, leicht verdickte Mundsaum ausgebreitet und umgeschlagen; der Oberrand an der Insertion vorgezogen, der Aussenrand entsprechend dem Kiele mitunter etwas winkelig ausgezogen. Die kurze, abgerundete Spindel ist nach vorne gebogen und bildet am Uebergange in den Basalrand der Mündung eine scharf vorspringende Ecke. Der gelbe gekörnelte Basalkallus ist wenig glänzend, nur in der Mitte stärker verdickt, ziemlich undeutlich begrenzt; in der Nabelgegend ein deutlich eingedrücktes, furchenartiges Grübchen.

$\mathrm{D}=13, \mathrm{~d}=11, \mathrm{H}=9 \mathrm{~mm}$.

Deckel abgerundet dreieckig, lebhaft rotbraun mit gelbem Nukleus und Spindelrand; die dünne, feingekörnelte Kalkplatte am Spindelrande leistenartig verdickt und erhoben; in den übrigen Verhältnissen typisch.

Fundorte: Honduras, Guatemala (Panzos, Peten), und Mexiko (Vera Cruz); die Exemplare von letztgenanntem Fundort mit tiefer eingedrückten, auch auf der Unterseite deutJichen Spiralfurchen.

\section{Helicina ghisbrechti Pfeiffer.} Taf. 59, Fig. 3-5.

Helicina ghisbrechti Pfeiffer Pr. Z. S. p. $381,1856$.

$" \quad$ Mon. Pneum. II p. 215, 1858.

Sowerby Thes. III, p. 293, T. 277, F. 432, 1866.

Martens, Biol. Zentr, Amer., p. 28, 1890.

A. J. Wagner Helicinenstudien in Denk. Ak. Wien, v. 78, p. 220, T. 11. F. 12, 1905. 
Gehäuse breitkegelförmig mit flach gewölbter Basis, festschalig, wenig glänzend bis matt; gelblich weiss oder hellgelb mit weissem Kiel und Nahtbande, mitunter auch einigen undeutlichen weissen Striemen und Flecken. Die Skulptur besteht nebst deutlichen, etwas ungleichmässigen Zuwachsstreifen aus ziemlich weitläufigen und unterbrochenen Spiralfurchen, welche auch auf der Unterseite gleich stark entwickelt sind ; unter der Lupe erscheint ausserdem die Epidermis sehr fein gerunzelt. Das leicht konvexe Gewinde besteht aus $5 \frac{1}{2}$ ziemlich rasch zunehmenden, schwach gewölbten oder nahezu fiachen Umgăngen, welche durch eine leicht eingedrückte Naht geschieden werden; der letzte ist unten flacher gewölbt, an der Peripherie kantig bis stumpf gekielt und steigt vorne nicht herab; der Kiel häufig beiderseits durch eingedrückte Linien berandet. Die abgerundet dreieckige Mündung ist schief, der weisse Mundsaum verdickt, gut ausgebreitet und umgeschlagen; der Oberrand an der Insertion vorgezogen, der Aussenrand entsprechend dem Kiel, häufig etwas winkelig ausgezogen. Die kurze, leicht abgerundete Spindel ist etwas nach aussen gebogen und bildet am Uebergange in den Basalrand der Mündung eine stumpfe, aber deutlich vorspringende E'cke. Der weisse, gekörnelte Basalkallus ist in der Mitte ziemlich dick, an der Peripherie undeutlich begrenzt; in der Nabelgegend ein seichtes, furchenartiges Grübchen.

$$
D=19, d=16, H=12 \mathrm{~mm} \text {. }
$$

Deckel abgerundet dreieckig, lebhaft kastanien- bis schwarzbraun; die ziemlich feste gelbliche und feingekörnelte Kalkpiatte am Spindelrande leistenartig verdickt und erhoben: in den übrigen Verhältnissen typisch.

Fundorte: Chiapas und Izapuato in Südmexiko.

\section{Helicina sinuos a Pfeiffer.} Taf. 59, Fig. 1-2.

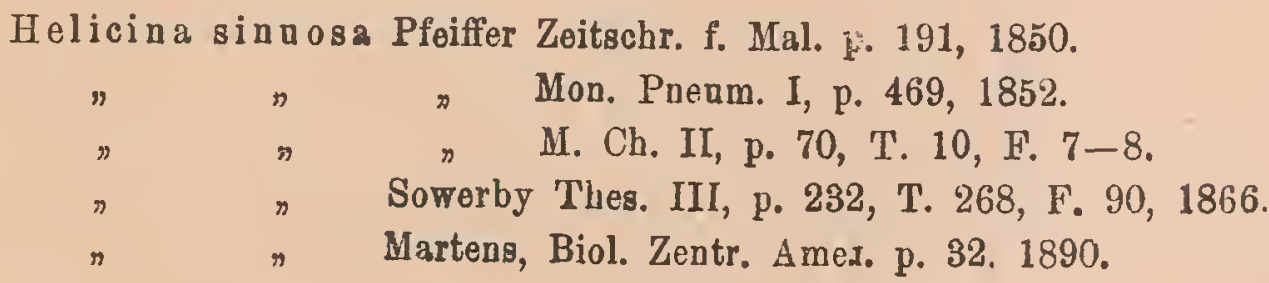

Gehäuse breitkegelförmig mit gewölbter Basis, festschalig, leicht glänzend, einfarbig weiss. Die Skulptur besteht nebst deutlichen, ungleichmăssigen Zuwachsstreifen aus dichten Spiralfurchen auf den unteren Umgängen, welche am letzten Umgange leicht wellig gebogen, auf der Unterseite weitläufiger, aber nur wenig schwächer werden. Das regelmässig kegelförmige Gewinde besteht aus $51 / 2$ schwach gewölbten Umgăngen; die oberen nehmen langsam, die 2 letzten auffallend rascher zu und werden durch eine deutlich eingedrückte Naht geschieden; der letzte ist doppelt so breit wie der vorletzte, beiderseits gleichmässig gewölbt, an der Peripherie kantig und steigt vorne deutlich auf den vorletzten Umgang hinauf. Die 
buchtig dreieckige Mündung ist senkrecht, der weisse Mundsaum lippenartig verdickt, ziemlich ausgebreitet und umgeschlagen; der Oberrand zunächst von oben etwas eingedrückt, dann zurückweichend und im Bogen über dem Kiele inseriert; der Kiel an dieser Stelle durch einen knotenartigen Callus verdickt, so dass die Mündung hier einen engen Kanal bildet. Die kurze, dreieckige Spindel ist etwas ausgehöhlt und bildet am Uebergange in den Basalrand der Mündung eine scharf vorspringende, spitze Ecke. Der dünne, glänzende Basalkallus ist undeutlich begrenzt; in der Nabelgegend ein deutlich eingedrücktes, furchenartiges Grübchen.

Deckel unbekannt.

$$
\mathrm{D}=16 \cdot 5 \mathrm{~d}=13, \mathrm{H}=12 \mathrm{inm} \text {. }
$$

Fundort: Mexiko. Ich beurteile diese Art nach einem mir von den Herrn Sowerby und Fulton mitgeteilten, tadellos erhaltenen Exemplar; dementsprechend ist diese merkwürdige Form gewiss keine Abnormität und schliesst sich, abgesehen von den Verhältnissen der Münlung, gut den in diesem Formenkreise angeführten Formen an. Mit Beziehung auf meine bei anderen Gruppen der Heliciniden gemachten Erfahrungen ist es wohl auch möglich, dass vorstehende Art nur Geschlechtsform der Helicina ghisbrechti Pfr. oder einer sehr ähnlichen Art ist.

\section{Formenkreis Cinstella.}

\section{Helicina cinctell a Shutteworth. Taf. 59, Fig. $13-17$.}

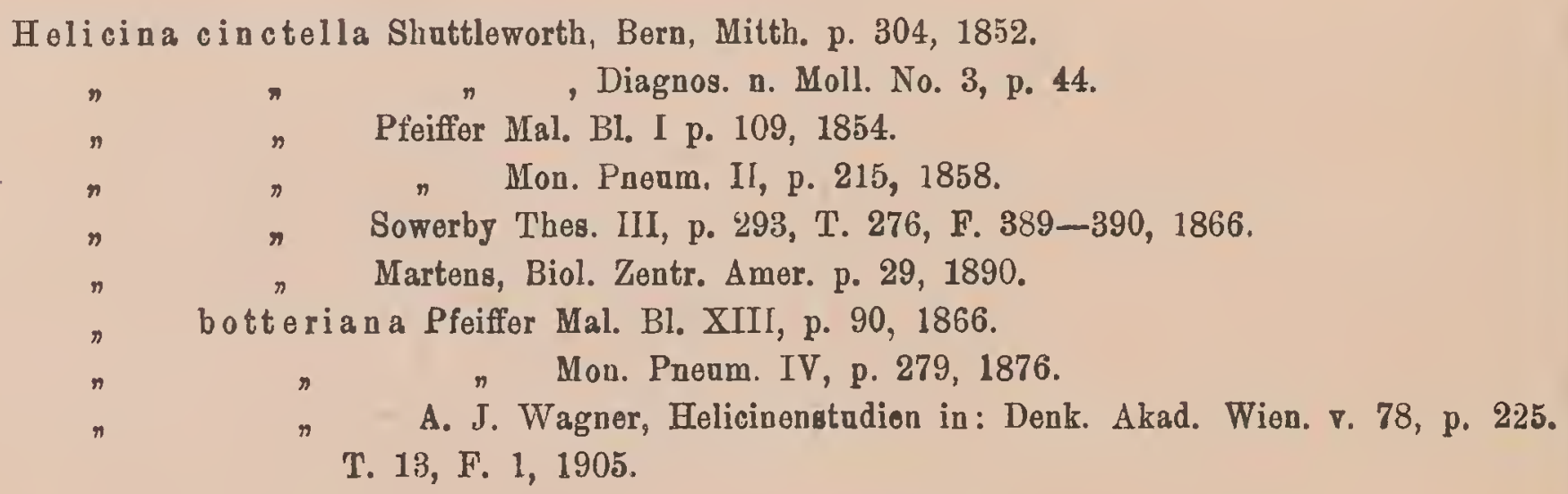

Gehăuse kegelförmig mit gewölbter Basis, ziemlich festschalig, leicht glänzend; die Grundfarbe gelblichweiss bis hellzitrongelb mit einem rotbraunen, nach unten scharf begrenzten, nach oben zu meist verwaschenen Bande über dem Kiel und der Naht. Die Skulptur besteht nebst sehr feinen, etwas ungleichmässigen Zuwachsstreifen aus dichten, sehr feinen bis undeutlichen Spiraliinien. Das nehr minder erhobene, etwas konvexe Gewinde besteht aus $5^{1} / 2$ leicht bis deutlich gewölbten, regelmässig zunehmenden Umgängen, welche durch 
eine leicht eingedrückte Naht geschieden werden; der letzte ist beiderseits gleichmässig gewölbt, etwas zusammengedrückt und an der Peripherie bald stumpfer, bald schärfer gekielt, vorne wenig, aber deutlich unter den Kiel herabsteigend. Die abgerundet dreieckige Mündung ist schief, innen gelblich mit durchscheinendem Band; der weisse oder gelbliche, leicht verdickte Mundsaum ist ausgebreitet und umgeschlagen, der Oberrand an der Insertion etwas vorgezogen. Die kurze, abgerundete Spindel ist nach aussen gebogen und bildet am Uebergang in den Basalrand der Mündung eine knotenartige wenig oder kaum vorspringende Verdickung. Der gelbe, gekörnelte Basalkallus ist in der Mitte ziemilich verdickt, an der Peripherie dünn und undeutlich begrenzt; in der Nabelgegend ein seichtes furchenartiges Grübchen.

$$
\mathrm{D}=10-12 \cdot 5, \mathrm{~d}=8 \cdot 5-10, \mathrm{H}=8 \cdot 5-9 \mathrm{~mm} \text {. }
$$

Deckel abgerundet dreieckig, gelbbraun mit lichterem Nukleus und Spindelrand. Die weisse, krustenartig dünne und feingekörnelte Kalkplatte ist auch am Spindelrande wenig stärker; in den übrigen Verhältnissen typisch.

Fundorte: Cordova, Vera Cruz und Orizaba in Mexico. Die Form von Orizaba bezeichnete Pfeiffer als Helicina botteriana, ich finde dieselbe vollkommen mit vorstehender Art identisch; geringe Abweichungen bezüglich der Höhe des Gewindes und der Schärfe des Kieles finden sich an allen mir bekannten Fundorten.

\section{Helicina bautistae n.}

Taf. 59, Fig. 18-20.

Gehäuse breitkegelförmig mit gewölbter Basis, festschalig, leicht glänzend, schmutzig gelb. Die Skulptur besteht nebst feinen, etwas ungleichmässigen Zuwachsstreifen aus ziemlich weitläufigen und niedrigen Spiralreifen auf den unteren Umganngen, welche auf der Unterseite schwächer bis undeutlich werden. Das konvexe Gewinde besteht aus 5 ziemlich langsam zunehmenden, leicht gewölbten Ungången; der letzte ist beiderseits gleichmässig gewölbt, stumpf gekielt und steigt vorne fast gar nicht herab. Die halbeiförmige Mündung ist schief, der weisse oder gelbliche Mundsaum leicht verdickt ausgebreitet und umgeschlagen; der Oberrand an der Insertion vorgezogen. Die kurze, abgerundete Spindel bildet am Uebergange in den Basalrand der Mündung eine knum vorspringende, knotenartige Verdickung. Der weisse, glänzende Basalkallus, ist nur in der Mitte stärker verdickt, an der Peripherie undeutlich begrenzt; in der Nabelgegend ein deutliches furchenartiges Grübchen.

Deckel unbekannt.

$$
\mathrm{D}=10, \mathrm{~d}=8.5 \mathrm{H}=8 \mathrm{~mm} \text {. }
$$

Fundort: S. Juan Bautista in der Provinz Tabasco, Mexiko. Ich beschreibe diese neue Form nach einem in der Farbe verblichenen Exemplare aus dem k. Museum in Berlin; dasselbe zeigt wohl einige Aehnlichkeit mit Helicina cinctella Shuttleworth, unterscheidet sich jedoch von dieser Art durch geringere Dimensionen, das mebr konvexe Gewinde, die stärker gewölbten, langsamer zunehmenden Umgänge und besonders durch die kräftige Spiralskulptur. 


\title{
445. Helicina cordillerae (Sallé) Pfeiffer.
}

Taf. 59, Fig. 21-25.

\author{
Helicina cordillerae (Sallé) Pfeiffer Pr. 7. S. p. 323, 1856.

$\begin{array}{lll}n & n & \text { Mon. Pneum., II, p. 193, } 1858 . \\ n & n & \text { Sowerby, Thes. III p. 288, T. 272, F. 261-263, } 1866 . \\ n & n & \text { Martens, Biol. Ceutr. Amer. p. 32, 1890. }\end{array}$

Gehăuse breitkegelförmig mit gewölbter bis annähernd halbkugeliger Basis, festschalig, leicht glänzend; die Grundfarbe weiss oder gelblich mit 1-3 rotbraunen, schmalen Băndern, welche auf den oberen Umgăngen die Grundfarbe mitunter verdecken (1 breiteres Band über, 2 schmale, oft undeutliche unter der Peripherie). Die Skulptur besteht nebst feinen Zuwachsstreifen aus einigen eingedrückten und punktierten Spirallinien auf der Oberseite der unteren Umgänge. Das regelmässig kegeltörmige Gewinde besteht aus 5 regelmăssig zunehmenden, schwach gewölbten Umgängen; der letzte ist gedrückt gerundet, in Beginne oft undeutlich kantig und steigt vorne langsam und wenig herab. Die halbeiförmige Mündung ist schief, innen mit durchscheinenden Băndern; der weisse Mundsaum schwielig verdickt, oft nahezu verdoppelt, kurz ausgebreitet und umgeschlagen. Die kurze abgeflachte Spindel ist etwas nach aussen gebogen und bildet am Uebergange in den Basalrand der Mündung eine stumpfe wenig vorspringende Ecke. Der weisse, gekörnelte Basalkallus ist nur in der Mitte stärker verdickt, an der Peripherie undeutlich begrenzt; in der Nabelgegend ein seichtes, oft undeutliches Grübchen.

$$
\mathrm{D}=12, \mathrm{~d}=9 \cdot 5, \mathrm{H}=8 \mathrm{~mm} .
$$

Deckel eiförmig mit scharfem oberen Winkel, gelbbraun mit lichterem Spindelrand; die zarte, krustenartige Kalkplatte auch am Spindelrande nur wenig dicker; in den übrigen Verhältnissen typisch.

Fundorte: Ozizaba und Yacale in Mexiko. Von Atoyac in Mexiko kenne ich ausserdem eine kleine Form dieser Art, welche zum Teile einfärbig gelblichweiss, zum Teile mit einem breiten gelbbraunen Bande versehen ist, welches die lichte Grundfarbe auf der Oberseite der Umgänge vollkommen verdeckt, auch erscheinen die Spiralfurchen auf der Oberseite nahezu erloschen.

$\mathrm{D}=8 \cdot 5, d=7, \mathrm{H}=6.5 \mathrm{~mm}$. Die Abbildung auf T. $59, \mathrm{~F} .25$.

\section{Helicina borealis Martens. \\ Taf. 60, Fig. 1-3.}

Helieina borealis Martens, Biol. Central. Amer. Moll. p, 40, T. 1, F. 15, 1890,

A. J. Wagner Helicinenstudien in Denk. Ak. Wien. v. 78, p. 239, T. 14, F. 8,1905 . 
Gehäuse flach kegelförmig mit gewölbter Basis, festschalig, leicht glänzend, kalkartig weiss, oben mit zwei Reihen undeutlicher, etwas durchscheinender Flecke. Die Skulptur besteht nur aus feinen, etwas ungleichmässigen Zuwachsstreifen. Dảs niedrige, regelmässig Hachkegelförmige Gewinde besteht aus 5 kaum gewölbten, langsam zunehmenden Umgängen, welche durch eine leicht eingedrückte Naht geschieden werden; der letzte ist etwas zusammengedrückt, an der Peripherie gerundet und steigt vorne langsam und deutlich herab. Die annähernd halbkreisförmige Mündung ist schief; der weisse, verdickte Mundsaum kurz ausgebreitet, kaum umgeschlagen. Die kurze, leicht ausgehöhlte Spindel ist etwas nach vorne und aussen gebogen und bildet am Uebergange in den Basalrand der Mürdung eine deutlich vorspringende, ziemlich scharfe Ecke. Der weisse, gekörnelte Basalkallus ist ziemlich dick, an der Peripherie undeutlich begrenzt. In der Nabelgegend eine seichte, quere Furche.

$$
\mathrm{D}=10-12, \mathrm{~d}=9-10, \mathrm{H}=7 \cdot 5-8 \mathrm{~mm} \text {. }
$$

Deckel unbekannt.

Fundort: Durango in Mexiko; ich beurteile diese Art nach Originalexemplaren des Autors.

\section{Helicina orbiculata Say.}

Taf. 61, Fig. 1-6.

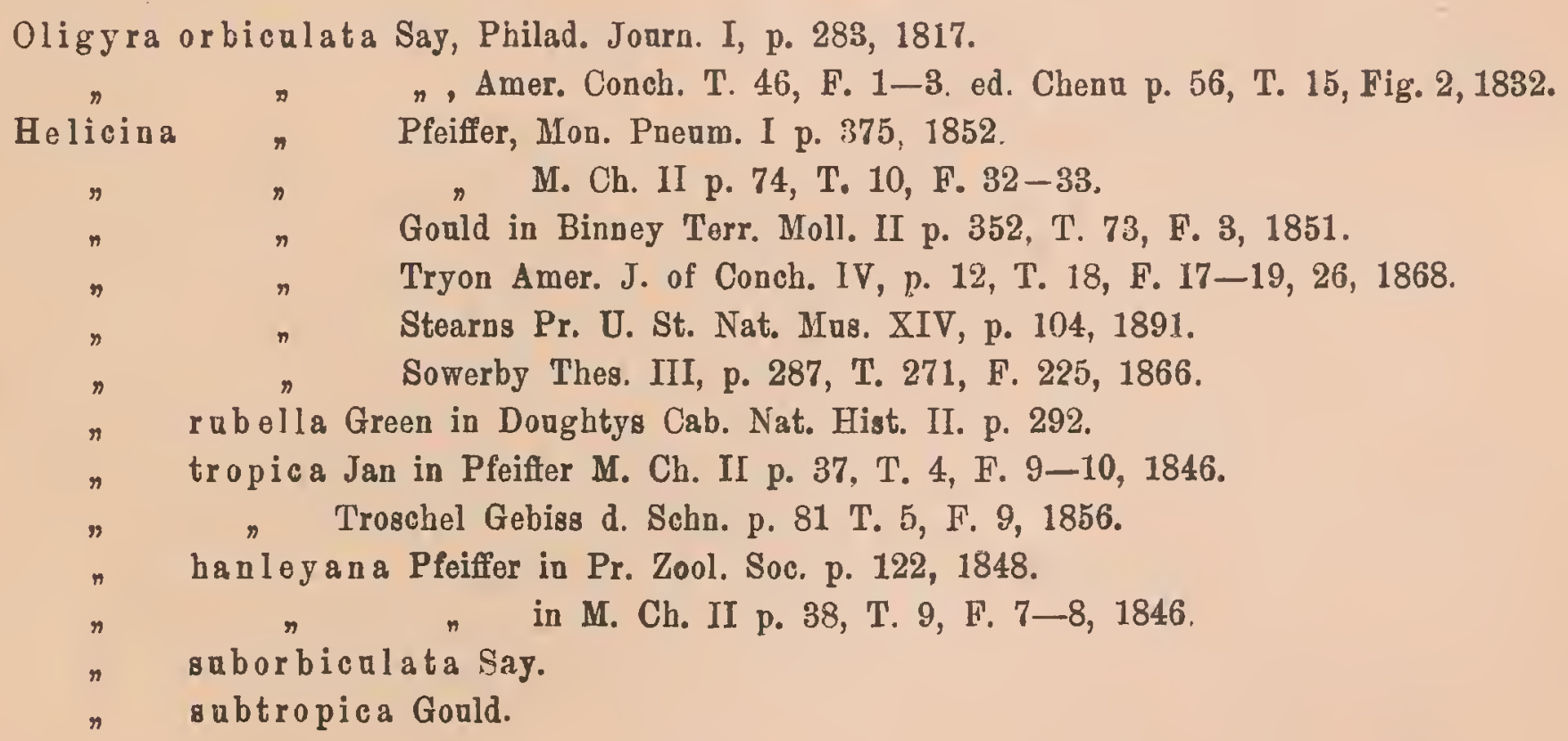

Gehăuse kugelig mit kegelförmigem Gewinde, festschalig, mehr minder durchscheinend, leicht glänzend bis matt; die Grundfarbe gelblich, grünlich, gelbbraun oder rötlich, hăufig mit lichteren bis milchig opaken Binden entlang der Peripherie und der Naht der unteren Umgånge, mitunter auch einigen schmalen und undeutlichen Binden auf der Unterseite. Die Skulptur besteht nebst sehr feinen bis undeutlichen Zuwachsstreifen aus einigen ziemlich 
weitläufigen und sehr hinfälligen Spiralfalten der Epidermis, welchen an abgeriebenen Exemplaren mitunter eingedrückte Spirallinien entsprechen, zumeist aber fehlen. Das breitkegelförmige, mitunter leicht konvexe Gewinde besteht aus 5 gewölbten, ziemlich langsam zunehmenden Umgängen; der letzte ist gleichmässig gerundet und steigt vorne nicht herab. Die halbkreisförmige Mündung ist wenig schief, der weisse oder gelbliche Mundsaum entweder leicht verdickt, kurz ausgebreitet und schwach umgeschlagen oder mehr minder schwielig verdickt bis verdoppelt. Die kurze dreieckige Spindel ist etwas ausgehöhlt und nach vorne gebogen, am Uebergange derselben in den Basalrand der Mündung findet sich stets eine etwas stumpfe, aber deutlich vorspringende Ecke. Der mit dem Gehäuse gleichfarbige, feingekörnelte und wenig glänzende Basalkallus ist dünn und undeutlich begrenzt; in der Nabelgegend ein seichtes, furchenartiges Grübchen.

$$
\mathrm{D}=6.5-9, \mathrm{~d}=5.5-7.5, \mathrm{H}=5.5-7.5 \mathrm{~mm} \text {. }
$$

Deckel birnförmig mit gekrümmter Spitze, beiderseits gelbbraun; die dünne, feingekörnelte Kalkplatte am Spindelrande zu einer stumpfen Leiste verdickt; in den übrigen Verhăltnissen typisch.

Fundorte: der Südosten der Vereinigten Staaten von Nordamerika und die angrenzenden Gebiete von Mexiko; Florida, Mississipi, Lousiana, Alabama, Texas, Tennesse. Diese Art erscheint besonders mit Rücksicht auf die Dimensionen, die Dicke der Schale und dementsprechend die Beschaffenheit des Mundsaums, weniger bezüglich der Höhe des Gewindes und der Färbung veränderlich; es ist wohl nur das grosse Verbreitungsgebiet Ursache gewesen, dass dieselbe so viele Namen erhalten hat.

\section{Formenkreis Tenuis.}

448. Helicina tenuis Pfeiffer. Taf. 60, Fig. 15-25.

Helicina tenuis Pfeiffer, Pr. Z. S. p. 124, 1848.

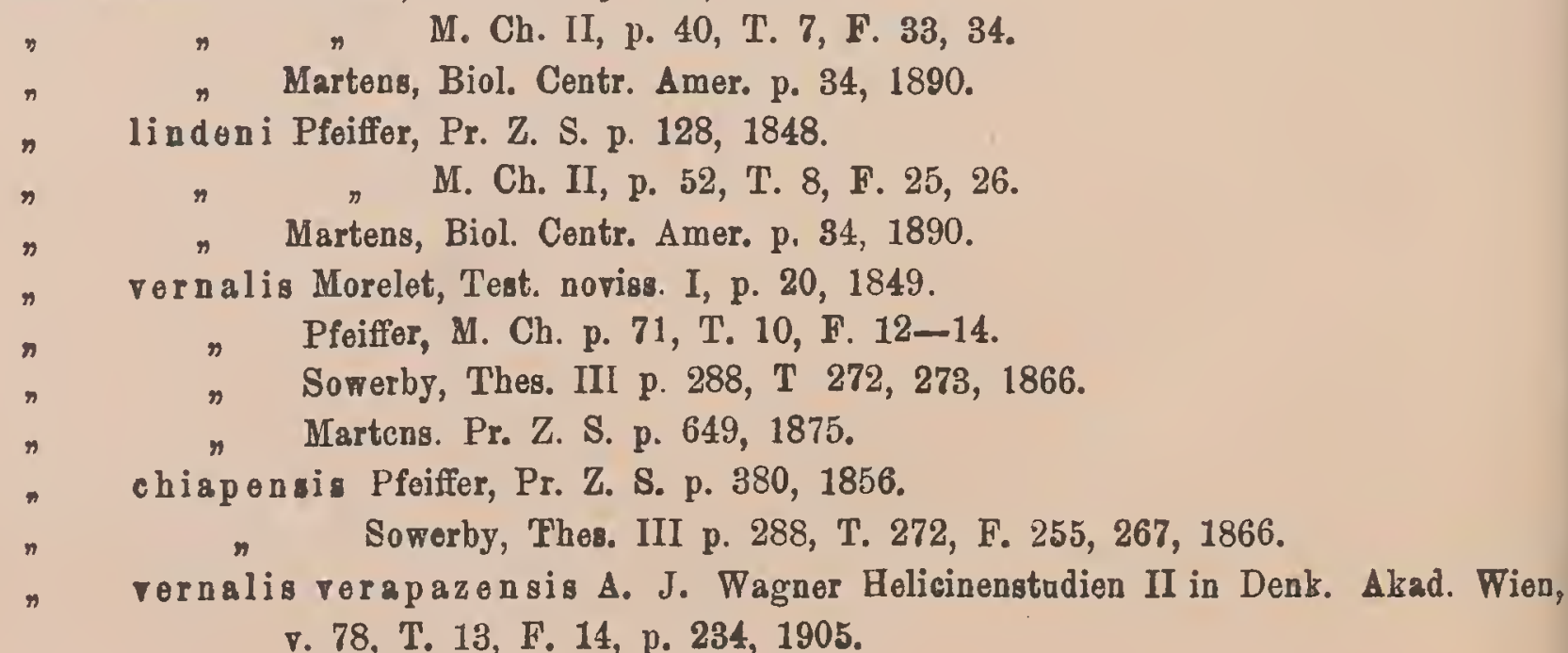


Gehäuse kegelförmig mit gewölbter bis nahezu halbkugeliger Basis, dünn bis zienilich festschalig, leicht glänzend; gelblichweiss, grünlich gelb, gelb rötlich bis rotbraun; einfarbig oder durch milchig getrübte Linien und Flecke gesprenkelt und marmoriert; häufig mit zwei rotbraunen Binden unter der Naht und der Peripherie; die Spitze mitunter karminrot. Die Skulptur besteht aus feinen, ungleichmässigen Zuwachsstreifen, ausserdem erscheint die Epidermis unter der Lupe faltig gerunzelt, mitunter gehämmert oder mit einigen undeutlichen, feinen Spirallinien versehen. Das regelmässig kegelförmige Gewinde besteht aus $5^{1} / 2-6$ ziemlich langsam zunehmenden leicht bis deutlich gewölbten Umgängen; der letzte ist zumeist etwas aufgeblasen, unten kaum oder wenig flacher, gerundet oder mit einer schwachen Kante im Beginne und steigt vorne nicht herab. Die halbkreisförmige Mündung ist wenig schief, der ziemlich dünne oder leicht verdickte, weisse Mundsaum breit und im Winkel umgeschlagen. Die abgerundete Spindel ist leicht nach vorne und links gebogen und bildet am Uebergange in den Basalrand der Mündung eine zahnartig vorspringende Ecke. Der dünne, mit dem Gehäuse gleichfarbige Basalkallus ist undeutlich begrenzt.

$\mathrm{D}=8-9, \mathrm{~d}=6.5-7, \mathrm{H}=7 \cdot 5-8 \mathrm{~mm}$. Fundort: Teapa, Mexiko.

$\mathrm{D}=7-8.5, \mathrm{~d}=5.5-7, \mathrm{H}=6-7.5 \mathrm{~mm}$. $\quad$ : Chiapas, Mexiko.

$\mathrm{D}=7 \cdot 5-9 \cdot 5, \mathrm{~d}=6-7 \cdot 5, \mathrm{H}=6.5-8 \cdot 5 \mathrm{~mm}$. Fundort: Coban, Guatemala.

$\mathrm{D}=6, \mathrm{~d}=5, \mathrm{H}=5.5 \mathrm{~mm}$. Fundort: Totonicapan, Guatemala.

$\mathrm{D}=7, \mathrm{~d}=6, \mathrm{H}=6.5 \mathrm{~mm}$. Fundort: Alajuela, Costarica.

Deckel birnförmig mit gekrümmter Spitze, dunkelrotbraun bis schwarzbraun mit lichterem Nukleus; die zarte, krustenartige Kalkplatte ist sehr fein gekörnelt, am Spindelrande zu einer dünnen Leiste verdickt und erhoben; in den übrigen Verhältnissen typisch.

Das Verbreitungsgebiet dieser Art erstreckt sich anscheinend von Südmexiko über ganz Zentralamerika bis Panama; icb kenne dieselbe von nachstehenden Fundorten: Tabasco und Chiapas in Mexiko; Coban, Totonicapan, St. Isidoro, Rio Polochic, Mercedes, Vera Paz in Guatemala; Turrubares, Alajuela in Castarica. Die zahlreichen Exemplare, welche ich untersucht habe, zeigen wohl einige Veränderlichkeit bezüglich der Dimensionen, Färbung, der Höhe des Gewindes, der mehr minder starken Wölbung und Auftreibung des letzten Umganges, doch finden sich diese Unschiede auch bei Exemplaren des gleichen Fundortes und erscheint nicht einmal die Abgrenzung von konstanten Lokalformen durchführbar. Nur von der südlichen Grenze des Verbreitungsgebietes ist mir eine auffallender unterschiedene und anscheinend konstante Form bekannt geworden.

\section{Helicina tenuis pittieri n.}

Taf. 60, Fig. 24.

Gehäuse kegelförmig mit gewölbter Basis, ziemlich glänzend, grünlichgelb mit zwei weissen, milchig getrübten Binden an der Peripherie und der Naht der unteren Umgänge 
Die Skulptur besteht nur aus sehr feinen bis undeutlichen Zuwachsstreifen, daneben sind auch unter der Lupe keine Runzeln der Epidermis zu bemerken. Das kegelförmige, ziemlich erhobene Gewinde ist deutlich konvex und besteht nur aus 5 stärker gewölbten, rascher zunehmenden Umgängen; der letzte ist an der Peripherie stumpfkantig. Der zitrongelbe Mundsaum ist entsprechend der peripheren Kante etwas winkelig ausgezogen.

$$
\mathrm{D}=10, \mathrm{~d}=8.5, \mathrm{H}=9.5 \mathrm{~mm} \text {. }
$$

Deckel wie bei der typischen Form.

Fundort: Rio de los Plutunales, am Golfe Dolce in Costarica. Das abgebildete Exemplar im k. zoologischen Museum in Berlin.

\section{Helicina senachuensis A. J. Wagner. Taf. 61, Fig. 7-10.}

Helicina vernalis senachuensis A. J. Wagner Helicinenstudien in Denk. Ak. Wien, v. 78, p. 234, T. 13, F. 15, 1905.

Gehăuse kegelförmig mit gewölbter Basis, dünnschalig, durchscheinend, glänzend; gelblichweiss, grünlichgelb oder hellrotbraun, einfarbig oder mit einer lichten, milchig getrübten Kiel- oder Nahtbinde, häufig auch mit einer rotbraunen, scharfbegrenzten Binde über dem Kiel und der Naht der unteren Umgänge. Die Skulptur besteht nur aus sehr feinen, undeutlichen Zuwachsstreifen, sonst erscheint die Oberfläche auch unter der Lupe glatt. Das regelmässig kegelförmige Gewinde besteht aus $5-5^{1} / 2$-gewölbten, regelmăssig zunehmenden Umgängen; der letzte ist beiderseits gleichmässig gewölbt, an der Peripherie ziemlich scharf gekielt und steigt vorne nicht herab. Die abger'undet dreieckige Mündung ist ziemlich schief, der leicht verdickte, gelbliche oder rötliche Mundsaum gut ausgebreitet und winkelig umgeschlagen. Die abgerundete Spindel ist nahezu senkrecht oder leicht nach rechts gebogen und bildet am Uebergange in den Basalrand der Mündung eine stumpfwinkelige Ecke (bei der Ansicht von vorne). Der sehr dünne Basalkallus ist nur im Umkreise der Spindel angedeutet; in der Nabelgegend erscheint das furchenartige Grübchen nur durch einen schwachen Eindruck angedeutet.

$$
\mathrm{D}=9 \cdot 5, \mathrm{~d}=8, \mathrm{H}=8 \mathrm{~mm} .
$$

Deckel halbkreisförmig mit spitzem oberen Winkel, gelbbraun mit grünlichem Stich sehr zart und durchscheinend; die sehr zarte Kalkplatte besteht nur aus einem reifartigen Belage und erscheint auch am Spindelrande kaum stärker entwickelt; in den übrigen Verhältnissen typisch.

Fundort: Senachu in Guatemala. Von H. tenuis Pfr. unterscheidet sich vorstehende Art durch die glatte Schale, die Beschaffenheit des Gewindes, den stets gut entwickelten, ziemlich scharfen Kiel und die Beschaffenheit der Spindel. 


\title{
451. Helicina durangoana Mousson.
}

\author{
Taf. 60, Fig. 4-6.
}

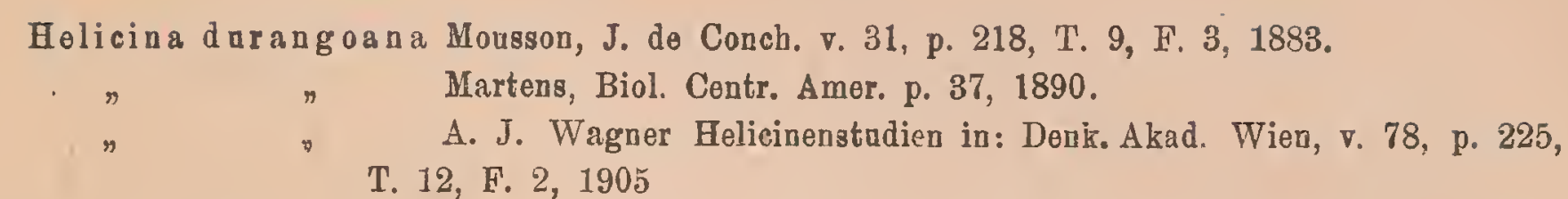

Gehäuse breitkegelförmig mit gewölbter Basis, dünnschalig, durchscheinend, leicht glănzend, einfarbig weiss oder schmutziggelb. Die Skulptur besteht nebst feinen bis undeutlichen Zuwachsstreifen aus ziemlich weitläufigen, niedrigen bis undeutlichen Spiralreifen auf der Oberseite der unteren Umgänge. Das regelmässig kegelförmige oder schwach konkave Gewinde besteht aus $5 \frac{1}{2}$ leicht gewölbten, ziemlich langsam zunehmenden Umgängen; der letzte ist etwas zusammengedrückt, an der Peripherie gerundet kantig, im Beginne nahezu stumpf gekielt und steigt vorne nicht herab. Die abgerundet dreieckige Mündung ist schief, der weisse schwach verdickte Mundsaum kurz ausgebreitet und umgeschlagen, der Oberrand an der Insertion vorgezogen. Die kurze, dreieckige Spindel ist leicht nach lechts und vorne gebogen, am Uebergange in den Basalrand der Mündung findet sich eine stumpfe, aber deutlich vorspringende Ecke. Der ziemlich dünne, feingekörnelte und mit dem Gehäuse gleichfarbige Basalkallus ist wenig deutlich begrenzt. In der Nabelgegend ein deutliches furchenartiges Grübchen.

$$
D=10, d=9, H=7 \cdot 5-8 \mathrm{~mm} .
$$

Deckel halbeiförmig mit spitz ausgezogenem oberen Winkel, gelbbraun mit rotbrauner Zone am Aussenrand; die krustenartige Kalkplatte gekörnelt, am Spindelrand stärker verdickt und leistenartig erhoben; in den übrigen Verhältnissen typisch.

Fundort: Durango in Mexiko.

\section{Helicina durangoana sagulensis.}

Taf. 60, Fig. 7.

Gehäuse ohne Spiralleisten, der letzte Umgang gerundet oder nur sehr undeutlich kantig; die Mündung innen, ebenso der Basalkallus hellzitrongelb; die Spindel stärker nach vorne gebogen, am Uebergange derselben in den Basalrand der Mündung eine zahnartige stark vorspringende Ecke.

Deckel wie bei der typischen Form.

$$
\mathrm{D}=11, \mathrm{~d}=9, \mathrm{H}=8.5 \mathrm{~mm} \text {. }
$$

Fundort: Sagula in der Provinz Jalisco, Mexiko.

I. 18. II.

9. VI. 1910. 


\section{Helicina bourguignatiana Ancey.}

Taf. 60, Fig. 8-14.

Helicina bourguignatiana Ancey, J. of Conch. Leeds. VII, p. 96.

Gehäuse kegelförmig mit flachgewölbter Basis, ziemlich dünnschalig, leicht glänzend; lebhaft gelb mit einer weissen, milchig getrübten Binde entlang der Peripherie und Naht. Die Skulptur besteht nur aus sehr feinen, nahezu undeutlichen Zuwachsstreifen, daneben sind nur bei stärkerer Vergrösserung sehr feine Runzeln der Epidermis zu bemerken. Das regelmässig kegelförmige Gewinde besteht aus 5 langsam zunehmenden, wenig gewölbten'Umgängen; der letzte ist deutlich stumpfkantig, unten flacher und steigt vorne nicht herab. Die abgerundet dreieckige Mündung ist schief, der leicht verdickte, gelbe Mundsaum kurz ausgebreitet und umgeschlagen. Die kurze, abgerundete Spindel ist leicht nach aussen und vorn gebogen und bildet am Uebergange in den Basalrand der Mündung eine ziemlich scharfe, deutlich vorspringende Ecke. Der dünne Basalkallus ist kaum angedeutet; in der Nabelgegend ein deutliches, furchenartiges Grübchen.

$$
\mathrm{D}=9, \mathrm{~d}=8, \mathrm{H}=9 \mathrm{~mm} \text {. }
$$

Deckel abgerundet dreieckig mit ziemlich spitz ausgezogenen oberen Winkel, leblaft kastanienbraun mit lichterem Nukleus und Spindelrand; die dünne Kalkplatte ist am Spindelrand leistenartig erhoben; in den übrigen Verhältnissen typisch.

Fundort: Santa Cruz de la Sierra, Bolivia. Ich beurteile diese Art nach einem Originalexemplare des Autors, mitgeteilt von Dautzenberg. Eine kleine Form dieser Art mit nur $4^{1}{ }_{2}$ Umgängen sowie einer rotbraunen Zone unter der weissen Nahtbinde, welche mitunter auf der Oberseite der unteren Umgänge die gelbe Grundfarbe verdeckt, kenne ich von Urubamba in Peru; abgebildet auf Taf. 60, Fig. 13-14.

\section{Formenkreis Turbinata.}

454. Helicina f $u_{n}^{n}$ cki Pfeiffer.

Taf. 61, Fig. 11-15.

Helicina funcki Pfeiffer Pr. Z. S. p. 121, 1848.

$\begin{array}{ll}n & n \\ n & n \\ n & n \\ n & n \\ n & n\end{array}$

» M. Ch. II, p. 33, T. 9, F. 1, 2.

" Mon. Pneum., I, p. 361, 1852.

Sowerby, Thes. III p. 288, T. 272, F. 271, 1866.

Angas, Pr. Z. S. p. 448, T. 40, F. (animal),, 1879.

Martens, Biol. Central. Amer. p, 33, 1890.

A. J. Wagner Helicinenstudien II in Denk. Ak. Wien. จ. 78, p. 232, 233, T. 13, F. 12, 190 5. 
Gehäuse kegelförmig mit flach gewölbter Basis, festschalig, wenig glänzend bis matt; die Grundfarbe gelbweiss oder schmutziggelb, durch unregelmăssige milchige Flecken und Striemen marmoriert, die oberen Umgänge und die Oberseite des letzten Umganges häufig lebhaft rotbraun oder rotorange augelaufen. Die Skulptur besteht aus schwachen bis undeutlichen.Zuwachsstreifen, ausserdem erscheint die Epidermis unter der Lupe faltig gerunzelt. Das regelmässig kegelförmige, mehr minder erhobene Gewinde besteht aus $5-5^{1} / 2 \mathrm{kaum}$ gewölbten Umgängen, von welchen die oberen langsam, die zwei letzten etwas rascher zunehmen; der letzte ist unten schwächer gewölbt, an der Peripherie mehr minder deutlich stumpfkantig und steigt vorne langsam und wenig herab. Die abgerundet dreiekige Mündung ist schief, innen gelb oder rotbraun; der gelbliche, leicht verdickte Mundsaum an der Insertion schmal und vorgezogen, entsprechend dem Aussen- und Basalrande breit umgeschlagen. Die kurze etwas abgeflachte Spindel ist nach aussen gebogen und bildet am Uebergange in den Basalrand der Mündung eine stumpfe, deutlich vorspringende Ecke. Der dünne mit dem Gehäuse gleichfarbige Basalkallus ist nur im Umkreise der Spindel deutlich; in der Nabelgegend ein deutliches furchenartiges Grübchen.

$$
\mathrm{D}=12-14 \cdot 5, \mathrm{~d}=10-11, \mathrm{H}=9-11 \mathrm{~mm} \text {. }
$$

Deckel halbeiförmig mit spitzem oberen Winkel, beiderseits dunkel kastanienbraun bis schwarzbraun. Die dünne, krustenartige Kalkplatte am Spindelrande zu einer deutlich erhobenen, gelben Leiste verdickt; in den übrigen Verhältnissen typisch. Verbreitungsgebiet: Neu Granada = Columbia (anscheinend nur im heutigen Gebiete von Panama) und Costarica; meine Exemplare von Azachar Centajo und Tarbaca in Costarica.

\section{Helicina funcki costaricensis A. J. Wagner.}

Taf. 61, Fig. 16 .

Helicina funcki costaricensis A. J. Wagner Helicinenstudien in Denk. Akad. Wien v. 78, p. 233,1905 .

Gehäuse grösser, festschaliger, hellgelb bis gelbbraun, weiss marmoriert mit deutlicheren Zuwachsstreifen und mitunter einigen undeutlichen Spirallinien am letzten Umgange.

Der letzte Umgang ist unten stärker gewölbt, häufig etwas aufgeblasen und zumeist vollkommen gerundet. Der weisse oder nur schwach gelbliche Mundsaum ist dicker und breiter umgeschlagen; die Ecke am Uebergange der Spindel in den Basalrand der Mündung schärfer und stärker vorspringend.

$$
\mathrm{D}=15-18, \mathrm{~d}=12-14, \mathrm{H}=12-15 \mathrm{~mm} \text {. }
$$

Deckel wie bei der typischen Form.

Fundorte: St. José und Sta. Clara in Costarica. Eine ăhnliche Form, jedoch mit deutlicher Kante am letzten Umgang und höherem Gewinde liegt in meiner Sammlung mit der Fundartsangabe Ylalag in Mexicc. 


\section{Helicina pitalensis $n$. \\ Taf. 61, Fig. 17-19.}

Gehäuse kegelförmig mit gewölbter Basis, festschalig, leicht glänzend, zitrongelb mit undeutlichen weissen Flecken und Punkten, sowie einer schmalen rotbraunen Binde über der Naht und dem Kiel. Die Skulptur besteht aus feinen, etwas ungleichmässigen Zuwachsstreifen auch erscheint die Epidermis unter der Lupe sehr fein gerunzelt. Das regelmässig spitzkegelförmige Gewinde besteht aus 5-51/2 leicht gewölbten, langsam zunehmenden Umgängen, welche durch eine hell berandete, schwach eingedrückte Naht geschieden werden; der letzte ist beiderseits gleichmässig gewölbt, an der Peripherie deutlich kantig bis stumpf gekielt und steigt vorne nicht herab (unmittelbar vor der Mündung ein wenig hinauf). Die abgerundet dreieckige Mündung ist schief, innen gelb mit durchscheinender Binde. Del leicht verdickte, gelbliche Mundsaum erweitert; der Oberrand schmal und an der Insertion vorgezogen, der Aussen- und Basalrand breit umgeschlagen. Die kurze, abgerundete Spindel ist senkrecht oder leicht nach links gebogen; am Uebergange derselben in den Basalrand der Mündung eine zahnartig vorspringende Ecke. Der sehr dünne, feingekörnelte Basalkallus nur im Umkreise der Spindel deutlich. Das Grübchen in der Nabelgegend undeutlich.

$$
\mathrm{D}=14, \mathrm{~d}=11.5, \mathrm{H}=13.5 \mathrm{~mm} \text {. }
$$

Deckel birnförmig mit seitlich gekrümter Spitze schwarzbraun bis pechschwarz mit lichterem Streifen entlang der Sigmakante; die dünne, feingekörnelte Kalkplatte nur am Spindelrande etwas leistenartig verdickt; in den übrigen Verhaltnissen typisch.

Fundort: El Pital im Tale des Rio Naranjo im südwestlichen Costarica. Das abgebildete Exemplar im k. Museum zu Berlin.

Von der ähnlichen Helicina funcki Pfeiffer unterscheidet sich vorstehende neue Art durch die lebhafte Fărbung mit deutlicher Binde, die glänzende Oberfläche mit deutlicheren Zuwachsstreifen, das höhere Gewinde mit deutlich gewölbten langsam und regelmässig zunehmenden Umgängen, den weniger erweiterten, aber deutlich kantigen bis stumpfgekielten letzten Umgang, sowie besonders die abweichenden Verhältnisse der Mündung und des Mundsaumes.

\section{Helicina turbinata (Wiegman) Menke.}

Taf. 61, Fig. 20-25.

Helicina turbinata Wiegmann in: Menke Syrops. ed. II, p. 39, 1831.

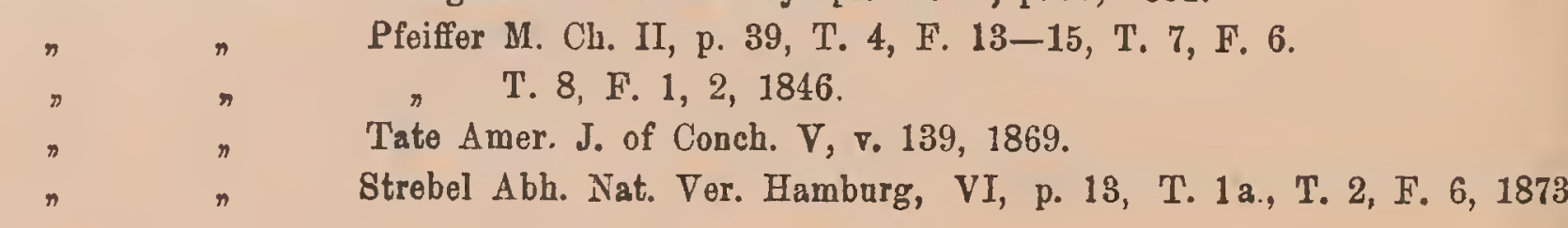




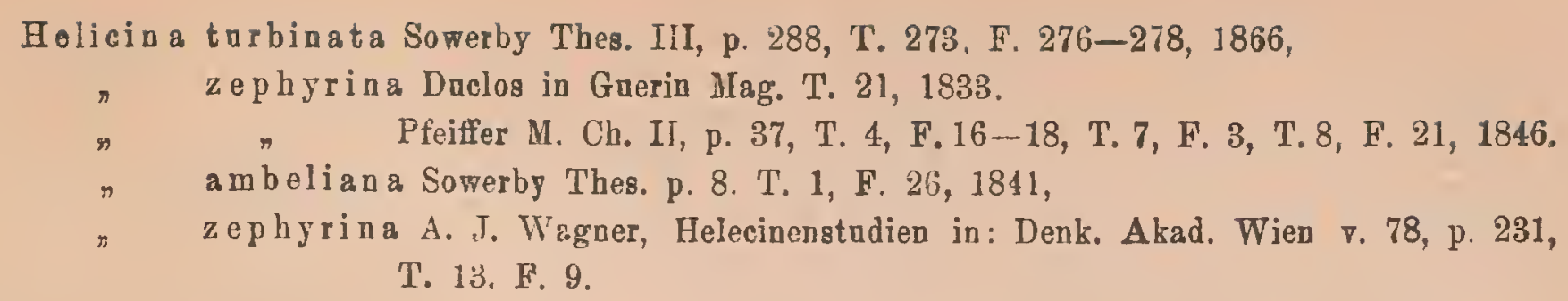

Gehäuse kreiselförmig, festschalig, leicht glänzend bis matt; die Grundfarbe gelblich weiss, gelh oder rötlich fleischfarben, einfärbig oder mit einer verschieden breiten, rotbraunen Binde (mitunter schrumpft dieselbe zu einer feinen und unterbrochenen Linie zusammen) über der Naht und der Peripherie der unteren Umgänge. Die Skulptur besteht aus feinen ungleichmässigen Zuwachsstreifen, ausserdem sind unter der Lupe sehr feine und undeutliche Spiralfalten der Epidermis sichtbar. Das etwas abgerundet kegelförmige Gewinde bestelst aus 51/2 -6 langsam zunehmenden, leicht bis kaum gewölbten Umgangen; der letzte ist gerundet und steigt vorne sehr wenig oder gar nicht herab. Die annähernd halbkreisförmige Mündung ist schief und etwas mondförmig ausgeschnitten, innell gelb oder rotbraun. Der weisse Mundsaum ziemlich verdickt; der Oberrand schmal, an der Insertion vorgezogen, der Aussen- und Basalrand ziemlich ausgebreitet und umgeschlagen. Die kurze, leicht abgeflachte Spindel ist nach aussen gebogen und bildet am Uebergange in den Basalrand der Mündung eine knotellartige, mehr minder vorspringende Ecke; in der Nabelgegend ein deutliches furchenartiges Grübchen. Der weisse oder gelbliche Basalkallus ist nur im Umkreise der Spindel leicht verdickt, sonst dünn und undeutlich begrenzt.

$$
\mathrm{D}=14, \mathrm{~d}=12, \mathrm{H}=12 \mathrm{~mm} \text {. }
$$

Deckel birnförmig mit seitlich gekrümmter Spitze, lebhaft rotbraun bis kastanienbraun. Die dünne, gekörnelte Kalkplatte nur am Spindelrande leistenartig verdickt; in den übrigen Verhältnissen typisch.

Fundorte: Cordova, Veracruz, Jalapa, Atoyac in Mexico.

Bei den Exemplaren von Jalapa und Consolapa finde ich die knotenartige Verdickung am Uebergange der Spindel in den Basalrand der Mündung besonders kräftig entwickelt (Taf. 61, Fig. 25). Eine auffallend kleine Form dieser Art erhielt ich ferner von Orizaba in Mexico, welche jedoch bis auf die Dimensionen: $\mathrm{D}=9 \mathrm{~d}=8, \mathrm{H}=8 \mathrm{~mm}$, vollkommen mit der typischen Form übereinstimmt. Ich zweifle heute nicht mehr, dass vorstehende Art mit Helicina zephyrina Duclos vollkommen identisch ist und wende aus diesem Grunde die altere Bezeichnung an.

458. Helicina deppeana Martens. Taf. 62, Fig. 1-3.

Helicin a deppeana Martens, Monatsb. Akad. Wisseusch. Berlin, p. 540, 1863.

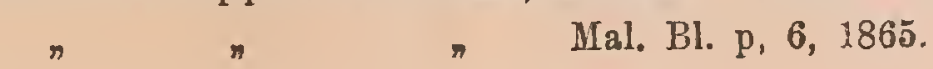


Helicina d eppeana Mon. Pneum. III, p. 229, 1865.
$\rightarrow$
Sowerby Thes., p. 298, T. 272, F. 264-265, nec 270, 1866.
$n$
Martens Biol. Centr. Amer. p. 52, 1890.
A. J. Wagner, 'Helicinenstudien in: Denk. Akad. Wien v. 78, p. 231, T. 13, F. 11, 1905.

Gehäuse breitkegelförmig mit flachgewölbter Basis, festschalig, mit ungleichmässigen, feinen Zuwachsstreifen und undeutlichen Spirallinien auf den unteren Umgängen; einfärbig gelblich hornfarben. Die mir vorliegenden Exemplare zeigen ferner unter der Lupe eine eigentümlich rauhe, sehr feingekörnelte Epidermis und könnten frische Exemplare mit Borsten oder Härchen versehen sein. Das regeimässig kegelförmige Gewinde besteht aus $5 \frac{1}{2}$ leicht gewölbten Umgängen, von welchen die ersten langsam, die zwei letzten rascher zunehmen; der letzte ist flacher gewölbt, an der Peripherie gerundet und steigt vorne langsam und ziemlich tief herab. Die annähernd kalbkreisförmige Mündung ist schief, innen gelblich; der Mundrand weiss und verdickt, der Oberrand an der Insertion vorgezogen, der Aussen- und Basalrand ausgebreitet und umgeschlagen. Die kurze abgeflachte oder leicht konkave Spindel ist nach aussen gebogen, am Uebergange derselben in den Basalrand der Mündung eine knotenartig vorspringende, abgerundete Ecke. Der weisse, feingekörnelte Basalkallus ist ziemlich dick, aber undeutlich begrenzt; in der Nabelgegend ein deutliches Grübchen.

$$
\mathrm{D}=15, \mathrm{~d}=12, \mathrm{H}=11 \mathrm{~mm} .
$$

Deckel unbekannt.

Fundort: Deppe in Mexico. Ich beurteile diese Art nach Originalexemplaren des Autors aus dem k. Musuum für Naturkunde in Berlin; Von Helicina turbinata Menke unterscheidet sich dieselbe durch das niedrigere, regelmässig kegelförmige, nicht konvexe Gewinde, die gewölbten, rascher zunehmenden Umgänge, die Beschaffenheit der Epidermis, den vorne tief herabsteigenden letzten Umgang, den dicken Basalkallus und die deutlicher vorspringende knotenartige Ecke am Uebergange der Spindel in den Basalrand der Mündung.

\section{Helicina delicatula Shuttleworth. Taf. 62, Fig. 4-9.}

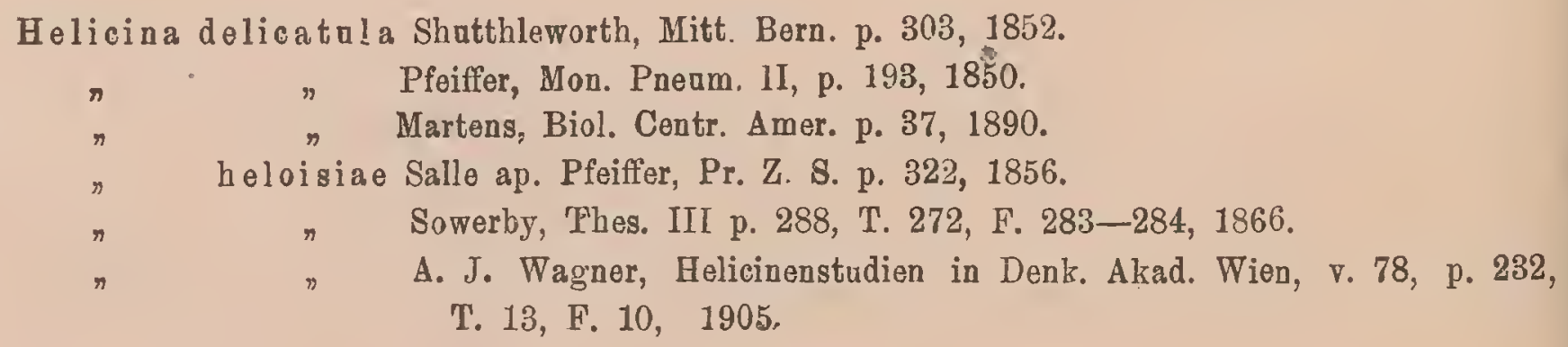


Gehäute kugelig mit breit kegelförmigem Gewinde, ziemlich dünnschalig, durchscheinend, glänzend mit feinen Zuwachsstreifen und sehr feinen, undeutlichen Spiralfalten der Epidermis unter der Lupe; die Grundfarbe weiss oder gelb mit einer breiten hell bis dunkelrotbraunen Binde über der Peripherie und Naht der unteren Umgänge, einer hellen bis weissen Zone entlang der Naht und gelbem bis karminroten Apex. Das abgerundet kegelförmige Gewinde besteht aus $5-5^{1} / 2$ leicht gewölbten, ziemlich langsam zunehmenden Umgängen; der letzte ist beiderseits gleichmässig gewölbt an derr Peripherie gerundet und steigt vorne deutlich herab. Die annähernd halbkreisförmige Mündung ist schief, innen mit dem Gehäuse gleichfarbig; der weisse oder gelbe, kaum verdickte Mundsaum kurz ausgebreitet und umgeschlagen; der Oberrand an der Insertion vorgezogen. Die kurze, abgeflachte Spindel ist nach aussen gebogen und bildet am Uebergange in den Basalrand der Mündung eine undeutliche knotenartige Verdickung, welche oft erlischt. Der glänzende mit dem Gehäuse gleichfarbige Basalkallus ist nur im Umkreise der Spindel deutlich verdickt und hier durch eine seichte Furche begrenzt; in der Nabelgegend ein deutlickes, furchenartiges Grübchen.

$$
D=7 \cdot 5-9 \cdot 5, d=6.5,-8, H=6-8 \mathrm{~mm} \text {. }
$$

Deckel: birnförmig mit seitlich gekrümmter Spitze, gelbbraun. Die krustenartig dünne Kalkplatte ist am Spindelrande leistenartig erhoben; die übrigen Verhältnisse des Deckels typisch.

Fundorte: Cordova, Vera Cruz und Atoyac in Mexico.

Die mir vorliegenden von den Originalfundorten stammenden Exemplare von Helicina heloisiae Pfeiffer finde ich mit vorstehender Art vollkommen identisch.

460. Helicina trossula Morelet.

Taf. 62, Fig. 10-14.

Helicina trossula Morelet, Test. Noviss. I, p. 19, Nr. 44, 1849.

Gehäuse breit kegelförmig mit flachgewölbter Basis, ziemlich dünıschalig und durchscheinend; glänzend mit sehr feinen Zuwachsstreifen; die Grundfarbe gelblich weiss oder gelb, häufig mit einer rotbraunen, breiten Binde über der Naht und der Peripherie, ebenso mit rotbraunem oder karminroten Apex. Das regelmăssig kegelförmige oder nur leicht abgerundete Gewinde besteht aus $4 \frac{1}{1}-5$ ziemlich langsam zunehmenden, kaum gewölbten Umgängen; der letzte ist deutlich kantig und steigt vorn nicht herab. Die abgerundet dreieckige Mündung ist wenig schief. Der weisse oder gelbliche Mundsaum ist leicht verdickt, kurz ausgebreitet und umgeschlagen. Die kurze, konkave Spindel ist etwas nach aussen gebogen, am Uebergange derselben in den Basalrand der Mündung eine deutlich vorspringende, ziemlich scharfe Ecke. Der dünne, mit dem Gehäuse gleichfarbige Basalkallus ist nur im Umkreise der Spindel deutlich verdickt und durch eine seichte Furche begrenzt; in der Nabelgegend ein deutliches furchenartiges Grübchen. 


$$
\mathrm{D}=7, \mathrm{~d}=6, \mathrm{H}=5.5 \mathrm{~mm} \text {. }
$$

Deckel abgerundet dreieckig mit spitzem oberen Winkel, gelbbraun; die zarte, feingekörnelte Kalkplatte auch am Spindelrande nur wenig dicker; in den übrigen Verhältnissen typisch.

Fundort: Vera Paz in Guatemale. Ich beurteile diese Art nach Originalexemplaren des Autors; dieselbe steht der Helicina delicatula Shuttl. sehr nahe, unterscheidet sich jedoch von derselben durch geringere Dimensionen, die breit kegelförmige Form mit deutlicher Kante am letzten Umgange, den Mangel der Spiralfalten und die scharfe Ecke am Uebergange der Spindel in den Basalrand der Mündung. Mit der verschollenen Helicina flavida Menke von Jamaica kann ich die vorstehende Art nicht identifizieren, wie es Pfeiffer und Reeve vorschlagen.

\title{
461. Helicina notata (Salé) Pfeiffer. Taf. 62, Fig. 23-27.
}

\author{
Helicina notata Salé apud Pfeiffer, Pr. Z. S. p. 323, 1856.
}

" $\quad$ Pfeiffer, Mon. Pneam. II, p. 203, 1858.

n Sowerby Thes. III, p. 287, T. 272, F. 239, 240, 1866.

" $x \quad$ Martens, Biol. Cent. Amer., p. 38, 1890.

$" \quad$ A. J. Wagner, Helicinenstudien in Denk. Akad. Wien, v. 78, p. 235, T. 13, H. 16,1905

Gehäuse kegelförmig mit gewölbter Basis, ziemlich festschalig leicht glänzend, gelb oder rötlich fleischfarbig mit weissberandeter Naht. Die Skulptur besteht nebst feinen etwas ungleichmässigen Zuwachsstreifen aus ziemlich weitläufigen, niedrigen, bis undentlichen Spiralreifen auf den unteren Umgängen, auch erscheint die Oberfläche uneben, wie gehämmert. Das regelmässig kegelförmige Gewinde besteht aus 5 leicht bis kaum gewölbten, langsam zunehmenden Umgängen; der letzte ist beiderseits gleichmässig gewölbt, an der Peripherie undeutlich kantig bis gerundet und steigt vorne etwas hinauf. Die halbkreisförmige Mündung ist schief, der weisse ziemlich dicke Mundsaum breit umgeschlagen. Die kurze abgeflachte Spindel ist nach aussen gebogen und bildet am Uebergange in den Basalrand der Mündung ein zahnartig vorspringendes Knötchen. Der weisse Basalkallus ist nur im Umkreise der Spindel deutlich verdickt, an den Rändern undeutlich begrenzt; in der Nabelgegend ein deutliches, furchenartiges Grübchen.

$$
\mathrm{D}=8, \mathrm{~d}=7, \mathrm{H}=7 \mathrm{~mm} .
$$

Deckel birnförmig mit seitlich gekrümmter Spitze, lebhaft orangerot mit lichterem Nukleus; die feingekörnelte, krustenartige Kalkplatte am Spindelrande etwas leistenartig verdickt; in den übrigen Verhältnissen typisch.

Fundorte: Cordova und Vera Cruz in Mexico.

Ich beurteile diese Form nach Originalexemplaren Sallés. 


\section{Helicina rostrata Morelet.}

Taf. 62, Fig. 15-18.

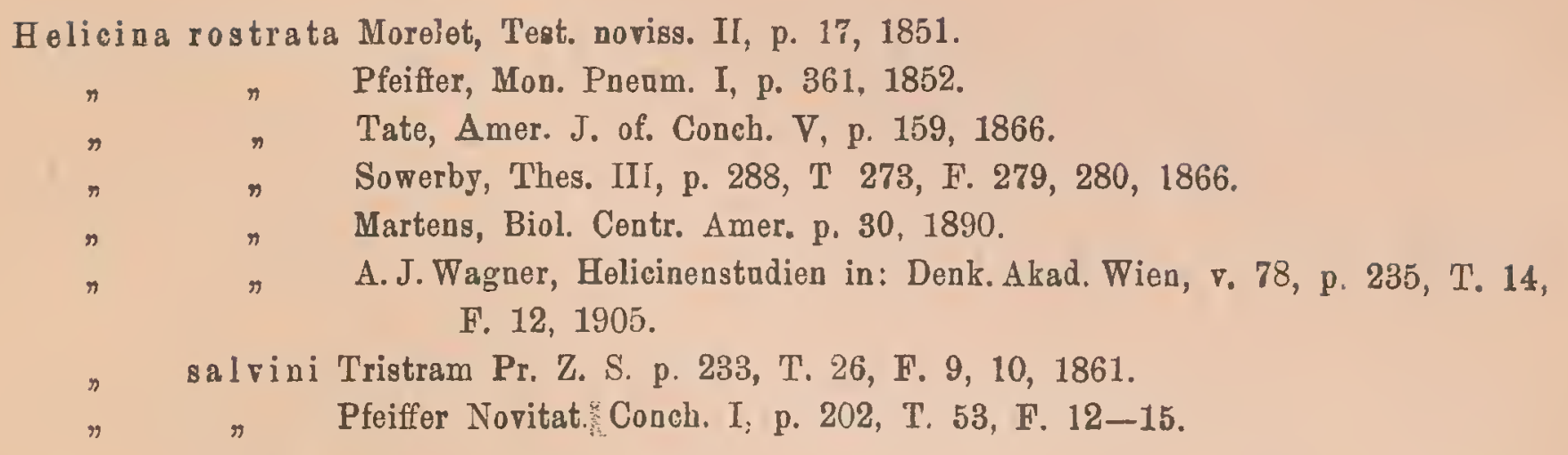

Gehäuse breitkegelförmig mit gewölbter Basis, festschalig, wenig glänzend bis matt; gelblich weiss mit zwei etwas durchscheinenden, gelben, gelbbraunen oder rotbraunen Binden über und unter der Peripherie. Dis Skuptur besteht nebst feinen Zuwachsstreifen aus sehr feinen und dichten, nur unter der Lupe sichtbaren Spirallinien auf den unteren Umgängen. Das schwach konvexe Gewinde besteht aus $5 \frac{1}{2}$ ziemlich langsam zunehmenden, kaum gewölbten, durch eine leicht eingedrückte Naht geschiedenen Umgängen; der letzte ist undeutlich kantig und steigt vorne langsam aber deutlich herab. Die abgerundet dreieckige Mündung ist sehr schief, innen mit durchscheinenden Binden, der gelbliche Mundsaum lippenartig verdickt; der Oberrand an der Insertion vorgezogen, der Aussenrand zu einem nach vorne und unten gerichteten Schnabel ausgezogen; Ober- und Basalrand ausserdem verhältnismässig kurz ausgebreitet und umgeschlagen. Die abgeflachte kurze Spindel ist nach aussen gebogen, am Uebergange derselben in den Basalrand der Mündung eine etwas abgerundete, nur in der Ansicht von unten deutlich vorspringende Ecke. Der weisse, glänzende Basalkallus ist nur in der Umgebung der Spindel deutlich verdickt, an den Rändern undeutlich begrenzt; in der Nabelgegend ein deutliches furchenartiges Grübchen.

$$
\mathrm{D}=15, \mathrm{~d}=13, \mathrm{H}=12 \mathrm{~mm} \text {. }
$$

Deckel birnförmig mit seitlich gekrümmter Spitze, lebhaft gelbbraun bis rotbraun; die zarte krustenartige Kalkplatte auch am Spindelrande wenig verdickt; in den übrigen Verhältnissen typisch.

Fundort: Guatemala (Verapaz). Helicina salvini Tristram ist dem Vergleiche von Originalexemplaren zur Folge mit vorstehender Art vollkommen identisch.

\section{Helicina rostrata mategalpensis n.} Taf. 62, Fig. 19.

Gebäuse kleiner, kugeliger mit deutlicheren Spirallinien und nur 5 langsamer zunehmenden I. 18. II. 9. VII 1910. 
Umgăngen; die Spitze und eine Zone hinter dem Mundsaum häufig zitronengelb gefärbt; der Schnabel am Aussenrande des Mundsaumes nach vorne und zumeist etwas nach oben gerichtet.

Deckel wie bei der typischen Form.

$$
\mathrm{D}=12 \cdot 5, \mathrm{~d}=10, \mathrm{H}=10 \mathrm{~mm}
$$

Fundort: Matagalpa in Nikaragna.

\title{
464. Helicina denticulata Pfeiffer.
}

Taf. 62, Fig. 20-22.

\author{
Helicina denticulata Pfeiffer, Pr. Z. S. p. 103, 1855.

$\begin{array}{ll}n & n \\ n & n \\ n & n \\ n & n \\ n & n\end{array}$ \\ ᄁ Novitat. I, p. 84, T. 23, E. 9, 10. \\ Mon. Pneum. II p. 208, 1858. \\ Sowerby, Thes. III, p. 288, T. 273, F. 281, 1866. \\ Tate, Amer. J. of. Conch. V, p. 159, 1870. \\ Martens, Biol. Centr. Amer. p. 30, 1890.
}

A. J. Wagner Helicinenstudien, in: Denk. Akad. Wien, v. 78, p. 236, T. 14, F. 13, 1905.

Gehăuse kegelförmig mit gewölbter Basis, festschalig, leicht glänzend bis matt; die Grundfarbe weiss, die innere Schalenwand jedoch lebhaft rotbraun, so dass je nach der Dicke der weissen Schichte die unteren Umgänge rötlich, die oberen gelbbraun durchscheinen, die Spitze opak gelblich. Die Skulptur besteht nebst etwas ungleichmässigen, feinen Zuwachsstreifen aus einigen niedrigen, undeutlichen Spiralleisten und dazwischen sehr feinen Spirallinien auf den unteren Ungängen; auf den unteren Umgängen sind ausserdem deutliche, weitläufige, schief nach vorne absteigende Runzelfalten sichtbar. Das leicht konvexe Gewinde besteht aus 5 nahezu flachen, langsam zunehmenden Umgängen, welche durch eine deutlich gezähnelte Naht geschieden werden; der letzte ist stumpł gekielt, beiderseits gleichmässig gewölbt und steigt vorne nicht herab. Die halbkreisförmige Mündung ist schief, innen lebhaft kastanienbraun; der weisse lippenartig verdickte Mundsaum kurz ausgebreitet und umgeschlagen; der Oberrand an der Insertion vorgezogen, der Aussenrand mit einem schief nach vorne und oben gerichteten, ziemlich spitzen Schnabel versehen. Die kurze, abgeflachte Spindel ist nach aussen gebogen, am Uebergange derselben in den Basalrand der Mündung eine abgerundete, leicht vorspringende Ecke. Der glänzende, weisse Basalkallus ist undeutlich begrenzt; in der Nabelgegend ein deutliches furchenartiges Grübchen.

$$
\mathrm{D}=11.5, \mathrm{~d}=9.5, \mathrm{H}=9.5 \mathrm{~mm} \text {. }
$$

Deckel birnförmig mit seitlich gekrümmter Spitze, lebhaft kastanienbraun; die zarte, krustenartige Kalkplatte auch am Spindelrande wenig dicker; in den übrigen Verhältnissen typisch.

Fundort: San Pedro in Honduras. 


\section{Formenkreis Succincta.}

\section{Helicina raresulcata Pfeiffer.}

Taf. 63, Fig. 1-5.

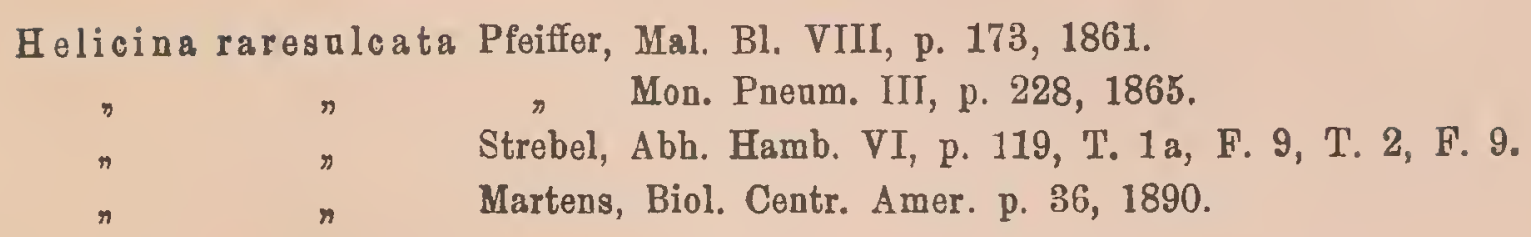

Gehäuse kegelförmig mit gewölbter Basis, ziemlich festschalig leicht glänzend, gelblich hornfarben; die Skulpur besteht nebst feinen ungleichmässigen Zuwachsstreifen aus ziemlich weitläufigen eingedrückten Spirallinien auf den unteren Umgängen, welche stellenweise unterbrochen sind, häufig undeutlich werden. Das regelmässig kegelförmige Gewinde besteht aus $5 \frac{1}{2}$ gewölbten, langsam zunehmenden Umgängen; der letzte ist undeutlich stumpf kantig, beiderseits gleichmässig gewölbt und steigt vorn nicht herab. Die halbkreisförmige Mündung ist schief, innen gelblich; der gelbliche Mundsaum leicht verdickt; der Oberrand an der Insertion wenig vorgezogen und gerade, der Aussen- und Basalrand kurz ausgebreitet. Die kurze ausgehöhlte Spindel ist nach vorne gebogen und bildet am Uebergange in den Basalrand der Mündung eine scharfe, deutlich vorspringende Ecke. Der dünne, durchsichtige Basalkallus ist undeutlich begrenzt; in der Nabelgegend ein seichtes, oft undeutliches Grübchen.

$$
\mathrm{D}=6, \mathrm{~d}=5, \mathrm{H}=5.5 \mathrm{~mm} \text {. }
$$

Deckel birnförmig mit gekrümmter Spitze, lebhaft gelbbraun; die dünne, feingekörnelte Kalkplatte am Spindelrande leistenartig verdickt und erhoben; in den übrigen Verhältnissen typisch.

Fundort: Vera Cruz in Mexico.

\section{Helicina succincta Martens.}

Taf. 63, Fig. 6-10.

Heli cina succincta Martens, Biol. Centr. Amer., p. 36, T. 1, F. 6-9, 1890.

$\eta \quad$ A. J. Wagner, Helicinenstadien in: Denk. Akad. Wien, v. 78, p. 236, T. 14, F. 1, 1905.

Gehäuse kegelförmig mit flachgewölbter Basis, festschalig, durchscheinend, leicht glănzend; hell bis zitrongelb mit weissen Flecken und Radialstriemen, sowie einem durch die Radialstriemen unterbrochenen, breiten braunem Bande auf der Oberseite der unteren Umgänge. Die Skulptur besteht nebst ungleichmässigen Zuwachsstreifen aus feinen, dichten Spiralfurchen, welche auf der Unterseite schwächer werden. Das schwach konvexe oder 
regelmässige kegelförmige Gewinde besteht aus $5 \frac{1}{2}$ leicht gewölbten langsam zunehmenden Umgängen; der letzte ist unten flacher, an der Peripherie undeutlich kantig und steigt vorne wenig oder gar nicht herab. Die halbkreisförmige Mündung ist schief, innen mit dem Gehäuse gleichfarbig; der gelbliche oder weisse Mundsaum leicht verdickt, kurz ausgebreitet und umgeschlagen. Die kurze abgeflachte Spindel bildet am Uebergange in den Basalrand der Mündung eine stumpfwinkelige, leicht vorspringende Ecke. Der gelbliche, feingekörnelte Basalkallus ist nur im Umkreise der Spindel leicht verdickt, an den Rändern undeutlich begrenzt; in der Nabelgegend ein deutliches, furchenartiges Grübchen.

$$
\mathrm{D}=8.5, \mathrm{~d}=7, \mathrm{H}=7.5-8.5 \mathrm{~mm} \text {. }
$$

Deckel birnförmig mit seitlich gelsrümmter Spitze, lebhaft kastanienbraun mit lichterem Nukleus; die krustenartig dünne Kaikplatte auch am Spindelrande wenig dicker; in den ïbrigen Verhältnissen typisch.

Fundorte: Cordova und Misanthe in Mexico; ich beurteile die Art nach Originalexmplaren des Autors.

\section{Helicina arenicola Morelet.}

Taf. 63, Fig. 11-13.

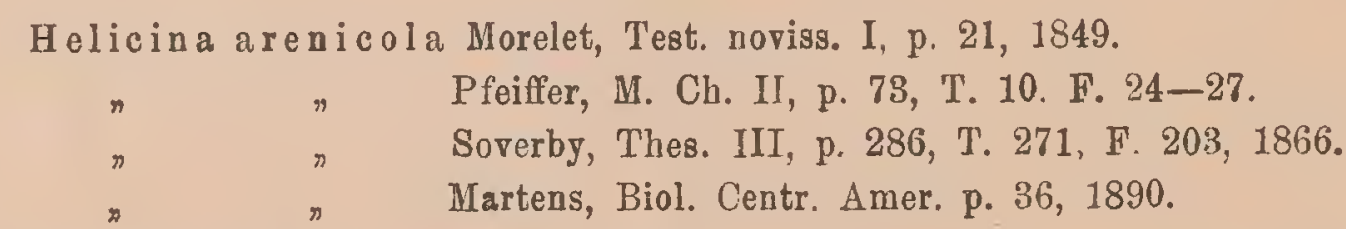

Gehäuse kegelförmig mit gewölbter Basis, leicht gläızend, festschalig; gelblichweiss mit einer gelbbraunen Fleckenbinde über der Peripherie und Naht der unteren Umgänge, die oberen Umgänge braungelb. Die Skulptur besteht nebst ungleichmässigen, feinen Zuwachsstreifen aus niedrigen, ziemlich dichten Spiralreifen, welche auf der Unterseite auffallend schwächer werden. Das schwach konvexe Gewinde besteht aus 5 nahezu flachen, langsam zunehmenden Umgängell, welche durch eine leicht eingedrückte Naht geschieden werden; der letzte ist beiderseits gieichmässig gewölbt, an der Peripherie kantig bis nahezu gerundet und steigt vorne nicht herab. Die halbkreisförmige Mündung ist ziemlich schief, innen gelblich; der weisse Mundsaum leicht verdickt kurz ausgebreitet und umgeschlagen. Die kurze, ausgehöhlte Spindel ist etwas nach aussen gebogen und bildet am Uebergange in den Basalrand der Mündung eine scharfe, deutlich vorspringende Ecke. Der weisse, glänzende Basalkallus ist ziemlich dünn und undeutlich begrenzt; in der Nabelgegend ein deutliches Grübchen.

Deckel unbekannt.

$$
\mathrm{D}=6, \mathrm{~d}=5 \cdot 5, \mathrm{H}=5 \text {. }
$$

Fundort: Sicul in Yucatan; ich beurteile die Art nach einem Originalexemplare des Autors. 


\section{Helicina brevilabris Pfeiffer.}

Taf. 63, Fig. 14-18.

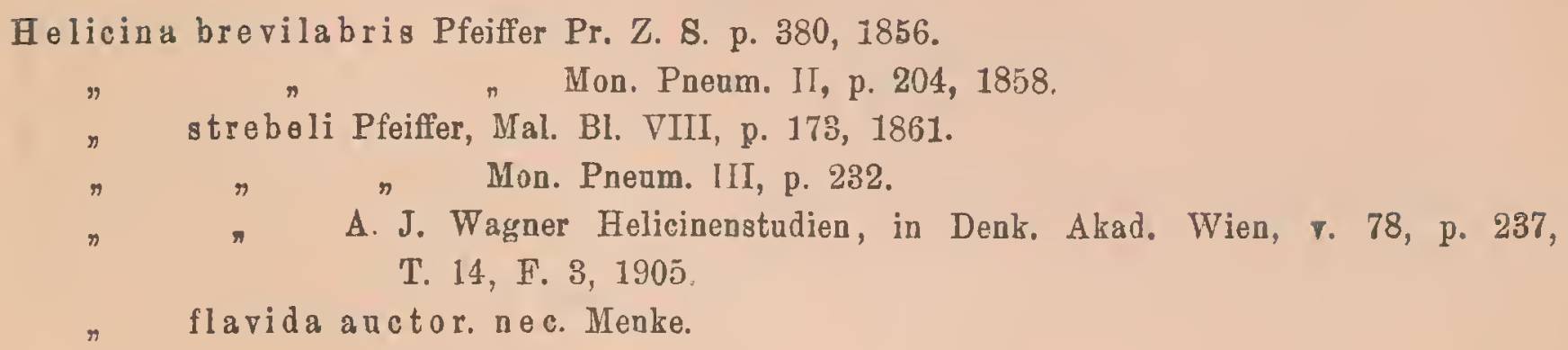

Gehäuse kegelförmig mit gewölbter Basis, ziemlich dünnschalig durchscheinend, leicht glänzend; einfärbig gelblich weiss, gelb oder rötlich, häufig mit einer schmalen rotbraunen Binde über der Peripherie und Naht der unteren Umgänge, sowie rotbrauner bis karminroter Spitze. Die Skulptur besteht aus sehr feinen und dichten Spirallinien, welche auf den oberen Umgängen und der Unterseite nahezu erlöschen. Das regelmässig kegelförmige oder nur schwach konvexe Gewinde besteht aus 5 bis $5 \frac{1}{2}$ leicht gewölbten, langsam zunehmenden Umgängen; der letzte ist gerundet, unten flacher gewölbt und steigt vorne sehr wenig herab. Die halbkreisförmige Mündung ist schief, innen mit durchscheinender Binde; der weisse, mehr minder deutlich verdickte Mundsaum ist kurz ausgebreitet oder fast gerade. Die kurze abgeflachte Spindel bildet am Uebergange in den Basalrand der Mündung eine schwache, oft undeutliche Ecke. Der dünne, mit dem Gehäuse gleichfarbige Basalkallus ist undeutlich begrenzt; in der Nabelgegend ein deutliches, furchenartiges Grübchen

$$
D=5.5-6.5, d=4.5-5.5, H=4.8-6.5 \mathrm{~mm} \text {. }
$$

Deckel birnförmig mit seitlich gekrümmter Spitze, gelblich hornfarben; die zarte, anflugartige Kalkplatte nur am Spindelrande etwas verdickt und erhoben; in den übrigen Verhältnissen typisch.

Fundorte: Chiapas, Tabasco, Cordova, Mirador, San Juan-Bautista, Papantha, Misanthe, Teapa in Mexico. Ich beurteile die Art zunächst nach Exemplaren vom Originalfundorte Chiapas, gesammelt von Sallé, dementsprechend ist die dieselbe vollkonmen identisch mit Helicina strebeli Pfr. von Mirador. Martens und andere Autoren ziehen die vorstehend angeführten Formen zu Helicina flavida Menke; der Originalfundort dieser verschollenen Art ist aber nach Menke Jamaica. Ich habe mich vergeblich bemüht eine Helicina von Jamaica zu erhalten, welche mit $H$. flavida zu indifizieren wäre; alle Exemplare, welche ich unter der Bezeichnung H. flavida Menke zu untersuchen Gelegenheit hatte wurden in Zentralamerika und Mexico gesammelt und waren $\mathrm{H}$. brevilabris Pfr. 


\title{
469. Helicina brevilabris incommoda A. J. Wagner. Taf. 63, Fig. 19.
}

\author{
Helicina microdina incommoda A. J. Wagner, Helicinenstudien in: Denk. Akad. Wien, \\ v. 78, p. 238 , T. 14, F. $2,1905$. \\ , flavida auctor. nec. Menke.
}

Gehäuse grösser mit höherem Gewinde, schwächeren bis undeutlichen Spirallinien; der Mundsaum stärker verdickt, breiter umgeschlagen, die Ecken am Uebergange der Spindel in den Basalrand der Mündung deutlicher vorspringend.

Deckel wie bei der typischen Form.

$$
\mathrm{D}=7, \mathrm{~d}=6, \mathrm{H}=7 \mathrm{~mm} \text {. }
$$

Fundort: Guatemala.

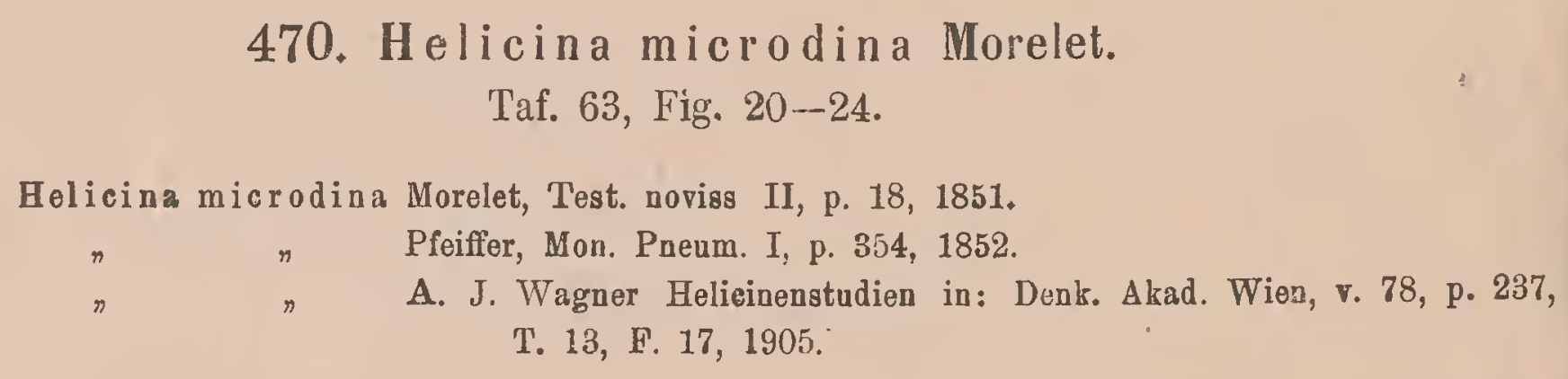

Gehäuse kegelförmig mit gewölbter Basis, ziemlich festschalig, glänzend gelblich weiss oder rötlich. Die Skulptur besteht nebst feinen, ungleichmässigen Zuwachsstreifen aus sehr feinen und dichten Spirallinien, welche auf der Unterseite schwächer werden. Das regelmässig kegelförmige Gewinde besteht aus $4 \frac{1}{2}$ bis 5 nahezu flachen, langsam zunehmenden Umgängen; der letzte ist mehr minder deutlich kantig, unten flacher und steigt vorne kaum oder gar nicht herab. Die abgerundet dreieckige Mündung ist schief; der weisse Mundsaum ziemlich verdickt und kurz ausgebreitet. Die kurze abgeflachte Spindel bildet am Uebergange in den Basalrand der Mündung eine ziemlich scharfe Ecke. Der dünne, mit dem Gehäuse gleichfarbige und glänzende Basalkallus ist undeutlich begrenzt; in der Nabelgegend ein deutliches, furchenartiges Grübchen.

$$
\mathrm{D}=5.5, \mathrm{~d}=4.5, \mathrm{H}=4.5 \mathrm{~mm} \text {. }
$$

Deckel halbkreisförmig mit spitzem oberen Winkel, gelblich hornfarben mit zarter, krustenartiger Kalkplatte; in den übrigen Verhältnissen typisch.

Fundort: Verapaz in Guatemala. 


\section{Formenkreis Festiva.}

\section{Helicina festiva Sowerby. Taf. 64, Fig. 1, Fig. 7.}

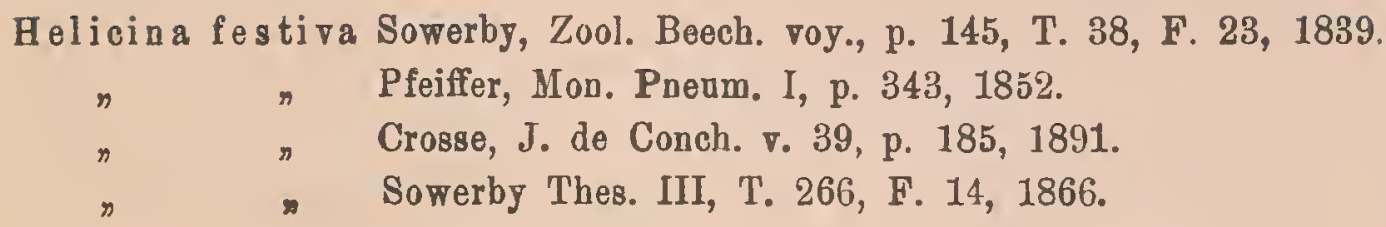

Gehäuse flachkegelförmig mit halbkugeliger Basis, ziemlich dickschalig, wenig glänzend; die Grundfarbe gelbbraun mit dunkleren, radial und spiral angeordneten Flecken und Striemen, der letzte Umgang mit braungrünen Striemen, welche gegen die Mündung zu die Grundfarbe nahezu verdecken. Die Skulptur besteht nebst ziemlich kräftigen, ungleichmässigen Zuwachsstreifen aus niedrigen bis undeutlichen, aber ziemlich dichten Spiralreifen auf dem letzten Umgange; ausserdem erscheint die Oberfläche auch auf den oberen Umgängen etwas runzlig uneben. Das flachkegelförmige, schwach konvexe Gewinde besteht aus $\mathbf{5}$ flachen Umgängen, von welchen die zwei ersten langsam, die folgenden rascher zunehmen; der letzte ist aufgeblasen undeutlich kantig, beiderseits gleichmässig gewölbt und steigt vorne wenig unter die Kante herab. Die halbkreisförmige, schwach ausgeschnittene Mündung ist wenig schief, innen hellrotbraun; der weisse, verdickte Mundsaum verhältnismässig kurz ausgebreitet. Die kurze, leicht konkave Spindel ist nach aussen und vorn gebogen, am Uebergange derselben in den Basalrand der Mündung eine stumpfe, deutlich vorspringende Ecke. Der dicke, glänzende, weisse Basalkallus ist deutlich begrenzt; in der Nabelgegend kein Grübchen.

$$
\mathrm{D}=22, \mathrm{~d}=18, \mathrm{H}=17 \text {. }
$$

Deckel birnförmig mit seitlich gekrümmter Spitze, unten schwarzbraun mit lichterem Nukleus und Spindelrand. Die verhältnismässig dünne, aber feste Kalkplatte ist konkav, weiss, gegen den Aussenrand zu auf dem schwarzen Grunde bläulich erscheinend; am Spindelrande dicker und leistenartig erhoben; in den übrigen Verhältnissen typisch.

Fundort: El Barro Abajo in St. Domingo. Ich beurteile diese Art nach einem mir von Dautzenberg mitgeteilten Exemplare, welches der Originaldiagnose vollkommen entspricht.

\section{Helicina festiva cumirgiana Pfeiffer.} Taf. 64, Fig. 2.

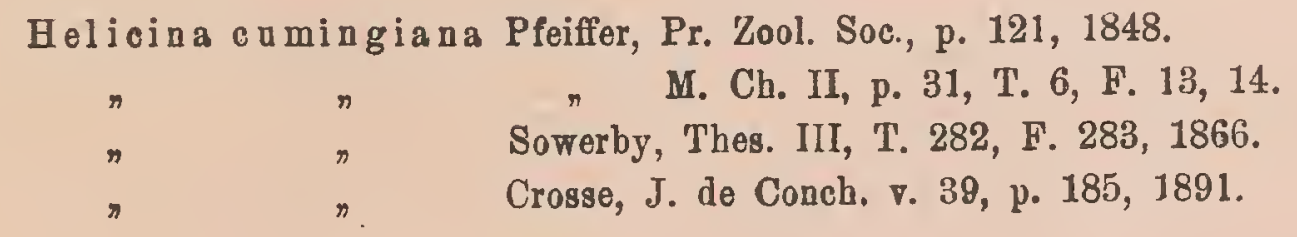


Gehäuse kugeliger mit höherem Gewinde, rötlich fleischfarben mit dunkleren Punkten und Striemen; die Spiralreifen am letzten Umgange deutlicher, ebenso die Ecke am Uebergange der Spindel in den Basalrand deutlicher vorspringend.

$$
\mathrm{D}=19-21, \mathrm{~d}=15 \cdot 5-17 \cdot 5, \mathrm{H}=17 \mathrm{~mm} \text {. }
$$

Deckel wie bei der typischen Form.

Fundort: die Insel Haiti.

\section{Helicina festiva malleata Peiffer.}

Taf. 64, Fig. $4-6$.

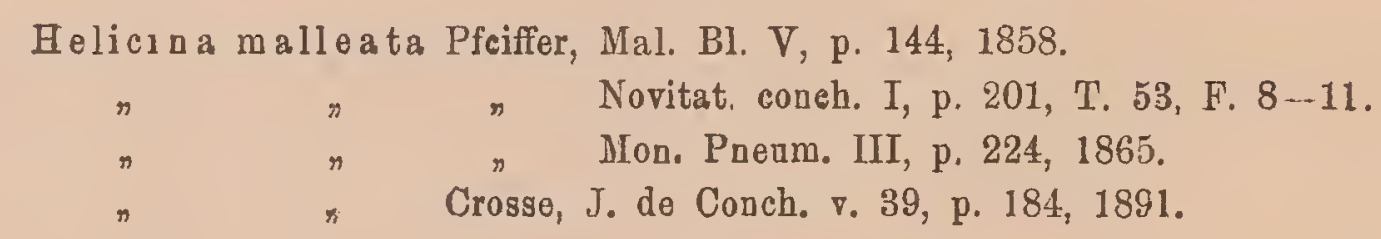

Gehäuse fast kugelig, olivenbraun mit dunkleren Punkten und Striemen; dünnschaliger mit deutlicher gewölbten Umgăngen. Die oberen Umgänge runzlig gehämmert, der letzte mit schwachen bis undeutlichen Spiralreifen. Der weisse Mundsaum schwächer verdickt, fast gerade, die Ecke am Uebergange der Spindel in den Basalrand der Mündung wie bei $H$. festiva cumingiana Pfr. Der letzte Umgang gerundet, ohne Kante.

Deckel wie bei der typischen Form.

$$
\mathrm{D}=16, \mathrm{~d}=13, \mathrm{H}=14 \mathrm{~mm} \text {. }
$$

Fundort: Ponton auf Haiti.

\section{Helicina festiva maltzani $n$. \\ Taf. 64, Fig. 3 .}

Helicina malleata A. J. Wagner, Helicinenstudien in: Denk. Akad. Wien. v. 78, p. 241, T. 14, F. 5, 1905.

Gehäuse dünnschaliger, kugelig mit höherem zugespitzen Gewinde, einfărbig grünlichgelb oder zitrongelb. Die zwei letzten Umgänge mit sehr feinen bis undeutlichen Spirallinien, daneben erscheint die Oberfläche leicht gehämmert und schwach gerunzelt. Der letzte Umgang ist vollkommen gerundet, weniger aufgeblasen und steigt vorne deutlich herab. Die halbeiförmige Mündung verhältnismässig höher und schmäler, innen gelb; der gelbe, leicht verdickte Mundsaum mehr ausgebreitet und umgeschlagen. Die Ecke am Uebergange der Spindel in den Basalrand der Mündung wie bei der typischen Form.

$$
\mathrm{D}=15, \mathrm{~d}=12, \mathrm{H}=14 \mathrm{~mm} \text {. }
$$


Deckel auf der Unterseite schwarz mit rotbraunen Rändern und lichterem Nukleus; in den übrigen Verhältnissen wie bei der typischen Form.

Fundort: Dondon auf Haiti.

\title{
475. Helicina viridis Lamarck.
} Taf. 64, Fig. 8-11.

\author{
Helicina viridis Lamarck, Anim. s. vert. VI 2, p. 103, 1822. \\ $» \quad$ Gray, Zool. Journ. I, p. 67, F. 7, 1828. \\ $n \quad$ Dellessert, RecueiJ, T. 27, F. 3, 1841.
}

Von dieser Art liegt mir ein unausgewachsenes Exemplar aus dem k. Museum für Naturkunde in Berlin vor, welches den oben angeführten Beschreibungen und Abbildungen entspricht.

Gehäuse gedrückt kugelig, ziemlich dünnschalig, durchscheinend lebhaft glänzend mit sehr feinen und undeutlichen Zuwachsstreifen. Von den vier Umgängen ist der letzte oben gelbgrün, mit einer scharf begrenzten rotbraunen Binde an der Peripherie, welche oben gelblich, unten weiss gesäumt ist und an den oberen Umgängen unter der Naht verschwindet. Die Spitze ist hellgelb, die zwei folgenden Umgänge gelbgrün mit einer unregelmässigen rotbrauen Binde, welche die Grundfarbe naheza verdeck $t$; auf der Oberseite des 3. und 4. Umganges sind ausserdem einige rotbraune Radialstriemen vorhanden. Das flachkegelförmige, schwach konvexe Gewinde besteht aus 4 rasch zunehmenden, Hachen Umgängen; der 4. Umgang ist gerundet, beiderseits gleichmässig gewölbt. Die halbeiförmige, etwas ausgeschnittene Mündung ist wenig schief, innen grün mit durchscheinender brauner Binde; der Mundsaum wie bei einem unausgewachsenen Exemplare dünn und scharf. Der weisse, dicke und glänzende Basalkallus ist deutlich begrenzt, die kurze Spindel nach aussen gebogen. - Bei ausgewachsenen Exemplaren soll nach Gray-Deshayes der letzte Umgang (die Zahl derselben wird nicht angegeben) etwas gekielt, der leicht verdickte, umgeschlagene Mundsaum gelb oder rot gefärbt sein.

$$
\mathrm{D}=6, \mathrm{~d}=5, \mathrm{H}=4.5 \mathrm{~mm} \text {. }
$$

Deckel (des mir vorliegenden unausgewachsenen Exemplars) halbeiförmig mit spitzem oberen Winkel, gelbbraun, durchscheinend; die Kalkplatte sehr zart, anflugartig; in den übrigen Verbältnissen typisch.

Fundort: die Insel Haiti.

$\mathrm{Zu}$ diesem Formenkreise dürften nachstehende Formen gehören, welche ich nicht gesehen habe: Helicina iris Weinland, H. versicolor Pfeiffer, H. cingulata Pfeiffer, H. faustini Weinland, H. anaquana Weinland, II. gabbi Crosse et Newcomb; alle von der Insel Haiti. 


\title{
Formenkreis Euneritella.
}

\author{
476. Helicina a ds persa Pfeiffer. \\ Taf. 63, Fig. 25-28.
}

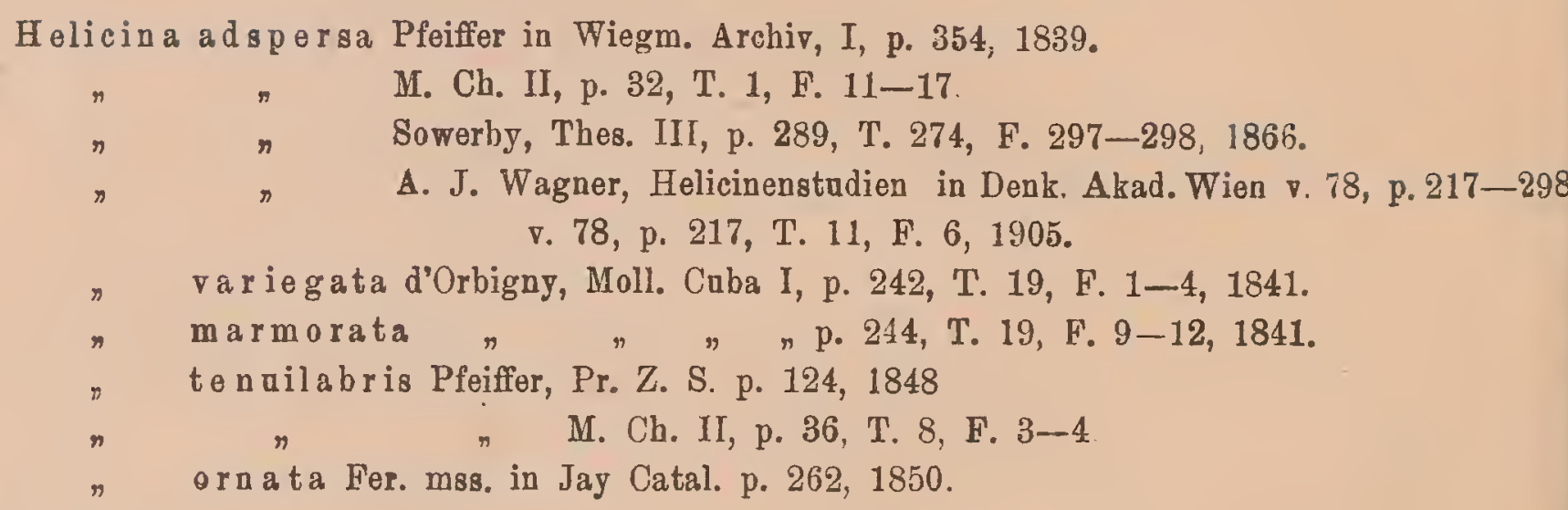

Gehäuse breitkegelförmig mit gewölbter Basis, festschalig, glănzend; einfärbig gelblich weiss oder zitrongelb oder in mannigfaltiger Weise braun und rotbraun gefleckt, gebändert und marmoriert. Die Skulptur besteht nebst deutlichen Zuwachsstreifen aus ziemlich dichten, einge drückten Spirallinien, welche stellenweisse punktiert und unterbrochen erscheinen, hăufig undeutlich werden und vollkommen erlöschen. Das abgerundet kegelförmige Gewinde besteht aus 5 leicht bis kaum gewölbten, ziemlich rasch zunelmenden Umgängen; der letzte ist abgerundet und steigt vorne deutlich herab. Die halbeliptische Mündung ist schief, innen mit dem Gehăuse gleichfärbig, der weisse oder gelbliche Mundsaum leicht verdickt, der Oberrand an der Insertion vorgezogen, fast gerade und herabgebogen, der Aussenrand ziemlich ausgebreitet, der Basalrand gegen die Spindelinsertion zu verschmälert und umgeschlagen. Die abgerundete Spindel ist nach aussen gebogen und gegen den Basalrand des Mundsaumes durch eine leichte Einschnürung abgesetzt. Der milchweisse, glänzende Basalkallus ist ziemlich dick und deutlicb begrenzt; in der Nabelgegend ein seichtes Grübchen.

$$
\mathrm{D}=11-19, \mathrm{~d}=9-15, \mathrm{H}=9-14 \mathrm{~mm} \text {. }
$$

Deckel halbkreisförmig mit leicht $\mathrm{S}$ förmig gebogenem Spindelrand, beiderseits lebhaft rotbraun gefärbt; die feste feingekörnelte Kalkplatte ist am Spindelrande zu einer deutlichen Spitze erhoben; in den übrigen Verhältnissen typisch.

Fundort: die Insel Cuba.

Helicina adspersa Pfr. steht einigen Formen der so veränderlichen Helicina neritella Lamareck sehr nahe; auch bei dieser Art sind mitunter eingedrückte Spirallinien vorhanden. Als konstante und sichere Unterscheidungsmerkmale führe ich besonders die Verhältnisse der Mündung an. Bei vorstehender Art ist der Oberrand des Mundsaums herabgebogen und fast gerade, die Spindel vom Basalrande des Mundsaumes durch eine Einschnürung abgesetzt; bei H. neritella Lam. erscheint der Oberrand des Munüsaums nicht herabgebogen, ausge- 
breitet und umgeschlagen, die Spindel geht ohne Einschnürung in den Basalrand über und das Grübchen in der Nabelgegend ist stets deutlich und tiefer.

\title{
477. Helicina neritella Lamarck.
}

Taf. 65, Fig. 18-22.

\author{
Helicina neritella Lamarck, Anim. s. vertebr. VI, p. 103, 1822, \\ Pfeiffer, M. Ch. II, p. 34, T. 1, F. 5-8, T. 6, F. 18, T. 8, F. $9-12$, \\ T. 9, F. 3, 4, 32, 33 . \\ variabilis Guilding, Zool. Journ. III, p. 529, T. 17, F. 6-13.
}

Helicina neritella Lam. ist in den Sammlungen regelmässig vertreten, dennoch ist ihr Verbreitungsgebiet nicht festzustellen, denn die Fundortsangaben lauten „Westindien oder Jamaica". Vom angeblichen Originalfundorte Barbados (nach Lister) habe ich noch kein Exemplar gesehen, ebenso erscheinen mir die Angaben über das Vorkommen dieser Art auf Cuba und Grenada zweifelhaft, da auf diesen Inseln sehr nahe verwandte, aber jedenfalls selbständige Arten auftreten. Sichere Fundortsangaben sind nir nur von der Insel Jamaica bekannt, aber hier tritt die Art in mehreren, zum Teile recht auffallend abweichenden Formen auf und war es notwendig eine dieser Formen als „typisch“ zu fixieren. Das auf T. 65, F. 18-22 abgebildete Exemplar entspricht der in den Sammlungen am häufigsten vertretenen Form, ebenso annähernd den Abbildungen Pfeiffers.

Gehäuse breitkegelförmig mit flachgewölbter Basis, ziemlich dünnschalig, leicht durchscheinend; wenig glänzend mit deutiichen, etwas ungleichmässigen Zuwachsstreifen, häufig auch mit einigen schwachen, bis undeutlichen, eingedrückien Spirallinien. Die Grundfarbe weiss, gelblich, seltener rötlich mit verschieden breiten rotbraunen bis violetten Binden über und unter der Peripherie, welche oft in mannigfaltige Flecken, Radial und Zickzackstriemen aufgelöst erscheinen, mitunter die Grundfarbe bis auf schmale Zonen verdecken. Das mehr minder erhobene; regelmässig kegelförmige oder leicht konvexe Gewinde besteht ans 5 leicht gewölbten, ziemlich rasch zunehmenden Umgängen; der letzte ist etwas zusammengedrückt, unten flacher, gerundet oder undeutlich kantig und steigt vorne langsam, aber deutlich herab. Die halbeliptische Mündung ist schief bis sehr schief, innen mit lebhaft durchscheinenden Binden. Der weisse oder gelbe Mundsaum ist leicht veraickt; der Oberrand an der Insertion vorgezogen und verschmälert. Die kurze abgeflachte Spindel ist etwas nach aussen gebogen; am Uebergange derselben in den nicht verschmälerten Basalrand der Mündung mitunter eine schwache knotenartige Verdickung، Der feingekörnelte weisse oder gelbliche Basalkallus ist nur in der Mitte deutlich verdickt, jedoch undeutlich begrenzt; in der Nabelgegend ein deutliches Grübchen.

$$
\mathrm{D}=12-14.5, \mathrm{~d}=9-11.5, \mathrm{H}=9-11.5 \mathrm{~mm} .
$$

Deckel abgerundet dreieckig, gelbbraun, bis dunkel rotbraun. Die dünne, bis krusten- 
artige Kalkplatte feingekörnelt, am Spindelrande leicht verdickt; in den übrigen Verhăltnissen typisch.

Fundort: die Insel Jamaica.

\title{
478. Helicina neritella diplocheila A. J. Wagner, Taf. 65, Fig. 25.
}

Helieina neritella diplocheila A. J. Wagner, Helicinenstndien in: Denk. Akad Wien, v. 78, p. 213, T. 11, F. $2,1905$.

G ehäuse dickschaliger, zum Teile grösser mit flacheren Umgängen; der letzte stumpfgekielt; gelblich oder weiss mit einer violetten oder rotvioletten Zone auf der Oberseite, selten mit deutlichen Binden und Flecken. Der weisse oder gelbliche Mundsaum auffallend verdickt bis verdoppelt, ebenso der gekörnelte Basalkallus dicker und deutlich begrenzt; das Grübchen in der Nabelgegend seicht bis undeutlich.

$$
\mathrm{D}=12 \cdot 5-18, \mathrm{~d}=10-13, \mathrm{H}=9-11 \mathrm{~mm} \text {. }
$$

Deckel wie bei der typischen Form.

Fundort: Montego Bay auf Jamaica.

\section{Helicina neritella reducta . Taf. 65, Fig. 23-24.}

Gehäuse kleiner mit $41 / 2-5$ rascher zunehmenden Umgängen, der letzte mehr zusammengedrückt und deutlich kantig; weiss, gelblich oder rötlich mit einer dunkleren Zone auf der Oberseite, aber obne deutliche Binde.

$$
\mathrm{D}=9-12, \mathrm{~d}=7-9, \mathrm{H}=6.5-8 \mathrm{~mm} \text {. }
$$

Deckel wie bei der typischen Form.

Fundort: die Insel Jamaica.

\section{Helicina heatei Pfeiffer. Taf. 66, Fig. $1-5$.}

Helicina heatei Pfeiffer, Pr. Z. S. p. 392, 1856.

\author{
Mn. Pnenm. II, p. 212, 1858.
}

" $\quad$ A. J. Wagner Helicinenstudien in: Denk. Akad. Wien. จ. 78, p. 214, T. 11, F. 3, 1905.

" keatei Smith, Pr. Mal. Soc. Lond. I, p. 318, 1895.

n $\quad$ Sowerby, Thes. III, p. 286, T. 274, F. 316, 1866. 
Gehäuse flachkegelförmig mit flachgewölbter Basis, ziemlich dünnschalig, durchscheinend, leicht glănzend bis matt. Die Gruudfarbe weiss, schmutziggelb oder rötlich fleischfarben, selten einfärbig, zumeist mit 1 bis 2 rotbraunen oder violettbraunen, mehr minder scharf begrenzten Binden von welchen die obere breit ist und auf den oberen Umgängen die Grundfarbe vollkommen verdeckt, während die untere schmal bleibt und oft vollkommen erlischt. Die Skulptur besteht nebst deutlichen, ungleichmässigen Zuwachsstreifen aus mehr minder deutlichen, ziemlich weitläufigen oft punktiert eingedrückten Spirallinien; auch erscheint die Oberfläche mitunter etwas uneben und gerunzelt. Das niedrige, deutlich konvexe Gewinde besteht aus 5-51/2 ziemlich rasch zunehmenden leicht gewölbten bis nahezu flachen Umgängen; der letzte ist zusammengedrückt, unten flacher, an der Peripherie stumpfkantig und steigt vorne langsam, aber deutlich herab. Die halbeliptische Mündung ist sehr schief, innen gelblich bis lebhaft gelbbraun mit durchscheinenden Binden. Der gelbliche bis lebbaft dunkelorangefarbene Mundsaum ist leicht verdickt; der Oberrand schmal und an der Insertion vorgezogen, der Aussen- und Basalrand ziemlich ausgebreitet und umgeschlagen. Die kurze, abgerundete oder etwas ausgehöhlte Spindel ist nach aussen gebogen; am Uebergange derselben in den Basalrand der Mündung eine schwache Einschnürung. Der dünne sehr fein gekörnelte Basalkallus ist gelblich oder lebhaft orangefarben und undeutlich begrenzt; in der Nabelgegend ein deutliches Grübchen.

$$
\mathrm{D}=15, \mathrm{~d}=12, \mathrm{H}=10 \mathrm{~mm} \text {. }
$$

Deckel abgerundet dreieckig, hautartig dünn und durchsichtig, gelblich hornfarben oder rotbraun. Die Kalkplatte anflugartig zart, auch am Spindelrand kaum erhoben und wenig dicker; in den übrigen Verhăltnissen typisch.

Fundort: die Insel Grenada.

\section{Helicina occidentalis Guilding.}

Taf. 66, Fig. 22-24,

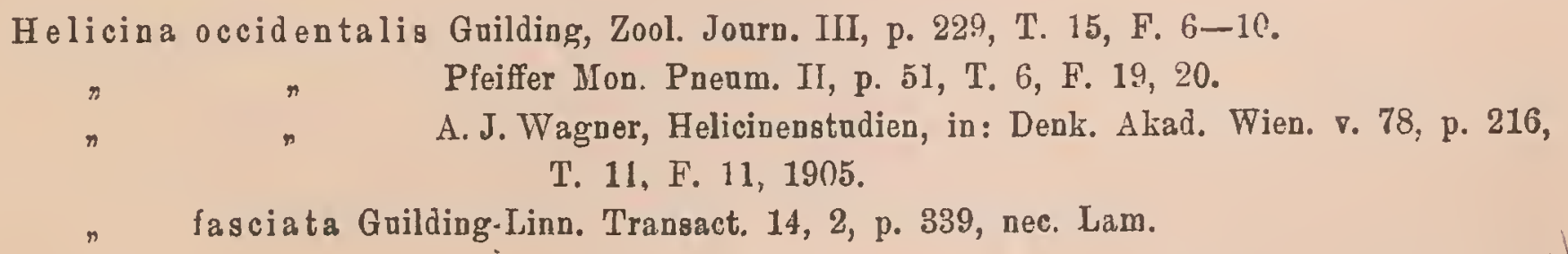

G ehäuse breitkegelförmig mit fiachgewölbter Basis, ziemlich dünnschalig, durchscheinend, wenig glănzend bis matt. Die Grundfarbe hellgelb mit einer gelbbraunen bis rotbraunen Binde auf der Oberseite, welche die Grundfarbe oft nahezu verdeckt und einer schmalen Binde unter dem Kiele, ferner erscheint die Oberfäche durch unregelmässige milchige Flecken und Striemen marmoriert. Die Skulptur besteht aus ziemlich deutjichen ungleichmässigen Zuwachsstreifen, daneben erscheint die Oberfläche mitunter etwas uneben und durch sehr 
feine, schief nach vorne gerichtete Falten gerunzelt. Das regelmässig kegelförmige Gewinde besteht aus $5 \frac{1}{2}$ ziemlich rasch zunehmenden, nahezu flachen Umgängen; der letzte ist beiderseits gleichmässig flachgewölbt, zusammengedrückt, an der Peripherie stumpf gekielt und steigt vorne sehr wenig oder gar nicht herab. Die dreieckige Mündung ist sehr schief, der gelbliche, leicht verdickte Mnndsaum gut ausgebreitet und umgeschlagen. Die sehr kurze, gerundete oder etwas abgeflachte Spindel bildet am Uebergange in den Basalrand der Mündung eine leichte knotenartige Verdickung. Der dünne, gelbliche und gekörnelte Basalkallus ist undeutlich begrenzt; in der Nabelgegend ein deutliches Grübchen.

$$
\mathrm{D}=15-20, \mathrm{~d}=12 \cdot 5-16, \mathrm{H}=10-12 \mathrm{~mm} \text {. }
$$

Deckel abgerundet dreieckig, beiderseits dunkel rotbraun bis schwarz; die dünne feingekörnelte Kalkplatte ist nur am Spindelrande leistenartig erhoben; in den übrigen Verhältnissen typisch.

Fundort: die Insel St. Vincent.

\title{
482. Helicina rhodostoma Gray.
} Taf. 66, Fig. 9, 10, 13.

\author{
Helicina rhodostoma Gray, Zool. Journ, I, p. 68, T. 6, F. 9. \\ \# $\quad$ Pfeiffer M. Ch. II, p. 60, T. 7, F. 4, 5. \\ » Sowerby Thes. III, p. 294, T. 277, F. 412, 413, 1866.
}

Gehäuse flachkegelförmig mit gewölbter Basis, ziemlich dünnschalig, durchscheinend, wenig glänzend; die Grundfarbe schmutziggelb oder rötiich gelb mit lebhaft karminrotem Kiel und einer rotbraunen bis karminroten Zone auf der Oberseite der unteren Umgänge, welche durch weissliche Flecken und Zickzackstreifen marmoriert erscheint. Die Skulptur besteht nebst feinen, ungleichmässigen Zuwachsstreifen aus einigen undeutlichen Spirallinien, welche häufig fehlen, auch erscheint die Oberfläche unter der Lupe fein gerunzelt und mitunter etwas uneben. Das regelmässig kegellörmige Gewinde besteht aus 5 leicht gewölbten, rasch zunehmenden Umgängen; der letzte ist zusammengedrückt, unten mehr gewölbt, an der Peripherie scharf gekielt und steigt vorne nicht herab. Die abgerundet dreieckige Mündung ist wenig schief innen mit der Oberfläche gleichfarbig; der leicht verdickte dunkel karminrote Mundsaum gut ausgebreitet und im Winkel umgeschlagen. Die abgerundete, verlängerte Spindel ist nahezu senkrecht und läuft unten in einen spitzen, zahnartigen Fortsatz aus. Der dünne, feingekörnelte Basalkallus ist lebhaft rotbraun oder dunkel karminrot und undeutlich begrenzt; in der Nabelgegend ein seichtes, furchenartiges Grübchen.

$$
\mathrm{D}=14, \mathrm{~d}=10, \mathrm{H}=10 \mathrm{~mm} \text {. }
$$

Deckel: abgerundet dreieckig, gelbbraun, dünn und durchscheinend; die Kalkplatte krustenartig dünn; in den übrigen Verhältnissen typisch.

Fundort: die Insel Guadeloupe. 
Ich habe von dieser Art mehrere Formen erhalten (alle mit der Fundortsausgabe Guadeloupe) welche bei Uebereinstimmung der wesentlichen Merkmale auffallende Unterschiede mit Rücksicht auf die Beschaffenheit des Mundsaumes aufweissen. Diese Unterschiede dürften auch in diesem Falle auf die beiden Geschlechtsformen zurückzuführen sein.

\section{Helicina rhodostoma inermis n.}

Taf. 66, Fig. 11, 12.

Gehäuse wie bei der typischen Form, der Mundsaum und Basalkallus jedoch zitrongelb; die Spindel ohne zahnartigen Fortsatz.

$$
\mathrm{D}=13, \mathrm{~d}=9, \mathrm{H}=8 \mathrm{~mm} .
$$

Deckel wie bei der typischen Form.

Fundort: die Insel Guadeloupe. Auf Taf. 66, Fig. 12 habe ich ferner eine Form abgebildet, welche kleiner und einfarbig graugelb ist; das leicht konvexe Gewinde besteht aus $41 / 2$ langsamer zunehmenden Umgăngen, der letzte ist stumpfer gekielț; Mundsaum und Basalkallus weiss, der zahnartige Fortsatz an der Spindel fehlt.

$$
\mathrm{D}=8.5, \mathrm{~d}=6.5, \mathrm{H}=5.5 \mathrm{~mm} \text {. }
$$

Deckel wie bei der tyipschen Form. Fundort: angeblich die Insel Guadeloupe.

\section{Helicina goldfussi Boettger.}

Taf. 66, Fig. 14-17

Helicina goldfussi Boettger, Jahrb. Mal. Ges. XXII, p. 108, T. 4, F. 10, 1887.

Gehäuse breitkegelförmig mit gewölbter Basis, ziemlich dünnschalig, durchscheinend, leicht glänzend; einfärbig milchweiss oder gelblich; häufig mit einer verwaschenen rotbrauren Binde auf der Oberseite der unteren Umgange, welche durch milchig getrübte Flecken und Striemen zum Teil verdeckt wird. Das regelmässig kegelförmige Gewinde besteht aus $4^{11} / 2$ schwach gewölbten, ziemlich rasch zunehmenden Umgängen; der letzte ist etwas zusammengedrückt, beiderseits gleichmässig gewölbt, an der Peripherie kantig bis stumpf gekielt und steigt vorne nicht herab. Die halbeiförmige Mündung ist schief, innen mit dem Gehäuse gleichfärbig; der leicht verdickte Mundsaum gelb oder rotorange gefärbt, ausgebreitet und umgeschlagen. Die abgerundete, kurze Spindel ist etwas nach aussen gebogen; am Uebergange derselben in den Basalrand der Mündung eine stumpfe Ecke. Der dünne, feingeliörnelte Basalkallus ist gelb oder rotorange und undeutlich begrenzt; in der Natelgegend ein seichtes Grübchen.

$$
\mathrm{D}=7, \mathrm{~d}=5, \mathrm{H}=5 \mathrm{~mm} \text {. }
$$

Deckel unbekannt.

Fundort: die Insel Dominica; nach Originalexemplaren des Autors. 


\title{
485. Helicina oxyrhyncha Crosse et Debeaux.
}

Taf. 66, Fig. 18-21.

\author{
Helicina oxyrhyncha Crosse et Debeaux, J. de Conch. p. 266, Г. 9, F. 4, 1863. \\ Sowerby Thes. III, p. 295, T. 277, F. 421, 1866. \\ A. J. Wagner Helicinenstudien in Denk. Akad. Wien v. 78 , p. 424 \\ T. 12 , F. 8, 1905.
}

Gehäuse dicklinsenförmig, ziemlich dünnschalig durchscheinend, wenig glänzend; zitronbis orangegelb, der letzte Umgang violett angelaufen. Die Skulptur besteht nebst deutlichen, ungleichmässigen Zuwachsstreifen aus einigen undeutlichen Spirallinien, auch erscheint die Oberfläche unter der Lupe fein gerunzelt. Das flachlegelförmige Gewinde besteht aus 5 kaum gewölbten, ziemlich rasch zunehmenden Umgängen; der letzte ist zusammengedrückt, beiderseits gleichmässig gewölbt, an der Peripherie stumpfgekielt und steigt vorne nicht herab; der Kiel beiderseits durch eine eingedrückte Linie berandet. Die dreieckige Mündung ist sehr schief, innen mit dem Gehäuse gleichfarbig; der leicht verdickte, weisse oder gelbliche Mundsaum ist ausgebreitet und umgeschlagen; der Oberrand an der Insertion vorgezogen, der Aussenrand entsprechend dem Kiele leicht geschnäbelt. Die kurze, abgerundete Spindel ist nach aussen gebogen und bildet am Uebergange in den Basalrand der Mündung eine stumpfe, aber deutllch vorspringende Ecke. Der glänzende gelbe Basalkallus ist dünn und undeutlich begrenzt; in der Nabelgegend ein seichtes, furchenartiges Grübchen.

$$
\mathrm{D}=14, \mathrm{~d}=11 \cdot 5, \mathrm{H}=8 \mathrm{inm} \text {. }
$$

Decken dreieckig, dunkelrotbraun mit dünner, krustenartiger Kalkplatte; in den übrigen Verhältnissen typisch.

Fundort: die Insel Bonacca in der Bai von Honduras.

486. Helicina jamaicensis Sowerby. Taf. 66, Fig. 6-8.

Helicina jamaicensis Sowerby, Thes. I, p. 2, T. 1, F. 3, 4, 1841.

" $\quad$ Pfeiffer M. Ch. II, p. 35, T. 1, F. 22, 26. 1846.

» Gloyne, J. de Coneh. XX, p. 41,

„ A. J. Wagner Helicinenstudien in Denk. Ak. Wien, v. 78, p. 217, T. 11, F. 9, 1905.

Gehäuse kegelförmig mit abgeflachter Basis, ziemlich festschalig, leicht glänzend; milchweiss oder gelblich mit einem rotbraunen, etwas verblichenen Bande über der Peripherie und Naht; mit sehr feinen bis undeutlichen Zuwachsstreifen. Das konvexe Gewinde besteht aus 5 leicht gewölbten, ziemlich rasch zunehmenden Umgängen; der letzte ist gerundet, unten 
flacher und steigt vorne tief herab. Die halbeliptische Mündung ist sehr schief, innen gelblich mit durchscheinendem Bande. Der gelbe, leicht verdickte Mundsaum ist ziemlich ausgebreitet und umgeschlagen; der Oberrand an der Insertion vorgezogen, verschmälert, deutlich herabgebogen und durch eine Furche eingeschnürt; der Basalrand von der sehr kurzen Spindel durch eine buchtige Einschnürung abgesetzt. Der gelbe, dicke und glănzende Basalkallus ist deutlich begrenzt; in der Nabelgegend ein seichtes Grübchen.

$$
\mathrm{D}=9-12, \mathrm{~d}=7-10, \mathrm{H}=7.5-9.5 \mathrm{~mm} \text {. }
$$

Deckel halbeiförmig, gelbbraun und durchscheinend mit dünner zarter nur am Spindelrande leicht erhobener Kalkplatte; in den übrigen Verhältnissen typisch.

Fundort: die Insel Jamaica.

Helicina jamaicensis Sow. wird vielfach mit Alcadia ampliata fuscocallosa A. J. Wagner verwechselt, mit welcher Form sie äusserlich grosse Aehnlichkeit hat; letztgenannte Form ist niemals gebändert, dafür sind auf gelblichem oder weissem Gewinde gelbgrüne oder rotbraune Radialstriemen vorhanden; unter der Lupe werden dichte und feine Spirallinien sichtbar, welchen bei frischen Exemplaren feine hinfällige Spiralfalten der Epidermis entsprechen; der Oberrand des Mundsaumes ist nicht eingeschnürt und herabgebogen, der Basalrand von der Spindel durch einen seichten Einschnitt geschieden; entscheidend ist schliesslich der charakteristische Alcadiadeckel.

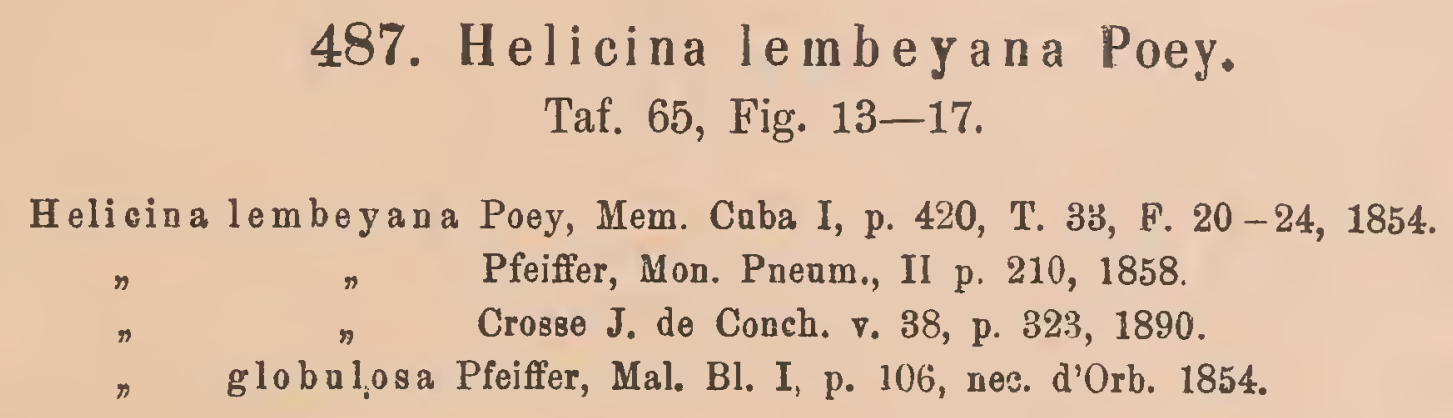

Gehăuse kugelig mit kegelförmigem Gewinde, festschalig, glänzend; einfärbig weiss oder gelb, häufig mit 2-3 gelbbraunen Binden oder durch unregelmåssige gelbbraune und rotbraune Flecken marmoriert. Die Skulptur besteht nebst feinen, ungleichmåssigen Zuwachsstreifen aus einigen eingedrückten Spirallinien, welche häufig vollkommen erlöschen. Das leicht konvexe Gewinde besteht aus $5 \frac{1}{2}$ langsam zunehmenden, nahezu flachen Umgängen mit deutlich vorspringendem Apex; der letzte ist gerundet und steigt vorne langsam, aber deutlich herab. Die halbeiförmige Mündung ist schief innen gelb oder gelbbraun; der ziemlich dicke, weisse Mundsaum kurz ausgebreitet. Die kurze Spindel ist stark nach aussen gebogen und bildet am Uebergange in den etwas eingeschnürten Basalrand der Mündung eine stumpfe, deutlich vorspringende Ecke. Der feingekörnelte, weisse oder gelbliche Basalkallus ist nur im Umkreise der Spindel dicker sonst undeutlich begrenzt; in der Nabelgegend ein deutliches Grübchen.

I. 18. II.

20. XI. 1910. 


$$
\mathrm{D}=8.5, \mathrm{~d}=6.5, \mathrm{H}=7 \mathrm{~mm} \text {. }
$$

Deckel birnförmig mit seitlich gekrümmter Spitze, beiderseits lebhaft kastanienbraun mit gelbbraunem Spindelrand. Die dünne, konkave Kalkplatte feingekörnelt; in den übrigen Verhältnissen typisch.

Fundort: Punta Mais auf Cuba.

\section{Helicina globulos a d'Orbigny.}

Taf. 65, Fig. 9-12.

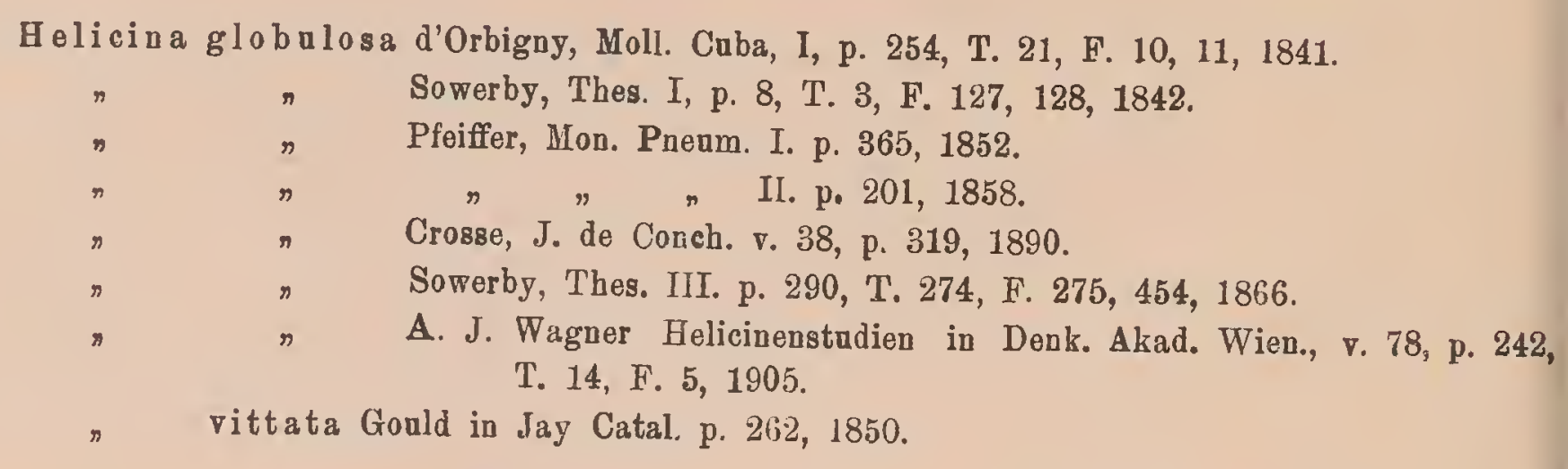

Gehäuse gedrückt kugelig, ziemlich dünnschalig, glänzend mit sehr feinen bis undeutlichen Zuwachsstreifen; weiss mit rotbraunen, violetten und gelbgrünen Bändern, welche auf den oberen Umgängen die Grundfarbe nahezu verdecken. Das niedrige, konvexe Gewinde besteht aus $4_{1}^{1} / 2-5$, kaum gewölbten, ziemlich rasch zunehmenden Umgängen; der letzte ist aufgeblasen, im Beginne stumpfkantig und steigt vorne mehr minder tief herab. Die halbkreistörmige Mündung ist schief, innen gelb mit durchscheinenden Bändern; der dünne, weisse Mundsaum kurz ausgebreitet. Die kurze abgerundete Spindel ist nach aussen gebogen und bildet am Uebergang in den Basalrand der Mündung eine stumpfe, wenig vorspringende Ecke. Der dünne, durchsichtige und glänzende Basalkalius ist undeutlich begrenzt; in der Nabelgegend ein seichtes Grübchen.

$$
\mathrm{D}=7 \cdot 5, \mathrm{~d}=6, \mathrm{H}=5 \cdot 5-6.5 \mathrm{~mm} \text {. }
$$

Deckel birnförmig mit seitlich gekrümmter Spitze, gelbbraun oder rotbraun und durchsichtig; die Kalkplatte krustenartig dünn; in den übrigen Verhältnissen typisch.

Fundort: die Insel Cuba (Cardenas).

\section{Helicina reeveana Pfeiffer.}

Taf. 65, Fig. 4-8.

Heliciea reeveana Pfeiffer, Pr. Z. S., p. 123, 1848.

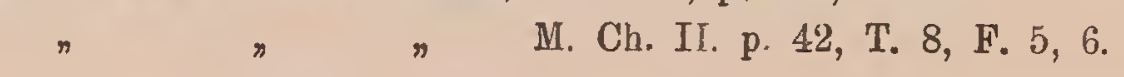


Helicina reeveana Crosse, J. de Conch. v. 5, p. 321, 1890.

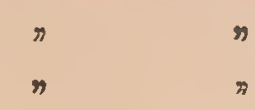
Sowerby, Thes. III. p. 286, T. 271, F. 201, 202, 1866.
A. J. Wagner, Helicinenstadien in: Denk. Akad. Wien v. 78, p. 218, T. 11, F. $10,1905$.

Gehäuse kugelig mit kegelförmigem Gewinde, ziemlich festschalig, wenig glänzend mit feinen ungleichmässigen Zuwachsstreifen un丸 sehr feinen Runzeln der Epidermis; einfärbig gelblich, zitrongelb oder rötlich fleischfarben, häufig mit rotbraunen Binden nnd Fleckenbändern, milchigen Flecken und karminroter Spitze. Das konvexe Gewinde besteht aus 5 kaum gewölbten, ziemlich langsam zunehmenden Umgängen; der letzte ist stumpfkantig bis gerundet und steigt vorne wenig oder gar nicht herab. Die halbkreisförmige Mündung ist wenig schief, innen mit der Oberfläche gleichfärbig; der weisse, leicht verdickte Mundsaum kurz ausgebreitet. Die kurze Spindel ist etwas nach aussen gebogen und bildet am Uebergange in den Basalrand der Mündung eine knotenartige, wenig vorspringende Verdickung. Der dünne durchscheinende Basalkallus ist undeutlich begrenzt; in der Nabelgegend ein seichtes Grübchen.

$$
\mathrm{D}=8-9 \cdot 5, \mathrm{~d}=6 \cdot 5-8, \mathrm{H}=6-8 \mathrm{~mm} \text {. }
$$

Deckel birnförmig mit seitlich gekrümmter Spitze, lebhaft rotbraun mit lichterem Spindelrand; die krustenartig dünne, konkave Kalkplatte, am Spindelrand leicht verdickt; in den übrigen Verhältnissen typisch.

Fundort: die Insel Cuba (Yateras).

\section{Helicina subglobulosa Poey.} Taf. 64, Fig. $12-17$.

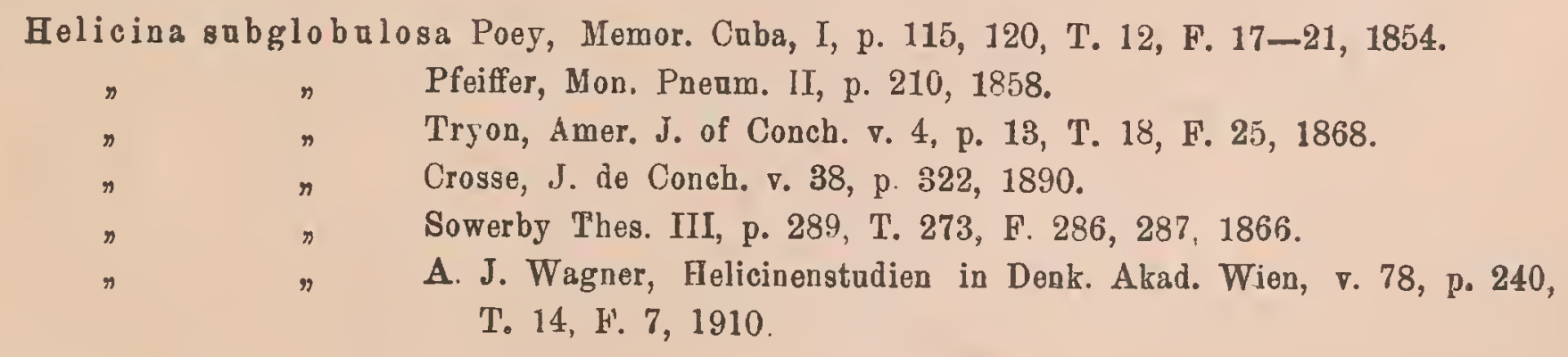

Gehäuse kegelförmig mit gewölbter Basis, festschalig, wenig glänzend mit feinen, ungleichmässigen Zuwachsstreifen und einigen weitläufigen, eingedrückten Spirallinien; auch erscheint die Oberfläche unter der Lupe fein gerunzelt; die Grundfarbe weiss, hellgelb oder rötlich fleischfarben, die oberen Umgänge und die Spitze dunkler bis gelbbraun; häufig sind auch zwei braune Binden vorhanden, welche mitunter in Flecken aufgelöst erscheinen. Das leicht konvexe, mehr minder erhobene Gewinde besteht aus $5-5 \frac{1}{2}$ leicht gewölbten bis nahezu flachen Umgängen, welche ziemlich langsam zunehmen; der letzte ist an der Peripherie mehr minder deutlich stumpfkantig und steigt vorne fast gar nicht herab. Die halbkreis= 
förmige Mündung ist schief, innen gelb oder gelbbraun; der weisse ziemlich dicke Mundsaum gut ausgebreitet und umgeschlagen, häufig rinnenförmig ausgehöhlt. Die kurze etwas ausgehöhlte Spindel bildet am Uebergange in den Basalrand der Mündung eine stumpfe, wenig vorspringende Ecke. Der ziemlich dünne, gelbliche Basalkallus ist undeutlich begrenzt; in der Nabelgegend ein deutliches Grübchen.

$$
\mathrm{D}=7-105, \mathrm{~d}=6-8, \mathrm{H}=5.5-8 \mathrm{~mm} \text {. }
$$

Deckel birnförmig mit seitlich gekrümmter Spitze, lechaft kastanienbraun oder dunkelkarmin mit gelbbraunem Spindelrande. Die dünne, feingekörnelte Kalkplatte ist konkav, am Spindelrande leistenförmig erhoben und verdickt; in den übrigen Verhältnissen typisch.

Fundorte: Brazo de Cauto, Santjago, Trinidad und Bayamo auf Cuba.

\section{Helicina subglobulosa poeyi Pfeiffer.} Taf. 64, Fig. 18-22.

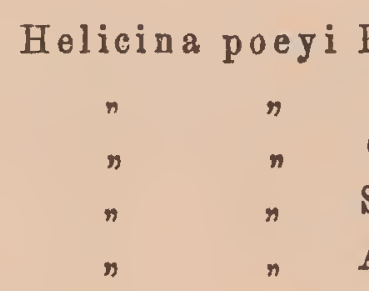

G ehäuse flachkegelförmig mit flacher Basis, die Oberfläche deutlicher gerunzelt; gelblich weiss mit rotbraunen Flecken und Fleckenbinden; der letzte Umgang mehr zusammengedrückt, deutlicher kantig.

$$
\mathrm{D}=10 \cdot 5, \mathrm{~d}=8, \mathrm{H}=7 \mathrm{~mm} \text {. }
$$

Deckel mit dickerer Kalkplatte, sonst wie bei der typischen Form.

Fundort: Guantanamo und Yateras auf Cuba.

$$
\begin{aligned}
& \text { 492. Helicina subglobulosa subdepressa Poey. } \\
& \text { Taf. 64, Fig. 23-26. } \\
& \text { Helicina subdep ressa Poey, Memor. Cuba, I, p. 420, T. 34, F. 22-26, } 1856 . \\
& \text { " } n \quad \text { Pfeiffer, Mon. Pneam. II, p. 207, } 1856 . \\
& \text { ๓ Crosse, J. de Conch. v. 38, p. 322, } 1890 .
\end{aligned}
$$

Gehäuse kleiner mit undeutlichen Zuwachsstreifen und sehr feinen Runznln der Epidermis; rotbraun mit unregelmässigen milchweissen Flecken, welche auf der Unterseite und hinter der Mündung die Grundfarbe verdecken; der Mundsaum dicker bis verdoppelt, die Ecke am Uebergange der Spindel in den Basalrand der Mündung deutlicher vorspringend. 
Deckel wie bei der typischen Form.

$$
\mathrm{D}=7, \mathrm{~d}=5.5, \mathrm{H}=5 \mathrm{~mm} \text {. }
$$

Fundorte: Cabo Cruz, Manzanillo, Cujimar auf Cuba.

\section{Helicina declivis Pfeiffer. \\ Taf. 65, Fig. 1-3.}

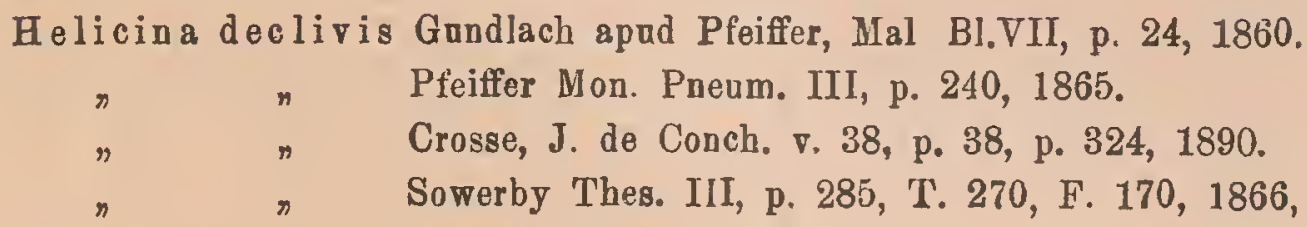

Gehăuse spitzkegelförmig mit flachgewölbter Basis, ziemlich festschalig, leicht glänzend mit feinen Zuwachsstreifen und einigen eingedrückten Spirallinien, sowie feingerunzelter Epidermis; gelblich weiss mit rotbraunen Punkten und Fleckenbändern. Das regelmässig spitzkegelförmige Gewinde besteht aus $4 \frac{1}{2}$ bis 5 leicht bis kaum gewölbten, ziemlich, langsam zunehmenden Umgängen; der letzte ist ziemlich scharf gekielt und steigt vorne nicht herab. Die dreieckige Mündung ist ziemlich schief, innen hellrotbraun; der weisse, leicht verdickte Mundsaum ziemlich kurz ausgebreitet. Die kurze abgerundete Spindel bildet am Uebergange in den Basalrand der Mündung eine a.bgerundete, wenig vorspringende Ecke. Der weisse, dünne und feingekörnelte Basalkallus ist undeutlich begrenzt; in der Nabelgegend ein seichtes bis undeutliches Grübchen.

$$
\mathrm{D}=6.5, \mathrm{~d}=5, \mathrm{H}=5.5 \mathrm{~mm} \text {. }
$$

Deckel dreickig, lebhaft rotbraun mit lichterem Spiralrand und dünner, konkaver Kalkplatte; in den übrigen Verhältnissen typisch.

Fundort: Baracoa auf Cuba.

\section{Helicina fasciata Lamarck.}

Taf. 67, Fig. 1-5.

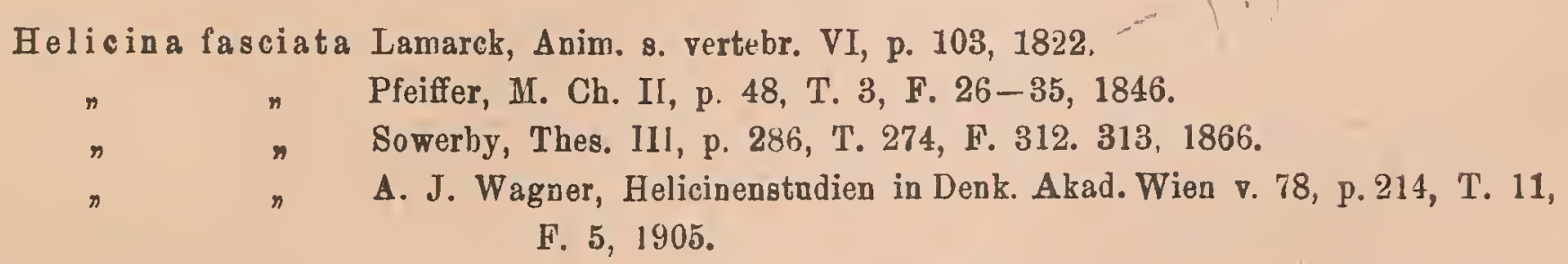

Gehäuse dicklinsenförmig oder mehr minder flachkegelförmig mit flachgewölbter Basis, ziemlich festschalig, leicht glänzend bis matt; einfärbig gelblichweiss, gelblich bis rötlich oder häufiger gebändert. Die einfachen oder doppelten Binden befinden sich über und unter der 
Peripherie der unteren Umgänge sind gelbbraun bis lebhaft rotbraun, scharf begrenzt oder mit gleichfarbigen radiären Striemen versehen, welche mitunter die Grundfarbe bis auf lichte Fleckenbinden verdecken. Die Skulptur besteht nur aus deutlichen, etwas ungleichmässigen Zuwachsstreifen. Das mehr minder flachkegelförmige Gewinde besteht aus $4 \frac{1}{2}$ nahezu flachen, rasch zunehmenden Umgängen; der letzte ist etwas zusammengedrückt, gerundet oder nur undeutlich stumpfkantig und steigt vorne langsam, aber deutlich herab. Die sehr schiefe, abgerundet dreieckige Mündung ist breiter als hoch, iunen weiss oder gelblich mit durchscheinenden Binden. Der weisse mitunter gelbbraune Mundsaum ist kurz ausgebreitet, leicht verdickt bis nahezu verdoppelt; der Oberrand an der Insertion vorgezogen. Der weisse, feingekörnelte Basalkallus ist ziemlich dick und besonders im Umkreise der Spindel deutlich begrenzt. Die kurze Spindel ist nach aussen gebogen und geht gleichmässig in den Basalrand der Mündung über. In der Nabelgegend ein seichtes Grübchen.

$$
\mathrm{D}=6.5-10.5, \mathrm{~d}=5-8, \mathrm{H}=4.5-6 \mathrm{~mm} \text {. }
$$

Deckel: halbeiförmig, durchscheinend, beiderseits gelbbraun mit sehr zarter, krustenartiger Kalkplatte; in den übrigen Verhältnissen typisch.

Das Verbreitungsgebiet dieser Art erstreckt sich anscheinend über einen grossen Teil der Antillen; ich kenne Exemplare von der Insel Vique bei Portorico, welche also dem Originalfundorte Lamarcks entsprechen, ferner von den Inseln Martinique, Guadeloupe und Trinidad. Abgesehen von der veränderlichen Bänderung, Färbung und Grösse zeigen die Exemplare dieser Fundorte nur geringe Abweichungen bezüglich der Höhe des Gewindes, der Wölbung und mehr minder raschen Zunahme der Umgänge.

\author{
495. Helicina fasciata substriata Gray. \\ Taf. 67, Fig. 6-7. \\ Helicina substriata Gray Zool. I, p. 66, T. 6, Fig. 4 \\ Pfeiffer, M. Ch. II, p. 69, T. 9, F. 30, 1846. \\ Sowerby, Thes. III, p. 287, T. 274, F. 322-323, 1866. \\ A. J. Wagner, Helicinenstndien, in Denk. Akkad. Wien v. 78, p. 215, \\ T. 11, F. 7, 1905.
}

Gehäuse kleiner, festschaliger mit höherem leicht konvexem Gewinde und einigen weitlăufigen eingedrückten Spirallinien auf den unteren Umgängen. Die nahezu flachen Umgänge nehmen langsamer zu, der letzte ist weniger zusammengedrückt, an der Peripherie stumpf gekielt und steigt vorne mehr herab. Die Mündung ist weniger breit, der Mundsaum dicker bis verdoppelt; der. dicke Basalkallus im Umkreise der Spindel leistenförmig vorspringend. Die Färbung wie bei der typischen Form, jedoch weniger lebhaft.

Deckel wie bei der typischen Form.

$$
\mathrm{D}=7-8.5, \mathrm{~d}=6-7, \mathrm{H}=5-5.5 \mathrm{~mm} \text {. }
$$

Fundort: die Insel Barbados. 
496. Helicina fasciata convexa Pfeiffer.

Taf. 67, Fig. 8-9.

\author{
Helic in a convera Pfeiffer Pr. Z: S. p. 120, 1848.
" $\quad$ " M. Ch. II, p. 53, T. 9, F. 9-10.
» $\quad$ Sowerby, Thes. III, p. 286, T. 271, F. 215-216, T. 274, F. 315, 1866.
" substriata convera A. J. Wagner, Helicinenstudien in: Denk. Akad. Wien v. 78, \\ p. 216, T. 11, F. 8, 1905.
}

Gehäuse kleiner, festschaliger mit höherem, kegelförmigem Gewinde und deutlichen etwas ungleichmässigen Zuwachsstreifen, jedoch obne Spirallinien; gelblichweiss, gelb bis rotbraun, häufig mit einer hellen Binde an der Peripherie des letzten Umganges und lebhafter gefärbten oberen Umgängen. Das Gewinde besteht aus $4^{1} / 2$ bis 5 nahezu flachen, langsam zunehmenden Umgängen; der letzte ist an der Peripherie im Beginne deutlich stumpfkantig, gegen die Mündung zu nahezu gerundet und steigt vorne weniger herab. Die sehr schiefe Mündung ist weniger verbreitet, der weisse Mundsaum verdickt bis verdoppelt. Am Übergange der Spindel in den Basalrand der Mündung eine abgerundete, wenig vorspringende Ecke. Der dicke, weisse Basalkallus ist fein gekörnelt, im Umkreise der Spindel leistenförmig erhoben.

$$
\mathrm{D}=7, \mathrm{~d}=6, \mathrm{H}=5.5 \mathrm{~mm} \text {. }
$$
Form.

Deckel mit etwas dickerer, feingekörnelter Kalkplatte, sonst wie bei der typischen

Fundort: die Insel Bermuda.

Die beiden zuletzt abgehandelten Formen erscheinen mir nur als wenig abweichende Lokalformen der H. fasciata Lamarck, welche an der Peripherie des ausgedehnten Verbreitungsgebietes dieser Art auftreten, jedoch durch Übergänge mit der typischen Form verbunden sind, Eine sichere Determination dieser Formen ist nur bei Kenntnis des Fundortes möglich.

\title{
Nachtrag zum Genus Helicina Lamarck.
}

\section{Helicina boettgeri $n$.}

Taf. 67, Fig. 10-12.

Gehäuse flachkugelig, ziemlich festschalig, leicht glänzend, einfärbig gelblichweiss, die oberen Umgänge gelblich. Die Skulptur besteht nebst feinen, ungleichmässigen Zuwachsstreifen aus feinen, dichten, eingedrückten Spirallinien, welche auf der Unterseite des letzten Umganges erlöschen. Das flachkegelïörmige schwach konvexe Gewinde besteht aus 4 kaum gewölbten langsam zunehmenden Umgången, welche durch eine seichte, kaum eingedrückte Naht geschieden werden; der letzte ist etwas aufgeblasen nimmt rascher zu, ist an der 
Peripherie gerundet und steigt vorne nicht herab. Die halbeiförmige Mündung ist wenig schief, höher als breit. Der weisse Mundsaum kurz ausgebreitet, aber lippenartig verdickt; die kurze Spindel ist stark nach vorne gebogen und bildet am Übergange in den Basalrand der Mündung eine abgerundete, aber stark vorspringende Ecke. Der gelblichweisse, feingekörnelte Basalkallus ist ziemlich dick und deutlich begrenzt.

Deckel unbekannt.

$$
\mathrm{D}=7 \cdot 5, \mathrm{~d}=6.5, \mathrm{H}=5.5 \mathrm{~mm} \text {. }
$$

Fnndort: Sâ̂ Leopoldo, Espiritu Santo in Brasilien.

Diese und die folgende neue Art verdanke ich der Güte meines soeben verstorbenen Freundes Professor Oskar Boettger, welcher mir dieselben mit seinen letzten Grüssen gesendet hat.

Helicina boettgeri n. gehört zum Formenkreise Variabilis m., zeigt aber bis auf die Verhältnisse der Mündung eine gewisse Übereinstimmung mit Formen der Helicina brasililensis Gray und dürfte eine Geschlechtsform derselben darstellen.

\section{Helicina oskari $n_{\text {. }}$ Taf. 67, Fig. 13-15.}

Gehäuse kegelförmig mit flachgewölbter Basis, ziemlich festschalig, wenig glănzend bis matt, einfärbig gelbbraun. Die Skulptur besteht nebst feinen, ungleichmăssigen Zuwachswachsstreifen aus dichten feinen, ungleich abstehenden Spiralreifen, welche auf der Unterseite auffallend schwächer werden. Das ziemlich erhobene, abgerundet kegelförmige Gewinde besteht aus $4^{1} /{ }_{2}-\left.4^{3}\right|_{4}$ langsam zunehmenden nahezu flachen Umgăngen, welche durch eine seichte Naht geschieden werden; der letzte ist ziemlich scharf, aber nicht zusammengedrückt gekielt und steigt vorne kaum oder gar nicht herab. Die abgerundet dreieckige Mündung ist schief, der gelbliche Mundsaum leicht verdickt, kurz ausgebreitet und umgeschlagen, der Oberrand an der Insertion etwas vorgezogen. Die kurze, dünne Spindel ist senkrecht und bildet am Uebergange in den Basalrand der Mündung eine wenig vorspringende, aber ziemlich scharfe Ecke. Der dünne, glänzende Basalkallus ist undeutlich begrenzt; in der Nabelgegend eine quäre Furche.

$$
\mathrm{D}=9, \mathrm{~d}=8, \mathrm{H}=6.5 \mathrm{~mm}
$$

Deckel unbekannt.

Fundort: Saô Leopoldo, Espiritu Santo in Brasilien.

Die vorstehende Art steht der Helicina inaequistriata Pilsbry sehr nahe, unterscheidet sich jedoch von derselben durch das höhere deutliche konvexe Gewinde, die langsamer zunehmenden Urngänge, die schärferen Spiralreifen, den deutlich schärferen Kiel und die deutlicher vorspringende Ecke am Übergange der Spindel in den Basalrand der Mündung. 


\title{
Genus Lucidella Swainson.
}

\author{
Lucidella Swainson Treatise on Malacol. p. 330, 1810.
}

Gehäuse klein bis sehr klein, linsenförmig, kegelförmig bis flachkugelig, mit kräftig ent= wickelter Radial- oder Spiralskulptur, sowie langsam zunehmenden Umgängen; der letzte gerundet bis gekielt in der Nabelgegend mehr minder eingedrü.kt. Die Mündung durch zahnartige Schwielen des Mundsaums, welchen aussen häufig Eindrücke und Grubell entsprechen, verengt; an der Insertion des Oberrandes der Mündung eine Einkerbung. Der dünne Basalkallus oft nur in der Nabelgegend deutlich, jedoch stets vorhanden.

Deckel halbeiförmig oder abgerundet dreieckig mit konkavem Spindelrande. Der Nukleus nahezu zentral oder dem Spindelrande genăhert, jedoch niemals randständig. Die Sigmakante sehr undeutlich. Die Kalkplatte krustenartig dünn und hinfällig, am Spindelrande jedoch verdickt und leistenartig erhoben.

Das Verbreitungsgebiet des Genus Lucidella in dem hier vorgesch!agenen Umfange umfasst die kleinen und grossen Antillen und reicht mit einer Art auf das benachbarte Festland Süd- und Zentralamerikas hinüber (von Venezuela bis Südmexico); es besteht also in dieser Beziehung eine auffallende Übereinstimmung mit den Geschlechtern Alcadia Gray und Eutrochatella Fischer. Das Genus Lucidella wurde bisher durch den Mangel des Basalkallus gekennzeichnet; nun ist sowohl bei Lucidella aureola Fer., als auch allen übrigen hierher gezogenen Formen ein zumeist sehr zarter, aber mit der Lupe doch nachweisbarer Basalkallus vorhanden. Wollte man einen zarten Basalkallus, welcher oft nur an dem stärkeren Glanz $\mathrm{zu}$ erkennen ist als nicht vorhanden bezeichnen, so müsste derselbe auch zahlreichen Heliciniden anderer Geschlechter abgesprochen werden. Der zarte Basalkallus ist aber nicht das einzige Merkmal, welches die Formen dieses Genus kennzeichnet. Besonders auffallend sind bei den meisten Formen die Verhăltnisse der Mündung; dieselbe erscheint mehr minder zusammengedrückt und verbreitert, ausserdem durch zahnartige Schwielen des Mundsaumes verengt. Diese Zähne sind auf den Mundsaum beschränkt, auch entsprechen denselben aussen Eindrücke und Gruben. An der Insertion des Oberrandes der Mündung findet sich bei den meisten Formen eine deutliche Einkerbung wodurch anscheinend auch bei geschlossenem Deckel ein kleiner Lufkkanal gebildet wird; eine ăhnliche Einrichtung besteht bei dem Genus Aleadia Gray, hier aber zwischen Spindel und Basalrand der Mündung. Sehr charakteristisch ist ferner die zumeist sehr kräftige Skulptur, welche aus spiral oder radial angeordneten Rippchen und Reifen besteht, mitunter auch gemischt vorkommt. Einzelne Formen weisen auch hinfallige Falten und kurze Borsten der Epidermis auf, welche in dichten Spiral- und Radialreihen angeordnet sind; diesen Epidermisfalten entsprechen an abgeriebenen und glatten Exemplaren, wie sie zumeist in den Sammlungen vorhanden sind, feine eingedrückte Spirallinien. Auch dieses Merkmal erinnert an ăhnliche Gebilde bei dem Genus Alcadia Gray.

I. 18. II.

22. XI. 1910. 
An dem dünnen und durchscheinenden Deckel weist der Nukleus eine mehr zentrale, dem Spindelrande etwas genăherte Lage auf, niemals ist derselbe aber randständig, wie bei den Formen des Genus Helicina, was eine sichere Abgrenzung nach dieser Seite ermöglicht. Die zarte, krusten- bis anflugartige Kalkplatte ist wie bei allen Heliciniden am Spindelrande immer etwas verdickt und $\mathrm{zu}$ einer deutlichen Leiste erboben. Im durchfallenden Lichte bemerkt man ferner entsprechend dem Aussenrande des Deckels radiär angeordnete Linien, deren Bedeutung mir unbekannt geblieben ist. Alle diese Merkmale sind bei den einzelnen Formen nicht vollzählig vorhanden und gleichmässig entwickelt; extreme Entwickelung einiger Merkmale bedingt häufig das Zurücktreten der übrigen. Dennoch erscheint das Genus Lucidella gut begrenzt, indem das Zusammentreffen einiger charakteristischen Schalenmerkmale in Verbindung mit der Beschaffenheit des Deckels immer eine sichere Beurteilung ermöglicht, Anklänge oder Übergänge zum Genus Alcadia Gray stellen die Formen aus der Reihe der Lucidella adamsiana Pfeiffer dar, welche unter Anderem hinfällige Spiralfalten der Epidermis und schwach entwickelte Zähne am Mundsaum besitzen.

Innerhalb des Genus scheinen die einzelnen Formen besonders mit Rücksicht auf die Skulptur des Gehäuses sehr veränderlich zu sein und dürfte bei reichlichem Material die Abgrenzung der Arten oft recht schwierig sein. Die zahlreichen Arten des Genus Lucidella (ich kenne wohl nur einen geringen Teil derselben) gelangen selten and in geringer Exemplarzahl in europäische Sammlungen.

\section{Lucidella undulata Pfeiffer.}

Täf. 67, Fig. 16-18.

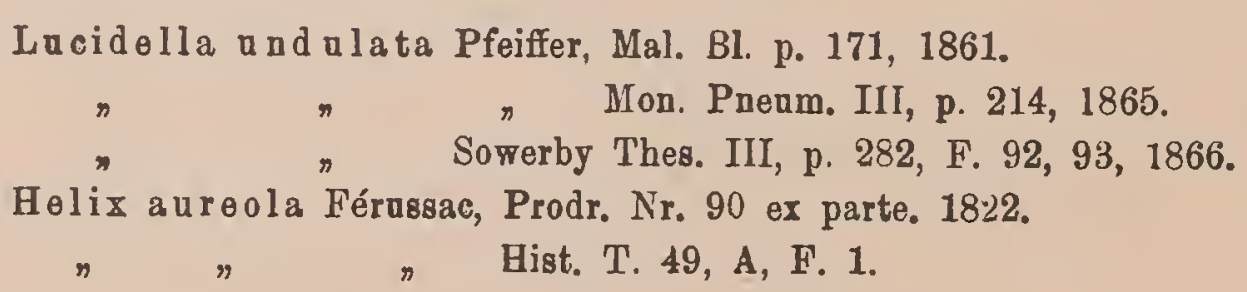

Gehäuse kegeltörmig mit gewölbter Basis und einer flachtrichterförmigen Vertiefung in der Nabelgegend; festschalig, weniger glänzend bis matt; schmutzig gelbbraun bis lebhaft rotbraun, unten heller, oben mit unregelmässigen gelblichen Flecken und Körnern. Die Skulptur besteht nebst einigen undeutlichen Zuwachsstreifen aus dichten ziemlich kräftigen Spiralreifen, welche auf der Unterseite schwächer werden, auf der Oberseite leicht wellenförmig gebogen und zum Teil regelmässig gekörnelt erscheinen; durch radiäre Gruppierung dieser Granula entstehen besonders auf den oberen Umgängen die für die Art charakteristischen Wellenfalten, welche aber bei den einzelnen Exemplaren verschieden kräftig entwickelt sind und mitunter undeutlich werden. Das leicht konvexe Gewinde besteht aus $5^{1} / 2$ langsam zunehmenden, schwach gewölbten bis nahezu flachen Umgängen, welche durch eine 
deutlich eingedrückte Naht geschieden werden; der letzte ist unten stärker gewölbt, etwas über der Mitte mit einem wellenförmig gekörnelten stumpfen Kiel versehen und steigt vorne ziemlich tief herab. Die unregelmässig dreieckige Mündung ist innen gelblich bis rotbraun und sehr schief; der weisse, lippenartig verdickte Mundsaum ausgebreitet und umgeschlagen; der Oberrand herabgebogen, aussen mit einem Eindruck, innen mit einem abgerundeten Zahne versehen, an der Insertion deutlich eingekerbt; der Basalrand ist am inneren Drittel ebenfalls mit einem abgerundeten, aber stark nach vorne und oben vorspringenden Zahne versehen; in dem Winkel, welchen der Basalrand mit dem Aussenrand bildet findet sich mitunter die Andeutung eines dritten Zahnes. Die kurze, dünne und abgerundete Spindel ist nahezu senkrecht oder etwas nach aussen gebogen und geht im Bogen in den Basalrand über. Der Basalkallus ist sehr dünn und undeutlich, nur in der Nabelgegend durch den stärkeren Glanz angedeutet.

$$
\mathrm{D}=7-8 \cdot 5, \mathrm{~d}=6-7 \cdot 5, \mathrm{H}=5-6 \mathrm{~mm} \text {. }
$$

Deckel birnförmig mit seitlich gekrümmter Spitze, sehr dünn und durchsichtig, gelbbraun; die anflugartige Kalkplatte am Spindelrande deutlich dicker und zu einer niedrigen Leiste erhoben; der Nukleus dem Spindelrande genähert.

Fundort: die Insel Jamaica.

Im Vorstehenden habe ich eine Form beschrieben, welche der Diagnose Pfeiffers vollkoinmen entspricht; neben dieser typischen Form kenne ich aber auch Exemplare (ob dieselben vom gleichen Fundorte stammen ist mir unbekannt, doch habe ich dieselben vermischt erhalten) welche namentlich mit Rücksicht auf die Körnelung und Bildung der Wellenfalten, ebenso des Kieles alle Übergänge zur typischen Lucidella aureola Fér. aufweisen. So besitzt eine Auzahl von Exemplaren übereinstimmend wohl deutlich bis kräftig eutwickelte Wellenfalten, aber keinen Kiel; ich erhielt solche Exemplare auch unter der Bezeichnung Lucidella granulosa C B. Adams, die entsprechende Beschreibung ist mir. leider unbekannt geblieben; dieselbe könnte auf eine konstante Lokalform begründet und beizubehalten sein. Andere Exemplare zeigen eine schwache Körnelung, welche ja angedeutet auch bei einzelnen Exemplaren der Lucidella aureola Fér. vorkommt, aber noch einen deutlichen Kiel.

\section{Lucidella a ure ol a Férussac.}

Taf. 67, Fig. 19-20.

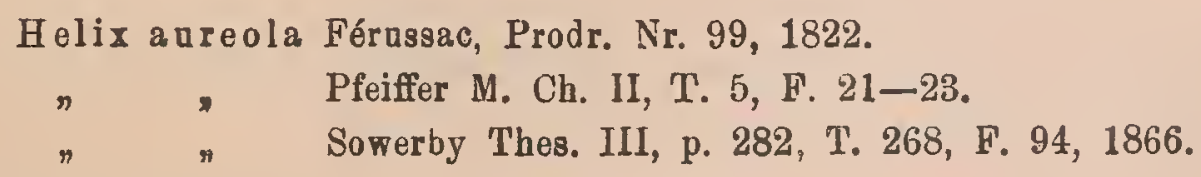

Diese Art unterscheidet sich von Lucidella undulata Pfeiffer vor allem durch die gleichmăssig dichten und feinen Spiralreifen, doch finden sich, wie oben erwăhnt einzelne Exemplare, welche eine schwache Körnelung aufweisen. Die Färbung ist gelb bis rotorange mit 
einer rotbraunen Zone hinter der Mündung; der letzte Ungang gerundet und ungekielt. Ein dünner und undeutlicher Basalkallus ist auch hier vorhanden.

$$
\mathrm{D}=7 \cdot 5-9 \cdot 5, \mathrm{~d}=6.5-8 \cdot 5, \mathrm{H}=5.5-7 \mathrm{~mm} \text {. }
$$

Deckel birnförmig mit seitlich gekrümmter Spitze und stark konkavem Spindelrand, sehr dünn und durchsichtig, gelbbraun. Die krustenartige Kalkplatte am Spindelrande zu einer deutlichen Leiste erhoben; in den übrigen Verhältnissen typisch.

Fundort: die Insel Jamaica.

\title{
501. Lucidella umbonata Shuttleworth.
}

Taf. 67, Fig. $21-24$.

\author{
Helicina umbonata Shattleworth, Diagn. n. Moll. Nr. 7, p. 153. \\ " $\quad$ Pfeiffer, Mon. Pnenm. II, p. 187, 1858. \\ ᄁ (Idessa) ambonata Adams, Genera p. 304, 1856.
}

Gehäuse flachkugelig, festschalig, matt, hellrotbraun. Die Skulptur besteht nebst einigen undeutlichen Zuwachsstreifen aus dichten, etwas ungleichmässigen Spiralreifen, welche auf der Unterseite dichter und schwächer, auf der Oberseite heller gokörnelt erscheinen. Das flachkegelförmige, leicht konvexe Gewinde besteht aus 5 langsam zunehmenden, flachen Umgängen, welche durch eine undeutliche Naht geschieden werden; der letzte an der Peripherie stumpf gekielt, vorne deutlich unter den Kiel herabsteigend. Die abgerundet dreieckige Mündung ist schief, innen gelbbraun, der gelbliche, leicht verdickte Mundsaum kurz ausgebreitet (das mir vorliegende Exemplar erscheint mit Rücksicht auf den Mundsaum nicht vollkommen entwickelt). Die kurze dünne Spindel ist etwas nach vorne gebogen und bildet am Übergange in den Basalrand der Mündung eine schwache Ecke. Der dünne Basalkallus undeutlich, die Nabelgegend nicht eingedrückt.

$$
\mathrm{D}=6 \cdot 5, \mathrm{~d}=5 \cdot 5, \mathrm{H}=4 \mathrm{~mm} \text {. }
$$

Deckel abgerundet dreieckig mit seitlich gekrümmtem oberen Winkel, sehr dünn, gelbbraun. Die krustenartige Kalkplatte am Spindelrande leistenartig erhoben.

Fundort: Arceibo auf Portorico.

Ich stelle diese Art nur mit Rücksicht auf die gekörnelte Spiralskulptur und die Beschaffenheit des Deckels zu Lucidella, doch ist das mir vorliegende Exemplar nicht vollkommen entwickelt, auch erwåhnt Shuttleworth in seiner Beschreibung eine Verdickung des Basalrandes, diese Verdickung entspricht wohl dem Basalzahne, welcher auch bei anderen Arten des Genus nur schwach entwickelt ist, mitunter sogar fehlt. 


\title{
502. Lucidella lirata Peiffer.
}

Taf. 68, Fig. 5-7.

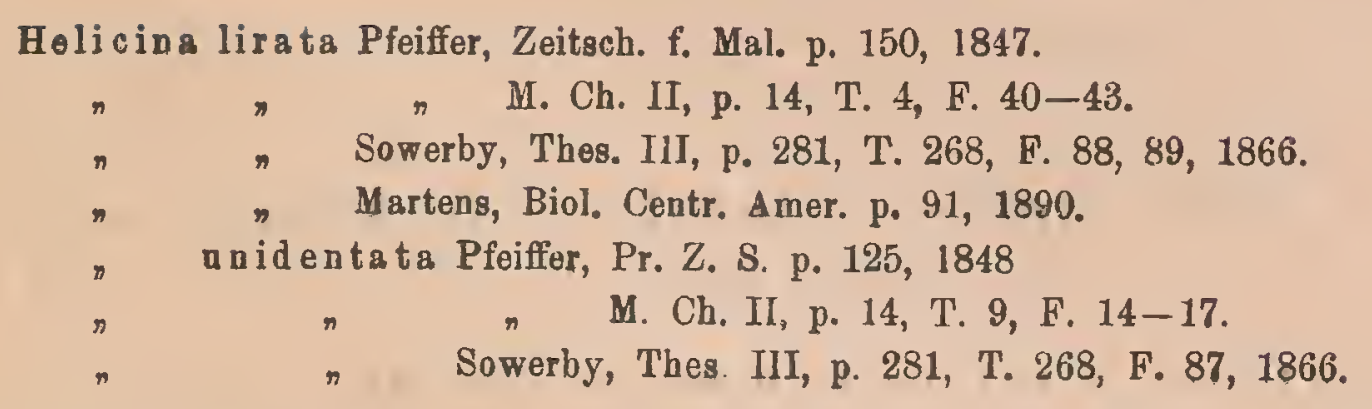

Gehäuse breitkegelförmig mit flachgewölbter Basis und einem flachtrichterförmigen Eindruck in der Nabelgegend, ziemlich dünnschalig, gelbbraun bis rötlich hornfarben, wenig glănzend. Die Skulptur besteht aus dichten, ziemlich scharfen, etwas ungleichmässigen Spiralreifen, welche auf der Unterseite zunehmend schwăcher und weitläufiger werden. Das regelmässig kegelförmige Gewinde besteht aus 5 gewölbten, langsam zunehmenden Umgängen, welche durch eine deutlich eingedrückte Naht geschieden werden; der letzte ist beiderseits gleichmăssig gewölbt, an der Peripherie ziemlich scharf gekielt und steigt vorne wenig oder gar nicht herab. Die abgerundet dreieckige Mündung ist schief, der weisse, verdickte Mundsaum kurz ausgebreitet und umgeschlagen; der Oberrand an der Insertion deutlich eingekerbt, der Basalrand mit einer abgerundeten zahnartigen Verdickung, welche häufig verkümmert oder fehlt. Der dünne, gekörnelte Basalkallus ist undeutlich begrenzt.

$$
\mathrm{D}=3.5-5, \mathrm{~d}=3-4, \mathrm{H}=2-3.5 \mathrm{~mm} \text {. }
$$

Deckel abgerundet dreieckig mit konkavem Spindelrande, sehr dünn und zart, gelblich; die Kalkplatte anflugartig, in den übrigen Verhältnissen typisch.

Fundorte: Südmexico, Guatemala, Honduras, Venezuela.

Diese Art ist abgesehen von den auch am gleichen Fundorte sehr verschiedenen Dimensionen der Schale besonders mit Rücksicht auf die Dichte und Höhe der Spiralreifen, sowie die Entwickelung des Basalzahnes sehr veränderlich; einen kräftig entwickelten Basalzahn haben immer nur einzelne Exemplare, während andere desseiben Fundorts diesen mehr minder verkümmert aufweisen; somit hat die Unterscheidung einer Lucidella unidentata Pfeiffer nicht einmal als Lokalform eine Berechtigung.

\section{Lucidella lirata lamell os a Guppy.}

Taf. 68, Fig. 4.

\author{
He licina (Perenna) lamellosa Guppy in: Ann. Mag. N. H. (3) XIX, p. 260, 1867. \\ Pfeiffer, Mon. Pneum. IV, p. 282, 1876. \\ "Crosse J. de Conch. v. 38, p 59, T. 2, F. 10, 1890. \\ rusticella Morelet in: Test noviss. p. 21, 1849.
}


Gehäuse rotbraun mit weitläufigeren, schärferen Spiralreifen, welche abwechselnd höher und niedrigen sind; der Mundsaum häufig am Rande gefältelt mit verkümmertem Basalzahn.

Fundort: die Insel Trinidad.

$$
\mathrm{D}=5, \mathrm{~d}=4.5, \mathrm{H}=3.5 \mathrm{~mm} \text {. }
$$

\title{
504. Lucidella lineata C. B. Adams. Taf. 68, Fig. 8-9.
}

\author{
Helicina lineata C. B. Adams, Pr. Boston Soc. p. 12, 1845. \\ » Pfeiffer, Mon. Pneum. I, p. 342, 1852. \\ " Sowerby, Thes. III, p. 281, T. 268, F. 85, 1866.
}

Gehăuse flachkegelförmig mit flacher, in der Nabelgegend eingedrückter Basis, dünnschalig, durchscheinend, gelblich hornfarben, wenig glänzend. Die Skulptur besteht aus sehr feinen, ziemlich niedrigen, dichten Spiralreifen, welche auf der Unterseite weitläufiger und schwächer werden. Das regelmässig flachkegelförmige Gewinde besteht aus $4^{1 / 2}$ leicht gewölbten, langsam zunehmenden Umgängen, welche durch eine deutlich vertiefte Naht geschieden werden; der letze ist etwas zuzammengedrückt, an der Peripherie gerundet und steigt vorne langsam aber deutlich herab. Die sehr schiefe Mündung ist breiter als hoch, der weisse Mundsaum kurz ausgebreitet und umgeschlagen; der Oberrand an der Insertion mit einer deutlichen Einkerbung, in der Mitte leicht herabgebogen und innen mit einem abgerundeten, schwachen Zahne versehen; der Basalrand mit einem starken, nach vorne und oben vorspringenden Zahne. Die kurze dünne Spindel ist nach aussen gebogen und geht im Bogen in den Basalrand über; der dünne, feingekörnelte Basalkallus ist undeutlich begrenzt.

$$
\mathrm{D}=35, \mathrm{~d}=3, \mathrm{H}=2 \mathrm{~mm} \text {. }
$$

Deckel unbekannt.

Fundort: die Insel Jamaica.

\author{
505. Lucideil a nana Pfeiffer. \\ Taf. 68, Fig. 12, 13. \\ Helicina nana Pfeiffer, Pr. Zool. Soc., p. 111, 1857. \\ $n \quad n \quad$ Mon. Pneam. II, p. 178, 1858. \\ » tridens (Shattleworth) Sowerby, Thes. III, p. 282, T. 268, F. 90-91, 1866.
}

Gehäuse breitkegelförmig mit flachgewölbter, in der Nabelgegend eingedrückter Basis, ziemlich festschalig, leicht glänzend, gelblich hornfarben. Die Skulptur besteht aus ziemlich weitlăufigen, verhältnismässig scharfen Spiralreifen, welche auf der Unterseite nahezu erlöschen. Das ziemlich erhobene leicht konvexe Gewinde besteht aus 4, nahezu flachen, lang- 
sam zunehmenden Umgängen, welche durch eine kielartig übergreifende Naht geschieden werden; der letzte ist an der Peripherie mit einem scharfen, wellenförmig gekörnelten Kiel versehen und steigt vorne wenig unter den Kiel herab. Die dreieckige Mündung ist sehr schief, der weisse verdickte Mundsam kurz ausgebreitet und umgeschlagen. Der Oberrand an der Insertion leicht eingekerbt, in der Mitte mit einem ziemlich scharfen Zahne versehen; am Übergange des Oberrandes in den Basalrand ein zweiter kleiner, aber spitzer Zahn, in der Mitte des Basalrandes ein dritter, abgerundeter, stark nach vorn und oben vorspringender Zahn; der dünne glånzende Basalkallus undeutlich begrenzt.

Deckel unbekannt.

$$
\mathrm{D}=3, \mathrm{~d}=2 \cdot 5, \mathrm{H}=1.8 \mathrm{~mm} \text {. }
$$

Fundort: die Insel Jamaica.

Pfeiffer beschreibt diese Art nur zweizähnig, doch entspricht die weitere Diagnose den von mir untersuchten Exemplaren vollkommen; der dritte Zahn mag eben zuweilen verkümmern.

\title{
506. Lu cidella f oxi Pilsbry.
} Taf. 68, Fig. 10-11.

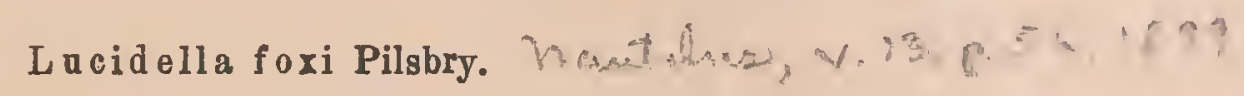

Gehäuse sehr ähnlich der Lucidella lineata C. B. Adams; die Spiralreifen oben etwas schärfer, auf der Mitte der Basis jedoch erloschen. Der letzte Umgang steigt vorne auffallend tiefer herab, die Mündung ist dreizähnig, der Mundsaum ausserdem leicht gefältelt. Der Oberrand der Mündung ist nicht herabgebogen, auch liegt der obere Zahn nicht am Mundsaum, sondern tiefer im Gaumen und stellt ein weisses, rundliches Knötchen dar. Der zweite Zahn am Übergange des Oberrandes in den Basalrand ist ebenfalls klein, liegt am Mundsaum, ist aber etwas nach innen verlängert; der grosse und abgerundete Basalzahn springt stark nach vorne und oben vor.

Deckel unbekannt.

$$
\mathrm{D}=3 \cdot 6, \mathrm{~d}=3 \cdot 3, \mathrm{H}=2 \cdot 3 \mathrm{~mm} \text {. }
$$

Fundort: Hôtel Fichfild in Port Antonio Jamaica.

\section{Lucidella granum Pfeiffer.}

Taf. 68, Fig. 14-15.

\author{
Helicuna granum Pfciffer in: Mal. Bl. III, p. 49, 1856. \\ $\eta \quad n$ Novitat. Conch. I, p. 86, T. 23, F. 20-23. \\ " $\quad$ Crosse, J. de Conch. v. 38, p. 321, 1890.
}


Gehăuse breitkegelförmig mit flachgewölbter, in der Nabelgegend nur leicht eingedrückter Basis, ziemlich dünnschalig, leicht glănzend, gelblich bis rötlich hornfarben. Die Skulptur besteht aus ziemlich dichten sehr feinen Spiralreifen, welche auf der Unterseite dichter und schwăcher werden, hăufig nahezu erlöschen. Das regelmässig flachkegelförmige Gewinde besteht aus $4^{1} / 2$ gewölbten, langsam zunehmenden Umgängen; der letzte ist gerundet und steigt vorne sehr wenig oder gar nicht herab. Die abgerundet dreieckige Mündung ist schief, der mit dem Gehăuse gleichfarbige Mundsaum leicht verdickt und kurz ausgebreitet; der Oberrand an der Insertion nur wenig vorgezogen und schwach eingekerbt. Die kurze, abgerundete Spindel ist leicht nach aussen gebogen und bildet am Übergang in den Basalrand der Mündung eine scharfe, deutlich vorspringende Ecke. Der dünne, feingekörnelte Basalkallus ist undeutlich begrenzt.

Deckel typisch.

$$
\mathrm{D}=3 \cdot 5, \mathrm{~d}=3, \mathrm{H}=2 \cdot 2 \text {. }
$$

Fundorte: Santjago de Cuba und Buenavista auf Cuba.

\title{
508. Lu cidella adamsiana Pfeilfer.
}

Taf. 68, Fig. 18-20

\author{
Helicina adamsiana Pfeiffer, Pr. Z. S. p. 119, 1848. \\ $" \quad$ M. Ch. II, p. 12, T. 7, F. 16, 17. \\ » Sowerby Thes. III, p. 281, T. 267, F. 71, 72, 1866.
}

Gehäuse flachkegelförmig mit gewölbter Basis, ziemlich dünnschalig gelblichweiss bis hellrotbraun; im frischen Zustande matt mit kurzen, hinfälligen Borsten besetzt, welche in dichten Spiral- und Radialreihen angeordnet sind; abgerieben glänzend mit sehr feinen Zuwachsstreifen und sehr feinen eingedrückten Spirallinien auf den oberen Umgängen. Das niedrige; abgerundete Gewinde besteht aus 5 ziemlich langsam zunehmenden, flachen Umgängen, welche durch eine seichte Naht geschieden werden; der letzte ist gerundet und steigt vorne langsam und wenig herab. Die abgerundet dreieckige Mündung ist schief, der lippenartig verdickte, mit dem Gehăuse gleichfarbige Mundsaum kurz ausgebreitet und umgeschlagen; der Oberrand an der Insertion deutlich eingekerbt, in der Mitte mit einer undeutlichen Verdickung, der Basalrand mit einem abgerundeten, wenig vorspringenden Zahn. Der lebhaft glånzende, weisse, an den Răndern durchsichtige Basalkailus ist ziemlich undeutlich begrenzt.

$$
\mathrm{D}=6 \cdot 5-8 \cdot 5, \mathrm{~d}=5 \cdot 5-7, \mathrm{H}=4 \cdot 5-6 \mathrm{~mm} .
$$

Deckel abgerundet dreieckig mit konkavem Spindelrande, gelbbraun; die weisse, feingekörnelte Kalkplatte ziemlich fest mit einer deutlichen Leiste am Spindelrande; in den übrigen Verhältnissen typisch.

Fundort: die Insel Jamaica. 


\title{
509. Lucidella adamsiana coronula (Shuttleworth) Pfeiffer.
}

Taf. 68, Fig. 21.

\author{
Helicina coronula Shuttleworth apad Pfeiffer in: Mal. Bl. IX, p. 155, 1862. \\ ᄁ $\gg$ Mon. Pnenm. III, p. 217, 1865. \\ n Somerby, Thes. III, p. 281, T. 268, F. 77, 78, 1866.
}

Gehäuse flacher mit regelmässig flachkegelförmigem Gewinde, welches nur aus $4^{1} / 2$ flachen, rascher zunehmenden Umgängen besteht; der letzte ist zusammengedrückt, an der Peripherie undeutlich kantig; gelblichweiss oder lichthornfarben mit dunkler getärbter Spitze. Die Skulptur besteht nebst deutlicheren Zuwachsstreifen aus dichten sehr feinen Spiralreifen, welche auf der Unterseite nahezu erlöschen; frische Exemplare besitzen wie die typische Form kurze, pustelartige Borsten. Die senkrechte Spindel geht im rechten Winkel in den Basalrand über, der Basalzahn schwächer wie bei der typischen Form.

$$
\mathrm{D}=8, \mathrm{~d}=6.5, \mathrm{H}=4.5 \mathrm{~mm} \text {. }
$$

Deckel wie bei der typischen Form.

Fundort: die Insel Jamaica.

510. Lucidella depressa Gray.

Taf. 68, Fig. 16-17.

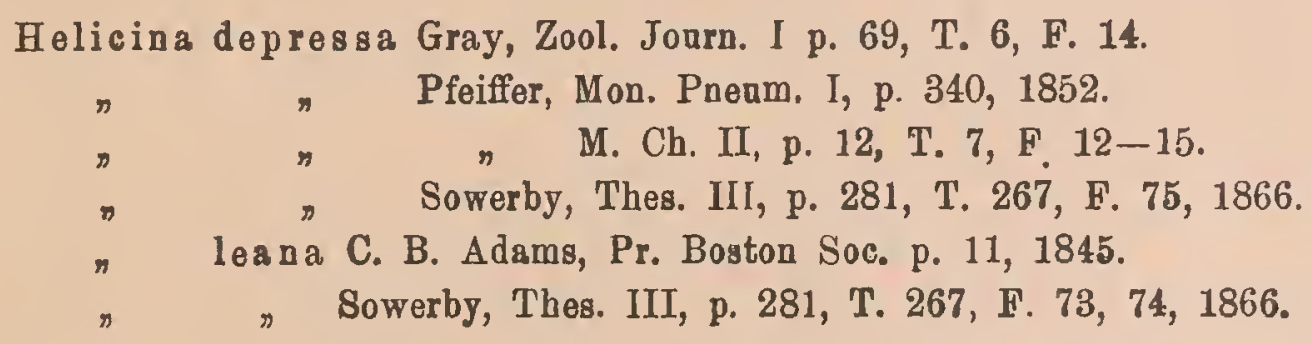

Gehăuse flachkegelig, ziemlich dünnschalig und durchscheinend gelblichweiss oder hell hornfarben; abgerieben glänzend mit sehr feinen und dichten Spiralreifen, welche auf der Unterseite nahezu erlöschen; im frischen Zustande matt mit sehr feinen, punktförmigen, in dichten Spiralreihen angeordneten, hinfälligen Borsten. Das niedrige, flachkegelförmige Gewinde besteht aus $4 \frac{1}{2}$ leicht gewölbten, ziemlich rasch zunehmenden Umgängen; welche durch eine leicht eingedrückte Naht geschieden werden; der letzte ist zusammengedrückt, an der Peripherie gerundet und steigt vorne wenig herab. Die abgerundet dreieckine, schiefe Mündung ist breiter als hoch; der weisse, lippenartig verdickte Mundsaum kurz ausgebreitet und umgeschlagen; der Oberrand an der Insertion deutlich eingekerbt in der Mitte mit einem abgerundeten, niedrigen Zahn versehen, welchem aussen ein seichter Eindruck entspricht; der Basalrand am inneren Drittel mit einem abgerundeten, wenig vorspringenden

I. 18. II.

26. XI. 1910. 
Zahne versehen. Die kurze dünne Spindel ist nahezu senkrecht und geht winkelig in den Basalrand über; der dünne, glänzende Basalkallus ziemlich deutlich begrenzt.

$$
\mathrm{D}=6, \mathrm{~d}=5, \mathrm{H}=3.5 \mathrm{~mm} \text {. }
$$

Deckel abgerundet dreieckig mit konkavem Spindelrande; sehr dünn und durchsichtig, hellhornfarben; die zarte krustenartige Kalkplatte am Spindelrand zu einer niedrigen Leiste erhoben; in den übrigen Verhältnissen typisch.

Fundort: die Insel Jamaica.

\section{Lucidella paivana Pfeiffer.}

Taf. 69, Fig. 1-2.

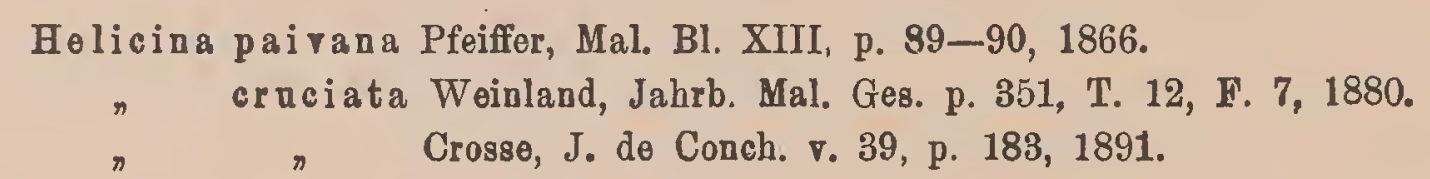

Gehäuse abgerundet kegelförmig mit abgeflachter Basis und nur schwach vertiefter Nabelgegend, ziemlich festschalig, wenig glänzend bis matt, gelblich weiss bis rötlich hornfarben. Die Skulptur besteht aus dichten, S-förmig gebogenen, verhältnismässig kräftigen Radialfalten, welche unterhalb der Naht gebogen und verdickt erscheinen; auf den unteren Umgängen und der Basis sind ausserdem sehr feine und dichte Spiralreifen vorhanden. Das abgerundet kegelförmige Gewinde besteht aus $5^{1} / 2$ kaum gewölbten bis flachen, langsam zunehmenden Umgängen, welche durch eine eingedrückte, krenulierte Naht geschieden werden; der letzte Umgang unten abgeflacht, unterhalb der Peripherie stumpf gekielt, vorne langsam und wenig herabsteigend. Die dreieckige Mündung ist sehr schief, der weisse Mundsam wenig verdickt, kurz ausgebreitet; der Oberrand etwas herabgebogen, an der Insertion deutlich eingekerbt, daneben auf der Mündungswand ein punktförmiges Knötchen; der Basalrand am inneren Drittel mit einem abgerundeten nach vorne und oben deutlich vorspringendem Zahn. Der dünne, weisse, feingekörnelte Basalkallus in der Nabelgegend ziemlich deutlich.

$$
\mathrm{D}=5.5, \mathrm{~d}=4.5, \mathrm{H}=3.5 \mathrm{~mm} \text {. }
$$

Deckel unbekannt.

Fundort: die Insel Haiti; Port-au-Prince, Mont Platon.

Pfeiffer erwähnt in seiner Beschreibung die feinen Spiralleisten und den stumpfen Kiel nicht, doch sind diese Merkmale mitunter undeutlich vorhanden.

\section{Lucidella paivana decussata Boettger.} Taf. 69, Fig. 3.

Helicina decussata Boettger, Jahrb. Mal. Ges. XIV, p. 102, T. 4, F. 8, 1887. 
Gehäuse weniger konvex kegelförmig mit schwachen bis undeutlichen Spiralreifen, schărferem Kiel und tiefer herabsteigendem letzten Umgang.

Fundort: Miragôane auf Haiti.

$$
\mathrm{D}=5 \cdot 8, \mathrm{~d}=5 \cdot 2, \mathrm{H}=3 \cdot 5-4 \mathrm{~mm} \text {. }
$$

\section{Lucidella rugosa Pfeiffer.}

Taf. 69, Fig. 8-9.

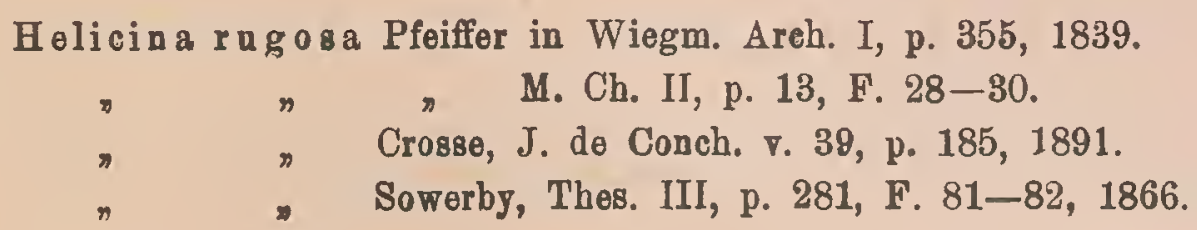

Gehäuse flachkegelförmig mit flacher Basis und leicht eingedrückter Nabelgegend, ziemlich festschalig glänzend, rötlich hornfarben. Die Skulptur besteht aus dichten, regelmässigen, S-förmig gebogenen Radialfalten. Das niedrige, regelmässig flachkegelförmige Gewinde besteht aus $4^{1} / 2$ ziemlich langsam zunehmenden, leicht gewölbten, durch eine eingedrückte Naht geschiedenen Umgăngen; der letzte ist zusammengedrückt, an der Peripherie gerundet und steigt vorne nicht herab. Die abgerundet dreieckige Mündung ist breiter als hoch, der weisse oder gelbliche Mundsaum leicht verdickt und kurz ausgebreitet; der Oberrand an der Insertion mit einer deutlichen Einkerbung, in der Mitte deutlich herabgebogen, aber kaum stärker verdickt; der Basalrand mit "einem abgerundeten, deutlich vorspringenden Zahne. Der dünne, mit dem Gehäuse gleichfarbige Basalkallus ist ziemlich deutlich begrenzt.

Deckel unbekannt.

$$
\mathrm{D}=3-4 \cdot 5, \mathrm{~d}=2 \cdot 5-3.5, \mathrm{H}=2-2.5 \mathrm{~mm} \text {. }
$$

Fundort: die Insel Cuba, meine Exemplare von Trinidad auf Cuba; Pfeiffer führt ausserdem El fundador und Sagua Grande an. Lucidella ignicoma Guppy (welche ich nicht kenne) steht der vorstehenden Form gewiss sehr nahe; mit der Fundortsangabe Tinidad habe ich nur Lucidella rugosa Pfr. erhalten, es war aber wohl Trinidad auf Cuba und nicht die gleichnamige Insel an der Mündung des Orinoco gemeint. Nach meiner Beobachtung beherbergen die einzelnen Antilleninseln wohl nahestehende doch zumeist artlich gut unterschiedene Formen des Genus Lucidella.

\section{Lucidella wolffi Boettger.}

Taf. 68, Fig. 22-23.

Heli ein a wolffi Boettger, Jahrb. Mal. Ges. XIV, p. 102, T. 4, F. 9, 1887.

Gehăuse sehr klein, konisch kugelig mit flacher, in der Nabelgegend leicht eingedrückter 
Basis, ziemlich festschalig, weisslich seidenglänzend. Die Skulptur besteht aus dichten, regelmässigen, S-förmig gebogenen Radialfalten ohne Spiralleisten. Das breitkegelförmige Gewinde ist etwas abgerundet und besteht aus 5 langsam zunehmenden, wenig gewölbten, durch eine eingedrückte Naht geschiedenen Umgängen; der letzte ist gerundet und steigt vorne wenig oder gar nicht herab. Die abgerundet dreieckige Mündung ist sehr schief; der leicht verdickte Mundsaum kurz ausgebreitet; der Oberrand an der Insertion eingekerbt, stark vorgezogen, in der Mitte sehr eingedrückt; der Basalrand mit einem abgerundeten stark nach vorne und oben vorspringendem Zahne. Der weisse, dünne, feingekörnelte Basalkallus ist ziemlich deutlich begrenzt.

Deckel unbekannt.

$$
\mathrm{D}=4, \mathrm{~d}=3 \cdot 5, \mathrm{H}=2.5 \mathrm{~mm}
$$

Fundort: Miragoôane auf Haiti; ich beurteile diese Art nach einem Originalexemplare des Autors.

\section{Lucidella vinos a Shuttleworth.}

Taf. 69, Fig. 10-11.

Helicina vinosa Shattleworth, Diagn, n. Moll. v. 7, p. 152, 1856.

$n \quad n \quad$ Pfeifter, Mon. Pnenm. II, p. 180, 1858.

Gehäuse breitkegelförmig mit abgeflachter, in der Nabelgegend eingedrückter Basis ziemlich festschalig, durchscheinend, glänzend, gelblich hornfarben bis rotbraun. Die Skulptur besteht aus regelmässigen, dichten, S-förmig gebogenen Radialfalten. Das regelmässig flachkegelförmige Gewinde besteht aus $4^{1} / 2$ kaum gewölbten, langsam zunehmenden Umgăngen, welche durch eine eingedrückte Naht geschieden werden; der letzte ist zusammengedrückt, undeutlich kantig und steigt vorne sehr wenig oder gar nicht herab. Die abgerundet dreieckige Mündung ist schief, der gelbliche Mundsaum kurz ausgebreitet und umgeschlagen; der Oberrand an der Insertion eingekerbt, der Basalrand am inneren Drittel konvex vorgezogen. Der dünne, feingekörnelte Basalkallus undeutlich begrenzt.

$$
\mathrm{D}=3 \cdot 8, \mathrm{~d}=3 \cdot 3, \mathrm{H}=2 \cdot 5 \mathrm{~mm} \text {. }
$$

Deckel typisch.

Fundort: San Juan auf Portorico.

\section{Lucidella denseplicatan.}

Taf. 69, Fig. 14-15.

Gehăuse abgerundet breitkegelförmig mit abgeflachter, in der Nabelgegend nicht eindrückter Basis, ziemlich festschalig, glänzend, gelblich hornfarben. Die Skulptur besteht aus 
regelmăssigen, sehr dichten und feinen, S-förmig gebogenen Radialfalten. Das abgerundet kegelförmige Gewinde besteht aus $4 \frac{1}{2}$ leicht gewölbten, langsam zunehmenden Umgängen, welche durch eine deutlich vertiefte, aber njcht eingedrückte Naht geschieden werden; der letzte Umgang ist gerundet und steigt vorne sehr wenig oder gar nicht herab. Die abgerundet dreieckige Mündung ist schief, der gelbliche, leicht verdickte Mundsaum kurz ausgebreitet; der Oberrand an der Insertion eingekerbt, der Basalrand am inneren Drittel mit einem abgerundeten schwach vorspringenden Zahne versehen. Der weisse, dünne gekörnelte Basalkallus ist deutlich begrenzt.

Deckel unbekannt.

$$
\mathrm{D}=4, \mathrm{~d}=3 \cdot 5, \mathrm{H}=2.5 \mathrm{~mm} .
$$

Fundort: die Insel Santa Lucia der kleinen Antillen.

Die vorstehende neue Art unterscheidet sich von den nahe verwandten Arten (Lucidella vinosa Shuttleworth und L. rugosa Pfr.) durch die auffallend feinen und schwăcheren Radialfalten, das höhere abgerundet kegelförmige Gewinde und den fehlenden Eindruck in der Nabelgegend; von L. rugosa Pfr. ausserdem durch den nicht herabgebogenen Oberrand der Mündung und das höhere Gewinde, von L. vinosa Shuttleworth durch den deutlichen Basalzahn, das konvexe Gewinde, den gerundeten und nicht zusammengedrückten letzten Umgang. Möglicherweise entspricht diese Form der mir unbekannten Lucidella ignicoma Guppy von der Insel Trinidad.

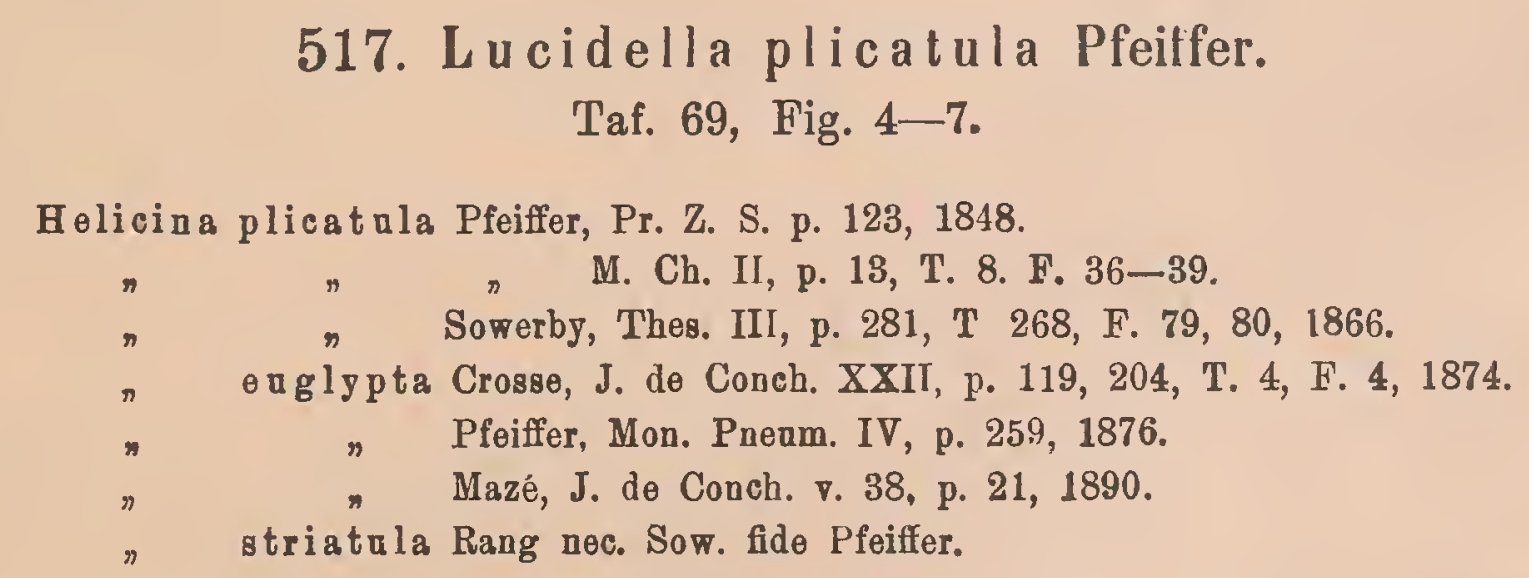

Gehäuse dicklinsenförmig ohne Eindruck in der Nabelgegend, festschalig, glänzend, gelblich hornfarben bis rötlich. Die Skulptur besteht aus ziemlich dichten S-förmig gebogenen, kräftigen Radialfalten, welche auf der Unterseite schwächer werden. Das regelmässig flachkegelförmige Gewinde besteht aus $4 \frac{1}{2}$ flachen, ziemlich langsam zunehmenden Umgăngen, welche durch eine seichte Naht geschieden werden; der letzte ist zusammengedrückt, mehr minder deutlich kantig und steigt vorne nicht herab. Die abgerundet dreieckige Mündung ist wenig schief, der gelbliche leicht verdickte Mundsaum kurz ausgebreitet; der Oberrand an der Insertion nicht eingekerbt, der Basalrand am inneren Drittel jedoch gezahnt. Der durchsichtige, glänzende, feingekörnelte Basalkallus ist ziemlich deutlich begrenzt.

$$
\mathrm{D}=5, \mathrm{~d}=4.5, \mathrm{H}=3.5 \mathrm{~mm} \text {. }
$$


Deckel abgerundet dreieckig mit ziemlich fester, weisser Kalkplatte, in den übrigen Verhältnissen typisch.

Fundort: die Insel Martinique.

\section{Lucidella Kobelti $n$. Taf. 69, Fig. 12-13.}

Gehäuse breitkegelförmig mit flacher, in der Nabelgegend leicht eingedrückter Básis und vorspringender Spitze, festschalig, leicht glänzend, schmutzig weiss oder gelbbraun. Die Skulptur besteht aus ziemlich dichten, kräftigen, S-förmig gebogenen Radialfalten, welche nach oben zu rasch dichter und schwächer werden, auf den ersten Umgängen erlöschen. Das breitkegelförmige, leicht konvexe Gewinde besteht aus $5^{1} / 2$ langsam zunehmenden, flachen Umgängen, welche durch eine eingedrückte Naht geschieden werden; der letzte ist zusammengedrückt, sehr undeutlich kantig und steigt vorne nicht herab. Die abgerundet dreieckige Mündung ist schief, der dicke weisse Mundsaum winkelig und breit umgeschlagen; der Oberrand an der Insertion deutlich eingekerbt. Zwischen der kurzen dünnen Spindel und dem Basalrand der Mündung eine seichte, aber deutliche Einkerbung. Der weisse, gekörnelte Basalkallus ist deutlich begrenzt.

Deckel unbekannt.

$$
\mathrm{D}=8, \mathrm{~d}=7, \mathrm{H}=5 \mathrm{~mm} .
$$

Fundort: diese auffallende Form, welche neben sicheren Merkmalen des Genus Lucidella auch eine Einkerbung zwischen Spindel und Basalrand der Mündung aufweist, also zu Alcadia hinüberleitet, erhielt ich seinerzeit von Schlütter in Halle mit der Fundortsangabe Jamaica.

\section{Lucidella holoserica n. \\ Taf. 69, Fig. 16-19.}

Gehäuse linsenförmig mit seichtem Eindruck in der Nabelgegend, ziemlich dünnschalig, durchscheinend, gelblich hornfarben bis rotbraun, mattseidenglänzend. Die Skulptur besteht aus sehr feinen und dichten Radialstreifen, welche auf den oberen Umgängen durch sehr feine Spirallinien gegittert erscheinen, auf der Unterseite nahezu erlöschen. Das regelmässig breit kegelförmige Gewinde besteht aus $4 \frac{1}{2}$ nahezu flachen langsam zunehmenden Umgängen, welche durch eine seichte Naht geschieden werden; der letzte ist zusammengedrückt, an der Peripherie stumpf bis scharfkantig und steigt vorne kaum herab. Die dreieckige Mündung ist schief, der kaum verdickte gelbliche Mundsaum fast gerade; der Oberand an der Insertion undeutlich eingekerbt, der Basalrand am inneren Drittel etwas konvex vorgezogen, häufig undeutlich gezahnt. Der dünne, gekörnelte Basalkallus ist durchscheinend und ziemlich undeutlich begrenzt.

$$
\mathrm{D}=5, \mathrm{~d}=4.5, \mathrm{H}=3 \mathrm{~mm} \text {. }
$$

Deckel dreieckig mit anflugartig zarter Kalkplatte, rotbraun; in den übrigen Verhältnissen typisch. 
Fundort: die Insel Barbados.

Ich habe diese Art früher mit Helicina barbadensis Pfeiffer verwechselt; doch beschreibt Pfeiffer seine Art als unregelmässig gerunzelt, mit $4 \frac{1}{2}$ rasch zunehmenden Umgängen und einem scharfen Kiel; die vorstehende Art ist sehr regelmåssig, seidenartig gestreift, die Umgănge nehmen langsam zu, der letzte ist mehr minder deutlich kantig.

\section{Genus Schasicheila Shuttleworth.}

Sehasicheila Shattleworth, Bern. Mitt. p. 301, 1852 und Diagn. n. Moll. III, p. 41.

Gehäuse kegelförmig bis kreiselförmig mit gewölbter, in der Nabelgegend eingedrückter Basis und einer eigentümlichen Spiralskulptur, welche aus hinfalligen Falten und Borsten der Epidermis besteht; abgeriebene Exemplare zeigen ausserdem deutliche, etwas ungleichmässige Zuwachsstreifen. Die Embryonalschale ist dicht und fein rippenstreifig. Die halbkreisförmige, wenig schiefe Mündung besitzt einen zusammenhängenden Mundsaum, welcher auf der Mün* dungswand von dem Basalkallus leistenförmig abgesełzt erscheint; der Oberrand ist ferner an der Insertion tief eingeschnitten, unter dem Einschnitt flügelartig verbreitet; der schmale, gekörnelte Basalkallus sichelförmig begrenzt.

Deckel halbkreisförmig mit schwach konvexem Spiralrand. Die feste, gekörnelte und leicht konkave Kalkplatte ist von der Hornplatte am Spindelrande durch eine Furche, am Aussenrande durch eine schmale Leiste abgesetzt; -ausserdem erscheint die Kalkplatte am oberen Winkel des Spindelrandes zu einem spitzen Schnabel, am unteren Winkel zu einem löffelförmigen nach innen rinnenartig ausgehöhlten Fortsatz verlängert. Der obere Fortsatz ist bei geschlossenem Deckel in den Einschnitt an der Insertion des Oberrandes der Mündung eingefügt, der untere nach innen hohle Fortsatz bildet dann anscheinend einen Luftkanal (Atemröhre). Die Hörnplatte mit nahezu zentralem Nukleus und einer niedrigen, oben deutlichen Sigmakante; neben dem unteren Aste der Sigmakante eine seichte, vom Nukleus zum Spindelwinkel verlaufende Furche.

Verbreitungsgebiet: Sichere Formen dieses Genus sind bis jetzt nur aus Mexico und Zentralamerika bekannt geworden; Schasicheila bahamensis Pfeiffer ist wie ich bei dieser Art ausgeführt habe eine sichere Alcadia.

Die Formen des Genus Schasicheila Shuttleworth zeigen gegenüber den anderen Gruppen der Hiliciniden auffallende und konstante Verhältnisse der Mündung und des Deckels; doch stehen diese Merkmale in der Familie nicht isoliert da, stellen vielmehr nur extreme Entwicklungsgrade ähnlicher Erscheinungen bei anderen Geschlechtern der Heliciniden dar. Der Einschnitt an der Insertion des Oberrandes der Mündung, der Findruck in der Nabelgegend findet sich auch bei dem Genus Lucidella Swainson, ebenso weisen zahlreiche Arten des Genus Alcadia Gray mehr minder deutliche Fortsätze am oberen und Spindelwinkel des Deckels 
auf. Im System stehen die Genera Lucidella Swainson und Schaisicheila Shuttleworth am besten zwischen Eutrochatella Fischer und Alcadia Gray.

\section{Schasicheila pannucea Morelet. Taf. 70, Fig. 1-4.}

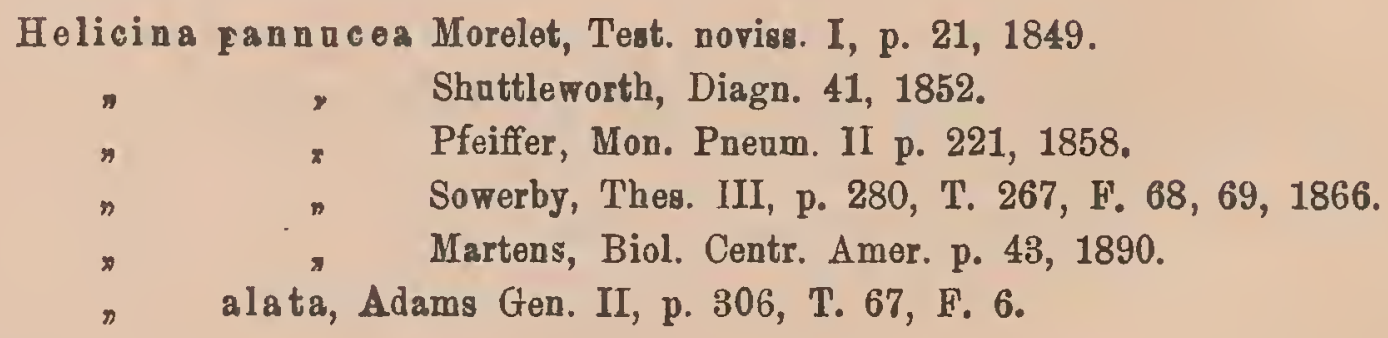

Gehäuse gedrückt kreiselförmig, ziemlich dünnschalig hornfarben, matt; frische Exem plare mit dichten Spiralreihen brauner Epidermisfalten, welche ausserdem von einer Schmutzkruste überzogen sind; abgerieben mit deutlichen etwas ungleichmässigen Zuwachsstreifen. Das flachkegelförmige, schwach konvexe Gewinde besteht aus $3^{3} / 4-4$ ziemlich rasch zunehmenden, nahezu flachen Umgängen, welche durch eine seichte Naht geschieden werden; der letzte ist unten mehr gewölbt, im Beginne kantig, gegen die Mündung zu gerundet und steigt vorne langsam und wenig herab. Die Verhältnisse der Mündung und des Mundsaumes typisch.

$$
\mathrm{D}=11, \mathrm{~d}=9, \mathrm{H}=9 \mathrm{~mm} \text {. }
$$

Deckel mit deutlich gekörnelter Kalkplatte und langen Fortsätzen am oberen und Spindelwinkel; in den übrigen Verhältnissen typisch.

Fundorte: San Luis, Senachu, Vera Paz in Guatemala.

\section{Schasicheila pilsbryi n. \\ Taf. 70, Fig. 9-11.}

Gehäuse breitkegelförmig mit gewölbter Basis, ziemlich dünnschalig, gelblich hornfarben mit rotbrauner oder rotorange farbener Spitze; im frischen Zustande matt mit sehr dichten Spiralreihen, kurzer dunkelbrauner Epidermisfalten, abgerieben glänzend mit deutlichen, ungleichmässigen Zuwachsstreifen. Das regelmässig kegelförmige Gewinde besteht aus $4-4^{1}{ }_{2}$ gewölbten, ziemlich rasch zunehmenden Umgängen, welche durch eine seichte Naht geschieden werden; der letzte ist beiderseits gleichmässig gewölbt, im Beginne stumpf gekielt, gegen die Mündung zu gerundet und steigt vorne langsam und sehr wenig herab. Die Verhältnisse der Mündung und des Mundsaumes typisch.

$$
\mathrm{D}=12, \mathrm{~d}=10, \mathrm{H}=10 \mathrm{~mm} \text {. }
$$


Deckel mit schwach gekörnelter Kalkplatte und kurzen Forsätzen am oberen und Spindelwinkel; in den übrigen Verbältnissen typisch.

Fundort: ich erhielt diese neue Art mit den Fundortsangaben Mexico und Guatemala (St. Geronimo); dieselbe unterscheidet sich von der nahestehenden Sch. pannucea Mart. durch das höhere, regelmässig kegelförmige Gewinde mit $\left.4^{1}\right|_{2}$ gewölbten, langsamer zunehmenden Umgången, den schärferen Kiel und den weiteren Einschpitt an der Insertion des Oberrandes der Mündung. Der Deckel mit kurzen Fortsätzen gleicht auffallend demjenigen von Sch. alata Menke.

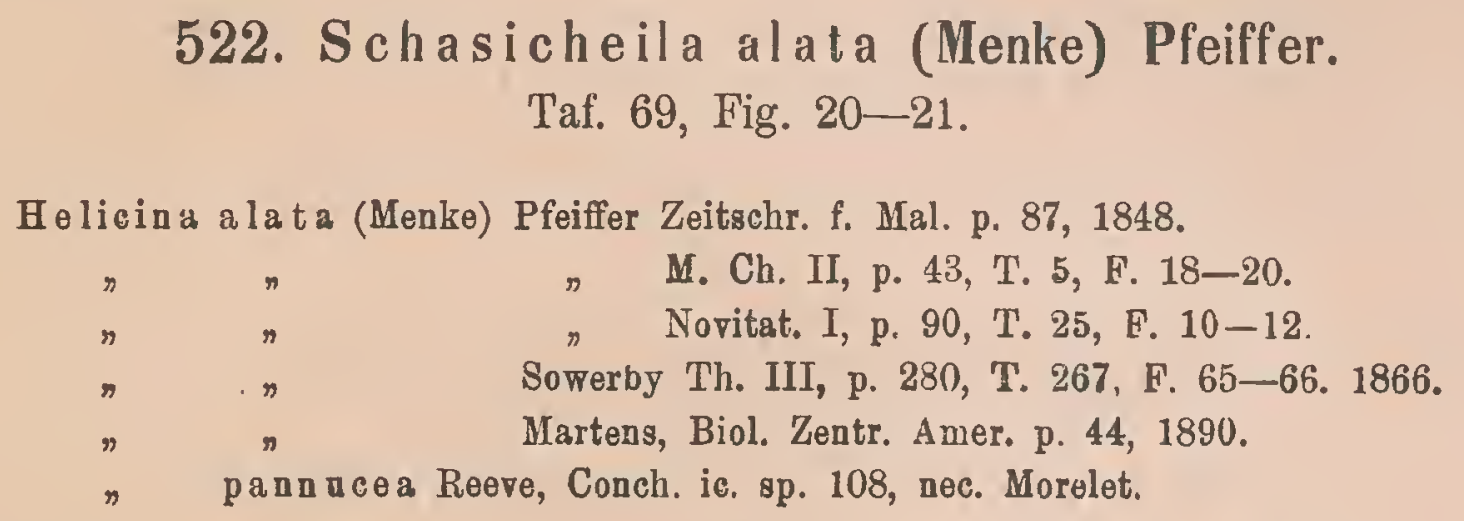

Die typische Art des Genus unterscheidet sich von den oben angeführten Formen durch das höhere, regelmässig kegelförmige Gewinde mit $\left.4^{1}\right|_{2}$ langsamer zunehmenden gut gewölbten Umgången und vollkommen gerundetem letzten Umgang, welcher vorne langsam und wenig herabsteigt. Die Fărbung frischer Exemplare mit Epidermisfalten und Schmutzkruste ist dunkelbraun, abgeriebene Exemplare sind schmutzigweiss oder gelblich hornfarben mit gelbbraunem Gewinde, leicht glänzend mit feinen etwas ungleichmässigen Zuwachsstreifen. In den übrigen Verhăltnissen die Merkmale des Genus. Der Deckel mit gekörnelter Kalkplatte und kurzen Fortsătzen.

Fundort: Mexico (Cordova).

$$
D=10 \cdot 5, d=8, H=9 \mathrm{~mm} .
$$

\title{
523. Schasicheila fragilis Pilsbry.
}

Taf. 70, Fig. 5-6.

\author{
Schasicheila fragilis Pilsbry in: Pr. Acad. Philadelphia, p. 391, 1899. \\ ? " miniascula Pfeiffer in: Pr. Z. S. London, p. 29, 1859. \\ ? minima Pfeiffer in: Strebel Beitr. Mex. Conch, p. 4, T. 3, F. 6.
}

Gehäuse kegelförmig mit annähernd halbkugeliger Basis, ziemlich dünnschalig, gelbbraun mit orangefarbener Spitze oder hellrotbraun; matt mit dichten Spiralreihen hinfalliger Epidermisfalten. Das regelmässig kegelförmige Gewinde besteht aus 4 gewölbten, ziemlich I. 18. II. 
langsam zunehmenden Umgängen; der letzte ist vollkommen gerundet und steigt vorne langsam und wenig herab. Die sehr wenig schiefe Mündung ist breit halbeiförmig mit spitzerem oberen Winkel; die übrigen Verhältnisse des Mundsaumes und der Mündung sind typisch.

Deckel unbekannt.

$$
\mathrm{D}=6, \mathrm{~d}=5, \mathrm{H}=5.5 \mathrm{~mm} \text {. }
$$

Fundort: Mexico, Nuovo Leon.

Diese Art sieht einer kleinen Sch. alata Pfeiffer sehr ähnlich; das Gehăuse ist regelmässig viel kleiner und dünnschaliger, das verhältnismässig etwas höhere Gewinde besteht aus 4 deutlicher gewölbten, langsamer zunehmenden Ungängen, der letzte ist weniger aufgeblasen. Die Mündung ist deutlich halbeiförmig mit spitzerem oberen Winkel, wăhrend diese bei Sch. alata Pfr. ausgesprochen halbkreisförmig ist.

Sch. miniuscula Pfeiffer ist vermutlich mit vorstehender Art identisch, doch unvollkommen und ohne Fundortsangabe beschrieben.

\section{Nachtrag zum Genus Alcadia Gray.}

\section{Alcadia (Eualcadia) iheringi n. \\ Taf. 70. Fig. 7-8.}

Gehăuse breitkegelförmig mit gewölbter Basis oder annähernd kugelig, weiss oder gelblich hornfarben mit dichten, sehr feinen erhobenen Spirallinien (ein verwittertes Exemplar besitzt auch am letzten Übergange verbăltnismässig kräftige Zuwachsstreifen, doch kann dies eben nur Verwitterungsprodukt sein). Das breitkegelförmige, leicht konvexe Gewinde besteht aus 4 langsam zunehmenden, etwas gewölbten Umgången, welche durch eine leicht eingedrückte Naht geschieden werden; der letzte ist undeutlich kantig bis gerundet und steigt vorne sehr wenig oder gar nicht herab.

Die abgerundet dreieckige Mündung ist wenig schief, der schwach verdickte Mundsaum kurz ausgebreitet und umgeschlagen; der Basalrand konvex vorgezogen. Die sehr kurze, dünne Spindel ist nach vorn und aussen gebogen; der dünne Basalkallus ziemlich deutlich begrenzt.

Deckel unbekannt.

$$
\mathrm{D}=3 \cdot 8, \mathrm{~d}=3 \cdot 3, \mathrm{H}=3 \cdot 1 \mathrm{~mm} \text {. }
$$

Fundort: Os Peras in Sao Paolo und angeblich Rio Janeiro in Brasilien.

Dies ist die zweite Art des Genus, welche aus Brasilien bekannt geworden ist; von Alcadia sericea paraensis Pfr, unterscheidet sich dieselhe durch geringere Dimensionen, die deutlichen Spirallinien und den Mundsaum, welcher keine Einkerbung am Übergange der Spindel in den Basalrand der Mündung, aber einen stark konvex vorgezogenen Basalrand besitzt. Alcadia sericea par aensis Pfeiffer kommt auch in Sao Leopoldo, Espiritu Santo in typischen Exemplaren vor. 


\title{
525. Alcadia (Analcadia) dominicensis Pfeiffer.
}

Taf. 68, Fig. 1-3.

\author{
Helicini dominiconsis Pfeiffer, Pr. Z. S. p. 149, 1850.

$\begin{array}{lll}\eta & \text { Mon. Pnenm. I. p. 352, } 1852 . \\ \eta & n & \text { Crosse, J. do Conch. v. 39, p. 185, } 1891\end{array}$

Gehăuse kugelig kegelförmig, ziemlich festschalig, gelbraun mit gelbem Gewinde und lichteren Streifen entlang der Naht der unteren Umgänge. Die Skulptur besteht neben schwachen Zuwachsstreifen aus dichten und feinen Spirallinien. Das breitkegelförmige Gewinde besteht aus $\left.5^{1}\right|_{2}-6$ leicht gewölbten, langsam zunehmenden Umgängen, welche durch eine deutlich vertiefte Naht geschieden werden; der letzte ist gleichmässig gerundet und steigt vorne sehr wenig herab. Die halbeiförmige Mündung ist wenig schief, leicht ausgeschnitten, der Mundsaum (mein Exemplar dürfte nicht vollkommen entwickelt sein) scharf, fast gerade. Die kurze Spindel bildet am Übergange in den Basalrand der Mündung eine vorspringende Ecke; der dünne Basalkallus ist undeutlich begrenzt.

$$
\mathrm{D}=6, \mathrm{~d}=5 \cdot 6, \mathrm{H}=5 \mathrm{~mm} \text {. }
$$

Deckel halbeiförmig mit spitzem oberen Winkel und leicht konkavem Spindelrand. Die Sigmakante deutlich erhoben mit einer Furche neben dem unteren Aste; die Kalkplatte ziemlich dick; in den übrigen Verhältnissen typisch.

Fundort: die Insel Haiti.

Die Verhältnisse der Mündung sind mir bei dieser Art nicht genau bekannt, da sowoh mir als Pfeiffer nur unausgewachsene Gehăuse vorgelegen haben; nach dem Deckel gehört die Art aber zum Genus Alcadia Gray.

\section{Alcadia (Leialcadia) schrammi Crosse. Taf. 70, Fig. 15-17.}

Helicina schrammi Crosse J. de Conch. v. XX, p. 212, XXI, p. 251, T. 11, F, 3, 1862.

$\begin{array}{lll}n & \text { Pfeiffer, Mon. Pneum IV, p. 247, } 1876 . \\ & n & \text { Crosse, J. de Conch. } \nabla .33, \text { p. 37, } 1883 .\end{array}$

Gehăuse kegelförmig mit gewölbter Basis, dünnschalig, glänzend, gelblich hornfarben mit rötlicher bis karminroter Spitze und sehr feinen bis undeutlichen Zuwachsstreifen. Das erhobene, regelmässig kegelförmige Gewinde besteht aus $\left.5^{1}\right|_{2}-6$ schwach gewölbten, langsam zunehmenden Umgängen, welche durch eine seicht eingedrückte Naht geschieden werden; der letzte ist unten deutlicher gewölbt, im Beginne kantig, gegen die Mündung nahezu gerundet (die Kante mitunter durch eine Epidermisfalte bezeichnet) und steigt.vorne nicht herab. Die abgerundet dreieckige Mündung ist wenig schief, der Mundsaum dünn, scharf und zerbrechlich. 
Die kurze Spindel ist nach vorne gebogen und bildet am Übergang in den Basalrand der Mündung eine deintliche, ziemlich scharfe Ecke; der sehr dünne Basalkallus ist undeutlich begrenzt.

$$
\mathrm{D}=5 \cdot 3, \mathrm{~d}=4.5, \mathrm{H}=4.5 \mathrm{~mm} .
$$

Deckel abgerundet dreieckig mit konkavem Spindelrand und spitzem oberen Winkel; sehr dünn und durchsichtig mit sehr zarter, anflugartiger Kalkplatte. Der Nukleus dem Spindelrande genăhert, die Sigmakante níedrig mit einer seichten Furche neben dem unteren Aste. Fundort: die Insel Guadeloupe.

Auch diese Art scheint mit Rücksicht auf den dünnen, zerbrechlichen Mundsaum nur in unausgewachsenen Exemplaren bekannt zu sein.

\section{Alcadia (Analcadia) moussoniana Pfeiffer. Taf. 70, Fig. 12-14. \\ Helicina moussoniana Pfeiffer, in: Mal. Bl. XIII, p. 89-90, 1866.}

Gehäuse dicklinsenförmig, festschalig, wenig glänzend, kalkartig weiss mit undeutlichen, durchscheinenden Flecken auf der Oberseite. Die Skulptur besteht neben feinen, undeutlichen Zuwachsstreifen aus ziemlich dichten, feinen Spiralreifen, welche auf der Unterseite schwächer bis undeutlich werden. Das flachkegelförmige, leicht konvexe Gewinde besteht aus $4^{11} / 2$ nahezu flachen, langsam zunehmenden Umgăngen, welche durch eine seichte Naht geschieden werden; der letzte ist kantig bis stumpf gekielt und steigt vorne langsam, aber deutlich herab. Die abgerundet dreieckige Mündung ist schief, der innen leicht verdickte Mundsaum gerade. Die kurze, nach vorne gebogene Spindel bildet am Übergang in den Basalrand der Mündung eine zahnartig vorspringende Ėcke. Der dünne, weisse Basalkallus ist undeutlich begrenzt.

Deckel unbekannt.

$$
D=4 \cdot 6, d=4, H=3 \mathrm{~mm} \text {. }
$$

Fundort: die Turks Inseln.

\section{Nachtrag zum Genus Geophorus Fischer.}

\section{Ge ophorus oxytropis opacus Boettger.}

Taf. 70 , Fig. $18-20$.

Gehăuse kleiner mit niedrigerem Gewinde, welches aus $\left.4\right|_{2}$ auffallend rascher zunehmenden flachen Umgängen besteht; der letzte Umgang ist mehr zusammengedrückt; die Ecke am Übergange der Spindel in den Basalrand der Mündung schärfer und deutlicher vorspringend. 
Deckel unbekanut.

$$
D=9, d=7 \cdot 5, H=5 \mathrm{~mm} \text {. }
$$

Fundort: die Insel Tjerah der Tenimber Inseln.

\title{
Nachtrag zum Genus Aphanoconia A. J. Wagner.
}

\author{
529. Aphanoconia subsuturalis Boettger. \\ Taf. 70, Fig. 21-24.
}

Gehäuse linsenförmig, festschalig, glănzend mit sehr feinen, undeutlichen Zuwachsstreifen; gelblichweis bis gelbbraun mit dunkler gefärbter rotbrauner oder kastanienbrauner Unterseite, auf der Oberseite sind ausserdem auf milchig getrübtem Grunde entweder rotbraune bis dunkelbraune Fleckenbinden oder abwechselnd milchig getrübte und rotbraune Zickzackstriemen vorhanden. Das abgerundet flachkegelförmige Gewinde besteht aus 4 flachen, ziemlich langsam zunehmenden Umgängen, welche durch eine flache oder kaum eingedrückte Naht geschieden werden; der letzte ist ziemlich scharf gekielt und steigt vorne kaum unter den Kiel herab. Die dreieckige Mündung ist schief, der gerade Mundsaum innen mit einer weissen lippenartigen Verdickung. Die kurze Spindel geht in gleichmässigem Bogen in den Basalrand über; der glasglänzende Basalkallus ist ziemlich dick und deutlich begrenzt.

$$
\mathrm{D}=4, \mathrm{~d}=3.5, \mathrm{H}=2.5 \mathrm{~mm} \text {. }
$$

Deckel abgerundet dreieckig mit geradem Spindelrand, gelbbraun mit verhältnismässig dicker Kalkplatte; in den übrigen Verhăltnissen typisch.

Fundort: die Marschall Inseln.

Diese Art unterscheidet sich von der nächst verwandten Aphanoconia oceanica H. Pease durch das konvexe Gewinde, die seichte, nicht eingedrückte Naht, den dickeren glasglănzenden Basalkallus, sowie die fehlende Ecke am Übergange der Spindel in den Basalrand der Mündung. 


\section{Systematisches Verzeichnis}

\section{der beschriebenen und abgebildeten Formen.}

\section{Familia Helicinidae. Subfamilia Apiopomatinae.}

Genus Waldemaria A. J. Wagner.

- japonica A. Adams. Јapan.

- japonica reiniana Kobelt. Japan.

- japonica expolita Pilsbry. Japan.

- japonica azensis Pilsbry. Japan.

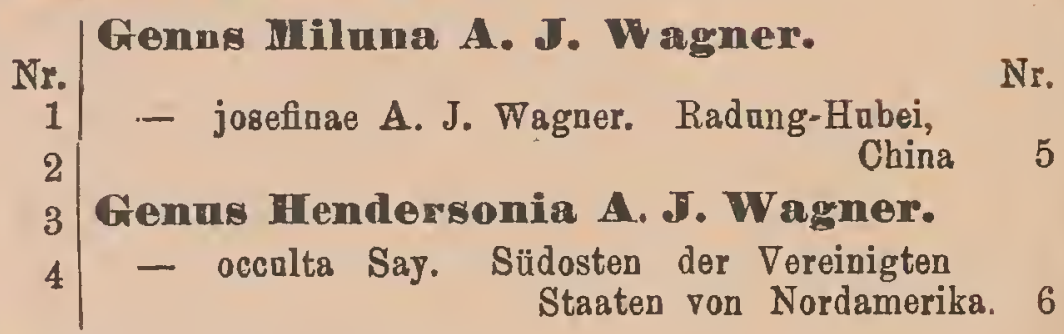

\section{Subfamilia Pseudotrochatellimae.}

Gemus Pseudotrochatella Nevil.

- undulata Morelet. Mauritius (8ubfossil).

Fenus Geotrochatella P. Fischer.

- monhoti Pfeiffer. Siam, Tonkin.

- jourdyi Dantzenberg. Tonkin.

- jourdyi excelsa A. J. Wagner. Tonkin.

- martensi Gredler. Süd-China
Geotrochatella insignis Dautzenberg. Tonkin.

7 - nogieri Dantzenberg et d'Hamonville. Tonkin. 12

Genus Calybium I. Norelet.

8 - masiei L. Morelet. Laos.

9 Genus Protrochatella Fischer.

237 - constellata Morelet. Isla de Pinos.

10 - stellata Velasquez. Isla de Pinos.

6

\section{Sublamilla Felfeinimae.}

Gemus Geophorus Fischer.

Formenkreis Agglutinans.

- agglutinans Sowerby. lnseln Panay, Guimaras, Tablas. 206

- agglutinans solidulus Sowerby. Insel Labsn. 207

- agglutinans cyrtopoma Möllendorff, Morong

auf Lazon. 208

- agglutinans versicolor Mülllendorf. Sibuyan, Tablas, Polillo, Romblon. 209

- agglutinans mindorensis A. J. Wagner.

- agglntinans eos A. J. Wagner. Gunung Sekarat Osthnrneo.
Geophorus lazarus Sowerby. Nord- u. Mittellazon. 212

- lazarns transitans A. J. Wagner. Libmanan anf Lazon. 213

- Lazarus nanus Möllendorff. Sibul Mittellazon. 214

- lazarus monticolas Möllendorff, Morong

Mittelluzon. 215

- orytropis Gray. Insel Celebes. 216

- oxytropis orientalis A.J. Wagner. Insel Timor. 217

- orytropis jagori Martens. Insel Java. 218

- oxptropis opacus Boettger, Tjerah Tenimber Inseln. $\begin{array}{lll} & - \text { exsertus Martens, Insel Saleier. } & 219 \\ 211 & - \text { exsertus major 8mith. Insel Saleier } & 220\end{array}$ $\begin{array}{lll}211 & - \text { exsertus Martens, Insel Saleier. } & 219 \\ - \text { exsertus major 8mith. Insel Saleier } & 220\end{array}$ 
Nr. Entrochatella littoricola Pfeiffer. Caba. 163

- rollei Sykes. Kangean Inseln.

- acutus Pfeiffer. Inseln Cebr, Samar, Leyte, Siargao, Mindazao.' 223

- acutus peracutus A. J. Wagner. Insel Tablas, 224

- acutus intermedins Möllendorff. Insel Ceba. 225

- nitidulas Möllendorff. Montalban auf Lazon, 226

- psendomphalas Möllendorff. Sibal, Mittel\begin{tabular}{l} 
Iazon. 227 \\
\hline
\end{tabular}

Formenkreis Bothropoma.

- bothropoma Möllendorff, Caramuan Ost-

- acutissimus Sowerby. Inseln Bohol, Leyte, Siquijor. 229

- acutissimas peracutissimus A. J. Wagner. Inseln Ceba, Negros. 230

- acutissimus trochulus Möllendorff. Insel

Romblon. 231

- trochiformis Sowerby. Insela Negros, Karamuan auf Luzon. 232

- trochiformis subtrochiformis Möllendorff.

Insel Marinduque. 233

- trochiformis conoidalis Mölleadorff. Insel

- trochiformis gibbosulus Möllendorff. Tayabas auf Mittelluzon. 235

Genus Eutrochatella Fischer. Subgenus Eutrochatella s. str.

Formenkreis Granifera.

- pulchella Gray. Jamaica.

- tankervillii Gray. Jamaica.

- chittiana Pfeiffer. Jamaica.

- josefinae C. A. Adams. Jamaica.

Formenkreis Excavata.

- globosa Gray. Haiti.

- viriginea Lea. Haiti. virginea crassicostata Sowerby. Haiti, 155

- opima Shuttleworth. El Rincon San Domingo. 156

- chrysostoma Pfeiffer. Caba.

- costata Gray. Jamaica.

- eugeniana Weinland. Haiti.

$-$

$-$ engeniana weinlandi A. J. Wagner, Haiti, 160 elegantula Ffeiffer. San Domingo. $\quad 161$ Formentreis Callida.

- callida Weialand. Crooked Insel der Bahamas. 162
- bryanti Pfeiffer. Jnagua der Bahamas. 164

- candida Pfeiffer. Turks Inseln. 165

\section{Subgenus Ustronia A. J. Wagner.}

- acuminata Poey, Rangel auf Cuba. $\quad 166$

- acuminata columellaris Gundlach. Rangel auf Cuba, 167

-- acuminata blandiana Gundlach. San Diego de los Banos auf Caba. 168

- sloanei d'Orbigny. . Cuba. 169

- remota Poey. Guane, Vignales auf Cuba. 170

- wrighti Pfeiffer. Cuba. 171

-. wrighti xanthacme A.J. Wagner. Guajaibon anf Cuba. 172

- scopulorum Morelet. Fichteninsel bei Caba. 173

- pyramidalis Sowerby. Rangel auf Caba. 174

- pyramidalis percarinata A. J. Wanger. Rangel auf Cuba, 175

- straminea Morelet, Rancho Lucas auf Cuba. 176

- straminea rabromarginata Poej, Guajaibon auf Caba. 177

- straminea festa Sowerby, Guajaibon anf Caba. 178

- straminea nodae Arango. Sierra de Guira auf Cuba. 179

- straminea politula Poey. Rangel auf Cuba. 180

- cisnerosi Arango. Pinar del Rio auf Cnba. 181

- fuscula Pfeiffer. Guajaibou, Luis Lazo auf Cuba. 182

- alboviridis Pfeiffer, lsabel Maria auf Caba. 183

- methfesseli Pfeiffer. Sagua auf Cuba. 184

- rubella Pfeiffer. Cayos de San Helipe, Cayos de San Diego bei Cuba. 18.

- rubella citrino callosa A. J. Wagner. Vignales auf Cuba. 186

- jugulata Poey. Guane auf Cuba. 187

- chrysochasma Poey. Taco-Taco und Vignales anf Cuba. 188

- chrysochasma jucuada Pfeiffer. Guajaibon, Rangel, Vignales auf Cuba. 189

- chrysochasma heraandezi Wright. Vignales auf Cuba, 190

- mestrei Arango. Pinar del Rio auf Cuba. 191 Subgenus Hapata Gray.

- regina Morelet. Cuba.

- regina laevigata Pfeiffer. Pan de Azucar, Portales de Guane auf Cuba. 193 
Eatrochatella (Hapata) regina subunguicnlata Poey. Vignales, Guane auf Cuba

Subgenus Artecallosa A. J.Wagner.

- petitiana d'Orbigny. Jagua, Banao, Trinidad anf Cuba. 195

- petitiana laticosta A. J. Wagner. Caba. 196

- rubicunda Pfeiffer. Trinidad anf Caba. 197

- petrosa Pfeiffer. Trinidad auf Cuba. 198

- rupestris Pfeiffer. Matanzas, Managna auf Caba. 199

- elongata d'Orbigny. Guajaibon auf Cuba.

- conica Pfeiffer. Matanzas anf Caba.

- continua Poey. Guisa auf Cuba.

- callosa Poey. Fichteninsel bei Caba.

- pfeifferiana Pfeiffer. Baracoa anf Cuba.

- microdina Morelet. Vera paz in Gnatemala. 205

\section{Genus Incidella Swainson.}

- andulata Pfeiffer. Jamaica.

- aureola Férusae. Jamaica.

- umbonata Suttleworth. Portorico.

- lirata Pfeiffer. Südmexico, Zentralamerika, Venezuela. 502

- lirata lamellosa Guppy. Insel Trinidad.

- lineata C. B. Adams. Jamaica.

- nana Pfeiffer. Jamaica.

- foxi Pilsbry. Port Antonio anf Jamaica.

- granum Pfeiffer. Cuba.

- adamsiana Pfeiffer. Jamaica.

- adamsiana coronula. Jamaica.

- depressa Gray. Jamaica.

- paivana Pfeiffer. Haiti.

- paivana decussata Boettger. Miragoano auf

- rugosa Pfeiffer. Cuba.

- wolffi Boettger. Miragoane anf Haiti.

- vinosa Shuttleworth. Portorico.

- denseplicata A. J. Wagner. Santa Lucia.

- plicatula Pfeiffer. Martinique.

- kobelti A. J. Wagner. Jamaica.

- holoserica A. J. Wagner. Insel Barbados. 519

\section{Genus Schasicheila Shuttleworth.}

- pannucea Morelet. Guatemala. Haiti. 512

- pilsbryi A. J. Wagner. Mexico,
Nr. Schasicheila alata Pfeiffer. Mexico. - fragilis Pilsbry. Mexico, Guatemala.

\section{Genus Alcadia Gray.}

\section{Subgr.nus Gualeadia A.J. Wagner.}

Formenkreis Palliata.

- palliata C. P. Adams. Jamaica.

- palliata brownei Gray. Jamaica

- hollandi C. B. Adams. Jamaica.

- major Gray. Jamaica.

- citrinolahris C. B. Adams. Jamaica.

- consanguinea C. B. Adams. Jamaica.

- microstoma C. B. Adams. Jamaica.

- solitaria C. B. Adams. Jamaica.

- gonostoma Poey. Trinidad auf Cuba.

Formenkreis Hispida.

- velutina Poey. Guane auf Cuba.

- dissimulans Poey. Guane auf Caba.

- hispida Pfeiffer. Cnba.

- fallar A. J. Wagner. Nen-Providence der

Bahama.

- minima d'Orbigny. Caba.

- proxima Gundlach. Bayamo anf Caba.

- foveâta Pfeiffer. St. Thomas, St. Jan, Vieque, Portorico.

- hahamensis Pfeiffer. Neu-Providence der Bahamas. 81

Formenkreis Intusplicata.

- intnsplicata Pfeiffer. Mt. Platon anf Haiti. 82

- intnsplicata smithiana Pfeiffer. Port-anPrince und Miragoane auf Haiti. 83

- succinea Pfeiffer. St. Domingo.

Formenkreis Sericea.

- sericea Drouet. Cajenne.

- sericea Kühni Pfeiffer. Surinam.

- sericea paraensis Pfoiffer. Para Jakaty and Sao Leopoldo in Brasilien. 87

- iheringi A. J. Wagner. Sao Paolo, Rio Janeiro Brasilien. 524

\section{Formenkreis Incrastata.}

520 - incrastata Pfeiffer. Cuba. 
Subgenns Leialeadia A. J. Wagner.

Formenkreis Megastoma.

- megastoma C. B. Adams. Jamaica.

- megastoma dubiosa C. B. Adams. Jamaiea. 91

- neebiana Pfeiffer. Monte Toro anf Cuba.

- hjalmarsoni Pfeiffer. Portorico.

Formenkreis Nitida.

- nitida Pfeiffer. Caba.

- rotunda d'Orbigny. Cuba.

- rotunda campanula Pfeiffer. Caba.

- rotunda glabra Gould. Guane auf Cuba.

- rotunda montana Wright. Cuba.

- trochulina d'Orbigny. Portorico.

- schrammi Crosse. Insel Guadeloupe.

Formenkreis Mamilla.

- mamilla Weinland. Haiti.

- concinna Pfeiffer. Cuba.

- gundlachi Pfeiffer. San Juan de los Pinos.

Formenkreis Bellula.

- belluja Pfeiffer. Yateras auf Cuba.

- bellala bellissima A. J. Wagner. Baracoa

- bellula leptochila A. J. Wagner. Monte

- spectabilis Poey. Cuba.

Toro anf Cuba. 105

- spectabilis venusta A. J. Wagner.

Formenkreis Ampliata.

- ampliata C. B. Adams. Jamaica.

- ampliatu fusco callosa A. J. Wagner. Jamaica. 10

- aurantia Gray. Jamaica.

Formenkreis Tamsiana.

- nemoralis Guppy. Insel Trinidad.

- tamsiana Pfeiffer. Venezuela.

- tamsiana appani Martens. Porto Cabello in

Venezuela.

- columbiana Philippi. Columbien and Vene-

Formonkreis Gemma.

- oweniana Pfeiffer. Südmerico.

zuela. 114

- oweniana anozona Martens. Guatomala.

- owoniana coccinostoma Morelet. Guatemala.

- gemma Preston. Costarica.

I. 18. II.

Nr. Alcadia (Leialcadia) beatrix Angas Costarica. 119

$\mathrm{Nr}$.

- beatrix nicaragnae A.J. Wagner. Nikaragua. 120

- beatrix confusa A. J. Wagner. Costarica. 121

- fragilis Morelet. Guatemala. 122

- fragilis mohriana Pfeiffer. Mexico. 123

Subgenus Analcadia A. J. Wagner.

- antillarum Sowerby. Guadeloupe, Martinique. 124

- rufa Pfeiffer. San. Domingo. 125

- rufa salleana Pfeiffer. Haiti. 126

- humilis Guppy. Insel Dominica der Antillen. 127

- haitensis Maltzan. Haiti. 128

- dysoni Pfeiffer. Venezuela and Insel Trinidad. 129

- dysoni bocourti Crosse et Fischer. Britisch Honduras and Insel Bonacca. 130

- guadeloupensis Sowerby. Insel Guadelonpe. 131

- macmurrayi Pfeiffer. Insel Santa Lucia. 132

- platychila Mühlfeldt. Inseln Martinique, Guadeloupe, Santa Lucia. 133

- phasianella Pfeiffer. Inseln Portorico, Vicque, St. Jan. 134

- striata Lamarck. Insel Portorico, St. Thomas, Tortola. 135

- dominicensis Pfeiffer. Haiti. 525

- moussoniana Pfeiffer. Tarks Juseln. 527

\section{Subgenus Lmoda H. et A. Adams.}

- sagraiana d'Orbignj. Westenba. 136

- sagraiana catalinensis Pfeiffer. Catalina

in Westcuba, 137

- sagraiana emoda Pfeiffer. Cuba. 138

- briarea Poey. Trinidad anf Cuba. 139

- pulcherrima Lea. Santjago de Caba. 140

- pulcherrima crassa d'Orbigny. Cajo Seco bei Cuba. 141

111

112

- palcherrima planospira A. J. Wagner. Cuba. 142

- pulcherrima bayamensis Poey. Bayamo,

Caimanera auf Cuba. 143

- pulcherrima titanica Poey. Baracoa auf Caba. 144

- silacea Morelet. Gibara nnd Baracoa auf

Cuba. 145

- submarginata Gray. Cuba. 146

- ciliata Poey. Trinidad and Banao anf Cuba. 147

- ciliata guisana A. J. Wagner. Guisa anf Cuba. 148
118

30, XI. 1910. 


\section{Genus Sulfurina Millendorf:}

Formenkreis Citrina.

- citrina Gratelonp. Luzon, Alabat, Catan-

- citrina apostasis A. J. Wagner, Camarines, Mazaraga anf Luzon.

- citrina bicolor Möllendorff. Klavera Nord-

- citrinella Möllendorff. Lnzon.

- citrinella celebica Sarasin. Celebes.

- citrinella subglobosa Möllendorff. Luzon.

- euchromia A. J. Wagner. Insel Olango

bei Cebu.

- eachromia bicincta Möllendorff. Inseln Panaon,

- euchromia apicata Möllendorff. Nordost

Mindanao.

- ouchromia tariensis A. J. Wagner. Suln und

Tawi-Tawi

- martensi Jssel. Labuan, Paluan, Borneo.

- martensi snmatrana. A. J. Wagner, Sumatra.

- behniana Pfeiffer. Nikobaren.

- neglecta Tapparone-Canefri. Insel Jobbi.

- lanrae A. J. Wagner. Halmahera.

- bensoni A. J. Wagner. Nikobaren.

- sphaeridinm Möllendorff. Tablas.

Formenkreis Globulina.

- crossei Pfeiffer. Nordost-Luzon.

- parva Sowerby. Lnzon, Catandnanes, Marinduque, Panay, Cebu, Balagnan, Mindoro, Panglao, Samar, Mindanao, Bohol.

- parva minima A. J. Wagner. Katanduanes.

- parva globnlina Möllendorff. Tablas, Rom-

blon, Luzon.

- parva hjalina Hartmann. Mindoro.

- parva electrina Pfeiffer. Halmahera, Bat-

- parva elata A. J. Wagner. Celebes.

- parva tomiana Rolle. Insel Tukan Bessi.

- parva selajarensis A. J. Wagner. Insel Selajer.

-- parva micholitzi Möllendorff. Inseln Ilin

- zelebori Pfeiffer. Nikobaren. and Calamian.

- zelebori amphibola A. J. Wagner. Andamanen. 4 - jickelii A. J. Wagner. Stirling range in
Nr.

Sulfurina staranyi A. J. Wagner. Aibukit der Palau-Inseln. 46

- hnmilis Hombron et Jaquinot, Ponapé Ostkarolinen. 47

Nr.

Subgenus Kosmetopoma A. J. Wagner.

- amaliae Kobelt. Mindanao.

\section{Genus Sturanya A. J. Wagner.}

- plicatilis Mousson. Samoa-Inseln.

- beryllina Gould. Viti-Inseln.

berjllina tntuilana A. J. Wagner. Tutnila

- jetschini A. J. Wagner. Samoa- und VitiInseln. 52

- singularis A. J. Wagner. Insel Uea.

- carolinaram Möllendorff. Ponapé der Caro-

- epicharis A. J. Wagner. Insel Lukunor

der Carolinen.

- multicolor Gould. Tonga-Tabu.

- mnlticolor vavauensis A. J. Wagner. Vavau der Tonga Inseln.

- rnbiginosa A. J. Wagner. Tonga Tabu.

- interna Mousson. Viti-Inseln.

- parvala Pease. Herrey, Sandwichs-Inseln.

- modesta Pfeiffer. Salomonen.

- laciniosa Mighels. Sandwichs-Inseln.

- nesiotica Dall. Insel Albemarle der Galapagos. 63

- nesiotica wolfi Reibisch. Insel Chattam der Galapagos.

\section{Grenus Aphanoconia A. J. Wagner.}

\section{Subgenus Aphanoconia s. str.}

\section{Formenkreis Fulgora.}

- samoana A. J. Wagner. Samoa-Inseln.

- samoana vicina A. J. Wagner. Viti-Inseln. 239

- samoana diruinuta Mousson. Tonga-Inseln. 240

- heterochroa A. J. Wagner. Palan-Inseln. 401

- zigzag Pease. Die Inseln Oualan und Ponopé der Ostkarolinen. 241

- zigzag ponapensis A. J. Wagner. Ponapé der Ustkarolinen. 242

- articulata Pfeiffer. Neue Hebriden. 243

- oceanica H. Pease. Insel Apaiang der Gilbert-Insel. 244 
Aphanoconia subsutaralis Boettger. Marschall-Inseln. 529

- fulgora Gould. Sandwich-Inseln.

- suturalis Martens. Ambon, Ceram, Bura, Saparaa der Molukken. 246

- suturalis dammerensis A. J. Wagner. Insel Dammer der Molukken 247

- altivaga Ancey. Samoa-Inseln.

- gallina Gassies. Nen-Caledonien, die Pinien und Loyslty-Inseln. 249

Formentreis Discoidea.

- pentheri A. J. Wagner. Tahiti.

- discoidea Pease. Tahiti, Tahaă, Raiatea. 251

- diecoidea tumidior A. J. Wagner. Tachiti

- discoidea subrufa A. J. Wagner. Insel

- corrugata Pease. Raiatea.

- villosa Anton. Insel Opara.

Formenkreis Albocincta.

- papuana E. A. Smith. Konstantinharen in Nea-Gainea. 400

- keiensis A. J. Wagner. Kei-Inselu. 256

- albocincta Hombron et Jaquinot. Ara- und

Kei-Inseln. 257

- albocincta bandana Boettger. Die Banda-

- dichroa Möllendorff. Insel Cebr.

- dichroa boholensis Möllendorff. Bohol, Cinalisayan. 260

- dichroa siquijorica Möllendorff. Insel Siquijor. 261

\section{Formenkreis Trichroa.}

- trichroa A. J. Wagner. Insel Banguei bei

- trichroa candaramanica A. J. Wagner. Candaramanes. 263

- trichroa calamianica A. J. Wagner. Insel Buspanga. 264

- derouledei Wattebled. Turon in Annam. 26

- borneensis Martens. Borneo.

icobarica Philippi. Nikobaren, Andamanen, Mergai Inseln and Tenasserim. sykesi Möllendorff. Insel Tomia.

- andamanica Benson. Andamanen.

- theobaldiana G. und H. Nevill. Seychellen. 270

- dunkeri Pfeiffer. Nicobaren.

\section{Formenkreis Serlpta.}

Aphanoconia sculpta Martens. Insel Timor. 272

- kalaoensis E. Smith. Insel Kalao. 273

- submucronata Möllendorff. Konstantinhaven

in Nen-Guinea. 274

- timorensis A. J. Wagner. Insel Timor. 275

- semisculpta Ancey. Kei-Inseln. 276

- parumsculpta A. J. Wagner. Insel Viti Lewu. 277

Formenkreis Geophoroides.

- tectiformis Mousson. Viti-Inseln. 278

- sophiae Brazier. Treasury-Inseln. 279

- rogosiuscula Ancey. Samoa-Inseln. 280

Formenkreis Ogasawarana.

- hirasei Pilsbry. Bonin-Inseln. 399

- ogasawarana Pilsbry. Bonin-Inseln. 281

- ogasawarana discrepans Pilsbry. Bonin.

Inseln. 282

- ogasawarana imotojimana Pilsbry. Bonin. Inseln. 283

- ogasararana optima Pilsbry. Bonin-Inseln. 284

- ogasawarana arata Pilsbry. Bonin-Iuseln. 285

- Joshiwarana Pilsbry. Bonin-Inseln. 286

- yoshiwarana microtheca Pilsbry. Bonin-

Inseln. 287

- yoshiwarana comes Pilsbry. Bonin-Inseln. 288

\section{Subgenus Sphaeroconia}

\section{A. J. Wagner.}

Formenkreis Verecunda.

- rerecunda Gould. Lin-Kin-Insel. 289

- hungerfordiana Möllendorff. Hongkong. 290

- hungerfordiana formosana Schmacker et Boettger. Formosa. 291

- hungerfordiana tonkinensis Möllendorff. Tonkin. 292

- hungerfordiana halongensis A. J. Wagner. Halong in Tonkin. 293

- hajnanensis Möllendorff. Insel Hajnan. 294

- haynauensis badia Schmacker et Boettger.

Formosa. 295

- osnmiensis Pilsbry. Osumi Japan. 296

- capsula Pilsbry. Bonin-Inseln. 297

- Jaejamensis Pilsbry. Loo-choo-Inseln. 298

\section{r.} (2)

4




\section{Formenkreis Reticulata.}

Aphonoconia (Sphaeroconia) sphaeroconus Möllen. dorff. Konstantinhaven und Astrolabebai in

- gouldiana Forbes. Queensland. Neu-Guinea.

- subreticulata A. J. Wagner. Neue Hebriden. 301

- macgillivrayi Pfeiffer, Neu-Caledonien,

- macgillivrayi mediana Gassies. Nen-Cale-

- togatula Morelet. Neu-Caledonien.

- gassiesiana Crosse. Neu-Caledonien.

- gassiesiana sticta A. J. Wagner. Neu-Caledonien.

- gassiesiana allochroa A. J. Wagner. PinienInsel bei Neu-Caledonien.

- laeta Crosse. Neu-Caledonien.

- noumeensis Crosse Neu-Caledonien.

- eduardi A. J. Wagner. Insel Tagula der

Lonisiaden. 310

- braueri A. J. Wagner. Insel Woodlark. 311

- pelevensis Shykes. Coröre der Palau-Inseln. 312

Formenkreis Porphyrostoma.

- rossiteri Crosse. Neu-Caledonien.

- porphyrostoma Crosse. Neu-Caledonien.

- mariae A. J. Wagner. Viti-Inseln.

- sublaevigata Pfeiffer. Espiritu Sarto, Nene

- mouensis Crosse. Berg Mou auf Neu-Cale-

- mondaini Crosse. Nea-Caledonien.$$
\text { donien. } 317
$$

- mondaini fasciolata A. J. Wagner. Canala in Neu-Caledonien. 319

- alrici Crosse. Nea-Caledonien and Pinien-

insel. 320

- dautzenbergi A. J. Wagner. Neu-Caledonien. 321

Formenkreis Pachystoma.

- pachystoma E. A. Smith. Admiralitätsinsel und Neu-Pommern. $\overline{3} 22$

- pachystoma ponsonbyi E. A. Smith, Admiralitäts-Inseln. 323

- garettiana Hartmann. Tu Apu der Marquesas. 324 Formenkreis Musiva.

- musiva Gould. Tonga-Iuseln Uea.

- musiva rotundata Mousson. Ellice-Inseln. 326
Aphonoconia (Sphaeroconise) musiva vitiensis Mousson. Viti-Inseln.

- mariei Crosse. Neu-Caledonien.

- baudinensis E. A. Smith. Insel Baudir. 329

- littoralis Montronzier. Neu-Caledonien. $\quad 330$

- minutissima A.J. Wagner. Neu-Caledonien. 331 Formenkreis Inconspicua.

- küsteriana Pfeiffer. Inseln Tahiti und Bora-

bora. 332

- rustica Pfeiffer. Tahiti.

333

- rusticana A. J. Wagner. Bora-bora. 334

- minuta Sowerby. Inseln Opara und Oheatora. 335

- inconspicua Pfeiffer. Tahiti.

336

- pazi Hidalgo. Mangarewa Gruppe. 337

Genus Orobophana A. J. Wagner.

- sphaeroidea Pfeiffer. Neu.Caledonien, Lo. yalty and Pinieninsel. 338

- sphaeroidea lifonana Crosse. Lifu der Loyalty. 339

- tahitensis Pease. Inseln Tahiti, Raiatea, Huahine und Tubai. 340

- Havescens Pease. Hervey-Inseln. 341

- brazieri Pease. Die Savage-Insel Niue. 342

- solidula Gray. Elisabeth-Insel der Paumota

Gruppe. 343

- solidula colorata Paese. Die Insel Anaä der Paumotu. 344

- solidula raiateae A. J. Wagner. Raiatea. 345

- culminans Mousson. Vavau der Tonga Inseln. 346

- oberwimmeri A. J. Wagner. Samoa-Inseln. 347

- semperi Mousson. Oneata der Viti-Inseln. 348

- pohliana Garrett. Vatu der Viti-Iaseln. 349

- miniata Lesson. Insel Bora-bora. 350

- albolabris Hombron et Jaquinot. Tahiti. 351

- maggeriae Gray, Tahiti, Raiatea. 352

- mangeriae albinea Pease. Insel Tahaä. 353

- rohri Pfeiffer. Marquesas-Inseln. 354

- rohri nukahivana A. J. Wagner. Insel Nukahiva. 355

- uberta Gould. Sandwich-Inseln. 356

- constricta Pfeiffer. Sandwich-Inseln. 357

Genus Palaeohelieina A. J. Wagner. Subgenus Palaehelicina s. str.

Formenkreis Kalokonia.

- moquiniana Recluz. Salomons Inseln. 
Palaeohelicina moquiniana christovalensis A. J. Wagner. Insel San Christoval. 359 - moquiniana ecarinata A. J. Wagner. Salomonen. 360

- spinifera Pfeiffer. Guadalcanar der Salomonen. 361

- spinifera inflata A. J. Wagner. Neu-Irland and Isabel der Salomonen.

- egregia Pfeiffer. Insel Guadalcanar.

- egregia isabelensis A. J. Wagner. Isabel der Salomonen. 364

- egregia incerta A. J. Wagner. Isabel der Salomonen, 365

- solitaria E. A. Smith. Mont Astrolabe in Britisch Neu-Guinea. 366

Formenkreis Rhabdokonia.

- fischeriana Montrouzier. Insel Woodlark. 367

- fischeriana congener E. A. Smith. Insel St. Aignan. 368

- fischeriana phronema A. J. Wagner. Insel Fergusson. 369

- fischeriana elegans A. J. Wagner. Insel Fergusson. 370

- insularam Hedley. Insel Sudest der Loni-

- coxeni Brazier. Yule-Iusel. siaden. 371

- fliae A. J. Wagner. Lonisiaden.

- ruffocallosa Sykes. Palau-Inseln.

- har hara A. J. Wagner. Britisch Nen-Guinea. 375

- stanleyi Forbes. Mailu, Lorne Range in Nen-Guinea, Louisiaden.

- stanleyi sinus Hedley. Nen-Guinea.

- stanleyi rosselensis Hedley. Insel Rossel. 378

- stanleyi asphaleia A. J. Wagner. NenFommern and Neu-Mecklenbarg. 379

\section{Subgenuis Ceratopoma Möllendorif.}

Formenkreis Contermina.

- caroli Kobelt. Siargao der Philippinen.

- caroli emaculata, Möllendorff. Mindanao, Samar Leyte.

- hennigiana Möllendorff. Nord-Luzon.

- contermina Kobelt. Luzon.

- contermina camiguinensis A. J. Wagner.

- rosaliae Pfeiffer. Nord-Lazon. Caniguin Nord-Luzon.

- quadrasi Möllendorff. Luzon.
Formenkreis Taeniata.

Nr.

Palaeohelicina (Ceratopoma)idae Pfeiffer. Molukken. 387

- zoae Pfeiffer. Halmahera. 388

- zoae gebeana E. A. Smith. Insel Gebi bei Halmahera. 389

- jobiensis Tapparone-Canefri. Inseln Jobi und Kapaur. 390

- primeana Gassies. Neu-Caledonien, Loyaltyand Pinien-Insel. 391

- layardi Hartmann. Neue Hebriden. 392

Formenkreis, Diversicolor.

- diversicolor Cox. Queensland.

- jana Cox. Ostaustralien.

- gladstonensis Cox. Gladstone in Queensland. 395

- fumigata Cox. Queensland. 396

\section{Genus Hemipoma A. J. Wagner.}

- hakodadiense Hartmann. Japan.

397

- sadoense Pilsbry. Japan. 398

\section{Genus Helicina Lamarck.}

Formenkreis Angulata-Variabilis.

- brasiliensis Gray. Südbrasilien. 402

- brasiliensis menkeana Philippi. Sao Paolo Brasilien, 403

- densestriata A. J. Wagner. Rio grande do Sul. 404

- angalata Sowerby. Sao Paolo Brasilien. 405

- angulata leopoldinae A. J. Wagner. S. Leopoldina in Brasilien. 406

- inaequistriata Pilsbry. Sao Paolo in

Brasilien. 407

- wettsteini A. J. Wagner. Sao Paolo in

- caracolla Moricand. Südbiavilien. Brasilien. 408

- caracolla moreletiaua Pfeiffer. Bahia. 410

- ignapensis Pilsbry. Iguape Sao Paolo. 411

- leptotropis A. J. Wagner. Sao Paolo. 412

- variabilis Wagner. Bahia, Sao Paolo. 413

- angulifera A. J. Wagner. Bahia. 414

- tilei Pfeiffer. Brasilien. $\quad 415$

- rotundata A. J. Wagner. Brasilien. 416

- boettgeri A. J. Wagner. Sao Leopoldo. 497

- oskari A. J. Wagner. Sao Leopoldo. 498

- haemastoma Moricand. Brasilien. 
Helicina besckei Pfeiffer. Nou.Ereiburg Brasilien 418 - Iundi Beck. Lupa da Pedro Brasilien.

Formenkrois Concontrica.

- concentrica Pfeiffer. Veneznela.

- pandiensis A. J. Wagner. Pandi Columbia. 42

- schlüteri A. J. Wagner. Callanga Peru. 422

- sehlnteri chanchamajontis A. J. Wagner. Chanchamayo Pern. 423

- schln̈teri densesulcata A. J. Wagner. Chan. chamayo Peru. 424

- lirifera Ancey. St. Crnz de la Sierra Bolivia. 425

- fulva d'Orbigny. Corumba Agosta Bolivia. 426

- ernesti Martens. Caracas Venezuela. 427

- ernesti rhynchostoma Pfeiffer. Colnmbien. 428

- laus A. J. Wagner. Rio Ucayali, Rio Jurna Nord-Pera. 429

- conus A. J. Wagner. Chanchamayo Pern. 430

- phakos A. J. Wagner. Rio Jnraty Nord

$\begin{array}{lll} & & \\ \text { - infesta A. J. Wagner. Venezuela. } & 431 \\ & & 432\end{array}$

- sulfurea Ancoy. St. Cruz do la Sierra Bolivia. 433

- decorosa A. J. Wagner. Mazo Columbien. 434

- steindachneri A. J. Wagner, Frontino Nen Granada. 435

- steindachneri snperstrncta A. J. Wagner.

Frontino Nen-Granada. 436

- ocanensis A. J. Wagner. Ocana Nou-Granada. 437

\section{Formenkreis Punctisuleata.}

- punetisulcata Martens. Gnerero Mexico. 438

- punctisnlcata znnilensis A. J. Wagner.

Vnlkan Znnil Gnatemala. 439

- amoena Pfeiffer. Hondnras, Guatemala,

- ghisbrechti Pfeiffer. Südmexico. Mexico. 440

- sinuosa Pfoiffer. Morico.

$$
\text { Formenkeis Cinctella. }
$$

- cinctella Shuttloworth.C ordova, Orizaba

- bautistae A. J. Wagner. Tabasco Mexico.

- cordillerae Pfeiffer. Orizaba Merico.

- borealis Martens. Durango Mexico.

- orbiculata Say. Südosten der Vereinigten Staaten von Nordamerika nnd Nordmerico, 447

\section{Formonkreis Tenuis.}

Nr.

Helicina tenuis Pfeiffer. Südmercio and Zentralamerika. 448

- tenuis pittieri A. J. Wagner. Costarica. 449

- senachuensis A. J. Wagner. Senachu

Guatemala. 450

- durangoana Mousson. Durango, Mexico. 451

- durangoana sagulensis A. J. Wagner. Yalisco

Mexico. 452

- bourguignatiana Ancey. St. Crnz de la Sierra Bolivia. 45 ?

\section{Formenkreis Turbinata.}

- funcki Pfeiffer. Columbia und Costarica. 454

- funcki costaricensis A. J. Wagner. St. Clara,

S. José Costarica. 455

- pitalensis A. J. Wagner. Costarica. 456

- turbinata Menko. Mexico. 457

- deppeana Martens. Deppo Merico. 458

- delicatnla Shuttleworth. Mexico. 459

- trossula Morelet. Vera Paz Guatemala. 460

- notata Pfeiffer. Moxico.

- rostrata Morelet. Gnatemala.

- rostrata mategalpensis A. J. Wagner.

- denticulata Pfeiffer. Honduras.

Nikaragua 463

- snecincta Martens.' Merico.

- arenicola Morelot. Sicnl Yucatan.

- brevilabris Pfeiffer. Südmexico.

- brevilabris incommoda A. J. Wagner. Gnatemala. 469

- microdina Morelet. Verapaz Gnatemala. 470 Formenkrois Festira.

- festiva Sowerby. St. Domingo. 471

- festiva oummingiaua Pfeiffer. Haiti. 472

- festiva malleata Pfoiffer. Ponton anf Haiti. 473

- festiva maltzani A. J. Wagner. Dondon

viridis Lamarck Haiti Haiti. 474

Formenkrois Enneritella.

- adspersa Pfeiffer. Caba.

- neritella Lamarck. Jamaica.

- neritella diplochila A. J. Wagner. Montego Bay Jamaica. 478 
Nr. $\quad \mathrm{Nr}_{\text {. }}$

Helicina neritella reducta A. J. Wagner. Jamaica. 479 Helicina lembeyana Poej. Cuba. 487

- heatei Pfeiffer. Insel Grenada. $480 \quad$ - globalosa d'Orbigny. Cuba. 488

- occidentalis Guilding. St. Vincent. 481 - reeveana Pfeiffer. Cuba. 489

- rhodostoma Gray. Insel Guadelonpe. $482 \quad$ - subglobulosa Poey. Cuba. 490

- rhodostoma inermis A. J. Wagner. Insel - subglobulosa poeyi Pfeiffer. Caba. 491

- goldfussi Boettger. Insel Dominica. 484 - subglobnlosa declivis Pfeiffer. Cuba. 493

- oxyrhyncha Crosse et Debeanx. Insel Bonacca - fasciata Lamarck. Portorico, Antillen. 494

\begin{tabular}{lll|lll} 
& Honduras. & 485 & - fasciata substriata Gray. Insel Barbados. 495 \\
- jamaicensis Sowerby. Jamaica. & 486 & - fasciata convexa Pfeiffer. Bermudas. & 496
\end{tabular} 


\section{Alphabetisches Verzeichnis der Gattungen nud Formen mit ihren Synomymen.}

Aleadia Gray 46.

ampliata C. B. Adams 76.

ampliata fuscocallosa A. J. Wagner 77.

antillarum Sowerby 86 .

anozona Martens 82.

aurantia Gray 78.

bahamensis Pfeiffer 59.

bayamensis Poey 99

beatrix Angas 83.

beatrix nicaraguaeA.J.Wagner84.

beatrix confusa A.J. Wagner 84 .

bellala Pfeiffer 74 .

bellala bellissima A. J. Wagner 75 .

bellala leptochila 75 .

boconrti Crosse et Fischer 90.

briarea Poey 96.

brownei Gray 48.

catalinensis Pfeiffer 95.

ciliata Poey 102.

ciliata guisana A. J. Wagner 102. citrinolabris C. B. Adams 50 . coccinostoma Morelet 82. colnmbiana Philippi 80. concinna Pfeiffer 72.

consangninea C. B. Adams 51.

crassa d'Orbigny 98.

dissimulans Poej 55.

dominicensis Pfeiffer 355.

dubiosa C. B. Adams 66.

dysoni Pfeiffer 89.
(Synonymen sind Karsiv gedrackt.)

Alcadia dysoni bocourti Crosse et

Fischer 90.

emoda Pfeiffer 96.

fallax A. J. Wagner 56 . foveata Pfeiffer 58.

fragilis Morelet 84.

fragilis mohriana Pfaiffer 85.

gemma Preston 83.

gonostoma Poey 53.

guadelonpensis Sowerby 90.

gandlachi Pfeiffer 73.

haitensis Maltzan 88.

hjalmarsoni Pfeiffer 68 .

hispida Pfeiffer 55.

hollandi C. B. Adams 49.

hnmilis Guppy 88.

iheringi A. J. Wagner 354.

incrustata Pfeiffer 64.

intusplicata Pfeiffer 60.

intusplicta smithiana Pfeiffer 61.

kühni Pfeiffer 63.

macmurrayi Pfeiffer 91.

major Gray 49.

mamilla Weinladd 71.

megastoma C. B. Adams 66 .

microstoma C. B. Adams 52.

minima d'Orbigny 57.

mohriana Pfeiffer 85.

monssoniana Pfeiffer 356.

neebiana Pfeiffer 67.

nemoralis Guppy 78.
Alcadia nitida Pfeiffer 68. nada Pfeiffer 64.

oweniana Pfeiffer 81.

oweniana anozona Martens 82. oweniana coccinostoma More. let 82 .

palliata C. B. Adams 47. palliata brownei Gray 48.

paraensis Pfeiffer 63.

phasianella Pfeiffer 92.

platychila Mühlfeldt 91.

proxima Gundlach 58.

pulcherrima Lea 97.

pulcherrima crassa d'Orbigny 98. pulcherrima planospira A. J.

Wagner 98.

pulcherrima bayamensis Poey 99. pulcherrima titanica Poey 99. rotunda d'Orbigny 69.

rotunda campanula Pfeiffer 70. rotunda glabra Gould 70 .

rotunda montana Wright 70 . rubella Pfr. 59.

rufa Pfeiffer 87.

rufa salleana Pfeiffer 87.

sagraiana d'Orbigny 94.

sagraina catalinensis Pfeiffer 95.

sagraiana emoda Pfeiffer 96.

schrammi Crosse 355.

sericea Drouet 62.

sericea kühni Pfeiffer 63. 
Alcadia sericea parasnsis Pfeiffer 63. Aphanoconia discoidea faba A. J. silacea Morelet 100. solitaria C. B. Adams 52. spectabilis Poey 75. spectabilis venusta A. J. Wagner 76.

striata Lamarck 93. submarginata Gray 101. succinea Pfeiffer 61. tamsiana Pfeiffer 79. tamsiana appuni Martens 80. trochulina d'Orbigny 71. velntina Poey 54.

A phan oconia A. J. Wagner 158. albocincta Hombron et Jacquinot

170.

albocincta bandana Boettger 171 . alrici Crosse 210.

altivaga Ancey 165. andamanica Benson 177. arata Pilsbry 187. articulata Pfeiffer 162. badia Boettger 193. bandana Boettger 171. baudituensis Smith 217. borneensis Nartens 175 . braneri A. J. Wagner 204. boholensis Möllendorff 172. calamianica Möllendorff 174. capsula Pilsbry 194. comes Pilsbry 188. corrugata Pease 168. dautzenbergi A. J. Wagner 211. derouledei Wattebled 174. dichroa Möllendorff 171. dichroa boholensis Möllendorff

dichroa pallescens Möllendorff 172.

dichroa siguijorica Möllendorff

172.

discoidea Pease 167.

discoidea tumidior A.J. Wagner

167.
Wagner 167.

discoidea subrufa A. J. Wagner

168.

dunkeri Pfeiffer 179.

ednardi A. J. Wagner 203.

faba Pease 167.

formosana Schmacker et Boettger 191.

fulgora Gould 163.

gallina Gassies 165.

garretiana Hartmann 213.

gassiesiana Crosse 200.

gassiesiana sticta A. J. Wagner

201.

gassiesiana allochroa A. J. Wayner 201.

gouldiana Forbes 196.

hainanensis Möllendorff 192.

hainanensis badia Boettger 193.

heterochroa A. J. Wagner 268.

hirasei Pilsbry 266.

hangerfordiana Möllendorff 190. hnngerfordiana formosana

Schmacker et Boettger 191. hnngerfordiana tonkinensis Möllendorff 191.

hungerfordiana halongensis $\mathrm{A}$. J. Wagner 192.

joschiwarana Pilsbry 187.

joschiwarana microtheca Pilsbry

187.

joshiwarana comes Pilsbry 188. inconspicna Pfeiffer 221. kalaoensis E. A. Smith 180. keiensis A. J. Wagner 169. küsteriana Pfeiffer 219.

laeta Crosse 202.

littoralis Montrouzier 217. macgillivrayi Pfeiffer 197. mariae A. J. Wagner 207. mariei Crosse 216. mediana Gassies 198. minuta Sowerbs 221. 30 I. 1911.
Aphonoconia minutissima A. J. Wagner 218.

mondaini Crosse 209.

mondaini fasciolata A.J. Wagner

210.

monensis Crosse 208.

musiva Gould 214.

musiva rotundata Mousson 215. musiva vitiensis Mousson 215.

nicobarica Philippi 176.

noumeensis Crosse 203.

oceanica Pease 162.

ogasawarana Pilsbry 184. ogasawarana discrepans Pilsbry

ogasawarana imotojimana Pils. bry 186.

ogasa warana optima Pilsbry 186. ogasawarana arata Pilsbry 187. osumiensis Pilsbry 193.

pachystoma E. A. Smith 212. papuana E. A. Smith 267. parumseulata A. J. Wagner 182. pazi Hidalgo 222.

pelevensis Sykes 20 ว. pentheri A. J. Wagner 166. ponsonbyi E. A. Smith 212. porphyrostoma Crosse 206. rogosiuscula Ancey 184. rossiteri Crosse 205. rustica Pfeiffer 219. rnsticana A. J. Waguer 220. samoana A. J. Wagner 159. samoana vicina A. J. Wagner 160. samoana diminata Mousson 160. sculpta martens 179

semisculpta Aneey 182.

sophiae Brazier 183.

sphaeroconus Möllendorff 195.

snblaevigata Pfeiffer 208.

snbmucronata Möllendorff 181 . subreticulata A. J. Wagner 196. subsuturalis Boettger 357. suturalis Martens 164.

I. 18. II. 
Aphanoconia suturalis dammerensis A. J. Wagner 164. sykesi Möllendorff 177. tectiformis Monsson 183. theobaldiana G. H. Nevill 178 . timorensis A. J. Wagner 181. togatula Morelet 199. trichroa A. J. Wagner 173. trichroa candaramanica A. J. Wagner 174.

trichroa calamianica A.J. Wagner 174.

verecnnda Gould 190.

villosa Anton 169.

yaeyamensis Pilsbry 194.

zigzag Pease 161.

zigzag ponapensis A.J. Wagner 161.

Calybiam L. Morelet 15. masiei L. Morelet 15.

Eutrochatella Fischer 103. acuminata Poey 116.

acuminata colnmellaris Gundlach

117.

acuminata blandiana Gundlach

117.

alboviridis Pfeiffer 125 .

blandiana Gnndlach 117.

bryanti Pfeiffer 115.

callida Weinland 113.

callosa Poey 137.

candida Pfeiffer 115.

capillacea Pfeiffer 133.

chittiana Pfeiffer 107.

chrysochasma Poey 127.

chrysochasma jucunda Pfeiffer

128.

chrysochasma hernandezi Wright

128.

chrysostoma Pfeiffer 111.

cisnerosi Arango 124.

colnmellaris Gundlach 117.

conica Pfeiffer 136.

continua Poey 136.
Eutrochatella costata Gray 111. crossicostata Sowerby 11 . elegantula Pfeiffer 113. elongata d'Orbigny 135. engeniana Weinland 112. engeniana weinlandi A. J. Wagner 112.

excavata Pfiffer 110.

festa Sowerby 122.

festa nodale Arango 123.

fasta politula Poej 123.

fuscula Pfeiffer 124.

globosa Gray 108.

hanandezi Night 128.

josephinae C. B. Adams 107.

jucunda Pleiffer 128.

jugulata Poey 127.

littoricola Pfeiffer 114.

mestrei Arango 129.

methfesseli Pfeiffer 125.

microdina Morelet 138 .

nodae Arango 123.

opima Suttleworth 110.

petitiana d'Orbigny 132.

petitiana laticosta A. J. Wagner

133

petrosa Pfeiffer 134.

pfeifferiana Pfeiffer 138.

politula Poey 123.

pulchella Gray 104.

pyramidalis Sowerby 120 .

pyramidalis parcarinata $\dot{A}$. J. Wagner 121.

regina Morelet 130 .

regina laevigata Pfeiffer 131.

regina subunguiculata Poey 131.

remota Poey 118.

rubella Pfeiffer 126.

rubella citrinocallosa A. J.

Wagner 126.

rubromarginata P'oey 122.

rubicunda Ffeiffer 133.

rupestris Pfeiffer 134.

scopuloram Morelet 120.
Entrochatella sloanei d'Orbigny 118. straminea Morelet 121.

straminea rubromarginata $\mathrm{P}$ oey

122.

tankervillii Gray 106.

virginea Lea 109

virginea crassicostata Sowerby

wrighti Pfeiffer

110.

119

wrighti xanthacme A. J. Wagner

119

Geophoras Fischer 139. acutas Pfeiffer 149.

scutus peracutus A. J. Wagner

acutns intermedius Möllendorff 150.

acutissimas Sowerby 153.

acntissimus peracntissimus $A$

J. Wagner 154 .

acutissimus trochalus Möllendorff 154.

agglutinans Sowerby 140.

agglutinans solidulus Möllendorff

141.

agglutinans cyrtopoma Möllendorff $14 \%$.

agglutinans versicolor Möllesdorff 142.

agglatinans mindorensis A. J. Wagner 143.

agglutinans eos A. J. Wagner 143.

agglutinans conoidalis Möllendorff 156.

agglntinans subtrochifirmis Möllendorff 156 .

bothropoma Möllendorff 15?. cyrtopoma Möllendorff 142. exsertus Martens 147. exsertus major Smith 148 . exsertus solidior Smith 148. gibbosulus Möllendorff 156. lazarus Sowerby 144. 
Geophoras lazarus transitans A.

J. Wagner 144.

lazarus naaus Möllendorff 145.

lazarus monticolns Möllendorff

145 .

nitidnlus MIöllendorff 151.

oxytropis Gray 145.

oxytropis orientalis A. J. Wagner

oxytropis jagori Martens 147.

psendomphalus Möllendorff 151.

rellei Sykes 148.

trochiformis Sowerby 155.

trochiformis subtrochiformis

Möllendorff 156 .

trochiformis conoidalis Möllen-

dorff 156 .

trochiformis gibbosulas Möllendorff 156 .

Geotrochatella P. Fischer 10. gredleriana Dautzenberg 13.

jourdyi Dantzenberg 12.

jourdyi excelsa A. J. Wagner

157.

inignis Dautzenberg 13.

martensi Gredler 13.

mouhoti Pfoiffer 11.

nogieri Dautzenberg et d'Hamonville 14 and 157.

Helicina Lamarck 269.

acuminata Poey 116.

acuta Pfeiffer 149.

acutissima Sowerby 153

adamsiana Pfeiffer 344.

adspersa Pfeiffer 322.

affinis C. B. Adams 66.

agglutinans Sowerby 140.

agglutinans var. conoidalis Möl-

lendorf 156.

agglutinans var. subtrochiformis

Möllendorff 156.

agglutinauts var. versicolar Möl-

lendorff 142.

alata (Menke) Pfeiffer 353.
Helicina albinea Pease 234.

albocincta Hombron et Jaequinot 170 .

albolabris Hombron et Jaequinot 232.

alboviridis Pfeiffer 125.

alrici Crosse 210.

aldta Sowerby 71.

altivaga Ancey 165 .

amaliae Kobelt 350 .

ambelliana Sowerby 309.

amoena Pfeiffer 295.

ampliata C. B. Adams 76 .

ampulina Férussae 109.

anaensis Mlousson 228.

anaquana Weinland 321.

andamanica Benson 177.

angulata Sowerby 273.

angulata leopoldinae A. J. Wagner 274.

angulifera A. J. Wagner 279.

anozona Martens 82.

antillarum 86.

appuni Martens 80.

aracanenvis Blanford 176.

arenicola Morelet 316.

articulata Pfeiffer 162.

aruana Pfeiffer 182.

aurantia Gray 78.

aureola Férussac 339.

badia Schunacker et Boettger

193.

bahamensis Pfeiffer 59.

bandana Boettger 173 .

bairdi Reeve 261.

barbadensis Pfeiffer 351.

burbata Guppy 89.

baudinensis Smith 217.

bautistae A. J. Wagner 299

bayamensis Pfeiffer 99.

beatrix Angas 83 .

behniana Pfeiffer 24.

bellala Pfeiffer 74 .

beryllina Gould 37.
Helicina besckei Pfeiffer 281.

blandiana Gundlach 117.

bocourti Crosse et Fischer 90.

boettgeri A. J. Wagner 335.

borealis Martens 300.

borneensis Martens 175.

bothropoma Möllendorff 152.

botteriana Pfeiffer 298.

bourguignatiana Ancey 306.

brasiliensis Gray 271.

braneri A. J. Wagner 204.

brazieri Pease 227.

hrevilabris Pfeiffer 317.

brevilabris incommoda A. J.

briarea Poey 96.

Wagner 318.

brownei Graj 48.

bryanti Pfeiffer 115.

callida Weinland 113.

callosa Poey 137.

campanula Pfeiffer 70.

candida Pfeiffer 115.

capsula Pilsbry 194.

caracolla Moricand 275.

caroli Kobelt 252.

caroli emaculata Möllendorff 253. carolinarum Möllendorff 39.

castanea Gulding 93.

catalinensis Pfeiffer 95.

chiapensis Pfeiffer 302.

chryseis Tristram 138.

chrysochasma Poey 127.

ciliata Poey 102.

cinctella Shuttleworth 298.

cingulata Pfeiffer 321.

cisnerosi Arango 124.

citrina Grateloup 19.

citrina bicolor Möllendorff 20 .

citrinella Möllendorff 21.

citrinella celebica Sarasin 20.

citrinella subglobosa Möllendorff

21.

citrinella bicincta Möllendorff 22 .

citrinella apicata Möllendorff 23. 
Helicina citrinolabris C. B. Adams

50 .

coccinostoma Morelet 82. colorata Pease 228.

columbiana Philippi 80.

columbiana var. appuni Martens

colamellaris Gundlach 117.

comes Pilsbry 188.

concentrica Pfeiffer 282.

concentrica ernesti Martens 287.

concinna Peiffer 72.

congener E. A. Smith 245.

conica Pfeiffer 136.

consanguinea C. B. Adams 51.

constellata Morelet 16.

constricta Pfeiffer 236.

contermina Kobelt 254.

continua Poey 136.

conus A. J. W Wagner 290.

convexa Pfeiffer 335.

cordillerae Pfeiffer 300.

corronula Pfeiffer 345 .

corrugata Pease 168.

costata Gray 111.

coxeni Brazier 247.

erassa d'Orbigny 98.

crassicostata Sowerby 110.

crossei Pfeiffer 27.

cruciata Weinland 346.

culminans Mousson 229.

cumingiana Pfeiffer 319.

cyrtopoma Möllendorff 142.

declivis Gundlach 333.

decorosa A. J. Wagner 292.

decussata Boettger 346 .

delicatula Shattleworth 310 .

densestriata A. J. Wagner 272.

denticulata Pfoiffer 314.

dentigera d'Orbigny 56.

dentoni Pilsbry 243.

deppeana Martens 309.

depressa Gray 345.

derouledei Wattebled 174.
Helicina dichroa Möllendorff 171.

dichroa var. boholensis Möllendorff 172.

dichroa var. pallescens Möllendorff 172.

discoidea Pease 167.

discolor Mühlfeldt 221.

dissimulans Poey 55.

diversicolor Cox 262.

dominicensis Pfeiffer 355.

dryatonensis Pfeiffer 262.

dubiosa C. B. Adams 66.

dunkeri Pfeiffer 179.

durangoana Mousson 3iว.

durangoana sagulensis A. J. Wagner 305.

dysoni Pfeiffer 89.

egregia Pfeiffer 241.

electrina Pfeiffer 30.

elegans d'Orbigny 136.

elongata d'Orbigny 135.

elongata Pieiffer 120.

emoda Pfeiffer 96.

ernesti Martens 287.

erythraea Wright 126.

ougeniana Weinland 112.

euglypta Crosse 349.

excacuta Poey 121.

exserta Guadlach 72

exserta Martens 147.

faba Pease 167.

fasciata Lamarck 333.

fasciata substriata Gray 334.

tasciata convexa P feiffer 335.

fasciata Guilding 325.

fasciata Delessert 272.

fasciata Spix 278.

faustini Weinland 321.

festa Sowerby 122.

festiva Sowerby 319.

fischeriana Montrouzier 244.

flamulata Mühlf. 221 .

flava Spix 278.

flavescens Pease 226.
Helicina flavida auctor 317.

formosana Schmacker et Boett-

ger 191.

foveata Pfeiffer 58.

fragilis Pilsbry 353.

fragilis Morelet 84.

fulgora Gould 163.

fulgora auctor. nec. Gould 159

fulva d'Orbigny 287.

fumigata Cos 264.

funcki Pfeiffer 306.

funcki costaricensis A. J. Wag-

ner 307

fuscula Peiffer 124.

gabbi Crosse et Newcomb 321. gallina Gassies 165.

garrettiana Hartmann 213.

gassiesiana Crosse 200.

gebeana E. A. Smith 259

gemma Preston 83.

ghisbrechti Pfeiffer 296.

gibbosula Miöllendorff 156.

glabra Gould 70.

gladstonensis Cox 263.

globosa Gray 108.

globulosa d'Orbigny 330

goldfussi Boettger 327.

gonostoma Poey 53.

gouldiana Forbes 196.

granum Pfeiffer 343.

gredleriana Möllendorff 13.

guadeloupensis Sowerby 90.

guildingiana Pfeiffer 52.

gundlachi Pfeiffer 73.

guppyi Pease 88.

guttula Pfeiffer 30.

haemastoma Moricand 280.

hainanensis Möllendorff 192.

haitensis Maltzan 88.

hakodadiensis Hartmann 265.

hanlegana Pfiffer 301.

heatei Pfeiffer 324.

keloisae Sallé 310.

hennigiana IIöllendorff 254. 
Helicina beraandezi Wright 128. Helicina laeta Crosse 202. hjalmarsoni Pfeiffer 68. hirasei Pilsbry 266. Lispida Pfeiffer 55. hollandi C. B. Adams 49. hornkecki Philippi 98. humilis Hombron et Jacquinot

humilis Guppy 88. hungerfordiana Möllendorff 190. byalina Hartmann 30. jagori Martens 147. jamaicensis Sowerby 328. jana Cox 262. japonica C. B. Adams 5. japonica var. reiniana Kobelt 6 . japonica var. expolita Pilabry 6. japonica var. uzensis Pilsbry 7. jobiensis Tapparone-Canefri 259. josefinae C. B. Adams 107. joshiwarana Pilsbry 187. joshiwarana var. arata Pilsbry 187. joshiwarana var. microtheca Pils bry 188.

jucunda Pfeiffer 128. jugulata Poey 127. idae Pfeiffer 257. iguapensis Pilsbry 277. isaequistriata Pilsbry 274. inconspicua Pfeiffer 221. induta Shuttlevort? 93. infesta A. J. Wagner 291. insularum Hedley 246. insularum var. sinus Hedley 251. insularum var. rosselensis Hedley 251. intermedia Möllendorff 150. interna Mousson 42. intusplicata Pfeiffer 60. iris Weinland 321. kalaoensis E. A. Smith 180. küsteriana Pfeiffer 219. laciniosa Mighels 43. lamellosa Goppy 341.

lagardi Hartmann 261.

lazarus Sowerby 144.

leana C. B. Adams 345. lembeyana Poey 3:9.

lcopoldinae A. J. Wagner 274.

leptotropis A. J. Wagner 277.

lindeni Pfeiffer 302.

lineata C. B. Adams 342.

lifonana Crosse 225 .

lirata Pfeiffer 341.

lirifera Ancey 286.

litoralis Montzouzier 217. littoricola Pfeiffer 114.

lundi Beck 28:.

lutea Sowerby 91.

lutescens Newcomb 116.

luteo apicata Poey 120.

Tuteo punctata Pocy 120.

macgillivruyi Pfeiffer 197.

macleayi Brazier 263.

macmurrayi Pfeiffer 91.

maculosa Nervcomb 130.

magdalenae Ancey 236.

major Gray 49.

inalleata Pleiffer 320.

maltzani A. J. Wagner 320.

mariei Crosse 216.

martensi Issel 24.

mormorata d'Orbigny $3: 2$. marmorata Velasquez 120.

maggeriae Gray 233.

mazei Crosse 86.

mediana Gassies 198.

megastoma C. B. Adams 66 .

menkeana Philippi 242.

merguiensis Pfeiffer 176.

mestrei Arango 129.

micholitzi Möllendorff 31.

microdina Morelet 1 อิ8.

microstoma C. B. Adams 52.

miniata Lesson 232.

winima d'Orbigny 57.
Helieina miniuscula Binney 59. miniuscula Pfeiffer 199.

minuta Sowerby 221.

modesta Pfeiffer 43.

mohriana Pfeiffer 85.

mondaini Crosse 209.

montana Wright 70.

monticola IIöllendorff 145.

moquiniana Reclaz 238.

moreletiana Pfeiffer 276.

monensis Crosse 209.

mouhoti Pfeiffer 11.

musiva Gould 214.

musiva var. rotandata Mousson

215.

musiva var, vitiana Mousson 215.

musiva var. subcarinata Mousson

215.

moussoniana Pfeiffer 336.

multicolor Gould 40.

multistriata Velasquez 130.

nana 'f feiffer 342 .

neebiana Pfeiffer 67.

neglecta Tapparone Canefri 25. nemoralis Guppy 78.

neritella Lamarck 323.

neritella diplochila A. J. Wagner

neritella reducta A. J. Wagner

324.

nesiotica Dall 45.

nicobarica Philippi 176.

nitida Pfeiffer 68.

nitidula Möllendorft 151.

nodae Arango 123.

notata Sallé 312.

nunmeensis Crosse 203.

nuda Pfeiffer 64.

canersis A. J. Wagner 294.

occidentalis Guilding 325.

occulta Say 8.

uceanica Pease 162.

ochracea Poey 100.

ogasawarana Pilsbry 184. 
Helicina ogasawarana var. discrepans Pilsbry 185. ogasarawana var. imotojimana Pilsbry 186.

ogasawarana var. optima Pilsbry 186. ogasawarana var. rex Pilsbry 186.

opaca Boettger 356.

orbiculata Say 301.

orbiculata Sowerby 68. oresigena d'Orbigny 272. ornata Férussae 322. oscari A. J. Wagner 336. osumiensis Filsbry 193. oweniana Pfeiffer 81. oxyrhyncha Crosse et Debeaux 328.

oxytropis Gray 145.

oxytoma Sowerby 145.

paivana Pfeiffer 346.

pachystoma E. A. Smith 212.

pacifica Pease 226.

palliata C. B. Adams 47.

pallida Pfeiffer 219.

pandiensis A. J. Wagner 283.

pannucea Morelet 352.

papuana E. A. Smith 267.

paraensis Pfeiffer 63.

parva Sowerby 28.

parvula Pease 42.

pazi Hidalgo 222.

pelevensis Sykes 205.

pentheri A. J. Wagner 166.

p feifferiana Pfeiffer 138.

phakos A. J. Wagnes 290.

phasianeila Sowerby 92.

pilosa Sowerby 169.

pitalensis A. J. Wagner 308.

platgchila Mühlfeld 91.

plicatilis Mousson 36.

plicatula Pfeiffer 349.

poeyi Pfeiffer 332.

pohliana Garret 231.
Helicina polita Sowerby 19. politala Poey 123. ponsonbyi E. A. Smith 212 . porphyrostoma Crosse 206. primeana Gassies 260. proxima Gundlach 58. pseadomphala Möllendorff 151. pulchella Gray 104. pulcherrima Lea 97. pulla Martens 30. punctisulcata Martens 294. pnnctisulcata zunilensis A. J. Wagner 295. pyramidalis Sowerby 120. pyrrhostoma Menke 78. quadrasi Möllendorff 256. raresulcata Pfeiffer 315. reeveana Pfeiffer 330. regina Morelet 130. remota Poey 118. reticulata Pfeiffer 196. rhodostoma Grey 326. rhodostoma inermis A. J. Wagner 327.

rhodostoma Mighels 236. rhynchostoma Pfeiffer 288. rogosinscula Ancey 184. rohri Pfeiffer 234. rollei Sykes 148. rosaliae Pfeiffer 256. rosea Mühlfeldt 278. rossiteri Crosse 205. rostrata Morelet 313. rostrata mategalpensis A. J. rota Newcomb 17 Wagner 313. rotellina Potiez et Michaud 93. rotunda d'Orbigny 69. rotundata A. J. Wagner 280. ruhella Pfeiffer 126. rubella Green 301. rabicunda Pfoiffer 133. rubicunda Pease 233. rubiginosa A. J. Wagner 41.
Helicina rubra Pfeiffer 101. rubrocincta Poey 97. rubromarginata Gundlach 122. rufa Pfeiffer 87

rufocallosa Sykes 248. rngosa Pfoiffer 347. rupestris Pfaiffer 134. rustica Pfeiffer 219. rusticclla Morelet 341. sadoensis Pilsbry 266. sandwichens is Souleyet 163. sagra Sowerby 94. sagraiana d'Orbigng 94. salleana Pfeiffer 87. salvini Tristram 313. scopulorum Morelet 120. schrammi Crosse 355. schläteri A. J. Wagner 284. schlüteri chanchamayensis A. J. Wagner 285.

schlüteri densesulcata A. J, Wagner 285.

scitula Wood 104.

scrupalam Benson 27. sculpta Martens 179. semiscu!pta Ancey 182 semperi Mousson 230. genachnensis A. J. Wagner 304. sericea Drouet 62.

silacea Morelet 100 . simulans Garrett 167. sinuosa Pfeiffer 297. siquijorica Möllendorff 172 sloannii Férassae 104. sloanei d'Orbigny 118. smithiana Pfeiffer 61. solidula Gray 227. solitaria C. B. Adams 52. solitaria E. A. Smith 243. sophiae Brazier 183. spectabilis !'oey 75 . sphaeridinm Möllendorff 27. sphaeroconus Möllendorff 195. sphaeroidea Pfeiffer 224. 
Helicini spinifera Pfeiffer 240. stanleyi Forbes 250. seindachneri A. J. Wagner 293. steindachneri superstructa A. J. Wagner 293.

stellata Velasquez 17. straminea Norelet 121. striata Lamarck 93. striatnla Rang 349. strebeli Pfeiffer 317. subảepressa Poey 332. subfusca Mentie 93. subglobulosa Poey 331. sublaevigata Pfeiffer 208. submarginata Gray 101. submucronata Möllendorff 180. suborbiculata Say 301. substriata Gray 334. subsuturalis Boettger 357. subtropica Gould 301. succinea Pfeiffer 61. succincta Siartens 315. sulfurea Ancey 292. sundana Ancey 147. soturalis Martens 164. sykesi Möllendorff 177. taeniata Quoy 261. tahitensis Pease 225. tamsiana Pfeiffer 79. tankervillii Gray 106. tectiformis Monsson 183. tenuilabris Pfeiffer 322. tennis Pfeiffer 302 tenuis pittieri A. J. Wagner 303. theobaldiana G. et $H$. Neovill

178.

tilei Pfeiffer 279.

titanica Poey 99. togatula Morelet 199. tridens Sowerbg 342. trochiformis Sowerby 155. trochulina d'Orbigny 71. trochulns Möllendorff 154. tropica Jan 301.
Helicina trossula Morelet 311. turbinata Menke 308. aberta Gould 236. ueana Mousson 214. umbonata Shnttleworth 340 . undulata Morelet 10. unicolor Férussae 91. unidentor Pfeiffer 341. vagans Ancey 169. variabilis Gulding 323. variabilis Wagner 278. variegata d'Orbigny 322. velntina Poey 54. verecunda Gonld 190. vernalis Morelet 302. versicolor Pfeiffer 321. villosa Anton 169. vinosa Shattleworth 348. virginea Lea 109. virginea d'Orbigny 130. viridis Lamarck 321. vitiensis Mousson 215. walkeri A. J. Wagner 217. wettsteini A. J. Wagner 275. wolffi Boettger 347. wrighti Pfeiffer 119. yaeyamensis Pilsbry 194. zelebori Pfeiffer 32. zephyrina Potiez et Michaud 278.

zephyrina Duclos 309.

zigzag Pease 161.

zoae Pfeiffer 258.

zonata Sowerby 278.

zonata Guppy 79.

Hemipoma A. J. Wagner 265. hakodadiense Hartmann 265. sadoense Pilsbry 266.

Hendersonia A. J. Wagner 8. occulta Say 8.

Lucidella Swainson 337.
Lacidella adamsiana Pfeiffer 344. adamsiana coronula Pfeiffer 345. aureola Férnssac 339. denseplicata A. J. Wagner 348. depressa Gray 345. foxi Pilabry 343. granum Pfeiffer 343. holoserica A. J. Wagner 350. kobelti A. J. Wagner 350. lineata C. B. Adams 342. lirata Pfeiffer 341. lirata lamellosa Gappy 341. nana Pfeiffer 342. paivana I feiffer 346. paivana decussata Boettger 346. plicatula If feiffer 349. rugosa Pfeiffer 347. undulata Pfeiffer 348. umbonata Shuttleworth 340. vinosa Suttleworth 348. wolffi Boettger 347 .

Miluna A. J. Wagner 7.

josephinae 7 .

Orobophana A. J. Wagner 223.

albolabris Hombron et Jacquinot 232.

brazieri Pease 227.

constricta Pfeiffer 236.

culminans Mousson 229.

flavescens Pease 2:6.

mangeriae Gray 233.

mangeriae albinea Pease 234.

miniata Lesson 232.

oberwimmeri A. J. Wagner 230.

pisum Philippi 226.

pohliana Garrett 231.

rohri Pfeiffer 234.

rohri nukahivana A J. Wagner

semperi Monsson 230.

solidula Gray 227. 
Orobophona solidula colorata Pease 228. solidula raiateae A. J. Wagner 229.

sphaeroidea Pfeiffer 224. sphaeroidea lifouana Crosse 225. tahitensis Pease 225.

uberta Gould 236.

Palaeobelicina A. J. Wagner 237.

caroli Kobelt 252.

contermina Kobelt 254. caroli emaculata Möllendorff 253.

coxeni Brazier 247.

diversicolor Cox 262.

egregia Pfeiffer 241.

egregia isabelensis A. J. Wagner

242.

egregia incerta A. J. Wasner

243.

filiae A. J. Wagner 247.

fischeriana Montroazier 244.

fischeriana congener E. A. Smith

245.

fischeriana phronema A. J.

Wagner 245.

fischeriana elegans A. J. Wagner

245.

fischeriana lampra A.J. Wag-

fumigata Cox 264.

gebeava Smith 259.

gladstonensis Cox 263.

hara A. J. Wagner 249.

henigiana Möllendorff 20 4.

jana Cox 262.

jobiensis Taparone-Canefri 259.

idae Pfeiffer 257.

insularum Hedley 246.

layardi Hartmann 261.

moquiniana Recluz 238.

moquiniana christovalansis A. J.

Wagner 239.
Palaeohelicina moquiniana ecarinata A. J. Wagner 240.

primeana Gassies 260.

quadrasi Möllendorff 256 .

rosaliae Pfeiffer 256.

ruffocallosa Sykes 248.

solitaria E. A. smith 243.

spinifera Pfeiffer 240.

spinifera inflata A. J. Wagner

241.

stanleyi Forbes 250.

stanleyi sinus Hedley 251.

stanleyi rosselensis Hedley 251.

stauleyi asphaleia A. J. Wagner

252.

zoae Pfeiffer 258.

zoae gebeana Smith 259.

Priotrochatella Fischer 16. constellata Morelet 16. stellata Velasquez 17.

Pseudotrochatella Nevill 9. undulata Morelet 10.

Schasicheila Shattleworth

alata Pfeiffer 353.

bahamensis Pfeiffer 59.

fragilis Pilsbry 355.

miniuscula Pfeîffer 353.

pannucea Morelet 352.

pilsbryi A. J. Wagner 352.

Sturanya A. J. Wagner 36. beryllina Goold 37.

beryllina tatuilaua A. J. Wagner

38.

carolinarum Möllendorff 39.

epicharis A. J. Wagner 39.

jetschini A. J. Wagner 38.

interna Mousson 42.

laciniosa Hlighels 43 .

modesta Pfeiffer 43.

multicolor Gould 40 .
Staranya multicolar vavauensis A.

J. Wagner 41 .

nesiotica Dall 45.

parvula Pease 42.

plicatilis Mousson $30^{\circ}$

rubiginosa A. J. Wagner 41. singularis A. J. Wagner 38 . test dinalis Mousson 41. viridocolore Hartmann 43. wolfi Reibisch 45.

\section{Sulfurina Möllendorte 18.} amaliae Kobelt 35. behniana Pfeiffer 24.

bensoni A. J. Wagner 2ti. citrina Gratelonp 19.

citrina apostasis A. J. Wagner

citrina bicolor Möliendorff 20 . citrinella Möllendorff 21.

citrinella celebica Sarasin 20. citrinella sabglobosa Möllendorft

crossei Pfeiffer 27.

enchromia A. J. Waguer 22. enchromia bicincta illöllendorff

22.

euchromia apicata Möllendorff

euchromia taviensis A. J. Wagner 2.3 .

humilis Hombron et Jacquinot

jickelii A. J. Wagner 33.

laurae A. J. Wagner 26.

martensi Issel 24.

martensi sumatrana A. J. Wag-

ner 24

neglecta Tapparone-Canefri 25. parva Sowerby 28.

parva electrina Pfeiffer 30.

parva elata A. J. Wagner 30. parva globulina Möllendorff 29. parva byalina Hartmann 30. 
Salfurina parva minima A. J. Sulfurina staranii A. J. Wagner 33. Wagner 29. zelebori Pfeiffer 32.

Waldemaria A. J. Wagner 5. parva selajarensis A. J. Wagner zelebori amphibola A.'J. Wagjaponica A. Adams 5. 31. ner 32 . parva tomiana Rolle 31 . serupulum Benson 33. sphaeridium Möllendorff 27.

Trochatella Swainson= Entrochatella Fischer 103. japonica expolita Pilsbry 6. japonica reiniana Kobelt 6 . japonica azensis Pilsbry 7.
I. 18. II.
2. II. 1912 . 


\title{
Erklärung der Tafeln.
}

\author{
Tafel 1.
}

Fig. 1. Deckel von Waldemaria japonica reiniana Kobelt, Vergrösserung 1/8. Fig. 2. Deckel von Hendersonia occulta Say, Vergr. 1/8. Fig. 3. Deckel von Miluna josefinae A. J. Wagner, Vergr. 1/8. Fig. 4. Deckel von Priotrochatella stellata Velasquez, Vergr. 1/8. Fig 5-6. Deckel von Geotrochatella mouhoti Pfeiffer, Vergr. 1/10. Fig. 7-9. Miluna josefinae A. J. Wagner, Fundort: Radnng-Hubei Vergr. 1/4,5. Fig. 10-12. Hendersonia occulta Say, Fnndort: Jowa City, Vergr. 1/5. Fig. 13-15 Waldemaria japoponica A. Adams, Fundort: Tsukuba, Vergr. 1/3,5. Fig. 16-17. Geotrochatella [nogieri Dautzenberg et d'Hamonville, Fundort: Than-moi, Vergr. 1/2,5. Fig. 18-19. Geotrochatellu jonrdyi Dautzenberg Fundort: Krieu, Vergr. 1/2,5. Fig. 20-21. Geotrochatella mouhoti Pfeiffer, Fundort: Lnang-Prabang, Vergr. 1/2,5.

\section{Tafel 2.}

Fig. 1-2. Geotrochatella martensi Gredler. Fundort: Guang-Hsi' Vergr. 1/4. Fig. 3-4. Geotrochatella insignis Dautzenberg, Fnndort: Haiphong, Vergr. 1/2,5. Fig. 5-7. Pseudotrochatella undulata Morlet, Fundort: Mauritius, Vergr. 1/4. Fig. 8-11. Calybinm massiei L. Morlet, Fundort: Khain-Kent, Laos. Vergr. 1/2.5. Fig. 12-13. Priotrochatella stellata Velasquez, Fundort. Isla de Pinos, Vergr. 1/3. Fig. 14. Deckel von Sulfurina euchromia apicata Möllendorff, Fundort: Bislig, Vergr, 1/8. Fig. 15. Deckel von Sulfurina citrina Grat., Fundort: Tayabas, Vergr. 1/5. Fig. 16. Deckel von Sulfarina citrinella Möllendorff, Fundort: Dingalan, Vergr. $1 / 8$.

\section{Tafel 3.}

Fig, 1-3. Salfurina citrina Grateloup, Fundort: Tayabas, Vergr. 1/3. Fig.4. Salfurina citrina apostasis A. J. Wagner, Fundort: Kamarines, Vergr. 1/3,3. Fig. 5. Sulfurina citrinella eelebica Sarasin, Fundort: Kalaina, Celebes, Vergr. 1/6. Fig. 6. Sulfurina citrina bicolor Möllendorff, Fundort: Klavera, Vergr. 1/3,3. Fig. 7-10. Sulfurina citrinella Möllendorff, Fundort: Dingalan, Vergr. 1/3,3. Fig. 11-12. Sulfurina eachromia taviensis A. J. Wagner, Fundort: Tawi-Tawi, Vergr. 1/5. Fig. 13-14. Sulfurina euchromia A. J. Wagner, Fundort: Olango, Vergr. 1/3.3. Fig. 15-17. Sulfurina enchromia bicincta Möllendorff, Fundort: Panaon, Vergr, 1/3,3. Fig. 18. Sulfurina euchromia apicata Möllendorff, Fundort: Bislig, Vergr. 1/3,3. Fig 19-21. Sulfurina behniana Pleiffer, Fnndort: Nikobaren, Vergr. 1/5. Fig. 22-24. Sulfurina martensi Issel, Fundort: Labuan, Vergr. 1/5,3. Fig. 25-27. Sulfurina laurae A. J. Wagner, Fundort: Halmahera, Vergr. 1/3,2. Fig. 28-30. Sulfurina neglecta Tapparone-Canefri, Fundort: Jobbi, Vergr. 1/6.

\section{Tafel 4,}

Fig. 1-3. Sulfurina bensoni n., Fundort: Nikobaren. Vergr. 1/10. Fig. 4-5. Sulfurina sphaeridium Möllendorff, Fundort: Tablas, Vergr. 1/8. Fig. 6-7. Sulfurina citrinella subglobosa Möllendorff, Fundort: 
Palanan, Vergr. 1/4,5. Fig. 8-10. Sulfurina sturanii A. J. Wagner, Fundort: Aibukit, Vergr. 1/6. Fig. 11-13. Sulf. hamilis Hombron et Jaquinot, Fundort: Ponapé, Vergr. 1/6. Fig. 14-16. Sulfurina crossei Pfeiffer, Fundort: Palanan, 1/3. Flg. 17-19: Sulfurina parva Sowerby. Fundort: Cebu, Vergr. 1/5,2. Fig. 20-21. Sulfurina parva globulina Möllendorff, Fundort: Romblon, Vernr. 4/4,3. Fig. 22. Sulfurina parva electrina Pfeiffer, Fundort: Batjan, Vergr. 1/5,2. Fig, 23. Sulfurina parva electrina, Fundort: Arulnseln, Vergr. 1/5,2. Fig. 24=25. Sulfurina parva hyalina Hartmann, Fundort: Mindoro, Vergr. 1/5,2. Fig. 26. Sulfurina parva elata n., Fundort: Maros, Celebes, Vergr. 1/6. Fig. 27-28. Sulfurina parva minima A. J. Wagner, Fundort: Katanduanes, 1/5,2. Fig. 29-30, Sulfurina parva selajarensis A. J. Wagner, Fundort: Selajer, Vergr. 1/5,2. Fig. 31-32. Sulfarina parra tomiana Rolle, Fundort: Tukan Bessi, Vergr. 1/5,2.

Tafel 5.

Fig. 1-3. Salfurina zelebori Pfeiffer, Fundort: Nikobaren, Vergr. 1/5. Fig. 4. Sulfurina zelebori amphibola A. J. Wagner, Fundort: Andamanen, Vergr. 1/5. Fig. 5-6. Sulfurina parva micholitzi Möllendorff, Fundort: Jlin, Vergr. 1,6. Fig. 7-9. Sulfurina jickelii A. J. Wagner, Fundort: Stirling-Range Vergr. 1/8. Fig. 10-13. Salfurina (Kosmetopoma) amaliae Kobelt, Fundort: Mindanao, Vergr. 1/2. Fig. 14-18. Sturanya plicatilis Mousson, Fundort:-Upola, Vergr. 1/3. Fig. 19-21. Sturanya beryllina Gould, Fundort: Viti-Inseln, Vergr. 1/3. Fig. 22-24. Sturanya beryllina tatuilana n., Fundort: Tatuila, Vergr. 1/5. Fig. 25-29. Sturanya jetschini A. J. Wagner, Fundort: Upola, Vergr. 1/J. Fig. 30. Sturanya jetschini, Fundort: Kanathea, Vergr. 1/o.

\section{Tafel 6.}

Fig. 1-3. Sturanya singularis no, Fundort: Uea, Vergr. 1/5. Fig. 4-6. Sturanya caroliuarum Möllendorff, Fundort: Ponapè, Vergr. 1/6. Fig. 7-9. Sturanya epicharis n., Fundort: Lugunor, Vergr.1/6. Fig. 10-12. Sturanya multicolor Gould, Fundort: Tongatabu, Vergr. 1/6. Fig. 13-14. Sturanya multicolor vavauensis n., Fundort: Vavan, Vergr. 1/6. Fig. 15-17. Sturanya interna Monsson, Fundort: Viti-Inseln, Vergr. 1/5. Fig. 18-21. Sturanya rabiginosa n., Fundort: Tongatabu, Vergr. 1/6. Fig. 22-24. Sturanya, parvula Pease, Fundort, Hervey-Inseln, Vergr. 1/10. Fig. 25-29. Staranya modesta Pfeiffer, Fundort: Salomonen, Vergr. 1/6. Fig. 30-33. Sturanya laciniosa Mighels, Fundort: Oabu, Vergr. 1/6.

\section{Tafel 7.}

Fig. 1-4. Alcadia (Eualcadia) palliata-C. B. Adam», Fundort: Jamaica, Vergr. 1/2,5. Fig. 5-8. Alcadia (Eualcadia) palliata brownei Gray, Fundort: Jamaica, Vergr. 1/3. Fig. 9-12. Alcadia (Eualcadia) hollandi Gray, Fnndort:Jamaica, Vergr. 1/3. Fig. 13-15. Alcadia (Eualcadia) citrinolabris C. B. Adams, Fundort: Jamaica, 1/2,5. Fig. 16-18. Alcadia (Eualcadia) citrinolabris C. B. Adams, Fundort: Jamaica, Vergr. 1/2,5. Fig. 19-21. Alcadia (Eualcadia) consangainea C. B. Adams, Fundort: Jamaica, Vergr. 1/2,5. Fig. 22-24. Alcadia (Eualcadia) microstoma C. B. Adam», Fundort: Jamaica, Vergr. 1/2,5, Fig. 25. Deckel von Alcadia major Gray, Vergr. 1/5.

\section{Tafel 8.}

Fig. 1-3. Alcadia (Enalcadia) velntina Poey, Fundort: Gnane auf Cuba, Vorgr. 1/5. Fig. 4-7. Alcadia (Eualcadia) dissimulans Poey, Fnndort: Guane anf Caba, Vergr. 1/5. Fig. 8-11. Alcadia (Eualcadia) hispida Pfeiffer, Fundort: Craba, Vergr. 1/6. Fig. 12. Alcadia (Eualcadia) hispida Pfeiffer, Fundort: Matanzas auf Cuba, Vergr. 1/6. Fig. 13-15. Alcadia(Eualcadia) fallax, n, Fundort: Ner Providence, Bahamas. Vergr. 1/5. Fig. 16-19. Alcadia (Eualcadia) gonostoma Gundlach, Fundort: Trinidad auf Cubb, Vergr. 1/5. Fig. 20-23. Aleadia (Eualcadia) minima d’Orbigny; Fundort: Havana anf Caba, Vergr: 1/6. Fig. 24. Aleadia (Eualcadia) dissimulans Poey, Fundort: Cuba, Vergr. 1/4. 
Tufel 9.

Fig. 1-3. Alcadia (Eualcadia) foveata Pfeiffer, Fundort: St. Thomas, Vergr. 1,6. Fig. 4-8. Alcndia (Eualcadia) proxima Gundlach, Fundort: Bayamo auf Cuba, Vergr. 1/6. Fig. 9-12. Alcadia (Eualcadia) bahamensis Pfeiffer, Fundort: Neu Providence, Vergr. 1/6. Fig. 13-16. Alcadia (Eualcadia) succinea Pfeiffer, Fundort: Haiti, Vergr. 1/5. Fig. 17-19. Alcadia (Eualcadia) intusplicata Pfeiffer, Fundort: Haiti, Vergr. 1/5. Fig. 20-22. Alcadia (Enalcadia) intusplicata smithiaua Pfeiffer, Fundort: Haiti. Vergr. 1/4. Fig. 23-26. Alcadia (Eualcadia) solitaria C. B. Adams, Fundort: Jamaica, Vergr. 1/5.

Fig. 10.

Fig. 1-4. Alcadia (Eualcadia) sericea Droüet, Fundort: Cayenne, Vergr. 1/6. Fig. 5-7. Alcadia (Eualcadia) sericea Kühni Pfeiffer, Fundort: Cayenue, Vergr. 1/6. Fig. 8-11. Alcadia (Eualcadia) sericea paraensis Pfeiffer, Fundert: Para, Brasilien, Vergr. 1/6. Fig. 12-15. Alcadia (Leialcadia) megastoma C. B. Adams, Fundort: Jamaica, Vergr. 1,5. Fig. 16-20. Alcadia (Leialcadia) megastoma dubiosa C. B. Adams, Fundort: Jamaica, 1/5. Fig. 21-25. Alcadia (Leialcadia) neebiana Pfeiffer, Fuudort: Noute Toro auf Cuba, Vergr. 1/4.

Tafel 11.

Fig. 1-4. Alcadia (Leialcadia) hjalmarsoui Pfoiffer, Fundort: Portorico, Vergr. 1/5. Fig. 5-8. Alcadia (Leial cadia) nitida Pfeiffer, Fundort, Cuba, Vergr. 1/6. F'ig. 9-12. Alcadia (Leialcadia) rotunda campanula, Pfeiffer, Fundort: Caba, Vergr. 1/4. Fig. 13. Alcadia (Leialcadia) rotuuda d'Orbigny, Fundort: Rangel auf Cuba. Vergr. 1/4. Fig. 14. Alcadia (Leialcadia) rotunda d'Orbigny, Fuudort: Cuba, Vergr. 1/5. Fig.15-18. Alcadia.(Leialcadia) rotunda glabra Gould,Fundort; Guane auf Cuba, Vergr. 1/6. Fig. $19-21$. Alcadia (Leialcadia) rotrinda montana Wright, Fundort: Cuba, Vergr, 1/6. Fig. 22-25. Alcadia (Leialcadia) gundlachi Pfeiffer, Fundort: San Juan de los Pinos, Gergr. 1,6.

Tafel 12.

Fig. 1-5. Alcadia (Leialcadia) bellula Gundlach $\alpha_{\text {., }}$ Fundort: Yateras auf Caba, Vergr. 1/4. Fig. 6-8. Aleadia (Leialcadia) bellula Gundlach, $\beta$., Fundort: Yateras auf Cuba, Vergr. 1/4. Fig. 9-10. Alcadia (Leialcadia] bellula bellissima n., $\alpha$., Fundort: Baracoa auf Cuba, Vergr. 1/4. Fig. 11-12. Alcadia (Leialcadia) bellula bellissima ß., Fundort: Baracoa auf Cuba, Vergr. 1/4. Fig. 13-14. Alcadia (Leialcadia) bellula leptochila n., Fundort: Monte Toro auf Cuba, Vergr. 1/4. Fig. 15-18., Alcadia (Leialcadia) concinna Gundlach, Fundort: Santjago de Cuba, Vergr. 1/5. Fig. 19-20. Alcadia (Lcialcadia) mamilla Weinland, Fundost: Haiti, Vergr. 1/5. Fig. 21-25. Alcadia (Leialcadia) oweniana Pfeiffer, Fundort: Mexico, Vergr. 1/3. Fig. 26-28. Alcadia (Leialcadia) oweniana anozona Martens, Fundort: Verapaz, Guatemala, Vergr. $1 / 4$. Fig. 29. Alcadia (Leialcadia) oweniana coccinostoma Morelet, Fundort: Guatemaa, Vergr. 1/4a.

Tafel 13.

Fig. 1-5. Alcadia (Lelaicadia) ampliata fuscocallosa n. Jamaica, Vergr. 1/3. Fig. 6-9. Alcadia (Leialcadia aurantia Gray, Jamaica, Vergr. 1/3. Fig. 10-12. Alcadia ampliata C. B. Adams, Jamaica, Vergr. 1/2,5. Fig. 13-16. Alcadia (Leialeadia) spectabilis Gundlach, Caba, Vergr. 1/5. Fig. 17-18. Alcadia (Leialcadia) spectabilis venusta n. Santjago de Cuba, Vergr. 1/6. Fig. 19-21. Alcadia (Leialcadia) nemoralis Guppy, Trinidad, Vergr. 1/3. Fig. 22-24. Alcadia (Leialcadia) trochalina d'Orbigny, Portorieo, Vergr. 1/6.

Tafel. 14.

Fig. 1. Deckel ron Aleadia nemoralis Guppy, Trinidad, Vergr. 1/5. Fig. 2. Deckel von Alcadia trochulina d’Orbigny, Vergr. 1/10, Fig. 3-6. Sturanya nesiotica Dall, Albemarle Insel, Vergr. 1/6. Fig. 7-8. Sturanya nesiotica wolf Reibisch, Chattam Insel, Vergr 1/6. Fig. 9-12. Alcadia (Leialcadia) fragilis Morelet, Vera 
paz, Vergr. 1/5. - Fig. 13. Alęadia (Leialcadia) fragilis mohriana Pfeiffer, Cordova Vergr. 1/5. Fig. $14-16$. Alcadia (Leialcadia) fragilis mohriana Pfeiffer Orizaba, Vergr. 1/5. Fig, 17-18. Alcadia (Leialcadia) gemma Preston, Costarica. Vergr. 1/4. Fig. 19-22. Alcadia (Leialcadia) beatrix Angas, Costarica, Vergr. 1/3. Fig. 23-21. Alcadia (Leialcadia) beatrix nigaragnae Nicaragua, Vergr. 1/3. Fig. 25. Alcadia (Leialcadia) beatrix confusa u. Nicaragua, Vergr. 1/3. Fig. 26-29. Alcadia (Leialcadia) tamsiana Pfeiffer, Venezuela Vergr. 1/4. 30-31. Alcadia (Leialcadia) tamsiana appuni Martens, Porto Cabello, Vergr. 1/3. Fig. 32-35 Alcadia (Leialcadia) colnmbiana Philippi‘ Caracas, Vergr. 1/3.

Tafel 15.

Fig. 1-3. Alcadia (Analcadia) antillarnm Sowerby, Martinique, Vergr. 1/2,5. Fig. 4-6. Alcadia (Analcadia) rufa Pfeiffer, Ynnca suf St. Domingo, Vergr. 1/4. Fig. 7-9. Alcadia (Analcadia) rufa salleana Pfeiffer, St. Domingo, 1/5. Fig. 10-12. Alcadia (Analcadia) humilis Guppj, Dominica, Vergr. 1/5. Fig. $13-15$. Alcadia (Analcadia) haitensis Maltzan, Haiti, Vergr. 1/4. Fig. 16-19. Alcadia (Analcadia) dysoni boconrti Crosse et Fischer, Nicacragua, Vergr. 1/6. Fig. 20-22. Alcadia (Analcadia) dysoni Pfeiffer, Trinidad, Vergr. 1/5.

Tafel 16.

Fig. 1-2. Alcadia (Analcadia) platyehila Mühlfeldt, Martinique, Vergr. 1/4. Fig. 3-4. Alcadia (Analcadia) phasianella Pfeiffer, Vieque. Vergr. 1/4. Fig. 5-8. Alcadia (Enalcadia) incrnstata Pfeiffer, Baracoa, Vergr. 1/4. Fig. 9-12. Alcadia (Eualcadia) nuda Pfeiffer, Barigua, Vergr. 1/2,5. Fig. 13-16. Alcadia (Analcadia) striata Lamarck, Portorico, Vergr. 1/3,5. Fig. 17-19. Alcadia (Analcadia) macmurrayi Pfeiffer, Santa Lucia, Vergr. 1/3. Fig. 20-22. Alcadia (Analcadia) guadelonpensis So-werby Guadeloupe, Vergr. 1/4.

Tafel 17,

Fig. 1-4. Aleadia (Emoda) sagraiana d'Orbigny, Fundort Rangel, Vergr. 1/4. Fig. 5-6. Alcadia (Emoda) sagraiana catalinensis, Pfeiffer, Fundort: Catalina. Vergr. 1/4. Fig. 7-9. Alcadia (Emoda) sagraiana emoda Pfeiffer, Fundort: Sumitero, Vergr. 1/4. Fig. 10-12. Alcadia (Emoda) briarea Poey, Fundort: Trinidad anf Cuba, Vergr. 1/4. Fig. 13-15. Alcadia (Emoda) pulcherrima titanica Poey, Fundort: Baracoa anf Cuba, Vergr. 1/4.

Trfel 18.

Fig. 1-4. Alcadia (Emoda) pnlcherrima bayamensis, Pundort: Bayamo anf Cuba, Vergr. 1/4. Fig. 5-6. Alcadia (Emoda) ciliata Poey, Fundort: Banao anf Cuba, Vergr. 1/4. Fig. 7-9. Alcadia (Emoda) ciliata guisana n., Fnndort: Gnisa anf Cuba, Vergr. 1/4. Fig. 10-12. Alcadia (Emoda) silacea Morelet, Fundort: Yunque bei Baracoa, Vergr. 1/4. Fig. 13. Deckel von Aleadia (Emoda) sagraiana d'Orbigny, Vergr. 1/3. Fig. 14. Deckel von Alcadia (Emoda) briarea Poey, Vergr. 1/3. Fig. 15. Deckel von Alcadia (Emoda) silacea Morelet, Vergr. 1/3. Fig. 16. Deckel von Alcadia (Emoda) pulcherrima titanica Poey, Vergr. $1 / 3$.

Tafel 19.

Fig. 1-4. Alcadia (Emoda) pnlcherrima Lea, Fundort: Santjago de Cnba, Vergr. 1/2,6. Fig. 5-6Alcadia (Emoda) pulcherrima crassa d'Orbigny, Fundort: Cajo seco, Vergr. 1/2,5. Fig. 7. Deckel von Aleadia (Emoda) submarginata Gray,. Fig. 8-10. Alcadia (Emoda) pulcherrima planospira, n., Fuadort: Cuba, Vergr, 1/2,5. Fig. 11-13. Alcadia (Emoda) submarginats Gray, Fundort: Matanzas, Vergr. 1/2,5. Fig. $14-17$. Alcadia (Emoda) ciliata Poey, Fundort: Trinidad anf Cuba, Vergr. 1/2,5.

Tafel 20.

Fig. 1-4. Entrochatella (Eutrochatella) tankervillii Gray, Fundort: Jamaica, Vergr. 1/2,5. Fig. 5-7, Eatrochatella (Eatrcchatella) palchella Gray, Fundort: Jamaica, Vergr. 1/3.5. Fig. 8-9. Eutrochatella (En. 
(rochatella) pulchella (Eutrochatella grayana Pfeiffer) Fundort: Jamaica, Vergr. 1/5. Fig. 10-11. Eutrochatella (Eutrochatella) chittiana Pfeiffer, Fundort: Jamaica, Vergr. 1/3. Fig. 12-14. Eutrochatella (Eutrochatella) josefinae C. B. Adams, Fundort: Jamaica, Vergr. 1/4,5. Fig. 15-16. Eutrochatella (Eutrochatella) globosa Gray, Fundort: Haiti, Vergr. 1/2,5. Fig. 17. Eutrochatella (Entrochatella) palchella Gray, Fundort: Jamaica, Vergr. 1/4.

\section{Tafel 21.}

Fig. 1. Eutrochatella (Eutrochatella) virginea Lea, Fnndort: San Domingo, Vergr. 1/2,5. Fig. 2. Eutrochatella (Eutrochatella) virginea crassicostata Sowerby, Fundort: San Domingo, Vergr. 1/2,5. Fig. 3-5. Entrochatella (Eutrochatella) chrysostoma Pfeiffer, Fundort: Insel Cuba, Vergr. 1/3. Fig. 6-8. Eutrochatella Eutrochatella) opima Shuttle worth, Fundort: El Rincon, San Domingo, Vergr.1/3. 9-12. Eutrochatella (Eutrochatella) costata Gray, Fundort: St. Anns, Jamaica, Vergr. 1,45. Fig. 13-14. Eutrochatella (Eutrochatella) eugeniania Weinland, Fundort: Jéremié auf Haiti, Vergr. 1/6. Fig. 15. Eutroehatella (Eutrochatella) engeniana weinlandi n., Fundort: Insel Haiti, Vergr. 1/6. Fig. 16-17. Eutrochatella (Eutrochatella) elegantula Pfeiffer, Fundort: San Domingo, Vergr. 1/6. Fig. 18-21. Eutrochatella (Eutrochatella) callida Weinland, Fundort: Crooked Insel, Vergr. 1/5. Fig. 22-23. Eutrochatella (Eutrochatella) littoricola Pfeiffer, Fundort: Baracoa anf Cuba, 1/6. Fig. 24-25. Eutrochatella (Eutrochatella) bryanti Pfeiffer, Fundort: Jnagua der Bahamas, Vergr. 1/5.

\section{Tafel 22}

Fig. 1-3. Eutrochatella (Eutrochatella) candida Pfeiffer, Fundort: Turks Insel, Vergr. 1/6. Fig. 4-7. Eutrochatella (Artecallosa) petitiana d'Orbigny, Fundort: Banao, Cuba, Vergr, 1/5. Fig. 8-9. Eutrochatella Artecallosa) rubicunda Pfeiffer, Fundort: Trinidad, Cuba, Vorgr. 1/6. Fig. 10-12. Eutrochatella (Artecallosa) petrosa Pleiffer, Fundort: Trinidad, Cuba, Vergr. 1/6. Fig. 13-14. Eutrochatella (Artecallosa) rupestris Pfeiffer, Fundort: Managua auf Cuba, 1/6. Fig. 15-16. Eutrochatella (Artecallosa) pfeifferiana Pfeiffer, Fundert: Yunque di Baracoa, Vergr. 1/10. Fig. 17-20, Eutrochatella (Artecallosa) microdina Morelot, Fundort: Verapaz Guatemale, Vergr. 1/10. Fig. 21-24. Eutrochatella (Artecallosa) continua Poey, Fundort: Guisa auf Cuba, 1/10. Fig. 25-28. Eutrochatella (Artecallosa) callosa Poej, Fundort: Fichteninsel bei Cuba, Vergr. $1 / 6$.

\section{Tafel 23}

Fig. 1-4. Eutrochatella (Artecallosa) elongata d'Orbigny, Fundort: Guajaibon auf Cuba, Vergr. 1/5. Hig. 5-6. Eutroehatella (Artecallọa) conica Pfeiffer, Fundort: Matanzas a uf Cuba, Vergr. 1/5. Fig. 7, 8, 10, 11. Eutrochatella (Ustronia) acuminata Poey, Fundort: San Diego bei Rangel, Vergr. 1/2,5. Fig. 9. Eutrochatella (Ustronia) acuminata columellaris Gundlach, Fundort: Rangel, Vergr. 1/2,5. Fig. 12. Eutrochatella (Ustronia) acuminata blandiana Fundort: San Diego, Vergr. 1/2,5 Fig. 13-15. Eutrochatella (Utronia) remota Poey, Fundort: Vignales Cuba, Vergr. 1/2,5. Fig. 16. Eutrochatella (Ustronia) sloanei d'Orbigny, Fundort: Havanna, Vergr. 1/3. Fig. 17. Eutrochatella (Ustronia) pyramidalis Sowerby, Fundort: Rangel, Vergr. 1/4. Fig. 18-21. Eutrochatella (Ustronia) straminea Morelet, Fundort: Raucho Lucas. Vergr. 1/4. Fig. 22-23. Eutrochatella (Ustronia) straminea rubromarginata Poej, Fundort: Guajaibon, Vergr. 1/4. Fig. 24. Eutrochatella (Ustronia) straminea politula Poey, Fundort: Rangel, Vergr. 1/4. Fig. 25. Eutroehatella (Ustronia) pyramidalis percarinata w., Fundort: Rangel, Vergr. 1/6.

\section{Tafel 24.}

Fig. 1-4. Eutrochatella (Ustronia) straminea nodae Arango, Fundort: Guira, Vergr. 1/4. Fig. 5. Eutrochatella (Ustronia) straminea festa Sowerhy, Fundort: Guajaibon; Vergr. 1/4. Fig. 6-7 Eutrochatella (Ustronia) wrighti Pfeiffer, Fundort: Vignales, Vergr. 1/3. Fig. 8-9. Eutrochatella (Ustronia) methfesseli 
Pfeiffer, Fundort: Sagua auf Cnba, Vergr. 1/10. Fig. 10-11. Eutrochatella (Ustronia) wrighti ranthaeme n., Fundort: Guajaibon, Vergr. 1/3. Fig. 12-13. Entrochatella (Ustronia) alboviridis Pfeiffer, Fundort: Isabel Maria auf Cuba, Vergr. 1/5. Fig. 14-15. Eutrochatella (Ustronia) fuscula Pfeiffer, Fundort: Luiz lazo auf Cuba, Vergr. 1/6. Fig. 16-18. Eutrochatella (Ustronia) scopulorum Morelet (luteo apicata Poey), Fundort: Fichteninsel, Vergr. 1/6. Fig. 19-21. Eutrochatella (Ustronia) cisnerosi Arango, Fundort: Pinar del Rio, Vergr. 1/10. Fig. 22-23. Eutrochatella (Ustronia) scopulorum Morelet. Fundort:| Fichteninsel, Vergr. 1/5. Fig. 24-35. Eutrochatella (Ustronia) rubella (Wright) Pfeiffer, Fundort: CaJos de \$an Felipe, Vergr. 1/6. Fig. 26-27. Eutrochatella (Ustronia) rabella citrino callosa n., Fundort: Vignales, Vergr. $1 / 5$.

Tafel 25.

Fig. 1, 2. Eutrochatella (Ustronia) jugulata Poey, Fundort: Guane, Vergr. 1/3. Fig. 3, 4. Eutrochatella (Ustronia) chrysochasma hernandezi Wright, Fundort: Vignales, Vergr. 1/5. Fig. 5, 6. Eutrochatella (Ustronia) chrysochasma jucunda Pfeiffer, Fundort: Guajaibon, Vergr. 1/3. Fig. 7. Eutrochatella (Ustronia) chrysochasma jucunda Pfeiffer, Fundort: Vignales, Vergr. 1/5. Fig. 8, 9. Eutrochatelca (Ustronia) chrysochasma Poey Pfeiffer, Fundort: Vignales, Vergr. 1/5. Fig. 10, 11. Eutrochatella (Ustronia) mestrei $\theta$ dango, Pfeiffer, Fundort: Pinar del Rio, Vergr. 1/5. Fig. 12. 13. Entrochatella (Bapata) regina Morelet, Fundort: Organosgebirge, Vergr. 1/2,5. Fig. 14. Eutrochatella (Hapata) regina laevigata Pfeiffer, Enndort: Portales de Guane, Vergr. 1/2,5. Fig. 15. Entrochatella (Hapata) regina laevigata Pfeiffer, Fundort: Pan de.Azucar, Vergr. 1/2,5. Fig. 16. Eutrochatella (Hepata) regina subunguiculata Poey, Fundort: Vignales, Vergr.1/25. Fig. 17. Eutrochatella (Hapata) regina subonguiculata Poey, Fundort: Salto Manantiales, Vergr. 1/2,5. Fig. 18, 19. Deckel von Eutrochatella (Hapata) regina Norelet vom Organosgebirge, Vergr. 1/5.

\section{Tafel 26.}

Fig. 1-5. Geophorus agglutinans Sowerby, Fundort: Dingle auf Panay, Vergr. 1/3. Fig. 6. Geophoras agglutinans Sowerby, Fundort: Guimaras, Vergr. 1/3. Fig. 7. Geophoras agglutinans solidulus Möllendorff, Fundort: Luban, Fergr. 1/3. Fig. 8-10. Geophorus agglutinans versicolor Möllendorff, Fundort: Sibuyan, Vergr. 1/3. Fig. 11. Geophorus agglutinans versicolor Möllendorff, Fundort: Tablas, Vergr. 1/3. Fig. 12-14. Geophoras agglutinans versicolor Möllendorff, Fandort: Romblon, Vergr./1/3. Fig. 15. Geophorus agglutinans versicolor Möllendorff.Fundort: Polillo, Vergr. 1/3. Fig. 16-17. Geophorus agglutinnns mindorensis n., Fundort: Mindoro, Vergr. 1/3. Fig. 18. Geophorns lazarus transitans n., Fundort: Libmannan, Vergrösserung 1/3. Fig. 19-23. Geophorus agglatinans cyrtopoma Möllendorff, Fundort: Morong, Vergr. 1/6.

\section{Tafel 27.}

Fig. 1-5. Geophorus lazarus Sowerby, Fundort: Palanan, Vergr. 1/3. Fig. 6-7. Geophorus lazarus uanus Möllendorff, Fundort: Sibul, Vergr. 1/6. Fig. 8-10. Geophorus lazarus monticolus Möllendorff, Fundort: Morong, Vergr. 1/6. Fig. 11. Geophorus oxytropis Gray, Fundort: Malawa, Celebes, Vergr. 1/6. Fig. 12-14. Geophoros.ozytropis Gray, Fnndort: Maros Celebes, Vergr. 1/6. Fig. 15-17. Geophorus oxytropis orientalis n., Fuudort: Kupang, Timor, Vergr. 1/6. Fig. 18-20. Geophoras oxytropis orientalis n.; Fundort: Amboina, Vergr. 1/6. Fig. 21-24. Geophorus oxytropis jagori Martens, Fundort: Java, Vergr. 1/8.

Tafel 28.

Fig. 1. Geophorus acutus Pfeiffer, Fundort: Leyte, Vergr. 1/3. Fig. 2-6. Geophoras acutus Pfeiffer, Fundort, Nord Samar, Vergr. 1/3. Fig. 7-9. Geophorus acutus peracutus, Fundort: Tablas, Vergr. 1/3. Fig. 10. Geophorus acutus Pfeiffer: Fundort: Bislig, 1/3. Fig. 11-12. Geophoras acutus intermedius Möllendorff, Fundort: Ceba, Vergr. 1/6. Fig. 13-17. Geophorus, nitidulus Möllendorff, Fundort: Manila, Vorgr. 1;3. Fig. 18-20. Geophorus rollei Sykes, Fundort: Insel Kangean, Vergr. 1/3. 
Tafel 29.

Fig 1-5. Geophoras psendomphalus Möllendorff, Fundort: Sibal, Vergr, 1/6. Fig. 6-8. Geophorns trochiformisSowerby, Fundort: Negros, Vergr. 1/6. F'ig. 9-11. Geophoras trochiformis Sowerby, Fundort: Karamaan, Vergr, 1/6. Fig. 12-14. Geophoras trochiformis subtrochiformis Möllendorff, Fundort: Monte Estravio, Vergr. 1/6. Fig. 15-16. Geophorus trochiformis conoidalis Möllendorff, Fundort: Marinduque, Vergr. 1/3. Fig. 17-19. Geophorus trochiformis gibbosulus Möllendorff, Fundort: Tayabas, Vergr. 1/6. Fig. 20-23. Geophoras bothropoma Möllendorff, Fundort: Karamuan, Vergr. 1/2,5.

Tafel 30.

Fig. 1-3. Geophorns aecutissimus Sowerby, Fundort: Leyte, Vergr. 1/3. Fig. 4-7. Geophorus accutissimns peracntissimas n., Fundort: Cebn, Vergr. 1/3. Fig. 8-9. Deckel von G. acntissimus Sowerby, Vergr, 1/10. Fig. 10-13. Geophorus acatissimas trochalas Möllendorff, Fundort: Romblon, Vergr. 1/6. Fig. 14-16. Geophorus exsertus Martens, Fundort: Saleier, Vergr. 1/6. Fig. 17-19. Geophorns exsertus major Smith, Fundort: Saleier, Vergr. 1/6. Fig. 20. Geophorns exsertus solidior Smith, Fundort: Kalao, Vergr. 1/6. Tafel 31.

Fig. 1-4. Geophorns agglntinans eos n., Fundort: Gunung Sekarat, Vergr. 1/3. Fig. 5. Geotrochatella nogieri Dantzeuberg et d'Hamonville, Fundort: Than-Moi, Vergr. 1/2,5. Fig. 6-8. Geotrochatella jourdyi excelsa n., Fandort: Pedalonga, Vergr. 1/3. Fig. 9-13. Aphanoconia samoana n., Fundort: Upolu, Vergr. 1/5. Fig. 14. Aphanoconia samoana vicina n., Fundort: Viti-Isseln, Vergr. 1/5. Fig. 15-16. Aphanoconia samoana diminata Mouson, Fundort: Tonga-Tuseln, Vergr. 1/5. Fig. 17-19. Aphanoconia zigzag Pease, Fandort: Ponape, Vergr. 1/5.

Tafel 32.

Fig. 1-3. Aphanoconia articulata Pfeiffer, Fundort: Neue Hebriden. Vaté, Vergr. 1/7. Fig. 4-8. Aphanoconia suturalis Martens, Fundort: Saparna, Vergr. 1/5. Fig. 9. Aphanoconia sutaralis Martens, Fundort: Kajeli, Bura, Vergr. 1/5. Fig. 10. Aphanoconia suturalis dammerensis A. J Wagner, Fundort: Dammer, Vergr. 1/5. Fig. 11. Aphanoconia altivaga Ancey, Fundort: Upola. Vergr. 1/5. Fig. 12-15. Aphąnoconia fnlgora Gould, Fundort: Sandwich-Inseln, Vergr. 1/7. Fig. 16-19. Aphanoconia gallina Gassies, Fundort: Loyalty-Inseln, Vergr. 1/7. Fig. 20-22. Aphanoconia oceanica Pease, Fondort: Apaiang, Vergr. 1/8. Fig. 23-26. Aphanoconia pentheri A. J. Wagner, Fundort: Tahiti, Vergr. 1/3.

\section{Tafel 33.}

Fig. 1. Aphanoconia sykesi Möllendorff, Fundort: Tomia, Vergr. 1/5. Fig. 2-3. Aphanoconia sykesi Möllendorff, Fundort: Tomia, Vergr. 1/3. Fig. 4-7. Aphanoconia discoidea Pease, Fundort: Tahiti, Vergr. 1/5. Fig. 8-9. Aphanoconia discoidea tumidior A. J. Wagner, Fundort: Raiatea, Vergr. 1/5. Fig. 10. Aphauoconia diseoidea subrufa, A. J. Wagner, Fundort: Raiatea, Vergr. 1/5. Fig. 11. Aphanoconia villosa Anton, Fundort: Opara, Vergr. 1/5. Fig. 12-14. Aphanoconia corrngata Pease, Fundort: Raiatea, Vergr. 1/7. Fig. 15-19. Aphanoconia timorensis n., Fundort: Atapapa, Timor, Vergr. 1/5. Fig. 20-24. Aphanoconia Keiensis A. J. Wagner, Fundort: Kel-Inseln, Vergr. 1/5.

\section{Tafel 34.}

Fig. 1-5. Aphanoconia dichroa Möllendorff, Fundort: Cebn, Vergr. 1/7. Fig. 6. Aphanoconia dichroa boholensis, Fundort: Ubay, Bohol, Vergr. 1/7. Fig. 7. Aphanoconia dichroa siquijorica, Fundort: Siquijor, Vergr. 1/7. Fig. 8-10. Aphanoconia theobaldina G. et H. Nevill, Fundort Silhuette, Sejchellen, Vergr. 1/5. Fig. 11-13. Aphanoconia andamanica Benson, Fundort: Andamanen, Vengr. 1/5. Eig. 14-19. Aphanoconia dunkeri Pfeiffer, Fundort: Camorta, Vergr. 1/3. Fig. 20-22. Aphanoconia nicobarica Philippi, Fundort: Mergui-Inseln, Vergr. 1/7. Fig. 23-26. A phanoconia deronledei Wattebled, Fundort: T'nron, Annam, Vergr. 1/7. 
Tafel 35.

Fig. 1-4. Aphanoconia borneensis Martens, Fnndort: Borneo. Vergr. 1/7. Fig. 5-9. Aphanoconia rlbocincta Hombron et Jacquinet, Fnndort: Aru-Inseln, Vergr. 1/5. Fig. 10-13. Aphanoconia trichroa A. J. Wagner, Fundort: Banguey, Vorgr. 1/5. Fig. 14. Aphanoconia trichroa calamianica A. J. Wagner, Fnndort: Insel Busnanga, Vergr. 1/5. Fig. 15-17. Aphanoconia submncronata Möllendorff, Fundort: NenGuinea, Vergr. 1/5. Fig. 18-20. Aphanocenia sculpta Martens, Fnndort: Knpang, Timor, Vergr. 1,5. Fig. 21-22. Aphanoconia Kalaoensis E. Smith, Fundort: Kalso, Vergr. 1/7.

Tafel 36.

Fig. 1-5. Aphanoconia semisculpta Ancey, Fnndort: Tenimber-Inseln, Vergr. 1/3. Fig. 6-10. Aphanoconia parnmscnlpta A. J. Wagner, Fundort, Viti-Inseln, Vergr. 1/4,5. Fig. 11-15. Apbanoconia tectiformis Monsson, Fundort: Viti-Inseln, Vergr. 1/3. Fig. 16-20. Aphanoconia sophiae Brazier, Fnndort: TreassnryInseln, Vergr. 1/5. Fig. 21-25. Aphanoconia rogosinscula Ancey, Fnndort: Samoa-Inseln, Vergr. 1/5.

Tafel 37.

Fig. 1-5. Aphanoconia ogasawarana Pilsbry, Fundort: Hahajima Ogasawara, Vergr. 1/5. Fig. 6. Aphanoconia ogasawarana.discrepans Pilsbry, Fnndort: Chichijima Ogasawara, Vergr. 1/6,5. Fig. 7. Aphanoconia ogasawarana imotojimana Pilsbry, Fundort: Imotojima Ogasawara, Vergr. 1/6,5. Fig. 8-10. Aphanoconia ogasawarana optima Pilsbry, Fnndort: Nishijima Ogasawara, Vergr. 1/5. Fig. 11. Aphanoconia ogasawarana arata Pilsbry, Furdort: Chichijima Ogasawara, Vergr. 1/5. Fig. 12. Aphanoconia ogaswarana optima Pilsbry, Fundort: Hahajima Ogasawara, Vergr. 1/5. Fig. 13-14. Aphanoconia yoshiwarana Pilsbry, Fundort: Hahajima Ogasawana, Vergr. 1/6,5. Fig. 15-19. Aphanoconia yoshiwarana microtheca Pilsbry, Fnndort: Hahajima Ogasawara, Vergr. 1/6,5. Fig. 20-22. Aphanoconia yoshiwarana comes Pilsbry, Fnndort: Nakanoshima, Vergr. 1/10. Fig. 23-24. Aphanoconia (Sphaeroconia) verecunda Gonld, Fundort: Loochoo. Vergr. 1/5.

Tafel 38.

Fig. 1-5. Aphanoconia (Sphaeroconia) hungerfordiana Möllendorff, Fundort: Hongkong, Vergr. 1/6. Fig. 6-9. Aphanoconia (Sphaeroconia) hungerfordiana tonkinensis Möllendorff, Fundort: Bach-Mru, Vergr. 1/5. Fig. 10-14. Aphanoc. (Sphaer.) hnngerfordiana formosana Schmacker et Boettger, Fnndort: Formosa, Vergr.1/6. Fig. 15-17. A phanoconia (Sphaeroconia) hnngerfordiana halongensis A.J. Waguer, Fnndort: Halong, Vergr. $1 / 6$. Fig. 18-20. Aphanoconia (Sphaeroconia) haynanensis Möllendorft, Fnndort: Haynan, Vergr. 1/6. Fig. 21-22. Aphanoconia (Sphaeroconia) haynanensis badia Schmacker et Boettger, Fundort: Formosa, Vergr $1 / 6$. Fig. 23-26. Aphanoconia (Sphaeroconia) osnmieusis Pilsbry, Fnndort: Kikai Osnmi, Vergr. 1/6.

Tafel 39.

Fig. 1-6. Aphanoconia (Sphaeroconia) capsnla Pilsbry, Fnndort: Hahajima Ogasawara, Vergr. 1/6. Fig. 7-10. Aphanoconia (Sphaeroconia) yaeyamensis Pilsbry, Fundort: Yaejama, Loochoo, Vergr. 1/6. Fig. 11-14. Aphanoconia (Sphaeroconia) pelewensis Shykes, Fundort: Coròre. Palan-Inssln, Vergr. 1/6 Fig. 15-18. Aphanoconia sphaeroconns Möllendorff, Fundort: Constantinhaven, Vergr. 1/5. Fig. 19-23. Aphanoconica (Sphaeroconia) eduardi A. Wagner, Fnndort: Tagnla, Lonisiaden, Vergr. 1/5. Fig. 24-27. Aphanoconia (Sphaeroconia) braueri A.J. Wagner, Fundort: Insel Woodlark, Vergr. 1/4.

Tafel 40.

Fig. 1-4. Aphanoconia (Sphaeroconia) gonldiana Forbes, Fnndort: Cap. Flattery, Vergr. 1/5. Fig. 5-9. Aphanṇconia (Sphaeroconia) subreticulata u., Fundort: Neue Hebriden, Vergr. 1/5. Fig. 10-12. Aphanoconia (Sphaeroconia) laeta Crosse, Fundort: Nen-Caledonien, Vergr. 1/3. Fig. 13-15. Aphanoconia I. 18. II. 2. II. 1911. 
(Sphaeroconia) noumeensis Crosse Fundort: Nouméa, Vergr. 1/10. Fig. 16-18. Aphanoconia (Sphaeroconia) gassiesiana Crosse, Fundort: Mont Cogui, Vergr. 1/4. Fig. 19-23. Aphanoconia (Sphaeroconia) gassiesiana allochroa n., Fundort: Pinieninsel, Vergr. 1/5. Fig. 24-25. A phanoconia (Sphaeroconia) gassiesiana sticta n.s Fundort: Nen-Caledonien, Vergr. 1.5.

Tafel 41.

Fig. 1-5 Aphanoconia (Sphaeroconia) macgillivrayi Pfeiffer, Fundort: Pinieninsel, Vergr. 1/5. Fig. 6. Aphanoconia (Sphaeroconia) macgillivrayi mediana Gassies, Fundort: Nouméa, Vergr. 1/5. Fig. 7-11. Aphanoconia (Sphaerocouia) togatula Merelet, Fundort: Neu-Caledonien, Vergr. 1/6. Fig. 12-15. Aphanoconia (Sphaeroconia) rossiteri Crosse, Fundort: Nen-Caledonien, Vergr. 1/3. Fig. 16-17. Aphanoconia (Sphaeroconia) porphyrostoma Crosse, Fundort: Neu Caledonien, Vergr. 1/5. Fig. 18-22. Aphanoconia (Sphaeroconia) mariae n., Fundort: Viti-Inseln, Vergr. 1/4. Fig. 23-2\%. Aphanoconia (Sphaeroconia) sublaevigata Pfeiffer, Fundort: Neu-Hebriden, Vergr. 1/4.

Tafel 42.

Fig. 1-5. Aphanoconia (Sphaeroconia) alrici Crosse, Fundort: Pinieninsel, Vergr. 1/5. Fig. 6-8. Aphanoconia (Sphaeroconia) dautzenbergi n., Fundort: Neu-Caledonien, Vergr. 1/5. Fig. 9-13. Aphanoconia (Sphaeroconia) mondaini Crosse, Fundort: Baie da Prony, Vergr. 1/6. Fig. 14-17. Aphanoconia (Sphaeroconia) mondaini fasciolata n., Fundort: Canala, Fen-Caledonien, Vergr. 1/5. Fig. 18. A phanoconia (Sphaeroconia) pachystoma ponsonbyi E. A. Smith, Fundort: Wild-Insel, Vergr. 1/4. Fig. 19-22. Aphanoconia (Sphaeroconia) pachystoma E. A. Smith, Fundort: Nen-Pommern, Vergr. 1/4. Fig. 23-24. Aphanoconia (Sphaeroconia) mouensis Crosse, Fundort: Mont Mou. Vergr. 1/4. Fig. 25-26. Deckel von Aphanoconia dautzenbergi $n$.

$\mathrm{Ta}$ (el 43 .

Fig. 1-3. Aphanoconia (Sphaeroconia) mariei Crosse, Fundort: Ile des Pins bei Neu-Caledonien, Vergr. 1/6. Fig. 4. Aphanoconia (Sphaeroconia) musiva vitiensis Mousson, Fundort: Viti Levu, Vergr. 1/6. Fig. 5-9. Aphanoconia (Sphaeroconia) musiva Gould, Fundort: Tonga-Inseln, Vergr. 1/6. Fig. 10. Aphanoconia (Sphaeruconia) musiva rotundata Monsson, Fundort: Tunafati (Ellice-Inseln, Vergr. 1/6. Fig. 11-13. Aphanoconia (Sphaeroconia) baudinensis E A. Smith, Fundort: Insel Baudin, Vergr. 1/6. Fig. 14-16. Aphanoconia (Sphaeroconia) minutissima n., Fundort: Nen-Caledonien, Vergr. 1/10. Fig. 17-21. Aphanoconia (Sphaeroconia) littoralis Montrouzier, Fundort: Neu-Caledonien, Vergr. 1/10. Fig. 22-25. Aphanoconia (Sphaeroconia) Küsteriana Pfeiffer, Fundort: Bora-Bora, Vergr. 1/8. Fig. 26. Aphanoconia (Sphaeroconia) Küsteriana Pfeiffer, Fundort: Tahiti, Vergr. 1/8.

\section{Tafel 44.}

Fig. 1-4. Aphanoconica (Sphaeroconia) rustica Pfeiffer, Fundort: Tahiti Vergr. 1/10. Fig. 5-7. Aphanoconia (Sphaeroconia) minuta Sowerby, Fundort: Opara, Vergr. 1/8. Fig. 8-10. Aphanoconia (Sphaeroconia) rusticana n., Fondort: Bora-Bora, Vergr. 1/10. Fig. 11-13. Aphanoconia; (Sphaeroconia) inconspicua Pfeiffer, Fundort: Tahiti, Vergr. 1/10. Fig. 14-18. Aphanoconia (Sphaeroconia) pazi Crosse, Pfeiffer, Fundort: Gambier-Inselu. 1/10. Fig. 19-23. Orobophana sphaeroidea Pfeiffer, Eundort: Ile des Pins, Vergr. 1/4. Fig. 24. Orobophana sphaeroidea Pfeiffer, Fundort: Prony-Bai in Nen-Caledonien, Vergr. 1/6. Fig. 25. Orobophana sphaeroidea Pfeiffer, Fundort: Nen-Caledonien, Vergr. 1/6. Fig. 26. Orobophana sphaeroidea lifouana Crosse, Fundort: Ile des Pins, Verge. 1/6.

Tafel 45 .

Fig. 1-2. Orobophana sphaeroidea lifouana Crosse, Fundort: Lifou-Inseln, Vergr. 1/4. Fig. 3. Orobophana flaveseens Pease, Fundort: Raratonga, Vergr. 1/5. Fig. 4-7. Orobophana tahitensis Pease, Fundort: 
Tahiti, Vergr. 1/5. Fig. 8. Orobophana brazieri Pease, Fundort: Nine, Vergr. 1/5. Fig. 9-10. Orobophana solidula colorata Pease, Fundort: Anaä, Vergr. 1/5. Fig. 11. Orobophana soliciula raiateae A. J. Wagner, Fundort: Raiatea, Vergr. 1/5. Fig. 12. Orobopbana calminans Monsson, Fundort: Vavaa, Vergr. 1/5. Fig. 13. Orobophana solidala Gray, Fundort: Elisabeth-Insel, Vergr. 1/5. Fig. 14-18. Orobophana oberwimmeri n., Fundort: Samoa, Vergr. 1/6. Fig. 19-21. Orobophana rohri Pfeiffer, Fundort: Marquesas. Vergr. 1/4. Fig. 22. Orobophana rohri nukahiwana n., Fundort: Nukahiwa, Vergr. 1/4. Fig. 23-24. Deckel von Orobophana miniata Lesson, Fundort: Bora-Bora.

\section{Tafel 46.}

Fig. 1-4. Orobophana albolabris Hombr. et Jaqu., Fundort: Tahiti, Vergr. 1/4. Fig. 5-7. Orobophaua mangeriae Gray, Fondort: Tahiti, Vergr. 1/3. Fig, 8. Orobophana mangeriae albinea Pease, Fnndort: Tabaä, Vergr. 1/3. Fig. 9-12. Orobophana uberta Gonld, Fundort: Sandwich-Inseln, Vergr. 1/5. Fig. 13-14. Orobophana constricta Pfeiffer, Fandort: Oaha, Vergr. 1/6. Fig. 15-16. Orobophana semperi Mousson. Fundort: Oneata, Viti-lnseln, Vergr. 1/4. Fig. 17-18. Orobophana pohliana Garrett, Fandort: Vata, Viti.Inseln, Vergr. 1/4. Fig. 19-21. Orobophana miniata Lesson, Fundort: Bora-Bora, Vergr. 1/4.

\section{Tafel 47.}

Fig. 1-5̃. Aphanoconia (Sphaeroconia) garrettiana Hartmann, Fundort: Marquesas, Vergr. 1/6. Fig. 6-10. Palaohelicina moquiniana Recloz, Fundort: Salomonen, Vergr. 1/2,5. Fig. 11. Palaeohelicina moquiniana christovalensis A. J. Wagner, Fundort: S. Christoval. Vergr. 1/2,5. Fig. 12. Palaeohelicina moquiniana ecarinata n., Fundort: Salomonen, Vergr. 1/2,5. Fig. 13-16. Palaeohelicina spinifera Pfeiffer, Fundort: Gaadalcanar, Vergr. 1/3,5. Fig. 17-18. Palaeohelicina spinifera inflata A. J. Wagner, Fundort: Neu-Irrland, Vergr. 1/3,5. Fig. 19-22. Palaeohelicina egregia Pfeiffer, Fundort: Gaadalcanar, Vergr. 1/3,5 Fig. 23-24. Palaeohelicina egregia incerta n., Fundort: Isabel, Vergr. 1/3,5.

Tafel 48.

Fig. 1-2. Palaeohelicina egregia isabelensis A. J. Wagner, Fundort: Isabel, Vergr. 1/3,5. Fig. 3-5, Palaeobelicina solitaria E. A. Smith, Fundort: Mont A strolabe, Vergr. 1/5. Fig. 6-9. Palaeohelicina Fischeriana MIontroazier, Fundort: Insel Woodlark, Vergr. 1/3. Fig. 10. Palaeohelicina Fischeriana congener E A. Smitb, Fondort: Insel St. Aignan, Vergr. 1/2,5. Fig. 11-12. Palaeohelicina Fischeriana phronema A. J. Wagner, Fundort: Insel Fergusson, 1/2,5. Fig. 13. Palaeohelicina Fischeriana elegans n., Fundort: Insel Fergusson. Vergr. 1/3. Fig. 14-18. Palaeohelicina insularnm Hedley, Fandort: Sudest-Insel, Vergr. 1/3.

Tafel 49.

Fig. 1-4. Palaeohelicina coxeni Brazier, Fundort: Yale-Inseln, Vergr. 1/3. Fig. 5-8. Palaeohelicina filiae A. J. Wagner, Fundort: Lousiaden, Vergr. 1/3, Fig. 9-12. Palaeohelicina ruffocallosa E. R. Sykes, Fundort: Palan-Inseln, Vergr. 1/3,5. Fig. 13-15. Palaeohelicina hara A. J. Wagner, Fundort: Louisiaden, Vergr. 1/4,5. Fig. 16-20. Palaeohelicina stanleyi Forbes, Fundort: Mailu, Neu Guinea, Vergr. 1/5. Fig. 21-22. Palaeohelicina stanleyi sinus Hedley, Fundort: Milne Bay, Nen-Guinea, Vergr. 1/5.

Tafel 50.

Fig. 1. Palaeohelicina stanleyi asphaleia A. J. Wagner, Fundort: Gazellen-Balbinseln, Vergr. 1/5. Ftg. 2-3. Palaeohelicina stanleyi rosselensis Hedley, Fundort: Insel Rossel, Vergr. 1/4. Fig. 4-8. Palaeohelicina (Ceratopoma) primeana Gassies, Fundort: Ile des Pins, Vergr. 1/4. Fig. 9-12. Palaeohelicina (Ceratopoma) caroli Kobelt, Fundort: Siargao, Philippinen, Vergr. 1/3,5. Fig. 13. Palaeohelicina (Ceratopoma) caroli emaculata Möllendorff, Fundort: Calbayoc, Samar, Vergr. 1/3,5. Fig. 14-16. Palaeohelicina (Ceratopoma) hennigiana Möllendorff, Fundort: Kagayan, Lazon, Vergn. 1/3,5. Fig. 17-19. Palaeohelicina 
(Ceratopoma) contermina Kobelt, Fundort: Paurian, Vergr. 1/4,5. Fig. 20-21. Palaeohelicina (Ceratopoma) contermina camigninensis A. J. Wagner, Fundort: Camignin, Lazon, 1/4,5. Fig. 22-24. Palaeohelicina (Ceratopoma) idae Pfeiffer, Fundort: Hulaliu-Haruka, Molukken, Vergr. 1/45.

\section{Tafel 51.}

Fig. 1-3. Palaeohelicina (Ceratopoma) rosaliae Pfeiffer, Fundort: Baler, Lazon, Vergr. 1/4,5. Fig. 4-6. Palaeohelicina (Ceratopoma) quadrasi Möllendorff, Fundort: Manamban, Lazon, Vergr. 1/4,5. Fig. 7-9. Palaeohelicina (Ceratopoma) zoae Pfeiffer, Fundort: Halmahera, Vergr, 1/4,5. Fig. 10-13. Palaeohelicina (Ceratopoma) zoae gebeana E. A. Smith, Fundort: Insel Gebi, Vergr. 1/4,5. Fig. 14, Palaeohelicina (Ceratopoma) jobiensis Tapparone Canefri, Fundort: Kapaor in Nen-Gainea, Vergr. 1/4,5. Fig. $15-17$. Palaeohelicina (Ceratopoma) jobiensis, Fundort: Insel Jobi, Vergr. 1/4,5. Fig. 18-21. Palaeohelicina (Ceratopoma) layardi Hartmann, Fundort: Espirita Santo, Vergr. 1/4. Fig. 22. Palaeohelicina (Ceratopoma) layardi Hartmann, Fundort: Esfoti Neue Hebriden, Vergr. 1/4. Fig. 23-25. Palaeobelicina (Ceratopoma) fumigata Cor, Fundort: Rockhampton in Queensland, Vergr. $1 / 6$.

Tafel 52.

Fig. 1-4. Palaeohelicina (Ceratopoma) jana Cox, Eundort: Port Macquarie, Vergr. 1/6. Fig. 5-7. Palaeohelicina (Ceratopoma) diversicolor Cox, Fundort: Richmond, Oneensland, Vergr. 1/4,5. Fig. 8. Palae0helicena (Ceratopoma) gladstonensis Cox, Fundort: Queensland, Vergr. 1,8. Fig. 9-10. Palaeohelicina (Ceratopoma) gladstonensis Cox, Fundort: Gladstone Queensland, Vergr. 1.8. Fig. 11-13. Hemipoma sadoense Pilsbry, Fundort: Sado, Japan, Vergr. 1/7,5. Fig. 14-17. Hemipoma hakodadiense Hartmann, Fundort: Hakodati Japan, 1/7,5. Fig. 18-19. Aphanoconia hirasei H. A. Pilsbry, Fondort: Bonin-Inseln, Vergr. 1/7. Fig. 20-24. Aphanoconia papuana E. A. Smith, Fandort: Konstantinharen, Vergr. 1/5.

Tafel 53.

Fig. 1-4. Aphanoconia heterochroa A. J. Wagner, Fundort: Palan-Inseln, Vergr. 1/3,5. Fig. 5-7. Helicina brasiliensis Gray, Fundort: Blumenan, Brasilien, Vergr. 1/5. Fig. 8. Helicina brasiliensis Gray, Fundort: Sao Paolo, Brasilien, Vergr. 1/5. Fig. 9-10. Helicina brasiliensis menkeana Philippi: Fundort: Sao Paolo, Brasilien, Vergr. 1/5. Fig. 11-13. Helicina densestriata n., Fundort: Serra do Mar, Sao Paolo, Brasilien, Vergr. 1/5. Fig. 14-16. Helicina brasiliensis menkeana, Philippi, Fundort: Minas Geraes, Brasilien, Vergr. 1/3. Fig. 17-19. Helicina wettsteini A. J. Wagner, Fundort: Serra Parana, Sao Paolo, $\nabla$ crgr. $1 / 3,5$.

\section{Tafel 54.}

Fig. 1-5. Helicina angulata Sowerby, Fundort: Sao Paolo, Brasilien, Vergr. 1/3. Fig. 6-10. Helicina inaequistriataPilsbry, Fundort: Ruiz de la Sierra, Brasilien, Vergr. 1/3. Fig. 11. Helicina angulata leopoldinae, Fundort: St. Leopoldina, Brasilien, 1/2:5. Fig. 12-15. Helicinae caracolla Moricand, Fundort: Brasilien, Vergr. 1/2,5. Hig. 16. Helicina caracolla moreletiana Pfoiffer, Fundort: Bahia, Vergr. 1/2,5. Fig. 17-19. Helicina iguapensis Pilsbry, Fundort: Ignape, Brasilien, Vergr. 1/2,5. Fig. 20-21. Helicina leptotropis $\mathrm{n}_{\text {, }}$ Fundort: Sao Paolo, Brasilien, Vergr. 1/3.

\section{Tafel 55.}

Fig. 1-б. Helicina variahilis Wagner, Fundort: Bahia, Vergr. 1/2,5. Fig. 6-8. Helicina angulifera n. Fundort: Bahia, Vergr. 1/3. Fig. 9. Helicina variabilis Wagner, Fundort: Ignape, Brasilien, Vergr. 1/2,5. Fig. 10. Helicina besckei Pfeiffer, Fundort: Nen Freiburg, Brasilien, Vergr. 1/2,5. Fig. 11-12. Helicina tilei Pfeiffer, Fundort: Brasilien Vergr. 1/3. Fig. 13-14. Helicina haemastoma Moricand, Fundort: Brasilien, Vergr. 1/3. Fig. 15-16. Helicina rotundata n., Fundort: Brasilien, Vergr. 1/5. Fig. 17-19. Helicina lundi 
Pfuiffer, Fundort: Brasilien, Vergr. 1/5. Fig. 20-21. Helicina fulva d'Orbigny, Fundort: Coramba Agosta, Bolivia, Vergr. 1/3,5. Fig. 22-23. Helicina fulva d'Orbigny, Fundort: Chiquita, Bolivia, Vergr. 1/3,5.

Tafel 56

Fig. 1-5. Helicina concentrica Peiffer, Fundort: Merida, Venezuela, Vergr. 1/3,5. Fig. 6-10. Helicina pandiensis A. J. Wagner, Fundort: Pandi, Neu Granada, Vergro 1/3,5, Fig. 11-14. Helieina schlüteri A. J. Wagner, Fundort: Callanga, Pern, Vergr. 1/3,5. Fig. 15-17. Helicina schlüteri chanchamayensis n., Fundort: Chanchamayo, Vergr. 1/3,5, Pera. Fig. 18. Helicina schlüteri densesuleata n., Fundort: Chanchamayo, Pera. Vergr. 1/3,5. Fig. 19-23. Helicina lirifera Aneey, Fundort: St. Cruz de la Sierra, Bolivia, Vergr. 1/3,5. Fig. 24. Helicina ernesti rhynchostoma Shattleworth, Fundort: Columbia, Vergr. 1/2,5.

Tafel 57.

Fig. 1-5. Helicina ernesti Martens, Fundort: Caracas, Veneznela, Vergr. 1/2,5. Fig. 6-8. Helieina conus n., Fundort: Chanchamayo, Pern, Vergr. 1/3,5. Fig. 9-12. Helicina laus A. J. Wagner, Fundort: Ucagalital in Pera., Vergr. 1/3,5 Fig. 13-16. Helicina phakos $n_{0}$, Fundort: Yucatital in Pera, Vergr. 1/6. Fig. 17-19. Helicina infesta A. J. Wagner, Fundort: Venezuela, Vergr. 1/2,5.

\section{Tafel 58 .}

Fig. 1-3. Helicina sulfurea Ancey, Fundort: St. Cruz de la Sierra, Bolivia, Vergr. 1/6. Fig. 4-6. Helicina decorosa n., Fundort: Mrzo, Columbien, Vergr. 1/3,5. Fig. 7-11. Helicina oeanensis A. J. Wag. ner, Fundort: Ocana, Columbien, Vergr. 1/2,5. Fig. 12-16. Helinia steindachneri A. J. Wagner, Fundort: Frontino, Columbien, Vergr. 1/2,5. Fig. 17. Helicina steindachneri superstructa, A. J. Wagner, Fundort: Frontino Columbien, Vergr. 1/2,5.

Tafel 59.

Fig. 1-2. Helicina sinuosa Pfeiffer, Fundort: Merico, Vergr. 1/2,5. Fig. 3-5. Helicina ghisbrechti Pfeiffer, Fundort: Izapuato in Mexico, Vergr. 1/2,5. Fig. 6-8. Helicina punctisculcata Martens, Fundort: Omitteme in Merico, Vergr. 1/3. Fig. 9. Helicina punetisuleata zunilensis n., Fundort: Vulkan Zunil, Guatemala., Vergr. 1/3. Fig. 10-12. Helicina amoena Pfeiffer, Fundort: Panzos, Guatemala, Vergr. 1/3. Fig. 13. Helicina cinctella Shattleworth, Fundort: Orizaba, Mexico, Vergr. 1/3,3. Fig. 14-17. Helieina cinctella Shuttleworth, Fundort: Cordoba, Mexico, Vergr. 1/3,3 Fig. 18-19. Helicina bautistae n. Fundort: S. Juan Bantista, Mexico, Vergr. 1/3,3. Fig. 21-24. Helicina cordillerae (Sallé) Pfeiffer, Fundort: Jacale, Mexico, Veegr. 1/3. Fig. 25. Helicina cordillerae (Sallé) Pfeiffer, Fundort: Atayoc, Merieo, Vergr. 1/3.

Tafel 60.

Fig. 1-3. Helieina borealis Martens, Fundort: Durango. Mexico, Vergr. 1/3,3. Fig. 4-6. Helicina durangoana Monswon, Fundort: Darango, Merico, Vergr. 1/3,3. Fig. 7. Helicina durangoana saynlensis vo, Fundort: Sayula, Jalisco, Merico, Vergr. 1/3,3. Fig. 8-12. Helicina bourguignatiana Ancey, Fundort: Santa Cruz de la Sierra, Verar. 1/3,3. Fig. 13-14. Helicina bourguignatiana Ancey. Fundort: Urubamba, Pera, Vergr. 1/3,3. Fig. 15-19. Helicina tenuis Pfeiffer, Fundort: Merzedes, Guatemala, Vergr. 1/3. Fig. 20. Helicina tenuis Pfeiffer, Fundort: Totonicapan, Guatemala, Vergr. 1/3,3. Fig. 21. Helieina tenuis Pfeiffer, Fundort: Coban, Gaatemala, Vergr.1/3. Fig. 22. Helicina tenuis Pfeiffer, Fundort: Chiapas, Mexico. Vergr. 1/3, Fig. 23. Helicina tenuis Pfeiffer, Fundort: Teapa. Merieo, Vergr. 1/3. Fig. 24. Helieina tenuis pittieri n., Fundort: Rio de los Platanales, Costarica, Vergr. 1/3. Fig. 25. Helicina tenuis Pfeiffer, Fundort; $\Delta$ lajuela, Costarica, Vergr. 1/3. 
Tafel 61.

Fig. 1-5. Helicina orbicnlata Say, Fondort: Woodville in Alabama, Vergr. 1/3,3. Fig. 6. Helicina orbiculata Say, Fundort: Texas, Vergr. 1/3,3. Fig. 7-10. Helicina senachnensis A. J. Wagner, Fundort: Senachu in Guatemala, Vergr. 1/3,3. Fig. 11-15. Helicina Funcki Pfeiffer, Fundort: Azachar Centajo in Costarica, Vergr。 1/2,3. Fig. 16. Helicina Funcki costaricensis A. J Wagner, Fundort: St. Clara in Costarica, Vergr. 1/2 3. Fig. 17-19. Helicina pitalensis n., Fundort: El Pital in Costarica, Vergr. 1/2,3. Fig. 20-24. Helicina turbinata Menke, Fundort: Cordova in Mexico, Vergr. 1/2,3. Fig. 25. Helicina tarbinata Menke, Fnndort: Jalapa in Mexico, Vergr. 1/2,3.

Tafel 62.

Fig. 1-8. Helicina deppeana Martens, Fnndort: Deppe in Mexico, Vergr. 1/2,5. Fig. 4-8. Helicina delicatula Shnttleworth, Fnndort: Cordova in Mexico, Vergr. 1/8,3. Fig. 9. Helicina delicatnla Shattleworth, Fundort: Vera Craz in Mexico, Vergr. 1/3,3. Fig. 10-14. Helicira trossula Morelet, Fnndort: Vera paz in Gnatemale, Vergr. 1/3,3. Fig. 15-18. Helieina rostrata Morelet, Fundort: Guatemala, Vergr. 1/2,5. Fig. 19. Helicina rostrata mategalpensis n., Fundort: Mategalpa in. Nikaragua, Vergr. 1/2,5. Fig. 20-22. Helicina denticulata Pfeiffer, Fundort: San Pedro in Honduras, Vergr. 1/2,5. Fig. 23-27. Helicina notata Pfeiffer, Fundort: Cordova in Mexico. Vergr. 1/3,3.

Tafel 63.

Fig. 1-5. Helicina raresulcata Pfeiffer, Fnndort: Verz Crns in Mexico, Vergr. 1/5,3. Fig. 6-10. Helicina succincta Martens. Fundort: Misanthe in Mexico, Velgr. 1/3,3. Fig. 11-13. Helicina arenicola Morelet, Fundort: Sicul in Xucatan, Vergr. 1/5,3. Fig. 14. Helicina brevilabris Pfeiffer, Fundort: Tabaseo in Mexico, Vergr. 1/5,3. Fig. 15-18. Hel. brevilabris Pfeiffer, Fundort: Mirador, Vergr. 1/5,3. Fig 19. Hel. brevilabris incommoda A. J. Wagner, Enndort: Guatemala. Vergr. 1/5,3. Fig. 20-24. Helicina microdina Morelet, Fundort: Vera paz in Gnatamala, Vergr. 1/5,3. Fig. 25-27. Helicina adspersa Pfeiffer, Fundort: Cuba, Vergr. 1/2,3. Fig. 28. Helicina adspersa Pfeiffer, Fundort: Organos Gebirge anf Caba, Vergr. 1/2,3. Tafel 64.

Fig. 1. Helicina festiva Sowerby, Fundort: El Barro Ahajo in St. Domingo, Vergr. 1/2,2. Fig. 2. Helicina festiva enmingiana Pfelffer, Fondort: Insel Haiti, Vergr. 1/2,2. Fig. 3. Helicina festiva maltzani n., Fundort: Dondon anf Haiti, Vergr. 1/2,2. Fig. 4-6. Helicina festiva malleata Pfeiffer, Fundort: Insel Haiti, Vergr. 1/2,2. Fig. 7. Deckel von H. festiva Sowerby. Fig. 8-11. Helicina viridis Lamarck, Fnndort: Insel Haiti, Vergr. 1/5,3. Fig. 12-17. Helicina subglobulosa Poey, Fundort: Bayamo auf Cuba, Vergr. 1/2 8. Fig. 18-22. Helicina subglobulosa poeyi. Pfeiffer, Fundort: Guantanamo anf Cnba, Vergr. 1/3,3. Fig. 23-26. Helicina subglobulosa snbdepressa Poey, Fundort: Cabo Cruz auf Cuba, Vergr. 1/5,3.

Tafel 65

Eig. 1-3. Helicina declivis Pfeiffer, Fundort: Baracoa anf Cnba, Vergr. 1/5,3. Fig. 4-8. Helicina reeveana Pfeiffer, Fundort: Yateras auf Caba, Vergr. 1/3,3. Fig. 9-12. Helicina globulosa d'Orbigny, Fundort: Cardenas anf Cuba, Vergr. 1/5,3. Fig. 13-17. Helicina lembeyana Poey, Fundort: Punta Mais anf Cubs, Vergr. 1/5 3. Fig. 18-22. Helicina neritella Lamarck, Fundort: Jamaica, Vergr. 1/2,8. Fig. 23-24. Helicina neritella reducta n., Fundort: Jamaica, Vergr. 1/2.8. Fig. 25. Helicina neritella diplocheila A. J. Wagner, Fundort: Montego Bay, Jamaica, Vergr. 1/2,8.

Tafel 66.

Fig. 1-5. Helicina heatei Pfeiffer, Fundort: Grenada, Vergr. 1/2,8. Fig. 6-8. Helicina jamaicensis Pfeiffer, Fundort: Jamaica, Vergr. 1/3,3. Fig. 9-10. Helicina rhodostoma Gray, Fundort: Guadelonpe, Vergr. 1/2 8. Fig 11-13. Helicina rhodostoma inermis n., Fundort: Guadeloupe, Vergr. 1/2.8. Fig. 14-17. 
Helicina goldfassi Boettger, Fandort: Insel Dominica, Vergr. 1/5,3. Fig. 18-21. Helicina oxyrhyncha Crosse et Debeaux, Fundort: Insel Bonacca in Honduras, Vergr, 1/2,8. Fig. 22-24. Helicina oceidentalis Gailding, Fundort: St. Vincent, Vergr. 1/2,8.

\section{Tafel 67.}

Eig. 1-4. Helicina fasciata Lamarck, Fundort: Insel Vique bei Portorico, Vergr. 1/3,8. Fig. 5. Helicina fasciata Lamarck, Fundort: Antillen, Vergr. 1/5,3. Fig. 6-7. Helicina fasciata substriata Gray, Fundort: Barbados, Vergr. 1/3,8. Fig. 8-9. Helicina fasciata convexa Pfeiffer, Fundort: Bermadas, Vergr. 1/3,8. Fig. 10-12. Helicina boettgeri n., Fundort: SaoLeopoldo, Espiritu Santo, Vergr. 1/5. Fig. 13-15. Helicina oskari n., Fundort: Sao T,eopoldo, Espirita Santo, Vergr. 1/4. Fig. 16-18. Lacidella undulata Pfeiffer, Fundort: Jamaica, Vergr. 1/4. Fig. 19-20. Lucidella aureola Ferassac, Fundort: Jamaica, Vergr. 1/8. Fig. 21-24. Lucidella umbonata Shuttleworth, Fundort: Portorico, Vergr. 1/6.

\section{Tafel 68.}

Fig. 1-3. Alcadia (Analcadia) dominicensis Pfeiffer, Fundort: Haiti, Vergr. 1/6. Fig. 4. Lucidella lirata lamellosa Gappy, Fundort: Trinidad, Vergr. 1/6,5. Fig. 5-7. Lucidella lirata Pfeiffer, Fundort: San Juan Bantista, Vergr. 1/b,5. Fig. 8-9. Lacidella lineata C. B. Adams, Fundort: Jamaica, Vergr. $1 / 8$. Fig. 10-11. Lucidella fori Pilsbry, Fundort: Jamaica, Vergr 1/8. Fig. 12-13. Lucidella nana Pfeiffer, Fundort: Jamaica, Vergr. 1/10,3. Fig. 14-15. Lacidella granum Pfeiffer, Fundort: Caba Buenarista, Vergr. $1 / 8$. Fig. 16-17. Lucidella depressa Gray, Fundort: Jamaica, Vergr. 1/5,5. Fig. 18-20. Lacidella adamsiana Pfeiffer, Fundort: Jamaica, Vergr. 1/4. Fig. 21. Lacidella adamsiana coronula Pfeiffer, Fundort: Jamaica. Vergr. 1/4. Fig. 22-23. Lacidella wolffi Boettger, Fundort: Miragoane Haiti, Vergr. 1/5.

Tafel 69.

Fig. 1-2. Lucidella paivana Pfeiffer, Fundort: Port an Prince, Haiti, Vergr. 1/5. Fig. 3. Lucidella paivana decussnta Boettger, Fundort: Miragoana Haiti, Vergr. 1/5. Fig 4-7. Lucidella plicatala Pfeiffer, Fundort: Martiniqne, Vergr. 1/8. Fig. 8-9. Lucidella ragosa Pfeiffer, Fundort: Trinidad auf Caba, Vergr. 1/6,5. Fig. 10-11. Lacidella vinosa Shattle. worth, Fundort: San Jaan auf Portorico, Vergr, 1/8. Fig. $12-13$. Lacidella Kobelti n., Fandort: Jamaica. Vergr. 1/5. Fig. 14-15. Lacideila denseplicata n. Fund ort: St. Lacia, Vergr. 1/8. Fig. 16-19. Lacidella holoserica n., Fundort: Barbados, Vergr. 1/8. Fig 90-21. Schasicheila alata Pfeiffer. Fundort: Cordova in Mexico, Vergr. 1/3,2.

Tafel 70.

Fig. 1-4. Schasicheila pannucea Morelet, Fundort: Senachu Guatemala, Vergr. 1/3,2 Fig. ๖-6. 8chasicheila fragilis Pilsbry, Fundort: Mexico, Vergr. 1/.,2. Fig. 78 Alcadia iheringi n., Fundort: Sao Paalo Brasilien. Vergr. 1/8. Fig. 9-11. Schasicheila pilsbryi. Merico Vergr. 1/3,2. Fig. 12-14. Aleadia (Analcadia) moussoniana Pfeiffer, Fundort: Turks Inseln, Vergr. 1/i,5. Fig. 15-17. Alcadia (Leialcadia) schrammi Grosse, Fundort: Guadeloupe, Vergr. 1/6,5. Fig. 18-20. Geophorue oxytropis opacus Boettger, Fundort: Tjerah, Tenimber Inseln, Vergr. 1/4. Fig. 21-24. Aphanoconia subsuturalis Boettger, Fandort: Marschall Inseln, Vergr. 1/6,5. 

I.18. II.
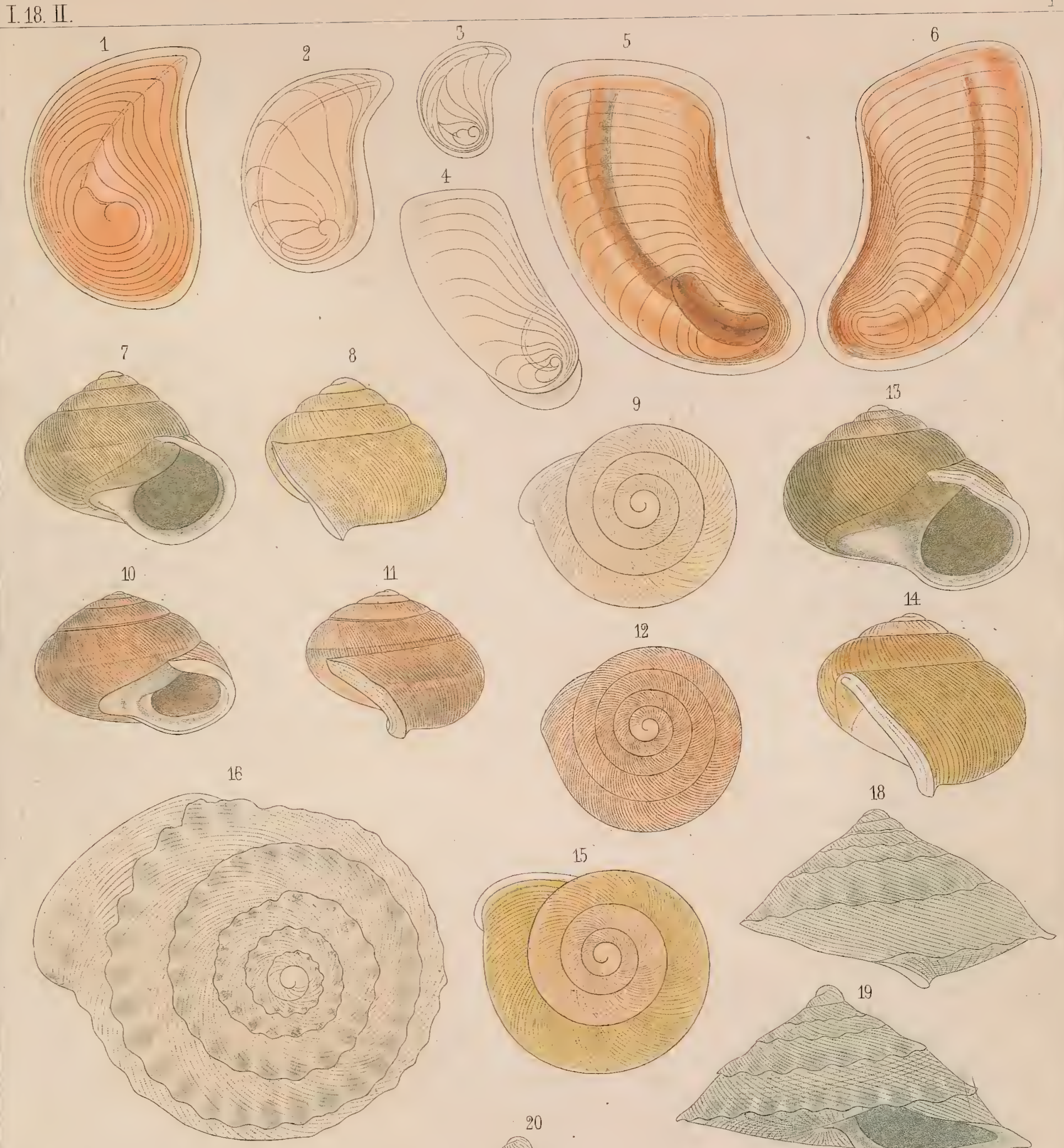

20
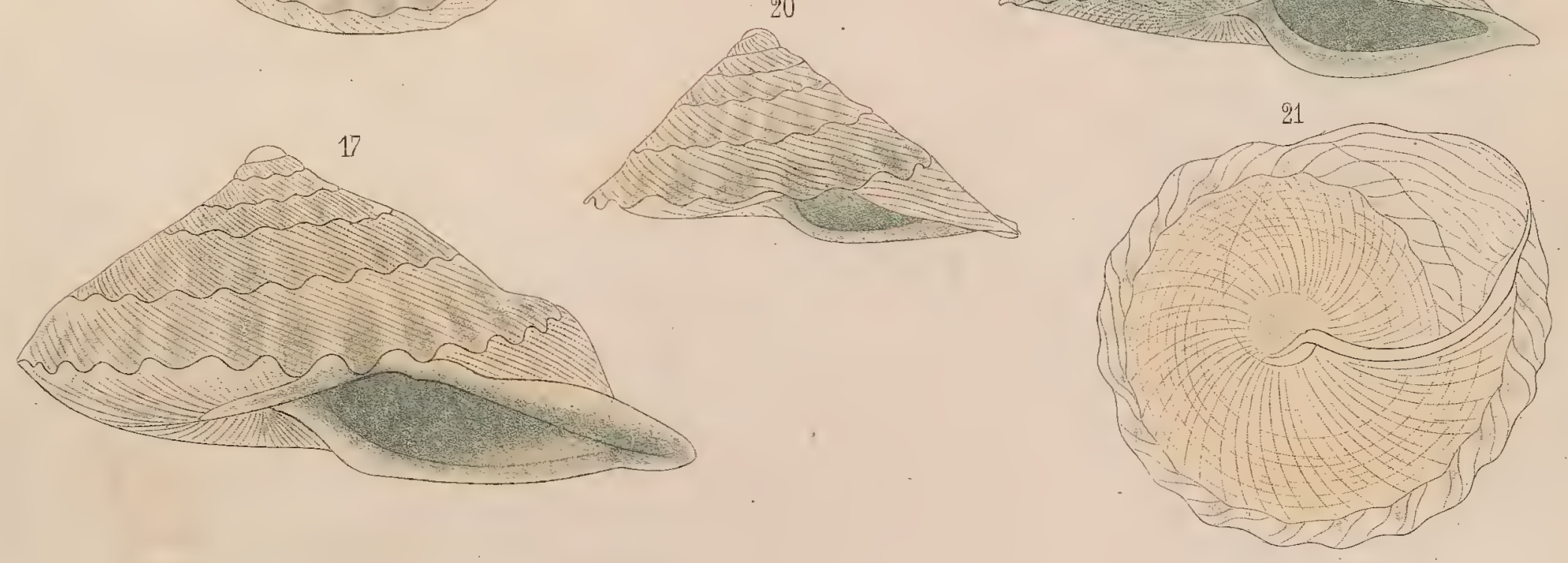


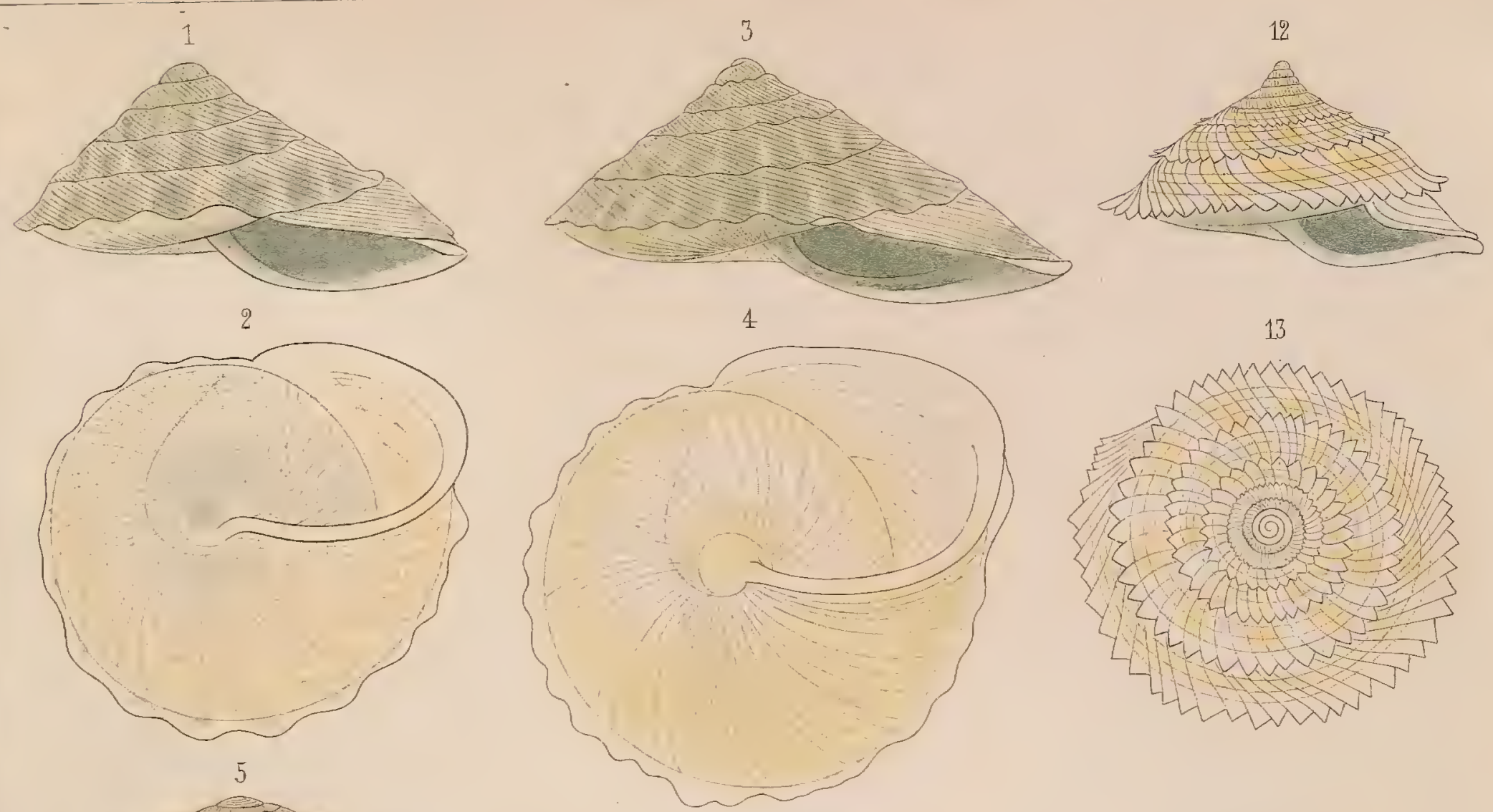

13
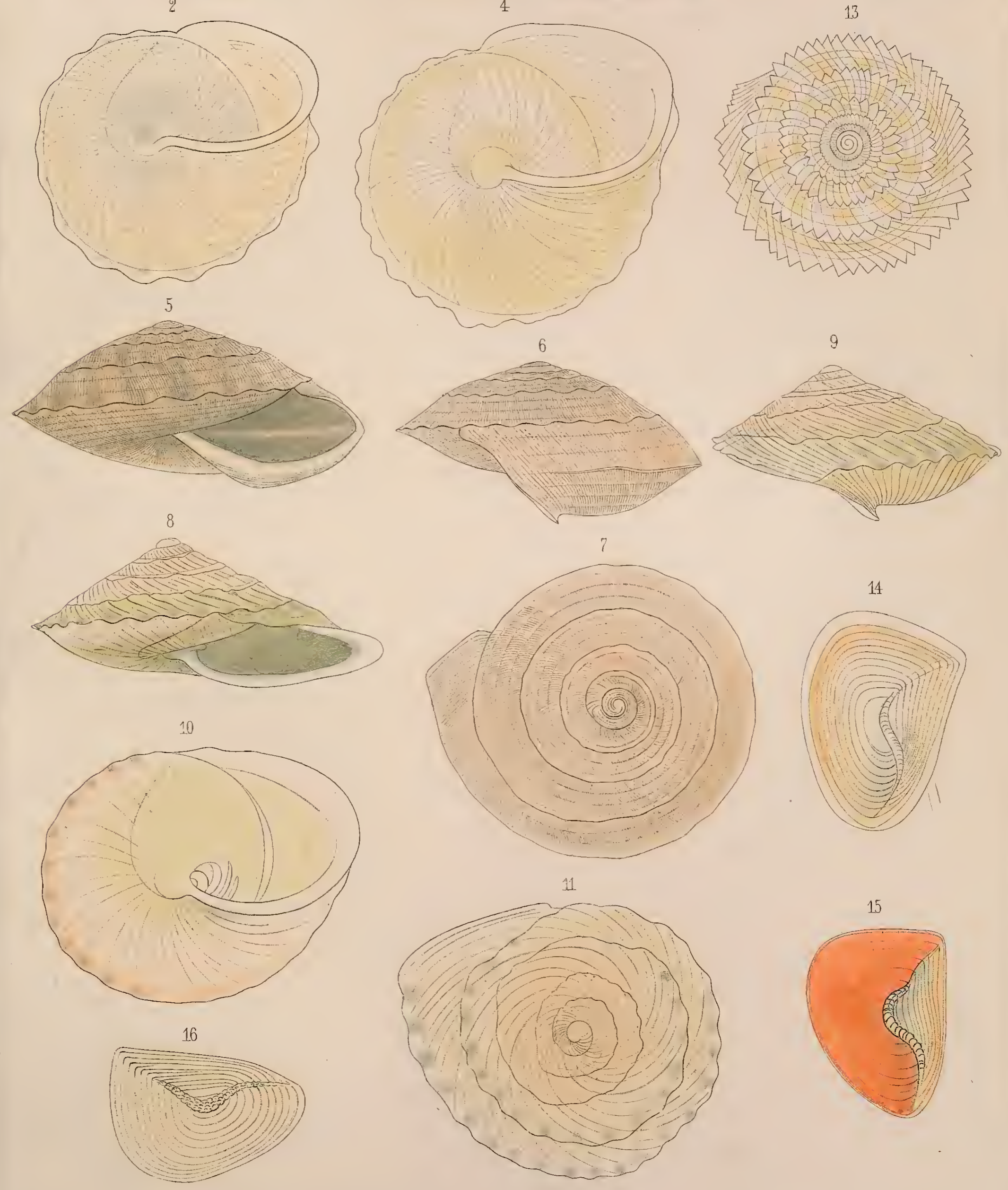

I.18 II.

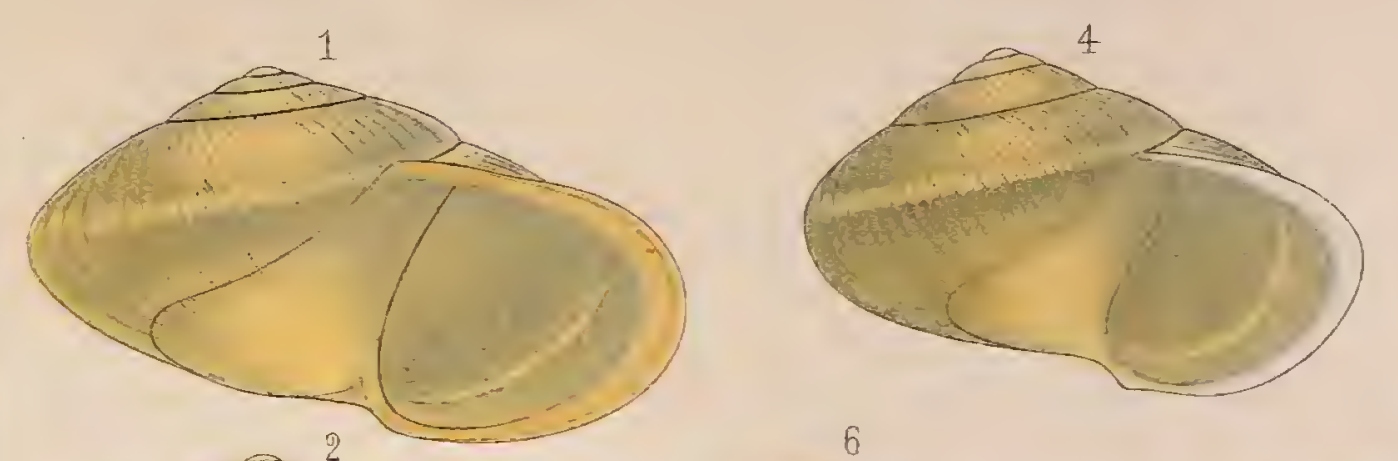

3.
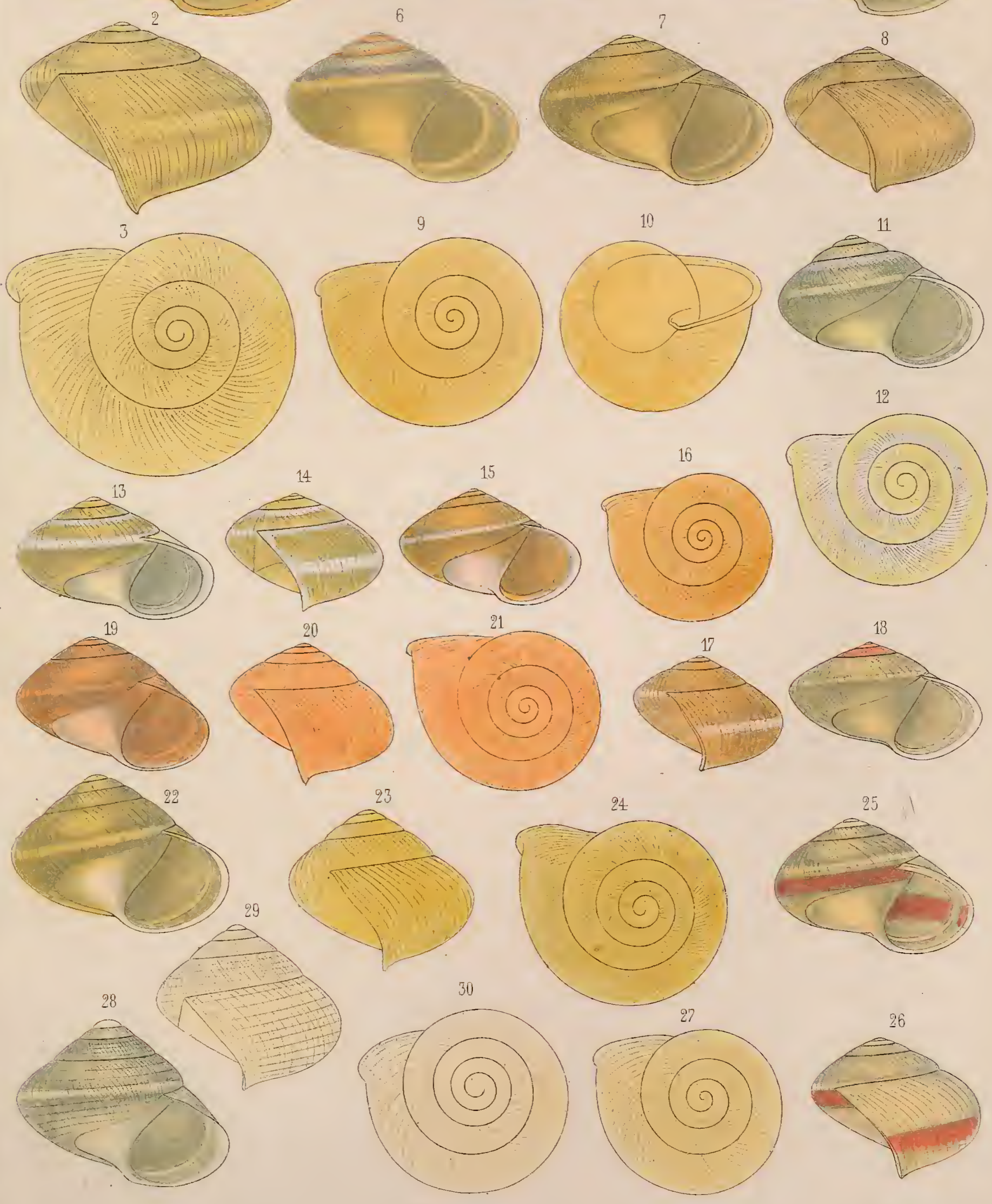

I.18. II.

4.

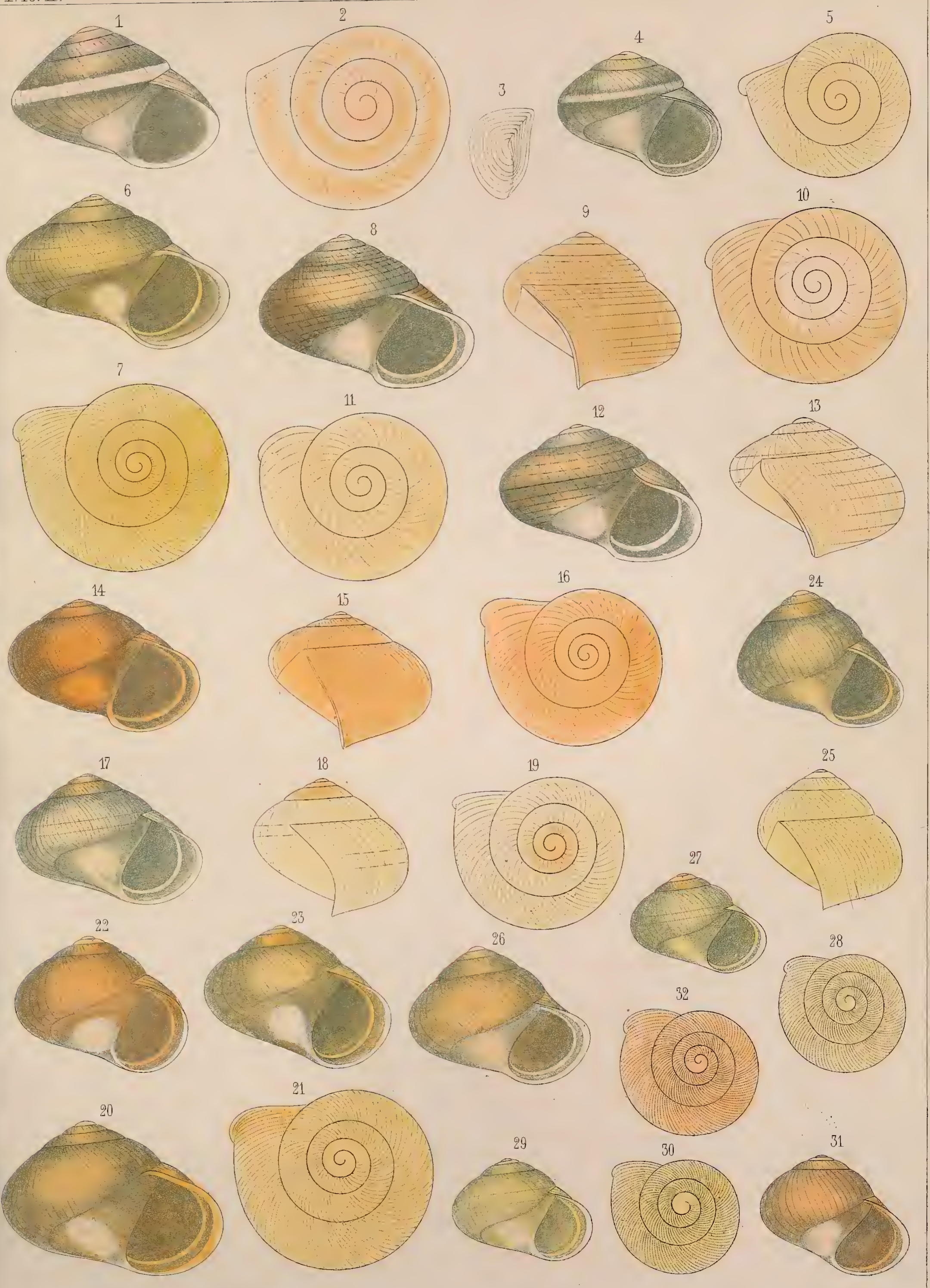



I.18. II.
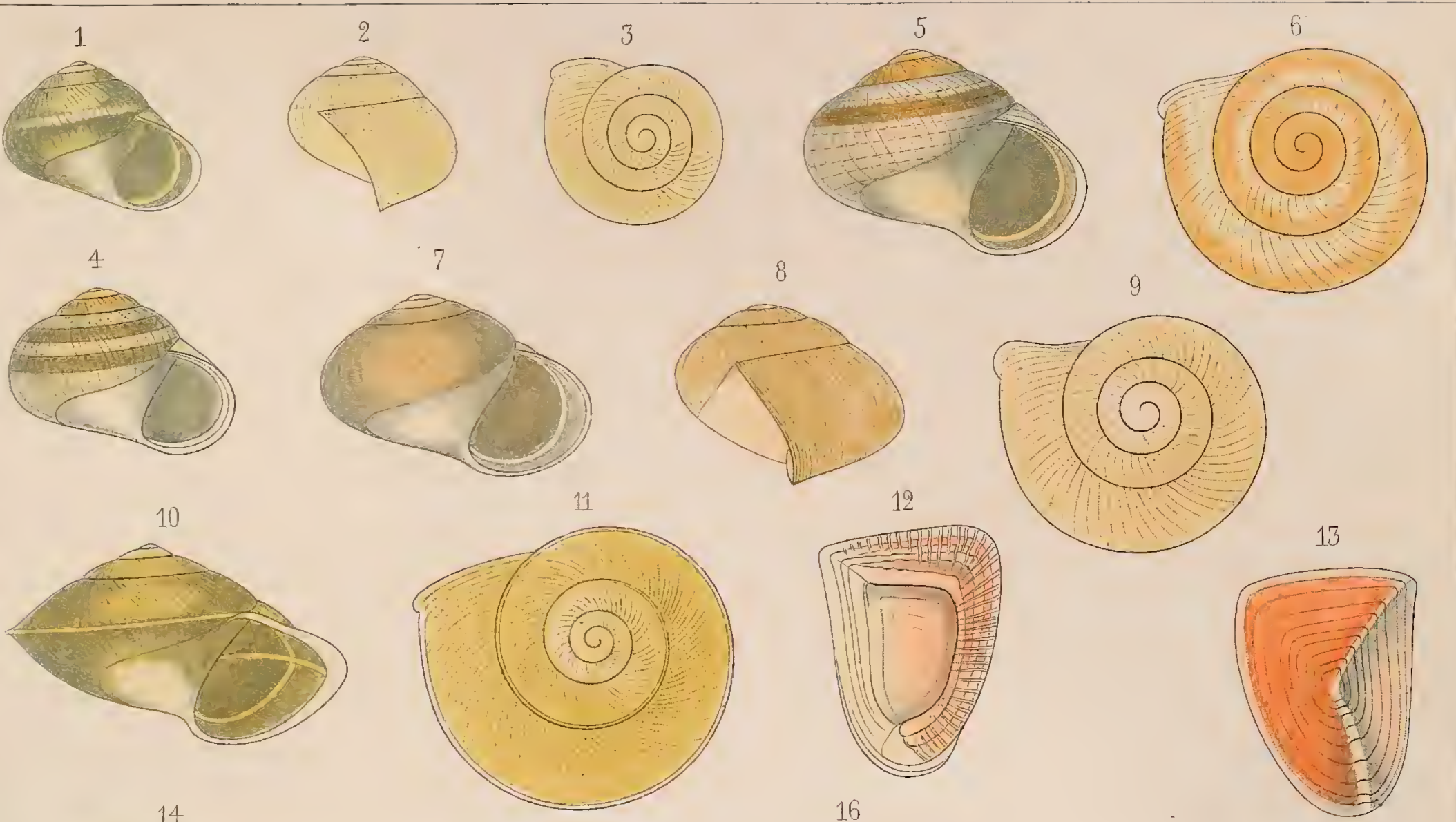

13
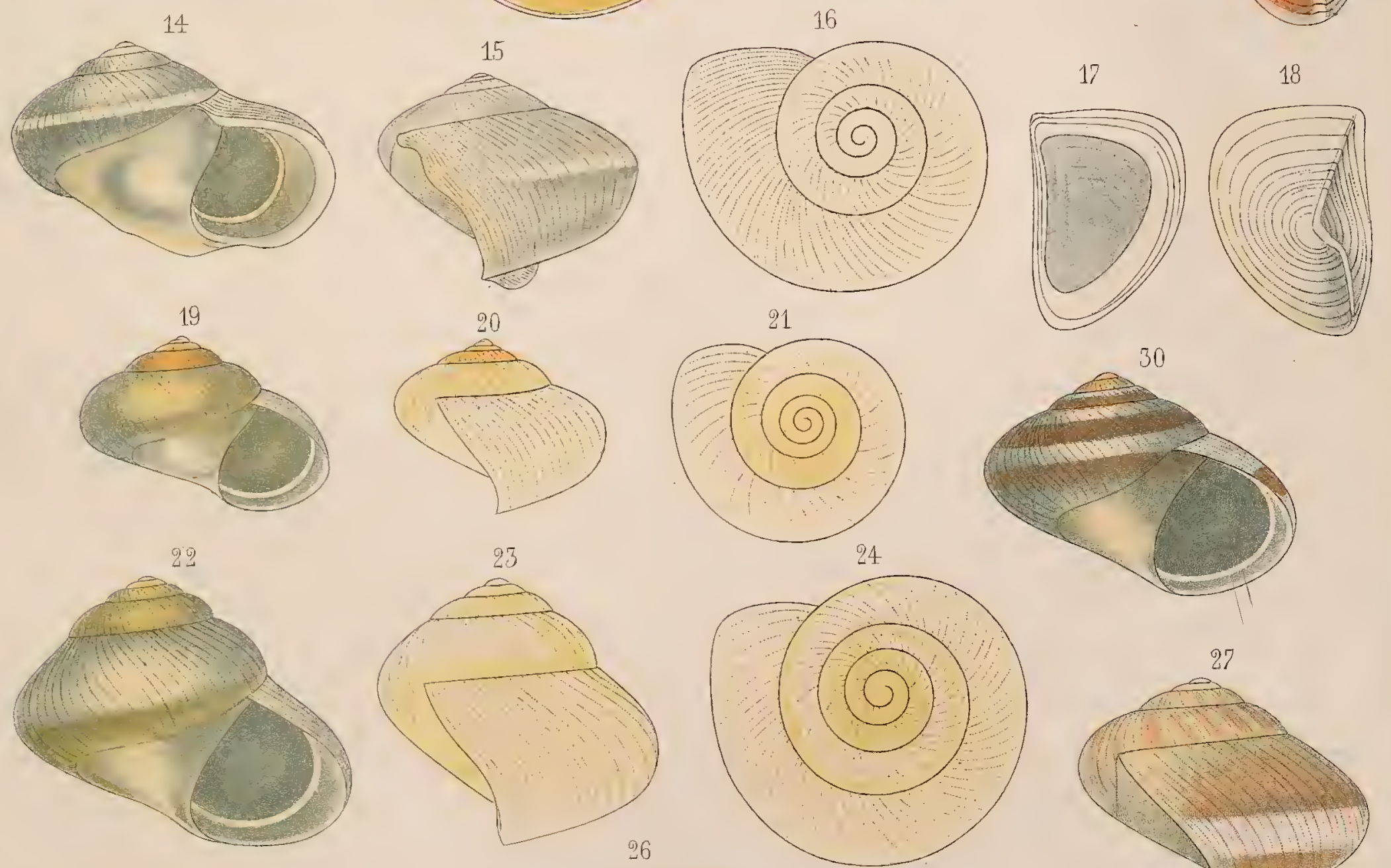

24
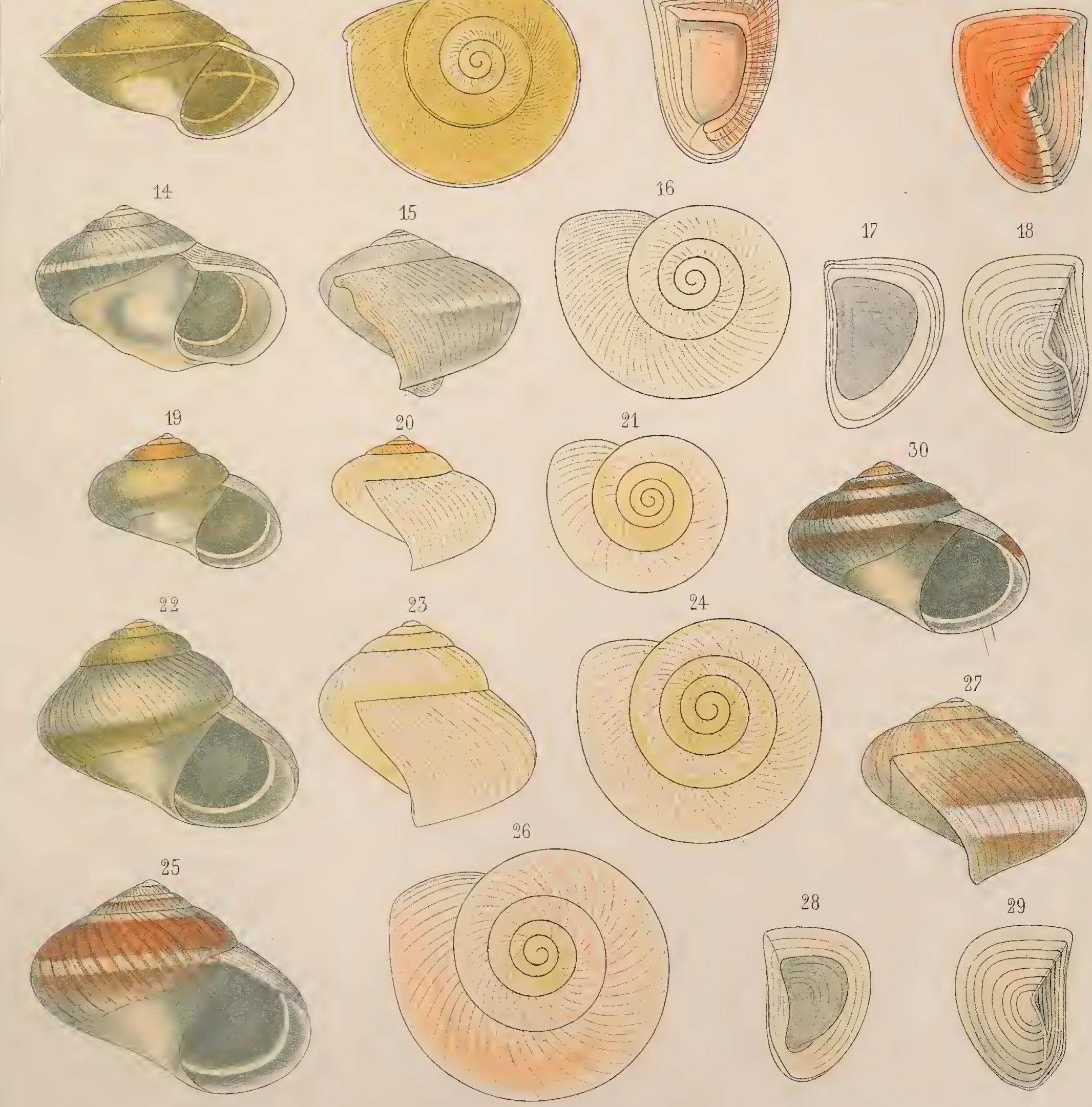

I.18. II.
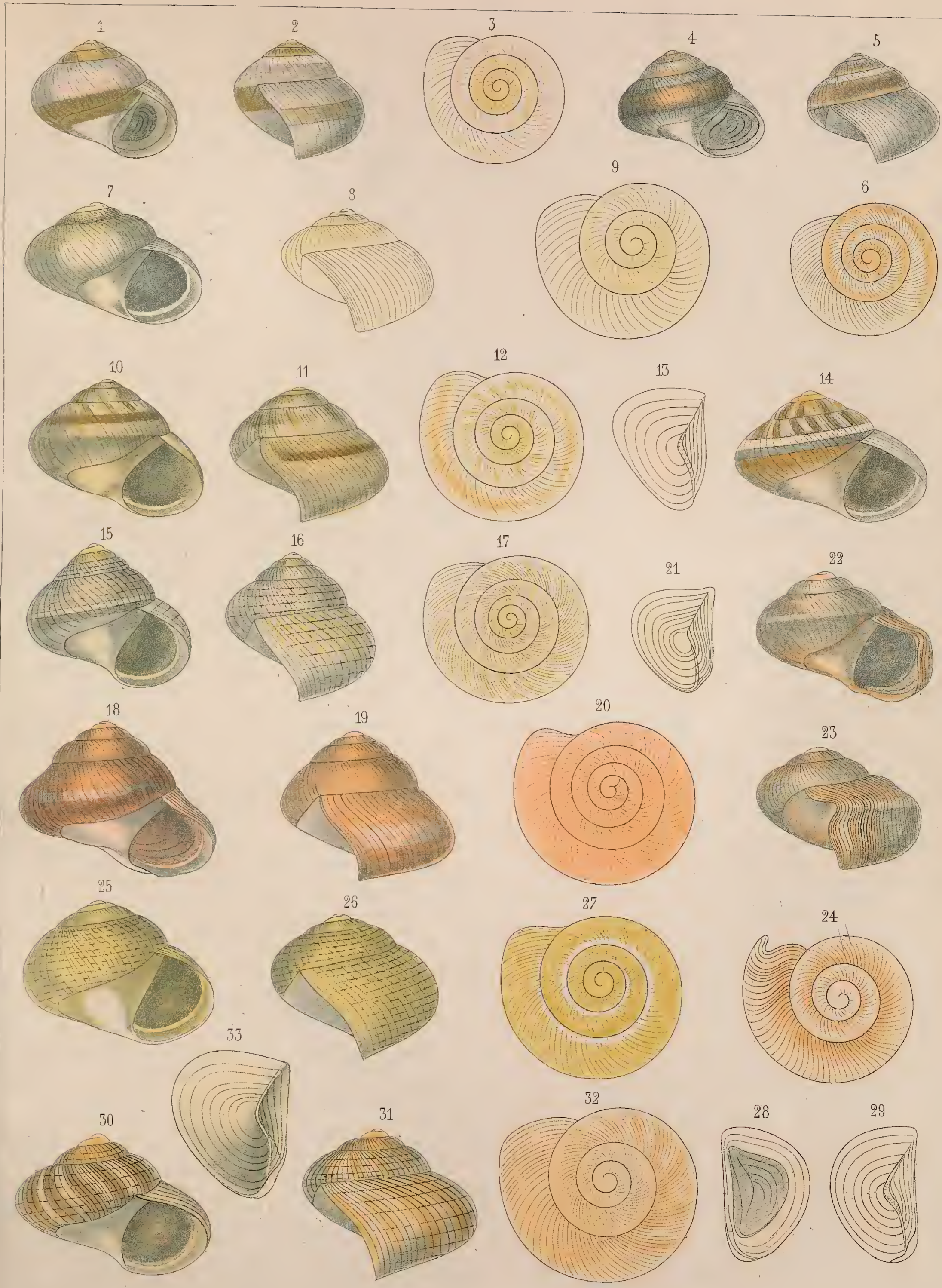

I.18.II.
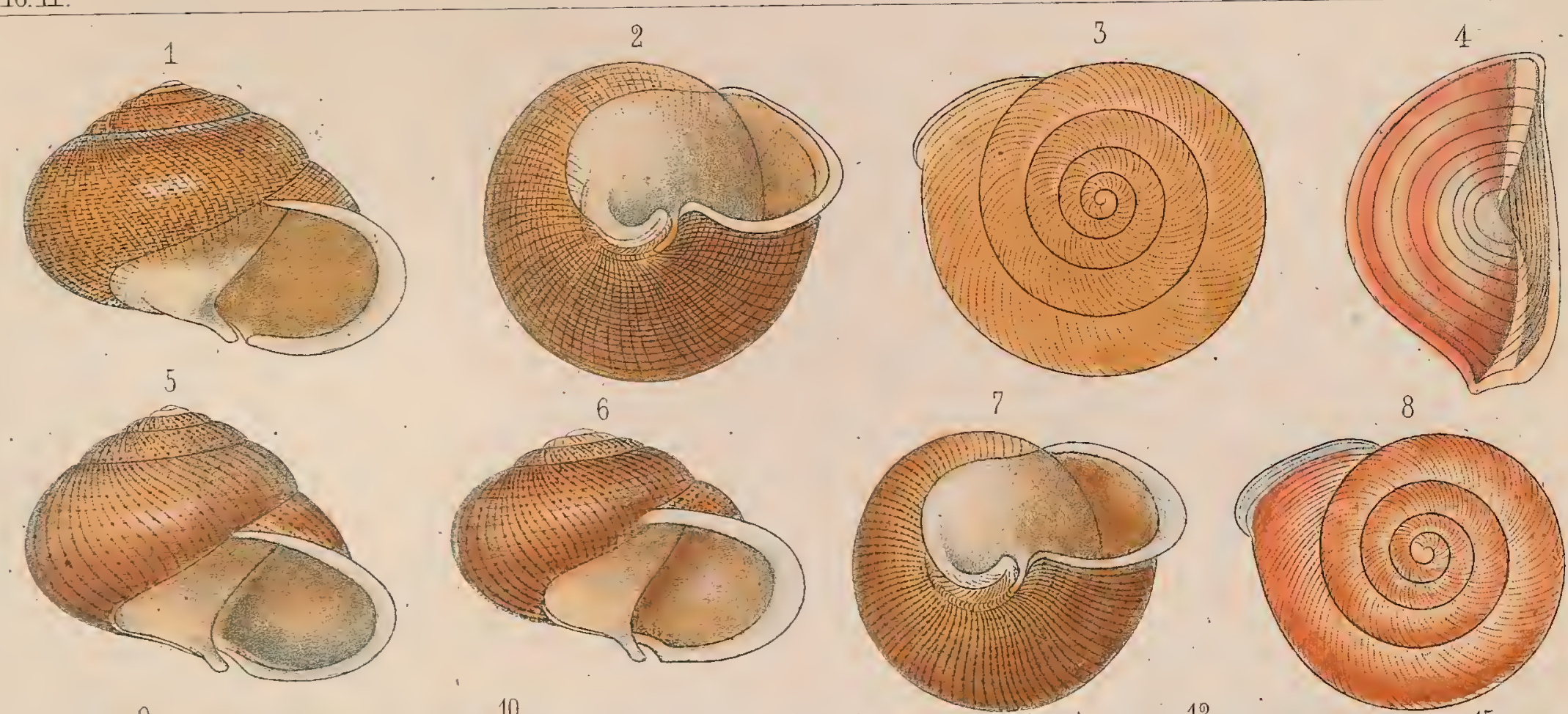

8
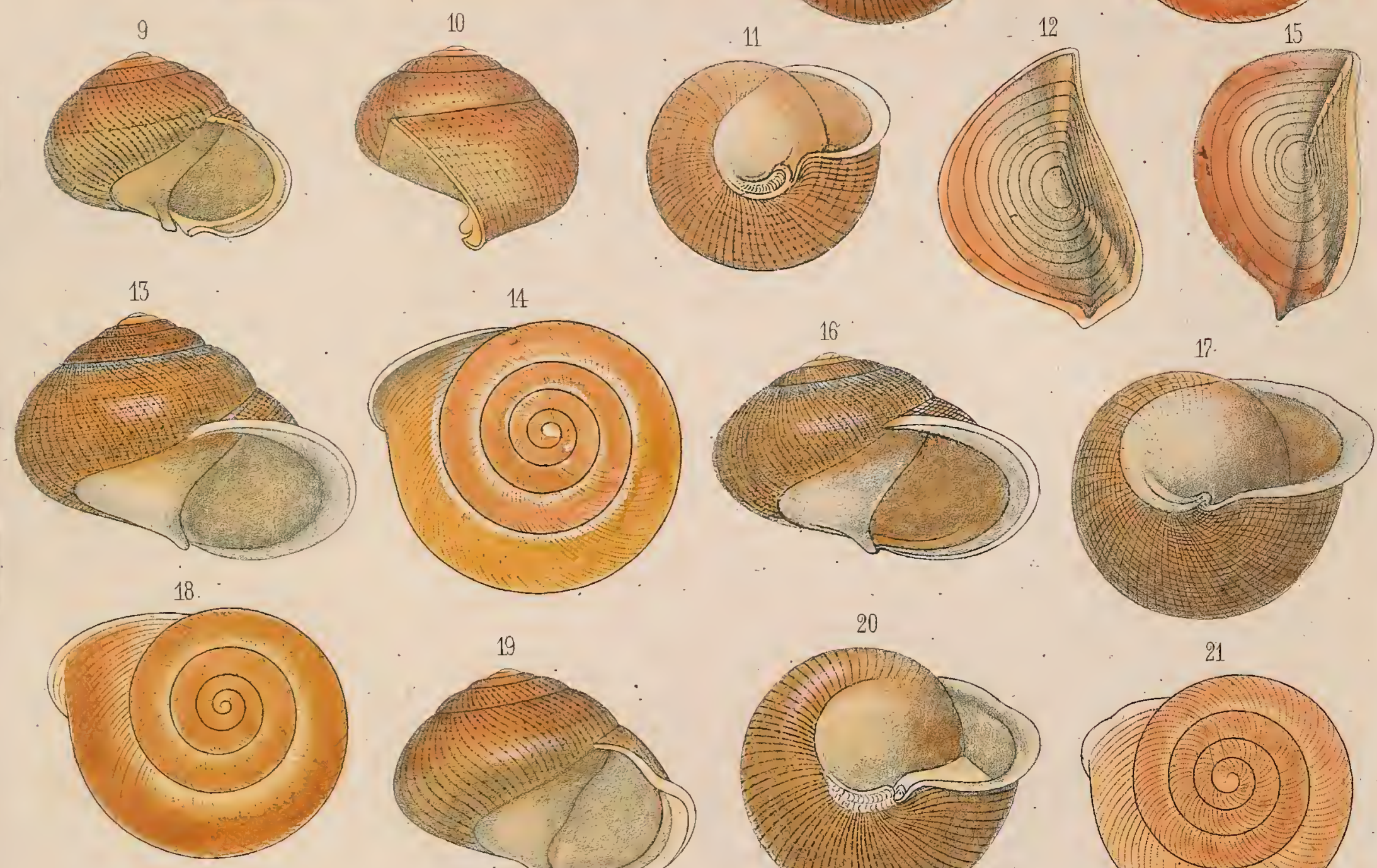

25
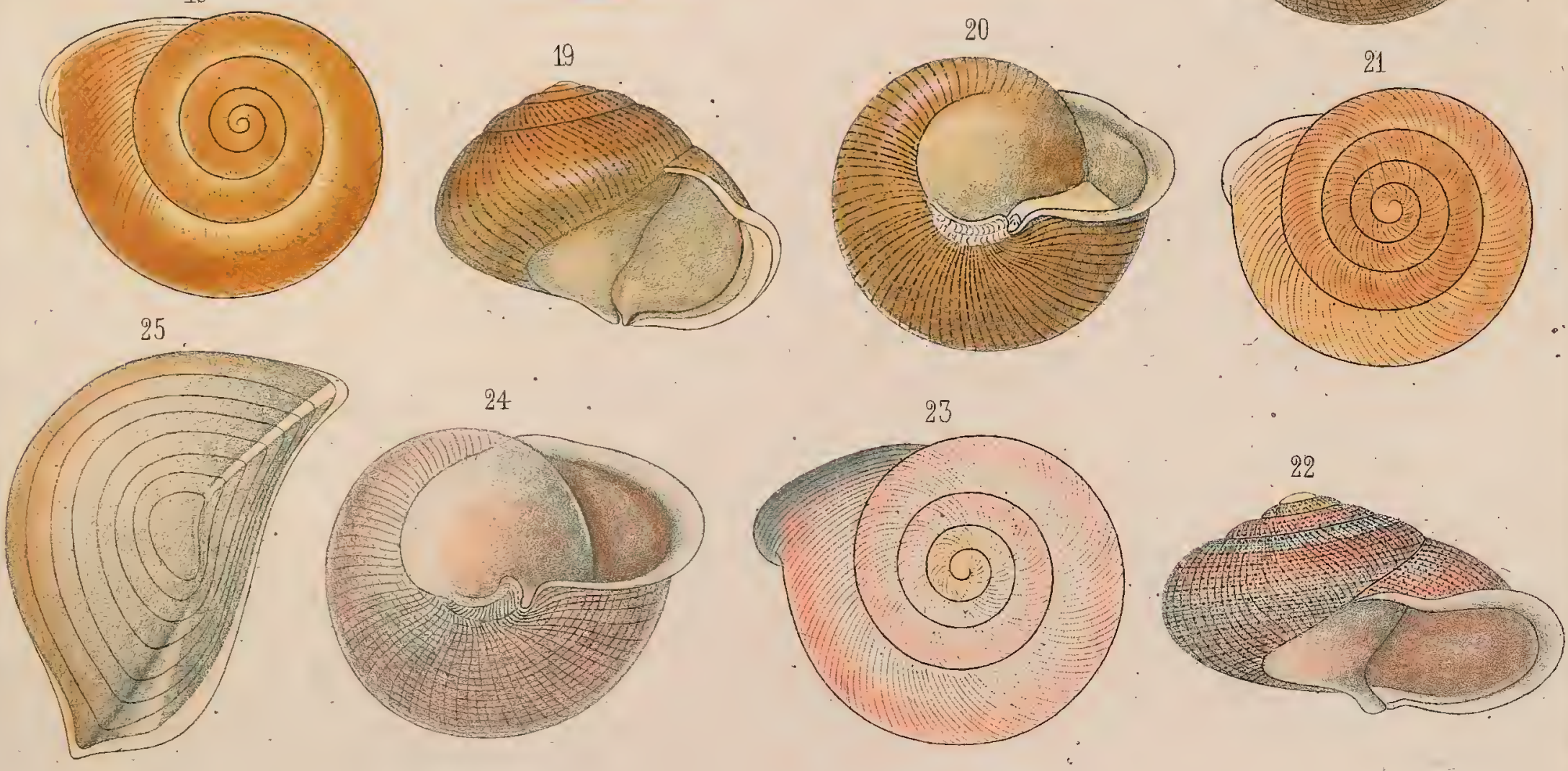

I.18.II.

8.
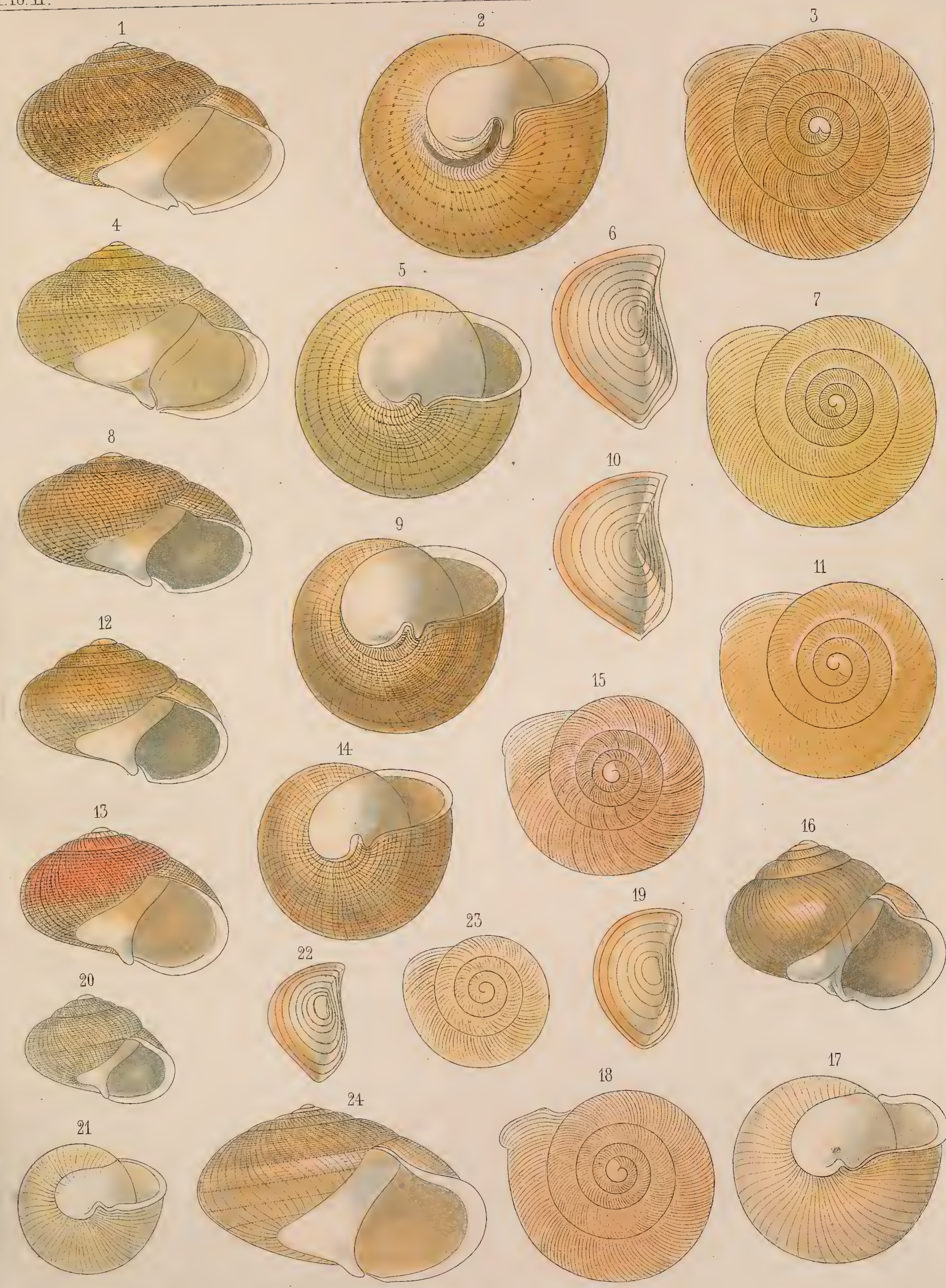

I.18. II.

9.
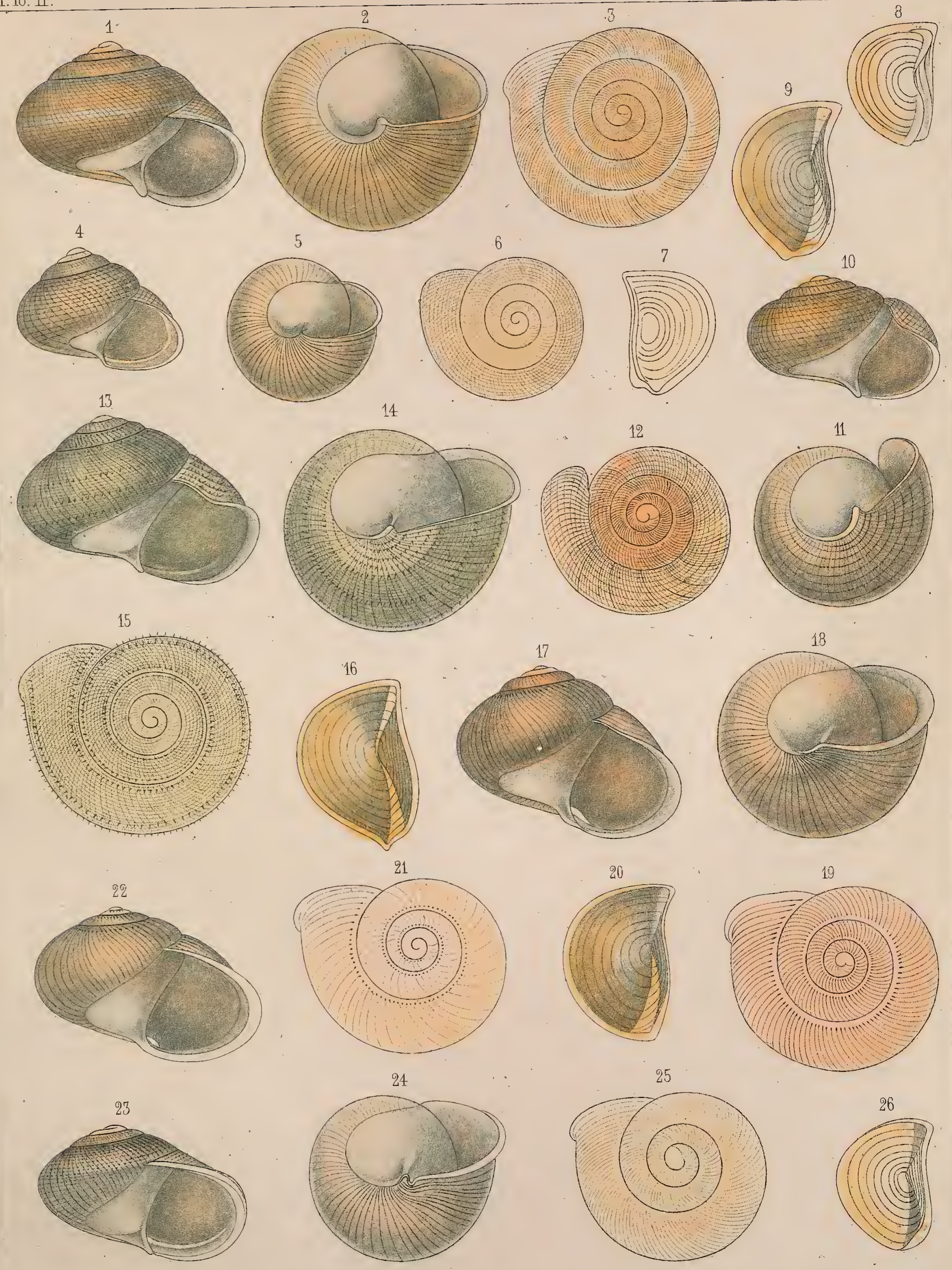


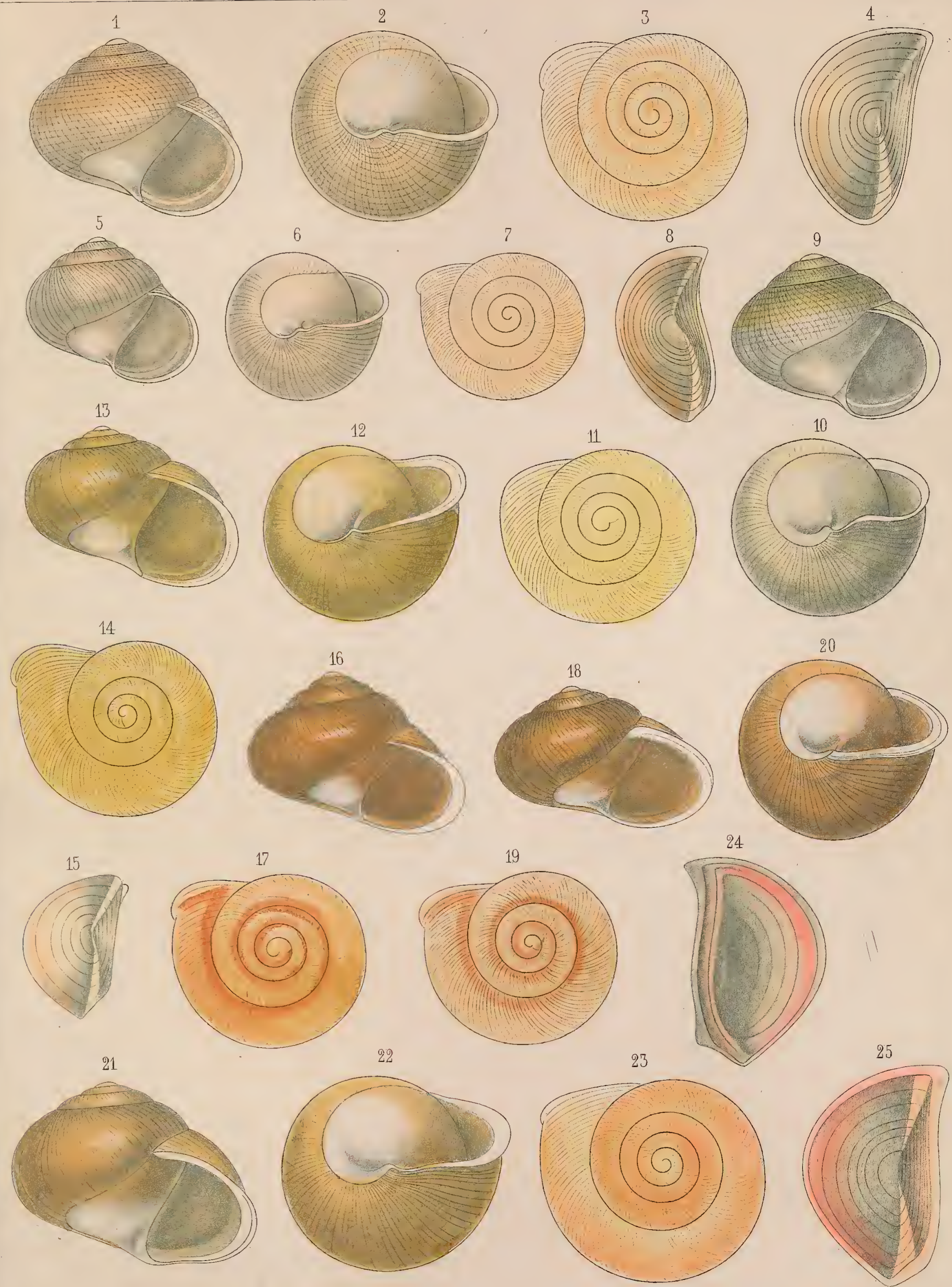
$\checkmark$ 
I.18.II.

11
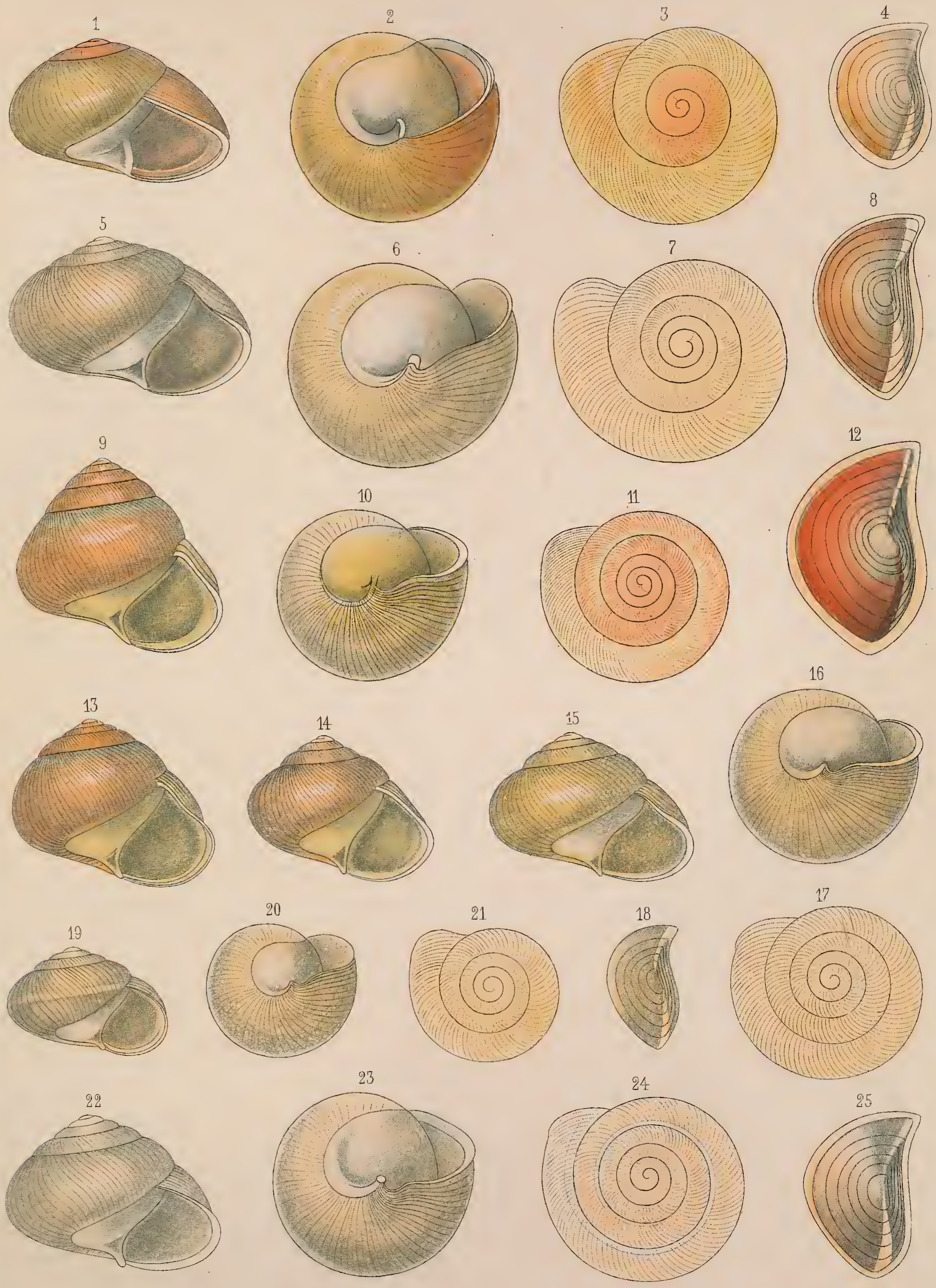


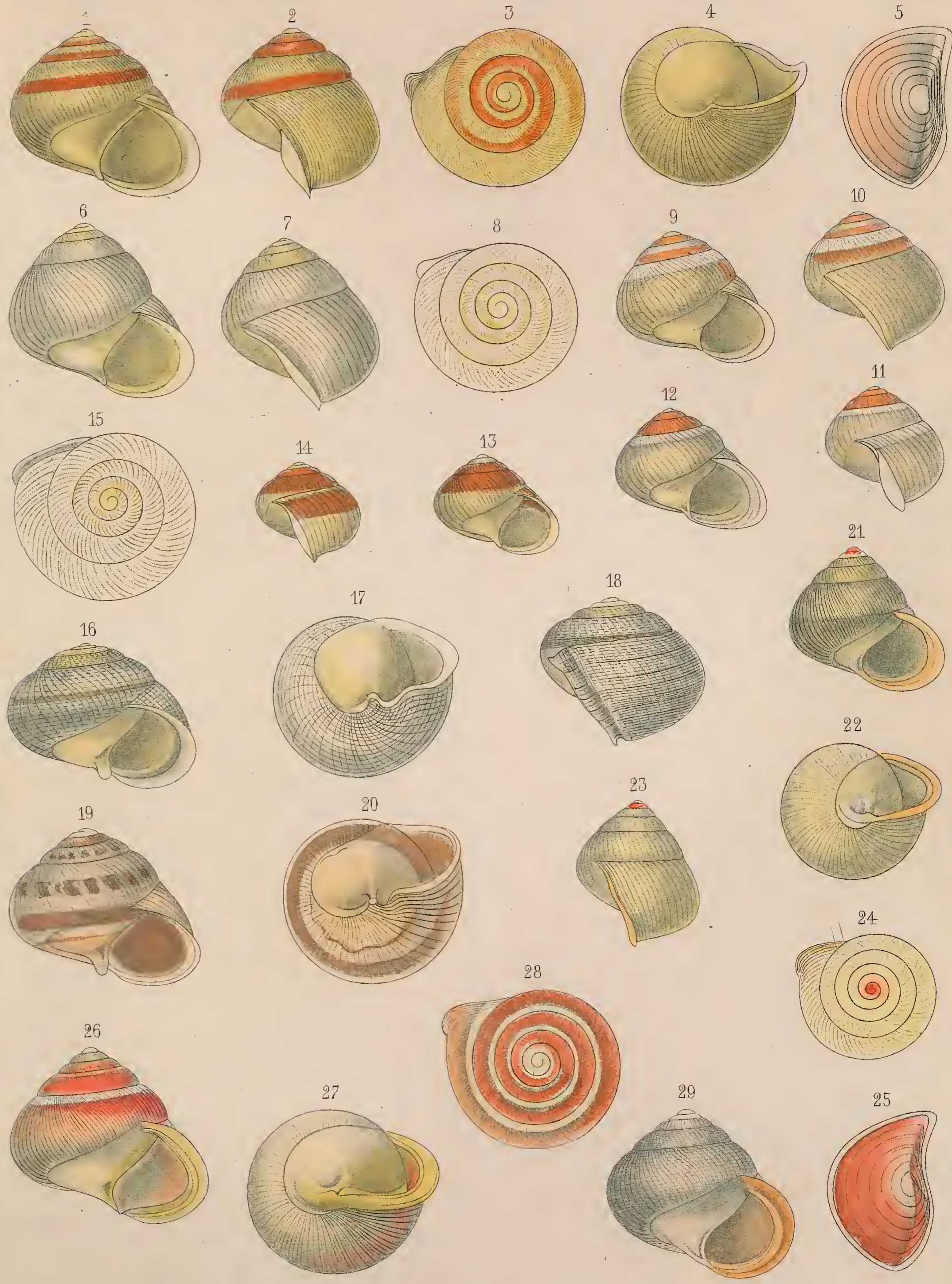

I.18. II

13
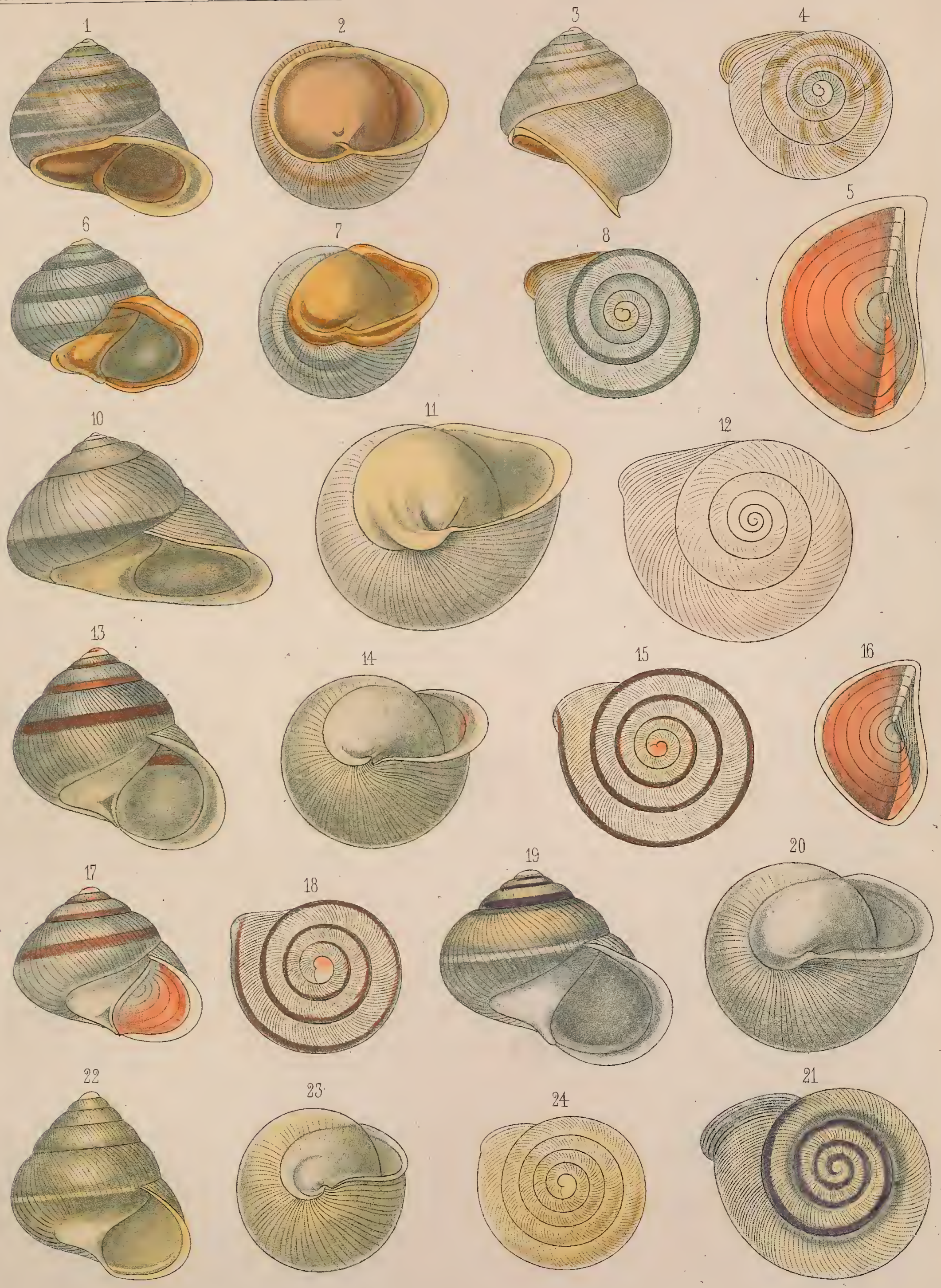


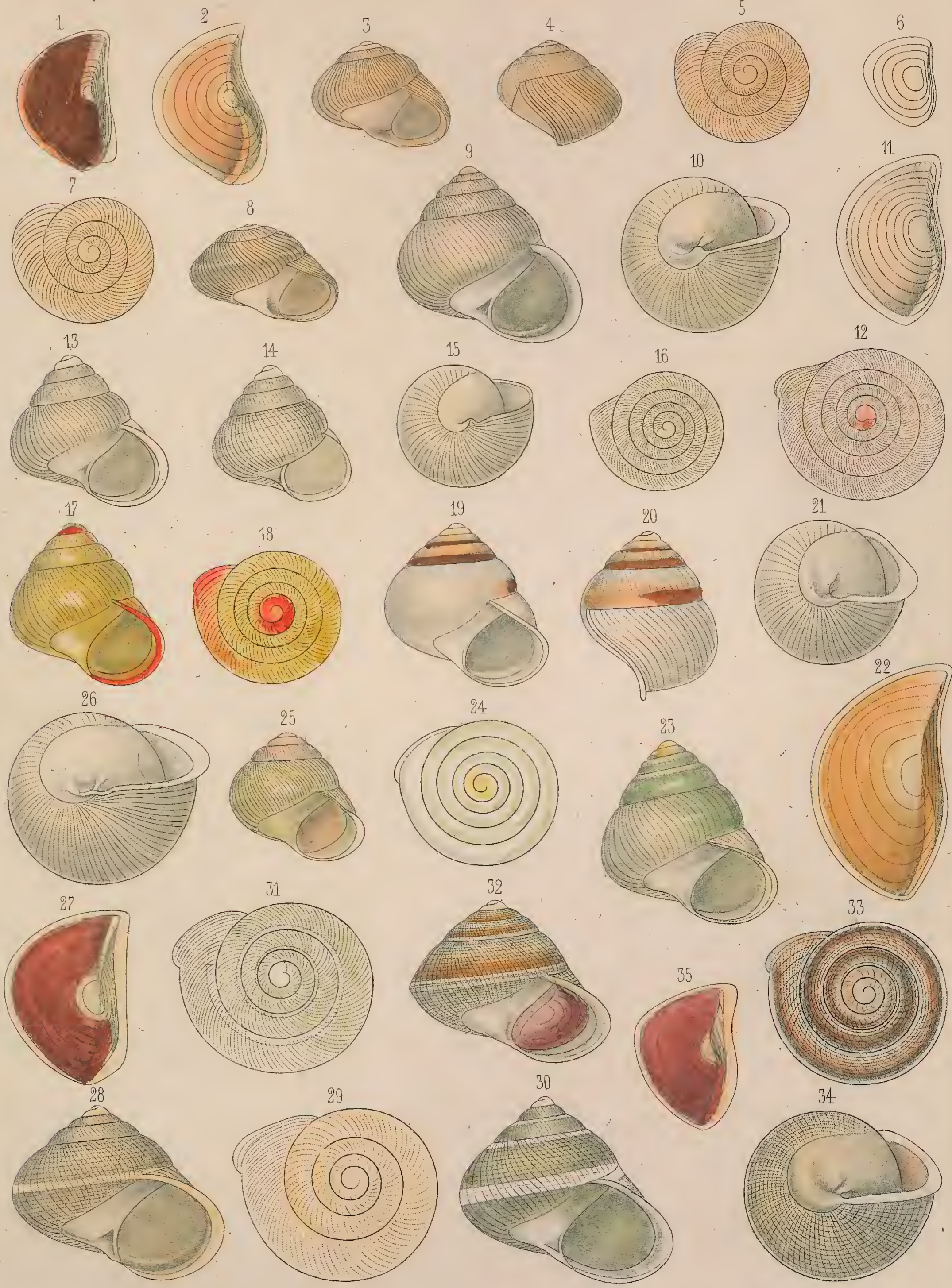


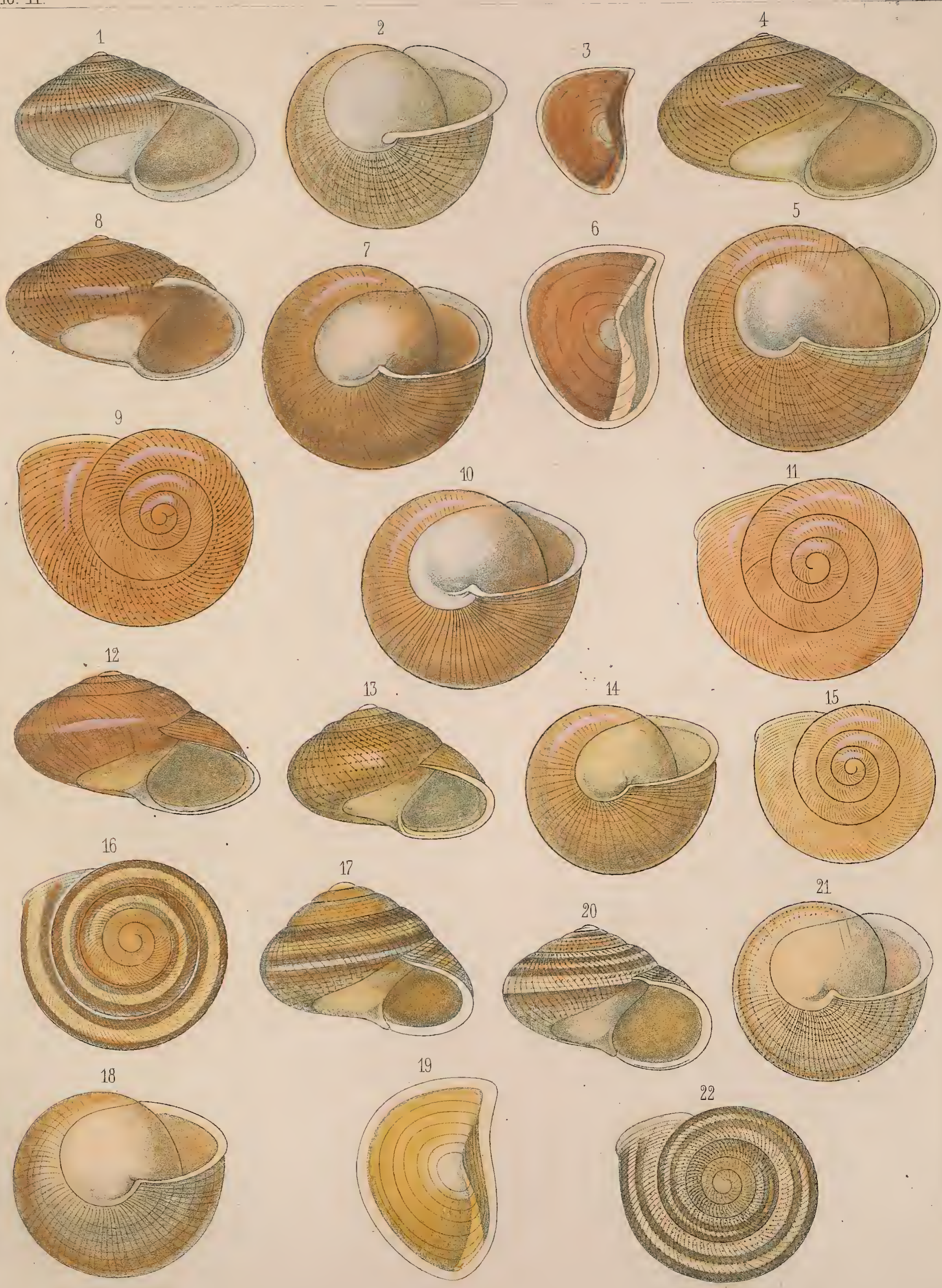


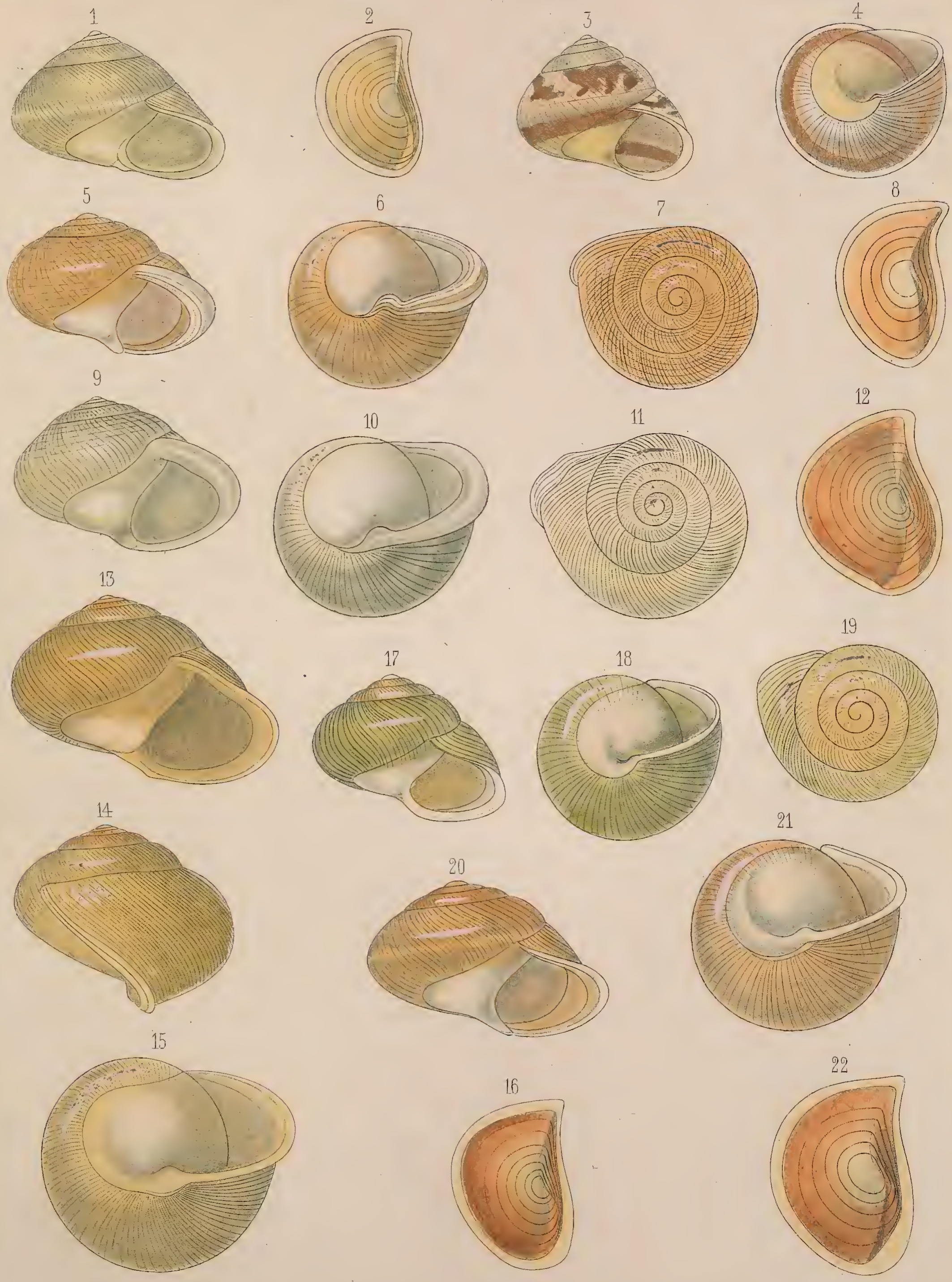


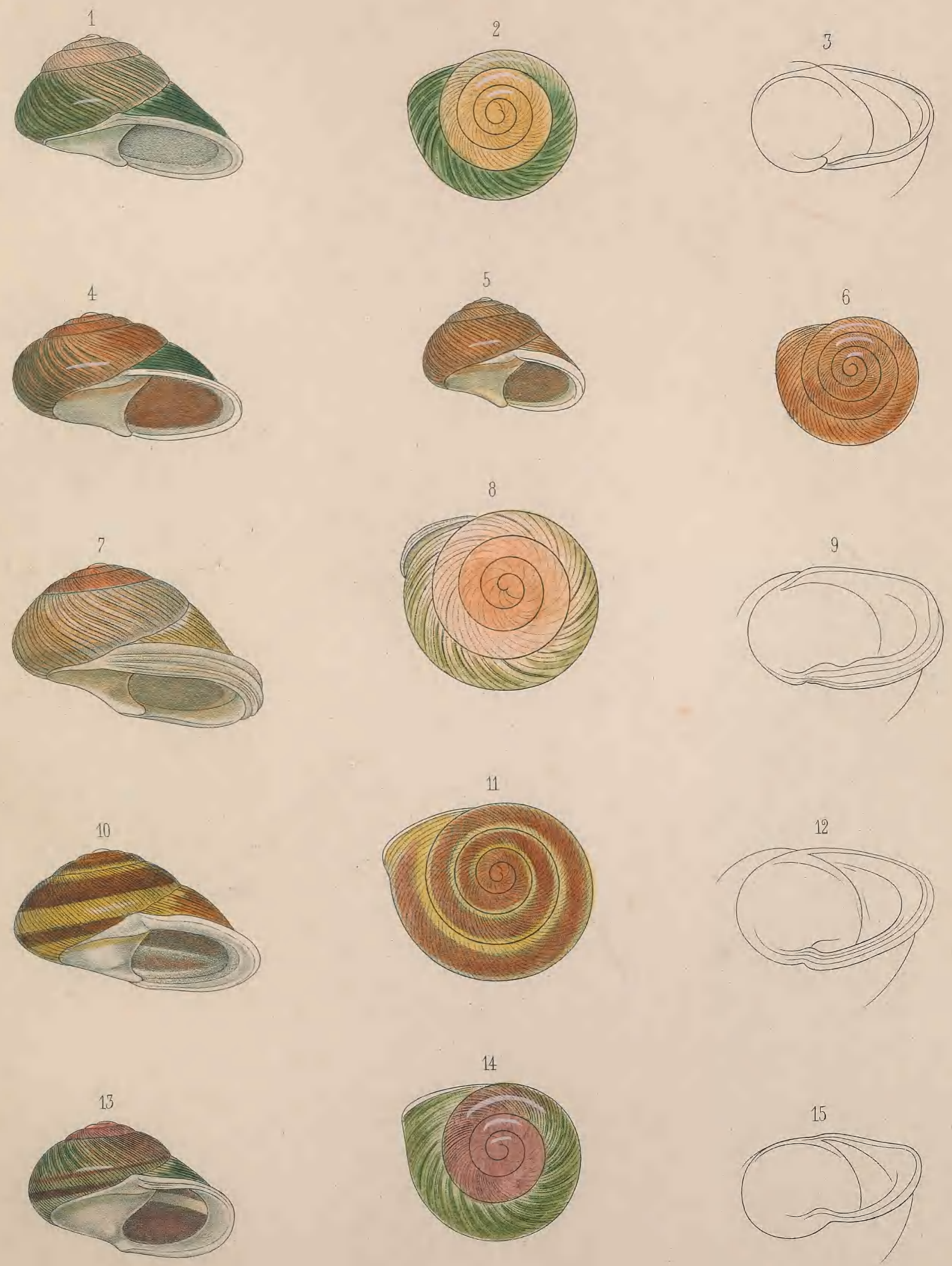


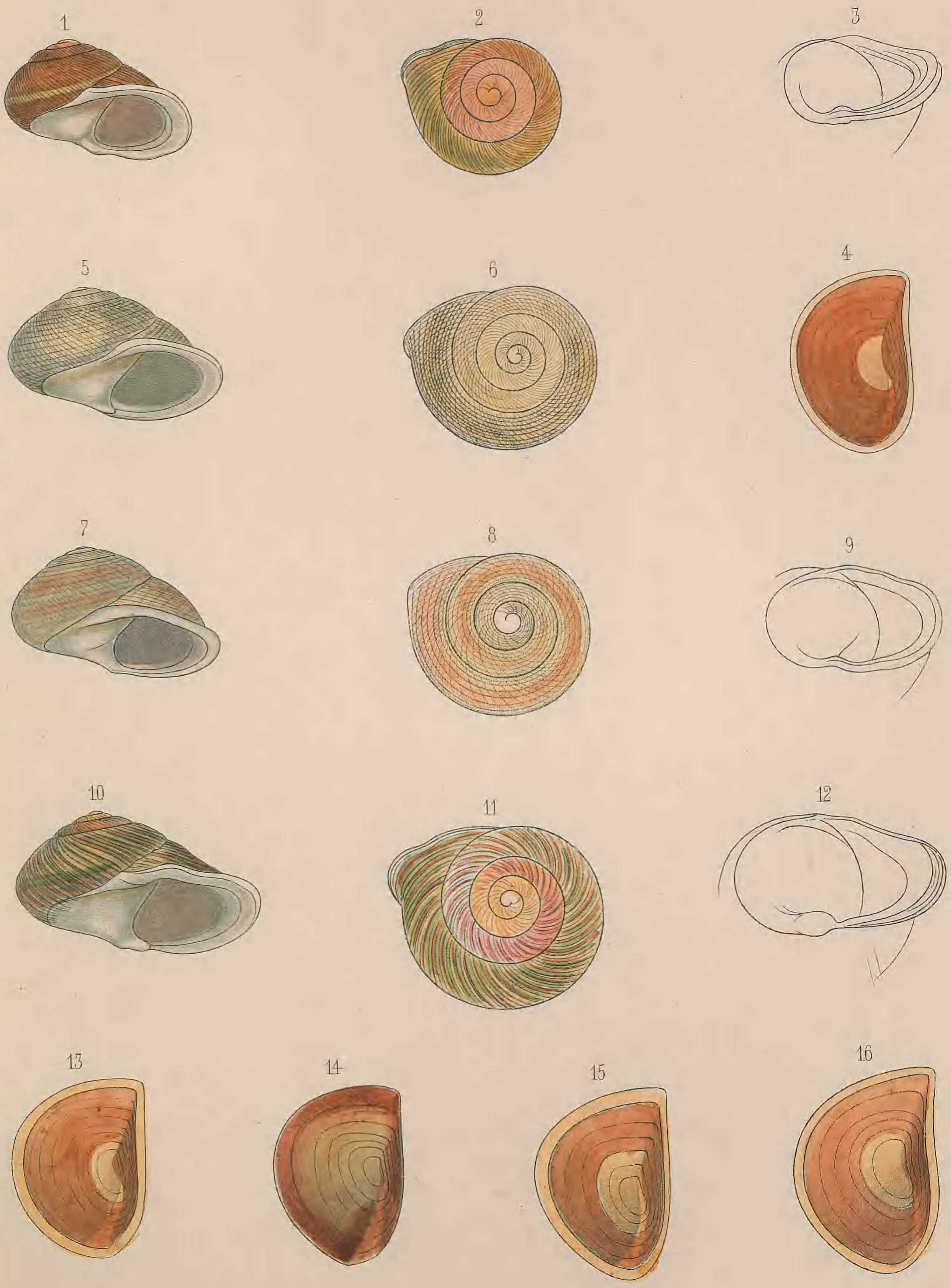

I.18. II.
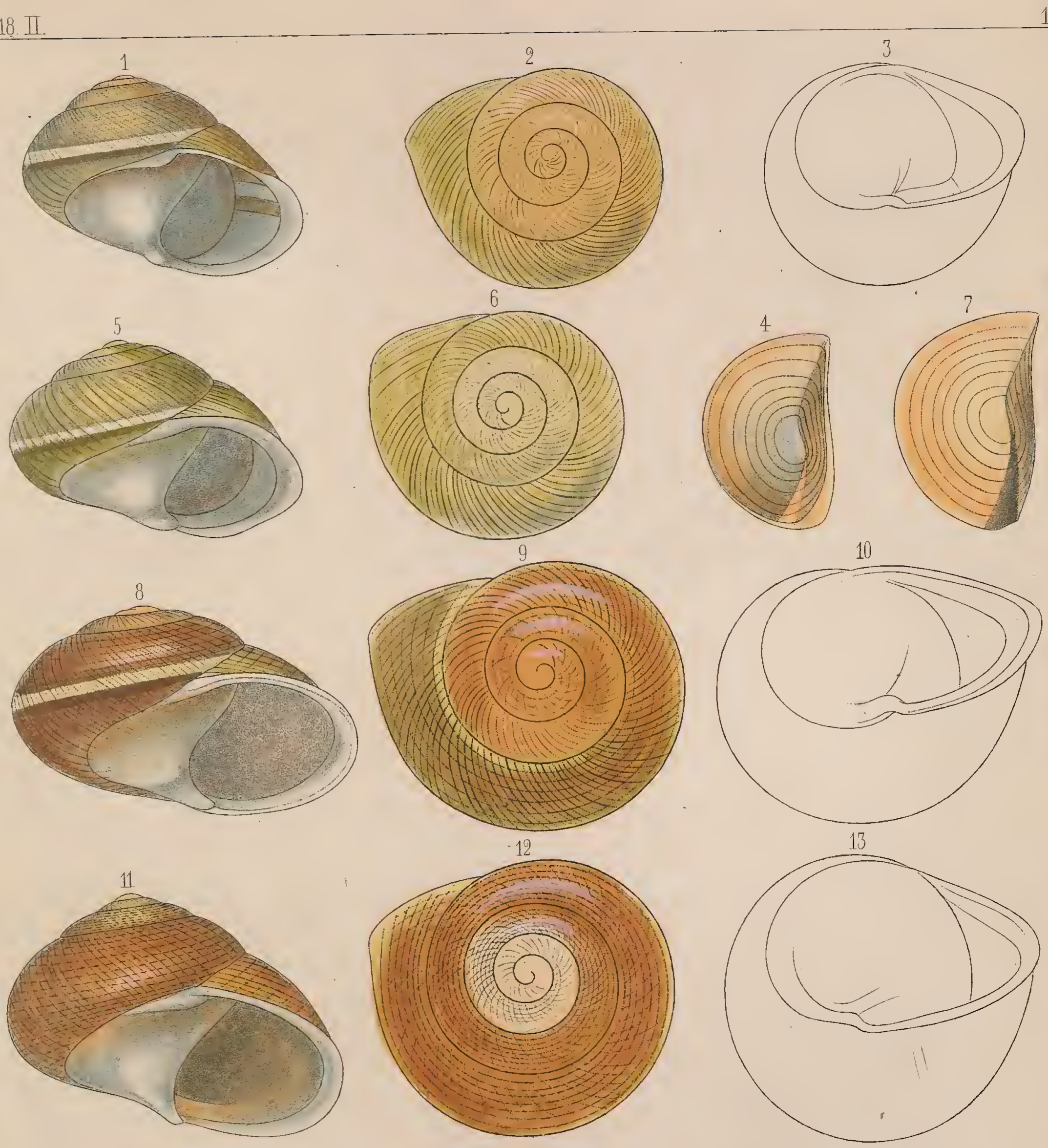

19.
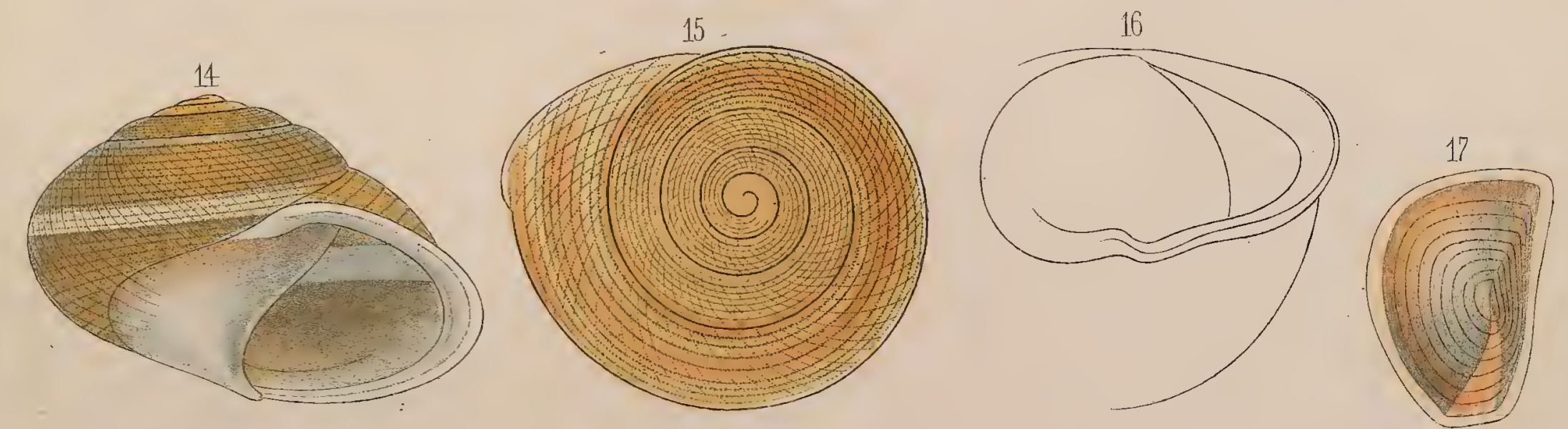



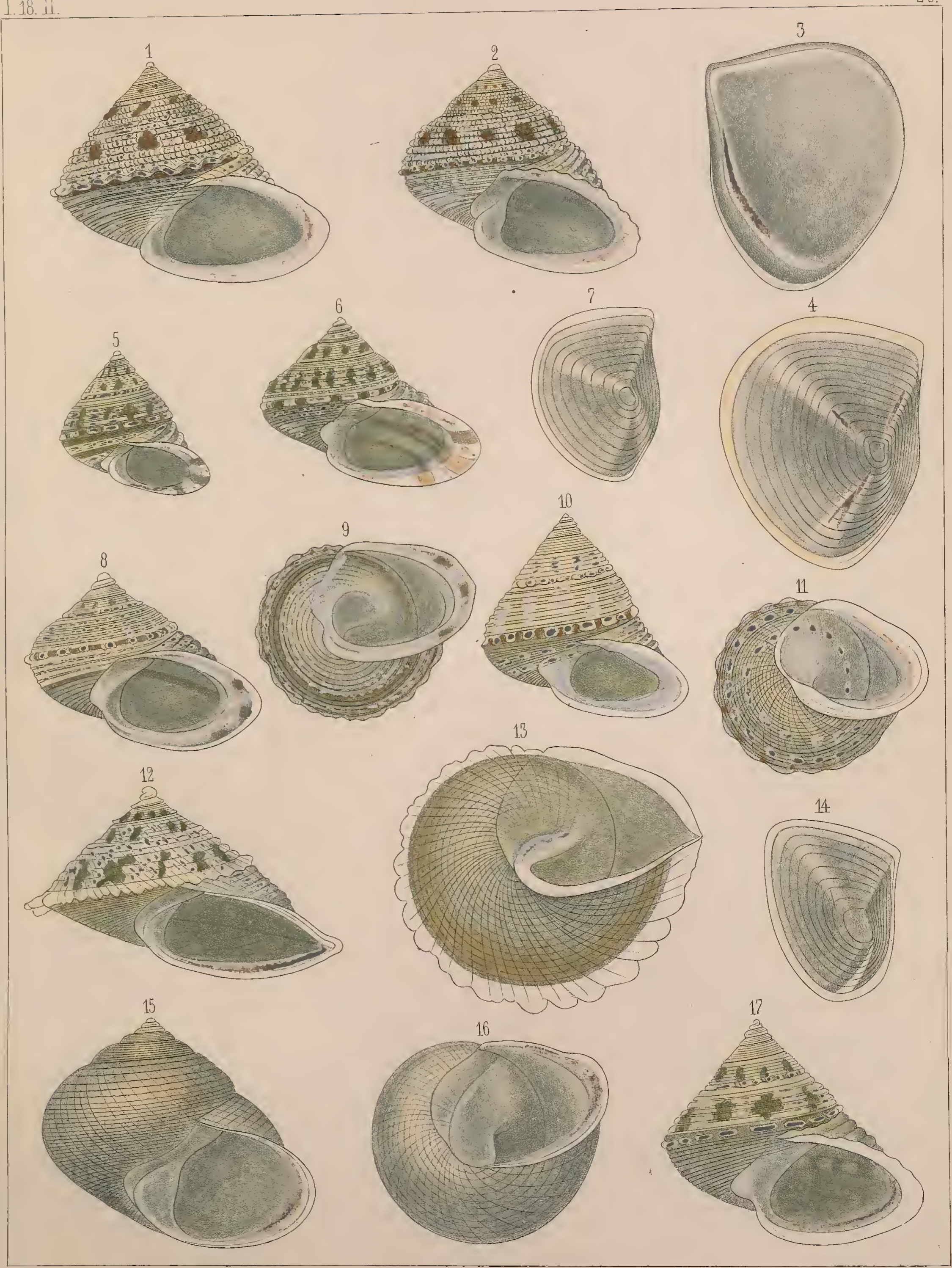




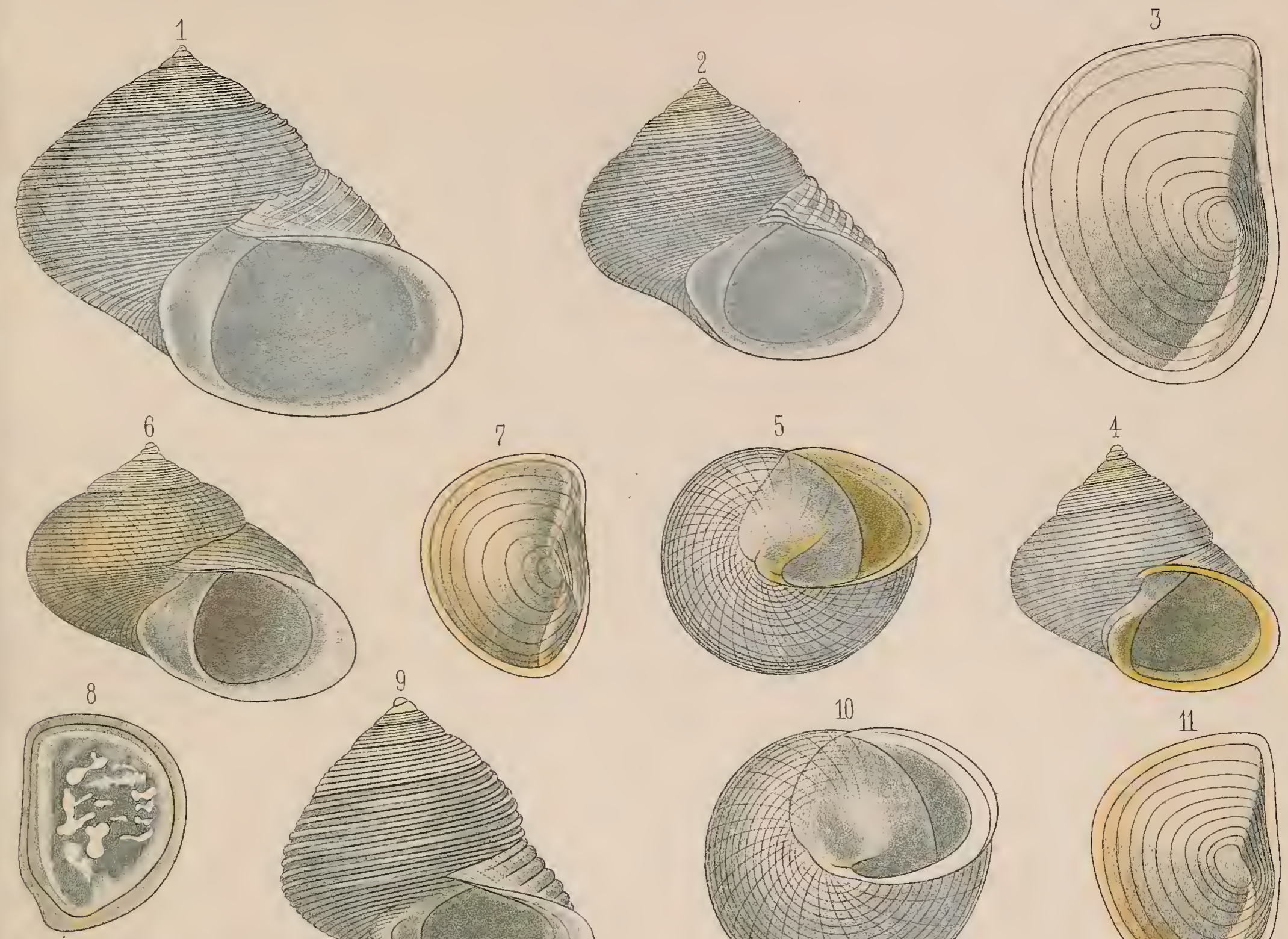

13
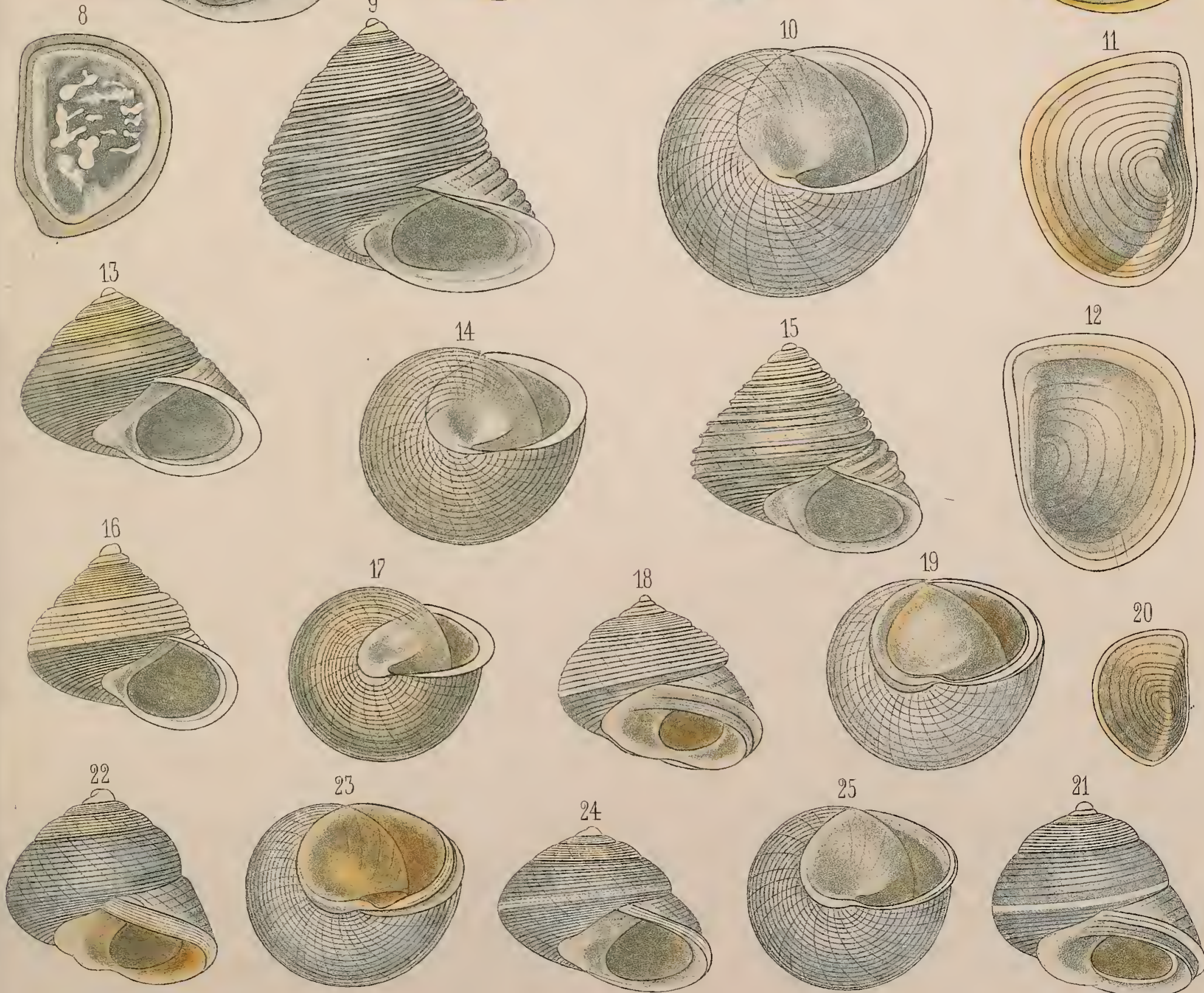

23
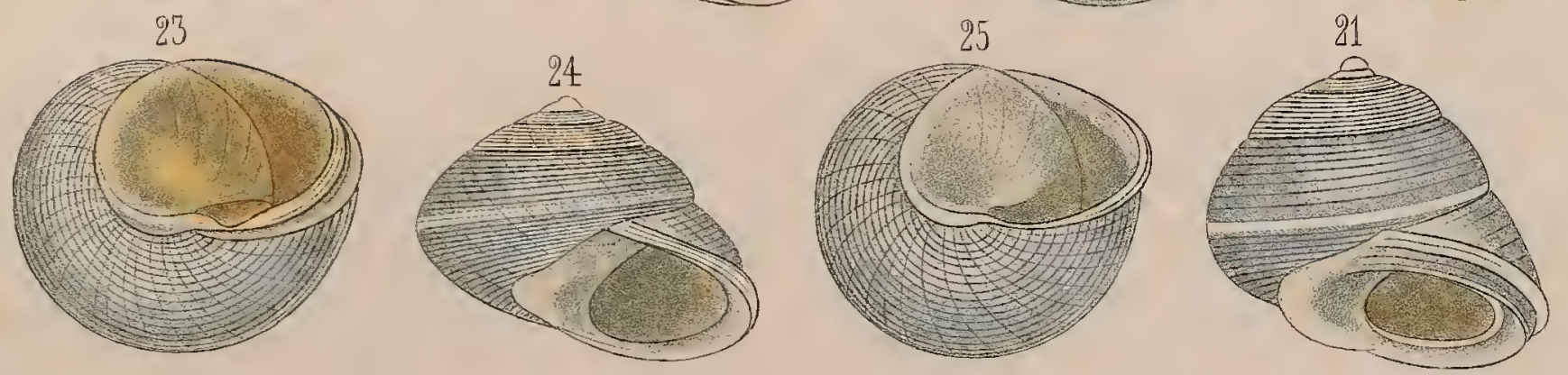


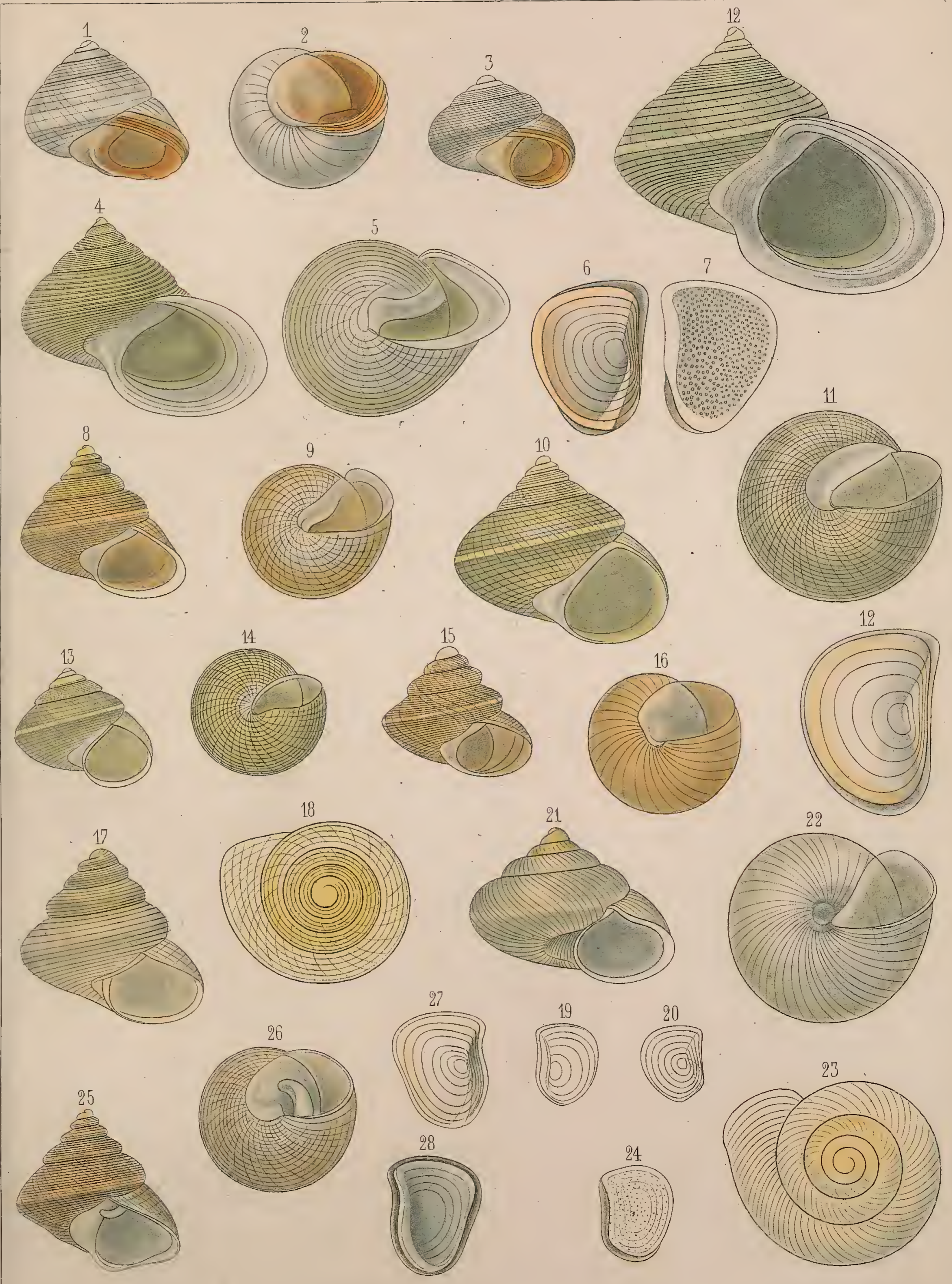

(2)
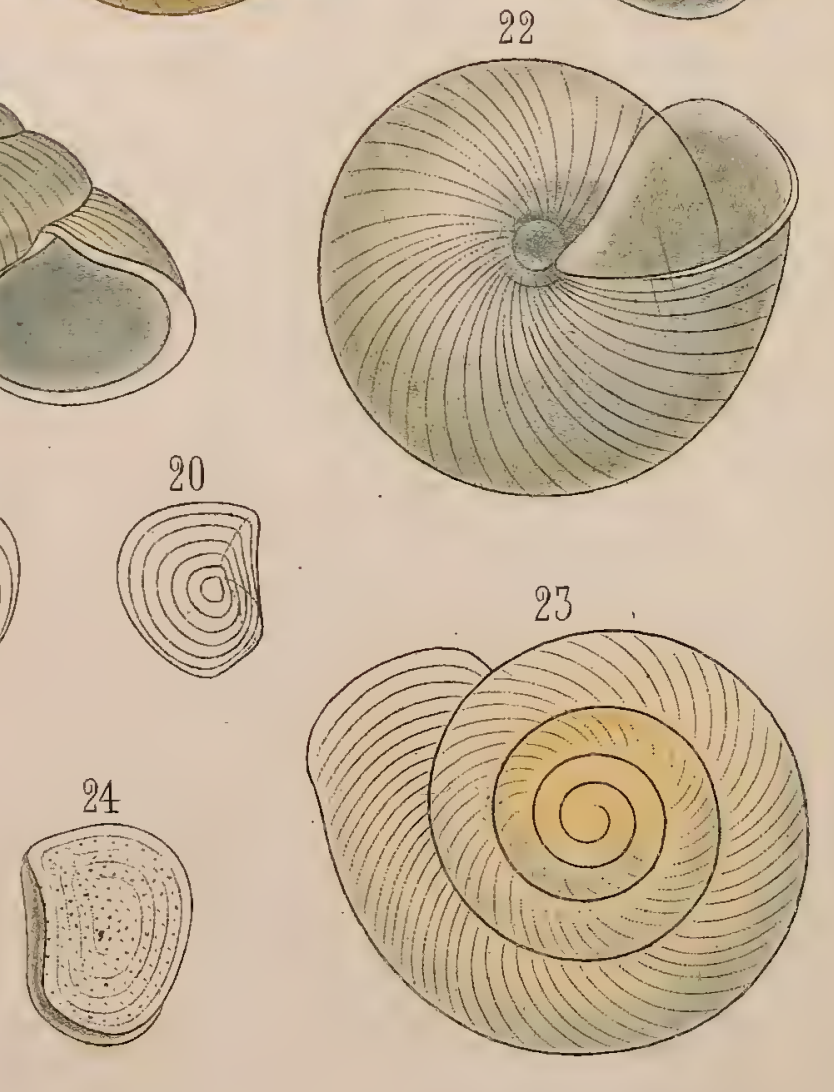


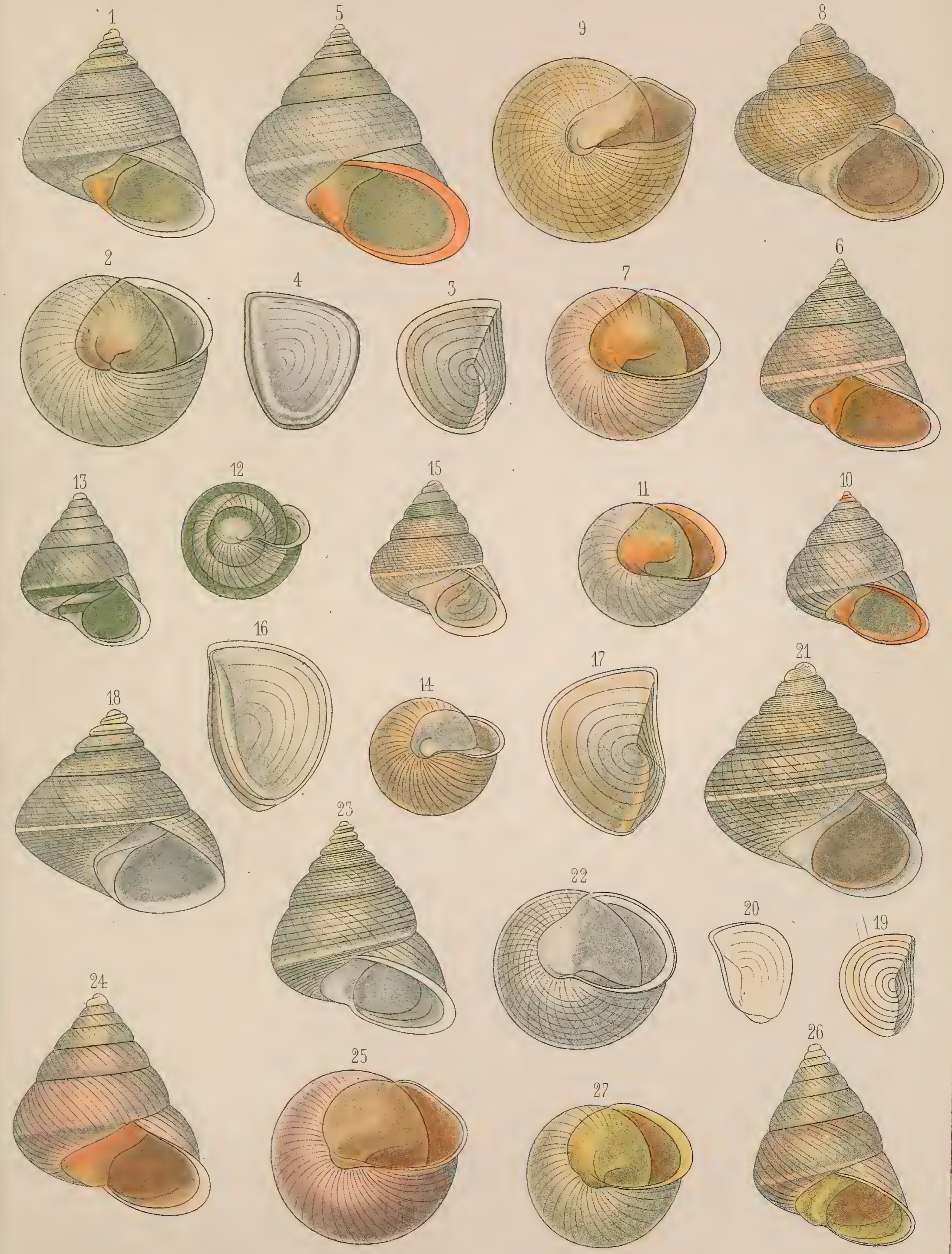


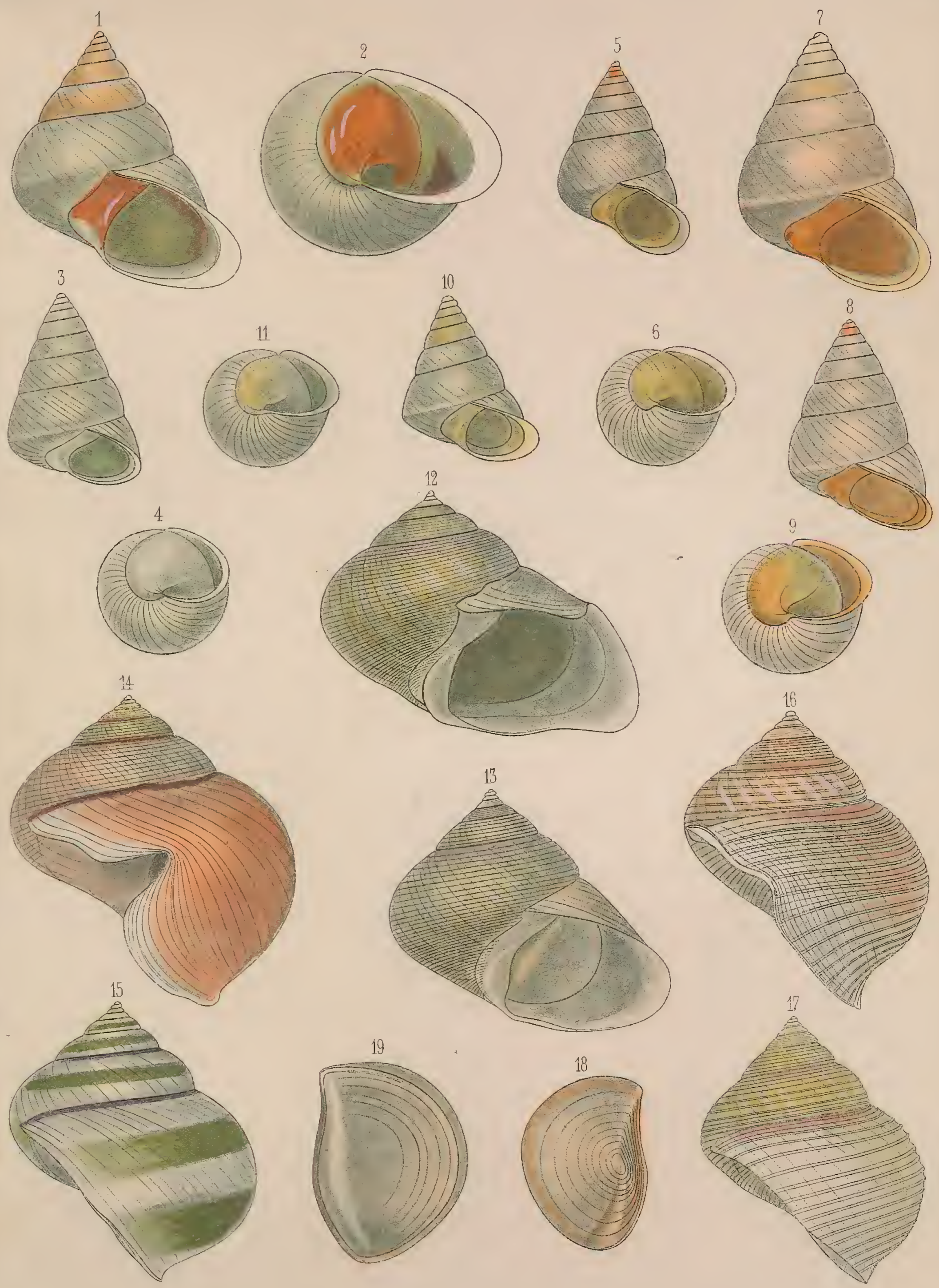


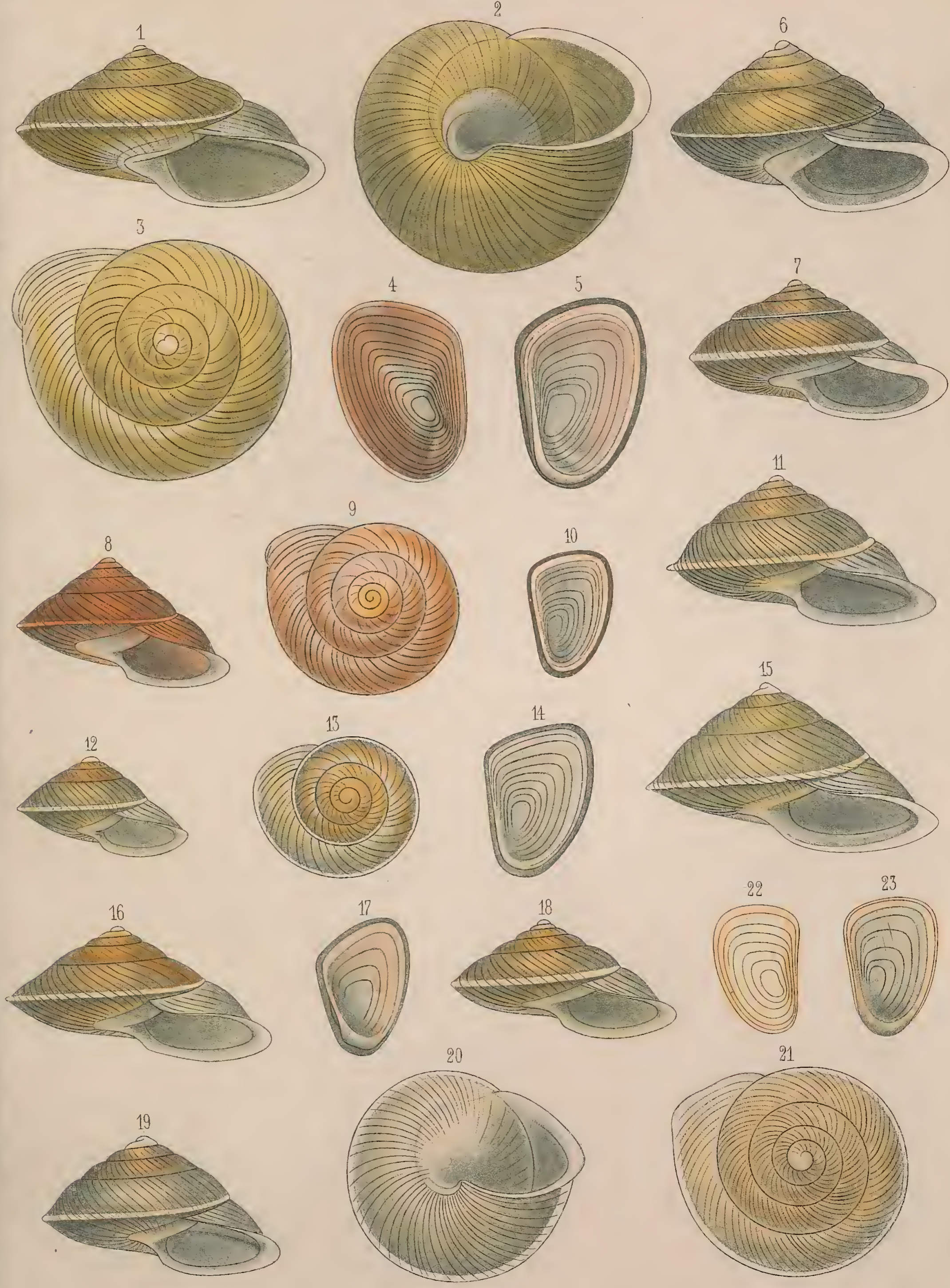


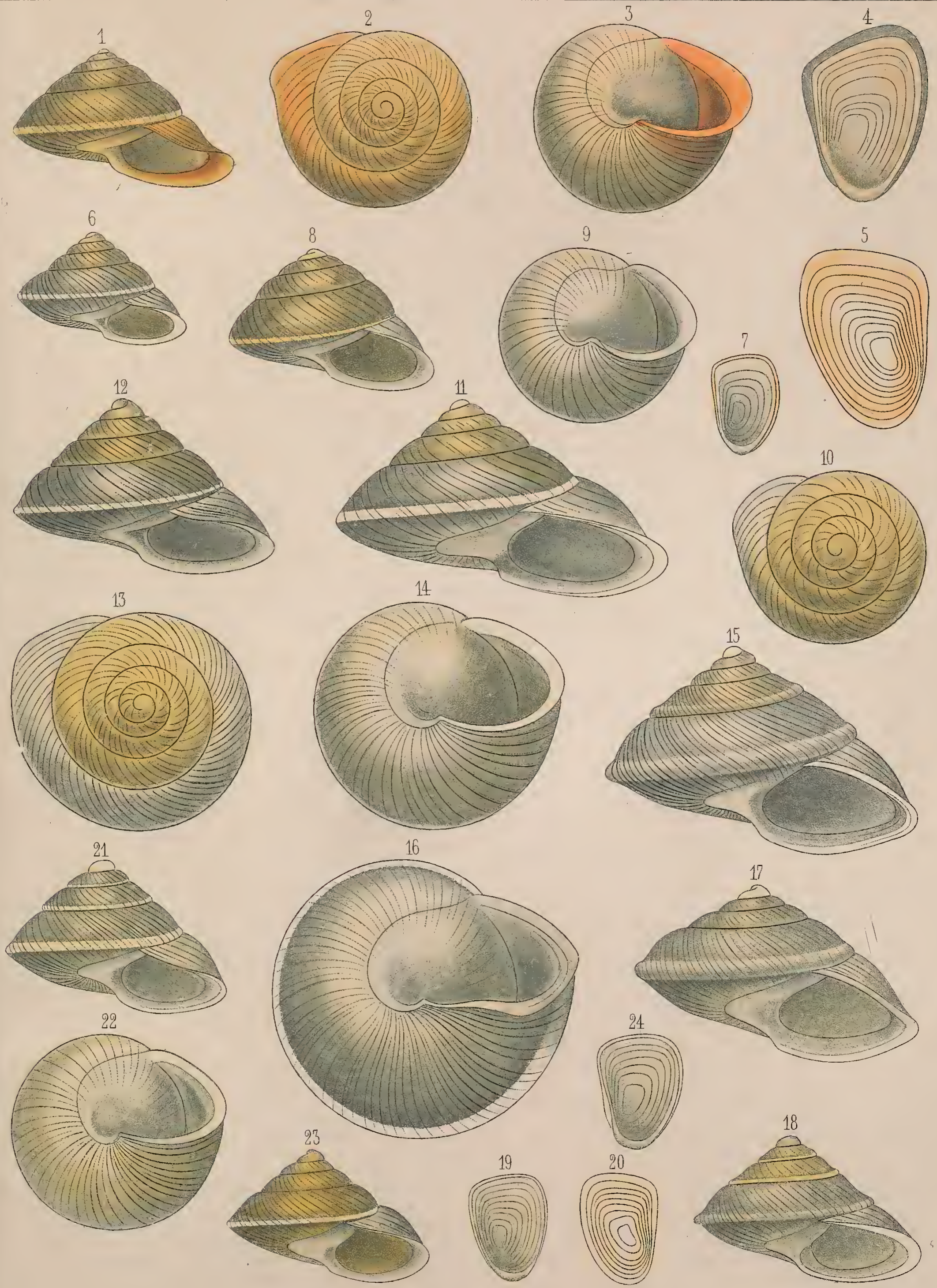



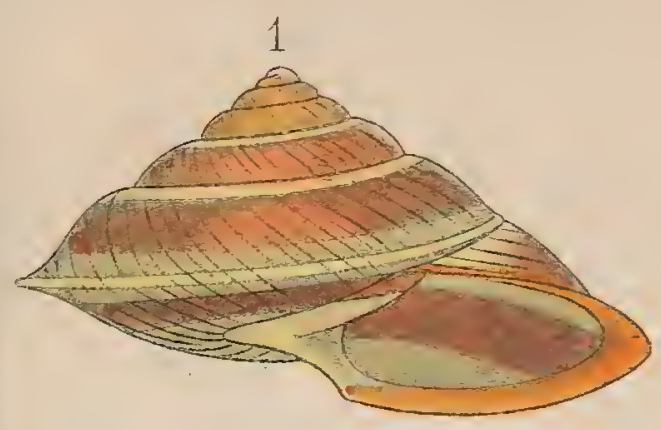

7
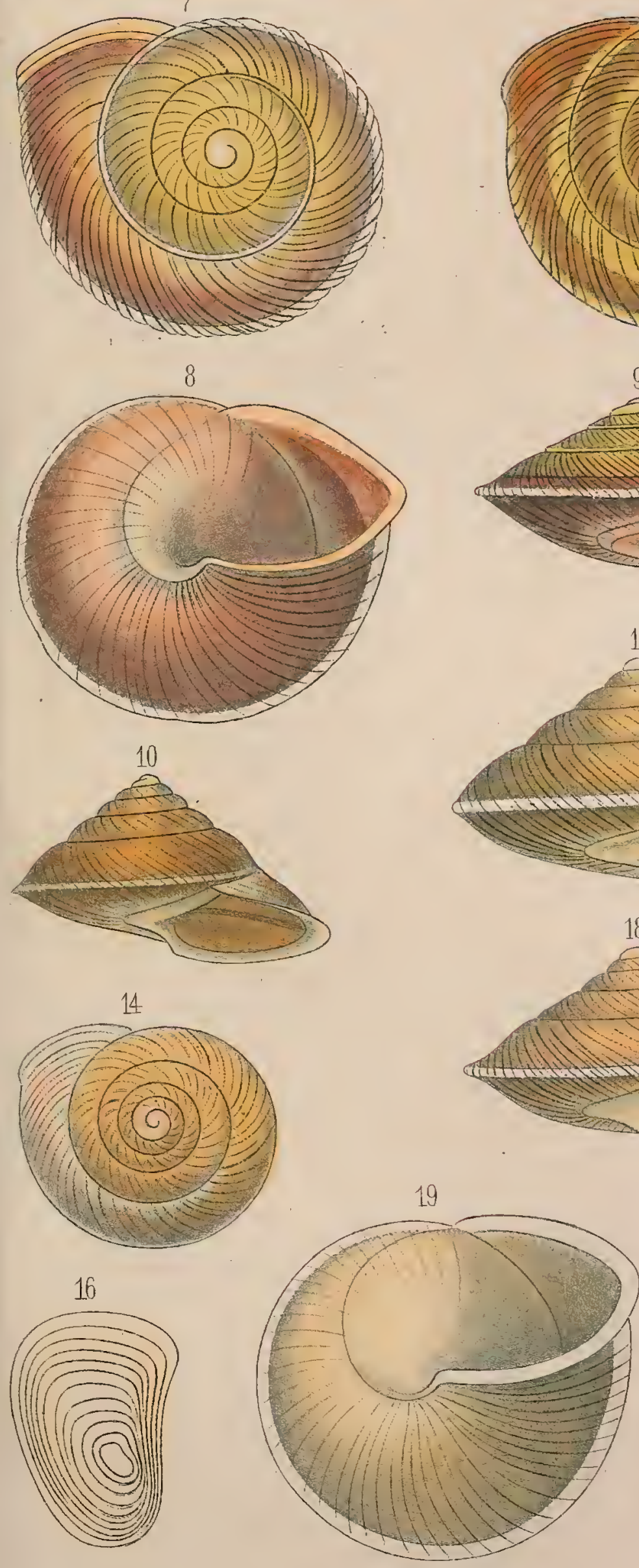
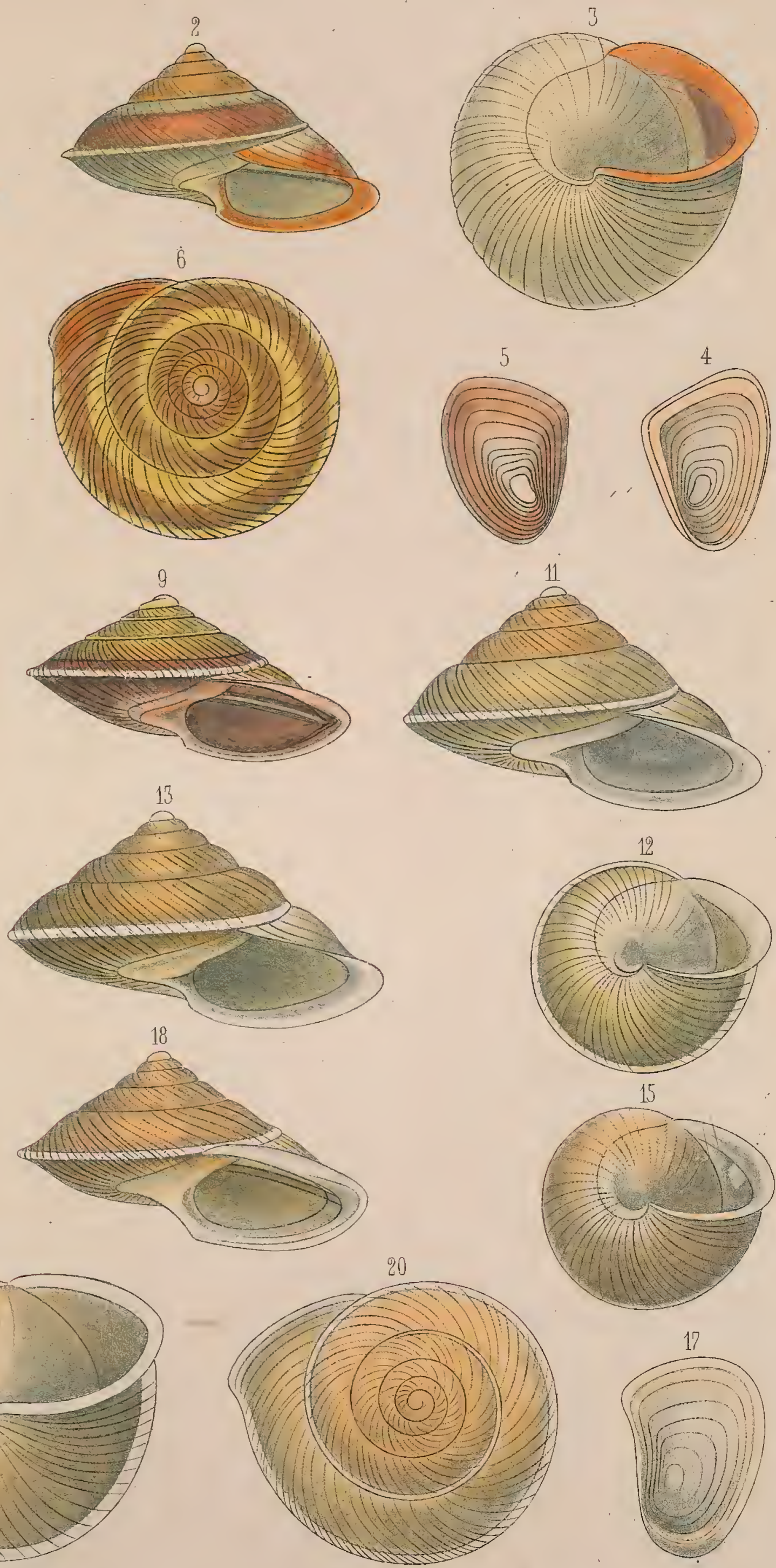


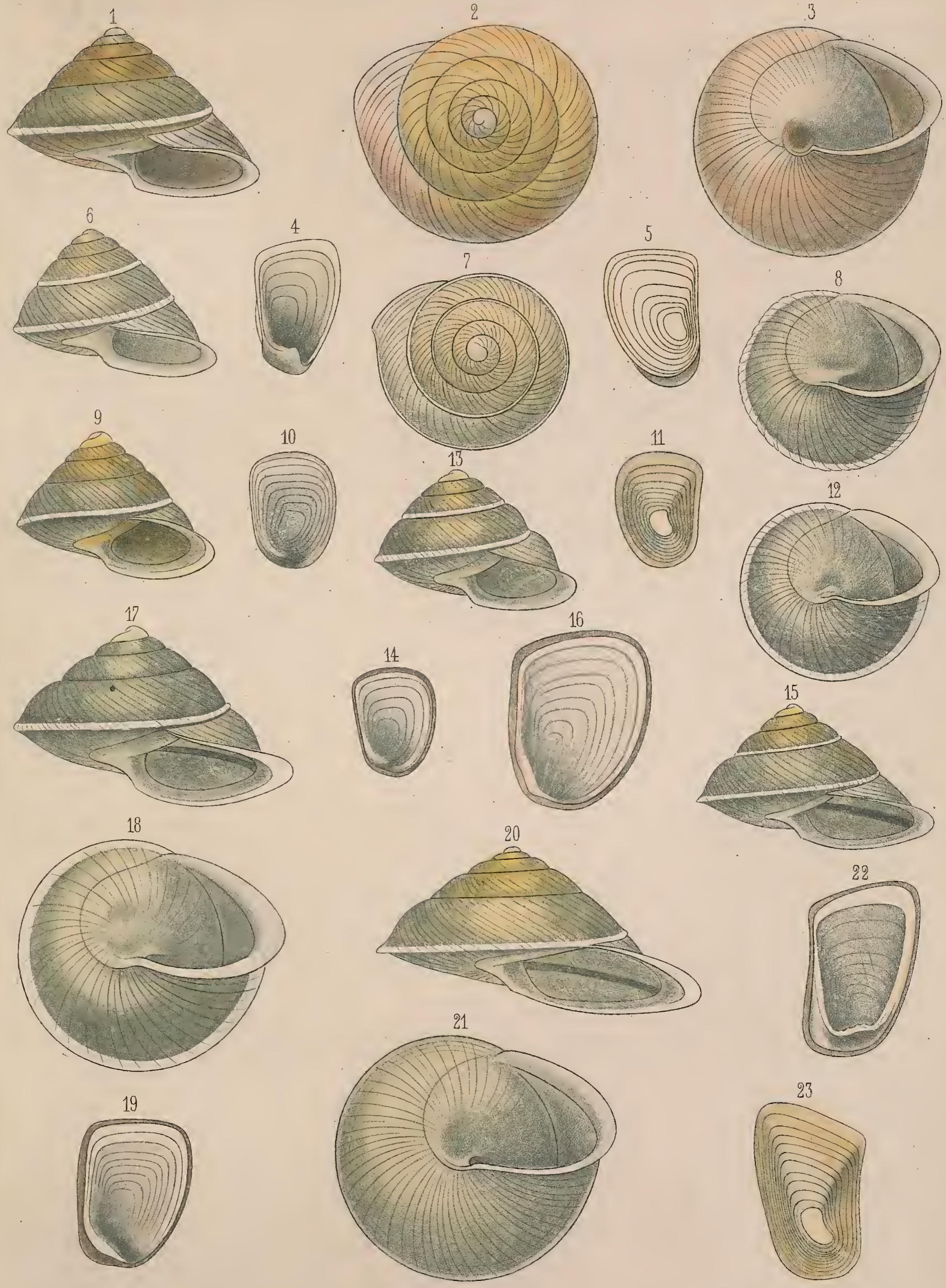

18. II.

30.
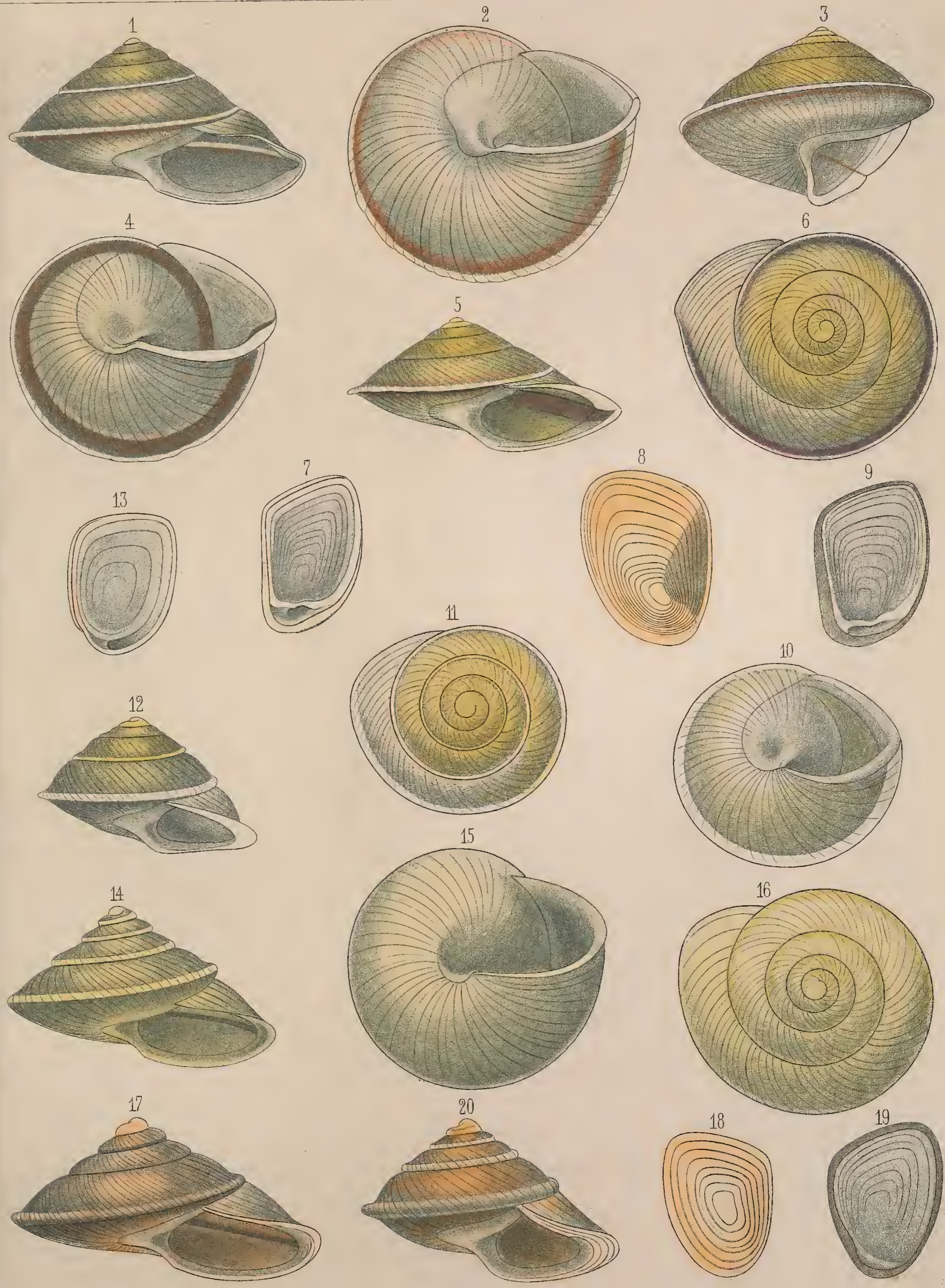


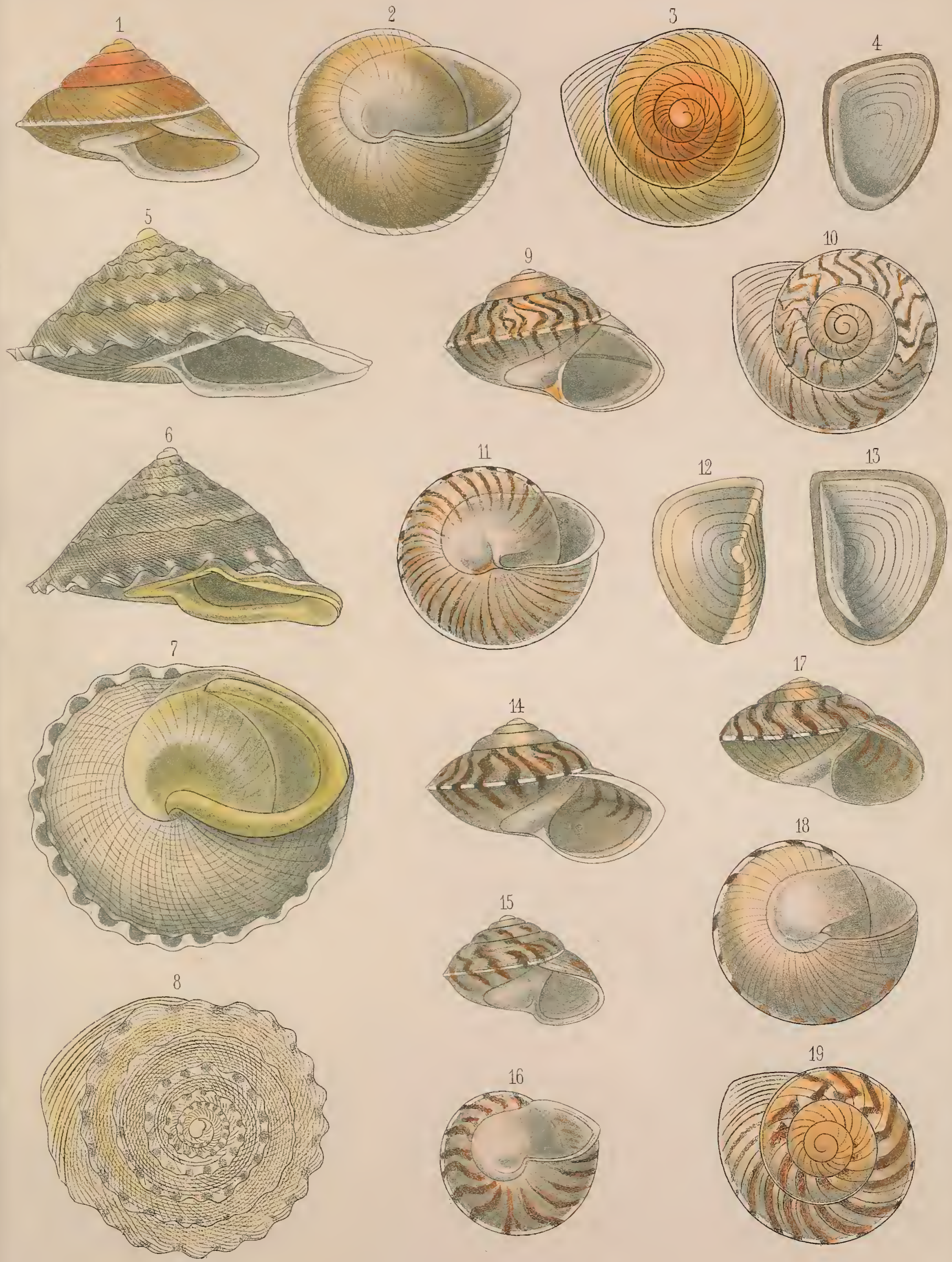


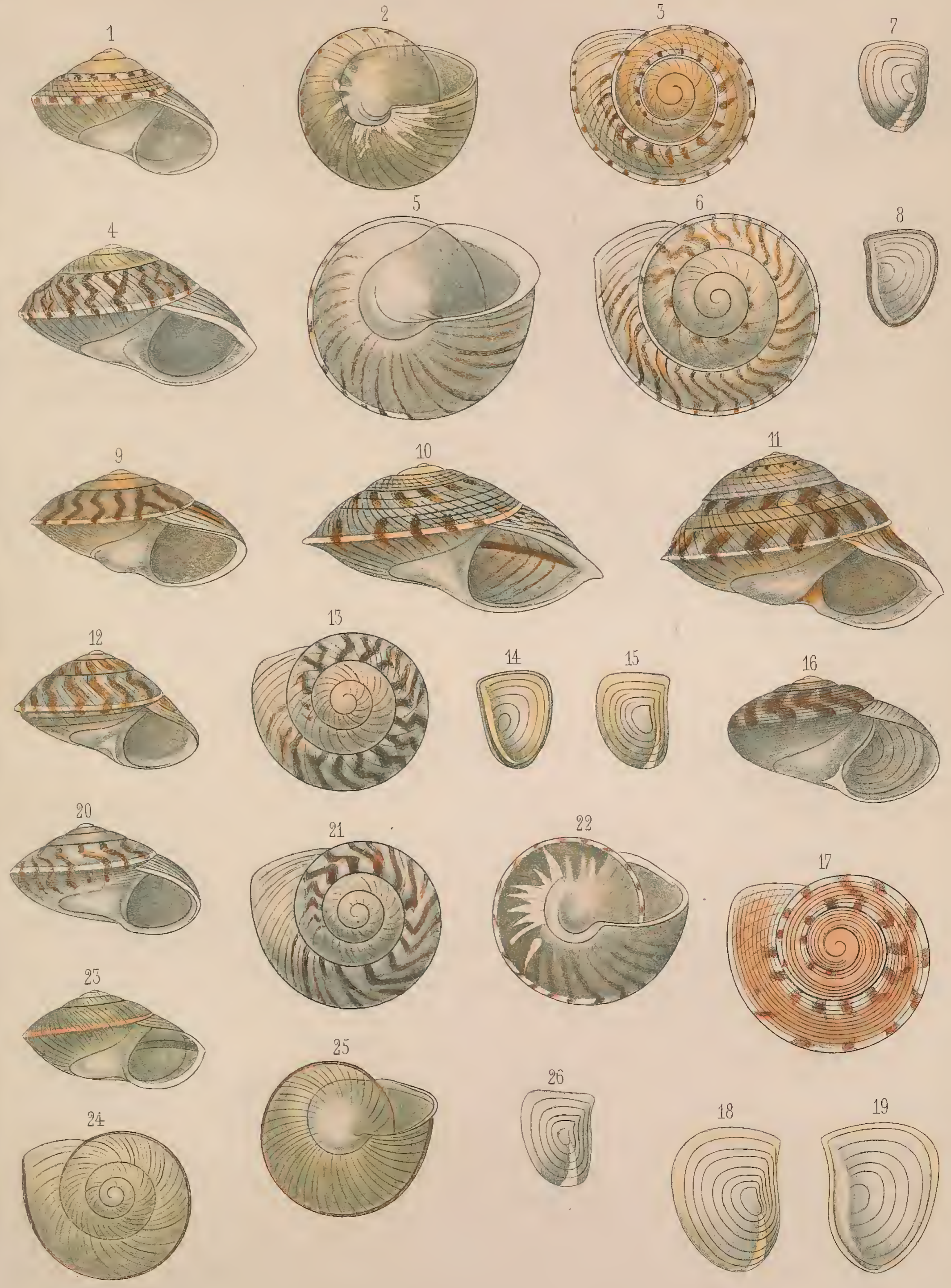


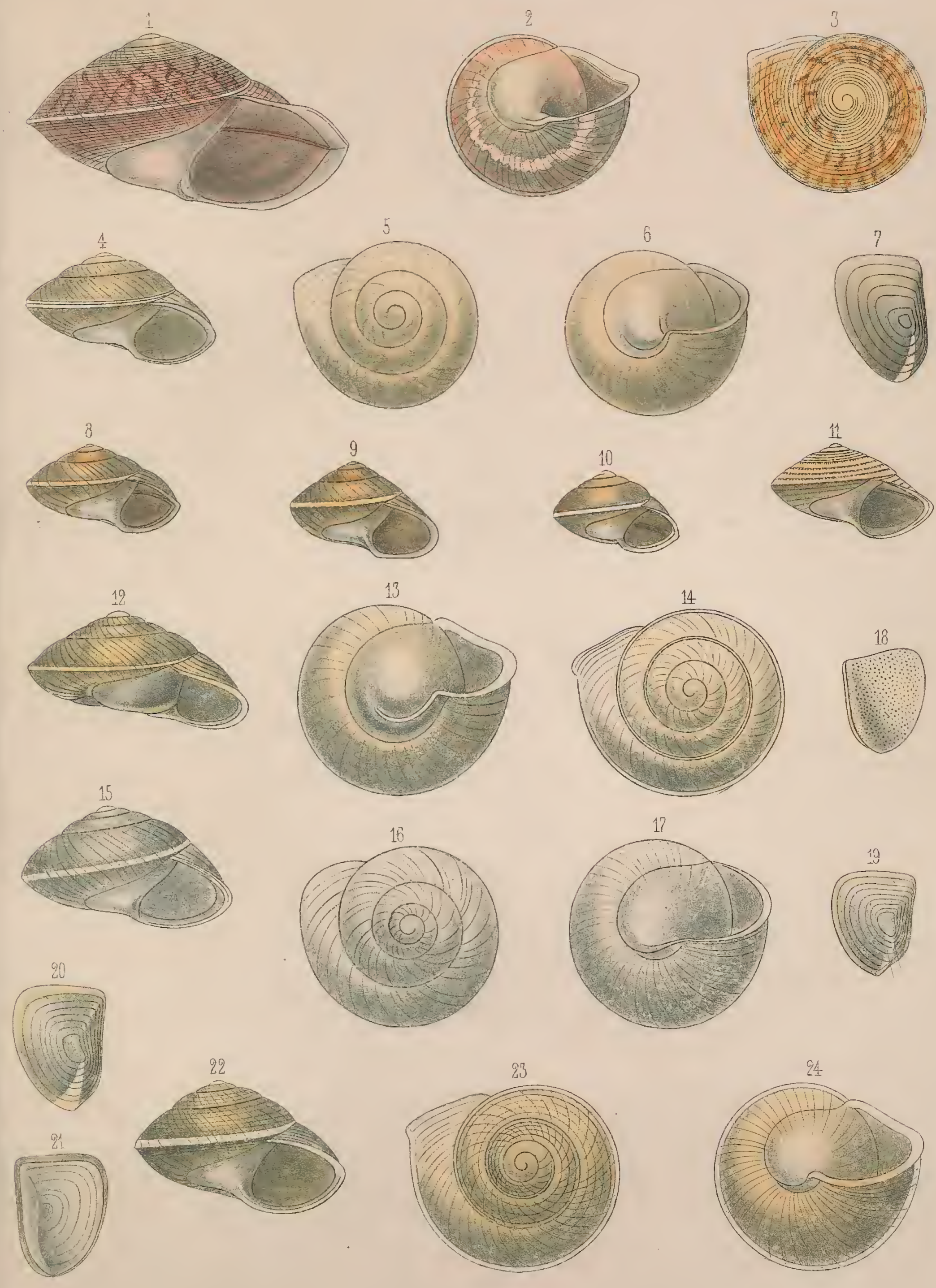


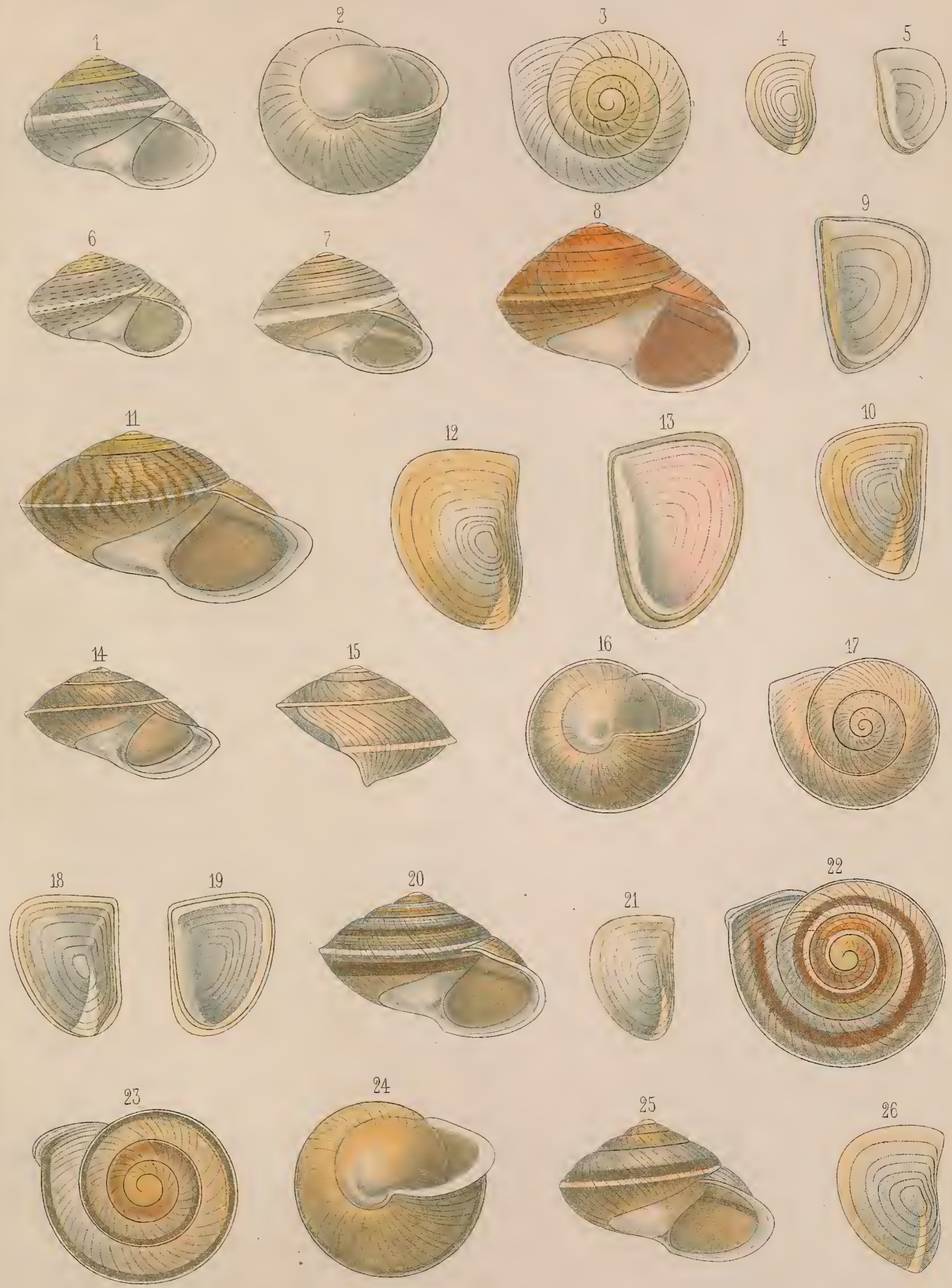


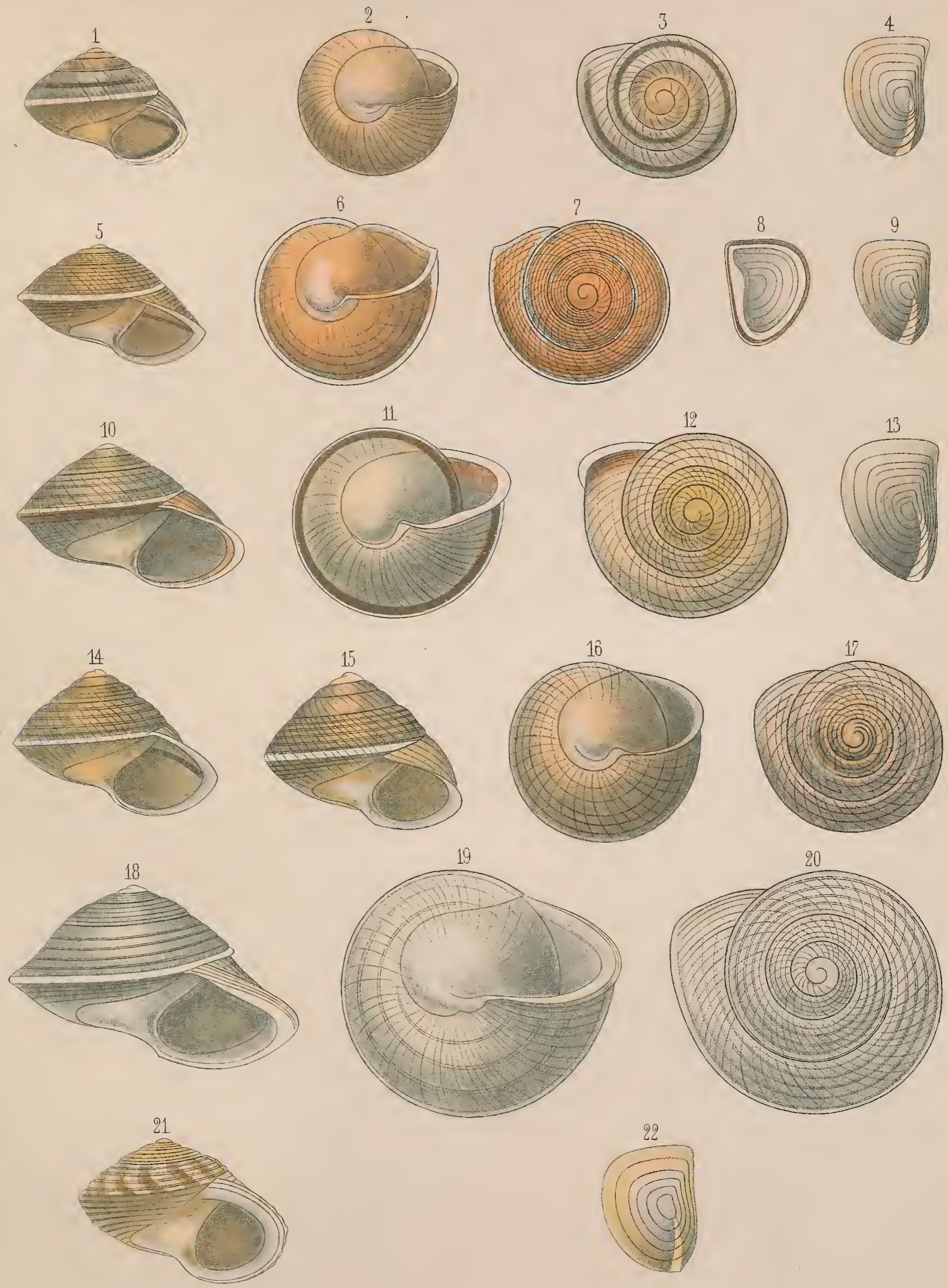

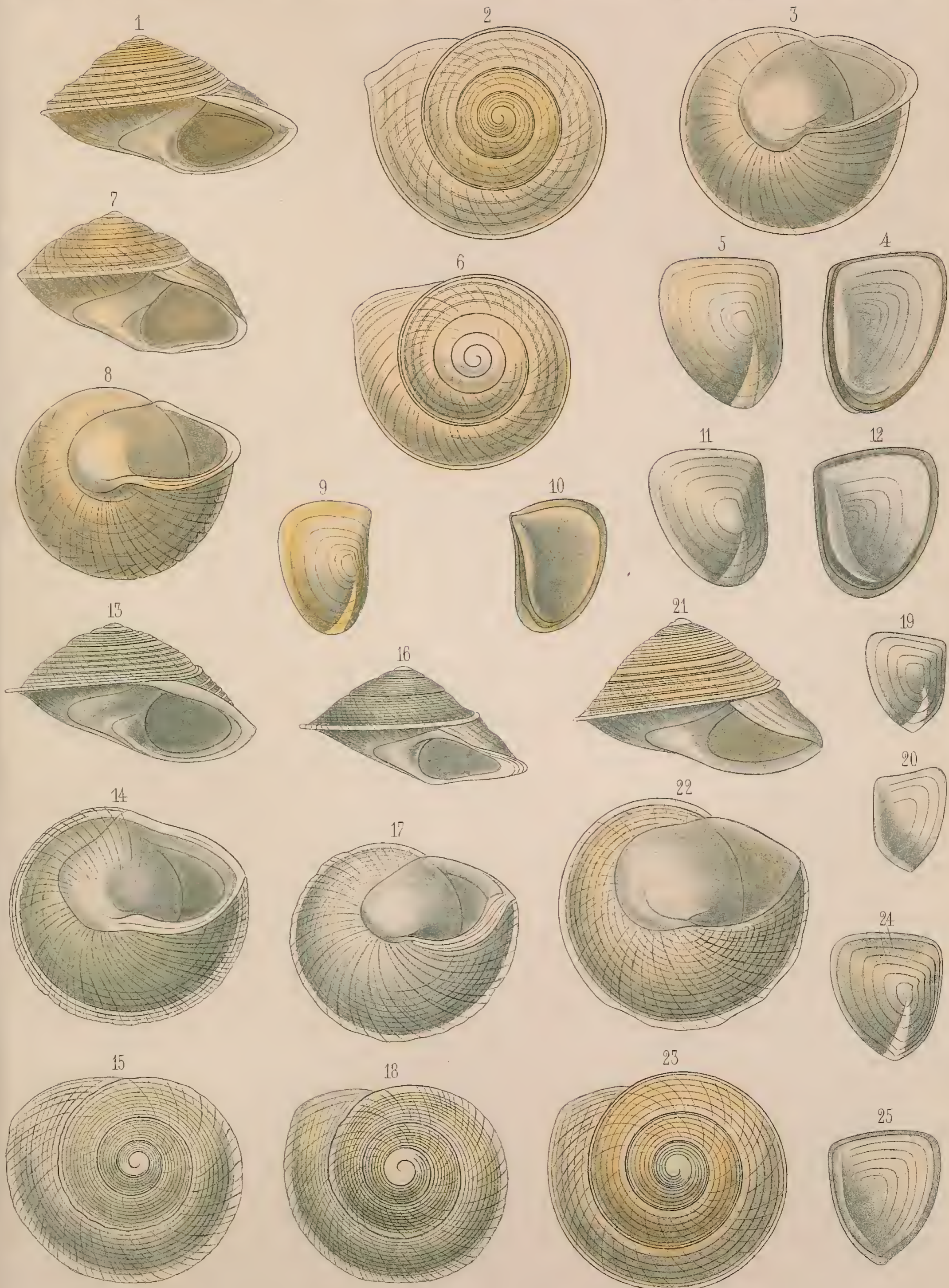

23
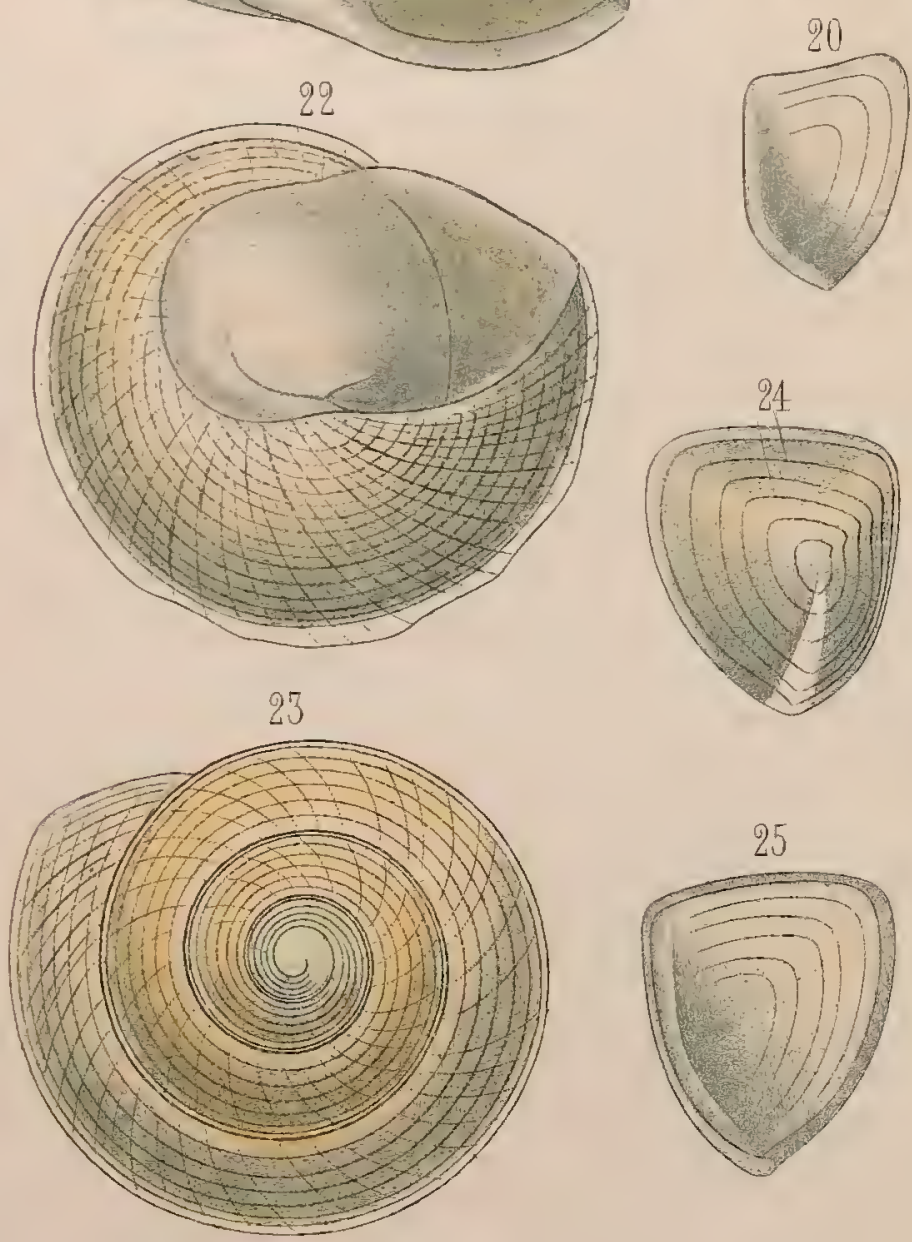


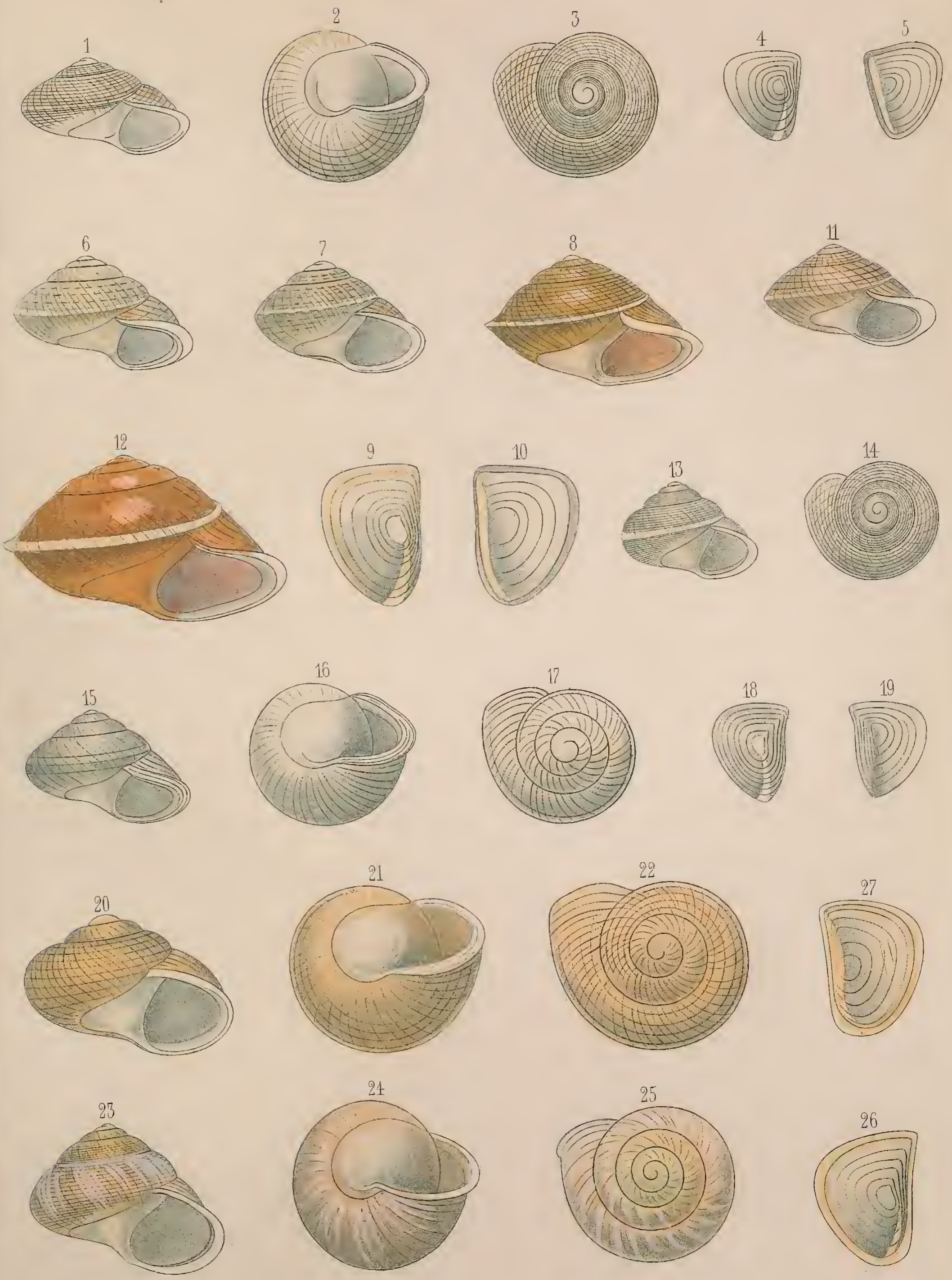


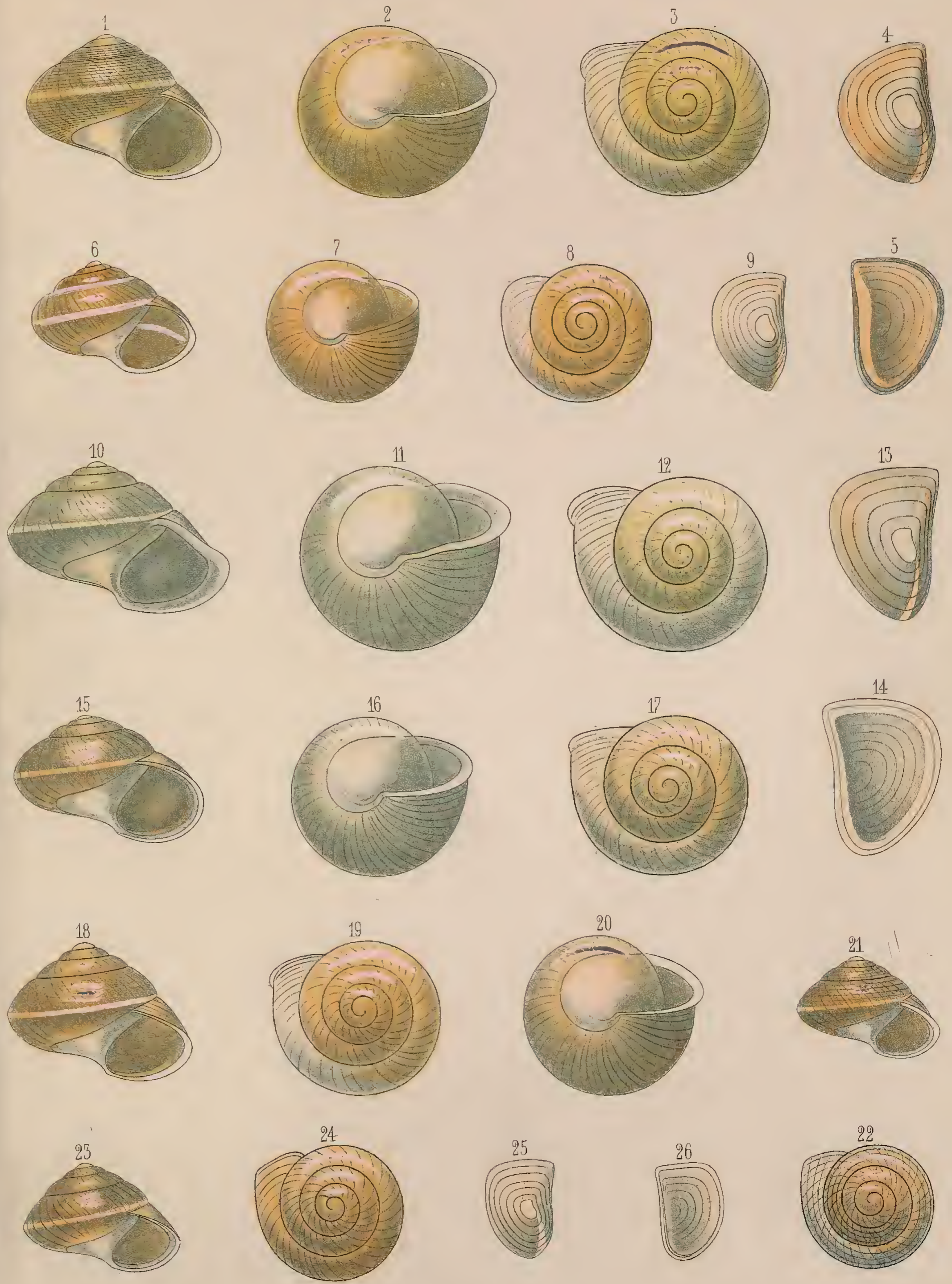


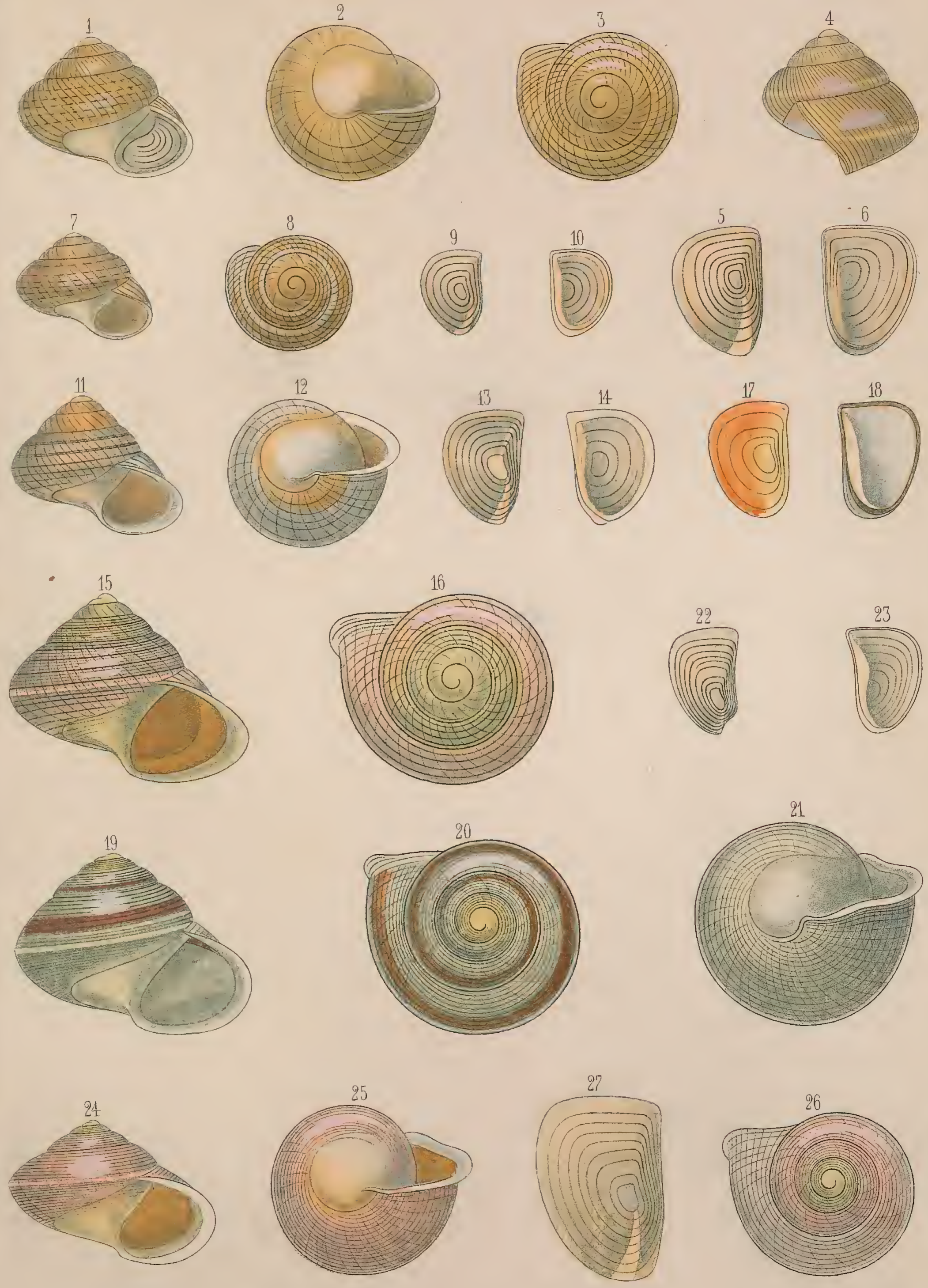


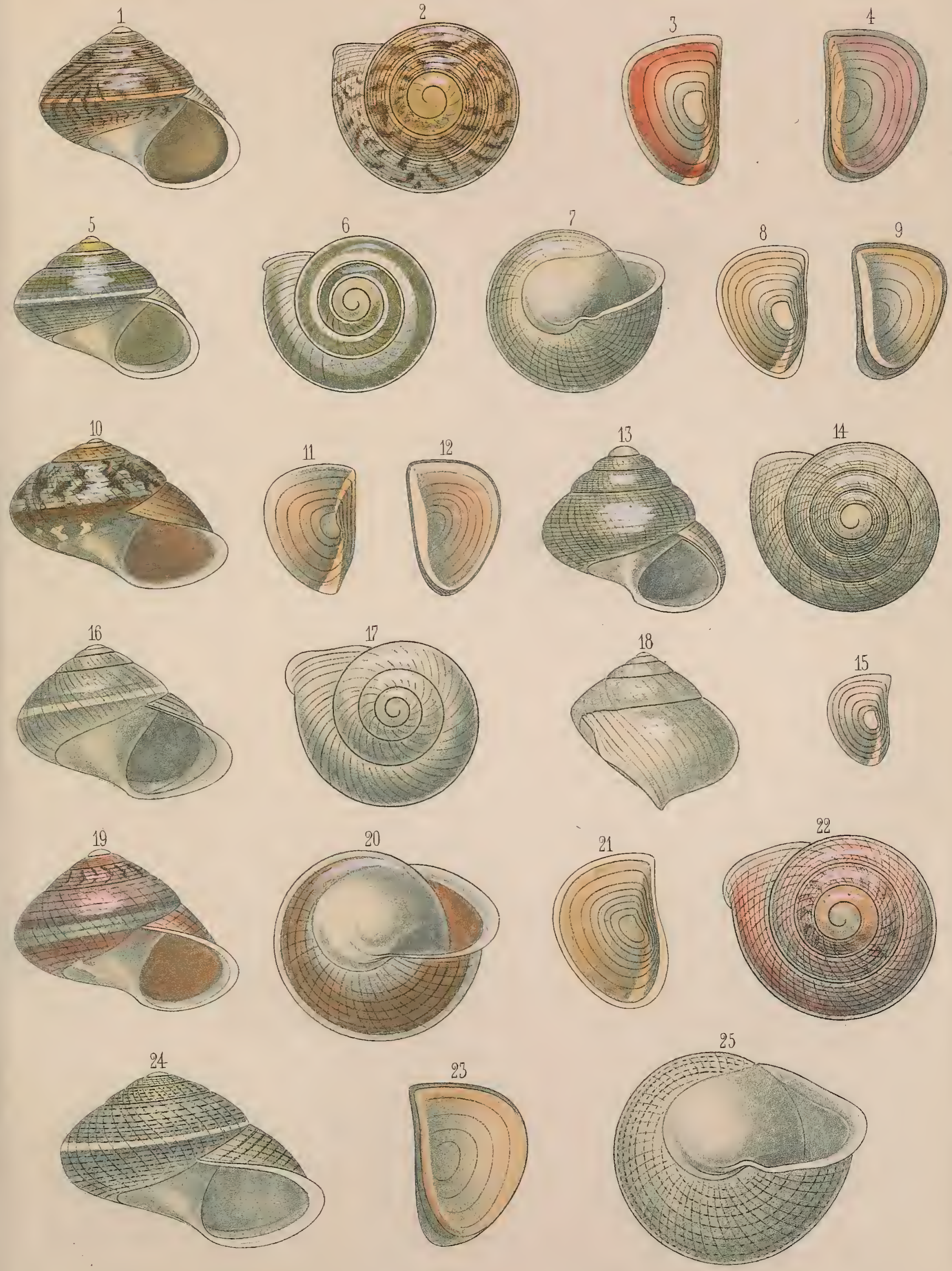

I.18 TI.

4
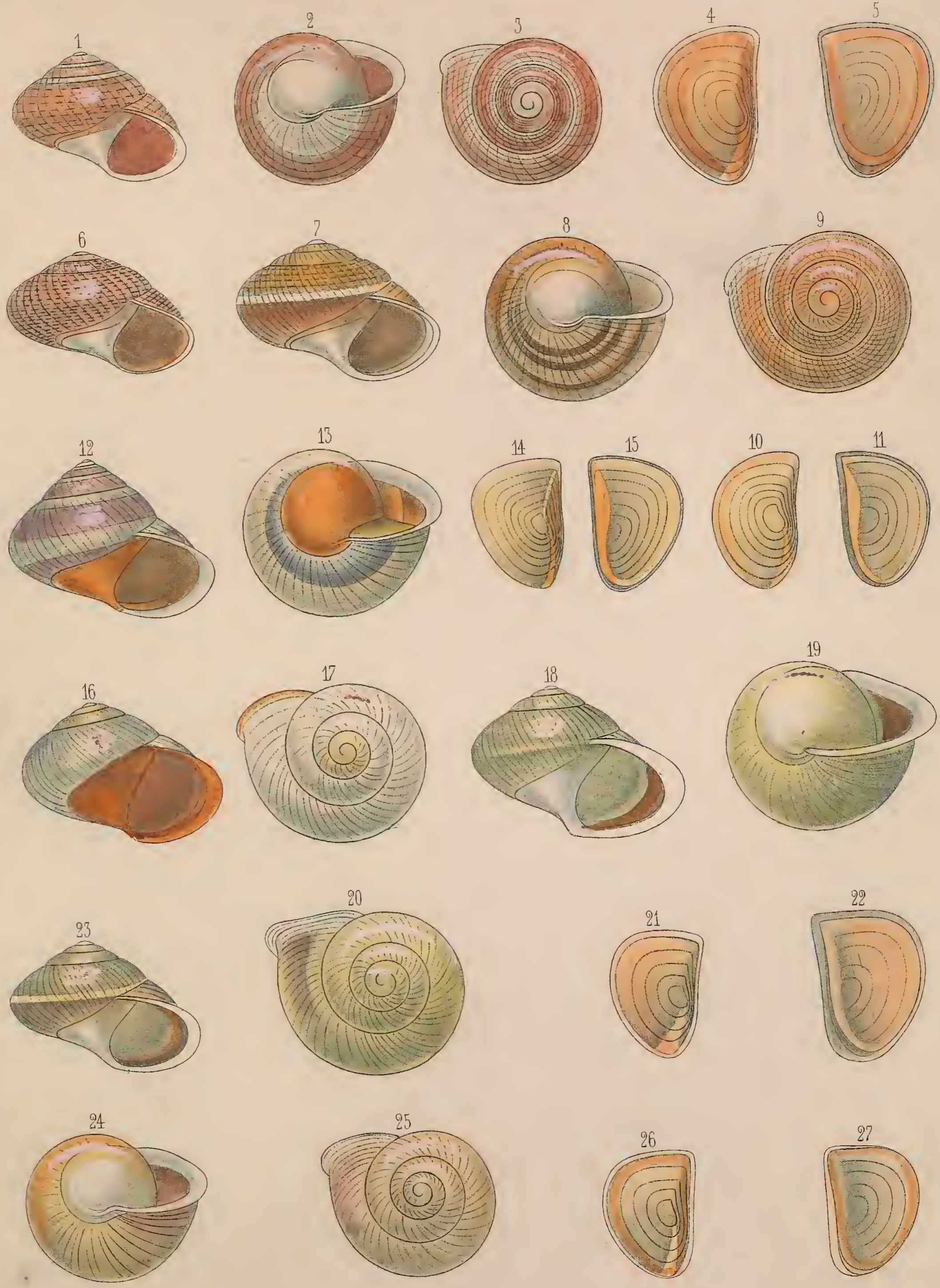


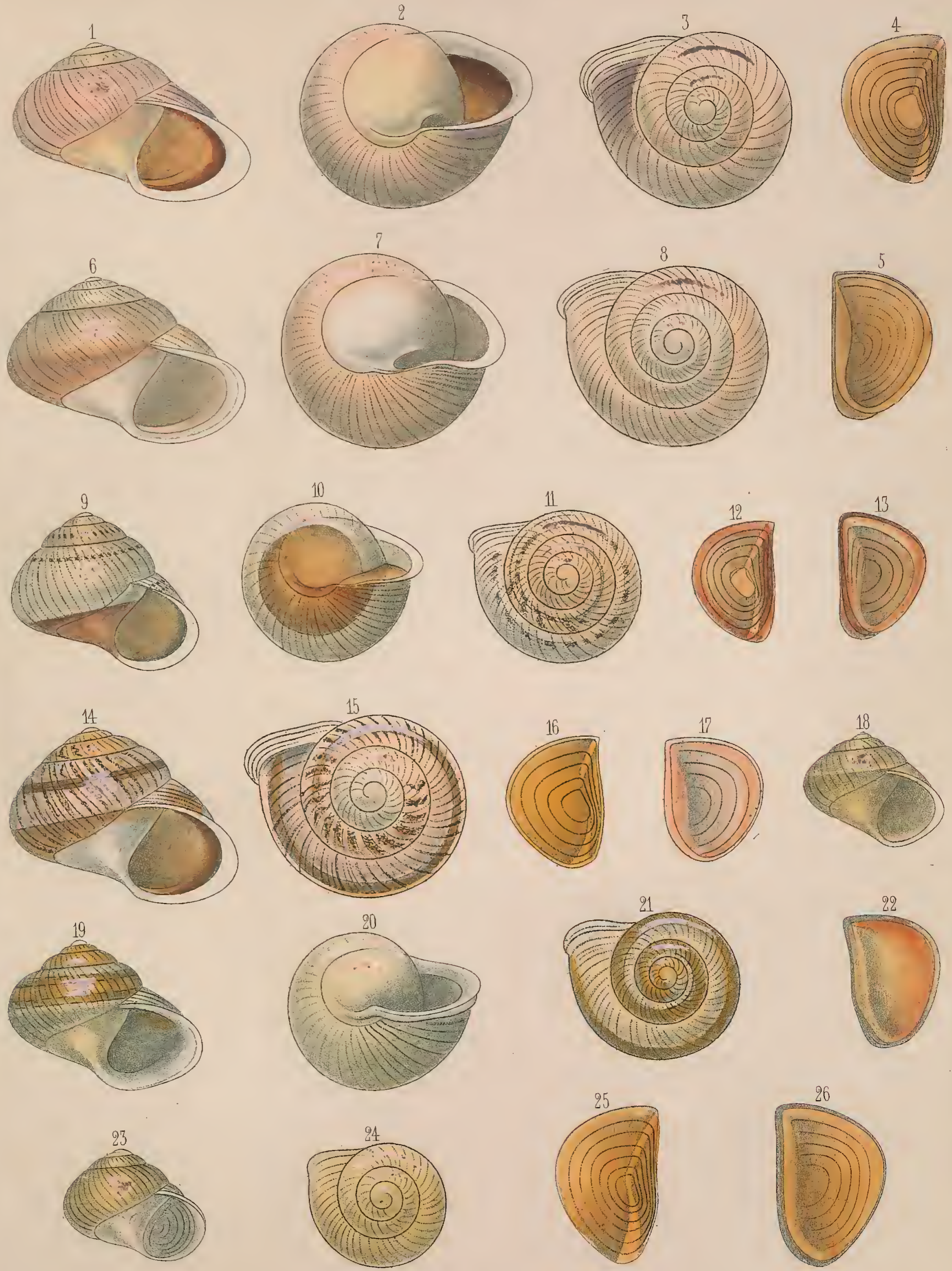


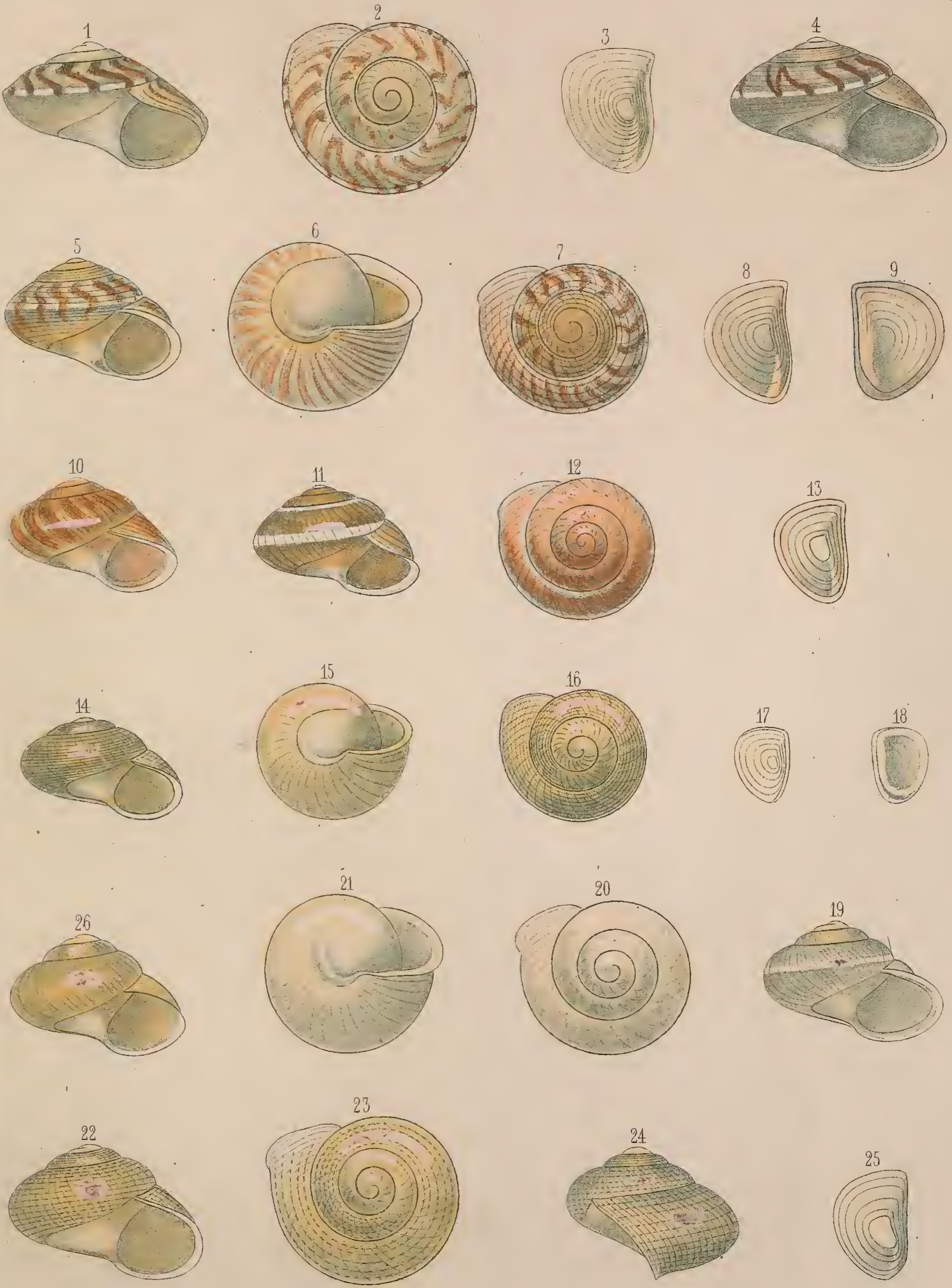


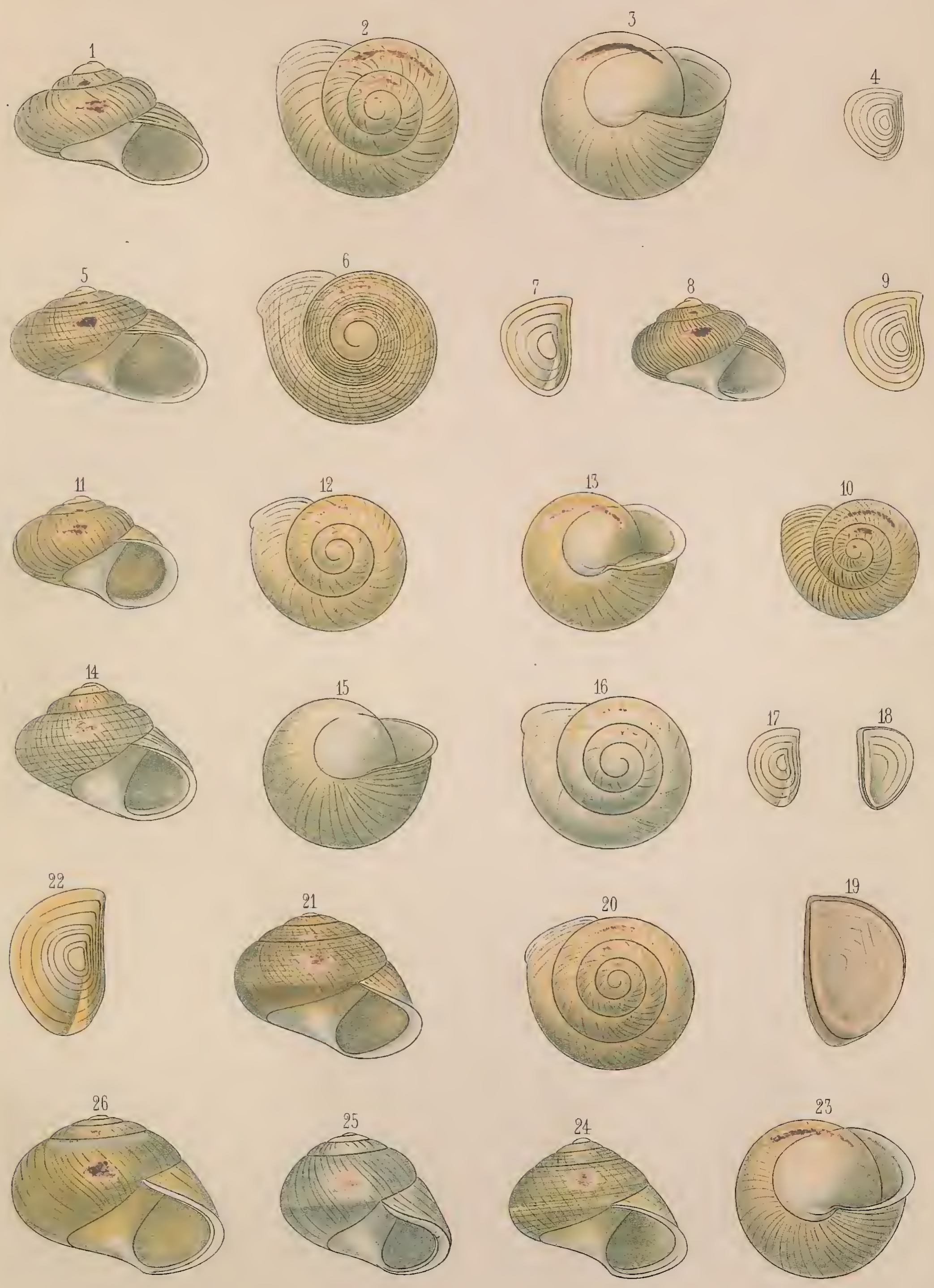


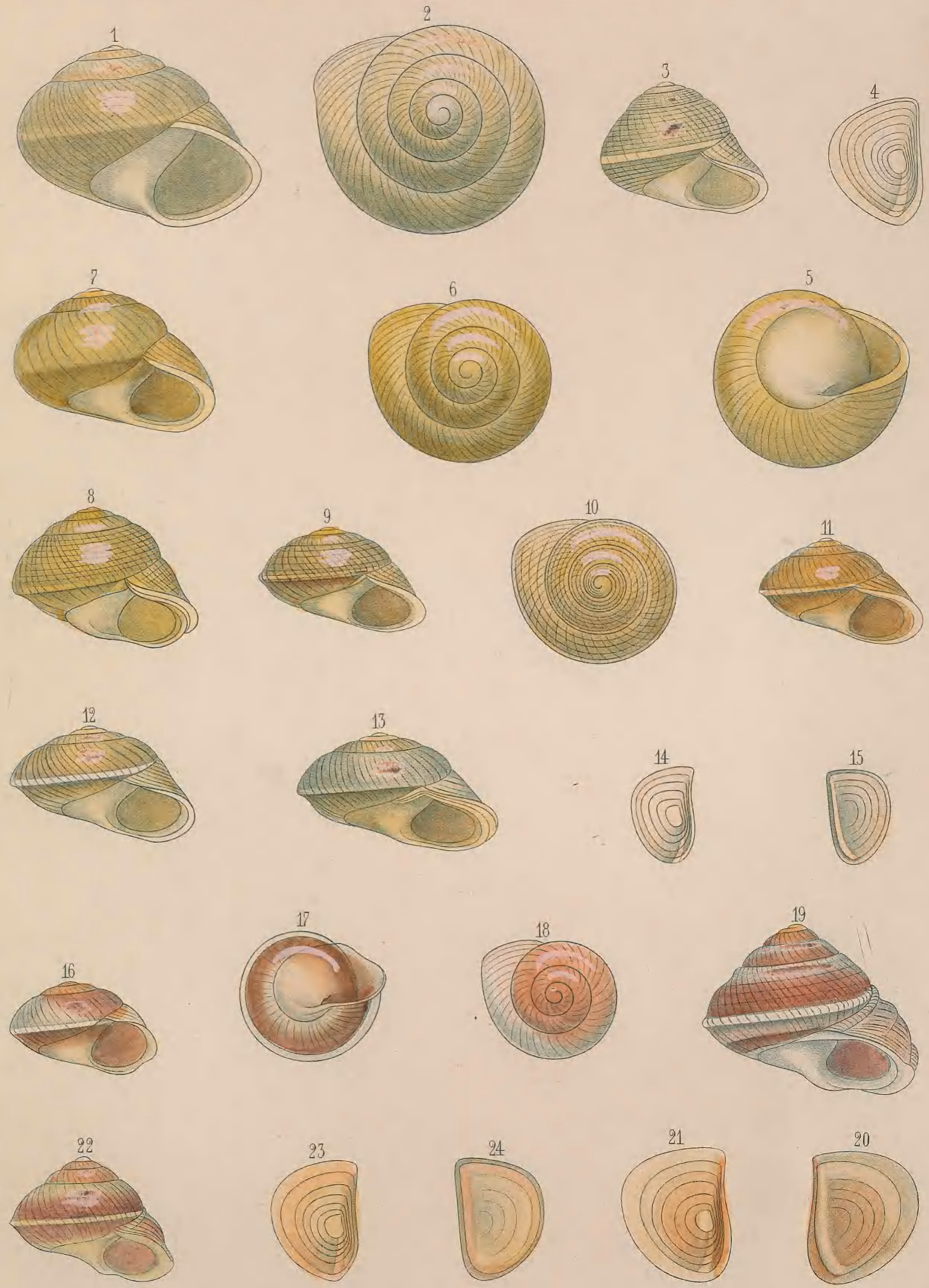


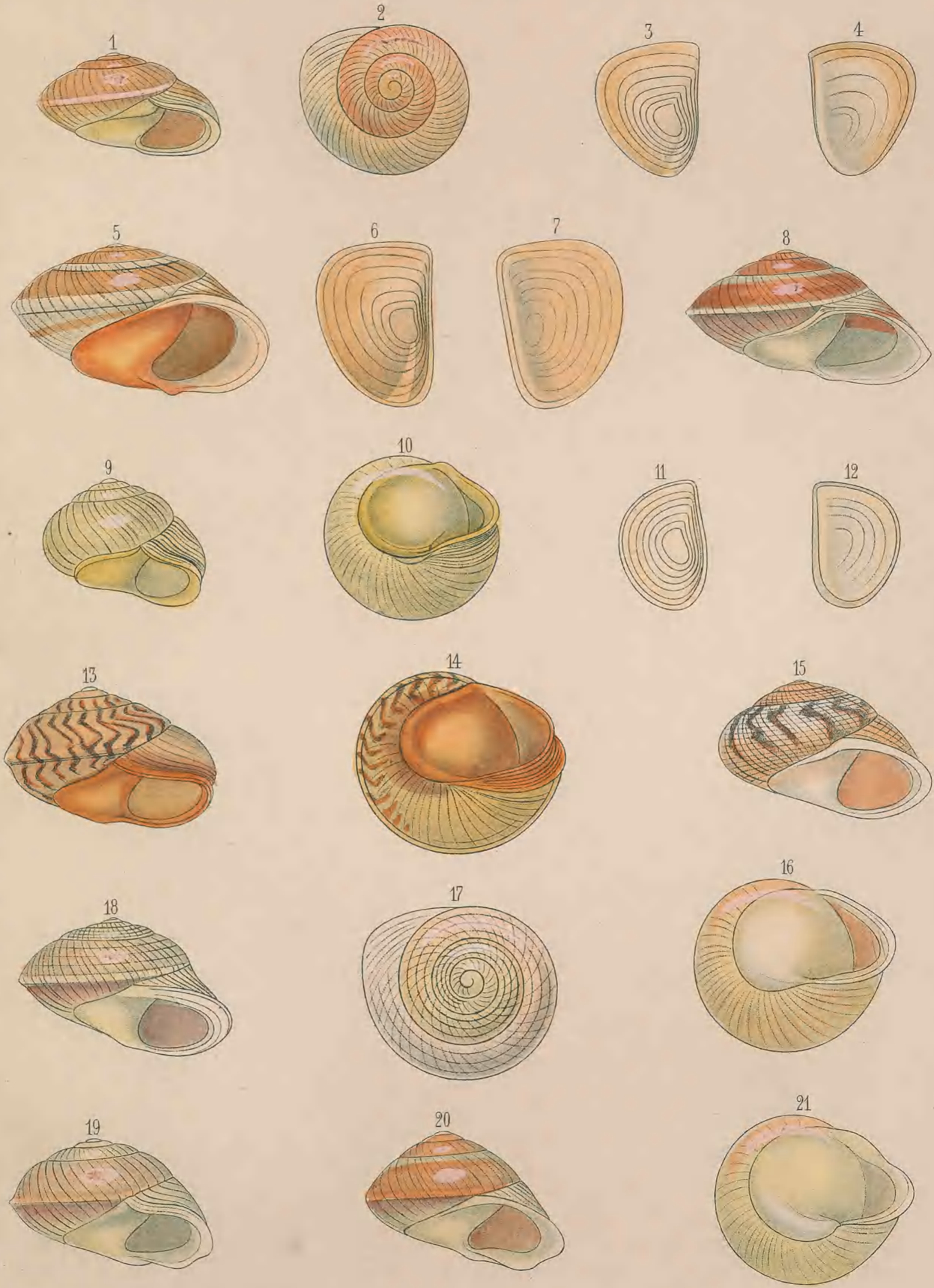


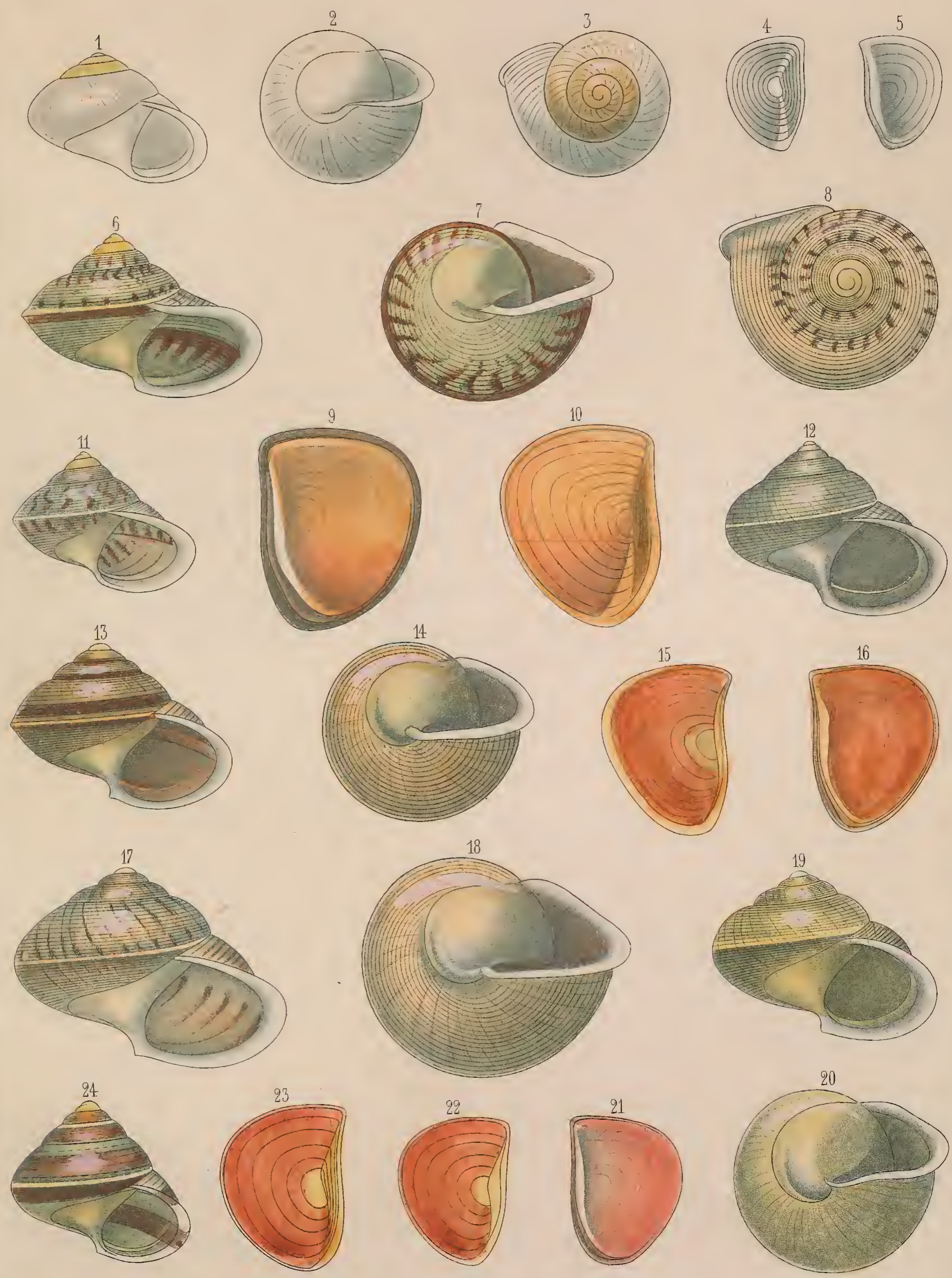


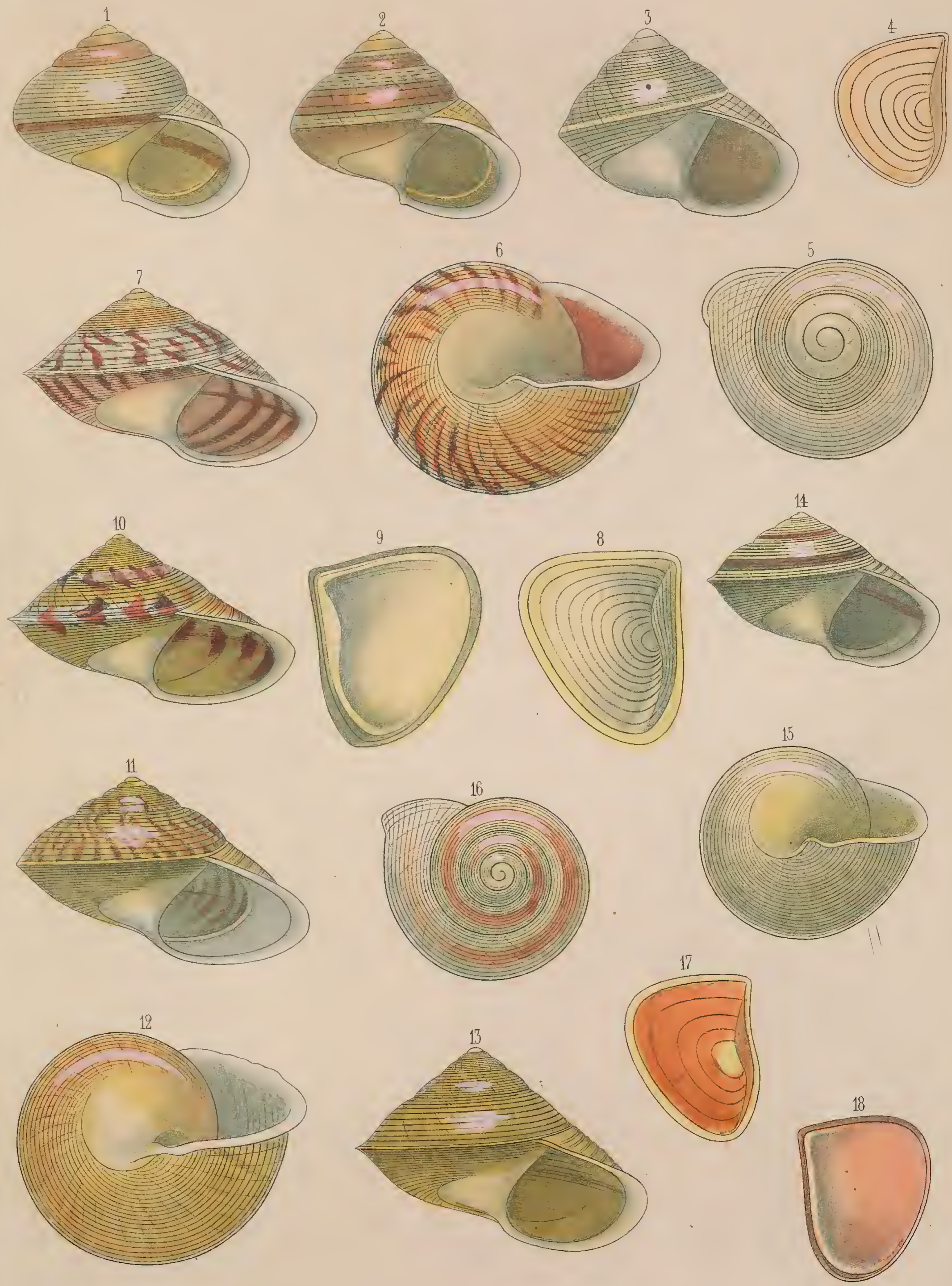


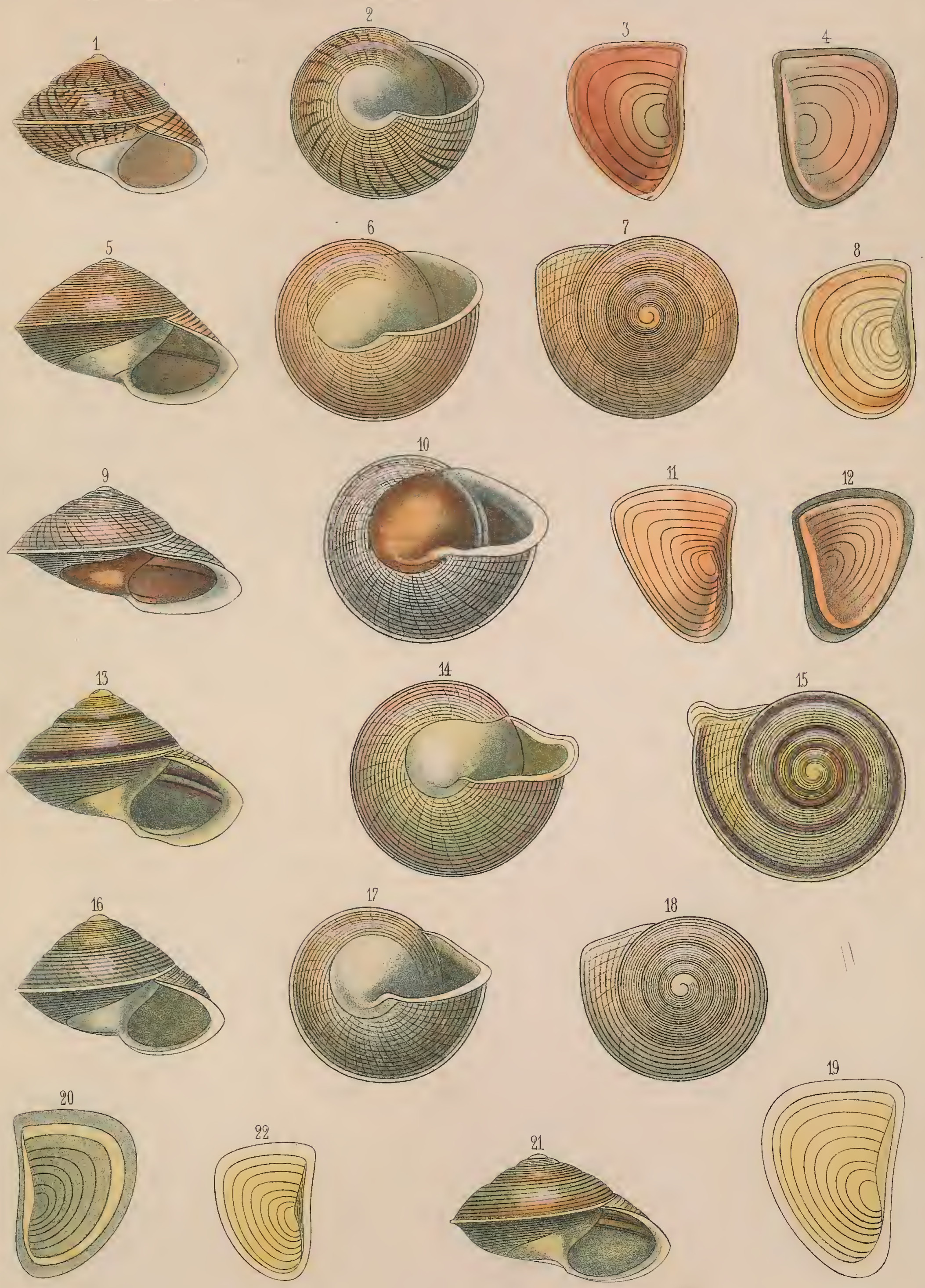


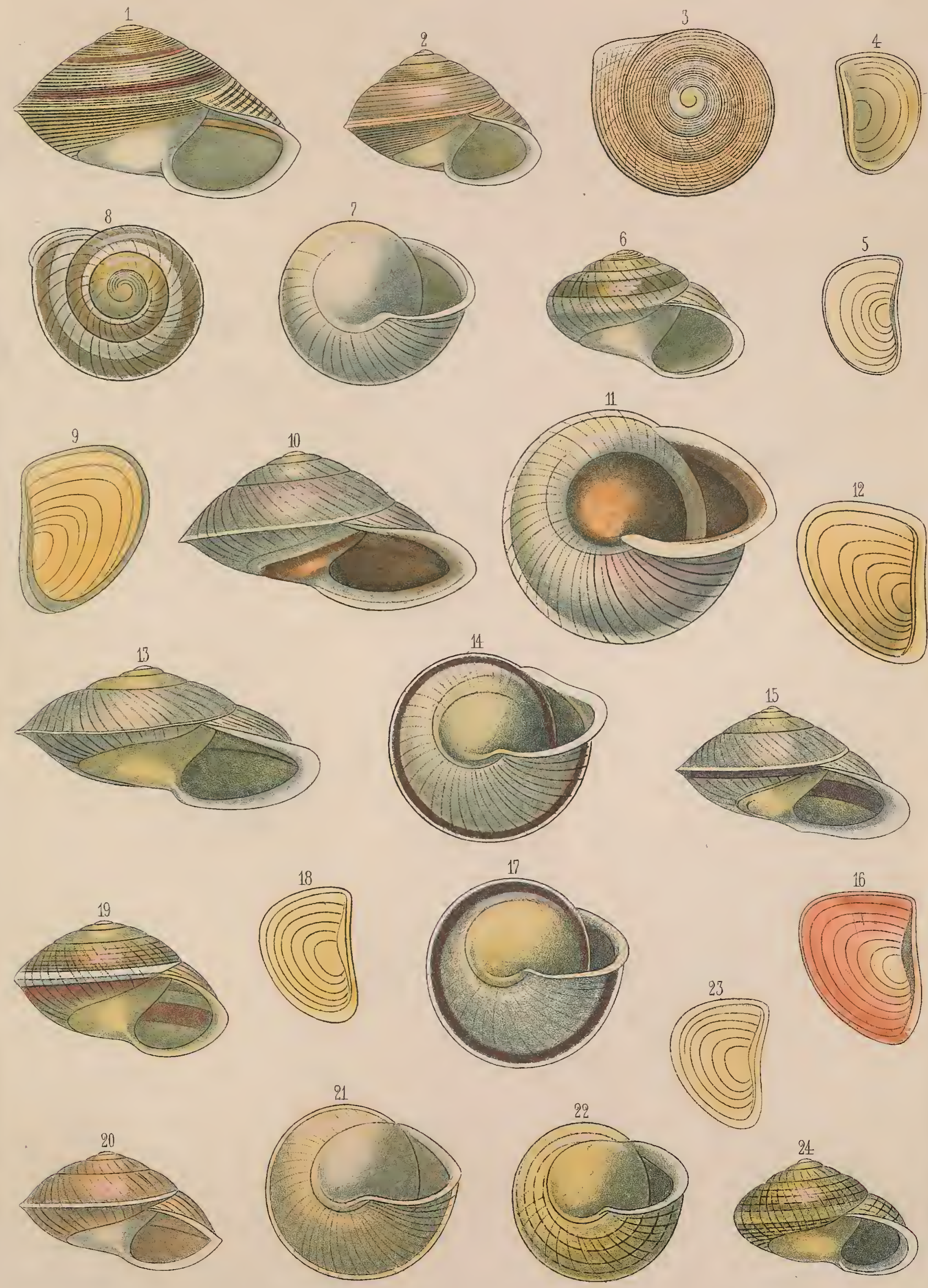

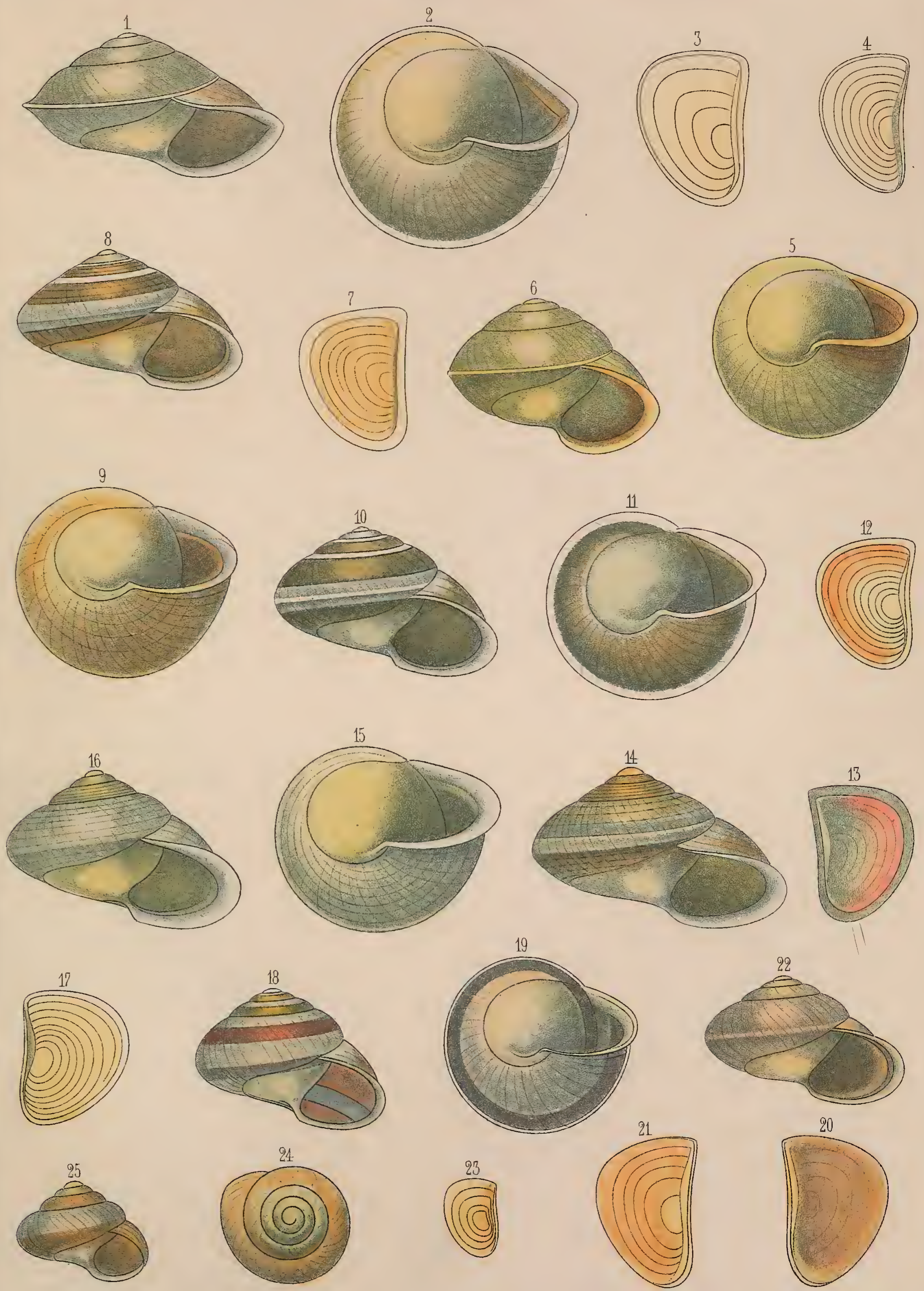


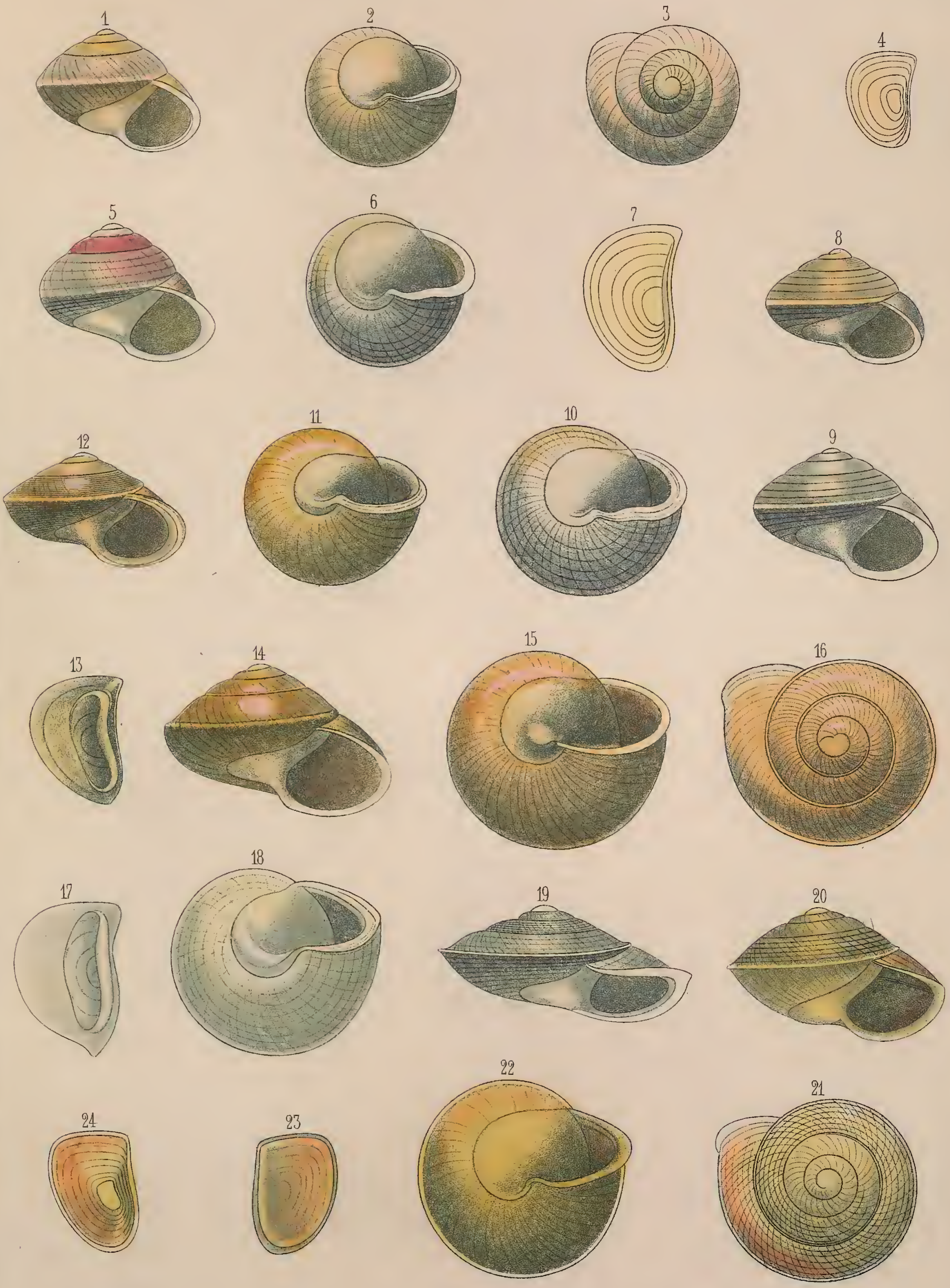

I. 18. II.

53.
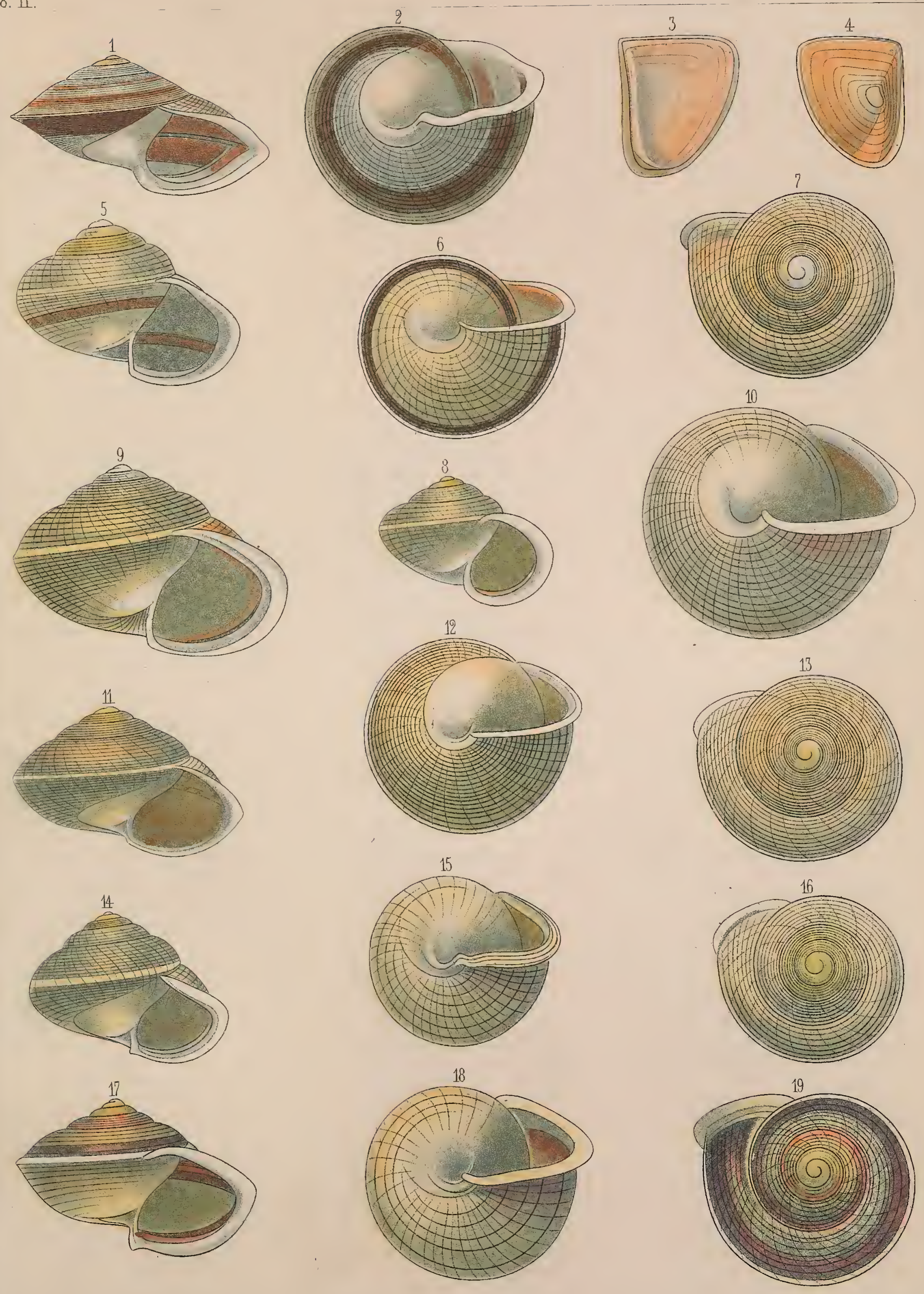


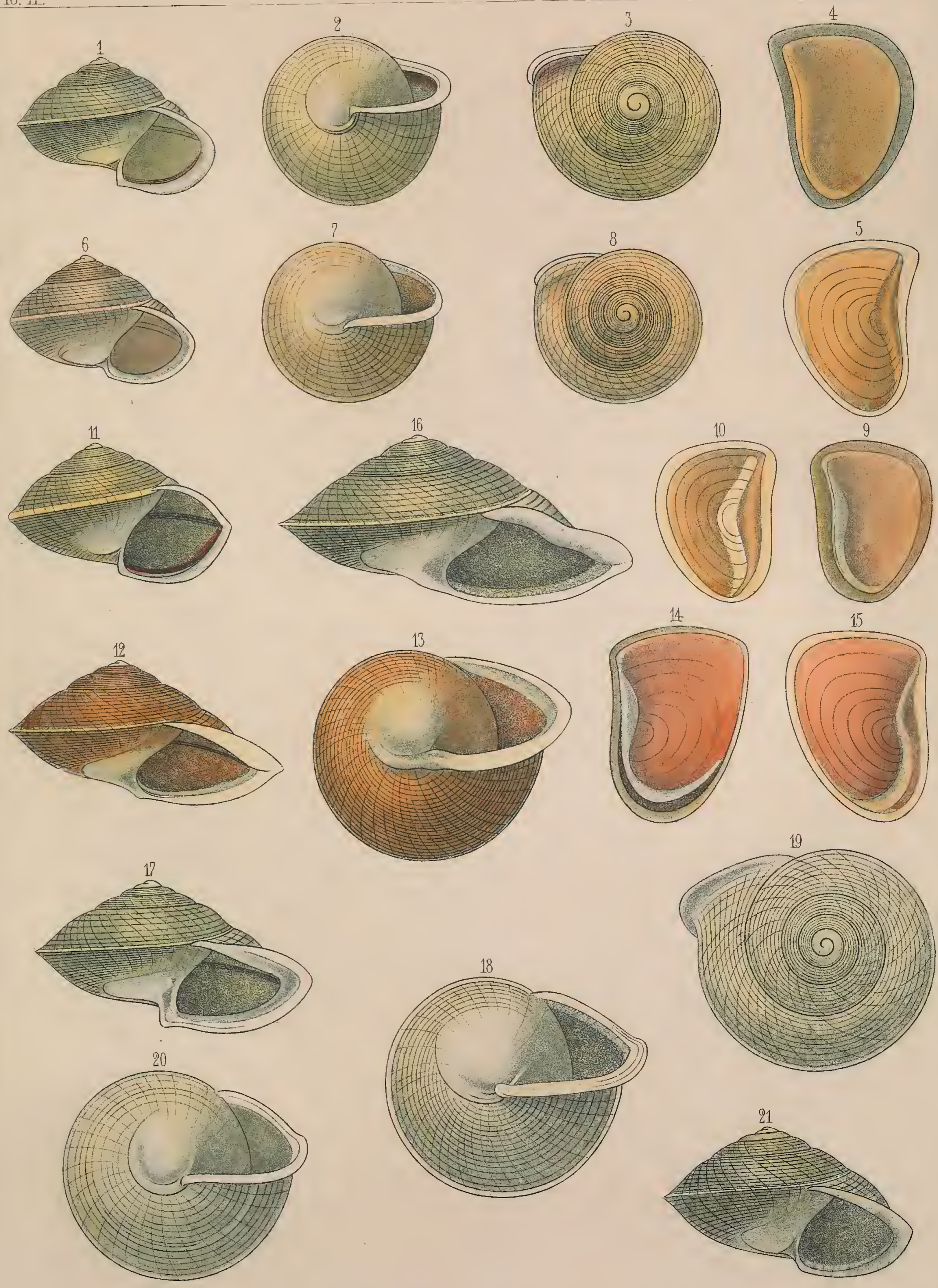


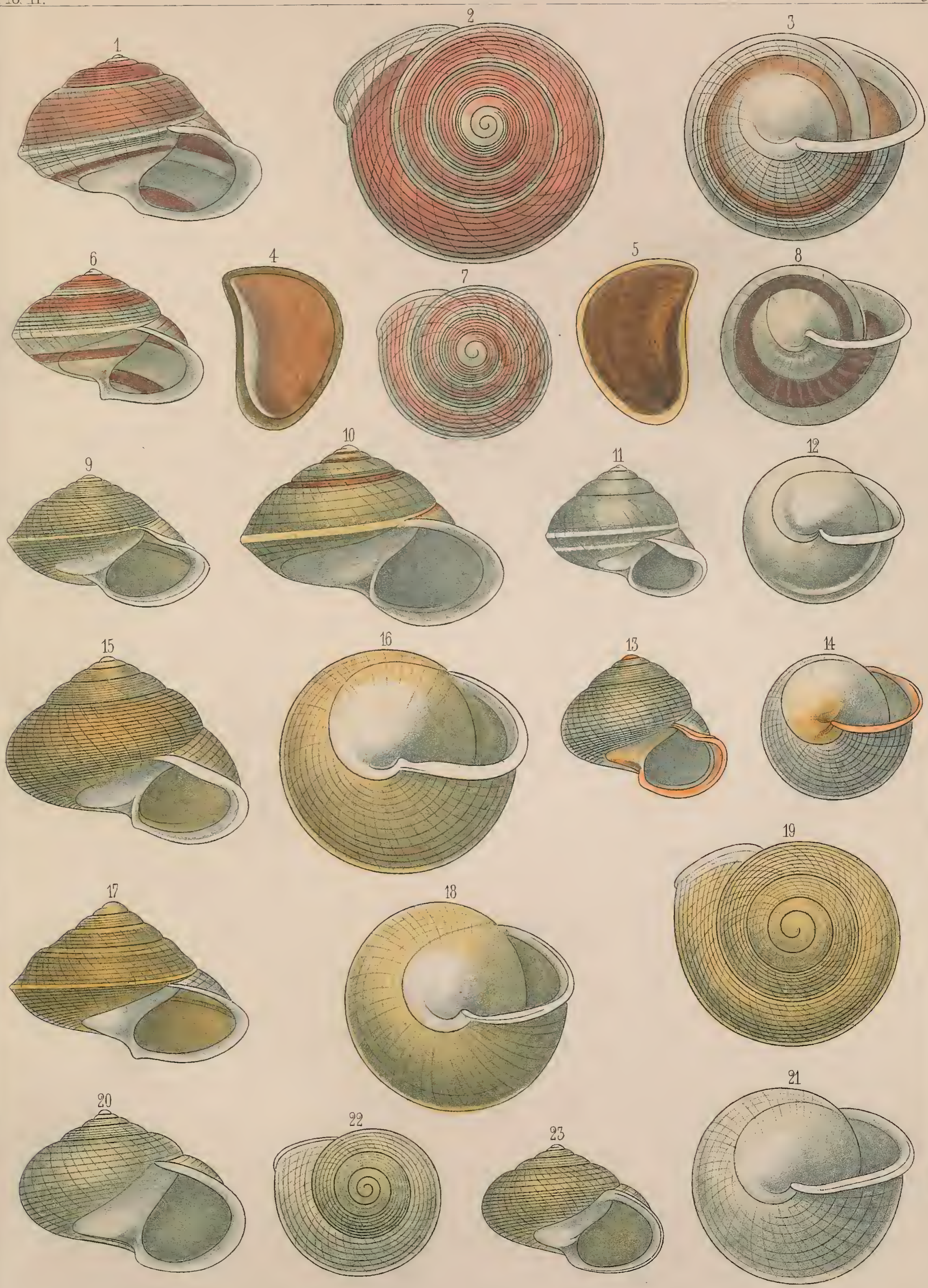

I.18. II.

56.
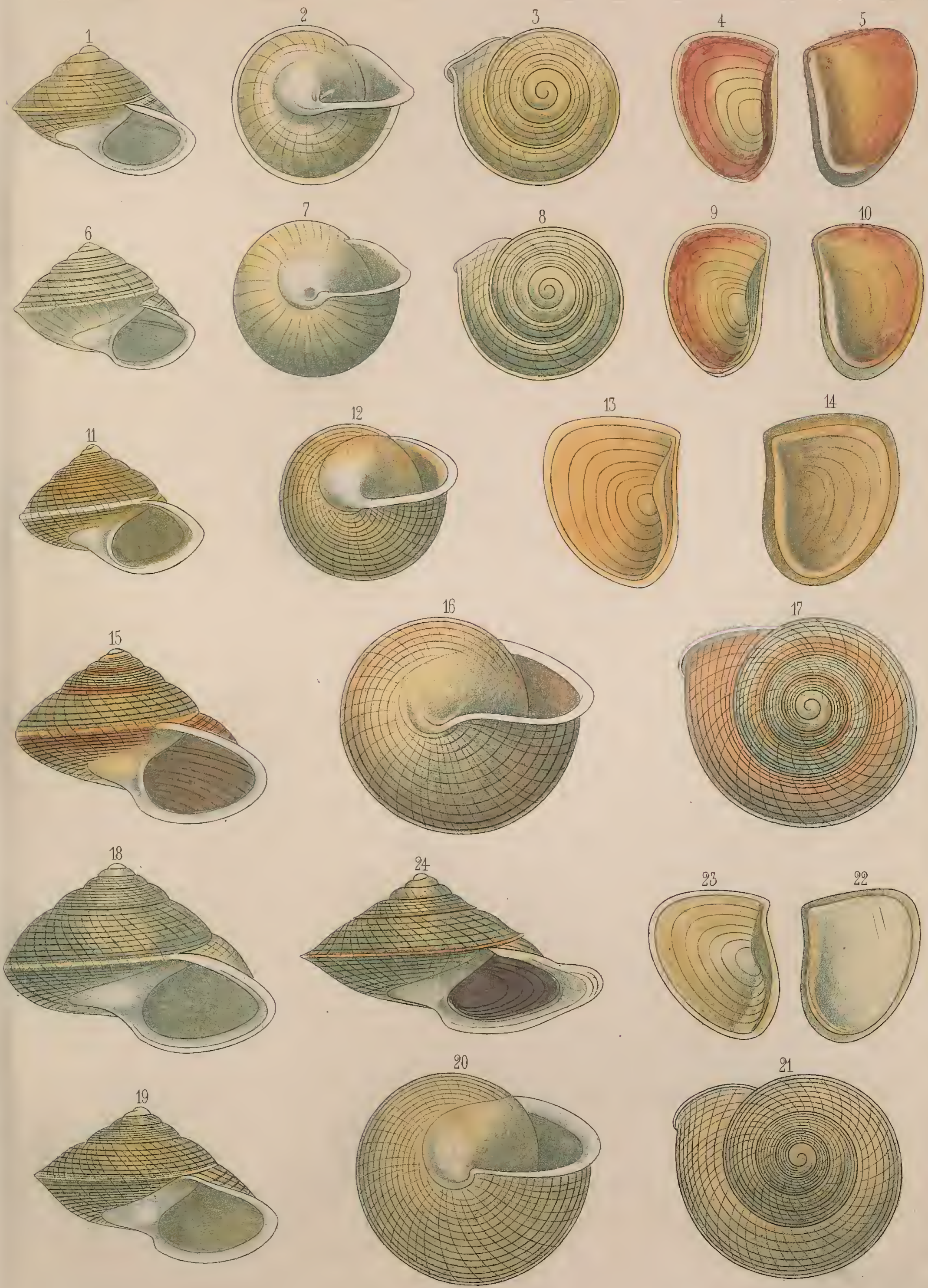

I. 18. II.
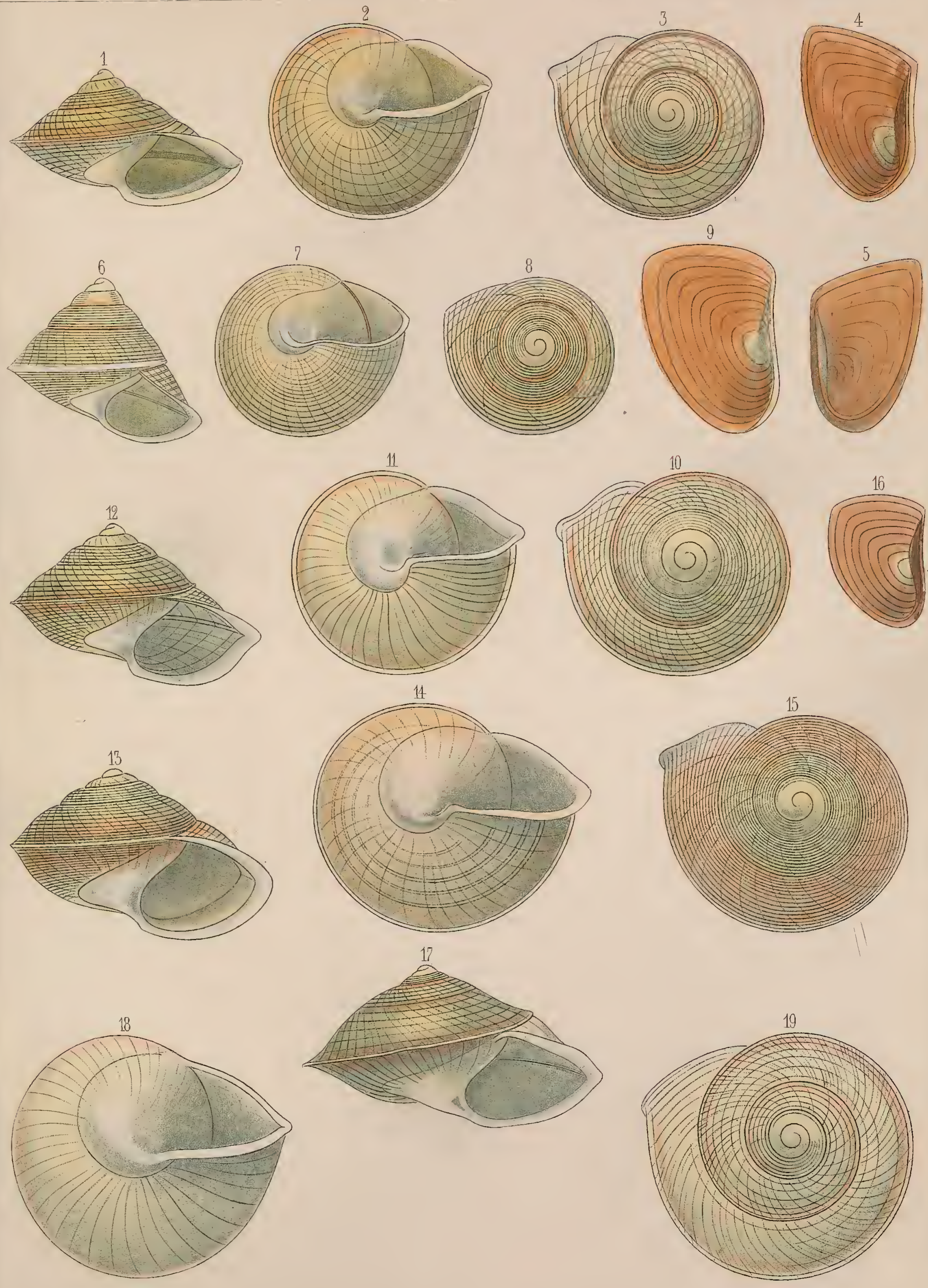


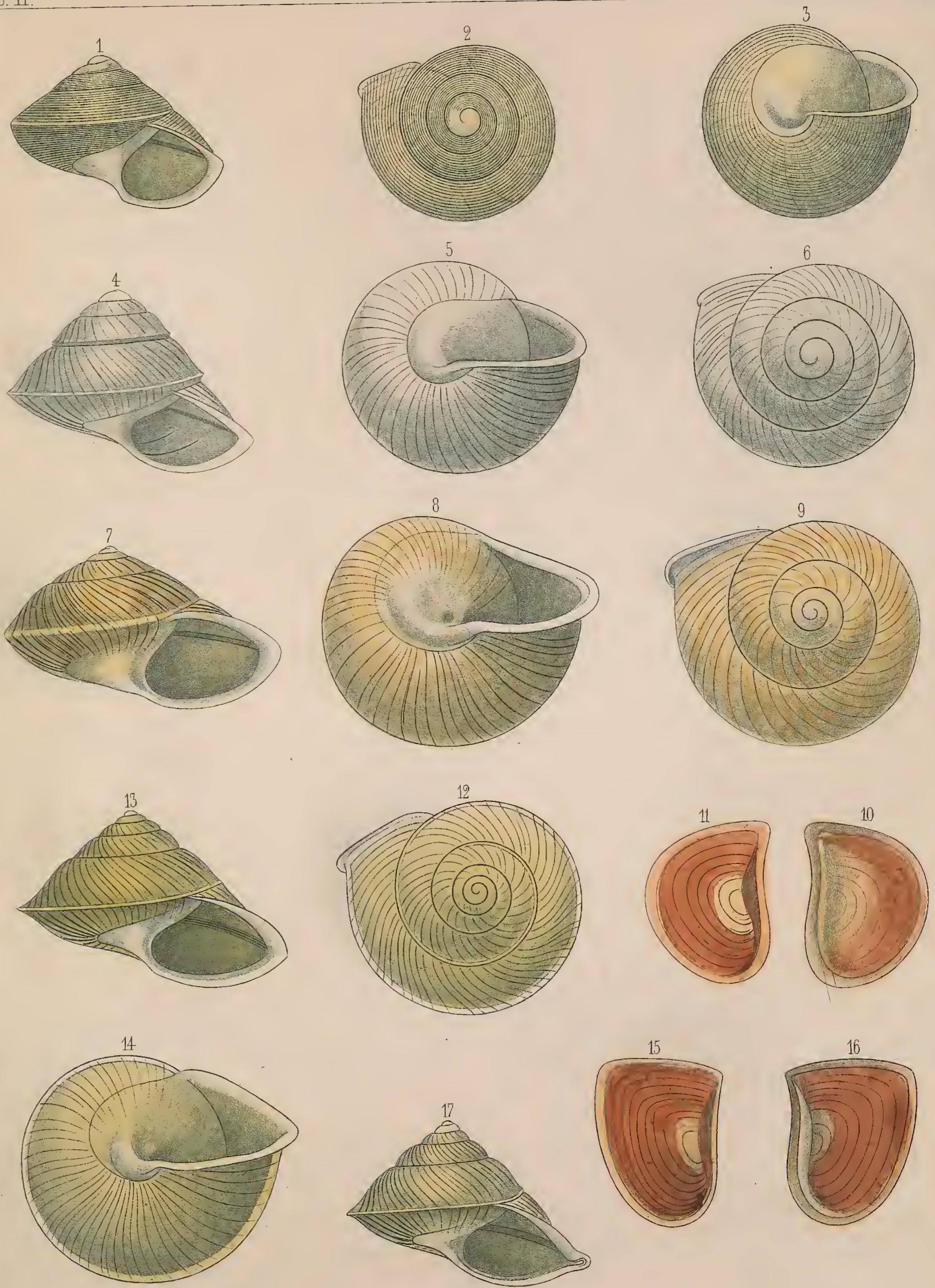


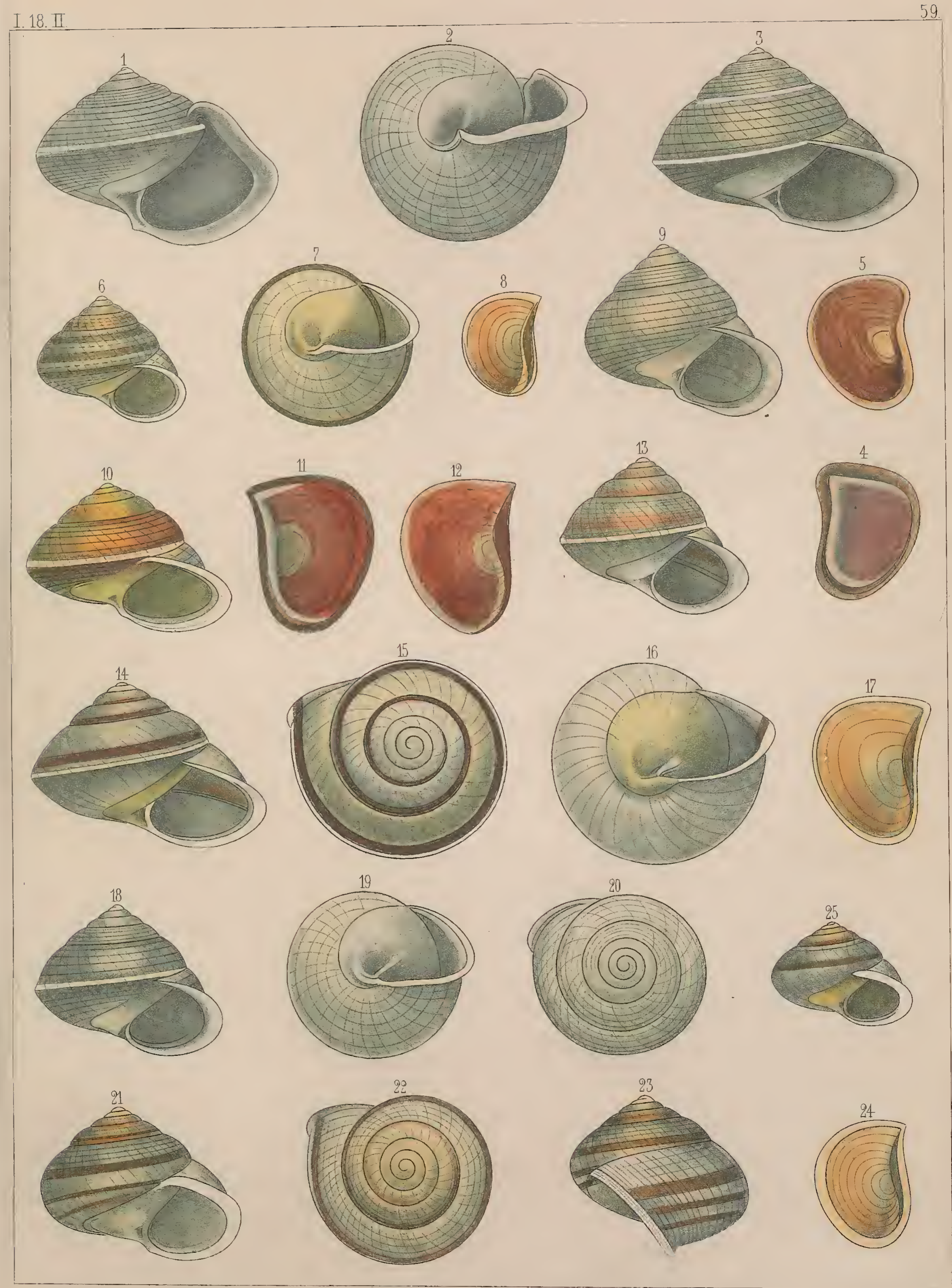




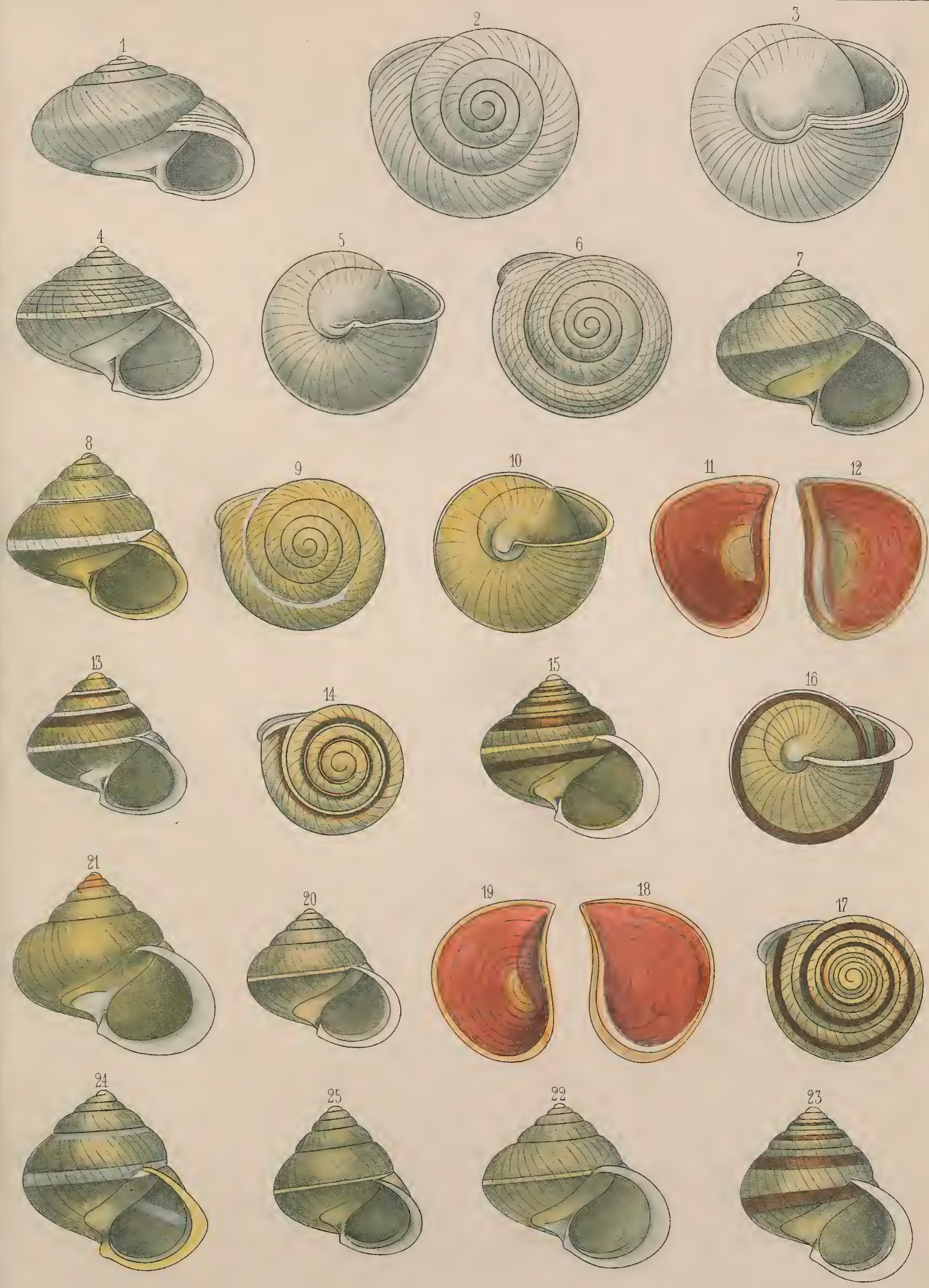


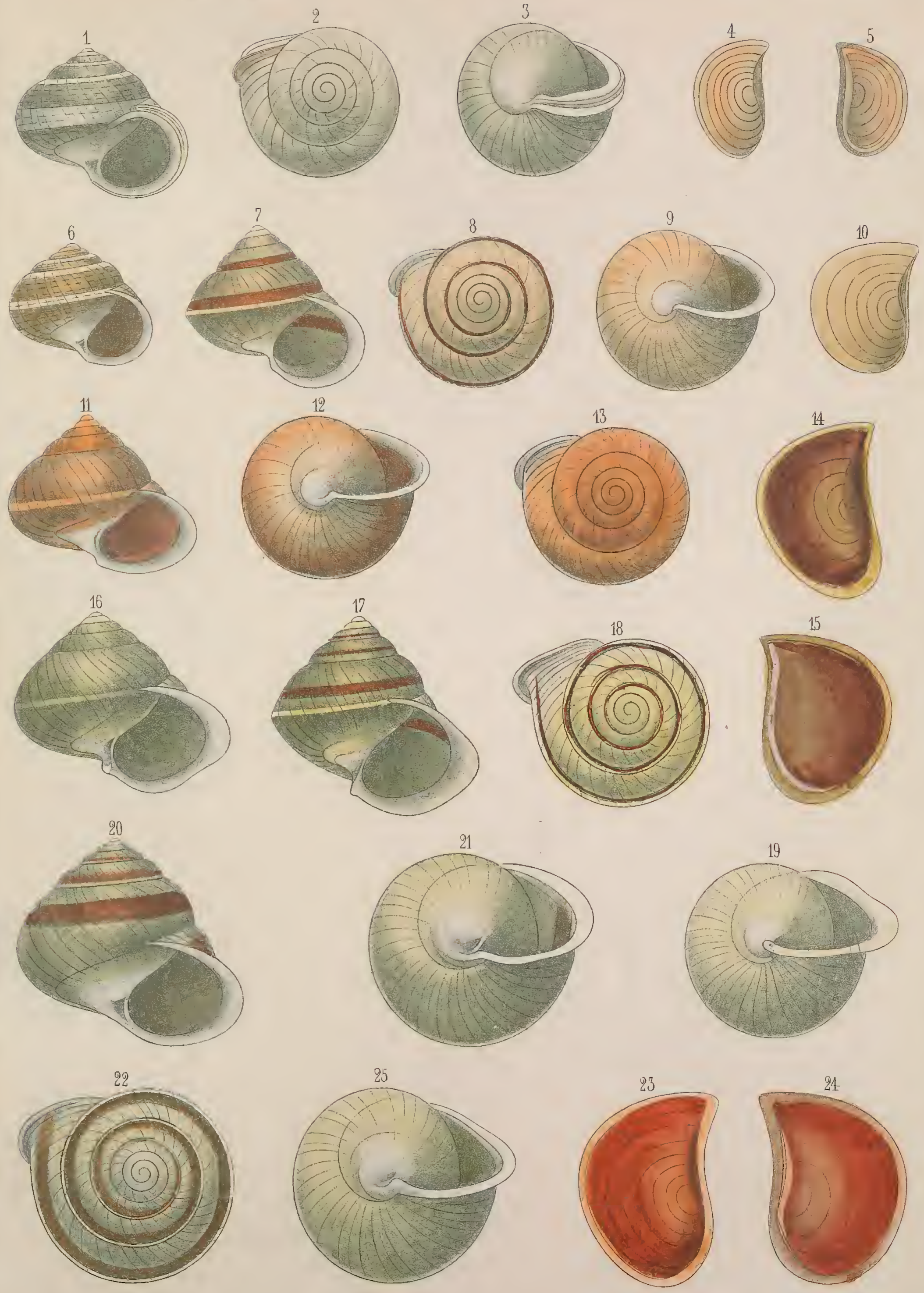


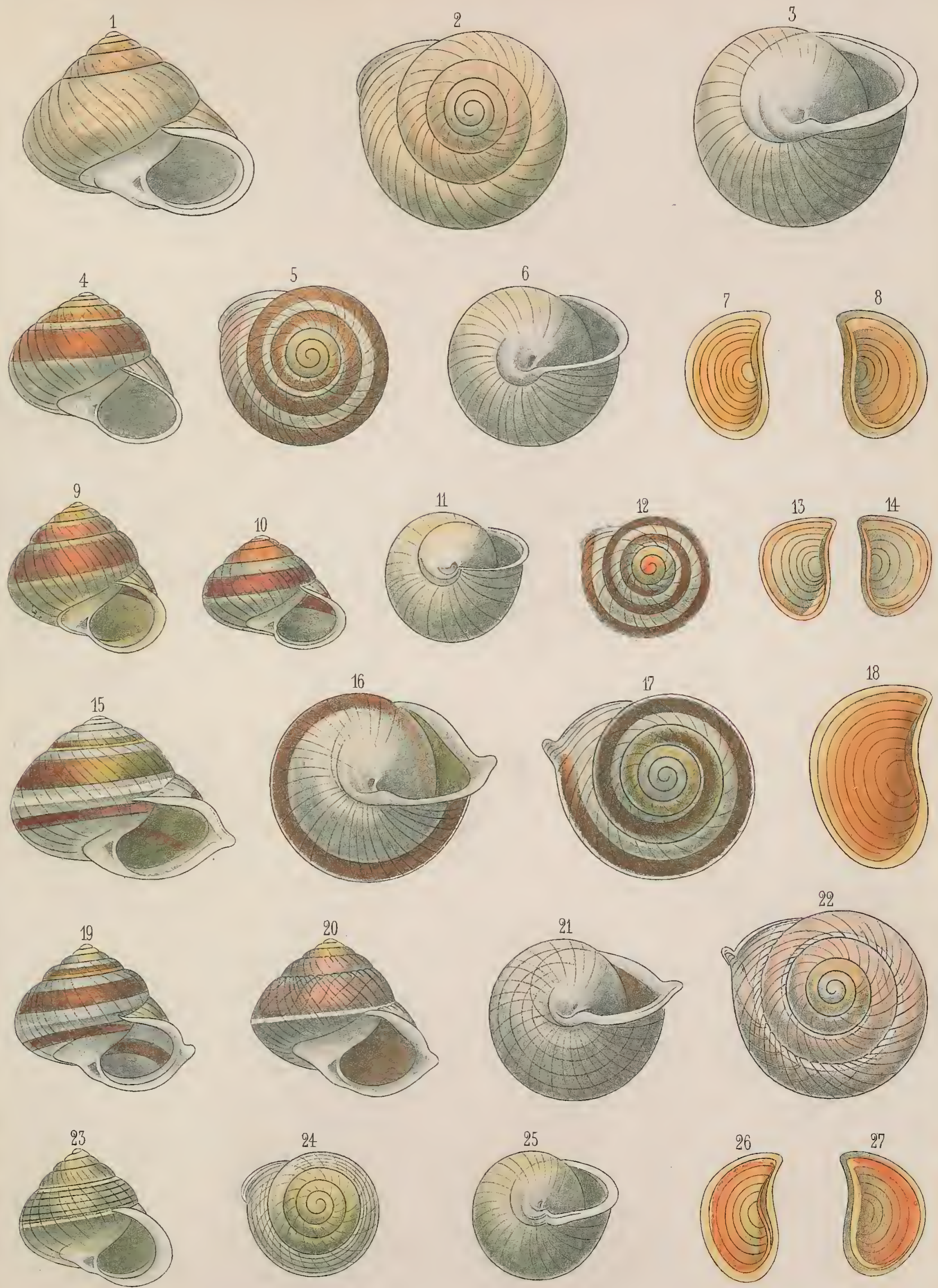


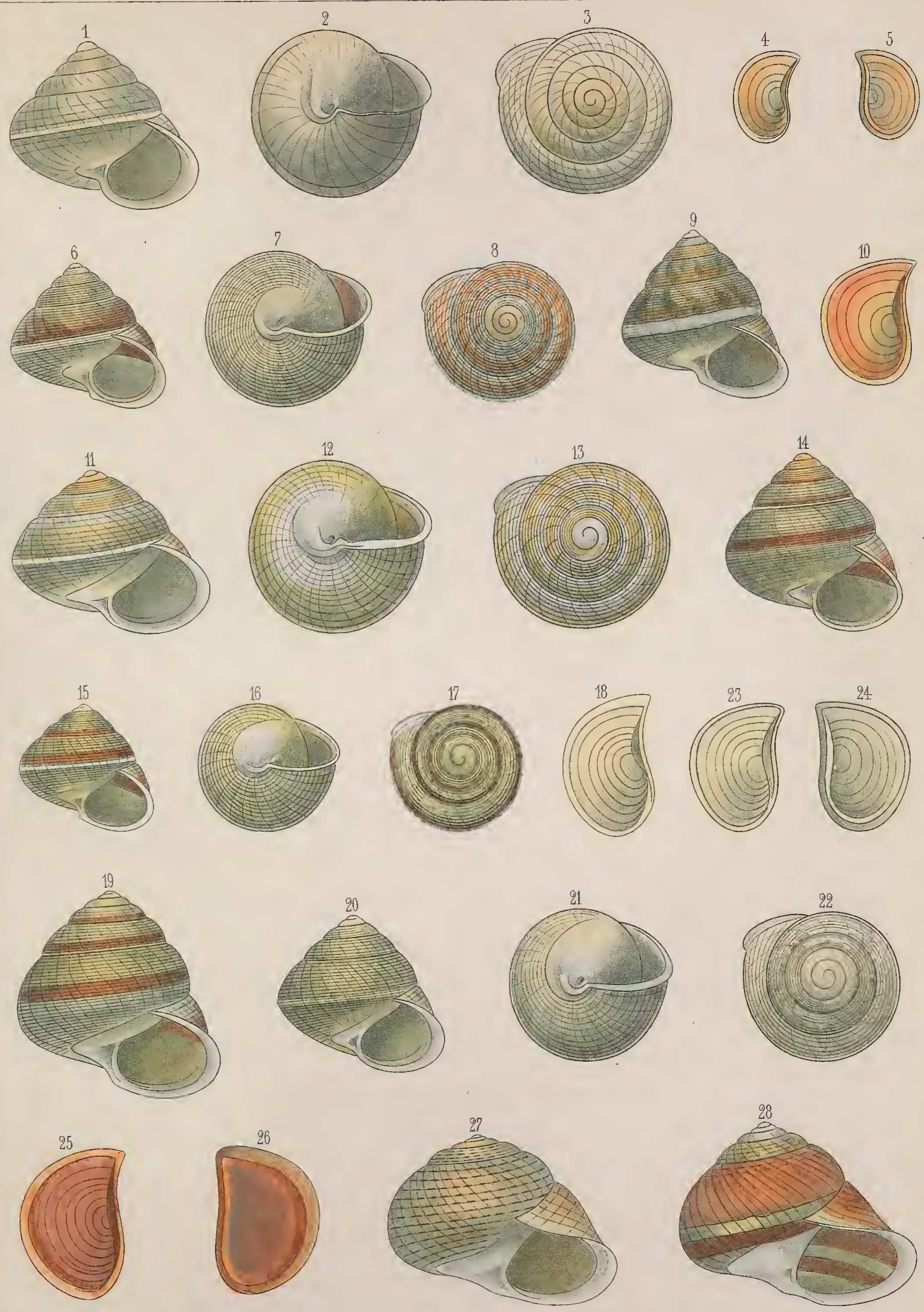


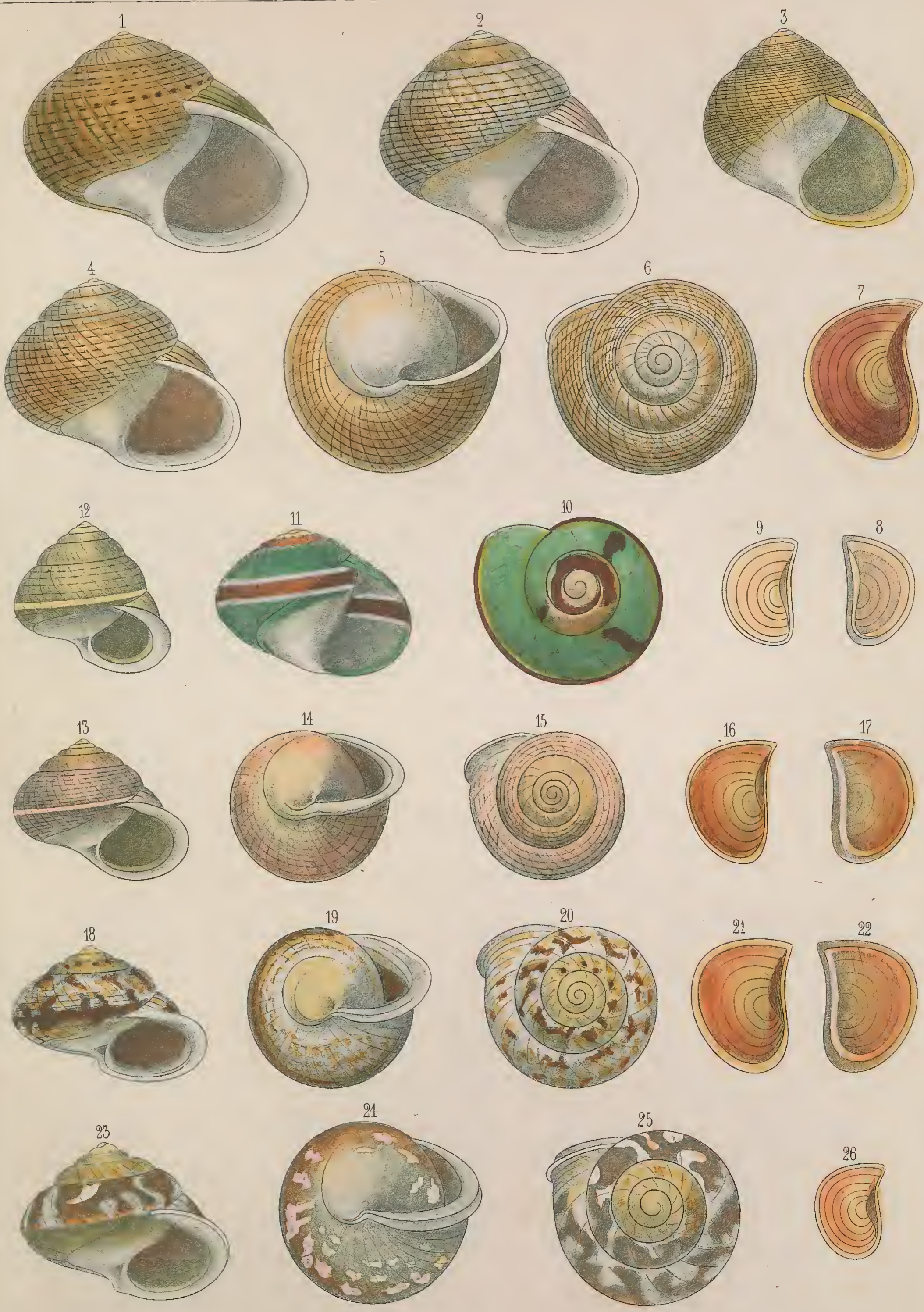


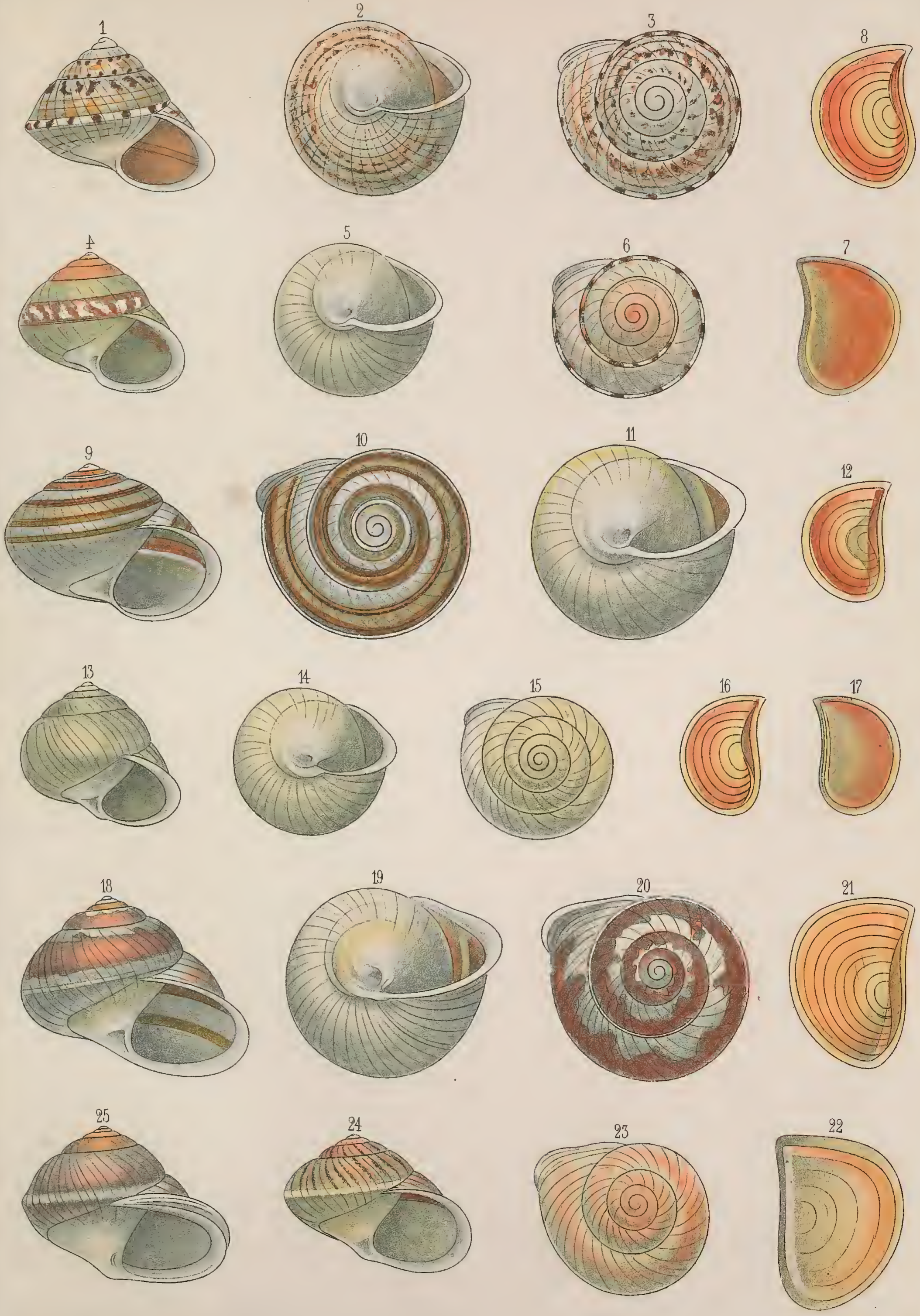

I.18. II.

66.
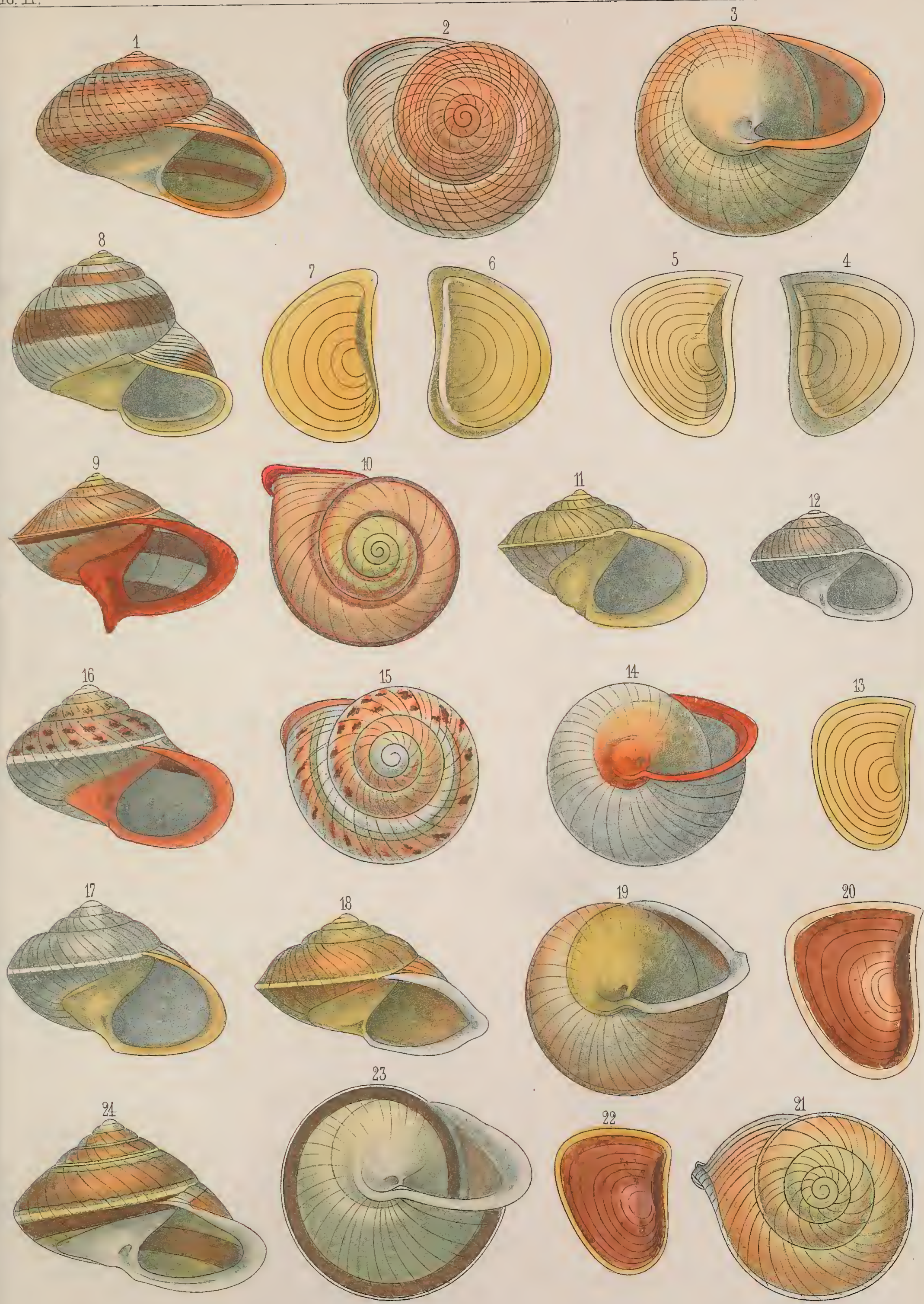


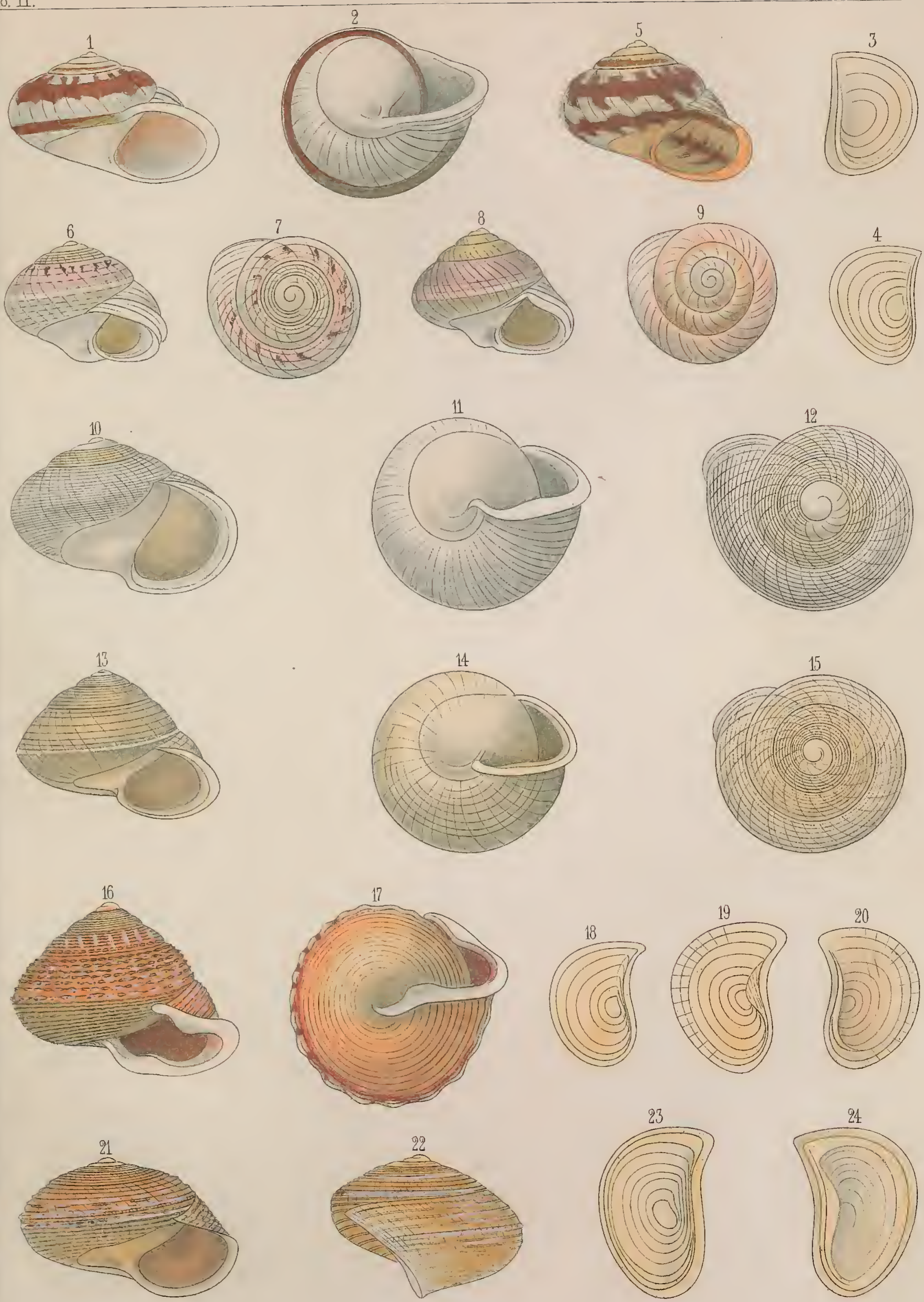

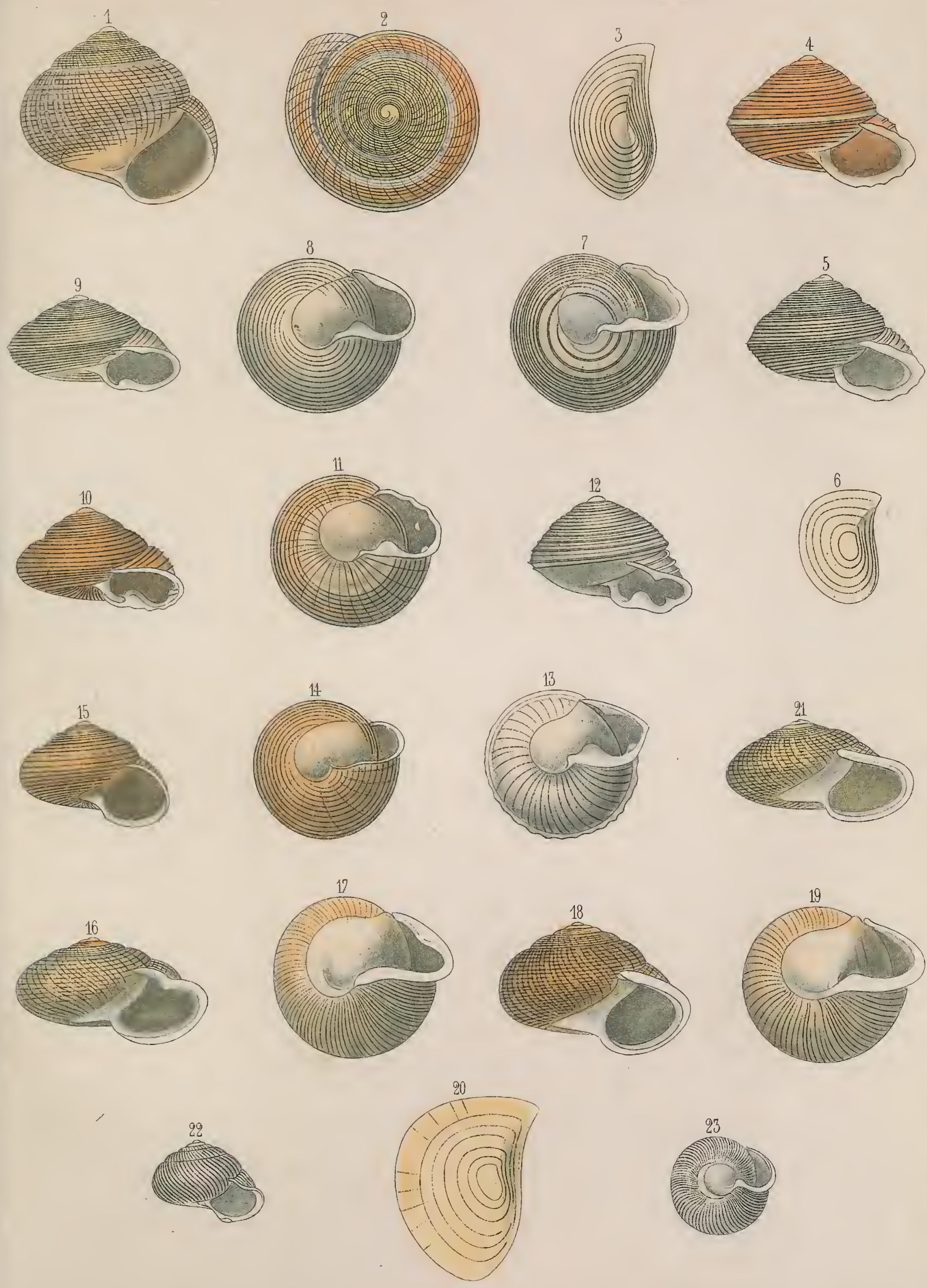

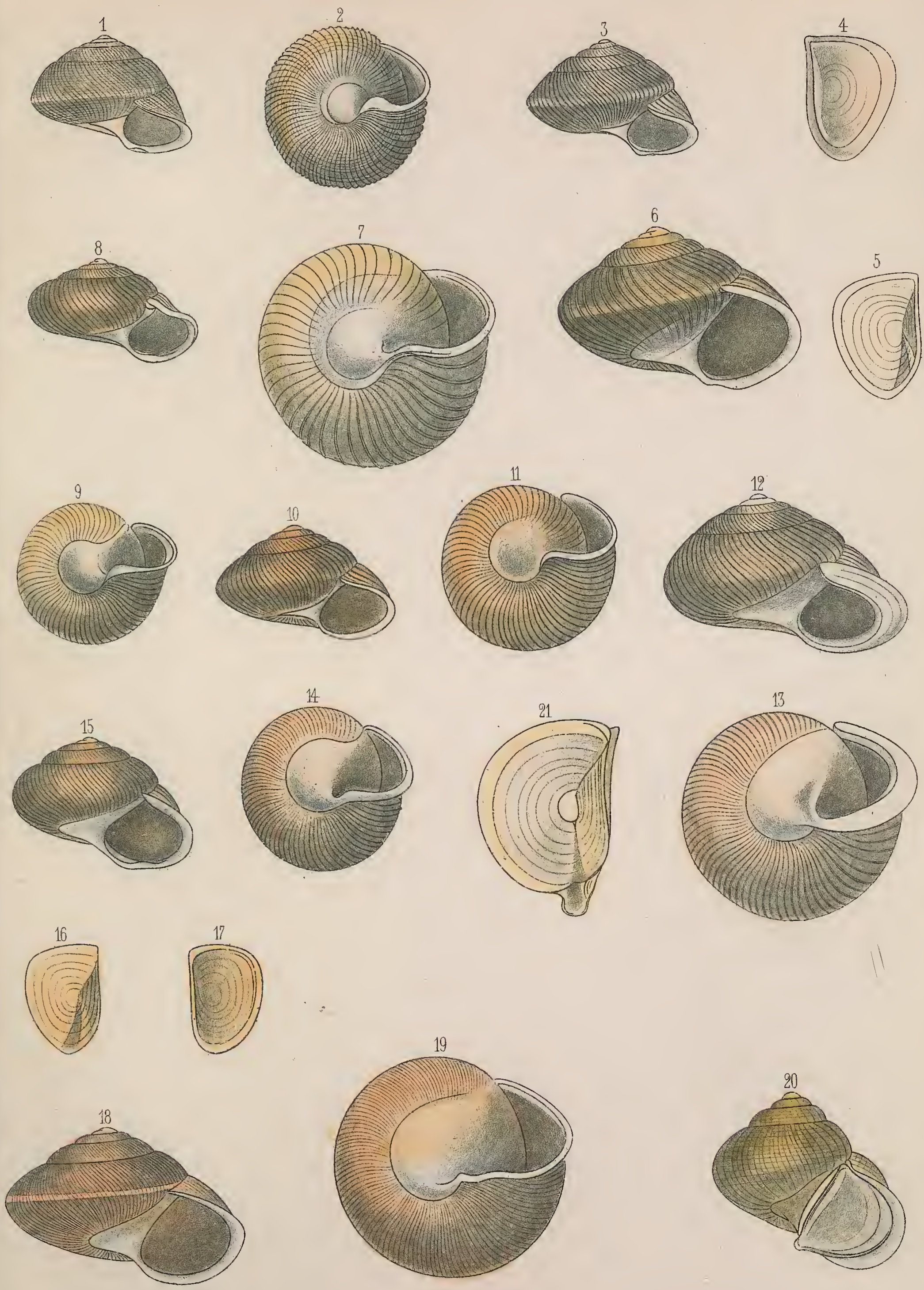

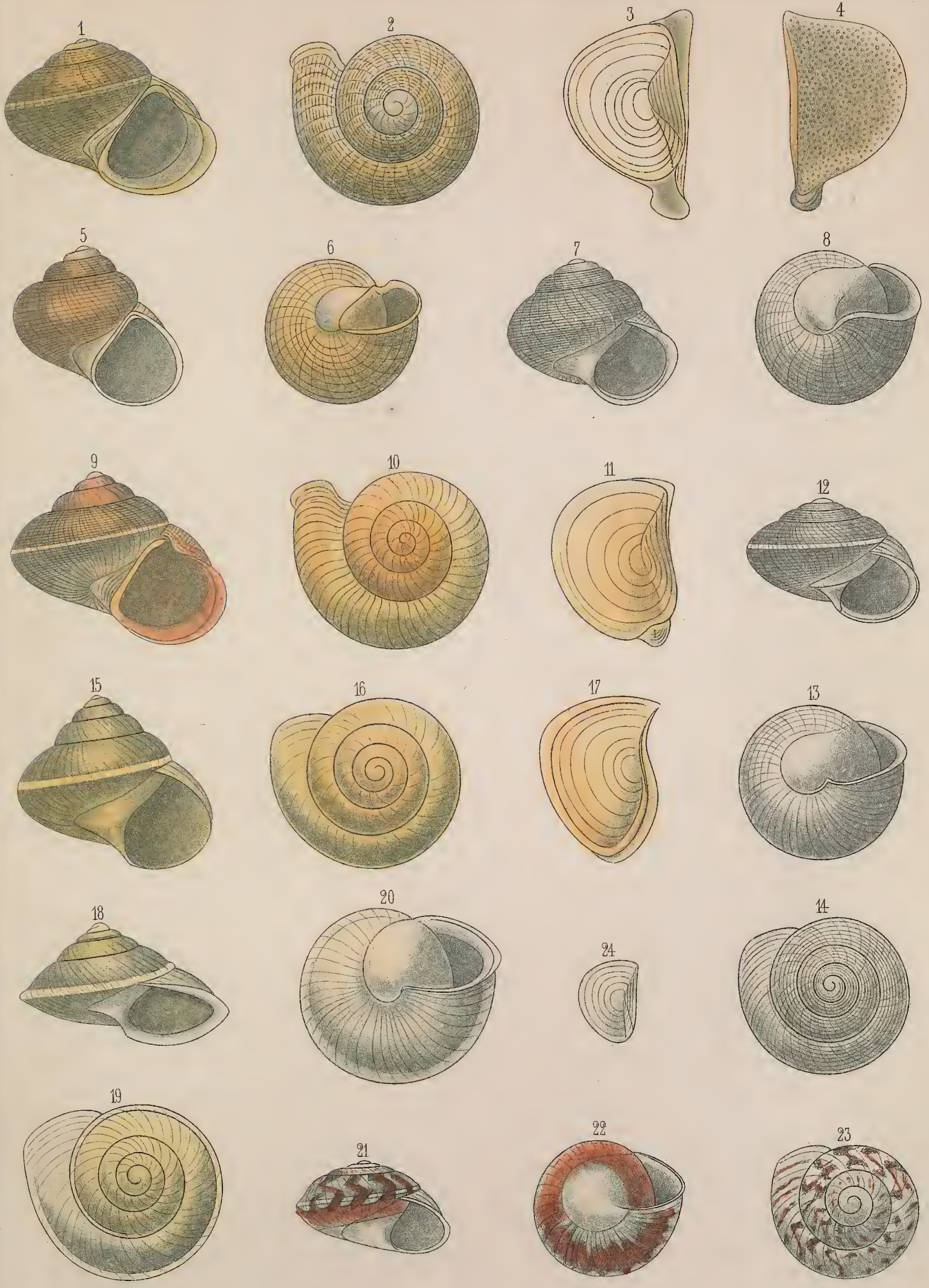
3 

ARIES SMITHSONIAN INSTITUTION NOIINLILSNI NHINOSHLIWS SJIYVYGIT LIBRARIES SMITHSONIAN

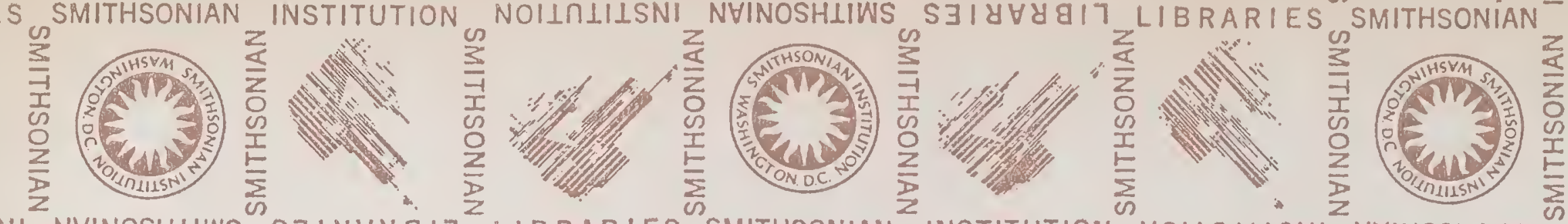

NSTITU

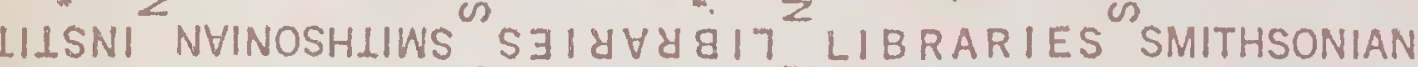

_INSTITUTION NOILILILSNI NHINOSHLIWS ${ }^{\text {I }}$ S
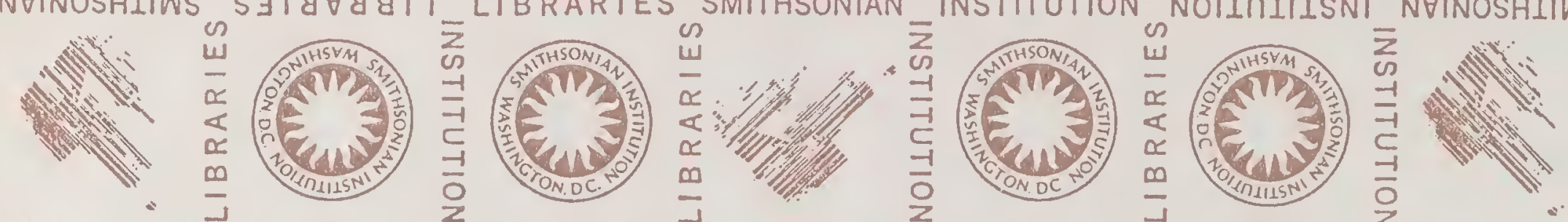

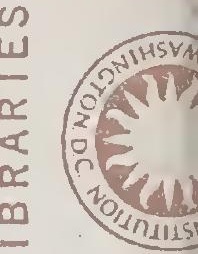

$A R \mid E S^{2}$
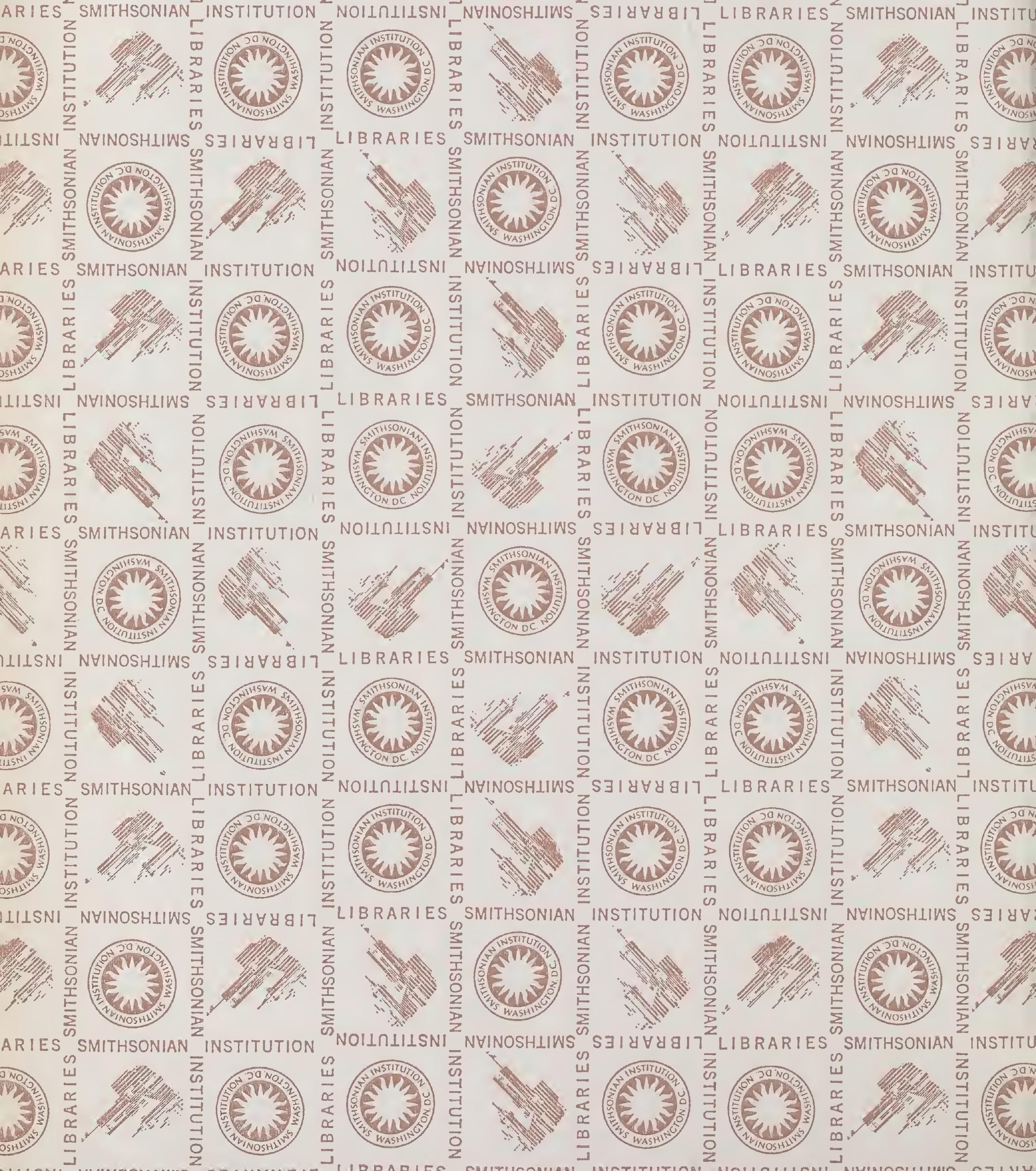


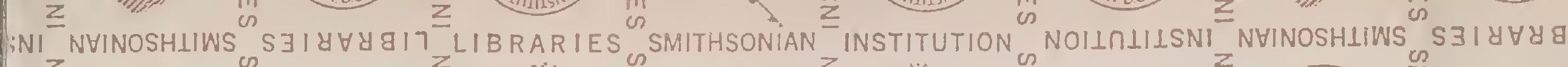

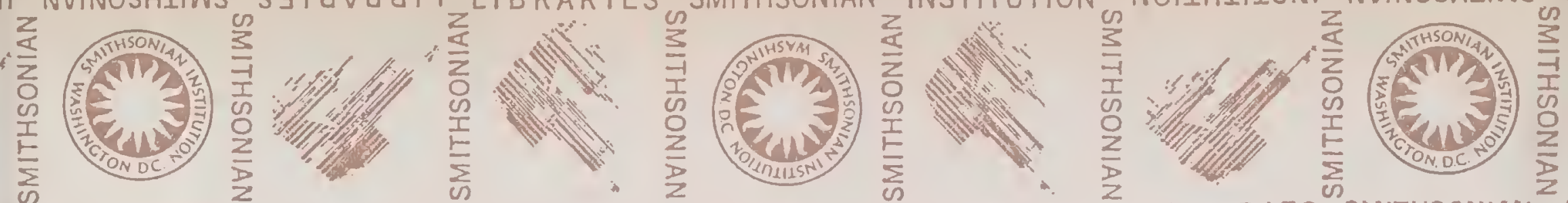

ES "SMITHSONIAN INSTITUTION NOIINIIISNI NVINOSHIIWS SJIYVYGI7" LIBRARIES SMITHSONIAN
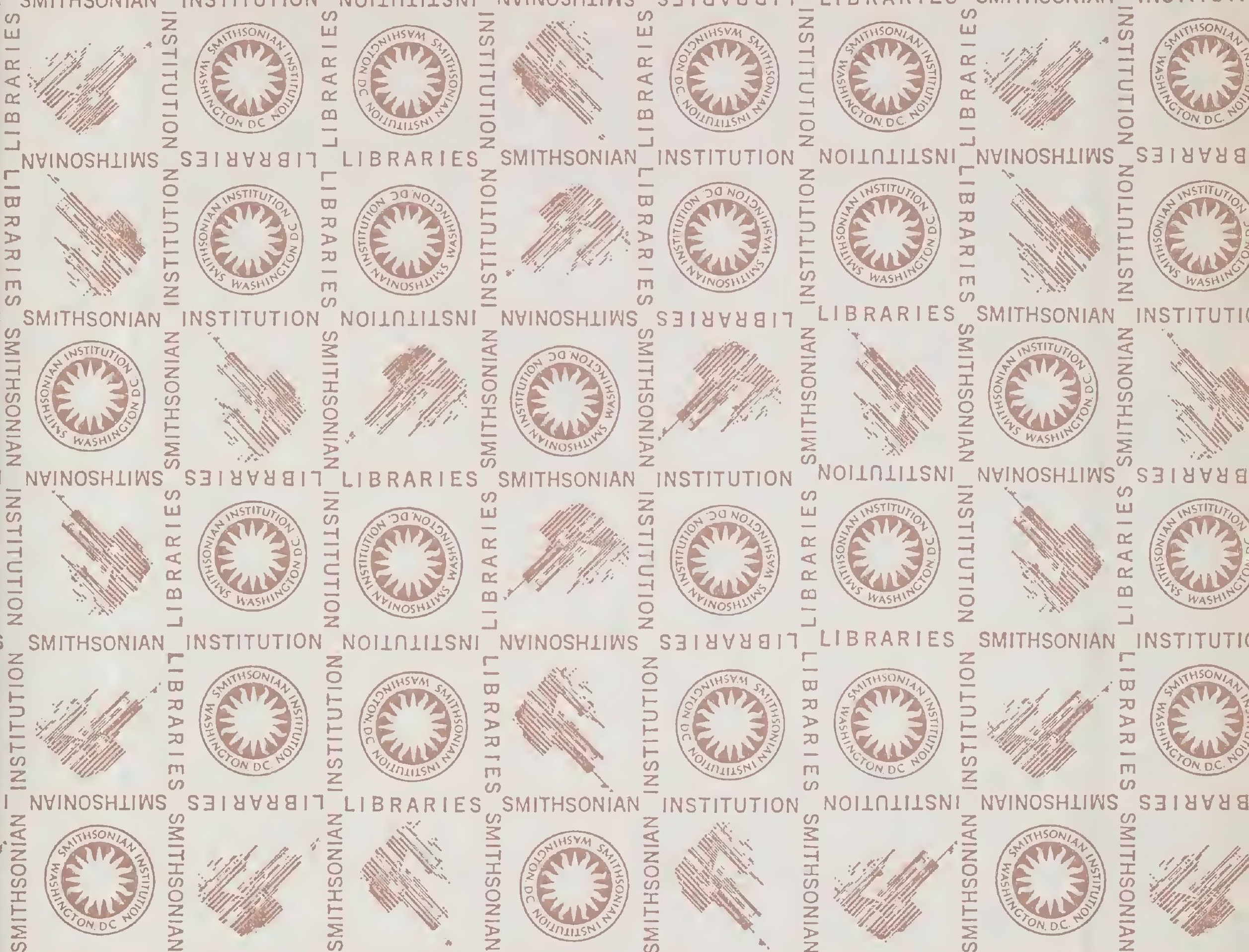

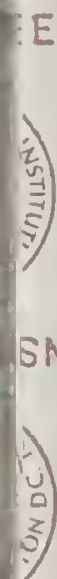
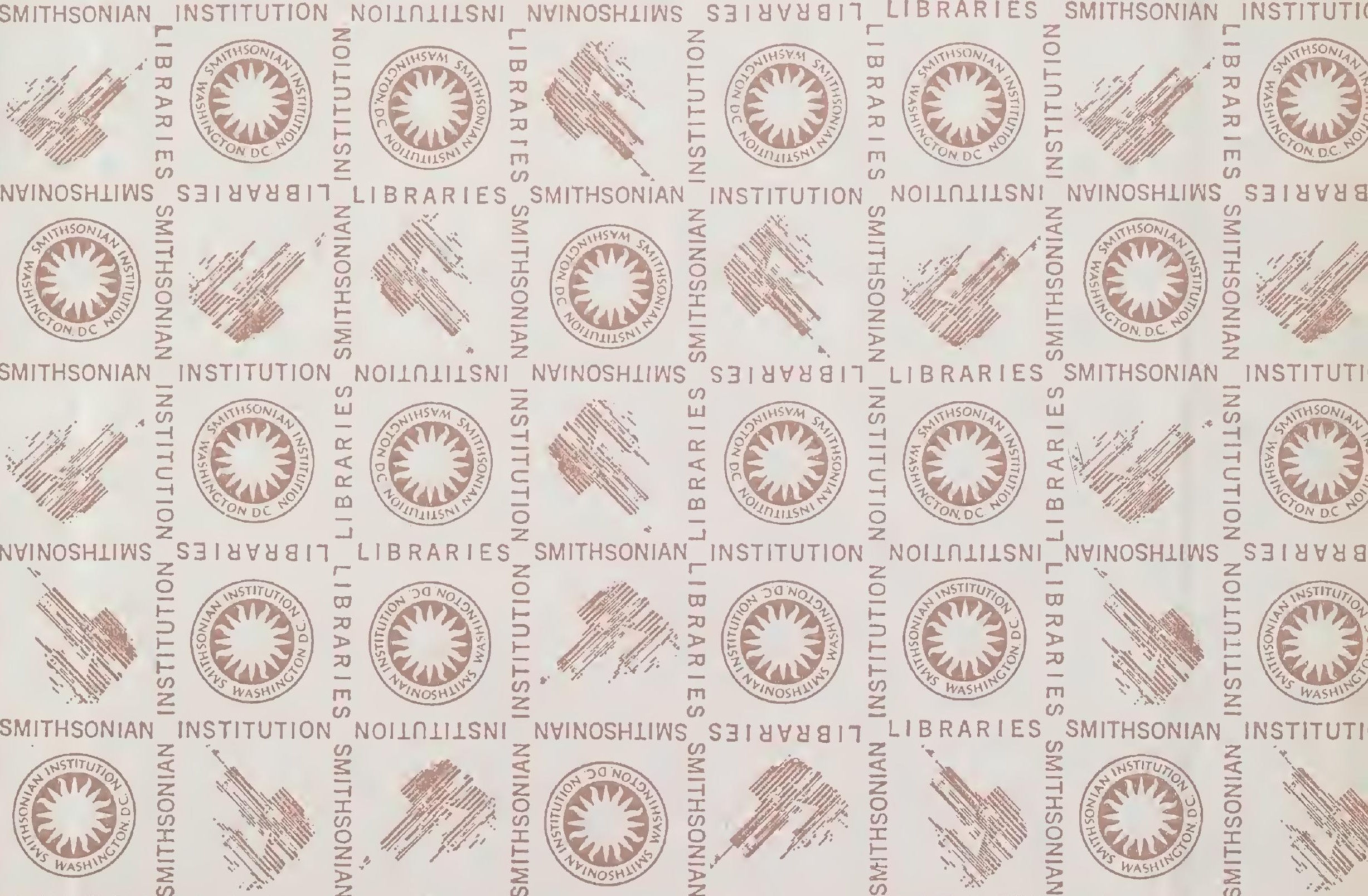

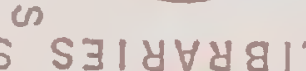
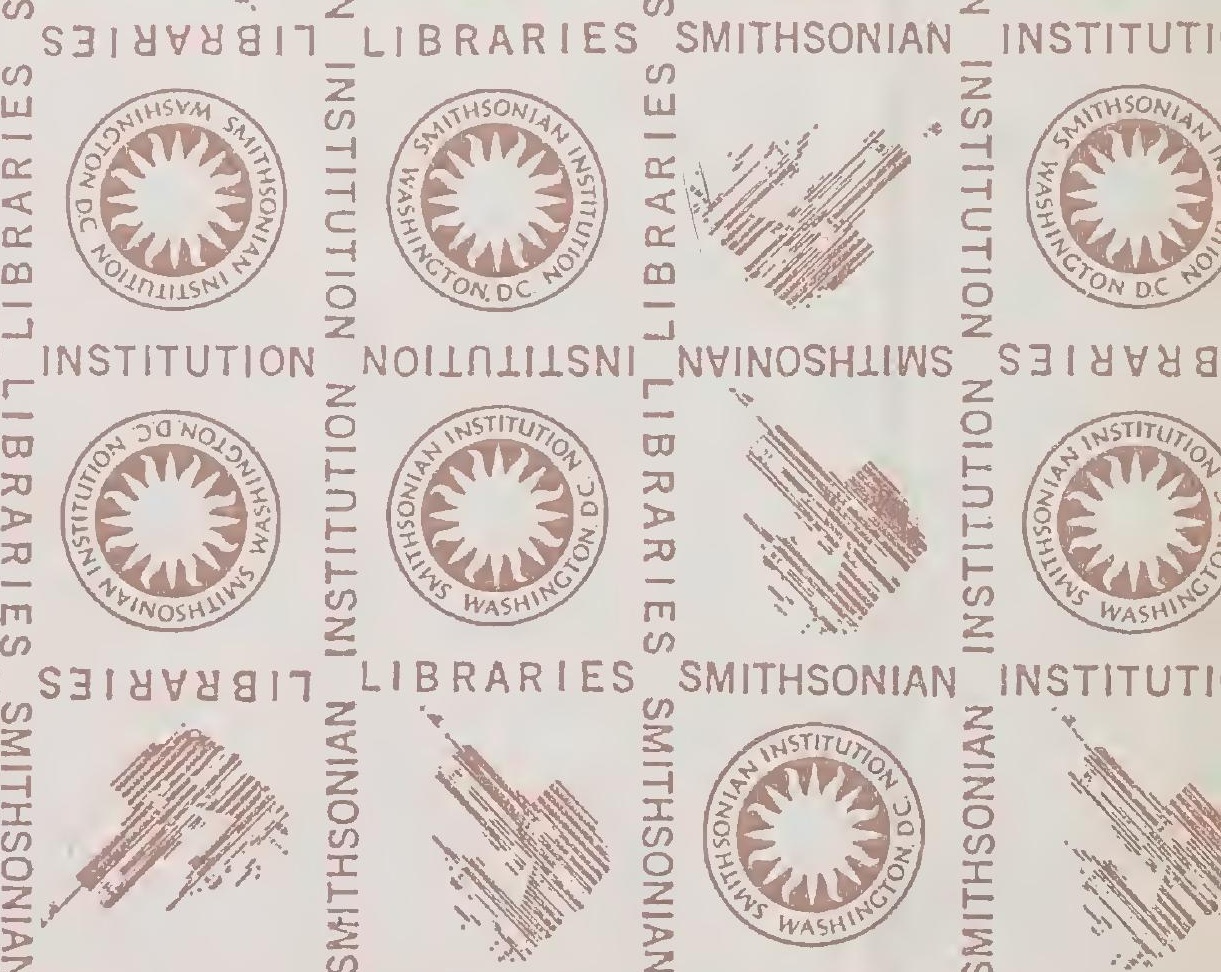

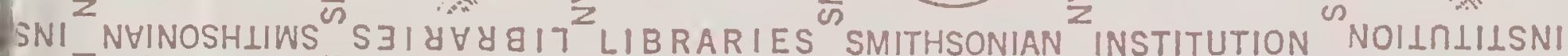
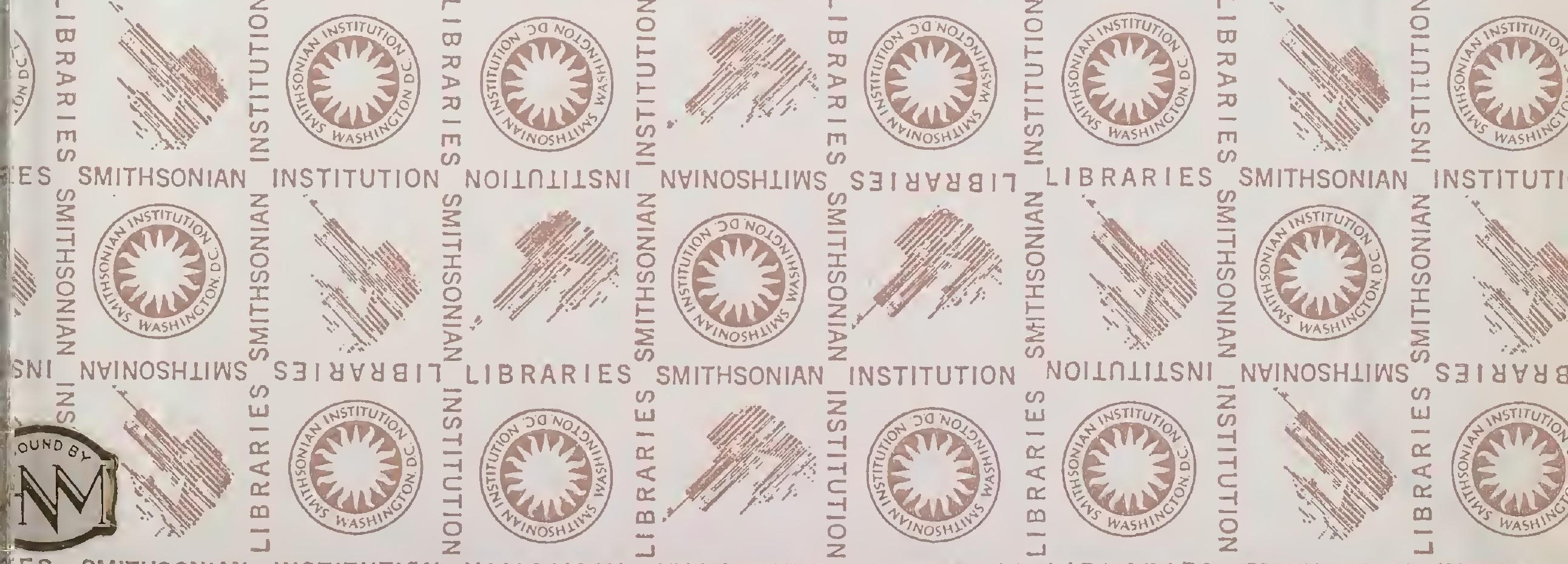
